UNIVERSITÉ BORDEAUX 3 - MICHEL DE MONTAIGNE

UNIVERSIDADE DE SÃO PAULO - ESCOLA DE COMUNICAÇÕES E ARTES

ÉCOLE DOCTORALE EDILEC

Doctorat Arts (histoire, théorie, pratique)

Doutorado em Ciências da Comunicação

Études Cinématographiques

Comunicação e Estética do Audiovisual

Bertrand FICAMOS

\title{
CINEMA NOVO ET CONSCIENTISATION
}

Thèse dirigée par M. Jean-Claude BERNARDET, professeur à l'Université de São Paulo, et M. Jean-Pierre BERTIN-MAGHIT, professeur à l'Université Bordeaux 3

Soutenue le 22 novembre 2007

Jury :

M. Jean-Claude BERNARDET, professeur à l'Université de São Paulo

M. Jean-Pierre BERTIN-MAGHIT, professeur à l'Université de Bordeaux 3

M. Michel MARIE, professeur à l'Université Paris 3 - Sorbonne Nouvelle

M. Roberto MOREIRA, professeur à l'Université de São Paulo 


\section{REMERCIEMENTS}

Je tiens à remercier chaleureusement toutes les personnes qui m'ont aidé au cours de mes recherches :

Dedy Lherm qui m'a généreusement donné accès aux archives privées de son compagnon Claude Antoine, producteur du Cinema Novo aujourd'hui décédé ;

Nataraj Trinta, archiviste stagiaire de l'Arquivo Estadual do Rio de Janeiro, qui m'a guidé dans ma consultation des archives de la police politique ;

Karl Gomide Freitas, archiviste de l'Arquivo Nacional à Brasília, dont les conseils ont été très précieux au cours de mon exploration des dossiers de la censure cinématographique ;

Lúcia et João Rocha, respectivement mère et neveu du cinéaste Glauber Rocha, et Lécio Augusto Ramos, conservateur, au Tempo Glauber pour l'accueil chaleureux, les bons repas, les longues conversations et l'accès sans restriction aux archives ;

Fernão Ramos et Sheila Schvarzman, professeurs à l'Université de Campinas, qui m'ont introduit au monde universitaire brésilien ;

les cinéastes, critiques ou producteurs Diogo Gomes dos Santos, Marina Person, Maurice Capovilla, Nelson Pereira dos Santos, Eduardo Coutinho, Eduardo Escorel, Ruy Guerra, José Carlos Avellar, Paulo César Saraceni, Gustavo Dahl, Zelito Viana, Luiz Carlos Barreto, Carlos Diegues (dans l'ordre chronologique de nos rencontres) qui ont tous accepté de me parler longuement et avec une très grande sincérité ;

Je remercie mes directeurs de recherche Jean-Claude Bernardet et Jean-Pierre BertinMaghit pour l'intelligence de leur orientation et la qualité de leurs conseils et corrections ;

Je remercie enfin tout particulièrement mon épouse, Bruna Marina Alves de Rezende Teixeira, la seule avec moi à connaître toutes les péripéties qui ont jalonné mon travail de recherche et d'écriture. Elle sait toute l'histoire qui se cache derrière les lignes que vous allez lire et l'importance du rôle qui a été le sien. Son soutien et ses encouragements ont été constants ;

Cette thèse lui est dédiée. 


\title{
RÉSUMÉS ET MOTS CLÉS
}

\author{
RÉSUMÉ DE LA THÈSE EN FRANÇAIS
}

Les objectifs de cette thèse sont de mettre à jour, d'analyser et de critiquer la conception du cinéma révolutionnaire qui a été portée par le Cinema Novo et s'est fondée sur le concept de " conscientisation » tel qu'il a été formulé par les sciences sociales brésiliennes dans les années cinquante. Le Cinema Novo, que nous définirons comme un groupe de cinéastes, soutient une production suivie dans le Brésil des années soixante et se présente comme un cinéma humaniste, ayant pour but la prise de conscience par la population brésilienne des mécanismes sociaux, culturels, économiques et politiques qui expliquent le sous-développement, afin qu'elle se révolte et fasse la révolution.

Glauber Rocha fut la figure de proue de ce cinéma qui ne se résume pas à lui et qui a beaucoup évolué au cours de ses dix ans d'existence. Nous le verrons en étudiant, entre autres : Sécheresse (Vidas secas) de Nelson Pereira dos Santos, Les Fusils (Os Fuzis) de Ruy Guerra, Le Dieu noir et le diable blond (Deus e o diabo na terra do sol), Terre en transe (Terra em transe) et Antonio-das-Mortes (O Dragão da maldade contra o santo guerreiro) de Glauber Rocha.

Notre approche s'insère dans le champ cinéma-histoire et applique à un nouvel objet d'étude les méthodes développées sur d'autres sujets par Michel Marie, Jean-Pierre Esquenazi ou encore Jean-Pierre Bertin-Maghit. Nous verrons ici comment, assimilant cinéma d'auteur et cinéma révolutionnaire, le Cinema Novo a évité les schémas classiques et manipulateurs d'un cinéma de propagande sans pour autant établir avec le grand public une relation suivie et devenir ce cinéma populaire de conscientisation idéalisé à ses débuts.

\section{RÉSUMÉ DE LA THÈSE EN PORTUGAIS}

A tese apresentada pretende revelar, analisar e criticar a concepção do cinema revolucionário defendida pelo Cinema Novo fundada no conceito de conscientização formulada pelas ciências sociais brasileiras nos anos cinqüenta. O Cinema Novo, definido aqui como um grupo de cineastas, produz um volume conseqüente de filmes durante os anos sessenta. Ele se apresenta como um cinema humanista que tem por objetivo provocar a compreensão, pela população brasileira, dos mecanismos sociais, culturais, políticos e econômicos que explicam o subdesenvolvimento, para que esta se revolte e faça a revolução. 
Glauber Rocha foi o líder incontestável deste cinema que no entanto não se restringe a ele e que muito evoluiu durante seus dez anos de existência como veremos estudando entre outros : Vidas secas de Nelson Pereira dos Santos, Os Fuzis de Ruy Guerra, Deus e o diabo na terra do sol, Terra em transe e O Dragão da maldade contra o santo guerreiro de Glauber Rocha.

Nossa perspectiva se insere no campo de estudo das relações entre cinema e história e aplica a um novo objeto métodos anteriormente desenvolvidos por Michel Marie, Jean-Pierre Esquenazi e Jean-Pierre Bertin-Maghit. Nós veremos como, a partir da assimilação entre cinema de autor e cinema revolucionário, o Cinema Novo conseguiu evitar os esquemas clássicos do cinema de propaganda sem no entanto estabelecer com o público uma relação estável, nem se tornar esse cinema popular de conscientização idealizado no início dos anos sessenta.

\section{TITRE DE LA THÈSE EN PORTUGAIS}

Cinema novo e concientização

\section{RÉSUMÉ DE LA THÈSE EN ANGLAIS}

The aims of this doctoral thesis were to reveal, to analyse and to criticize the approach to the revolutionary cinema shouldered by the Cinema Novo which was based on the concept of conscientisation as it was defined by Brazilian social scientists in the 1950s. The Cinema Novo, that we defined as a group of film-makers, was responsible for a sustained film production during the 1960s in Brazil. It stands as a humanist cinema that intends to provoke an awareness-raising in Brazilian population in which concerns the social, cultural, political and economical mechanisms to blame for underdevelopment so that this population would rebel against them and start a revolution.

Glauber Rocha was the unquestionable leader of this cinema, which is nevertheless not summarized by him, and which knew a strong evolution during its ten years existence. Barren Lives (Vidas secas) by Nelson Pereira dos Santos, The Guns (Os Fuzis) by Ruy Guerra, Black God, White Devil (Deus e o diabo na terra do sol), Land In Anguish (Terra em transe) and Antonio das Mortes (O Dragão da maldade contra o santo guerreiro) by Glauber Rocha are some of the examples of this evolution.

Our approach belongs to the field of the relations between cinema and history. It applies methods previously developed by Michel Marie, Jean-Pierre Esquenazi and Jean- 
Pierre Bertin-Maghit to a new object. We show how, by identifying the French concept of « cinéma d'auteur » to that of revolutionary cinema, Cinema Novo succeeded in avoiding classical manipulation techniques of propaganda without being able to build a strong relationship with the public, nor to become the popular cinema of conscientisation idealized in the 1960s.

\section{TITRE DE LA THÈSE EN ANGLAIS}

Cinema Novo and conscientisation

\section{MOTS CLÉS EN FRANÇAIS}

1. Cinema Novo

2. Cinéma brésilien

3. Cinéma politique

4. Cinéma-histoire

\section{MOTS CLÉS EN PORTUGAIS}

1. Cinema Novo

2. Cinema brasileiro

3. Cinema político

4. Cinema-história
5. 1960-1975

6. Brésil

7. Critique et interprétation

8. Économie du cinéma
5. 1960-1975

6. Brasil

7. Crítica e interpretação

8. Economia do cinema

\section{MOTS CLÉS EN ANGLAIS}

1. Cinema Novo

2. Cinema of Brazil

3. Political cinema

4. History and cinema
5. 1960-1975

6. Brazil

7. Critics and interpretation

8. Economics of the cinema 


\section{Table des matières}

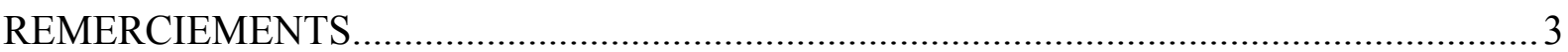

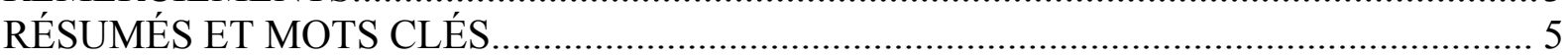

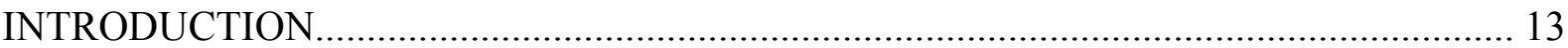

Origine de l'intérêt pour le Cinema Novo.................................................................. 13

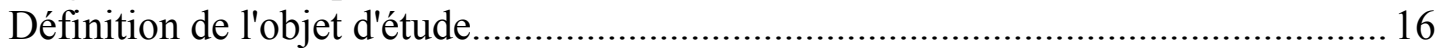

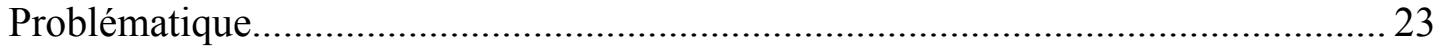

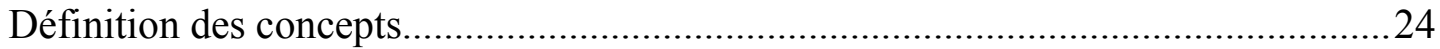

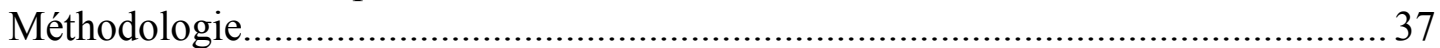

Annonce du plan............................................................................................. 40

PREMIÈRE PARTIE. La genèse du Cinema Novo............................................................. 41

Chapitre premier : Élaboration d'un concept critique......................................................43

1.1 Le dialogue entre Bernardet, Dahl, Sales Gomes et Rocha.........................................4

Situation du cinéma brésilien en 1960.................................................................... 45

Modification de la critique.....................................................................................5

Du cinéma indépendant au cinéma d'auteur................................................................5

1.2 Bahia de todos os santos, modernité de langage, distanciation brechtienne et

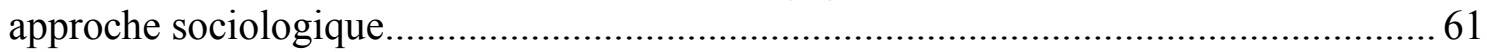

Rupture avec le langage académique et rôle de Trigueirinho Neto.................................... 62

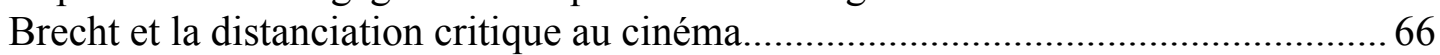

L'approche cinématographique des contradictions sociales et politiques.....................70

1.3 Arraial do Cabo et Aruanda, précarité, histoire et anthropologie................................75

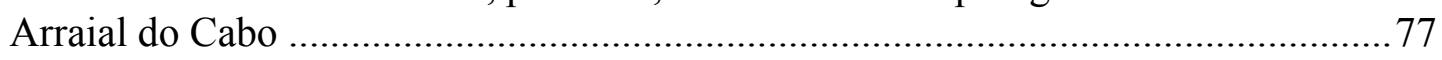

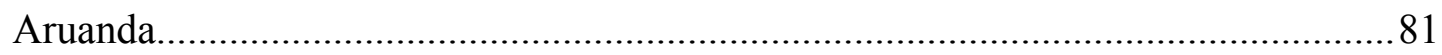

Une idée dans la tête et une caméra à l'épaule, le cinéma-vérité mystifié....................85

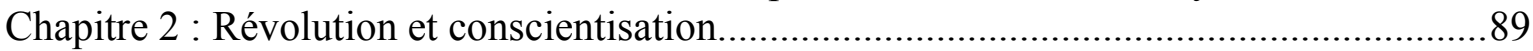

2.1 L'idéologie de l'ISEB : identification des contradictions économiques, sociales et culturelles du Brésil, complexe colonial et aliénation, rôle des élites intellectuelles......92

Roland Corbisier, rôle des élites et aliénation culturelle............................................ 94

Álvaro Vieira Pinto, de la conscience critique à une politique nationaliste................98

Nelson Werneck Sodré et le matérialisme dialectique.............................................. 102

2.2 La dispute entre le CPC et le Cinema Novo Art ou militantisme, une opposition

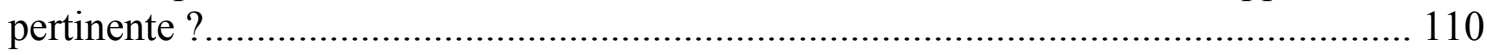

Combat politique et mouvements sociaux sous la présidence de João Goulart.........111

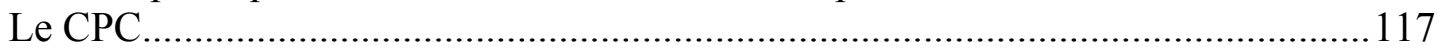

La controverse entre le Cinema Novo et le CPC....................................................... 121

Chapitre 3 : Constitution du groupe du Cinema Novo....................................................... 129

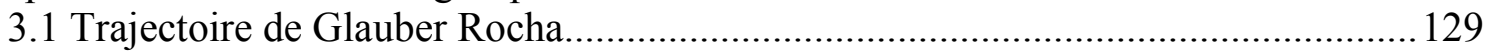

3.2 Le groupe du Cinema Novo.................................................................................. 141

3.3 Des idéaux convergents (A Revisão crítica do cinema brasileiro)...........................161

Conclusion de la première partie.........................................................................172

DEUXIÈME PARTIE : Le Cinema Novo première forme (1960-1964)................................ 175

Chapitre 4 : Stratégies économiques et commerciales du Cinema Novo.............................177

4.1 Le Cinema Novo à la conquête du monde (les festivals, la critique internationale)

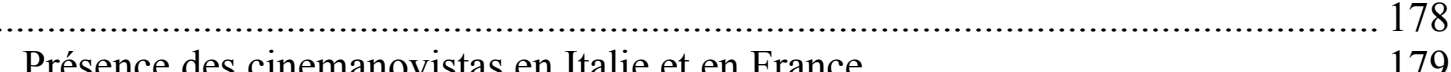

Présence des cinemanovistas en Italie et en France...………………………………...179

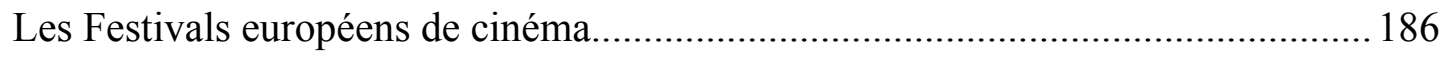

4.2 Le Cinema Novo à l'épreuve du marché (volontarisme et mécénat)......................... 189

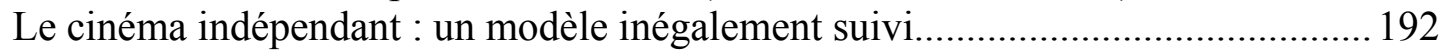

Mécénat et collecte de subventions officielles...........................................................194 


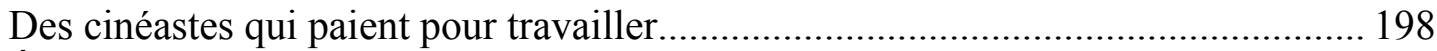

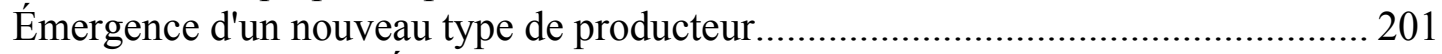

4.3 Le Cinema Novo et l'État (Geicine, CAIC).............................................................205

Constitution des deux principales propositions d'une politique de cinéma.............. 207

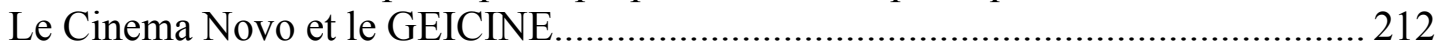

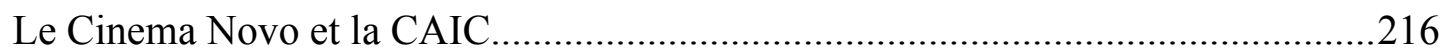

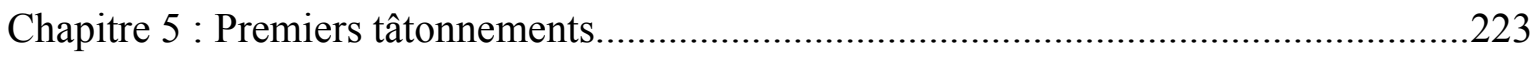

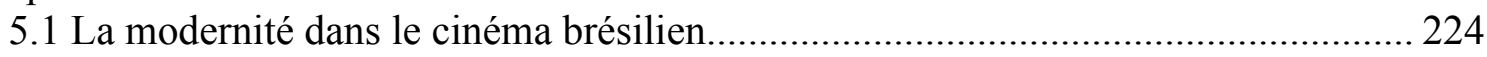

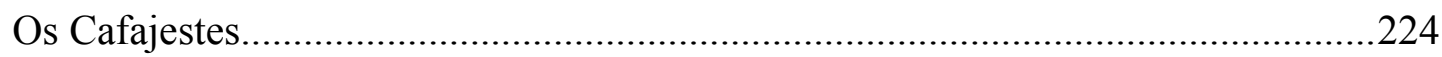

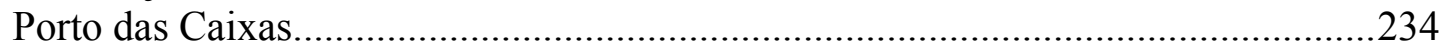

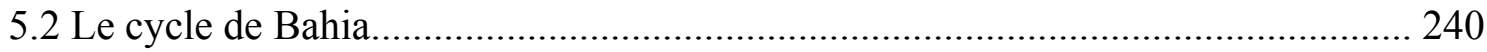

A Grande Feira et Tocaia no asfalto....................................................................... 240

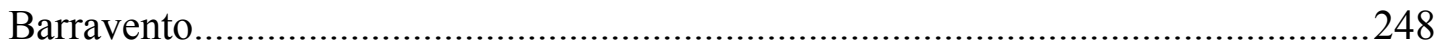

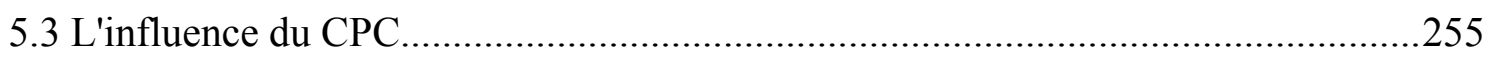

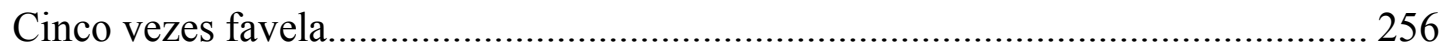

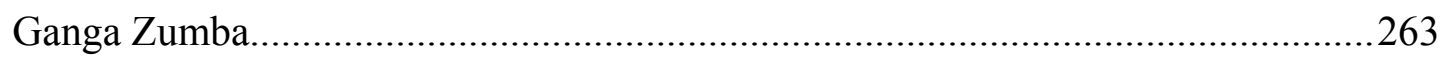

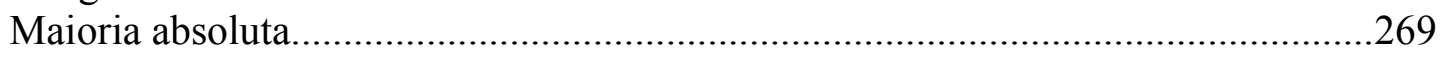

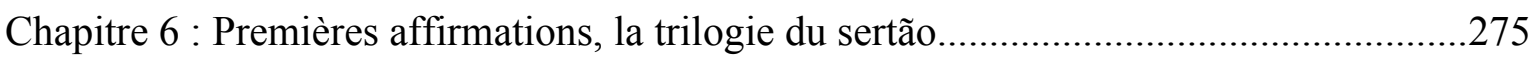

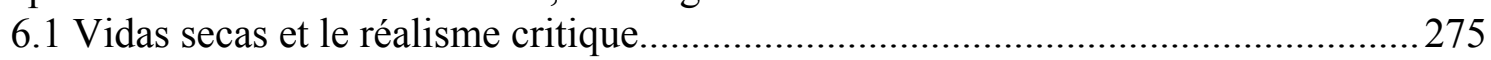

6.2 Deus e o diabo na terra do sol : la conscientisation inachevée..............................283

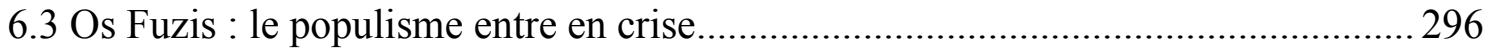

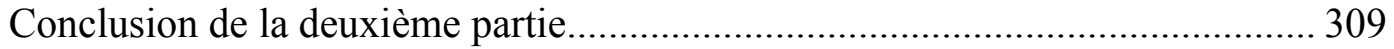

TROISIÈME PARTIE : Le Cinema Novo deuxième forme (1964-1968).............................313

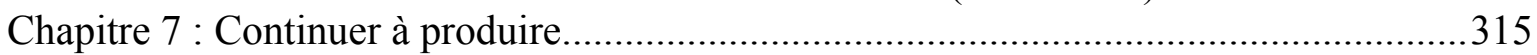

7.1 Continuation d'un cinéma d'auteur sans thématique politique explicite..................316

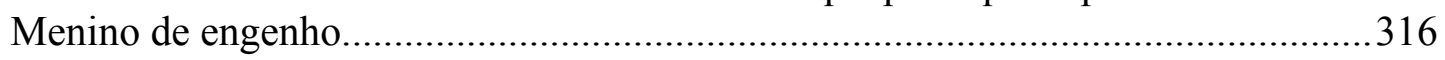

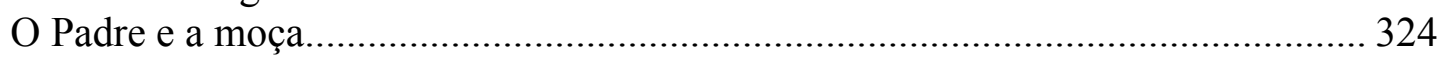

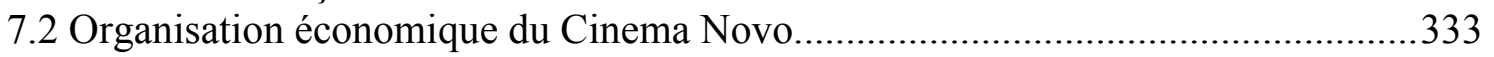

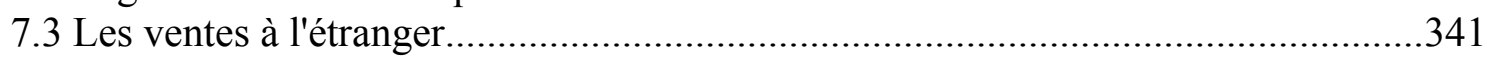

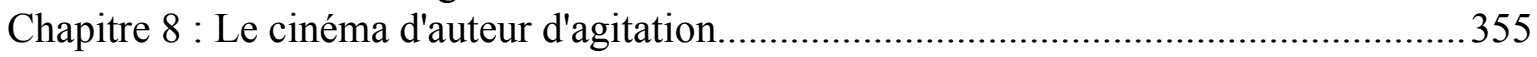

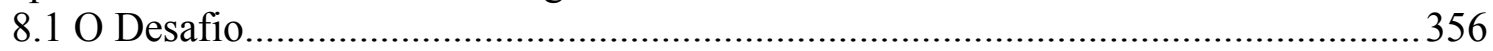

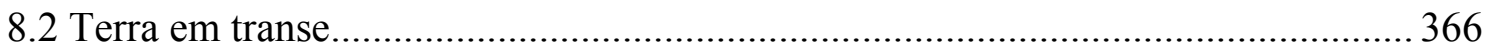

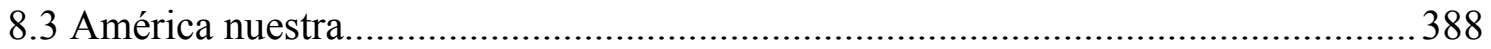

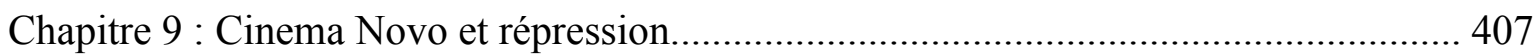

9.1 La diffusion des films politiques sous la dictature ............................................... 409

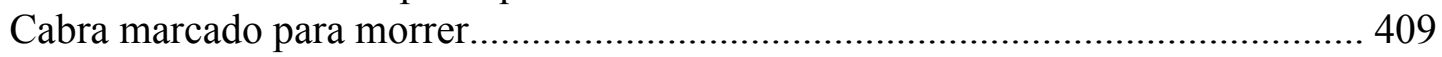

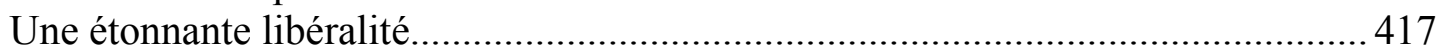

Les Années de plomb.......................................................................................... 423

9.2 Le Cinema Novo et les services de censure des divertissements publics..................424

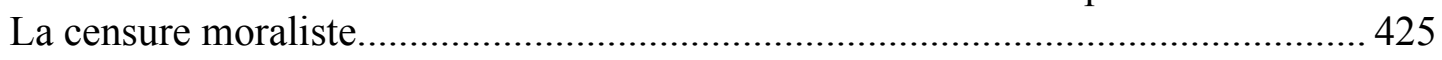

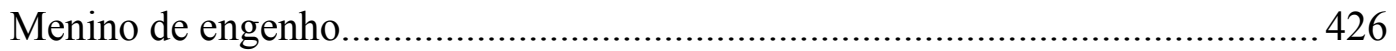

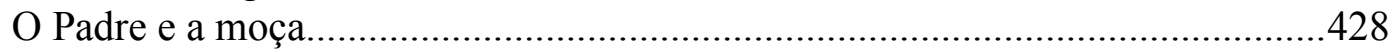

La censure moraliste après 1968, Macunaíma..................................................... 429

Como era gostoso o meu francês.......................................................................431

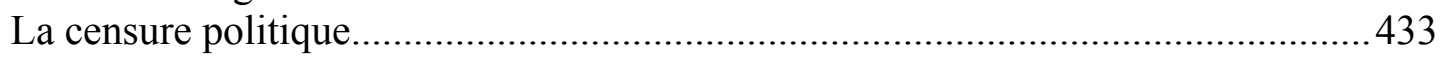

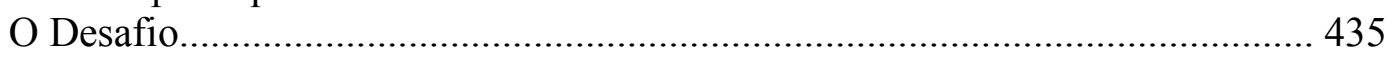

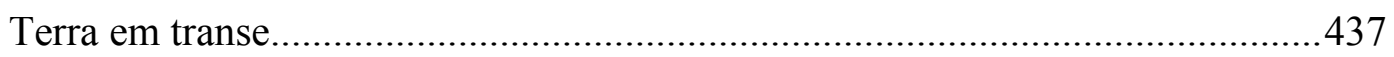

La censure politique à partir de 1968, Os Herdeiros..........................................438

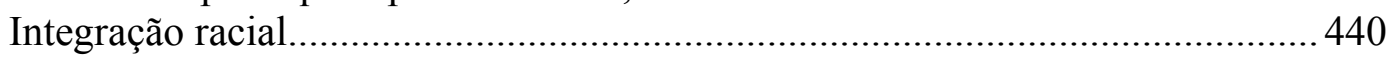

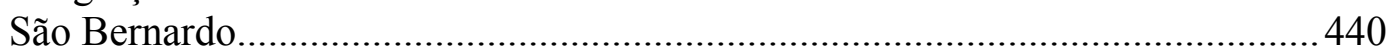

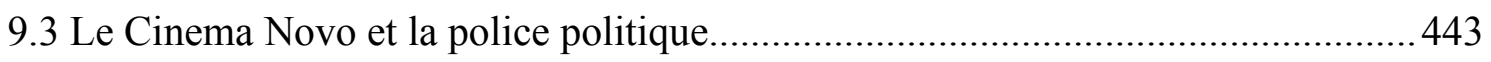

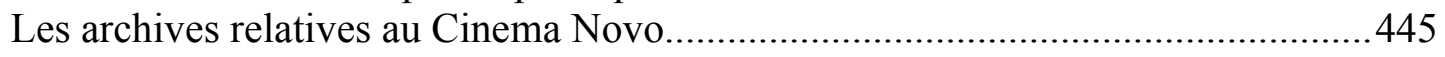




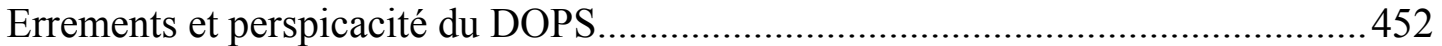

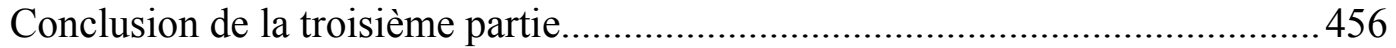

QUATRIÈME PARTIE : Le Cinema Novo troisième forme (1968-1972)........................... 459

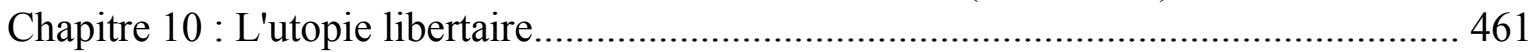

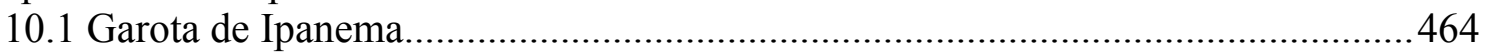

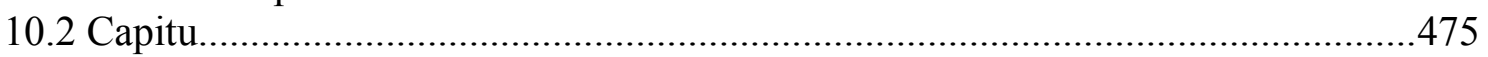

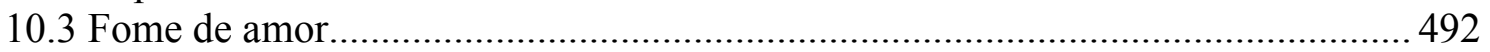

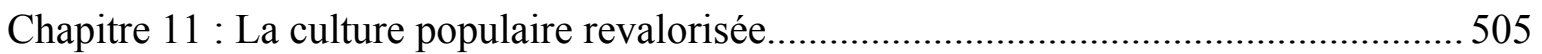

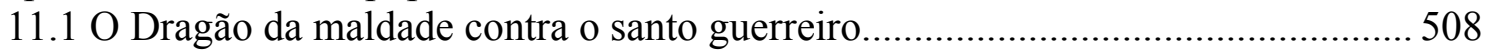

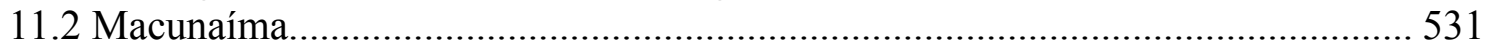

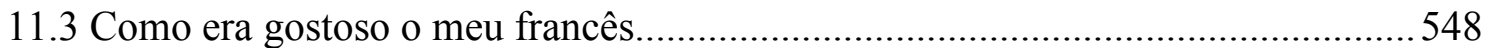

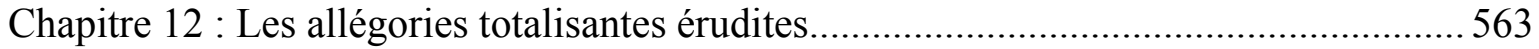

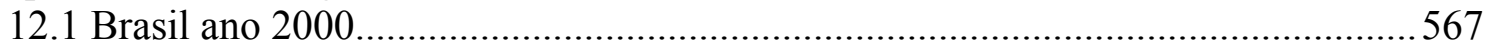

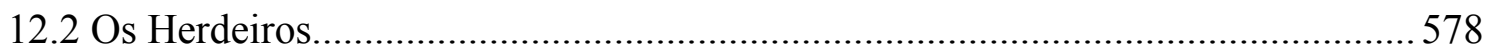

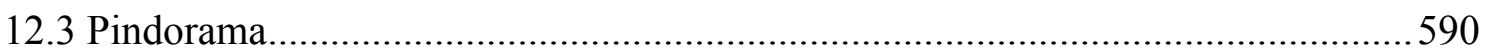

Conclusion de la quatrième partie...............................................................69 609

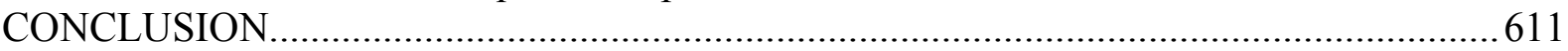

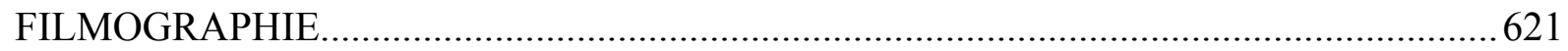

1. Filmographie détaillée (Cinema Novo et films annexes analysés dans la thèse)...... 621

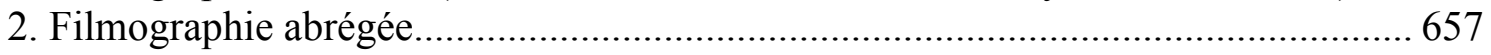

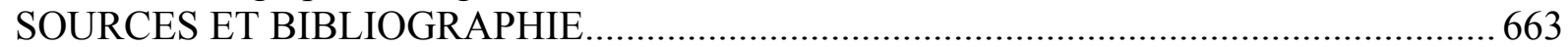

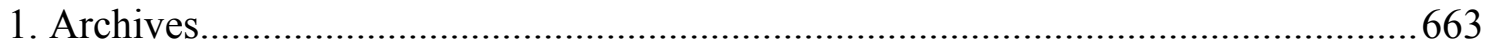

1.1. Archives privées de Claude Antoine (Bize Minervois, France)........................663

1.2 Arquivo Edgard Leunroth (Instituto de Filosofia e Ciências Humanas,

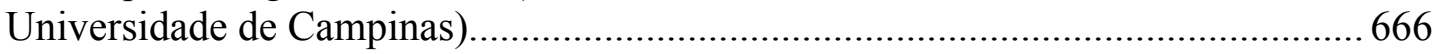

1.3 Arquivo estadual do Rio de Janeiro, Fonds « Polícias políticas no Rio de

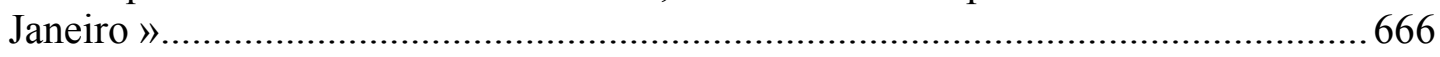

1.4 Arquivo nacional - COREG DF (Brasília), Fonds « Divisão de Censura de

Diversões Públicas - DCDP, Seção Censura Prévia, Série Cinema, Subséries Filmes

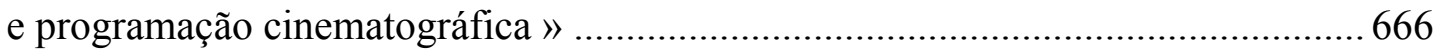

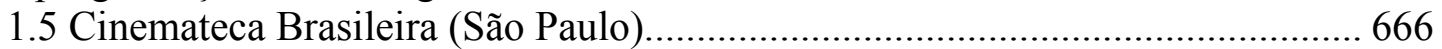

1.6 Cinemateca do Museu de Arte Moderna (Rio de Janeiro)..................................669

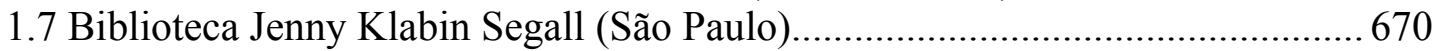

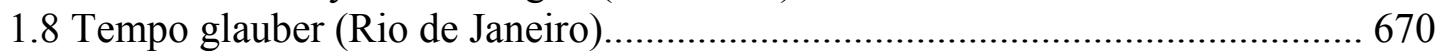

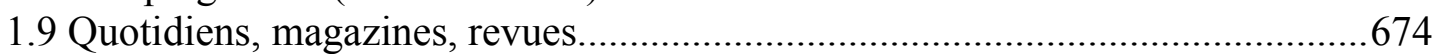

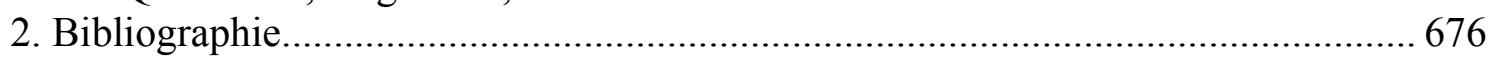

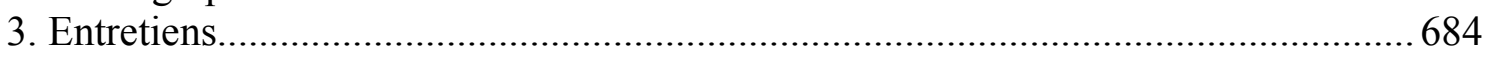

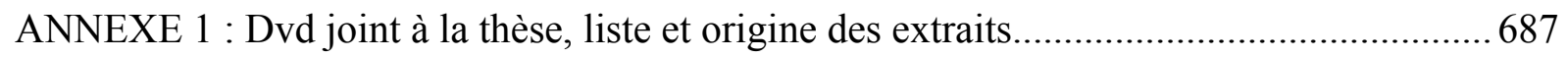

ANNEXE 2 : Distribution en pourcentage du chiffre d'affaire des salles de cinéma en 1964

ANNEXE 3 : Évolution de la réserve de marché pour les longs métrages...............................691

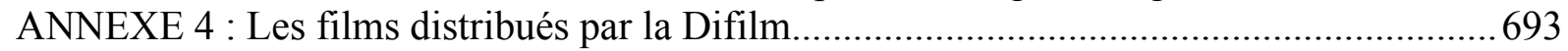

ANNEXE 5 : Chiffres disponibles sur le succès commercial du Cinema Novo.................... 695 


\section{INTRODUCTION}

\section{Origine de l'intérêt pour le Cinema Novo}

Le travail de recherche présenté ici sous le titre «Cinema Novo et conscientisation » s'inscrit dans la continuité d'une réflexion sur le cinéma que nous avons initiée en Sciences de l'Éducation sous la direction d'Alain Jeannel avec notre mémoire de maîtrise consacré au Nom de la Rose. Nous avons alors étudié ce que nous avons appelé des «dispositifs didactiques », autrement dit les stratégies discursives, mises en œuvre dans le roman d'Umberto Eco et dans le film de Jean-Jacques Annaud, qui visent à la transmission de savoirs (sur le Moyen-Âge) et de valeurs (essentiellement humanistes). Le choix de cet objet d'étude était motivé par la même conviction qui guidera ensuite notre étude du Cinema Novo. Étant nous-même un spectateur assidu de cinéma depuis l'enfance, il nous semble que le cinéma joue, pour nous comme pour d'autres, un rôle informel mais décisif dans notre éducation, le terme étant entendu dans son acception la plus large. Il ne nous intéresse pas d'étudier le cinéma didactique et comment le langage cinématographique peut se prêter à la transmission de savoirs rationnels et quantifiables dans une situation pédagogique. Ce qui nous intéresse, c'est de savoir comment le cinéma participe de notre façon de voir le monde et peut vouloir jouer de cette influence de façon réfléchie dans la relation la plus commune que nous avons avec lui et qui consiste en une relation commerciale (la salle de cinéma ou la télévision) motivée par la recherche d'un spectacle.

Le choix du film Le Nom de la Rose était étroitement lié à notre propre expérience de spectateur lorsque nous avions vu le film à sa sortie en salle. Bien qu'étant de facture académique, le long métrage possède plusieurs éléments qui nous avaient marqués. Ces éléments sont liés aux thématiques du rire, de l'amour, du désir sexuel et de la bibliothèque, lieu du conflit entre le savoir révélé et le savoir construit par l'usage de la raison. Le rire qui, selon les points de vue antagoniques retranscrits dans le film, avilit ou ennoblit, précipite une paisible abbaye du Moyen-Âge dans une série de crimes atroces qui n'est résolue que trop tard par un moine inspecteur nommé Guillaume de Baskerville en référence au héros de Conan Doyle, Sherlock Holmes. Conscient des spécificités des langages littéraire et cinématographique, l'étude du roman et de L'Apostille du Nom de la Rose devait nous révéler que le projet d'Umberto Eco, fondé sur ses propres études de la sémiologie et les conclusions obtenues dans son livre Lector in fabula, dépassait de beaucoup celui du cinéaste au moment 
de son adaptation. Dans son travail d'écriture, Eco avait projeté un dispositif de transmission de savoirs et de valeurs qui inclut une réflexion sur la liberté interprétative du lecteur. Le Nom de la rose est ainsi un faux-roman policier et un véritable essai philosophique. Trompé par le contrat de lecture apparent du roman policier, le lecteur doit revenir sur sa première actualisation du livre quand celle-ci se révèle insatisfaisante et en chercher une deuxième, celle de l'essai philosophique, essentiellement concentrée autour de la quête initiatique d'Enzo, le disciple de Guillaume de Baskerville. Au cours de cette quête, il n'est pas transmis au lecteur un message clair et concis, il se fait la dévolution d'un questionnement. Le film reprend la structure générale de la narration d'Eco et respecte même la lettre de chapitres entiers. Mais en ne reprenant que les épisodes les plus à même d'impressionner le spectateur et en supprimant les passages les plus abstraits, il échoue à devenir pour le cinéma ce que le roman représente pour la littérature.

Après notre étude du Nom de la rose, nous avons recherché un objet d'étude mieux adapté à nos interrogations. C'est à ce moment-là que nous avons fait la découverte du Cinema Novo. Celle-ci s'est faite à partir de la lecture de textes remontant aux années soixante-dix : L'Encyclopédie alpha du cinéma qui reproduit des photogrammes à même de frapper l'imagination, et deux numéros des Études cinématographiques, "Le ' cinema nôvo ' brésilien », 1 et 2 . Dans ces textes, nous était présenté un mouvement cinématographique brésilien dont l'existence pouvait être circonscrite aux années soixante et qui avait obtenu une renommée internationale grâce au succès des films de Glauber Rocha : Deus e o diabo na terra do sol (1964), Terra em transe (1967) et Antônio das Mortes (1968); de Nelson Pereira dos Santos, Vidas secas (1964), de Ruy Guerra, Os Fuzis (1964) et Joaquim Pedro de Andrade, Macunaíma (1969).

Dans ces textes, le Cinema Novo est décrit comme un cinéma politique, de critique sociale, qui avait pour objectif de provoquer la prise de conscience des mécanismes de tout ordre (sociaux, culturels, politiques et économiques) qui maintiennent le Brésil dans le sousdéveloppement. Cinéma engagé en faveur des idéaux progressistes de lutte contre l'impérialisme et les injustices sociales, le Cinema Novo devait également opter pour une rénovation et une «nationalisation» du langage cinématographique afin de provoquer des changements culturels dans l'appréciation des brésiliens de leur propre situation. Ces changements culturels devaient entraîner à leur tour les changements politiques désirés. L'objectif final était l'instauration d'un régime socialiste non totalitaire selon des modalités non définies mais qui devait émerger des conditions particulières du processus historique brésilien. L'idée principale sur laquelle Rocha et ses amis fondèrent leur praxis pendant environ une décennie est qu'il ne peut y avoir de cinéma révolutionnaire sans un langage 
esthétiquement révolutionnaire. Dans le cas du Brésil qui souffre de mécanismes d'exploitation néo-coloniaux, l'originalité de ce langage devait aussi être profondément liée à l'originalité de la situation brésilienne et à sa culture.

En approfondissant nos premières lectures, nous nous sommes aperçu que cette première interprétation était massivement soutenue par le discours des propres cinéastes. $\mathrm{Ce}$ qui a le plus attiré notre attention dans cette interprétation est son fondement humaniste qui devra pourtant être questionné. Ce fondement humaniste se résume à un mot, « conscientisation », qui signifie « faire prendre conscience, donner la conscience de ${ }^{1}$. Le terme existe en français et en portugais, nous l'expliquerons plus tard en détail, anticipons déjà qu'il contient en lui-même un point de vue sur la société et l'histoire, une éthique et une méthode. Se refusant à tirer profit des recours offerts par le langage cinématographique pour guider l'émotion du spectateur ou l'enfermer dans des discours où la circulation du sens ne laisse pas d'autre alternative que d'adhérer aux thèses et aux valeurs défendues par le film, le Cinema Novo préfère s'appuyer sur des œuvres à la structure ouverte. Il s'inspire en cela des innovations esthétiques apportées par le Néo-Réalisme et la Nouvelle Vague et s'oppose radicalement au réalisme socialiste et au cinéma classique hollywoodien. Il s'agit pour le cinéaste d'exprimer les contradictions sociales qui lui semblent agiter la société brésilienne tout en dénonçant, dans le style du film, l'autonomie de son point de vue. Le but est donc moins de «faire faire » que de «faire penser» en cherchant à provoquer l'autonomie du spectateur. Celui-ci ne serait donc pas regardé comme un objet du discours mais comme un acteur ou un sujet. Le cinéaste, qui se conçoit comme un « auteur » selon l'acception donnée au terme par la Nouvelle Vague, fait confiance au spectateur pour qu'une fois éveillé aux problématiques soulevées par le film, il adopte ensuite, par l'usage de sa raison, les conclusions qui s'imposent.

Parallèlement à cette découverte du Cinema Novo, nous avons pris connaissance des travaux de Jean-Pierre Bertin-Maghit sur le cinéma de propagande pendant l'Occupation qui, directement et indirectement, ont influencé notre réflexion. Par rapport à l'idée que nous nous faisions du Cinema Novo, le cinéma de propagande tel qu'il pouvait être défini au travers de ses analyses jouait le rôle de repoussoir. Conçu comme un discours fermé et s'appuyant sur des «figures de manipulation» comme le fondu enchaîné ou la surimpression aptes à effectuer le transfert symbolique de propriétés entre divers éléments de discours, le cinéma de propagande apparaît comme cherchant à provoquer une action déterminée de la part du spectateur sans le convaincre du bien-fondé de cette action. Celle-ci doit être accomplie sans examen critique par un spectateur qui, réduit à la dimension d'objet, peut ainsi réaliser une 1 Selon le dictionnaire en ligne Mediadico, http://dictionnaire.tv5.org/. 
action contraire à ses intérêts ou à son idéologie sans s'en apercevoir ou parce qu'il a le sentiment de ne pas avoir d'autres choix. Dans les différentes modalités de relation d'un film avec ses spectateurs que nous commencions à pouvoir nous figurer, il nous apparaissait donc une contradiction essentielle entre un film qui programme son spectateur comme un sujet et s'appuie sur son autonomie interprétative et un film qui circonscrit au contraire cette autonomie par diverses stratégies et nie le sujet dans le spectateur. Cela confirmait notre choix du Cinema Novo comme objet d'étude idéal dans la recherche d'un cinéma politique qui ne serait pas un cinéma de propagande.

Outre cet apport notionnel, les travaux de Bertin-Maghit devaient également nous introduire au cadre scientifique, aux concepts et à la méthodologie, qui nous permettraient de transformer des interrogations jusque là assez vagues en une véritable problématique et d'organiser notre recherche. Comme les travaux de Bertin-Maghit, notre étude se situera donc dans le champ cinéma-histoire et se rattachera à la sociologie du cinéma.

\section{Définition de l'objet d'étude}

Il existe déjà une production académique relativement abondante sur le Cinema Novo mais notre travail se distinguera des recherches précédentes pour au moins deux raisons. La première est notre parti pris à traiter du Cinema Novo dans sa globalité en apportant à ce phénomène culturel une définition assez précise. La seconde raison à l'originalité de notre travail est liée à l'évolution même de notre discipline, les études cinématographiques. Celle-ci, comme nous le verrons plus bas, tente actuellement de concilier l'approche sémiologique qui l'avait caractérisée dans les années soixante-dix avec l'étude du cadre économique et technique de l'apparition des films afin de pouvoir ancrer les phénomènes esthétiques dans le contexte historique qui les a vu se développer. À ce titre, toutes les étapes du fait filmique seront convoquées : production, distribution et réception. Avant d'aller plus avant dans la définition de notre objet d'étude, nous allons rapidement résumer quelques uns des plus importants travaux qui ont déjà été faits sur le Cinema Novo. Cela aidera le lecteur à mieux comprendre la singularité de notre approche.

Les premières études du Cinema Novo appartiennent au domaine de l'essai critique et sont réalisées au Brésil au moment même de l'émergence de ce phénomène culturel. Les critiques, Alex Viany et Paulo Emílio Sales Gomes, s'intéressent au Cinema Novo car ils y voient la première tentative de développer au cinéma une esthétique authentiquement brésilienne. Le cinéma «nouveau » brésilien est compris comme le cinéma décolonisé qui 
s'oppose au «vieux» cinéma, symptôme de l'aliénation coloniale ${ }^{2}$. Le Cinema Novo représente le « bon » cinéma brésilien qui mérite d'être défendu et de conquérir un marché qui appartient depuis 50 ans et à près de $90 \%$ au cinéma américain. Les textes de Viany et de Sales Gomes peuvent être rapprochés de ceux de Glauber Rocha qui écrira abondamment tout au long de sa carrière. Les quotidiens d'information sont le principal support éditorial de ces auteurs, les livres qui viendront plus tard représentent souvent la somme de leur réflexion critique. Sales Gomes publie en 1973 Trajetória no subdesenvolvimento ${ }^{3}$ dans lequel il réfléchit à la possibilité d'un cinéma national dans un pays sous-développé. Les principaux écrits et entretiens de Viany seront réunis en 1999 dans un ouvrage posthume intitulé $O$ Processo do Cinema Novo ${ }^{4}$. Rocha traite déjà du Cinema Novo dans Revisão crítica do cinema brasileiro $(1963)^{5}$ mais son œuvre la plus importante demeure A Revolução do Cinema Novo $(1981)^{6}$ qui consiste en un recueil de textes écrits entre 1957 et 1980.

La production académique sur le Cinema Novo débute en 1967 avec un livre qui fera date, Brasil em tempo de cinema. ${ }^{7}$. Dans cet ouvrage, Jean-Claude Bernardet dresse le panorama de la production brésilienne des années 58 à 66 et montre l'existence d'orientations communes dans la "politique» des jeunes auteurs brésiliens. Bien que le terme "Cinema Novo » ne soit utilisé que deux fois dans l'ouvrage, Brasil em tempo de cinema est une première tentative de remise en question de l'identité du Cinema Novo comme modèle de cinéma révolutionnaire, une identité qui aura été acceptée de façon quelque peu dogmatique sous la pression des cinéastes et de la presse étrangère mais qui avait déjà divisée la critique brésilienne. Brasil em tempo de cinema initie aussi la manipulation du Cinema Novo comme un objet d'étude qui permet à la gauche de revenir sur sa trajectoire idéologique et sur les erreurs tactiques qui l'auront conduite à la déroute dans les affrontements politiques des années soixante. Avec une approche différente, notre travail reprendra les questionnements initiés par ce livre.

Le Cinema Novo est l'objet d'une attention particulière dans les histoires et encyclopédies du cinéma brésilien. En 1987, Fernão Ramos reprend partiellement les analyses de Bernardet dans História do cinema brasileiro ${ }^{8}$. Dans le chapitre consacré au Cinema Novo,

2 Le vieux cinéma est représenté par la chanchada (comédie populaire avec numéros musicaux de faible budget) et le cinéma d'imitation dans la continuité de ce que faisait la Vera Cruz (maison de production ayant tenté de développer à São Paulo un cinéma suivant les modèles américains classiques de narration et de production). $C f$. VIANY, Alex. $O$ Velho e o novo. SAC.

3 GOMES, Paulo Emílio Sales. Cinema : trajetória no subdesenvolvimento, coll. Leitura, Paz e Terra, São Paulo, 1996 (réédition).

4 VIANY, Alex. O processo do Cinema Novo. Rio de Janeiro, Aeroplano, 1999.

5 ROCHA Glauber. Revisão crítica do cinema brasileiro. Rio de Janeiro, Civilização brasileira, 1963.

6 ROCHA, Glauber. Revolução do Cinema Novo. Rio de Janeiro, Alhambra/Embrafilme, 1981.

7 BERNARDET, Jean-Claude. Brasil em tempo de cinema. Rio de Janeiro, Paz e Terra, 1967.

8 RAMOS, Fernão (org.). História do cinema brasileiro. São Paulo, Art editora, 1987. 
il met en relation l'idéologie exprimée dans les films avec le fait que l'absence de succès commercial du Cinema Novo l'a empêché de développer la praxis politique à laquelle il aspirait. Son travail se situe dans le cadre d'une histoire du cinéma qui accorde une place prédominante aux grandes œuvres et développe avant tout les questions d'esthétique. D'autres histoires du cinéma brésilien ont été publiés qui ne se démarquent pas de cette approche 9 .

Des analyses filmiques sont publiées dans les années quatre-vingts. En 1982, JeanClaude Bernardet et Coelho Teixeira publient un recueil d'analyses filmiques concernant Terra em transe et $O s$ Herdeiros ${ }^{10}$. Bernardet seul propose un peu plus tard un recueil d'analyses de documentaires parmi lesquels Maioria absoluta, autre film important de la cinématographie du Cinema Novo ${ }^{11}$. À peu près à la même époque, Ismail Xavier publie des analyses filmiques de Barravento et Deus e o diabo na terra do sol $^{12}$. Quelques années plus tard, Xavier poursuit son étude du Cinema Novo dans une thèse qui concerne les films sortis entre 1968 et 1970 : Brasil ano 2000, Macunaíma, Os Herdeiros, O Dragão da maldade contra o santo guerreiro, Os Deuses e os $\operatorname{mortos}^{13}$. Au sujet des analyses filmiques les plus importantes du Cinema Novo, comptons encore avec José Carlos Avellar, un critique en activité depuis les années soixante, qui revient sur Deus e o diabo na terra do sol en $1995^{14}$. Notons enfin, qu'en marge de ces analyses filmiques, ont été publiés au moins une biographie ou série d'entretiens pour chaque cinemanovista mais qu'il ne s'agit pas de publications de caractère scientifique malgré la profusion d'informations qu'elles peuvent contenir ${ }^{15}$.

En France, comme au Brésil, le Cinema Novo est d'abord le sujet d'essais critiques. Dès 1963, Les Cahiers du cinéma et Positif publient plusieurs dossiers et entretiens. En 19721973, les deux volumes des Études cinématographiques dont nous avons déjà parlés, constituent une somme représentative de l'interprétation classique du Cinema Novo tel qu'elle a été développée dans ces revues prestigieuses. Ils regroupent, sous la direction de Michel Estève, des analyses écrites par Barthélémy Amengual, René Gardies, Lino Micciché, Vincent

9 Comme par exemple : MORENO, Antônio. Cinema brasileiro, História e relações com o Estado. Niterói/Goiânia, EDUFF/UFG, 1994.

10 BERNARDET, Jean-Claude, TEIXEIRA, Coelho (org.). Terra em transe Os Herdeiros : Espaços e poderes - Texto de trabalho. São Paulo, ed. Com-Arte, 1982.

11 BERNARDET, Jean-Claude. Cineastas e imagens do povo. São Paulo, ed. Brasiliense, 1985.

12 XAVIER, Ismail. Sertão Mar - Glauber Rocha e a estética da fome. São Paulo, ed. Brasiliense, 1983.

13 XAVIER, Ismail. Alegorias do desengano : a resposta do cinema novo a modernizacao conservadora. Thèse de livre docência, Escola de Comunicação e Arte - Universidade de São Paulo, São Paulo, 1989, 239 p.

14 AVELLAR, José Carlos. Deus e o diabo na terra do sol - a linha reta, o melaço de cana e o retrato do artista quando jovem. Rio de Janeiro, Rocco, 1995.

Nous n'avons pas retenu dans ce relevé le livre de Raquel Gerber sur l'œuvre de Glauber Rocha car elle recourt dans ses analyses à la psychanalyse, outil auquel nous-mêmes ne nous sommes pas intéressé. GERBER, Raquel. O mito da civilização Atlântica : Glauber Rocha, cinema, política e a estética do inconsciente. Petrópolis, Vozes, 1982.

$15 \mathrm{La}$ liste exhaustive de ces biographies se trouve dans notre bibliographie. 
Pinel et René Prédal ${ }^{16}$. Leur mérite est d'apporter des éléments de compréhension de l'esthétique du Cinema Novo qui abonde en références et emprunts remettant à l'histoire du Brésil et à sa culture. Il s'agit d'abord «d'élucider» le sens de films qui ont totalement désorienté le public européen par leur nouveauté. Ces textes peinent cependant à prendre du recul vis à vis des préoccupations politiques de l'époque et des discours des propres cinéastes qui sont les principales sources des auteurs. L'émergence de l'approche sémiologique déplace l'axe d'étude du Cinema Novo de la défense d'un modèle de cinéma révolutionnaire vers l'analyse de ses innovations formelles rapportée à une histoire esthétique du cinéma. À ce titre, la thèse présentée par René Gardies en $1972^{17}$ est un travail pionnier. Après lui, il faudra attendre 1987 et la publication par Sylvie Pierre d'une biographie de Glauber Rocha pour retrouver un travail d'envergure sur le Cinema Novo ${ }^{18}$.

En marge de l'activité académique européenne et brésilienne, rappelons aussi le travail de Robert Stam et Randal Johnson. Ensemble ou séparément, Stam et Johnson ont publié plusieurs ouvrages qui ont bénéficié d'une importante diffusion : Brazilian cinema, Cinema Novo $x$ 5, The Cinema and the state, Tropical multiculturalism ${ }^{19}$. Se faisant l'interprète pour les lecteurs de langue anglaise des cinéastes, critiques et chercheurs brésiliens, ils restent proches de leurs sources et étudient le Cinema Novo en tant que mouvement de résistance à l'impérialisme américain. Aussi s'intéressent-ils autant à l'esthétique développée dans les films (résistance culturelle) qu'aux modes de défense de la production nationale (résistance économique) développées en collaboration avec l'État et avec la participation active des membres du Cinema Novo, en particulier à l'époque d'EMBRAFILME ${ }^{20}$.

Plus récemment, plusieurs thèses ont été soutenues en France et au Brésil sur des thèmes en relation avec le Cinema Novo sans toutefois rencontrer la même répercussion que les travaux que nous venons de citer. Les approches ont également varié sans s'identifier encore avec celle que nous allons pratiquer. Alexandre Figueiroa Ferreira et Claudio Valentenetti se sont intéressés à la réception qui a été faite du Cinema Novo en Europe,

16 MICCICHE, Lino et allii, ss la dir. de ESTEVES, Michel. Le "cinema nôvo" brésilien - Gláuber Rocha. Paris, coll. Etudes cinématographiques, Lettres Modernes, 1973.

17 GARDIES, René. L'oeuvre de Glauber Rocha : analyse structurale d'un système textuel. Thèse de doctorat dirigée par Bernard Teyssèdre, Université de Paris 1, Paris, 1972.

18 PIERRE, Sylvie. Glauber Rocha. Paris, ed. Cahiers du cinéma, 1987.

19 JOHNSON, Randal, STAM, Robert. Brazilian cinema. Columbia University Press, 1995 (reed. 1982). JOHNSON, Randal. Cinema Novo $x 5$ : Masters of contemporary Brazilian film. Austin, University of Texas, 1984.

RANDAL, Johnson. The film industry in Brazil : Culture and the state. Pittsburgh, University of Pittsburgh Press, 1987.

STAM, Robert. Tropical multiculturalism - A Comparative history of race in brazilian cinema and culture. Duke University Press, 1997.

20 EMBRAFILME est une entreprise de capital mixte mise en place par le régime militaire et ayant abouti à la quasi complète nationalisation de l'activité cinématographique brésilienne dans les années soixante-dix. 
principalement en étudiant les critiques publiées pendant les années soixante ${ }^{21}$. Duvaldo Bamonte a étudié les relations existantes entre le Cinema Novo et le cinéma moderne italien au travers des rencontres qui ont eu lieu entre les cinéastes des deux pays dans les années soixante et a ensuite pratiqué des rapprochements entre l'œuvre de Glauber Rocha et celle de Pier Paolo Pasolini ${ }^{22}$. Nous nous intéresserons quant à nous à la réception du Cinema Novo au Brésil.

Christiane Carvalho da Nova, Fátima Gomes Lisboa et Tereza Ventura se sont exclusivement penchées sur l'œuvre de Glauber Rocha. La première a choisi pour objet d'étude la conception de l'histoire dans le film Terra em transe et a cherché à se rapprocher d'études récentes (européennes et nord-américaines) qui abordent le cinéma en tant que possibilité de discours sur l'histoire ${ }^{23}$. Lisboa a étudié la trajectoire de Rocha entre 1958 et 1971 sur la base de sa production filmique et écrite et a montré comment il avait lui-même encouragé la presse étrangère à le considérer comme un prophète du tiers-monde animé d'un projet de révolution culturelle relative à l'image que l'on pouvait se faire du Brésil de l'extérieur ${ }^{24}$. Ventura a été la première à avoir accès aux scénarios restés inédits de Rocha et les a analysés en tentant de les mettre en relation avec son projet d'une esthétique révolutionnaire $^{25}$. Leonor Estela Pinto a rejoint une approche généraliste et s'est intéressée au cinéma brésilien dans sa globalité. Son travail a consisté à identifier différents moments dans l'action de la censure sur le cinéma brésilien pendant la dictature militaire. Il s'agit d'une analyse des documents officiels de la censure récemment libérés à la consultation. L'étude de la réception des films du Cinema Novo par la censure occupe une place importante dans son travail sans toutefois être différenciée de celle des autres films ${ }^{26}$.

Au fil de la lecture de l'ensemble de ces études en relation avec le Cinema Novo, un paradoxe curieux nous est apparu. L'appellation «Cinema Novo » n'est jamais clairement

21 FERREIRA, Alexandre Figueiroa. La Vague du Cinema Novo en France fut-elle une invention de la critique? , Paris, L'Harmattan, 2000.

VALENTINETTI, Claudio M.. Glauber, um olhar europeu. Rio de Janeiro : Prefeitura do Rio : Instituto Lina Bo e P.M. Bardi, 2002.

22 BAMONTE, Duvaldo. Afinidades eletivas : o diálogo de Glauber Rocha com Pier Paolo Pasolini (19701975). Thèse de doctorat dirigée par Ismail Xavier, Escola de Comunicação e Arte - Universidade de São Paulo, São Paulo, 2002.

23 CARVALHO DA NOVA, Christiane. L'histoire en transe : le temps et l'histoire dans l'oeuvre de Glauber Rocha. Thèse de doctorat dirigée par Michèle Lagny, Université de la Sorbonne nouvelle-Paris III, Paris, 2003.

24 LISBOA, Fátima Gomes. Un Artiste intellectuel : Glauber Rocha et l'utopie du Cinema Novo (1955-1971). Thèse de doctorat dirigée par Pierre Vayssière, Études Latino-Américaines - Université de Toulouse 2, Toulouse, décembre 2000.

25 VENTURA, Tereza. A Poétika polytika de Glauber Rocha. Rio de Janeiro, Ministério da Cultura, Funarte, 2000.

26 SOUZA PINTO, Leonor Estela. Le Cinéma brésilien au risque de la censure pendant la dictature militaire de 1964 à 1985. Thèse de doctorat dirigée par Guy Chapouillie, 441 pages et 1 cd-rom, Université ToulouseLe Mirail, École Supérieure d'Audiovisuel, Toulouse, décembre 2001. 
définie. Les différentes histoires du cinéma brésilien qu'il est possible de compulser, évoquent les différents cinéastes ou films sans pour autant sentir la nécessité de conceptualiser le Cinema Novo avec précision et les recherches qui portent sur un auteur ou un corpus d'œuvres limité ne passent pas non plus par cette conceptualisation qui, dans le cadre de notre thèse, nous paraît au contraire indispensable ${ }^{27}$. Selon les auteurs, le Cinema Novo peut être qualifié d'école, de mouvement ou de chapelle, sans qu'il soit pour autant expliqué précisément ce que l'on entend par le terme employé.

La définition du Cinema Novo ne va pas de soi. La première difficulté réside dans la diversité des styles des films qui sont généralement identifiés au Cinema Novo et par le grand dynamisme de son esthétique qui a beaucoup évolué entre les années soixante et soixante-dix. La deuxième difficulté réside dans les discours des cinemanovistas et les contradictions que l'on peut discerner dans l'interprétation qu'ils donnent du cinéma qu'ils pratiquent. Pour palier à ces difficultés, nous avons beaucoup emprunté à la méthode qu'emploie Michel Marie pour définir la Nouvelle Vague comme une école artistique. Il ne nous intéressait pas cependant de donner une définition a posteriori passant par l'utilisation d'un cadre théorique étranger à l'histoire du Cinema Novo. Cela était gênant pour nous qui voulons, entre autres choses, rester au plus près des conceptions des différents acteurs de l'histoire du Cinema Novo sans pour autant en demeurer le simple relais. L'étude de sources primaires, écrits et entretiens des cinéastes, montrent d'ailleurs que le manque de conceptualisation de l'expression Cinema Novo que nous constatons dans les sources secondaires était aussi le leur.

Dans le cadre de notre étude, il nous a semblé important de nous attacher à cette diversité de styles que nous avons déjà évoquée et aux contradictions ayant pu apparaître dans les films et les discours des cinéastes au fil de l'évolution du contexte historique sur lequel il prétendaient agir. Sur la base des entretiens que nous avons menés avec une bonne partie d'entre eux ${ }^{28}$, nous avons choisi de considérer que le Cinema Novo devait être conçu comme un groupe de cinéastes et d'y rattacher le corpus des films qu'ils ont produits pendant le temps où le groupe est resté uni. L'unité de ce groupe était fondée sur deux principes assez simples.

Le premier est celui de l'amitié, thème récurrent dans les entretiens accordés par les cinemanovistas depuis le début des années soixante jusqu'à aujourd'hui. Il s'agissait d'un groupe de copains qui se voyaient régulièrement, ont travaillé sur les films des uns des autres

27 La démonstration de cet état de fait peut être faite à partir de l'article sur le Cinema Novo de l'Enciclopédia do cinema brasileiro organisée par Fernão Ramos, un ouvrage de référence. Dans ce texte, Paulo Antônio Paranaguá s'inscrit dans la perspective des essais critiques de Viany et Sales Gomes remontant aux années soixante et remettant à cette opposition entre le neuf et le vieux, le décolonisé et le colonisé, en concluant : « Cinema Novo é paradigma de cinema brasileiro em liberdade » (Le Cinema Novo est paradigme de cinéma en liberté). Ce n'est pas forcément faux, mais c'est tout de même assez vague. RAMOS, Fernão et MIRANDA, Luís Felipe (org.). Enciclopédia do cinema brasileiro. São Paulo, SENAC, 2000.

$28 C f$. liste exhaustive dans la partie « Sources et bibliographie ». 
et ont également démontré de forts liens de solidarité pour assurer leur promotion dans la presse ou même pour se financer. Nous reviendrons en détail sur cet élément dans le corps de la thèse.

Le deuxième principe sur lequel reposait l'unité du groupe est qu'il s'agissait d'une communauté de pensée très homogène. Tous possédaient un point de vue commun sur l'histoire, la politique ${ }^{29}$, la fonction du cinéma et celle de l'intellectuel. Cette identité de point de vue passait par la même conviction quant à l'importance de la conscientisation qui apparaissait aux yeux de tous comme le chemin de la transformation du Brésil. Selon nous, le Cinema Novo existe tant que le groupe reste uni et tant que le concept de conscientisation reste pour ses membres un concept opérant.

Cette approche nous permet de circonscrire un corpus de films et un ensemble de personnes. Les cinéastes du Cinema Novo sont Joaquim Pedro de Andrade, Carlos Diegues, Ruy Guerra, Leon Hirszman, Arnaldo Jabor, Walter Lima Júnior, David Neves, Glauber Rocha, Nelson Pereira dos Santos et Paulo César Saraceni. Le Cinema Novo correspond, à quelques exceptions près, aux films qu'ils ont réalisé entre 1959 et 1972:

1960 : Arraial do cabo (Saraceni), Couro de gato (Andrade)

1962 : Barravento (Tempête, Rocha), Os Cafajestes (La Plage du désir, Guerra), Cinco vezes favela (O Favelado, Farias, Zé da Cachorra, Borges, Escola de samba Alegria de viver, Diegues, Couro de gato, Andrade et Pedreira de São Diogo, Hirszman), Garrincha, alegria do povo (Andrade), Porto das caixas (Saraceni)

1963 : Vidas secas (Sécheresse, Santos)

1964 : Deus e o diabo na terra do sol (Le Dieu noir et le diable blond, Rocha), Os Fuzis (Les Fusils, Guerra), Ganga Zumba (Ganga Zumba, Diegues), Integração racial (Saraceni), Maioria absoluta (Hirszman)

1965 : O Desafio (Le Défi, Saraceni), A Falecida (La Morte, Hirszman), A Grande Cidade (Diegues), Menino do engenho (L'Enfant de la plantation, Lima)

1966 : Amazonas, Amazonas (Rocha), O Circo (Jabor), Maranhão 66 (Rocha), O Padre e a moça (Andrade)

1967 : Brasília, contradições de uma cidade nova (Andrade), Cinema Novo (Andrade), Garota de Ipanema (Hirszman), A Opinião pública (Opinion publique, Jabor), Terra em transe (Terre en transe, Rocha)

1968 : Capitu (Saraceni), Fome de amor (Santos)

1969 : Brasil ano 2000 (Lima), Bravo guerreiro (Dahl), O Dragão da maldade contra o santo guerreiro (Antonio das Mortes, Rocha), Macunaíma (Macunaíma, Andrade), Memória de Helena (Neves)

1970 : Os Deuses e os mortos (Les Dieux et les morts, Guerra), Os Herdeiros (Les Héritiers, Diegues)

1971 : Azyllo muito louco (Santos), Como era gostoso o meu francês (Qu'il était bon mon petit français, Santos), Pindorama (Jabor)

29 La communauté de pensée sur le plan politique repose sur un diagnostic commun des problèmes du Brésil et sur la pratique de la politique elle-même. Sur le plan de l'appartenance ou de la sympathie envers tel ou tel parti, les membres du Cinema Novo pouvaient présenter des divergences mais celles-ci n'ont pas eu d'incidence sur la période qui va nous intéresser. Certains sont plus proches de la gauche catholique (Diegues, Saraceni), d'autres sont plus proches du PC (Hirszman), d'autres refusent un rapprochement avec les vieilles structures (Dahl estime qu'il était New Left avant la lettre), d'autres encore n'ont pas d'appartenance ni de sympathie particulière pour un parti ou un autre, voire même, aussi surprenant que cela puisse paraître, une opinion établie et se conçoivent comme « oscillant ». Le cas Rocha est sans doute le plus compliqué mais il faut noter dès à présent que, contrairement à certains de ses camarades, il ne s'est jamais intégré à une structure politique. 
1972 : Os Inconfidentes (Andrade), São Bernardo (Hirszman), Uirá, um índio em busca de Deus (Dahl)

Les signes de désagrégation du groupe sont visibles à partir de la fin des années soixante. Les liens d'amitié se distendent, parfois en conséquence des exils. Diegues reste en France pendant un an entre 1969 et 1970. Rocha, qui voyage déjà énormément à partir du succès de Deus e o diabo na terra do sol, doit rester à l'étranger entre 1971 à 1976. Sur le plan professionnel, les collaborations sont rares et tous ne vivront pas de la même manière la période Embrafilme. Certains participeront directement de la création de l'entreprise par l'État (1974) et y conserveront leur accès (Diegues, Jabor, Dahl, Pereira dos Santos, Andrade), d'autres resteront en marge (Saraceni, Rocha). Tous ont manifesté à peu près au même moment la volonté de s'affranchir de la tutelle du Cinema Novo, autant par des déclarations dans la presse que par un renouvellement de leur cinéma (1969-1972). Enfin, à partir du début des années soixante-dix, avec l'échec des guérillas urbaines et rurales, le Brésil passe par un changement de paradigme politique. La gauche n'est plus mobilisée autour du projet de la révolution totale mais par celui, plus pragmatique, du retour à la démocratie. Dans un tel contexte, et même s'il avait commencé à être mis à mal dès le coup d'État de 1964, le concept de conscientisation tombe en désuétude. Le Cinema Novo qui, comme nous allons le vérifier, s'identifiait avec l'idéologie qui est liée à ce concept, cesse alors d'exister.

\section{Problématique}

À partir de notre questionnement personnel sur la capacité du cinéma à modifier la conception du monde des spectateurs, l'objet principal de notre recherche consistera à nous interroger sur l'identité du Cinema Novo avec ce modèle du cinéma révolutionnaire que la critique européenne a vu en lui et à prendre au mot les cinéastes qui ont justifié leurs œuvres par leur prétention à intervenir dans la vie politique et sociale. Deux versants du problème devront être examinés. Le premier concerne la praxis des cinéastes et se décline sur deux axes. Quelles stratégies ont-ils mises en œuvre pour réaliser et diffuser leurs films ? Quels dispositifs filmiques ont-ils employés pour transformer les consciences ? Le deuxième versant du problème est celui de la réception qui, dans une certaine mesure, peut être envisagé de façon totalement indépendante au premier.

Nous considérons en effet, comme le fait Roger Odin à la suite de l'ethnologue Sol Worth dans l'article «The development of a semiotic of film », que la situation dans laquelle nous nous trouvons quand nous regardons un film de cinéma ne correspond pas au schéma classique de la communication conceptualisée par Roman Jakobson. Un film n'a pas de sens 
en lui-même et n'acquiert de sens que dans sa relation à un sujet percevant. La séparation qui existe entre l'espace du destinateur et du destinataire ainsi que la fragilité du langage cinématographique fait que la signification naît de façon quasi indépendante. Il n'y a pas communication au sens de la transmission d'un message d'un émetteur à un récepteur mais un double processus de production de $\operatorname{sens}^{30}$. Cette théorie se vérifie en observant les interprétations absolument dissemblables qui peuvent être données à un film par ses spectateurs en fonction de la situation dans laquelle le film est vu ou en comparant les intentions d'un cinéaste avec la trajectoire que peut prendre son film une fois terminé. Dans le cadre de notre recherche, cela nous incite à refuser toute relation mécanique entre un film et son public et à envisager qu'un film, réalisé sans intention de conscientisation ou mal conçu dans une telle perspective, puisse être suivi d'effets et engendrer ou participer à des changements sociaux. Réciproquement, un film extrêmement sophistiqué dans ce sens pourrait, même s'il atteignait le public, ne produire aucun effet.

\section{Définition des concepts}

Notre intention initiale consistant à étudier le Cinema Novo à partir de la prétention des cinéastes à agir sur l'histoire nous oblige à nous dégager d'une approche traditionnelle se limitant à confiner les films dans l'histoire des langages cinématographiques. Nous irons donc plus loin en tentant de situer les films dans l'histoire culturelle et en leur restituant leur statut de fait social. Dans cette perspective, les concepts que nous allons mobiliser appartiennent au champ cinéma-histoire que nous avons mentionné plus haut et dont le principal initiateur est Marc Ferro. Pionnier de l'utilisation du film comme archive digne d'étude par l'historien, Ferro a montré que celui-ci devait être l'objet d'un questionnement critique de la part du chercheur en relation non seulement à la spécificité du cinéma en comparaison avec l'écrit mais aussi à sa complexité en tant que mode d'expression dépendant d'un appareillage industriel sur lequel pèse de lourdes contraintes techniques, économiques et politiques. Ses travaux ont remis en cause la conception des productions cinématographiques comme «reflet» des sociétés qui les produisent en faveur d'une conception plus nuancée et contradictoire. Dans cette nouvelle conception, le cinéma, conçu comme «agent de l'histoire », peut être mis au service de gouvernements ou de groupes d'influence (propagande politique), peut servir au renforcement ou à la légitimation de valeurs qui fondent un ordre social sans pour autant être le produit d'un commanditaire distinct (propagande sociologique)

30 Voir ESQUENAZI, Jean-Pierre, ODIN Roger. « Cinéma et réception », in Réseaux, Paris, Hermès Sciences Publication, 2000, p. 53. 
ou encore être le produit de groupes minoritaires de contestation des idéologies dominantes. Bien qu'invalidant la conception du cinéma comme reflet d'une société en mettant à jour les contraintes et les intérêts particuliers qui le traversent, cette conception du cinéma n'exclut pas qu'il soit aussi le « produit de l'histoire » dans la mesure où un ensemble de films réalisés dans un certain contexte peut traduire une conception originale du cinéma qu'il peut être intéressant de mettre au jour.

L'analyse historique du cinéma s'est appliquée aux objets d'étude les plus divers tout en prenant bien en compte qu'un film ne pouvait être jugé seulement sur la base de ses dialogues, de son scénario ou de tout ce qui pourrait le réduire à une trace écrite. Le « style » (ou " écriture cinématographique ») est la base principale de jugement d'un texte filmique. Nous devons les concepts sur lesquels nous avons fondé notre méthodologie de recherche à des études qui se sont appliquées sur des objets tout à fait distincts du nôtre. Le livre de Michel Marie sur la Nouvelle Vague ${ }^{31}$ nous a permis de nous interroger sur la manière dont s'écrivent les mouvements, les courants ou les écoles dans l'histoire du cinéma. Son apport a été décisif pour définir notre objet d'étude. Nous utiliserons en particulier le concept de « corps doctrinal» ou « concept critique » qui permettra de définir une éthique au Cinema Novo à partir d'un certain nombre de partis pris esthétiques. Notre conception du film luimême est la même que celle de Jean-Pierre Bertin-Maghit dans Les Documenteurs des années noires $^{32}$, Sylvie Lindeperg dans Les Écrans de l'ombre ${ }^{33}$ ou encore Jean-Pierre Esquenazi dans Godard et la société des années soixante ${ }^{34}$. Il s'agit d'une conception récente dans les études cinématographiques qui rompt avec celle que nous offrait la sémiologie et qui peut être définie dans ces termes. Selon Bertin-Maghit :

« Le film tient de l'individuel et du collectif ; c'est en outre un médium dans lequel interfèrent systèmes de productions, mentalités, horizons d'attente du spectateur, données politiques et économiques. $»^{35}$

Lindeperg exprime une conception similaire quand elle nous invite à considérer un film comme le résultat d'une opération :

« [...] je définirai cette « opération cinématographique » comme le rapport entre une place (le métier, l'histoire du temps présent), un ensemble de procédures (la pratique cinématographique) et la construction d'un récit (celui du film comme celui produit sur le

31 MARIE, Michel. La Nouvelle Vague - une école artistique. Paris, coll. 128, Nathan, 1997.

32 BERTIN-MAGHIT, Jean-Pierre. Les Documenteurs des années noires. Paris, Nouveau Monde Éditions, 2004.

33 LINDEPERG, Sylvie. Les écrans de l'ombre - La Seconde Guerre Mondiale dans le cinéma français. Paris, CNRS Éditions, 1997.

34 ESQUENAZI, Jean-Pierre. Godard et la société française des années 1960. Paris, coll. Armand colin Cinéma, Armand Colin, 2004.

35 BERTIN-MAGHIT, Jean-Pierre. Op. cit., p. 18. 
film). $»^{36}$

Cette conception du film implique de s'intéresser à toutes les étapes du fait filmique. Outre le texte filmique lui-même, il est indispensables de recueillir des archives concernant les phases de production, de distribution et d'exploitation.

Dans notre thèse, nous nous appuierons aussi sur les travaux de Roger Odin dans le cadre de la sémio-pragmatique. Odin définit l'objectif de la sémio-pragmatique dans ces termes :

«Christian Metz avait décrit l'axe de pertinence de la sémiologie comme ' comprendre comment le film est compris ' [in Langage et cinéma]. Pour la sémio-pragmatique le programme se reformule en ' comprendre comment les textes sont construits ' (dans le mouvement de la lecture tout comme dans celui de la réalisation). La sémio-pragmatique s'intéresse en priorité aux grandes modalités de la production du sens et de l'affect (vs sens produit) ainsi qu'à leur condition de mise en œuvre. $»^{37}$

Cet inversement de perspective par rapport à l'approche traditionnelle des études cinématographiques tournée vers la sémiologie est motivée par cette reconnaissance de la fragilité du texte filmique que nous mentionnions plus haut. Odin en déduit que si l'approche sémiologique ne saurait être invalidée et présente encore une grande valeur, elle doit être confrontée à une approche pragmatique qui vise à mettre en évidence les conditions de production et de réception qui vont peser sur la production de sens effectuée à partir du film par les différents acteurs en présence.

L'approche que nous allons mettre en pratique conjugue la nouvelle conception du film que nous avons mentionnée plus haut avec la nécessité de prise en compte des publics soulignée par Odin. Cette approche a déjà été conceptualisée par Esquenazi dans un article intitulé « Un film, un fait social» paru dans un numéro spécial de la revue Réseau en $2000^{38}$. Lui-même a d'ailleurs appliqué cette approche dans l'ouvrage sur Godard que nous avons cité. La thèse de l'article est la suivante :

«Un film, comme tout autre ensemble de signes publiques se présentant comme un tout, n'est compréhensible qu'en raison du statut social qu'il acquiert ou est capable d'acquérir. » (p. 15)

Il développe sa démonstration en deux points. Tout d'abord, il rappelle les grandes étapes de l'histoire des études cinématographiques. À la cinéphilie a succédé la critique et à la critique la tentative d'une approche scientifique pluridisciplinaire dont les signes avantcoureur remontent à la filmologie des années 50. Il raconte ensuite comment un nouveau regard a émergé ces vingt-cinq dernières années qui concilie l'analyse interne du film et 
l'analyse externe du contexte de réception et contraint à ne plus considérer l'art comme un domaine à part.

Les années 50 et 60 marquent l'apogée de la critique qui, elle-même, est dominée par la " politique des auteurs » fondée par Les Cahiers du cinéma dans les années cinquante. Selon Esquenazi, la théorie du cinéma a souffert des excès de ce concept critique :

« [...] à partir d'un point de vue à la fois formaliste [emphase sur l'objet film et la qualité de la mise en scène] et spiritualiste [emphase sur le film comme expression d'une individualité], les Cahiers $d u$ cinéma instituent un point de vue sur le cinéma qui ne retient de ce dernier que que sa destinée artistique, et qui ne s'intéresse à un film que lorsque celui-ci peut être considéré comme une oeuvre en soi exprimant la personnalité d'un auteur. Cette doctrine suppose une conception de l'art comme un domaine à part, planant au-dessus du temps social et de toute immanence. $»^{39}$

La sémiologie du cinéma hérite des conceptions ayant dominées les années soixante, l'auteur devient «producteur d'imaginaires» et «l'oeuvre», « texte filmique ». Dans le triangle producteur - film - spectateur, la sémiologie isole le couple producteur - film et, dans une confrontation-duel avec le texte filmique, le chercheur s'attache à découvrir comment il fonctionne. On s'intéresse au film comme à un discours dont il convient de mettre à jour les propriétés internes. C'est l'exercice devenu classique de l'analyse filmique.

Pour Esquenazi, la limite de cette approche, est que le chercheur qui se lance dans une analyse filmique, naturalise son savoir en faisant comme si tout un ensemble d'éléments qui doivent être connus avant de voir un film allaient de soi. Ainsi, il se lancerait dans l'analyse d'un documentaire comme si le fait de savoir ce qu'est un documentaire allait de soi et en se préoccupant seulement de la spécificité sémiologique d'un film en particulier. Esquenazi nous dit que quelques soient les exploitations auxquelles l'analyse structurale du film a donné lieu, « elle a systématiquement ignoré le réel d'où provient le film comme le réel où il est vu et interprété. $»^{40}$ Or, il semble important à Esquenazi, non pas de rejeter la sémiologie, mais de « réconcilier l'étude du film et son interprétation par les publics ${ }^{41}$ Cette réconciliation nécessite le recours aux apports de l'histoire de l'art, à l'herméneutique de la réception, à la pragmatique et à la sociologie.

De nombreuses études ont montré que « le sens émerge des rapports motivés entre des signes et des acteurs sociaux $»^{42}$ Ainsi, l'interprétation d'un film peut varier en fonction de la communauté qui le reçoit, du lieu, de l'époque ou encore des conditions dans lequel il est vu. La compréhension d'un film repose sur des savoirs partagés entre les producteurs du film et son public : «Les mondes fictionnels sont imaginés par des hommes et destinés à d'autres 
hommes, à partir de leurs connaissances communes. $)^{43}$

Selon Esquenazi, trois concepts permettent de comprendre comment fonctionne un film : « le jeu de langage » qui est l'affaire de la sémiologie, "l'interprétant» qui est le spectateur (le sujet percevant de Sol Worth et Roger Odin) et la «médiation » qui désigne l'ensemble des éléments qui ont assuré le transport du film jusqu'à l'interprétant. L'une des remarques importantes que formule Esquenazi est que «le genre peut jouer le rôle de médiateur ». Esquenazi reprend encore un concept de Odin quand il évoque la « médiation », celui-ci est d'ailleurs proche du concept de «contrat de lecture » utilisé en linguistique et notamment par Eco dans Lector in fabula. La «médiation » englobe des éléments qui sont aussi bien externes qu'internes au texte filmique et qui «programment» le spectateur dans son interprétation des images en l'orientant vers la mobilisation de tel ou tel référent culturel, ou telle ou telle stratégie de lecture, qu'il connaît déjà car acquise dans sa pratique antérieure de la culture. Ainsi, ce ne sont pas les mêmes savoirs et les mêmes stratégies qui sont mobilisés suivant que l'on pense avoir affaire à une fiction ou à un documentaire, à un polar ou à une comédie musicale.

L'approche d'Esquenazi repose sur une prise de conscience qui guidera constamment nos analyses. Celle-ci se résume à la proposition suivante. Les productions culturelles n'ont pas de significations immanentes et les variations d'interprétations auxquelles une œuvre peut donner lieu possèdent des fondements historiques qui méritent d'être mis au jour. Dans notre travail, il s'agira donc moins d'interpréter des textes que de comprendre des interprétations. Le film est compris comme un événement culturel complexe qui possède une nature double. Il est à la fois un fait esthétique et un fait social toute la difficulté consistant à « découvrir comment l'esthétique exprime et provoque le social, comment le premier est un point de passage particulier pour le second. $»^{44}$

Cette duplicité du fait filmique permet de comprendre la nécessité qu'il y a à pratiquer une approche pluridisciplinaire articulée aux trois concepts cités plus haut : «le jeu de langage », «l'interprétant» et la «médiation ». Nous avons déjà cité différentes disciplines auxquelles nous aurons recours : la sémiologie du cinéma, l'histoire de l'art, l'herméneutique de la réception, la pragmatique et la sociologie. Il faudra encore rajouter à cette liste l'économie du cinéma. Dans ce domaine, nos principales références seront les écrits de Laurent Creton $^{45}$ qui pose la question de la création cinématographique dans une économie de

43 Ibid., p. 42.

44 ESQUENAZI, Jean-Pierre. Godard et la société française des années 1960. Op. cit., p. 3.

45 CRETON, Laurent. « De l'indépendance en économie de marché : le paradigme stratégique en question », in Cinéma et indépendance : une économie politique. Paris, coll. Théorème, Presse de la Sorbonne Nouvelle, 1998.

CRETON, Laurent. Économie du cinéma : perspectives stratégiques. Paris, Nathan, 1994. 
marché et démystifie le concept «d'indépendance artistique » souvent revendiqué par des producteurs marginaux.

Détaillons à présent notre approche sociologique. Parmi les outils qui nous seront utiles pour comprendre l'interprétant et la médiation, nous utiliserons le concept de champ de Pierre Bourdieu. Celui-ci définit la société comme une imbrication de champs (économique, culturel, artistique, sportif, religieux...) à l'intérieur desquels se dégage une logique propre déterminée par la spécificité des enjeux et des atouts que l'on peut y faire valoir compte tenu des règles y prévalant. Les interactions se structurent en fonction des atouts et des ressources que chacun des acteurs mobilise, c'est à dire de son capital, qu'il soit économique, culturel, social ou symbolique. Nous mobiliserons le concept de champ lors de l'étude de la trajectoire et des conceptions des cinemanovistas ainsi que lors de l'étude de la réception du Cinema Novo. L'application de ce concept à la société brésilienne des années soixante nous permettra de prendre conscience de la spécificité de la pratique culturelle du cinéma des cinemanovistas rapportée aux autres secteurs de la population. Il sera aussi utile à la compréhension de la représentation qu'ils se font de la société dans laquelle ils vivent. Le sujet est important puisque l'identité du Cinema Novo se fonde sur la singularité de son rapport au politique et au social. Si la Nouvelle Vague française est imprégnée d'une approche spiritualiste pour laquelle un film ne vaut que dans la mesure où il est l'expression de la personnalité de l'individu qui l'a conçu, pour le Cinema Novo, un film ne vaut que dans la mesure où il participe à un processus d'émancipation nationale culturelle et politique.

Le concept de champ ne résume pas notre approche sociologique. Si l'étude du Cinema Novo correspond bien à une étude spécifique de l'origine et de l'appartenance sociale des cinemanovistas dans la mesure où celle-ci nous apporte des éléments de compréhension quant à leur pratique culturelle du cinéma, elle nécessite aussi un questionnement plus global sur la façon dont la société brésilienne s'est historiquement structurée et sur ce qu'elle est au moment où le Cinema Novo apparaît. Les discours des cinemanovistas comme ceux qui sont prononcés sur le Cinema Novo se fondent une représentation de l'espace social particulière. Au début des années soixante, le cinéaste se conçoit comme un «intellectuel» persuadé d'avoir un accès privilégié à la « réalité brésilienne ». Pour cette raison, il est convaincu de devoir participer, par le cinéma, à la construction d'un pays en devenir. Le sujet et le destinataire de son discours est le «peuple» dont il se sent distinct sinon étranger tant ses conditions de vie sont éloignées des siennes. Le peuple représente l'ensemble des populations opprimées par « l'élite » qui est conçue comme une minorité toute puissante concentrant les pouvoirs économiques, politiques et financiers. Avant le coup d'État de 1964 et conformément à l'idéologie dominante de la gauche de l'époque, les cinéastes imaginent que cette élite est 
divisée entre une haute bourgeoisie nationaliste progressiste et une haute bourgeoisie conservatrice connivente de l'exploitation impérialiste qui maintient le Brésil dans le sousdéveloppement. Après le coup d'État de 1964, cette conviction quant à la polarisation politique des classes supérieures s'effondre et, parallèlement, se pose le problème de la fragmentation de la classe moyenne dans laquelle les cinéastes s'insèrent. Paradoxalement, alors qu'elle est omniprésente depuis les débuts du Cinema Novo, la question populaire est la moins bien élaborée.

Il convient bien de préciser que les cinemanovistas n'ont jamais conceptualisé leur pensée sociologique même si les références à cette catégorisation reviennent régulièrement de façon explicite et implicite dans leur discours. Autre point important, les conceptions politiques et sociales des cinemanovistas s'identifient complètement avec celles de l'Instituto Superior de Estudos Brasileiros - ISEB qui rassemblait au début des années soixante quelques uns des plus prestigieux chercheurs en Sciences Humaines du Brésil. C'est un élément sur lequel nous reviendrons de façon détaillée dans la première partie de notre thèse. Ce que nous comprenons bien au travers de la synthèse que nous venons de rédiger, c'est la prégnance du concept de classe sociale qui est un apport du marxisme, lequel a acquis une position hégémonique dans les Sciences Humaines brésiliennes des années soixante alors même que son application à l'étude du Brésil était un fait récent. Le matérialisme dialectique fait ses premiers pas dans l'historiographie brésilienne en 1938 avec História da Literatura Brasileira de Nelson Werneck Sodré et surtout en 1942 avec Formação do Brasil contemporâneo de Caio Prado Júnior.

Notre étude du Cinema Novo ne pourrait être menée à bien sans que nous ayons nousmême le souci de nous dégager des sources scientifiques qui furent celles des cinemanovistas. Cela est d'autant plus nécessaire que l'approche marxiste de l'histoire et de la sociologie a connu des excès dans la période immédiatement antérieure au coup d'État. L'un d'eux a consisté à penser que l'histoire avait un sens, l'application du matérialisme dialectique tendait à prouver que tôt ou tard, une révolution socialiste devait éclater et transformer les structures sociales et économiques. Cette dimension prophétique du marxisme est très présente au cours de la première phase du Cinema Novo. Un autre excès a résidé dans l'application du concept de classe sociale. Dans la conception marxiste, une classe sociale se définit sur la base de critères statistiques mais aussi sur la base de l'existence d'un sentiment d'appartenance des individus à ladite classe. Autrement dit, pour qu'une classe sociale soit une classe sociale, il faut que ses membres possèdent une «conscience de classe». Si l'étude de la société brésilienne montrait bien que celle-ci était effectivement très hiérarchisée, la volonté de voir se réaliser le scénario révolutionnaire écrit par le marxisme conduisait à supposer une 
conscience de classe ou la possibilité de son acquisition rapide à des segments de la population sans prendre suffisamment en compte l'extrême fragmentation culturelle, ethnique ou géographique du Brésil. De fait, le concept de classe sociale ne pouvait véritablement s'appliquer qu'à des segments spécifiques de la population : la haute bourgeoisie et la classe ouvrière localisée dans les quartiers industrialisées des métropoles du Sud-Est.

Pour assumer une distance critique vis à vis des référents théoriques du Cinema Novo, nous choisirons de citer des sources étrangères aux leurs. Indépendamment des travaux de l'ISEB, l'une des études sociologiques les plus importantes menées sur le Brésil est celle de Roger Bastide intitulée Brésil : Terre de contrastes publiée en 1957. Dès l'introduction, Bastide procède à cette mise en garde : «[...] le sociologue qui étudie le Brésil ne sait plus quel système de concepts utiliser. Toutes les notions qu'il a apprises dans les pays européens ou nord-américains ne valent plus. [...] Les mêmes mots comme ceux de ' classe sociale ' ou de ' dialectique historique ' n'ont pas la même signification, ne recouvrent pas les mêmes réalités concrètes. $»^{46}$ Prudent quant à l'application du concept de classe sociale, le sociologue français préfère développer la question de l'extrême fragmentation de la société brésilienne. Cette fragmentation est géographique, économique, ethnique et culturelle. La première donnée prise en compte par Bastide est celle de la colonisation. La faible démographie du Portugal et la découverte tardive de métaux précieux au Brésil (XVIIe siècle) sont deux facteurs qui ont joué en la faveur de la formation d'une société esclavagiste et agraire notamment au travers du choix d'une économie basée sur l'exploitation de la canne à sucre et le partage des terres nouvellement acquises en grandes propriétés foncières. L'entreprise coloniale détermine aussi les caractéristiques spécifiques du peuplement du pays. La carence de femmes blanches dans le Brésil portugais encourage au métissage des blancs avec la population indigène et la population noire qui ne cesse de croître après la mise en place de la traite négrière. Pour autant, des clivages ethniques s'installent et recouvrent les clivages sociaux au fur et à mesure du développement de la colonie. L'indépendance politique du Brésil qui survient en 1822 ne remet pas en cause la structure économique et sociale du pays qui est dominée par une élite blanche.

Aux données historiques s'ajoutent les données géographiques. Le Brésil est un pays aux dimensions continentales et aux paysages diversifiées. Cette diversité est renforcée par le développement inégal qu'impose l'économie coloniale et une histoire ponctuée de cycles économiques (la canne à sucre, l'or, le café, le caoutchouc, le cacao) au cours desquels on assiste au brusque enrichissement d'une région avant son irrémédiable déclin provoqué soit par l'épuisement des ressources, soit par la chute des cours internationaux de la denrée 46 BASTIDE, Roger. Brésil : Terre de contrastes. Paris, L'Harmattan, 1999 (Première édition, 1957), pp. 15-16. 
exportée. Ainsi, le littoral, favorisé par les échanges commerciaux avec les grandes métropoles, s'oppose à l'intérieur des terres, pauvre en infrastructures. Le Nordeste marqué par l'économie de la canne à sucre et des grandes propriétés foncières s'oppose au Sud-Est ayant d'abord bénéficié de la manne apportée par le café puis s'étant industrialisé. Les grandes métropoles modernes comme Rio de Janeiro ou São Paulo s'opposent aux grands espaces sauvages et faiblement peuplés. La forêt tropicale de l'Amazonie offre un contraste saisissant avec les pampas du Sud. La présence indigène ou cabocla (métis de blanc et d'indien) est forte dans les régions du centre-ouest (Mato Grosso) ou du Nord (région de l'Amazone). Au Sud et au Sud-Est, les vagues d'immigration européenne massive du XIX et XX siècle ont favorisé la prévalence de la population blanche. Au Nord-Est et dans les centres historiques, l'héritage de l'esclavage est visible au travers de la forte concentration de la population noire. Si les différences de ressources, de peuplement et de développement déterminent des us et coutumes singulièrement différents entre les différentes régions du Brésil, les clivages sociaux, ethniques ou religieux favorisent aussi la juxtaposition de modes de vie très divers dans un même espace géographique.

Bien que Bastide ne cherche pas, comme ses pairs brésiliens, à vérifier l'adéquation du Brésil de son temps avec le schéma de la lutte des classes, il n'en néglige pas pour autant ce qu'il nomme le «problème social» et distingue trois classes, la classe haute, la classe moyenne et la classe basse ${ }^{47}$. La classe haute réunit les grands propriétaires terriens des campagnes et les capitalistes des villes, elle est constituée d'un petit nombre de personnes qui concentrent dans leurs mains la quasi intégralité des richesses du pays. La classe moyenne, inexistante dans les campagnes, est le produit de l'urbanisation et de l'industrialisation. La classe basse, le «peuple », rassemble les petits propriétaires, métayers et ouvriers agricoles des campagnes et le prolétariat des grandes villes. Le classement de Bastide est fondé sur des critères statistiques. Le fait que le niveau de vie général soit bas et la répartition des richesses, très inégale, ramène le problème social à un problème économique. Le sujet pourra être développé avec un autre livre bien postérieur au sien, História do Brasil (1995) de Boris Fausto. Dans ce livre qui fait autorité, l'auteur consacre un chapitre aux principaux changements arrivés entre 1950 et $1980^{48}$. Le choix de ces dates n'est évidemment pas fait au hasard. Elle s'appuie sur l'idée selon laquelle, malgré les changements de dirigeants, le Brésil n'a pas connu de rupture majeure dans sa politique économique et sociale à partir du moment où le processus d'industrialisation a été pleinement installé selon les modalités que lui imposait l'idéologie nationale-développementiste qui a dominé l'ensemble de la période. 
Fausto s'appuie essentiellement sur les chiffres fournis par l'IBGE ${ }^{49}$. Nous recouperons ses analyses avec celles de deux autres ouvrages récents, Histoire du Brésil de Bartolomé Bennassar et Richard Marin et O Governo João Goulart : As Lutas sociais no Brasil 19611964 de Luiz Alberto Moniz Bandeira.

Une première donnée intéressante est l'évolution du PIB du Brésil comparé à celui des EUA. En 1960, la valeur du PIB du Brésil est inférieure à un trentième du PIB des EUA. En 1997, après une croissance régulière des PIB des deux pays respectifs, celui du Brésil dépasse pour la première fois le dixième de celui des EUA. En 1998, le PNB du Brésil est le huitième PNB mondial et sa valeur le place largement en tête des autres pays d'Amérique Latine ${ }^{50}$. Pendant cette même période, des années 50 aux années 90, alors que la population totale du pays a plus que triplé, passant de 51 millions à 165 millions, pour la première fois le taux d'urbanisation dépasse $50 \%$ et la population active employée dans les secteurs secondaires et tertiaires devient numériquement plus nombreuse que celle du secteur primaire. Pour ces deux derniers chiffres, le point de bascule se situe au cours des années soixante. Entre 1960 et 1970, le taux d'urbanisation est passé de 44,6\% à 55,9\% et la population active dans le secteur primaire de $54 \%$ à $44,3 \%$. Au début des années soixante, la seule et unique révolution anticipée par Gilberto Freyre et qui est celle de l'industrialisation est donc en train de s'accomplir. À ce sujet, Moniz Bandeira observe :

« [...] conforme salientei em $O$ Caminho da Revolução Brasileira, escrito no primeiro semestre de 1962 [...] com base em levantamentos econômicos, em dados estatísticos, demonstrei que o Brasil deixara de ser um país semicolonial e agrário, conforme a teoria defendida pelo PCB, mas já apresentava o perfil de uma economia capitalista madura, dado que o valor da produção industrial, inclusive com um setor bastante adiantado de máquinas e equipamentos, já superava o da agricultura, acelerando a concentração tanto do capital quanto do proletariado, ao mesmo tempo que o rápido processo de urbanização, intensificado por inaudito êxodo rural, acentuava o predomínio da cidade sobre o campo. ${ }^{51}$

Ces différents indicateurs tendent à donner l'image d'un pays dont la croissance économique a suivi un rythme régulier et soutenu qui lui donnerait le droit d'entrer bientôt dans le cercle des nations les plus riches. La réalité est cependant différente. La modernisation de l'économie brésilienne pendant ces cinquante dernières années s'est accompagnée d'un

49 Instituto Brasileiro de Geografia e Estatística, l'équivalent de l'INSEE en France.

50 BENNASSAR, Bartolomé, MARIN, Richard. Histoire du Brésil - 1500-2000. Paris, Fayard, 2000, p. 603.

51 «[...] dans $O$ Caminho da Revolução Brasileira, écrit au premier semestre de 1962 [...] sur la base d'enquêtes économiques, de données statistiques, je démontrais que le Brésil avait cessé d'être un pays semi-colonial et agraire, comme le pensait le PCB, et qu'il présentait les caractéristiques d'une économie capitaliste mature, la valeur de la production industrielle, comportant un secteur très avancé de fabrication de machines et d'équipements mécaniques, dépassait déjà celle de la production agricole, accélérait la concentration du capital et du prolétariat, alors qu'une urbanisation rapide, intensifiée par un exode rural inédit, accentuait la prévalence de la ville sur la campagne. » in BANDEIRA, Luiz Alberto Moniz. O Governo João Goulart - As Lutas sociais no Brasil 1961-1964. Rio de Janeiro / Brasília, Revan / ed. Universidade nacional de Brasília, 2001, p. 13. 
accroissement des inégalités sociales. Pendant la décennie des années soixante, le pourcentage du revenu attribué au 50\% les plus pauvres de la population active a diminué de plus de deux points passant de $17,7 \%$ à $15 \%$ alors que le pourcentage des $10 \%$ les plus riches a augmenté de presque 7 points passant de 39,6\% à 46,4\%. Cette tendance à l'augmentation des inégalités de distribution de revenu s'est confirmée les quatre décennies suivantes ${ }^{52}$. Parallèlement, la concentration foncière rurale a augmenté. En 1970, les exploitations d'une surface inférieure à 100 hectares représentaient $23,5 \%$ de la surface totale des exploitations agricoles alors que celle de plus de 1000 hectares représentaient 39,5\% de cette surface ${ }^{53}$. Bien que la part de population active du secteur primaire ait fortement diminué, les conflits sociaux en milieu rural ont gagné en intensité et en violence. L'opposition entre les sem terra (sans terre), les posseiros (propriétaires modestes ou occupants du sol sans titre), et de l'autre côté, les grands propriétaires, depuis les années cinquante jusqu'à aujourd'hui finissent régulièrement dans le sang $^{54}$.

L'un des points les plus importants à retenir est que la transformation du Brésil d'une société agraire et rurale en une société industrielle et urbaine n'a pas remis en cause son identité de pays riche mais terriblement injuste ${ }^{55}$. Les inégalités sociales et régionales se sont au contraire accrues. Quelques indicateurs sociaux nous permettront de le montrer pour la période historique qui nous intéresse. Le New York Times du 31 octobre 1960 donnait l'information suivante :

« Il y a des zones dans la région du Nordeste aride où le revenu annuel est d'environ 50 dollars per capita. Environ $75 \%$ de la population est analphabète. La consommation journalière moyenne de calories est de 1644 . L'espérance de vie est de 28 ans pour les hommes et de 32 ans pour les femmes. La moitié de la population meurt avant 30 ans. Le taux annuel de natalité est de 2,5\%. Dans deux localités de l'état de Piauí, prises comme exemple, aucun enfant n'a vécu plus d'une année. ${ }^{56}$

Le milieu rural en général et les États du Nord et du Nordeste en particulier représentent les espaces les plus défavorisés. Selon Boris Fausto :

«A massa de produtores pobres ou miseráveis continua a ser enorme. Em 1975, cerca de 3,64 milhões de estabelecimentos agrícolas, ou 73\% do total, cultivavam a terra sem uso do arado, fosse ele mecânico ou de tração animal. A mesma proporção de famílias rurais (73\%) tinha uma renda per capita de metade do salário mínimo, ou menos, em 1980. $»^{57}$

52 BENNASSAR, Bartolomé, MARIN Richard. Op. cit., p. 606.

53 Ibid., p. 605.

54 Cf. FAUSTO, Boris. Op. cit., pp. 538.

55 En 1980, le Brésil est un des pays du monde où l'écart entre les revenus des plus riches et des plus pauvres est le plus grand. Pour une étude comparative avec d'autres pays, $C f$. ibid., p. 548.

56 CIMENT, Michel. « Le Dieu, le diable et les fusils » in Positif, Paris, n`84, mai 1967, p. 25. Sur Deus e o diabo na terra do sol et Os Fuzis, Michel Ciment cite Josué de Castro qui cite lui-même le New York Times du 31/10/60.

57 « La masse des producteurs pauvres ou misérables continue à être énorme. En 1975, dans près de 3,64 
La dureté de la vie dans les campagnes favorise l'exode rural et l'expansion des favelas (bidonvilles) à la périphérie des métropoles. Les populations les plus pauvres souffrent de la faim, du manque d'infrastructures et du manque d'éducation même si, dans ces deux derniers domaines, des progrès sont enregistrés. En 1960, 21,08\% des domiciles particuliers bénéficient de l'eau courante et 40,15\% sont reliés au réseau électrique. En 1970, les chiffres restent assez faibles, respectivement $32,81 \%$ et $47,56 \%$. L'analphabétisme a régressé entre 1950 et 1980 passant de 57,25\% à 35\%. Il faut cependant prendre en compte que pendant la même période, la croissance la plus forte par niveau d'éducation a été celle des troisièmes cycles universitaires (31\%) suivie des premier et deuxième cycles universitaires (12\%) devant l'enseignement secondaire $(12 \%)$ et primaire $(4 \%)^{58}$. Le même décalage peut être observé dans l'accès aux biens de consommation :

«Após a implantação do regime militar, a industrialização cresceu consideravelmente, prescindindo da reforma agrária. Esse fato não foi ocasional, mas conseqüência de uma escolha. Os governos militares abandonaram a perspectiva de ampliar a demanda através da maior capacidade de consumo da população pobre. Preferiram, ao invés disso, incentivar a produção de bens de consumo duráveis - caso típico dos automóveis -, destinados às classes de renda média e alta. ${ }^{59}$

Autrement dit, la modernisation du Brésil a avant tout profité aux classes supérieures dont les indicateurs sociaux ont accompagné l'évolution qu'ils connaissaient dans les pays riches alors que les classes les plus défavorisées ont continué à vivre dans un extrême dénuement qui s'accentue selon la région considérée ${ }^{60}$. Il est usuel de diviser ces classes en trois catégories : pauvres, indigents et misérables. En 1984, un tiers de la population active du Brésil recevait moins d'un salaire minimum et pouvait donc être considéré comme indigente ou misérable ${ }^{61}$.

Cette fragmentation sociale intense qui est un trait caractéristique du Brésil doit nous amener à deux réflexions majeures quant à notre objet d'étude qui demeure le cinéma. La première est d'ordre strictement économique et concerne les conditions d'accès concrètes de la

millions des exploitations agricoles, soit 73\% du nombre total des exploitations, la terre était cultivée sans que soit utilisée l'araire à traction animale ou mécanique. La même proportion des familles rurales $(73 \%)$ vivait avec la moitié ou moins d'un salaire minimum per capita en 1980. » in FAUSTO, Boris. Op. cit., p. 539.

58 Ibid., p. 544.

59 «Après l'installation du régime militaire, l'industrialisation fut considérablement accrue alors que la réforme agraire était évitée. Ce fait ne fut pas le fruit du hasard mais la conséquence d'un choix. Les gouvernements militaires abandonnèrent l'idée d'amplifier la demande au travers d'une plus grande capacité de consommation de la population pauvre. Ils préférèrent, à l'inverse, encourager la production de biens de consommation durables - comme les voitures - destinés aux classes de revenus moyens et hauts. » in ibid., p. 538.

60 Cf. ibid., p. 547.

61 Ibid. 
population brésilienne à tout ce qui fait la culture cinématographique. La seconde est d'ordre culturel. Dans la mesure où il faut bien se représenter le Brésil comme une mosaïque de communautés aux contours plus ou moins bien délimités et différenciées les unes des autres par des variables sociale, géographique, ethnique, religieuse ou encore éducationnelle, dans la mesure où ces différents groupes possèdent une expérience absolument distincte de la vie quotidienne et des modes de représentation du monde variés, il faut aussi s'attendre à ce que la relation des uns et des autres au cinéma, quand il existe bien une relation, soit extrêmement différente.

Par le terme «culture cinématographique », nous n'entendons pas seulement les conditions d'accès à la production cinématographique mais aussi tout ce qui existe en périphérie de l'acte de visionnage des films et qui oriente la relation que le spectateur peut avoir avec eux, autrement dit, pour les années soixante, les publications sur le cinéma, les ciné-clubs et les cinémathèques. Les données chiffrées et fiables qu'il est possible de réunir sur la filière cinématographique brésilienne dans les années soixante sont insuffisantes pour apprécier la carrière des films du Cinema Novo avec précision. Cependant, la situation générale du cinéma brésilien à cette époque est connue. D'un côté, nous disposons des statistiques de l'IBGE sur l'évolution du nombre des écrans de cinéma et leur répartition sur l'ensemble du territoire. De l'autre, nous avons aussi accès aux enquêtes contemporaines de la création des institutions de soutien à la production cinématographique brésilienne.

Les statistiques montrent que la répartition des salles sur l'ensemble du territoire brésilien était, comme cela est toujours le cas aujourd'hui, très inégale en quantité et en qualité. Ainsi, l'axe Rio de Janeiro-São Paulo concentre plus de 50\% du nombre total des écrans et possède les salles de plus grand confort avec la programmation la plus variée. Parce qu'elles sont les mieux dotées en infrastructure, ces deux villes sont donc très logiquement les pôles de culture cinématographique les plus dynamiques. Elles le sont pour leurs activités éditoriales, pour leurs nombreux ciné-clubs et pour leurs deux cinémathèques. Les autres métropoles brésiliennes ne rivalisent pas. L'accès aux films et à la culture cinématographique y est longtemps très limité par une carence générale en infrastructure et peut être comparé pour les années soixante à celui dont pâtissait une petite ville de province européenne, la distance avec un grand centre étant au Brésil plus grande et difficile à parcourir. Parallèlement à cette pauvreté en infrastructures, la pauvreté des personnes elles-mêmes interdisait, et interdit toujours, l'accès aux salles de cinéma de larges fractions de la population.

Le deuxième point à prendre en compte et relié à cette question de la fragmentation sociale du Brésil est celui de la culture. S'il faut bien se représenter la société brésilienne comme une société fragmentée à l'extrême avec trois classes sociales vivant chacune en vase 
en clos, même si elles peuvent partager le même espace physique, et, à l'intérieur de ces classes, des groupes différenciés par leur origine ethnique ou géographique, alors il faut bien comprendre que ces différents groupes plus ou moins bien délimités possèdent une culture différente et donc une pratique du cinéma, quand celle-ci existe, qui peut être très éloignée de celle des groupes dont l'hégémonie culturelle empêche de prendre en compte les autres pratiques qui l'entourent. Nous verrons quant à nous que la pratique du cinéma des cinemanovistas s'identifie parfaitement avec celle que nous pouvions avoir à la même époque en Europe au moment où, grâce à la Nouvelle Vague, le septième art entrait dans la modernité et que le cinéma d'auteur gagnait sa place au sein de la culture classique. Or, il va sans dire que la majorité de la population brésilienne, pour les raisons exposées ci-dessus, ne pouvait partager le même type de rapport au cinéma.

\section{Méthodologie}

Nous partirons, à chaque fois que possible, de tout ce qui pourra renseigner la préparation des films (aspects financiers et artistiques), leur tournage (conditions et méthodes de travail) ainsi que leur exploitation et leur réception par la société brésilienne. Pour que notre étude de la praxis du Cinema Novo comme cinéma de conscientisation soit complète, nous évoquerons aussi la trajectoire ${ }^{62}$ des cinemanovistas. Cette étude nécessitera des connaissances sur l'histoire du Brésil, en particulier son histoire contemporaine des années cinquante à nos jours, ainsi que sur celle du cinéma brésilien. Cette approche nous permettra de mettre à jour les stratégies du Cinema Novo pour un cinéma de conscientisation sans dissocier les aspects esthétiques des aspects économiques. Nous pourrons ainsi vérifier leur cohérence du point de vue des dispositifs de langage mais aussi des modes de production et de diffusion. L'étude de la réception des films du Cinema Novo apparaît aussi comme une deuxième forme d'évaluation, cette fois-ci pragmatique et non plus critique, de son succès à réaliser ses intentions initiales.

Notons aussi, que le contexte historique ne sera pas mobilisé pour «expliquer» le Cinema Novo mais construit à partir de notre objet d'étude et de ce qu'il réclame effectivement comme éclairage. Notre souci a été de partir des films et des discours des cinéastes et de construire, à partir du corpus qui nous était offert, une méthodologie adéquate à son étude. En aucun cas, nous n'avons voulu appliquer sur ce corpus des instruments

62 Le terme « trajectoire », préféré au terme « biographie », désigne une approche se limitant à l'organisation des faits immédiatement liée à la carrière d'une personne et aux idées qu'elle a défendu pendant cette carrière. L'objectif de cette approche est de mettre au jour les confrontations éventuelles entre logiques personnelles, professionnelles et / ou politiques. Sur la définition du terme « trajectoire », $C f$. LINDEPERG, Sylvie. $O p$. cit., p. 17. 
méthodologiques choisis a priori et sans prise en compte du réel.

Afin de réaliser cette recherche et de mettre en œuvre la méthodologie que nous venons de décrire, nous avons résidé deux ans au Brésil, de 2001 à 2003 afin de nous immerger dans la culture brésilienne pour d'un côté, mieux la connaître et la comprendre et, de l'autre, mesurer ce qu'il pouvait rester aujourd'hui du Cinema Novo. Au cours de ce séjour, nous avons été inscrit à un niveau équivalent au troisième cycle français à l'Instituto de Artes de l'Universidade de Campinas - UNICAMP et à l'Escola de Comunicação e Artes - ECA de l'Universidade de São Paulo - USP avec qui a été signée la convention de co-tutelle de cette thèse. Ce contact avec le milieu universitaire nous a permis de savoir où en était la recherche brésilienne dans le domaine des études cinématographiques et quel y avait été l'impact du Cinema Novo. Dans l'année précédant notre voyage au Brésil, nous avions appris le portugais, précaution indispensable à un tel travail de recherche comprenant notamment le démarchage des lieux de ressources susceptibles d'abriter des sources primaires.

Toute étude de la cinématographie brésilienne se heurte à un premier écueil d'envergure : la disponibilité des films. Les vidéothèques des universités cités ci-dessus sont des lieux de ressources estimables qui permettent l'accès à nombre de films par ailleurs introuvables. Les vidéo-clubs possèdent également, dans des grandes villes comme São Paulo et Campinas, des rayons de «Cinema Nacional » même s'ils sont assez réduits. Il s'agit alors de passer de l'un à l'autre afin d'épuiser le stock des films disponibles à la location. Le Centro Cultural do Banco do Brasil - CCBB à São Paulo et Rio de Janeiro, en plus de posséder des vidéothèques très fournies en cinéma brésilien, propose des rétrospectives qui permettent de voir certains films sur grand écran. À l'achat, sous forme de dvd ou cassettes vhs, très peu de films sont disponibles. Enfin, la chaîne de télévision Canal Brasil, transmise par câble ou par satellite, entièrement dédiée au cinéma brésilien, donne accès à un très grand nombre de films. Tout cela concerne néanmoins le support vidéo, la Cinemateca Brasileira à São Paulo, dans le cadre de rétrospectives, et la Funarte à Rio de Janeiro, en libre consultation, permettent l'accès au film sur son support pellicule original et sur grand écran. Cette énumération ne doit pas tromper le lecteur. Voir les films du Cinema Novo et toute une cinématographie annexe mais néanmoins fondamentale à sa compréhension est possible mais très difficile. Cela suppose la connaissance des lieux de ressources, de nombreux déplacements et un bon nombre de coïncidences heureuses entre la disponibilité du chercheur et le passage exceptionnel d'un film par ailleurs introuvable dans telle ou telle rétrospective.

Au sujet des documents papiers, les bibliothèques universitaires, la bibliothèque Jenny Klabin Segall de São Paulo, les cinémathèques de São Paulo et Rio de Janeiro donnent accès à des dossiers assez complets de coupures de presse par film ou par cinéaste. L'étude de ces 
coupures de presse possède une place très importante dans notre travail. Soucieux d'appliquer l'approche sémio-pragmatique qui nous semblait la mieux adaptée au traitement de notre problématique, nous nous sommes attaché autant à étudier les films qu'à étudier ce qui avait pu en être dit et les réactions qu'ils avaient suscitées. Dans les archives des cinémathèques, nous trouvons quelques scénarios originaux, parfois des versions intermédiaires au film effectivement filmé ou des projets inachevés des cinemanovistas. Ce type de document nous intéressait dans la mesure où il pouvait nous aider à déceler les contraintes et les principes qui avaient imprégné chaque cinemanovista dans sa quête d'un cinéma de conscientisation. De ce point de vue, un dernier lieu mérite d'être mentionné avec une emphase particulière : le Tempo Glauber à Rio de Janeiro. Dans cette maison transformée par la mère du cinéaste en musée de l'œuvre de Glauber Rocha, il est possible d'accéder à tous types de documents, les plus intéressants étant les innombrables scénarios qu'il a écrit tout au long de sa carrière. Nous en avons lu et étudié plus d'une trentaine, pratiquement tous inédits.

Si les documents sur les conceptions et les méthodes de travail des cinemanovistas sont assez nombreux et relativement accessibles ${ }^{63}$, les documents concernant les aspects économiques sont rares. Le matériel publicitaire est disponible dans les cinémathèques mais, pour tout ce qui concerne les budgets, les arrangements avec les exploitants et les recettes des films, il faudra s'en remettre aux témoignages, parfois contradictoires, des cinéastes euxmêmes. Pour ces questions, nous avons procédé par recoupements et nous nous sommes appuyé sur le travail déjà existant dans les biographies de Leon Hirszman, Walter Lima Júnior, Nelson Pereira dos Santos et l'autobiographie de Paulo César Saraceni. Un complément d'information non négligeable devait cependant nous arriver par voie indirecte avec la découverte des archives privées de Claude Antoine ${ }^{64}$, co-producteur de Antônio das Mortes et mandataire exclusif de la production pour la vente en Europe de la majorité des films du Cinema Novo. Au-delà des contrats de vente des films pour l'étranger, un certain nombre de documents concerne le montage de la production de films de Rocha et d'un film de Walter Lima Júnior : Brasil ano 2000.

De plus, la singularité de la situation politique au Brésil dans les années soixante et soixante-dix nous oblige à nous intéresser à deux sources supplémentaires : les archives de la police politique et celle de la censure. Nous avons consulté les archives du Departamento de Ordem Política e Social - DOPS de Rio de Janeiro et celle du Serviço de Censura das Diversões Públicas à Brasília. Ces archives nous renseignent sur le regard que portaient ces deux instances de contrôle sur un cinéma « révolutionnaire » et nous montre comment elles

63 Les archives privées de Glauber Rocha et Leon Hirszman sont ouvertes au public.

64 Ces archives seront bientôt concédés à la cinémathèque de Toulouse par sa compagne Dedy Lherm. 
l'ont finalement toléré. Indirectement, ces archives nous apportent aussi des informations sur d'autres sujets d'intérêts contribuant ainsi à procéder aux recoupements cités plus haut.

Enfin, un complément indispensable à notre travail a été la rencontre avec les cinemanovistas eux-mêmes et un certain nombre de personnes, critiques, réalisateurs ou parents de cinemanovistas qui, pour avoir été impliqué à divers degrés dans l'aventure du Cinema Novo, avaient un regard particulier à nous faire partager, à nous qui étions parfaitement étranger à cet univers. Ces entretiens, pratiquement une vingtaine, nous ont été très utiles pour cerner notre objet d'étude.

\section{Annonce du plan}

Notre étude, du fait même du dynamisme et de la versatilité de la praxis du Cinema Novo, va suivre un ordre chronologique. Dans la première partie, nous allons voir l'intense réflexion critique qui préside à l'élaboration du concept critique du Cinema Novo. Nous verrons aussi quelles sont les influences philosophiques de ce concept et comment certains événements indépendants de la volonté des acteurs historiques influeront sur leur pratique future. Enfin, nous rappellerons comment et sur quelles bases se forme le groupe du Cinema Novo à Rio de Janeiro entre la fin des années cinquante et le début des années soixante. La seconde partie sera dédiée à l'étude de la première phase du Cinema Novo qui englobe les films produits et distribués entre 1960 et 1964. La troisième partie sera consacrée aux transformations qui touchent le Cinema Novo après le coup d'État de 1964. La quatrième partie va concerner la dernière phase du Cinema Novo qui est marqué par l'atteinte d'une certaine maturité critique vis à vis de son projet initial d'un cinéma de conscientisation mais aussi par l'éclatement du groupe qui sera consommé au cours de la première partie des années soixante-dix. Tous les films ne seront pas analysés en détail mais seulement ceux qui ont apporté une contribution originale à la réflexion sur un cinéma de conscientisation. Le découpage de l'histoire du Cinema Novo en trois phases se justifie par le fait que les événements politiques connus par le Brésil pendant les années soixante ont eu une incidence directe sur la praxis des cinemanovistas. Le découpage de notre plan s'appuie sur les deux plus importants d'entre eux : le coup d'État du 1er avril 1964, et la promulgation de l'AI-5 du 13 décembre 1968, souvent considéré comme « un coup d'État dans le coup d'État » et qui clôt une année de conflits sociaux et politiques intenses. 


\section{PREMIÈRE PARTIE. La genèse du Cinema Novo}

L'expression « Cinema Novo » est utilisée pour la première fois par Glauber Rocha le 12 août 1961 pour désigner un mouvement cinématographique qui serait en train de naître ${ }^{65}$. Le texte dont elle est extraite «Arraial do Cabo, cinema nôvo e câmara na mão » (Arraial do Cabo, cinéma nouveau et caméra portée) pourrait d'ailleurs très bien faire figure de manifeste si, à cette condition, ne lui disputaient plusieurs autres articles du même Rocha qui, parallèlement à d'autres critiques, appelle de ses vœux l'émergence d'un cinéma brésilien formellement ambitieux et capable de participer à la vie sociale et politique du pays. L'étude détaillée des articles de journaux et les témoignages recueillis sur les débuts du Cinema Novo nous conduisent à distinguer deux moments précis dans sa genèse. Le premier moment, entre 1960 et 61 , se caractérise par une intense réflexion critique qui aboutira à l'établissement d'un corps doctrinal pour un nouveau cinéma brésilien. Dans cette période, peu de films sont produits et la discussion reste cantonnée au domaine du cinéma. Cette discussion intéresse un petit nombre de critiques mais elle est relayée par deux des plus grands quotidiens du pays et rencontre un profond écho auprès des cinéphiles intéressés par les destinées du cinéma national. Elle sera l'objet de notre premier chapitre.

Entre 1961 et 62, la réalité vient perturber la théorie. D'un côté, l'arrivée au pouvoir de João Goulart plonge le pays dans un contexte de mobilisation sociale et politique jusque là inédit. Malgré une première tentative de coup d'État militaire avortée au moment de sa prise de fonction, le nouveau président se dit décidé à réaliser les réformes de base réclamées par la gauche dont la réforme agraire dans un pays dominé par le latifundium. La polarisation de la vie politique va croissante et, pour beaucoup, le Brésil traverse une période prérévolutionnaire. De nouveaux acteurs relancent la réflexion critique sur le Cinema Novo qui sort du domaine cinématographique et se politise. D'un autre côté, les succès commerciaux et critiques inattendus de trois films brésiliens dont aucun ne correspond parfaitement au concept critique préétabli, Os Cafajestes, O Pagador de promessas et Assalto ao trem pagador, provoquent la confusion. L'expression «Cinema Novo » échappe à ses auteurs et devient très à la mode dans la presse entre 1961 et 1962 sans pour autant être l'objet d'une conceptualisation précise. Simple phénomène de renouvellement générationnel ou émergence d'une nouvelle esthétique, les journalistes ne tranchent pas et appellent « Cinema Novo » ce

65 L'expression apparaît simultanément dans deux articles du 12 août 1961. Azeredo annonce la publication d'une revue portant ce nom et Rocha l'utilise pour désigner le nouveau cinéma qui naît avec Arraial do Cabo. La revue ne verra jamais le jour. $C f$. AZEREDO, Ely. «Cinema Novo fala alto » in Tribuna da Imprensa, Rio de Janeiro, 12-13/08/1961, et ROCHA, Glauber. « Arraial, Cinema Novo e câmara na mão » in O Jornal do Brasil, Rio de Janeiro, 12/08/1961. 
qui est jeune et s'oppose au cinéma des années cinquante. Dans le courant de l'année 1962, la controverse éclate. Rocha et un groupe de jeunes réalisateurs rejettent les demandes concernant un cinéma propagandiste et la voie d'un cinéma politique qui ne serait pas formellement novateur. Les disputes et les remises en cause de l'année 1962 seront l'objet du chapitre 2.

Dans le troisième chapitre, nous essaierons d'en savoir plus sur ce groupe du « Cinema Novo » qui apporte au concept critique initialement établi une interprétation précise au travers de ses films et d'un discours théorique qui se prolonge jusqu'à aujourd'hui dans les témoignages de ses membres. Cet ensemble de personnes que nous nommerons cinemanovistas s'est caractérisé par une grande unité de pensée et d'action pendant plus de dix ans, entre environ 1960 et 1972 . Nous constaterons ici que ce sont des gens qui partagent la même origine sociale, la même formation et le même point de vue sur la société et la culture même si leurs opinions politiques peuvent varier. 


\section{Chapitre premier : Élaboration d'un concept critique}

Avant même qu'aucun film ne sorte sur les écrans brésiliens et avant que le Cinema Novo ne prenne son nom, il est l'objet de rencontres et d'articles dans les quotidiens les plus importants du pays. Quatre critiques en particulier se penchent entre 1960 et 1961 sur les chemins que devrait prendre le cinéma brésilien : il s'agit de Jean-Claude Bernardet, Gustavo Dahl, Paulo Emílio Sales Gomes et Glauber Rocha. Il s'établit alors entre les textes qu'ils écrivent un véritable dialogue qui nous paraît des plus importants puisque nous estimons qu'à la fin de l'année 1961, il aura posé les bases du corps doctrinal du Cinema Novo. Celui-ci changera pas pendant toute la durée du vie du phénomène et, d'une certaine façon, A Revisão crítica do cinema brasileiro écrit par Rocha en 1963 en constitue à la fois, l'application, la synthèse et l'appropriation.

\subsection{Le dialogue entre Bernardet, Dahl, Sales Gomes et Rocha}

Bernardet, Dahl et Sales Gomes écrivent dans le Suplemento Literário do Estado de São Paulo et travaillent à la Cinemateca brasileira, à São Paulo. Rocha publie ses articles les plus importants dans le Suplemento Dominical do Jornal do Brasil, journal de Rio de Janeiro. Dans chacun des cas, il s'agit des suppléments culturels hebdomadaires de deux quotidiens de très grande renommée. Le principal sujet de ces articles concerne l'orientation que doit adopter un cinéma brésilien qui n'existe pas encore et la réflexion s'articule sur une poignée de films dont deux des plus importants : Arraial do Cabo et Aruanda, ne connaissent qu'une circulation très confidentielle.

Pour mieux situer le débat, il faut préciser que la part qui est attribuée au cinéma dans chacun des suppléments culturels que nous avons cité est minime. Il s'agit en général d'une colonne alors que la littérature, le théâtre, la musique et les arts plastiques s'étalent en couverture ou sur des doubles pages. Le fait est assez significatif du manque de prestige culturel dont souffre alors le cinéma au Brésil. Il ne doit cependant pas nous tromper sur l'exacte nature du débat qui est alors en cours. La modestie de l'espace accordé au cinéma ne rend pas compte de l'intense activité qui est alors menée par les cinémathèques et les cinéclubs et à laquelle les critiques que nous avons cités prennent part.

En 1960, au Brésil, les trois principaux centres de cinéphilie sont Rio de Janeiro, Salvador et São Paulo ${ }^{66}$. Rocha établit la liaison entre Salvador et Rio de Janeiro. Originaire 
de Bahia, il doit une bonne part sa formation cinématographique au Clube de Cinema de Salvador dirigé par Walter da Silveira. Ses allers-retours sur Rio de Janeiro lui permettent de s'intégrer aussi au monde du cinéma de la capitale fédérale. À cette époque, l'activité de la Cinemateca do Museu de Arte Moderna est à son maximum avec des centaines de films projetés dans le cadre de rétrospectives importantes des cinémas français, américain, italien, japonais.

La Cinemateca Brasileira, à São Paulo, a été fondée en 1957 suite à la destruction de la Filmoteca do Museu de Arte Moderna ${ }^{67}$, et parmi ses fondateurs compte Sales Gomes (19161977) qui est déjà un personnage d'importance dans le panorama culturel de la mégalopole ${ }^{68}$. Très rapidement, cette nouvelle entité joue un rôle moteur dans la divulgation de la culture cinématographique et organise deux événements qui nous intéresseront ici directement : la I Convenção da Crítica Cinematográfica ${ }^{69}$ en octobre 1960 et l'Homenagem ao Cinema Brasileiro $^{70}$, rétrospective de 7 films dans le cadre de la VI Bienal de São Paulo, en octobre 1961. Nous verrons d'ailleurs bientôt que la cinémathèque ne limite pas ses activités à la conservation et à la mise à disposition d'archives cinématographiques. Malgré la précarité de ses moyens, elle possède une véritable politique culturelle et les deux événements que nous avons cités, sont représentatifs de cette politique.

Toutes ces informations sont importantes pour bien se représenter que le dialogue qui s'établit alors entre Bernardet, Dahl, Sales Gomes et Rocha n'est pas une simple correspondance entre critiques. Les articles que nous allons étudier sont écrits par des personnes qui se connaissent entre elles ou vont avoir rapidement l'occasion de se rencontrer physiquement du fait de leurs activités respectives et qui, parallèlement, participent aux discussions sur le cinéma dans leurs villes à un moment historique privilégié. Si le cinéma n'est pas le sujet de prédilection des suppléments culturels et autres revues consacrées à l'art, il n'en excite pas moins l'imagination de nombreux jeunes qui voient en lui un moyen d'expression moderne par excellence.

Trois thèmes principaux occupent les débats : la débilité du secteur cinématographique brésilien («Uma Situação Colonial » et le problème de l'héritage de la chanchada et de la Vera Cruz), le rôle de la critique («Três filmes » : l'importance de la position de l'auteur, rejet du cinéma hollywoodien et du réalisme socialiste), le choix du cinéma d'auteur à budget restreint (« Coisas nossas »).

Revista de Cultura Cinematográfica.

67 Rio de Janeiro et São Paulo ont chacune un musée d'art moderne prestigieux.

68 Des quatre critiques qui nous intéressent, Sales Gomes est le seul à être né dans les années 10, les autres appartiennent tous à la génération du Cinema Novo née dans les années 30.

69 Première Convention de la Critique Cinématographique.

70 Hommage au Cinéma Brésilien. 


\section{Situation du cinéma brésilien en 1960}

Au début des années soixante, le contexte de la production de longs métrages de fiction est au Brésil particulièrement sombre. La législation destinée à contrôler et réguler le marché cinématographique est largement défaillante et il n'existe pas d'institutions destinées à soutenir la production nationale à l'exception de celle de la ville de São Paulo qui peine pourtant à remplir son rôle et à stimuler l'émergence d'une activité consistante et pérenne. Parmi les quatre critiques qui nous intéressent, Sales Gomes est celui qui s'inquiète le plus des relations entre économie et esthétique. L'article le plus important qu'il écrit à l'époque est «Uma situação colonial $»^{71}$ dans lequel il assimile la situation du cinéma brésilien de 1960 à une situation coloniale. Dans un autre article intitulé « O Dono do mercado » ${ }^{72}$, il insiste sur le fait que le « propriétaire » du marché, c'est le producteur de cinéma étranger. Avant d'analyser ces articles, nous dresserons un bilan de la santé du cinéma brésilien juste avant l'apparition du Cinema Novo et nous remarquerons que les analyses de Sales Gomes, au-delà de la tonalité polémique de titres des articles, s'accordent assez bien avec les études approfondies qui seront faites par la suite sur les mêmes sujets ${ }^{73}$.

À la fin des années 50 avec plus de 3000 salles de cinéma et une fréquentation annuelle supérieure à 280 millions de spectateurs, le marché de l'exploitation cinématographique du Brésil se situe entre les dix plus importants du monde. Il est aussi celui sur lequel circule le plus grand nombre de longs métrages, pour 1960, 683 contre 525 aux États-Unis où le nombre de spectateurs annuel est plus de huit fois plus grand. Il atteint alors le chiffre de 2300000 000. L'écrasante majorité des films en circulation sont des films étrangers qui laissent peu de place à la production nationale. En 1958, le nombre de longs métrages brésiliens en circulation sur le marché était de 62 contre 718 étrangers, en 1959, 41 contre 645, en 1960, 37 contre $749^{74}$. La part du film brésilien oscille alors entre 4 et $8 \%$ du nombre de total de films en circulation à un moment, paradoxalement, de bonne santé de la production nationale puisque, comme nous allons le voir plus bas, le nombre de films produits dépasse 40 films par an. Cette situation de complète hégémonie du produit étranger n'est pas nouvelle. Elle doit être mise en relation avec des données plus anciennes :

71 GOMES, Paulo Emílio Sales. « Uma Situação colonial ?» in O Estado de São Paulo - Suplemento literário, São Paulo, 19/11/1960.

72 GOMES, Paulo Emílio Sales. «O Dono do mercado » in O Estado de São Paulo - Suplemento literário, São Paulo, 21/01/1961.

73 BERNARDET, Jean-Claude. Cinema brasileiro : propostas para uma história. Op. cit., 1978. RANDAL, Johnson. The film industry in Brazil : Culture and the state. Op. cit., 1987.

SANTOS PEREIRA, Geraldo. Plano geral do cinema brasileiro:história, cultura, economia e legislação. Rio de Janeiro, Borsoi, 1973.

SIMIS, Anita. Estado e cinema no Brasil. São Paulo, Annablume, 1996.

74 SANTOS PEREIRA, Geraldo. Op. cit., p. 64. 
«Alguns números ilustrativos : em 1941, foram lançados no Brasil 460 filmes de longa-metragem dos quais quatro brasileiros ; 1942 : 409/1 ; $1943: 362 / 6$; 1953 : 578 / 34 ; 1954 : 490/21 (dados Cine Reporter). $»^{75}$

L'article «O Dono do mercado » montre que le marché de l'exploitation est dominé par le cinéma étranger car il s'est structuré comme marché importateur dès ses origines ${ }^{76}$. Subjugué par le volume et la qualité technique de la production cinématographique des grands centres industrialisés, surpris par la force et l'agressivité des techniques commerciales étrangères ${ }^{77}$, le secteur cinématographique brésilien a rapidement abandonné jusqu'à l'idée d'une production de longs métrages de fiction, se concentrant sur celles de films institutionnels, d'information, de propagande et de publicité et développant avant tout les activités de distribution et d'exploitation du long métrage de fiction étranger. Sales Gomes observe justement que, depuis la Belle Époque jusqu'au début des années cinquante, «O filme brasileiro era concebido em termos de curiosidade episódica e não como produto destinado a alimentar um mercado. $\rangle^{78}$

Sales Gomes montre également que la façon dont le marché cinématographique brésilien s'est structuré a eu une incidence directe sur le travail du législateur. Confronté à l'insignifiance de la production nationale de longs métrages et à l'étendue du secteur de l'exhibition, ce dernier s'est appliqué à protéger les emplois des exploitants de salles, des distributeurs de films étrangers et des laboratoires. La législation a ainsi favorisé l'importation avec des taxes douanières symboliques et l'activité des laboratoires nationaux en imposant

75 «Quelques chiffres illustratifs : en 1941, 460 longs métrages sont sortis au Brésil, 4 d'entre eux étaient brésiliens ; en $1942: 409 / 1 ; 1943: 362 / 6$; $1953: 578$ / 34 ; $1954: 490 / 21$ (source : Cine

Reporter). »BERNARDET, Jean-Claude. Cinema brasileiro : propostas para uma história. Op. cit., pp. 1112. Aujourd'hui, la situation n'est pas très différente, le Brésil produit environ 30 films par an. Sur ces 30 films, un ou deux accèdent à la condition de grand succès brésilien de l'année, A Cidade de Deus (Fernando Meirelles, 2002), Carandiru (Hector Babenco, 2003), Deus é brasileiro (Carlos Diegues, 2003), alors que les autres passent totalement inaperçus du grand public, souvent mal distribués et sans campagne promotionnelle suffisante.

76 L'auteur ne parle pas de la Belle Époque du cinéma brésilien entre 1908 et 1912 où la production locale a concurrencé la production étrangère. Avec la première guerre mondiale, Hollywood se trouve dans une situation de quasi monopole. La production cinématographique européenne est ralentie par la guerre et les pays périphériques se trouvent confrontés aux difficultés d'importation de pellicules et des caméras dont ils ne maîtrisent pas la fabrication. La production nord-américaine accède à une position hégémonique qu'elle ne va pas cesser de renforcer.

77 Très rapidement, les compagnies étrangères les plus puissantes et en particulier nord-américaines installent des succursales au Brésil. Elles bénéficient du soutien du gouvernement américain qui défend le cinéma dans les accords de commerce internationaux dès les années 30. Elles utilisent des techniques de vente souvent interdites dans leur propre pays comme la vente par lot qui permet de négocier l'achat d'une douzaine de films de façon indissociable à un ou deux grands succès internationaux porteurs. Confrontées à un marché mal réglementé, elles peuvent également baisser la part revenant au producteur et augmenter celle revenant à l'exploitant puisque leurs films sont déjà amortis. Elles s'assurent ainsi la sympathie des grands circuits d'exploitation qui les soutiennent dans leur action de lobbying visant à empêcher toute modification législative qui pourrait induire une diminution de leurs bénéfices.

78 « Le film brésilien était vu comme une curiosité épisodique et non comme un produit destiné à alimenter un marché. » in SALES GOMES, Paulo Emílio. «O Dono do mercado », op. cit. 
qu'y soient développées les copies destinées au marché national ${ }^{79}$. La prospérité du secteur de l'exhibition et sa capacité à générer des emplois ont donc été liées très tôt au succès du film étranger. Pour encourager la croissance de ce secteur, le législateur devait donc aussi faciliter l'entrée du produit étranger. Un cercle vicieux s'est mis en place qui a fait que l'unique réalité du secteur cinéma était, pour le législateur, le cinéma étranger.

Malgré cette situation défavorable, le nombre de longs métrages réalisés a pu atteindre des valeurs significatives avec plus de 40 films par an produits en 1957, 1958 et $1959^{80}$. Ce pic de production se concentre cependant autour d'un corpus de films de série b, la chanchada, qui connaît alors son apogée avec les films de Carlos Manga et de Watson Macedo. Films parodiques aux budgets étriqués, les chanchadas sont originellement construites autour du talent d'artistes venus du théâtre de boulevard. Sketchs et numéros de variétés se succèdent souvent de façon impromptue sans beaucoup de souci pour la cohérence du scénario. Le genre est absolument méprisé par la critique et le public de classe moyenne et de classe supérieure qui le considèrent comme un divertissement vulgaire et grossier. Il est évident qu'il participe de ce jugement des préjugés de classe assez forts et il nous sera assez difficile d'évaluer dans quelle mesure Bernardet, Dahl, Sales Gomes et Rocha partagent ces préjugés car aucun de leurs articles n'a pour sujet la chanchada ${ }^{81}$. Elle n'est l'objet d'aucune analyse critique en profondeur. Elle est évidemment présente, en toile de fond, car elle est une référence incontournable du panorama cinématographique brésilien des années cinquante et du tout début des année soixante, mais elle n'est, le plus fréquemment, même pas nommée.

Il existe aussi dans le panorama de la production brésilienne des tentatives de cinéma « sérieux ». Celui-ci a survécu aux faillites successives des grands studios implantés par la bourgeoisie pauliste au début des années cinquante. On continue donc à faire des films dans le style de ceux de la Vera Cruz dont de nombreux techniciens, d'origine européenne, s'étaient installés au Brésil. Par opposition à la chanchada, souvent décriée pour ses faibles budgets et ses défaillances de réalisation technique, il s'agit de réaliser un cinéma de «niveau international », dans lequel les différents secteurs de la production seraient irréprochables : lumière, scénographie, continuité, fluidité du montage, élaboration du scénario, etc. Le modèle de ce cinéma est évidemment ce que certains critiques appellent « le bon cinéma hollywoodien » : il en respecte les règles d'écriture, recycle plusieurs de ses clichés et colle au moralisme de l'époque. Évidemment, la chanchada et le film « sérieux » n'appartiennent pas à

79 Cf. SALES GOMES, Paulo Emílio. « O Dono do mercado », op. cit.

80 Cf. SILVA NETO, Antônio Leão Da. Dicionário de filmes brasileiros. São Paulo, Gráfica Editora, $2002, \mathrm{p}$. 940.

81 Nous pourrons également remarquer qu'il était inimaginable qu'un supplément culturel comme ceux où ils publiaient leurs articles accepte une exégèse de la chanchada. 
deux mondes séparés. Producteurs et cinéastes de chanchadas ambitionnent de réaliser à un moment ou un autre le film «sérieux » qui a tant de mal à s'imposer sur le marché. D'autre part, l'augmentation de la production à laquelle nous assistons à la fin des années cinquante s'accompagne d'importantes transformations qualitatives.

Dans la deuxième partie des années cinquante, la chanchada est de moins en moins la comédie carnavalesque aux numéros musicaux téléphonés et répétitifs qu'elle a été jusqu'à récemment, les budgets et le niveau de réalisation technique deviennent équivalents à ceux des films sérieux et elle se rapproche de la comédie urbaine. C'est le cas par exemple de Absolutamente certo d'Anselmo Duarte (1957). Elle présente même parfois une dimension de commentaire social comme Nem Samsão nem Dalila (Carlos Manga, 1955). L'émergence de la télévision comme média concurrentiel au début des années soixante porte un coup assez rude à son évolution. La télévision récupère à son compte le type de divertissement que ce genre offrait et bientôt public et artistes migrent vers ce nouveau média. Au début des années soixante, la production de cinéma a rechuté à moins de trente longs métrages par an.

Ces changements structurels passent inaperçus aux yeux des quatre critiques qui nous intéressent. Ils souhaitent et ils attendent un cinéma brésilien qui ne soit ni la chanchada, ni ce cinéma « sérieux » qu'ils jugent assez faible pour n'être qu'un cinéma d'imitation, ils veulent un cinéma qui soit à la fois typiquement national et capable de produire des œuvres à la hauteur de leurs modèles. Le cinéma dont ils rêvent est un cinéma capable de produire de grandes œuvres comme celles de Welles, Renoir, Eisenstein, Kurosawa et Visconti, dans lequel au moins certains films, puissent accéder au rang des grandes productions de l'esprit humain. Or, le cinéma brésilien leur semble ne pas avoir encore atteint ce niveau. «Uma Situação colonial ? » résume leur perception de la situation du cinéma brésilien. À l'époque où il a été écrit et présenté, il participait d'une démarche de recherche et apportait une vision nouvelle sur la situation. Le texte commence par la déclaration suivante :

«O denominador comum de todas as atividades relacionadas com o cinema é em nosso país a mediocridade. A indústria, as cinematecas, o comércio, os clubes de cinema, os laboratórios, a crítica, a legislação, os quadros técnicos e artísticos, o público e tudo o mais que se relacione com o cinema no Brasil apresenta a marca cruel do subdesenvolvimento. $\gg{ }^{82}$

Selon Sales Gomes, il est impossible de réfléchir à la situation du cinéma brésilien sans prendre en compte ses aspects culturels, industriels et commerciaux de façon globale. Or,

82 « Le dénominateur commun de toutes les activités en relation avec le cinéma est, dans notre pays, la médiocrité. L'industrie, les cinémathèques, le commerce, les clubs de cinéma, les laboratoires, la critique, la législation, les cadres techniques et artistiques, le public et tout le reste qui a à voir avec le cinéma au Brésil présentent la marque cruel du sous-développement. » in GOMES, Paulo Emílio Sales. « Uma Situação colonial ? », op. cit. 
toutes les activités liées au cinéma au Brésil sont placées sous le signe de la médiocrité et même celles qui prospèrent comme la distribution et de l'exploitation des films étrangers ou la production nationale (sous-entendu mais pas nommée : la chanchada) parce qu'elles ne participent en rien du développement culturel et économique du pays.

Les jeunes qui s'essayent à produire un cinéma de prétentions artistiques échouent car le public préfère l'équivalent étranger dont les moyens sont nettement supérieurs. Plein d'amertume, ils abandonnent alors cette ambition ce qui constitue un énorme gaspillage de temps, d'énergie et de talent et quittent le cinéma ou se consacrent aux activités précédentes qui précisément empêchent le développement d'un cinéma brésilien de qualité.

La bureaucratie administrative est l'un des principaux obstacles au bon fonctionnement des institutions culturelles comme la Cinemateca Brasileira et limite ainsi leur pouvoir de pénétration culturelle au-delà des classes privilégiées de Rio et São Paulo. Celles-ci ne peuvent donc pas jouer leur rôle et modifier la perception du cinéma par le public.

Le faible espace qui est accordé au cinéma national et son manque de qualité conduisent les critiques à écrire avant tout sur le cinéma étranger. Or il n'y a pas de dialogue possible avec ce cinéma puisque les réalisateurs se préoccupent logiquement des critiques de leurs pays d'origine et non pas de celles d'un pays périphérique. Et cette absence de dialogue est préjudiciable au propre critique puisque son avis ne compte que pour un public « secondaire » : la censure, les exploitants et en dernière instance, le public. Spécialiste d'un cinéma en relation avec des réalités sociales étrangères, il finit donc par vivre dans un « ailleurs » qui l'écarte autant des réalités de son propre pays qu'il ne l'est des réalités des pays dont il critique les films. Enfin, le cinéma national est pour lui un élément perturbateur dont il ne sait que faire oscillant entre la condescendance et le sarcasme.

Ce panorama suggère donc que le cinéma brésilien vit une « situation coloniale», impression renforcée si l'on considère que les co-productions avec l'étranger sont un moyen d'exploiter de façon cinématographique la «matière première » filmique nationale, acteurs, histoires et paysages.

Le texte présente évidemment un très fort impact polémique. En identifiant la situation du cinéma au Brésil au sous-développement du pays, Sales Gomes, nous dit de façon tout à fait explicite que si le pays possède un cinéma de seconde classe, il possède également une critique de seconde classe, et comme nous savons par ailleurs que celle-ci cultive son goût pour le cinéma étranger comme un signe de distinction sociale et de sophistication intellectuelle ${ }^{83}$, nous pouvons mesurer la violence de cette remise en cause de son statut. Mais

83 Il faut se souvenir qu'à cette époque, la majorité de la population du pays est analphabète or les films étrangers ne sont pas doublés mais sous-titrés. Si l'on rajoute à cela le fait que les cinémas, du centre à la périphérie des villes ou à la province, étaient encadrés par une hiérarchie assez stricte déterminée par le prix 
il va bien plus loin dans l'analyse puisqu'en assimilant la condition du cinéma à une « situation coloniale », il indique que le statu quo est déterminé par les intérêts de certains groupes qui prospèrent au détriment de l'intérêt général de ce secteur d'activité et même du pays en entier compte tenu de l'importance économique et culturelle du cinéma dans les sociétés modernes.

Cette approche, même si elle trouve ses racines dans les débats sur le cinéma qui sont menés depuis le début des années cinquante, a connu une maturation rapide dans les mois qui ont précédé. Son caractère novateur réside dans le refus de dissocier les aspects culturels, économiques et commerciaux du cinéma et de montrer à quel point ils sont dépendants les uns des autres. En éclairant la situation sous un jour nouveau, elle indiquait déjà des orientations de travail qui, pour certaines d'entre elles, avaient déjà commencé à être empruntées par luimême et d'autres critiques. Le maître mot serait celui de la participation. Pour devenir acteur et non plus spectateur passif, il fallait apprendre à voir le cinéma brésilien et étranger autrement, modifier son approche critique pour modifier le cinéma.

\section{Modification de la critique}

Le changement de posture de la critique ne doit évidemment pas consister à considérer qu'un mauvais film est un chef d'œuvre ${ }^{84}$, mais à abandonner certaines habitudes que l'absence de responsabilité vis à vis des films avait fait contracter. L'une de celles qui va se perpétuer encore longtemps consiste, grosso modo, à noter indépendamment les différents aspects techniques d'une réalisation puis à calculer la moyenne pour donner une évaluation globale du film. L'autre de ces pratiques consiste à considérer un film comme un chef d'œuvre pour des raisons qui sont de l'ordre de l'immanence, autrement dit une conception du beau et du désirable comme quelque chose qui relève de l'absolu, du métaphysique, d'un agencement interne heureux des différentes parties de l'œuvre, sans interroger toutefois ses conditions de réalisation et les significations sociales, idéologiques et économiques que l'œuvre peut présenter.

Présentée de cette façon, l'on pourrait croire que cette modification de la critique correspond à peine à une mise à jour rendue nécessaire par les révolutions successives du Néo-Réalisme, de la Nouvelle Vague et du Cinéma Direct. Le problème ne saurait être réduit à cela. Il s'agit également de penser le cinéma au Brésil à partir du Brésil, c'est à dire en prenant en compte les circonstances particulières qui font la vie du pays et en pensant au

des entrées et la qualité des salles, il est facile de comprendre combien le parc cinématographique reproduisait les clivages sociaux et participait à leur intériorisation par les individus.

84 Rocha commettra pourtant parfois cet excès. C'est le cas par exemple pour Mandacaru vermelho, un film mineur qui reçoit une critique dithyrambique : « Mandacaru vermelho » in O Jornal do Brasil - Suplemento Dominical, Rio de Janeiro, 11/11/1961. 
développement économique et culturel de la cinématographie nationale. Évidemment, la conséquence logique de cette posture, consiste à penser que, si le cinéma brésilien vient un jour à exister, il possédera un langage propre, reconnaissable entre tous et qui ne pourra pas être jugé de la même façon que les expériences cinématographiques déjà connues sont jugées.

Vis à vis du cinéma national, il n'est donc pas demandé au critique de se montrer condescendant, il lui est demandé d'abandonner la quête du chef d'œuvre, d'adopter une attitude de recherche visant à détecter toute œuvre qui présenterait des aspects novateurs et d'établir un dialogue avec les films qui permettraient de contribuer à l'élévation de la qualité globale de la production. Vis à vis d'un film étranger, il s'agit de se demander ce qu'il peut représenter pour la société brésilienne dans son ensemble et ce qu'il peut apporter en relation avec le développement de la cinématographie nationale.

Cette position est conceptualisée par Bernardet dans un article intitulé « Impressões da Convenção » qui prend pour point de départ l'article de Sales Gomes publié la semaine précédente et qui relate la I Convenção da Crítica Cinematográfica :

«Os cineastas brasileiros devem reconhecer que não lhes é possível, no momento presente, realizar o grande filme de sua vida. Por seu lado, os críticos devem admitir que não podem assumir posições sólidas, porque só se nutrem de obras estrangeiras ; assim as suas posições são sempre abstratas e fracas, porque não conseguem atingir o autor estrangeiro, e um crítico que não pode dialogar com o autor vivo da obra que comenta - o que é essencial para a formação crítica - ou não é um crítico (pode ser um cronista, um teórico...) ou é um crítico frustrado. É um círculo vicioso ; sem realizadores não há críticos, e vice-versa. Uns e outros devem confessar a humildade de sua condição, e somente essa tomada de consciência poderá criar um clima favorável. $\gg{ }^{85}$

Après s'être interrogé sur le regard que le critique peut avoir sur le cinéma national pour contribuer à son développement, Bernardet observe que le niveau du débat s'est appauvri lors de la convention quand on en est revenu aux questions du «contenu » du cinéma brésilien. Il estime alors que l'on ne peut pas décider a priori de ce qu'il doit être et qu'il faut abandonner définitivement cette distinction qui est systématiquement établie entre le « fond» et la «forme » d'un film. C'est aussi la conception de Dahl quand il écrit :

« Hoje sabe-se que o cinema não pode nem deve ser meio de expressão, mas sim expressão pura. Um filme não tem que exprimir, não tem que servir de veículo a uma visão do mundo existente a priori,

85 « Les cinéastes brésiliens doivent reconnaître qu'il ne leur est pas possible, dans le moment présent, de réaliser le grand film de leur vie. De leur côté, les critiques doivent admettre qu'ils ne peuvent pas assumer des positions solides, parce qu'ils ne se nourrissent que d'œuvres étrangères ; ainsi, leurs positions sont toujours abstraites et fragiles, parce qu'ils ne peuvent atteindre l'auteur étranger, et un critique qui ne peut pas dialoguer avec l'auteur vivant de l'œuvre qu'il commente - ce qui est essentiel pour sa formation critique ou, n'est pas un critique (il peut être un chroniqueur, un théoricien...), ou il est un critique frustré. C'est un cercle vicieux : sans réalisateur, il n'y a pas de critiques, et vice-versa. Les uns et les autres doivent confesser l'humilité de leur position, et seulement cette prise de conscience pourra créer un climat favorable. » in BERNARDET, Jean-Claude. « Impressões da Convenção » in O Estado de São Paulo - Suplemento literário, São Paulo, 03/12/1960. 
mas ser ele próprio uma visão do mundo. A primaria distinção entre forma e conteúdo, fruto de cérebros mirrados ou fanáticos, ainda paira, no entanto, como um fantasma sobre a concepção cinematográfica de vários de nossos diretores. A simples aceitação destes terços implica na negação da validez artística do cinema. Ou a forma é conteúdo e o conteúdo, forma, ou nenhum é nada. $»^{86}$

Le critique, dans son approche d'un film, ne peut donc plus considérer que le langage cinématographique est indépendant du «message » du film, et donc également de la position assumé par ses auteurs. En plus de remettre le film dans son contexte économique, politique et social de fabrication et de réception, il est question d'interroger le type de relation qu'il établit avec le spectateur et le type de relation qu'il établit avec le monde, autrement dit la politique de ses auteurs. Cette position est encore expliquée par deux autres articles de Bernardet : « Três filmes ${ }^{87}$ et « Questão de higiene $)^{88}$.

Dans « Três filmes », il écrit au sujet de The Magnificent Seven ${ }^{89}$ (John Sturges, USA, 1960), Plein Soleil (René Clément, France, 1959) et Ballada o soldatye $e^{90}$ (Grigori Tchoukhraï, URSS, 1959). Il montre alors que bien que ces trois films servent a priori des idéologies différentes, ils provoquent tous les trois l'évasion du spectateur, le coupe de la réalité, et contribuent ainsi à le maintenir dans des idées fausses sur le fonctionnement du monde et sur l'inutilité de sa participation. Le critique ne peut plus assumer une position libérale et passive, il doit prendre position face à l'idéologie du film : il rejette ici un langage d'aliénation, proche ou assimilable à un cinéma de propagande dont les objectifs premiers seraient dissimulés par les alibis du film de divertissement ou du film artistique. Nous reviendrons sur cet article qui anticipe sur le corps doctrinal du Cinema Novo.

Dans « Questão de higiene », Bernardet réaffirme ses positions en montrant qu'il est nécessaire de rompre avec un type de critique communément appliquée qui consiste à dissocier le fond de la forme et à ne juger que la forme selon des critères de bon goût, de savoir-faire ou de technique. Selon lui, il faut aussi, et avant tout, critiquer la position des auteurs, c'est à dire leur position sociale et idéologique par rapport au cinéma. Finalement, il s'agit du pendant de la politique des auteurs dans le camp de la critique.

86 « Aujourd'hui, nous savons que le cinéma ne peut être, ni ne doit être un véhicule d'expression, mais une expression pure. Le film n'a rien à exprimer, il n'a pas à servir de véhicule à une vision du monde existant a priori, mais il doit lui-même être une vision du monde. La distinction primaire entre la forme et le contenu, fruit de cerveaux malades ou fanatiques, pèse encore, cependant, comme un fantôme sur la conception cinématographique de nos directeurs. La simple acceptation de ces principes implique la négation de la validité artistique du cinéma. Ou la forme est contenu et le contenu est forme, ou les deux ne sont rien. » in DAHL, Gustavo. «Importância de Khouri » in O Estado de São Paulo - Suplemento literário, São Paulo, 21/05/1960.

87 BERNARDET, Jean-Claude. « Três filmes » in O Estado de São Paulo - Suplemento literário, São Paulo, 13/05/1961.

88 BERNARDET, Jean-Claude. « Questão de higiene » in O Estado de São Paulo - Suplemento literário, São Paulo, 26/08/1961.

89 Les Sept Mercenaires.

90 La Ballade du soldat. 
«A atuação do crítico não pode ser de apreciação plástica ou técnica, mas sim de 'demistificação'. Só assim, ao falar de fitas estrangeiras, falará também do Brasil, isto é, só assim se dirigirá também aos diretores brasileiros.

Porque o crítico pode ter uma atuação junto aos cineastas. E deve tê-la. Deve orientá-los, não significando isto que formule regras, nem dite atitudes a seguir. Deve criar um clima para que certos temas sejam tratados e o sejam inteligentemente. Por isso, a posição do autor não é em nada intocável. Ao contrário, o esforço crítico consiste em pôr em evidência esta posição e criticá-la. É o mais urgente. $\rangle^{91}$

Cette nouvelle position de la critique explique évidemment comment et pourquoi, simultanément, la réflexion au sujet de la production cinématographique aboutit à l'idée selon laquelle le cinéma d'auteur à petit budget est « la solution unique » à l'indigence culturelle et esthétique du cinéma brésilien. Tout commence ainsi dans cette insatisfaction d'une parcelle de la critique envers le cinéma national. Nous allons développer dans le paragraphe suivant les orientations que ce dialogue par articles interposés pouvait offrir à ceux qui voudraient bien les prendre en compte. Il convient auparavant de préciser que si Dahl et Rocha s'intéressent avant tout aux questions de production, Bernardet et Sales Gomes traitent également des questions de la vulgarisation de la culture cinématographique et de l'importance de la mission des cinémathèques et des ciné-clubs.

Cette dernière dimension de leur discours ne semble pas, au premier abord, au centre de nos intérêts. Mais les préoccupations dont ils témoignent alors peuvent cependant apporter un certain éclairage sur un aspect de notre problématique : la relation culture - population.

Dans les documents en relation avec le Cinema Novo qui seront produits les années suivantes, cette problématique ne sera plus jamais traitée en profondeur, même lorsque l'on s'interrogera sur le dialogue du Cinema Novo avec le public. Un seul texte, à notre avis, y reviendra véritablement, bien des années plus tard, il s'agit de « Trajetória no subdesenvolvimento » de Sales Gomes. Mais nous y reviendrons.

Le thème est abordé dans « Uma Situação colonial» :

« As instituições que promoveram durante os últimos seis anos os grandes ciclos de projeções culturais manifestam um justificado orgulho por esses empreendimentos. 'Os grandes momentos do cinema', a 'Homenagem a Erich Von Stroheim', a 'Retrospectiva do Cinema Internacional', os 'Dez anos de filmes sobre arte' e os festivais históricos dedicados ao cinema norte-americano, francês e italiano são com efeito manifestações que não temem a comparação com o que se tem feito de melhor, no gênero, nos países mais adiantados do mundo. [...] Ao mesmo tempo, porém, não é esse evidentemente o trabalho que se espera das cinematecas no terreno da difusão. Esses grandes festivais foram reservados para setores

91 « Le rôle du critique ne peut pas être d'appréciation plastique ou technique, mais si de ' démystification '. Seulement ainsi, en parlant des films étrangers, il parlera aussi du Brésil, autrement dit, seulement ainsi, il parlera aussi aux directeurs brésiliens.

Parce que le critique peut avoir un rôle pour les cinéastes. Et qu'il doit l'avoir. Il doit les orienter, non pas qu'il doive formuler des règles, non plus qu'il dicte des attitudes à suivre. Il doit créer un climat favorable à ce que certains thèmes soient traités et bien traités. Pour cela, la position de l'auteur n'est en rien intouchable. Au contraire, l'effort critique consiste à mettre en évidence cette position et à la critiquer. C'est le plus urgent. » in BERNARDET, Jean-Claude. « Questão de higiene », op. cit. 
privilegiados do Rio e de São Paulo, ao passo que a verdadeira tarefa educativa impõe a sua extensão, horizontal e vertical, a toda a comunidade brasileira, através de escolas, bibliotecas, museus, sindicatos e órgãos espontâneos de cultura como os clubes de cinema. $»^{92}$

Sales Gomes est l'un des rares critiques de l'époque à se poser la question du partage de la culture dans une société extrêmement hiérarchisée où le savoir, avant d'être un facteur de progrès, est un élément de distinction. Il est aussi l'un des rares à se rendre compte que la culture cinématographique ne va pas de soi et qu'un travail pédagogique doit être mené. Sa perspective est celle d'un humaniste et il pense que la culture cinématographique, au même titre que la culture littéraire par exemple, peut non seulement apporter de nombreuses satisfactions sur un plan personnel mais aussi éclairer les individus quant à leur relation avec le monde. Il pense alors également que, dans un pays sous-développé, le développement culturel entendu au sens large comme l'élévation du degré d'instruction de la population, la multiplication des manifestations culturelles et l'augmentation du niveau et du nombre des productions artistiques, est aussi important que le développement économique et technologique. Cinémathèques et ciné-clubs lui apparaissent donc comme des vecteurs de culture privilégiés.

Bernardet s'intéresse aussi à cette problématique de la relation culture - population dans un article intitulé « Do Cineclubismo » où il s'inquiète de l'efficacité pédagogique des ciné-clubs. Selon lui, ceux-ci devraient se diviser en deux catégories, d'un côté, la formation de cinéastes et, de l'autre, la formation du public. Pour mener une action culturelle efficace, chacun devrait donc décider de la catégorie à laquelle il souhaite appartenir et adapter sa programmation et ses activités en fonction. Le ciné-club des « futurs cinéastes » serait un lieu d'échanges entre individus qui relient tout au cinéma. Le ciné-club de « formation de public» serait un ciné-club dont le public est en quête d'informations et de culture sans pour autant que ce soit une activité centrale de son existence. À ce public-là, il pense qu'il faut éviter de présenter directement les chefs d'œuvres en lui assénant : «Voilà les chefs d'œuvre » mais bien plutôt arriver aux classiques par paliers en commençant par une programmation qui corresponde à ses goûts et ses demandes. Or, c'est là un défaut qu'il observe fréquemment en plus de celui de chercher à substituer les goûts du public par ses propres goûts ou encore de

92 «Les institutions qui ont réalisé ses six dernières années de grands cycles de projection culturels en conçoivent un orgueil justifié. 'Les grands moments du cinéma', 'Hommage à Erich Von Stroheim', 'Rétrospective du cinéma international', 'Dix ans de films sur l'art' et les festivals historiques dédiés au cinéma nord-américain, français et italien sont des manifestations qui ne craignent pas la comparaison avec ce qui se fait de mieux dans les pays les plus avancés. [...] En même temps, ce n'est évidemment pas ce travail que l'on attend des cinémathèques sur le plan de la diffusion. Ces grands festivals ont été réservés à des secteurs privilégiés de Rio et São Paulo alors que leur véritable rôle éducatif impose leur extension, horizontale et verticale, à toute la communauté brésilienne, au travers d'écoles, de bibliothèques, de musées, de syndicats et d'associations culturelles spontanées comme les ciné-clubs. » in GOMES, Paulo Emílio Sales. « Uma Situação colonial ? », op. cit. 
mépriser un public rapidement jugé inculte.

Établir que la critique devait se montrer participative pour contribuer au développement du cinéma brésilien devait nécessairement amener à s'interroger sur le rôle ou, tout au moins, la réaction du public, voire sur le public tout court. Or, la relation du Cinema Novo avec le public sera toujours jugée très insatisfaisante et les observations faites par Bernardet dans le microcosme des ciné-clubs anticipent assez bien, d'une certaine manière, ce qui va se produire entre d'un côté un cinéma qui se proclame à la fois populaire et avantgardiste, et de l'autre, un public qui peine à suivre et se voit rapidement jugé inculte. La complexité de la relation public - population - culture cinématographique aurait méritée d'être étudiée plus en détail. Mais au moment de penser le Cinema Novo, on s'est avant tout tourné vers la relation auteur - cinéma.

\section{Du cinéma indépendant au cinéma d'auteur}

Avant même d'être conceptualisée, la nouvelle approche critique que nous avons décrite est déjà pratiquée et Rocha peut légitimement apparaître comme l'un de ses pionniers. Dans A Revolução do Cinema Novo, compilation de ses articles qu'il fait publier en 1981, le cinéaste sélectionne «Raízes mexicanas de Benito Alazraki» (1958). La réflexion sur le cinéma étranger est ici entièrement orientée vers l'étude des chemins que pourraient emprunter le cinéma brésilien. Dans « Bossa-nova no cinema brasileiro »" ${ }^{93}$, il s'agit bien de détecter, aussi timides soient-ils, les signes avant-coureurs d'une rénovation de la cinématographie nationale. Rocha commence à raisonner à partir de films auxquels l'histoire n'accordera par la suite guère d'importance et que lui-même pourra violemment critiquer ${ }^{94}$.

L'une des principales contributions de ce texte est de réanimer l'espoir que le cinéma indépendant avait pu constituer pour le cinéma brésilien dans les années cinquante avec les tentatives de Nelson Pereira dos Santos, Rio, quarenta graus (1955) et Rio, zona Norte (1957), et de Roberto Santos, O Grande Momento (1958). Contrairement à ce que la force de conviction de ses articles de la période pourrait laisser penser, rien n'était moins évident que de parier sur le cinéma indépendant. Si ces trois films avaient suscité un vif intérêt auprès de la jeune génération de cinéphiles et d'une fraction de la critique, ils demeuraient jusqu'alors des événements isolés. Incapable de se maintenir économiquement, le cinéma indépendant ne semblait pas en mesure d'aller plus loin que ces trois films. Peu après la sortie de $O$ Grande

93 ROCHA, Glauber. « Bossa-Nova no cinema brasileiro » in O Jornal do Brasil - Suplemento Dominical, Rio de Janeiro, 12/03/1960.

94 Ce sera le cas de Walter Hugo Khoury dont la cinématographie apparaîtra par la suite comme l'exemple type de ce qu'il ne faut pas faire, un cinéma étranger aux problématiques sociales, incapable de dépasser ses modèles déclarés : Antonioni et Bergman. 
Momento dont il était producteur, Pereira dos Santos dépeignait la situation dans ces termes :

«Dos filmes que produzi o único que conseguiu ser pago foi Rio 40 graus, e só após dois anos de exibição. Rio, zona norte, que custou 2 milhões de cruzeiros, ainda não deu o suficiente para cobrir o seu custo. $O$ Grande Momento, ainda em exibição, ainda não nos fornece elementos para um juízo exato. Esses resultados mostram que o público não tem aceitado nossos filmes, e acredito que por nossa culpa : ainda não sabemos fazer o filme que seja entendido por todos, porque ainda não dominamos o cinema como meio de expressão, e porque nos faltam, tradição, escola e habilidade artesanal. Todos os filmes que fizemos e que faremos não se destinam a meia dúzia de pessoas, mas a grande maioria do nosso povo. $\mathrm{E}$ as rendas insignificantes que produziram mostram que não conseguiram ainda transmitir ao povo, com clareza e eficiência, a linguagem de emoção que o atinge diretamente. $)^{95}$

O Grande Momento se révélant un nouvel échec commercial, pour survivre, Pereira dos Santos s'était converti à des activités de journalisme ${ }^{96}$. Quant à Roberto Santos, il ne reviendrait à la direction de films qu'en 1965.

Rocha, quant à lui, n'accorde guère d'importance aux énormes difficultés matérielles rencontrées par ces deux cinéastes. En 1960, Pereira dos Santos commence à travailler sur un nouveau projet et c'est bien là pour le critique tout ce qui compte. Armé d'une bonne dose de partialité, il rassemble des réalisateurs apparus après la faillite de la Vera Cruz et issus d'expériences cinématographiques fort diverses entre elles mais qui formeraient la «bossa nova » du cinéma brésilien : Nelson Pereira dos Santos, Walter Hugo Khoury, Galileu Garcia, Roberto Santos, Trigueirinho Neto, Carlos Alberto de Sousa Barros et César Memolo. Réunis par l'absence de moyens et les faibles budgets, ces cinéastes seraient en train de démontrer que la voie du cinéma indépendant non seulement, est viable économiquement mais aussi adéquate à la construction d'une cinématographie de caractéristiques nationales.

Il attire également l'attention sur de plus jeunes cinéastes qui pourraient s'unir à ces pionniers, c'est la « bossa novíssima » du cinéma brésilien : Joaquim Pedro de Andrade, Paulo César Saraceni, Luís Paulino dos Santos, Marcos Farias, Miguel Borges, Leon Hirszman, Carlos Perez. Selon lui, le cinéma brésilien doit naître de l'entraide entre ces différentes générations et non de grandes entreprises comme la Vera Cruz. Avec la «Bossa Nova » du

95 « Des films que j'ai produit, le seul qui a réussi à se payer fut Rio 40 graus, et seulement après deux ans d'exploitation. Rio, zona norte, qui a coûté deux millions de Cruzeiros, n'a pas encore eu une recette permettant de couvrir son coût de production. O Grande Momento, encore en exploitation, n'a pas encore fourni d'éléments pour un jugement exact. Ces résultats montrent que le public n'a pas accepté nos films, et, selon moi, de notre faute : nous ne savons pas encore faire des films qui sont compris par tous, parce que nous ne dominons pas encore le cinéma comme moyen d'expression, et parce qu'il nous manque, tradition, école et habilité artisanale. Tous les films que nous avons faits et que nous ferons ne se destinent pas à une demi-douzaine de personnes, mais à la grande majorité de notre peuple. Et les recettes insignifiantes qu'ils produisent montrent que nous n'avons pas réussi à transmettre au peuple, avec clarté et efficacité, le langage de l'émotion qui les atteigne directement. » in SANTOS, Nelson Pereira dos. "O Grande Momento :

Entrevista com Joaquim Pedro de Andrade e Claudio Mello e Souza » in Jornal do Brasil, Rio de Janeiro, $11 / 01 / 1959$.

96 SALEM, Helena. Nelson Pereira dos Santos - O Sonho possível do cinema brasileiro. Rio de Janeiro, ed. Nova Fronteira, 1987, p. 140. 
cinéma brésilien apparaîtrait un nouveau modèle de développement basé sur les principes du cinéma indépendant et de la coopération : à petits budgets et petites structures pourraient correspondre de grands films.

Dans un article intitulé « Coisas nossas », Dahl cite le texte de Rocha « Bossa-Nova no cinema brasileiro » et en confirme tous les points. Selon lui, la rénovation du cinéma brésilien sera le fait d'un phénomène de génération. La collaboration, l'entraide et la solidarité y joueront un rôle important malgré les différences idéologiques et culturelles qu'il est déjà possible de relever entre les nouveaux cinéastes et les aspirants au métier :

«Evidentemente será difícil conciliar o irracionalismo lírico dos paulistas com o racionalismo realístico dos cariocas, ou convencer os baianos da capacidade de uma cultura cosmopolita ser profundamente brasileira. Ou ainda convencerem uns aos outros que o existencialismo de uns não esconde irremediáveis tendências fascitoides, ou que o marxismo, muitas vezes superficial e terminológico, de outros, não os levará a cairem na imbecilidade comunista. Não será porém tão difícil obter um pouco mais de confiança mútua, indispensável para a união dos esforços, sem a qual correremos o risco de perder mais uma vez a oportunidade de termos logo um cinema brasileiro. Não é necessário que ninguém esteja de acordo com ninguém, a única coisa verdadeiramente indispensável é que todos acreditem na sinceridade da busca dos outros e na irresistível capacidade que tem o homem, o artista, o criador, de revelar-se, quaisquer que sejam as barreiras e os caminhos. $\rangle^{97}$

Dahl rajoute aux arguments de Rocha que le cinéma indépendant, aux structures et aux budgets réduits, correspond à la situation d'un pays sous-développé qui, par définition, ne peut pas se permettre un cinéma de pays riche. Il va cependant plus loin en montrant que ce type de production est intimement lié au concept de cinéma d'auteur, concept qui, d'un côté, représente le seul moyen de développer un langage cinématographique national authentique, et, de l'autre, apparaît à ce moment-là comme l'avenir du cinéma mondial.

Dans «Importância de Khouri »" ${ }^{98}$, Dahl explique en quoi Walter Hugo Khoury présenterait les qualités idéales d'un réalisateur de cinéma brésilien tel qu'il reste à construire (le cinéaste lui-même n'est pas encore considéré comme pleinement réalisé). Dahl explique que le cinéma produit par des structures industrielles est dépassé et que le cinéaste doit devenir un « auteur ». Nous sommes proches de l'idée de la « caméra-stylo » dans la mesure où l'auteur reprend les idées et les références d'Alexandre Astruc. Il s'agit d' « escrever

97 « Évidemment, il sera difficile de concilier l'irrationalisme lyrique des paulistas avec le rationalisme réaliste des cariocas, ou convaincre les bahianais de la capacité d'une culture cosmopolite à être profondément brésilienne. Ou encore convaincre les uns et les autres que l'existentialisme des uns ne cache pas d'irrémédiables tendances fascisantes, ou que le marxisme, souvent superficiel et de terminologie des autres, ne les entraînera pas à tomber dans l'imbécillité communiste. Il ne sera pas facile pour autant d'obtenir un peu de confiance mutuelle, indispensable à l'union des efforts, sans laquelle nous courons le risque de perdre encore une fois la chance d'avoir un cinéma brésilien. Il n'est pas nécessaire que tout le monde soit d'accord avec tout le monde, l'unique chose vraiment indispensable est que tous croient dans la sincérité de la recherche de chacun et de l'irrésistible capacité que possède l'homme, l'artiste, le créateur, de se révéler, quels que soient les obstacles et les chemins. » in DAHL, Gustavo. « Coisas nossas » in O Estado de São Paulo Suplemento literário, São Paulo, 14/01/1961.

98 DAHL, Gustavo. « Importância de Khouri », op. cit. 
diretamente em cinema » avec une caméra qui serait comme « o olho na cabeça de um poeta » (citation d'Orson Welles). Avec cette approche, le cinéaste pourrait construire son univers dans le dialogue avec une figure féminine extraordinaire comme Greta Garbo, Marlene Dietrich, Jeanne Moreau ou Brigitte Bardot. Le revers de cette conception du cinéma, c'est la stricte hiérarchisation des relations dans l'équipe : les techniciens doivent se mettre au service du réalisateur. En contrepartie, le réalisateur se doit d'être présent à toutes les étapes de la production. Enfin, il doit avoir un solide bagage de cinéphile.

L'importance de la figure féminine sera rapidement oubliée et substituée par l'importance croissante qui sera attribuée à la réalité sociale. Cette prise en compte de la réalité sociale comme élément de dialogue et de référence dans la construction d'un langage cinématographique brésilien est bien sûr motivée par les expériences de Pereira dos Santos et toute la réflexion qui a lieu sur l'importance d'une thématique brésilienne depuis près de dix ans. Mais, elle est aussi lié à la modification de la critique. Bernardet est celui qui pose le plus clairement le problème :

\begin{abstract}
« Há, enfim, uma situação complexa e esta situação é social. Dentro dela as fitas têm um sentido. Há fitas que são descrições complacentes e outras que são críticas à decadência burguesa. Há fitas reacionárias e outras que não o são. Há fitas que descrevem piedosamente a miséria e fazem poesia, outras que a analisam. É isto, antes de mais nada, que o crítico deve deixar o mais claro possível. [...] Qualquer fita, desde a mais despreocupada narração policial até as fitas que tratam conscientemente dos valores, pressupõe um certo conceito de liberdade, favorece um certo regime político. Não há fitas inocentes. Os valores implícitos, é urgente que os críticos se esforcem em desvendá-los. Este é um primeiro passo. $»^{99}$
\end{abstract}

Si, d'un côté, il convient de critiquer la position de l'auteur, de l'autre, il convient au cinéaste de savoir prendre position. L'auteur est jugé au travers de sa capacité à prendre position et au travers de la qualité de cette position :

«Apelo, fita de curta metragem, a mais recente de Trigueirinho Neto, é um documentário que nos parece novo no panorama paulista pela sua expressão e pelo fato de não se limitar em descrever, mas de ser também uma tomada de posição. $\rangle^{100}$

Le concept d'auteur dépasse donc ici assez radicalement les perspectives qui lui étaient

99 « Il y a, enfin, une situation complexe et cette situation est sociale. Dans cette situation, les films ont un sens. Il y a des films qui sont des descriptions complaisantes e il y en a qui sont des critiques à la décadence bourgeoise. Il y a des films réactionnaires e il y en a d'autres qui ne le sont pas. Il y a des films qui décrivent avec pitié la misère et font de la poésie, d'autres qui l'analysent. C'est cela, avant tout, que le critique doit rendre le plus clair possible. [...] N'importe quel film, depuis la plus neutre narration policière jusqu'aux films qui traitent consciemment de valeurs, présuppose un certain concept de liberté, favorise un certain régime politique. Il n'y a pas de films innocents. Les valeurs implicites, il est urgent que les critiques s'efforcent à les dévoiler. C'est un premier pas. » in BERNARDET, Jean-Claude. «Questão de higiene », op. cit.

100«Apelo, film de court métrage, le plus récent de Trigueirinho Neto, est un documentaire qui nous paraît nouveau dans le panorama paulista par son expression et par le fait de ne pas se limiter à décrire, mais d'être aussi une prise de position. » in BERNARDET, Jean-Claude. «Apelo, um documentário » in O Estado de São Paulo - Suplemento literário, São Paulo, 30/09/1961. 
attribuées en France dans son contexte d'origine. Il ne suffit plus que l'artiste possède un univers personnel, il faut aussi que son cinéma soit l'expression d'une prise de position face à une réalité sociale et culturelle complexe et qu'il soit capable d'apporter de cette situation une intelligence nouvelle :

« O cinema que devemos tentar agora não parte mais do apego ao Brasil, mas sim de uma visão dos seus problemas. [...] Assim, ele [le cinéaste] atua, e a atuação faz com que passe a pertencer a um grupo. Em suma, ele seria uma liberdade, mas uma liberdade que não deve ficar no vazio, mas ao contrário, comprometer-se. Apelo parece ser obra de um homem deste tipo. Que Trigueirinho Neto esteja ligado ao Brasil e sofra com os seus problemas, nem há dúvida : provam-no a violência (e também o amargor) do seu filme. Mas esta ligação não o levou a mostrar os sofrimentos da terra brasileira. Do Brasil, não se vê nada. Levou-o a desnudar os mecanismos destes sofrimentos. ${ }^{101}$

Une telle conception du cinéma implique aussitôt, comme nous l'avons vu à la lecture de l'article «Três filmes », le rejet de tout langage qui, au lieu de révéler au spectateur des aspects de la réalité, l'éloignerait de la compréhension du monde dans lequel il vit. Il s'agit de rejeter les films que l'on va juger «aliénant» ou «d'évasion» et a fortiori les films jugés ouvertement fascistes ou racistes (comme c'est le cas pour The Magnificent Seven). Ces films sont systématiquement articulés sous la forme de discours fermés ne laissant pas de liberté d'interprétation au spectateur, utilisent souvent la figure du héros invincible et à la moralité irréprochable, offrent du monde une vision réduite et manichéiste, et ont recours à l'émotion facile pour «forcer» la conscience du spectateur. Bernardet donne un exemple du fonctionnement de ces films :

«A Balada do soldado é ainda mais significativa : tem estilo e esta qualidade é abertamente posta ao serviço de uma ideologia repugnante : o herói sem mancha. O personagem é definido como herói logo na segunda seqüência e a fita encerra-se pelas três palavras 'soldado - herói - russo'. Esta fita toma para si tudo o que foi dito a respeito do herói. ${ }^{102}$

Et plus loin :

«Quais são os corações que resistem a este menino, de olhos cândidos, que, após ter aniquilado dois tanques, deseja apenas seis dias de licença para consertar o teto da casa materna ; que respeita a pureza de uma moça inerme ; que defende os fracos e combate a imoralidade e que, finalmente, por um

101 « Le cinéma que nous devons essayer maintenant ne part pas de l'affection pour le Brésil, mais bien de la vision de ses problèmes. [...] Ainsi, lui [le cinéaste] agit, et son action fait qu'il commence à appartenir à un groupe. En somme, il serait une liberté, mais une liberté qui ne doit pas rester dans le vide, mais, au contraire, se compromettre. Apelo paraît être l'œuvre d'un homme de ce type. Que Trigueirinho Neto soit lié au Brésil et souffre avec ses problèmes, il n'y a pas de doute : nous le prouvent la violence (et aussi l'amertume) de son film. Mais ce lien ne l'a pas porté à montrer les souffrances de la terre brésilienne. Du Brésil, on ne voit rien. Ce lien l'a porté à dénuder les mécanismes de ces souffrances. »Ibid.

102 « La Ballade du soldat est encore plus significative : il a un style et cette qualité est mise au service d'une idéologie répugnante : le héros sans tâche. Le personnage est défini comme un héros dès la seconde séquence et le film se termine par ces trois mots ' soldat - héros - russe '. Ce film prend pour lui tout ce qui a été dit au sujet de la figure du héros. » in BERNARDET, Jean-Claude. "Três filmes », op. cit. 
desencontro como 'a vida apresenta tantos', perde seu amor ? Quem resiste aos olhos tristes e interrogadores da mãe frente à estrada pela qual seu filho se foi e não voltou etc. ? Assim, logo de início, o espectador é preso na teia da emoção, cada vez mais sólida, e não pode escapar. A palavra 'fim' devolve-o à realidade, mas fica o filme-sonho como uma nostalgia, um paraíso perdido, um ideal. $»^{103}$

Cette position implique le rejet d'un côté du cinéma hollywoodien et de l'autre du réalisme socialiste pour offrir tous deux de la réalité une expression faussée dans laquelle des préoccupations idéologiques ou commerciales perturbent la relation dialectique que l'auteur doit établir avec le monde dans le processus de la création artistique. Pour que le cinéma puisse jouer son rôle de révélateur, l'acte de filmer est assimilé à un acte de recherche, de compréhension et d'explication du réel. Le nouveau cinéma brésilien devrait donc mieux se caractériser par une méthode que par des préceptes rigides établis a priori. D'une certaine façon, Dahl effectue la synthèse entre les arguments plaidant en la faveur du cinéma indépendant, les influences européennes liées au concept de l'auteur et la exigences mises en exergue par la réflexion portée sur le rôle de la critique :

«O público descobre que ao cinema se vai para ver o verdadeiro gesto e ouvir a verdadeira voz do Homem. E sua situação, acrescentaria Jean-Claude. Cinema é o diálogo do filme com seu público, e não o canto enganador de uma sereia em três mil metros de celuloide, do qual ele se libera. E o diálogo só é possível quando o filme traz a presença do Homem, que é a presença do autor. 'Il n'y a qu'auteurs de films, et sa politique, en raison même des choses, inattaquable' (Truffaut) [sic]. A arte é do artista, artista é o homem, o homem que é, é em liberdade. O cinema, que é do homem e do Homem, é livre, livre sobretudo da pressão econômica que traz em si a organização industrial. $»^{104}$

Tout converge donc vers la solution unique du cinéma d'auteur pour un ensemble de raisons qui échappent d'ailleurs à la simple relation linéaire que notre texte pourrait suggérer. Parallèlement à la réflexion dont nous avons retracé ici les principaux développements surgissent des films qui inspirent ou confirment les positions adoptées par les critiques. Aussi, les considérations portant sur la construction d'un langage brésilien, le rôle de l'émotion et l'apport des nouvelles technologies comme la caméra portée et le son direct vont s'articuler à des expériences concrètes : Arraial do cabo, Aruanda, Bahia de todos os santos et le cycle de

103 « Quels sont les cœurs qui résistent à cet enfant, aux yeux candides, qui, après avoir détruit deux tanks, désire à peine six jours de congé pour réparer le toit de la maison maternelle ; qui respecte la pureté d'une jeune fille vierge ; qui défend les faibles et combat l'immoralité et qui, finalement, par un malentendu comme ' la vie en présente tant ', perd son amour? Qui résiste à ces yeux tristes et interrogateurs de mère face à la route par où son fils est parti et n'est pas revenu etc. ? Ainsi, dès le départ, le spectateur est prisonnier de la toile de l'émotion, chaque fois plus solide, et ne peut s'échapper. Le mot ' Fin ' le rend à la réalité, mais il reste le film-rêve comme une nostalgie, un paradis perdu, un idéal. » in ibid.

104« Le public découvre que le cinéma sert à voir le véritable geste et entendre la véritable parole de l'Homme. Et sa situation, ajouterait Jean-Claude. Le cinéma est le dialogue d'un film avec son public, et non le chant enchanteur d'une sirène sur trois mille mètre de celluloïde, duquel il se libère. Et le dialogue est seulement possible quand le film apporte la présence de l'Homme, qui est la présence de l'auteur. ' Il n'y a qu'auteurs de films, et sa politique, en raison même des choses, inattaquable ' (Truffaut). L'Art est de l'artiste, l'artiste est l'homme, l'homme qui est, est en liberté. Le cinéma, qui est de l'homme et de l'Homme, est libre, libre avant tout de la pression économique qu'amène avec elle l'organisation industrielle. » in DAHL, Gustavo. « Algo de novo entre nós » in O Estado de São Paulo - Suplemento literário, São Paulo, 07/10/1961. 
Bahia. Ce n'est qu'à la suite de tous ces événements que Dahl pourra affirmer au sujet du cinéma indépendant :

« Não é ele o sistema de produção que mais facilmente permite ao artista reencontrar a sua função anárquica, revolucionária, anticonformista, reveladora, destrutiva e construtiva a um só tempo, e o seu sentido individual e social, geral e particular ? Enfim, não é a solução, justamente porque é a solução ? » ${ }^{105}$

\subsection{Bahia de todos os santos, modernité de langage, distanciation brechtienne et approche sociologique}

Des trois films qui nous semblent avoir apporté les contributions les plus décisives quant à ce que sera par la suite le Cinema Novo, Bahia de todos os santos est celui qui est aujourd'hui le moins commenté et le plus difficile à revoir ${ }^{106}$. Ce fait tient sans doute à la personnalité de son auteur, José Hipolito Trigueirinho Neto, qui, après avoir pourtant représenté l'un des grands espoirs du cinéma brésilien, a totalement abandonné le cinéma. Bahia de todos os santos représente pourtant beaucoup, autant pour les chemins qu'il a ouvert et qui seront suivis que pour ceux qui ne le seront pas et feront de lui un film à part.

La première contribution fondamentale qu'il apporte est celle de la rupture avec le langage académique et la nouvelle conception de cinéma dont il procède. La seconde est la réflexion qu'il initie quant à la transposition au cinéma des théories de Brecht sur la distance à établir entre spectacle et spectateur. Alors que le film est aujourd'hui tombé dans un relatif oubli $^{107}$, il fut à l'époque l'objet de sérieuses controverses. Deux retiendront particulièrement notre attention. La réception du film anticipe celles des « films maudits » du Cinema Novo et se caractérise par une franche opposition entre quelques critiques vivement intéressés, mettant très rapidement en exergue les contributions du film à l'esthétique du cinéma brésilien, et ceux qui le rejetteront violemment. La seconde controverse, un peu plus tardive, aura trait au dénouement de l'histoire. Un des aspects les moins discutés du film, et qui le différencie sensiblement de ceux du Cinema Novo est le regard qu'il apporte sur la société brésilienne.

105 « N'est-ce pas là le système de production qui permet le mieux à l'artiste de retrouver sa fonction anarchique, révolutionnaire, anticonformiste, révélatrice, destructive et constructive en même temps, et son sens individuel et social, général et particulier? Enfin, n'est-ce pas là solution, justement parce que l'on nous dit que ce n'est pas la solution. » in DAHL, Gustavo. « A Solução única » in O Estado de São Paulo Suplemento literário, São Paulo, 21/10/1961.

106Bahia de todos os santos n'a pas été réédité en vidéo. Ces dernières années, il a été possible de le voir lors de passages en festival comme « Glauber crítico » à São Paulo du 22 avril au 4 mai 2003, le 16e festival «Théâtre au cinéma » de Bobigny du 16 mars au premier avril 2005, le festival des 3 Continents à Nantes du 22 au 29 novembre 2005.

107Seuls, Bernardet et Rocha, ont rappelé l'importance de Bahia de todos os santos dans leurs écrits respectifs postérieurs à 1960-62, soit la période durant laquelle il a pu constituer un sujet d'actualité. Un ouvrage de référence comme l'Enciclopédia do cinema brasileiro ne consacre pas d'article à Trigueirinho Neto. 
C'est le dernier point que nous développerons à son sujet.

\section{Rupture avec le langage académique et rôle de Trigueirinho Neto}

La principale surprise qui peut être ressentie à la vision de Bahia de todos os santos est la modernité du film. La surprise est d'autant plus grande si, en se référant à l'historiographie classique du cinéma brésilien, il avait été admis que le premier film «moderne » produit au Brésil était Os Cafajestes de Ruy Guerra sorti un an et demi plus tard. Par moderne, nous entendons une rupture avec le langage cinématographique tel qu'il s'était figé depuis les années trente après la maîtrise de l'élément sonore. Il s'agit d'un nouveau rapport au temps et à l'espace mais aussi au cinéma lui-même dans la mesure où le cinéma moderne découvre l'immense malléabilité du langage cinématographique et ose déroger aux règles établies.

Dahl, dans les articles qu'il a publiés entre 1965 et 1966 dans la revue Civilização Brasileira, comme dans ses articles pionniers de O Suplemento literário do Estado de São Paulo, n'a eu de cesse de montrer combien il était important de percevoir les modifications d'ordre économique et esthétique, qui étaient intervenues dans le cinéma après la seconde guerre mondiale. Ayant des conceptions du cinéma d'auteur très proches de celles exprimées dans les Cahiers du Cinéma où il a également écrit, il explique dans «Cinema Novo e seu público $»^{108}$ que les cinquante premières années du cinéma furent celles de la découverte d'un langage alors que les vingt suivantes ont été marquées par le développement du cinéma moderne. Roma, cittá aperta correspondrait alors à la perte de l'innocence par le septième art. Le cinéma d'auteur s'inscrivant dans une évolution esthétique irréversible, non sans relation avec l'avènement de la télévision et les modifications qu'il a entraîné dans la relation du public aux films, le Cinema Novo se devait donc d'emprunter ses voies sans quoi il perdait toute validité culturelle. Entre 1962 et 1966, Dahl estime qu'il parcourt le chemin qui va du Néoréalisme à Pierrot le fou avant de se lancer à la recherche d'une voie parfaitement originale.

Le même Dahl nous rappelle dans l'entretien qu'il nous a accordé que Bahia de todos os santos est un film précurseur par rapport à la possibilité de produire un cinéma d'auteur au Brésil et qu'il a fortement influencé Rocha. Celui-ci a en effet assisté au tournage à Salvador, moment au cours duquel il a pu échanger assez longuement avec Trigueirinho Neto. À la sortie du film, il sera l'un de ses principaux défenseurs. Dahl nous donne une anecdote assez significative selon laquelle Rocha aurait vu Trigueirinho Neto utiliser une lentille de $25 \mathrm{~mm}$ pour filmer un personnage en gros plan. Une telle manipulation produit une déformation de l'image et donne un peu le même effet que celui qui est obtenu en regardant au travers du fond 
d'un verre. Il s'agissait à l'époque d'une manipulation tout à fait erronée d'un point de vue académique. Mais ce qui compte, à partir de là, n'est plus tant le respect des règles que la recherche de moyens qui permettent d'exprimer au mieux des idées. Dahl met cette anecdote en relation avec le rejet du champ / contre-champ par le Cinema Novo. Cette nouvelle approche du langage cinématographique faite à la fois d'une volonté de rupture et d'une recherche d'expression est le premier retournement introduit dans le cinéma brésilien par Bahia de todos os santos.

En plus d'inaugurer au Brésil un nouveau rapport au cinéma qui rend possible les expérimentations sans pour autant négliger la fonctionnalité du langage en relation à l'expression de réalités sociales et psychologiques, les autres caractéristiques de la modernité présentées par Bahia de todos os santos sont les suivantes :

- œuvre «ouverte» (absence d'explication ou de justification univoque pour un certain nombre d'éléments filmiques décisifs, le langage peut être fonctionnel par rapport aux éléments de réflexion que l'on veut donner au spectateur et non par rapport à la cohérence de la narration);

- manque de définition des personnages (ambiguïté et imprévisibilité des réactions des personnages qui permettent que leurs comportements évoluent au cours de la narration);

- fragmentation de la narration ;

- montage elliptique ou discontinu (dans la mesure où, en comparaison avec le langage académique, certains plans ou certaines séquences semblent coupés et posent des questions qui ne seront pas forcément résolues dans les plans ou séquences suivantes);

- rupture avec l'ordre usuel de succession des plans selon la prise de vue.

Contrairement à Aruanda ou Arraial do cabo, les innovations de Bahia de todos os santos ne peuvent être attribuées au manque d'expérience ou à l'absence de moyens mais à une démarche consciente et pleinement maitrisée. Au moment du tournage du film, Trigueirinho Neto apparaît comme le jeune réalisateur le mieux préparé de sa génération. Né la même année que Pereira dos Santos (1928), il fut l'assistant d'Alberto Cavalcanti quand il occupait le poste de producteur général de la Vera Cruz et travailla comme assistant de direction sur Caiçara (Adolfo Celi, Brésil, 1950). Il passa par la suite une très longue période en Italie où il suivit les cours du Centro Sperimentale di Cinematografia. C'est là qu'il devait réaliser son premier film, le court métrage Nasce um mercatto, primé par le gouvernement italien. En Europe, il devait également écrire un argument pour le film à sketchs Die Windrose (URSS, RDA, Brésil, 1957), coordonné par Joris Ivens. 
De retour au Brésil, en 1958, Trigueirinho Neto emporte le prix Fábio Prado du meilleur scénario pour Bahia de todos os santos. Cette récompense lui permet de commencer à monter le financement du film. Il fait appel au programme du Banco Estadual de São Paulo - BANESPA ${ }^{109}$, destiné au cinéma, programme mis en place grâce à l'intervention de l'État pour soutenir la production cinématographique au moment des faillites consécutives des grands studios paulistes. Parallèlement à ce travail, le cinéaste expose dans la presse ses conceptions sur le cinéma. Son article intitulé «Nos Abismos do cinema brasileiro : Depoimento sobre os países novos sem cinema $»^{110}$ préfigure le discours des cinemanovistas, notamment au travers des notions quelque peu abstraites et moralistes de «corruption » et «d'honnêteté » des cinéastes. La tonalité bombástica ${ }^{111}$ qu'il utilise rappelle de façon troublante celle qu'adoptera plus tard Rocha :

\begin{abstract}
« O cinema no Brasil se encontra à beira do abismo e falta pouco para que o público abandone completamente as salas de espetáculos. Não é o caso de descer a particularidades pois, o Brasil não tem fitas importantes nem autores representativos ; eis porque é mais útil conservar o discurso nas linhas gerais. O que notei aqui foi sobretudo a formação de grupos, espécie de parasitas, que justamente por se sentirem fracos, se mantêm uns aos outros, mutuamente, num círculo vicioso. Fecham-se em muralhas de ferro, onde o elemento novo não se pode introduzir. Só o mau profissional pode obstar a evolução do seu meio e o seu alargamento. O incompetente, covarde moral, o egoísta, esquece que é só até certo ponto, que ele poderá perpetuar a resistência ; a vida prossegue independentemente dos planos dele e quando menos se espera chega uma palavra nova, mais eficiente e que se pensarmos bem, ele mesmo poderia ter dito - se não tivesse sido corrompido. $\gg^{12}$
\end{abstract}

Dans cet article, Trigueirinho Neto ne parle pas véritablement du cinéma brésilien. Après avoir expliqué que celui-ci ne compte pour rien, il aborde le cinéma français et en particulier le cinéma italien qui a marqué sa formation. Nous comprenons alors, quand il défend Le Chanois, Visconti et surtout Claudio Gora pour Febbre di vivere, que «l'honnêteté » dont il parle anticipe ce retournement dans le rapport du réalisateur au langage

109MELO SOUZA, José Inacio de. «Fontes para o estudo do financiamento de filmes : a carteira de crédito do Banco do Estado de São Paulo », http://www.mnemocine.com.br/pesquisa/pesquisatextos/banespa.htm, consulté le 06/08/2005.

110«Dans les abîmes du cinéma brésilien : Témoignage sur les pays nouveaux sans cinéma»

111Du portugais bomba, littéralement en français «bombe », la traduction la plus correcte serait peut être « incendiaire » ou « explosif ». L'expression bombástica est employée, notamment par Fernão Ramos, pour signifier le ton à la fois provocateur et polémiste fréquemment adopté par Rocha tout au long de sa carrière.

112«Le cinéma au Brésil se trouve au bord de l'abîme et, d'ici peu, le public aura totalement abandonné les salles de projection. Il n'est pas utile de détailler la situation puisque le Brésil ne possède ni films importants ni auteurs représentatifs; voilà pourquoi il vaut mieux poursuivre la discussion sur un plan général. Ce que j'ai noté ici fut avant tout la formation de groupes, d'espèces de parasites, qui, justement parce qu'ils se savent en situation de faiblesse, se protègent les uns les autres, mutuellement, comme dans un cercle vicieux. Ils s'enferment derrière des murailles de fer où l'élément nouveau ne peut s'introduire. Seul, le mauvais professionnel peut empêcher l'évolution de sa profession et son développement. L'incompétent, le couard égoïste, oublie que ce n'est que jusqu'à un certain point qu'il pourra résister; la vie continue indépendamment de ses projets et c'est au moment où on l'attend le moins qu'arrive une parole nouvelle, plus efficace et qui, si nous y réfléchissons bien, il aurait pu dire lui-même, s'il n'avait pas été corrompu.» in TRIGUEIRINHO NETO, José Hipólito. « Nos Abismos do cinema brasileiro : Depoimento sobre os países novos sem cinema » in Folha da noite, São Paulo, 26/06/1958. 
cinématographique que nous évoquions plus haut. La rupture avec les règles académiques de narration est rendue nécessaire car la soumission à celles-ci est assimilée à du mercantilisme, le terme étant entendu ici dans ses connotations les plus péjoratives. Rocha adoptera par la suite la même attitude en allant jusqu'à voir dans l'académisme une forme de «prostitution » du langage cinématographique. Enfin, bien que conscient de l'ambiguïté que peut présenter cette opposition, Paulo César Saraceni continue jusqu'à aujourd'hui à considérer que le cinéma d'auteur est l'antithèse du cinéma commercial, que le premier est progressiste alors que le second est réactionnaire.

«L'honnêteté » correspondrait alors à cette inversion des motivations qui marque le passage du cinéma classique au cinéma moderne. Dans le cinéma classique, prévalent par ordre de priorité : les relations de causalité, le réalisme (cohérences des lois physiques régissant la diégèse), l'intertextualité (citation d'autres films, respect des genres) et, en dernier lieu, les motivations artistiques, tout cela dans le but de favoriser une narration claire et intelligible par tous (se souvenir également des règles de redondance édictées par Hitchcock qui expliquait qu'un élément devait être répété au moins trois fois pour être assimilé par le spectateur). Dans le cinéma moderne, cet ordre est inversé puisque ce qui compte avant tout est l'expression par le réalisateur d'un regard particulier qu'il porterait sur le monde et le cinéma (motivation artistique). «L'honnêteté » ou la «sincérité » de l'artiste résiderait donc dans sa rigueur dans la quête d'une expression. L'œuvre révélerait autant son auteur que le monde dans lequel il vit et c'est dans cette tension entre deux pôles apparemment distants et les risques assumés dans l'exposé d'une expérience du réel qui, par définition, est intime que devraient s'exercer à la fois le jugement esthétique et le jugement moral sur la position de l'auteur.

Trigueirinho Neto exposera encore ses conceptions sur le cinéma au moment de la sortie du film à São Paulo. Le film était d'abord sorti à Salvador mais il semble qu'à ce moment là, Rocha se soit fait l'interprète du réalisateur. Les similitudes que nous pouvons observer entre l'article intitulé «Filme choque $»^{113}$ et les déclarations de Trigueirinho Neto à la presse pauliste sont frappantes. Une fois de plus, la précision des conceptions du cinéaste attire l'attention, non seulement par rapport à toutes les notions que nous avons commentées jusqu'à présent mais aussi par la façon qu'il a d'anticiper l'interaction entre le film et les spectateurs :

«Essa fita exigirá total destaque do espectador e seus personagens e situações estão expostos linear e didaticamente, sem o menor artifício. Só há corte de montagem quando o interesse de um quadro se esgota e não há o tradicional suspense, a não ser dez segundos, em hora e meia de projeção. Isso, em 
outras palavras, é abandonar as normas comerciais. $\rangle^{114}$

Et encore :

« No atual estágio do cinema em geral e na precariedade do cinema brasileiro em particular, todo filme que se resumir unicamente num exercício de ordem estética, embora bem realizado, não passa de divertimento. A fim de contribuir para a melhoria geral, um filme precisa partir, neste momento que atravessamos, de uma ambição polêmica. Se ela for enquadrada dentro dos programas de qualquer manifestação extra artística, seu efeito será limitado aos adeptos desses credos. Nesse caso, o filme deixará de servir a esses mesmos adeptos, quando eles mudarem de credo. A finalidade do cinema não é angariar adeptos : é contribuir, mesmo anonimamente, para a evolução de quem o assistir. $»^{115}$

Trigueirinho Neto cherche à provoquer l'activité critique du spectateur en relation au film et à insérer celui-ci dans un processus d'évolution sociale et historique selon les méthodes spécifiques que nous allons étudier maintenant.

\section{Brecht et la distanciation critique au cinéma}

À l'exception de Rocha, qui en assimile les leçons, la modernité de Bahia de todos os santos est peu discutée par les critiques de l'époque ou alors, en creux, dans la mesure où beaucoup réclament de la direction des acteurs, de l'absence d'une véritable histoire voire « d'un message $»^{116}$ dans de ce qui leur paraît être une suite de séquences sans relation entre elles. La critique de M. Cantalice est caractéristique des griefs qui peuvent être portés contre le film de Trigueirinho Neto. Elle traduit notamment cette incompréhension totale face à un nouveau langage propre à ce que les cinemanovistas appelleront avec ironie «les veuves d'Hollywood » :

« Apesar de algumas boas fotografias e uns desempenhos satisfatórios, o filme não convenceu. Falta-lhe continuidade. Motivação. Movimentação. Não existe propriamente uma história e sim uma seqüência de 'estórias' : fatos isolados que não chegam a constituir um todo homogêneo. Houve dispersão. Em noventa minutos de projeção foram levantados problemas em demasia. O resultado foi que nenhum

114 «Ce film exigera une entière attention du spectateur et ses personnages et situations sont exposées sur un mode linéaire et didactique, sans le moindre artifice. Il n'y a de coupe dans le montage que lorsque l'intérêt d'un plan est épuisé et il n'y a pas le traditionnel suspens, à moins que ce ne soit pendant dix secondes au cours d'une heure et demie de projection. Ceci, en d'autres termes, revient à abandonner les normes commerciales.» in TRIGUEIRINHO NETO, José Hipólito. « Bahia de todos os santos na palavra de Trigueirinho Neto, seu autor» in Folha de São Paulo, São Paulo, sans date.

115 «Au stade actuel de l'évolution du cinéma en général et dans la précarité du cinéma brésilien en particulier, tout film qui se résumera uniquement à un exercice d'ordre esthétique, même bien fait, ne sera qu'un simple divertissement. Afin de contribuer au progrès général, un film doit partir, dans le moment que nous traversons, d'une ambition polémique. Si un film est réalisé dans le cadre d'une manifestation extra-artistique, son effet sera limité aux adeptes des credos de ses commanditaires. Dans ce cas, le film cessera de servir ces mêmes adeptes quand ils auront changé de credo. La finalité du cinéma n'est pas d'engranger des adeptes : elle est de contribuer, même anonymement, à l'évolution des spectateurs.» in TRIGUEIRINHO NETO, José Hipólito. « Dia sim, dia não (entrevista de Trigueirinho Neto por Vilela Neto) » in Diário da noite, Rio de Janeiro, 05/04/1961.

116ALBUQUERQUE, Matias de. «Bluff » in Jornal da Bahia, Salvador, 21/09/1960. 
desses ficou solucionado. Apenas levantado. Trigueirinho mergulhou fundo demais. Não teve fôlego para voltar à tona. $»^{117}$

Pour ou contre le film qui provoque maintes controverses, plusieurs critiques notent qu'il constitue l'une des tentatives les plus singulières de transposer les théories de Brecht au cinéma. B. J. Duarte, après avoir rapporté que cette transposition faisait partie des intentions de l'auteur, cherche à comparer le film aux adaptations du dramaturge allemand :

\begin{abstract}
« Impressionou-me, contudo, sem me entusiasmar, o resultado obtido por Trigueirinho Neto em sua fita ; impressionou-me sua audácia de estreante numa empreitada em que tantos homens de cultura madura e vastíssima experiência houveram malogrado infelizmente, como Cavalcanti em Sr. Puntilla e seu Criado Matti ${ }^{18}$, ou Pabst, em A Ópera dos Malandros ${ }^{119}$, segundo afirma um autorizado exegeta de Brecht, Bernard Dort, dizendo ipsis litteris : ' De cada vez que um cineasta pôs a mão numa obra de Brecht, resultou ou uma traição ou um malogro. Traição, como no caso de A Ópera dos Malandros, de Pabst ; malogro, com Sr. Puntilla e seu Criado Matti. ' (Bernard Dort, em Cahiers du cinéma, de dezembro de 1960). » ${ }^{120}$
\end{abstract}

Le critique nous confie pourtant que, pour ne pas connaître l'œuvre de Brecht, il ne peut s'avancer plus loin dans l'analyse, et pour juger qu'il s'agit là d'une voie par trop cérébrale, il attribue au film un certain hermétisme, il estime que le choix de cette influence a constitué une erreur. Le Cinema Novo choisira pourtant la même voie et la référence à Brecht reviendra inlassablement pendant les dix années à venir. À la fin de la décennie, c'est encore cette référence que Rocha utilise en évoquant sa recherche d'un cinéma épico-didactique. Mais de quel Brecht s'agit-il ?

S'il y a une erreur à ne pas commettre dans l'analyse du Cinema Novo, c'est bien celle qui supposerait des relations mécaniques entre les influences dont les cinéastes se réclament et leurs œuvres. Bernardet, qui a connu Trigueirinho Neto quand le film est sorti à São Paulo, déclarera bien plus tard :

«[...] Brecht no cinema, me lembro que Trigueirinho e eu saímos falando em Brecht

117 «Malgré quelques plans bien réussis et le travail satisfaisant de quelques individualités, le film n'a pas convaincu. Il lui manque de la continuité. De la motivation. Du mouvement. Il ne raconte pas vraiment une histoire mais se présente comme une séquence de petites histoires : des faits isolés qui n'arrivent pas à constituer un tout homogène. Il y a eu dispersion. En quatre-vingt-dix minutes de projection, trop de problèmes ont été soulevés. Le résultat est qu'aucun ne fut résolu. Seulement soulevé. Trigueirinho s'est trop immergé dans son sujet et n'a pas eu le souffle nécessaire pour revenir à la surface.» in CANTALICE, M. «Bahia de todos os santos» in Diário de notícias, Salvador, 24/09/1960.

118 Herr Puntila und sein Knecht Matti (M. Puntila et son valet Matti, RFA / Autriche, 1955).

119L'Opéra de quat'sous (Allemagne, 1931).

120 « Ce qui m'a impressionné, sans toutefois m'enthousiasmer, est le résultat obtenu par Trigueirinho Neto dans son film ; j'ai été impressionné par son audace de débutant dans une entreprise où tant d'hommes de culture mature et de vaste expérience ont échoué, comme Cavalcanti dans M. Puntilla et son valet, ou Pabst, dans L'Opéra de quat'sous, selon ce qu'affirme un exégète de Brecht, Bernard Dort : ' À chaque fois qu'un cinéaste a mis la main sur une œuvre de Brecht, il en a résulté une trahison ou un échec. Trahison, comme dans le cas de L'Opéra de quat'sous de Pabst ; échec, avec M. Puntilla et son valet. ' (Bernard Dort, dans les Cahiers du cinéma, de décembre 1960). » in DUARTE, B. J. « Bahia de todos os santos » in LABAKI, Amir et alii. $O$ Cinema Brasileiro - de O pagador de promessas a Central do Brasil. São Paulo, PubliFolha, 1998, réédition d'un article du 17/03/1961. 
sem eu saber muito bem o que fosse e talvez ele também não muito, mas esse fetiche aparecia, e aparecia muito em termos da personagem. E era uma obsessão de nossas conversas. ${ }^{121}$

Pour comprendre ce que signifie parler de Brecht pour cette génération du cinéma brésilien, il vaudra donc mieux se fier à l'interprétation qui en est donnée à l'époque que rechercher à vérifier la conformité des œuvres produites avec les idées du dramaturge. Au moment de sa sortie, Bernardet écrit ce que le film lui semble devoir à Brecht dans une critique globalement positive : «Bahia distante » ${ }^{122}$. Cet article est le pendant de «Três filmes » dans lequel il dénonçait le «film d'évasion » et, d'une certaine façon, il détaille les pistes quant à ce que pourrait être un film « brechtien ».

En évoquant Brecht, il pense à un art du spectacle qui n'éloigne pas le spectateur de la réalité mais lui en révèle au contraire des aspects qu'il pourrait ignorer. Le chemin supposé pour aboutir à cette révélation est l'établissement d'une distance entre spectacle et spectateur qui permette à ce dernier l'exercice de la critique. Mais comme il le remarque rapidement, cette distance ne peut pas être établie au cinéma de la même façon qu'elle l'est au théâtre. Il note alors que le jeu brechtien d'un acteur qui joue le rôle important d'un capitaine ne fonctionne pas. Les pistes valides se trouvent selon lui dans la structure narrative (absence d'un héros, absence de conclusion, nivellement entre l'importance attribuée aux conflits vécus par les différents personnages), la présence d'éléments «perturbateurs », ici la musique («O violoncelo erudito e barroco não coincide com a pobreza mostrada. ${ }^{123}$ ) et le montage qui donne sans cesse cette impression de discontinuité. Nous voudrions à présent détailler le travail de distanciation portant sur la structure narrative mais il est pour cela nécessaire de résumer le film.

Bahia de todos os santos comprend deux lignes narratives principales qui, ellesmêmes, permettent de présenter plusieurs sous-histoires. L'ensemble nous permet d'accéder à l'ambiance de Salvador de Bahia ${ }^{124}$ et surtout à ses principales contradictions sociales. La première ligne narrative est celle de l'histoire de Tônio. Il s'agit d'un marginal. Sans emploi, pour vivre, il fait le pickpocket sur le port de plaisance et le gigolo auprès d'une anglaise. Il est aussi mulâtre. Ni blanc, ni noir, il connaît les communautés blanche et noire sans pouvoir s'y intégrer. Il ne connaît pas son père (blanc) et se trouve rejeté par sa famille maternelle

121 « [...] Brecht au cinéma, je me souviens que Trigueirinho et moi nous avons discuté de Brecht sans que je sache très bien de quoi il s'agissait et lui ne le savait peut être pas non plus très bien, mais ce fétiche revenait souvent et surtout au sujet des personnages. C'était une obsession qui revenait dans nos conversations. » in BERNARDET, Jean-Claude. Bernardet e Trigueirinho Neto. Entrevue, Archives Cinemateca Brasileira, 10 pages, 1986.

122BERNARDET, Jean-Claude. « Bahia distante » in O Estado de São Paulo - Suplemento literário, São Paulo, 20/05/1961.

123 « Le violoncelle classique et baroque ne coïncide pas avec la pauvreté qui nous est montrée. » in ibid. 124Le film porte le nom de la baie au bord de laquelle a été construite Salvador, grande ville portuaire. 
(noire). Sa grand-mère qui est « mãe de santo », sacerdote dans la religion afro-brésilienne du Candomblé, est particulièrement sévère envers lui. Tônio habite dans une paillote sur la plage avec un groupe multiracial de marginaux qui partage son sort. L'ensemble des particularités présentées par ce personnage lui permettent de nous présenter les différentes formes de racisme et de ségrégation sociale qui caractérisent la société bahianaise.

La seconde ligne narrative principale est celle de l'oppression des dockers du port de Salvador. Ceux-ci préparent une grève afin d'obtenir le droit de créer un syndicat qui leur permettrait de lutter contre l'exploitation dont ils sont victimes et qu'ils ne veulent plus supporter. Le moment choisi pour déclencher la grève est celui de l'arrivée d'un bateau américain transportant des fruits. Si leurs revendications ne sont pas rapidement acceptés, les fruits pourriront. La grève a lieu, il y a répression policière et mort d'homme. Le frère de Pitanga, l'un des marginaux amis de Tônio, est tué. Les persécutions policières ne s'arrêtent pas là et rendent nécessaire la fuite de la famille de Pitanga. Tônio, bien qu'il insiste pour ne pas passer pour un « communiste », reste solidaire de ses amis, vole de l'argent à sa maîtresse pour permettre leur fuite et reste muet pendant l'interrogatoire de police.

Parallèlement au développement de ce conflit social, Tônio vit assez mal le fait d'être relégué à la condition d'objet sexuel dans sa relation avec l'anglaise. À la fin du film, la tentative d'organisation des dockers a échoué, la famille (noire) de Pitanga a fuit, Tônio quitte l'anglaise et empêche un autre de ses amis, Manuel, (blanc celui-là) de voler dans une séquence semblable à celle du début du film où lui-même volait une montre en or. Selon lui, Manuel, parce qu'il est blanc, a des chances de promotion sociale et doit donc choisir d'autres voies pour assurer la subsistance de la famille qu'il vient de fonder.

Comme Rocha l'avait remarqué dans son article «Filme choque ${ }^{125}$, le personnage de Tônio, par ses caractéristiques d'anti-héros, est la clef d'une construction narrative qui interdit au spectateur la fruition d'un spectacle qui le laisse immune de préoccupations quant à ses propres responsabilités dans la société à laquelle il appartient :

«De heróis positivos estamos cheios. Trigueirinho não podia ser demagógico a ponto de provocar uma revolução. Os 'canalhas' (o povo) não escapará. É aquela prisão dos grevistas fugidos que condensa o drama e estabelece o contexto do Brasil. Por que fomos tão covarde ao ponto de não admitir que somos múmias como Tônio, que somos comprometidos, que não temos coragem de reagir ? ${ }^{126}$

Tônio est à la fois le personnage qui révèle au spectateur des réalités particulièrement

125ROCHA, Glauber. « Filme choque », op. cit.

126« Nous en avons assez des héros positifs. Trigueirinho ne pouvait pas se montrer démagogique au point de provoquer une révolution. Les ' canailles ' (le peuple) ne s'échapperont pas. C'est l'emprisonnement des grévistes en fuite qui condense le drame et établit le contexte du Brésil. Pourquoi avons-nous été si lâches au point de ne pas admettre que nous sommes des momies comme Tônio, que nous sommes compromis, que nous n'avons pas le courage de réagir?» in ibid. 
désagréables et celui qui le laisse ensuite à sa (mauvaise) conscience puisqu'il ne lui offre pas de solutions. Si nous comparons cette structure à celle du cinéma classique, nous pouvons remarquer que le cinéma classique peut également nous emmener dans des univers assez désagréables mais qu'il nous permet d'en sortir en nous permettant de nous identifier confortablement à un héros positif et en nous offrant un climax qui marque à la fois la résolution des conflits et provoque une catharsis renforçant de façon émotionnelle la satisfaction de voir les conflits résolus.

Mais, Tônio n'est pas seulement un anti-héros, c'est aussi une conscience inquiète, oscillante. Au chaos social correspond un chaos intime et une angoisse existentielle qui ne sont pas moins dérangeants que les réalités auxquelles il nous introduit. Rejeté par les différentes communautés, évitant de s'engager dans la lutte contre l'oppression au-delà de compromis individuels, Tônio se révèle incapable de réagir et de changer sa propre vie. Si la structure que nous avons décrite, organisée autour du personnage de Tônio, est évidemment propre à Bahia de todos os santos, ce personnage oscillant à la conscience en crise deviendra récurrent dans la cinématographie du Cinema Novo.

Pour certains observateurs de l'époque, et en particulier Bernardet et Rocha, le film de Trigueirinho Neto correspondait à une attente, celle d'un cinéma qui suscite l'activité du spectateur et le renvoie à une réflexion concernant la réalité sociale et politique qui l'entoure. Il avait déjà été établi que créer une cinématographie brésilienne ne passerait pas seulement par le traitement de thématiques brésiliennes mais par la création d'une dramaturgie originale et que celle-ci ne pourrait pas seulement décrire mais devrait aussi offrir des interprétations de la réalité dont elle serait issue. Bahia de todos os santos offrait des pistes concrètes quant à la réalisation d'un tel cinéma. L'inversion des motivations que nous évoquions plus haut du cinéma classique au cinéma moderne, associée au concept de distanciation, ouvrait le champ des possibles et permettait de penser à subordonner les motivations dites de l'intertextualité à l'expression d'une réalité sociale. L'évocation de Brecht n'allait pas plus loin que l'évocation de quelques principes généraux, mais cette évocation devait s'avérer très stimulante pour les cinéastes : elle leur permettait notamment de se démarquer du modèle Néo-Réaliste. Cette contribution décisive, parfaitement comprise à l'époque, constituait une profonde rupture par rapport aux films pourtant pionniers de Pereira dos Santos et Roberto Santos et inaugurait un cinéma parfaitement original en comparaison aux autres cinémas nouveaux qui devaient apparaître dans le monde à peu près simultanément.

\section{L'approche cinématographique des contradictions sociales et politiques}


L'une des particularités les plus importantes de Bahia de todos os santos et qui, au contraire des précédentes, le distingue très fortement des films à venir du Cinema Novo, est la perspective qu'il apporte sur les contradictions sociales et politiques du Brésil. Au contraire des films du Cinema Novo qui, comme nous le verrons, focalisent sur la passivité des masses populaires tenue en dernière instance pour inexplicable, Bahia de todos os santos met en exergue de façon extrêmement complète et explicite la violence des différentes formes d'oppression des classes inférieures, la fragmentation du corps social et les différences de culture entre les classes qui expliquent combien l'espoir d'une entente sociale au travers des structures politiques occidentales est de l'ordre de l'idéalisme.

Nous pourrions citer à titre d'exemple la séquence de l'invasion du terreiro de Candomblé où le capitaine de la police demande à la grand-mère de Tônio ses papiers. Elle lui répond sans se démonter qu'elle n'en a pas. Autant la façon dont la scène est filmée (violence de l'intervention policière, position relative des personnages : les policiers à cheval / la vieille femme à pied, interprétation de cette dernière) que ce qui est en jeu (il s'agit d'une violation des droits de l'homme au travers de la répression d'un culte millénaire) nous permettent de comprendre le véritable sens de la réponse de la sacerdote. Pourquoi aurait-elle des papiers puisque ceux-ci font partie des institutions de l'élite blanche et qu'ils ne pourraient lui servir, à elle, que pour être présentés en cas d'arrestation?

Cette séquence, comme beaucoup d'autres du film, nous révèle les caractéristiques d'une situation typiquement coloniale dans laquelle la majorité noire est maintenue dans la sujétion par l'élite blanche qui possède tout, non seulement les capitaux et les moyens de production, mais aussi les institutions de l'État créées par elle et pour protéger non seulement ses intérêts matériels (la répression du mouvement ouvrier) mais aussi sa domination culturelle et idéologique (la répression du Candomblé).

Dans le même ordre d'idées, Bahia de todos os santos est aussi le premier film qui conçoit la culture populaire comme une forme de résistance à l'oppression alors que le Cinema Novo va longtemps se défier de cette culture avec laquelle il entretient un rapport ambigu. La culture populaire sera en effet à la fois reconnue comme une source d'inspiration et une forme d'aliénation des masses, il s'agira de combattre le mysticisme, le football et le carnaval considérés comme des instruments de manipulation détournant les populations les plus pauvres d'une action révolutionnaire en leur permettant de supporter l'exploitation dont elles sont victimes.

Il n'est pas sûr, évidemment, que Trigueirinho Neto ait jamais conceptualisé les questions qu'il a pourtant soulevées dans son film ${ }^{127}$ et qui, d'une certaine manière, se révèlent 127Le fait que Trigueirinho Neto ne se soit pas attaqué à la religion s'explique peut être tout simplement par sa 
mieux à présent alors que toute une réflexion a déjà pu être menée sur le complexe colonial. Mais, comme ce sera aussi le cas pour Rocha, la sensibilité et la lucidité politiques de l'artiste dans le travail de la matière filmique, se montrent souvent supérieures à ses capacités d'analyste ou d'observateur démontrées dans la vie quotidienne, voire dans certaines prises de position rendues publiques par voies de presse.

Curieusement, si la «méthode » du film est parfaitement assimilée et entraînera des conséquences immédiates, le point de vue développée par Trigueirinho Neto sur les contradictions sociales et politiques du Brésil ne sera pas repris par le groupe du Cinema Novo. Il faudra du temps avant que l'on analyse au cinéma de façon aussi fine les mécanismes de la répression, le potentiel de résistance de la culture populaire et la double nature de la culture de l'élite blanche, à la fois colonisée dans son rapport aux cultures des grandes puissances et colonisatrice, en relation aux cultures des classes inférieures.

Le Cinema Novo, victime de préjugés de classe et des excès de l'idéologie nationaliste, commettra l'erreur de ne pas chercher les raisons de ce qu'il prendra pour une sorte d'apathie congénitale des masses et mettra également un certain temps à comprendre que la culture du Brésil n'est pas une mais plurielle et que toutes ses cultures ne sont pas forcément conciliables entre elles et ce, pour des raisons historiques et sociales. Mais nous reviendrons plus loin sur toutes ces questions. Pour l'heure, nous pourrons constater qu'il est paradoxal que Rocha n'ait pas poursuivi dans son œuvre l'approche de Trigueirinho Neto puisqu'il en saisit aussitôt des aspects importants :

«A polêmica do filme está no seu tema. Daremos, como roteiro prévio, alguns elementos.

A época, Bahia de 1940, ditadura getulista. Isto é claro. A polícia fascista é violenta : invade a cavalaria casas de candomblé, prende arbitrariamente, ataca greves e luta contra o operariado. É a primeira visão deste recém morto Brasil ${ }^{128}$ fascista que vemos tão fortemente tratado tanto na literatura, no teatro quanto no cinema brasileiro.

Havendo um clima politicamente de restrição ao homem, existe conseqüentemente uma subversão psicológica e social : Tônio é um mulato, fusão de duas raças, que vive roubando no Mercado Modêlo. Seu amigo é um operário que arma uma greve no porto e este operário é irmão do moleque Pitanga que faz parte da turma de Tônio satisfaz a Europa decadente e ávida de excitantes aventuras que se desloca para uma terra tropical : os negros são belos e ardentes no amor. $O$ fato existe sociologicamente na Bahia e Trigueirinho mostrou de frente : a louríssima Lola Brah, uma inglesa com restos de uma aristocracia perdida, emprêsa Tônio como seu amante. É uma branca que ama um negro, mas acha que ele só presta 'na cama'. » ${ }^{129}$

trajectoire. Le peu que nous savons du personnage est qu'il a par la suite consacré sa vie au mysticisme. JeanClaude Bernardet. Entretiens avec l'auteur, mars et juillet 2003.

128De nombreux critiques vont placer le film à l'époque de l'Estado Novo. Rien dans le film ne confirme cette datation. Le fait a en soit peu d'importance. Ce qui compte, c'est qu'il ne pouvait pas échapper au spectateur de l'époque que les exactions commises dans le film par la police sous le couvert de la loi était encore d'actualité. Quant à l'État fasciste récemment décédé, l'histoire allait montrer qu'il ne tarderait pas à se réincarner.

129« La polémique du film est comprise dans son thème. Nous donnerons, pour résumé le film, les éléments suivants.

L'époque, Bahia en 1940, dictature de Getúlio Vargas. C'est clair. La police fasciste est violente : elle envahit 
Autrement dit, nous nous retrouvons pratiquement dans une transposition aux temps modernes de Casa grande e senzala. Dans cet ouvrage qui est une référence pour les cinemanovistas $^{130}$, Gilberto Freyre montrait comment, à l'époque coloniale, l'exploitation de la force de travail des esclaves noirs allait de pair avec une exploitation de caractère sexuel ${ }^{131}$. Cette double exploitation devait rendre au métissage, que l'on commençait alors à reconnaître comme un trait caractéristique de l'identité nationale, le lourd héritage de violences directes (les viols) ou indirectes (les relations sexuelles consenties pour obtenir des faveurs sociales ou pécuniaires) qui l'avait caractérisé. Bahia de todos os santos montre la permanence des mécanismes d'exploitation sexuelle et leurs conséquences au travers de l'histoire de Tônio, métis de père inconnu, et de sa liaison avec l'anglaise.

La perception de l'approche sociologique de Trigueirinho Neto se révélera en creux dans les critiques négatives, orientées à droite, qui refuseront, comme cela était prévisible, la représentation qui est donnée de Salvador. La critique de M. Cantalice est assez représentative des positionnements que pouvaient provoquer l'expression des conflits sociaux :

« Aquela greve surgiu sem quê nem prá quê. Qual foi o motivo ? Só para que se ouvissem uns gritos, se contemplasse uma correria, e dois tiros roubassem duas vidas ? - De outro lado não entendemos o 'enxêrto' das cenas de candomblé. Só porque é moda?

Resumindo, diríamos : Trigueirinho quis forçar um novo caminho no cinema nacional ;

à cheval les maisons de candomblé, elle emprisonne de façon arbitraire, elle casse les grèves et lutte contre la classe ouvrière. C'est la première vision de ce Brésil fasciste récemment décédé que nous voyons si fortement discuté aussi bien dans la littérature, qu'au théâtre et dans le cinéma brésilien.

Étant posé un climat politique de restriction à l'expression de l'humain, il existe en conséquence une subversion psychologique et sociale : Tônio est mulâtre, fusion de deux races, qui vit comme pickpocket au marché Modêlo. Son ami est un ouvrier qui déclenche une grève sur les docks et cet ami est le frère du jeune Pitanga qui fait partie de la bande de Tônio qui satisfait l'Europe décadente et avide d'aventures excitantes qu'elle vient chercher sous les tropiques : les nègres sont beaux et ardents pour l'amour. Le fait existe d'un point de vue sociologique et Trigueirinho l'a montré sans faux-semblant : la blondissime Lola Brah, une anglaise avec les manières d'une aristocratie disparue, engage Tônio pour être son amant. C'est une blanche qui aime un noir, mais pense qu'il n'est bon à quelque chose qu'au lit. » in ROCHA, Glauber. « Bahia de todos os santos » in Jornal da Bahia, Salvador, 18/09/1960.

130Joaquim Pedro de Andrade commencera à travailler à son adaptation cinématographique à la fin de sa carrière. Un nouveau projet sera mené à son terme par Nelson Pereira dos Santos à la fin des années quatrevingt-dix. Mais le livre de Gilberto Freyre fut une référence du Cinema Novo dès avant son origine dans la mesure où il représentait une des premières tentatives de penser le Brésil à partir du Brésil. Le premier film de Joaquim Pedro de Andrade, O Mestre de Apipucos, documentait, non sans une subtile irrévérence, la vie quotidienne du sociologue dans sa riche demeure de Recife, entouré de ses domestiques.

131«En 1933, le sociologue Gilberto Freyre se lance dans le débat sur la quête des 'origines de l'homme brésilien', avec son livre Casa grande e senzala (Maîtres et esclaves). Cet ouvrage a été perçu comme une révolution dans les études sociologiques au Brésil. Ce sociologue suit les idées d'Alberto Torres et Silvio Romero sur le métissage. Néanmoins, il ose dénoncer la pratique courante des relations sexuelles entre les propriétaires et leurs esclaves, pendant toute la période esclavagiste. [...] Cependant, il est encore imprégné d'une vision conservatrice du métissage, qui est perçu comme une solution au retard économique et social du Brésil. Gilberto Freyre utilise la théorie de l'égalité des races, pour exalter les vertus du colonisateur portugais. » in LISBOA, Fátima Gomes. Un Artiste intellectuel : Rocha et l'utopie du Cinema Novo (19551971). Thèse de doctorat dirigé par Pierre Vayssière, décembre 2000, p. 186. 
infelizmente, apenas enveredou por um desvio... à esquerda. $»^{132}$

Le gouvernement, quant à lui, interdira la sortie du film du pays alors qu'il avait été invité à participer à des Festivals aussi importants que celui de Venise et San Francisco ${ }^{133}$. La raison en est simple : Bahia de todos os santos apporterait une vision à la fois déprimante et dégradante du pays. Pour toute une fraction de l'opinion, il s'agissait d'un film ou mensonger, ou équivoque, et, quoiqu'il en soit, il portait atteinte à l'image du pays.

Quant à la critique orientée à gauche, il semble qu'elle ait été gênée par le dénouement de l'intrigue, dans laquelle elle a vu l'expression d'une morale de « petit-bourgeois ». Maurice Capovilla écrit par exemple :

«O filme continha elementos indispensáveis para se estruturar dentro do critério do realismo crítico, mas certas constantes psicológicas e subjetivas de Trigueirinho entraram na história, interferiram no processo, e a película termine com uma lição de moral que não serve para ninguém. $»^{134}$

Bernardet revient sur le film en 1965-66 :

«Trigueirinho Neto quer que a sociedade mude, pois é insustentável que fique como está, mas seu antiburguesismo primário não leva a coisa alguma a não ser reforçar a moral burguesa. $»^{135}$

Cette lecture du film est justifiée par d'autres passages du film que le dénouement. Tônio manifeste son moralisme dans son incapacité à assumer sa liaison avec le personnage de la prostituée, Alice. Son refus de s'engager auprès des grévistes ou d'être pris pour un communiste est également significatif. Ce sont d'ailleurs sans doute en partie ces éléments qui ont permis la libération des financements du film par la Banespa. Comme José Inácio de Melo Souza nous le raconte, devant un premier refus de la direction, l'un des avalistes qui avait été séduit par le scénario demande le réexamen du dossier. Cet avaliste est lui même un exséminariste, et, voyant dans le film l'histoire d'un individu, Tônio, évoluant vers sa

132 « Cette grève a surgi sans cause ni finalité. Quelle en était la motivation? S'agissait-il seulement de faire entendre des cris, de montrer un mouvement de panique, et voir deux coups de feu voler deux vies ? D'un autre côté, nous ne comprenons pas ' l'insertion de scènes de candomblé '. Juste parce que c'est la mode ? En résumé, nous dirons que Trigueirinho a voulu offrir un nouveau chemin au cinéma national ; malheureusement, il a seulement fait un écart... vers la gauche. » in CANTALICE, M. « Bahia de todos os santos», op. cit.

133 «Bahia de todos os santos : Um Film proibido de viajar » in O Dia, Rio de Janeiro, 02/02/1961.

134 «Le film possédait les éléments indispensables pour se structurer dans le respect des critères d'un réalisme critique, mais certaines caractéristiques psychologiques et subjectives de Trigueirinho sont entrées en ligne de compte, ont interféré dans le processus, et le film termine avec une leçon de morale qui ne sert à personne. » in CAPOVILLA, Maurice. «Um cinema entre a burguesia e o proletariado ». Revista Brasiliense, São Paulo, nº43, set-out. 1962, p. 192.

135 « Trigueirinho Neto veut que la société change, car il est insupportable qu'elle reste comme elle est, mais son dégoût primaire de la bourgeoisie n'amène à rien sinon à renforcer la morale bourgeoise. » in BERNARDET, Jean-Claude. Brasil em tempo de cinema. Op. cit., p. 75. 
« conversion », il mobilise la Confederação das Famílias Cristãs, entité catholique extrémiste, qui apporte la caution morale qui manquait à la banque pour prendre sa décision. Voici le résumé de sa lecture du scénario :

« A procura do homem ' rosselliniano', de fundas raízes católicas, se resolveria no filme por meio de uma dramaturgia em que Tonio, sustentado pela amante inglesa, libertava-se da sujeição para encontrar a plenitude do ser em sua conversão. O conceito de conversão, tirado de Ignace Lepp em Itinerário de Marx a Cristo, definia não uma ' ruptura com o passado, mas a realização plena desse passado, sua integração a uma síntese existencial nova e superior à precedente. A ruptura de 'Tonio' com 'Miss Collins' não se integra a uma tergiversação da questão: é mais um ato preparatório à conversão. E o que houve com 'Tonio' foi a plena realização de seu ser, embora tenha utilizado, como instrumento, a libertação.' A purificação é o resultado final do processo de busca do homem como elemento temático. $»^{136}$

Selon les éléments qui pouvaient être valorisés par le spectateur, le film pouvait ainsi se prêter à des interprétations extrêmement contradictoires. Sauvé par un sympathisant de la Confederação das Famílias Cristãs, il recevra une critique très défavorable de M. Cantalice dans la colonne «Vida católica ». Loué tout d'abord pour les pistes qu'il ouvrait quant à la création d'un cinéma «brechtien », il est ensuite laissé de côté de par l'individualisme et le nihilisme de son personnage principal. Cette dernière critique, il est vrai, ne surgit qu'à partir de 1962, année de la radicalisation politique.

Quoiqu'il en soit, nous maintenons pour nous que l'analyse du complexe colonial faite par Bahia de todos os santos représentait une avancée qui ne sera pas assimilée au moment de sa sortie. Nous n'en retrouverons l'équivalence qu'en fin de carrière du Cinema Novo et, d'une façon beaucoup plus claire et précise dans le texte de Sales Gomes : "Trajetória no subdesenvolvimento ». Mais, notons le bien, sans qu'il ne soit établi, à ce moment-là, aucune relation avec le film de Trigueirinho Neto. Des conclusions proches ou similaires seront obtenues au terme d'un parcours étranger aux éléments de Bahia de todos os santos que nous venons de commenter.

\subsection{Arraial do Cabo et Aruanda, précarité, histoire et anthropologie}

136« La recherche de l'homme ' rosselinien ', aux profondes racines catholiques, devait se résoudre dans le film par le biais d'une progression dramatique au cours de laquelle Tônio, entretenu par son amante anglaise, se libérait progressivement de la sujétion afin d'entrer dans la plénitude de l'être qui se convertit. Le concept de conversion, tiré de Ignace Lepp dans Itinéraire de Marx au Christ, se définit, non comme une ' rupture avec le passé, mais comme la pleine réalisation de ce passé, son intégration dans une synthèse existentielle nouvelle et supérieure à la précédente. La rupture de Tônio avec Miss Collins ne laisse planer aucun doute : il s'agit d'un acte préparatoire à la conversion. Ce qui est arrivé avec Tônio, c'est la pleine réalisation de son être, bien qu'il ait utilisé comme instrument, la libération. ' La purification est le résultat final de ce processus de recherche de l'homme comme élément thématique. » in MELO SOUZA, José Inacio de. « Fontes para o estudo do financiamento de filmes : a carteira de crédito do Banco do Estado de São Paulo », http://www.mnemocine.com.br/pesquisa/pesquisatextos/banespa.htm, consulté le 06/08/2005. 
Au côté de Bahia de todos os santos, Arraial do Cabo et Aruanda furent les deux films les plus commentés de la période allant de 1960 à 1961 et contribuèrent de façon considérable à la réflexion sur l'esthétique du Cinema Novo qui était alors menée. Par des chemins différents, ils ont amené la réflexion à des conclusions proches de celles de Bahia de todos os santos, le maître-mot était « interprétation ». Le cinéma devait à tout prix éviter de se cantonner à une simple description, aussi émouvante soit-elle, de la misère et du retard du Brésil, il devait dévoiler les mécanismes invisibles qui en assuraient la pérennité. L'œil cinématographique se devait de traverser le voile opaque des apparences pour révéler les contradictions d'un pays à la fois si grand et si riche, découvrant, quand il voulait bien se l'admettre, son rang de nation sous-développée.

Comment procéder? Bahia de todos os santos apportait certains éléments de réponse, simultanément, Arraial do Cabo et Aruanda en apporteront d'autres. Avant d'entrer dans les détails, il est cependant important de préciser que les trois films partent de projets totalement distincts, réalisés par des personnes qui ne se connaissent pas entre elles et dans des lieux très distants les uns des autres ${ }^{137}$. Bahia de todos os santos, le projet le plus ancien puisque son scénario date de 1957-58, est réalisé par un réalisateur pauliste, avec un financement pauliste, à Salvador avec une équipe de techniciens et d'acteurs de Bahia. Arraial do Cabo est réalisé par un directeur carioca avec une équipe carioca dans l'État de Rio de Janeiro. Aruanda est réalisé dans l'État de la Paraíba, par des intégrants de la vie cinématographique de João Pessoa et Recife (Pernambuco). Enfin, le premier film est un long métrage de fiction alors que les deux autres sont des courts métrages documentaires.

Ajoutons encore que Bahia de todos os santos est produit par un cinéaste aux conceptions déjà matures, ouvrant les voies de la modernité et de la distanciation «brechtienne ». Arraial do Cabo et Aruanda sont les œuvres d'apprentis cinéastes qui, par intuition, découvrent les voies de l'approche anthropologique, assument une perspective historique et font d'un handicap une qualité en intégrant la précarité des moyens de production à leur esthétique. Comment mieux représenter un pays sous-développé qu'en assumant la pauvreté des moyens, humains, techniques et financiers, dont on dispose ? Il n'est pas possible de toute façon de faire autrement. Arraial do Cabo et Aruanda, parce qu'ils présentent d'importantes similitudes dans leurs approches, ont été l'objet de trois articles décisifs mettant immédiatement à jour les avancées qu'ils introduisaient :

- ROCHA, Glauber. « Documentários : Arraial do Cabo e Aruanda » in O Jornal do Brasil - Suplemento Dominical, Rio de Janeiro, 06/08/1960.

137Seul, Rocha connaissait à la fois les membres de l'équipe de Arraial do Cabo et ceux de Bahia de todos os santos. Éloigné du tournage de Arraial do Cabo, il ne pouvait cependant pas en anticiper le résultat. L'arrivée d'Aruanda était, pour sa part, totalement imprévisible des observateurs de Salvador, Rio ou São Paulo. 
- BERNARDET, Jean-Claude. «Dois documentários» in O Estado de São Paulo Suplemento literário, São Paulo, 12/08/1961.

- ROCHA, Glauber. «Arraial, Cinema Novo e câmara na mão » in O Jornal do Brasil, Rio de Janeiro, 12/08/1961.

\section{Arraial do Cabo}

Comme le raconte Paulo César Saraceni dans son autobiographie, Arraial do Cabo n'est pas né d'une idée qui lui était propre. Quand il se lance dans ce projet, il avait réalisé un premier court métrage à la circulation restreinte, Caminhos, fin 1958, début 1959, et venait de gagner une bourse du gouvernement italien pour aller étudier au Centro Sperimentale di Cinematografia à Rome. Alors qu'il prépare son voyage pour l'Italie, il rencontre dans un bistrot l'anthropologue Geraldo Markam qui venait de faire des recherches à Arraial do Cabo. Ce dernier convainc le jeune cinéaste de filmer son travail. Le lendemain, Saraceni entre en contact avec la direction du Museu Nacional qui coordonnait les recherches sur le site. Parallèlement, il joint deux de ses amis, Joaquim Pedro de Andrade et Mário Carneiro. Joaquim Pedro travaille à la Saga Filmes, une petite maison de production possédant une caméra de $35 \mathrm{~mm}$. Mário Carneiro possède déjà une petite expérience de cameraman mais n'avait jamais manipulé de caméra de $35 \mathrm{~mm}$.

La directrice du Museu Nacional est enthousiasmée par le projet et la participation des deux amis du cinéaste dont elle connaissait les pères respectifs. L'obtention d'un subvention de Cr\$300 000 permet de commencer le travail et devait suffire à l'ensemble des dépenses, de l'achat de la pellicule à la restauration des membres de l'équipe sur les lieux du tournage. De la rencontre avec Geraldo Markam au départ des cinéastes pour Arraial do Cabo tout va donc très vite. Jusqu'à ce moment-là, ni Saraceni, ni Carneiro ne connaissent la ville ${ }^{138}$ quant à Andrade, il n'était pas prévu qu'il se rende sur le lieux du tournage. C'est son associé, Sérgio Montagna, qui devait gérer la production sur place.

L'originalité de la démarche de Saraceni a alors consisté à ne pas s'en remettre exclusivement aux travaux des anthropologues mais à rechercher à s'immerger dans la vie de la cité pour peu à peu construire son propre regard. Après un certain nombre d'aller-retour en autobus, la petite équipe, Carneiro, Montagna et Saraceni, restent un mois sur place sans filmer, observent les transformations provoquées par la création d'une fabrique de produits chimiques et participent à la vie des pêcheurs :

138SARACENI, Paulo César. Por dentro do Cinema Novo - Minha Viagem. Rio de Janeiro, Nova Fronteira, 1993, p. 51. 
«Acordávamos antes das 4:00h e saíamos para pescar com os pescadores. Ficávamos horas esperando o sinal do guia que nos avisava da chegada dos peixes. Jogávamos muito futebol na areia da praia. Mário era um bom goleiro e Sérgio Montagna um beque da roça. Eu estava em grande forma, corria o tempo todo, jogava bem e os pescadores gostavam. [...] Éramos o pessoal do Museu, gente de casa, podíamos entrar e sair em qualquer lugar. Íamos à igreja aos domingos com a comunidade. $\gg{ }^{139}$

Le langage du film devait être conçu à partir de ce vécu pour aboutir à l'expression cinématographique d'une ville jusque là isolée et brusquement soumise à un processus de transformation rapide. Comme il l'a par la suite raconté, Saraceni observe que l'apparition de la fabrique dans ce lieu dont les habitants subsistaient selon des modes de vie centenaires et primitifs, forcent deux mondes distincts à cohabiter. Le premier est le monde des pêcheurs qui se sont refusés à travailler à l'usine et continuent à vivre au rythme de la nature (réveil au lever du jour, marées, passage du poisson) avec une organisation sociale peu hiérarchisée et solidaire dans laquelle hommes, femmes et enfants ont un rôle précis à jouer. Le second est le monde de l'usine, avec ses horaires, sa technologie et ses chefs invisibles qui organisent la venue d'ouvriers du Nordeste pour pallier aux difficultés de recrutement.

Un autre point important est que l'activité industrielle se développe au détriment des activités traditionnelles. L'usine rejette dans la mer des substances toxiques et cela contraint les pêcheurs à aller pêcher de plus en plus loin et à prendre de plus en plus de risques pour continuer leurs activités. Au même moment où Saraceni observe la vie de la communauté, il pense déjà à la façon dont il va filmer et il n'est alors pas exclu de penser qu'il va tourner sans avoir encore clairement conceptualisé ses idées sur cette transformation par laquelle passe la ville. Les conclusions du documentaire ne sont pas prêtes avant la première prise mais elles vont se construire tout au long du processus de la réalisation : de la préparation du film au montage.

L'acte de création cinématographique devient un véritable acte de recherche sur une réalité donnée dans la mesure où c'est dans la recherche du meilleur angle de prise de vue, de la meilleure illumination, etc. que l'auteur structure sa propre pensée. Pour décrire et critiquer la transformation par laquelle passe le village côtier, Saraceni s'inspire du montage intellectuel et de la théorie des attractions d'Eisenstein tant discutés avec l'ami Leon Hirszman. L'idée est simple, il s'agit de filmer différemment les pêcheurs et les ouvriers de l'usine, notamment en s'appuyant sur les caractéristiques des univers physiques dans lesquels ils évoluent. Nous aurons donc un montage serré pour exprimer la gestion du temps dans

139 « Nous nous réveillions avant quatre heures du matin et nous sortions pour pêcher avec les pêcheurs. Nous attendions des heures le signal de la vigie qui prévenait de l'arrivée des poissons. Nous jouions beaucoup au football sur la plage. Mário était un bon goal et Sérgio Montagna un attaquant agressif. J'étais en grande forme, je courais tout le temps, je jouais bien et les pêcheurs appréciaient. [...] Nous étions le personnel du Musée, des gens de la maison, nous pouvions entrer et sortir n'importe où. Le dimanche, nous allions à l'église avec la communauté. » in SARACENI, Paulo César. Op. cit., pp. 52-53. 
l'usine et des prises de vue marquées par la verticalité en syntonie avec l'architecture des lieux mais aussi pour exprimer les caractéristiques d'une nouvelle organisation sociale marquée par un nouveau rapport entre l'homme et le travail. Les exemples les plus évidents de cette approche sont les plans, en plongée et contre-plongée, des ouvriers montant et descendant dans l'ascenseur.

Pour la pêche, nous aurons des séquences longues, des temps morts, pour exprimer l'attente du passage des bancs de poisson et une vie réglée par le rythme de la nature, et des prises de vue marquées par horizontalité, à hauteur d'homme, et ce, évidemment en référence à l'horizon de la mer ${ }^{140}$ mais aussi pour exprimer une organisation sociale peu hiérarchisée. Dans le montage, les pêcheurs, le guetteur, les femmes sont séparés par des plans distincts, voire des blocs narratifs distincts, qui indiquent une répartition des tâches équitable, prenant en compte les aptitudes de chacun (le guetteur est un vieil homme par exemple). La tonalité des plans de la fabrique est grise, celles des plans de la pêche, blanche :

« Mário era um grande artista e ficava imaginando como captar aqueles brancos sobre brancos de Arraial num filme em preto e branco. A realidade física, tonal e humana de Arraial era a nossa mestra. $»^{141}$

Il est également associé à chacun des deux groupes humains un thème musical diffèrent. Les images des ouvriers sont accompagnées par de la musique concrète : un bruit de martellement régulier et sourd et des percussions comprenant notamment des roulements de batterie. Les images des pêcheurs sont accompagnées par de la guitare classique. Les activités laborieuses des ouvriers et des pêcheurs sont présentées dans un montage alterné ce qui permet au spectateur de les comparer. Tout est conçu pour exprimer un antagonisme entre les deux modes vies même s'il n'est à aucun moment expliqué en quoi la fabrique menace le mode de vie des pêcheurs. Les interventions de la voix off sont rares et assez contradictoires avec les autres éléments du film. Alors que son discours est à faveur de l'industrialisation qui vient apporter le progrès dans un village jusqu'alors « abandonné par la civilisation », le film se positionne clairement en faveur des pêcheurs dont le mode de vie est menacé.

La dernière séquence constitue la clef de l'ensemble : après le travail, ouvriers et pêcheurs sont réunis au bistrot. L'antagonisme n'existe pas entre les hommes qui, tous de classe modeste, affrontent avec la même dignité, chacun de leurs côtés, des conditions de travail difficiles (nombreux gros plans sur les visages sérieux et appliqués à la tâche).

140Parallélisme entre le regard du guetteur et l'angle de la caméra ou dans un autre plan, parallélisme entre la ligne de l'eau, la ligne de la plage et le vol rasant d'oiseaux.

141 « Mário était un grand artiste et passait son temps à rechercher comment capter ces blancs sur blancs d'Arraial dans un film en noir et blanc. La réalité physique, tonal et humaine d'Arraial était notre maîtresse. » in SARACENI, Paulo César. Op. cit., p. 53. 
L'antagonisme apparaît entre l'ancien et le nouveau, entre une économie industrielle et une économie primitive, et le passage de l'une à l'autre pose problème (dans la dernière séquence, un vieil homme discoure avec véhémence sur son balcon devant une rue déserte, ses propos sont incompréhensibles mais il est évident qu'il parle politique). Ouvriers et pêcheurs sont les jouets passifs du progrès et, à ce moment historique précis, ils se trouvent confrontés à une transformation qu'ils n'avaient pas choisi et à laquelle tous ne pourront s'adapter. Le caractère tragique de l'histoire qui avance inéluctablement est renforcé par le fait que le film, en noir et blanc, est quasiment muet. Alors qu'au moment où il a été réalisé ce court métrage documentait une réalité encore vivante, tous ces visages dont nous voyons remuer les lèvres mais dont nous n'entendons pas les paroles, semblent déjà appartenir à un passé lointain.

L'intention du projet était de conserver un témoignage filmé d'un mode de vie en voie de disparition pour les anthropologues et historiens des temps futurs. Le sujet initial était donc la communauté de pêcheurs. Mais, comme le note Paulo César Saraceni ${ }^{142}$, le film a évolué vers une critique de l'idéologie du desenvolvimentismo qui connaissait alors son apogée. Nous sommes alors à l'époque du président Juscelino Kubitschek, l'industrialisation du pays s'effectue à un rythme accélérée et, sans trop s'interroger sur les modalités selon lesquelles elle s'effectue, une partie de l'opinion veut croire que le Brésil est en train d'effectuer le saut qualitatif qui fera de lui un pays du premier monde. Le film est critiqué d'un côté pour son schématisme, de l'autre pour son formalisme :

« O homem, junto à natureza, trabalhando os elementos naturais com as mãos, conhece uma espécie de paz, é feliz - o que é a visão rousseauniana de citadino, bastante discutível. O homem da fábrica é infeliz. Então, defendamos a felicidade do primeiro. Esta luta contra a industrialização, que consiste em ignorá-la, é a atitude de avestruz que esconde a cabeça na areia. Além de se tratar de uma atitude reacionária, por ser nostálgica, não sabemos em que situação a fábrica colocou os pescadores. $\mathrm{E}$ tudo deixa supor que no fundo a situação seja boa, já que a fita acaba com uma alegre reunião musical (apesar, talvez, das intenções ligeiramente cínicas dos realizadores). Talvez tudo o que está na fita seja verdade, mas o naturalismo não basta. Não adianta mostrar as coisas como são sem se atingir o que há de problemático nelas.

Mas Arraial do Cabo nem chega a ser naturalista : está demasiadamente comprometido com o esteticismo. [...] O fato de a realidade dar a impressão de ser manipulada não é mau, mas a manipulação deve ser feita em função desta mesma realidade e não em função de um ideal estético que lhes é exterior. $\gg{ }^{143}$

142Le fait est d'autant plus remarquable que Saraceni quand il arrive à Arraial do Cabo, est juscelinista. Comme beaucoup d'autres de sa génération, il croit à la politique du constructeur de Brasília sans en saisir encore toutes les contradictions. Au moment où il commente son film, un an après l'avoir fait, il est beaucoup plus critique : « A fábrica, que tem mais de 20 anos, não só não fez nada para economizar divisas do Brasil, como também nada fez de bem para Arraial e seus habitantes. [...] sou a favor da industrialização do Brasil - sou contra esta fábrica. » in «VI Bienal : Homenagem ao cinema brasileiro » in O Estado de São Paulo Suplemento literário, São Paulo, 14/10/1961.

143 «'homme, en contact avec la nature, travaillant les éléments naturels à la main, connaît une sorte de paix, il est heureux - ce qui est la vision rousseauiste du citadin qui est assez discutable. L'homme de la fabrique est malheureux. Alors, il faut défendre le bonheur du premier. Cette lutte contre l'industrialisation, qui consiste à l'ignorer, est l'attitude de l'autruche qui se cache la tête dans le sable. En plus de s'agir d'une attitude réactionnaire, pour être nostalgique, nous ne savons pas dans quelle situation la fabrique a mis les pêcheurs. 
Arraial do cabo, au travers de ses qualités comme de ses imprécisions, permit de progresser et de préciser encore ce qui était attendu du Cinema Novo. Aruanda donna par la suite très opportunément la possibilité de continuer les réflexions qu'il initiait.

\section{Aruanda}

Aruanda est réalisé dans un État bien distant de Rio de Janeiro et de São Paulo : la Paraíba. Alberto Cavalcanti avait réalisé dans cet État $O$ Canto do mar en 1953, et, selon l'enquête menée par David Neves et dont il fait le compte-rendu dans son petit livre Cinema novo no Brasil, ce tournage aurait apporté une certaine impulsion permettant l'éclosion d'une « mentalité ${ }^{144}$ cinématographique concrétisée par la création du ciné-club João Pessoa. Linduarte Noronha, réalisateur d'Aruanda, João Ramiro Mello et Vladimir Carvalho, assistants et co-scénaristes, firent leur formation cinématographique dans ce ciné-club. L'idée originale du film partit d'un reportage que Linduarte Noronha avait publié dans la revue $O$ Cruzeiro sous le titre : Talhado, a citadela do barro.

Le film est tourné grâce au concours de l'Instituto Nacional de Cinema Educativo INCE, qui prête une caméra et facilite les travaux de laboratoire, du sociologue Odilon Ribeiro Coutinho, qui fournit la pellicule, et de l'Instituto Joaquim Nabuco de Pesquisas Sociais de Recife qui concède une subvention de Cr\$ 100 000. Comme ce fut le cas pour Arraial do Cabo, l'équipe dispose d'un budget extrêmement réduit et d'un matériel, à l'époque, complètement dépassé. Dans l'impossibilité de capter le son en direct, le film est également doublé avec une voix off et de la musique. L'approche anthropologique est ici aussi de mise. Sur Aruanda, son auteur Linduarte Noronha écrit : «As pesquisas sociológicas, antropológicas, ecológicas na região estão a exigir a presença do cinema documentário. [...] O documentarista deve ser capaz de narrar com a estética e a poesia sem deturpar o

Et tout laisse penser que, dans le fond, la situation est bonne, puisque le film termine avec une joyeuse réunion en musique (malgré, peut être, les intentions légèrement cyniques des auteurs). Peut être que tout ce qui est dans le film est vrai, mais le naturalisme ne suffit pas. Cela ne sert à rien de montrer comment sont les choses sans chercher à atteindre ce qu'elles présentent de problématique.

Mais Arraial do Cabo ne parvient même pas à être naturaliste : il est beaucoup trop compromis avec l'esthétisme. [...] Le fait que l'on ait l'impression que la réalité a été manipulée n'est pas mauvais, mais la manipulation doit être faite en fonction de cette même réalité et non d'un idéal esthétique qui lui est étranger. » in BERNARDET, Jean-Claude. « Dois documentários » in O Estado de São Paulo - Suplemento literário, São Paulo, 12/08/1961. Rocha critique également le fait que Saraceni n'ait pas approfondi le conflit entre la pêche et la fabrique et qu'il se soit laissé allé au « lyrisme » dans la séquence de la pêche (ROCHA, Glauber. « Documentários : Arraial do Cabo e Aruanda » in O Jornal do Brasil - Suplemento Dominical, Rio de Janeiro, 06/08/1960).

144C'est là le terme employé par David Neves (NEVES, David. Cinema Novo no Brasil. Petrópolis, coll. Nosso Tempo, ed. Vozes, 1966, pp. 26-27). 
conteúdo. $»^{145}$

Aruanda nous raconte, nous montre et nous explique l'histoire et la vie d'un petit village du sertão de la Paraíba nommé Olho D'água. Le générique qui dure pratiquement deux minutes établit avec le spectateur un contrat de confiance quant à la validité des informations qui vont lui être apportées, notamment en nommant et en remerciant les institutions scientifiques et éducatives qui ont appuyé la réalisation du film et en donnant les crédits complets et l'origine des musiques qui vont accompagner la narration. Dans Arraial do Cabo, les musiques trouvaient leur origine dans l'univers culturel des auteurs (musique concrète et Villa-Lobos pour le thème à la guitare) et, comme les gravures du générique, tendaient plus à exprimer le regard des cinéastes sur le village côtier qu'à rendre compte de la culture et du point de vue de ses habitants. Dans Aruanda, il nous est au contraire précisé que les musiques sélectionnées appartiennent au folclore du Nordeste et donc à l'univers culturel des sujets filmés. Dans la séquence de la foire, les plans d'un accordéoniste renforcent ce lien entre les personnages et la musique en off.

Le générique est suivi de deux cartons qui nous introduisent à la problématique du film ou comment, dans leur lutte pour la survie et la liberté, une famille noire fuyant l'asservissement des grandes plantations de canne à sucre a préféré affronter, dans l'isolement le plus total, les conditions de survie précaires que pouvait offrir une terre aride et, plus grave encore, comment le village a pu grandir selon les mêmes conditions jusqu'à 1960, preuve de la permanence des mécanismes d'exclusion sociale et d'abandon de la part des institutions du pays :

\begin{abstract}
«Os quilombos marcaram época na história econômica do Nordeste canavieiro. A luta entre escravos e colonizadores terminava, às vezes, em episódios épicos, como Palmares. Olho d'Água da Serra do Talhado, em Santana do Sabugi (PB), surgiu em meados do século passado, quando o ex-escravo e madeireiro Zé Bento partiu com a família à procura da terra de ninguém. Com o tempo, Talhado transformou-se num quilombo pacífico, isolado das instituições do país, perdido nas lombadas do Chapadão nordestino, com uma pequena população presa a um ciclo econômico trágico e sem perspectivas, variando do plantio de algodão à cerâmica primitiva, vendida na feira ao pé da serra. ${ }^{146}$
\end{abstract}

Le court métrage est ensuite divisé en séquences présentant de forme didactique le

145 «La recherche dans le domaine de la sociologie, de l'anthropologie ou de l'écologie, exige la présence du cinéma documentaire. [...] Le documentariste doit être capable de recourir à l'esthétique et à la poésie sans trahir son sujet. » («VI Bienal : Homenagem ao cinema brasileiro », op. cit.)

146« Les quilombos ont marqué l'histoire économique du Nordeste producteur de canne à sucre. La lutte entre les colons et les esclaves terminait, parfois, dans des épisodes épiques comme celui de Palmares. Olho d'Água da Serra do Talhado, à Santana do Sabugi (Paraíba), a surgi au cours du siècle dernier [XIXe siècle], quand un ex-esclave et charpentier Zé Bento est parti avec sa famille à la recherche d'une terre sans propriétaire. Avec le temps, Talhado s'est transformé en quilombo pacifique, isolé des institutions du pays, perdu entre les collines du Chapadão nordestin, avec une population prisonnière d'un cycle économique tragique et sans perspective, alternant entre la culture du coton et un artisanat primitif de céramiques, vendues à la foire se trouvant au pieds de ces collines. » in ibid. 
mode de vie de ce peuplement. La première séquence est consacrée au voyage de Zé Bento et sa famille. La seconde à son installation au près du trou d'eau qui donnera son nom au village : Olho D'água (littéralement, « œil d'eau »). Dans cette séquence, nous voyons la construction de la maison selon la technique du pau-a-pique, l'alimentation à base de farine, le travail de la terre. La troisième séquence, cent ans plus tard, nous montre que la petite maison des premiers jours a fait place à un hameau. Les maisons sont plus grandes mais le mode de vie n'a pas changé. Nous avions laissé Zé Bento en train de bêcher la terre caillouteuse, nous retrouvons ici un groupe de femmes en train de bêcher et de ramasser de la terre. Toutes les étapes de la fabrication d'ustensiles de cuisine en céramique nous sont alors présentées. La quatrième et dernière séquence est consacrée à la vente de ces objets dans une foire : le long voyage jusqu'à la foire, le transport des céramiques à dos de mulets, l'ambiance de la foire et les autres commerces, le retour.

Deux thématiques sont exprimées au travers du film : l'intégration de l'homme au milieu naturel et l'anachronisme de la persistance d'une économie primitive à l'ère moderne. L'intégration de l'homme au milieu naturel est traduite par l'alternance de plans généraux montrant les différentes caractéristiques physiques du paysage, avec les plans rapprochés ou les gros plans des personnages en contre-champ, ainsi que par les plans généraux de la famille sur le chemin. L'intégration de l'homme au milieu naturel est également traduite par l'omniprésence de la terre tout au long de la narration. Le film réussit même à nous rendre concrète cette terre blanche, poudreuse et caillouteuse, des plans des pieds nus des enfants sur les pierres aiguisées du chemin dans la première séquence, aux plans rapprochés de la terre creusée, retournée, mouillée et travaillée quand il s'agit de fabriquer la maison, d'ensemencer ou de préparer l'argile. Dans toutes les activités présentées, c'est de la terre dont l'homme tire sa subsistance, c'est son horizon et c'est aussi sa limite. En dehors de la terre il n'y a rien et cette terre donne trop peu pour offrir une quelconque perspective de progrès.

Les cartons initiaux et le commentaire dit en voix off souligne l'anachronisme de cette situation et nous retrouvons alors, comme dans Arraial do Cabo, la mise en perspective historique d'une réalité sociale et économique contemporaine. Dans Arraial do Cabo, au côté du commentaire, c'est le montage parallèle entre les scènes de l'usine et les scènes de la pêche qui nous introduit à ce décalage qui naît de la persistance de modes de vie primitifs dans le monde moderne. Dans Aruanda, le décalage avec le monde moderne est introduit par le commentaire et la troublante similitude entre les séquences consacrées à la création du village par Zé Bento et celles consacrées à la vie du village aujourd'hui. Une écoute inattentive du commentaire rend parfaitement imperceptible le passage du XIXe siècle au XX siècle et ce 
qui, d'un point de vue académique ${ }^{147}$, pourrait passer pour une erreur, traduit parfaitement l'idée de l'isolement. Le village subsiste éloigné dans l'espace (plusieurs jours sont nécessaires pour rejoindre la foire la plus proche ${ }^{148}$ ) et en dehors du temps, en dehors de la chronologie de la civilisation qui fut marquée par l'introduction d'objets technologiques provoquant la transformation du quotidien.

Aruanda est montré lors de le première convention nationale de la critique cinématographique organisée en novembre 1960 par Sales Gomes et la Cinemateca Brasileira. Il jouit lors de cette représentation d'un franc succès qui n'est pas sans coïncider avec l'exposé de la thèse de l'éminent critique pauliste, «Uma situação colonial ». Le film a été découvert quelques mois plus tôt par Rocha qui le rapproche du court métrage de son ami Paulo César Saraceni. Il déclare :

\begin{abstract}
« Em Pernambuco já houve cinema no passado. Mas tudo morreu. Linduarte Noronha e Rucker Vieira não parecem ser rapazes de cinemateca. Desconhecem as leis gramaticais da montagem e devem ter assistido a alguns documentários, mas talvez nenhum de grande importância. São dois primitivos, dois selvagens, diríamos, com uma câmera na mão. Mas Aruanda é um documentário de grandes qualidades, é um filme de criação, é um filme. $»^{149}$
\end{abstract}

La photographie visiblement déficiente d'Aruanda est interprétée comme un mode d'expression du sous-développement qui correspond tout à fait au thème $\mathrm{du}$ film, la permanence d'un mode de vie précaire et d'une économie primitive dans le Nordeste brésilien. Le manque d'incitations officielles ${ }^{150}$ et de structures cinématographiques ${ }^{151}$ apparaît comme devant être intégré à l'esthétique des films. Les limitations techniques provoquées par le manque de moyens financiers généré par le propre sous-développement du cinéma brésilien sont alors considérés comme des éléments de langage. Autre élément important, dans Aruanda comme dans Arraial do Cabo, l'approche scientifique n'exclut pas le recours à l'émotion. Il ne s'agit pas, évidemment, d'une émotion construite par le biais du montage, de l'encadrement et de la musique sur des situations mélodramatiques ou épiques plus ou moins

147D'un point de vue académique, le passage du temps devrait être signalé par divers éléments filmiques redondants avec le commentaire. Même en l'absence totale de moyens, il était facile de placer un carton indiquant : «Cent ans plus tard... » ou « De nos jours... », un peu plus compliqué : une séquence avec des changements climatiques ou l'arrivée de nouveaux immigrants et la construction de nouvelles maisons. Il ne s'agit pourtant pas là d'une erreur.

148Information apportée par le commentaire en voix off.

149« Au Pernambuco, il y a déjà eu du cinéma dans le passé. Mais tout est mort. Linduarte Noronha e Rucker Vieira ne semblent pas être des habitués de cinémathèque. Ils ignorent les lois grammaticales du montage, ils ont dû assister à quelques documentaires mais peut être sans grande importance. Ce sont deux primitifs, deux sauvages avec une caméra à la main. Mais Aruanda est un documentaire de grandes qualités, c'est un film de création, c'est un film. » (ROCHA, Glauber. « Documentários : Arraial do Cabo e Aruanda », op. cit.)

150Bien que les réalisations d'Aruanda et de Arraial do Cabo soient rendues possibles par les subventions d'institutions publiques, il s'agit alors de cas isolés et la classe cinématographique réclame depuis près de dix ans une intervention de l'État significative dans ce secteur d'activité.

$151 \mathrm{Il}$ n'existe pas d'écoles de cinéma ou de possibilité de prêt étendu de matériels comme celui dont Aruanda a bénéficié auprès de l'INCE. 
originales comme dans le cinéma classique, mais d'une émotion qui est recherchée dans l'interaction avec la réalité.

Selon Bernardet, Aruanda constituait un film pionnier ouvrant des voies que le Cinema Novo se devait d'emprunter :

« Aruanda é a melhor prova da validade, para o Brasil, das idéias que prega Rocha: um trabalho feito fora dos monumentais estúdios que resultam num cinema industrial e falso, nada de equipamento pesado, de rebatedores de luz, de refletores, um corpo a corpo com uma realidade que nada venha a deformar, uma câmera na mão e uma idéia na cabeça apenas. O que fazer? Aruanda o dizia. ${ }^{152}$

Comme pour Bahia de todos os santos, il n'est cependant pas possible d'attribuer à Aruanda une identification totale avec l'esthétique du Cinema Novo, le film sera suivi sur certains de ses aspects et pas sur d'autres. Sa filiation est directe avec le filon documentaire qui est contemporain au Cinema Novo. Ce dernier accordera la primauté à la fiction et, comme dans Arraial do Cabo, à la sensibilité de l'auteur, ce qui le distinguera des documentaires à l'approche sociologiquement plus rigoureuse, plus soucieux, comme Aruanda, d'épouser « les reliefs du réel $»^{153}$.

\section{Une idée dans la tête et une caméra à l'épaule, le cinéma-vérité mystifié}

Comment concilier modernité et précarité des moyens de production ? Voici l'une des problématiques qui se posent au Cinema Novo au début des années soixante. Comme insistaient à le montrer Rocha et Dahl, le Néo-réalisme, la Nouvelle Vague et le Free Cinema avaient tour à tour indiqué qu'il était possible de faire un cinéma valide, d'un point de vue culturel, en s'éloignant du modèle technique et économique du cinéma classique. Loin des studios, loin des contraintes d'une production coûteuse et avec des équipes réduites, il était possible de faire de grands films comme $A$ bout de souffle ou Shadows. Le cinéma brésilien, de ce point de vue, offrait les conditions adéquates, un élément de taille pourtant manquait : le matériel adéquat aux ambitions anthropologiques et sociologiques du Cinema Novo, des

152«Aruanda est la meilleur preuve de validité, pour le Brésil, des idées prêchées par Rocha :

un travail réalisé en dehors des studios monumentaux qui produisent un cinéma industriel et faux, aucun équipement lourd, pas de réflecteurs de lumière, un corps à corps avec la réalité que rien ne vient déformer, une caméra à la main et une idée dans la tête. Que faire ? Aruanda le disait. » in BERNARDET, Jean-Claude. Brasil em tempo de cinema. Op. cit., p. 27.

153Nous essayons de traduire par cette expression la valorisation par l'auteur dans l'esthétique du film des éléments caractéristiques du sujet étudié. Si nous considérons qu'il existe une tension entre les pôles « auteur » et « réel » dans la création filmique, le Cinema Novo serait plus proche de la mise en valeur de la subjectivité de l'auteur dans sa relation au réel alors que les documentaires de la veine sociologique, plus proche de l'expression des contradictions du réel. Ce renversement de perspective est facilement visible dans les films post-années soixante de de Vladimir Carvalho et Eduardo Coutinho malgré leurs importantes différences de style. Mais, par un étrange paradoxe, plus l'auteur laisse la parole au sujet, plus son style s'affirme et devient reconnaissable. Réflexion entendue au Festival « É tudo verdade », São Paulo, 2003. 
caméras légères et la possibilité d'enregistrer le son en direct. Durant le tournage de Arraial do Cabo, Saraceni se lamentait de ne pas posséder un Nagra :

\begin{abstract}
«Os peixes estavam ali, onde as mulheres os salgavam e cantavam músicas antigas e tristes. Suas vozes estridentes produziam um som que penetrava em nossas almas. Depois contavam histórias de Arraial. Eu lamentava não ter um bom gravador. Reclamava do Montanha e da Saga por não ter um Nagra, que um suiço, um tal de Kudelski, tinha inventado : pequeno, do tamanho de uma malinha, com microfones-gravata que captam o menor ruído. Afinal, cinema é imagem e som. $\gg^{154}$
\end{abstract}

Pour qui, à la suite de Dahl, voulait entendre la voix de l'homme brésilien ${ }^{155}$, l'absence du son direct devait logiquement causer une grande frustration. Mais les caméras aussi n'étaient pas vraiment adaptées à l'usage qu'il leur était réservé. Mário Carneiro témoigne des soins particuliers qu'il dut prodiguer à sa caméra dans ses allées et venues à Arraial do Cabo :

« Tinha a cámera do Sergio Montanha, que era uma Cameflex que ele tinha comprado do Fellini, com uma óptica Cooke maravilhosa. [...] Todos os dias tinha que desmontar, limpar, porque lá era areia prá todo o lado. E aí fiz esse outro curso que foi fazer o "Arraial do Cabo", já fazendo a cámera, fazendo luz um pouquinho (a gente tinha uma maleta de luz, rebatedores e tal...) E aí a gente toca a subir e descer. Eu carregava a camera e tudo mais por aí a fora. $\gg{ }^{156}$

Quant à la caméra Bell \& Howell-Eyemo utilisée sur le tournage d'Aruanda, il s'agissait certes d'une caméra capable d'être utilisée dans les plus diverses positions et dans des conditions climatiques et de terrain adverses mais dont le caractère avant-gardiste remontait au années quarante. Dans les deux cas, les possibilités des caméras ont une incidence directe sur le langage cinématographique, le plan fixe domine et nous sommes loin des mouvements de caméra portée très rapides auxquels Saraceni dit qu'il rêvait dès mars 1960. ${ }^{157}$ Aussi, quand le slogan du Cinema Novo, « uma idéia na cabeça e uma câmera na mão » est diffusé par Rocha dans le courant de l'année 1961 ou quand il écrit «Arraial, Cinema Novo e câmara na mão » en août de la même année, il en va pour une bonne part de

154 «es poissons étaient là, où les femmes les salaient et chantaient leurs musiques anciennes et tristes. Leurs voix stridentes produisaient un son qui pénétrait nos âmes. Ensuite, elles contaient les histoires d'Arraial. Je me lamentais de ne pas avoir un bon enregistreur. Je réclamais auprès de Montanha et de la Saga de ne pas avoir un Nagra, qu'un suisse, un certain Kudelski, avait inventé : petit, de la taille d'une mallette, avec des microphones-cravates qui captaient le moindre bruit. Dans le fond; le cinéma est image et son. » in SARACENI, Paulo César. Op. cit., p. 53.

155DAHL, Gustavo. «Algo de novo entre nós », op. cit.

156« Nous avions la caméra de Sérgio Montanha qui était une Cameflex qu'il avait acheté à Fellini, avec un jeu de lentilles Cooke merveilleux. [...] Tous les jours, il fallait démonter, nettoyer, parce qu'il y avait du sable partout. C'est là que j'ai fait cet autre court métrage que fut Arraial do Cabo, en faisant déjà le cameraman, la lumière (nous avions une mallette avec le matériel adéquat, des réflecteurs, etc...). Et dans tous nos déplacements, je transportais la caméra et tout le matériel d'éclairage. » in http://www.abcine.org.br/ABC_html/textos/mario_carneiro/mariocarneiro.htm, consulté le 21 décembre 2004.

157SARACENI, Paulo César. Op. cit., p. 67. Récit du séjour de Saraceni à Salvador, il venait de terminer Arraial do Cabo, rencontre avec Rocha et Nelson Pereira dos Santos avant le tournage de Mandacarú vermelho. 
mystification. Aucun des films alors déjà produits ou en cours de production ne présentera les caractéristiques d'une caméra portée.

L'approche anthropologique, en même temps qu'elle offrait une voie à la construction d'une esthétique nationale, devait logiquement conduire à s'intéresser au cinéma-vérité et aux expériences de Jean Rouch qui vient successivement de réaliser ses deux films les plus connus Moi, un noir (1959) et Chronique d'un été (1960). Il est difficile de dire à quel moment précis ces films ont été connus au Brésil. Ce qui est certain, c'est que Dahl et Paulo César Saraceni rencontrent Jean Rouch au Festival du cinéma latino-américain organisé par le Columbianum à Santa Margherita Ligure en 1961 et ils ne cesseront plus, à partir de ce moment-là, de se référer à son œuvre. À son retour au Brésil, après un an passé à Rome, Saraceni fait un compte-rendu de l'actualité cinématographique internationale dans « Depoimento Saraceni » :

«Câmara na mão, baixo preço de produção para mostrar o verdadeiro rosto e gesto do homem. $\gg^{158}$

Quand nous avons rencontré Saraceni en février 2004, sous le coup de l'émotion provoquée par le récent décès du cinéaste (le 19 février), il nous déclare que le Cinema Novo, c'est Jean Rouch et Rosselini. Dahl, quant à lui, après avoir suivi, en même temps que Saraceni, les cours du Centro Sperimentale di Cinematografia de Rome, est parti à Paris suivre le cours du cinéma ethnographique administré par Jean Rouch au Musée de l'Homme à Paris. La caméra à l'épaule, les dialogues improvisés, la liberté de ton, caractéristique du « cinétranse », s'imposent comme des fantasmes séducteurs dans les esprits des cinemanovistas qui ne pourront les pratiquer et, encore partiellement, qu'à partir de 1963 avec l'arrivée de caméras plus légères et du Nagra. Le doublage va demeurer la règle dans le cinéma de fiction jusqu'à 1968 et quand le son direct va s'imposer ce seront au contraire les caméras qui vont s'immobiliser avec l'arrivée de l'Eastmancolor.

L'influence esthétique du cinéma-vérité va donc se révéler plus tardivement, notamment au travers de l'idée de filmer la fiction comme un reportage présente dans $O$ Desafio et Terra em transe. Associer le Cinema Novo à la caméra portée, en 1961, présentait avant tout un caractère programmatique. Les relations entre cinéma et anthropologie ne devait pourtant pas s'arrêter là. Les leçons d'Aruanda, quant à l'adéquation du langage avec la réalité filmée, s'avéraient quant à elle distinctes mais non moins importantes que celle de Jean Rouch. La première leçon concerne la photographie. Le chef opérateur Walter Carvalho, frère de Vladimir Carvalho qui fut l'assistant de Linduarte Noronha sur Aruanda, déclare :

158« La caméra portée, des coûts réduits de production pour montrer le véritable visage et le véritable geste de l'homme. » in SARACENI, Paulo César. « Depoimento Saraceni » in O Jornal do Brasil, Rio de Janeiro, 12/08/1961. Article accompagnant celui de Rocha : «Arraial, Cinema Novo e câmara na mão », op. cit. 
«A fotografia de Aruanda, feita pelo Rucker, antecipou a fotografia de Vidas Secas, trabalho magistral de Luiz Carlos Barreto. Tenho para mim que Barreto, na época um dos maiores nomes do fotojornalismo brasileiro (integrava o time de craques da revista "O Cruzeiro"), viu Aruanda na famosa sessão do filme no Rio. Ela aconteceu no comecinho dos anos 60. Se o Glauber viu, tenho para mim que a turma que começava a se aglutinar em torno do que viria a ser o Cinema Novo toda deve ter visto. Sendo fotógrafo, o Barreto devia estar muito interessado na movimentação cinematográfica que acontecia naquele momento. Ele deve ter ficado muito tocado por aquele filme que se parecia com suas reportagens fotográficas, imagens colhidas na hora, sem artifícios, sem maquiagem. Não sei se o Barreto confirma esta minha intuição, mas creio que ele descobriu, vendo aquela pequena obra-prima, que ela continha toda a questão da imagem do sertão. $\gg{ }^{159}$

La seconde leçon concerne la structure narrative qui présente des similarités avec le roman nordestin des années trente et, dans ce sens, anticipe encore Vidas secas : «É o ciclo econômico que fornece ao filme sua estrutura. O documentário, portanto, não se limita a mostrar flagrantes de uma vida atrasada, mas pretende apresentar o mecanismo dessa vida. Logo, trata-se de uma fita que está no caminho do realismo. $»^{160}$

L'approche anthropologique deviendra après Arraial do Cabo et Aruanda, un élément récurrent du Cinema Novo et deviendra la caractéristique principale de certains films ou sera présente diluée avec des éléments de fiction dans d'autres films. Elle sera pratiquée de façon explicite dans Couro de gato, Integração racial, Vidas secas, A Opinião pública, Como era gostoso o meu francês, São Bernardo et Uirá, um índio em busca de Deus, autrement dit des films qui visent à mettre en évidence les interactions existant entre un individu ou un groupe d'individus et le milieu naturel et social dans lequel il évolue et comment ces interactions sont rationalisées ou vécues d'un point de vue psychologique et culturel.

Barravento, Deus e o diabo na terra do sol, Os Fuzis, O Dragão da maldade contra o santo guerreiro participent quant à eux de démarches mixtes en intégrant des séquences complètes ou des éléments isolés issus d'une approche anthropologique à un ensemble s'écartant du réalisme et relevant de l'invention de l'auteur, d'une écriture mythologique.

159« La photographie de Aruanda, faite par Rucker, a anticipé celle de Vidas secas, travail magistral de Luiz Carlos Barreto. J'ai pour moi que Barreto, à l'époque l'un des plus grands noms du reportage-photo brésilien (il faisait partie de l'équipe de cracks de la revue $O$ Cruzeiro), a vu Aruanda au cours de la fameuse session du film à Rio. Elle a eu lieu au tout début des années soixante. Si Glauber l'a vu, je pense que toute la bande qui commençait à se rassembler autour de ce qui deviendra le Cinema Novo, a dû y assister. En tant que photographe, Barreto devait s'intéresser aux nouveautés cinématographiques qui arrivaient à ce moment-là. Il a dû être très touché par ce film qui ressemblait à ses reportages photographiques, des images captées sur le moment, sans artifice ni maquillage. Je ne sais pas si Barreto confirmerait mon intuition, mais je crois qu'il a découvert, en voyant ce petit chef d'œuvre, qu'il contenait toute la question de l'image du sertão. » in http://www2.uol.com.br/revistadecinema/edicao28/entrevista/index.shtml, consulté le 11/08/2005.

160 « C'est le cycle économique qui fournit au film sa structure. Le documentaire, en ce sens, ne se limite pas à capter des instantanées d'une vie arriérée, mais il prétend élucider les mécanismes de cette vie. Aussi, s'agit-il d'un film qui est sur le chemin du réalisme. » in BERNARDET, Jean-Claude. Brasil em tempo de cinema. Op. cit., p. 26. 


\section{Chapitre 2 : Révolution et conscientisation}

Entre 1960 et 1961, la réflexion autour du Cinema Novo, bien qu'elle se développe par voie de presse, ne touche guère qu'un microcosme composé de personnes qui, comme le définissait si bien Bernardet dans son article sur les ciné-clubs, n'étaient capables de ne concevoir la vie qu'au travers du cinéma ${ }^{161}$. Les idées se développent sur une base relativement abstraite puisque les films du cinéma brésilien qui sont évoqués ne connaissent qu'une circulation extrêmement restreinte. Seul, des trois films que nous avons commentés, Bahia de todos os santos est lancé commercialement ${ }^{162}$. Arraial do Cabo fait l'objet de quelques articles de presse grâce aux prix qu'il remporte dans des festivals européens mais, malgré cela, aucun exploitant ne l'inclut à sa programmation ${ }^{163}$. Enfin, selon David Neves, Aruanda et les autres documentaires en provenance de la Paraíba, ont connu un énorme succès dans des sessions spéciales et ont été diffusés dans des écoles et des universités ${ }^{164}$. Il est cependant difficile d'évaluer l'ampleur de ce succès selon toute vraisemblance accumulé sur plusieurs années.

En 1962, les débats sur le Cinema Novo gagnent de toutes autres proportions avec les succès aussi massifs qu'imprévisibles remportés par Os Cafajestes (Ruy Guerra), O Pagador de Promessas (Anselmo Duarte) et Assalto ao trem pagador (Roberto Farias). Aucun de ces trois films ne correspond parfaitement au concept critique élaboré autour de cette appellation les deux années précédentes. O Pagador de Promessas et Assalto ao trem pagador en sont même radicalement opposés dans la mesure où le premier est un film de producteur proche de ce que faisait la Vera Cruz et le second affiche comme influence le film policier nordaméricain. Os Cafajestes, quant à lui, est souvent assimilé à une imitation de la Nouvelle Vague française et accusé de pratiquer un esthétisme vain. La confusion est d'autant plus grande que les deux premiers ne sont pas des films «d'auteurs » mais abordent, de façon jusque là inédite, les thèmes du syncrétisme religieux et de la favela alors que le troisième est bien un film «d'auteur» mais dans lequel beaucoup de critiques peinent à reconnaître une quelconque portée politique ou sociale.

Quoiqu'il en soit, dans le premier semestre de l'année 1962, ces trois films montrent que le cinéma brésilien peut se développer économiquement et conquérir son marché interne.

161Cf. BERNARDET, Jean-Claude. « Do Cineclubismo » in O Estado de São Paulo - Suplemento literário, São Paulo, 28/01/1961.

162 À Salvador fin septembre 1960 puis à Rio de Janeiro et à São Paulo en mars 1961

163TINHORÃO, J. Ramos. « Europeus aplaudem e premiam documentário brasileiro que os brasileiros não conhecem » in Jornal do Brasil - Caderno B, Rio de Janeiro, 08/02/1961.

164NEVES, David. Cinema Novo no Brasil. Petrópolis, coll. Nosso Tempo, ed. Vozes, 1966, p. 28. 
L'impact de la victoire à Cannes de O Pagador de promessas est sans commune mesure, beaucoup l'assimilent à une victoire en Coupe du Monde de football. Elle est aussi la preuve, comme l'ont été les succès de l'équipe nationale de football mais aussi ceux de la bossa-nova et le retentissement de la construction de Brasília, que le Brésil peut gagner sa place dans le concert des nations qui se trouvent à la pointe de la civilisation et assumer le destin grandiose que l'on suppose être le sien. Dans le climat d'exaltation nationaliste et de foi dans le développement du pays qui perdure après l'ère $\mathrm{JK}$, la presse s'empare du cinéma qui, mieux que tout autre discipline artistique, s'identifie au progrès et à la modernité. Le Cinema Novo est un terme qui sonne bien et exprime parfaitement l'idée non pas de rénovation mais de l'avènement d'un pays nouveau. Les discussions sur le septième art dépassent le cercle des critiques spécialisés et tout long métrage réalisé par un jeune metteur en scène devient « Cinema Novo ».

Os Cafajestes, O Pagador de Promessas et Assalto ao trem pagador, parce qu'ils représentent alors la réalité du cinéma brésilien, semblent annuler de façon temporaire le concept critique qui avait été élaboré autour du Cinema Novo. Rocha, lui-même, peut être pour des raisons de stratégie, plébiscite non seulement $O$ Pagador de promessas mais aussi deux films de Nelson Pereira dos Santos, Mandacarú vermelho et Boca de ouro, qui, proches du cinéma classique, sont encore loin de remplir les exigences précédemment établies autour de Bahia de todos os santos, Arraial do Cabo et Aruanda. Il ne faut cependant pas oublier qu'à cette époque, rien de significatif n'a encore été obtenu et le destin du Cinema Novo paraît bien incertain. Si le concept critique qui avait été élaboré pouvait représenter un idéal, l'important était d'exister ou de réunir les conditions qui permettraient un jour d'accéder à une production cinématographique pérenne et de qualité internationale.

Parallèlement, l'histoire du Brésil semble s'accélérer. Le président Jânio Quadros qui a succédé à Juscelino Kubitschek en 1961, renonce après huit mois d'exercice dans le cadre d'une manœuvre politique malheureuse au terme de laquelle il s'imaginait reprendre son poste avec des pouvoirs renforcés. Il voulait ainsi faire face de façon autoritaire à une situation caractérisée par une inflation galopante et l'augmentation des tensions sociales. Sa succession provoque une grave crise politique au travers de l'ensemble du pays. Les ministres militaires opposent leur veto à la prise de pouvoir pourtant prévue par la Constitution du vice-président. Leur attitude s'explique par l'antagonisme idéologique qui les oppose au futur président, lequel n'est autre que João Goulart, l'héritier politique de Getúlio Vargas. Les conditions semblent réunies pour un coup d'État qui serait appuyé par la même coalition de forces qui provoqua, en 1954, la chute de l'ancien dictateur mais la mobilisation obtenue par la Rede da legalidade organisée par le gouverneur du Rio Grande do Sul, Leonel Brizola, décourage 
l'Armée qui se divise entre putschistes et légalistes. L'accès au pouvoir de João Goulart, dit aussi Jango, n'est cependant concédé qu'au prix de l'établissement d'un régime parlementaire synonyme d'une importante diminution des pouvoirs du président.

Bien que relative, cette victoire sur les forces de droite configure un panorama politique inédit et ravive les antagonismes qui avaient marqué la fin de l'ère Vargas. Pour des raisons que l'histoire explique mal ${ }^{165}$, l'ancien dictateur qui avait en son temps établit avec l'Estado Novo (1937 - 1945) un régime proto-fasciste ouvertement inspiré des modèles italiens et allemands, s'était transformé au moment de son retour au pouvoir (1950-54) en défenseur de la cause populaire. Dans les années soixante, il était encore l'objet d'une véritable adoration cristallisée autour du mythe du « petit père des pauvres ».

Partisan de la conciliation sociale et instigateur d'une politique nationaliste contrariant les intérêts des multinationales installées au Brésil, son dernier gouvernement devait se caractériser par ce que l'on appellera alors le populisme. Aussi contradictoire que cela puisse paraître, Vargas fut pourtant le seul président de l'histoire du Brésil à avoir articulé certaines de ses actions politiques les plus décisives à des mouvements de mobilisation sociale. Tel fut le cas de la création de la Petrobrás, entreprise d'état destiné à l'exploitation du pétrole et haut symbole du nationalisme. La lettre testament diffusée après son suicide, en 1954, devait révéler au grand public la nature des conflits qui avaient eu raison de ses capacités de résistance et orienter le débat politique pour les décennies à venir autour du paradigme nationalisme / impérialisme.

Ancien ministre du travail de Vargas, au moment où il accède au pouvoir, João Goulart est identifié aux aspects les plus progressistes de son dernier gouvernement. Il ne va pas tarder à confirmer les expectatives en affirmant vouloir appliquer une politique nationaliste passant notamment par l'application des réformes de base dont la réforme agraire. Entre 1954 et 1961-62, la situation a cependant beaucoup évoluée et les antagonismes qui ont provoqué la chute de Vargas, se sont encore approfondis. D'un point de vue strictement politique, pour pouvoir mettre en œuvre ses projets, Jango doit à la fois reconquérir le pouvoir dont sa fonction a été amputée et rassembler les forces qui lui permettront de faire face à des adversaires politiques qui sont puissants et nombreux. Mais pour toute une fraction de la société, la présence de Jango signifie que les conditions sont réunies pour effectuer la « Révolution brésilienne » récemment théorisée par l'ISEB.

L'idéologie de l'instituto Superior de Estudos Brasileiros - ISEB - imprègne alors l'ensemble de la pensée de la gauche brésilienne et joue un rôle décisif. Au travers du pays, la rapides et simplistes. 
mobilisation est intense dans les syndicats ouvriers et paysans et dans divers mouvements qui visent à sensibiliser la population aux enjeux de la situation. La réflexion sur le Cinema Novo ne peut échapper à ce climat de radicalisation politique. Quelle participation, concrète, immédiate, le cinéma peut-il avoir dans le processus historique alors en cours ? Entre 1960 et 1961, la discussion qui fut à l'origine du Cinema Novo, malgré son relatif intimisme, ne s'était pas développée en vase-clos. Les textes du Sales Gomes et Rocha démontraient que l'idéologie nationaliste de l'ISEB se manifestait également dans le secteur cinématographique. Mais la problématique principale était celle de la création d'un cinéma " authentiquement» national et populaire.

À partir de 1962, de nouveaux acteurs, imprégnés de la même idéologie, interviennent dans la réflexion sur le Cinema Novo et l'extraient du domaine strictement cinématographique auquel elle s'était jusque là cantonnée. Le Cinema Novo doit être révolutionnaire, il doit provoquer et soutenir le processus d'émancipation dans lequel le pays est engagé. Une controverse a lieu entre les partisans d'un cinéma de propagande, le Centro Popular de Cultura - CPC réuni derrière son principal théoricien, Carlos Estevam Martins, et les partisans d'un cinéma artistique, le groupe du Cinema Novo uni derrière Rocha. Finalement, dans A Revisão crítica do cinema brasileiro (1963), celui-ci expose et applique le concept critique tel qu'il était déjà établi deux ans plus tôt. Le concept critique initial du Cinema Novo se trouve donc réaffirmé, toujours à titre programmatique puisque les films produits sont encore peu nombreux, mais avec une visée plus large. Il ne s'agit plus à présent d'opérer seulement une révolution dans le cinéma mais de créer un cinéma de conscientisation qui participe au processus révolutionnaire et l'accélère. Le Cinema Novo se conçoit comme la manifestation d'une culture " désaliénée », c'est à dire débarrassée des complexes d'infériorité coloniaux, mais aussi capable de désaliéner, c'est à dire de réveiller les consciences aux véritables problèmes du pays. L'intellectuel-cinéaste reçoit pour mission de révéler le réel au peuple afin que celui-ci fasse la révolution.

\subsection{L'idéologie de l'ISEB : identification des contradictions économiques, sociales et culturelles du Brésil, complexe colonial et aliénation, rôle des élites intellectuelles}

Les publications de l'ISEB ainsi que les cours que l'institut administre à Rio de Janeiro lui permettent de marquer considérablement la pensée brésilienne de gauche dans la fin des années cinquante et au début des années soixante. Telle n'était pourtant pas son projet original. Créé par un décret du Ministério da Educação e da Cultura - MEC sous la présidence 
de Café Filho (1954-55), l'ISEB emprunta ses cadres à l'Instituto Brasileiro de Economia, Sociologia e Política - IBESP qui était lui même issu du "grupo Itatiaia » lequel réunissait déjà des intellectuels provenant de diverses disciplines dans le but de discuter les problèmes de la nation ${ }^{166}$. Promu au rang d'organe technique du gouvernement, la vocation première de l'ISEB était de produire une idéologie du desenvolvimentismo et d'appuyer la politique inaugurée par Café Filho et Juscelino Kubitschek. Selon cette idéologie, seule l'industrialisation accélérée, soutenue par des investissements étrangers massifs, pouvait permettre de rattraper le ' retard ' du pays.

Cependant, en 1958, une crise agite la direction. Les investigations menées au sein de l'institut amènent certains de ses membres à revoir leurs positions ${ }^{167}$. Le recours aux capitaux étrangers apparaît à présent comme un facteur de dépendance de l'économie et de la politique brésilienne vis à vis des puissances étrangères. L'ISEB obtient la liberté d'expression pour ses professeurs en 1959 et se désolidarise de l'idéologie du gouvernement. C'est à partir de ce moment-là qu'il prend la configuration avec laquelle il va rester dans l'histoire et devient la matrice d'un certain type de pensée qui va dominer toutes les discussions sur la culture brésilienne pendant près de vingt ans. Les concepts de « culture aliénée », de « colonialisme » ou encore « d'authenticité culturelle» sont des productions de l'ISEB ${ }^{168}$.

Ces concepts se diffusent rapidement dans les milieux de la gauche marxiste et de la gauche chrétienne. La conception de la culture comme élément de transformation sociale que l'ISEB apporte, introduit une rupture dans les modes de pensée de ces tendances politiques et provoque une reformulation de leur activisme social, en particulier dans les domaines des arts et de l'éducation. Suivant les analyses de l'ISEB, les militants de gauche pensent que le peuple est aliéné, qu'il possède une culture inauthentique qui empêche la prise de conscience et la révolte qui mettront fin aux injustices dont il est victime. Ils pensent également que le réveil de la conscience des masses peut être permis par une action culturelle et qu'une fois cette prise de conscience accomplie, le peuple les rejoindra pour construire une société plus juste.

En lisant cette description, il ne faudrait cependant pas penser que l'idéologie de l'ISEB est homogène et qu'il s'agit d'un centre d'endoctrinement. Après 1959, il s'agit toujours d'un centre de recherche et de formation qui s'articule autour de cinq disciplines : la philosophie, l'histoire, la politique, la sociologie et l'économie. Ses principaux penseurs sont Candido Mendes de Almeida, Roland Corbisier, Hélio Jaguaribe, Álvaro Vieira Pinto,

166JURANDIR, Carlos. « Corbisier, filósofo da geração que pensou o Brasil », article publié sur internet à la page http://www.abi.org.br/primeirapagina.asp?id=948, consulté le 12/08/2005.

167PEREIRA, Osny Duarte. «O ISEB : O Desenvolvimento e as reformas de base » in Revista Brasiliense, São Paulo, n47, mai-juin 1963.

168Cf. ORTIZ, Renato. Cultura brasileira \& identidade nacional. São Paulo, ed. Brasiliense, 1985, p. 46. 
Guerreiro Ramos et Nelson Werneck Sodré. Autour d'une position de consensus centrée autour du rejet du latifundium et du recours au capital étranger, les pensées de ces personnalités évoluent et vont même parfois jusqu'à adopter des différences de perspectives significatives. Nous étudierons ici la pensée de trois auteurs dont les idées ont influencé très fortement les cinemanovistas : Roland Corbisier, Álvaro Vieira Pinto et Nelson Werneck Sodré.

\section{Roland Corbisier, rôle des élites et aliénation culturelle}

Des trois penseurs sur lesquels nous allons nous attarder, Roland Corbisier (19142005) est celui dont la pensée a le plus évolué entre 1947 et 1964. Thomiste et integralista à vingt ans, marxiste et communiste à soixante ans ${ }^{169}$, il est, au moment où il assume la direction de l'ISEB (1955-60), sur le point de bascule entre ces deux moments de l'évolution de sa pensée. Philosophe intégré au microcosme intellectuel de Rio de Janeiro, les membres du Cinema Novo ont l'occasion de le côtoyer. Paulo César Saraceni se souvient, dans son autobiographie, des discours enflammés que le philosophe prononçait entre 1963 et 64, alors qu'il était député du Partido Trabalhista Brasileiro - PTB, le parti de Jango et Leonel Brizola. Il se souvient également des appels à la révolution socialiste qu'il lança le jour même du coup d'État dans l'immeuble de la $\mathrm{CGT}^{170}$ où s'étaient rassemblés une partie de la gauche de l'époque $^{171}$. Corbisier fut également le professeur de philosophie de Nelson Pereira dos Santos $^{172}$. Rocha, tout au long de sa carrière, manifestera dans ses écrits des similitudes troublantes avec les idées du philosophe. Les apports les plus importants de Corbisier sont relatifs à ses idées sur le rôle des élites et sur la culture brésilienne.

De façon très symbolique, le premier livre que Corbisier publie au moment où l'ISEB est fondé, s'intitule Responsabilidade das elites ${ }^{173}$. Il s'agit d'une compilation de textes écrits entre 1948 et 1955 dans lesquels les traces du fascisme et du positivisme sont visibles. Articulant ses réflexions à une analyse de la situation politique nationale et internationale, le philosophe critique la démocratie qui, selon lui, assure soit la promotion des plus médiocres, soit la promotion des démagogues et des subversifs qui obtiennent le pouvoir en manipulant les masses qu'il se représente ignorantes et frustes. À partir de cette position, il idéalise une aristocratie élective caractérisée par le rejet de la participation populaire et où le privilège de

169MONTEIRO, Geraldo Tadeu Moreira. « Corbisier, o homem-filósofo ». Article publié sur internet, http://www2.uerj.br/ clipping/0001805_v.htm, consulté le 12/08/2005.

170Central Geral dos Trabalhadores.

171SARACENI, Paulo César. Op. cit., pp. 164 et 170.

172Ruy Guerra nous a aussi appris que le fils de Roland Corbisier fut son assistant et qu'à ce titre il a fréquenté la maison du philosophe engagé. Cependant, il rejette toute influence directe de sa part.

173CORBISIER, Roland. Responsabilidades das elites. Rio de Janeiro, Livraria Martias Edição, 1955. 
diriger ne serait pas conféré par la naissance ou l'argent mais par l'intelligence. La défiance envers les masses populaires et leur capacité à comprendre et défendre leurs propres intérêts sera une constante du Cinema Novo. De même, la position moraliste du philosophe et ses implications. La misère est condamnée d'un point de vue moral qui doit pour les uns à l'humanisme cartésien et pour d'autres, comme ici Corbisier, à l'humanisme catholique. Les responsables désignés de cette situation sont les élites bourgeoises jugées corrompues, égoïstes et irresponsables. Pour le philosophe, comme plus tard pour le Cinema Novo : « A culpa das elites é sempre a maior culpa. $\gg{ }^{174}$

Pour Roland Corbisier, l'ascétisme des élites authentiques est la seule réponse possible à la corruption des élites politiques et financières. Les élites intellectuelles doivent assumer un rôle de premier plan dans la prise de décision sur les destins de la nation et ce, dans une totale indépendance :

« Aceitamos a responsabilidade dos intelectuais e a necessidade de sua participação ativa na vida da nação. Não aceitamos, porém, o imperativo totalitário da 'politização' obrigatória, incompatível com a liberdade necessária à vida do espírito. [...] Seria fazer inconscientemente o jogo do marxismo, acusar de marginalismo ou de traição aqueles que, permanecendo fiéis a si mesmos, se recusam a qualquer participação direta na luta política. Há muitas maneiras de viver o presente, de sentir a História e de prestar serviços à nação. [...] Que cada um procure ser integralmente o que é, que cada um se realize plenamente na sua esfera e no seu campo, que cada um permaneça fiel à sua vocação. [...] Cederíamos ainda ao marxismo, e não seríamos cristãos, se quiséssemos sacrificar o pessoal ao social e ao histórico. $\gg{ }^{175}$

Cette idée selon laquelle l'intellectuel, pour maintenir sa position critique, doit demeurer extérieur aux conflits politiques est une idée que nous retrouverons aussi dans le Cinema Novo tout comme la représentation que Corbisier se fait de sa mission :

« A função animadora e vivificante, o esforço no sentido de esclarecer, de definir, de decifrar e resolver os problemas, o esforço tendente a configurar e criar o que ainda não existe e precisa existir, o trabalho, o ingente trabalho de estruturação nacional, esse não poderá ser feito de baixo para cima, como as hervas que nascem espontaneamente do chão. Esse trabalho é o destino e a missão das elites brasileiras. $\gg{ }^{176}$

$174 \ll$ La faute des élites est toujours la faute la plus grande. » in ibid., p. 42.

175 « Nous acceptons la responsabilité des intellectuels et la nécessité de leur participation active dans la vie de la nation. Nous n'acceptons pas, cependant, l'impératif totalitaire de la ' politisation ' obligatoire, incompatible avec la liberté nécessaire à la vie de l'esprit. [...] Ce serait faire inconsciemment le jeu du marxisme, accuser de marginalisme ou de trahison ceux qui, en restant fidèles à eux-mêmes, se sont refusés à toute participation directe à la lutte politique. Il y a plusieurs manières de vivre le présent, de sentir l'Histoire et de rendre service à la nation. [...] Que chacun cherche à être intégralement ce qu'il est, qu'il se réalise pleinement dans son domaine, que chacun soit fidèle à sa vocation. [...] Nous céderions encore au marxisme, et nous ne serions pas chrétiens, si nous voulions sacrifier l'intime au social et à l'historique. » in ibid., p. 27.

176« La fonction motivante et vivifiante, l'effort dans le sens d'éclairer, de définir, de déchiffrer et résoudre les problèmes, l'effort tendant à configurer et crier ce qui n'existe pas encore et doit exister, le travail, le travail prenant de la structuration nationale, ne pourra être fait de la base vers le sommet, comme l'herbe qui pousse instantanément du sol. Ce travail est le destin et la mission des élites brésiliennes. » in ibid., p. 43. 
Dans l'organisation sociale idéale imaginée par le philosophe, l'exclusion du système démocratique n'est en rien incompatible avec le respect des libertés individuelles et la réalisation de l'homme et de la civilisation, bien au contraire. L'accomplissement des potentialités humaines doit se traduire, sur un plan individuel, par le choix d'une fonction qui corresponde aux goûts et aptitudes de l'individu, et, sur un plan collectif, par l'édification d'une civilisation. La civilisation ne peut être le résultat de compromis médiocres entre les différentes strates ou fractions de la société, elle doit être l'expression de ce que, dans tous les domaines qui le définissent, l'homme est capable de faire de meilleur, de plus grand, de plus beau, de plus puissant, etc. La civilisation doit être l'expression maximale du génie humain.

À partir de cette conception de l'homme, de la civilisation et de l'histoire, se pose assez naturellement le problème du Brésil et, en particulier, celui de la culture brésilienne. Pour Corbisier, le problème de la culture brésilienne est avant tout celui de ses élites intellectuelles. En s'appuyant sur son expérience personnelle, il se souvient de la frustration que signifiait pour un intellectuel vivre au Brésil avant la prise de conscience de son rôle et de sa responsabilité envers le pays :

« Era a contra gosto e mal à vontade que habitávamos o Brasil, cuja pobreza e ignorância nos pareciam insuportáveis. Como viver em um país de analfabetos, em que ninguém lia, em que ninguém se interessava pelas ' coisas do espírito ', as únicas que nos interessavam a nós ? Como viver em um país quase primitivo, cuja população se consumia na luta pela sobrevivência ? [...] Como suportar o desterro, o exílio do velho mundo, e como tolerar o convívio de um povo primário e tosco, inconsciente e inculto ? ${ }^{177}$

Prenant pour point de départ l'analyse de ce sentiment de frustration de l'intellectuel vis à vis des limitations d'un pays sous-développé, Corbisier décrit ce qui lui semble être un état d'aliénation. Parce qu'il possède une culture formelle en tout point identique à celle de l'homme de la métropole, l'intellectuel du Brésil partage avec lui les mêmes préjugés et le même pessimisme quant aux capacités de développement de son propre pays. L'intellectuel dont la mission est d'éclairer les pas de la nation est ignorant de son propre pays, incapable donc du moindre diagnostic sur les difficultés qu'il rencontre :

« [...] a cultura dos países liderados faz, involuntariamente, o jogo de seus competidores, aplica à própria realidade uma tábua de valores que não lhe convém, e entra na crise da objetividade, que tanto nos desespera quando temos de obter de nossos intelectuais ou dos nossos homens públicos um

177 «C'était à contre-cœur et de mauvaise volonté que nous habitions au Brésil, dont l'ignorance et la pauvreté nous paraissaient insupportables. Comment vivre dans un pays d'analphabètes, dans lequel personne ne lisait, dans lequel personne ne s'intéressait aux ' choses de l'esprit ', les seules qui nous intéressaient à nous ? Comment vivre dans un pays quasi primitif, dans lequel la population s'épuisait dans la lutte pour sa survie ? [...] Comment supporter l'éloignement, l'exil du vieux monde, et comment tolérer la compagnie d'un peuple primaire et fruste, inconscient et inculte?» in ibid., p. 13. 
pronunciamento sobre um problema. $»^{178}$

Corbisier met donc alors en évidence le fait que le Brésil, bien qu'il ait conquis son indépendance politique depuis longtemps n'en a pas pour autant conquis son indépendance économique et culturelle. Cette dernière idée va non seulement marquer les débats sur la culture brésilienne pour les années à venir mais aussi profondément imprégner le discours et les options adoptées par le Cinema Novo. Dans un texte intitulé « Significação e alternativas da cultura brasileira » (1955), il cite comme référence Georges Balandier dont le principal apport fut d'associer le concept d'aliénation à la domination coloniale ${ }^{179}$. Malgré son indépendance politique, le Brésil est une colonie et, comme dans toute colonie, la société brésilienne est économiquement et culturellement aliénée ${ }^{180}$. La culture brésilienne est une culture «transplantée », autrement dit importée. Elle favorise les pays qui exploitent économiquement le Brésil et leur permet de maintenir leur domination car elle fut construite pour expliquer et justifier la supériorité du colon sur le l'homme colonisé. Et Corbisier développe ici toutes les analogies entre la situation coloniale et la dialectique du maitre et de l'esclave qui seront reprises plus tard par Rocha dans A Estética da fome même si elles seront passées entre-temps par le prisme des écrits de Frantz Fanon qui traite de la colonisation française en Algérie.

Mais la culture coloniale ne favorise pas seulement l'oppresseur, elle est également « inauthentique ». C'est à dire que dans la mesure où l'on considère que la culture se développe dans une relation dialectique avec les transformations économiques par lesquelles passent une société donnée, celle-ci est le résultat d'un processus historique particulier en constante transformation. Pour promouvoir le développement du Brésil, il est donc impossible de se satisfaire de la culture des pays dominants car celle-ci n'est pas adaptée à un pays qui ne partage ni leur histoire, ni leurs paysages, ni les ressources physiques. La prise de conscience par lui-même d'un pays dominé non seulement indique mais aussi implique la rupture du complexe colonial. L'avènement de la conscience critique, la conscience qui se substitue à la conscience aliénée, va permettre la découverte de ce qui constitue la réalité nationale et, par voie de conséquence, la construction d'une idéologie capable de forger son destin.

178 « [...] la culture des pays dominés fait, involontairement, le jeu de ses concurrents, applique à leurs propres réalités, une échelle de valeurs qui ne leur convient pas, et entre dans la crise de l'objectivité, qui nous désespère tant quand nous devons obtenir de nos intellectuels ou de nos hommes publiques un avis sur un problème. » in CORBISIER, Roland. Formação e problema da cultura brasileira. Deuxième édition, Rio de Janeiro, coll. Textos brasileiros de filosofia, Ministério da Educação e da Cultura, Instituto Superior de Estudos Brasileiros, 1960 [1956], p. 40.

179BALANDIER, Georges. «Contribution à une sociologie de la dépendance » in Cahiers Internationaux de Sociologie, n'XII, 1952.

180L'erreur de ce raisonnement, à notre avis, est de considérer que la culture est une « totalité », en particulier au Brésil, mais nous y reviendrons. 
Corbisier voit dans les thèses de Balandier une totale adéquation avec sa propre conception du rôle de l'élite intellectuelle. La description que ce dernier donne des résultats et des symptômes du processus de prise de conscience attribuerait en effet son déclenchement à l'intelligentsia : d'abord, surgit une intelligentsia sensible aux problèmes du pays et capable de se convertir en organe de conscience nationale, en conséquence de l'avènement de la «conscience nationale» surgit la «conscience nationale populaire », autrement dit la connaissance des problèmes de base du pays, surgit ensuite un mouvement ouvrier encadré par des idéologies travaillistes et nationalistes, et le processus se conclut par l'organisation d'un mouvement de libération nationale. Pour Corbisier, il ne devrait pas en aller autrement pour le Brésil.

En rupture avec les conceptions nationalistes ayant marquée l'Estado Novo, il ne s'agit plus de rechercher dans le passé les éléments de l'identité nationale tel qu'ils y seraient gravés de façon intemporelle. Il s'agit ici de construire, d'inventer une nation pour le futur, il s'agit de créer une culture nouvelle et originale à partir de ce que le Brésil est au présent. Le Cinema Novo va se situer dans cette perspective notamment avec le slogan : « Câmara na mão, tratase de construir » (Caméra à la main, il s'agit de construir).

Álvaro Vieira Pinto a repris de nombreux éléments de l'analyse de Roland Corbisier pour développer les concepts de conscience ingénue et conscience critique puis pour établir les grands axes qui devrait guider une politique authentiquement nationaliste.

\section{Álvaro Vieira Pinto, de la conscience critique à une politique nationaliste}

Comme nous allons le voir, bien qu' Álvaro Vieira Pinto (1909-1987) reprenne et développe les concepts de Corbisier à partir de l'assimilation du Brésil à une société coloniale, il diverge sur des points très importants et en particulier sur sa conception des masses populaires ${ }^{181}$. Philosophe également, Vieira Pinto accorde une place prédominante à la philosophie dans la constitution de ce qu'il nomme la « conscience critique ». Celle-ci serait l'outil indispensable à la découverte et à l'analyse du pays et pourrait fournir les prémisses de son émancipation. D'un point de vue politique, la position de Vieira Pinto est profondément réformiste. Aucune rupture violente n'est envisagée avec le régime en place, ni même avec le passé en général. Rien de plus éloigné des projections de l'ISEB que l'image d'Épinal du « grand soir ». L'action des individus de bonne volonté, engagés dans un processus de prise de

$181 \mathrm{Il}$ faut cependant noter que les écrits de Álvaro Vieira Pinto sont postérieurs à ceux du directeur de l'ISEB et ce dernier avait, peut être, déjà, à ce moment-là, modifié son point de vue. Quoiqu'il en soit, il est intéressant de noter ce décalage. Dans la mesure où il n'est pas possible de concevoir une transposition rigoureuse et mécanique des idées de l'ISEB dans la sphère sociale, ce décalage peut nous éclairer efficacement quant aux inévitables distorsions survenues dans la diffusion de ses idées. 
conscience des problèmes réels de leur pays, doit être coordonnée par les pouvoirs publics. Eux-mêmes seraient peu à peu contrôlés par des représentants de la conscience critique élus par l'intermédiaire du vote populaire : «[...] não pode haver solução política para os problemas brasileiros fora do voto do povo $\|^{182}$. Vieira Pinto étaye sa démonstration autour de quatre thèses centrales :

- «Sem ideologia do desenvolvimento não há desenvolvimento nacional. »

- «A ideologia do desenvolvimento tem necessariamente de ser fenômeno de massa. »

- «O processo de desenvolvimento é função da consciência das massas »

- «A ideologia do desenvolvimento tem de proceder da consciência das massas. ${ }^{183}$

Nous reconnaissons ici, reformulés, les postulats de Balandier. La grande différence avec Corbisier, c'est que l'emphase a glissé sur la «masse ». Contrairement à ce dernier, Vieira Pinto estime que l'idéologie du développement doit être conçue à partir de la conscience populaire, quelque soit son degré d'aliénation actuel, et qu'elle ne peut être imposée dans une relation verticale, de l'élite à la masse. Selon lui, la condition sine qua non pour que surgisse l'idéologie du développement, «é a existência de quadros intelectuais capazes de pensar o projeto de desenvolvimento sem fazê-lo à distância, mas consubstancialmente com as massas. ${ }^{184}$ Vieira Pinto se rapproche du concept d'intellectuel organique développé par Antonio Gramsci et s'écarte de l'aristocratie élective de Corbisier. La masse n'est plus considérée comme une horde barbare menaçant par sa médiocrité les piliers de la civilisation et de l'intelligence humaine, elle est le levier de la Révolution. Selon des conceptions empruntées au marxisme, Vieira Pinto considère que la masse est la force de travail et, si elle est aujourd'hui aliénée aux intérêts coloniaux, elle n'en demeure pas moins la puissance transformatrice du réel. C'est le travail de la masse qui fait du monde ce qu'il est concrètement, qui agit directement sur la matière et la transforme, c'est donc aussi la masse qui jettera bas les anciennes structures qui sont contraires à ses intérêts.

Ces conceptions s'inscrivent en rupture totale avec celles de Corbisier quand elles étaient encore marquée par le fascisme et le positivisme et seront aussi très diversement assimilées. L'idée selon laquelle les masses seraient capables de se libérer d'elles-mêmes ne sera pas acceptée ou comprise par de larges secteurs de la gauche. Ceux-ci considéreront que

182 « [...] il ne peut y avoir de solution politique aux problèmes du Brésil en dehors du vote du peuple » in PINTO, Álvaro Vieira. Consciência e realidade nacional - 2e vol : a consciência crítica. Terceira edição. Rio de Janeiro, coll. Textos brasileiros de filosofia, Ministério da Educação e da Cultura, Instituto Superior de Estudos Brasileiros, 1963, p. 41.

183« - Sans idéologie du développement, il n'y a pas de développement national.

- $\quad$ L'idéologie du développement doit nécessairement être un phénomène de masse.

- $\quad$ Le processus de développement est fonction de la conscience des masses.

L'idéologie du développement doit procéder de la conscience des masses. » in ibid., p. 31. 184Ibid., p. 35. 
l'intervention de l'intellectuel de classe moyenne est indispensable et que lui seul peut éclairer les masses rendues abruties par l'oppression. Nous verrons que le Cinema Novo et le CPC, bien que divergeant sur la définition d'un cinéma révolutionnaire, se verront cantonnés dans cette même position élitiste. Bien que le rôle des masses aient été diversement compris dans l'avènement de la conscience critique, la nécessité de cette conscience et ces différentes modalités seront unanimement reconnues. Le Cinema Novo, quant à lui, va se concevoir comme l'expression cinématographique de la conscience critique du Brésil.

Selon Vieira Pinto, la conscience critique doit obéir aux catégories de l'objectivité, de l'historicité, de la raison, de la totalité, de l'activité, de la liberté, et de la nationalité. L'objectivité consiste à partir toujours du réel et non à projeter sur lui des concepts lui préexistant. C'est ainsi notamment que Vieira Pinto accorde aux manifestations populaires une valeur avant-gardiste : «As condutas reclamadoras, reivindicadoras, as agitações e inquietudes populares são indícios da percepção crítica iletrada. ${ }^{185}$

La catégorie de l'historicité permet de voir l'histoire comme un processus dialectique, il ne s'agit pas de s'approprier les vieilles idées positivistes et d'adopter une théorie déductive de l'histoire mais de concevoir que le présent contient en lui, à l'état virtuel, les états futurs : « Nosso modo de pensar [...] procura manter viva a idéia da originalidade do acontecer, do imprevisível e do insuspeitado, sempre possíveis, sem, contudo, é claro, cair no erro oposto, a presunção da contingência radical. $»^{186} \mathrm{La}$ conscience critique doit mettre à jour les contradictions du présent afin de concevoir une idéologie qui permettra d'exploiter ces contradictions pour transformer le réel.

La catégorie de la totalité conduit à considérer que la nation, à ce stade du processus historique mondial, est la totalité à partir de laquelle la pensée et l'action doivent se développer. L'idéologie du développement est un humanisme et cet humanisme est lui-même un nationalisme. Dans la mesure où l'objectif est la libération de l'homme et qu'à ce stade de l'histoire, la nation est la totalité au travers de laquelle l'individu « est» au monde, dans la mesure où la nation est victime de l'impérialisme selon un schéma analogue à celui de la dialectique du maître et de l'esclave, le stade à atteindre du développement national n'est pas l'accès au statut de puissance impérialiste mais l'accès à un stade encore supérieur, dont les caractéristiques sont inconnues mais qui devrait s'approcher d'une société chaque fois plus juste, plus équitable et capable de favoriser l'expression de ce qui fait l'homme en l'homme et

$185 \ll$ Les réclamations, les revendications, le climat d'agitation et d'incertitude populaires sont les indices de la perception critique illettrée. » in Ibid., p. 17.

186« Notre façon de penser [...] cherche à maintenir vivante l'idée de l'originalité de ce qui est à venir, de l'imprévisible, de l'insoupçonné, toujours possible, sans, toutefois, tomber dans l'erreur opposée, la présomption de la contingence radicale. » in ibid., p. 35. 
dans tous les hommes ${ }^{187}$. «Não terá verdade lógica nem mérito moral qualquer teoria que propugne pelo desenvolvimento do país sem ao mesmo tempo assegurar às massas, que o devem executar, o término de toda justiça e exploração. ${ }^{188}$ Les divergences d'intérêt entre les intérêts nationaux et impérialistes sont le moteur de la révolution.

La catégorie de l'activité signifie que la conscience critique doit s'inscrire dans une praxis. Il faudrait être en effet constamment attentif aux transformations sociales et économiques qui marquent des étapes déterminantes dans le combat qui se livre les forces qui sont favorables au développement et celle qui y sont opposés. L'opposition que conçoit alors le philosophe recoupe les catégories de l'ancien et du nouveau. Il s'agit là d'une terminologie qui sera largement reprise par la gauche et notamment par le Cinema Novo pendant les années soixante. Dans une réalité en constante transformation, les valeurs qui autrefois pouvaient représenter un progrès peuvent, à un autre stade de développement, représenter une entrave à la poursuite du progrès. Le vieux, c'est donc les structures économiques, sociales et mentales aliénés, la conscience ingénue, le nouveau, c'est le contraire, c'est tout ce qui assume une dimension progressiste.

La catégorie de l'activité conduit ainsi à considérer que la participation, l'engagement, de l'intellectuel sont nécessaires. Selon Corbisier, il était possible de participer en assumant sa vocation et, pour l'intellectuel, en se maintenant à l'écart des partis. Comme l'histoire l'a montré, il a changé d'avis. Vieira Pinto, quant à lui, dénonçait cette posture. Elle sera pourtant assumée par les membres du Cinema Novo. Au début des années soixante, le terme «participation » est devenu le mot d'ordre général mais il est très diversement interprété. Certains l'interpréteront comme la nécessité d'un engagement politique direct et l'assimileront à du militantisme, d'autres, comme les cinemanovistas l'interpréteront comme un investissement critique dans leur domaine d'activité particulier.

L'un des aspects les plus remarquables de la pensée de Vieira Pinto est que la nation y apparaît comme le prédicat maximal. C'est elle qui permet de délimiter les camps des opposants et les stratégies à adopter avec précision. Comme Corbisier, Vieira Pinto estime que la contradiction principale vécue par le pays est le complexe colonial et que le schéma de la lutte des classes n'est pas encore adapté à l'interprétation de la réalité nationale. À partir de cette position, les deux philosophes conçoivent que l'antagonisme des intérêts nationalistes et

187L'influence du structuralisme est ici évidente. Le développement par palier, par sauts qualitatifs globaux, répond à des règles d'économie et d'efficacité. Le stade supérieur au féodalisme et le capitalisme et le stade supérieur au capitalisme et un socialisme dont les modalités exactes restent encore à déterminer mais en tout état de cause la transformation ne sera possible que si le stade suivant correspond mieux aux attentes et aux besoins humains. Le développement est donc une question de temps...

188 « Ne possédera aucun fondement logique ou moral toute théorie qui proposera de développer le pays sans, en même temps, promettre aux masses, qui doivent exécuter cette théorie, la fin de l'injustice et de l'exploitation. » in PINTO, Álvaro Vieira. Op. cit., p. 204. 
impérialistes va permettre de diviser la société en deux camps. Dans le camp du développement, du «nouveau », apparaissent unies la bourgeoisie industrielle nationale qui cherche à substituer ses produits aux importations, et les classes ouvrières et paysannes qui recherchent de meilleures conditions de travail et l'élargissement du marché de consommation interne. Dans le camp impérialiste, apparaissent la bourgeoisie dont la fortune est basée sur sa qualité d'intermédiaire des intérêts étrangers et le latifundium qui marque la permanence du Brésil colonial. Une politique nationaliste authentique doit se décliner sur les treize axes suivant :

- incorporation du travail national au profit du paysan ;

- participation des masses aux institutions de décision politique ;

- plein-emploi des ressources nationales ;

- répression du capital étranger ;

- politique de développement tournée vers l'amélioration des conditions de vie des masses populaires ;

- monopole d'État sur les secteurs économiques stratégiques (énergie, ressources minières, transport, éducation, santé, etc.) ;

- défense de l'industrie nationale authentique ;

- politique d'occupation du territoire ;

- réforme agraire ;

- politique extérieure indépendante ;

- éducation populaire ;

- valorisation de la culture populaire ;

- solidarité avec les autres nations luttant pour leur émancipation.

Les analyses de Nelson Werneck Sodré nous aideront à mieux comprendre certains points de ce programme qui va guider toute la pensée de gauche, y compris des artistes.

\section{Nelson Werneck Sodré et le matérialisme dialectique}

L'historien Nelson Werneck Sodré (1911-1999) fut sans doute l'un des intellectuels les plus discutés de la période historique que nous étudions. Auteur pléthorique, militaire de carrière, sa réputation a souffert de son engagement au PCB dont il fut membre actif. Son œuvre nous intéresse pour plusieurs raisons. La première concerne la méthode, quand Rocha, pendant les vingt années qui vont suivre, va prétendre appliquer dans ses analyses le matérialisme dialectique, il vaudra beaucoup mieux s'en remettre à l'exemple qu'en donne Sodré qu'aux auteurs marxistes classiques. La seconde raison concerne la conception de 
l'histoire qui en découle. $\mathrm{Si}$, comme nous allons le voir, le Cinema Novo va accorder une place prépondérante à l'histoire dans son étude du Brésil, ce n'est pas seulement pour éviter de traiter de l'actualité et se préserver ainsi les foudres de la censure, c'est aussi parce que l'on voit dans l'étude et la connaissance du passé les clefs de la compréhension et de l'action sur le présent. Le titre même du livre que nous allons étudier, Formação histórica do Brasil $(1961)^{189}$ (Formation historique du Brésil), est à ce titre significatif quant à la démarche adoptée. La révision critique de l'histoire permet d'identifier dans le présent les forces en présence et leurs fondements historiques, le dénouement de conflits aujourd'hui dépassés ou, au contraire, la persistance dans l'actualité de conflits déjà anciens, permet la démystification de certains préjugés et le diagnostic des issues possibles aux problèmes traversés par le pays.

Enfin, la dernière raison que nous avons de nous intéresser à Sodré, réside dans ses propres conclusions. Si la pensée de l'ISEB confiait une mission à l'élite intellectuelle scientifique et artistique, elle lui apportait également un cadre à partir duquel développer son action. Or l'influence du découpage historiographique proposé par Sodré et les informations qu'il apporte auraient sans doute pu se prêter à de très diverses utilisations cinématographiques. Le conflit que nous allons étudier dans le chapitre suivant entre le CPC et le Cinema Novo en apporte déjà la preuve. Il faudra aussi constater qu'un cinéma du type de celui que pratique Solanas dans La Hora de los hornos (Argentine, 1968) et Memoria del saqueo (Argentine, 2004), malgré la différence de nationalité, s'appuie sur une approche historique rigoureusement identique à celle de Sodré et utilise les informations précises (événements, noms des personnages historiques, statistiques) qu'il aurait apporté s'il avait été argentin. Ce cinéma ne sera absolument pas pratiqué par le Cinema Novo. De l'histoire du Brésil écrite par Sodré, les cinemanovistas vont retenir :

- l'approche globalisante (rejet de l'historicisme, l'histoire de la nation est considérée comme un tout, les cinemanovistas vont développer la problématique de l'aliénation et intégrer aux conflits socio-économiques les déterminismes culturels, sociologiques ou même psychologiques qui empêchent les acteurs sociaux, soit d'accéder à la conscience exacte de leurs intérêts, soit, possédant cette conscience, d'agir);

- la dichotomie entre l'ancien et le nouveau (emphase sur la persistance de modes de travail et d'échanges primitifs dans le monde moderne, report sur la situation agricole de la responsabilité du retard de la nation, intérêt pour la situation du Nordeste : le latifundium, la plantation de cannes à sucre représentent l'ancien) ;

- la dévalorisation de tous les conflits historiques auxquels auront participé les masses

189SODRÉ, Werneck Nelson. Formação histórica do Brasil. Treizième édition, Rio de Janeiro, Bertrand Brasil, 1990 [1962]. 
populaires car ceux-ci sont considérés comme des épiphénomènes sans réel incidence sur le cours du processus historique jusqu'à 1960.

L'histoire du Brésil écrite par Sodré rompt avec l'histoire traditionnelle accordant une place privilégiée aux grands événements et aux grands personnages. Il s'agit cependant d'une histoire dans laquelle le peuple est constamment absent car il est considéré que son action n'a jamais pesé sur les destins de la nation. Seuls comptent les conflits entre les grandes puissances impérialistes et les élites brésiliennes qui ont surgi au gré des différents cycles économiques et se sont affrontées pour assurer leur hégémonie sur un territoire immense aux ressources apparemment illimitées. Ainsi, pour la période coloniale (1500-1822), la résistance indigène à la colonisation ou les révoltes des esclaves contre leurs seigneurs et les autorités portugaises ne sont guère développées. Ce qu'il importe à l'historien, c'est de montrer comment le Portugal va réussir à conserver son emprise sur le Brésil et comment le mode de colonisation qu'il choisit va déterminer de façon durable la structure économique et sociale du pays. Selon lui, la faible capacité d'investissement du Portugal et l'impossibilité d'établir des échanges commerciaux substantiels avec le Brésil, comme cela était le cas avec l'Inde, conduisent à l'adoption de la culture de la canne à sucre. La couronne distribue de larges extensions de terre et, malgré les difficultés initiales inhérentes à l'entreprise, cette stratégie s'avère payante dans le Nord-Est du pays. La plantation de canne à sucre se développe et commence à produire des richesses. La colonisation est réalisée sur la base d'exploitations agricoles de très grandes dimensions et le recours au travail esclave.

Le succès de l'exploitation de la canne à sucre entraîne la formation d'une élite rurale de grands propriétaires dont les intérêts convergent avec ceux du Portugal. Ils sont les producteurs d'une marchandise dont la métropole assure la commercialisation. La force de cette association permet de résister successivement aux tentatives de colonisation des français et de la compagnie des Indes. Alors que la canne à sucre permet le développement du NordEst, le Sud végète et se trouve livré à lui-même. Selon l'historien, cet isolement va s'avérer profitable. Bien que le développement du Sud soit très lent en raison de son incapacité à profiter de la manne du commerce du sucre, il va développer une économie de subsistance et des coutumes propres qui apporteront bientôt au Brésil les premiers éléments de son indépendance économique et de son identité culturelle. L'exploration du territoire brésilien se fait à partir de São Paulo grâce aux expéditions des bandeirantes qui recherchent une main d'œuvre moins coûteuse que la main d'œuvre esclave noire et capturent les indigènes. Parallèlement les exploitations agricoles se diversifient, la culture de la terre et l'élevage se dissocient. Ce deuxième type d'activité connaît un essor très important dans l'intérieur des terres et l'émergence d'une véritable civilisation du cuir dont les produits répondent aux 
besoins internes. L'élevage permet d'occuper progressivement l'intérieur des terres et de rompre l'isolement en établissant des échanges avec le Nordeste, il restera par la suite un élément prééminent de l'économie et de la culture brésilienne ${ }^{190}$.

Le XVIIIe siècle est un siècle de bouleversement. La découverte de l'or provoque un boum démographique sans précédent et une explosion du trafic négrier. Le Portugal se vide du quart de sa population et des mesures devront être prises pour interdire l'immigration vers le Brésil. Salvador perd sa place de capitale au profit de Rio de Janeiro, port par lequel l'or est expédié vers la métropole. La colonie passe alors par des transformations qui préparent son accès à l'indépendance politique. Le pays gagne les frontières qui seront toujours les siennes après l'indépendance, de nouvelles capitanias sont créées, l'appareil administratif et les transports sont améliorés pour servir le transit et la fiscalisation de l'exploitation de l'or. Mais surtout, l'or provoque en Europe le passage dans les zones les plus avancées de la phase mercantile à la phase capitaliste. Le Portugal qui s'est alors engagé dans une dépendance de plus en plus grande envers l'Angleterre ne fait pas partie des nations capables du saut qualitatif. Il n'est qu'un intermédiaire coûteux dans l'exportation des marchandises produites au Brésil, impose des taxes non moins coûteuses sur les importations et, enfin, fait peser autour de l'exploitation de l'or des exigences qui deviendront impossibles à satisfaire. Les contradictions entre l'élite coloniale et l'élite métropolitaine s'accroissent alors considérablement.

Les invasions napoléoniennes (1807) sonnent le glas de la domination du Portugal. Le transfert de la cour du Portugal à Rio de Janeiro provoque l'identification de l'élite métropolitaine à l'élite coloniale, le renforcement de l'appareil administratif de la colonie et l'affaiblissement politique et militaire de la métropole. Le Portugal apparaît comme un intermédiaire coûteux et inutile dont il faut se débarrasser. Les grands propriétaires terriens qui détiennent à présent le pouvoir, maintiennent la monarchie car il leur importe avant tout que l'indépendance politique n'entraîne aucune transformation de la structure sociale. L'indépendance du Brésil est proclamée en 1822. La nouvelle nation devient un empire dont le souverain est Dom Pedro I, le fils de l'ancien monarque portugais, Dom João VI. Cette première révolution de palais en préfigure bien d'autres puisqu'il apparaît clairement à l'historien que chacune des transformations politiques majeures par lequel va passer le Brésil correspond à une mise en adéquation du pays avec les nouvelles formes de domination impérialistes et non à un véritable processus d'émancipation.

L'Empire présente l'avantage de parvenir à conserver intacte l'unité territoriale du pays. Il est aussi le moment de la transition entre une économie encore dominée par la canne à 190Cf. ibid., p. 124. 
sucre (le cycle de l'or a fait son temps) et une économie dominée par le café. L'Angleterre est la nouvelle métropole d'un pays qui conserve une structure typiquement coloniale mais la domination qu'elle exerce est d'une nature bien différente de celle qu'exerçait le Portugal. Selon Sodré ${ }^{191}$, la dépendance du Brésil est clairement exprimée par la balance du commerce extérieur. Le Brésil exporte massivement des produits agricoles et importe tout aussi massivement les produits manufacturés qu'il ne produit pas mais qui sont absolument nécessaires, soit à la consommation de sa population disposant d'un pouvoir d'acquisition, soit à la modernisation de ses infrastructures. Le déséquilibre entre la valeur des produits exportés et des produits importés provoque cependant de lourds déficits qui ne peuvent être soldés qu'au travers d'une politique d'emprunts qui accroît continuellement la dépendance du pays. Le Brésil est prisonnier d'un cercle vicieux.

L'État favorise constamment les grands propriétaires pour essayer de rééquilibrer ses comptes au détriment du développement d'autres secteurs économiques. Réciproquement, les grands propriétaires trouvent leur pouvoir renforcé et font systématiquement appel à l'aide de l'État : dans les périodes de prospérité, pour obtenir le financement des infrastructures nécessaires à l'essor de la production, dans les situations de crise, pour limiter les pertes selon diverses méthodes qui vont de l'inflation à l'achat des excédents dans le but de maintenir les cours des denrées exportées. De fait, les préjudices sont répartis sur l'ensemble de la population alors que les bénéfices répondent à des règles de concentration. Dans les deux cas, les déficits augmentent sans cesse, les emprunts succèdent aux emprunts, la capitalisation qui permettrait le développement d'une industrie de substitution est faible et aucune nouvelle classe ne peut émerger qui contre-balancerait le pouvoir des oligarchies terriennes. La chute de l'Empire marque avant tout la détérioration complète du pouvoir des seigneurs de la canne à sucre et du coton. L'aristocratie du café prend le pouvoir avec l'aide de l'Armée, celle-ci représente, selon l'historien, les classes moyennes et ce serait donc la première participation politique de son histoire.

L'apogée de l'aristocratie du café et de cette logique économique de la dépendance se situe dans la dernière décennie du XIXe siècle avec l'élection de Campos Sales :

\footnotetext{
« Em sua mensagem de maio de 1899, o presidente Campos Sales definia a sua política da forma seguinte : 'É tempo de tomar o caminho certo ; e o que nós devemos fazer para esse fim é nos esforçarmos para exportar tudo quanto pudermos produzir em melhores condições do que os outros países, e importar tudo quanto eles possam produzir em melhores condições do que nós. ' Nesse simplismo aparentemente lógico, estava todo o segredo de uma política que se reduzia em paralisar justamente o que era novo e progressista, reduzindo, por um sistema de força, o impulso renovador. ${ }^{192}$
}

191Cf. ibid., p. 255.

192« Dans son message de mai 1899, le président Campos Sales définissait sa politique de la façon suivante : ' Il est temps de prendre le bon chemin; dans ce but, nous devons nous efforcer d'importer tout ce que nous ne 
Bien que dénoncée par quelques uns, la main-mise de l'oligarchie du café sur l'appareil d'État est alors totale. Il n'existe aucune force capable de s'opposer à son pouvoir. Le mandat de Campos Sales correspond à la paralysie presque totale du développement industriel. Le raisonnement simpliste selon lequel il vaut mieux importer ce que le pays ne sait pas produire, renforce le mythe de l'incompétence technique des pays tropicaux et s'impose comme une évidence à de larges fractions de l'opinion qui voient la réalité le confirmer. L'industrie locale, faiblement capitalisée et soumise à une politique gouvernementale contraire à ses intérêts, peine à réaliser des produits capables de rivaliser en qualité et en prix avec les produits importés qui saturent le marché. Cependant, la chute continue des cours du café depuis le début du siècle fragilise la position de l'oligarchie du café. Celle-ci devient intenable avec la crise financière de 1929. Le mécanisme qui consistait à répartir les préjudices sur l'ensemble de la société en période de crise atteint alors un niveau d'extorsion qui provoque la rébellion des fractions de l'élite qui ne partagent pas ses intérêts et marque le retour de l'Armée à la participation politique. Vargas est porté au pouvoir par la Révolution de 1930.

L'isolement de la première guerre mondiale, l'incapacité du marché interne à absorber l'augmentation des prix des produits d'importation avec la crise de 1929, puis le nouvel isolement provoqué par le seconde guerre mondiale, permettent l'émergence de nouvelles forces sociales liées au développement industriel : la bourgeoisie urbaine et la classe ouvrière. Ces nouvelles forces seront prises en compte par Vargas dont la politique populiste vise à concilier les intérêts contradictoires de ces classes antagoniques. Il le fait notamment au travers de l'instauration d'un régime inspiré du modèle fasciste italien, l'Estado Novo (193745). Ce régime autoritaire ne résistera pas à la victoire des démocraties même s'il est entré en guerre aux côtés des alliés. Une fois de plus, la reformulation interne du régime politique correspond à une mise en adéquation du pays avec les nouvelles formes de domination impérialistes :

« As formas de ação do imperialismo começaram a variar, desde então. A mais utilizada é a do estabelecimento de indústrias estrangeiras no mercado interno, em muitos casos, ao aproveitamento da mão-de-obra abundante e barata, à eliminação dos custos de transporte, pela colocação junto ao consumidor. São falsas indústrias, em sua maioria, que desdobram o processo de produção em duas partes, a externa e a interna, sendo esta uma parte de simples acadamento, de montagem, de empacotamento, não correspondendo de forma alguma à introdução de equipamentos fabris complexos, nem mesmo à de técnica. Outras indústrias estrangeiras aqui instaladas atendem tão-somente a necessidade de avizinhar-se da matéria-prima, que recebem daqui, e dos produtos acabados, que nos enviam, tais indústrias instalam-se no próprio mercado a que atendem eliminando fretes de ida e volta,

pouvons pas produire dans de meilleures conditions que les autres pays, et exporter tout ce qu'ils ne peuvent pas produire dans de meilleures conditions que nous. ' Dans ce raisonnement simpliste mais apparemment logique, reposait le secret d'une politique qui se résumait à paralyser ce qui était nouveau et progressiste, réduisant, par la force, l'impulsion rénovatrice. » in ibid., p. 305. 
que encarecem a produção. $»^{193}$

Ainsi, de nouveaux mécanismes de domination s'ajoutent aux anciens et marquent l'intervention des puissants monopoles étrangers dans l'économie interne qui, par diverses stratégies, tentent de s'en assurer le contrôle. Selon Sodré, les nouvelles contradictions économiques qui surgissent dans l'après-guerre apportent sa configuration à la période qu'il intitule «Révolution ». D'un côté, le développement industriel a permis l'amplification du marché interne et l'émergence d'une bourgeoisie nationale dont les revenus proviennent de l'exploitation de ce marché. Cette bourgeoisie nationale qui se répartit sur l'ensemble des secteurs d'activité, est à présent assez forte pour faire entendre ses intérêts dans la dispute pour le pouvoir. D'un autre côté, demeurent les traditionnels secteurs agricoles tournés vers l'exportation et se fortifie la bourgeoisie mandataire des monopoles étrangers qui disputent avec la bourgeoisie « nationaliste » le marché et les ressources internes en matière-première.

Entre 1945 et 1961, l'équilibre des forces favorisent les secteurs contraires au développement du pays. Les difficultés de Vargas (1950-1954) à imposer une politique nationaliste le prouve. Entre 1945 et 1950, puis entre 1954 et 1961, l'application d'une politique de développement rapide basée sur le recours massif aux capitaux étrangers se révèle hautement prédatrice. L'activité des entreprises étrangères disposant de facilités fiscales pour s'installer et rapatrier leurs bénéfices provoque une évasion de devises et de capitaux sans précédent :

«As remessas de lucros dos capitais estrangeiros instalados no Brasil funcionam como operações de debilitamento profundo de uma economia a que se propõe uma política de desenvolvimento. Em milhões de dólares, tais remessas evoluíram, nos últimos anos, da maneira seguinte : [...] TOTAIS.........1954: 4 594... $1955: 5337 \ldots 1956: 6729 \ldots 1957: 9609 \ldots 1958: 17682 . »^{194}$

Sodré démystifie ainsi la politique dont Juscelino Kubitschek est devenu le symbole et qui séduit de larges fractions de l'opinion. La présence de nouvelles industries et la proximité

193« Les formes d'action de l'impérialisme ont commencé à varier à partir d'alors. La plus utilisée est celle de l'établissement d'industries étrangères sur le marché interne, dans de nombreux cas, elle permet de cumuler le bénéfice d'une main d'œuvre abondante et bon marché et l'élimination des coûts de transport en produisant la marchandise au plus près du consommateur. Ce sont de fausses industries qui, dans leur majorité, dédoublent le processus de production en deux parties, une partie externe et une interne, cette dernière correspondant à une étape de finition, de montage, d'emballage, et ne correspondant en rien à l'introduction de matériels de fabrication complexes, ni même à celle de technologie. Les autres industries étrangères qui sont installées ici répondent seulement à la nécessité de se rapprocher de la matière première, qu'ils reçoivent d'ici, et des produits finis, dont elles sont fournisseurs, de telles industries s'installent sur le même marché qu'elles fournissent, éliminant ainsi les coûts de transports qui augmentent le coût de la production. » in ibid., p. 315.

194« Le rapatriement des bénéfices des capitaux étrangers investis au Brésil fonctionne comme une opération d'affaiblissement profond d'une économie qui se propose à engager une politique de développement. En millions de dollars, de tels rapatriements ont évolué, au cours de ces dernières années, de la façon suivante :

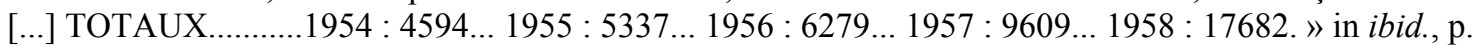
377. 
des technologies modernes donnent en effet l'illusion d'un développement sain et rapide mais consiste en fait à une subordination du développement national aux intérêts étrangers. Selon lui, la Révolution Brésilienne sera le fait de l'ascension des masses populaires à la condition d'acteur politique. Absentes du processus historique jusqu'aux années cinquante, elles ont pourtant grandi grâce au développement industriel. L'amélioration des conditions de vie dans certaines régions du pays et la croissance des inégalités sociales entre les campagnes et les villes auraient permis à la paysannerie de prendre conscience de sa condition (apparition des ligues paysannes) et à la classe ouvrière d'assumer peu à peu les caractéristiques d'expression politique qu'elle a déjà en Europe. L'alliance des masses populaires à la bourgeoisie nationaliste serait à même de provoquer le saut qualitatif qui permettrait au Brésil de s'émanciper de la main-mise impérialiste. Encore fallait-il que chacun accède à une conscience assez claire de son rôle et de ses intérêts, l'historien reconnaissait alors que la confusion idéologique des partis et des alliances ne facilitait pas l'identification des hommes avec les forces qu'ils servaient ou allaient servir une fois élus.

Il est bon de garder à l'esprit l'histoire du Brésil tel que l'écrit Sodré car les cinemanovistas en sont totalement imprégnés ${ }^{195}$. Leurs discours et surtout leurs films ne tarderont pas à le montrer. Même après le coup d'État de 1964 qui prouvera l'utopie d'une alliance entre la bourgeoisie nationaliste et la classe ouvrière, il restera l'idée que la Révolution Brésilienne n'est possible qu'à condition que les masses populaires émergent à la qualité d'acteurs politiques. Le revers de cette conception de l'histoire fondée sur l'affrontement des forces économiques et sociales dominantes est qu'elle reste une histoire des vainqueurs. Le raccourci est vite emprunté qui conduit à penser que les masses populaires ont toujours été soumises parce qu'elles ne se sont jamais battues et si elles ne se sont jamais

195Rénovatrice et particulièrement osée pour l'époque, la vision de l'histoire de Sodré fut durement combattue pour avoir dénoncé deux idées-forces de l'économie brésilienne. La première, c'est que ce n'est pas le secteur agricole de l'exportation qui subventionne l'économie nationale mais l'économie nationale qui subventionne le secteur agricole au travers des mécanismes d'inflation que nous avons décrits. La seconde idée-force, c'est que les investissements étrangers ne soutiennent pas le développement du pays mais au contraire ont diversifié et renforcé l'exploitation dont il est victime. Malgré la qualité de l'argumentation de l'historien, appuyé à l'époque par les économistes de l'ISEB, ces idées qu'il dénonce sont encore aujourd'hui largement défendues par les médias et ont servi les gouvernements qui se sont succédés depuis celui du Maréchal Castello Branco, en 1964, à légitimer, selon des modalités variables, leurs politiques. L'influence de Sodré et de l'ISEB sur les Sciences Politiques fait cependant long feu. C'est ainsi que les antagonismes qu'il délimite, se retrouvent dans les analyses actuelles. Celles-ci réduisent les conflits politiques vécus par le Brésil à l'opposition entre trois projets distincts :

- $\quad$ le libéralisme économique qui vise à faciliter l'intégration des secteurs de l'exportation à l'économie mondiale : Empire, Première République, gouvernements Dutra (45-50), Café Filho (54-55), Castelo Branco (64-67) et Fernando Henrique Cardoso (1994-2002);

l'étatisme nacional-desenvolvimentista ou nacional-conservador : Estado Novo (1937-1945), gouvernements Juscelino Kubitschek (1955-1961) et Ernesto Geisel (1974-1979) ;

l'étatisme du desenvolvimentismo nacional-popular : jamais réellement appliqué mais théorisé par l'ISEB, puis par Celso Furtado, ministre de l'économie de João Goulart (1963), et qui revient dans les projets du Partido Trabalhista - PT, dans les années quatre-vingt.

Cf. FIORI, José Luís. « Adeus aos moedeiros falsos » in Carta Capital, n²13, São Paulo, 30/10/2002. 
battues c'est parce qu'elles n'ont jamais été conscientes des mécanismes d'oppression qui sont inscrits dans l'histoire. Dans le Cinema Novo, ce point de vue va se traduire par une représentation des masses populaires dans laquelle elles sont caractérisées par la passivité. Ce point de vue simplificateur était évidemment abusif mais il présentait l'avantage de désigner la conscientisation comme la solution à tous les maux du pays. Un peuple conscient ne pourrait manquer de provoquer l'émancipation culturelle et économique du pays.

\subsection{La dispute entre le CPC et le Cinema Novo Art ou militantisme, une opposition pertinente?}

1962 fut pour le Cinema Novo une année de définition face à un contexte social, culturel et politique brutalement transformé. Premièrement, les succès successifs de $O S$ Cafajestes, Assalto ao trem pagador et $O$ Pagador de promessas modifient les idées et les perspectives que l'on pouvait avoir les années précédentes sur le cinéma brésilien. Il faut donc se positionner par rapport à cette nouvelle donne cinématographique. Deuxièmement, l'apparition et le développement rapide du Centro Popular de Cultura - CPC qui s'investit immédiatement dans des activités s'appuyant sur l'utilisation des arts comme élément de transformation des consciences et de politisation, bouleverse le paysage culturel carioca. L'Avant-Projet du CPC, rédigé par Carlos Estevam Martins, est à l'origine d'une dispute théorique quant à ce que doit être un art révolutionnaire. Troisièmement, il y a aussi la situation sociale et politique que traverse le pays. Les succès politiques de João Goulart qui obtient bientôt le retour au présidentialisme et ses promesses quant à la réalisation des réformes de base plongent le pays dans une grande fébrilité. Le cinéma doit se positionner par rapport à une situation inédite dans l'histoire du Brésil.

La dispute entre le CPC et le Cinema Novo porte sur la participation que devait avoir le cinéma dans le processus révolutionnaire et permet au groupe du Cinema Novo de prendre forme et de préciser ses propres idées. Celui-ci va devoir se définir simultanément sur les trois problématiques que nous avons exposé. Cette dispute a souvent été réduite au conflit entre des conceptions politiques et esthétiques complètement opposées : d'un côté, le communisme dogmatique et contraire à l'expression des libertés individuelles, de l'autre la nouvelle gauche libertaire ; d'un côté un cinéma de propagande, de manipulation des consciences, sans valeur esthétique, et de l'autre un cinéma révolutionnaire et humaniste, transformé et transformateur, inaugurant une nouvelle dramaturgie et permettant à ses spectateurs de prendre conscience de la réalité sociale et politique. Cet antagonisme fut souvent comparé par ses propres acteurs, comme Gustavo Dahl, à l'antagonisme qui avait opposé le Front de Gauche de l'Art - LEF à la 
Culture Prolétarienne - Prolekult, dans la jeune Union Soviétique. Si une telle comparaison possède ses fondements, elle n'en est pas moins une simplification qui nous dissimule des aspects importants du problème rarement étudiés.

Nous voudrions donc revenir ici tout d'abord sur le conflit politique qui se joue entre 1962 et 1964 et dont l'issue va marquer les destins du Brésil. Revenir sur le contexte politique ne nous servira pas ici à «expliquer » les actions des acteurs sociaux mais au contraire à comprendre quelle fut la véritable valeur de leurs prises de position. Nous reviendrons ensuite en détail sur cette fameuse dispute entre le CPC et le Cinema Novo, d'abord du point de vue théorique sur lequel elle s'est située, puis, d'un point de vue pratique, notamment au travers de l'analyse des faits et des œuvres incriminées. En particulier, Assalto ao trem pagador et $O$ Pagador de promessas.

\section{Combat politique et mouvements sociaux sous la présidence de João Goulart}

À droite comme à gauche, la période allant de 1961 à 1964 est une période d'agitation intense dont le climax sera atteint avec le coup d'État du premier avril 1964. À droite, des groupes d'influence puissants constitués de chefs d'entreprise, de militaires de haut-rang et d'hommes politiques organisent avec l'aide des États-Unis une politique de déstabilisation du gouvernement au travers du financement de partis et de mouvements d'opposition. Il s'agit d'unir les forces politiques et militaires contraires au gouvernement de Goulart et de préparer psychologiquement l'opinion à accepter la légitimité d'un coup d'État.

C'est dans le cadre de cette stratégie que sont créées deux entités qui vont jouer un rôle décisif dans l'articulation des forces de droite et d'extrême-droite : l'Instituto de Pesquisas e Estudos Sociais - IPÊS et l'Instituto Brasileiro de Ação Democrática - IBAD. L'IPÊS est fondé en janvier 1962 et sera dirigé par le Général Golbery do Couto e Silva, future éminence grise de la dictature. L'importance qu'il va prendre pendant cette période est telle que c'est à partir de ses bureaux que Golbery conseillera le Maréchal Castelo Branco devenu président dans les premiers jours d'avril 1964. C'est aussi à partir des fichiers de renseignements de l'IPÊS que sera monté le Serviço Nacional de Informação - SNI, service de renseignements qui va concentrer tous les pouvoirs pendant la période dictatoriale ${ }^{196}$. L'IPÊS est une structure prétendument scientifique qui affiche dans ses statuts les objectifs suivants : «accélérer le développement du pays, assurer une meilleure distribution du revenu national, élever le niveau de vie du peuple, préserver l'unité nationale à travers l'intégration des régions moins

196GASPARI, Elio. As Ilusões armadas - A Ditadura envergonhada. São Paulo, Companhia das letras, 2002, p. 153. 
développées. $\gg{ }^{197}$ Évidemment, ses méthodes et ses véritables objectifs sont autres.

Cet institut se manifeste auprès du public au travers du travail de propagande intense qu'il développe au travers de cours, de publications et de films. Son objectif est clair, dénoncer la politique de Goulart et convaincre de larges secteurs de l'opinion que celui-ci prépare ou favorise l'établissement d'un régime communiste totalitaire au Brésil. Il s'agit de défendre la « démocratie » contre la «République syndicale» ou la «bolchévisation » du pays.

Les films de l'IPÊS connaissent une diffusion remarquable. Ils sont projetés sur l'ensemble du territoire national en lieu et place du traditionnel court métrage du programme de cinéma ${ }^{198}$. L'emploi de camions équipés de projecteurs qui sont de véritables ' cinémas itinérants ' permet de prolonger cette diffusion dans les favelas, les banlieues, les entreprises, les universités, les syndicats, les églises et les places de village, à l'initiative de chefs d'entreprise, d'entités politiques ou d'associations ${ }^{199}$. L'irréprochable qualité technique des films séduit et flatte « la fierté nationale ${ }^{200}$ d'autant plus qu'ils offrent du pays une image positive entachée cependant par les risques que lui feraient courir communisme international.

Les objectifs des films de l'IPÊS sont clairs et se déclinent selon un certain nombre de mots d'ordre que nous retrouveront identiques dans la propagande de la dictature pour les vingt années à venir ${ }^{201}$ :

- pour la « démocratie » et la libre initiative ;

- pour l'Église catholique ;

- contre le communisme et le gouvernement de João Goulart ;

- contre la nationalisation du transport maritime et ferroviaire ;

- contre la réforme agraire ;

- contre l'organisation politique des étudiants.

Les courts métrages prêchent l'harmonie entre les classes et la confiance dans le patronat. Ils défendent l'idée selon laquelle l'enrichissement de celui-ci, qui est conscient de

197Extrait du document de fondation de l'institut, p. 13, traduit et cité dans : SOUZA PINTO, Leonor Estela. Op. cit., p. 36.

198Une séance de cinéma se composait, d'une façon générale, d'un court métrage, suivi d'un ciné-journal, et finalement de la projection du long métrage.

199Cf. SOUZA PINTO, Leonor Estela. Op. cit., p. 106.

200Ces films sont produits par le français Jean Manzon. Né en 1915, il travaille pour Paris-Match, Vu et Paris Soir. En 1940, il s'installe à Rio de Janeiro. Au Brésil, il collabore au Departamento de Informação e de Propaganda - DIP de l'Estado Novo puis participe au magazine O Cruzeiro. A partir de 1952, il va tourner et produire près de 900 documentaires. Il meurt à São Paulo en 1990. Parce qu'il accordait une importance capitale à la qualité techniques de l'image et occultait soigneusement tout ce qui aurait pu dénoncer les injustices sociales, on a dit que ses films ressemblaient à des cartes postales. « Certains me reprochent de donner une image fausse du Brésil, expliquait Jean Manzon. A ceux-là je réponds que ce que je montre c'est la réalité, mais avec optimisme et confiance dans le futur. » L'optimisme et la confiance de Jean Manzon étaient telles qu'il participa sans état d'âme aux deux régimes dictatoriaux que connut le Brésil.

201SOUZA PINTO, Leonor Estela. Op. cit., p. 106. 
ses responsabilités envers le pays, profitera forcément aux salariés et, dans ce sens, il privilégiera toujours la modernisation et la rationalisation de l'économie. La structure des films est celle d'un discours fermé alternant conseils et menaces et utilisant des extraits et images de l'encyclique Mater et Magistra de Jean XXIII. La caution de l'Église catholique est alors un argument de poids.

Ce travail de propagande médiatique est relayé par l'action sur le terrain des associations conservatrices catholiques ou des mouvements féminins comme A União Cívica Feminina et la Campanha da Mulher - CAMDE pela Democracia que l'IPÊS a créés et financés. Ces mouvements associent souvent un travail de nature humanitaire à un travail d'endoctrinement idéologique. La CAMDE intervient dans les favelas pour donner des cours d'artisanat et défendre les valeurs de «bon sens » : la famille, la morale chrétienne et la démocratie, prétendument menacés par le communisme international. La CAMDE et l'União Cívica Feminina sont les organisatrices de la Marcha da família com Deus pela liberdade, le 19 mars 1964 à São Paulo, manifestation de masse qui sera utilisée par la suite comme une preuve de la légitimité populaire du coup d'État.

L'extraordinaire vitalité de l'IPÊS ne vient pas de l'unique force de conviction de ses participants. Toutes ses activités ont fait l'objet d'une planification rigoureuse et ont été rendues possibles par les donations de cinq entreprises liées aux monopoles étrangers : Refinaria União, Light \& Power, Cruzeiro do Sul, Icomi, Listas Telefônicas Brasileiras, qui s'ajoutent à 300 entreprises américaines de moindre importance opérant sur le marché brésilien $^{202}$. Selon Luiz Alberto Moniz Bandeira, entre décembre 1961 et août 1963, la compagnie Light \& Power aurait versé Cr\$ 4200 000, 00 à l'IPÊS à raison de 200000 par mois, versement qu'elle aurait poursuivi jusqu'au coup d'État ${ }^{203}$. Dans l'ombre, l'IPÊS tisse les alliances qui seront nécessaires à la réalisation des objectifs de ses commanditaires et réalise, en dehors de toute légalité, un travail de renseignement extrêmement étendu dans le cadre duquel est mis en place un large réseau d'écoute téléphonique ${ }^{204}$.

L'IBAD, pour sa part, existe depuis 1959 mais prend son véritable essor au moment de l'accès au pouvoir de João Goulart. Il est directement subordonné à la CIA et coordonne le travail de ses agents infiltrés au Brésil. Il crée, en 1962, l'Ação Democrática Popular - ADEP qui lui permet d'intervenir directement dans les campagnes pour les élections législatives et pour les élections des gouverneurs d'État. Il subventionne généreusement les candidats de droite qui s'engagent à défendre les investissements étrangers et à lutter contre la réforme agraire. L'ambassadeur des États-Unis de l'époque, Lincoln Gordon, admet que 5 millions de 202http://pt.wikipedia.org/wiki/IPÊS, page consultée sur Internet le 21/08/2005. 203BANDEIRA, Luiz Alberto Moniz. Op. cit., p. 82. 204http://pt.wikipedia.org/wiki/IPÊS, page consultée sur Internet le 21/08/2005. 
dollars ont été injectés dans la campagne, fonds ayant pour origine exclusive la CIA et non les donations de grandes entreprises ${ }^{205}$. Pour l'époque, c'est une somme phénoménale. L'IBAD, pour ses autres activités, reçoit aussi de l'argent de nombreuses autres entreprises américaines parmi lesquelles Texaco, Shell et Coca-cola, pour ne citer que les trois plus célèbres.

Avec de tels budgets, l'IBAD, comme l'IPÊS, finance de nombreuses entités sociales de droite ou d'extrême-droite, en plus de l'ADEP : l'Ação Democrática Parlamentar - ADP, la CAMDE, la Frente Juventude Democrática - FJD. Enfin, dans le but de contrôler le mouvement ouvrier, l'IBAD crée les syndicats Resistência Democrática dos Trabalhadores Livres - RESDETRAL et Movimento Sindical Democrático - MSD, et, dans le but de contrôler la paysannerie du Nordeste, il crée le Serviço Rural de Pernambuco - SORPE. Enfin, l'IBAD met en place un vaste système de corruption des politiciens et des militaires et un service de renseignement basé au sein de la IVe Armée basée dans le Nordeste. Une commission d'enquête parlementaire est ouverte en 1963 pour faire la lumière sur les activités de l'IBAD. Elle ne donne rien, l'histoire révélera que majorité des députés participant à cette commission bénéficiait des largesses de l'institut ${ }^{206}$.

Face à la droite, l'accès à la présidence de Goulart et ses victoires politiques successives créent un immense enthousiasme et favorisent l'expression des mouvements de gauche. Son accès à la présidence, même s'il se fait sur la base du compromis humiliant que constitue le parlementarisme, représente un premier succès face à la menace de putsch des ministres militaires et à l'opposition d'un congrès majoritairement conservateur. Les élections législatives d'octobre 1962 sont une deuxième victoire puisque le PTB, son parti, devient majoritaire. Enfin, le référendum sur le rétablissement du présidentialisme de janvier 1963 tourne au plébiscite. Jango, par la voie du vote populaire, récupère les pouvoirs dont les manipulations illégales du congrès l'avaient privé en 1961. Les sondages confirment sa popularité un peu plus tard la même année ${ }^{207}$. Le Brésil a alors à sa tête un président qui cherche à mettre en place son programme de « réformes de base » en faveur de la réforme agraire, de la réforme des universités, du droit de vote aux illettrés, de la légalisation du Parti Communiste brésilien et de la consolidation des syndicats qui, avec l'industrialisation, avaient pris une envergure considérable, et dont le poids politique ne pouvait plus être ignorée ${ }^{208}$.

Le fait que la gauche gagne subitement un espace d'une envergure jusque là inédite

205BANDEIRA, Luiz Alberto Moniz. Op. cit., p. 83.

206Ibid., p. 85.

207GASPARI, Elio. As Ilusões armadas - A Ditadura envergonhada. Op. cit., p. 380.

208Selon toute vraisemblance, João Goulart n'envisageait certainement pas l'implantation d'un régime socialiste. Selon des raisonnements communs à ceux développés par l'ISEB, ces réformes avaient pour but de viabiliser le capitalisme brésilien. Le premier effet attendu de l'application de la réforme agraire et de l'établissement d'une plus grande justice sociale, était, et demeure aujourd'hui pour ses partisans, une amplification du marché de consommation interne à terme profitable à tous. 
dans la vie politique brésilienne ne doit cependant pas nous laisser penser qu'elle est unie et soutient de façon inconditionnelle le Président. L'activisme de gauche se répartit entre les partis, les syndicats et les mouvements de base, parmi les membres desquels nous comptons des révolutionnaires et des réformistes, des catholiques et des marxistes et ceux qui oscillent entre diverses positions. Les statistiques de la répression qui a immédiatement suivi le coup d'État, peuvent nous donner une image assez juste de la mobilisation politique et sociale que vivait le Brésil : entre 5000 et 7000 prisons, 500 exilés politiques, 2000 fonctionnaires licenciés ou mis à la retraite, 386 élus privés de leur mandat et de leurs droits politiques pendant 10 ans, parmi les militaires, 421 départs obligés à la retraite dans le corps des officiers dont 24 sur les 91 généraux existants, enfin, 7 sur 10 directions de syndicats ou de confédérations de travailleurs de plus de 5000 membres ont été dissoutes ${ }^{209}$. Il est important de préciser, pour que ces chiffres soient bien compris, que la dictature ne s'est alors attaquée qu'aux personnes et aux entités qui, par leur activité, nuisaient de façon directe et explicite aux intérêts et à la politique qu'elle souhaitait défendre. À partir d'avril 1964, la liberté d'expression sera encore globalement respectée pendant environ quatre ans, dans l'immédiat, c'est la liberté d'action qui est abolie.

Parmi les mouvements sociaux qui composent le panorama de 1962-1964, nous avons ceux qui existaient avant 1962 et ceux qui sont apparus spontanément avec l'accès au pouvoir de Goulart. Les mouvements sociaux les plus anciens sont ceux que l'ISEB voyait comme la preuve de l'émergence des classes populaires au combat politique. Parmi eux, nous comptons les très controversées Ligas Camponesas (ligues paysannes) ${ }^{210}$. Les ligues paysannes sont des sociétés de travailleurs ruraux qui se forment spontanément afin de défendre leurs intérêts contre la toute puissance des grands propriétaires.

La toute première ligue paysanne s'intitule en fait Sociedade Agrícola e Pecuária de Plantadores de Pernambuco - SAPPP. Elle est créée en 1954 sur le site d'une ancienne plantation de cannes à sucre nommée Galiléia à Vitória de Santa Antão au Pernambouc. Les objectifs de la nouvelle société consistent à aider ses sociétaires à couvrir les dépenses funéraires d'un enterrement décent, apporter une assistance médicale et juridique, assurer l'accès à l'éducation et former une coopérative de crédit permettant peu à peu de se libérer du joug du latifundium. Entre 1955 et 1964, les Ligas Camponesas se multiplient. Au début des

209GASPARI, Elio. As Ilusões armadas - A Ditadura envergonhada. Op. cit., p. 130.

210Le nom de « ligas camponesas » leur a été donné par la presse conservatrice de l'époque en référence à d'autres mouvements de paysans sans grande répercussion datant des années 40. Sur les ligues paysannes, nous avons consulté :

BENNASSAR, Bartolomé, MARIN Richard. Op. cit., pp. 386-388.

CAMARGO, Aspásio. As Ligas Camponesas. Site officiel de la Fundação Getúlio Vargas, http://www.cpdoc.fgv.br/dhbb/verbetes_htm/7794_1.asp, consulté le 24/12/2005. 
années soixante, elles se répartissent sur 13 états. Le Pernambouc en compte 25. La Paraíba abrite la ligue de Sapé qui atteint le nombre record de 10000 membres. Le I Congresso de Lavradores e Trabalhadores Agrícolas do Brasil ${ }^{211}$ à Belo Horizonte en novembre 1961 apporte la preuve de la vitalité des ligues paysannes. Le président Goulart assiste à cet événement. C'est à cette occasion que Francisco Julião, qui est entre-temps devenu l'un des leaders du mouvement, proclame la «reforma agrária na lei ou na marra » (« la réforme agraire par la loi ou par la force »). La montée en puissance des ligues paysannes et la pression exercée sur le gouvernement alimentent les espoirs de réalisation d'une réforme agraire.

Le combat pour une meilleure distribution des terres est l'un des plus emblématiques de la période. Le combat pour l'alphabétisation des masses en est autre ${ }^{212}$. Tout commence avec la fondation du Movimento de Cultura Popular - MCP au début des années soixante. C'est au sein de cette institution que le pédagogue Paulo Freire développe la méthode d'alphabétisation qui le rendra célèbre. Son succès est tel qu'il est rapidement décidé l'extension de son application à grande échelle. Mais, précisément en raison l'impact politique que lui devinent aussitôt ceux qui sont les premiers témoins de son efficacité, elle souffrira de graves distorsions :

\begin{abstract}
« Nem todos os militantes do MCP interpretavam a prática educativa da mesma forma. Católicos, protestantes e comunistas encaravam a alfabetização com diferentes perspectivas. Episódio ocorrido em torno da elaboração de uma cartilha para a alfabetização de trabalhadores deu origem a conflito que opôs as facções existentes no interior do movimento. A partir das palavras geradoras ' povo, voto, vida, saúde, pão ', os autores da cartilha apresentavam aos alfabetizandos frases feitas como ' o voto pertence ao povo ' ou ' o povo sem casa vive nos mocambos '. $»^{213}$
\end{abstract}

Le MCP et la méthode de Paulo Freire vont ensuite influencer le Movimento de Educação de Base - MEB qui va connaître les mêmes dérives propagandistes. Le MEB est un projet de l'épiscopat fondé dans l'intention de contrer les Ligas Camponesas et le progrès des idées socialistes dans le Nordeste. Le mouvement échappe cependant rapidement à ses commanditaires :

211Premier Congrès National des Laboureurs et Travailleurs Agricoles.

212Le Nordeste offrait une vision critique de la situation, sur 25 millions d'habitants, 15 millions étaient analphabètes in BESSA V., BLAITT A., MAGNONI M.S., Lima Barreto, Paulo Freire,coll. Caros Amigos, Rebeldes brasileiros : homens e mulheres que desafiaram o poder, Casa amarela, São Paulo, 2001, p368 à 383., p372.

213« Tous les militants du MCP n'interprétaient pas la pratique éducative de la même façon. Catholiques, protestants et communistes ne voyaient pas l'alphabétisation avec les mêmes perspectives. Un épisode arrivé lors de l'élaboration d'un abécédaire pour l'alphabétisation de travailleurs a donné lieu à un conflit entre les factions coexistant à l'intérieur du mouvement. A partir des mots générateurs, povo, voto, vida, saúde, pão, les auteurs de l'abécédaire ont présenté aux élèves des phrases toutes faites comme "o voto pertence ao povo" (le vote appartient au peuple), ou "o povo sem casa vive nos mocambos" (le peuple sans maison vit dans les mocambos[nom donné aux cachettes dans la forêt où se réfugiaient les esclaves]. » in ibid., p372. 


\begin{abstract}
«Du sage projet initial, placé sous la tutelle d'un lointain conseil national de dix évêques, il ne reste souvent que peu de choses. Sur le terrain, un fort noyau de l'Action catholique ${ }^{214}$, désireux de mettre en pratique leur engagement social sans délai, l'orientent dans de tout autres voies, autour du tryptique : alphabétisation, conscientisation, syndicalisation. Le livret d'alphabétisation national de 1963 : Savoir pour vivre, suivi de Vivre c'est lutter marque la politisation croissante du projet [...]. La première leçon en donne bien le ton : 'Je vis et je lutte. Pierre vit et il lutte. Le peuple vit et lutte. Moi, Pierre et le peuple, nous vivons. Moi, Pierre et le peuple, nous luttons. Nous luttons pour vivre. Vivre, c'est lutter.' La saisie chez l'imprimeur, à Rio, le 20 février 1964, sur ordre du gouverneur Carlos Lacerda ${ }^{215}$, de 3000 exemplaires de Vivre c'est lutter porte au grand jour les dissensions de la hiérarchie. Le cardinal conservateur de Rio, dom Jaime Câmara, se désolidarise publiquement du MEB. $»^{216}$
\end{abstract}

Mais l'alphabétisation ne va pas seulement être utilisée à des fins d'endoctrinement. Dans un pays où les analphabètes sont interdits de vote, les dispositifs d'alphabétisation des adultes apparaissent comme des pièces stratégiques des batailles électorales. Les maires de gauche élus en 1960, Miguel Arraes à Recife et de Djamal Maranhão à Natal, vont chercher à tirer parti de l'augmentation provoquée par l'exode rural de la population d'origine paysanne dans les centres urbains. Le calcul va s'avérer payant pour l'État du Pernambouc dont Miguel Arraes devient gouverneur en 1962.

Enfin, le gouvernement fédéral lui-même s'intéresse au programme d'alphabétisation réalisé à Angicos (Pernambouc) en 1963 par l'Union d'État des Étudiants du Rio Grande do Norte dirigé par Paulo Freire en partenariat avec le gouvernement de l'État (Sudene ${ }^{217}$ / USAID et Ministère de l'éducation). L'expérience est alors dénoncée par le journal $O$ globo comme étant un programme intensif de «communisation» dans le Nordeste. L'USAID retire son soutien au moment où les États-Unis évaluent la méthode comme une «fabrique de révolutions ». Le gouvernement de João Goulart décide au contraire d'appliquer ce programme à l'échelle fédérale. Une fois de plus, les calculs politiques ne sont pas absents de cette décision. Il s'agit bien de favoriser une participation croissante des masses populaires au combat politique. C'est à ce même contexte d'intense mobilisation, de tensions, de conflits et de tentatives de manipulation des masses, prélude à de grands affrontements, que participe le CPC.

\title{
Le CPC
}

214Il s'agit de l'Ação Popular, mouvement de gauche chrétien créé en 1962.

215De son nom complet, Carlos Frederico Werneck de Lacerda est gouverneur de l'État de Rio de Janeiro, alors circonscrit aux limites de l'ex-capitale fédérale, de 1960 à 1965. C'est un personnage sur lequel nous aurons l'occasion de revenir souvent.

216BENNASSAR, Bartolomé, MARIN, Richard. Op. cit., p389.

217La SUDENE ou Surintendance de développement du Nordeste est une agence gouvernementale créée en décembre 1959, dotée de moyens autonomes et directement subordonnée à la présidence de la République. Dans l'esprit développementiste qui a présidé à sa création, son objectif est de planifier le développement du Nordeste et d'encourager l'implantation d'industries lourdes. Les objectifs et méthodes de cette organisme se sont souvent trouvés opposés à ceux de l'USAID. 
Dans un certain sens, le CPC s'apparente aux mouvements d'alphabétisation et en particulier au MPC avec lequel il partage les influences dominantes de l'ISEB et du marxisme. Il s'agit d'un mouvement de base composé d'étudiants qui cherchent à mener une action concrète auprès des masses populaires. Dans tous les cas, l'objectif est de faire prendre conscience à la population des mécanismes sociaux et économiques qui la maintiennent dans la pauvreté afin que celle-ci s'engage dans une action politique lucide. Pour provoquer cette prise de conscience, le CPC valorise le rôle de la culture, débute avec le théâtre et développe diverses autres activités : musique, littérature et cinéma. Comme les mouvements d'alphabétisation, le CPC doit composer avec les institutions officielles auquel il doit son statut légal et une part de ses revenus.

Le $\mathrm{CPC}$ est à son origine une tentative de réponse à une problématique strictement théâtrale. Au début des années soixante, Oduvaldo Vianna Filho, acteur et dramaturge, membre de la compagnie Teatro de Arena, se déclare insatisfait par les perspectives qu'offre le théâtre professionnel. Sa compagnie s'est pourtant distinguée la décennie précédente par son caractère rénovateur, son goût pour les thématiques sociales et l'immense succès rencontré par la pièce Eles não usam black-tie. Vianinha, comme il est surnommé, voudrait dépasser le cercle traditionnel des spectateurs de théâtre. Il l'expliquera plus tard dans ces termes :

«O Arena era o porta-voz das massas populares num teatro de cento e cinqüenta lugares... O Arena não atingia o público popular e, o que é talvez mais importante, não podia mobilizar um grande número de ativistas para o seu trabalho. A urgência da conscientização, a possibilidade de arregimentação da intelectualidade, dos estudantes, do próprio povo, a quantidade de público existente, estavam em forte descompasso com o Teatro de Arena enquanto empresa. Não que o Arena tenha fechado seu movimento em si mesmo ; houve um raio de ação comprido e fecundo que foi atingido com excursões, com conferências, etc. Mas a mobilização nunca foi muito alta porque não podia ser muito alta. E um movimento de massas só pode ser feito com eficácia se tem como perspectiva inicial a sua massificação, sua industrialização. É preciso produzir conscientização em massa, em escala industrial. Só assim é possível fazer frente ao poder econômico que produz alienação em massa. $»^{218}$

La question de la rénovation de l'art théâtral ne devait cependant pas se limiter à une

218« L'Arena était le porte-parole des masses populaires dans un théâtre de cent cinquante places... L'Arena n'atteignait pas le public populaire et, ce qui est peut être plus important, ne pouvait pas mobiliser un grand nombre d'activistes pour son travail. L'urgence de la conscientisation, la possibilité d'enrôler les intellectuels, les étudiants, le propre peuple, le volume de public existant, étaient fortement décalés avec l'envergure de l'Arena comme entreprise. Cela ne signifie pas que l'Arena se soit repliée sur elle-même ; elle a eu un rayon d'action grand et fécond qui a été obtenu par la réalisation d'excursions, de conférences, etc. Mais la mobilisation ne fut jamais très importante car elle ne pouvait pas l'être. Et un mouvement de masse ne peut être fait avec efficacité que s'il a pour perspective initiale sa massification, son industrialisation. Il faut produire de la conscientisation en masse, à l'échelle industrielle. C'est seulement ainsi qu'il sera possible de faire face au pouvoir économique qui produit de l'aliénation en masse. » in VIANA FILHO, Oduvaldo. « Do Arena ao CPC » in Movimento, $\mathrm{n}^{\circ}$ 6, octobre 1962. Texte reproduit dans son intégralité in PEIXOTO, Fernando (org.). Vianinha : teatro, televisão, politica. São Paulo, coll. Antologias e biografias, ed. Brasiliense, 1983, pp. 90-95. 
question de structure. Commence alors pour Vianinha une quête esthétique dominée par la conception selon laquelle le dialogue avec le public représente l'essence de la pratique théâtrale. Au terme de cette quête, il aboutit aux conclusions suivantes :

« Todos os dados para que o espectador seja sensibilizado por uma peça devem estar dentro da própria peça. Não podem haver cenas, acontecimentos, personagens, situações que necessitem de uma visão de mundo que esteja acima e fora do mundo teatral criado. As peças ideologicamente perfeitas podem ser mudas para o povo se não lhe dão meios para a compreensão. É preciso um teatro ajustado à capacidade intelectual do povo brasileiro. Um teatro com formas já consagradas pela percepção popular. A forma nova será nova historicamente, será nova em relação à situação cultural da sociedade - não será necessariamente nova na história da arte. $\rangle^{219}$

Comme les divergences avec le Teatro de Arena augmentent, Vianinha décide de s'établir à Rio en 1960. Il travaille alors à l'écriture et au montage de la pièce A Mais Valia vai acabar, seu Edgar. Pour approfondir les questions économiques qu'il souhaite traiter, l'auteur fréquente l'ISEB et rencontre Carlos Estevam Martins. Ce dernier est alors l'assistant d'Álvaro Vieira Pinto. À la suite de la représentation de la pièce dans les locaux de la Faculdade de Arquitetura da Universidade do Brasil ${ }^{220}$, les deux hommes concordent pour développer un travail politique au travers du théâtre.

Le CPC est fondé en décembre 1961 et ses statuts sont soumis à l'União Nacional dos Estudantes - UNE, en assemblée générale, le 8 mars $1962^{221}$. Le CPC devient alors l'organe culturel du syndicat étudiant tout en jouissant de l'autonomie administrative et financière. Le deuxième article de ses statuts définit ses objectifs. En résumé, il s'agit de promouvoir des activités culturelles dans les domaines du théâtre, du cinéma, de la musique et des arts plastiques afin, comme cela est écrit, d' « elevar o nível de conscientização das massas populares. $\gg{ }^{222}$ La proposition du CPC emporte l'adhésion de plusieurs artistes et intellectuels entre lesquels : Ferreira Gullar, Francisco de Assis ${ }^{223}$, Paulo Pontes, Armando Costa, Carlos

219« Toutes les données pour qu'un spectateur soit sensibilisé par une pièce doivent être contenues dans la pièce. Il ne peut pas y avoir de scènes, d'événements, de personnages, de situations qui nécessitent une vision du monde qui soit au-dessus et en-dehors du monde théâtral qui a été créé. Des pièces parfaites du point de vue idéologique peuvent être muettes pour le peuple s'il ne lui est pas donné les moyens de les comprendre. Il est nécessaire d'ajuster le théâtre à la capacité intellectuelle du peuple. Un théâtre avec des formes déjà consacrées par la perception populaire. Cette forme nouvelle sera historiquement nouvelle en relation à la situation culturelle de la société - elle ne le sera pas nécessairement dans l'histoire de l'art. » in VIANA FILHO, Oduvaldo. « Do Arena ao CPC » in Movimento, $\mathrm{n}^{\circ} 6$, octobre 1962. Texte reproduit dans son intégralité in PEIXOTO, Fernando (org.). Vianinha : teatro, televisão, política. São Paulo, coll. Antologias e biografias, ed. Brasiliense, 1983, pp. 90-95.

220Selon Helena Salem, la pièce a été représentée au Teatro de Arena de la Faculdade de Arquitetura do Rio, à la Praia Vermelha, une salle de 1200 places. Elle est par la suite restée presque deux ans à l'affiche, in SALEM, Helena. Leon Hirszman : o navegador das estrelas. Rio de Janeiro, Rocco, 1997, p. 103.

221PEIXOTO, Fernando (org.). Vianinha : teatro, televisão, política. Op. cit., p. 97.

222 « [...] élever le niveau de conscientisation des masses populaires. » in PEIXOTO, Fernando. O Melhor Teatro do CPC da UNE. São Paulo, Global Editora, 1989, p. 13.

223Francisco de Assis est un autre assidu de l'ISEB, il deviendra notamment l'ami de Roland Corbisier, in SALEM, Helena. Leon Hirszman : o navegador das estrelas. Op. cit., p. 103. 
Lyra et João das Neves qui participent donc au mouvement côte à côte avec des étudiants. Le $\mathrm{CPC}$ est également à l'origine de l'UNE-Volante qui voyage dans tout le pays et assure la diffusion du mouvement. D'autres CPC sont créés dans les capitales des états, associés aux syndicats étudiants locaux. Le CPC cherche également a se développer au sein d'entités sociales paysannes et ouvrières. Malgré les tentatives allant dans ce sens, il n'y a que dans le Sindicato dos Metalúrgicos de Rio de Janeiro qu'est monté un CPC.

Le CPC connaît un véritable succès auprès de la population étudiante. Ainsi, en plus des financements concédés par l'UNE ${ }^{224}$, la vente de ses propres productions artistiques lui assure un revenu complémentaire non négligeable. Les concerts de musique et les représentations théâtrales, la vente du disque $O$ povo canta, la collection de livres Cadernos do povo brasileiro, et, à partir de 1963, la collection de recueils de poésie intitulée Violão de rua permettent au CPC de marquer son temps et s'ajoutent aux cours de théâtre, de cinéma, d'arts visuels et de philosophie qu'il administre ${ }^{225}$.

Pour en revenir à ce qui fait l'essence du CPC, la pratique théâtrale, celui-ci intègre à son répertoire des pièces du Teatro de Arena comme Eles não usam black-tie, mais il crée aussi pour les syndicats et s'attache à traiter des thèmes politiques d'actualité, plaide la cause de la réforme agraire et dénonce l'impérialisme. Le but est d'amener le théâtre là où, traditionnellement, il n'est pas et d'aborder les sujets que, traditionnellement, il ne traite pas. Les titres des créations du CPC sont très explicites. En voilà un échantillon :

- Não tem imperialismo no Brasil (littéralement, Il n'y a pas d'impérialisme au Brésil, titre évidemment ironique) d'Augusto Boal ;

- O Petróleo ficou nosso (Et Le Pétrole fut à nous) de Armando Costa ;

- Petróleo e guerra na Argélia (Pétrole et guerre d'Algérie) de Carlos Estevam Martins ;

- Clara do Paraguai (Claire du Paraguay) de Armando Costa ;

- A Estória do formiguinho ou Deus ajuda os bão (L'Histoire de la petite fourmi ou Dieu aide les justes) d'Arnaldo Jabor ;

- Auto dos 99 \% (L'Auto des 99 \%) de Antônio Carlos Fontoura, Armando Costa, Carlos Estevam Martins, Cecil Thiré, Marcos Aurélio Garcia et Oduvaldo Vianna Filho ;

- A Vez da recusa (Cette fois-ci, c'est non) de Carlos Estevam Martins ;

- Brasil versão brasileira (Brésil version brésilienne) de Oduvaldo Vianna Filho.

224Celle-ci est elle même financée par le Ministério de Educação e Cultura - MEC.

225Le disque $O$ Povo Canta avec $A$ Canção do subdesenvolvimento (littéralement, La Chanson du sousdéveloppement) de Chico de Assis et Carlos Lyra se vend à 11000 exemplaires. Parmi les recueils de poésie, Cabra marcado para morrer de Ferreira Gullar est un de ceux qui se vend le mieux. Enfin, plus de 20 Cadernos do povo brasileiro ont été publiés. Cette collection est dirigé par Ênio Silveira (futur éditeur de $A$ Revista da Civilização Brasileira) et Álvaro Vieira Pinto. Le premier numéro s'intitule « O que são as Ligas Camponesas » (littéralement, « Que sont les ligues paysannes »). Informations recueillies dans PEIXOTO, Fernando. O Melhor Teatro do CPC da UNE. Op. cit., pp. 15-16. 
Selon Fernando Peixoto, à l'époque acteur et directeur du CPC de Porto Alegre :

« Nessa época assumia-se integralmente, com plena consciência de sua necessidade e limites, uma tarefa de agitação e propaganda deliberadamente circunstancial. E sem medo de um inevitável esquematismo : o objetivo não era substituir o imprescindível comício ou passeata, mas sim ajudar com o espetáculo teatral - geralmente uma sátira de efeito imediato - contribuindo, graças ao quase improvisado trabalho histriónico dos atores, como urgente elemento lúdico e participante. ${ }^{226}$

Les cinemanovistas sont d'abord parties intégrantes de ce mouvement avec lequel ils partagent la même idéologie. Nous aurons noté parmi les auteurs des pièces de théâtre la participation d'Arnaldo Jabor. Leon Hirszman est l'un des co-fondateurs du CPC, il a notamment réalisé le montage d'archives cinématographiques qui a constitué la partie audiovisuelle de la pièce pionnière A Mais Valia vai acabar, seu Edgar. Simultanément, il devient le secrétaire général du secteur cinéma du CPC. Carlos Diegues est son principal conseiller et devient président du CPC en décembre 1962 pour une durée de trois mois ${ }^{227}$.

\section{La controverse entre le Cinema Novo et le CPC}

La dispute entre le CPC et le Cinema Novo surgit autour de la question de la définition d'un art révolutionnaire et du concept de «Cultura popular» tel qu'il est théorisé par Carlos Estevam Martins dans l'avant-projet du manifeste du CPC $^{228}$ en mars 1962. Il s'agit à la fois d'une dispute de personnes et d'une dispute théorique. Elle doit son origine à l'insatisfaction de Carlos Estevam Martins et d'une partie du CPC vis à vis des réalisations des cinemanovistas achevées durant le deuxième semestre de l'année, Cinco vezes favela et Porto das Caixas.

L'avant-projet du manifeste du CPC est un texte de six mois antérieur à la controverse que nous allons commenter. En aucun endroit, le cinéma n'y est mentionné et il n'est pas, au premier semestre de 1962, l'objet de commentaires ayant été rendus publiques de la part des cinéastes. Il s'agit néanmoins d'un texte intéressant pour nous, car Carlos Estevam Martins y défend une conception de la culture qui, appliquée au cinéma, causera de vives réactions.

Force est de constater que de nombreuses idées présentes dans le texte de Martins

226« À cette époque, nous assumions entièrement, et avec une pleine conscience de sa nécessité et de ses limites, une mission d'agitation et de propagande volontairement circonstancielle. Et sans peur d'un inévitable schématisme : l'objectif n'était pas de substituer l'inévitable meeting ou la manifestation, mais d'aider avec un spectacle théâtral, généralement une satyre d'effet immédiat, contribuant, grâce au travail des acteurs d'improvisation et de jeu avec le public, avec un élément de participation urgente et ludique. » in PEIXOTO, Fernando. O Melhor Teatro do CPC da UNE. Op. cit., p. 9.

227Les présidents du CPC furent Carlos Estevam Martins, de décembre 1961 à décembre 1962, Carlos Diegues, de décembre 1962 à février 1963 et Ferreira Gullar, de février 1963 au coup d'État qui a mis un terme aux activités du CPC.

228MARTINS, Carlos Estevam. " Anteprojeto ao manifesto do CPC », reproduit in HOLLANDA, Heloísa Buarque de. Impressões de viagem - cpc, vanguarda e desbunde : 1960/70. São Paulo, ed. Brasiliense, 1980, pp. 121-144. 
auraient pu être endossées par les cinemanovistas. Il en va ainsi de la nécessité de la conscientisation des masses populaires et de la responsabilité des élites intellectuelles à exercer une action culturelle qui permettrait cette conscientisation. Les différences interviennent en relation au concept de culture. Comme Álvaro Vieira Pinto, Martins estime qu'il ne peut exister de culture parfaitement désaliénée avant l'accomplissement de la Révolution or, les cinemanovistas prétendront que le cinéma qu'ils pratiquent est déjà un cinéma «libre », manifestation d'une culture désaliénée. Il s'agit d'une différence de perspective considérable d'ailleurs développée en creux dès l'avant-projet de manifeste de Martins. Pour lui, l'artiste ne doit pas seulement identifier sa pensée et ses actions avec la cause de la classe opprimée, il doit subordonner son art aux impératifs propres à la conscience de cette classe. Autrement dit, il doit produire un art qu'elle puisse comprendre et assimiler. Martins explique ensuite qu'il existe trois formes d'art : l'art du peuple, l'art populaire et l'art populaire révolutionnaire.

L'art du peuple est l'art produit dans les communautés primitives qui n'ont pas encore été atteintes par l'industrialisation. L'artiste et le public se confondent dans le même anonymat. L'art populaire est présent dans les centres urbains développés et se caractérise par la séparation qui intervient entre un public consommateur et improductif et les artistes en tant que groupe professionnel spécialisé. L'art populaire révolutionnaire est celui produit et défendu par le CPC. Au-delà du simplisme de cette classification, Martins démontre la force des préjugés de classe qui l'animent et dont il se défend constamment en niant tout validité, esthétique ou politique, aux deux premières manifestations artistiques : « [...] a arte do povo é tão desprovida de qualidade artística e de pretensões culturais que nunca vai além de uma tentativa tosca e desajeitada de exprimir fatos triviais dados à sensibilidade mais embotada. É ingênua e retardária e na realidade não tem outra função que a de satisfazer necessidades lúdicas e de ornamento. $\gg{ }^{229}$

Par contre, Martins accorde une validité esthétique à l'art de l'élite. Celui-ci, bien que condamné car n'étant pas solidaire du peuple end $^{230}$ aurait été jusque là le domaine de «l'expression », autrement dit de l'invention et du perfectionnement des formes artistiques, de

229 «.... l'art du peuple est si dépourvu de qualité artistique et de prétentions culturelles qu'il ne va jamais audelà de la tentative fruste et maladroite consistant à exprimer des faits triviaux accessibles à la sensibilité la plus grossière. C'est un art ingénu et retardé qui n'a en réalité d'autres fonctions que celle de satisfaire des nécessités ludiques et de décoration. » in ibib. En tout état de cause, Martins n'avait lu ni Lévi-Strauss ni Bastide et manifeste ici de forts préjugés de classe. Il est difficile de savoir dans quel mesure les cinemanovistas partageaient ces idées qui ont aussi été celles de Corbisier et Vieira Pinto. Dans le contexte de l'idéologie du développement, à droite comme à gauche, tous valorisaient l'industrialisation. Il faudra attendre au moins la fin de la décennie pour que la culture populaire et la culture indigène soient valorisées.

$230 \mathrm{Il}$ ne s'agit pas seulement d'une condamnation morale. Comme il assimile le peuple au nouveau, l'avènement du peuple, c'est à dire la Révolution, amènera forcément l'émergence d'une culture populaire authentique. In fine, la culture populaire surclassera la culture de l'élite, représentante obsolète d'un ancien stade du processus historique. 
leur développement illimité. Il cherche ainsi à établir une distinction entre expression et communication et s'appuie pour cela sur la dichotomie entre la forme et le contenu. L'artiste qui travaille pour l'élite ne se soucierait pas d'être compris, son public ferait naturellement l'effort de se mettre à la hauteur de son œuvre. Au contraire, l'artiste qui travaille pour les masses populaires ne peut s'attendre à une telle démarche de la part de son public, aussi doit-il faire passer les impératifs de la communication avant ceux de l'expression. Son but est d'être compris, de faire passer les contenus révolutionnaires afin, concrètement, que le peuple prenne les armes et fasse la Révolution :

\begin{abstract}
« Desejando acima de tudo que sua arte seja eficaz, o artista popular não pode jamais ir além do limite que lhe é imposto pela capacidade que tenha o espectador para traduzir, em termos de sua própria experiência, aquilo que the pretende transmitir o falar simbólico do artista. A quem nos disser que isto representa um cerceamento da liberdade criadora, responderemos que sim. [...] O que só não podemos aceitar é a afirmação de que os valores formais sejam tão valiosos que em seu nome se justifique o nosso afastamento do povo. Se estamos solidários com o povo é porque afirmamos que nossa arte só irá onde o povo consiga acompanhá-la, entendê-la e servir-se dela. $»^{231}$
\end{abstract}

Comme nous allons le voir, c'est sur ce point que va porter la mésentente. Les cinemanovistas ne peuvent accepter ni ses arguments (dichotomie entre le fond et la forme), ni ses conclusions (utiliser des formes déjà connues en introduisant des informations ou en défendant une morale révolutionnaire). Le concept de culture populaire va cependant demeurer au centre des débats, chacun prétendant produire l'authentique culture populaire révolutionnaire. Pour les deux partis cependant, la culture populaire n'est pas, comme on l'entend généralement, la culture produite ou consommée par les masses mais la culture fabriquée par les artistes détenteurs de la conscience critique et vecteur de transformation :

« Radical como é, nossa arte revolucionária pretende ser popular quando se identifica com a a aspiração fundamental do povo, quando se une ao esforço coletivo que visa dar cumprimento ao projeto de existência do povo o qual não pode ser outro senão o de deixar de ser povo tal como ele se apresenta na sociedade de classes, ou seja, um povo que não dirige a sociedade da qual é o povo. $»^{232}$

La controverse éclate le 26 septembre 1962 avec un article de Rocha intitulé « Cinema

231« Désirant par-dessus tout que son art soit efficace, l'artiste populaire ne peut jamais aller au-delà de la limite qui lui est imposée par la capacité que possède le spectateur pour traduire, au niveau de son expérience personnelle, tout ce que l'artiste prétend lui transmettre dans son langage symbolique. À ceux qui nous diront qu'il s'agit d'une restriction à la liberté créatrice, nous répondrons que cela est vrai. [...] Ce que nous ne pouvons pas accepter est l'affirmation selon laquelle les valeurs formelles sont si précieuses qu'en leur nom soit justifiée la mise à l'écart du peuple. Si nous sommes solidaires avec le peuple, nous devons affirmer que notre art n'ira que là où le peuple réussira à le suivre, le comprendre et en tirer profit. » in MARTINS, Carlos Estevam. « Anteprojeto ao manifesto do CPC », op. cit.

$232 \ll$ Radical comme il est, notre art révolutionnaire prétend être populaire quand il s'identifie à l'aspiration fondamentale du peuple, quand il s'unit à l'effort collectif qui vise à apporter un support au projet d'existence du peuple lequel ne peut être autre que de cesser d'être comme il se présente dans la société de classes, autrement dit, de cesser d'être un peuple qui ne dirige pas la société dont il est le peuple. » in ibid. 
Novo, fase morta e crítica» («Cinema Novo, phase morte et phase critique »). Martins répond à cet article le 3 octobre, et, le même jour, Diegues publie dans le même journal «Cultura popular e Cinema Novo » dans lequel il défend Rocha et ridiculise la position de Martins. À l'origine, Rocha, qui vient de terminer Barravento, cherche à reprendre le contrôle sur l'étiquette «Cinema Novo» dont il constate qu'elle a été fort galvaudée par sa récente popularité. Deux ans et demi après Arraial do Cabo, il s'agit de séparer le bon grain de l'ivraie et de définir ce qui est Cinema Novo et ce qui ne l'est pas. Selon lui, la situation a changé, Assalto ao trem pagador a conquis le public au cinéma brésilien et $O$ Pagador de promessas a détruit l'état colonial en obtenant la Palme d'Or à Cannes, la chanchada a décliné, Os Cafajestes a joué le rôle d'un électro-choc en provoquant la polémique et en secouant l'inertie de la profession et les préjugés du public et de la critique sur le cinéma brésilien. Une première phase est achevée, une seconde va commencer avec Barravento, Os Fuzis, Garrincha, Porto das Caixas, Sol sobre lama, Vidas Secas. Il effectue un tri :

«É bom, pois, enumerar nomes, à medida que se delineia um conceito : Anselmo Duarte, Aurélio Teixeira, Carlos Coimbra, Rubem Biáfora, Lima Barreto, Roberto Faria, estão verdadeiramente preocupados com um cinema de espetáculo, cinema que dê dinheiro e tire prêmios, enquanto Rui Guerra, Miguel Torres, Alex Viany, Paulo Saraceni, Nelson Pereira dos Santos e o grupo de Cinco vezes favela se preocupam mais com um cinema que exprima a transformação de nossa sociedade, comunicando e processando esta transformação. ${ }^{233}$

Martins réagit à l'article de Rocha dans un texte au titre explicite : «Artigo vulgar sobre aristocratas $»^{234}$ (« Article vulgaire sur des aristocrates »). Il transpose alors au domaine du cinéma les idées développées sur l'art en général dans l'avant-projet du manifeste du CPC. Il entre en profond désaccord sur la sélection effectuée par Rocha et sur l'importance accordée à la notion d'auteur :

\footnotetext{
« O que interessa são as obras e estas, do ponto de vista revolucionário (único de que me ocupo), dividem-se em socialmente revolucionárias e socialmente anti-revolucionárias. Para exemplificar, pode-se dizer que a atual safra do Cinema Novo só deu dois filmes socialmente revolucionários : Pagador de promessas e Assalto ao trem pagador. [...] Os filmes acima foram ambos entendidos, amados e assimilados pelas grandes massas populares, as massas que farão a revolução. Os freqüentadores de cineclubes e os cineastas 'novos' torcem a cara : são filmes comerciais. Para assuntos extra-cinematográficos,
}

233 « Il est bon de citer des noms afin de délimiter un concept : Anselmo Duarte, Carlos Coimbra, Rubem Biáfora, Lima Barreto, Roberto Farias, sont vraiment préoccupés par un cinéma de spectacle, qui rapporte de l'argent et qui remporte des prix, alors que Rui Guerra, Miguel Torres, Alex Viany, Paulo Saraceni, Nelson Pereira dos Santos et le groupe de Cinco vezes favela, sont préoccupés par un cinéma qui exprime la transformation de notre société, qui communique et qui soit un facteur actif de cette transformation. » Une liste plus complète est ensuite ajoutée « Ruy Guerra \& Nelson Pereira dos Santos \& Paulo Saraceni \& eu mesmo \& Alex Viany \& Jean-Claude Bernardet \& Gustavo Dahl \& Luis Carlos Barreto \& Joaquim Pedro \& Leon Hirszman \& Roberto Pires \& Miguel Torres \& Mário Carneiro \& Miguel Borges \& Marcos Farias \& Eli Azeredo \& David Neves »in ROCHA, Glauber. « Cinema Novo, fase morta (e crítica) » in $O$ Metropolitano, Rio de Janeiro, 26/09/1962.

234MARTINS, Carlos Estevam. « Artigo vulgar sobre aristocratas » in Diário de notícias, Salvador, 1962 , réédition de l'article publié dans O Metropolitano, 03/10/1962. 
estes rapazes se dizem ideologicamente conseqüentes e sobre isso fundam sua superioridade sobre os demais cineastas. Se assim fosse, deveriam colocar em primeiro lugar a revolução, em segundo os requintes artísticos, e deveriam, que o leitor me desculpe o primarismo, entender por revolução alguma coisa que acontece na sociedade e não no cinema. Indo por aí, não teriam igualmente dúvidas de que são as grandes massas que fazem a revolução e tratariam de encarar o cinema, uma arte de massas, acima de tudo como arma cultural que pode abrir o caminho para o fuzil. $»^{235}$

Martins en revient ensuite au problème du langage :

« Temos um povo inculto e alienado que vibra com os 'pagadores' e pode assimilar o conteúdo desses filmes porque não encontra obstáculos formais naquela linguagem fácil, convencional, 'comercial', familiar, popular. Os rapazes, ao contrário, estão ' empenhados ' em derrotar esta linguagem chinfrim. Para eles é como se ela fosse mais inimiga do que o imperialismo, o latifúndio, a burguesia. Querem criar uma nova linguagem e, por isso mesmo, o que conseguem é ficar falando sozinhos enquanto a platéia solta piadas e prefere se divertir consigo mesma, desinteressada daquela linguagem que, de tão nova e diferente, até parece estrangeira. $\rangle^{236}$

L'article de Martins entraînera de violentes réactions parmi lesquelles la plus notable reste celle de Diegues ${ }^{237}$. Ce dernier estime que, dans la situation présente, le principal est de rallier des intellectuels de véritable talent à la cause populaire avant de se soucier d'aller plus avant. Selon lui, la culture populaire traverse encore une phase de définition et son édification ne sera pas possible au travers d'une bureaucratie sectaire et dogmatique, qui décidera a priori ce qu'elle doit être. Selon lui, la culture populaire devra être conçue par l'élite intellectuelle, en se plaçant du côté du peuple, mais en prenant aussi en compte les spécificités de chaque discipline artistique.

À ce titre, il dit se méfier d'une culture qui est le fruit de plusieurs siècles d'oppression et qui, si elle remporte du succès, n'en est pas moins aliénante. L'art doit transformer mais aussi être libre. Il réitère ses réserves vis à vis de Assalto ao trem pagador et de O Pagador

235« Ce qui est intéressant, ce sont les œuvres et celles-ci, du point de vue révolutionnaire (le seul dont je m'occupe), se répartissent entre celles qui sont socialement révolutionnaires et celles qui sont socialement anti-révolutionnaires. Pour donner un exemple, nous pouvons dire que l'actuelle moisson du Cinema Novo n'a donné que deux œuvres socialement révolutionnaires : Pagador de promessas et Assalto ao trem pagador. [...] Ces films ont été compris, aimés et assimilés par les grandes masses populaires, les masses qui feront la révolution. Les assidus des ciné-clubs et les cinéastes ' nouveaux ' font la grimace : ce sont des films commerciaux. Sur les sujets extra-cinématographiques, ces jeunes gens se disent conséquents d'un point de vue idéologique et ils fondent sur cette prétention leur supériorité sur les autres cinéastes. S'il en était ainsi, ils devraient accorder la priorité à la révolution sur les raffinements artistiques, et ils devraient aussi, que le lecteur me pardonne ce raccourci primaire, comprendre que la révolution est quelque chose qui doit arriver dans la société et non au cinéma. En poursuivant dans cette direction, ils ne pourraient pas non plus avoir de doutes quant au fait que ce sont les grandes masses qui font la révolution et ils tâcheraient de voir le cinéma, un art de masses, avant tout comme une arme culturelle qui peut ouvrir le chemin du fusil. » in ibid.

236« Nous avons un peuple inculte et aliéné qui vibre avec les ' pagadores ' et peut assimiler le contenu de ces films parce qu'il ne rencontre pas d'obstacles formels dans ce langage facile, conventionnel, ' commercial ', familier, populaire. Nos jeunes gens, au contraire, s'appliquent à mettre en déroute ce langage commun. Pour eux, c'est comme s'il était plus dangereux que l'impérialisme, le latifundium, la bourgeoisie. Ils veulent créer un nouveau langage et, pour cela même, tout ce à quoi ils parviennent, c'est à parler seuls alors que le public, devant leurs films, échange des plaisanteries et préfère se divertir tout seul, ne manifeste aucun intérêt face à ce langage qui, pour être si nouveau et différent, paraît même étranger. " in ibid.

237Diegues et Rocha sont appuyés par le critique Sérgio Augusto. Cf. AUGUSTO, Sérgio. « A Mistificação da cultura » in Diário de notícias, Salvador, 10/1962. 
de promessas, dont il avait déjà souligné les ambiguïtés indiquant qu'il s'agissait d'un film qui pouvait plaire aussi bien à la gauche qu'à la droite. Ayant pris soin de nuancer sa position quant à la définition de la culture populaire, le cinéaste rejette violemment la conception de la culture populaire exprimée par Martins :

« O que esse intelectuais desejam é o bolero e o twist com a letra da Internacional? [...] Para o intelectual realmente de esquerda, dois problemas se colocam juntos, um decorrendo dos outros: Por um lado a preocupação com uma arte que transforme; por outro a garantia de liberdade entre as alternativas que esta arte possa ter como expressão / comunicação [...] Estamos preocupados em transformar consciências, não levá-las a uma forma de entorpecimento. Transformá-las profundamente, levá-las a novas formas de raciocínio [...] condizentes com sua situação de classes novas. ${ }^{238}$

La position de Diegues s'identifie ainsi parfaitement avec celle de Rocha. Ce qu'il faut comprendre c'est l'affirmation ici de ce qui restera une caractéristique du Cinema Novo : la recherche esthétique prévaut sur toute autre considération, elle est la priorité. Cela ne veut pas dire que le Cinema Novo abandonne l'idée de développer un cinéma de conscientisation, bien au contraire. La conviction que partage les cinemanovistas est que l'art, compris comme l'expression authentique et libre de l'artiste, constitue en lui-même, un discours désaliénant. Il est donc moins important de travailler un thème qui soit clairement politique que de réaliser un film qui soit créatif dans son esthétique. Nous pouvons lire ici l'influence directe de la réflexion de la Nouvelle Vague sur la représentation des camps de concentration (Kapo / Nuit et brouillard) qui les amènera à faire de la phrase : «Les travellings sont une affaire de morale », l'un de leurs gimmicks. L'adage de Maïakovski, «il n'existe pas d'art révolutionnaire sans un langage révolutionnaire », en est un autre.

Le Cinema Novo refusera donc de pratiquer un langage qui fonctionne par identification et catharsis, celui-ci étant considéré manipulateur, et produire des films qui s'organisent comme des discours fermés, imposant au spectateur une morale ou une idéologie sans laisser de marges d'interprétation. Les films seront ouverts et encourageront la distanciation critique du spectateur. Il faut susciter l'activité du spectateur. Le Cinema Novo oppose donc une nouvelle éthique aux simplifications du CPC. Tel fut tout au moins la résolution apportée en son temps à la dispute théorique qui opposa le CPC au Cinema Novo et tel est également l'analyse généralement pratiquée par les historiens du cinéma. Dans les faits,

238 « Ce que veulent ces intellectuels est-il le boléro et le twist avec les paroles de l'Internationale ? [...] Pour

l'intellectuel réellement de gauche, deux problèmes apparaissent étroitement liés, l'un étant la conséquence de l'autre : d'un côté nous avons le préoccupation de créer un art qui transforme : de l'autre la volonté de garantir la liberté dans le choix des alternatives que cet art peut avoir dans le choix d'un mode d'expression, de communication. [...] Nous nous intéressons à un art qui transforme les consciences, et non à un art qui les plongent dans la torpeur. Il s'agit de les transformer profondément, de les amener à de nouvelles formes de raisonnement [...] en accord avec leur appartenance à une classe nouvelle. » in DIEGUES, Carlos. « Cultura popular e Cinema Novo » in Diário de notícias, Salvador, 1962, réédition de l'article publié dans $O$ Metropolitano, 03/10/1962. 
si les positions de Martins étaient effectivement peu défendables, ses critiques et celles d'autres membres du CPC à l'encontre du Cinema Novo quant à son caractère populaire et à sa capacité à traiter des problèmes politiques les plus urgents ne vont pas rester lettre morte et miner les propres réflexions des cinemanovistas pendant au moins les dix années à venir. Même bien après l'extinction du CPC par les autorités militaires en 1964.

La réduction de la controverse entre le CPC et le Cinema Novo à une irréconciliable opposition cinéma de propagande / cinéma artistique restera toujours comme une conclusion finalement trop commode. Cette dichotomie va longtemps rester présente dans les réflexions des cinemanovistas comme une question à la résolution peu sûre. Même si les positions paraissent fermes, de nombreux documents nous montrent que plane l'idée d'un cinéma pamphlétaire, militant, ancrée dans l'actualité et manifestant des prises de position sans équivoque. Terra em transe est habité par l'ambiguïté entre un cinéma va-t-en guerre, d'appel à la guérilla et un cinéma de réflexion politique. Dans l'un de ses scénarios préliminaires, América nuestra, le personnage principal, Juan Morales, assume le rôle d'un authentique propagandiste, averti des nouvelles techniques de la guerre psychologique, quand il s'engage auprès de la Révolution. Entre les cinemanovistas, le doute persiste quant à savoir si le moment historique exige, ou non, un tel engagement de la part des cinéastes. Joaquim Pedro de Andrade estime que non dans un entretien accordé à Hablamos del cine en 1971239. Il s'agit pratiquement d'une question existentielle et morale pour des cinéastes qui ont réellement à cœur de pratiquer au travers de l'art une action utile à la lutte contre les inégalités sociales et la misère.

Enfin, il est important de noter que la controverse entre le CPC et le Cinema Novo s'est jouée sur un plan exclusivement théorique. Du cinéma qu'aurait pu créer le CPC nous ne savons rien puisque la durée de vie du mouvement n'a pas pu excéder deux ans et demi. Selon Eduardo Coutinho qui commence à l'époque le second long-métrage du CPC qui restera inachevé, Cabra marcado prá morrer, aucun dirigisme n'a été exercé à son encontre dans le choix et l'exécution de son projet. La crainte d'une planification bureaucratique des productions culturelles étaient donc de l'ordre du procès d'intention. Si l'on considère aussi le projet initial du CPC tel que le définit Oduvaldo Viana Filho, rien ne nous interdit de penser qu'il était possible que surgisse un cinéma militant, d'agitation sociale, mais distinct d'un cinéma de propagande classique basé sur des figures de manipulation. Un cinéma d'un format et d'un style différent de celui du Cinema Novo aurait peut être pu naître de la pratique du CPC basée sur la recherche de la rencontre directe avec les masses populaires, peut être au 
travers de la formule d'un cinéma itinérant. Quant aux thématiques traitées par le Cinema Novo, le contraste avec celles traitées par théâtre du CPC est frappant. Des conflits politiques résumés dans la première partie de ce chapitre, des stratégies de déstabilisation de la droite comme de l'activisme de la gauche, aucun des films du Cinema Novo n'en gardera la trace, chacun d'eux se concentrant sur les grands mouvements de l'histoire et les aliénations à combattre. 


\section{Chapitre 3 : Constitution du groupe du Cinema Novo}

\subsection{Trajectoire de Glauber Rocha}

Parallèlement aux débats d'idées et aux pratiques qui se mettent en place au travers du pays, le champ culturel brésilien est profondément remodelé entre la deuxième moitié des années cinquante et le début des années soixante. Des groupes se forment en fonction d'intérêts, d'affinités idéologiques ou encore selon de simples liens d'amitié. Entre 1962 et 1964, le groupe du Cinema Novo émerge de l'anonymat à mesure que les films et les prises de position de ses membres lui apportent des contours de plus en plus précis. Son origine est en fait très antérieure à cette période. Les témoignages concordent pour dater leurs premières rencontres entre 1957 et 1959 et attribuer la cohésion du groupe à la présence de Glauber Rocha. Nelson Pereira dos Santos répète d'ailleurs depuis les années soixante que le Cinema Novo, c'est Glauber Rocha à Rio de Janeiro. Pour une fois, la formule colle à la réalité et les éléments biographiques qui nous permettent de retracer sa trajectoire confirment pleinement l'idée selon laquelle le Cinema Novo fut avant tout le produit de sa volonté et de son travail. Entre 1955 et 1964, la création d'un mouvement de rénovation de la cinématographie nationale constitue même l'objet principal de ses différentes activités.

Né à Vitória da Conquista, état de Bahia, en 1939, Glauber Rocha (1939-1981) vient habiter avec sa famille à Salvador en 1948. Passionné par le cinéma dès son plus jeune âge, il intègre le Clube de Cinema da Bahia en 1952, ce sera là un lieu important de sa formation ${ }^{240}$. Reconnu comme l'un des plus actifs du Brésil, ce ciné-club est dirigé par Walter da Silveira (1915-1970) qui passe pour l'un des plus éminents spécialistes de cinéma de son temps au côté d'Alex Viany (1918-1992) et de Paulo Emílio Sales Gomes. Silveira est vite considéré comme un maître par Rocha qui fréquente assidûment le ciné-club jusqu'au début des années soixante. Selon le témoignage de Márcio Souza, son correspondant du Grupo de Estudos Cinematográficos do Amazonas, il fait alors partie de sa direction ${ }^{241}$. En 1954, Rocha entre au Colégio Central da Bahia (l'équivalent du lycée) et devient membre du Círculo de Estudos, Pensamento e Ação - CEPA, un groupe de réflexion nationaliste et integralista ${ }^{242}$. Le cinéma

240Selon le témoignage d'Orlando Senna, Silveira a montré dans son ciné-club absolument tout qu'il était nécessaire de connaitre en matière de cinéma. Les films étaient vus et commentés, il s'agissait donc d'un véritable cours d'histoire et d'esthétique du cinéma. In Deus e o diabo na terra do sol. DVD Versatil / Riofilmes, São Paulo / Rio de Janeiro, 2002. Silveira, Viany et Sales Gomes sont trois personnages de la même génération, le premier est basé à Salvador, le second à Rio et le troisième à São Paulo.

241VENTURA, Tereza. Op. cit., p. 17.

242Le parti integralista s'est illustré dans les années trente. Directement inspiré par le parti fasciste de Mussolini et le parti nazi allemand, il en était l'étrange transposition brésilienne. Si la pureté de la race pouvait difficilement être poursuivie, il s'agissait de construire un nationalisme brésilien basé sur les traits distinctifs 
et la politique, les deux principaux centres d'intérêts de Glauber Rocha tout au long de sa vie, sont donc présents, dès son adolescence même si son premier positionnement politique est très clairement à l'extrême-droite ${ }^{243}$.

Les archives conservées au Tempo Glauber montre que Rocha écrit indifféremment des nouvelles, des essais et des scénarios de films depuis son adolescence. Biographe et ami de lycée du cinéaste, João Carlos Teixeira Gomes témoigne avec émotion de la lecture par Rocha d'une de ses premières créations, une pièce de théâtre, à ses camarades de classe ${ }^{244}$. Le théâtre marque ses débuts puisque c'est avec les Jogralescas, en 1956, qu'il connaît sa première expérience artistique. Le groupe des Jogralescas est fondé sur une idée de Fernando da Rocha Peres. Son objectif est de mettre en scène des poèmes. Il ne s'agit pas de les déclamer selon la vieille tradition des récitals poétiques mais de valoriser leur dimension dramatique par le jeu théâtral et la scénographie. Les participants du groupe sont des camarades de lycée de Rocha, notamment Paulo Gil Soares qui travaillera ensuite sur plusieurs de ses films. Cinq ou six représentations ont lieu entre 1956 et 57. La vocation initiale du groupe est de promouvoir la poésie moderniste, notamment de Mário de Andrade, Manuel Bandeira, Carlos Drummond de Andrade, mais d'autres auteurs, même étrangers comme Federico García Lorca, sont intégrés au répertoire. Les participants du groupe, bien

de la nation et d'y adapter la pensée d'extrême droite européenne : le travail (idéologie anti-capitaliste), la famille (respect des valeurs chrétiennes et de l'Église), la patrie (mythe de la découverte du Brésil, rencontre des trois races, blanche, indienne et noire, apport à l'identité nationale selon les spécificités supposées de chacune). L'idéologie integralista est très fortement inspirée par le positivisme qui avait déjà eu beaucoup d'impact au Brésil. Le parti integralista adopte un décorum identique aux partis fascistes européens : milices para-militaires et uniformes avec pour symbole la lettre grecque epsilon et un salut martial en langue indienne « akanawé ». Le coup d'État de l'Estado Novo par Gétulio Vargas, en 1937, est en grande partie une tentative magistralement réussie de doubler les integralistas. Le parti mené par Plínio Salgado avait en effet réussi à fédérer des centaines de milliers d'hommes et semblait sur le point de réaliser lui-même un coup d'État d'extrême droite quand il fut pris de vitesse par le caudilho. Dans les années cinquante, il ne s'agit plus d'une force politique significative.

243« O símbolo do CEPA é eminentemente nacionalista : dois braços, um másculo e outro feminil, seguram em respectivo um martelo (símbolo do trabalho nacional) e uma cruz (símbolo do trabalho da Redenção Humana e primeiro símbolo nacional). » (« Le symbole du CEPA est éminemment nationaliste : deux bras, un masculin e un féminin, tiennent respectivement un marteau (symbole de travail national) et une croix (symbole de la rédemption humaine et premier symbole national ») in VENTURA, Tereza. Op. cit., p. 37. Bien qu'ayant recueilli des témoignages sur le CEPA, l'auteur n'analyse pas la participation de Rocha à ce groupe par ailleurs qualifié de « prestigieux » de part la qualité de ses participants, futurs compagnons de route de Rocha : Luís Paulino dos Santos (qui aurait dû réaliser Barravento), José Telles Magalhães et João Carlos Teixeira Gomes. Ce dernier réfute catégoriquement dans la biographie qu'il dédie à son ami l'attachement du CEPA au mouvement integralista. Selon lui, il s'agissait avant tout d'un espace de discussion, tous étant déjà très clairement de gauche (GOMES, João Carlos Teixeira. Glauber Rocha - Esse vulcão. Rio de Janeiro, ed. Nova Fronteira, 1997, p. 59). Au-delà des étiquettes, les relations entre nationalisme, extrême-droite et socialisme sont complexes. Rocha n'a jamais été militant fasciste mais, comme nous l'avons vu dans nos commentaires sur l'œuvre de Corbisier, il était sensible à certains éléments de l'idéologie integralista.

244GOMES, João Carlos Teixeira. Op. cit., p. 28. La pièce s'intitulait Séfanu e o diabo. La pièce devient un ballet avec la complicité d'un ami musicien. Rocha se souviendra plus tard de l'opinion de ses aînés : Séfanu fut « criticado pelos líderes intelectuais do terceiro ano Klassyko como Exoteryko e Homossexual » (« critiqué par les leaders intellectuels de troisième année du cours classique comme ésotérique et homosexuel ») in tempoglauber.com.br, rubrique « biografia ». 
qu'étant tous issus du Colégio Central, ont toujours tenu à montrer que les Jogralescas étaient venues de leur propre initiative et non de celle des professeurs. Selon Tereza Ventura et João Carlos Teixeira Gomes, les représentations ont obtenu un véritable succès de public et reçu les éloges de la presse et de l'élite intellectuelle de Salvador.

Exactement à la même période, Rocha crée avec plusieurs de ses amis des Jogralescas, la Sociedade Cooperativa de Cultura Cinematográfica Yemanjá dont les statuts furent enregistrées officiellement par l'Associação Comercial da Bahia. Selon son propre témoignage ${ }^{245}$, en essayant de capitaliser sur le succès théâtral, une campagne fut menée pour recueillir des fonds par voie d'affichage ${ }^{246}$, article de presse, appel radiophonique et même porte à porte. Rocha et ses amis cherchent à vendre des actions pour leur société et à obtenir des subventions de la municipalité. Le futur cinéaste qui commence juste sa carrière de critique et de journaliste publie un article intitulé «Você acredita em cinema na Bahia ?» («Vous croyez au cinéma à Bahia ?», 1957). De nombreuses idées de films sont formulées. Toutes tournent autour de la volonté de filmer Salvador et de s'appuyer sur la richesse de la culture de la ville et de ses environs. Bahia de todos os santos ou Bahia de todos sambas devait être un film composé de cinq épisodes. Rocha prépare un scénario semi-documentaire nommé Senhor dos Navegantes du nom d'une procession maritime rituelle au cours de laquelle une image du Christ est emmené en bateau dans la baie de Salvador.

Le court métrage de Luiz Paulino dos Santos, Um Dia na rampa (tourné en 1956 et vraisemblablement monté ou remonté plus tardivement), est associé par Tereza Ventura à Yemanjá Filmes mais il est peu probable que la coopérative ait joué un rôle significatif dans la production ${ }^{247}$. Si Paulino dos Santos fait bien parti des proches de Rocha, la production est attribuée à l'Universidade da Bahia par le journal Estado de São Paulo ${ }^{248}$. La participation de Yemanjá Filmes a été certainement plus humaine que financière et matérielle. Il est intéressant de noter qu'il s'agit d'un documentaire sur un lieu emblématique de Salvador, la Rampa du marché de Bahia où se croisent deux groupes distincts, les gens de Reconcavo qui

245ROCHA, Glauber. Revolução do Cinema Novo. Op. cit., p. 276. Nous retrouvons également quelques lettres concernant Yemanjá Filmes dans ROCHA, Glauber. Cartas ao mundo. São Paulo, Companhia das letras, 1997, p. 85-91.

246Reproduction de l'affiche in ROCHA, Glauber. Cartas ao mundo. Op. cit., p. 734. Rocha fait également référence à cette campagne dans : ROCHA, Glauber. « Bahia de todos os santos e Mandacarú vermelho: $\mathrm{O}$ Cinema descobre a Bahia » in Leitura, Rio de Janeiro, n³6, jun. 1960.

247Ventura et Teixeira évoquent tous les deux Yemanjá Filmes mais il leur importe avant tout de démontrer qu'au travers de cette initiative Rocha faisait preuve d'esprit d'entreprise, une qualité qui ne colle pas au cliché du génie détaché des contingences matérielles. Voir VENTURA, Tereza. Op. cit., p. 46. Tereza Ventura fait cependant l'erreur de confondre Bahia de todos os santos, le projet de Yemanjá Filmes avec Bahia de todos os santos, le film de Trigueirinho Neto.

248BERNARDET, Jean-Claude. «VI Bienal : Homenagem ao cinema brasileiro » in O Estado de São Paulo Suplemento literário, São Paulo, 14/10/1961. Um Dia na rampa est le film le plus ancien au programme de l'hommage au cinéma brésilien présenté à la biennale de São Paulo. 
viennent vendre leurs produits et les gens de la ville qui viennent acheter. L'idée du film semble donc proche de celle du projet de Yemanjá Filmes d'un cinéma nourri par la culture de Salvador. Paulino dos Santos devait également être le réalisateur de Barravento.

Le projet initial de ce qui deviendra le premier long métrage de Rocha date également de l'époque de Yemanjá filmes. Teixeira cite une lettre du cinéaste de 1958 où il décrit déjà le sujet $\mathrm{du}$ film ${ }^{249}$. Son argument est écrit par Paulino dos Santos. Rocha se réserve le rôle de producteur. Il ne pourra cependant réaliser ce projet, affiché depuis la fondation de Yemanjá Filmes, que quelques années plus tard, au sein d'Iglu Filmes. Conformément à ses projets de l'époque, c'est bien en tant que producteur qu'il fera plus tard ses premiers pas dans le cinéma. Il assume pleinement ce rôle sur le film de Roberto Pires, A Grande Feira, et c'est aussi dans ce rôle qu'il débute le tournage de Barravento. Si Yemanjá Filmes ne porte aucun fruit concret, le fait que Rocha s'intéresse avant tout à la production et à la création d'une maison de production démontre sa volonté d'initier un mouvement cinématographique collectif.

D'autres éléments démontrent cette volonté de création d'une dynamique collective. En 1957, Rocha voyage à Belo Horizonte pour rencontrer les membres du Centro de Estudos Cinematográficos - CEC de Belo Horizonte, et à Rio de Janeiro pour rencontrer Nelson Pereira dos Santos qui s'est déjà fait remarqué deux ans auparavant avec la sortie de Rio, quarenta graus $(1955)^{250}$. Ces voyages pourraient être interprétées de façon tout à fait banale dans le cadre des années cinquante où les ciné-clubistes les plus passionnés étaient en effet amener à correspondre et parfois même à voyager pour rencontrer leurs homologues des autres grandes villes du pays. Rocha agit pourtant en dehors du cadre des rencontres organisées par les fédérations de ciné-club et dans un but qui dépasse le cadre habituel de ce type d'échanges, il souhaite en effet convaincre d'autres passionnés de cinéma de se joindre à lui pour se lancer dans la production. Son objectif premier est d'établir des contacts qui seraient utiles à Yemanjá Filmes mais il prétend avant tout vouloir défendre le cinéma brésilien $^{251}$. Sa démarche est totalement volontariste, Rocha n'a rien d'autre que son enthousiasme. À Salvador, l'incapacité de Yemanjá Filmes à rassembler des fonds prouve combien son projet peut paraître utopique ${ }^{252}$.

249GOMES, João Carlos Teixeira. Op. cit., p. 47.

250Les lettres publiées dans Cartas ao mundo nous permettent de dater ce voyage entre janvier et mars 1957, in ROCHA, Glauber. Cartas ao mundo. Op. cit., 1997, pp. 84-85. Rocha fait lui-même référence à ce voyage dans plusieurs de ses textes comme notamment «O Cinema nasceu na Bahia » (« Le Cinéma est né à Bahia ») in ROCHA, Glauber. Revolução do Cinema Novo. Op. cit., pp. 310-316.

251Dans une lettre écrite de Rio à l'attention de Yemanjá Filmes début 1957, Rocha conclut : « Amanhã vou pedir o artigo a Jorge Amado. Espere cartão. E meus artigos ? Vão sair na Tarde ? É fundamental que saiam. Não por mim. Sim pela Yemanjá e pelo cinema brasileiro. » (« Demain je vais demander son article à Jorge Amado. Attendez ma carte postale. Et mes articles ? Vont-ils être publiés dans la Tarde ? Il est fondamental qu'ils sortent. Pas pour moi mais pour le cinéma brésilien. ») in ROCHA, Glauber. Cartas ao mundo. Op. cit., p. 88.

252Pour bien comprendre l'originalité de la démarche de Rocha, il faudrait la comparer à un aspirant réalisateur 
Sa première option consiste à partir à Belo Horizonte car le CEC est connu au travers de l'ensemble du pays grâce à la Revista de Cinema, l'une des rares revues de cinéma ayant existé au Brésil et selon Rocha, la meilleure du Tiers Monde ${ }^{253}$. Selon le propre témoignage de l'un des membres du groupe, Maurício Gomes Leite ${ }^{254}$, Rocha passe pour un exalté et ne reçoit aucun crédit. Dans un pays où l'édition d'une revue dans le style des Cahiers du cinéma passe déjà pour un exploit, le projet de ce qui n'est pas encore le Cinema Novo, semble absolument prématuré et irréalisable. À Rio, Rocha s'intègre à l'équipe de Rio, zona Norte pour y accomplir des tâches d'intérêt mineur ${ }^{255}$. Le contact avec Nelson Pereira dos Santos ne s'avère pas non plus décisif. Les deux hommes feront réellement connaissance lors du voyage de Santos à Salvador, juste avant le tournage de Mandacarú vermelho en 1960. Le premier voyage «d'affaires » de Rocha termine sur un constat d'échec qui est aussi celui de la précarité des moyens du cinéma brésilien dans son ensemble. Rocha découvre que les « grands », Pereira dos Santos et Alex Viany, ont énormément de difficultés à concrétiser leurs projets et n'ont pas le pouvoir de prêter assistance aux aspirants à la réalisation ${ }^{256}$. Jusqu'à l'approvisionnement en pellicule vierge est problématique. Santos interrompt le tournage de Rio, zona norte à cause d'une rupture de stock. La législation est défavorable au développement de la production nationale et Rocha dit rencontrer des hommes de cinéma vivant presque dans la misère ${ }^{257}$.

En 1957, conformément au parcours classique d'une jeune homme issu de la petite bourgeoisie, Rocha s'inscrit à la faculté de droit de Salvador. Cette discipline ne le passionne guère et il abandonnera ses études trois ans plus tard. Les biographes du cinéaste insistent souvent sur le fait qu'il ne s'est inscrit que sous la pression parentale. Il ne faudrait cependant pas oublier que le fait d'être étudiant en droit confère au futur cinéaste un statut et lui apporte des facilités qui vont s'avérer décisives. Parallèlement aux Jogralescas et aux tentatives de mettre sur pied Yemanjá Filmes, c'est dans la critique et le journalisme que Rocha conquiert

dans un pays qui possède une industrie cinématographique solide. La première idée est d'écrire un scénario et de tenter de le faire passer à un producteur ou à une institution publique dispensant subventions ou aides à la réalisation. Comme aucune institution n'existe à Bahia et que le cinéma qui se fait au Brésil ne convient pas à Rocha, il s'agit pour lui de créer à partir du vide. L'ordre des priorités se trouvent donc inversé, il apparait donc tout à fait cohérent qu'il cherche d'abord à créer une maison de production et parallèlement à mobiliser un maximum de personnes, avant tout par affinité culturelle, autour du projet de la création d'une cinématographie nationale. Pour lui, pour pouvoir faire du cinéma, il fallait d'abord que le cinéma existe. 253ROCHA, Glauber. Revolução do Cinema Novo. Op. cit., p. 290.

254IstoÉ, São Paulo, n²45, 02/09/1981.

255Le futur cinemanovista, Leon Hirszman, s'est aussi immiscé, comme Rocha, sur le plateau de Rio, zona norte pour tenter d'approcher de près une réalisation de cinéma (in SALEM, Helena. Leon Hirszman : o navegador das estrelas. Op. cit., p. 92). Rien ne nous permet cependant de dire que c'est là que les deux futurs cinéastes se sont rencontrés pour la première fois.

256Nous sommes à l'époque où Viany échoue à monter la production de Estouro na praça. Une expérience douloureuse qu'il racontera plus tard dans une entrevue. In VIANY, Alex. « Entrevista a Sérgio Payrell Porto : Alex Viany fala do Cinema Novo » in Revista de Cultura Cinematográfica, n³4, janvier-avril 1963. 257ROCHA, Glauber. Cartas ao mundo. Op. cit., pp. 86 -87 et 90-91. 
un espace d'expression significatif. Ses premiers textes sur le cinéma sont publiés dans un journal de gauche, O Momento, mais, très rapidement, il écrit dans Mapa et Angulos, deux revues financées par l'intermédiaire du recteur de l'Université de Bahia, Edgard Santos, et dans laquelle plusieurs figures de la culture bahianaise font leurs premières armes. La relation qui s'établit entre l'élite politique de Salvador et la génération montante est celle d'un mécénat entrant dans le cadre de la politique culturelle du gouverneur Juracy Magalhães.

«O Magnífico Reitor Edgard Santos era o Doge Mecenas Papa Justiceiro Deus maior Presidente que JK. Dava-me ao luxo da rebeldia. Edgard Santos não deu dinheiro pró Pátio mas financiou Ângulos e Mapa sem a menor restrição ao marxismo barroco tropicalista das publicações. $\rangle^{258}$

Nous retrouvons à la rédaction de Mapa les membres les plus importants du groupe des Jogralescas, Paulo Gil Soares, Fernando da Rocha Peres, Calasans Neto, João Carlos Teixeira Gomes et Glauber Rocha. Chroniques, contes, poèmes et essais en relation avec diverses disciplines artistiques composent la matière de la revue qui comptera 3 numéros entre 1957 et 1958. La revue Angulos de la faculté de droit de l'Université de Bahia dure plus longtemps, Rocha y est à la fois critique cinématographique et littéraire. Les contacts et les compétences démontrées lors de ses premières expériences dans l'édition lui permettent de participer au lancement d'un nouveau quotidien destiné à rivaliser avec les plus grands déjà existant à Salvador. O Jornal da Bahia est publié à partir du 21 septembre 1958 et Rocha y assume les fonctions de reporter d'histoires policières. Quelques temps plus tard, il dirige le supplément littéraire et permet à ses amis d'intégrer la rédaction. Parallèlement à ses activités dans l'édition, Rocha n'oublie pas le cinéma.

Alors que le projet de Yemanjá Filmes peine à se concrétiser, un autre jeune de Salvador, Roberto Pires (1934-2000) parvient à réaliser le premier long métrage de fiction produit à Bahia, Redenção, tourné en 1958 et sorti en 1959. Il s'agit d'un film de débutant, réalisé avec peu de moyens, mais il possède le mérite d'avoir été fait et de montrer qu'il est possible de faire du cinéma à Salvador. Rocha se rapproche aussitôt de Pires avec lequel il se lie immédiatement de sympathie. D'ailleurs, ce dernier l'assiste pour réaliser son premier court métrage, $O$ Pátio, qui est tourné avec les restes de pellicule de Redenção ${ }^{259}$. L'esthétique de ces deux films est assez éloignée des films à venir. Redenção (Rédemption) est un thriller inspiré par la tradition nord américaine du genre qui raconte l'histoire d'un violeur psychopathe qui est mis hors d'état de nuire par deux jeunes hommes dont l'un appartient à la police et qui trouve la « rédemption » en sauvant in extremis une jeune femme ${ }^{260}$. O Pátio est 
une exercice assez formaliste inspiré par le mouvement concretista alors en vogue. Au son d'une musique concrète, un couple évolue couché sur un échiquier géant cerné d'arbres et de plantes tropicales. Le cadrage et le montage, pensés en fonction de la musique, apporte sa dynamique à l'ensemble. Malgré leurs défauts, ces films réalisés dans un cadre semiprofessionnel vont ouvrir des portes. D'un côté, $O$ Pátio et les articles publiés dans la presse de Salvador vont constituer une excellente carte de visite pour Rocha lors de son deuxième voyage à Rio en 1959. D'un autre côté, Redenção peut légitimement être considéré comme le premier long métrage du cycle de Salvador dont il va être l'un des principaux artisans.

Contrairement au voyage de 1957, celui de 1959 va s'avérer extrêmement fructueux. Rocha rencontre enfin des jeunes qui partagent la même culture que lui, tous ont déjà derrière eux une longue pratique des ciné-clubs, et qui ont aussi cette volonté de faire du cinéma, que ce soit dans la réalisation, la production ou la critique. Ce sont les futurs cinemanovistas dont nous détaillerons les trajectoires dans le paragraphe suivant: Miguel Borges, Carlos Diegues, David Neves, Mário Carneiro, Paulo César Saraceni, Leon Hirszman, Marcos Farias et Joaquim Pedro de Andrade. Tous appartiennent déjà à des groupes constitués et feront profiter Rocha de leur connaissance des milieux cariocas. Dans ce groupe, seul Saraceni a déjà réalisé un court métrage, Caminhos. Rocha et Saraceni commencent d'ailleurs ensemble à fréquenter le bar en face du laboratoire Líder, à Botafogo, alors qu'ils montent leurs premiers courts métrages respectifs. Ce bar deviendra, pendant les années 60, le principal point de rencontre des cinemanovistas. Saraceni ouvre à Rocha les portes du Rio de Janeiro bohème et artistique de la fin des années cinquante. Il compare d'ailleurs celui-ci au Montmartre du XIXe siècle pour évoquer le dynamisme et la convivialité qui régnaient alors dans un monde encore étranger aux règles du star system moderne ${ }^{261}$. C'est ainsi que lui-même, jeune homme anonyme, se lie d'amitié avec Antônio Carlos Jobim ${ }^{262}$ qui, s'il n'est pas encore un musicien consacré à l'échelle planétaire, n'en est pas moins, comme le poète Vinicius de Morais, une personnalité déjà très en vue. Saraceni est aussi l'ami d'écrivains, comme Lúcio Cardoso et Otávio de Faria, ou encore des peintres et des graveurs, déjà célèbres comme Iberê Camargo, Newton Cavalcanti ou Goeldi ou d'autres, débutants, qui auront leur place dans l'histoire du Cinema Novo comme Fernando Campos et Rogério Duarte, l'auteur de l'affiche de Deus e o diabo na terra do sol. Saraceni est aussi l'ami de Paulo Carneiro chef opérateur et cameraman de nombre de films à venir à commencer par Arraial do Cabo.

Dans A Revolução do Cinema Novo, Rocha revient souvent sur cette période où il fit

261SARACENI, Paulo César. Op. cit., p. 45.

262Dans l'entretien qu'il nous a accordé, Saraceni nous a expliqué qu'il était très simple alors de rencontrer de tels personnages. Lui-même avait connu Jobim dans un bar. Pour preuve de cette amitié, celui-ci compose en 1962 la musique du premier long métrage de Saraceni : Porto das Caixas. 
son entrée dans le petit monde de l'intelligentsia carioca et il reconnaît l'importance des rencontres qu'il a pu faire en suivant Saraceni dans les nuits festives de la zone Sud de Rio. Sa rencontre avec Leon Hirszman a aussi été très importante dans la mesure où ce dernier connaissait la troupe du Teatro de Arena : Oduvaldo Viana Filho, Francisco de Assis, Nelson Xavier, Augusto Boal, Gianfrancesco Guarnieri ainsi que les membres du mouvement Neoconcretista de Rio, Ferreira Gullar, Lígia Pape, Lígia Clark, Hélio Oiticica et Norma Pereira Rego. Dès 1959, un cadre est donc posé qui va finalement peu changer pendant au moins les dix années à venir. Même si tous n'ont pas encore réellement commencé leur carrière, les principaux artistes qui vont faire l'actualité de la culture pendant cette période, sont présents et se connaissent déjà. D'autres, surtout en provenance de Salvador ou São Paulo, viendront encore s'intégrer à ce milieu mais sans altérer ses bases matérielles. Il faudra attendre les années 70 pour que Rio perde son hégémonie culturelle du fait du naturel renouvellement des générations mais aussi de la profonde transformation des infrastructures médiatiques impulsée par le régime dictatorial et des transformations, à l'échelle mondiale, de l'économie de l'art et de la communication.

Une anecdote nous montre la facilité et la rapidité avec laquelle Rocha évolue dans les milieux cariocas. Lors de ce même voyage de 1959, il présente $O$ Pátio chez Lígia Pape en présence, entre autres, de Mário Pedrosa, Lígia Clark, Ferreira Gullar, Hélio Oiticica et Reinaldo Jardim. Conjointement, Saraceni présente Caminhos. La projection est suivie d'un débat au cours duquel, Jardim, alors rédacteur en chef du Suplemento Dominical do Jornal do Brasil - SDJB, propose aux jeunes cinéastes de lancer le mouvement cinématographique auquel ils rêvent dans les pages de son journal. Rocha suggère que ce soit Miguel Borges qui rédige le manifeste. Une réunion est programmée à laquelle participent aussi Marcos Faria et Hirszman. Joaquim Pedro de Andrade est absent car il prépare son premier court métrage. L'histoire du manifeste du cinéma « bola-bola », littéralement du «ballon-ballon », appartient désormais à la légende du Cinema Novo. Borges présente un texte qu'il ne termine pas de lire, vexé par les railleries des ses camarades. Son préambule est cependant caractéristique de l'inspiration formaliste qui règne alors. Celle-ci est étroitement liée au succès des mouvements concretista et neoconcretista dans les autres disciplines artistiques à São Paulo comme à Rio mais aussi à l'influence des nostalgiques du cinéma muet qui sont souvent aussi les créateurs historiques des ciné-clubs les plus importants ${ }^{263}$ :

263Walter da Silveira était un spécialiste de Charlie Chaplin. Otávio de Farias, bien qu'écrivain, était aussi un cinéphile accompli, fan de Chaplin, et faisait partie de ceux qui pensèrent longtemps que le son avait brisé la magie du cinéma. Fondateur en 1928 du premier ciné-club du Brésil, le Chaplin Club, il participa à la diffusion de la culture cinématographique au Brésil avant que les cinémathèques de Rio et São Paulo ne soient fondées. Il fut un maître pour Saraceni mais il ne jouit pas de la même considération que Silveira, Sales Gomes ou Viany dans le monde du cinéma. Notamment, pour être de droite et avoir été integralista. 
« Não queremos mais cinema-literatura. Não queremos mais cinema-escultura. Não queremos mais cinema-música. Não queremos mais cinema-dança. Não queremos mais cinema-teatro. Queremos cinema-cinema. » Saraceni trouve ce préambule ridicule : «Parece o filho pedindo para o pai : Quero uma bola. Não uma bola de futebol, não uma bola de basquetebol, não uma bola de vôlei, não uma bola de pólo aquático, não uma bola de tênis, não uma bola de bilhar, não uma bola de pingue-pongue. Quero uma bola-bola! » ${ }^{264}$

Le manifeste du cinéma «bola-bola» ne doit cependant pas passer pour un fauxdépart car à cette époque, selon le propre aveux de Rocha ${ }^{265}$, tout est encore confus. Ce qu'il est important de retenir c'est que Rocha étend alors ce que nous appellerions aujourd'hui son « réseau » à la ville de Rio. C'est notamment à la suite de ce voyage qu'il commence à publier ses critiques de cinéma dans le prestigieux $S D J B$. La tribune qui lui est alors offerte lui permet d'initier et d'alimenter le débat avec Bernardet, Dahl et Sales Gomes que nous avons déjà largement détaillé au chapitre 1. Le prestige que lui apportent ses articles et les relations qu'il a à Salvador faciliteront grandement son insertion dans les milieux artistiques de Rio de Janeiro. Il s'installera d'ailleurs dans cette ville en 1961, au moment du montage de Barravento. Dans l'intervalle, et parallèlement à l'édification du concept critique du Cinema Novo, il se distingue comme l'un des principaux responsables du cycle de Bahia.

Les historiens du cinéma brésilien, à la suite de ce qui en était dit par la presse à l'époque $^{266}$, désignent par l'expression «cycle de Bahia », l'ensemble des films réalisés à Salvador entre 1958 et 1962 et donc, indifféremment, les films dont l'initiative revient à la société de Salvador et ceux, dirigés et produits par des personnes étrangères à cette ville. Ainsi, sont rassemblés Bahia de todos os santos (1960) et O Pagador de promessas (1962), deux projets paulistas, Mandacaru vermelho (1961), d'origine carioca, et Redenção (1959), A Grande Feira (1961), Tocaia no asfalto (1962) et Barravento (tourné en 1960 et terminé en 1962), réalisés par des gens de Salvador avec des capitaux originaires de Salvador ${ }^{267}$.

Voir sur ce sujet l'article « Cineclube » dans RAMOS, Fernão et MIRANDA, Luís Felipe (org.).

Enciclopédia do cinema brasileiro. Op. cit., 2000.

264 « Nous ne voulons plus de cinéma-littérature. Nous ne voulons plus de cinéma-sculpture. Nous ne voulons plus de cinéma-musique. Nous ne voulons plus de cinéma-danse. Nous ne voulons plus de cinéma-théâtre. Nous voulons du cinéma-cinéma ». In SARACENI, Paulo César. Por dentro do Cinema Novo - Minha Viagem. Op. cit., p. 47.

265ROCHA, Glauber. Revolução do Cinema Novo. Op. cit., p. 16.

266Le soudain dynamisme de Salvador en matière de cinéma coïncidant avec l'intérêt tout aussi soudain des producteurs paulistes et cariocas pour filmer à Bahia crée le mythe d'une nouvelle capitale cinématographique. La presse carioca et pauliste se penche sur le nouveau phénomène alors que la municipalité tente de capitaliser sur le succès de $O$ Pagador de promessas pour attirer de nouveaux tournages. Voir à ce sujet la campagne par voies de presse et d'affichage, encadré à côté de l'article : GOMES, Paulo Emílio Sales. « Calor da Bahia » in O Estado de São Paulo - Suplemento literário, São Paulo, 24/11/1962.

267Furent encore tournés à Bahia dans la même période : Três Cabras de Lampião (Aurélio Teixeira, 1962); $O$ Caipora (Oscar Santana, 1963) ; Sol sobre lama (Alex Viany, 1963) ; O Grito da terra (Olney São Paulo, 1964). 
Paradoxalement, les films de la trilogie du sertão, Deus e o diabo na terra do sol, Vidas secas et Os Fuzis, tournés dans le même état et dont les repérages et même les tournages ont pu commencer en 1962 ne portent plus cette étiquette du cycle de Bahia. Nouveau rebondissement, quinze ans plus tard, Dona Flor e seus dois maridos (1976) ressuscitera le mythe d'une cité qui offrirait une scénographie parfaite. La ville ne retrouvera cependant pas la dynamique qui en avait fait autrefois l'éphémère capitale du cinéma brésilien. En 1960, Rocha suit de près les tournages de Bahia de todos os santos et de Mandacaru vermelho, il apporte éventuellement son aide à la réalisation de ces projets mais sa participation est d'un tout autre ordre dans le cas des longs métrages dont l'initiative revient à la ville.

D'un point de vue historique, Salvador n'a pas encore vécu, à la fin des années cinquante, un seul de ces cycles mythiques qui ont fait jusque là l'histoire du cinéma de fiction brésilien. Pour cette raison, Redenção (1959) fait date et attire l'attention de Rex Schindler et Braga Netto deux personnages issus de la moyenne bourgeoisie qui décident de tenter l'aventure du cinéma en créant une maison de production, Iglu Filmes, laquelle va produire coup sur coup Barravento, A Grande Feira et Tocaia no asfalto. Selon André Setaro, Iglu Filmes est créée suite à la rencontre de Rocha avec Schindler dans le bureau de Leão Rosemberg, photographe ${ }^{268}$. Iglu Filmes apparaît alors clairement comme le fruit de sa persévérance dans son projet de créer une infrastructure cinématographique à Salvador et la concrétisation du projet avorté de Yemanjá Film. Nous détaillerons l'histoire d'Iglu Filmes, d'un point de vue économique et commercial dans une autre partie. Il apparaît aux observateurs de l'époque, et en particulier à Sales Gomes qui effectue un voyage à Salvador au moment de l'apogée du cycle de Bahia, que Rocha est le mentor intellectuel de l'entreprise. Producteur exécutif de $A$ Grande Feira et consultant pour Tocaia no asfalto, il suit ces films de la première idée de scénario jusqu'à leur sortie commerciale. Sa collaboration avec Pires est étroite. Les films sont en effet discutés collectivement même si, paradoxalement, c'est bien Pires qui devient le réalisateur vedette de l'époque grâce au succès que rencontre $A$ Grande Feira à Salvador. À titre de comparaison, insatisfait par son premier long métrage, Rocha mettra presque deux ans avant de terminer le montage de Barravento qui devra encore attendre deux ans avant de connaître sa première sortie commerciale.

L'aventure d'Iglu Filmes va rapidement péricliter en raison de désaccords esthétiques et politiques opposant les producteurs à leurs jeunes protégés. L'intégration de Rocha à Rio lui offre également de nouvelles perspectives même s'il n'oubliera pas ses attaches à Salvador. Alors que le Cinema Novo commence à prendre forme autour de la production de ses amis cariocas, Rocha va cependant inclure systématiquement Pires aux listes qu'il fait des 268RAMOS, Fernão et MIRANDA, Luís Felipe (org.). Enciclopédia do cinema brasileiro. Op. cit., p. 135. 
participants du mouvement ${ }^{269}$. Parallèlement, il exclut Roberto Farias, cinéaste dont Pires pouvait paraître proche ${ }^{270}$. Ce manque de cohérence est aussitôt remarqué par les autres critiques mais il s'explique facilement par l'amitié qui les relie. Pires a suivi Rocha à Rio où il réalise son quatrième film, Crime no Sacopã (1963) produit par Copacabana Filmes, la maison de production de Jarbas Barbosa. Il s'agit d'un thriller basé, comme Assalto ao trem pagador, sur un fait divers célèbre. Le film sort à l'époque dans une totale indifférence et il est aujourd'hui pratiquement oublié. La carrière de Pires marque le pas alors que celle de Rocha décolle. En 1964, le succès de Deus e o diabo na terra do sol apporte à ce dernier une projection internationale. L'apogée de la carrière de Rocha va plus ou moins correspondre à la période d'existence du Cinema Novo (1962-1972). Rocha devient le leader de ce qu'il conçoit comme un mouvement même s'il faudra prendre garde à ne pas confondre ses idées avec celle $\mathrm{du}$ groupe dans son ensemble. Cette identification n'est valable, comme nous allons le voir, que pour le livre Revisão crítica do cinema brasileiro et pour ses trois plus grands films, Deus e o diabo na terra do sol (1964), Terra em transe (1967) et O Dragão da maldade contra o santo guerreiro (1969). A Estética da fome (1965), son manifeste le plus connu, ne remporte pas une adhésion unanime auprès des autres membres du groupe même si aucun désaccord explicite n'est exprimé. Leader du Cinema Novo, Rocha n'en est pas moins, comme nous aurons l'occasion de le détailler très largement, le cinéaste à la trajectoire la plus singulière.

Pendant cette période de succès, Rocha obtiendra de la Mapa Filmes qu'elle confie à Pires la réalisation d'un long métrage. En marge du Cinema Novo, Máscara da traição (1969) est un thriller quasi hitchcokien qui, sans être un blockbuster, est un véritable succès auprès du public. Dans les années 70, Rocha et Pires collaborent de nouveau ensemble puisque ce dernier monte Di Cavalcanti (1977) et occupe la fonction de chef opérateur sur A Idade da Terra (1981). Cette dernière période de la carrière de Rocha est la plus sombre. Après le succès international obtenu par O Dragão da maldade contra o santo guerreiro, Rocha refuse les propositions de l'establishment du cinéma et notamment d'Hollywood adoptant en cela une option opposée à celle de Bernardo Bertolucci, un cinéaste ami et comme lui marqué à gauche. Rocha tourne à l'étranger en 1969. Il réalise Der Leone have sept cabeças au Congo et Cabezas cortadas en Espagne. Ces deux films qui prolongent les expériences esthétiques les plus extrêmes du Cinema Novo (voir dans la quatrième partie l'analyse consacré à Pindorama) ne sortent pas au Brésil et sont reçus avec frilosité dans les rares pays où ils

269Cf. ROCHA, Glauber. « Cinema Novo, fase morta (e crítica)» in O Metropolitano, Rio de Janeiro, 26/09/1962 ; cf. aussi le livre ROCHA, Glauber. Revolução do Cinema Novo. Op. cit., p. 438.

270Les deux cinéastes ont en commun leur goût pour le thriller nord-américain, et, de façon plus générale, pour un cinéma narratif au montage dynamique. Redenção, Tocaia no asfalto et Crime no Sacopã, de Pires, s'inscrivent ainsi dans la même veine que Cidade ameaçada et, surtout, Assalto ao trem pagador de Farias. 
sortent (en France). En 1971, commence l'exil de Rocha qui n'était déjà présent au Brésil que de plus en plus intermittente depuis 1964.

Pendant cette période, Rocha perd progressivement son espace d'expression. Après un séjour d'un an où il ne parvient à conclure aucun projet, il part en Italie où, comme nous le Cinema Novo avait ses réseaux. Pendant cette période, il tente de terminer Câncer, filmé en 1968 et monté à Cuba. Il met aussi en train le documentaire fleuve História do Brasil, film d'archives commencé à Cuba et continué en Italie. Ces travaux seront connus du public dans les années quatre-vingt dans des versions restées inachevées. En 1974, il est au Portugal au moment de la Révolution des EEillets et participe à la réalisation d'un documentaire sur l'événement: As Armas e o povo (1975) signé par un collectif, le Sindicato dos Trabalhadores da Produção de Cinema e Televisão. En 1975, il filme les grandes manifestations organisées par le PCI en Italie et les inclut à un nouveau film de fiction réalisé dans ce pays, Claro (1975) qu'il parvient à conclure mais qui ne sera pas commercialisé. Paradoxalement, alors même que ses prises de position dans la presse et cette nouvelle orientation dans son œuvre semblait cohérent avec un positionnement politique constamment revendiqué à l'extrême gauche, Rocha envoie au Brésil un article dans lequel déclare son admiration pour le général Golbery de Couto e Silva, principale éminence grise du régime dictatorial, et prône l'ouverture en faveur des militaires.

Article visionnaire pour les uns, retournement de veste indécent pour les autres, l'article publié dans la revue Visão pour le dixième anniversaire de la « Révolution » anticipe la fin de son exil. Le scandale provoqué par le texte et les négociations occultes qui permettent son retour en 1976 ouvre la dernière phase de sa carrière. Pendant son absence, l'Empresa Brasileira de Filme - EMBRAFILME a été créée avec le concours des plus éminents cinemanovistas : Luiz Carlos Barreto, Zelito Viana, Gustavo Dahl, Joaquim Pedro de Andrade, Nelson Pereira dos Santos, Arnaldo Jabor et Carlos Diegues. Bien que se déclarant chacun comme appartenant à l'opposition, ils acceptent tous de collaborer avec les militaires pour la création d'une entreprise à capital mixte qui aboutira de fait à la quasi nationalisation du cinéma brésilien. La main mise d'Embrafilme sur la production et la distribution des films brésiliens divisent le groupe du Cinema Novo. Les cinéastes et producteurs cités ci-dessus conserveront leurs entrées dans l'entreprise alors que d'autres comme Saraceni ou Hirszman entreront en conflit avec elle et ne parviendront pas à en tirer beaucoup de profit. Paradoxalement, alors que Rocha continue à afficher son appui au militaire au point de rompre avec la majorité de ses anciens amis, il rencontre les plus grandes difficultés pour réaliser A Idade da Terra (1980) dont le tournage va s'étirer sur plusieurs années. Dans l'intervalle, il réalise un documentaire sur la mort du peintre Di Cavalcanti, $D i$ 
(1977) qui remporte le prix du meilleur court métrage à Cannes, écrit un roman, Riverão Suassurana (1977) et anime un programme de télévision sur Canal Tupi qui remporte un vif succès, Abertura.

En 1980, quand il parvient enfin à conclure A Idade da Terra, le film est mal compris à Venise où Rocha fait scandale et proteste contre la soumission du festival aux intérêts commerciaux. Embrafilme enfin qui semble n'avoir produit le film que dans le but de remplir une «obligation» se désintéresse totalement de sa promotion. Lancé maladroitement au Brésil, le film ne remporte aucun succès auprès du public. Il ne sort pas non plus à l'étranger malgré les bonnes critiques recueillies en France. Co-producteur du film, Rocha sort ruiné et écœuré de cet échec. L'orientation que prend le cinéma ne lui convient pas et son retour au pays, pourtant si ardemment attendu pendant les années d'exil, l'a confronté à maintes désillusions. Déprimé, il quitte de nouveau le Brésil et part habiter à Sintra au Portugal. Làbas, la mort le surprend de façon prématurée alors qu'il commençait à nourrir de nouveaux projets. Rocha décède dans des conditions dramatiques en août 1980 juste après avoir été rapatrié d'urgence à Rio de Janeiro. Son enterrement rassemble les cinemanovistas dont un certain nombre avec lesquels il s'était pourtant disputé et de nombreux artistes et intellectuels dans un climat d'exaltation et de révolte.

\subsection{Le groupe du Cinema Novo}

Le groupe du Cinema Novo se structure autour de la présence et de l'activisme de Rocha entre 1957 pour les tous premiers contacts et 1964 pour les dernières rencontres déterminantes comme celle de Zelito Viana qui, comme nous le verrons, deviendra l'un des producteurs les plus importants du groupe. Premier membre du groupe d'abord désigné comme figure tutélaire et finalement adopté par cooptation au début des années soixante : Nelson Pereira dos Santos.

Santos est né à São Paulo en 1928. Issu d'un famille d'un niveau de vie assez modeste sans pour autant connaître la pauvreté, il poursuit sa scolarité jusqu'à l'Université où il apprend le droit. Affilié au PCB depuis le lycée, son principal objectif est pourtant le cinéma. Il débute dans la réalisation en 1950 en tournant un premier documentaire, Juventude, sur les jeunes travailleurs de São Paulo pour le Festival de la Jeunesse de Berlin qui réunissait des jeunes communistes du monde entier. En 1951, il est assistant de réalisation sur le long métrage de fiction $\mathrm{O}$ Saci dirigé par Rodolfo Nanni et destiné à un public infantil. Le film obtient différents prix au Brésil. L'appartenance de Santos au PCB lui permet de s'appuyer sur ses réseaux afin de faire ses premiers pas dans le métier. Chef opérateur du Saci et camarade 
au parti, Ruy Santos invite le jeune homme à l'assister sur son propre film, Aglaia qui ne sera pas terminé. Pereira dos Santos enchaîne cependant comme assistant de direction sur un autre film d'un membre du PCB, Agulha no palheiro (1952) d'Alex Viany. Il participe d'ailleurs aux côtés de ce dernier aux congrès sur le cinéma qui sont organisés dans le climat nationaliste qui domine la présidence de Vargas (1950-1954) : I Congresso Paulista de Cinema (São Paulo, 1951) ; I Congresso Nacional de Cinema (Rio de Janeiro, 1952) et II Congresso Nacional de Cinema (São Paulo, 1953). Pereira dos Santos se distingue alors comme l'un des pionniers de l'organisation du secteur cinématographique et de son action auprès de l'état pour obtenir satisfaction vis à vis d'une série de revendications qui devaient permettre le développement du cinéma brésilien. Après un dernier film en tant qu'assistant-réalisateur, Balança mas não cai, une chanchada de Paulo Vanderley (1953), le jeune cinéaste décide de tourner son premier long métrage, Rio quarenta graus (1954) qui sera tourné avec des moyens dans un régime de coopérative. Se faisant, il inaugure la voie du cinéma indépendant brésilien que nous avons déjà commenté.

À sa sortie en 1955, le film est interdit par le préfet de police sous le prétexte véritable qu'il donnerait une image dégradante du Brésil dissimulé par le prétexte fallacieux qu'il ne ferait jamais $40^{\circ} \mathrm{C}$ à Rio de Janeiro. L'interdiction du film à Rio déclenche un scandale national permet le ralliement de nombreux intellectuels importants comme l'écrivain Jorge Amado à un jeune homme qui n'était jusque là qu'un anonyme. La campagne qui suit permet la libération du film qui remporte un succès de scandale. Les spectateurs qui avaient pu s'imaginer que l'interdiction avait été dû à des scènes osés en seront pourtant pour leur frais. Inspiré par le Néo-réalisme italien, Rio quarenta graus raconte la journée d'un groupe d'enfants vendeurs de cacahuètes grillées qui, descendus de la favela, se trouvent disséminés dans les coins les plus chics de la capitale afin de vendre leur produit. Tourné en extérieur, saisissant le contraste insupportable entre les nantis qui s'adonnent aux loisirs et les enfants qui vivent diverses mésaventures, le film joue sur l'empathie et cherche à briser l'indifférence qui entoure les modestes vendeurs de cacahuètes. Il devient un modèle pour les jeunes qui aspirent à un cinéma différent de la Vera Cruz ou de la chanchada. Avant même que les cinemanovistas ne se connaissent entre eux, la plupart auront individuellement élu Pereira dos Santos comme un modèle. Rocha ira même jusqu'à faire de Rio quarenta graus le premier film du Cinema Novo ce qui ne nous semble pas juste même s'il est bien, et à plusieurs titres, un film précurseur.

Après Rio quarenta graus, Pereira dos Santos poursuit son expérience du cinéma d'indépendant. Comme nous l'avons vu, il produit un deuxième film qu'il réalise lui-même, Rio zona Norte et le premier long métrage du pauliste Roberto Santos, O Grande Momento. 
Les films sont malheureusement des échecs commerciaux et le cinéaste-producteur se voit contraint d'accepter des métiers alimentaires (correcteur d'un quotidien, assistant du cinéaste de documentaire et de publicité Jean Manzon dont nous aurons l'occasion de reparler). La carrière de Santos reprend au début des années soixante avec deux films mineurs, Mandacaru vermelho (1961) et Boca de ouro (1963). Maintenant intégré au groupe du Cinema Novo, il s'est définitivement lié avec Rocha au moment du tournage de Mandacaru vermelho à Bahia, il tourne Vidas secas (1963) qui sera pour lui le film de la consécration. La période du Cinema Novo n'est pourtant pas pour Santos une période faste. Malgré le succès de ce dernier film, il peine à réunir les conditions nécessaires à la réalisation de son nouveau projet qui ne sera tourné qu'en 1970, Como era gostoso o meu francês (1971). Il se tourne donc vers l'enseignement du cinéma et participe aux côtés de Sales Gomes et Bernardet à la création d'un cours de cinéma dans la jeune université de Brasília - UnB. Conçu sur la base du projet de Darcy Ribeiro, ancien ministre de Goulart, et doté d'une orientation pédagogique innovante et progressiste, l'université entre rapidement en conflit avec le régime militaire. La répression dont elle est l'objet contraint à la démission des ses meilleurs professeurs qui, pour la plupart, retournent à leurs postes d'origine à São Paulo ou Rio de Janeiro. Santos poursuivra sa carrière à l'Universidade Federal Fluminense - UFF à Niterói.

Avant de pouvoir réaliser Como era gostoso o meu francês, il accepte cependant des films de commande qu'il réalise sans enthousiasme comme le premier, El Justicero (1966) ou dans la confrontation, Fome de amor (1968). Alors que le premier peut être de nouveau considéré comme un film mineur dans lequel l'auteur s'est peu investi, le second marque son retour dans les débats esthétiques qui font le Cinema Novo. Après Fome de amor, Santos réalise coup sur coup dans la petite ville côtière de Paraty : Azyllo muito louco (1969), Como era gostoso o meu francês (1970) et Quem é Beta ? (1972). Très différents l'un de l'autre, ces trois films témoignent de son intérêt pour les différentes orientations esthétiques qui sont alors envisagées au sein du groupe du Cinema Novo. Nous reviendrons sur cette trilogie dans la quatrième partie. Quem é Beta ? est déjà un film de rupture avec l'esthétique et l'idéologie du Cinema Novo auxquelles il avait jusque là adhéré même s'il est possible de lire dans ses films une certaine distanciation d'avec les ambitions révolutionnaires et de conscientisation du groupe. En 1974, une nouvelle phase de sa carrière commence. Après avoir été un acteur acharné pour l'adoption d'une politique d'encouragement et de défense de la production cinématographique brésilienne depuis plus de vingt ans, Santos, avec Joaquim Pedro de Andrade, fait partie des principales personnalités consultées par le gouvernement du président Ernesto Geisel dans le but reformuler la politique de l'État en la matière. Les négociations qui sont menées dans le plus grand secret aboutissent à la reformulation d'Embrafilme qui existait 
déjà depuis 1969, et à la création du Concine. Roberto Farias, un proche du Cinema Novo malgré le rejet de ses films par Rocha au moment de la crise avec le CPC, devient le président de l'entreprise qui, en l'espace de quelques années, parviendra à occuper 30\% du marché intérieur et amener le volume de la production au-dessus de 100 longs métrages par an (117 en 1977). Une période faste commence pour le cinéma brésilien, elle durera jusqu'à l'accès au pouvoir du président Fernando Collor (1990-1992) qui, d'idéologie ultra-libérale, considère que l'État n'a pas à intervenir dans le domaine de la culture et décide l'extinction de ces structures. L'arrêt brutale des activités d'Embrafilme provoque une chute vertigineuse de la production qui montre, comme l'admettra également Santos, que l'entreprise n'avait pas atteint son principal objectif qui consistait à imposer le cinéma brésilien d'un point de vue culturel et permettre le développement d'un secteur cinématographique fort et autonome d'un point de vue économique.

Parallèlement à sa participation à la reformulation d'Embrafilme, Santos donne une nouvelle impulsion à sa carrière avec $O$ Amuleto de Ogum (1974) qui rompt avec l'idée d'un cinéma dont la dramaturgie est pensée par une élite pour le peuple et tente au contraire l'expérience d'une dramaturgie conçue uniquement à partir de valeurs populaires ${ }^{271}$. Le cinéma de Santos, à partir de cette époque, rompt avec l'idée d'un cinéma de conscientisation dans lequel, même de manière très ouverte, le cinéaste estime en savoir plus que le public et tente de lui apporter des savoirs, de transformer ses valeurs, et de faire de lui l'acteur politique qu'il suppose qu'il n'est pas. À partir de $O$ Amuleto de Ogum, Santos tente un cinéma d'identification populaire et se concentre sur l'objectif exclusif du développement d'une dramaturgie brésilienne débarrassée finalement des visées immédiates politiquement révolutionnaires, du Cinema Novo. Entre 1975 et 1980, il poursuit dans cette voie qui peut être identifiée avec l'esthétique nacional-popular d'Embrafilme même si celle-ci compte aussi avec les contributions des autres cinemanovistas. Au début des années quatre-vingt, alors que la dictature chemine vers sa fin et que la répression devient moins forte. Santos réalise son dernier grand film dans un style assez classique : Memórias do cárcere (1983). À cette époque-là, les ambitions de rénovation esthétique du Cinema Novo ont été abandonnées depuis longtemps et, avec beaucoup de pragmatisme, les anciens cinemanovistas ont adopté une vision du langage cinématographique très pluraliste et se sont détachés de l'analyse politique systématique telle qu'elle pouvait être pratiquée vingt ans plus tôt. Memórias do cárcere est l'adaptation d'un récit autobiographique de l'écrivain Graciliano Ramos. C'est un

271À l'occasion de la sortie de $O$ Amuleto de Ogum, Santos a demandé à Bernardet de se faire l'interprète de ses nouvelles positions. Il l'a fait dans le texte suivant. BERNARDET, Jean-Claude. «O Amuleto mudou tudo » in Manifesto por um cinema popular, fascicule de la Federação dos Cineclubes do Rio de Janeiro, Rio de Janeiro, 1975, p.12. 
film qui rencontre une répercussion particulière puisque, en traitant de la répression politique pendant l'Estado Novo et de la place d'un intellectuel dans un tel contexte, il renvoie évidemment à l'histoire récente du pays. Après ce film, Pereira dos Santos signe encore trois longs métrages de fiction à l'impact plus mesuré dans lesquels il poursuit son travail sur la valorisation de la culture brésilienne et même latino-américaine. Aujourd'hui d'un âge assez avancé, il continue sa carrière de cinéaste en se consacrant au documentaire. Son dernier travail d'envergure porte sur le sociologue Sérgio Buarque de Hollanda mais ces films connaissent une diffusion très restreinte.

Après Santos, le pionnier du Cinema Novo, nous avons les cinemanovistas de la «première génération » comme les appellent souvent les historiens du cinéma, c'est à dire ceux qui sont présents aux côtés de Rocha en 1959-60 et réaliseront leurs premiers films avant le coup d'état : Miguel Borges, Carlos Diegues, David Neves, Mário Carneiro, Paulo César Saraceni, Leon Hirszman, Marcos Farias et Joaquim Pedro de Andrade ${ }^{272}$. Dans ce premier groupe du Cinema Novo, certains joueront par la suite des rôles secondaires. Miguel Borges (né en 1937) s'efface rapidement après sa participation à Cinco vezes favela (1962) et s'écartera par la suite radicalement du Cinema Novo que ce soit par ses déclarations ou par ses films. Marcos Farias (1933-1985) quant à lui participe également à Cinco vezes favela mais il abandonne par la suite la réalisation pendant plus de dix ans et participe à l'aventure du Cinema Novo en tant que producteur associé à Leon Hirszman. Ami d'enfance de Carlos Diegues, David Neves (1938-1994) est d'abord critique dans le journal étudiant Metropolitano (1960-1962). Il y appuie les positions déjà assumées dans le SDJB par Rocha, vitupère la Nouvelle Vague française pour son absence de prise de position politique explicite et encourage les premiers films de Andrade et Saraceni ${ }^{273}$. Par la suite, il obtiendra un poste aux ministères des affaires étrangères (Itamaraty) qui lui permettra de jouer un rôle décisif dans la diffusion internationale du Cinema Novo. Il ne passera à la réalisation qu'en 1969 avec Memória de Helena qui se rapproche de la ligne du cinéma d'auteur libertaire et féministe empruntée avant lui par Saraceni. C'est son seul film qui peut être inclus dans la cinématographie du Cinema Novo. L'essentiel de sa carrière se fait entre 1979 et 1988, à l'époque d'Embrafilme qui lui permet de réaliser cinq longs métrages en dix ans. L'œuvre de Neves qui se concentre autour de la ville de Rio de Janeiro et de personnages féminins marquant peine à transmettre les préoccupations politiques initiales du Cinema Novo. Le

272Composition du groupe qui se réunit avec Rocha à partir de son deuxième voyage à Rio de Janeiro en 1959. Cf. ROCHA, Glauber. Revolução do Cinema Novo. Op. cit., p. 15.

273NEVES, David. « O Mestre e o poeta » in O Metropolitano, Rio de Janeiro, 03/01/1960. NEVES, David. « Os Moleques e os bichanos de Couro de gato » in Correio da manhã, Rio de Janeiro, 1961. NEVES, David. «O Filme e a crítica » in Correio da manhã, Rio de Janeiro, 23/09/1961. 
cinéaste décède prématurément en 1994.

Selon Diegues ${ }^{274}$, le groupe du Cinema Novo se structure autour de deux groupes qui étaient déjà formés : le groupe de l'université catholique auquel il appartient avec Neves et qui comprend aussi de futurs critiques de cinéma qui discuteront la production du Cinema Novo dans leurs quotidiens et le groupe de la Faculdade Nacional de Filosofia auquel appartenaient Leon Hirszman, Marcos Farias, Miguel Borges et Joaquim Pedro de Andrade. Paulo César Saraceni, bien qu'il soit déjà connu par les futurs cinemanovistas ne s'intègrent pleinement au groupe qu'avec l'arrivée de Rocha. Enfin, Ruy Guerra qui n'a pas encore été cité, ne participe aux réunions du groupe qu'à partir de 1960. Nous verrons sa trajectoire au moment de développer l'analyse de son premier long métrage, Os Cafajestes. Né en 1940 à Macéio, Carlos Diegues et sa famille déménage très vite à Rio de Janeiro dans un quartier favorisé de la zone Sud, Botafogo, où il passera la majeure partie de son enfance et son adolescence. Fils d'un professeur universitaire, le futur cinéaste connaît à peu près le même parcours que ses collègues qui, après une scolarité sans histoire dans de très bonnes écoles, se trouve orienté vers la faculté de droit. Très tôt cependant, les principaux intérêts du jeune homme sont le cinéma et la politique. À quatorze ans, dans le contexte du second gouvernement Vargas, il participe à la campagne «O Petróleo é nosso. » qui permit la création d'une entreprise nationale d'exploitation du pétrole, la Petrobrás, qui demeure jusqu'à aujourd'hui dans le giron de l'État et s'affirme comme un fleuron du parc industriel brésilien.

En 1955, Diegues participe à la campagne de libération de Rio quarenta graus qui marque sa première approximation avec les luttes du champ cinématographique. Cinéphile assidu, il fréquente les séances de cinéma de l'Associação Brasileira da Imprensa - ABI organisées par la Cinemateca do $\mathrm{MAM}^{275}$ et premier lieu de rencontre des futures cinemanovistas. Par la suite, il entre dans le militantisme étudiant et adhère à l'União Metropolitana dos Estudantes - UME. Dans cette période qui va de 1960 à 1962, il ne distingue pas militantisme politique et cinéma. Il participe à la fondation du Grupo de Estudos Cinematográficos - GEC (Groupe d'études cinématographiques) de l'UNE qui rassemble les anciens du ciné-club de la faculté nationale de philosophie sous la direction de Cosme Alves Neto, un autre critique qui soutiendra activement le Cinema Novo dans les années qui vont suivre. Rédacteur en chef du Metropolitano dans lequel écrit David Neves, il fait du journal étudiant un espace de discussion sur les destinées du cinéma national. En 1962, il adhère au

274Cf. VIANY, Alex. O processo do Cinema Novo. Op. cit., p. 435. Le témoignage de Diegues concorde avec ceux de Rocha et Saraceni. Cf. ROCHA, Glauber. Revolução do Cinema Novo. Op. cit., pp. 384, 407 et 409 ; et SARACENI, Paulo César. Op. cit., p. 43.

275Le ciné-club de la Cinemateca do MAM ne fonctionnait pas au MAM mais dans la salle de projection de l'ABI, dans l'immeuble du Ministère de l'Éducation. In ROCHA, Glauber. Revolução do Cinema Novo. Op. cit., p. 407. 
CPC dont il devient le second président après Carlos Estevam Martins et avant Ferreira Gullar. Nous avons déjà évoqué dans un chapitre précédent sa participation à la controverse opposant Rocha et Martins en 1962. Après des débuts moins applaudis que ses amis, son premier court métrage professionnel, Escola de samba alegria de viver, inclus au film du $\mathrm{CPC}$, Cinco vezes favela est reçu assez froidement, Diegues se distingue par sa contribution au Cinema Novo avec trois longs métrages de fiction, Ganga Zumba (1964), A Grande Cidade (1966) et Os Herdeiros (1969). L'échec commercial de ce dernier film et les persécutions politiques dont il est victime provoque un exil d'un an du Brésil (1969-1970) et un changement d'orientation esthétique.

En 1972, Diegues signe un film sans prétention intitulé Quando o carnaval chegar, sorte de roman photo ponctué de numéros musicaux avec trois grandes vedettes de la chanson, sa femme Nara Leão, Chico Buarque et Maria Bethânia. Après un rapide intermède dans une co-production française avec Jeanne Moreau qui semble renouer avec certains éléments esthétiques du Cinema Novo, Joana Francesa (1973), Diegues participe pleinement de l'esthétique nacional-popular d'Embrafilme. La période allant de 1975 à 1984 marque l'apogée de sa carrière. C'est le moment où il obtient la plus grande projection internationale et où il bénéficie de grands succès commerciaux comme Xica da Silva (1975) et Bye-bye Brasil (1979). La superproduction Quilombo en 1984 reçoit un accueil publique et critique mitigé. Loin des expérimentations esthétiques qui avaient marqué le Cinema Novo, Diegues intègre progressivement les éléments de l'esthétique télévisuelle à son cinéma et cherche à atteindre le plus large public possible. Comme tous les cinéastes brésiliens, la fermeture d'Embrafilme le contraint à faire une pause dans sa carrière. En 1992, Veja esta canção qui est un film à sketch autour de quatre chansons très populaires de MPB est réalisé pour la télévision. Ces dix dernières années Diegues est revenu sur le devant de la scène grâce à son pragmatisme. Il a obtenu de nouveaux grands succès auprès du public comme Deus é brasileiro (2002) même si la critique, quant à elle, reste plutôt sceptique.

Proche de Diegues au moment du militantisme étudiant, Leon Hirszman (1937-1987) est né dans la banlieue nord de Rio de Janeiro de parents polonais immigrés fuyant les persécutions dont étaient déjà victimes les juifs dans les années trente. Les grands parents d'Hirszman du côté paternels sont d'ailleurs tous les deux tués au début de la guerre en Pologne. Éduqué dans une école juive, le futur réalisateur s'intéresse très tôt à la politique et au cinéma. À quatorze ans, encouragé par son père, il s'inscrit au PCB et fréquente rapidement les ciné-clubs où il nourrit une passion particulière pour Eisenstein. À l'université, il suit une formation d'ingénieur qu'il mènera jusqu'à son terme sans pour autant jamais exercer cette profession. C'est d'ailleurs au cours de ses études qu'il rencontre Zelito Viana que nous 
retrouverons bien plus tard, en 1965, au moment où le Cinema Novo se dote de véritables structures économiques. Pour l'heure, Hirszman s'investit dans les ciné-clubs et le militantisme étudiant. Incapable de séparer art et politique, il est l'un des fondateurs du CPC aux côtés du dramaturge Oduvaldo Viana Filho pour lequel il réalise un montage d'archives cinématographiques qui sera projeté pendant la représentation de la pièce $A$ Mais valia vai acabar seu Edgar (1961). Cinemanovista le plus investi dans le CPC et le plus proche du gouvernement Goulart, Hirszman est à l'origine du projet Cinco vezes favela. Il se distingue ensuite avec la réalisation du court métrage documentaire Maioria absoluta qui, bien que confiné à une diffusion extrêmement réduite, acquiert un grand prestige auprès de ses amis, notamment pour son succès à Gênes en janvier 1965 dans le cadre du festival du cinéma latino-américain organisé par le Columbianum. Mais c'est un événement sur lequel nous reviendrons.

Après le coup d'État, craignant d'être atteint par la répression, Hirszman adopte un profil bas et adapte une pièce de théâtre apparemment éloigné de ses préoccupations politiques, A Falecida de Nelson Rodrigues. Le film est un échec commercial retentissant. Hirszman réagit avec le projet Garota de Ipanema dont nous ferons une analyse détaillée. À la fin du Cinema Novo, il revient au réalisme critique qui avait constitué l'une de ses orientations les plus explicites et réalise une adaptation d'un roman de Graciliano Ramos : São Bernardo. Le film est tourné dans des conditions extrêmement précaires, la maison de production qu'Hirszman a reprise en association avec Farias, la Saga Filmes, est sur le point de faire faillite. São Bernardo ne sort qu'en 1974 grâce à l'intervention d'Embrafilme. Malgré ce sauvetage, Hirszman reste plusieurs années sans travailler de nouveau pour le cinéma. À la fin des années soixante-dix, il tourne un documentaire qu'il va laisser inachevé sur les grèves ouvrières massives au cours desquels le futur président, Luiz Inácio Lula da Silva se distingue comme leader politique. En 1980, il réalise Eles não usam black-tie une adaptation de la pièce à succès du Teatro de Arena remontant aux années cinquante. Le film remporte le Lion d'Or à Venise et lui apporte la consécration internationale. Curieusement, il ne capitalise pas sur ce succès. Il consacre les années suivantes à la réalisation d'un documentaire intitulé Imagens do inconsciente sur trois artistes internés en asile psychiatrique et souffrant de schizophrénie. Hirszman décède victime du VIH en 1987.

Proche d'Hirszman au temps du ciné-club de la Faculdade Nacional de Filosofia, Joaquim Pedro de Andrade (1932-1988), comme nous le verrons plus bas en évoquant le concept de capital social, est issu d'une illustre famille de Minas Gerais. Fils d'un intellectuel reconnu et haut-fonctionnaire dirigeant l'Instituto do Patrimônio Histórico e Artístico Nacional - IPHAN de sa création en 1936 jusqu'à 1967, le jeune Andrade étudie la physique à 
la Faculdade Nacional de Filosofia. Parallèlement, il assiste aux séances organisées par le ciné-club de la faculté depuis 1953 et rencontre Plínio Sussekind Rocha, professeur universitaire, pionnier du ciné-clubisme au Brésil et gardien de la copie du film mythique, Limite que nous évoquerons dans le paragraphe 3.3. Après avoir conclu sa formation en physique, Andrade passe par diverses expériences professionnelles et notamment le journalisme. Il interviewe d'ailleurs Rosselini lors de sa visite au Brésil en 1957, un événement largement commenté par Saraceni dans son autobiographie ${ }^{276}$. La même année, il décide de se lancer dans le cinéma. Il est assistant-réalisateur sur le film des frères Geraldo et Renato Santos Pereira, Rebelião em vila rica. Associé à Gérson Tavares et Sérgio Montagna, il fonde ensuite la Saga filmes, une maison de production qu'il revendra en 1961 avant de partir étudier en Europe et aux États-Unis. L'entreprise sera rachetée par Hirszman et Farias qui la « réactiveront » en 1965. En 1958, la Saga filmes se consacre à la réalisation de courts métrages publicitaires et institutionnels. En 1959, cette maison de production joue un rôle historique pour le Cinema Novo en produisant coup sur coup O Mestre de Apipucos e o poeta do castelo (Andrade, 1959), Arraial do Cabo (Saraceni, 1960) et Couro de gato (Andrade, 1960).

En 1960, Andrade commence un voyage de deux ans au cours duquel il va étudier le cinéma à l'IDHEC à Paris puis à la Slade School of Art de Londres avant de partir aux ÉtatsUnis pour un stage auprès des frères Maysles, pionniers du cinéma direct nord américain. Pour la dernière partie de son voyage, le jeune homme bénéficie d'une bourse d'études de la fondation Rockfeller. À son retour au Brésil, Andrade participe pleinement à l'éclosion du Cinema Novo avec le moyen métrage Garrincha alegria do povo (1963) sur le joueur de football Mané Garrincha, vainqueur de la coupe du monde en 1958 et 1962. Nous détaillerons dans les chapitres suivants les analyses de ses deux premiers longs métrages de fiction, $O$ Padre e a moça (1966) et Macunaíma (1969). Macunaíma est pour Andrade le film de la consécration critique et publique internationale. Après ce succès, il réalise deux films moins accessibles de recherche esthétique et de réflexion politique explicite : Os Inconfidentes (1972) sur la fronde de la haute-bourgeoisie de Minas Gerais envers la couronne portugaise au XVIIIe siècle, et $O$ Homem do pau-brasil (1981) sur l'écrivain modernista Oswald de Andrade. Dans l'intervalle, en 1975, il connaît un nouveau grand succès commercial avec Guerra conjugal qui joue sur les codes de la pornochanchada alors à son apogée.

Pendant toute sa carrière, Andrade réalise aussi des documentaires qui sont moins connus que ses films de fiction mais qui devraient être mis en perspective avec l'intégralité de son œuvre pour que celle-ci soit mieux comprise. Citons à titre d'exemple Brasília, 276SARACENI, Paulo César. Op. cit., p. 31. 
contradições de uma cidade nova (1967) qui est l'un des premiers films à entamer le mythe de la Novacap. En 1981, mal reçu par le public et la critique, O Homem do pau-brasil contraint le cinéaste carioca à une pause assez longue dans sa carrière. Au cours de celle-ci, il écrit plusieurs scénarios et notamment une adaptation de Casa grande e senzala du sociologue Gilberto Freyre, lui-même sujet de son premier court métrage, O Mestre de Apipucos. Aucun de ces projets ne sera réalisé, Andrade est fauché par un cancer du poumon en 1988. Deux scénarios seront publiés à titre posthume.

Au travers de la Saga Filmes et de leur ami commun Mário Carneiro, les débuts d'Andrade sont étroitement liés à ceux de Paulo César Saraceni. Né à Rio de Janeiro en 1933, descendant d'immigrés italiens, à la fin de son adolescence, le jeune Saraceni se distingue d'abord dans la pratique du sport, en particulier le football dans lequel il commence à faire carrière. Également passionné par les arts, il s'essaye au théâtre entre 1955 et 58 dans la filiale carioca du prestigieux Teatro Brasileiro de Comédia - TBC. Il est notamment l'assistant de metteurs en scène consacrés comme Adolfo Celi et Ziembesky. Dans l'intervalle, Saraceni avait aussi rencontré le personnage qui deviendra pour lui une sorte de mentor intellectuel, Otávio de Faria (1908-1980). Membre bienfaiteur du Fluminense Futebol Club où jouait Saraceni, auteur de la Tragédia burguesa (La Tragédie bourgeoise, une série de romans sur le modèle de La Comédie humaine), critique de cinéma et co-fondateur du Chaplin Club avec Plínio Sussekind Rocha, de façon informelle, Faria va orienter la formation intellectuelle de Saraceni. Parallèlement, l'intérêt du jeune homme pour le cinéma ne cesse de grandir au détriment d'orientations professionnelles plus «sûres ». Étudiant en droit, Paulo César a la possibilité de travailler avec son père comme fonctionnaire des douanes ou de suivre les traces de son frère aîné qui est avocat. Assidu du ciné-club de la Faculdade Nacional de Filosofia depuis 1953, inconditionnel de Rosselini, en 1957, il rejoint Andrade qui vient de fonder la Saga Filmes et commence avec lui à réaliser les courts métrages publicitaires et institutionnels qui assurent le fond de roulement de l'entreprise. Attiré par un cinéma artistique, en marge de la Saga Filmes et inspiré par l'œuvre d'Otávio Faria, Saraceni réalise alors son premier court métrage, Caminhos, dont l'acteur principal est Andrade.

À l'époque de Caminhos, nous sommes déjà rendu en 1959. L'amitié avec Faria d'un côté, l'expérience théâtrale de l'autre et enfin le goût du jeune cinéaste pour les soirées bohèmes des milieux artistiques cariocas lui ont permis de développer un vaste réseau. Parallèlement, le groupe du Cinema Novo a déjà commencé à se constituer autour du cinéclub du MAM, Caminhos est projeté avec $O$ Pátio et ouvre les portes du SDJB à Rocha. L'étape suivante est la réalisation de Arraial do Cabo que nous avons déjà traitée. Par la suite, Saraceni obtient une bourse qui lui permet de partir étudier deux ans au Centro Sperimentale 
de Cinematografia - CEC à Rome. Le voyage va s'avérer décisif non pas tant du point de vue de la formation que des réseaux que le jeune homme va développer toujours un peu sous le signe du hasard et par le jeu informel des affinités électives. L'Italie, comme nous le verrons plus tard, présente à cette époque une disposition pour accueillir et lancer un certain type de cinéma latino-américain qui correspondrait à ses propres aspirations. De retour à Rio en 1962, précédé par le succès d'Arraial do Cabo auprès de la presse spécialisé et dans les festivals, Saraceni se pose comme l'un des principaux contributeurs de l'esthétique du Cinema Novo avec trois longs métrages de fiction que nous analyserons en détail Porto das Caixas (1962), O Desafio (1965) et Capitu (1968).

Après ce dernier film, et selon ce qu'il indique lui-même dans sa biographie, un renouvellement thématique s'opère dans sa filmographie qui commence avec $A$ Casa assassinada (1970). À la fois libertaire et très attaché à la religion catholique, Saraceni se désolidarise des objectifs à court terme d'un cinéma de conscientisation et poursuit l'idéal d'un cinéma d'émotion, de sensibilité, ouvert à l'irrationnel des comportements humains et emprunt de mysticisme, orientation absolument contraire à celle d'un Ruy Guerra qui restera fidèle aux principes du matérialisme marxiste et nous avouera ne pas comprendre les choix de son ancien collègue. En 1976, Anchieta do Brasil marque l'un des moments forts de sa carrière même si le film est tourné dans des conditions tumultueuses, Saraceni est arrêté pour possession de marijuana, et dans le conflit avec Embrafilme. Situé au XVIe siècle, le long métrage raconte la vie d'un des plus célèbres missionnaires jésuites de l'histoire du Brésil qui, selon le cinéaste, n'a pas été un simple colonisateur mais a été « colonisé » par le Brésil autant que lui a participé à la naissance d'un nouveau pays. Le rappel de ses conflits avec Embrafilme et en particulier son président Roberto Farias sont aussi une manière pour le cinéaste d'affirmer sa différence par rapport à la politique et aux pratiques adoptées à cette époque par les autres cinemanovistas, en particulier Barreto, Diegues et Jabor. Dans les années 80 et 90, les réalisations de Saraceni se font de plus en plus rares et rencontrent fréquemment de grandes difficultés pour être conclues et diffusées commercialement.

Bahia de todos os sambas, réunissant les plus célèbres musiciens de Bahia lors d'un spectacle exceptionnel à Rome, est filmé avec Hirszman en 1983 mais ne sera monté et lancé au Festival de Venise qu'en 1996. Natal da Portela, biopic du directeur d'une école de samba devant sa fortune à l'organisation de jeux d'argent illégaux, est privé de sortie commerciale au Brésil après avoir connu des contentieux avec les co-producteurs français. En 1998, $O$ Viajante, nouvelle adaptation de l'un de ses auteurs fétiches, Lúcio Cardoso, connaît une carrière plus sereine tout comme Banda de Ipanema (2000), documentaire dans lequel Saraceni manifeste son attachement au cinéma vérité de Jean Rouch. 
Après Rocha, Diegues, Hirszman, Andrade et Saraceni qui sont véritablement le noyau dur de la première génération et qui apparaissent réellement soudés dès que leur relation devient suivie, c'est à dire à partir de 1959, d'autres personnages vont apparaître. Ruy Guerra, qui arrive un tout petit peu plus tardivement et occupe une place particulière nous développerons sa trajectoire au cours de l'analyse de la première phase du Cinema Novo, celle où son intervention a été la plus importante avec Os Cafajestes (1962) et Os Fuzis (1964). D'autres cinéastes sont souvent désignés avec l'appellation deuxième génération du Cinema Novo parce qu'ils réalisent leurs premiers longs métrages après 1964. Ils sont cependant déjà présents dès le début de la première phase. Il s'agit de Gustavo Dahl, Arnaldo Jabor et Walter Lima Júnior.

Né à Buenos Aires en 1938, fils de diplomate, Gustavo Dahl passe son adolescence à São Paulo où il réside entre 1947 et 1960. C'est dans la métropole brésilienne qu'il découvre le cinéma parallèlement aux études de droit qu'il poursuit à l'université Mackenzie. Pendant cette période, il est président du ciné-club du centre Dom Vital et intègre l'équipe de la Cinemateca Brasileira, composée de Sales Gomes, Rudá de Andrade, Jean-Claude et Lucila Bernardet. Parallèlement à une première expérience professionnelle dans le domaine de la publicité, il commence aussi, en même temps que Jean-Claude Bernardet et sous l'impulsion de Sales Gomes, à écrire dans le supplément littéraire du quotidien Estado de São Paulo où l'imminent critique avait déjà sa tribune. Comme nous l'avons vu dans le chapitre 1.1, Dahl apporte une contribution importante à l'édification du concept critique à partir duquel s'articulera plus tard le Cinema Novo. Ayant fait connaissance avec Rocha en 1959, il entame avec lui une correspondance qui sera régulièrement suivie pendant les quatre années qu'il passe à l'étranger de 1960 à 1964. À ce titre, plusieurs articles publiés dans l'Estado de São Paulo sont en fait écrits à distance. La première destination de Gustavo Dahl est Rome où il étudie au CEC en même temps que Saraceni. C'est d'ailleurs à ce moment que se joue sa pleine intégration au noyau dur du Cinema Novo. Après Rome, il se dirige vers Paris où il retrouve Andrade. Làbas, il suit le cours de cinéma ethnographique administré par Jean Rouch au Musée de l'Homme. Il commence aussi à écrire dans Les Cahiers du cinéma dont il restera un correspondant intermittent à son retour au Brésil.

Dahl débarque à Rio une semaine exactement avant le coup d'État. Il ne partage pas l'optimisme de ses camarades quant aux destinées du pays. Selon lui, le Brésil aurait vraiment beaucoup changé pendant son absence si une révolution progressiste était effectivement en train de se jouer. Les événements lui donne malheureusement raison. Il commence ses activités dans le cinéma comme monteur pour Saraceni et Diegues et réalise un court métrage documentaire en 1965, Em busca do ouro. Parallèlement à cela, il reprend ses activités de 
théoricien et reprend la plume pour la revue Civilização brasileira qui, après 1964, devient le principal support éditorial du Cinema Novo. Ses nouveaux articles témoignent de son intérêts pour les questions économiques et commerciales qui domineront le reste de sa carrière. Dahl ne réalise en effet que trois longs métrages, O Bravo Guerreiro (1968), Uirá um índio em busca de Deus (1972) et Tensão no Rio (1982), les deux premiers participants pleinement de la proposition du Cinema Novo. Impliqué de près dans la reformulation d'Embrafilme en 1974, il est d'abord conseiller du président Roberto Farias puis superintendant du secteur de la distribution lequel accroît significativement son activité pendant son administration (19751979). Embrafilme atteint alors son apogée en parvenant à contrôler 30\% du marché interne. Dahl à cette époque est considéré comme l'idéologue de la suprématie du marché ${ }^{277}$ pour favoriser des titres qui ne correspondent pas aux canons esthétiques autrefois revendiqués par le Cinema Novo. Dans les années quatre-vingt, le rapide retour du technocrate à la réalisation ne convainc pas. Tensão no Rio est un échec auprès de la critique et du public. Par la suite, Dahl succède à Pereira dos Santos à la tête de l'Associação Brasileira de Cineastas - ABRACI (1981-1983) ; il est conseiller de la Fundação do Cinema Brasileiro en 1988 ; président du Conselho Nacional de Direito Autoral (1989/90) et du Congresso Brasileiro de Cinema (2001). En 2001, il est devient président directeur général de l'Agência Nacional do Cinema Ancine, chargé de l'encouragement à la production, de la régulation et de la fiscalisation du secteur cinématographique.

Né en 1940, Arnaldo Jabor qui connaîtra aussi le succès à l'époque d'Embrafilme étudie dans le lycée jésuite Santo Inácio aux côtés de Carlos Diegues. Plus tard; les deux hommes se retrouvent à PUC où Jabor étudie le droit. Sa sensibilité artistique le fait d'abord s'intéresser à la poésie et au théâtre. Entré dans le militantisme étudiant, il écrit dans le journal $O$ Metropolitano et s'inscrit au CPC qui mettra en scène les pièces qu'il aura écrites. Comme Dahl, il débute au cinéma dans des rôles de techniciens. Après avoir suivi le cours de Arne Sucksdorff en 1962, il est technicien de son pour Diegues sur Ganga Zumba et pour Hirszman sur Maioria absoluta. En 1964, il assiste aussi Saraceni à la direction sur Integração racial. Cette première incursion dans le cinéma vérité n'est pas sans relation avec ses premières productions, un documentaire sur la décadence du cirque, $O$ Circo (1965), et un autre sur l'aliénation de la classe moyenne, A Opinião pública (1967), qui participe pleinement de l'expérience du Cinema Novo. Ce deuxième film qui est un long métrage précède son premier travail de fiction, Pindorama (1970), que nous analyserons en détail et qui pousse jusqu'à ses dernières conséquences l'orientation d'innovation formelle du Cinema Novo. L'échec retentissant du film contraint le cinéaste à une profonde remise en cause. À partir de son film 277RAMOS, Fernão et MIRANDA, Luís Felipe (org.). Enciclopédia do cinema brasileiro. Op. cit., p. 166. 
suivant, Toda nudez será castigada (1973), il rompt avec le radicalisme esthétique et politique du Cinema Novo, adopte, comme le ferons aussi Diegues et Santos, un langage plus classique et se spécialise dans la comédie de mœurs notamment en adaptant pour le cinéma les pièces de Nelson Rodrigues. Au cours des dix années suivantes, parfaitement soutenu par Embrafilme, Jabor persévère dans cette voie et rencontre systématiquement le succès. Il se désintéresse de la réalisation dans les années quatre-vingt après une expérience hollywoodienne sans retentissement (Love at first sight, 1990) et se consacre au journalisme. Ses chroniques dans la presse écrite, publiées sous forme de recueil, et ses interventions dans le journal télévisé le plus regardé, celui de la TV Globo, en ont fait une célébrité du paysage audiovisuelle brésilien. Personnage provocateur, détesté ou adoré par le public, parmi les anciens admirateurs ou participants du Cinema Novo, beaucoup se défie de ses prises de position en faveur du libéralisme.

Loin de susciter les mêmes passions, ni de manifester un positionnement politique aussi marqué, Walter Lima Júnior est l'un des cinemanovistas les plus discrets. Né à Niterói en 1938, diplômé en droit à l'UFF, Lima connaît le parcours classique du cinéphile. Assidu des cinéclubs, il écrit ses premières critiques dans le Diário do povo de sa ville qui est à l'époque la capitale de l'État de Rio de Janeiro. La capitale fédérale n'est cependant pas loin puisque 40 minutes en bateau suffisent pour traverser la baie de Guanabara et se trouver au centre de la capitale fédérale qui restera encore quinze ans district fédéral après la fondation de Brasília. Lima fréquente les séances organisées par la Cinemateca do MAM à l'ABI et commence à écrire dans un journal plus important, O Correio da Manhã sous la houlette de l'un des plus prestigieux critiques cinématographiques de l'époque, Antônio Moniz Vianna qui sera pourtant l'un des principaux contempteurs du Cinema Novo. La rencontre de Lima avec Rocha est décisive, celui-ci l'invite en 1963 à être son assistant au cours de la réalisation de Deus e o diabo na terra do sol. Lima accepte et initie ainsi sa carrière cinématographique. Celle-ci se poursuit l'année suivante, quand il entreprend de réaliser lui-même un long métrage de fiction. Ce sera Menino de engenho sorti en 1966. Dans l'intervalle, il se marie avec l'actrice Anecy Rocha, la sœur de Glauber. Sa troisième contribution importante au Cinema Novo sera Brasil ano 2000 qui sera aussi étudié en détail dans ce texte. Avant que le film ne sorte sur les écrans, Lima est victime de persécutions policières pour avoir transmis des messages entre guérilleros. Son implication est mineure mais il est incarcéré et sort très éprouvé de cette douloureuse expérience. Par la suite, il se désolidarise du Cinema Novo. Endetté par l'échec commercial de Brasil ano 2000, il réalise un film underground peu diffusé, Na Boca da noite (1970), puis travaille pour TV Globo et signe un certain nombre de documentaires pour cette chaîne. Il revient au cinéma plusieurs années plus tard en essayant 
de concilier son expérience dans le Cinema Novo avec son goût pour le cinéma classique. Il s'attachera notamment à rendre hommage à Lima Barreto, le réalisateur tant décrié de $O$ Cangaceiro (1954), en filmant le scénario de l'un de ses projets restés inachevés, Inocência (1982). Il poursuit aujourd'hui sa carrière après avoir participé à la retomada du cinéma brésilien dans les années 90 avec $O$ Monge e a filha do carrasco (1995) ou encore A Ostra e o vento (1997).

En plus de cinéastes, il serait aussi légitime de citer dans le groupe du Cinema Novo deux de ses principaux producteurs : Luiz Carlos Barreto et Zelito Viana. Mais nous parlerons d'eux de façon détaillée au moment d'évoquer les stratégies commerciales mises en place par le groupe pour réaliser et diffuser ses films. Certains techniciens occupent aussi une place privilégié : les chefs opérateurs et cameramen Mário Carneiro et Dib Lufti, le monteur Eduardo Escorel. Pour l'heure, ce qui peut paraître surprenant malgré l'enchaînement apparemment naturel des événements, c'est la précocité remarquable de l'accès aux supports éditoriaux les plus importants de l'époque (le Jornal do Brasil et l'Estado de São Paulo pour citer les deux plus prestigieux) et à la réalisation de longs métrages de fiction. Si l'on excepte Santos qui est d'une autre génération que l'ensemble du groupe, en 1962, Diegues a 22 ans, Hirszman, 25 ans, Andrade, 30 ans, Saraceni, 29 ans, Dahl, 24 ans, Jabor, 22 ans et Lima 24 ans. La facilité de transit de Rocha dans les différents cercles de l'élite intellectuelle de Salvador puis de Rio de Janeiro et la rapidité de son «ascension» sont particulièrement spectaculaires. Certes, Rocha ne conquiert pas une position de pouvoir mais il réussit ce qui paraissait inconcevable quelques années plus tôt : « faire du cinéma », autrement dit, accéder au genre « noble » du long métrage de fiction. L'ensemble des contacts qu'il a su tisser à Rio et à Salvador lui ont permis de publier ses articles dans les plus importants quotidiens de deux métropoles et d'avoir accès à des personnages clés qui lui offriront les financements nécessaires à la réalisation de ses films. Il tourne son premier long métrage, Barravento, à seulement 22 ans et le deuxième, Deus e o diabo na terra do sol à 24 ans, à 25 ans, il est reconnu comme un jeune talent prometteur à l'échelle internationale. Comment expliquer un tel succès ?

Dans sa thèse de doctorat sur la trajectoire de Rocha en tant qu'intellectuel brésilien ${ }^{278}$, Fátima Gomes Lisboa utilise les concepts de capitaux sociaux et culturels forgés par Pierre

278L'auteur résume en ces termes sa problématique : «Utilisant les concepts de Pierre Bourdieu tels que : "capital social", "capital culturel", ' champ intellectuel ' et ' habitus de classe ' nous cherchons à démontrer que l'image de ' prophète du tiers-monde ', souvent attribuée à Glauber Rocha, par la critique cinématographique européenne, fut construite, inconsciemment par l'artiste et son entourage, depuis sa jeunesse. Elle serait la force de sa production culturelle, car dans un moment d'utopie révolutionnaire, cette image répond aux espoirs de transformation portés par le mouvement cinématographique brésilien, ainsi que par celui des pays comme l'Italie et la France. » in LISBOA, Fátima Gomes. Op. cit., p. 27. 
Bourdieu $^{279}$ pour expliquer son ascension. Évoquer Bourdieu nous semble tout à fait approprié pour tenter de mieux comprendre comment Rocha obtient un large espace d'expression dans les journaux et la possibilité de faire du cinéma. Le capital social et le capital culturel dont il est le détenteur, associés aux qualités propres aux personnages, expliquent en partie son succès.

Selon Lisboa, si le capital économique de la famille est assez important pour que Rocha puisse partager le train de vie des milieux bourgeois de Salvador ${ }^{280}$, c'est le capital social, le prestige qu'il possède en tant que descendant d'une famille de l'aristocratie rurale, Glauber Rocha est le petit-fils d'un authentique coronel du sertão de Bahia, qui facilite son insertion au microcosme de l'élite de la capitale. Dans les années cinquante, Salvador est encore très liée au monde rural, les cycles du cacao et de la canne à sucre sont à l'origine des plus grandes fortunes de la ville même si celles-ci doivent moderniser leurs activités pour conserver leur rang. Autre atout du futur cinéaste, son capital culturel. Le jeune Glauber se fait remarquer par ses pairs et ses professeurs dès son entrée au lycée, le Colégio Central qui

279« Selon Pierre Bourdieu, le ' capital social ' et le ' capital culturel ' sont des variétés du capital qui convergent vers le capital économique, dans la formation de groupes et de classes d'une société donnée. Pour mieux comprendre les individus, leurs appartenances à certains groupes, leurs choix politiques et culturels, il faut comprendre ces espèces du capital qui sont à la base des relations sociales. Le ' capital social ' serait, selon Bourdieu, ce que dans le langage ordinaire on appelle "les relations". Le capital social serait alors :

' l'ensemble des ressources actuelles ou potentielles qui sont liées à la possession d'un réseau durable de relations plus ou moins institutionnalisées inter connaissance : ou, en d'autres termes, à l'appartenance à un groupe, comme ensemble d'agents qui ne sont pas seulement dotés de propriétés communes (susceptibles d'être perceptibles par l'observateur, par les autres ou par eux-mêmes) mais sont aussi unis par des liaisons permanentes et utiles. ' BOURDIEU, Pierre. ' Le Capital social ' in Actes de la recherche en Sciences Sociales, n`31, 1980, pp. 2-3. BOURDIEU, Pierre. Questions de sociologie. Paris, Éditions de Minuit, 1984, p. 56. Le "capital culturel" serait représenté par des biens subjectifs (intellectuels) et objectifs (les richesses matériels liées à la culture), accumulés tout au long d'une existence. Selon Bourdieu, il existe sous trois formes : à l'état incorporé, ' c'est à dire sous forme de dispositions durables de l'organisme : à l'état objectivé sous forme de biens culturels, tableaux, livres, dictionnaires, instruments, machines qui sont la trace ou la réalisation de théories, de problématiques, etc. et enfin à l'état institutionnalisé, forme d'objectivation qu'il faut mettre à part parce que, comme on voit avec le titre scolaire, elle confère au capital culturel qu'elle est censée garantir des propriétés tout à fait originales. (...) La plupart du capital culturel peut se déduire du fait que, dans son état fondamental, il est lié au corps et suppose l'incorporation '. BOURDIEU, Pierre. in Actes de la Recherche en Sciences Sociales, n³0, 1979, pp. 3-5. Les concepts d'habitus et de champ, Pierre Bourdieu explique « le champ » comme étant des ' lieux où se construisent des sens communs, des lieux communs, des systèmes de topiques irréductibles les uns aux autres. Le champ serait un espace social spécifique constitué de relations objectives entre les postes; dont les propriétés dépendent de leurs positions dans ces espaces et qui peuvent être analysées indépendamment des caractéristiques de leurs occupants (en partie déterminées par elles). Chaque champ fonctionne de manière indépendante, mais avec des relations entre eux et la société globale. ' BOURDIEU, Pierre. ' Quelques Propriétés des champs ', in Questions de Sociologie, op. cit., p. 113. L'habitus serait : la ' nature socialement constituée ', le système de dispositions durables, acquis par l'individu au cours du processus de socialisation. L'habitus ' se présente à la fois comme le produit agissant de conditions sociales passées et comme principe générateur des pratiques et de représentations permettant à l'individu de construire des stratégies anticipatrices ', in FERREOL, G. et alii. Dictionnaire de Sociologie. Paris, Armand Colin, 1991, p. 107-108. ACCARDO A. et CORCUFF P., La Sociologie de Bourdieu - Textes choisies et commentés, 2ème édition. Bordeaux, Éditions Le Mascaret, 1986, p. 98. » In LISBOA, Fátima Gomes. LISBOA, Fátima Gomes. Op. cit., p. 28.

280 « Dans la mesure où les Rocha étaient une famille de migrants plutôt aisée, cela va permettre au jeune Glauber de fréquenter le milieu bourgeois de Salvador qui était, lui aussi, à l'époque, très lié au monde rural. Les Rocha ne sont pas entrés dans la capitale la tête basse, comme des centaines de vrais pau-de-araras qui migraient vers les grandes villes dans les années 1940-50. » in ibid., p. 121. 
est l'un des mieux côtés de Salvador ${ }^{281}$. Il entre au CEPA sur l'invitation d'un professeur, Germano Machado, qui l'a remarqué et veut pouvoir le compter parmi les autres élèves qui fréquentent ce groupe de réflexion ${ }^{282}$. Rocha correspond également avec certains de ses professeurs, notamment pour leur demander un avis détaillé sur ses productions littéraires ${ }^{283}$. Le fait qu'il se spécialise dans le cinéma acquiert à ce moment-là une dimension tout à fait particulière. À ce sujet, trois éléments entrent en jeu. Le premier est le contexte historique général du Brésil desenvolvimentista des années JK, le second est le contexte particulier de l'état de Bahia à la même époque et le troisième est la valeur symbolique du cinéma au sein de l'élite culturelle et économique brésilienne.

Bien que la politique desenvolvimentista de Juscelino Kubitschek ait été critiquée par l'ISEB dès la fin des années cinquante ${ }^{284}$, celle-ci est idéalisée par de nombreux secteurs de la société brésilienne et, en particulier, par la classe moyenne qui adhère à la mystique de ce président jeune et dynamique qui prétend pouvoir faire progresser le Brésil de cinquante ans en cinq ans. La réalisation de Brasília et le développement exponentiel de certains secteurs industriels dont la fabrication d'automobiles signifient pour beaucoup que le rêve devient réalité : le Brésil entre dans la modernité. Le succès international de la bossa-nova et de l'équipe nationale de football en Coupe du Monde participent à entretenir un climat d'euphorie et de confiance dans les capacités du pays à assumer un destin que l'on imagine grandiose. La façon dont Orlando Senna cette période, est tout à fait exemplaire d'un certain état d'esprit :

«É uma época em que o Brasil inteiro está muito novo, está muito voltado para se renovar, está muito voltado prá trilhar caminhos ainda não percorridos, está vindo do governo desenvolvimentista de Juscelino Kubitschek, ou seja, em que as coisas deviam ser feitas apesar de tudo e que qualquer obstáculo, qualquer empecilho, prá que as coisas deviam ser feitos, devia ser superado com inteligência e imaginação. $»^{285}$

Dès la fin de l'Estado Novo, en 1945, la libéralisation du régime permet à la haute bourgeoisie de prendre des initiatives importantes dans le domaine culturel. Celui-ci apparaît alors comme un lieu de légitimation sociale et de prestige, la conception de la culture qui 281GOMES, João Carlos Teixeira. Op.cit., p. 30.

282Ibid., p. 59.

283Correspondances avec Ruy Simões, professeur ayant encouragé les Jogralescas, et Adalmir da Cunha

Miranda, directeur de la revue universitaire Ângulos, in ROCHA, Glauber. Cartas ao mundo. Op. cit., pp. 82 et 91-104.

284L'ambiguïté quant à l'image du mandat de JK demeure encore aujourd'hui dans la société brésilienne. D'un côté, les critiques de l'ISEB ont été reprises dans l'historiographie officielle. Le fait que la politique de JK ait accru la dépendance économique du pays passe donc pour acquis et ne prête plus à discussion, tout au moins pour les historiens. D'un autre côté, dans la mesure où il reste le symbole d'une idéologie qui est toujours d'actualité, en plus des livres et articles qui lui sont consacrés, de nombreux hommages lui sont régulièrement rendus qui entretiennent la mystique d'un âge d'or pour le Brésil. Le fait que JK, à cause de sa popularité et de son libéralisme, ait été persécuté par la Dictature et soit mort dans des circonstances tragiques contribuent aussi à conserver l'image d'un président flamboyant et progressiste.

285In Deus e o diabo na terra do sol. DVD Versatil / Riofilmes, São Paulo / Rio de Janeiro, 2002. 
domine est très largement élitiste. On entend alors généralement par ce terme : « l'ensemble des productions les plus sophistiquées dans le monde des lettres et des arts de l'occident européen ». Même si, comme nous le verrons plus tard, l'intérêt de certains artistes pour la culture populaire amène à des découvertes remettant en cause les fondements même de l'approche pratiquée ${ }^{286}$. Toujours est-il qu'il existe une certaine disponibilité pour que soient réalisés des investissements massifs dans ce domaine et une grande réceptivité par rapport aux idées nouvelles. C'est dans ce contexte que sont construits les Musées d'Art Moderne de Rio de Janeiro et São Paulo. En matière de cinéma, la création de la compagnie Vera Cruz est aussi une tentative de la haute-bourgeoisie pauliste issue de l'industrialisation d'investir le domaine du cinéma.

Salvador n'échappe pas à cette fièvre de réalisations. Les années cinquante se caractérisent par un regain de prestige pour l'ancienne capitale coloniale qui cherche à combler le retard accumulé sur les grandes villes du Sud. Cette réaction de la métropole du Nordeste est rendue possible par un contexte politique dans lequel coïncident la politique fédérale de JK et les ambitions d'Edgard Santos, recteur de l'Universidade de Bahia, et de Juracy Magalhães, le gouverneur de l'état. L'amitié entre Magalhães et Santos remonte aux années trente. Le premier est alors nommé interventor par Gétulio Vargas quand celui-ci suspend de façon autoritaire les élections à la charge de gouverneur. Le jeune lieutenant ne réussit alors à s'imposer politiquement que grâce à l'appui de la famille d'Edgard Santos, famille de l'élite bahianaise qui, dans son ensemble, est hostile au choix de Vargas. Les idéaux d'un « nationalisme modernisateur » et « d'un progrès dans l'ordre » qui résument la pensée de Vargas scelle néanmoins durablement l'union du gouverneur et du recteur.

Dans les années cinquante, la vision de Santos est en parfaite syntonie avec les courants de pensée qui émergent et que nous avons déjà décrits dans notre partie consacrée à l'ISEB $^{287}$. Selon lui, l'union entre le capital économique et l'Université, détentrice du savoir, devait résoudre le problème de l'intégration des couches sociales les plus démunies des villes $\mathrm{du}$ Nordeste. Pour accomplir son travail d'éducation des masses, il choisit l'avant-garde artistique et ouvre les portes de l'Université au peuple à travers ses cours libres d'art et de

286Ce qui arrivera au Cinema Novo, est également arrivé à d'autres représentants de la culture érudite s'étant intéressé à la condition populaire dans les années cinquante. Partis à la rencontre des masses afin de les sortir de leur « retard », qu'il soit ou éducationnel, ou spirituel, ou encore politique, ils découvraient que ces masses construisaient, elles aussi, leurs propres ordres culturels et leurs modèles hiérarchiques pour la représentation du réel en marge de la culture formelle légitimée par les instances de pouvoir.

287D'un autre côté, ces courants de pensée ne sont pas non plus totalement nouveaux. Vargas avait déjà associé, au sein de l'Estado Novo, les intellectuels à une politique culturelle destinée à apporter la culture aux masses frustres et ignorantes. Le musicien Heitor Villa-Lobos et le médecin Edgard Roquette-Pinto, fondateur de l'Instituto Nacional do Cinema Educativo, furent deux artisans importants de la politique culturelle de Gétulio Vargas. Il serait d'ailleurs intéressant de comparer les conceptions des années 30 à celles des années 50 et 60 . Au-delà d'une évolution notable, et malgré qu'elles aient été formulées par des personnalités par ailleurs politiquement opposées, il me semble peu probable qu'une réelle rupture soit constatée. 
langues étrangères. Comme d'autres personnalités de son temps, Santos avait une vision conservatrice et élitiste de la culture, mais la haute idée qu'il se faisait du rôle de l'Université l'amenait, dans un double-mouvement, à l'ouvrir à la fois au peuple et à l'avant-garde de l'art moderne. Parallèlement à cette mission sociale, il cherchait aussi à placer sa ville au centre de la scène culturelle brésilienne.

L'appui de Juracy Magalhães permet à Santos de poursuivre la mise en pratique de ses idéaux mais son attrait l'avant-garde européenne entraîne une rupture radicale avec la tradition qui ne va pas sans heurt. Les artistes européens qu'ils invitent à Bahia dérangent la haute société de Salvador. À titre d'exemples, les recherches de Koelreuter sur la musique atonale et dodécaphonique déstabilisent l'élite locale ayant une autre représentation de la musique classique. La danseuse et chorégraphe polonaise Yanka Rudzka qui s'inspire du langage gestuel des cultes afro-brésiliens, choquent des personnes pour lesquels la culture afrobrésilienne serait justement « l'anti-culture ». Santos devient le « recteur fou », son libéralisme entre en choc avec les fractions plus conservatrices de l'élite.

Dans ce contexte, l'ascension de Rocha est favorisée par le fait qu'il devient l'un des participants les plus actifs de la politique de modernisation culturelle promue par la recteur. Il le fait sans calcul mais sur la base d'une véritable connivence idéologique même si celle-ci n'est pas véritablement consciente. Il s'agit pour eux de mettre fin à la mentalité provinciale des élites de la ville pour que Salvador retrouve son prestige perdu.

Salvador, dont le dynamisme étonne dans le pays entier, fonctionnera comme un véritable marche-pied dans l'intégration consécutive de futur cinéaste à l'élite intellectuelle de Rio. Un autre élément favorise Rocha, c'est que sa spécialité soit le cinéma, une discipline artistique sur laquelle il existe alors peu de personnes compétentes, qui occupe encore peu d'espace dans les suppléments culturels des quotidiens mais qui fascine profondément.

Si l'élite brésilienne méprise ouvertement le cinéma populaire, et, par voie de conséquence la chanchada, elle ne cultive pas moins le goût du cinéma étranger. Dans les années 30, le cinéma est perçu comme synonyme de modernisation, donc de «progrès » et de « civilisation ». Dans une période de développement industriel et de modernisation des villes, être au courant de l'actualité cinématographique représente à la fois un rapprochement avec la « civilisation» et une marque de distinction sociale. Le cinéma, de part sa dimension technique, colle aussi au concept américain du modernisme. Selon ce concept, une société est moderne si elle domine les nouvelles techniques du monde industrialisé. Ce rapport au cinéma est cependant très ambiguë car au même moment où les longs métrages étrangers de fiction sont admirés, la débilité de l'industrie nationale conduit le gouvernement à reconnaître que le pays ne peut pas en produire et à ignorer totalement ce type de production. Il encouragera 
seulement le cinéma éducatif et le cinéma de propagande. Il n'en reste pas moins vrai que les mots «art» et «industrie » seront cultivés par l'élite des années trente jusqu'aux années soixante.

Selon Lisboa, les connaissances approfondies de Rocha dans un domaine encore mal connu au Brésil, représentent un capital culturel qui lui permettra de circuler dans les instances de légitimation, les suppléments littéraires ou culturels des grands journaux. Le statut auquel Rocha a accédé au début des années soixante sera évidemment profitable à ses amis. Dans ses articles, il n'hésite pas à risquer sa crédibilité pour défendre des films qui, de l'aveu même de leurs auteurs, resteront des œuvres mineures. Tel est le cas, par exemple, de Mandacaru vermelho de Pereira dos Santos en 1961. Il est bien évident cependant que les autres membres du Cinema Novo ne doivent pas leur accès aux moyens de production à la seule influence de Rocha même si l'on sait qu'en dehors de ses articles, celui-ci pouvait aussi les aider à faire des contacts professionnels. En fait, malgré des origines diverses et parfois même des idées politiques divergentes, les membres du Cinema Novo partagent un socle culturel commun et appartiennent à des familles de niveau social comparable.

Si l'on veut leur appliquer les concepts de capitaux économiques, sociaux et culturels, nous pourrions dire qu'aucun n'est issu de la haute bourgeoisie et serait donc détenteur d'une capacité d'investissement conférant un réel pouvoir économique. Beaucoup cependant disposent d'un capital social leur donnant accès à un réseau dont ils sauront tirer profit, non pas forcément en sollicitant des aides directes même si cela va sarriver, mais simplement par la connaissance des institutions et de leur fonctionnement qu'un réseau apporte. Tous possèdent une solide éducation formelle qui les a mené jusque sur les bancs de l'Université et notamment cet atout supplémentaire que constitue une solide culture cinématographique acquise dans la pratique assidue des ciné-clubs.

Parmi les cinemanovistas à l'ascendance illustre, nous avons Joaquim Pedro de Andrade. Son père, le docteur Rodrigo Mello Franco de Andrade, ami de l'écrivain Mário de Andrade, avait créé avec le ministre de l'Estado Novo, Gustavo Capanema, le Serviço do Patrimônio Histórico e Artístico Nacional - SPHAN. En plus de Mário de Andrade, il avait pour ami les poètes modernistes, Carlos Drummond de Andrade et Manuel Bandeira, les architectes de Brasília, Oscar Niemeyer et Lúcio Costa, le poète Vinícius de Moraes et le sociologue Sérgio Buarque de Hollanda ${ }^{288}$. Manuel Bandeira qui fut aussi le parrain de baptême de Joaquim Pedro, est le sujet, avec le sociologue Gilberto Freyre, de son premier court métrage $O$ Mestre de Apipucos e o poeta do castelo. Le SPHAN va apporter une aide 
concrète dans le montage de la production des premiers films de Joaquim Pedro de Andrade et Paulo César Saraceni.

Mário Carneiro, co-réalisateur de Arraial do Cabo, ami des deux précédents cinéastes, est le fils de l'ambassadeur Paulo Carneiro, en poste à Paris pendant les années soixante ${ }^{289}$. Le père de David Neves, Luiz Neves, est militaire et ingénieur civil. Dans les années 60, il est directeur de l'Instituto Militar de Engenharia et accède au grade de général, il s'agit d'un hautfonctionnaire de l'État. ${ }^{290}$ Neves ne passe à la réalisation qu'à la fin des années soixante après un passage par la critique et surtout la diplomatie où, en tant qu'attaché culturel, il assure la promotion du Cinema Novo dans le monde entier. Enfin, le père de Carlos Diegues, Manuel Diegues Junior, est un universitaire reconnu. Dans les années soixante-dix, il est directeur du Departamento de Assuntos Culturais du ministère de l'Éducation dirigé par Ney Braga. En 1974, il remettra en main propre à Leon Hirszman le prix du meilleur réalisateur décerné par l'Instituto Nacional de Cinema - INC ${ }^{291}$.

Cet inventaire hétéroclite et partiel n'a pas d'autres ambitions que de démontrer la réalité du capital social que possédaient les membres du groupe du Cinema Novo. Il n'est évidemment pas question d'insinuer qu'il a pu se substituer au travail ou au talent mais il a bien constitué un atout décisif pour que les films soient tournés et diffusés. Le cadre est donc posé quant à la situation initiale des cinemanovistas au moment où le groupe se constitue. Nous allons voir maintenant comment ses conceptions esthétiques ont mûri. Une fois de plus, Rocha joue un rôle de premier plan, l'ensemble du groupe se reconnaît dans son livre Revisão crítica do cinema brasileiro (1963).

\subsection{Des idéaux convergents (A Revisão crítica do cinema brasileiro)}

Comme nous l'avons vu, le corps doctrinal du Cinema Novo se fixe entre 1960 et 1961 dans le dialogue qui s'établit entre Rocha, Dahl, Bernardet et Sales Gomes par l'intermédiaire des articles qu'ils écrivent dans les suppléments culturels de leurs journaux respectifs. Sur un plan strictement théorique, le livre Revisão crítica do cinema brasileiro ${ }^{292}$ n'apporte pas de nouveautés. Il vaut cependant pour deux raisons. La première, c'est qu'il constitue l'application à l'histoire du cinéma brésilien du concept critique établi les années précédentes. Il s'agit d'une œuvre de synthèse mais aussi de réponse aux récents bouleversements de 1962 .

\footnotetext{
289Saraceni souligne dans son autobiographie le soutien alors apporté par le père de son ami au Cinema Novo. 290Dans le cadre de ses fonctions, il rencontre le président Kennedy aux USA et participe à certaines cérémonies au côté du président Castelo Branco. In NEVES, David. Muito prazer. Catalogue de la rétrospective des films de David Neves organisée par le CCBB - Centro Cultural do Banco do Brasil du 9 au 21 septembre 2004, pp. 11 et 27.

291 Filme Cultura, Rio de Janeiro, n²6, septembre 1974.

292ROCHA Glauber. Revisão crítica do cinema brasileiro. Op. cit.
} 
Dans un sens, les succès de Assalto ao trem pagador et $O$ Pagador de promessas donnaient tort aux critiques, le succès était possible en dehors du cadre de la chanchada, les emprunts à des structures de production et des modes de narration traditionnelles pouvaient aussi représenter une voie de développement pour le cinéma brésilien digne d'un traitement plus nuancé que celui qui leur était adressé. Quoiqu'il en soit, le critique choisit de persévérer dans la ligne qu'il s'était tracée avant la réalisation de ces films. Il adopte une perspective historique afin de voir plus loin que l'actualité et affirme articuler son projet de rupture à la réalité culturelle, sociale et économique du cinéma brésilien. La seconde raison de l'intérêt du livre, est qu'il participe, à la suite d'articles comme « Cinema Novo, fase morta (e crítica)», de la tentative de reprendre la main sur l'appellation «Cinema Novo». Une identité s'affirme autour de principes et d'opinions déjà consensuels dans le groupe du Cinema Novo. Selon Ruy Guerra ${ }^{293}$, le livre est le fruit des discussions menées à l'intérieur du groupe depuis le début des années soixante. À sa sortie, il constituera pour ses membres une œuvre de référence.

Revisão crítica do cinema brasileiro se divise en huit chapitres dont sept s'imposeront comme autant de « dates » de l'histoire du cinéma brésilien : « Mauro e a situação histórica », «O Mito Limite », « Cavalcanti e a Vera Cruz », «Lima Barreto », «Independentes », «Origens de um novo cinema » et «Esboço de uma escola baiana ». À chaque fois, l'auteur part d'événements factuels, et tente d'analyser les faits de façon à en dégager une analyse quant au développement du cinéma brésilien tant d'un point de vue économique qu'esthétique. Ayant expliqué dans l'introduction qu'il adopte la méthode de la politique des auteurs tel qu'elle a été conceptualisée par la Nouvelle Vague, ce qui lui importe avant tout, c'est de mettre à jour les « auteurs » qui méritent d'être pris en considération et d'étudier comment il leur a été possible de développer, ou non, leur œuvre. Rocha assume pleinement sa partialité mais ne cède en rien au relativisme. Le discours est argumentatif et son ambition est bien, au travers de cette «révision critique» de donner des orientations pour le futur. Les approximations sont nombreuses ${ }^{294}$, les oublis opportuns et les partis pris évidents. Ainsi faitil exister le Cinema Novo qui ne s'est alors encore ni imposé, ni même trouvé ; et relègue-t-il O Pagador de promessas à d'infimes proportions, lui qui fut pourtant le film le plus récompensé dans le monde au cours de l'année $1962^{295}$.

293Entretien à l'auteur, février 2004.

294Rocha consacre tout un chapitre au film Limite de Mário Peixoto alors même qu'il ne l'a pas vu. Son travail se base sur la seule foi des témoignages de Plínio Sussekind et Saulo Pereira qui participèrent, 30 ans plus tôt à l'aventure du film.

295Information entendue dans l'émission télévisée « Retratos Brasileiros : Anselmo Duarte », diffusée sur Canal Brasil. Nous n'avons pas vérifié cette information selon d'autres sources mais elle nous paraît parfaitement plausible. Le film d'Anselmo Duarte remporte la Palme d'Or à Cannes en 1962. En 1963, il est nominé à l'Oscar du meilleur film étranger à Hollywood. Emportant plus facilement le consensus que ses prestigieux 
Il apparaît alors très clairement une sorte de téléologie de l'histoire du cinéma brésilien dans la mesure où tout converge vers l'avènement présenté comme inéluctable et proche d'un nouveau cinéma brésilien, le Cinema Novo, dont les signes avant-coureurs se multiplient. La conception de Rocha du Cinema Novo n'est évidemment pas celle d'une chapelle même si, objectivement, il défend ses amis, leurs films et une vision commune du cinéma. Il pense à une révolution esthétique qui, si elle accompagne la révolution mondiale des cinémas nouveaux, n'en a pas moins au Brésil une signification particulière. Ce qui distingue ce pays des grandes nations, c'est qu'il ne possède pas de véritable tradition cinématographique. Ainsi les deux premiers chapitres du livre sont consacrés à la débilité passée du cinéma brésilien au travers de deux exceptions, de deux auteurs qui ont su faire du cinéma un art envers et contre tout : Humberto Mauro et Mário Peixoto.

Entre 1925 et 1950, alors que le nombre de longs métrages produits excède difficilement la trentaine dans les années fastes, dans des conditions extrêmement précaires, Mauro réalise douze films. Rocha se concentre sur un seul d'entre eux, Ganga bruta de 1933, qu'il considère comme un authentique chef-d'œuvre et un point de référence pour le cinéma brésilien :

«Esquecer Mauro hoje - e antes não se voltar constantemente sobre sua obra como única e poderosa expressão do ' cinema-nôvo ' no Brasil - é tentativa suicida de partir do zero para um futuro de experiências estéreis e desligadas das fontes vivas do nosso povo, triste e faminto, numa paisagem exuberante. $»^{296}$

Parler de Mauro est avant tout l'occasion pour l'auteur de développer ses idées sur le cinéma brésilien à commencer par le rejet de l'esthétisme. Dans ce sens, Rocha oppose Mauro à Peixoto, très influencé par l'Avant-Garde française. Selon lui, tout effet visuel qui ne serait pas «signifiant», doit être rejeté et le cinéma de Mauro révélerait justement un regard capable de situer l'homme dans le monde et d'extraire une signification de cette observation, autrement dit un regard capable, dans le même mouvement de montrer le monde avec justesse et de l'interpréter. La «justesse », le mot « vérité » est souvent employé, ne recouvre pas ici l'idée selon laquelle il serait possible de filmer la vie « telle qu'elle est». Rocha est conscient que cette idée est dépassée. La justesse désigne bien plutôt l'idée selon laquelle l'auteur ne doit pas appliquer au réel des représentations qui lui préexistent mais, dans une relation dialectique d'appréhension ou d'apprentissage découvrir et révéler ce que seul le cinéma peut exprimer.

concurrents, il est devenu l'outsider heureux de nombre de compétitions internationales.

296« Oublier Mauro aujourd'hui - et ne pas revenir constamment sur son œuvre comme unique et puissante expression du ' cinema-nôvo ' au Brésil - revient à adopter un comportement suicidaire consistant à partir de zéro vers un futur d'expériences stériles et sans connexion avec les sources vives de notre peuple, triste et affamé, dans un paysage exubérant. » in ROCHA Glauber. Revisão crítica do cinema brasileiro. Op.cit., p. 31 . 
Le succès de l'entreprise cinématographique dépend ainsi largement de valeurs aussi subjectives que la sincérité, la sensibilité et l'intelligence. Le film constitue une expression matérielle, concrète, de la confrontation d'un auteur avec le réel.

Rocha voit dans Mauro les prémisses d'un réalisme critique brésilien qui, après un détour par la littérature de Graciliano Ramos, viendrait seulement s'affirmer au début des années soixante dans Porto das Caixas (1962) et Vidas secas (1963) : «Embora certos críticos não sejam dotados de uma intencionalidade maior, a verdade com que Mauro penetra no quadro é suficiente para informar, sem rodeios, o problema social. ${ }^{297}$ Au-delà de cette qualité à exprimer visuellement des problèmes sociaux, Rocha veut démontrer que, si le fait d'être brésilien et de travailler dans la précarité a nui à la reconnaissance de Mauro, l'absence de moyens n'a pas nui à la qualité artistique de ses films. Mauro prouve que le film à petit budget produit en marge des règles du cinéma industriel est une solution viable d'un point de vue culturel pour peu que le cinéaste soit un véritable « auteur ». Pour Rocha, Mauro est aussi le premier cinéaste qui filme dans un authentique dialogue avec la réalité nationale. Par conséquent, il doit être déclaré influence majeure du Cinema Novo.

Ce premier chapitre est bien dans le ton polémique de l'intégralité du livre puisque Rocha réduit au néant deux cinéastes alors consacrés du cinéma brésilien, Lima Barreto et Rubem Biáfora, au profit d'un inconnu. L'œuvre de Mauro n'a en effet commencé à être réhabilitée qu'au début des années soixante et la majorité de ses films incluant Ganga bruta étaient passés inaperçus au moment de leur première sortie au cinéma. Il est aussi évident que vouloir faire de Mauro une influence majeure du Cinema Novo est assez artificiel puisque, lorsque ses films parviennent aux cinemanovistas, leur formation cinématographique est faite $^{298}$. Rocha, comme les autres, n'a vu son œuvre de fiction qu'en 1961, au festival de Cataguases, ville d'origine de Mauro, en compagnie d'Eli Azeredo, Walter Lima Jr, Alex Viany, Sérgio Augusto et Saraceni ${ }^{299}$. Il faut également signaler, sans vouloir pour autant rien ôter au talent de Mauro, que la vision de Rocha est largement idéalisée. Bien des aspects de

297 « Bien que certains critiques ne manifestent pas une intentionnalité plus grande, la vérité avec laquelle Mauro pénètre le cadre est suffisante pour informer, sans détour, le problème social. » in ibid., p. 30.

298Nous pourrons pour nous en convaincre nous reporter à toutes les entrevues concédées par les cinemanovistas dans lesquelles ils citent leurs influences. Saraceni nous a dit dans notre premier contact téléphonique que le Cinema Novo venait des influences conjuguées de Rosselini et Jean Rouch, Leon Hirszman était connu pour être un spécialiste d'Eisenstein... Enfin, le livre $O$ Século do cinema de Rocha reprend finalement les axes classiques de l'historiographie du cinéma en se divisant en trois parties « Hollywood », « Neo-Realismo » et « Nouvelle Vague » et en commentant dans l'ordre les « grands » cinéastes de Griffith à Pasolini en passant par John Ford, Visconti et Godard. Malgré l'illustration de sa couverture, un œil dans lequel sont inscrits « Hollywood Europa III Mundo », les cinémas du Tiers Monde ne sont pas traités dans ce livre. Les écrits de Rocha ou d'autres cinemanovistas sur ce thème sont rares et souvent dépréciatifs malgré leur actualité dans les années soixante et soixante-dix. Voir ROCHA, Glauber. $O$ Século do cinema. Rio de Janeiro, Alhambra/Embrafilme, 1985.

299ROCHA Glauber. Revisão crítica do cinema brasileiro. Op. cit., p. 25. 
son œuvre et de sa trajectoire sont peu congruents avec le concept critique et les idées politiques affichées par le Cinema Novo.

Une étude plus attentive du pionnier du cinéma brésilien montre qu'à ses débuts, loin de démontrer une quelconque préoccupation sociale, le jeune Mauro cherche à imiter le film d'aventure nord-américain avec ses principaux ingrédients : de l'action, une énigme et du romantisme. C'est le cas de ses premiers films, Na Primavera da vida (1926) et Tesouro perdido (1927). Remarqué par les critiques de la revue Cinearte, Mauro se trouve encouragé à produire des films dont les protagonistes seraient des personnages de la haute société et non plus de la campagne, évoluant dans des décors luxueux et raffinés. Encore une fois, il s'agit d'imiter ou de transposer le modèle hollywoodien, c'est ce que Mauro tente de faire dans Braza dormida (1928) et Sangue mineiro (1928) et enfin Lábios sem beijos (1930). Or, comme nous le savons déjà, rien n'est plus éloigné du concept critique du Cinema Novo que le principe de « l'imitation » de modèles étrangers et en particulier celui d'Hollywood.

Autre incohérence dans le choix de Mauro comme modèle, son rapprochement avec l'Estado Novo. En 1936, il accepte l'invitation de l'anthropologue Edgard Roquette-Pinto qui vient de créer l'Instituto Nacional de Cinema Educativo - INCE. Le rôle de cette institution est de produire et diffuser des films didactiques. Mauro va assurer le gros de sa production pendant les quinze ans qui vont suivre. C'est aussi par l'intermédiaire de l'INCE qu'il réalise le long métrage O Descobrimento do Brasil (1937). Comme le montre l'analyse de ces films, l'ensemble de ce que réalise Mauro en relation avec l'INCE, défend l'idéologie positiviste et conservatrice du régime. Nous pouvons même observer que les luttes d'influence entre cet institut à vocation éducative et les organes de propagande ${ }^{300}$ ont abouti à une répartition des tâches tout à fait originale entre les régimes autoritaires qui furent contemporains à l'Estado Novo. L'INCE s'est vu interdit de traiter des sujets d'actualité qui étaient pris en charge par les services de propagande et réciproquement les services de propagande n'avaient pas à traiter des thèmes historiques. Comme il n'existait pas à l'époque la perception d'une contradiction possible entre propagande et éducation, il est revenu aux organes de propagande de défendre les actions du gouvernement et de promouvoir les manifestations civiques en son honneur alors que l'INCE assurait un travail plus en profondeur. En reformulant l'histoire avec des documentaires ne laissant aucune alternative dans l'interprétation qui pouvait en être faite, l'institut montrait de façon implicite que l'idéologie du régime était fidèle aux traits caractéristiques de la nation qui seraient immuables et seraient apparus dès sa naissance ${ }^{301}$.

\footnotetext{
300Le Departamento de Propaganda e de Difusão Cultural - DPDC, lié au ministère de la justice est contemporain à la création de l'INCE. Il devient par la suite le Departamento da Informação e Propaganda DIP, qui va devenir le symbole de l'autoritarisme de la dictature de Vargas.

301Le documentaire ou le film didactique apparaissent alors comme de puissants instruments de propagande.
} 
Rocha concède dans son texte que les conceptions de Mauro étaient « romantiques et socialement inconséquentes » et dès l'introduction il a annoncé au lecteur qu'il serait partial. Le Mauro du Cinema Novo est un cinéaste idéalisé, consacré sur la foi de son chef-d'œuvre, Ganga bruta (1933), qui rassemble ses qualités déjà énoncées et, en particulier, cette étrange propriété que possèdent ses films à dénoncer par leur propre forme les intentions initiales selon lesquelles ils programment le spectateur. Au début, le protagoniste principal, Marcos, un riche ingénieur, tue son épouse pendant leur nuit de noces. Il découvre en effet à ce moment-là qu'elle en aime un autre et qu'elle s'est déjà donnée à lui. Le drame est l'objet d'un article de faits divers ${ }^{302}$ que l'assassin lit dans un bus en se demandant comment oublier ${ }^{303}$. Il accepte un emploi dans une usine éloignée de tout, hors de Rio de Janeiro. Cependant, le destin veut qu'il revive là-bas un drame similaire dans le rôle de l'amant. Il rencontre en effet Sônia dont il tombe amoureux, l'attirance qu'exerce sur lui la jeune femme est réciproque mais elle est déjà fiancée à un nommé Décio. Bien qu'essayant de combattre ses sentiments et de la chasser par sa mauvaise humeur, Marcos succombe à la passion et déflore Sônia après une séquence où celle-ci a exprimé toute sa sensualité ${ }^{304}$. La confrontation avec Décio est alors inévitable, celui-ci meurt accidentellement dans le duel qui marque le climax de la narration... Le couple reconstitué devra vivre dans le souvenir de l'épouse et du fiancé morts pour que leur union se réalise.

Comme nous le voyons ici, une histoire initialement simple et à la morale conservatrice se dénonce par glissements successifs mais sans véritable inversion des codes. Il est impossible de savoir s'il s'agit d'un processus conscient chez l'auteur. Pour Sales Gomes, cet étrange retournement serait dû à l'incapacité du brésilien à imiter. L'importation de modèles étrangers ne pourrait pas être faite sans d'importantes distorsions qui deviendraient à leur tour signifiantes. Le film deviendrait ainsi critique malgré lui, de par ses défauts et les ajustements qu'il aurait concédé au moment de sa réalisation vis à vis du modèle initial. Les films de Mauro constitueraient un parfait exemple de ce phénomène. Mauro séduit la

Présentant la caution d'une supervision « scientifique » et recourant à toutes les techniques visant à limiter la circulation du sens dans le texte filmique, ils tendent à désamorcer la tentation de la critique chez le spectateur pour imposer une idéologie. $C f$. : FICAMOS Bertrand. «Educação e propaganda no cinema de Mauro : Uma Outra Abordagem do filme O Descobrimento do Brasil (1937)» in Locus : revista de história. Juiz de Fora, vol. 8, ${ }^{\circ} 2,2002$.

302Selon la législation brésilienne de l'époque, le mari était dans son bon droit. C'est la raison pour laquelle il n'est pas inquiété par la police et reste libre.

303Comme c'est un film muet, nous ne pouvons pas savoir ce qui le blesse le plus, la désillusion amoureuse (il l'aimait, elle ne l'aimait pas), le fait d'avoir du sang sur les mains ou le déshonneur d'avoir été trompé qui, pour lui et la loi, justifie son geste. Le public de 1933 pouvait sans doute répondre à cette question, les mœurs ayant évoluées, il nous est difficile de connaître les intentions de l'auteur ou même de savoir ce que l'on en pensait en 1963. La mise en scène d'un article de journal nous montre cependant qu'il s'agit pour l'auteur d'une « situation limite. »

304Cette séquence dans laquelle Sônia achève de séduire Marcos est devenue une séquence d'anthologie pour le cinéma brésilien. 
génération des cinemanovistas car au-delà de l'ambiguïté des démarches auxquelles il participe successivement, l'originalité de son talent, son nationalisme et même son primitivisme, parviennent à convaincre qu'il est le premier à réussir à donner du Brésil une vision juste. Le « génie » du cinéaste semble atteindre un niveau qui permette de passer outre les nombreux éléments qui seraient contradictoires avec l'idéologie affichée par le Cinema Novo. Lima Barreto ou Alberto Cavalcanti sont deux cinéastes qui ne réussissent pas cette transformation même si, comme le deuxième avec $O$ Canto do mar, la préoccupation envers les injustices sociales est manifeste.

Alors que les deux chapitres consacrées à Mauro et Peixoto relèvent de l'écriture mythologique $^{305}$ et font de ces personnages des modèles fascinants de par l'emphase qui est donnée à leur anachronisme, la rigueur reprend ses droits dans l'analyse des œuvres de Barreto et Cavalcanti, deux figures étroitement associées à la Vera Cruz. À aucun moment, Rocha ne souhaite contester l'importance que peut avoir Alberto Cavalcanti dans l'histoire du cinéma. Selon lui, après avoir brillé dans l'Avant-Garde française puis dans le réalisme anglais aux côtés de Flaherty, après, enfin, s'être imposé à Hollywood, le cinéaste brésilien expatrié, aura connu une carrière à tous les égards exceptionnelle. Paradoxalement, et malgré d'excellentes intentions, son retour au pays va s'avérer un échec total. Les chapitres consacrés à Cavalcanti et Barreto sont donc pour Rocha l'occasion de dénoncer l'entreprise de la Vera Cruz, véritable antithèse du Cinema Novo, mais aussi de développer ses idées quant à un cinéma d'authentiques préoccupations sociales et politiques au travers des critiques de $O$ Canto do mar (Cavalcanti) et de Painel et Santuário (Barreto).

Nous reviendrons sur la critique de la Vera Cruz au moment de commenter les stratégies économiques qui furent celles du Cinema Novo. Pour le moment, il convient de rappeler que Rocha et les autres cinemanovistas ne font finalement que reprendre les reproches qui lui furent adressées dès sa création. Ceux-ci portent sur l'importation de cadres techniques étrangers et sur le choix d'un cinéma classique de grands studios basé sur le modèle hollywoodien. Nous sommes alors à l'époque du dernier gouvernement Vargas et, alors même que le sentiment nationaliste se transforme et se renforce, il est attribué aux films

305Malgré les critiques violentes de Rocha envers l'esthétisme de Peixoto, sa curiosité n'en est pas moins évidente envers ce cinéaste «maudit» qui n'aura pu achever son chef-d'œuvre et se verra dans l'impossibilité de continuer sa carrière. En opposant l'authenticité de Mauro au formalisme de Peixoto, Rocha paraît même vouloir appliquer au cinéma brésilien un paradigme qui est avant tout le sien. Comment concilier recherche expérimentale et cinéma populaire, l'expression individuelle de l'artiste et celle de la nation ? Beaucoup de commentateurs de l'œuvre de Rocha commettent l'erreur d'établir une opposition entre art et politique (autrement dit, pour eux, entre le fond e la forme) alors que, s'il existe vraiment une contradiction dans l'œuvre de Rocha, elle ne se situe pas sur ce plan. Rocha n'oscille pas entre formalisme et cinéma politique, deux catégories qui sont, pour le Cinema Novo, peu explicatives, mais, concevant le cinéma comme une pratique politique, recherche justement une forme d'expression qui résiste à ce type de classification et fasse de l'art un acteur de la vie politique. 
de la Vera Cruz un caractère anti-national, en particulier par ceux qui, venus du parti communiste, souhaitent un autre cinéma pour le Brésil. C'est le cas de Pereira dos Santos qui présente au I Congresso Paulista do Cinema Brasileiro une communication intitulée « $\mathrm{O}$ Problema do conteúdo do cinema brasileiro $»^{306}$ et d'Alex Viany qui milite à l'époque pour un cinéma social. Les influences du Néo-Réalisme et du réalisme socialiste se font alors sentir ${ }^{307}$. La faillite de la Vera Cruz constituera pour ses opposants la preuve de l'exactitude de leurs opinions.

En ce qui concerne la filmographie de cette entreprise, la principale critique qui lui est faite est celle d'avoir pratiqué un cinéma d'imitation de l'esthétique hollywoodienne. C'est cette critique que Rocha adresse à $O$ Cangaceiro (Lima Barreto, 1954) qu'il juge être une transposition douteuse du western à l'espace et à la culture du sertão brésilien. $O$ Canto do mar échappe à ce type de critique comme Painel et Santuário car ces trois films abordent ostensiblement une thématique brésilienne et, simultanément, ne paraissent pas marqués par le modèle hollywoodien. Malgré cela, ils sont tous les trois rejetés par Rocha. Les deux courts métrages didactiques de Lima Barreto sont repoussés pour constituer l'expression d'une idéologie fascisante et rétrograde. Ces deux documentaires sont consacrés à des monuments importants de l'art brésilien. Painel explique aux enfants la fresque du peintre Portinari qui raconte l'Inconfidência Mineira. Santuário suit les pas d'un pèlerin jusqu'au pieds des sculptures d'Aleijadinho qui représentent les prophètes nous présentant des extraits de la Bible. Dans les deux cas, l'encadrement et le montage permettent de mettre en mouvement la matière inerte et de souligner le dynamisme de la peinture ou des statues. Le cadrage et l'angle de vue permettent de décomposer les œuvres et de les réorganiser ensuite au sein d'une chronologie qui permet d'en conduire l'interprétation de façon claire mais restrictive. La voix off dans le premier cas participe à la conduite de l'interprétation, dans le second cas, elle permet aux statues de parler et de reprendre le prêche religieux déjà symbolisé par la présentation des Écritures. Rocha critique de façon véhémente l'idéalisation de l'Inconfidência mineira. Barreto, au lieu d'apporter une vision critique de l'histoire, entretient le mythe romantique tel qu'il a été diffusé au 19ième siècle pour apporter une légitimité historique à la Première République. Pour Rocha, ce mythe est attaché à un patriotisme conservateur et rétrograde, aussi dangereux finalement que l'impérialisme dans la mesure où il empêche une

306SANTOS, Nelson Pereira dos. « O Problema do conteúdo do cinema brasileiro ». Texte retranscrit dans les actes du I Congresso Paulista do Cinema Brasileiro, archives de la Cinemateca Brasileira, pp. 159-163, sans date.

307Alex Viany consacre un article assez volumineux à la défense du réalisme socialiste dans la Revista de Cinema qui se distingue aussi par son rôle de divulgation du Néo-Réalisme. Voir VIANY, Alex. « O Realismo socialista no cinema e a revisão do método crítico » in Revista de cinema, Belo Horizonte, $\mathrm{n}^{\circ} 3$, juin 1954. 
véritable compréhension du Brésil. Santuário lui paraît encore plus irritant dans la mesure où il célèbre un mysticisme conformiste invitant une fois de plus les humbles à s'en remettre à Dieu et à supporter stoïquement leurs souffrances terrestres. Ce qui agace beaucoup Rocha, c'est la façon dont les propriétés du langage cinématographique sont mises à profit pour verrouiller le sens de ces œuvres, voire, dans le cas des statues d'Aleijandinho, d'en occulter la véritable force. Ainsi écrit-il que le film fut consacré à Venise « especialmente pela grande força do Aleijadinho, que neutralizava a demagogia das fotografias $»^{308}$.

Plus proche d'une idéologie progressiste, les raisons de l'échec d'O Canto do mar sont plus complexes. L'adaptation du classique En Rade au contexte du Nordeste brésilien était en effet destiné à dénoncer la misère et les conditions de vie extrêmement précaires pour lesquelles la région était depuis longtemps connue. Rocha établit pratiquement une liste de défauts à éviter dans son analyse du film. Il critique une mise en scène académique au lieu de la captation « nua e crua da realidade » (nue et crue de la réalité), le choix d'un scénariste sans réelle connaissance du Nordeste, l'individualisme de la trajectoire du personnage principal, le physique de l'acteur qui ne correspond pas au type de Recife et enfin un certain esthétisme social qui valoriserait le beau dans l'expression de la misère. Cavalcanti applique selon lui une approche qui, si elle fut d'avant-garde dans les années vingt, est désormais dépassée. Il lui reproche enfin de ne pas avoir su interpréter la réalité, de ne pas avoir été plus loin que la description de la misère pour atteindre ses causes, à savoir, au-delà de la sécheresse, le latifundium qui limite l'accès à la terre et empêche la réalisation des infrastructures nécessaires à son exploitation rationnelle et socialement responsable.

La moitié de Revisão crítica do cinema brasileiro permet donc ainsi, souvent de façon partiale, de situer le concept critique du Cinema Novo vis à vis de ce que le cinéma brésilien a pu produire de mieux en matière de longs métrages de fiction. La seconde moitié du livre est consacrée aux années ayant suivi la faillite de la Vera Cruz, la fragile émergence d'un cinéma indépendant préparant le chemin au cycle de Bahia et au Cinema Novo. Rocha, en commentant les premiers films de Pereira dos Santos, Roberto Santos, Trigueirinho Neto et Pires réaffirme l'idée selon laquelle le cinéma d'auteur à petit budget sera une voie féconde pour le cinéma brésilien et ce malgré les nombreux défauts qu'il concède aux films. Enfin, entre les trois grands succès de 1962, Os Cafajestes, Assalto ao trem pagador et O Pagador de promessas, il préfère celui dont la dimension politique est a priori la moins évidente : Os Cafajestes. Il convient pour l'instant de noter qu'au-delà du rôle stratégique de l'ouvrage que nous allons à présent commenter, au lieu de changer d'orientation et de travailler dans les 
directions désignées par Assalto ao trem pagador et $O$ Pagador de promessas, Rocha et les autres membres du Cinema Novo préfèrent la fidélité à leurs convictions et c'est ainsi notamment qu'il peut reconnaître des qualités au film d'Anselmo Duarte mais expliquer :

\footnotetext{
« No texto de Dias Gomes, um equívoco : a força do povo, a revolta do povo, a dignidade do povo resultam num gesto evasivo : entram na igreja, consagram o místico aos pés do altar, é o supremo catolicismo alcançado pelo sacrifício ; o povo, explodindo, santifica Zé do Burro. [...] O Pagador de promessas excita o tempo todo : não provoca a menor reflexão. $»^{309}$
}

Si les choix alors opérés sont cohérents d'un point de vue critique, ils représentaient une prise de risque et ne sont pas allés de soi. L'étude des écrits publiés et inédits de Rocha montrent en effet que jusqu'à la rédaction de Revisão crítica do cinema brasileiro, il oscille. Comme cela se vérifiera par la suite, il est avant tout un pragmatique et un nationaliste. Aussi sa première critique sur $O$ Pagador de promessas est-elle dithyrambique ${ }^{310}$. Malgré le fait que ce film soit d'un point de vue esthétique, proche de la Vera Cruz, quand Rocha comprend que le film va rencontrer un énorme succès, il est prêt à remettre en cause ses convictions. Il ne le fait pas parce que ses amis rejettent le film et soulignent ses ambiguïtés idéologiques. Lima et Bernardet, en particulier, écrivent aussitôt ce que Rocha ne fait que reprendre ${ }^{311}$.

Au sujet de Assalto ao trem pagador, sa position est encore plus ambiguë puisque c'est lui-même qui avait conseillé à Roberto Farias de travailler avec Luiz Carlos Barreto pour écrire un film policier. À partir d'un fait divers connu, il s'agissait d'évoquer la vie de la favela et les injustices sociales dont sont victimes ses habitants. Assalto ao trem pagador, en plus d'être un véritable succès populaire avec une problématique sociale conséquente, ouvrait également la voie de la collaboration avec la banque de Minas-Gerais qui financerait tant de films du Cinema Novo. À plus d'un titre, vis à vis du public, de la critique internationale et des investisseurs, refuser de «capitaliser» sur le succès de ces deux films représentait un risque. Le pari du Cinema Novo qui est alors pris, sera gagné grâce aux succès de 1964. Sans eux, l'orientation choisie par Rocha aurait vraisemblablement été totalement discréditée. Le contenu du livre marque ainsi autant un pont vers l'avenir que l'aboutissement d'une réflexion personnelle et collective qui s'est développée au fil des articles de presse, des premières expériences cinématographiques et des rencontres.

Le groupe du Cinema Novo évolue beaucoup entre 1959 et 1964 . Certaines personnalités, lui appartenant initialement vont prendre du recul, c'est le cas de Marcos Faria

309ROCHA Glauber. Revisão crítica do cinema brasileiro. Op. cit., p. 135.

310ROCHA, Glauber. « Cinema Novo arrebata o Brasil » in Diário de notícias, Salvador, 08/04/1962.

311BERNARDET, Jean-Claude. « Pagador e compromissos » in O Estado de São Paulo - Suplemento literário, São Paulo, 08/09/1962.

LIMA JUNIOR, Walter et alii. «O Pagador de promessas » in Correio da manhã, Rio de Janeiro, 02/09/1962. 
qui reste un proche collaborateur de Leon Hirszman mais abandonne temporairement la réalisation pour se consacrer à la production ${ }^{312}$. Sa participation devient donc moins évidente. C'est le cas aussi de Miguel Borges qui est l'auteur du manifeste Bola-bola et signe l'un des épisodes de Cinco vezes favela. Le fait que ses films n'enthousiasment guère ses collègues explique sans doute son effacement progressif. Sa carrière prend ensuite rapidement une orientation radicalement distincte de la ligne du Cinema Novo ${ }^{313}$. Paradoxalement, les voyages à l'étranger de Dahl, Saraceni et Andrade resserrent leurs liens avec le groupe qui accueille successivement Guerra et Lima Jr au début des années 60. Les contacts avec le nouveau cinéma italien et les expériences européennes de Dahl et Saraceni ne sont pas pour rien dans les choix du livre de Rocha ${ }^{314}$, de même, la formation en cinéma vérité suivie par Andrade auprès des frères Maysles à New York.

Revisão crítica do cinema brasileiro est aussi un livre de promotion du Cinema Novo avant sa seconde tentative de s'imposer aux travers de longs métrages de fiction. La première tentative qui comptait avec les sorties de Barravento, Porto das Caixas et Cinco vezes favela, annoncée dans les articles de Rocha de $1961 / 1962^{315}$ fut en effet un échec, chacun de ces films ayant reçu un accueil critique mitigé et n'ayant peu ou pas été exploité commercialement. Le livre de Rocha vient donc très opportunément préparer le terrain de trois films en cours de préparation : Vidas secas (largement commenté), Os Fuzis (évoqué au travers de l'hommage à Miguel Torres et de la critique de Os Cafajestes) et Deus e o diabo na terra do sol (qui n'est pas mentionné). Cette dimension du livre nous est confirmée par les éléments concernant le contexte dans lequel il fut écrit.

Enfin, il faut noter que Revisão crítica do cinema brasileiro est aussi une déclaration d'émancipation par rapport aux pères symboliques du cinéma indépendant et constitue un saut qualitatif décisif dans la réflexion sur le cinéma brésilien. En 1951, Santos plaidait pour un

312Farias ne dirige aucun film entre Um Favelado (dans Cinco vezes favela, 1962) et A Cartomante (1974). 313 Canalha em crise (1963), parfois cité dans les filmographies du Cinema Novo, ne convainc ni la critique ni les cinemanovistas. Miguel Borges affirme ensuite son indépendance avec Maria Bonita, rainha do cangaço produit par Cinedistri en 1968, c'est à dire en-dehors des structures du Cinema Novo. Il s'agit d'un film d'aventures très éloigné du cinéma d'auteur et dans lequel il conteste la représentation du cangaço et du sertão présente dans les films du Cinema Novo. En 1970, As Escandalosas apparaît comme l'une des premières pornochanchadas, un genre de comédie érotique auquel le Cinema Novo sera opposé. Pecado na sacristia de 1976 est cependant cité par Rocha dans Revolução do Cinema Novo comme un exemple de ce que serait le Cinema Novo des années soixante-dix. Enfin, selon Avellar, la position que Borges a assumé en tant que rapporteur auprès du gouvernement en s'exprimant en faveur de la liquidation d'Embrafilme, en 1990, exclurait définitivement ce personnage du combat du Cinema Novo puisqu'Embrafilme représentait à la fois l'héritage de ce groupe et la tentative de conquérir le marché brésilien (entretien à l'auteur).

314 Voir à ce sujet le témoignage de Saraceni à son retour d'Italie : SARACENI, Paulo César. « Depoimento Saraceni » in O Jornal do Brasil, Rio de Janeiro, 12/08/1961.

315ROCHA, Glauber. «Luz Atlântica 1962 » in Diário de notícias, Salvador, 31/12/1961. ROCHA, Glauber. « 1962 : Ano zero do cinema brasileiro » in Diário de Minas, Belo Horizonte, 08/04/1962. 
cinéma de «contenu» national ${ }^{316}$, la réflexion sur le langage cinématographique et ses implications idéologiques étaient alors balbutiantes. Force est de constater que la génération du Cinema Novo propose un concept critique et un programme beaucoup plus élaborés. À la soumission dont Viany et Santos faisaient preuve envers l'idéologie du parti communiste dont ils étaient membres, les cinemanovistas opposent une totale indépendance d'esprit. À l'adaptation qu'ils faisaient du Néo-Réalisme au contexte brésilien, les cinemanovistas veulent répondre par une synthèse des plus grands maîtres du cinéma mondial, du cinéma brésilien et de la culture brésilienne passée et présente ${ }^{317}$. Le Cinema Novo ne s'intègre donc pas dans un mouvement qui commence dans les années cinquante comme le suggèrent certains historiens ${ }^{318}$. C'est le contraire qui arrive, c'est le Cinema Novo qui intègre à lui les idées et l'expérience du cinéma indépendant comme il intègre la Vera Cruz, Mauro et Mário Peixoto. Le Cinema Novo ne résulte pas, il effectue une synthèse critique des expériences passées et se projette dans le futur, réclamant par là même la place centrale qui lui sera accordée dans l'histoire du cinéma brésilien.

\section{Conclusion de la première partie}

En 1960-61, la réflexion critique qui s'articule autour du cinéma brésilien, du cinéma étranger, de la saturation du marché de l'exploitation cinématographique et de la sortie de quelques films atypiques dans le panorama général, restait circonscrite au domaine du cinéma (Chapitre 1). Il fallait un nouveau cinéma au Brésil, dont les productions, d'un point de vue critique, puissent égaler les meilleures productions des grandes cinématographies mondiales. L'orientation principale est alors celle d'un cinéma d'auteur et de recherche sur le Brésil, un cinéma qui décrive et interprète la situation sociale de ce pays du tiers-monde et en permette une compréhension fine, mais aussi un cinéma dont l'originalité esthétique remette à l'originalité historique, sociologique, et, en un mot, culturelle de ce pays.

À partir de 1962, l'influence croissante de l'ISEB, l'émergence du CPC et les succès inattendus de Assalto ao trem pagador et $O$ Pagador de promessas concourent à la remise en cause du concept critique initial du Cinema Novo (Chapitre 2). Le groupe de jeunes cinéastes qui s'est réuni autour de Rocha ne cède pas à ces pressions et réaffirme l'orientation d'un

316SANTOS, Nelson Pereira dos. «O Problema do conteúdo do cinema brasileiro ». Op. cit.

317Rocha évoque son intérêt pour l'actualité de l'ensemble des disciplines artistiques dans ROCHA, Glauber. «Luz Atlântica 1962 », op. cit.

318Voir : GERBER, Raquel. «O processo cinemanovista », in O Mito da civilização atlántica, Petrópolis, ed. Vozes, 1977, pp. 152-169. Voir aussi : MORENO, Antônio. Cinema brasileiro, história e relações com o Estado. Op. cit. 
cinéma d'auteur à petit budget. Leur discours témoigne cependant qu'un glissement s'est opéré par rapport à la doctrine initiale. Il ne s'agit plus de réaliser une révolution cinématographique et un cinéma de participation sociale mais de produire une révolution politique avec un cinéma de conscientisation (chapitre 3). La courte période pendant laquelle João Goulart est président de la république (1962-1964) est le moment de toutes les espérances à gauche. Le groupe du Cinema Novo émergeant affiche pour objectif la conscientisation des masses par le cinéma afin que les masses conscientisées fassent la révolution sociale et politique qui transformera le Brésil et le monde. Nous allons voir dans la deuxième partie quelle a été la pratique cinématographique qui a correspondu à cette intention. 


\section{DEUXIÈME PARTIE : Le Cinema Novo première forme (1960- 1964)}

La période de production allant de 1960 (tournage de Barravento) à avril 1964 (coup d'État militaire), constitue la première phase du Cinema Novo. En 1964, le contexte social et politique change une première fois, il changera de nouveau en 1968 et nous verrons dans d'autres parties de cette thèse quelles furent les conséquences concrètes de ces changements pour le Cinema Novo. Au début, nous avons deux centres de production : Salvador et Rio de Janeiro. Peu de films sortent avant 1962 mais nous verrons que l'activité qui règne à Salvador, bien qu'elle ait été éphémère, possède un statut particulier qu'il sera utile d'étudier. Entre 1962, année de la sortie des premiers longs métrages, et 1964, année de la chute de João Goulart, le Cinema Novo a le temps d'articuler une proposition consistante et cohérente dans le champ cinématographique en réponse au climat de mobilisation sociale et de fébrilité révolutionnaire caractéristique de ces années. En l'espace de deux ans, pas moins de sept longs métrages sont produits. Nous allons des tâtonnements de Cinco vezes favela à la consécration de Deus e o diabo na terra do sol en passant par : Porto das Caixas ; Garrincha, alegria do povo ; Ganga Zumba; Vidas secas et Os Fuzis.

Parmi tous ces films, nous notons la présence d'un seul documentaire, Garrincha, alegria do povo. À l'origine du Cinema Novo avec les précurseurs Arraial do Cabo et Aruanda, le documentaire passe au second plan derrière la fiction. Hirszman, Saraceni, Andrade, Rocha, Dahl ou encore Jabor réaliseront des documentaires dans les années soixante mais, à l'exception de trois d'entre eux, Maioria absoluta, Integração racial et A Opinião pública, ces films sont considérés par les auteurs eux-mêmes comme secondaires dans leur filmographie. Enfin, seuls Garrincha et A Opinião pública connaîtront une diffusion effective dans les salles de cinéma. Par ailleurs, Diegues, Guerra, Lima et Santos ne filment aucun documentaire. Dès la première phase, le Cinema Novo affiche donc très clairement une préférence pour la fiction qui se confirmera par la suite ${ }^{319}$.

Une autre préférence qui se confirmera est celle du film historique. Alors qu'Arraial do Cabo indiquait le chemin de la recherche anthropologique et Bahia de todos os santos celui d'une approche sociologique, en accord finalement avec l'ISEB qui s'appuie avant tout sur une analyse historique pour expliquer le Brésil contemporain, le Cinema Novo situe l'action d'un nombre significatif de ses films dans le passé. C'est le cas avec Vidas secas (1940), Ganga Zumba (XVIIe siècle) et Deus e o diabo na terra do sol (les années 1930). 
Après 1964, cette orientation persiste ${ }^{320}$ et si leur action n'est pas effectivement située dans le passé, certains films s'inscriront dans une perspective historique en mettant en relation passé et présent ou en conférant aux événements récents (le coup d'État), le statut d'événement historique ${ }^{321}$. Après 1964, le choix du film historique sera présenté comme une stratégie d'évitement des sanctions éventuelles de la censure. Avant le coup d'État, nous pourrons cependant nous étonner qu'un cinéma qui se prétend révolutionnaire ne mette pas en scène les luttes sociales et les affrontements politiques de son temps et ne cherche pas non plus à répondre à la propagande massive d'extrême droite que nous avons évoquée dans la première partie.

Bien que les cinéastes soient jeunes et que l'improvisation et le volontarisme prévalent, le Cinema Novo constitue rapidement une proposition de cinéma cohérente. Nous allons voir dans cette deuxième partie quelles ont été les stratégies économiques et les premières grandes orientations esthétiques qui ont fondé son identité et comment ces choix manifestent un positionnement politique et un point de vue de classe en phase avec l'idéologie populiste alors dominante. Le populisme ne sera pas entendu dans son acception classique dans laquelle un leader charismatique prétend pouvoir incarner et défendre les intérêts du «peuple » compris comme une entité indifférenciée. Le populisme dont nous parlerons est étroitement lié à l'idéologie de l'ISEB qui reconnaît aux intellectuels un accès privilégié à la « réalité brésilienne » (la conscience critique), les considère comme une catégorie sociale à part, audessus des clivages sociaux, et leur confie la responsabilité de conscientiser le peuple supposé incapable d'accéder par lui-même à la condition de sujet politique. Au contraire du CPC, le Cinema Novo se saisira de cet objectif de «conscientisation» comme justificatif d'une activité pleinement artistique et rejettera toute forme de militantisme.

320L'action de 12 longs métrages du Cinema Novo est située dans le passé. 


\section{Chapitre 4 : Stratégies économiques et commerciales du Cinema Novo}

L'un des aspects les plus remarquables du concept critique du Cinema Novo est de s'articuler directement à une réflexion concrète sur l'économie du cinéma. Malgré cela et bien que le rôle décisif des distributeurs et des exploitants soit connu, la volonté de «faire œuvre » l'emporte sur toute autre considération et les cinemanovistas s'intéressent avant tout à produire. La question est de savoir comment. Avec son article intitulé «A Solução única » Dahl lance le modèle d'un cinéma d'auteur «indépendant» qui serait permis par l'emploi d'équipes réduites et de très faibles budgets dans un régime d'autoproduction. L'idéal de l'autoproduction ne sera cependant que très imparfaitement réalisé. Même si les coûts de production sont faibles, les cinemanovistas sont contraints dès leurs débuts à faire appel à des fonds publics ou privés, ce qui provoquera, comme nous allons le voir, des associations surprenantes.

Les premiers films du Cinema Novo sont tournés sans négociation préalable avec un distributeur et, dans certains cas, sans que le budget initial soit suffisant pour garantir que le film soit terminé. Les conséquences de cette absence de planification seront souvent catastrophiques d'un point de vue commercial. La perspective des cinemanovistas cependant est autre. Les prix remportés par Arraial do Cabo dans un certain nombre de festivals européens révèle la disponibilité de la critique européenne envers un nouveau cinéma brésilien. Ce succès va déterminer les modes d'affirmation du Cinema Novo. Premièrement, celui-ci va rechercher et emporter la reconnaissance de la critique internationale en investissant les festivals et les revues de cinéma les plus prestigieuses. Largement répercutées dans le presse nationale, les victoires du Cinema Novo vont permettre la légitimation des prétentions artistiques du groupe au Brésil et contribuer à faire vaciller l'opposition des critiques ne jurant justement que par le cinéma étranger. Le prestige culturel acquis à l'extérieur permet d'intéresser des investisseurs privés mais aussi des politiques qui chercheront à capter une part de ce prestige à leur profit. Le développement des institutions de soutien à la production cinématographique au Brésil est en grande partie la conséquence immédiate du succès critique du Cinema Novo en Europe. Après une première série de films réalisés dans des conditions extrêmement précaires, le projet du Cinema Novo est viabilisé sur la base d'emprunts bancaires et de subventions publiques.

Les stratégies économiques et commerciales du Cinema Novo vont correspondre à son positionnement sur le marché international comme un cinéma d'art et d'essai. Les 
contradictions entre ce positionnement et l'idéal initial d'un cinéma national populaire révolutionnaire n'apparaîtront pas de prime abord. Au cours de la première phase du Cinema Novo, il n'est pas conçu d'opposition entre les logiques culturelles et commerciales. Aussi, les cinemanovistas s'imaginent-ils que les nouveaux cinémas qui émergent seront les cinémas hégémoniques de demain. Les succès commerciaux, au Brésil, des 400 coups et de Hiroshima mon amour semblent confirmer ce point de vue. Il faut donc produire jusqu'à réussir à s'imposer sur le marché. Les choix économiques effectués au cours de la première phase du Cinema Novo vont influer sur l'esthétique des films produits et ne seront pas remis en cause au cours de ses deuxièmes et troisièmes phases. La viabilité de ce cinéma continuera à reposer sur son succès à l'étranger et sa capacité à obtenir des financements de l'État et de banques privées. Le volontarisme initial cédera cependant à l'assimilation des logiques du marché et l'adoption d'une mentalité d'entreprise. Mais nous verrons cela dans une autre partie. Pour l'heure, intéressons-nous en priorité aux stratégies mises en place au cours de la première phase du Cinema Novo.

\subsection{Le Cinema Novo à la conquête du monde (les festivals, la critique internationale)}

L'une des particularités du Cinema Novo aura sans doute été d'être vu et de se faire connaître d'abord en Europe avant de réussir à percer dans son propre pays. C'est ce qui arrive avec Arraial do cabo qui n'est pas distribué au Brésil et remporte plusieurs prix dans des festivals européens avant que la presse n'en parle et qu'il soit projeté sur un mode volontariste dans les premiers festivals brésiliens de fait dédiés au lancement du Cinema Novo. Cette particularité est aussi un paradoxe puisque l'intention des cinéastes est de discuter du Brésil avec les brésiliens et d'offrir au pays un cinéma qui soit enfin à la hauteur des grandes cinématographies mondiales. Le public brésilien sera pourtant systématiquement le dernier atteint. Dans le contexte du début des années soixante, en l'absence de toute infrastructure de support au cinéma national, obtenir le succès à l'extérieur apparaît comme le seul moyen de s'imposer aussi sur le plan intérieur. Les récompenses obtenues dans les festivals internationaux apparaissent comme une source de prestige et de légitimation, elles seront systématiquement utilisées par les cinemanovistas dans leurs négociations avec les financiers, les distributeurs et les exploitants de salle ou encore l'État dont il est attendu qu'il mette en place une législation permettant le développement du cinéma brésilien. Cette quête du succès international par le Cinema Novo n'a jamais réellement été traitée dans toute sa complexité du point de vue brésilien. La plupart des chercheurs qui se sont penchés sur l'histoire du 
mouvement ont toujours partagé la même approche des prix remportés dans les festivals internationaux que les cinemanovistas eux-mêmes. Il convient cependant de préciser comment s'est faite cette « conquête du monde » par le Cinema Novo et quelles ont été ses véritables conséquences.

\section{Présence des cinemanovistas en Italie et en France}

Selon l'étude pratiquée par Ivana Bentes de la correspondance de Rocha, tout indique que l'investissement des festivals européens par le Cinema Novo a été l'objet d'une stratégie précise qui a été mise en œuvre très tôt et qui s'est trouvée facilitée par la dispersion des cinéastes entre l'Europe et le Brésil ${ }^{323}$. N'oublions pas en effet que si Diegues, Guerra, Hirszman, Santos et Rocha restent à Rio de Janeiro (ou Salvador), Dahl passe quatre ans entre Rome et Paris de 1960 à 1964, Saraceni passe un an et demi à Rome entre 1960 et 1961 et Andrade étudie d'abord à Paris puis à New York entre 1961 et 1962. Parallèlement à la série d'articles qu'il publie dans $O$ Estado de São Paulo où il développe l'idée d'un cinéma d'auteur artisanal, la «solution unique » pour le développement du cinéma brésilien, Dahl écrit à Rocha :

« Tenho impressão que paradoxalmente a conquista do público brasileiro deverá ser feita de dentro para fora. Aliás a conquista não é tanto do público como da máquina distribuidora-exibidora. $\mathrm{O}$ fenômeno aliás não seria novo, os neo-realistas só se impuseram em seu próprio país após se terem imposto ao mundo, e o mesmo aconteceu, por exemplo, com Akira Kurosawa. E o mercado internacional, para o qual eu acho, como você, indispensável que nos dirijamos, só é conquistável na base dos festivais. $»^{324}$

Quelques années plus tard, Dahl résume en quelques mots la stratégie volontariste du Cinema Novo et l'option de l'investissement des petits et grands festivals européens qui, d'une certaine façon, s'est imposée d'elle-même :

« Usando os jovens que estudavam cinema na Europa como agentes de infiltração, os filmes do Cinema Novo obtiveram prêmios em festivais e abriram um crédito de confiança para os novos realizadores. Argumentando que as limitações do mercado brasileiro não comportavam uma produção industrial de filmes, exigindo antes um artesanal, que favorecia a criação de um cinema de autor, lançaram-se à realização de filmes de longa-metragem uns des ou doze diretores estreantes. Os recursos provinham ainda uma vez do mecenato de particulares, que viam através dele a possibilidade de ingressarem no mundo mítico do cinema e eventualmente receberem o capital investido através da venda

323ROCHA, Glauber. Cartas ao mundo. Op. cit., p. 24.

324« J'ai le sentiment que, paradoxalement, la conquête du public brésilien devra être faite de l'extérieur vers l'intérieur du pays. D'ailleurs la conquête ne sera pas tant du public que du binôme distribution-exploitation. Le phénomène n'est pas nouveau : les néo-réalistes ne se sont imposés dans leur propre pays qu'après s'être imposés au monde, il en a été de même avec Akira Kurosawa, et le marché international, auquel je pense, comme toi, qu'il faut que nous nous adressions, ne pourra être conquis qu'à partir des festivals. » in ibid., p. 116. 
ao exterior. $»^{325}$

L'usage du terme «stratégie » nécessite cependant de la prudence. Les séjours en Europe de Dahl, Saraceni et Andrade sont d'abord motivés par des objectifs personnels de formation et se déroulent à un moment où le Cinema Novo est encore bien plus un projet qu'une réalité. Leur présence entre Rome et Paris va cependant s'avérer extrêmement féconde dans la mesure où elle va leur permettre d'établir des réseaux dans le monde cinématographique européen et de découvrir cette voie des festivals qui, pour des raisons propres au contexte de l'époque, est ouverte aux manifestations artistiques venues du tiersmonde et contient cette attente d'un cinéma de thématiques politiques et sociales. Avant de développer plus avant le sujet, précisons encore que les trois cinemanovistas voyagent séparément même si, ultérieurement, Saraceni et Dahl se retrouvent au CEC de Rome. Notons aussi que c'est en Italie que les deux cinéastes font la connaissance l'un de l'autre et qu'ils ne s'étaient jamais rencontrés avant ${ }^{326}$.

Saraceni est le premier à arriver au CEC où il initie une série de contact avec les collègues de sa génération du futur cinéma nouveau italien, Bernardo Bertolucci, Marco Bellochio et Guido Gosulich qui sera le chef opérateur de $O$ Desafio et plus tard de Brasil ano 2000 et Macunaíma. Les relations d'amitié qui commencent alors seront maintenues tout au long de sa carrière ${ }^{327}$. Très rapidement, il s'intègre à ce que le cinéaste Gianni Amico, dont il fera la connaissance plus tard, appelle la « génération Rosati » du nom d'un café chic de Rome où l'élite du cinéma italien avait l'habitude de se réunir. C'est dans ce bar, entre autres lieux, qu'il aura l'opportunité de rencontrer Pier Paolo Pasolini, Michelangelo Antonioni, Alberto Moravia $^{328}$. Nous croiserons plus tard ces personnages dans l'histoire du Cinema Novo. Le Bellochio de I Pugni in tasca (1965) écrira «La Révolution au cinéma » ${ }^{329}$, Moravia rédigera de très intéressantes critiques de Barravento et Deus e o diabo na terra do sol ${ }^{330}$, enfin

\footnotetext{
325 « En utilisant les jeunes qui étudiaient en Europe comme des agents d'infiltration, les films du Cinema Novo ont obtenu des prix dans les festivals et ouvert un crédit de confiance favorables aux nouveaux réalisateurs. Argumentant que les limitations du marché brésilien ne permettaient pas la production industrielle de films, ils ont exigé avant tout un cinéma artisanal, orientation qui favorisait la production d'un cinéma d'auteur, et entre dix et douze jeunes se sont lancés dans la réalisation de leur premier long métrage. »in DAHL, Gustavo. « Cinema Nôvo e estruturas econômicas tradicionais » in Revista Civilização Brasileira, Rio de Janeiro, n 5 6, mars 1966.

326SARACENI, Paulo César. Op. cit., p. 84.

327Quand nous avons rencontré Saraceni en février 2004, il était alors en pleine négociation avec des producteurs italiens pour viabiliser la réalisation d'un nouveau film.

328 Ibid., p. 72.

329BELLOCHIO, Marco. «La Révolution au cinéma » in Cahiers du cinéma, Paris, nº176, mars 1966.

330Des traductions en portugais de ces deux articles a été publié dans le livre Deus e o diabo na terra do sol sous les titres « Os Ritos voluptuosos dos magos brasileiros » et « O Profeta da revolução », littéralement «Les Rites voluptueux des mages brésiliens » et « Le Prophète de la révolution ». Selon les indications qui nous sont données le premier article est paru dans L'Espresso du 16 juin 1963 et le deuxième dans le même journal le 16 août 1964. In ROCHA Glauber et alii. Deus e o diabo na terra do sol. Rio de Janeiro, ed. Civilização brasileira, 1965, pp. 3-7.
} 
Pasolini se référera directement à Rocha dans son texte «Le cinéma de poésie $»^{331}$. Nous ne citons ici que les traces écrites les plus illustres qui nous restent de ces rencontres entre l'Italie et le Cinema Novo mais de très nombreux témoignages concordent sur la permanence des échanges entre les cinemanovistas et ces différentes personnalités, en particulier dans les festivals où ils vont se retrouver au fil des ans, mais aussi, dans certains cas, comme pour Bertolucci, dans le domaine amical. Ces relations commencent par l'intermédiaire de Saraceni qui a une vision très internationaliste du Cinema Novo et le conçoit comme partie intégrante de tous les mouvements de cinéma moderne des années soixante.

À son arrivée à Rome, Dahl est introduit à la « génération Rosati » par Saraceni. Il profitera aussi de son séjour en Italie pour rencontrer les grands maîtres dont Luchino Visconti avec lequel il s'entretient lors de la première de $\dot{A}$ bout de souffle ${ }^{332}$. Par la suite, Dahl reviendra à Paris où il avait commencé son séjour européen et écrit aux Cahiers du cinéma ${ }^{333}$. L'intégration de Dahl à la critique française se révélera rapidement un soutien important. Louis Marcorelles s'intéresse au Cinema Novo avant sa révélation au festival de Cannes de 1964 avec Deus e o diabo na terra do sol et Vidas secas. Entre 1963 et 1966, à une époque où le Cinema Novo n'est connu que par le cercle restreint du public des festivals, il inaugure la publication d'articles et de longues entrevues ${ }^{334}$. Du côté de Positif, Robert Benayoun manifeste son intérêt pour le Cinema Novo dès $1964^{335}$ suivi par Michel Ciment qui recevra personnellement Glauber Rocha en $1968^{336}$ et échangera avec lui quelques correspondances. Nous ne citons ici que les plus éminents défenseurs du cinéma brésilien de l'époque. La presse quotidienne, parfois avec des articles de ces mêmes auteurs, a également couvert la présence des films dans les festivals et rétrospectives alors même qu'ils restaient totalement inaccessibles au grand public. L'intérêt de la critique française pour le Cinema Novo est en partie due à la présence et à l'activisme de Gustavo Dahl à Paris.

Andrade ne semble pas avoir participé autant que Saraceni ou Dahl, au moins à cette

331PASOLINI, Pier Paolo. «Le cinéma de poésie » in L'expérience hérétique. Paris, Payot, 1976, p. 18. 332SARACENI, Paulo César. Op. cit., p. 88.

333DAHL, Gustavo. «Lettre de Rio » in Cahiers du Cinéma, Paris, n¹68, juillet 1965.

DAHL, Gustavo. « Le Défi de Saraceni » in Cahiers du cinéma, Paris, n ${ }^{\circ}$ 172, novembre 1965.

DAHL, Gustavo. « Petit historique du Cinema Nôvo » in Cahiers du cinéma, Paris, ${ }^{\circ}{ }^{176}$, mars 1966.

334MARCORELLES, Louis. «L'Autre Amérique » in Cahiers du cinéma, Paris, n¹41, mars 1963.

MARCORELLES, Louis. «Le Cinema Novo brésilien » in Cahiers du cinéma, Paris, n ${ }^{\circ}$ 164, mars 1965.

MARCORELLES, Louis. « Rio : Bravo » in Cahiers du cinéma, Paris, n¹72, novembre 1965.

MARCORELLES, Louis. « Rencontre avec le Cinema Nôvo : Joaquim Pedro de Andrade, Gustavo Dahl, Carlos Diegues, Leon Hirszman, Glauber Rocha, Paulo Cézar Saraceni » in Cahiers du cinéma, Paris, n 176, mars 1966.

335Robert Benayoun et Albert Cervoni (du magazine Cinéma) sont cités par les cinemanovistas parmi les critiques français qui n'ont pas une approche paternaliste du cinéma brésilien à leur retour de Gênes, début 1965. In VIANY, Alex. O processo do Cinema Novo. Op. cit., p. 107. BENAYOUN, Robert. « Cangaços 65 : Cris du Brésil » in Positif, Paris, ${ }^{\circ} 73$, février 1966, pp. 1-21.

336Cf. ROCHA, Glauber. Cartas ao mundo. Op. cit.,, pp. 309 et 314-316. 
époque, à l'établissement de réseaux qui permettront ensuite la promotion du Cinema Novo et l'établissement de contrats de co-production et de diffusion des films. Il est pourtant le premier à se confronter concrètement aux questions d'ordre économique avec des interlocuteurs européens. Arrivé en France en 1960 avec la pellicule de Couro de gato qu'il lui restait encore à monter et sonoriser, il parviendra finalement, au prix de difficiles négociations avec Sacha Gordini, producteur de Orfeu negro (Marcel Camus, France, 1959), à finaliser le film et à en vendre les droits de distribution pour la France et la Belgique ${ }^{337}$. Il n'est pas impossible que cette première expérience ait été utile au cinéaste brésilien qui renouvellera par la suite ses collaborations avec des producteurs européens. Ce sera le cas avec la chaîne allemande ZDF et le producteur K.M. Eckstein pour Improvisiert und Zielbewusst ${ }^{338}$ (littéralement : Improvisation avec un objectif défini, 1967) et surtout Macunaíma. Nous retrouverons aussi K.M. Eckstein parmi les producteurs de Como era gostoso o meu francês. Enfin, au début des années soixante-dix, Os Inconfidentes est réalisé pour la RAI selon un accord assez similaire à celui de Antônio das Mortes, la chaîne finance le film en échange de l'exclusivité des droits de diffusion télévisée.

La présence des trois cinéastes en Europe n'auraient bien entendu pas pu se révéler aussi féconde sans d'autres auxiliaires. Le ministère des affaires étrangères brésiliens et les délégations diplomatiques de Rome et Paris vont jouer un rôle décisif. Comme Saraceni l'explique dans son autobiographie, c'est à son insu qu'Arraial do cabo, est présenté successivement au festival du cinéma documentaire ibéro-américain de Bilbao et au Festival del Popolo de Florence. La copie arrive à Rome où le cinéaste l'a beaucoup attendu fin 1960 après un détour par l'Espagne :

« Ninguém tinha me escrito avisando que o filme tinha ido para o Festival de Bilbao. [...] Arraial do Cabo, depois que chegou à Europa, só deu prazer. As portas ficaram abertas para mim. E foi ganhando vários prêmios. Sete ao todo. Eu só participei de um, quando eu mesmo o inscrevi, que foi o de Santa Margherita. Dos outros só tomei conhecimento depois, junto com os prêmios. $\rangle^{339}$

Selon le témoignage du cinéaste, l'ambassadeur du Brésil à Rome, Hugo Gouthier, et l'attaché culturel, Regina Castelo Branco, ont donné un appui total au film à commencer par

337Voir la biographie de Joaquim Pedro de Andrade sur son site officiel à l'adresse http://www.filmesdoserro.com.br/jpa_bio.asp, consulté le 10/05/2006. Les informations présentées recoupent celles de ses autres biographies et notamment celles des informations contenues dans les lettres reproduites par Saraceni dans son autobiographie. SARACENI, Paulo César. Op. cit., pp. 102-103.

338Le film est connu au Brésil sous le titre Cinema Novo.

339« Personne ne m'avait averti que le film avait été à Bilbao. [...] Arraial do Cabo, après être arrivé en Europe, n'a donné que du plaisir. Il m'a ouvert des portes. Et il a gagné plusieurs prix. Sept en tout. Je n'ai participé que d'un seul, quand j'ai moi-même inscrit le film au Festival de Santa Margherita. Des autres, je n'ai eu connaissance qu'au moment de recevoir les prix. » in SARACENI, Paulo César. Op. cit., p. 81. 
l'achat de la copie et son envoi au Festival de Florence ${ }^{340}$. Exactement à la même époque, Paulo Carneiro, le père de Mário Carneiro, co-réalisateur de Arraial est ambassadeur à Paris. Ce sont ses relations avec le producteur Sacha Gordini qui conduiront ce dernier à s'intéresser au film d'Andrade, Couro de gato. C'est aussi par le biais de l'ambassade du Brésil qu'Arraial do cabo est projeté au Musée de l'Homme de Paris et qu'il recueille dans le journal Combat l'une des premières critiques françaises favorables au Cinema Novo (nous sommes en 1961) ) $^{341}$ . Saraceni cite également l'attaché culturel de l'ambassade à Paris, Francisco Luís de Almeida Salles, comme une aide inestimable. Ce support initial des ambassades parisienne et romaine a sans doute considérablement favorisé l'essor d'un mouvement encore embryonnaire. C'est cependant entre 1963 et 1966, avec la présence du consul Arnaldo Carrilho à Rome et de l'attaché culturel, David Neves, à un moment où le Cinema Novo est entré dans une phase de production intense, que l'appui de l'Itamaraty va fonctionner à plein rendement.

Passionné de cinéma à tel point qu'il participera lui-même de certaines productions, Carrilho est sans aucun doute une personnalité à part dans le monde de la diplomatie. Dans un article de 2005, il résumait sa trajectoire dans les termes suivants :

« Fui produtor de Maioria Absoluta, de Leon Hirszman, de Integração Racial, do Saraceni, $O$ Circo, do Arnaldo Jabor, de Marimbás, de Wladimir Herzog, que deveria ser sincronizado mas não foi, e do primeiro filme de Gustavo Dahl no Brasil, Em Busca do Ouro. Além disso, fui assistente do Geraldo Sarno no filme Deus é um Fogo, nos episódios de Lima e Riobamba. Durante o Cinema Novo, todo mundo se ajudava. Diziam: ' Carrilho, quero uma câmera. Filme virgem. ' Eu conseguia através do Itamaraty. Havia um inspetor geral na alfândega do Rio de Janeiro, um indivíduo sobre quem eu quero escrever um dia, chamado Epaminondas Moreira do Valle, que liberava filme, negativos de som, mesa de montagem, câmeras, entre outras coisas, sempre que a gente confessava que era para matéria-prima para o cinema brasileiro. $\gg{ }^{342}$

Carrilho est intervenu dans tous les domaines où il pouvait le faire, dans et hors de ses fonctions de diplomate, à Rio comme à l'étranger. En 1962, il est l'un des artisans de la venue du cinéaste Arne Sucksdorf, d'une table de montage, d'une caméra et d'un magnétophone Nagra au Brésil. Le cours assuré par le cinéaste suédois va permettre la formation de toute une génération de techniciens que nous retrouverons au générique des films du Cinema Novo.

340Ibid., pp. 80 et 93.

341 Ibid., p. 91.

342 « J'ai été producteur de Maioria Absoluta, de Leon Hirszman, de Integração Racial, de Saraceni, O Circo, d'Arnaldo Jabor, de Marimbás, de Wladimir Herzog, qui devait être post-synchronisé mais ne l'a pas été, et du premier film de Gustavo Dahl au Brasil, Em Busca do Ouro. En plus de cela, j'ai été assistant de Geraldo Sarno sur le film Deus é um Fogo, dans les épisodes de Lima e Riobamba. Durant le Cinema Novo, tout le monde s'aidait. On me demandait : ' Carrilho, je veux une caméra. Du film vierge. ' Et j'en obtenais par l'intermédiaire de l'Itamaraty. Il y avait un inspecteur général à la douane de Rio de Janeiro, un individu sur lequel je veux écrire un jour qui s'appelait Epaminondas Moreira do Valle, qui libérait film, négatifs de son, table de montage, caméras, entre autres choses, à chaque fois que nous disions que c'était destiné au cinéma brésilien. » in CARRILHO, Arnaldo. « Em busca do bom cinema brasileiro : entrevista a Rodrigo Fonseca ». Article de la revue électronique Revista de cinema, http://www2.uol.com.br/revistadecinema/edicao32/entrevista/index.shtml, consulté le 20/12/2005. 
Juste après le coup d'État du premier avril 1964, il négocie la libération de Deus e o diabo na terra do sol que les militaires risquaient d'empêcher de participer au festival de Cannes ${ }^{343}$. Il reçoit également Rocha à Rome en 1965 au moment où celui-ci commence à écrire Terra em transe. Son action va être particulièrement efficace en Europe où il travaille en partenariat avec Neves afin d'assurer la meilleure visibilité possible pour le Cinema Novo dans les festivals et la presse. Leur action se fait sentir à partir du quatrième festival organisé par le Columbianum, à Sestri Levante en 1963, et l'apothéose sera le cinquième festival organisé à Gênes en 1965. Neves a témoigné de ce qu'était son travail à l'époque, entre sa carrière de critique du début des années soixante et celle de cinéaste qui commence en 1969 :

\footnotetext{
« Durante treze anos eu viajei muito para a Europa, duas ou três vezes por ano para organizar... [...] fazia umas palestras. Começou uma vez e aí não parei mais. Treze anos! Houve ano em que viajei quatro vezes. Eu fui ao júri de Berlim e Locarno e organizei uma retrospectiva de cinema brasileiro com vinte e três films em Gênova, em 1965, e uma outra com dez filmes em Berlim, em 1968-69. » ${ }^{344}$
}

Ajoutons néanmoins que l'appui de l'Itamaraty n'a pas été inconditionnel et a toujours étroitement dépendu des personnes qui étaient en place. Pendant toutes les années soixante et même avant l'implantation de la dictature plusieurs films se voient opposer le veto des autorités quant à leur participation dans les festivals internationaux. Le prétexte est arbitraire et se résume souvent de la même manière : il est jugé qu'ils donnent une image dépréciative du Brésil. En 1961, Bahia de todos os santos voit sa participation au festival de San Francisco interdite pour ce motif ${ }^{345}$. La prohibition peut émaner d'à peu près n'importe quel organe de l'État où une personne suffisamment influente saura se faire entendre. Elle peut également s'exprimer de façon officielle ou officieuse, nous verrons dans un autre chapitre que les cinemanovistas ont été victimes de manœuvres d'intimidations. Enfin, comme il était normalement de l'autorité des services de censure des diversions publiques d'autoriser l'exportation d'un film, sa décision devait logiquement l'emporter. Pour autant, ce service était fréquemment discréditée par l'exercice de pressions externes. Ainsi, pour revenir au ministère des affaires étrangères, l'Itamaraty empêche en 1964 la participation de Ganga Zumba au Festival de Karlovy-Vary alors que son exportation est permise et qu'il a déjà participé au Festival de Cannes dans une section parallèle en présence de son auteur. À cette occasion, c'était même l'Itamaraty, qui lui avait payé son billet d'avion ${ }^{346}$ !

343 Voir son témoignage dans les extras du dvd de Deus e o diabo na terra do sol.

344 « Durant treize ans, j'ai beaucoup voyagé en Europe, deux ou trois fois par an pour organiser des événements... [...] je donnais des conférences. J'ai commencé un jour et je n'ai plus arrêté. Treize ans ! Une année, j'ai voyagé quatre fois. J'ai participé du jury de Berlin et de Locarno et j'ai organisé une rétrospective du cinéma brésilien avec 23 films à Gênes en 1965 et dix films à Berlin en 68-69 » in NEVES, David. Muito prazer. Op. cit.

345« Bahia de todos os santos: Um Filme proibido de viajar » in O Dia, Rio de Janeiro, 02/02/1961.

346« Itamarati veta exibição de Ganga Zumba no Festival de Karlovy-Vary » in Jornal do Brasil, Rio de 
Les anecdotes sont nombreuses quant aux revirements de ce ministère. Tout indique que ses fonctionnaires étaient traversés par les mêmes contradictions qui habitaient une bonne part de la classe moyenne en relation au Cinema Novo, certains le rejetaient comme un cinéma sur la pauvreté qui ne montrait que les aspects négatifs de la vie, d'autres au contraire l'applaudissaient pour constituer un cinéma d'art de niveau international. Nous retrouverons ces contradictions au moment de traiter des luttes pour la réglementation du secteur cinématographique et l'implantation de politiques de soutien au cinéma national. Nouvel exemple, à Gênes en 1965, à la veille du Festival qui marquera la consécration du Cinema Novo en Europe, l'ambassadeur et l'ambassadrice accompagnés de l'attaché militaire demandent à assister à trois films de la sélection brésilienne, Arraial do Cabo, Vidas secas et Deus e o diabo na terra do sol. Scandalisés par ce qu'ils voient, ils interdisent la projection des films ${ }^{347}$. Seule la détermination des organisateurs italiens garantit la réalisation de l'événement. Notons enfin qu'entre 1967 et 1970, les cinemanovistas se plaindront du manque de soutien sinon du sabotage pratiquée par les ambassades en Europe ${ }^{348}$.

Dans un tel contexte, un élément décisif pour la diffusion du Cinema Novo en Europe a été l'intérêt d'organisateurs de festivals avec, en tout premier lieu, Gianni $\mathrm{Amico}^{349}$ et le père Angelo Arpa, président du Columbianum. Cette institution culturelle créée par les jésuites à Gênes en 1959 est l'organisatrice de la Rassegna del Cinema Latino Americano qui va connaître cinq éditions successives et jouer le rôle d'une véritable plate-forme de lancement du Cinema Novo. Les deux premières éditions auront lieu à Santa Margherita Ligure en 1960 et 1961. Les deux suivantes se dérouleront à Sestri Levante en 1962 et 1963 . La dernière prendra place à Gênes en janvier 1965. Les cinemanovistas s'intéressent au festival du Columbianum à partir de 1961. C'est Andrade qui conseille à Saraceni d'y participer dans une

Janeiro, 06/06/1964.

347SARACENI, Paulo César. Op. cit., p. 180.

348Dans un texte resté jusqu'à aujourd'hui inédit et qui était destiné au ministre Magalhães Pinto à l'occasion d'une réunion de la classe cinématographique pour un déjeuner de fraternisation, Rocha a dressé un historique des relations entre l'Itamaraty et le cinéma. Son témoignage recoupe exactement les autres témoignages sur lesquels nous nous sommes appuyés. Parmi les hauts fonctionnaires du ministère, il salue l'action de l'ambassadeur Lauro Escorel, du ministre Carlos Jacyntho de Barros, du ministre Mario Dias Costa et du secrétaire Carlos Perez. Pour le reste, il critique très durement l'action de l'Itamaraty. Selon lui, à partir de 1967, la participation du Cinema Novo aux festivals européens est permise par la notoriété du mouvement. Les films sont invités à participer et se passent de l'aide du gouvernement du Brésil. In ROCHA, Glauber. O Itamaraty e o cinema. Document dactylographié de 8 pages avec annotation, Paris, sans date, probablement 1968, juste avant le Festival de Rio, archives Tempo Glauber.

349Gianni Amico (1933-1990) est co-scénariste de Prima della revoluzione (Italie, 1964) et de Partner (Italie, 1968) de Bernardo Bertolucci. Sa passion pour le Brésil est bien connue par les cinemanovistas puisqu'il est souvent rapporté qu'il possédait une collection de disques de musique brésilienne extrêmement complète. En 1969, il réalise dans le Nordeste le film Tropici qui compte avec la participation des acteurs du Cinema Novo, Joel Barcellos et Antônio Pitanga. À la même époque, il collabore avec Rocha sur le scénario de Der Leone have sept cabeças. Plusieurs années plus tard, il réalise avec Hirszman et Saraceni le long métrage Bahia de todos os sambas à partir d'un concert filmé à Rome en 1983. Le film est terminé en 1996 et compte avec la participation de Caetano Veloso, Gilberto Gil, Nana et Dorival Caymmi, João Gilberto et Tom Zé. 
lettre du 22 mars $1961^{350}$. Il a alors appris par l'intermédiaire de l'ambassade du Brésil en France que le cinéaste Gianni Amico, qu'ils ne connaissent pas encore, s'est rendu à São Paulo pour sélectionner les films qui seront projetés lors d'une rétrospective du cinéma brésilien dans le cadre du festival ${ }^{351}$. L'initiative de l'événement appartient donc exclusivement à la partie italienne, elle entre dans le contexte de la papauté de Jean XXXIII, du Concile de Vatican II et d'un changement notable de perspective d'une partie de l'Église quant aux questions sociales. Le père Arpa est connu pour ses opinions progressistes. La réalisation du festival du cinéma latino-américain procède d'une véritable démarche de recherche quant aux problèmes du tiers-monde et s'inscrit dans les débats internes à l'Église qui amèneront à la formulation de la théologie de la libération la décennie suivante.

\section{Les Festivals européens de cinéma}

La Rassegna del Cinema Latino Americano est un événement prestigieux qui réunit dans ses jurys successifs des membres éminents de l'élite intellectuelle européenne et bénéficie d'une bonne couverture de la presse cinématographique internationale. Saraceni, Dahl et Andrade assistent effectivement à la deuxième édition du festival à Santa Margherita. Arraial do Cabo participe à la compétition et remporte son prix le plus important. Les jeunes cinéastes rencontrent Jean Rouch qui est, pour Saraceni, la grande figure inspiratrice du Cinema Novo avec Roberto Rosselini ${ }^{352}$. L'expérience concluante du français quant à la validité artistique d'un cinéma à petit budget, de la caméra portée et de l'approche anthropologique nourrit l'idée d'un cinéma d'auteur artisanal sensible aux problématiques sociales. À la suite de cette rencontre, Andrade partira en stage à New York auprès des frères Maysles, pionniers du cinéma direct américain avec Richard Leacock. De retour à Paris, Dahl suivra le cours de cinéma ethnographique administré par Jean Rouch lui-même au Musée de l'Homme. L'année suivante, la participation du Cinema Novo se renforce avec la participation de trois films, O Poeta do castelo, Couro de gato, A Grande Feira et la présence de Rocha ${ }^{353}$. Son premier voyage en Europe va se révéler extrêmement fécond. En plus de gagner le prix

350La lettre est reproduite dans l'autobiographie de Paulo César Saraceni. Voir : SARACENI, Paulo César. $O p$. cit., p. 91.

351La rétrospective du cinéma brésilien de Santa Margherita permettra au public d'assister à Ganga Bruta (Humberto Mauro, 1933), O Canto do mar (Alberto Cavalcanti, 1952) et O Cangaceiro (Lima Barreto, 1954). In SARACENI, Paulo César. Por dentro do Cinema Novo - Minha Viagem. Rio de Janeiro, Nova Fronteira, 1993, p. 106.

352Paulo César Saraceni. Entretien avec l'auteur, février 2004.

353Le troisième Festival du Cinéma latino-américain organisé par le Columbianum s'est déroulé à SestriLevante du 01 au 08/06/1962. La délégation brésilienne comptait également avec la présence de Walter da Silveira et Anselmo Duarte. C'est l'année du triomphe de O Pagador de promessas qui n'est pourtant pas projeté au festival. In BARROS, José Tavares de. « Festival do cinema de Sestri-Levante » in Revista de Cultura Cinematográfica, Belo Horizonte, n³2, mai-août 1962. 
« Opera Prima » à Karlovy Vary pour son premier long métrage, Barravento, il tire partie des contacts établis en Italie par Saraceni et s'entend très bien avec Amico qui invite Barravento au festival de Porreta Terme ${ }^{354}$. Le jury du festival de 1962 comptait avec la participation de Luís Buñuel, Chris Marker, John Grierson, Edgard Morin et Georges Sadoul ${ }^{355}$.

En 1963, la participation du Cinema Novo s'accroît encore avec la projection de deux longs métrages, Porto das Caixas et Barravento, le festival qui compte avec la présence de Saraceni et de ses amis Bellochio et Bertolucci marque également le début des activités de promotion de Carrilho et Neves. À ce moment-là, le Cinema Novo possède déjà le réseau qui ne cessera par la suite de l'appuyer dans ses pérégrinations européennes et les critiques française et italienne sont déjà sensibilisées à son émergence. Barravento a suffisamment intrigué pour que Sadoul échange quelques lettres avec Rocha qu'il a rencontré à Karlovy Vary ${ }^{356}$. Le terrain est donc propice pour la consécration de 1965. Après le passage remarqué de Vidas secas et Deus e o diabo na terra do sol à Cannes en mai 1964, le Columbianum décide de consacrer une rétrospective au Cinema Novo. Arraial do Cabo, Porto das Caixas, Deus e o diabo na terra do sol, Vidas secas et Maioria absoluta font partie d'une sélection d'une vingtaine de film. Le film de Pereira dos Santos reçoit le prix du meilleur long métrage du jury officiel alors que le Cinema Novo dans sa globalité est primé par le jury parallèle de la critique patronnée par la Fipresci ${ }^{357}$. Venus en nombre, les cinemanovistas, Dahl, Diegues, Neves, Saraceni et Rocha, ont l'occasion de s'exprimer dans un événement qui a encore gagné en importance et au cours duquel ils rencontreront Robert Benayoun, Albert Cervoni, Louis Marcorelles, Jean Rouch, Guido Aristarco et Henri Langlois ${ }^{358}$. Ce festival est aussi le moment de la divulgation par Rocha de «L'Esthétique de la faim » dont le texte sera reproduit dans plusieurs journaux européens. Sommé aux retentissements successifs de Deus e o diabo na terra do sol et Terra em transe, ce nouveau manifeste apporte au cinéaste une projection internationale sans égale parmi les autres membres du Cinema Novo.

Le festival du Columbianum est un lieu de rencontre qui permet au Cinema Novo d'articuler ses réseaux en Europe. Paradoxalement, il va aussi contribuer à son insertion dans les débats brésiliens et à l'établissement de ses réseaux dans son pays d'origine. En 1961, le premier festival auquel les cinemanovistas avaient assisté, avait joué le rôle de diviseur des eaux. Le Brésil avait envoyé une importante délégation mandatée par le GEICINE et dirigé par le cinéaste vétéran Fernando de Barros. Le GEICINE, qui comme nous le verrons, est

354SARACENI, Paulo César. Op. cit., p. 128.

355ROCHA, Glauber. Cartas ao mundo. Op. cit., p. 173.

356 Ibid., p. 185 et 210.

357VIANY, Alex. O processo do Cinema Novo. Op. cit., p.101.

358Après avoir assisté à Porto das Caixas à Gênes, ce dernier organise une rétrospective des films de Saraceni à la Cinémathèque française. In SARACENI, Paulo César. Op. cit., p. 185. 
alors le principal organe de l'État dans le cinéma défend l'idée d'un cinéma industriel de divertissement qu'il ne se donnera jamais les moyens de réaliser. Dans un article de l'époque, Dahl décrit en ces termes la prestation des représentants du GEICINE à Santa Margherita :

« As mesas redondinhas explicaram tudo. Na brasileira havia arrogância, se falava do futuro, se contava que o então presidente da República via um filme por dia. Nós vamos ser grandes, nós vamos entrar no mercado mundial, nós vamos fazer co-produções, vamos ser agressivos, vamos meter medo a Deus e a todo mundo, os distribuidores americanos serão obrigados a produzir filmes no Brasil (que Alá que é grande e misericordioso nos livre desta praga !), teremos uma indústria forte, nadaremos na gaita. Nenhuma palavra sobre a situação atual, nenhuma tentativa de compreensão, de reflexão, mas planos, muitos planos. Os argentinos estavam longe porém dessa confiança e dessa satisfação, para minha surpresa, pois habituado ao deplorável nível do cinema brasileiro, pensava que o cinema deles se exercitasse no mesmo plano, e não no nível de Prisioneros de la noche, por exemplo. $\rangle^{359}$

Arraial do Cabo gagne le prix du meilleur court métrage alors que la délégation brésilienne officielle n'a même pas pris connaissance du film. Selon Saraceni, lui-même, Andrade, Dahl, Alberto Cavalcanti, Sandro Francini et Bertolucci forment un noyau de résistance au discours démagogique de Barros. Il rencontreront aussi un allié dans le critique portugais Joachim Novais Teixeira qui est le correspondant en Europe des quotidiens brésiliens importants, $O$ Estado de São Paulo et $O$ Globo. Celui-ci entre en contact avec Rocha lors de son premier voyage en Europe par l'intermédiaire de l'ambassade du Brésil à Paris $^{360}$. Il se révélera un défenseur du Cinema Novo au Brésil au travers de la couverture apportée aux festivals européens. En Europe, il intègre son réseau de promotion. Après le deuxième festival de Santa Margherita, il semble que le GEICINE se soit désintéressé de l'événement ou que les organisateurs du festival ait soigneusement évité d'inviter de nouveau ses représentants. À partir des éditions suivantes, les délégations brésiliennes qui font le déplacement se composent de personnalités appréciés par les cinemanovistas et qu'ils rencontrent parfois pour la première fois. C'est le cas avec l'écrivain Guimarães Rosa dont le livre Grandes sertões, veredas est l'une des sources d'inspiration de Deus e o diabo na terra do sol. Cette rencontre émeut si profondément Rocha qu'il la racontera à deux reprises, la première dans le livre $O$ Século do cinema $^{361}$, la seconde, dans son roman, Riverão

359 « Les tables rondes ont tout expliqué. La table brésilienne n'était qu'arrogance, on n'y spéculait sur l'avenir, on y disait que le président de la République voyait un film de cinéma par jour. Nous allions être grands, nous allions entrer dans le marché mondial, nous allions faire des co-productions, nous allions faire peur à Dieu et à tout le monde, les distributeurs américains allaient être obligés à produire des films au Brésil (qu'Allah qui est grand nous protège de cette calamité), nous allions être forts, nous allions nager dans l'oseille. Aucun mot sur la situation actuelle, aucune tentative de compréhension, de réflexion, mais des projets, toujours des projets. Les argentins étaient loin de cette confiance et de cette satisfaction. À ma grande surprise, car habitué au niveau déplorable du cinéma brésilien et pensant que leur cinéma évoluait au même niveau, j'ai découvert par exemple Prisioneros de la noche, un film d'une autre classe. » in DAHL, Gustavo. " A Solução única », Op. cit.

360ROCHA, Glauber. Cartas ao mundo. Op. cit., p. 215.

361ROCHA, Glauber. O Século do cinema. Op. cit., 1985. 
Sussuarana en $1977^{362}$. Grâce à la Rassegna del Cinema Latino-Americano, les cinemanovistas pourront rencontrer Alberto Cavalcanti, Almeida Sales et Rudá de Andrade de la Cinemateca Brasileira en 1962 363 , en 1965, en plus de Guimarães Rosa, Antônio Cândido, l'un des plus grands critiques littéraires brésiliens, participe à la délégation brésilienne.

Ces quatre premières années de présence du Cinema Novo dans les festivals européens lui permettent d'accumuler un important prestige culturel et de construire un réseau auprès du monde du cinéma européen suffisamment fort pour prendre le relais du ministère des affaires étrangères quand celui-ci ne lui apportera plus aucun soutien. Dans la seconde moitié des années soixante, sa présence dans les festivals se maintient et atteint son apogée avec l'obtention par Rocha du prix de meilleur metteur en scène à Cannes en 1969. Réseau et prestige culturel permettent de lutter contre les attaques venues de l'intérieur du Brésil et vont jusqu'à convaincre des partis a priori opposés au Cinema Novo de son utilité. Nous verrons en effet dans d'autres chapitres que le capital culturel qu'il apporte au Brésil va entrer en ligne de compte dans la prise décision des plus hautes instances de l'État. Selon la comptabilité que nous avons tenue, le nombre de récompenses obtenues dans des festivals internationaux entre 1961 et 1972 atteint le nombre de 45. Parmi ces récompenses, 12 ont été obtenues dans l'un des trois festivals majeurs, Berlin, Cannes ou Venise. Enfin, le nombre de participations à ces trois festivals atteint le nombre 27 , un seul film ayant pu participer à plusieurs festivals selon diverses modalités. Ce nombre de participations a garanti une présence continue du Cinema Novo parmi les cinématographies les plus en vues entre 1964 et 1972. Cette importante participation peut être mise en relation avec la couverture reçue dans les principaux magazines de cinéma qui, dans la même période, ont consacré plusieurs dossiers sur le sujet dépassant chacun une dizaine de pages et contenant analyses de films et entrevues avec les cinéastes.

\subsection{Le Cinema Novo à l'épreuve du marché (volontarisme et mécénat)}

Dans son livre, Revisão crítica do cinema brasileiro, Rocha décrit dans ces termes les perspectives de l'aspirant réalisateur dans le contexte du début des années soixante :

«O aspirante a realizador sofre mais que o crítico : não há campo profissional, não há escolas de formação técnica, não há produções suficientes para manter uma prática ininterrupta e evolutiva. $\mathrm{O}$ aspirante é um suicida que se obriga a deixar os compromissos e sofrer as humilhações até, por jogo de azar, dirigir um filme. Neste processo, os mais despretenciosos, aqueles que intencionam apenas a profissão, o possível dinheiro e o sucesso, cedo ou tarde se equilibram : bolam argumentos de efeitos narrativos espúrios, pouco se interessam pelo sentido ideológico do filme ou pela significação cultural do 
cinema ; fazem filmes apesar do cinema e desconhecendo cinema. Os autores são, ao contrário, esmagados com facilidade. Se na Europa e nos Estados Unidos ainda existem reservas para um diretor dotado de inteligência, cultura e sensibilidade - no Brasil estas qualidades são sinônimos de loucura, irresponsabilidade e comunismo. $»^{364}$

À la fin des années cinquante, le cinéma brésilien offre deux voies à l'aspirant réalisateur. La première est celle décrite par Rocha et dont Roberto Farias et Anselmo Duarte vont finalement constituer les prototypes. Ces deux cinéastes se sont formés aux métiers du cinéma avec la chanchada et se sont effectivement toujours préoccupés de la viabilité commerciale de leur cinéma avant de s'intéresser au septième art en tant que mode d'expression d'une sensibilité et d'une vision du monde personnelles. Pour autant, leurs cinématographies respectives ne sont pas dénués d'intérêt si nous voulons bien nuancer l'opposition, utilisée comme concept opérant par les cinemanovistas, entre cinéma d'auteur et cinéma commercial. Selon nous, il y a bien dans Assalto ao trem pagador et $O$ Pagador de promessas, des éléments capables d'alimenter une discussion sur le Brésil. Dans les deux cas, même si les carrières des deux cinéastes n'ont pas confirmé cette capacité à produire un cinéma commercial qui soit aussi un cinéma de réflexion sociale et politique, ces deux films en ont incarné la possibilité selon des voies différentes de celles du Cinema Novo ${ }^{365}$. La formation par la chanchada n'équivalait donc pas à une absence totale de perspective et n'interdisait pas à ceux qui avaient suivi cette école d'imprévisibles changements de ligne esthétique dans leur travail.

La seconde voie offerte aux aspirants réalisateurs est celle de la réalisation de cinéjournaux, de reportages institutionnels et de propagande, de publicités commerciales. L'ensemble de ces films de commandes constitue le gros de la production brésilienne et représente le seul lieu d'une activité cinématographique suivie depuis le début du siècle.

364 « L'aspirant réalisateur souffre plus que le critique, il n'y a pas de secteur professionnel, il n'y a pas d'école de formation technique, il n'y a pas une production suffisamment maintenue pour permettre une pratique régulière et évolutive. L'aspirant est un être suicidaire qui accepte de tout abandonner et de souffrir toutes les humiliations avant de pouvoir un jour, par chance, diriger un film. Ayant choisi cette voie, les moins prétentieux, ceux qui ambitionnent seulement de faire cette profession, de gagner de l'argent et, peut être d'avoir du succès, parviennent tôt ou tard à s'installer : ils écrivent des arguments aux effets narratifs grossiers, ils s'intéressent peu au sens idéologique du cinéma ou à sa signification culturelle; et finissent par faire des films envers et contre le cinéma, ignorant le cinéma. Les auteurs, au contraire, sont écrasés avec facilité. Si en Europe et aux États-Unis, il existe encore un espace pour des réalisateurs dotés d'intelligence, de culture et de sensibilité - au Brésil, ces qualités sont synonymes de folie, d'irresponsabilité et de communisme. » in ROCHA Glauber. Revisão crítica do cinema brasileiro. Op. cit., p. 12.

$365 \mathrm{Il}$ ne s'agit pas pour nous d'adopter le point de vue largement répandu selon lequel il n'existe pas de contradiction entre la qualité artistique du septième art et les règles de l'économie de marché dans lequel il s'insère. Nous ne pensons pas non plus que des idées nouvelles peuvent être avancées dans un langage académique. Pour autant, nous serons plus nuancé que Rocha et nous pensons qu'il peut arriver, à divers degré, qu'une tension s'établisse entre les règles du marché et des éléments esthétiques nouveaux qui participent à la critique des valeurs établies d'une société donnée. Autrement dit, la volonté de composer avec les règles du marché et le souci de la communication avec le public ne sont pas a priori incompatibles avec l'acte consistant à dire et révéler des choses nouvelles. 
Beaucoup de cinemanovistas devront d'ailleurs en passer par là à un moment difficile de leur carrière pour pouvoir tout simplement survivre. À la fin des années cinquante, Pereira dos Santos travaille pour Jean Manzon ${ }^{366}$. Saraceni lui-même, pourtant l'un des plus ardents défenseurs du cinéma d'auteur, se plie à l'exercice de la publicité à la fin des années soixante, d'ailleurs non sans plaisir ${ }^{367}$. Au début des années soixante pourtant, le radicalisme des cinemanovistas les empêche de concevoir dans ce domaine d'activité ne serait-ce qu'un lieu de formation technique. Aucun cinéaste ou technicien notable ne sera d'ailleurs issu de ce milieu. Pour autant, nous verrons plus bas, avec la trajectoire du producteur Jarbas Barbosa, que non seulement ce type d'activité pouvait apporter les éléments de pratique technique dont Rocha déplore le manque mais aussi un complément de revenu et la connaissance des réseaux de distributions et d'exploitation brésiliens qui constituent en dernière instance la clef du marché.

Quoiqu'il ait été des véritables opportunités que pouvaient offrir ces deux voies, il est vrai qu'aucune d'elle ne correspondait à l'idée que les cinemanovistas se faisait du cinéma. Par préjugé ou par méconnaissance, ils vont donc s'en détourner et essayer d'inventer de nouvelles voies pour faire du cinéma au Brésil. Reprenant à son compte la critique de la génération des années 50 à l'encontre de la Vera Cruz, le Cinema Novo déclare adopter le modèle du cinéma indépendant, coopératif et à petit budget. Il en hérite les contradictions tant politiques qu'économiques. Dans les faits, ce modèle ne sera pas rigoureusement appliqué et la première phase du Cinema Novo se caractérise par une grande imprécision au niveau des stratégies économiques à employer. L'idéalisme initial des cinéastes et leur volonté de filmer à tout prix conduisent à négliger les problèmes de distribution et d'exploitation. En matière de production, comme l'indique Barbosa, il n'y avait qu'une méthode, demander, demander et demander encore ${ }^{368}$ aux banques et aux institutions de l'État.

D'abord seuls face à l'épineuse question de la captation de ressources, les réalisateurs frappent à toutes les portes, institutions officielles, mécènes potentiels, banquiers, et investissent souvent de leur poche contractant des crédits personnels qu'ils rembourseront à dure peine. Une solution mixte de mécénat, de collecte de subventions et de système coopératif basé sur des prêts à particulier va prévaloir selon des modalités diverses accordant plus ou moins d'importance à un élément qu'à un autre. Pendant toute la première phase du Cinema Novo, le volontarisme domine.

366SALEM, Helena. Nelson Pereira dos Santos - O Sonho possível do cinema brasileiro. Op. cit., p. 140. 367Cf. SARACENI, Paulo César. Op. cit., p. 245.

Dans les années soixante-dix, malgré le succès de Toda nudez será castigada, Arnaldo Jabor sera contraint de réaliser 125 publicités pour vivre. $C f$. JABOR, Arnaldo. « Arnaldo Jabor : Um Depoimento à repórter Izilda Alves » in O Estado de São Paulo, 20/01/1979.

368Cf. OROZ, Silvia. 30 anos de Cinema Novo : Jarbas Barbosa - Entrevista a Silvia Oroz. Rio de Janeiro, Imprensa da Cidade, 1993, p. 12. 


\section{Le cinéma indépendant : un modèle inégalement suivi}

Le concept de cinéma indépendant apparaît au Brésil en même temps que sont créées les grandes compagnies paulistes de cinéma : la Vera Cruz, la Maristela et la Multifilmes. Alex Viany, Rodolfo Nanni, Mário Civelli et Nelson Pereira dos Santos sont les premiers théoriciens d'un concept nouveau, imprécis et dont les présupposés dépassent largement la sphère économique. Celui-ci est développé dans les premiers grands congrès de cinéma qui ont lieu au début des années cinquante. L'originalité des tenants du cinéma indépendant par rapport à leurs contemporains est de remettre les questions économiques en perspective avec les questions culturelles et de repousser le traitement de la question cinématographique comme une question strictement industrielle. Pour eux, le cinéma n'est pas une marchandise comme une autre mais un art qui a un rôle à jouer dans la défense de l'identité nationale brésilienne. Bien que conscients de la précarité de la production cinématographique, ils sont très critiques envers la tentative d'industrialisation du cinéma brésilien par la bourgeoisie pauliste. Ils doutent de ses capacités à promouvoir la création d'un cinéma brésilien « authentique » qui participe réellement à l'élévation du niveau artistique du cinéma national. Maria Rita Galvão, qui a étudié l'émergence de ce concept de cinéma indépendant, résume la position de Viany quant à cette question d'authenticité :

« [...] há a idéia de que nenhum cinema brasileiro ' autêntico ' - por isto se entende qualquer coisa voltada criticamente para a realidade - sairá dos grandes estúdios. Deles pode-se esperar o aprimoramento técnico e nada mais. Os estúdios são fábricas, empreendimentos capitalistas por excelência, e enquanto tal visando primordialmente o lucro. A visão crítica da realidade brasileira, para a qual a literatura brasileira já havia contribuído com o romance nordestino, só poderia chegar ao cinema com a produção independente, porque as grandes empresas são parte do sistema que se critica ; é preciso extrair delas as vantagens que elas podem oferecer, sem no entanto se deixar engolir pelo esquema. ${ }^{369}$

Au début des années cinquante, le concept de cinéma d'auteur n'existe pas encore mais l'influence du néo-réalisme italien se sentir. La nécessité d'indépendance du cinéaste apparaît indispensable à la réalisation d'un cinéma authentiquement brésilien dont les trois principales caractéristiques seraient traiter de thématiques brésiliennes, véhiculer une vision critique de la société et approcher la réalité quotidienne de l'homme du peuple. Ce programme peut sembler

369 « [...] il y a l'idée qu'aucun cinéma brésilien ' authentique ' - et par ce mot, il faut entendre tourné de façon critique vers la réalité - ne sortira des grands studios. De ceux-ci, il est possible d'attendre une meilleure exécution technique mais rien de plus. Les studios sont des usines, des investissements capitalistes par excellence, et leur unique objectif est de faire des bénéfices. La vision critique de la société brésilienne, à laquelle la littérature avait déjà contribué avec le roman nordestin, ne pourra arriver au cinéma que par le biais d'une production indépendante, parce que les grandes entreprises font partie du système qui est critiqué ; il faut profiter des avancées qu'elles peuvent apporter sans pour autant se laisser dévorer par le système. » in GALVÃO, Maria Rita. «O desenvolvimento das idéias sobre cinema independente ». Cadernos da cinemateca, n4, São Paulo, 1980, p. 14. 
proche de celui du Cinema Novo mais il n'inclut pas l'impératif de la rénovation du langage qui viendra à la fin des années cinquante. La qualité technique est reléguée au second plan après la qualité de l'histoire qui doit s'imprégner et défendre la culture brésilienne face aux menaces d'acculturation que font peser sur elle l'omniprésence du cinéma américain. Selon Pereira dos Santos qui défend à l'époque une thèse intitulée O Problema do conteúdo do cinema brasileiro $^{370}$, le public accordera forcément sa préférence aux films de thématiques brésiliennes. Si les objectifs à atteindre semblent relativement clairs, la question de «l'indépendance » est quant à elle plus complexe. L'ambiguïté des défenseurs du cinéma indépendant est grande dans leur relation à l'État et aux grandes compagnies. Alors même qu'ils se défient de la capacité de ces deux interlocuteurs à promouvoir un cinéma authentiquement brésilien, ce sont précisément vers eux qu'ils se tournent pour réclamer des changements de leur politique.

Nous verrons dans le chapitre suivant que c'est à cette époque que surgissent tout un ensemble de revendications qui seront reprises par le Cinema Novo et qui aboutiront, au terme d'un processus long de plus de vingt ans à la reformulation d'Embrafilme et à la création du Concine. Pour l'heure, le premier réflexe des partisans du cinéma indépendant est de réclamer un changement de la ligne de production des grandes compagnies ou d'espérer les changer de l'intérieur quant ils y travaillent. Ces espoirs seront rapidement déçus et, deux ans après leurs inaugurations triomphales, les faillites successives des grands studios provoqueront la maturation du concept de cinéma indépendant. L'incapacité de la Vera Cruz, de la Maristela et de la Multifilmes à équilibrer leurs comptes semblent prouver aux partisans du cinéma indépendant la justesse de leurs vues. Le cinéma à petit budget et de thématique nationale est la seule issue.

Sur le modèle des cinémas indépendants français et italiens, il est alors envisagé de réaliser l'union de petits producteurs indépendants dans de grandes coopératives de production. La mise en commun des matériels les plus coûteux permettrait de résoudre les problèmes d'équipements. Surgit alors l'idée paradoxale d'une industrialisation d'un cinéma artisanal qui sera reprise et défendue par le Cinema Novo à partir de sa restructuration économique en 1965. Dans les faits, cette union ne se réalise pas. Trois films seulement s'apparenteront concrètement au concept de cinéma indépendant, Rio quarenta graus, Rio zona Norte et $O$ Grande Momento, mais ils seront financés par le biais d'un système coopératif extrêmement précaire. L'idée de base consiste à rassembler le budget nécessaire à la production du film en faisant appel aux participations de particuliers, à commencer par le 
cinéaste lui-même et les membres de l'équipe de tournage. Ces participations, qui sont généralement modestes, nécessitent d'être nombreuses. Un certain nombre de personnes payent pour réaliser un film et il est prévu qu'en retour elles reçoivent une part des bénéfices sur l'exploitation du long métrage proportionnelle à ce qu'aura été leur participation initiale. Le principe est simple et équitable. L'inconvénient est que le montant des budgets qui peut être atteint ne permet pas de concurrencer les compagnies de production traditionnelles sur le plan de la qualité technique et sur le plan promotionnel. Enfin, les problèmes de distribution et d'exploitation ne sont pas résolus.

Du fait de la précarité des moyens matériels réunis, les conditions de tournage de Rio, quarenta graus sont extrêmement difficiles et contraignent les membres de l'équipe à des privations. Initialement interdit par le chef de la police de Rio de Janeiro, le film obtient un succès de scandale qui permet à Pereira dos Santos d'envisager la production de deux nouveaux films, Rio, zona norte, qu'il dirigera lui-même, et $O$ Grande Momento réalisé par Roberto Santos. Les deux longs métrages seront des échecs commerciaux et le cinéaste doit alors arrêter une première fois sa carrière pour rembourser ses dettes et assurer la subsistance de sa famille. Le cinéma indépendant tel qu'il est alors réalisé ne fait pas d'émules et ne s'avère pas viable économiquement. Quelques années plus tard, les cinemanovistas vont pourtant le réclamer comme modèle. Dans les faits, ils feront dans un premier temps appel au mécénat et aux subventions éparses qui pourraient être collectées auprès des institutions culturelles officielles. Dans un second temps, l'obtention de prêts bancaires à un taux préférentiel et l'arrivée d'un nouveau type de producteur permettent de réaliser des projets plus ambitieux.

\section{Mécénat et collecte de subventions officielles}

En 1979, Arnaldo Jabor décrit dans ces termes les conditions initiales de financement du Cinema Novo :

\footnotetext{
«Um sujeito de 20 anos quer fazer cinema ? Faça. Descubra uma maneira. Descole uma grana. Pegue a mulher de um milionário. Arranque a grana de um otário. Vai num banco, não paga. Pede um empréstimo, não paga, foge. E faz o filme. Eu fiz isso ! [...] Prostituta-se ! Faça qualquer negócio. [...] Quando ' seu ' Glauber Rocha veio da Bahia, com 22 anos, ele não tinha um tostão no bolso, andava de chinelo no meio da rua, e fez os maiores filmes brasileiros. Como é que isto aconteceu ? Porque era um momento histórico privilegiado ? Não! Foi em pleno 1964, que nós fizemos o cinema brasileiro. Os principais filmes brasileiros foram feitos depois de 64, em plena Revolução. » ${ }^{371}$
}

371 «Un jeune de vingt ans veut faire du cinéma ? Qu'il en fasse. À lui d'en découvrir un moyen. À lui de trouver du fric. Il peut séduire la femme d'un millionnaire. Il peut plumer un pigeon. Il peut aller à la banque et ne pas payer. Il peut demander un emprunt bancaire, ne pas le payer et fuir. J'ai fait cela ! [...] Qu'il se prostitue ! Il peut faire n'importe quoi. [...] Quand Glauber Rocha est arrivé de Bahia à 22 ans, il n'avait pas un sou en poche, il marchait en claquettes et il a fait les meilleurs films brésiliens. Comment cela est-il arrivé ? Parce 
La description que fait Jabor des premiers temps du Cinema Novo comme de temps héroïques où chaque membre du groupe est parti de rien est partiellement fausse. S'il n'est pas question ici de minimiser les difficultés rencontrés et les sacrifices consentis par les jeunes cinéastes pour assouvir leur passion, il serait néanmoins mensonger de prétendre qu'ils n'avaient aucun atout pour réussir. Comme nous l'avons déjà montré dans la première partie, même si aucun cinemanovistas n'est issu des classes supérieures et ne possède une fortune personnelle lui permettant de s'autofinancer, chacun possède un capital social et culturel qui va faciliter la découverte de sources de financement qui étaient restées interdites à leurs prédécesseurs du cinéma indépendant. Si le modèle coopératif inauguré par Pereira dos Santos avec Rio, quarenta graus reste une référence et sera éventuellement repris avec succès sous une forme plus avancé dans la seconde phase du Cinema Novo, le recours au mécénat et / ou la collecte de subventions officielles d'origine diverses prévalent dans le montage financier des films de la première phase. Les exemples sont nombreux.

La formule s'impose naturellement dès 1958 quand Rocha cherche à réaliser son premier court métrage Pátio. Le cinéaste a décrit la production du film sans équivoque :

«Helena Ignês pediu ao banqueiro Pamphilo de Carvalho dez contos prá que seu noivo fizesse um film, Pátio. O resto o Rosalvo Barbosa Romeu deu pela Prefeitura. Idéia na cabeça, câmara na mão. $35 \mathrm{~mm}$ Arry Flex. Três lentes. Mil metros de negativos preto e branco. Casa do milionário Luiz Viana na ladeira... $»^{372}$

Arraial do cabo est réalisé avec une subvention du Museu Nacional suite à une conversation de Saraceni avec l'anthropologue Geraldo Markam. Aruanda bénéficie du soutien de l'INCE, du sociologue Odilon Ribeiro Coutinho et d'une subvention de l'Instituto Joaquim Nabuco de Pesquisas Sociais de Recife. O Poeta do castelo e o mestre de Apipucos est financé par l'Instituto Nacional do Livro do Ministério da Educação e Cultura. Cinco vezes favela est viabilisé grâce à une subvention du MEC obtenu par Leon Hirszman grâce à la médiation de Ferreira Gullar ${ }^{373}$. Bien plus tard, Jabor reçoit l'aide d'un notable de São Paulo, Jorge da Cunha Lima, pour réaliser A Opinião pública ${ }^{374}$ Pour tous ces premiers films prévaut donc le système $\mathrm{D}$ dans lequel le cinéaste met à profit la moindre opportunité pour se lancer

qu'il s'agissait d'un moment privilégié ? Non. C'est en 1964 que nous avons fait le cinéma brésilien. Les principaux films ont été faits après 1964, en pleine Révolution. » in JABOR, Arnaldo. « Arnaldo Jabor : Um Depoimento à repórter Izilda Alves » in O Estado de São Paulo, 20/01/1979.

372 «elena Ignês a demandé au banquier Pamphilo de Carvalho dix briques pour que son fiancé fasse un film, Pátio. Le reste, Rosalvo Barbosa Romeu l'a donné par l'intermédiaire de la Mairie. Une idée dans la tête, une caméra à la main. $35 \mathrm{~mm}$ Arry Flex. Trois lentilles. Mille mètres de négatif noir et blanc. La maison du millionnaire Luiz Viana et son magnifique panorama... » in ROCHA, Glauber. Revolução do Cinema Novo. Op. cit., p. 310.

373Cf. SALEM, Helena. Leon Hirszman : o navegador das estrelas. Op. cit., p. 106.

374BLANCO, Armindo. «Cinema Nôvo : Vento ardente do trópico » in O Globo, Rio de Janeiro, sans date. 
dans la réalisation de son film, parfois sans avoir la certitude de pouvoir le finir. Avec les premiers longs métrages apparaissent de nouveaux personnages qui vont assumer un rôle mixte entre mécène et producteur. Pour Porto das Caixas, Saraceni s'associe avec Elísio Freitas, un représentant spécialisé dans la vente aux hôpitaux de film vierge pour radiographie. Personnage étranger au milieu du cinéma, Freitas investit 12000 dollars de l'époque sur le film de Saraceni à partir du résumé oral que ce dernier lui fait de son scénario et du choix de l'actrice principale, Irma Álvarez :

« Elísio me disse : ' Você não ganha nada, mas fica sendo meu sócio. Se der dinheiro, 50 \% para cada um. Se não der, só eu perco. ' Topei. Vi logo o que seria o produtor modelo do Cinema Novo. O autor-realizador tem que correr os riscos junto com o produtor, que cuida das finanças, enquanto o realizador cuida da criação, mas com responsabilidade de parte a parte. Melhor que os produtores baianos do Glauber. » ${ }^{375}$

Saraceni compare avec raison Elísio Freitas à Rex Schindler, propriétaire de Iglu Filmes et producteur de Rocha et Roberto Pires. La situation est en effet très proche. Dans les deux cas, nous avons des personnages, détenteurs d'une fortune personnelle, qui décident, par passion, d'investir dans le cinéma et de faire confiance à des jeunes réalisateurs sur la base des idées nouvelles qu'ils défendent et auxquelles, au moins en théorie, ils adhèrent ${ }^{376}$. Iglu Filmes est créé suite à la rencontre de Rocha avec Schindler dans le bureau de Leão Rosemberg, photographe. Rocha a décrit son entente avec Schindler de la façon suivante :

«Através de Leão Rozemberg conheci o médico, pintor e construtor civil, o judeu Rex Schindler, mulato inteligente, simpático, visionário. Adorava meus artigos. Topou co-produzir Barravento com a Iglu. Lutei pra impor Paulino na direção. Sacrifiquei A Ira de Deus. A criação de um movimento coletivista deveria evitar personalismos. $»^{377}$

En 1962, de visite à Salvador, Sales Gomes décrit Schindler dans ces termes :

375« Elísio m'a dit : ' Tu ne gagnes rien mais je fais de toi mon associé. Si le film fait de l'argent, c'est $50 \%$ pour chacun. S'il ne se vend pas, il n'y a que moi qui perdrait de l'argent. ' J'ai accepté. J'ai tout de suite vu quel serait le producteur modèle du Cinema Novo. L'auteur-réalisateur doit courir les risques financiers avec le producteur, qui gère les finances, pendant que le réalisateur s'occupe de la création, mais avec le sens des responsabilités des deux côtés. Mieux que les producteurs bahianais de Glauber. » in SARACENI, Paulo César. Op. cit., p. 134.

$376 \mathrm{Il}$ n'est pas sûr en effet qu'en pratique les produits finis aient toujours bien correspondu à ce qu'ils avaient pu imaginer à partir du discours des cinemanovistas. Aucun des producteurs-mécènes n'a produit plus qu'un film du Cinema Novo mais toutes ces productions ont été décisives.

377 « Par l'intermédiaire de Leão Rozemberg j'ai rencontré le médecin, peintre et constructeur civil, le juif Rex Schindler, un mulâtre intelligent, sympathique, visionnaire. Il adorait mes articles. Il a accepté de co-produire Barravento avec Iglu. J'ai lutté pour imposer Paulino au poste de réalisateur. J'ai sacrifié $A$ Ira de Deus. La création d'un mouvement collectif ne pouvait aller de pair avec le personnalisme. » in ROCHA, Glauber. Revolução do Cinema Novo. Op. cit., p. 304. Information confirmée (ou répétée ?) dans l'article d'André Setaro sur Iglu Filmes. In RAMOS, Fernão et MIRANDA, Luís Felipe (org.). Enciclopédia do cinema brasileiro. Op. cit., p. 135. 
«Esse médico apaixonado por teatro amador obteve enorme sucesso no comércio imobiliário e reagiu a tempo contra o absurdo de apenas enriquecer. Pintar aquarelas, algumas impregnadas de ágil movimento, não lhe deu satisfação duradoura, pois não era um 'hobby' que procurava mas um tipo de atividade que mobilizasse num só movimento suas múltiplas facetas de comerciante, artista e cidadão. No momento Rex Schindler é o produtor número um e o principal argumentista do cinema baiano. ${ }^{378}$

Avec le succès de $A$ Grande Feira, Schindler a nourri des projets grandioses dont une nouvelle société de cinéma, Cinema da Bahia S.A. - CINEBASA,qui devait produire Tocaia no asfalto de Pires et Rebelião camponesa de Rocha. Les déclarations du producteur-mécène témoignaient d'un alignement quasi total avec les positions du Cinema Novo :

« A temática dos nossos filmes deverá se apoiar principalmente no homem em confronto com a realidade brasileira de cada região. O cinema nacional, pois, será um grande cinema cultural e concomitantemente uma indústria potente capazes de criar nova consciência integrada nos graves problemas do nosso atual momento histórico. Os nossos filmes devem encarar os problemas de frente e colaborar para resolvê-los, em vez de escondê-los criminosamente, como os produtores vêm fazendo há muito tempo. O cinema no Brasil tem um compromisso com o povo brasileiro. Falo do cinema novo. $»^{379}$

Iglu Filmes ne marquera pourtant pas le Cinema Novo au-delà des trois longs métrages de Pires et Rocha. Pour des raisons différentes, les deux cinéastes se brouillent avec leur producteur. Selon Walter da Silveira ${ }^{380}$, Pires ne comprenait pas bien les préoccupations sociales de Schindler ${ }^{381}$. Rocha se tourne vers d'autres partenaires quand l'ancien médecin lui propose de faire filmer le scénario de Deus e o diabo na terra do sol par Carlos Coimbra dans une co-production avec Osvaldo Massaini, producteur de O Pagador de promessas. Malgré les déclarations d'intentions initiales, les motifs des disputes finales montrent une complète divergence de vue entre les différents partenaires. Par la suite, les cinemanovistas apprendront à s'accommoder de profonds désaccords idéologiques pourvu que les compromis financiers soient fermes et leur permettent de réaliser leurs projets. Après Schindler, le dernier des producteurs-mécènes du Cinema Novo est Luiz Augusto Mendes qui co-produit Deus e o

378 « Ce médecin passionné de théâtre a fait fortune après une certain nombre d'opérations immobilières et a réagi à temps contre l'absurde consistant à consacrer sa vie au seul enrichissement. Peindre des aquarelles, certaines imprégnées d'un mouvement agile, ne lui a pas procuré une satisfaction suffisamment durable car il ne recherchait pas un ' hobby ' mais un nouveau type d'activité qui mobilise à la fois ses multiples facettes de commerçant, d'artiste et de citoyen. Aujourd'hui, Rex Schindler est le producteur ${ }^{\circ} 1$ et le principal argumentiste du cinéma de Bahia. » in GOMES, Paulo Emílio Sales. « Perfis bahianos » in O Estado de São Paulo - Suplemento literário, São Paulo, 24/03/1962.

379 « La thématique de nos films devra s'appuyer principalement sur l'homme confronté avec la réalité brésilienne de chaque région. Le cinéma national devra donc être un grand cinéma culturel et, en même temps, une industrie puissante capable de créer une conscience nouvelle intégrée aux graves problèmes du moment historique actuel. Nos films doivent aborder les problèmes de front et collaborer à les résoudre au lieu de les occulter criminellement comme les producteurs le font depuis longtemps. Le cinéma au Brésil a un devoir à remplir auprès du peuple brésilien. Je parle du cinema novo. » in SENNA, Orlando. « Schindler arma cine-indústria e anuncia programa monstro : 62 » in Diário de notícias, Salvador, 24/12/1961.

380SILVEIRA, Walter da. « Caráter do cinema baiano » in O Estado de São Paulo-Suplemento literário, São Paulo, 16/11/1963.

381Barbosa confirme qu'à ce moment de sa carrière Pires souhaitait se tourner vers un cinéma commercial. In OROZ, Silvia. 30 anos de Cinema Novo : Jarbas Barbosa - Entrevista a Silvia Oroz. Op. cit., p. 59. 
diabo na terra do sol.

Contrairement à Freitas et Schindler, Mendes n'est pas un petit bourgeois ayant réussi dans les affaires qui, fasciné par le cinéma, étudie la possibilité d'en faire l'un de ses nouveaux domaines d'activité. Il s'agit d'un membre de la haute société de Salvador qui poursuit des objectifs de promotion personnels et dont la participation à la production du nouveau film de Rocha n'est pas exempt de calculs politiques. Dans les faits, ses idées sont absolument antagoniques avec celles des membres du Cinema Novo. C'est un proche de Carlos Lacerda, gouverneur de la Guanabara très marqué à droite et principal fomenteur civil du coup d'État de 1964. Dans A Revolução do Cinema Novo, Rocha se souvient du playboy habitué aux réceptions mondaines et fils de l'un des chefs de l'UDN, Luiz Mendes ${ }^{382}$. Mário Carneiro se souvient quant à lui qu'il était membre d'un mouvement anti-communiste et qu'il gérait les contributions financières que le mouvement recevait ${ }^{383}$. L'association avec le Cinema Novo va pourtant se révéler sans heurt, Mendes laissant une liberté totale à Rocha et se contentant de conditionner sa contribution dans le financement du long métrage à l'obtention par sa future femme, Yoná Magalhães, de l'un des rôles principaux. Celle-ci jouera le personnage de la paysanne Rosa. Le contraste est saisissant entre les photos de l'époque où nous la retrouvons à la ville et son rôle dans le film ${ }^{384}$. Mendes est le dernier des producteurs-mécènes du Cinema Novo. Après 1964, le Cinema Novo se dote de véritables structures économiques et s'appuie sur les subventions d'État nouvellement créées pour le cinéma. Avant cela, chacun s'était aussi personnellement endetté pour filmer.

\section{Des cinéastes qui paient pour travailler}

Parallèlement aux subventions obtenues et aux contributions de ces différents producteurs-mécènes qui apparaissent providentiellement, les cinemanovistas vont également avoir l'idée de recourir à des prêts bancaires. Ils contracteront des emprunts auprès de banques

382ROCHA, Glauber. Revolução do Cinema Novo. Op. cit., p. 300.

383LINHART, Clara, MAROJA, Camila et CAETANO, Daniel. « Entrevista com Mário Carneiro » in Contracampo, ${ }^{\circ} 42$, http://www.contracampo.com.br/42/frames.htm, consulté le 29/12/2005.

384Co-producteur du film, Barbosa confirme que Mendes fut la pièce maîtresse du montage financier, selon lui dans le but de séduire Yoná Magalhães : « A peça chave da produção foi Luiz Augusto Mendes da Costa, o Gugú Mendes, que foi quem botou o dinheiro. Acontece que ele queria namorar a Yoná Magalhães ; queria transformá-la numa atriz. [...] Eles se casaram, e eu acabei padrinho da boda. Na verdade, o Gugú entrou no cinema para fazer um filme para a Yoná Magalhães. » (« La pièce maîtresse de la production a été Luiz Augusto Mendes da Costa, dit Gugú Mendes, c'est lui qui a financé le film. Le fait est qu'il voulait séduire Yoná Magalhães ; il voulait en faire une actrice. [...] Ils se sont mariés et j'ai été témoin de ce mariage. En vérité, Gugú est entré dans le monde du cinéma pour faire un film pour Yoná Magalhães. ») in OROZ, Silvia. 30 anos de Cinema Novo : Jarbas Barbosa-Entrevista a Silvia Oroz. Op. cit., p. 15. Dans les archives du Tempo Glauber, un document montre que Mendes a pris à sa charge une partie des frais de production pendant le tournage et le paiement des salaires des acteurs et techniciens. Despezas do produtor Luiz Augusto Mendes no filme " Deus e o diabo na terra do sol ». 3 pages dactylographiées indiquant les sommes reçues par les différents membres de l'équipe, 9/11/1963, 07/01/1963 et 28/12/1963, archives Tempo Glauber. 
diverses tout au long de l'histoire du Cinema Novo. L'argent ainsi obtenu leur permettra de devenir co-producteurs de leurs propres films, généralement pour une part du budget inférieure à $30 \%$, mais il constituera une forme d'implication particulièrement risquée. À un moment ou un autre, tous les cinemanovistas devront interrompre momentanément leur carrière pour se consacrer à des activités alimentaires leur permettant de rembourser leurs dettes $^{385}$. Au cours de la première phase du Cinema Novo, cette stratégie va cependant permettre la réalisation de plusieurs films. Le principal prêteur est alors le Banco Nacional de Minas Gerais - BNMG. Le premier prêt de la banque est consenti dans le cadre de la réalisation de Assalto ao trem pagador. Le succès du film permet de viabiliser ce système de financement. La banque concède immédiatement d'autres prêts pour une longue série de films. Le premier film du Cinema Novo à en bénéficier est Vidas secas, immédiatement suivi par Ganga Zumba ${ }^{386}$, Garrincha, alegria do povo, Deus e o diabo na terra do sol et Os Fuzis. Ses prêts sont consentis par l'intermédiaire de José Luiz Magalhães Lins dont Rocha fait à l'époque un portrait élogieux dans la presse :

« A grande figura do cinema novo em 1962 foi o banqueiro José Luiz Magalhães Lins, um dos presidentes do Banco Nacional de Minas Gerais, que financiou $O$ Assalto ao trem pagador, Garrincha, Subliminar Arma Secreta, Vidas Secas e concedeu financiamento para Deus e o diabo na terra do sol et Os Fuzis [...] José Luiz Magalhães Lins, com a idade de 33 anos, compreendeu a importância econômica e política do novo cinema brasileiro o mesmo enfrentando os riscos naturais de uma indústria desprotegida está fazendo a prova do fogo, testando os melhores projetos ; nesse ponto a adesão do famoso repórter-fotográfico Luis Carlos Barreto teve importância fundamental. Luis Carlos Barreto atuou diretamente junto a José Luiz Magalhães Lins de forma que, enquanto o poder federal, através do Banco do Brasil, enrola o financiamento o Banco Nacional de Minas Gerais, particular constitui mola propulsora do cinema novo. [...] O exemplo merecia ser seguido pelos banqueiros locais [em outros estados]. Será, inclusive, através do grande prestígio de José Luiz Magalhães Lins que o cinema brasileiro poderá em 63, ser salvo da catástrofe perseguidora dos trustes, esse jovem banqueiro que se interessa detalhadamente por cada filme por ele financiado, reúne poderes para conseguir a aprovação de todas as leis necessárias à manutenção de nossa indústria em termos regulares e consequentes para o Brasil. ${ }^{387}$

385Andrade après $O$ Padre e a moça, Saraceni après Capitu, Lima après Brasil ano 2000, Hirszman après São Bernardo.

386« A maior parte dos recursos de produção foi levantada num empréstimo pessoal que fiz no Banco Nacional de Minas Gerais, por intermédio de seu diretor José Luiz de Magalhães Lins, o mesmo que emprestou dinheiro para que se fizesse, nessa mesma época, Assalto ao trem pagador, de Roberto Farias, Vidas secas, de Nelson Pereira dos Santos, Deus e o diabo na terra do sol, de Glauber Rocha, e Os Fuzis, de Ruy Guerra, entre outros clássicos do Cinema Novo. » (« La plus grande partie du budget a été rassemblée grâce à un prêt personnel que j'ai obtenu auprès du Banco Nacional de Minas Gerais, par l'intermédiaire de son directeur José Luiz de Magalhães Lins, le même qui a prêté de l'argent, à la même époque, pour que soient réalisés Assalto ao trem pagador, de Roberto Farias, Vidas secas, de Nelson Pereira dos Santos, Deus e o diabo na terra do sol, de Glauber Rocha, et Os Fuzis, de Ruy Guerra, entre autres classiques du Cinema Novo. ») in DIEGUES, Carlos, CAMARGO, Maria Silvia. O que é ser diretor de cinema - Memórias profissionais de Cacá Diegues. Rio de Janeiro, Record, 2004, p. 110.

387« Le grand personnage du cinema novo en 1962 a été le banquier José Luiz Magalhães Lins, un des présidents du Banco Nacional de Minas Gerais, qui a financé O Assalto ao trem pagador, Garrincha, Subliminar Arma Secreta, Vidas Secas et a concédé un financement pour Deus e o diabo na terra do sol et Os Fuzis [...] José Luiz Magalhães Lins, 33 ans, a compris l'importance politique et économique du cinéma brésilien et, affrontant les risques auxquels est exposée une industrie sans protection, passe l'épreuve du feu, testant les meilleurs projets ; sur ce point l'adhésion du fameux reporter-photographe Luis Carlos Barreto a eu une importance fondamentale. Luis Carlos Barreto a intercédé directement auprès de José Luiz Magalhães 
Tout au long de sa carrière, Rocha rendra des hommages appuyés au banquier qu'il tient pour responsable de l'existence du Cinema Novo. Une fois de plus cependant, la situation est complexe. Le BNMG est au main de la famille d'Antônio Magalhães Pinto alors gouverneur du Minas Gerais et un des principaux artisans de la chute de Goulart. José Luiz est un de ses parents et c'est aussi un membre de la haute bourgeoisie. Selon le témoignage de Barbosa, les relations qu'il pouvait entretenir avec le Cinema Novo étaient ambiguës. D'un côté il finançait des cinéastes de gauche, de l'autre il pouvait ne partager ni leurs opinions politiques, ni aimer leurs longs métrages. Ainsi, invité à assister à Deus e o diabo na terra do sol au cours d'une session privée organisée immédiatement après la fin du montage, il aurait reçu le film avec une extrême froideur ${ }^{388}$. Il faut également préciser qu'en aucun cas le BNMG n'avait mis au point un programme spécifique adapté au financement de la production cinématographique. Les prêts consentis étaient des prêts au particulier qui bénéficiaient à l'époque du taux très intéressant de $3 \%$, lequel avait pu être renégocié par les cinéastes individuellement et réduit de moitié afin de leur permettre de rembourser l'intégralité des sommes empruntées ${ }^{389}$. Enfin, la contribution du BNMG n'était pas désintéressée comme le montre la séquence consacrée à la visite « hebdomadaire » de Garrincha dans l'une de ses agences dans le documentaire que consacre Andrade au célèbre footballeur. Symbole de modernité et de progrès, le cinéma est synonyme de prestige. Barbosa le confirme :

«E foi no ano em que o Banco Nacional de MG, na pessoa de José Luiz Magalhães, estava dando dinheiro para o pessoal que queria fazer cinema, que botava sempre, nos letreiros dos filmes, um agradecimento expresso a ele. Só esse agradecimento valia uma fortuna em termos de publicidade. $»^{390}$

L'importance du BNMG est décisive entre 1962 et 1964. Par la suite, le Cinema Novo va diversifier ses ressources.

Lins de façon à ce que, pendant que le pouvoir fédéral, au travers du Banco do Brasil, complique l'accès au financement, le Banco Nacional de Minas Gerais, propulse le cinema novo. [...] L'exemple mériterait d'être suivi par les banquiers d'autres régions. Ce sera notamment, au travers du grand prestige de José Luiz Magalhães Lins que le cinéma brésilien pourra en 63, survivre à la persécution des trusts, ce jeune banquier qui s'intéresse dans tous les détails aux films qu'il finance, dispose également de pouvoirs qui pourront permettre l'approbation des lois nécessaires à l'élévation de notre industrie à un niveau conséquent et prospère pour notre pays. » in ROCHA, Glauber. « Cinema brasileiro 1962 » in Diário de notícias, Salvador, $13 / 01 / 1963$.

388Cf. OROZ, Silvia. 30 anos de Cinema Novo : Jarbas Barbosa-Entrevista a Silvia Oroz. Op. cit., p. 32. 389Ibid., pp. 16-17.

390« Et ce fut l'année pendant laquelle le Banco Nacional de MG, en la personne de José Luiz Magalhães, a donné de l'argent à ceux qui voulaient faire du cinéma, qui, en retour, incluaient systématiquement au générique du film un mot de remerciement. Ce simple remerciement valait une fortune en termes de publicité. » in ibid, p. 12. 


\section{Émergence d'un nouveau type de producteur}

Parallèlement au recours des cinéastes à l'emprunt bancaire surgissent de nouveaux producteurs qui ne sont plus seulement des pourvoyeurs de fonds mais partagent avec eux une vision commune sinon très proche du cinéma et du monde. Les trois principaux sont Jarbas Barbosa, Luiz Carlos Barreto et Zelito Viana. Les caractéristiques du producteur modèle du Cinema Novo que nous pourrons dégager de l'étude des méthodes de travail de ces trois personnalités sont assez similaires à celles de leurs contemporains de la Nouvelle Vague tel que les décrit Michel Marie ${ }^{391}$. Dans tous les cas, nous avons affaire à des professionnels qui, s'ils ne le sont pas déjà avant le Cinema Novo, comme c'est le cas de Jarbas Barbosa, vont le devenir avec lui. Les méthodes peuvent différer de l'un à l'autre, Barbosa et Viana investissent financièrement dans les films et gèrent leur production au jour le jour dans les différentes étapes de la réalisation jusqu'au lancement commercial. Barreto se spécialise dans la captation de ressources financières extérieures au monde du cinéma et l'articulation d'une politique de production grâce au réseau très dense de relations qu'il s'est fait au plus haut niveau depuis le début de sa carrière dans le journalisme. Le producteur est solidaire de la démarche esthétique de l'auteur ${ }^{392}$ et se donne pour mission de réunir les moyens matériels nécessaires à sa pleine et entière réalisation. Il partage, souvent pratiquement à égalité, les risques financiers avec le cinéaste qui est toujours co-producteur pour environ un tiers du budget et il est son principal partenaire puisqu'il est le seul membre de l'équipe du film à être présent de l'idée initiale à l'encaissement des recettes.

Barbosa fait son entrée dans le monde du Cinema Novo en 1963 afin d'assurer le sauvetage de Ganga Zumba de Carlos Diegues. À l'origine, le système de financement consistait en une solution mixte basée, en partie, sur une imitation du système coopératif de Rio, quarenta graus, et, en partie, sur des prêts bancaires à particulier. Les fonds réunis devaient se révéler insuffisants. Le tournage avait commencé sur des bases extrêmement précaires et, à un certain point, les frais quotidien de restauration de l'équipe, qui était pourtant assez réduite, ne pouvaient plus être assumés. La situation était aggravée par le fait que la Tabajara Filmes, qui fournissait l'équipement, la pellicule vierge et le laboratoire, était au bord de la faillite. Le BNMG qui avait déjà prêté $50 \%$ de la valeur total du budget du film, se refusait à prêter plus d'argent à Diegues qui, très jeune, pouvait paraître trop idéaliste et inexpérimenté. Lins lui-même part à la recherche d'un producteur professionnel qui pourrait

391MARIE, Michel. Op. cit., 1997.

392Les conflits seront très rares entre producteurs et réalisateurs, le seul qui soit véritablement important et dont nous ayons connaissance est celui qui a opposé Ruy Guerra à Jarbas Barbosa au moment du lancement commercial de Os Fuzis. 
contrôler la finalisation du film et, de fait, permettre le retour des sommes prêtées. Sur les conseils d'Herbert Richers, producteur de Assalto ao trem pagador et de Vidas secas, il demande à Barbosa d'assurer cette mission de "sauvetage » et lui prête les sommes nécessaires. Celui-ci accepte et rachète la part de la production de la Tabajara Filmes.

$\mathrm{Au}$ moment où Barbosa reprend la production de Ganga Zumba, il est déjà un professionnel aguerri. Il débute dans le cinéma en 1949 comme secrétaire dans l'entreprise Cinegráfica São Luiz. Il devient ensuite l'assistant d'Herbert Richers avec lequel il collabore pendant plus de dix ans. Ce dernier est alors en pleine ascension. Ayant débuté dans la réalisation de ciné-journaux dans les années quarante, Richers monte sa propre maison de production au début des années cinquante et diversifie rapidement ses activités. Il produit des actualités filmées, des publicités, c'est un des pionniers de la production de spots publicitaires pour la télévision, mais aussi des chanchadas. À la fin des années cinquante, il possède à Rio plusieurs studios de cinéma, 12 tables de montage, et appuie une part de ses activités sur le doublage de films étrangers. Ces infrastructures qui sont parmi les plus importantes de l'époque lui permettront de produire plus de 50 longs métrages au cours de sa carrière. Barbosa se spécialise dans la partie commerciale. Il se distingue en trouvant le moyen de distribuer les ciné-journaux de Richers dans les capitales du Nord et du Nordeste plus rapidement que ne le fait la concurrence (à l'époque, trois mois étaient nécessaires avant que les ciné-journaux ne parviennent jusqu'à ces villes). Il monte également une maison de distribution nationale avec des filiales à São Paulo et Porto Alegre. Il se sépare de Richers au début des années soixante et crée sa propre maison de production, Copacabana Filmes.

Barbosa est une des premières personnalités qui va chercher à anticiper le déclin de la chanchada et à rechercher un produit de substitution. Son discours témoigne cependant d'un grand pragmatisme. D'un côté, il se montre sensible à la proposition du Cinema Novo mais de l'autre il consacre la plus grande part de sa carrière au cinéma commercial. Dans cette recherche d'une nouvelle orientation pour le long métrage de fiction, il participe à la production de Os Cafajestes par l'intermédiaire de Jece Valadão qui se révèle être un producteur essentiellement préoccupé par la rentabilité économique des films. Après ce premier succès, toujours avec Valadão, Barbosa produit Boca de ouro, un long métrage de Pereira dos Santos qui est étranger à la ligne du Cinema Novo mais devient son plus gros succès commercial de la décennie. Ce film est le premier à être produit par Copacabana Filmes qui deviendra ensuite aussi une maison de distribution. Ganga Zumba est le premier film produit dans une démarche consciente d'adhésion au Cinema Novo. Simultanément, Barbosa accepte de s'engager pour Os Fuzis et Deus e o diabo na terra do sol. Le mode de financement était à chaque fois assez similaire, le réalisateur entrait avec $30 \%$ du budget 
emprunté au BNMG, Barbosa avec $30 \%$ pour Deus e o diabo et $40 \%$ pour Os Fuzis, un tiers complétait. Des trois, Os Fuzis a été le film le plus cher, son équipe a été la plus nombreuse et elle a compté avec des professionnels confirmés comme le chef-opérateur Ricardo Aronovich. L'investissement se justifiait par le succès de Os Cafajestes. C'est aussi le film dont Barbosa suit la production de plus près, se rendant plus fréquemment à Milagres qu'à Monte Santo et se contentant, de là-bas, de suivre la réalisation de Deus e o diabo na terra do sol à distance ${ }^{393}$.

$\mathrm{Au}$ moment du lancement commercial des films, les priorités de Barbosa sont cependant inversées. Copacabana Filmes a distribué les trois films selon des circuits commerciaux différents. Le succès des sessions privés et avant-premières de Deus e o diabo na terra do sol a encouragé un lancement à grande échelle avec une quinzaine de copies. Le producteur ne croyait pas beaucoup à Ganga Zumba, quant à Os Fuzis, les controverses qu'il génère avant sa sortie et les désaccords entre Guerra et Barbosa au moment du montage, nuisent à son exploitation commerciale. Ganga Zumba et Os Fuzis bénéficient d'un lancement modeste sur la base de trois copies. Selon Barbosa, Deus e o diabo na terra do sol est le seul film qui a « donné quelque chose » en termes de box office :

«Os Fuzis não pagou as cópias, com Ganga Zumba mal se pagaram as cópias. Deus e o diabo... teve uma carreira melhor no Brasil. Imagine, Silvia : Ganga Zumba até hoje não foi exibido na Bahia. Os distribuidores de lá nunca quiseram o filme. Agora, por incrível que pareça, Os Fuzis é o filme brasileiro mais exibido no exterior depois de Deus e o diabo... $»^{394}$

Après les échecs commerciaux de Ganga Zumba et Os Fuzis, Copacabana Filmes fait faillite et Barbosa se détourne du Cinema Novo. Il crée JB Produções qui va lui permettre de se refaire une santé financière en produisant des films commerciaux différents de la chanchada et plus en phase avec l'esthétique télévisuelle et le temps des yéyé : Entre o amor e o cangaço, 007 1/2 no Carnaval, Na Onda do Iê Iê Iê. Pour le Cinema Novo, il ne produira plus qu'un seul film, Os Herdeiros, dont le financement est permis par un nouvel impôt qui prélève des capitaux sur le rapatriement des bénéfices des grandes compagnies de cinéma étrangères au profit du cinéma national. En 1975, de nouveau associé avec Diegues, il produit Xica da Silva, un gros succès qui ouvre la voie du cinéma national-populaire d'Embrafilme. Un nouveau compromis est trouvé entre les attentes du public et les préoccupations éthiques et politiques des cinéastes sur des bases différentes des compromis qui pouvaient être

393OROZ, Silvia. 30 anos de Cinema Novo : Jarbas Barbosa-Entrevista a Silvia Oroz. Op. cit., p. 17.

394« La recette de Os Fuzis n'a pas suffit à rembourser les copies du film, avec Ganga Zumba la recette a à peine permis de payer les copies. Deus e o diabo... a connu une carrière bien meilleure au Brésil. Imagine, Silvia : Ganga Zumba, jusqu'à aujourd'hui n'a pas été projeté à Bahia. Les distributeurs de là-bas n'ont jamais voulu le film. Aujourd'hui, aussi incroyable que cela puisse paraître Os Fuzis est le film brésilien le plus projeté à l'étranger derrière Deus e o diabo... » in ibid., p. 18. 
envisagés dans les années soixante. Pour revenir à cette période, il est intéressant de noter que Richers, dont Barbosa s'est séparé à l'époque de Os Cafajestes parce qu'il était d'abord réticent à l'idée d'un nouveau cinéma d'orientation sociale va produire deux films du Cinema Novo : Vidas secas et Fome de amor. Paradoxalement, son intérêt pour le Cinema Novo aura commencé avec Assalto ao trem pagador, un film périphérique au mouvement mais dont la réalisation a compté avec les articulations de Rocha et Barreto. Dans les deux cas, les films ne lui portent pas de préjudice économique, son pragmatisme et sa connaissance des circuits de distribution et d'exploitation du cinéma brésilien lui permettant de choisir et de développer des stratégies commerciales adaptées. Barbosa et Richers pourront de nouveau s'associer de façon ponctuelle. Ce sera le cas avec Os Herdeiros.

Au contraire de Barbosa, Luiz Carlos Barreto n'est pas un professionnel du cinéma avant de commencer à produire les films du Cinema Novo et ceux-ci vont constituer l'essentiel de son activité dans les années soixante. Barreto co-produit : Vidas secas, Garrincha, alegria do povo, O Padre e a moça, A Grande Cidade, Terra em transe, Capitu, Brasil ano 2000, O Dragão da maldade contra o santo guerreiro, Os Herdeiros, Azyllo muito louco et Como era gostoso o meu francês. Cette filmographie est développée en parallèle à d'autres films de vocation plus commerciale dont les succès $O$ Assalto ao trem pagador (Roberto Farias, 1962) et Toda Donzela tem um pai que é uma fera (Roberto Farias, 1965) qui lui ont certainement permis de s'équilibrer d'un point de vue financier. À la fin de la seconde guerre mondiale, Barreto commence à travailler très jeune dans le journal d'orientation communiste $O$ Democrata. À la même époque, il est militant communiste mais l'interdiction du parti en 1947, le force à changer de profession. Après un court intermède comme secrétaire dans une entreprise de sidérurgie, il revient au journalisme à la fin des années quarante et devient reporter-photographe pour les revues $A$ Cigarra puis $O$ Cruzeiro pour laquelle il va travailler pendant plus de dix ans. Ses activités de journaliste lui permettent de développer plusieurs compétences qu'il mettra à profit à l'époque du Cinema Novo. D'un côté, il se distingue comme un photographe de talent capable de saisir des paysages et des visages du Brésil jusqu'alors inconnus du grand public. D'un autre côté, il développe un réseau très dense de relations dans la haute-bourgeoisie et les sphères politiques à l'échelle nationale. Il effectue également de nombreux voyages à l'étranger et assure la couverture du Festival de Cannes.

Sa rencontre avec le Cinema Novo se fait sur la plage de Buraquinho au moment du tournage de Barravento. Barreto s'est rendu sur le plateau sur la suggestion d'un ami de Salvador, il rencontre alors pour la première fois Rocha qui le décrira dans ces termes : 
roedores de Chatô e buscava um saída pro impasse do império em transe : Chatô era paralítico, morreria e nâo tinha sucessores. Barreto herdaria de um posto que Chatô the deu reconhecendo seu talento, inteligência, cultura, coragem inventiva. Barreto era a imagem síntese da Nouvelle Vague, do neorealismo e da roliude. Com tempero neo-realista da dolce vita em Roma e Grécia ocidente/oriente com Chatô nos Palácios, Embaxaidas, Jet Set, Carnavais. Cearense, moreno, alto, bonito de corpo e cara, desbundado, elegante, casado com Lucy saída de um romance de Fitzgerald e Machado de Assis. E Barreto não curtia mais a Europa e sua cultura. Estava fazendo 33 anos e o encontrei lendo Machado de Assis num quarto de luxo no Hotel da Bahia. $»^{395}$

Barreto va se montrer très efficace pour capter les capitaux nécessaires à la production des longs métrages, autant auprès des interlocuteurs privés que public. Il est un des principaux responsables de l'investissement dans le Cinema Novo de José Luís Magalhães Lins à partir de la production de $O$ Assalto ao trem pagador, et, par la suite, il sera aussi l'un des principaux intermédiaires des négociations qui vont se dérouler entre le Cinema Novo et la CAIC. N'hésitant pas à se projeter dans les journaux et quotidiens de l'époque, il est dès les années soixante et jusqu'à aujourd'hui, un des personnages principaux de tous les débats concernant la législation des activités cinématographiques. Nous développerons mieux son rôle dans le chapitre que nous consacrerons à ces questions. Chef opérateur de Vidas secas et Terra em transe, Barreto se distingue aussi par le fait qu'il est l'un des rares producteurs à avoir apporté une contribution esthétique significative. Enfin, Zelito Viana est l'un des principaux artisans de la réorganisation économique du Cinema Novo qui arrive en 1965 et, pour cette raison, nous parlerons de lui dans une autre partie.

\subsection{Le Cinema Novo et l'État (Geicine, CAIC)}

La lutte pour une législation cinématographique d'encouragement à la production et de protection du marché va constituer l'un des principaux champs d'action du groupe du Cinema Novo, sinon le principal après la réalisation concrète des films. Contrairement à ce que pourrait suggérer la véhémence de leurs discours et comme nous pourrons le vérifier dans un des chapitres suivants, aucun membre du groupe ne développera d'activités politiques

395« Barreto détestait les coups bas, la stupidité, le conservatisme et la malhonnêteté de la majorité des proches de Chatô, il cherchait une sortie à l'impasse dans laquelle se trouvait l'empire en transe : Chatô était paralytique, il mourrait et il n'avait pas de successeur. Barreto devait recevoir un poste que Chatô lui réservait en reconnaissance à son talent, son intelligence, sa culture, son courage inventif. Barreto était l'imagesynthèse de la Nouvelle Vague, du Néo-Réalisme et d'Hollywood. Avec le tempérament néo-réaliste de la dolce vita à Rome et la Grèce occident/orient de Chatô dans les palais, ambassades, jet set, carnavals. Cearense, brun, grand, beau de corps et de visage, décontracté, élégant, marié avec Lucy sortie d'un roman de Fitzgerald et Machado de Assis. Et Barreto n'appréciait plus l'Europe et sa culture. Il avait 33 ans et je l'ai vu pour la première fois lisant Machado de Assis dans une chambre de luxe de l'Hotel da Bahia. » in ROCHA, Glauber. Revolução do Cinema Novo. Op. cit., p. 300.

L'un des événements qui va beaucoup marquer Rocha à la suite de cette première rencontre est que Barreto obtienne de mettre Helena Ignez et Luíza Maranhão en couverture de $O$ Cruzeiro. En plus de la projection apportée au cycle de Bahia, mettre des actrices brésiliennes en couverture de la prestigieuse revue représentait à l'époque une première puisque seules les actrices d'Hollywood pouvaient avoir ce privilège. 
consistantes et suivies étrangères au cinéma. Certains, comme Pereira dos Santos ou Barreto, ont pu être membre du $\mathrm{PCB}$ dans les années quarante ou cinquante mais, à l'époque du Cinema Novo, ils ont déjà rompu depuis longtemps avec le parti ${ }^{396}$. Dans les années soixante, seul Hirszman est membre du PCB et possède une appartenance politique bien définie ${ }^{397}$. Rocha, quant à lui, a pu promettre de s'y inscrire mais il ne le fera jamais. Aucun des cinemanovistas ne manifeste donc un investissement auprès d'un parti, d'un syndicat ou d'une association qui participerait directement au débat politique autrement que de façon épisodique et superficielle. Le CPC constitue une expérience unique en la matière et de courte durée. Aucun d'entre eux ne participe non plus au débat de façon critique comme le fait aujourd'hui Jabor comme chroniqueur politique de grands journaux de la presse écrite et télévisée. Tous se restreignent à la pratique d'une politique indirecte au travers des films et à celle d'une politique directe circonscrite au champ du secteur cinématographique.

Dans ce domaine, le Cinema Novo reprend à son compte un combat commencé avant lui et ne fera pas preuve de la même capacité d'innovation que celle qu'il manifeste en termes de production et d'esthétique cinématographique. Le point de vue, l'analyse et les revendications des jeunes cinéastes vont s'aligner sur les positions développées par Viany et Pereira dos Santos dès le début des années cinquante, parallèlement à l'organisation de la profession pour la défense de ses intérêts dans le contexte de la tentative d'implantation des grands studios paulistes. L'État coûtera beaucoup à entendre les revendications de la classe cinématographique et de nombreuses commissions ${ }^{398}$, dont les travaux auront un impact très

396Santos quitte le PCB en 1956. Il raconte en détail quelles furent ses relations avec le PC dans le livre suivant

DINES, Alberto, FERNANDES JÚNIOR, Florestan, SALOMÃO, Nelma. « Nelson Pereira dos Santos » in História do poder, 100 anos de política no Brasil, vol. 2 : Ecos do parlamento. São Paulo, Editora 34, 2000, pp. 115-135.

397Dans l'entretien qu'il nous a accordé, Zelito Viana a démenti formellement avoir été membre du PCB. Selon lui, tout le monde pensait qu'il était du PCB car nombre de ses proches était affilié au parti. Entre autres anecdotes, il nous a raconté que Carlos Marighella était présent à son mariage. Ce dernier était alors membre de la direction du PCB avec lequel il rompra après le coup d'état militaire pour devenir l'un des principaux leaders de la guérilla urbaine. Zelito Viana. Entretien avec l'auteur, septembre 2004.

Pour revenir à Leon Hirszman, nous pourrons remarquer que son appartenance au parti n'a pas entraîné sa participation à des actions significatives ni même à des activités de militantisme externes au cinéma.

398Les différentes procédures parlementaires qui finiront par aboutir à la mise en place d'une véritable politique cinématographique avec la création de l'INC en 1966 ont débuté en 1950 avec les travaux de la commission Cavalcanti auquel le gouvernement Vargas a commandité un projet d'institut national de cinéma. Une fois rédigé, le projet sera enterré par le congrès et la seule conséquence notable de la réflexion alors engagée sera la modification de la loi de réserve de marché. Le décret 30,179 du 19 novembre 1951 établit qu'un film brésilien devra être projeté tous les huit films étrangers mis en exploitation. La commercialisation du cinéma national est subordonnée à celle du cinéma étranger dans un cadre absurde qui ne peut en rien encourager son développement.

À la commission Cavalcanti succède en 1954 la Comissão Técnica de Cinema - CIC dépendant du MEC. Puis, sous le gouvernement Kubitschek, le 12 décembre 1956, la Comissão Federal de Cinema est constituée. Le 13 novembre 1958, il lui est substitué une quatrième institution, le Grupo de Estudo da Indústria Cinematográfica - GEIC. Lui-même est transformé en Grupo Executivo da Indústria Cinematográfica GEICINE, le 17 février 1961. Les avancées obtenues par les commissions ou groupes successifs sont très modestes et sans incidence significative sur le marché. Leur principal résultat consistera à chaque fois à 
limité, devront être mises en place avant que des mesures concrètes et significatives soient prises. Les événements se précipitent dans les années soixante, en partie en raison du succès international du Cinema Novo, mais certainement aussi en partie de l'intérêt croissant de l'État à investir et contrôler le secteur audiovisuel dans sa globalité. En l'espace de 10 ans, de la création du GEICINE à celle d'EMBRAFILME, le panorama législatif sera totalement transformé et les subsides d'aide à la production multipliés et diversifiés. Nous allons revenir dans ce chapitre sur l'organisation de la classe cinématographique et les principaux courants idéologiques qui se manifestent dès les années cinquante quant aux stratégies envisagées pour le développement d'une industrie de cinéma. Nous verrons ensuite comment le Cinema Novo prend part aux discussions et quel sera sa politique en relation aux GEICINE et à la CAIC.

\section{Constitution des deux principales propositions d'une politique de cinéma}

Les premières revendications de groupes industriels ou de professionnels du cinéma quant à une intervention directe de l'État dans ce domaine datent de la fin des années vingt. Le manque de puissance économique des demandeurs permettra cependant toujours à ce dernier de répondre à ces revendications avec une certaine distance et selon ses propres objectifs et priorités. Entre 1930 et 1966, date de la création de l'INC, l'intervention de l'État est minimale, il n'existe pas à proprement parler de politique nationale de cinéma ${ }^{399}$. Indirectement pourtant, le secteur cinématographique est depuis toujours dépendant des

planifier la création d'une nouvelle institution possédant un peu plus de pouvoir que la précédente. Le GEICINE est le premier groupe à disposer d'un pouvoir exécutif et d'une certaine agilité dérivant de sa capacité à entrer en relation avec les ministères et les agences gouvernementales à même de soutenir ses initiatives.

Pendant plus de 15 ans, la planification de l'INC est constamment réinscrite au cahier des charges des commissions gouvernementales. L'institut créé en 1966 est avant tout le fruit du travail du GEICINE et de son président Flávio Tambellini. Les résistances à la promulgation de ses statuts sont telles qu'il sera imposé par un décret-loi, c'est à dire de façon autoritaire, le décret-loi consistant en une décision unilatéral du président de la République, en l'occurrence le Maréchal Castello Branco. Costa e Silva ne remettra pas en cause les orientations de l'institution créée juste avant sa prise de pouvoir.

399En avril 1932, le décret $n^{\circ} 21240$ manifeste pour la première fois une attention de l'État à l'égard de l'industrie cinématographique, les organes de censures sont centralisés, une taxe est créé pour l'éducation populaire et le principe est établi, mais non encore appliqué, de l'imposition d'une réserve de marché au bénéfice du long métrage national. La loi aura pour effet pervers l'arrêt quasi total de la production de longs métrages. Quelques années plus tard, peu avant l'instauration de l'Estado Novo, l'Instituto Nacional de Cinema Educativo - INCE est créé. Entre 1930 et 1945, le Brésil gouverné par Vargas s'intéresse au cinéma exclusivement pour ses qualités didactiques ou propagandistes.

La part de marché réservée au film brésilien est graduellement et très lentement augmentée. En 1939, elle est de un film par an et par cinéma ! En 1945, elle est augmenté à trois films par an et par cinéma. Elle atteint des valeurs significatives à partir de 1959 avec 42 jours annuels. Entre 1963 et 1969, à l'époque de l'apogée du Cinema Novo, elle est fixée à 56 jours annuels.

D'une façon générale, nous pouvons considérer que de 1932 à 1966, l'action du gouvernement est dérisoire, la législation est mal conçue et son application est peu contrôlée. La réserve de marché qui est le principal levier d'action directe de l'état en matière de cinéma est considérée insuffisante jusque dans le milieu des années soixante-dix. Voir en annexe le tableau : «Évolution de la réserve de marché pour les longs métrages ». 
politiques publiques concernant les relations commerciales internationales et le taux de change des devises étrangères. La première raison à cela est la nécessité d'importation de tous les matériels techniques (caméras, pellicules, projecteurs, tables de montage, matériels de laboratoire) qui ne sont pas fabriqués au Brésil. La seconde raison de cette dépendance est l'absence de restriction quant à l'entrée des films étrangers au Brésil obtenue au cours de la signature d'accords commerciaux internationaux. Ce sont ces accords qui permettent la saturation du marché brésilien par le film étranger. Enfin, le prix du ticket de cinéma n'est pas libre mais strictement réglementé en fonction de la qualité des cinémas. L'industrie cinématographique n'a donc aucun moyen de peser sur la valeur marchande de ses produits.

Au début des années cinquante, le projet de création d'un institut national de cinéma rédigé par Alberto Cavalcanti à la demande de Vargas et la tentative d'implantation d'une industrie cinématographique par la haute bourgeoisie pauliste provoquent de grandes polémiques et stimulent l'émergence de nouvelles idées quant aux modes d'intervention que l'État doit développer en matière de cinéma. Trois grands congrès ont successivement lieu à l'initiative de la classe cinématographique qui s'organise. Voici les dates auxquelles ils ont eu lieu et leur intitulé respectif :

- 15/04/1951 : I Congresso Paulista de Cinema - São Paulo ;

- 22-28/09/1952 : I Congresso Nacional de Cinema - Rio de Janeiro ;

- 12-20/12/1953 : II Congresso Nacional de Cinema - São Paulo.

À chaque fois, le marché national est étudié en profondeur et les différentes formes possibles d'intervention de l'État sont débattues. L'un des principaux apports de ces congrès sera de permettre la reformulation totale des termes dans lesquels le problème du cinéma était posé au Brésil depuis la fin des années vingt. L'actualité aidant avec les difficultés rapidement rencontrées par les grands studios puis leur inévitable faillite, l'idée est battue en brèche selon laquelle il suffisait de bénéficier d'importants capitaux, de grands studios, d'un équipement de pointe, de bons techniciens et d'une gestion sérieuse pour réussir à implanter une industrie cinématographique prospère. À la pensée libérale qui avait jusque là dominé les réflexions sur le cinéma brésilien se substitue la certitude de la nécessité d'une intervention directe et vigoureuse de l'État. Les modalités de cette intervention ne font cependant pas l'objet d'un consensus, les lignes qui divisent la classe cinématographique recoupent les grandes divisions de la vie politique brésilienne de l'époque. Celles-ci sont au nombre de trois. La conception libérale hostile à l'intervention de l'état et favorable aux investissements étrangers et à la déréglementation des marchés a été balayée. Restent la conception nationaledéveloppementiste et la conception nationale-populaire. La deuxième est favorable à une rapide industrialisation basée sur un recours mixte aux aides publiques et aux investissements 
étrangers. Elle prévoit aussi bien de subventionner des entreprises privées que de stimuler la création d'entreprises mixtes ou publiques. La troisième conception est radicalement opposée au recours à des capitaux étrangers. D'inspiration socialiste, elle attend une profonde modification de la structure économique du pays.

Lors des trois grands congrès de cinéma qui se tiennent à Rio de Janeiro et à São Paulo, les deux dernières conceptions entrent en choc. Rapportées au domaine spécifique du cinéma, ces deux conceptions mobilisent deux groupes antagoniques commodément surnommés les «universalistes» et les «nationalistes». La vision du cinéma des universalistes est une vision cosmopolite qui consiste à copier ce qui se fait de mieux à l'étranger. L'idée se résume donc à imiter le modèle hollywoodien et à l'implanter au Brésil. Cette vision est incarné par la Vera Cruz et le premier projet d'institut du cinéma rédigé par Cavalcanti à la demande du président Vargas. En faisant appel à des techniciens, des scénaristes et des réalisateurs étrangers, la Vera Cruz reprend une vieille tradition brésilienne remontant aux missions françaises du XIXe siècle et consistant à demander à des spécialistes de renommée mondiale de venir faire au Brésil ce qu'ils font chez eux. Le groupe universaliste attend aussi que le cinéma soit considéré avant tout comme une industrie. Le groupe nationaliste fait prévaloir des préoccupations culturelles et politiques sur l'organisation économique et légale de l'activité. Le cinéma n'est pas un artefact industriel comme un autre et, à ce titre, il mérite un traitement particulier. Comme nous l'avons vu en évoquant l'émergence du concept de cinéma indépendant au Brésil, les propositions de ce groupe, autant en termes d'esthétique que de modèle économique, restent ambiguës.

L'opposition entre universalistes et nationalistes va traverser les années cinquante et soixante. Selon les situations et en raison de l'ambiguïté des propositions du second groupe, cette division pourra être jugée plus ou moins profonde. Elle met finalement surtout en jeu les stratégies envisagées pour parvenir à un même résultat, l'établissement d'une activité de production cinématographique forte et pérenne capable de dominer le marché interne. Après les trois premiers grands congrès de cinéma et la faillite de la Vera Cruz, les deux groupes se retrouvent sur une analyse commune de la situation et quatre revendications élémentaires. Un document traduit ce consensus, c'est le rapport rédigé par Jacques Deheinzelin sur la situation du cinéma national dans la perspective de la création d'un dispositif d'aide à la production par la municipalité de São Paulo. Ce document intitulé Situação econômica e financeira do cinema nacional ${ }^{400}$ comprend un compte-rendu de 17 pages daté de septembre 1955 et le texte de la loi municipale $n^{\circ} 4854$ du 30 décembre 1955 . Le compte-rendu sur la situation du 
cinéma brésilien est le fruit du travail d'une commission de 10 personnalités présidée par le représentant de la Secretaria de Educação e Cultura. Parmi ces personnalités, il y avait Benedito J. Duarte, Flávio Tambellini, Francisco Luiz de Almeida Salles, Jacques Deheinzelin lui-même (cinéaste), Lima Barreto et Paulo Emílio Sales Gomes, autrement dit des critiques, des cinéastes, des producteurs et des représentants des institutions culturelles en relation avec le cinéma. Parmi ces personnalités, nous avons des représentants des universalistes (Tambellini) et des nationalistes (Sales Gomes).

Le compte-rendu développe plusieurs points que Sales Gomes reprendra à l'identique dans ses articles du début des années soixante : le contraste entre le volume du marché de l'exhibition cinématographique et celui de la production nationale de longs métrages, la saturation du marché par les films étrangers et l'insignifiance des taxes pesant sur leur importation, les conditions inégales de la concurrence entre le film hollywoodien et le film brésilien. Le point de départ reste cependant l'analyse de la faillite des grands studios. Sur 25 films produits, un seul a présenté des bénéfices : O Cangaceiro. Pour le reste, toutes les compagnies présentent de lourdes pertes. Celle qui obtient les meilleurs résultats est la Vera Cruz avec $70 \%$ du rapport revenu / coût de production. Il faudrait réaliser le double pour que l'entreprise soit jugée économiquement rentable et puisse affronter les risques inhérents au commerce cinématographique et les taux d'intérêts importants qui pèsent sur les capitaux empruntés. À partir de cette analyse, la commission a envisagé deux solutions : réduire les coûts de production ou augmenter les recettes. Deux variables décisives étaient mises à jour et configuraient une équation qui ne sera jamais résolue.

La commission va rejeter la compression des coûts de production en argumentant qu'ils sont déjà très faibles comparés à ceux des autres pays. Elle va estimer que leur compression pourrait avoir pour résultat la production de films de trop faible qualité technique pour être compétitifs. Enfin, il est très justement consigné que les films ayant eu les meilleurs résultats commerciaux furent également ceux qui bénéficièrent des budgets les plus importants : O Cangaceiro et Sinhá Moça. La compression des coûts de production n'est donc pas envisagée. L'étude de l'augmentation des recettes commence par l'examen de la répartition de la somme encaissée au moment de la vente d'un ticket de cinéma. Il est rappelé que, sur le prix total, sont successivement prélevés $20 \%$ de taxes, les dépenses de l'exploitant (environ $4 \%$ ), la part de l'exploitant (50\% de ce qu'il reste), distributeur et producteur se partageant les $50 \%$ restant. La commission du distributeur qui représente les intérêts du producteur est en général de 20 à 30\%. Du total initial, le producteur empoche donc entre 25 et 30\%. Il apparaît impossible de modifier ce partage et d'augmenter la part du producteur car la part reçue par le distributeur (50\%) est déjà supérieure à ce qui se pratique dans les autres pays occidentaux 
(35\%). La commission du distributeur est par contre inférieure à celle des États-Unis.

Pour augmenter les recettes, la dernière solution consiste à augmenter le prix du billet. Le prix d'une entrée de cinéma au Brésil est l'un des plus bas du monde et c'est sans doute là la source de la crise. Cette situation provoque un nivellement entre les cinémas de différentes catégories qui va à l'encontre de l'exploitation des films sur la durée et favorise les grandes compagnies de l'exploitation cinématographique qui peuvent fournir un grand nombre de copies du même film au même moment et n'ont pas de préoccupations quant à l'amortissement des coûts de production. Le prix des billets étant contrôlé, les exploitants de salles n'ont pas pu accompagner l'inflation ce qui a aussi favorisé le regroupement en grands circuits d'exhibition. Comme le taux de change est extrêmement favorable aux producteurs étrangers (70\% au taux officiel plus $15 \mathrm{Cr} \$$ d'agio par dollar, 1 dollar $=54 \mathrm{Cr} \$$ ), le fait que le prix des tickets ait été contrôlé a été compensé par le taux de change. La politique consistant à maintenir des tickets de cinéma à bas prix n'a pas rempli ses objectifs consistant à lutter contre l'évasion de devises et le rapatriement des recettes des producteurs étrangers est resté constant. Le texte de la commission préconise d'augmenter les prix et de rétablir le nivellement entre cinémas populaires et cinémas de centre ville afin que les cinémas populaires ne souffrent plus de la concurrence déloyale des cinémas plus luxueux (meilleurs films et équipements pour les mêmes tarifs) et que l'exploitation du marché en profondeur puissent être assurée.

Les auteurs du rapport jugent enfin que, quand bien même seraient corrigés les problèmes du prix du billet et du dumping de films étrangers, il faudrait encore appuyer la production nationale par des institutions spécifiques d'aide financière comme il en existe au Mexique, en Argentine, en Espagne, en Italie, en France et en Angleterre. En premier lieu, ils remarquent que l'aide gouvernementale aux productions nationales existe sous diverses formes dans de nombreux pays, mais qu'elle s'appuie toujours sur les taxes et impôts appliqués à l'exploitation cinématographique. En second lieu, ils revendiquent la mise en place de crédits adaptés à la production cinématographique et dont la responsabilité devrait revenir à des banques officielles et non particulières.

La conclusion du compte-rendu est ouvertement revendicative. L'idée centrale est que le problème du cinéma au Brésil doit être considéré comme une affaire d'État et que les faiblesses artistiques du cinéma brésilien doivent être mises en relation avec la précarité de cette activité. Quand le cinéma sera libéré de ses entraves économiques et financières, alors il devra être jugé sur sa qualité. Quatre mesures doivent être prises :

- le réajustement du prix des entrées de cinéma;

- la limitation des importations ; 
- l'aide à la production ;

- le financement spécifique par les banques officielles.

Ce compte-rendu va recevoir une réponse positive avec la promulgation de la loi municipale $\mathrm{n}^{\circ} 4854$ du 30 décembre 1955 visant à favoriser la capitalisation de l'industrie cinématographique sur la base de primes et de subsides financiers auxquels pourront prétendre tous les films brésiliens produits et exploités dans l'état de São Paulo. Un additionnel de recette de $15 \%$ est prévu auquel pourra être ajouté une prime de qualité de $10 \%$ si le film possède une valeur artistique et technique reconnue. Une taxe supplémentaire portant sur le prix de l'entrée de cinéma est créée pour financer cette loi. Les quatre revendications formulées par la commission reviendront de façon régulière et sans grande modification jusque dans les années soixante-dix. Les cinemanovistas les reprendront toutes à leur compte à l'exception de la première sur laquelle ils n'insisteront pas beaucoup. La réponse apportée par la municipalité de São Paulo préfigure toutes celles qui suivront. Le prix des entrées de cinéma restera très bas, les importations ne seront pas limitées mais l'État consentira à mettre en place des mécanismes d'aide à la production, d'ailleurs selon le même principe de primes à la qualité, d'additionnels de recettes et d'ouvertures de crédits en destination du cinéma. D'une certaine façon, en se concentrant sur l'aide à la production, l'État accepte à chaque fois d'investir à perte. La structure du marché cinématographique brésilien n'est pas altérée et la domination du cinéma étranger n'est pas menacée. Elle demeure d'ailleurs jusqu'à aujourd'hui intacte.

\section{Le Cinema Novo et le GEICINE}

Dans les années soixante, l'opposition entre les universalistes et les nationalistes se cristallise autour des controverses suscitées par la trajectoire du Grupo Executivo da Indústria Cinematográfica -GEICINE (1961-1966) et la création l'Instituto Nacional de Cinema - INC (1966-1975). Pendant toute cette période, le premier groupe est celui qui est le mieux écouté des différents gouvernements successifs, de celui de Jânio Quadros en 1961 à celui de Médici en 1969. Le groupe universaliste est généralement associé à trois principaux cinéastes, Flávio Tambellini, Rubem Biáfora et Walter Hugo Khouri. Leur conception du cinéma s'inscrit dans la continuation de celle de la Vera Cruz. Les règles classiques du langage cinématographique ne sont pas remises en cause et l'achèvement technique en termes de photographie et de montage reçoit un traitement prioritaire visant, notamment, à bien distinguer leur production de celle de catégorie B. Leurs films mettent en scène les décors luxueux de la bourgeoisie urbaine et traitent des problèmes existentiels ou moraux de cette classe. Bien que luttant 
également pour le développement du cinéma national, les universalistes ne partagent pas la même analyse idéologique du cinéma hollywoodien que les cinemanovistas. Le principal concurrent du cinéma brésilien est au contraire conçu par eux comme un modèle. Pour les différents groupes en présence qui articulent leur conception du cinéma à des idéaux de gauche, le cinéma des universalistes est l'expression d'une conscience aliénée et pèche par un formalisme vain. Malgré les polémiques assez vives qui pourront opposer les universalistes aux nationalistes, malgré, surtout, les luttes d'influence auxquelles ils pourront se livrer pour s'assurer le contrôle des différentes institutions créées par le pouvoir, la conception du rôle de l'État des premiers va garantir un certain espace aux seconds. Les universalistes vont en effet concevoir le GEICINE et l'INC comme des organes essentiellement techniques sans responsabilité vis à vis de l'orientation esthétique que devrait prendre la production nationale. Le cinéma est traité comme un produit industriel et commercial sans les connotations éducatives, culturelles ou artistiques que lui confèrent les nationalistes.

Le GEICINE est créé avec la promulgation du décret 50, 278 du 17 février 1961 sous la courte présidence de Quadros. Il dépend du ministère de l'industrie et du commerce. Tambellini est choisi par le chef de l'État pour avoir été à la tête de la commission municipale de cinéma de la ville de São Paulo et, sans doute, pour être aussi le beau-frère de Roberto Campos, alors directeur du Banco Nacional do Desenvolvimento Econômico et futur ministre, à plusieurs reprises, au temps de la dictature. Bien qu'il s'agisse de l'institution de cinéma la plus puissante créée jusqu'alors, elle produit peu de mesures concrètes et réellement suivies d'effet $^{401}$. Les principales avancées du GEICINE sont la définition de ce qu'est un film brésilien ${ }^{402}$ et la loi de l'impôt pesant sur les profits rapatriés dans leur pays d'origine par les firmes étrangères. Cette loi intitulée «Lei de Remessa de lucros » prévoit de donner le choix suivant au contribuable. Il peut déposer les sommes à retenir sur un compte bloqué du Banco do Brasil ou investir dans la production de films brésiliens ${ }^{403}$. Comme Tambellini le reconnaîtra lui-même plus tard ${ }^{404}$, peu de co-productions seront réalisées avec les fonds qu'elle permettait de mettre à la disposition de la production nationale ${ }^{405}$. Paradoxalement, alors

401Voir : « Cronologia da ação do GEICINE » et « Capitais para a produção » in Filme cultura, Rio de Janeiro, $\mathrm{n}^{\circ} 1,1966$.

402Décret $n^{\circ} 51.106$ du 01/08/1961. Cette définition était nécessaire à la distinction des films qui pourraient bénéficier de l'aide de l'État de ce qui ne le pourraient pas. La classe cinématographique brésilienne craignait que des producteurs étrangers ne récupèrent à leur avantage leurs propres conquêtes par le biais de coproductions plus ou moins authentiques. Les nationalistes concevaient de façon générale toute intervention de l'étranger dans la production nationale comme un risque potentiel de dénationalisation que ce soit d'un point de vue économique ou culturel.

403Décret $n^{\circ} 52.405$ du 27/08/1963 modifiant les dispositions prévues dans l'article 45 de la loi $n^{\circ} 4.131$ (« Lei de Remessa de lucros ») du 03/09/1962.

404TAMBELLINI, Flávio. «Insurreição contra a derrota » in Filme Cultura, Rio de Janeiro, mars-avril 1967. 405Selon Randal Johnson, seulement sept films ont été financés sur la base de ce dispositif et aucun n'a marqué l'histoire du cinéma brésilien. Plusieurs sont à ranger dans la tendance universaliste (Tambellini, Cristensen, 
même qu'il reconnaît son échec partiel, il l'utilise comme contre-argument pour montrer qu'elle n'a pas non plus engendré les effets pervers que craignaient ses opposants. Les nationalistes pensaient en effet que ce type de mesure conditionnerait la production nationale en la soumettant aux diktats des décideurs étrangers.

Rocha et Dahl écrivent sur le GEICINE dès sa création, autrement dit à une époque où la modestie des réalisations n'a pas encore discrédité la grandeur des projets. Ceux-ci sont alors nombreux et surpassent les attentes formulées par la classe cinématographique depuis les congrès du début des années cinquante. Sont envisagées les créations d'une école de cinéma, d'une fabrique de film vierge, d'un service de statistique renseignant le marché d'exploitation cinématographique, d'un organisme de promotion du cinéma brésilien à l'étranger (type Unifrance ou Unitalia) et d'un festival de cinéma international dans une grande ville du Brésil. Aux côtés de ses grandes réalisations, le GEICINE entend non seulement promouvoir l'adoption par les municipalités les plus importantes du pays de lois équivalentes à celle de São Paulo mais aussi encourager les co-productions internationales et permettre l'établissement de normes de crédit financier adaptées aux spécificités de l'activité cinématographique au sein de la Carteira de Crédito Agrícola e Indústrial do Banco do Brasil. Les orientations du GEICINE s'identifient très clairement avec les conceptions du groupe universaliste, en particulier dans l'expectative alimentée autour des co-productions internationales qui pourraient contribuer à la capitalisation du cinéma brésilien et à la formation de ses cadres. Ces orientations ne manquent pas de susciter la polémique et c'est à l'occasion des débats qu'elles suscitent que les cinemanovistas se rangent résolument du côté des nationalistes. Les critiques adressées au GEICINE s'harmonisent également avec le choix du cinéma indépendant comme modèle de production.

Rocha s'intéresse pour la première fois en détail au nouveau groupe de cinéma dans un article intitulé : «Crise política e responsabilidade do GEICINE » ${ }^{406}$. Le texte est écrit après que Quadros ait renoncé à ses fonctions provoquant, entre autres perturbations plus importantes, l'arrêt provisoire des activités du GEICINE. Rocha critique les orientations politiques du GEICINE en faveur d'une industrie du cinéma visant, selon lui, à reproduire la tentative de la Vera Cruz. Il développe ensuite la thèse selon laquelle il est nécessaire de soutenir le cinéma indépendant : 1) parce que c'est le type de cinéma en ascension dans le

Khoury). Nous avons El Justicero (Nelson Pereira dos Santos), O Mundo alegre de Helô (Carlos A.S. Barros), O Beijo (Flávio Tambellini), Crônica da cidade amada (Carlos Hugo Cristensen), Amor e desamor (Gerson Tavares), O Corpo ardente (Walter Hugo Khoury), Três histórias de amor (Alberto d'Aversa). In RANDAL, Johnson. The film industry in Brazil : Culture and the state. Pittsburgh, University of Pittsburgh Press, 1987, p. 95.

406 ROCHA, Glauber. «Crise política e responsabilidade do GEICINE » in O Jornal do Brasil - Suplemento Dominical, Rio de Janeiro, 16/09/1961. 
monde entier ; 2) parce que le Brésil présente justement les conditions adéquates pour faire un cinéma très bon marché ; 3) parce que ce style de film correspond à la réalité économique d'un pays qui a connu une industrialisation tardive et mal assurée ; 4) parce que la validité culturelle de ce type de produit est supérieure à celle d'un cinéma d'imitation ; 5) pour participer au processus de décolonisation en proposant un cinéma désaliénant qui engage un dialogue avec le public sur la situation nationale. Sa conclusion exprime cependant parfaitement les contradictions de son camp quant à ses relations avec l'État. Il assure en effet que sa critique ne porte pas sur l'existence du GEICINE mais sur les orientations politiques adoptées par cette institution ${ }^{407}$. Il réitère son conseil d'une politique en faveur du cinéma indépendant et du court métrage même s'il est rare que les gouvernements manifestent de l'intérêt pour les « fitas de denúncia, fitas de polêmica, fitas de crítica ${ }^{408}$. Enfin, il souligne qu'au lieu de concentrer les capitaux sur une seule grosse production, il vaut mieux les répartir sur plusieurs afin de favoriser la création de petites maisons de production qui produiront 8 ou 10 films par an.

Le point de vue de Rocha s'identifie totalement avec celui de Dahl tel qu'il est exprimé dans son article «A Solução única ${ }^{409}$ publié moins d'un mois plus tard. Le critique pauliste commence par faire un bref historique du cinéma et souligne l'essoufflement du cinéma classique hollywoodien ou européen. Selon lui, la Nouvelle Vague, le nouveau cinéma polonais et le cinéma new-yorkais représentent l'avenir du cinéma et démontrent qu'il n'existe

407De façon similaire, comme l'a souvent précisé Nelson Pereira dos Santos par la suite, sa génération n'était pas contre la Vera Cruz mais pour un changement de sa ligne de production (Voir par exemple : D'AVILA, Roberto. Os Cineastas - Conversas com Roberto d'Avila. Rio de Janeiro, Bom Texto, 2002).

Dans le cas du GEICINE, la même ambiguïté se reproduit. Alex Viany écrit un article qui s'intitule «O Fim do ciclo do abacaxi » (littéralement, « La Fin du cycle du navet ») dans lequel il exprime ses restrictions à l'encontre du GEICINE tout en lui accordant un crédit de confiance. Voir : VIANY, Alex. « Cinema brasileiro : O Fim do ciclo do abacaxi ? » in Revista Senhor, Rio de Janeiro, n5, mai 1961, pp. 40-43. Cette ambiguïté provient en grande partie de la domination de l'idéologie nationale-développementiste et, du fait, que les nationalistes n'ont pas un modèle économique précis à proposer. Pour la droite comme la gauche, le progrès est synonyme d'industrialisation et, dans le domaine du cinéma, la formule d'un cinéma indépendant industrialisé, ou d'une industrie du cinéma indépendant, envisagée par les nationalistes reste à inventer et personne ne sait concrètement quelles formes elle pourrait prendre.

408 « des films de dénonciation, des films polémiques, des films critiques. » Une fois de plus, nous voyons ressurgir l'ambivalence des nationalistes dans leur relation à l'État. Dix ans plus tard, celle-ci n'aura absolument pas variée. Elle est particulièrement visible dans le discours de Rocha. Dans une lettre ouverte adressée en 1970 au ministre Magalhães Pinto, il va opiner sur la succession du président de l'INC après le préambule suivant:

« Prá começo de conversa, sou contra o INC porque acho que qualquer atividade cultural que se preze não deve ser estatal. Mesmo que o artista é financiado pelo Estado, só tem graça se ele criticar o Estado. Daí ser impossível prá mim conciliar com o INC que deseja direta ou indiretamente financiar, proteger e premiar aqueles filmes que possam direta ou indiretamente interessar o Estado. » («Pour commencer, je suis contre l'INC parce que je pense que toute activité culturelle qui se respecte ne doit pas être dirigée par l'État. Même si l'artiste est financé par l'État, cela n'a d'intérêt que s'il critique l'État. Aussi, il m'est impossible d'accepter la moindre conciliation avec l'INC qui désire financer, directement ou indirectement, protéger et récompenser les films qui peuvent, directement ou indirectement, intéresser l'État. ») In ROCHA, Glauber. « Uma Carta para o ministro Passarinho » in O Pasquim, n³2, Rio de Janeiro, 29/01/1970.

409DAHL, Gustavo. «A Solução única » in O Estado de São Paulo - Suplemento literário, São Paulo, 21/10/1961. 
pas de contradiction entre qualité artistique et petit budget. De fait, il n'existe pas d'obstacle à ce que le Brésil investisse ce domaine si ce n'était les conceptions rétrogrades des personnes en charge de l'établissement d'une politique de cinéma. L'État se trouve devant un choix stratégique décisif. Présent au festival de Santa Margaritha, Dahl témoigne de la différence d'attitude entre la délégation officielle brésilienne et la délégation argentine, plus humble et orientée vers un cinéma d'intégration au complexe socio-culturel de leur réalité nationale ${ }^{410}$. Il pose alors la question : quel cinéma pour le Brésil, celui de GEICINE ou celui du Cinema Novo ? Le choix est évident. Plutôt que bâtir de grands projets sans relation avec les possibilités offertes par le marché, Gustavo Dahl montre qu'il vaut mieux se référer à des pratiques ayant démontré leurs vertus à l'exemple de Shadows (Cassavetes, USA, 1959) : la solution unique, c'est la caméra portée et le cinéma indépendant.

Si l'État veut réellement aider la production de longs métrages de fiction, c'est donc le film d'auteur à petit budget qu'il doit encourager. Si ce type de cinéma ne domine pas encore le marché, il peut néanmoins s'avérer rentable et, surtout, dans la perspective des cinemanovistas, il est le mieux à même de servir le « développement culturel» du Brésil. Les rouages du GEICINE resteront cependant complètement hermétiques aux membres du groupe, y compris pendant la présidence de Goulart. Paradoxalement, ils seront mieux entendus à Rio de Janeiro, alors gouverné par Carlos Lacerda, l'un de ses plus farouches opposants.

\section{Le Cinema Novo et la CAIC}

L'un des impacts les plus importants de la crise de la Vera Cruz et des autres grands studios paulistes aura certainement été de sensibiliser une partie des élites politiques à l'importance culturelle et commerciale du cinéma. De fait, entre 1950 et 1966, les actions officielles les plus significatives seront réalisées à l'échelle municipale et régionale avec l'institution de la Comissão de Cinema de São Paulo et la Comissão de Auxílio da Indústria Cinematográfica - CAIC de Rio de Janeiro. Si les intentions partisanes et les calculs politiques ne sont pas étrangers à la création de ces dispositifs d'encouragement de la production cinématographique, les deux commissions vont respecter un certain pluralisme dans l'attribution des prix et financements. L'idée de la mise en place d'un cinéma de propagande politique est absolument étrangère aux intentions des maires et gouverneurs impliqués. Les retours attendus à leur action entrent dans le cadre classique du clientélisme et plus généralement de la récupération du prestige que le cinéma est susceptible de conférer. À 
ce titre, l'ambition est avant tout de stimuler l'émergence d'un cinéma de catégorie A, susceptible de satisfaire aux attentes des classes moyennes et supérieures. Les succès critiques régional puis national sont les premiers objectifs visés. Viennent ensuite le succès commercial et, éventuellement, le succès international.

Après l'échec de la tentative d'implantation d'une industrie cinématographique à São Paulo, le climat va longtemps rester morose en relation au cinéma et la commission qui a été créée ne va pas suffire à générer un nouveau cycle de production qui, par sa qualité ou son volume, puisse faire date dans l'histoire culturelle de la ville. Elle constituera cependant un modèle qui stimulera les imaginations dans les autres grandes villes. À Salvador, Walter da Silveira soumet à la municipalité un projet visant à mettre en place un dispositif comparable. À Rio de Janeiro, dès les années cinquante, des revendications sont également articulées dans ce sens, Alex Viany en est un fervent militant. Il faudra cependant attendre l'émergence du Cinema Novo pour que la CAIC soit fondée. Nous sommes en 1963, huit ans se sont écoulés depuis la mise en place de son équivalent pauliste. Plusieurs témoignages convergent pour indiquer que la création de l'institution est le résultat direct de l'activisme des membres du Cinema Novo appliquant des stratégies identiques à celles qui leur avaient permis de convaincre banques et particuliers de leur apporter un soutien financier. Selon Carneiro et Saraceni, José Luís Magalhães Lins est le premier à intervenir auprès de Carlos Lacerda pour obtenir la création de la $\mathrm{CAIC}^{411}$, Augusto Mendes prendra ensuite le relais :

«Gugu Mendes era filho do deputado baiano João Mendes, um fazendeiro rico e amigo de Carlos Lacerda. Ajudado pelo trabalho feito por Luís Carlos Barreto junto ao vice-governador, Rafael de Almeida Magalhães, Gugu convenceu Lacerda a criar a Comissão de Auxílio à Indústria Cinematográfica (CAIC). Pronto, acabou a miséria, ninguém mais ia segurar o cinema do Rio e do Brasil ! Gugu ficou sendo diretor da CAIC e premiou Vidas secas, Garrincha, alegria do povo, Porto e outros, mesmo antes de serem apresentados em cinemas. Com a CAIC e o Banco Nacional, estávamos feitos. Foi, de longe, a melhor ajuda governamental que o cinema brasileiro teve em toda a sua trajetória. ${ }^{412}$

La CAIC met en place un système de prix financiers, prix à la qualité et additionnels de recettes, ainsi qu'un dispositif de financement en partenariat avec le Banco do Estado da

411La participation de José Luís Magalhães Lins est évoquée par Mário Carneiro. In LINHART, Clara, MAROJA, Camila et CAETANO, Daniel. «Entrevista com Mário Carneiro » in Contracampo, $\mathrm{n}^{\circ} 42$, http://www.contracampo.com.br/42/frames.htm, consulté le 29/12/2005.

412«Gugu Mendes était le fils du député bahianais João Mendes, un grand propriétaire de terres ami de Carlos Lacerda. Précédé par le travail effectué par Luís Carlos Barreto auprès du vice-gouverneur, Rafael de Almeida Magalhães, Gugu [Mendes] a convaincu Lacerda de créer la Comissão de Auxílio à Indústria Cinematográfica (CAIC). Aussitôt, c'en était fini de la misère, personne n'allait plus empêcher l'essor du cinéma brésilien! Gugu est devenu le directeur de la CAIC et a primé Vidas secas, Garrincha, alegria do povo, Porto et d'autres, avant même qu'ils ne sortent au cinéma. Avec la CAIC et le Banco Nacional, nous étions servis. Ce fut, de loin, la meilleure aide gouvernementale que le cinéma brésilien a reçu dans toute son histoire. » in SARACENI, Paulo César. Por dentro do Cinema Novo - Minha Viagem. Rio de Janeiro, Nova Fronteira, 1993, p. 162. Saraceni avait déjà apporté le même témoignage à Viany plusieurs années plus tôt. In VIANY, Alex. O processo do Cinema Novo. Rio de Janeiro, Aeroplano, 1999, p. 336. 
Guanabara $^{413}$. Selon Miguel Pereira :

« De seus recursos, 40 \% era destinados à premiação, tanto a da renda quanto a da qualidade, e os $60 \%$ restantes eram para o financiamento da produção. Era, no entanto, freqüente que a verba da premiação não fosse entregue, pois o produtor ou cineasta-produtor devia à CAIC financiamentos não pagos. Assim, se dava à produção e se retirava na premiação. $»^{414}$

Selon lui, la CAIC s'est surtout distinguée par la souplesse de son fonctionnement qui lui a permis de répondre aux attentes exprimées par le terrain et de surpasser son modèle initial qui était la commission de São Paulo. La CAIC va constituer une aide décisive pour le Cinema Novo et assurer la pérennité de la production du groupe malgré ses nombreux échecs commerciaux. Plusieurs témoignages convergent dans ce sens. Andrade déclare :

« Mas nessa ocasião eu fui salvo pelo gongo porque criou-se a CAIC, no Rio de Janeiro que era a Comissão de Auxílio a Indústria Cinematográfica. E, logo que ela estreou, a primeira coisa que fez foi distribuir uma série de prêmios para os filmes feitos no Rio de Janeiro, entre os quais eu tinha dois. E os prêmios eram muito grandes, prêmios equivalentes a, era uma coisa muita louca, eles perguntavam ' quanto custou o filme? ' E você dizia a quantia que custou o filme. Aliás, eu acho que todo mundo ali foi honesto. E o prêmio era no valor da produção do filme, embora fosse dividido entre os diferentes sócios. Equivalia mais ou menos a dívida que a gente tinha. $>{ }^{415}$

Ruy Guerra est le seul à se déclarer opposé au système d'aide à la production mis en place par Lacerda. Il craint en effet qu'il ne serve d'un côté, à capter pour lui le prestige des cinéastes de gauche, et de l'autre, à les diviser en les mettant en compétition les uns avec les autres. Il indique aussi que, seul, le prix accordé à Vidas secas suffisait à couvrir l'intégralité de son budget, 20 millions de $\mathrm{Cr} \${ }^{416}$. Son hostilité vis à vis de la CAIC n'est pas bien acceptée par les autres cinemanovistas et entraîne une première rupture au sein du groupe. Trois ans plus tard, il précise son point de vue aux Cahiers du cinéma :

413 « Nossas Fitas vivem de prêmios » in Visão, São Paulo, 09/04/1965.

414 « $40 \%$ de ses moyens étaient destinés aux remises de prix, aussi bien sur recette qu'à la qualité, et les $60 \%$ restants étaient destinés aux financements de nouveaux projets. Il était cependant fréquent que la somme correspondante au gain d'un prix ne soit pas remise car le producteur ou cinéaste-producteur devait à la CAIC des financements non remboursés, Ainsi, ce qui était donné à la production était retiré de la remise des prix. » in XAVIER, Ismail, BERNARDET, Jean-Claude e PEREIRA, Miguel. O Desafio do cinema : a politica do Estado e a política dos autores. Rio de Janeiro, Jorge Zahar editor, Séries Brasil os anos de autorismo, 1985 , p. 55.

415« Mais, en cette occasion, j'ai été sauvé par le gong parce que la CAIC a été créée [...]. Et dès qu'elle a commencé à fonctionner, la première chose qu'elle a faite fut distribuer une série de prix pour les films qui avaient été réalisés à Rio de Janeiro, dont deux étaient de moi. Et les prix étaient de très grandes valeurs, c'était complètement fou, ils demandaient, ' combien a coûté le film ? ' Et vous disiez la somme qu'avait coûté le film. Je crois d'ailleurs que tout le monde a été honnête. Le prix recouvrait le total du budget du film, bien qu'il soit divisé entre les différents associés. Il équivalait à peu près à la dette que chacun devait. » in Programa Luzes, Câmera $n^{\circ} 31$ : Entrevista de Joaquim Pedro de Andrade a Sylvia Bahiense. Transcription d'une entrevue télévisée diffusée sur la chaîne TV Cultura le 08/06/1976, consulté sur le site http://www.filmesdoserro.com.br/, le 13/03/2006.

416VIANY, Alex. O processo do Cinema Novo. Rio de Janeiro, Aeroplano, 1999, p. 385. 
«Carlos Lacerda, qui était gouverneur à l'époque, a décrété une loi d'aide pour le cinéma. De façon très subtile et intéressante, car la loi était discrétionnaire et fasciste au fond. Elle était exactement celle du cinéma espagnol. Pour se rallier les cinéastes brésiliens, il a commencé à distribuer des prix en espèces aux uns et aux autres, mais le principe restait très faux. Tout le monde maintenant s'en est rendu compte mais j'avais tout de suite tiqué. Ce que nous voulions, c'était ' l'additionnel ', c'est à dire un pourcentage sur les recettes, pas cette libéralité arbitraire. Alors, et immédiatement, j'ai eu tout le monde contre moi. Le seul avec qui je gardais des contacts amicaux était Leon Hirszman. $»^{417}$

En fait, aucun des autres cinéastes n'est dupe des intentions du gouverneur de Rio de Janeiro mais ils acceptent tous de courir le risque des compromissions que pouvaient faire peser cette alliance de circonstance avec l'une des plus importantes figures politiques de la droite de l'époque ${ }^{418}$. Comment d'ailleurs continuer le cinéma qu'ils veulent réaliser sans cette manne providentielle distribuée par la CAIC ? Les craintes de Guerra ne vont cependant pas réellement se concrétiser du fait même des contradictions de la vie politique brésilienne. Lacerda termine son mandat de gouverneur en 1965. Il sera ensuite marginalisé par les militaires et, incapable d'obtenir de nouvelles responsabilités, il ne se trouvera plus jamais dans une position susceptible de lui permettre d'influencer le Cinema Novo malgré des velléités dans ce sens ${ }^{419}$. Son successeur à la tête de l'État de Guanabara, Francisco Negrão de Lima n'aura pas les mêmes ambitions de mise sous-tutelle du cinéma à des fins personnelles. Les circonstances imposeront donc à la CAIC une certaine pluralité. Si son action s'est révélée décisive pour la survie du Cinema Novo et si, au final, elle peut apparaître comme l'un de ses principaux appuis économiques, il ne s'agit pas d'une politique concertée dans ce sens sur le long terme mais des aléas des nominations successives à des postes clés.

Mendes est le premier président de la CAIC. La première remise de prix récompense des films remontant au début des années soixante : Arraial do cabo (prix Lulu de Barros), Porto das Caixas (prix Mário Peixoto ${ }^{420}$ ), Couro de gato, Garrincha alegria do povo et Vidas secas. Selon Maurício Gomes Leite, en 1963, la CAIC a distribué 110 millions de Cr\$ aux producteurs cariocas ${ }^{421}$. En 1964, des prix sont offerts aux meilleurs scénarios inédits et

417GUERRA, Ruy. «Entretien avec Ruy Guerra par Jean-André Fieschi et Jean Narboni » in Cahiers $d u$ cinéma, Paris, $\mathrm{n}^{\circ} 189$, avril 1967, p. 64.

418Andrade déclare aux Cahiers du cinéma : « Pourquoi Lacerda aurait-il financé nos films, sinon pour des raisons de tactique politique qui répondaient à certains besoins, à des moments déterminés ? Lorsqu'il a senti que le gouvernement lui échappait, après des élections difficiles, presque perdues, il a eu besoin des intellectuels pour des raisons de prestige. Il a d'abord essayé de faire notre conquête, puis nous a laissé faire des films sans imposer la censure sur le scénario, car il était engagé dans la campagne présidentielle et voulait apparaître comme le défenseur des libertés démocratiques. Nous avons profité de cet état des choses, mais nous sommes en fait à la merci de l'évolution des événements. » in MARCORELLES, Louis. « Rencontre avec le Cinema Nôvo : Joaquim Pedro de Andrade, Gustavo Dahl, Carlos Diegues, Leon Hirszman, Glauber Rocha, Paulo Cézar Saraceni » in Cahiers du cinéma, Paris, nº176, mars 1966.

419En 1970, dans un article du journal Pasquim, Rocha se moque des conceptions cinématographiques de Lacerda qu'il considère par ailleurs comme un dictateur frustré et méprise ouvertement. Voir : ROCHA, Glauber. «O Barato de Lacerda » in O Pasquim, n³7, Rio de Janeiro, 05/03/1970.

420SARACENI, Paulo César. Por dentro do Cinema Novo - Minha Viagem. Rio de Janeiro, Nova Fronteira, 1993, p. 162.

421 À titre de comparaison, rappelons que Vidas secas était tourné la même année avec un budget d'environ 20 
permettent de mettre en route plusieurs projets. Sur dix prix distribués quatre sont revenus à des réalisateurs du Cinema Novo : Andrade pour O Padre e a moça, Saraceni pour O Desafio, Hirszman pour $A$ Falecida et Lima pour Menino de engenho ${ }^{422}$. En 1965, le président de la CAIC a changé. Il s'agit à présent du critique Antônio Moniz Viana, un universaliste et un adversaire du Cinema Novo que nous retrouverons bientôt dans l'organigramme de l'INC. Les cinemanovistas lui reconnaissent cependant une véritable compétence en matière de cinéma et ils conservent l'accès à l'institution puisqu'il est secondé par David Neves ${ }^{423}$.

La même année l'INC concède 14 financements à des longs et des courts métrages dont seulement un bénéficie à un film du Cinema Novo, A Grande Cidade. Le groupe se rattrape sur les prix à la qualité qui sont distribués à la fin de l'année. Sur neuf films récompensés, quatre sont du Cinema Novo : Menino de engenho (15 millions de Cr\$), $O$ Padre e a moça (13 millions de Cr\$), A Falecida (8 millions de Cr\$), Os Fuzis (5 millions de $\mathrm{Cr} \$)$. Ces prix sont à rajouter à l'additionnel de recette (15\% de la recette brute). Celui-ci a atteint $2223575 \mathrm{Cr} \$$ pour A Falecida et $1508424 \mathrm{Cr} \$$ pour Os Fuzis ${ }^{424}$. À titre de comparaison, le budget de ce dernier film, pour avoir été tourné en 1963, ne doit pas excéder 30 millions de Cr\$ alors que le budget moyen des films réalisés en 1965 dépassait 50 millions de Cr\$. Dans tous les cas, un pourcentage important du budget initial était couvert par ces prix.

La création de l'INC va ensuite ralentir considérablement les activités de la CAIC et empêcher que ce type de dispositif ne fasse école et se multiplie dans les autres grandes capitales du Brésil. L'INC va en effet concentrer à son profit les taxes pesant sur les tickets de cinéma et priver ainsi les commissions régionales d'une grande partie de leurs revenus. Les activités de la CAIC décroissent ainsi progressivement. Selon Miguel Pereira, en 1971 et 1972, elle ne concède plus que l'additionnel de recette. Par la suite, elle disparaît sans faire de bruit. Le contexte est autre et la reformulation d'Embrafilme commence à être discutée dans les coulisses du pouvoir. Au cours de la fin des années soixante, la CAIC se présente cependant encore comme une alternative à la recherche de financements publics. À une époque où l'INC est dominé par les universalistes, les cinemanovistas vont obtenir auprès de la CAIC gérée par Fernando Ferreira des aides pour la réalisation de filmes aussi importants que A Opinião pública, Terra em transe, O Dragão da maldade contra o santo guerreiro,

millions de Cr\$. In LEITE, Maurício Gomes. « A Hora e vez do cinema nacional » in Jornal do Brasil, Rio de Janeiro, 09/03/1965.

422 ROCHA, Glauber. « Cinema Novo levanta a cabeça » in O Jornal, Rio de Janeiro, 04/10/1964.

423 Voir DAHL, Gustavo. « Cinema Nôvo e estruturas econômicas tradicionais » in Revista Civilização

Brasileira, Rio de Janeiro, n5-6, mars 1966, p. 199.

424 In « Distribuição dos prêmios da Guanabara » in Cine-reporter, São Paulo, janvier 1966. 
Macunaíma et São Bernardo ${ }^{425}$.

Une étude plus détaillée de l'aide apportée par la CAIC au Cinema Novo mérite certainement d'être menée. Jusqu'à présent, nous n'avons disposé que de témoignages et de coupures de presse. Les archives de la commission, si elles existent encore, n'ont pas pu être localisées. Les quelques chiffres dont nous disposons montrent cependant que les sommes concédées furent effectivement très importantes. Notons enfin que ce ne sont pas moins de 17 films du Cinema Novo qui ont reçu une aide directe de la CAIC, certains d'entre eux cumulant plusieurs prix. 


\section{Chapitre 5 : Premiers tâtonnements}

Le soutien de la critique étrangère, le mécénat privé puis l'accès aux aides de l'État vont servir un cinéma en cours de définition. Au début de l'année 1962, quelques mois avant la controverse avec le CPC, Rocha écrit ces quelques lignes qui montrent encore son indécision quant à la forme concrète que pourrait prendre le Cinema Novo :

«Mandacaru vermelho, de Nelson Pereira dos Santos ; Os Cafajestes, de Ruy Guerra ; Três cabras de Lampião (cores) de Miguel Torres ; O Pagador de promessas, de Anselmo Duarte ; A Ilha, de Walter Khoury ; Barravento, meu ; A Grande Feira, de Pires, e Assalto ao trem pagador, de Roberto Farias - são os filmes novos e independentes que serão lançados em 1962 e que representam um renascimento do pobre cine brasileiro. São tendências diversas - resultado de nossa imaturidade cultural mas todos esses filmes soam como protesto social e mesmo político. $\gg{ }^{426}$

Bien qu'il ait participé, comme nous l'avons vu, à l'établissement du corps doctrinal du Cinema Novo, il envisage ici des solutions qui sont contradictoires avec ses propres principes et qu'il rejettera avec véhémence quelques mois plus tard. En fait, la situation est encore plus confuse. D'un côté, les cinemanovistas sont sensibles à l'arrivée de la modernité dans le cinéma. Cette sensibilité explique leur intérêt pour Os Cafajestes et Porto das Caixas qui inaugurent la voie d'un cinéma d'auteur esthétisant, sophistiqué dans la forme et qui renvoie à la situation politique et sociale de façon indirecte et, éventuellement, métaphorique. Cette orientation, à terme, va dominer la cinématographie du Cinema Novo. Elle était déjà présente dans Arraial do Cabo et elle trouvera sa continuation dans O Padre e a moça, Capitú, Fome de amor, Azyllo muito louco... L'évolution de cette cinématographie est en phase avec l'évolution esthétique internationale des cinémas nouveaux et son caractère avant-gardiste n'est sans doute pas pour rien dans la modestie des résultats commerciaux atteints. La volonté de faire œuvre entre en conflit avec celle consistant à toucher le plus grand nombre. Commence la tradition des films maudits du Cinema Novo.

D'un autre côté, une autre orientation apparemment opposée se manifeste. Certains films comme Barravento, Cinco vezes favela ou Ganga Zumba, témoignent d'une orientation cepecista et présentent une dimension propagandiste au travers de mots d'ordre présents dans les dialogues ou les cartons voire même au travers de la morale, parfois simpliste de la

426« Mandacaru vermelho, de Nelson Pereira dos Santos ; Os Cafajestes, de Ruy Guerra ; Três cabras de Lampião (cores) de Miguel Torres ; O Pagador de promessas, de Anselmo Duarte ; A Ilha, de Walter Khoury ; Barravento, mon film ; A Grande Feira, de Roberto Pires ; et Assalto ao trem pagador, de Roberto Farias - sont les films nouveaux et indépendants qui seront lancés en 1962 et qui représentent la renaissance du pauvre cinéma brésilien. Ils incarnent des tendances diverses - résultats de notre immaturité culturelle mais tous ces films résonnent comme une protestation sociale, voire même politique. » in ROCHA, Glauber. Cartas ao mundo. São Paulo, Companhia das letras, 1997, p. 162. 
narration. La rupture formelle promise n'est pas réalisée, même dans certains films ayant bénéficié d'une excellente couverture critique comme Couro de gato. Ce court métrage comme d'autres de Cinco vezes favela se rapproche d'ailleurs de Rio, quarenta graus dans la mesure où l'on joue sur l'empathie. Entre ces deux orientations, l'éphémère cycle de Bahia présente un moyen terme entre innovation artistique et critique politique mais se trouve accusé d'exprimer une idéologie «petit-bourgeois» par des critiques comme Walter da Silveira.

\subsection{La modernité dans le cinéma brésilien}

\section{Os Cafajestes}

Os Cafajestes est le premier film de Magnus Filmes, la maison de production de l'acteur Jece Valadão, c'est aussi le premier long métrage de Ruy Guerra. Jece Valadão s'est illustré dans les deux premiers films de Pereira dos Santos, Rio, quarenta graus et Rio, zona norte. Acteur et producteur, Valadão est, au moment de la réalisation de ce premier film, proche du Cinema Novo. Il joue d'ailleurs l'année suivante dans un autre film de Pereira dos Santos, Boca de ouro. Ruy Guerra, quant à lui, n'est au Brésil que depuis 1958. Issu d'une famille portugaise, il est né et a passé son enfance dans la colonie du Mozambique. Dans les années cinquante, il suit les cours de l'IDHEC à Paris et débute dans le cinéma en tant qu'assistant de direction. Il fait également l'acteur dans quelques films. Il vient au Brésil dans le but de réaliser un projet qui ne verra pas le jour et décide de rester. Doté d'une formation professionnelle alors sans égale parmi les cinéastes de sa génération, Guerra gagne pourtant la réputation d'un réalisateur qui ne finit pas ses films. Orós (1960) puis O Cavalo de Oxumaré (1961), ses deux premiers documentaires, restent inachevés. Le deuxième dont la photo de l'actrice Irma Alvarez a été divulguée dans la presse, lui a valu une accusation de plagiat par Rocha. Les deux hommes se connaissent depuis 1960, ils se sont rencontrés à Salvador où Guerra était venu faire des recherches sur le candomblé. Malgré cet incident, le cinéaste d'origine portugaise s'intègre au Cinema Novo. En 1962, il monte Escola de samba, alegria de viver, le court métrage de Carlos Diegues destiné au film du CPC, Cinco vezes favela. Il a enfin pour proche collaborateur Miguel Torres $^{427}$ qui travaille avec lui sur $O$ Cavalo de

427Acteur et scénariste de la génération de Nelson Pereira dos Santos, Miguel Torres a sans aucun doute joué un rôle important auprès de Ruy Guerra en lui faisant partager sa connaissance et son expérience du Brésil. Au contraire des autres cinemanovistas, Torres a connu une autre vie avant de se consacrer au cinéma. Il sert dans la Marine durant la Seconde Guerre Mondiale et n'en sort qu'en 1953. À partir de ce moment-là, il va travailler au théâtre, à la télévision (un an à TV Tupi) et enfin au cinéma. Il joue dans l'épisode que filme Alex Viany pour la production est-allemande Die Windrose et collabore avec Alinor Azevedo, scénariste de cinéma et créateur de la maison de production Atlântida, célèbre pour ses chanchadas mais dont le projet initial était la création d'un cinéma « sérieux » et social. En 1960, il joue dans Mandacaru vermelho. Après 
Oxumaré, Os Cafajestes et Os Fuzis dans les phases d'écriture et de repérage.

Os Cafajestes $^{428}$ raconte une journée de la vie de deux amis désoeuvrés de la zone sud de Rio de Janeiro, Jandir et Vavá. Le film commence à la veille de cette journée. Jandir, est un marginal et un dur à cuire, c'est aussi, comme le montre la première séquence du film, un parfait cafajeste. Après avoir convaincu une prostituée de passer la nuit avec lui pour rien, il l'emmène dans son appartement. Tout se passe normalement jusqu'à ce qu'il décide de l'expulser sans ménagement. Pour cela, il use d'un stratagème assez simple. Réveillé bien avant elle, il avance le réveil de plusieurs heures et le fait sonner. La jeune femme se réveille brusquement et lui demande l'heure. Il lui montre le réveil, il est tard, elle doit partir. Elle s'apprête rapidement et descend dans la rue. En fait, le soleil ne s'est pas encore levé, elle s'étonne de l'obscurité et de l'absence de mouvement. Elle demande l'heure à un agent et s'aperçoit que Jandir s'est moqué d'elle. Pendant tout ce temps, celui-ci la regarde par la fenêtre en prenant des cachets. Quand il la voit lui faire de grands signes de rage, il savoure pleinement son mauvais tour. Le matin, Jandir retrouve Vavá, un fils à papa qui cherche à s'encanailler mais qui n'a pas, comme nous le verrons, la dureté de son compagnon. En quête d'argent facile, Jandir tire parti de cette amitié. Vavá lui permet de rencontrer des filles de la bonne société. Leur activité principale consiste à les séduire, les emmener sur des plages désertes, les convaincre de se déshabiller et ensuite les photographier pour faire chanter leurs amis ou les membres de leurs familles. Leda est la victime du jour. Une longue séquence est consacrée à l'humiliation qu'elle subit. La buick tourne en cercle autour d'elle alors que les deux amis se moquent de sa naïveté et la prennent en photo. Elle court après la voiture afin de reprendre ses vêtements et tombe épuisée.

Bien qu'ils aient réussi leur coup, les deux hommes apprennent ensuite que les photos de Leda n'ont aucune valeur. Il leur faut donc trouver une nouvelle victime, c'est elle-même qui va les aider à piéger sa cousine Vilma, dont Vavá est secrètement amoureux. Les sentiments de ce dernier compliquent alors considérablement la situation. Incapable d'assumer

avoir co-écrit l'argument de Os Cafajestes avec Guerra, Torres travaille de nouveau avec Viany sur le scénario de Sol sobre lama (1963). Parallèlement, il joue dans Três Cabras de Lampião (Aurélio Teixeira, 1963) dont il signe aussi le scénario. Son intention, en l'écrivant, était de montrer les relations entre le phénomène du cangaço et l'exploitation par le latifundium. Torres décède en 1962 dans un accident de voiture pendant la préparation de $O s$ Fuzis, film pour lequel il revenait à la thématique du Nordeste qui l'intéressait tant. Arthur Autran en fait l'un des théoriciens du Cinema Novo. Selon lui, l'interview qu'il accorde à David Neves pour la Revista de Cultura Cinematográfica aurait eu une forte influence. Il y défend un cinéma tourné vers la problématique sociale du Brésil, capable de témoigner des luttes qu'il traverse, et attaque le cinéma industriel entendu comme étant un cinéma de mystification et d'évasion de la réalité. Voir : RAMOS, Fernão et MIRANDA, Luís Felipe (org.). Enciclopédia do cinema brasileiro. São Paulo, SENAC, 2000, p. 544. Voir aussi : TORRES, Miguel. « Cinema Novo uma farsa : Impressões de Miguel Torres a David Neves » in Revista de Cultura Cinematográfica, Belo Horizonte, n³3, septembre-décembre 1962.

428Le mot « cafajeste » est une expression difficilement traduisible en français, nous pourrions avancer « salaud » ou « voyou » mais ça ne serait pas encore satisfaisant. Un cafajeste est un personnage à la moralité douteuse, égoïste, malhonnête et manipulateur, il est aussi un homme à femmes et un macho. 
son attirance pour Vilma, il se trouve confronté à un dilemme, tomber le masque et déclarer sa flamme à Vilma avec tous les risques que cela comporte, y compris qu'elle le repousse, ou bien s'identifier à Jandir et rester un cafajeste jusqu'au bout, en exploitant et humiliant Vilma. Des tensions naissent entre les quatre personnages qui sont confrontés à leurs faiblesses et au vide de leur propre existence. Leda et Jandir sont aussi attirés l'un par l'autre mais la réalisation de cet amour leur est impossible. Il se déroule alors sur la plage une sorte de huisclos qui se prolonge jusque dans la nuit entre ces personnages qui se trouvent coupés du monde. Vilma, que la lâcheté de Vavá irrite, offre alors sa virginité à Jandir en se détournant du jeune homme paniqué mais impuissant. Celui-ci s'écarte ensuite du groupe et on l'entend tirer un coup de pistolet que l'on prend pour un suicide. Il a tiré vers les dunes. Au matin, Vilma et Vavá décident de se marier alors que Leda et Jandir continueront leur vie solitaire. Chacun part de son côté. Jandir est victime d'une panne d'essence et doit laisser sa voiture au bord de la route.

À plus d'un titre, le film montre une parfaite assimilation des apports esthétiques de la Nouvelle Vague : tournage en extérieur, caméra portée, temps morts, longs plans séquences et montage non linéaire. Il s'inscrit alors en totale rupture avec la production brésilienne traditionnelle qui est très attachée au tournage en studio mais aussi avec le reste de la production du Cinema $\mathrm{Novo}^{429}$. Il faudra en effet longtemps pour que les autres cinemanovistas acquièrent la maîtrise du langage cinématographique que Ruy Guerra est d'ores et déjà capable de démontrer avec un petit budget : 5 millions de $\operatorname{Cr} \$ \$^{430}$. Le film se distingue également par la crudité et la complexité du propos. Les scènes de nu sont extrêmement osés pour l'époque. Os Cafajestes est sans doute aussi le premier film de l'histoire du cinéma brésilien à montrer la consommation de stupéfiants. Les personnages échappent à une caractérisation simple, leurs comportements sont parfois contradictoires et ne sont en aucun cas expliqués clairement ce qui laisse évidemment une large marge d'interprétation au spectateur.

Pourquoi Leda, après avoir été victime des deux cafajestes, devient-elle leur

429Comme nous allons le voir, cette rupture esthétique est immédiatement perçue par les critiques de l'époque.

Le critique José Lino Grünewald note, dans un article publié dans le Jornal de Letras en décembre 1962, que Os cafajestes a été « o primeiro filme nosso a se colocar, de forma radical, numa linha moderna de invenção, em termos de reformulação estrutural » (le premier film brésilien à se positionner de façon radicale sur une ligne moderne d'invention, de reformulation structurale) in GRUNEWALD, José Lino. Um filme é um filme. São Paulo, Companhia das letras, 2000, p. 112.

D'autres critiques, sans entrer dans les polémiques que nous allons évoquer, saluent l'importance du film : LIMA, Pedro. «O Momento é chegado » in O Cruzeiro, Rio de Janeiro, 28/04/1962. SPIEWAK, J.J. «A Falecida » in Diário de São Paulo, São Paulo, 02/12/1965.

430 C'est plus que Barravento et Bahia de todos os santos (entre 3 et 4 millions) mais c'est plus de deux fois moins que Assalto ao trem pagador dont le budget est lui-même inférieur aux plus gros budgets du cinéma brésilien de l'époque qui dépasse 25 millions. Voir : PAIVA, Salvyano Cavalcanti de. « Feiura para filme bonito e beleza em filmes medonhos » in Correio da manhã, Rio de Janeiro, 24/01/1962. 
auxiliaire ? Pourquoi Vilma, après avoir échappée au viol, se donne-t-elle spontanément à Jandir? Quelles sont les causes de la crise existentielle de Vavá ? Il apparaît également que le personnage de cafajeste bâti par Jandir n'est qu'un masque. Dans une séquence où il montre à Vavá que leurs origines sociales les opposent, dans sa confrontation avec Leda et dans sa propre solitude, le personnage offre au spectateur ses propres fissures. Nous avons enfin certaines séquences dont la présence au sein de la narration ne se justifient pas clairement comme celle de la rencontre des deux hommes avec deux jeunes filles innocentes et d'origine modeste dans un fort du bord de mer. Enfin, le film est ostensiblement amoral. Les personnages commettent un certain nombre d'actes répréhensibles sans encourir de punition au sein de la diégèse, ils ne sont pas punis pour ce qu'ils font, mais cette absence de punition ne peut pas passer pour de l'immoralisme. À aucun moment, il n'est possible de s'identifier aux personnages. D'autre part, la forme filmique ne valorise pas les nus ou la consommation de stupéfiants en cherchant à provoquer l'excitation du spectateur par le montage ou l'angle de prise de vue. Os Cafajestes s'inscrit dans l'ensemble des tentatives de transposition de l'effet de distanciation au cinéma. Résolument ouvert, le film apparaît donc comme la description froide d'événements et de personnages, au spectateur de construire la morale du film par rapport à ce qu'il ressent. La critique ne devrait donc pas porter sur la morale de la narration, car il n'y en a pas, mais sur la « sélection» des personnages ainsi que l'authenticité et la pertinence de l'expression cinématographique qui est atteinte.

Dès sa sortie, Os Cafajestes provoque des réactions violentes qu'il est intéressant d'étudier. La première est celle de la censure du film, quelques jours après sa sortie, par le chef de la police de l'État de Guanabara ${ }^{431}$. La situation est, à plusieurs titres, paradoxale même si elle n'est pas inédite. Dans le Brésil de la "parenthèse démocratique » (1953-1964), il arrivait en effet que le Chef de la Police outrepasse ses prérogatives et fasse interdire un film qui avait par ailleurs été libéré par les institutions officielles de censure. Le cas s'était déjà présenté avec Rio, quarenta graus en 1955. Nous avons donc d'un côté, la censure qui autorise la projection du film dans les salles avec d'éventuelles restrictions d'âge, et, d'un autre côté, une autorité locale qui peut aller à l'encontre de cette décision et faire retirer le film de l'affiche, le plus souvent sous la pression des ligues morales de la ville, voire, sur le conseil indigné de sa propre femme ${ }^{432}$. Os Cafajestes est ensuite interdit dans l'état de Minas Gerais,

431L'état de la Guanabara correspond en fait aux limites de la ville de Rio de Janeiro. Si Rio n'est plus la capitale fédérale du Brésil depuis l'installation officielle de Brasília, elle en garde dans les faits les caractéristiques administratives jusqu'à la fin des années soixante. L'actuel état de Rio de Janeiro est le fruit de la fusion de l'état de la Guanabara, ancien district fédéral, et de l'état de Rio de Janeiro qui, paradoxalement, n'incluait pas la ville qui lui donnait son nom. La fusion date de 1974. Rio de Janeiro est le lieu réel du pouvoir et de résidence des présidents de la République jusqu'à la fin des années soixante.

432D'innombrables anecdotes sur lesquelles nous aurons l'occasion de revenir, démontre la désinvolture et l'autoritarisme avec lesquelles les autorités pouvaient intervenir. Cette situation, comme nous le voyons ici, 
cette fois-ci sur l'initiative de son gouverneur, Magalhães Pinto. Le premier paradoxe est donc institutionnel. Le second est géographique. Os Cafajestes est interdit dans deux états du Brésil mais pas dans tous les autres. Lorsque l'on habite à Rio de Janeiro, il est facile de traverser la baie qui sépare l'ancienne capitale du Brésil de Niterói, alors capitale de l'état de Rio de Janeiro, et d'aller voir le film dans cette ville où il n'est pas interdit. Cette situation n'est pas, cependant, très satisfaisante. Dans les journaux, la controverse porte sur l'interdiction du film et, logiquement, sur le film lui-même.

Os Cafajestes divise la critique selon plusieurs lignes de force. La première est la question de l'interdiction. Une part de la critique, moraliste et conservatrice, appuie pleinement les mesures prises par les autorités et attaque sans ménagement le film et ses défenseurs. Parmi eux, nous avons des habitués de la critique de cinéma mais aussi des personnalités dont ce n'est pas le domaine. Tous sont liés aux associations catholiques et conservatrices. Humberto Didonet, de Porto Alegre, résume le point de vue de ses pairs dans une critique intitulée : «Filme formalista, inautêntico, desonesto e repugnante " ${ }^{433}$ (Film formaliste, inauthentique, malhonnête et répugnant). Guido Logger rapproche le film d'autres longs métrages ayant pris pour thématique la jeunesse et s'offusque du fait que Guerra ne condamne pas clairement ses deux personnages principaux :

«Os Cafajestes é um filme horrivelmente vazio. É um registro frio, sem vida, das bestialidades humanas, mais frio ainda que Um Dia de elouquecer de Bolognini. Este pelo menos acusa um determinado mundo corrompido, ainda tem um final esperançoso. $»^{434}$

Dans le Jornal do Brasil, l'avocate Maria Rita parle de « désintégration morale ». Ses arguments sont les mêmes que les autres. Le film montre des personnages pratiquant le mal corruption, usage de drogue, chantage, nudisme - sans condamnation morale explicite. Pire, l'absence de cette condamnation représente un encouragement à pratiquer de tels actes. Audelà de l'absence de position morale, elle juge que le film va à l'encontre même des notions d'art et de civilisation. Rita réclame que les auteurs du film soient punis et le film détruit, sa conclusion est éloquente :

« Nesse jornal de sarjeta, entretanto, nada há de belo, nem mesmo de horrível : há só e só imundicie. E como de sujeira estamos todos fartos, só um destino merece aquele pasquim filmado - a destruição.

ne date pas de l'instauration de la dictature. La peur de la censure et des réactions intempestives de telle ou telle personnalité date justement des mésaventures de Rio, quarenta graus et Os Cafajestes.

433DIDONET, Humberto. «Filme formalista, inautêntico, desonesto e repugnante » in Jornal do dia, Porto Alegre, 11/12/1962.

434«Os Cafajestes est un film horriblement vide. C'est l'enregistrement froid, sans vie, des bestialités humaines, plus froid encore que Um Dia de enlouquecer [?] de Bolognigni. Celui-ci, qui présente au moins le mérite d'accuser un certain monde corrompu, termine aussi avec un final porteur d'espoir. » in LOGGER, Guido. «O Mito da juventude moderna e Os Cafajestes » in O Dia, Rio de Janeiro, 13/05/1962. 
A sociedade da Guanabara, beija as mãos de S. Eminência, o Cardeal D. Jaime Câmara, pela iniciativa de defendê-la, inspirando a proibição e aplaude no Dr. Newton Marques Cruz, mais este exemplo de exação no cumprimento do dever. $»^{435}$

Le même cardinal, qui dit ne pas avoir vu le film, répète sa condamnation deux mois plus tard en se basant sur les témoignages de «personnes de confiance » :

« Se a Lei Magna nos obriga a defender a família, se o Código Penal estabelece severas sanções para os que atentarem contra o pudor público, não vejo como poderia ser permitida a exibição daquele enxurrada de torpezas. Houve, para vergonha nossa, um juiz que considerou inofensivo o filme. Terá filhos esse juiz ? Permitiria que sua família assistisse à cenas tão degradantes ? Ou pertence, também, à quinta-coluna soviética, que até na magistratura já penetrou ? $\gg^{436}$

Les réactions hostiles à Os Cafajestes mettent en évidence les contradictions importantes existant au sein de la société brésilienne. Comme le note Cláudio Mello e Souza dans son article contre l'interdiction du film :

« ... de repente, fomos chamados à realidade : fizeram-nos lembrar de que estávamos no Brasil, e não naquele país desejoso de civilização, para onde nos haviam conduzido as discussões em torno de um filme, coisa insólita em nosso País. De repente, leitor, um fato cultural, como o filme Os Cafajestes, se transforma num caso de polícia. $»^{437}$

La volonté de rénovation et de progrès, dans tous les domaines, y compris le cinéma, se heurte à une frange de la population pour qui le cinquième colonne soviétique est une réalité, qui considère que l'autoritarisme et la censure peuvent protéger la civilisation et les valeurs démocratiques, et qui ne voit pas de différence entre un film pornographique et $O s$ Cafajestes. À la mobilisation qui se fait par voie de presse pour l'interdiction du film, répond cependant une mobilisation toute aussi importante pour dénoncer cette violation de la liberté d'expression. Nous trouverons même parmi les opposants à l'interdiction du film, des personnes qui d'un point de vue critique, partage la même opinion que ses partisans. À savoir qu'il s'agit d'un film sensationnaliste, obscène et amoral. Cyro Siqueira, de Belo Horizonte,

435« Dans ce journal de bas-niveau, il n'y a cependant rien de beau ni même d'horrible : il n'y a que des immondices. Et, comme nous avons assez de tant de saleté, un tel pamphlet filmé ne mérite qu'un seul destin - la destruction. » in Maria Rita. « Desintegração moral » in Jornal do Brasil, Rio de Janeiro, 29/04/1962.

436 « Si la Lei Magna nous oblige à défendre la famille, si le Code Pénal établit de sévères sanctions pour ceux qui portent atteinte à la pudeur en public, je ne vois pas comment pourrait être autorisée la projection d'une telle compilation d'horreurs. Il y a eu, pour notre honte, un juge qui a considéré le film inoffensif. Ce juge aurait-il des enfants ? Permettrait-il que sa famille assiste à des scènes aussi dégradantes ? Ou, appartient-il aussi à la cinquième colonne soviétique, qui, jusque dans la magistrature, a déjà pénétré ? » in CÂMARA, Dom Jaime de Barros. «Condenado pelo Cardeal o filme Os Cafajestes » in O Globo, Rio de Janeiro, $18 / 06 / 1962$.

437 «... et soudain, nous avons été rappelés à la réalité : ils nous ont fait nous souvenir que nous étions au Brésil, et non dans ce pays avide de civilisation, où nous avaient conduits les discussions autour d'un film, fait inédit dans notre pays. Soudain, cher lecteur, un fait culturel, comme le film Os Cafajestes, se transforme en affaire policière. » in MELLO E SOUZA, Claudio. «A Censura a Os Cafajestes » in Jornal do Brasil, Rio de Janeiro, 17/04/1962. 
réagit à l'interdiction du gouverneur Magalhães Pinto :

«Devo dizer que vi Os Cafajestes em uma sessão especial à qual estiveram presentes vários oficiais da Polícia Militar do Estado que me parecem haver saido do cinema dotados dos mesmos principios morais anteriores à exibição. Confesso que, pessoalmente, o filme me deu a impressão de não passar, ele próprio de uma simples cafajestada. Por falta de principios morais, os realizadores da fita fizeram um 'pastiche' trivial de vários filmes europeus. $)^{438}$

Ce qui est plus troublant, c'est que parmi les membres du Cinema Novo, si l'on dénonce également la censure ${ }^{439}$, le film n'est pas unanimement apprécié. Premièrement, $O S$ Cafajestes est critiqué pour son cosmopolitisme et son formalisme, certains ne voient en lui qu'une pâle imitation de la Nouvelle Vague et une démonstration de la virtuosité de Guerra. Autrement dit, le film ne sert pas ce qui serait le versant culturel du Cinema Novo, à savoir la défense de la culture brésilienne. Le film est aussi rapproché de ceux de Walter Hugo Khoury et Rubem Biáfora, autrement dit l'école universaliste et intimiste comprise comme adverse au Cinema Novo. Comme pour confirmer ces critiques, les partisans de cette école accueillent très bien le premier long métrage de Guerra ${ }^{440}$. Notons également que Rogério Sganzerla, futur réalisateur et leader du Cinema Marginal, écrit de longs articles, dithyrambiques, sur $O s$ Cafajestes dans lesquels il abonde dans le sens d'une interprétation intimiste, existentielle et métaphysique. Pour lui, Os Cafajestes est avant tout un film sur l'impossibilité de l'amour, il n'établit aucune relation avec une éventuelle contestation politique et sociale qui serait contenue dans le film ${ }^{441}$.

La deuxième ligne de force qui divise la critique porte donc sur la validité idéologique du long métrage dans un contexte entendu comme pré-révolutionnaire. Celle-ci est très diversement appréciée car le film donne lieu à des interprétations totalement divergentes. L'heure, on le sait, n'est pas au formalisme et si le film est tenu pour formaliste, sa validité politique est nulle. David Neves exprime clairement cette posture dans sa critique :

438« Je dois dire que j'ai vu Os Cafajestes au cours d'une projection spéciale à laquelle assistaient également plusieurs officiers de la Polícia Militar de l'état qui m'ont paru sortir du cinéma dotés des mêmes principes moraux que ceux qu'ils possédaient avant de voir le film. Je confesse, personnellement, que celui-ci ne m'a pas donné l'impression d'être autre chose qu'une escroquerie. Par manque de principes moraux, les réalisateurs du film, firent un pastiche trivial de plusieurs films européens. » in SIQUEIRA, Cyro. «A Proibição de Os Cafajestes » sans source, 22/08/1962.Ely Azeredo recueille les propos de Nelson Pereira dos Santos, Rocha, Paulo César Saraceni, Miguel Borges et Alex Viany, tous en défense de la liberté d'expression. Voir aussi : NEVES, David. « União e censura cultural » sans origine, Rio de Janeiro, 28/04/1962.

439AZEREDO, Ely. « Cinema exige liberdade » in Tribuna da imprensa, Rio de Janeiro, 17/04/1962. 440« Os Cafajestes (Conclusão) » in Diário de São Paulo, São Paulo, 05/06/1962.

WINGE, Hélio Lima Carlos. « Os Cafajestes e o sentimento da realidade » in Diário de notícias -Suplemento Literário, sans lieu, sans date.

441SGANZERLA, Rogério. « Revisão de Os Cafajestes I » in O Estado de São Paulo-Suplemento literário, São Paulo, 04/01/1964.

SGANZERLA, Rogério. «Revisão de Os Cafajestes II » in O Estado de São Paulo-Suplemento literário, São Paulo, 11/01/1964. 
«Os Cafajestes segue a trilha de Walter Hugo Khoury (Na Garganta do diabo), Rubem Biáfora (Ravina) e Jorge Ileli (Mulheres e milhões). Os simbolismos de Bergman mal digeridos e pior ainda, refundidos no Brasil, usados pelos dois membros da escola sueca com filial nacional. Já o filme de Ileli é 'chanchada' envolta em policial norte-americano. No caso de Ruy Guerra há uma corajosa divisão. O movimento vertiginoso de seu início, os atos gratuitos, os trejeitos dos atores copiados de Belmondo, tudo calcado na 'nouvelle vague'. E a lentidão do meio para o fim, querendo chegar ao vazio estribado em um Antonioni mal assimilado. São influências que retiram a personalidade que todo diretor deve possuir. A história é limitada e superada ao relatar uma minoria deslocada e que não quer dizer nada no quadro humano povoado de problemas cruciais como é a cidade do Rio de Janeiro. O cinema novo, como bem conceituou Paulo Emílio Sales Gomes, deve estar dentro de um esquema social atual e de efeitos imediatos para conflitos presentes. $\mathrm{O}$ homem comum que integra uma maioria é que precisa ser foco de todas as preocupações. Já passou o tempo do cinema inútil, sem o menor sentido de comunicação porque não trata de nada sério, ficando na frivolidade marginal. $»^{442}$

Les critiques qui discutent la validité du film en tant que dispositif de prise de conscience des mécanismes maintenant les inégalités sociales du pays sont nombreuses ${ }^{443}$. Au mieux, comme Maurice Capovilla, admet-on que le film fournit un témoignage authentique sur un groupe de personnes marginales et aliénées. Mais, cela ne suffit pas à en faire une œuvre pertinente dans le contexte de 1962. Dahl lui-même, dans une lettre qu'il adresse à Rocha, note qu'il n'a pas aimé le film car les personnages sont vus isolés du monde ${ }^{444}$. C'est pourtant ce même Rocha qui prend la défense du film comme étant une œuvre qui participe bien de la lutte contre l'aliénation sociale et culturelle ${ }^{445}$. Selon lui, des détails glissés de façon

442«Os Cafajestes emprunte le même chemin que celui qui a déjà été emprunté par Walter Hugo Khoury ( $A$ Ilha), Rubem Biáfora (Ravina) et Jorge Ileli (Mulheres e milhões). Les symbolismes d'un Bergman mal assimilé et, pire encore, transposés au Brésil et utilisés par les deux membres de l'école suédoise avec filière nationale. De son côté, le film d'Ileli est une chanchada habillée en film policier nord-américain. Dans le cas de Ruy Guerra, il s'opère une courageuse division. Le mouvement vertigineux de son introduction, les actes gratuits, les manières des acteurs copiées sur Belmondo, tout est calqué sur la ' nouvelle vague '. Enfin, la lenteur du milieu vers la fin voulant amener au vide d'un Antonioni mal assimilé. Toutes ces influences retirent la personnalité que tout directeur devrait posséder. L'histoire est limitée et dépassée dans sa volonté de décrire une minorité extraite de son milieu et n'apporte rien du point de vue des problèmes cruciaux que connaît une ville comme Rio de Janeiro. Le cinema novo,, comme l'a bien conceptualisé Paulo Emílio Sales Gomes, doit faire référence à la situation sociale actuelle et avoir des effets immédiats dans les conflits du présent. L'homme commun qui intègre une majorité doit être le centre de toutes ses préoccupations. Il est déjà dépassé le temps du cinéma inutile, sans la moindre intention de communication parce qu'il ne traite de rien de sérieux, restant dans le cadre d'une frivolité marginale. » in NEVES, David et OLIVEIRA, José Eduardo Marques de. «Cafajestes duas vezes » in Revista de Cultura Cinematográfica, Belo Horizonte, n³2, mai-août 1962.

443CAPOVILLA, Maurice. « Testemunho não é acusação » in Revista Brasiliense, São Paulo, n², juillet-août 1962.

LEFÈVRE, Antonio Silvio. « Cinema-nôvo » in O Estado de São Paulo - Suplemento literário, São Paulo, 12/08/1964.

MARTINS, Carlos Estevam. « Artigo vulgar sobre aristocratas » in Diário de notícias, Salvador, 1962. MELLO E SOUZA, Claudio. «Sob o signo de $O$ Pagador cinema brasileiro é uma boa promessa para $1963 »$ in Jornal do Brasil, Rio de Janeiro, 27/12/1962.

PEREIRA, Geraldo Santos et PEREIRA, Renato Santos. « Breve introdução a um filme polêmico : Os Cafajestes » in Diario Carioca, Rio de Janeiro, 06/04/1962.

SANZ, José. «Festival de Berlim » in Revista de Cultura Cinematográfica, Belo Horizonte, n³2, mai-août 1962.

444Lettre datée du 10/03/63. In ROCHA, Glauber. Cartas ao mundo. São Paulo, Companhia das letras, 1997, p. 189.

445ROCHA, Glauber, BORGES, Miguel. « Os Jovens fazem cinema » in Metropolitano, Rio de Janeiro, 1962. ROCHA, Glauber. «Cinema Novo arrebata o Brasil » in Diário de notícias, Salvador, 08/04/1962. 
subreptice et intentionnelle produisent un impact politique :

« Nada do ponto de vista tradicional na ficção acontece. As coisas todavia se processam no ritmo de um domingo. [...] No plano inicial de Jandir e Vavá no carro, Vavá lê um jornal onde um título surge, discreto mas evidente : 'Dois mortos'. Valeria fazer um filme sobre 'Dois mortos' no momento de hoje, aquele momento conflagrado que o rádio anuncia no plano final ? Eis aí onde reside, fundamentalmente, o ponto polêmico de Os Cafajestes e sobretudo a coragem de Miguel Torres, Jece Valadão e Ruy Guerra em fazer um filme que retrata cruelmente uma classe brasileira alienada, marginal e neurótica, sem refletir um só momento sobre sua condição. $»^{446}$

\section{Et plus loin :}

«Considero deste ponto de vista, Os Cafajestes um filme político e mais do que isto um dos mais violentos impactos já acontecidos na cultura brasileira. A atitude crítica dos autores é evidente no comportamento da câmera. Um cinema de análise que nunca emociona. Um cinema de opressão que adquiri tremendo força simbôlica no 'travelling' circular que os cafajestes desenvolvem sobre Norma Benguell na praia : a mulher acuada, uma forma escultural de extrema beleza a um passo da tragédia. $\gg{ }^{447}$

Rocha et Capovilla ont des interprétations opposées en s'appuyant sur les mêmes éléments du film : la séquence du journal et la séquence finale dans laquelle Jandir s'éloigne de sa voiture en panne sèche alors que le journal radiophonique traite, en autres, de l'impérialisme américain en Amérique du Sud et de la guerre d'Algérie. Autant de sujets dont il nous ait montré que les personnages sont aliénés. Alors que Jandir quitte sa voiture, curieusement, il n'éteint pas la radio et le son continue à nous parvenir clairement malgré l'éloignement croissant. Pour Rocha, ces éléments montrent que le film, en plus d'amener une rupture esthétique dans l'histoire du cinéma brésilien, est porteur d'un regard critique sur la société. Ces deux caractéristiques en font pour lui un parfait exemple de Cinema $\mathrm{Novo}^{448}$.

D'autres critiques partagent son analyse ${ }^{449}$. En insistant sur le fait que les personnages sont en marge de l'histoire, le film interroge le spectateur sur sa position. Est-il aussi aliéné qu'eux ? Sont-ils vraiment des marginaux ou une face cachée de la société ? L'aliénation des

446« Rien d'habituel n'arrive du point de vue de la fiction traditionnelle. Aussi, les événements se déroulent au rythme d'un dimanche. [...] Dans le plan du début, Jandir et Vavá en voiture, Vavá lit un journal sur lequel surgit un grand titre, discret mais évident, ' Deux morts '. Cela vaut-il la peine de faire un film sur ' Deux morts ' dans le moment actuel, dans ce moment caractérisé par ce que la radio annonce dans le plan final ? C'est ici que réside, fondamentalement, le point polémique de Os Cafajestes et surtout le courage de Miguel Torres, Jece Valadão et Ruy Guerra à faire un film qui décrive cruellement une classe brésilienne aliénée, marginale et névrosée, qui ne réfléchit pas un seul instant sur sa propre condition. »

447 « Je considère de ce point de vue, Os Cafajestes comme un film politique et, plus encore que cela, comme l'un des plus violents impacts déjà arrivés dans la culture brésilienne. L'attitude critique des auteurs est évidente dans le comportement de la caméra. Un cinéma d'analyse qui ne provoque jamais l'émotion. Un cinéma d'oppression qui acquiert une force symbolique fantastique dans le ' travelling ' circulaire que les cafajestes parcourent autour de Norma Benguell sur la plage : une femme acculée, une forme sculpturale de beauté à un pas de la tragédie. » in ROCHA, Glauber. « Cinema Novo arrebata o Brasil » in Diário de noticias, Salvador, 08/04/1962.

448ROCHA, Glauber. « Cinema Novo, fase morta (e crítica)» in O Metropolitano, Rio de Janeiro, 26/09/1962. 449« Estilo e coragem num filme singular : Os Cafajestes » in Diário de São Paulo, São Paulo, 26/05/1962. OLIVEIRA, Júlio José de. «A Verdade proibida de Os Cafajestes » in Diário de notícias -Suplemento Literário, sans lieu, sans date. 
personnages du film renverrait à celle du spectateur. Ely Azeredo, corrobore cette thèse en adoptant une approche complémentaire à celle de Rocha. Il montre en effet que Os Cafajestes illustrerait les théories de Brecht sur le «spectateur-marchandise $»^{450}$. En contrariant les attentes communes du spectateur de cinéma dans sa quête d'évasion et en mettant en évidence ce qu'est le cinéma dans la société de consommation, Os Cafajestes permettrait de prendre conscience que les questions de goûts ne peuvent être considérés en dehors des relations de classe et qu'elles sont bien des marchandises et des moyens de lutte :

«O processo industrial exige para sua sobrevivência que a mercadoria seja consumida em massa, e, portanto, a fantasia coletiva deve permanecer ' fiel ' à forma. Com isso, o desenvolvimento do cinema se realizou segundo os cânones mágicos que promovem a ' identificação ' com os personagens e o sentido de ' participação'. Durante a projeção, cada espectador se julga proprietário do filme (o que equivale a dizer : do que o filme contém), quando, em verdade, é possuído. Possuído em dois sentidos : o mágico e o místico ; e o econômico. $»^{451}$

En refusant de jouer le jeu du cinéma classique, Os Cafajestes révélerait donc aux spectateurs leur propre aliénation. Selon Azeredo, les réactions violentes suscitées par le film en serait la preuve, Os Cafajestes choque alors que c'est le cinéma dominant qui devrait choquer :

« A doutrinação política disfarçada, a propaganda de sistemas de vida que não são nem podem ser nossos, o culto da violência gratuita, a neurose do ' sucesso pessoal ' - tudo o que há de mais nocivo pulula na produção comercial é recebido pelo espectador-médio com o ar passivo ou comovido de quem está em saudável relaxation ou presencia uma súmula da ' Comédia Humana '. ${ }^{452}$

S'il nous faut bien convenir que Os Cafajestes nous apporte peu d'informations sur la situation économique et sociale du pays, l'argumentation d'Azeredo, l'idée selon laquelle il empêcherait de "consommer en rond», est assez convaincante. Plus peut être que celle de Rocha, selon laquelle l'aliénation des personnages renvoie à celle du spectateur. La réaction des ligues conservatrices et des autorités confirme d'ailleurs l'importance de cette dénonciation du «spectateur-marchandise ». En provoquant comme aucun autre film, la furie

450BRECHT, Bertold. « Le Procès de L'Opéra de quat'sous » in Cahiers du cinéma, n 114 .

451 «e processus industriel exige pour sa survie que la marchandise soit consommée en masse, et, pour cette raison, la fantaisie collective doit rester ' fidèle ' à la lettre. Avec ceci, le développement du cinéma s'est réalisé selon des critères magiques qui promeuvent ' l'identification ' avec les personnages et le sentiment de ' la participation '. Durant la projection, chaque spectateur se juge propriétaire du film (ce qui revient à dire : de ce que le film contient), quand, en vérité, il est possédé. Possédé dans deux acceptions : le magique et le mystique ; et l'économique. » in AZEREDO, Ely. " Contra o espectador-mercadoria » in Tribuna da imprensa, Rio de Janeiro, 10/04/1962.

452 « L'endoctrinement politique dissimulé, la propagande de modes de vie qui ne sont ni ne peuvent être les nôtres, le culte de la violence gratuite, la névrose du ' succès personnel ' - tout ce qu'il y a de plus nocif et qui pullule dans la production commerciale est reçu par le spectateur moyen avec l'air passif ou ému de celui qui s'adonne à une saine relaxation [en français dans le texte] ou assiste à une manifestation de la ' Comédie Humaine '. » 
de cette frange de la population qui soutiendra le coup d'État militaire, Os Cafajestes montre qu'il est partie prenante dans le combat invisible qui est déjà engagé. La qualité du film ne vient pas seulement $\mathrm{du}$ fait qu'il constitue une agression contre le puritanisme et le conservatisme de la société, mais du fait qu'il pratique une nouvelle approche de l'homme et du cinéma. Oser un autre regard sur la sexualité dénué du traditionnel moralisme et dénoncer le mystification cinématographique apparaissent alors comme d'authentiques domaines de lutte. Os Cafajestes ouvre la voie d'un cinéma de conscientisation ouvert aux innovations du cinéma moderne. Cette voie sera poursuivie avec Porto das Caixas.

\section{Porto das Caixas}

Au contraire d'autres films du Cinema Novo qui lui sont contemporains, Porto das Caixas est déjà une proposition claire et assumée de la praxis cinématographique vers laquelle celui-ci peut évoluer. Aucune ambiguïté ne subsiste quant à une éventuelle orientation vers le cinéma militant ou le réalisme socialiste. Nous allons vers un cinéma non plus d'action immédiate mais de réflexion, de doute, de remise en cause des certitudes acquises, de recherche d'un réel social dont on sait par avance que l'appréhension est peu sûre. Il s'agit de critiquer les axiomes politiques, de droite ou de gauche, sur lesquels s'appuient généralement les discours. Cette réflexion n'exclut pas l'action qui vient dans un second temps et qui reste présente dans l'espace extra-diégétique. Le Cinema Novo n'appelle jamais à la simple jouissance des sensations que le spectateur peut ressentir à la vision d'un film. Il n'est jamais non plus seulement informatif ou réflexif. À l'image des œuvres à venir, Porto das Caixas est un discours organisé de façon à provoquer une réflexion qui, elle-même, appelle à l'action. La vision du film est destinée à provoquer une remise en cause et constitue parallèlement une provocation à agir ou à réagir. Trois éléments concourent à ce résultat :

- c'est l'histoire d'une libération ;

- au contraire de Bahia de todos os santos, la fin du film suggère un avenir meilleur ${ }^{453}$;

- de nombreux éléments de distanciation contraignent le spectateur à adopter une position critique.

Mais comme aussi les prochains films du Cinema Novo, la démarche adoptée est marquée par un éloignement apparent ${ }^{454}$ des problématiques politiques principales du Brésil en 1962. Alors que la mobilisation sociale atteint des niveaux rarement atteints dans l'histoire

453Dans Bahia de todos os santos ou dans Os Cafajestes, la structure narrative est circulaire, nous revenons au point de départ, ce n'est pas le cas de Porto das Caixas dans lequel le personnage subit une transformation décisive et positive.

454Une relation symbolique pourra toujours être établie entre la libération d'un personnage et celle du pays comme un tout. 
du Brésil et que le pays vient d'échapper à un premier coup d'état avec le refus des ministres militaires de laisser João Goulart assumer ses fonctions de président, la caméra investit une ville fantôme en marge de ce processus. Porto das Caixas est une petite ville déserte, abandonnée par le progrès et où la réforme agraire est le sujet de discussion de quelques hommes soûls et misérables.

L'idée initiale de Saraceni était de filmer un roman de Lúcio Cardoso, A Casa assassinada, et, pour cela, il avait déjà rencontré l'auteur afin de discuter avec lui de son projet. Celui-ci ne sera réalisé que dix ans plus tard. Dès leur première rencontre, le cinéaste et l'écrivain deviennent amis, et, devant l'impossibilité de filmer A Casa assassinada ${ }^{455}$, Cardoso propose d'écrire une histoire originale sur la ville de Porto das Caixas qu'ils ont traversé en train lors d'un voyage dans l'état de Rio de Janeiro. Saraceni adapte le nouveau texte sous la forme d'un scénario et prévoit un budget de 6 millions de Cr\$ (environ 12 mille dollars), une somme nettement inférieure aux budgets moyens du cinéma brésilien de l'époque. Le devis établi, il reste donc à trouver une source de financement. C'est chose faite après la rencontre du cinéaste avec Elísio Freitas avec lequel s'engage une relation de mécénat. Comme pour d'autres films du Cinema Novo, le réalisateur devient co-producteur en acceptant d'échanger un éventuel cachet contre une part des recettes devant revenir au producteur.

Le tournage commence à la fin du premier semestre de l'année 1962, peu de temps après la victoire de O Pagador de promessas à Cannes. Le film est projeté fin octobre 1962 au festival du cinéma brésilien organisé à Salvador ${ }^{456}$ mais il ne sortira dans les salles qu'un an plus tard, fin septembre $1963^{457}$, suite aux violentes polémiques qu'il suscite et à la frilosité des exploitants de salles. Il raconte l'histoire d'une belle jeune femme mariée à un fonctionnaire des chemins de fer qui habite avec elle une maison misérable dans une petite ville perdue (Porto das Caixas). La station ferroviaire, une fabrique abandonnée et un parc d'attractions désert laissent penser que la cité a connu des jours meilleurs. Écrasée par cette vie sordide et sans perspective, la jeune femme prémédite l'assassinat de cet époux dont la médiocrité fait écho au marasme ambiant. Le tuer devient une obsession et apparaît comme l'irrationnel exutoire de ses sentiments de révolte. Un simple accident domestique lui révèle

455Sur l'historique de Porto das Caixas, voir : SARACENI, Paulo César. Por dentro do Cinema Novo - Minha Viagem. Rio de Janeiro, Nova Fronteira, 1993, pp. 126-143. L'auteur ne donne pas de précisions quant à l'abandon de l'adaptation du roman autre qu'un budget estimé par avance trop important. Le scénario pourtant était prêt.

456 GOMES, Paulo Emílio Sales. «Crimes que compensam » in O Estado de São Paulo - Suplemento literário, São Paulo, 10/11/1962.

457 25/09/1963 : Projections commerciales de Porto das Caixas à Rio de Janeiro dans les cinémas Monte Castelo et Pirajá. In AZEREDO, Ely. « Porto das Caixas : Explicações agravam um filme indefensável » in Tribuna da imprensa, Rio de Janeiro, septembre 1963. 
quel doit être l'arme du crime : une hache. Usant de ses pouvoirs de séduction, elle demande alors successivement à son amant, à un soldat de passage et au barbier de l'aider. Tous se refusent à commettre un tel acte. Finalement, elle tuera son mari de sa propre main, pendant le sommeil de celui-ci et sous les yeux stupéfaits et terrorisés de son amant. Ce dernier, qui s'était dérobé juste avant le passage à l'acte, ne peut alors plus la suivre. Elle-même s'éloigne dans la brume matinale en marchant le long d'une voie ferrée, éclairée par le soleil de l'aube. Le dépouillement de la scénographie, les ambiances nocturnes, les clairs-obscurs, les tonalités grises et noires de la photographie, la rareté des dialogues et le faible nombre de personnages, les temps morts et les plans-séquences, tout contribue à traduire la décadence et l'aspect sordide de cet univers de périphérie. Le rythme très lent du montage, cette insistance sur le pénible écoulement du temps, l'absence même d'action soudainement rompue par le brusque passage à l'acte final, situent le long métrage aux antipodes des autres productions de l'année.

Selon ses propres termes, l'intention de Saraceni était de filmer une parabole sur la misère du pays et la révolution qu'il fallait faire ${ }^{458}$. Le personnage féminin, comme dans la suite de son œuvre, possède une importance particulière. Ici, l'enfermement de la femme dans une condition subalterne est mis en relation avec l'absence de perspectives offerte par une société sous-développée et machiste. Pour cette raison, la libération de la femme passe par le meurtre du mari et la séparation d'avec l'amant, il ne s'agit pas seulement pour la femme de passer d'une situation de pauvreté à une situation de moins grande pauvreté, ou de remplacer un homme qu'elle n'aime pas par un autre qu'elle aime plus, mais de rompre avec une situation de subordination devenue insupportable et qui s'identifie avec sa misère matérielle et affective. La révolution à laquelle pense Saraceni est féministe, anarchique et violente :

«Um filme revolucionário não pode ser organizado e panfletário como quer o CPC, com palavras de ordem como reforma agrária, mais-valia etc. Terá que ser uma revolta anárquica, mística, inconsciente, espiritual e com a cara do povo brasileiro. É preciso dar esse grito inconsciente para chegar a consciência do povo. Eu queria uma revolução e não uma reforma agrária que o povo esfomeado e analfabeto não sabia o que era. A mulher de Porto das Caixas precisava da redenção da miséria. E só pelo crime ela podia se salvar. $»^{459}$

La réception du film divise profondément la critique et le CPC. Le film reçoit le prix

458SARACENI, Paulo César. Por dentro do Cinema Novo - Minha Viagem. Rio de Janeiro, Nova Fronteira, 1993, p. 136.

459« Le film révolutionnaire ne peut pas être structuré et pamphlétaire comme le veut le CPC, avec des mots d'ordre comme réforme agraire, plus-value etc. Il devra être une révolte anarchique, mystique, inconsciente, spirituel et avec le visage du peuple brésilien. Je voulais une révolution et pas une réforme agraire dont le peuple affamé et analphabète ignorait le sens. La femme de Porto das Caixas avait besoin de cette rédemption par la misère. Et elle ne pouvait se sauver que par le crime. » in SARACENI, Paulo César. Por dentro do Cinema Novo - Minha Viagem. Rio de Janeiro, Nova Fronteira, 1993, p. 137. Bien qu'elle soit de trente ans plus vieille que le film et qu'il entre en elle beaucoup de la réflexion postérieure à la conception de Porto das Caixas, cette déclaration est assez fidèle à ce que pouvait représenter le film pour Saraceni à l'époque où il n'était pas encore capable de l'exprimer aussi clairement. 
de la critique au festival de Salvador à la fin octobre 1962. Il est très chaleureusement reçu par Sales Gomes qui écrit à son sujet plusieurs articles élogieux. Le fondateur de la Cinemateca Brasileira a eu l'occasion de voir une copie de travail à son retour du Festival de Florianópolis, en septembre 1962. À la fin de son compte-rendu enthousiaste sur le festival, il consacre un grand paragraphe à Porto das Caixas, qui, après Arraial do Cabo et Couro de gato, confirme à son avis l'existence du Cinema Novo. Il conclut par les lignes suivantes :

« Aquela Bovary que o contexto do subdesenvolvimento torna feroz, aquela fascinante e atroz Capitu suburbana é o primeiro grande personagem feminino nascido no cinema brasileiro. Para não asfixiá-lo dentro ou fora de mim, tão cedo não vou tentar definir o Cinema Brasileiro mas ele existe. $»^{460}$

Dans un second article au titre évocateur, "Crimes que compensam », il dresse le compte-rendu du Festival de Salvador et nous fait part de ses observations quant aux différences de réception entre Porto das Caixas et Assalto ao trem pagador. Selon lui, Porto das Caixas déçoit car il est un film qui déjoue les attentes du spectateur quant au doute conventionnel qu'il doit toujours y avoir vis à vis de la fin d'un film et sur le franchissement des obstacles qui incombe au personnage principal. L'émotion ne jaillit pas selon les procédés dramatiques usuels et, par conséquent, le spectateur se retire. Cette constatation ne l'incite pas à retirer son appui au film qu'il considère comme « o mais estimulante realizado na atual fase renovadora do cinema brasileiro. $»^{461}$

Parallèlement, une avant-première est organisée à Rio par Elísio Freitas, qui souhaite, après les trois grands succès de l'année, tirer parti de la "mode» du film brésilien. Une séance est prévue dans un cinéma de 600 places, 3000 personnes vont s'installer comme elles le peuvent dans une atmosphère survoltée. Le public est composé par l'intelligentsia locale et les curieux attirés par la renommée acquise par Saraceni grâce au succès d'Arraial do Cabo dans les festivals. Les cinemanovistas sont présents ainsi que les cepecistas qui nourrissaient déjà un fort ressentiment envers Saraceni, du fait, entre autres, de son parti-pris pour le cinéma d'auteur et de ses fortes critiques à l'encontre de $O$ Pagador de promessas. Le film provoque des réactions violentes, huées, applaudissements, Oduvaldo Viana Filho jette un chat qu'il avait amené exprès au milieu du public pendant la projection ${ }^{462}$. Disputes et provocations opposent $\mathrm{CPC}$ et Cinema Novo. La répercussion de cette avant-première est

460 « Cette Bovary qui, dans le contexte du sous-développement, devient féroce, cette fascinante et atroce Capitu suburbaine est le premier grand personnage féminin du cinéma brésilien. Pour ne pas l'étouffer en moi ou endehors de moi, je ne vais pas tenter de définir le Cinéma Brésilien si précocement mais il existe. » in GOMES, Paulo Emílio Sales. « Primavera em Florianopolis » in O Estado de São Paulo - Suplemento literário, São Paulo, 06/10/1962.

461 «... le plus stimulant réalisé dans la phase actuelle de rénovation du cinéma brésilien » in GOMES, Paulo Emílio Sales. « Crimes que compensam » in O Estado de São Paulo - Suplemento literário, São Paulo, 10/11/1962.

462Témoignage de Paulo César Saraceni à l'auteur, février 2004. 
négative pour la sortie commerciale du film qui est ajournée par les Severiano Ribeiro, détenteurs d'un important réseau de cinémas et avec qui des négociations avaient déjà été entamées. Le film ne sortira qu'après son passage à la Semaine de la Critique de Cannes et au Festival de Sestri-Levante en Italie où il reçoit un prix. Nous sommes alors en septembre 1963 mais les tensions ne se sont toujours pas apaisées. Le film jouit déjà de la réputation de « film maudit ${ }^{463}$, en ce sens il est le premier d'une longue liste qui continuera avec $A$ Falecida et $O$ Padre e a moça, autrement dit de films difficiles présentant des difficultés à convaincre, et le public, et la critique. Les critiques les plus négatives viennent de Ely Azeredo ${ }^{464}$ et de Cyro Siqueira qui ne concèdent pas à Saraceni d'avoir approché de façon authentique la vie d'une ville comme Porto das Caixas et lui reprochent d'avoir préféré à la réalité l'expressionnisme le plus éculé. Siqueira déclare :

«Do caso, passa-se à aspiração suprema, o cinema observando a realidade, uma realidade brasileira, Porto das Caixas, lugarejo do interior perdido na miséria. [...] Mas Saraceni está acostumado com o cinema - e muito menos com a realidade. A desarticulação é geral, do cinema boiando numa repetição de planos vazios que nada mais fazem do que repetir o visto e o revisto, velho e velhíssimo.» ${ }^{465}$

La critique contre le recyclage de l'esthétique expressionniste rejaillit dans d'autres critiques où le film est jugé formaliste ${ }^{466}$ et, au pire, prétentieux et vide ${ }^{467}$. Pour certains, Porto das Caixas s'inscrit dans la même ambiguïté que Os Cafajestes à savoir l'égale conviction de leurs auteurs à pratiquer un cinéma politique et la distance qu'ils mesurent entre les œuvres et la situation d'urgence pré-révolutionnaire traversée par le pays.

Outre Sales Gomes, les plus ardents défenseurs de la dimension politique du film sont Rocha et José Sanz. Dans Revisão crítica do cinema brasileiro, Rocha accorde à Porto das Caixas une place prépondérante au sein du nouveau cinéma brésilien. Selon lui, le long métrage de Saraceni est l'expression même de ce que doit être un film révolutionnaire, c'est à dire engageant le spectateur à une prise de conscience et digne de contribuer à l'édification du patrimoine culturel de la nation. Son interprétation de la trajectoire du personnage principal

463MELLO E SOUZA, Claudio. « Sob o signo de O Pagador cinema brasileiro é uma boa promessa para 1963 » in Jornal do Brasil, Rio de Janeiro, 27/12/1962. Mello e Souza est le premier à utiliser l'expression de « film maudit » pour qualifier un film du Cinema Novo. Il fait alors surtout référence à la catastrophique avant-première qui a compromis l'exploitation commerciale de Porto das Caixas.

464AZEREDO, Ely. «Porto das Caixas : Explicações agravam um filme indefensável » in Tribuna da imprensa, Rio de Janeiro, septembre ou novembre 1963.

465 « D'un fait divers, nous passons à l'aspiration la plus haute, le cinéma observant la réalité, une réalité brésilienne, Porto das Caixas, un village de la campagne perdu au milieu de la misère. [...] Mais Saraceni est familier du cinéma et beaucoup moins de la réalité. Le manque d'organisation est général, son cinéma se réduit à une répétition de plans vides qui ne sont rien d'autre que du déjà vu, du vieux et du très vieux. » in SIQUEIRA, Cyro. «Porto das Caixas » in Revista de Cinema, Belo Horizonte, n³, juillet-août 1964, p. 34.

466LEFÈVRE, Antonio Silvio. « Cinema-nôvo » in O Estado de São Paulo - Suplemento literário, São Paulo, 12/08/1964.

467DUARTE, B.J. « Porto das Caixas » in A Folha de São Paulo, São Paulo, 29/09/1963. 
recoupe exactement l'intention de Saraceni :

«Porto das Caixas é um seqüência de Arraial do Cabo. Se o documentário é um ensaio antropológico da cidadezinha ameaçada pela indústria, enquanto os pescadores sofrem na primitiva labuta do mar, Porto das Caixas é a novela de outra cidadezinha, subdesenvolvida e explorada pelos políticos, onde a mulher miserável mata o marido para se libertar. Não tendo consciência a não ser de sua individualidade oprimida, a mulher concentra no marido velho e sujo a imagem absoluta da miséria que precisa ser exterminada. $»^{468}$

La défense du film par Sanz est très proche de celle de Rocha, sinon totalement identique. Tous deux concluent sur la supériorité du film de Saraceni, d'un point de vue politique, sur un éventuel cinéma pamphlétaire :

«Quanto ao 'colonialíssimo' Porto das Caixas, confesso que não entendi. Por que colonialíssimo ? Porque não trata da luta de classes, da pressão das forças econômicas, da reforma agrária, do direito de greve?

Mas Porto das Caixas trata de tudo isso, só não usa palavras de ordem nem frases convencionais da bitolada linguagem partidária. Trata de tudo isso porque trata de seres humanos esmagados por uma sociedade que nega tudo isso, que se defende eliminando sistematicamente o conteúdo latente da vida, por conseqüência, as duas maiores armas revolucionárias do homem : o amor e a revolta. $)^{469}$

Le premier long métrage de Saraceni associait pour la première fois le thème de l'aliénation à celui de la décadence, thème que nous retrouverons dans Menino de engenho et $O$ Padre e a moça. Il inaugurait aussi une structure que nous retrouverons dans Os Fuzis et $A$ Falecida dans lesquels une situation de crise est confrontée à l'impuissance des personnages et à leur inaction jusqu'à la brusque explosion finale résolvant de façon temporaire et rarement satisfaisante le conflit principal de la narration. Ce qui a beaucoup choqué dans Porto das Caixas est le montage parallèle final entre le meurtre du mari et le meeting sur la réforme agraire où quelques personnages désespérés et soûls échangent des banalités devant un parterre clairsemé. L'euphorie desenvolvimentista et le réformisme socialiste étaient ainsi violemment jetés dos à dos. L'abandon de la ville apportait la preuve que le miracle desenvolvimentista était une illusion et le meeting politique que l'entente entre les élites socialistes et le peuple était sujette à caution. L'association du meurtre à la hache et du

468« Porto das Caixas est une copie de Arraial do Cabo. Si le documentaire est un essai anthropologique sur une petite ville menacée par l'industrie, alors que les pêcheurs souffrent dans le pénible travail de la mer, Porto das Caixas est une nouvelle sur une autre petite ville, sous-développée et exploitée par les hommes politiques, où la femme misérable tue son mari pour se libérer. N'ayant d'autre conscience que celle d'être une individualité opprimée, la femme concentre sur son mari vieux et sale, l'image absolue de la misère qui doit être exterminée. » in ROCHA Glauber. Revisão crítica do cinema brasileiro. Rio de Janeiro, Civilização brasileira, 1963, p. 116.

469« Quant au ' très colonisé ' Porto das Caixas, je dois confesser que je n'ai pas compris. Pourquoi très colonisé ? Parce qu'il ne parle pas de la lutte des classes, de la pression des forces économiques, de la réforme agraire, du droit de grève ? Mais Porto das Caixas traite de tout cela, seulement, il n'utilise pas les mots d'ordre ou les phrases conventionnelles d'un langage partisan étriqué. Il parle de tout cela car il traite d'êtres humains écrasés par une société qui nie tout cela, qui se défend en éliminant systématiquement le contenu latent de la vie, par conséquent, les deux armes révolutionnaires de l'homme : l'amour et la révolte. » in CANZ, José [J.S.]. « Cinema Novo : Pedra de toque », sans origine, octobre 1962. 
meeting reste cependant ambiguë. Signifiait-on ainsi l'incapacité du peuple à se mobiliser et se prendre en charge ou l'innocuité du dirigisme socialiste ? À qui revenait la faute de ce décalage entre les nécessités du peuple et la logique des partis ? Ce décalage était-il la problématique la plus urgente à traiter en 1962 ? Les interprétations de Porto das Caixas pouvaient une fois de plus diverger mais le film devait s'avérer prophétique. Le problème rencontré en 1964 sera bien en effet celui de l'absence de correspondance entre les nécessités et les dispositions des uns et la logique et la méthode des autres. La suite montrera la pertinence de la critique du populisme et des classes moyennes qui ne surent pas réellement comprendre la force de cette « Bovary suburbaine », capable de ce qu'aucun autre personnage réel ou imaginaire ne fera : rompre.

Curieusement, et malgré les accusations d'inauthenticité et d'aliénation politique, dont cette orientation du cinéma d'auteur sans thématique politique explicite pouvait être l'objet, elle se révélera a posteriori plus lucide et peut être aussi moins ambiguë que les films plus accessibles et de thématique politique explicite. C'est ce que nous allons voir avec les films du cycle de Bahia et du CPC.

\subsection{Le cycle de Bahia}

\section{A Grande Feira et Tocaia no asfalto}

Parallèlement aux débuts de la production cinemanovista carioca, entre 1960 et 1962 , Salvador anticipe la mode du Cinema Novo par l'intermédiaire du producteur Rex Schindler qui, encouragé et orienté par Rocha, découvre Roberto Pires et finance trois longs métrages : A Grande Feira, Tocaia no asfalto et Barravento. Loin des allégories globalisantes qui domineront la filmographie du Cinema Novo, A Grande Feira aborde le problème social et politique par le fait divers, et par définition, particulier. L'histoire du film est la suivante.

Nous sommes au début des années soixante, la foire populaire de Água de Meninos, dans la partie basse de Salvador, est menacée de disparaître, rachetée par des promoteurs dont l'objectif est de moderniser les infrastructures portuaires. Les négociations qui entourent la réalisation de ce projet se font sans aucune participation de la population qui vit et travaille dans cette foire. Notons que celle-ci est aussi un centre important d'échange entre les diverses couches sociales qui composent la population de la ville. Un lieu de substitution est prévu où les commerçants de la foire pourront se réinstaller mais celui-ci est trop exigu et mal placé. La modernisation du port de Salvador risque donc fort de provoquer la ruine des petits commerçants de la foire. Cette situation nous est exposée dès la première séquence par Cuíca 
de Santo Amaro, conteur public qui retranscrit les événements de l'actualité sous forme de poèmes épiques à la mode de la littérature de cordel du sertão. Dans la séquence suivante, son exposé est complété par une discussion de bar où les différents protagonistes commentent les diverses formes de réaction que pourrait adopter la population de la foire. La lutte pour la survie de la foire permanente de Água de Meninos est donc la première ligne narrative du film. Celle-ci va d'ailleurs peu avancer puisqu'à la fin de la narration, le problème du déplacement des commerçants ne sera toujours pas réglé.

À cette première ligne narrative se superpose une seconde dont le personnage principal est un marin appelé le Suédois (O Sueco, Geraldo del Rey) en raison de ses cheveux blonds. Celui-ci se trouve de passage à Salvador au moment où les tensions montent en raison du problème de la foire. Le Suédois ne s'intéresse pas vraiment aux événements, il en est avant tout, pour le spectateur, un témoin et un commentateur. Il nous permet de transiter de l'espace de la foire à celui de la bourgeoisie et d'entendre les différents protagonistes du conflits grâce à sa personnalité et à ses aventures amoureuses. Capable de se mêler à n'importe quel milieu social, le Suédois est partagé entre deux femmes. La première, une prostituée noire appelée Maria (Luiza Maranhão), appartient au monde pittoresque des camelots et des bars populaires. Elle est aussi la petite amie de Chico Diabo (Antônio Pitanga), un bandit favorable à l'emploi de la violence pour réagir à l'expropriation des camelots. La seconde, une jeune femme de la haute société appelée Ely (Helena Ignez), emmène le Suédois dans des milieux huppés. Elle l'a rencontré lors de l'une de ses escapades dans ce qu'elle se représente être les bas-fonds. Représentante de l'ennui bourgeois et de la décadence morale de cette classe sociale, elle fréquente les milieux populaires avec ses amies dans une quête commune de sensations fortes. Le comportement de ce personnage est similaire à celui de l'anglaise, amante de Tônio dans Bahia de todos os santos.

Nous pouvons constater beaucoup d'autres similitudes avec Bahia de todos os santos, la structure narrative est très proche. Sur fond de conflit social, nous retrouvons un personnage qui évolue entre les classes antagoniques, sans vraiment vouloir prendre parti pour l'une ou pour l'autre. Cette oscillation s'identifie d'ailleurs à chaque fois avec celle de ses relations amoureuses avec deux femmes, l'une bourgeoise, l'autre d'origine populaire, qui symbolisent elles-mêmes les deux mondes entre lesquels il va et vient. Mais le véritable souci de ce personnage semble à chaque fois de conserver une relation d'extériorité avec les événements. Rejeté des communautés blanche et noire parce qu'il est métis, Tônio optait pour l'individualisme. Marin de son état, le Suédois érige sa profession en seconde nature. S'il ne peut pas rester et s'impliquer dans la vie de la cité, c'est parce qu'il est toujours sur le départ, c'est là une vocation qui s'impose à lui et il ne peut y déroger. Dans la séquence finale, il 
explique à son amante bourgeoise qu'il doit partir parce qu'il est marin, c'est son destin et il est inéluctable. Il apparaît simultanément que c'est l'inverse qui est vrai. Il est marin parce qu'il cherche à fuir la réalité et à éviter de s'investir socialement et affectivement. Être marin est un alibi facile. Cette interprétation est renforcée par son goût pour la gaudriole, son côté mythomane. Dans plusieurs séquences, devant un public naïf, il n'hésite pas à inventer ou enjoliver les aventures que ses voyages lui auraient permis de vivre ${ }^{470}$.

A Grande Feira va cependant plus loin que Bahia de todos os santos pour justifier l'absence de participation du personnage principal. Alors que dans le film de Trigueirinho Neto, le peuple est vaincu mais pugnace et rebelle, dans le film de Pires, celui-ci se révèle incapable de s'organiser pour défendre ses intérêts. D'un côté, les syndicalistes « officiels » sont ridiculisés. De l'autre, les camelots semblent incapables de créer un syndicat alternatif capables de porter leurs revendications. Enfin, au côté des solutions politiquement réformistes, d'accommodation avec les classes dominantes, la solution révolutionnaire de l'affrontement violent est incarnée par un bandit et un meurtrier ${ }^{471}$, Chico Diabo. L'amalgame est donc complet entre l'action politique violente et la criminalité. Psychologiquement, Chico Diabo nous est présenté comme un personnage qui trouve dans la révolution un alibi à l'assouvissement de ses pulsions primaires. Le film atteint son climax lorsqu'il menace de faire sauter toute la ville plutôt que de laisser la population se faire déposséder sans rien obtenir de concret. Maria meurt en emportant les bombes qu'il avait déposées contre des citernes de pétrole et dont l'explosion aurait provoqué la terrible catastrophe. L'épilogue du film commence avec une séquence au cours de laquelle le Suédois assiste à un discours de syndicalistes dans la rue et déclare qu'il resterait si le peuple était capable de faire la révolution (sous-entendu, il n'en est pas capable).

$470 \mathrm{~A}$ Grande Feira reprend partiellement l'approche brechtienne de Bahia de todos os santos en ayant recours à une personnage auquel il est impossible de s'identifier. La vantardise que nous évoquons ici, est doublée par son goût pour les victoires faciles. Quand il humilie Maria en public, il lui est facile ensuite d'adopter une attitude chevaleresque en faisant taire l'assistance et en la recouvrant d'une veste. Il manifeste aussi dans cette séquence un des traits les plus irritants de son caractère, son moralisme. Dans une autre séquence, il demande à Ely ce que ça lui fait de lui prêter les costumes de son mari et de le traiter comme un objet. Dans la séquence de l'épilogue où il déclare qu'il resterait si le peuple était capable d'une révolution, apparaît encore son moralisme. Celui-ci est souligné par la mise en scène théâtrale qui renforce l'aspect péremptoire de ses déclarations. Enfin, l'égocentrisme du personnage se transforme en égoïsme et en cruauté notamment dans ses relations avec Ely et dans son indifférence à la cause populaire après le sacrifice de Maria. La séquence de sa déclaration sur le peuple suit immédiatement la mort de Maria. Enfin, dans ses relations avec Ely, le point de vue du film est que celle-ci traverse un processus de transformation au fil des événements. Elle tombe amoureuse du Suédois et accepte de quitter sa vie de perdition au sens propre (ses virées nocturnes) et figuré (la décadence bourgeoise). Sa souffrance est tangible dans la séquence où son amant la critique et dans la séquence où il la quitte et qu'elle doit revenir à son mari.

471Dans la dernière partie du film, Chico Diabo assassine avec beaucoup de cruauté le tenancier du bar qui l'a dénoncé à la police. Ce dernier est paralytique et vit dans une chaise roulante. Sous un prétexte quelconque, il emmène le tenancier qui ignore qu'il sait qu'il est le coupable à l'extérieur du bar, puis il le conduit à la plage et l'abandonne dans la mer à une dizaine de mètres du rivage. Le lendemain, le corps est retrouvé mort sur le sable. 
Selon Rocha, l'intention du film était la suivante :

«A Grande Feira pretendeu ser - desde a primeira conversa Rex \& Roberto em dezembro, 60 - um crônica sem preconceitos da província, tendo como juiz a moral do povo, configurada na mitológica figura de Cuíca de Santo Amaro. $»^{472}$

Selon les critiques de l'époque, cette intention fut assez mal réalisée, la plupart d'entre eux, et non des moindres comme Walter da Silveira et Sales Gomes, estiment au contraire qu'il s'agit d'un film « petit-bourgeois ». Cuíca de Santo Amaro, qui ouvre et conclut le film, fustige à chaque fois les « requins » qui sont les détenteurs de capitaux qui et décident de tout au détriment des petites gens, mais les « requins » restent invisibles du début à la fin du film. Le personnage d'Ely qui symbolise la bourgeoisie, en offre une image assez caricaturale qui, peut être parce qu'elle est liée au mythe de la décadence morale, nous éclaire assez peu quant aux raisons de la classe dominante dans la gestion de l'affaire de la foire de Água de Meninos. Quelle est cette classe ? Qu'est-ce qui fait son unité ? Quels sont ses objectifs, ses valeurs, ses méthodes, sa culture ? Rien ne nous permet de pénétrer vraiment les forces en présence et les intérêts en jeu au-delà de ce que nous dit le conteur dans son exposé initial. Sur la problématique politique, le film n'avance pas, nous ne trouvons pas l'interprétation de la réalité réclamée dans le concept critique du Cinema Novo. Reste la problématique sociologique et le thème de l'aliénation revendiqué par Rocha : la bourgeoisie et le peuple souffrent d'aliénation chacun à l'extrême opposé de l'opposition dialectique ${ }^{473}$. Le vide existentiel de la bourgeoisie est confronté à l'incapacité du peuple à se mobiliser et régler ses problèmes. Cette interprétation de la situation qui pose comme acquis l'immaturité des masses populaires est d'autant plus douteuse qu'elle est contemporaine de l'apogée des ligues paysannes et d'autres mouvements populaires dans le Nordeste.

L'approche sociologique du film ne sera pourtant pas discutée sur ce point. Selon Silveira, en assimilant la population de la foire à une poignée de marginaux, Pires et Schindler sont passés à côté du principal, le peuple travailleur qui vient quotidiennement y vendre ses produits :

« A crise temática de $A$ Grande Feira nasce da incerteza com que, ideologicamente, se projetam e se resolvem os problemas nacionais [...]. Dessa impropriedade conceitual igualmente nasce o erro de confundir a marginalidade humana com o povo, até com a classe trabalhadora. O equívoco não parte dos autores do filme. Em geral, se admite e aceita que uma ambiência tipicamente popular como Água de Meninos esteja habitadas por ladrões e assassinos como Chico Diabo, receptadores como Ricardo, prostitutas como Maria, ébrios como o filósofo, falsos mendigos como o da toca dos esmoleres. $\mathrm{Na}$

472«A Grande Feira devait être - depuis la première conversation Rex \& Roberto en décembre 60 - une chronique sans préjugés de la province, ayant pour juge la morale du peuple, incarnée par la figure mythologique de Cuíca de Santo Amaro. » in ROCHA, Glauber. « Depoimento (com biografia) » in Diário de noticias, Salvador, 26/11/1961.

473ROCHA, Glauber. « Depoimento (com biografia) » in Diário de notícias, Salvador, 26/11/1961. 
verdade, esses personagens também a povoam. Não são, todavia, os mais representativos da feira como o filme pretende. E converter Maria num símbolo da feira equivale a considerar-se que milhares de mulheres do povo que ali trabalham ou compram têm na prostituição uma companhia. $»^{474}$

Malgré ces réserves de la critique, A Grande Feira est un grand succès commercial à Salvador où ses recettes surpassent le record historique détenu par Ben-Hur (William Wyler, USA, 1959) ${ }^{475}$. Avec Os Cafajestes qui bénéficie d'un succès de scandale, A Grande Feira est d'ailleurs le seul véritable succès de la première phase du Cinema Novo auprès du public. Ce succès qui est essentiellement local s'explique sans doute par l'intérêt des gens de Salvador à voir pour la première fois leur ville et son actualité mises en scène dans un film de cinéma. Juste après $A$ Grande Feira, Pires réalise Tocaia no asfalto dont la réception critique est similaire, toujours par Silveira :

« Por desconhecimento ou temor, os problemas de $A$ Grande Feira et Tocaia no asfalto não vão ao centro da realidade baiana, permanecem em suas fronteiras. Água de Meninos pode resumir ecologicamente a Bahia. Os ladrões, os assassinos, os mendigos, as prostitutas, os falsos líderes sindicais de $A$ Grande Feira não resumem, porém, Água de Meninos. São a sua marginalidade, em vez de ser a sua característica. Em conseqüência, os conflitos da mudança do grande mercado popular resultam dramaticamente falsos, soltos das suas causas. O pistoleirismo nem atinge a condição de outra face típica da Bahia. É um fenômeno episódico e muito secundário. No entanto, Rex Schindler o elevou, em Tocaia no asfalto, a um grau representativo. De novo, marginais, como heróis, escondem os personagens verdadeiros da temática baiana. $»^{476}$

Rocha, dans une critique globalement positive, concède une absence de définition idéologique ${ }^{477}$. Pires a cependant essayé cette fois-ci d'aborder un sujet plus général et de réaliser un filme plus dérangeant en soulevant le problème de la corruption politique et de

474« La crise thématique de $A$ Grande Feira naît du manque d'assurance avec lequel sont projetés et résolus les problèmes nationaux [...]. De cette impropriété conceptuelle naît aussi l'erreur de confondre la marginalité avec le peuple, voire même avec la classe laborieuse. L'équivoque ne vient pas des auteurs du film. En général, il est admis et accepté qu'une ambiance typiquement populaire comme Água de Meninos soit habitée par des voleurs et des assassins comme Chico Diabo, des racketteurs comme Ricardo, des prostituées comme Maria, des alcooliques comme le philosophe et de faux mendiants. En vérité, ces personnages aussi l'habitent. Seulement, ils n'en sont pas les personnages les plus représentatifs comme le film le prétend. Et convertir Maria en symbole de la foire équivaut à considérer que les milliers de femmes du peuple qui travaillent ou achètent là ont élu la prostitution pour compagne. » in SILVEIRA, Walter da. «A Grande Feira : Origem $\mathrm{e}$ significado II » in Diário de notícias, Salvador, 10/12/1961.

475Cf. SANTOS, Nelson Pereira dos et GARCIA, Galileu. « Entrevista por David Neves e Ronald Monteiro » in Revista de Cultura Cinematográfica, Belo Horizonte, ${ }^{\circledR} 31$, mars-avril, 1962, et SENNA, Orlando. « Schindler arma cine-indústria e anuncia programa monstro : 62 » in Diário de notícias, Salvador, 24/12/1961.

476« Par méconnaissance ou timidité, les problèmes de $A$ Grande Feira et Tocaia no asfalto ne vont pas au centre de la réalité bahianaise, ils restent à ses frontières. Água de Meninos peut résumer écologiquement Bahia. Les voleurs, les assassins, les mendiants, les prostituées, les faux leaders syndicaux de $A$ Grande Feira ne résument pas, cependant, Água de Meninos. Ils sont sa marginalité au lieu d'être sa caractéristique principale. En conséquence, les conflits quant au déménagement du grand marché populaire sonnent dramatiquement faux, isolés de leurs véritables causes. Le recours aux tueurs à gage n'atteint pas non plus la condition d'une autre face typique de Bahia. C'est un phénomène épisodique et très secondaire. Cependant, Rex Schindler l'a élevé, dans Tocaia no asfalto, à un degré de représentativité. De nouveau, des marginaux, comme héros, cachent les personnages authentiques de la thématique bahianaise. » in SILVEIRA, Walter da. « Caráter do cinema baiano » in O Estado de São Paulo-Suplemento literário, São Paulo, 16/11/1963.

477ROCHA, Glauber. « Tocaia, Roberto e Schindler » in Diário de notícias, Salvador, 04/11/1962. 
l'utilisation de tueurs à gage par les coronéis du Nordeste. Comme dans A Grande Feira, nous retrouvons la volonté de traiter de l'actualité ${ }^{478}$. Le film raconte l'histoire d'un tueur à gage nommé Rufino. Celui-ci doit assassiner dans un délai de deux semaines un député conservateur de Salvador. Il se rend donc dans cette ville et loge dans une maison close qui lui a été indiquée par son intermédiaire avec le mandataire de l'assassinat. Rufino n'est cependant pas une brute. Ses réactions face aux procédés du maquereau et une série de flashbacks nous permettent de comprendre comment il s'est conformé à son destin de tueur, victime du déterminisme social et du traumatisme qu'a constitué l'assassinat d'un frère. Tout au long du film, alors même qu'il prépare l'exécution de son contrat, Rufino prend peu à peu conscience qu'il pourrait changer de vie. Il fuit avec une prostituée et «rachète » une jeune femme séquestrée dans le bordel. Une fois de plus cependant, le destin le rattrape. Pendant que Rufino découvre Salvador, le commanditaire de l'assassinat, un coronel du Nordeste, a réussi à rallier le député à sa cause par la corruption et désire annuler le contrat. Ignorant tout de Rufino, il lance son homme de main (le maquereau du bordel) à sa recherche. Afin de le retrouver, ce dernier commet une série d'exactions dont le viol de la jeune fille sauvée par Rufino de la prostitution. Profondément choqué, celui-ci décide de remplir son contrat. Il tue le député conservateur avant d'être rattrapé à son tour par les hommes de main du coronel qui l'abattent.

La structure narrative de Tocaia no asfalto est proche de celle de $O$ Assalto ao trem pagador. Tous deux appartiennent au genre du « film noir » et raconte l'histoire d'individus de classe populaire qui sont pris dans une série d'engrenages qui les condamne à un destin funeste. Dans Tocaia no asfalto, Rufino et sa compagne sont condamnés l'un à la criminalité, l'autre à la prostitution, du fait du lourd déterminisme social auquel ils sont soumis. Rufino devient tueur à gages dans un mouvement de révolte nihiliste envers cette société qui ne lui a laissé aucune chance. D'extraction modeste, après avoir commis un délit dont nous ignorons la nature, lui et son frère sont arrêtés. Tous deux sont emmenés avec d'autres prisonniers dans une camionnette mais toutes les prisons sont pleines. Arrivés en rase campagne, leur garde leur ordonne alors de fuir. Méfiants, certains refusent de descendre. Commence alors un massacre auquel Rufino échappe de peu. Dans la séquence d'ouverture du film, il retrouve l'assassin de son frère et l'abat froidement. Tuer devient ensuite la seule activité qu'il sache faire. La prostituée qu'il rencontre dans la maison close a, quant à elle, été contrainte à ce

478De passage à Salvador, Sales Gomes atteste de l'authenticité de l'histoire de Tocaia no asfalto au travers de sa rencontre avec un juge menacé par un tueur professionnel. Le juge lui raconte qu'il a contribué à faire incarcérer un tueur mais que celui-ci a été libéré par les autorités locales pour faire la chasse à un deuxième tueur jugé plus menaçant. Le juge craint que le tueur libéré ne se retourne contre lui afin de se venger de la peine qu'il a reçue... In GOMES, Paulo Emílio Sales. « Crimes que compensam » in O Estado de São Paulo - Suplemento literário, São Paulo, 10/11/1962. 
destin par la misère et la force. Après lui avoir fait miroiter un bon travail, le maquereau, comme il le fait à chaque fois, l'a logée dans sa "pension ». Rapidement endettée et sans avoir nulle part où aller, elle ne peut plus sortir sans avoir payé sa dette... Le même scénario se répète avec la fille sauvée par Rufino.

Tocaia no asfalto a suscité moins de commentaires que $A$ Grande Feira qui avait été précédé par son exceptionnel succès local. Il fut paradoxalement mieux accueilli à l'extérieur de Bahia, notamment par David Neves qui estime qu'il s'agit d'un film «très intéressant » caractérisé par l'authenticité des scènes de «marginalisme social» qui contrastent avec la fausseté des scènes consacrées à la bourgeoisie. Nous avons en effet dans Tocaia no asfalto une seconde ligne narrative parallèle à celle de l'histoire de Rufino. Il s'agit de celle d'un jeune député de l'opposition idéaliste qui, chargé d'une enquête parlementaire sur les activités du vieux député conservateur, a bien l'intention de mettre au clair les affaires de corruption auxquelles ce dernier serait lié. En plus de menacer ouvertement le député conservateur, il séduit sa fille. Plusieurs séquences sont consacrées aux intrigues impliquant le coronel et le vieux député, d'autres à l'idylle entre sa fille et son principal adversaire politique. Comme c'est le cas dans A Grande Feira et d'autres films de l'époque, la représentation de la bourgeoisie est caricaturale, le notable est présenté en costume, un verre de whisky à la main, dans des fêtes assez guindées ou à la plage, il est toujours abandonné à l'oisiveté quand ce n'est pas au libertinage. Nous pourrons d'ailleurs remarquer que rien ne distingue le jeune député de l'ancien, sinon leur discours respectif et leurs silhouette ${ }^{479}$.

Le film liquide les espoirs de Silveira dans le cinéma de Pires en accentuant les défauts qu'il trouvait déjà dans $A$ Grande Feira, en particulier le recours à un personnage principal marginal et individualiste :

«Roberto Pires, insistindo na disponibilidade artística, o compôs [Rufino] como um herói individual. A marginalização do personagem se acentuou. Como reflexo, a do tema. Há, no filme, um vingador. Rufino não ultrapassa do homem que mata porque mataram seu irmão. Jamais será para o público um homem vinculado às tragédias maiores do Nordeste : o latifundio, a seca, a fome, a injustiça. $\gg^{480}$

La critique de Silveira ne vaut évidemment que si l'on partage ce concept critique qui

479Le jeune député est mince et beau, toujours impeccable, habillé en costume comme dans la séquence de la réception où il va provoquer le député conservateur et où il croise sa fille. Nous le retrouvons plus tard torse nu au volant de sa voiture en bord de plage, il part alors à la rencontre de la fille de son adversaire qui l'attend sous un parasol.

480« Roberto Pires, en insistant sur la disponibilité artistique, l'a composé [Rufino] comme un héros individuel. La marginalisation du personnage s'est accentué. En conséquence de quoi, celle aussi du thème. Il y a, dans le film, un vengeur. Rufino ne dépasse jamais le statut de l'homme qui tue parce qu'ils ont tué son frère. Jamais il ne sera pour le public un homme lié aux plus grandes tragédies du Nordeste : le latifundium, la sécheresse, la faim, l'injustice. » in SILVEIRA, Walter da. « Caráter do cinema baiano » in O Estado de São PauloSuplemento literário, São Paulo, 16/11/1963. 
veut que le film permette une meilleure compréhension du réel et de ses contradictions sociales et politiques par le spectateur. Sans ce concept, qui est aussi celui du Cinema Novo et qui nous sert donc ici de référent à sa critique, nous n'aurions pas de raison de relever des éléments somme toute communs dans la fiction : le choix d'un marginal pour héros, une représentation superficielle sinon caricaturale des différentes classes sociales, des relations qu'elles entretiennent entre elles et des déterminismes provoqués par les modes d'échange et de production économiques. Ces déterminismes sont importants puisqu'ils pèsent sur les échanges sociaux et la culture en général. Si les films de Pires présentaient à cet égard les défauts que nous avons déjà relevés et qui préfigurent ceux que nous retrouverons dans le Cinema Novo, ils possédaient au moins deux qualités qui lui feront défaut et qui auraient méritées d'être développées. La première est la référence à l'actualité, la seconde est le caractère populaire de ces films. Malgré les réserves qui peuvent lui être adressées, Pires s'approche du difficile équilibre qui consiste à concilier une certaine exigence au niveau de l'intention du film et la satisfaction du public. C'est ce que son succès démontre mais c'est aussi ce que les critiques reconnaissent en évoquant "l'honnêteté » de ses intentions. Reconnaître cette «honnêteté » revient à admettre que Pires parvient à capter des fragments de réalité et, même de façon très imparfaite, à atteindre une expression qui soit utile au public et au cinéma brésilien ${ }^{481}$.

Dans le contexte des années soixante où l'on commence à chercher les traits caractéristiques de l'identité nationale du côté du peuple, une certaine authenticité est reconnue à Pires dans son approche de la culture populaire. A Grande Feira fera date pour son utilisation de la foire de Água de Meninos ${ }^{482}$ :

« é no ambiente das feiras que a alma do povo brasileiro pulsa em toda a sua heterogeneidade. Encaminhar o cinema nesta direção, seria levar a câmera de encontro ao íntimo do povo, na procura de um cinema autenticamente brasileiro. $1^{483}$

Cette trouvaille est accompagnée par celle qui consiste à faire intervenir un conteur populaire au début et à la fin du film :

481Il n'est pas exclu qu'un film idéologiquement imparfait mais communicatif soit pour ses spectateurs plus révélateur qu'un film à la conceptualisation plus complexe et plus juste. Dans cet ordre d'idée, les films de Pires pourraient avoir quelque chose du professeur ignorant qui permet à ses élèves d'avancer parce qu'il part de représentations de même niveau et de même nature et, parce que, justement, il cherche aussi. Un autre argument en faveur de ces films, toujours à partir de leur succès, est que, bons ou mauvais, ils offrent une perspective brésilienne sur une problématique brésilienne. Cet argument sera repris au moment des succès d'Embrafilme, films idéologiquement aussi ambiguës et discutables.

482L'histoire de la foire de Água de Meninos est reprise l'année suivante par Alex Viany dans son film Sol sobre lama.

483 « [...] c'est dans l'atmosphère des marchés que l'âme du peuple brésilien pulse dans toute son hétérogénéité. Entraîner le cinéma dans cette direction, ce serait emmener la caméra à la rencontre de l'intimité du peuple, à la recherche d'un cinéma authentiquement brésilien. » in REIS, Moura. « A Grande Feira » in Revista de Cinema, Belo Horizonte, n³, juillet-août 1964. 
«Cuíca de Santo Amaro abre o filme, fazendo anúncio dos seus livrinhos, com desenhos pendurados na parede : 'A feira de Água de Meninos vai se acabar'. Estabelece-se desde então caráter de exposição popular para a estória que se desenrola a partir desde momento. $)^{484}$

Le film n'entretient pas un rapport d'extériorité avec la culture populaire, celle-ci au contraire devient un élément à part entière de l'esthétique du film. Nous retrouvons ce rapport à la culture populaire approfondie dans un autre long métrage d'Iglu Filmes, Barravento, qui s'éloigne radicalement du référent à l'actualité.

\section{Barravento}

Barravento est en fait le premier film de la maison de production de Schindler mais son histoire est assez mouvementée. Le tournage a lieu entre octobre et novembre 1960 sur la plage de Burraquinho, à une dizaine de kilomètres de Salvador. La fonction de Rocha est d'abord celle de producteur exécutif, le réalisateur est Luiz Paulino dos Santos, auteur du court-métrage pionnier Um Dia na rampa et partenaire de l'aventure Yemanjá Film. Pour des raisons à ce jour mal élucidées, Rocha expulse son ami du plateau après quelques jours de tournage. Selon le futur leader du Cinema Novo, filant une parfaite idylle avec l'une des actrices du film, le réalisateur ne se dédiait pas avec assez de sérieux à sa tâche ${ }^{485}$. Rocha assume la direction du film et modifie le scénario dont il est déjà co-auteur. À la fin du tournage, lui-même n'est pas satisfait de son travail et il se passera plusieurs mois avant que le film ne soit monté à Rio de Janeiro avec l'aide de Pereira dos Santos ${ }^{486}$. L'influence du CPC est alors évidente au travers de l'insertion de carton qui « explique » le film et oriente son interprétation. Les premières projections ont lieu en 1962. Quelques critiques paraissent alors dans la presse ${ }^{487}$ mais, bien qu'elles soient positives, le film ne convainc ni distributeur, ni exploitant : Barravento ne sort pas en salles. Sa carrière est exclusivement festivalière, il

484 « Cuíca de Santo Amaro ouvre le film, faisant la réclame de ses petits livres, avec des dessins pendus aux murs : ' La foire de Água de Meninos va se terminer'. Il s'établit à partir d'alors un caractère d'exposition populaire pour l'histoire qui commence à cet instant. » in SENNA, Orlando. «A Grande (Crônica) Feira » in Diário de notícias, Salvador, 26/11/1961.

485Cf. ROCHA, Glauber. Cartas ao mundo. São Paulo, Companhia das letras, 1997, p. 124.

486Tout au long de sa carrière, Rocha va entretenir une relation ambivalente avec ce film qu'il va successivement désavouer et réintégrer à son œuvre. Voir par exemple : ROCHA, Glauber. «Rocha entre Deus e o Diabo» in sans origine, Salvador, sans date, certainement 1963 ou 64 ou ROCHA, Glauber. « Entretien avec Rocha » in Positif, Paris, n91, janvier 1968 : « Pour moi, Barravento n'est qu'un essai cinématographique, une expérience de débutant. » (p. 19)

487 « Barravento II » in Diário da noite, Rio de Janeiro, 28/05/1962.

NEVES, David. «Um Filme de autor » in Jornal da Bahia, Salvador, 24/06/1962.

BERNARDET, Jean-Claude. «Barravento e o recente cinema brasileiro » in Revista Brasiliense, São Paulo, n44, novembre-décembre 1962.

VELOSO, Caetano. «Um Filme de montagem » in Diário de notícias, Salvador, 1962. 
passe à Karlovy Vary et à Sestri Levante en 1962, à Londres et à New York en $1963^{488}$. Ivana Bentes mentionne un premier lancement commercial immédiatement consécutif au succès de Deus e o diabo na terra do sol à Rio de Janeiro le 26 juin $1964^{489}$. Nous n'avons pour notre part trouvé des annonces de l'exploitation de Barravento dans la presse qu'en $1967^{490}$.

L'intrigue du film est parfois comparée à celle de La Terra trema ${ }^{491}$ puisqu'il traite de la misère et de l'attachement aux traditions d'un village de pêcheurs et de la tentative de l'un de ses membres de mobiliser la communauté pour qu'elle s'affranchisse de l'exploitation économique dont elle est victime. Dans les deux cas, la figure du rebelle adopte un discours directement imprégné par la terminologie marxiste. Le rebelle du film de Rocha n'a cependant ni l'intelligence, ni l'esprit d'entreprise de celui de Visconti. De retour de Salvador à son village au bord de la mer, Firmino (de nouveau Antônio Pitanga) cherche à transformer les habitudes des siens par des harangues véhémentes, puis, les mots se révélant impuissants, par la sorcellerie, le sabotage et la manipulation. Les pêcheurs doivent leur misère au prix exorbitant qu'ils paient pour la location de leur outil de travail : le filet. Leurs tentatives de renégocier son prix se heurtent systématiquement à l'inflexibilité de l'employé qui vient régulièrement leur ôter une partie si importante du produit de leur travail qu'il leur reste à peine de quoi survivre. Soumis à cet état de fait qu'ils acceptent comme une fatalité, ils se réfugient dans la mysticisme et comptent sur Aruan, un jeune homme qu'ils imaginent être « l'élu » de la déesse de la mer, Yemanjá. En sa qualité « d'élu », celui-ci serait doué du pouvoir magique d'attirer le poisson.

Se prévalant de son expérience de la ville, Firmino va successivement discourir devant ses camarades, provoquer Aruan et son maître, le chef spirituel, puis, devant l'indifférence générale, adopte des moyens plus expéditifs et agit dans le secret, pendant la nuit. Il fait d'abord appel à la sorcellerie, en vain. Il détruit ensuite une première fois le filet à coup de rasoir afin d'acculer la communauté à la révolte. Celle-ci préfère réparer le filet. Il détruit une seconde fois le filet. Les pêcheurs décident de revenir à leurs pratiques ancestrales, sans filet, et comptent sur les pouvoirs d'Aruan qui ne se dérobe pas à sa mission. Finalement, Firmino incite sa compagne, Cota (Luiza Maranhão), à séduire Aruan et à lui faire perdre sa virginité et donc, ses pouvoirs. L'incident serait passé inaperçu si la même nuit une tempête n'avait éclaté et un homme ne s'était perdu en mer. Prise de remord, Cota tombe d'une falaise sans que l'on sache s'il s'agit d'un accident ou d'un suicide. Le lendemain, malgré le fait que la

488 ROCHA, Glauber. Cartas ao mundo. São Paulo, Companhia das letras, 1997, p. 708. 489ROCHA, Glauber. Cartas ao mundo. São Paulo, Companhia das letras, 1997, p. 709. 490Publicité parue dans O Estado de São Paulo, 29/09/1967. Il s'agit donc de la sortie du film à São Paulo. Pour celle de Rio de Janeiro, nous n'avons trouvé ni publicité dans la presse, ni critique du film datée de l'année 1964.

491La Terra trema, Luchino Visconti, Italie, 1946. 
situation ait empiré, le village ne remet pas en cause ses traditions et ses valeurs. La stratégie de Firmino a donc échoué. Seul, Aruan prend soudain conscience de l'aliénation des siens et décide de partir pour aller chercher en ville les richesses qui pourront améliorer leur condition.

La différence fondamentale qui intervient entre les films de Pires et celui de Rocha est que son univers diégétique est radicalement coupé du monde. Dans Tocaia no asfalto et $A$ Grande Feira, l'espace est ouvert, au sens spatial et symbolique, les personnages transitent d'une classe sociale à une autre, des lieux publics comme la rue et la foire, aux intérieurs privés comme la maison ou l'appartement. Dans Barravento, l'espace est réduit au village de pêcheurs très clairement délimité par une sorte de porte que l'on se figure placée à l'extrémité de la plage qui se trouve du côté de Salvador. Cette «porte» est le lieu par lequel arrive Firmino au début du film et celui par lequel s'en va Aruan au moment de l'épilogue. Le village de Barravento est cependant bien plus que coupé du monde par son confinement. Il est aussi coupé du monde par le mode de vie et les techniques intemporels de ses habitants. Seuls le costume de Firmino et le camion de l'employé du propriétaire du filet nous rappellent que nous sommes au XXe siècle. Enfin, le village est aussi un espace magique, habité par le surnaturel. Les intérieurs sont dédiés aux rituels nocturnes du candomblét ${ }^{492}$ alors qu'à l'extérieur on ne jure que par Yemanjá. Celle-ci semble d'ailleurs prendre possession des lieux dans la séquence qui succède à la profanation du corps d'Aruan puisque cette nuit-là les éléments se déchaînent et les tragédies se succèdent.

Une autre différence fondamentale avec les films de Pires est son anti-naturalisme. Tocaia no asfalto et A Grande Feira poursuivent une orientation réaliste et essayent de provoquer des effets de distanciation par la caractérisation des personnages et la mise en scène. Il en va ainsi pour les personnages du Suédois, comme nous l'avons déjà expliqué, mais aussi de Rufino. N'oublions pas que dans la séquence d'ouverture de Tocaia no asfalto, il tue un homme froidement avec une certaine cruauté. Comme les commentateurs de l'époque l'avaient remarqué, Barravento est un film de montage. Au lieu d'organiser la narration d'une façon transparente comme cela est la règle dans le cinéma classique, les manipulations du montage sont au contraire ostensibles. Ainsi, dans les séquences du candomblé, le montage et la musique des tams-tams visent à communiquer l'état de transe vécu par les personnages et à renforcer l'aspect mystérieux des rituels. Dans la séquence de la tempête, le montage hors

492Rocha se vantait d'ailleurs d'avoir réussi à filmer d'authentiques cérémonies. Il le fait notamment dans une lettre où il accuse Guerra de plagiat après avoir vu l'actrice blanche Irma Alvarez la tête rasée participant à un rituel de candomblé pour le film O Cavalo de Oxumaré (film resté inachevé). Barravento comporte une scène pratiquement similaire quand l'actrice Lucy Carvalho qui joue le rôle de l'unique jeune fille blanche de Buraquinho, a le crâne rasée pour participer à des rites initiatiques au cours desquels le sang d'un poulet sacrifié est versé sur son front. 
continuité exprime à la fois la panique de Cota et la colère des éléments. Toute la dimension magique du film, déjà présente dans l'organisation de l'espace, les scénographies, les costumes, est donc renforcée par le montage. Le résultat est l'exact opposé d'un film documentaire où le découpage nous permettrait de suivre et de comprendre les différentes étapes des cérémonies et leur symbolique.

Le montage participe aussi à la caractérisation des personnages, en particulier Firmino. Lorsque celui-ci harangue les pêcheurs qui réparent le filet nous avons deux séries de plans qui alterne. La première série nous montre Firmino en gros plan ou en plan rapproché qui crie et gesticule. La seconde nous montre les pêcheurs qui cousent patiemment, impassibles. Selon David Neves, l'effet obtenu est le suivant :

«Fica paradoxal a presença de Firmino (Pitanga), que age como catalizador e não passa de um personagem estranho ao meio cujo aparecimento, desapego e afastamento tomam um ar messiânico e, indireta e incoerentemente, sobrenatural. ${ }^{493}$

Le montage soulignerait ainsi les contradictions de Firmino. Le personnage nous est présenté comme machiavélique et rongé par la jalousie envers Aruan. Exclu de la communauté par sa différence, il est un sujet conscient au sein d'un microcosme aliéné. Il est aussi une figure messianique tragique. Détenteur du savoir, il est incapable de le partager et d'être reconnu pour ce qu'il est. Le fait qu'il pratique le mal pour faire triompher le bien, peut également apparaître comme une forme de sacrifice. Sa constante agitation, sa véhémence aussi, montrent que la rivalité avec Aruan et l'exclusion dont il est l'objet sont des motifs de souffrance personnelle. Mais son désir de reconnaissance est secondaire devant sa volonté de sauver les siens. Pour cette raison, il disparaît de l'écran à partir de la prise de conscience d'Aruan. Sa mission s'arrête quant apparaît celui que le peuple écoutera. Enfin, nous pourrons noter que, paradoxalement, il recourt à la magie noire pour lutter contre le mysticisme. Il est un personnage moderne qui connaît la grande ville, l'usine, les syndicats, le marxisme mais le fait est que, lorsqu'il revient dans le monde archaïque, il est de nouveau pénétré par sa mystique. Les rites et le comportement des habitants du village transforme Yemanjá en personnage réel. La magie et le mysticisme sont bien plus qu'un référent culturel, ils sont présents concrètement et régissent la vie des hommes.

La contradiction entre le mysticisme et la raison marxiste n'est pas seulement celle du personnage de Firmino, elle est celle de l'intégralité du film. C'est elle qui fit dire à Alberto Moravia que Rocha avait su sentir la magie afro-brésilienne. En même temps que le film vise

493« La présence de Firmino (Pitanga) est assez paradoxale dans la mesure où il agit comme un catalyseur mais semble étranger au milieu où il évolue, son apparition, son détachement et son éloignement lui donnent un air messianique et, indirectement et de façon incohérente, surnaturel. » in NEVES, David. « Um Filme de autor » in Jornal da Bahia, Salvador, 24/06/1962. 
à démontrer que le mysticisme est la cause du sous-développement et qu'il est une forme d'aliénation populaire, il est tout entier contaminé par la force de la culture noire, la sensualité des corps et des danses ${ }^{494}$, la poésie de cette imaginaire peuplé de divinités ${ }^{495}$, la violence des rites et de l'ascèse religieuse ${ }^{496}$. Comme dans la séquence où Firmino harangue les pêcheurs et que le montage le sépare de son public, ses cris et ses gesticulations apparaissent complètement vains par rapport à une force supérieure qui semble s'opposer à lui. Cette force n'est pas symbolisée par le maître, elle est intrinsèque à la communauté qui, elle-même, est unie par une culture commune qui se trouve être le mysticisme. Firmino propose à la communauté d'entrer dans la modernité. Mais cela signifiera-t-il vraiment un mieux être ? La distance qui s'établit par le biais du montage et de la caractérisation du personnage de Firmino exprime un certain scepticisme par rapport au progrès, voire, comme certains critiques l'ont dit, une certaine nostalgie envers la petite société archaïque formée par le village. Ce scepticisme est verbalisé par le personnage de Cota :

« Agora eu me lembrei do homem que um dia me convidou prá trabalhar na cidade. $\mathrm{O}$ serviço era na cama. Não liguei nada e um dia o camarada abriu a boca e falou que me amava... mas cadê coragem prá casar ? Prá ser cachorro de dia e mulher de noite, prefiro comer peixe aqui mesmo. $»^{497}$

Plus que tout autre film, Barravento expose ainsi les contradictions et les ambiguïtés de la démarche de son auteur voire, de toute une génération. L'étude des scénarios de Barravento et leur comparaison avec le film montre que le principal souci de Rocha fut de s'écarter d'une représentation superficielle de la culture populaire et de faire en sorte que ses éléments intègrent l'expression filmique elle-même. Nous sommes alors au cœur de cette démarche de recherche d'une dramaturgie typiquement brésilienne dans laquelle on entend se servir de la culture populaire comme étalon. Nous sommes dans un contexte où l'on se figure

494Comme dans le pourtant si décrié Orfeu negro, la moindre note de musique met les corps en mouvement. Il en va ainsi de la séquence consacrée à la capoeira, immédiatement accompagnée de la samba de roda, où la sensualité et la plastique de Luíza Maranhão qui interprète Cota sont parfaitement mis en valeur par le cadrage. Le montage, une fois de plus, suit le rythme de la musique.

495Yemanjá peut se manifester sous diverses formes et notamment apparaître sous la mer sous la forme d'une sirène et appeler les hommes. C'est une déesse qui inspire la crainte, elle donne la vie mais peut aussi la prendre. Le personnage de Vicente, le père de Naína, la fille blanche qui subit l'initiation du candomblé, est fasciné par Yemanjá. Quand Firmino lui annonce qu'il a vu la déesse au fond de l'eau, il se précipite à sa rencontre malgré la tempête et meurt noyé.

496Aruan et Naína sont, pour des raisons différentes, soumises à des contraintes précises. Aruan ne doit pas s'intéresser aux femmes et les femmes ne doivent pas s'intéresser à lui. Naína est punie quand elle déclare être attirée par lui. Elle-même, lors de la cérémonie initiatique qui coïncide avec la tempête, entre en transe et a la tête rasée puis recouverte de sang et de plume de poulet.

497« Maintenant, je me souviens de l'homme qui m'a invité un jour à travailler en ville. Le service devait être rendu au lit. Je n'ai rien répondu et, un jour, le camarade a ouvert la bouche de nouveau pour me dire qu'il m'aimait... mais où était le courage pour se marier ? Pour être son chien le jour et femme pendant la nuit, je préfère manger du poisson ici-même. » in ROCHA, Glauber. Roteiros do terceyro mundo. Rio de Janeiro, Alhambra/Embrafilme, 1985, p. 250. 
que les traits caractéristiques de la nationalité sont détenus par le peuple, qui a su garder et préserver voire même inventer une culture originale, par opposition aux classes moyennes et supérieures dont le cosmopolitisme est perçu comme une forme d'aliénation. C'est donc auprès du peuple, quasiment avec une approche d'ethnologue, qu'il faut rechercher les formes d'expression qui permettront de créer un art national. Paradoxalement, ceux qui pensent que l'art doit se nourrir de la culture populaire, pensent aussi que le peuple, parce qu'il ne fait pas la révolution, est soumis et incapable de s'organiser pour lutter. Et s'il est incapable de se révolter, c'est parce qu'il est lui-même aliéné. Le football, le mysticisme et le carnaval sont à la fois les formes d'expression de la culture populaire les plus marquantes et les manifestations de son aliénation. Firmino détruit le filet parce qu'il donne foi au raisonnement suivant :

« A barriga precisa doer mesmo. Quando tiver uma ferida bem grande então tudo mundo grita de vez. $»^{498}$

Rocha, ses amis du Cinema Novo et ses adversaires du CPC, pensent que si le peuple n'avait pas le carnaval, le football et le samba pour oublier la misère, alors, il se soulèverait d'un seul coup. C'est pourquoi le carton initial de Barravento et les encarts publiés dans la presse informe à l'avance de la morale du film :

« ... a beleza contagiante dos ritos negros são formas de alienação, são impedimentos trágicos a uma tomada de consciência para a liberdade... $»^{499}$

Plus que tout autre film de Rocha, Barravento serait donc proche de la rhétorique du CPC tel précisément que le cinéaste n'aura de cesse de la critiquer. Le fait en lui-même n'a rien d'étonnant puisque le film est monté à Rio au moment de la fondation du CPC et que Rocha, avant son altercation avec Martins, a envisagé d'adhérer au mouvement auquel participent déjà Diegues et Hirszman. Mais comme nous l'avons vu, cette morale que l'on cherche à imposer au spectateur est remise en doute par la forme du film elle-même, d'abord au travers de la valorisation de la culture populaire, ensuite au travers du recours à de nombreux effets de distanciation, dans le montage, dans la caractérisation du personnage de Firmino et dans les trajectoires d'Aruan et de Naína. Cette dernière non seulement est blanche mais elle passe également pour être maudite de Yemanjá pour des raisons qui sont mal éclaircies mais qui semblent liées à son histoire familiale. Depuis toute petite, elle est donc marginalisée dans cette communauté noire. Le fait qu'elle avoue publiquement son amour

$498 \ll$ Il faut vraiment avoir mal au ventre. Quand la blessure sera bien grande alors tout le monde va crier d'un seul coup. » in ROCHA, Glauber. Roteiros do terceyro mundo. Rio de Janeiro, Alhambra/Embrafilme, 1985, p. 250.

499 «... la beauté contagieuse des rites noirs sont des formes d'aliénation, ce sont des obstacles à une prise de conscience pour la liberté... » in Publicité parue dans O Estado de São Paulo, 29/09/1967. 
pour Aruan n'arrange pas les choses. Maintenant qu'elle est adulte, les femmes du village prennent la décision de lui faire subir les rites de leur religion afin de la «purifier». La trajectoire de Naína est donc celle de l'intégration au sein de la communauté par l'incorporation de ses coutumes. Elle effectue un chassé croisé avec Aruan qui l'aime aussi en secret. Le climax du film correspond à la prise de conscience d'Aruan, à sa rupture avec la tradition, et, exactement en même temps, à l'intégration de Naína en fille de saint. Appartenant désormais à la communauté, Naína promet d'attendre le retour d'Aruan, fortune faite. La rupture d'Aruan avec la tradition est contrebalancée par la fidélité de Naína en même temps qu'elle permet la réalisation de leur union.

La transformation promise par le titre du film n'est donc pas celle qui est voulue par son auteur, ni par le personnage de Firmino qui manifesterait sa présence au sein de la diégèse. La communauté de pêcheurs reste immuable, Cota est morte, Firmino s'efface, il n'y a que le destin d'Aruan et Naína qui est ouvert sur l'avenir. Le couple symbolise la recherche d'une accommodation entre tradition et modernité. Aruan part à la ville mais le spectateur un tant soi peu informé sait bien que son destin le plus probable est de venir grossir la main d'œuvre non qualifiée et sous-payée que l'exode rural concentre dans les métropoles brésiliennes. Firmino n'est pas revenu fortune faite, quelles sont les chances d'Aruan ? Le projet de celui-ci n'est pas de «faire la révolution », mais de trouver un travail, gagner un salaire et économiser tout ce qu'il pourra avant de pouvoir revenir au village. Faut-il voir dans cet épilogue la véritable morale du film qui viendrait se substituer à la morale « révolutionnaire » du carton initial. Rien n'est moins sûr. De la même façon que celle-ci a été mise en doute tout au long de la narration, une chanson nostalgique typique des émigrés du Nordeste $^{500}$ montre avec ironie que l'auteur a déjà anticipé sur ce que nous pourrions penser des chances d'Aruan. Le film dénonce ainsi constamment ces propositions au fur et à mesure qu'elles émergent. La narration reste résolument ouverte sans que nous soit offert le moindre élément de spéculation. Comme dans A Grande Feira, la nécessité de la révolution apparaît mais, dans le même temps, tout semble nous indiquer que sa réalisation est impossible. Rocha a souvent expliqué que les films devaient rester ouverts et ne pas apporter de solutions, contrairement notamment au réalisme socialiste qui produisait des œuvres fermées. Dans le cas présent, nous pourrions objecter que pour que l'intention révolutionnaire soit claire le film n'est ni assez fermé, ni assez ouvert.

Iglu Filmes ne marquera pas le Cinema Novo au-delà des trois films que nous venons de commenter. Après le succès de A Grande Feira, Schindler expose dans la presse de 500La chanson finale, Vou prá Bahia prá vê se dinheiro corre, fait écho à la chanson initiale de l'arrivée de Firmino, Quando eu venho d'Aruanda. Pour la petite histoire, toutes les deux sont chantées par Carlos Diegues. In NEVES, David. « Um Filme de autor » in Jornal da Bahia, Salvador, 24/06/1962. 
fabuleux projets qui ne se réaliseront pas $^{501}$. Nelson Pereira dos Santos lui-même qui a passé quelques temps à Salvador au moment de tourner Mandacaru vermelho, est invité à participer de la direction d'une nouvelle société de cinéma CINEBASA laquelle aurait déjà le projet de réaliser cinq films pour 1963. L'année où le cinéma de Bahia aurait dû monter en puissance correspond au contraire à la séparation entre Pires, Rocha et Schindler sur fond de mésentente professionnelle et idéologique. La situation, selon le témoignage de Sales Gomes, était prévisible. Lors d'un voyage qu'il fait à Salvador pour assister à une festival de cinéma mais aussi pour comprendre comment la ville est devenue la capitale du cinéma brésilien, il constate.

\footnotetext{
«É bastante saborosa a íntima associação que se estabeleceu entre este liberal cético e no fundo bastante conservador, e jovens devorados pelo ardor revolucionário. A palavra, provavelmente sugerida por Glauber, que Rex mais emprega é ' polêmica '. Suas dissertações e explicações são sempre em torno de um 'cinema polêmico' de uma 'visão polêmica' da vida brasileira atual. Esse homem 'polêmico', porém, é um dos seres mais alheios ao problema verdadeiro da demistificação. $~^{502}$
}

Les observations du critique pauliste sur les personnalités impliquées dans Iglu Filmes permettent ainsi de comprendre comment a pris fin cette expérience mais aussi d'où vient le caractère "petit-bourgeois » de sa production, si souvent soulignée dans les critiques de l'époque.

\subsection{L'influence du CPC}

Bien qu'ils aient été réalisés loin de Salvador et dans un contexte absolument différent, il existe, d'un point de vue idéologique, de nombreux points communs entre les films cariocas marqués par l'influence du CPC et ceux du cycle de Bahia. Dans tous ces films, nous retrouvons la même caricature de la bourgeoisie égoïste et décadente et la même défiance quant à la capacité du peuple à accéder à la condition d'acteur politique. En phase avec l'idéal d'un cinéma populaire de conscientisation, plutôt que d'aller vers un cinéma de critique des structures politiques et sociales, à Rio, on cherchera d'abord à lutter contre les grandes aliénations populaires : le football, le carnaval et la religion. Cette orientation est claire dans Cinco vezes favela et Garrincha, alegria do povo. La situation évolue cependant dans Ganga

501SENNA, Orlando. « Schindler arma cine-indústria e anuncia programa monstro : 62 » in Diário de notícias, Salvador, 24/12/1961.

$502 «$ L'étroite association qui s'est établie entre un libéral sceptique et dans le fond assez conservateur, et des jeunes dévorés par l'ardeur révolutionnaire, est assez savoureuse. Le mot, probablement suggéré par Glauber, que Rex emploie le plus est celui de ' polémique '. Ses démonstrations et explications tournent toujours autour d'un ' cinéma polémique ' d'une ' vision polémique ' de la société brésilienne actuelle. Cet homme ' polémique ' est pourtant l'un des êtres les plus étrangers au véritable problème de la démystification. » in GOMES, Paulo Emílio Sales. « Perfis bahianos » in O Estado de São Paulo - Suplemento literário, São Paulo, 24/03/1962. 
Zumba et, si l'on y retrouve les mots d'ordre et les simplifications du film précédent, on voit bien que la conception réductrice que l'on a du peuple commence à changer, principalement à partir de l'intérêt que l'on porte à la culture populaire. Cette évolution sera cependant très lente et il faudra attendre la troisième phase du Cinema Novo pour constater une véritable révolution dans ce domaine. Enfin, filmé à la veille du coup d'État, Maioria absoluta est un film à part dans la cinématographie du Cinema Novo. Parfaitement identifié avec la posture idéologique du gouvernement Goulart, il est le seul film militant du Cinema Novo.

\section{Cinco vezes favela}

Cinco vezes favela est une production du CPC au générique de laquelle nous retrouvons tous les intégrants du Cinema Novo à l'exception de Rocha. Il s'agit d'un longmétrage à « sketchs » dont les différents épisodes sont signés par Marcos Faria (O Favelado), Miguel Borges (Zé da Cachorra), Joaquim Pedro de Andrade (Couro de gato) ${ }^{503}$, Carlos Diegues (Escola de samba, alegria de viver) et Leon Hirszman (Pedreira de São Diogo). Nous retrouvons également Ruy Guerra sur le montage de Escola de samba, alegria de viver et Nelson Pereira dos Santos sur celui de Pedreira de São Diogo. Les deux hommes exécutent aussi le montage final du long métrage. Notons enfin la présence de Paulo César Saraceni à la production au côté de Faria et Hirszman. Autant dire qu'avant d'être un film du CPC, Cinco vezes favela est un authentique produit du Cinema Novo. Le fait que le CPC soit producteur du film n'est cependant pas anodin. Comme nous l'avons déjà vu, Hirszman est un de ses trois membres fondateurs avec Oduvaldo Vianna Filho et Martins. Le fait que le CPC ait été rattaché à l'União Nacional dos Estudantes - UNE au moment de sa création officielle ${ }^{504}$, lui a permis de bénéficier de subventions de l'État ${ }^{505}$. Cinco vezes favela constitue l'application de la proposition du CPC au domaine du cinéma. Il existe alors, avant la controverse du deuxième semestre de 1962, une convergence totale entre le CPC et le Cinema Novo. Martins apparaît d'ailleurs au générique de Cinco vezes favela, il joue un rôle dans Um Favelado et

503 Couro de gato, réalisé un an et demi avant les sketchs et dans une autre structure, est une pièce rapportée. Sa carrière festivalière a d'ailleurs commencé avant même que Cinco vezes favela ne soit achevé. Le fait que le court métrage ait été intégré au film du CPC est cependant significatif, d'un côté, sa participation a été sollicitée, de l'autre, Andrade a accepté d'être associé à ce projet.

504Vote des statuts du CPC en assemblée générale de l'UNE en mars 1962.

505Selon Salem, Hirszman est allé lui-même solliciter des crédits auprès de Ferreira Gullar qui administrait alors la Fundação Cultural de Brasília. Les deux hommes ne se connaissaient pas encore très bien. Nous sommes en 1961, avant même la création du CPC. Gullar témoigne avoir obtenu les fonds nécessaires grâce à son ami José Aparecido de Oliveira, secrétaire particulier du cabinet de la présidence de la république. Celui-ci l'avait chargé de dresser une liste d'institutions auxquelles pourraient être attribuées des subventions du Ministério da Cultura et da Educação - MEC. Cinco vezes favela fut donc financé par le MEC. Le film est réalisé pendant la présidence de Goulart et terminé vers la fin mars 1962. Voir SALEM, Helena. Leon Hirszman : o navegador das estrelas. Rio de Janeiro, Rocco, 1997, p. 106. 
signe avec Diegues, son successeur à la tête du CPC, l'argument de Escola de samba, alegria de viver.

Comme son titre l'indique, Cinco vezes favela investit différents aspects de la favela et s'inscrit dans la continuation du film pionnier de Santos : Rio, quarenta graus. Du point de vue de la prise de conscience, il en reprend la stratégie qui consiste à établir une relation d'empathie entre le spectateur et les personnages de la fiction qui sont, en général, des êtres fragilisées par leur condition et souffrant d'une totale absence de protection. Dans le premier épisode, Um Favelado, nous assistons ainsi à la rapide descente en enfer d'un homme qui, pour protéger sa famille, se trouve acculé au vol. Sans emploi et sans argent, le personnage interprété par Flávio Migliaccio est menacé d'expulsion par des hommes de main qui lui réclament un loyer. Pour bien se faire comprendre, ceux-ci le passent à tabac et le laissent à terre en lui laissant une journée pour réunir l'argent. Le lendemain, celui-ci quitte sa femme et son fils et déambule en ville en quête d'un travail. Après avoir essuyé un refus sur un chantier de construction, il hésite à cambrioler un kiosque à journaux, enfin, il s'en remet à un malfrat qui lui a souvent proposé de travailler avec lui et participe au vol de la recette d'un autobus. Au moment de l'attaque, abandonné par ses complices, il est rattrapé, battu et arrêté par la police. Le personnage principal et sa famille sont caractérisés comme étant des êtres pacifiques, modestes et simples. C'est l'indifférence de la société comme un tout et la violence de quelques uns qui précipitent le destin.

Le même schéma se reproduit de façon plus subtile dans Couro de gato grâce à l'originalité du choix du sujet. À l'approche du carnaval, les chats sont chassés pour leur peau, matière première à la fabrication des tambourins. Cette anecdote permet de montrer les relations qui s'établissent entre la société dans sa totalité et la vie de la favela. Au lieu d'être coupée du reste de la ville comme dans O Favelado, nous voyons ici que la favela est le lieu d'activités économiques subalternes et non moins vitales pour ses habitants. La fabrication des tambourins mobilise enfants et artisans. Le choix des enfants comme personnages principaux permet de renforcer le côté pathétique de l'intrigue. La chasse des chats est en effet un jeu cruel. Pratiquée la faim au ventre, elle confronte les enfants et les spectateurs aux contradictions sociales qui voient, dans le même espace géographique, cohabiter des enfants en haillons et des animaux domestiques parfaitement soignés et nourris. En plus de souligner cette injustice, le film nous montre une enfance à laquelle les plaisirs sont interdits. Dans la séquence finale, l'animal volé avec lequel l'enfant partage le peu de nourriture qu'il a avec lui, apparaît successivement comme l'image de la tendresse prohibée et, par un gros plan, comme un ogre égoïste, inconscient du sacrifice que constitue pour l'enfant le partage de son repas. Touché par des sentiments contradictoires, l'enfant remet le chat à l'artisan. Il s'agit d'un geste 
douloureux mais sans possibilité de remords.

$\mathrm{Au}$ contraire de ces deux épisodes qui visent à faire prendre conscience aux spectateurs des déterminismes sociaux pesant sur les marginaux et de ce que peut être leur expérience de la vie, Zé da Cachorra et Pedreira de São Diogo mettent en scène des personnages insérés dans la lutte de classe et y prenant part consciemment par l'affrontement direct ou par la ruse. Zé da Cachorra défend l'installation dans la favela d'une nouvelle famille malgré l'interdiction faite par le propriétaire du terrain. À la manière du Firmino de Barravento, il peine à être entendu par les siens qu'il tente de convaincre par l'harangue d'adopter une attitude d'insoumission. Son objectif est qu'ils cessent de reconnaître l'autorité du propriétaire et qu'ils ne craignent pas d'en arriver à la confrontation directe pour défendre leur droit d'avoir un toit. Dans Pedreira de São Diogo, des ouvriers conscients de mettre en péril l'existence d'une favela se trouvant au-dessus de la carrière qu'ils exploitent, réussissent à avertir ses habitants à temps pour que ceux-ci se présentent en haut de la falaise juste avant l'explosion fatidique. Le patron est alors obligé de renoncer à l'exploitation sans pouvoir reprocher à ses employés de refuser le travail. Dans ces deux épisodes, la relation d'empathie est toujours présente mais l'exposé ne s'en tient pas aux contradictions sociales, les antagonismes de classe apparaissent.

Escola de samba, alegria de viver est le seul épisode qui retrace une prise de conscience. Dans la favela, une école de samba se prépare au carnaval. Un nouveau président, jeune et dynamique, est élu. Il obtient un crédit pour acheter une nouvelle banderole et d'autres accessoires utiles au défilé. Ce même président est en conflit avec sa femme qui s'investit dans la vie syndicale et méprise l'école de samba. Lui-même ne comprend pas sa femme et assiste sans réagir aux brimades dont elle peut être l'objet par les autres favelados. Pendant le mois qui s'écoule, le couple se sépare et l'école est sans cesse relancée par ses créditeurs qui sollicitent le remboursement du crédit. Finalement, le jour même du carnaval, des hommes de main sont envoyés pour récupérer la somme. Juste avant le défilé, la confrontation est inévitable et la banderole est brûlée. En larmes, le jeune président décide de mener le défilé malgré tout. Le porte-étendard, par contre, abandonne la troupe et remonte vers les bidonvilles dans son déguisement. Dans cet épisode, l'antagonisme existant au sein du couple entre la femme syndicaliste et le mari permet de mettre l'emphase sur l'aliénation que représenterait l'investissement des personnes dans l'école de samba.

Le point de vue exprimé par l'auteur est assez moraliste, un parallèle pourrait même être établi avec la fable de La Cigale et la fourmi. D'un côté, la femme-cigale travaille à l'usine et investit son temps libre et son énergie dans une lutte qui sera utile à la libération de la communauté toute entière de l'oppression qui pèse sur elle. Elle prépare l'avenir. De l'autre 
côté, le mari-cigale ne travaille pas et consacre tout son temps à l'école de samba. Le titre «École de samba, joie de vivre » fait référence à son insouciance, il se consacre à des futilités alors qu'il est entouré par la misère. Le personnage, au travers des mésaventures occasionnées par le prêt, apparaît aussi plus clairement comme un irresponsable. Ayant contracté ce prêt auprès de personnes peu fiables, il exposait la communauté entière à des représailles violentes. Lors d'une séquence, après la séparation, il tente de reconquérir sa femme en allant avec un groupe d'enfants à la sortie de l'usine. En démontrant l'habileté des jeunes danseurs, il pensait sans doute montrer que son travail n'est pas aussi vain qu'elle le lui disait. Dans la séquence finale, la destruction de la banderole provoque un déclic. Le jeune homme est rappelé à la réalité de sa condition. La misère apparaît comme un frein à la réalisation de sa propre passion pour le Carnaval. Le porte-étendard qui s'enfuit, un adolescent qui a été témoin des disputes du couple, a, quant à lui parfaitement pris conscience de la vacuité de l'école.

Cinco vezes favela a été assez mal reçu pour des raisons parfois diamétralement opposées. Il déçoit d'abord ses propres auteurs et provoque immédiatement une forte polémique à l'intérieur du CPC. Celle-ci est à l'origine des dissensions qui éclateront au mois de septembre 1962 et que nous avons déjà commentées. Le CPC se divise en deux lignes opposées, celles de Martins et celle du Cinema Novo. Selon l'acteur Joel Barcellos :

\footnotetext{
« Lembro-me que, quando o filme ficou pronto, na primeira sessão pública, o Carlos Estevam apresentou o filme e se desculpou pelo caráter pequeno-burguês de alguns episódios. [...] Havia, por exemplo, em relação ao filme de Joaquim, uma queixa de que não era político. Quer dizer, essas contradições não demoraram muito a aparecer. Elas foram imediatas. Ao fim do primeiro ano do CPC, já havia claramente uma dissidência. E, antes que completasse seu secundo ano, nós já estávamos expelidos de dentro dele. $»^{506}$
}

Les critiques de Martins sont en général assez mal comprises et ce d'autant moins bien que le qualificatif de "petit-bourgeois » équivaut, dans ce contexte, à l'offense maximale. Elles s'expliquent pourtant facilement par l'ambiguïté des films en eux-mêmes, point que nous détaillerons plus bas. Notons également que la perspective de Martins est essentiellement pragmatique et qu'il recherche un résultat immédiat et observable à court terme. S'il désavoue Cinco vezes favela et, en particulier, Escola de samba, alegria de viver dont il a pourtant cosigné l'argument, c'est parce que ces films n'ont pas l'efficacité qu'il attribue à Assalto ao trem pagador et $O$ Pagador de promessas qui sont apparus entre-temps. Peu lui importent les simplifications sociologiques véhiculées par les films et reprochées par la critique et les membres du Cinema Novo eux-mêmes. Peu lui importe également le manque d'innovation en matière de langage cinématographique démontré par l'ensemble des courts métrages. Ce que 
voudrait Martins, c'est un cinéma réaliste socialiste à la brésilienne, qui, au contraire du cinéma dominant, serait du côté du peuple et l'engagerait dans les combats politiques. Les membres du Cinema Novo sont au contraire hostile au réalisme socialiste qu'ils pensent dépassé d'un point de vue esthétique et qu'ils assimilent à un cinéma de propagande.

Les deux partis n'étant pas satisfaits du film, ce double désaveu a considérablement nui à son exploitation. Cinco vezes favela ne connaît pas le succès des autres productions du CPC. Selon certains témoignages, le film n'est pas sorti en salles en-dehors de la ville de Rio de Janeiro $^{507}$. Nous avons pourtant retrouvé une invitation du CPC pour son avant-première à São Paulo (22 mars 1963) $)^{508}$. La réception de la presse écrite est globalement mauvaise. Une part de la critique s'aligne sur les positions exprimées par les membres du Cinema Novo. En général, un jugement est émis sur chacun des courts métrages séparément ${ }^{509}$. Ainsi, Couro de gato, qui a déjà reçu des prix aux festivals de Sestri-Levante et Obernhausen (1962) est bien accueilli. Pedreira de São Diogo est également salué pour constituer un brillant exercice de montage à la façon d'Eisenstein. Mais les trois autres films sont souvent qualifiés de « mauvais », que ce soient pour des raisons d'incompétence technique, réelle ou supposée, de leurs auteurs, ou pour jouer des clichés de façon outrancière. Le cliché du pauvre pur et humble dans $O$ Favelado et celui de la bourgeoisie décadente dans Zé da Cachorra sont, par exemple, violemment rejetés ${ }^{510}$. Ici encore, on craint une dérive vers le réalisme socialiste ou un « cinéma-pamphlet». De telles orientations sont condamnées car il est dit qu'elles entraîneraient un appauvrissement de la forme néfaste au développement du cinéma brésilien. Enfin, sans entrer dans des considérations aussi complexes, une autre part de la critique dénonce la propagation des idées bolcheviques par le cinéma ${ }^{511}$.

507Voir BERNARDET, Jean-Claude. Brasil em tempo de cinema. Rio de Janeiro, Paz e Terra, 1967, p. 32. 508Texte intégral de l'invitation : «' Centro popular de cultura ' São Paulo. Convite individual para ' pré-estréia ' do filme Cinco vezes favela. Cinco diretores do ' Cinema Novo '. Dia 22 março - 24 horas. Ciné Coral. » Archives Cinemateca do MAM, Rio de Janeiro.

509ESCOREL, Eduardo. «Cinco vezes favela » in Práxis, instauração crítica e criativa, São Paulo, $\mathrm{n}^{\circ} 2$, $1 \mathrm{er}$ semestre 1963.

NEVES, David. « A Média arithmética » in Jornal do Brasil, Rio de Janeiro, 07/12/1962.

510Dans cet épisode, le propriétaire du terrain de la favela est prévenu d'une nouvelle intrusion en pleine orgie. Quand il annonce à son fils que la fête est finie, celui-ci lui demande candidement : « Pourquoi, Maman va rentrer?». Par la suite, il essaye de soudoyer la délégation de la favela en étalant son argent, il leur offre du whisky importé et des cigares américains.

511 « característica da sessão [realizada no Cine Coral], desde o início até o fim, foi a presença do panfletismo, da demagogia comunista. Logo à entrada era entregue ao espectador um folheto de propaganda do ' Congresso Continental de Solidariedade a Cuba - Paz para Cuba '. » (La projection [au ciné Coral] a été caractérisée du début à la fin par le militantisme et la démagogie communiste. Dès l'entrée, il était distribué au spectateur un tract de publicité pour le ' Congrès Continental de Solidarité avec Cuba - Paix pour Cuba ') in $O$ Estado de São Paulo, 30/03/1963. La peur de la propagande bolchevique est également exprimée par Humberto Didonet de Porto Alegre qui assimile clairement Cinco vezes favela à un film de propagande communiste financé par le gouvernement Goulart. Son discours s'identifie quant à lui parfaitement à l'hystérie anti-communiste qui domine alors la droite. $C f$. DIDONET, Humberto. « Uma palavra amiga aos estudantes » in Jornal do dia, Porto Alegre, 05/05/1964 ; DIDONET, Humberto. « Ganga Zumba » in Jornal do dia, Porto Alegre, 29/07/1964. 
Si l'objectif de Cinco vezes favela est bien de dénoncer une situation contre laquelle tous devraient de révolter, il est cependant bien difficile de comprendre les craintes d'endoctrinement soulevées par le film. Sur les cinq courts métrages qui le composent, les injustices sociales sont certes exposées mais aucune propagande explicite n'est faite. Dans deux films, $O$ Favelado et Couro de gato, le message se limite à la compréhension des déterminismes sociaux par le spectateur, aucune solution n'est présentée. Dans Pedreira de São Diogo, le message est celui de la solidarité entre les classes populaires, ni parti, ni banderole, l'autorité du patron n'est d'ailleurs pas remise en cause. Celui-ci est mis en face de ses obligations morales face aux destructions et aux morts que pourraient causer la poursuite de l'exploitation de la carrière. Dans Escola de samba, alegria de viver, le message se résume à l'importance qu'il y a, pour les classes populaires, à investir les syndicats, là encore, aucun parti n'est indiqué aux spectateurs et nous savons bien qu'il existe des syndicats de droite comme de gauche. Zé da Cachorra est, de loin, l'épisode le plus subversif puisque l'on y voit un personnage remettre en cause la notion de propriété et inciter à ce que l'on appelait alors « la haine entre les classes ». Les caractéristiques révolutionnaires de ce personnage sont pourtant contrebalancées par le fait qu'il est isolé et que ses qualités de leadership sont douteuses. Pour qu'il y ait endoctrinement, il faudrait qu'une doctrine claire et explicite puisse être dégagé de l'analyse du film, or, ce n'est pas le cas.

Cinco vezes favela se distingue aussi par l'ambiguïté de sa destination. Si l'intention déclarée du film est de toucher la classe populaire et de faire prendre conscience des mécanismes sociaux, politiques et économiques qui la maintiennent dans la misère, force est de constater que le résultat obtenu ne coïncide pas ou mal avec cet intention. Tout d'abord parce que $O$ Favelado et Couro de gato semblent beaucoup plus expliquer les classes populaires aux classes moyennes que l'inverse. Chacun de ces deux films visent à dévoiler la vie de la favela à ceux qui l'ignorent et par là-même à dénoncer les préjugés que l'ignorance peut nourrir. Cette problématique n'est pas sans intérêt mais elle ne correspond pas à l'objectif du film. Notons ensuite, par rapport à un éventuel impact sur les classes populaires, que le schématisme de la représentation de la favela et l'inauthenticité qui en est la conséquence ne peut que discréditer les messages du film. Le choix systématique de situations-limites et de personnages caricaturaux ne permet ni de comprendre ce qu'est la favela, ni pourquoi elle ne cesse de grandir. L'une des erreurs les plus évidentes est de représenter la favela comme un espace géographique et sociologique coupé du reste du monde alors qu'elle est au contraire le produit direct du restant de la société avec laquelle ses relations économiques sont intenses. Notons qu'une bonne partie de la population des favelas, et pas seulement les enfants, travaillent dans les villes. 
Enfin, au contraire de Bahia de todos os santos, Os Cafajestes ou même Porto das Caixas, production contemporaine critiquée par Martins pour les mêmes motifs, Cinco vezes favela se caractérise par son classicisme dans les prises de vue, l'enchaînement des plans et le montage. Nous n'y relevons pas non plus d'effets de distanciation autrement que dans l'ambiguïté de la conclusion de certains épisodes comme Zé da Cachorra. L'incapacité de l'ensemble à participer d'une expression authentique de la favela et ces caractéristiques formelles mettent en évidence les contradictions internes au film en lui-même. Comme l'a déjà expliqué Bernardet :

« As estórias foram elaboradas para ilustrar idéias preconcebidas sobre a realidade, que ficou assim escravizado, esmagada por esquemas abstratos. [...] É uma espécie de realidade asséptica que permite uma interpretação única : a do problema enunciado. Além disso, o problema tende a ser apresentado junto com sua solução [Nous avons montré que les solutions présentées étaient souvent de portée limitée, sans remise en cause fondamentale du système, ou ambiguës, comme dans Zé da Cachorra . [...] O resultado dessa estrutura dramática simplista não era um convite à politização mas sim à passividade. [...] $\mathrm{O}$ espectador encontra-se diante de um circuito fechado : a realidade só se abre para um único problema, que está apresentado esquematicamente ; o problema tem uma única solução positiva, que também está apresentada esquematicamente [...]. O filme fecha-se sobre si próprio, e o espectador, limitando sua participação a aceitar ou recusar, fica de fora. $\rangle^{512}$

Il apparaît finalement que Cinco vezes favela est un film à mi-chemin entre deux options opposées, soit le film militant au discours fermé conduisant à une conclusion unique, claire et sans ambiguïté, soit le film de recherche sociale, voire ethnologique, de découverte de la favela, sans scénario rédigé en avance, mais avec une préparation cinématographique et scientifique ayant pour objectif de mettre les spécificités du cinéma au service de la connaissance du réel. Notons que le concept critique original du Cinema Novo se rapproche plus de cette seconde option, en ce sens, Cinco vezes favela s'en éloigne et doit être compris comme une œuvre de jeunesse, ses auteurs se cherchent encore. Notons aussi que les contradictions que nous avons relevées et commentées n'expliquent que très partiellement son échec commercial. D'abord, parce que beaucoup de films, techniquement imparfaits, usant et abusant des stéréotypes sociaux et conduisant à des conclusions sans nouveauté, rencontrent le succès. Ensuite, parce qu'il est impossible de juger de l'impact du film sur le public à partir d'une donnée quantitative alors que celui-ci n'a pas disposé d'une promotion et d'un circuit de diffusion qui le mette vraiment à la disposition du public. Enfin, à l'exception des critiques de

512 « Les histoires ont été élaborées pour illustrer des idées préconçues sur la réalité qui a été ainsi réduite, écrasée par des raisonnements abstraits. [...] C'est une espèce de réalité aseptique qui ne permet qu'une seule interprétation : celle du problème énoncée. En plus de cela, le problème est souvent présenté avec sa solution. [...] Le résultat de cette structure dramatique simpliste n'était pas une invitation à la politisation mais plutôt à la passivité. [...] Le spectateur se heurte à un circuit fermé : la réalité s'ouvre seulement sur un seul problème, qui est présenté de façon schématique ; le problème possède une solution positive unique, qui est aussi présentée de façon schématique [...]. Le film se ferme sur lui-même, et le spectateur, limitant sa participation à accepter ou refuser ce qui lui est dit, reste en-dehors du film. » in BERNARDET, Jean-Claude. Brasil em tempo de cinema. Rio de Janeiro, Paz e Terra, 1967, p. 31. 
cinéma, et d'autres éventuelles répercussions dans la presse, d'un point de vue qualitatif, nous ne savons rien de sa réception par le public qu'il visait : les classes populaires. Nous ne savons même pas si le film a jamais été vu par des membres de ces classes. Aucun témoignage ne porte là-dessus. Cinco vezes favela inaugure alors la principale ambiguïté du Cinema Novo de la première phase, cette ambiguïté sur la destination du discours que nous avons relevée dans la forme même du film se retrouve dans les commentaires et les analyses. Personne ne se soucie de savoir ce que les favelados peuvent penser du film. Centre de toutes les attentions déclarées au début du processus filmique, le peuple a complètement disparu à la fin.

\section{Ganga Zumba}

Le premier long métrage de Diegues qui sort en 1964, Ganga Zumba, est une expérience à part. Diegues, ne l'oublions pas, succède à Martins à la présidence du CPC juste après la polémique qui a divisé le mouvement étudiant autour de la question du cinéma révolutionnaire. Son film est réalisé dans le courant de l'année 1963, il est une réponse à la problématique qui agite alors les milieux intellectuels liés à la recherche d'un art participatif. Éloigné des audaces formelles de Os Cafajestes et Porto das Caixas, éloigné également de la complexité du propos de chacun de ces deux films, il est une tentative de renouer avec l'immédiateté et la clarté de Cinco vezes favela tout en évitant les écueils de la caricature et de la démagogie. La solution choisie par le jeune cinéaste est celle du film historique, à la mode finalement des collections Cadernos do povo brasileiro $^{513}$ ou encore Retratos brasileiros des éditions Civilização Brasileira, autrement dit de publications didactiques dont l'objectif était de transmettre l'histoire des grands événements et des grands hommes qui, dans l'histoire du Brésil, avaient lutté contre le système établi, c'est à dire contre l'impérialisme, le latifundium et l'esclavage. Le film est d'ailleurs une adaptation d'un roman de João Felício dos Santos ${ }^{514}$ publié en 1962 par cet éditeur qui, depuis les années cinquante, donne la parole à l'élite intellectuelle progressiste et s'exposera pendant la dictature aux aléas de la censure, directe ou indirecte, aux attentats d'extrêmes droite et aux persécutions policières ${ }^{515}$.

513Cette collection est réalisée en association par les éditions Civilização Brasileira et le CPC.

514SANTOS, João Felicio. Ganga-zumba. Rio de Janeiro : Civilização Brasileira, 1962. Le même auteur s'est spécialisé dans le roman historique et a écrit sur des personnages aussi emblématiques que Carlota Joaquina, le major Calabar, Xica da Silva ou encore Anita Garibaldi.

515La Civilização Brasileira est une maison d'éditions de Rio de Janeiro spécialisée dans les livres didactiques et déjà ancienne lorsqu'en 1951, elle est reprise en main par Ênio Silveira. Ce personnage reformule totalement sa ligne éditoriale, publie des œuvres internationales déjà consacrées et attire à lui l'élite intellectuelle progressiste afin d'offrir un catalogue qui réponde aux interrogations de son temps et participe à l'élaboration d'un projet de nation. À la fin des années cinquante, la sûreté des choix d'Ênio Silveira a déjà fait de sa maison d'édition l'une des plus prestigieuses du pays.

Parallèlement à cette ascension, celui-ci s'est progressivement de plus en plus impliqué en politique. Il fit parti des cadres du Parti Communiste qui, dans la période qui a suivi la dénonciation des crimes du stalinisme 
Ganga Zumba est le nom du premier roi de Palmares qui, au XVIe siècle avait réussi à unir les différents villages (mocambos) créés par les noirs ayant fui l'esclavage et s'étant réfugié dans l'intérieur des terres de ce qui constitue aujourd'hui l'état d'Alagoas, dans le Nordeste du Brésil. Il parvient ainsi à faire du quilombo de Palmares un véritable état qui, à son apogée, s'étend sur $27000 \mathrm{~km}^{2}$ d'une terre bien irriguée et fertile ${ }^{516}$. Pour signe de la prospérité du quilombo, la population atteint 20000 personnes. À la même époque, en 1672, la population totale du Brésil est estimée à 200000 personnes dont 110000 esclaves noirs. Le protagoniste principal du film de Carlos Diegues est Zumbi, neveu de Ganga Zumba, qui est choisi par la communauté de Palmares pour succéder à son oncle accusé de trahison après la signature d'un traité de paix avec les portugais. Zumbi deviendra un grand chef militaire qui permettra au quilombo de résister près de vingt ans aux expéditions militaires ayant pour objectif sa destruction complète (de 1674 à 1694). Le second roi de Palmares est devenu par la suite le symbole de la résistance afro-brésilienne à l'oppression politique et culturelle de la société blanche.

Ganga Zumba retrace la fuite de Zumbi de la maison des esclaves (senzala) dans laquelle il était retenu prisonnier et son voyage vers Palmares. Au début, Zumbi ${ }^{517}$ n'est qu'un

par Kroutchev, ont profondément remanié les orientations du parti. Partisan d'un discours humaniste, réformiste et nationaliste, son évolution est parallèle à celle de l'ISEB dont la Civilização Brasileira publie les textes. Celle-ci devient alors la référence quant à la ligne officielle du parti et participe à l'amplification du débat sur les inégalités sociales et l'urgence de la révolution brésilienne.

Pendant la présidence de Goulart, alors que les tensions se font de plus en plus vives, la Civilização Brasileira défend ouvertement les réformes de base et resserre ses liens avec les intellectuels de l'ISEB et du CPC. La réalisation de la collection Cadernos do Povo Brasileiro, em 1963, constitue la preuve de ce rapprochement. Le coup d'État de 1964 ne porte pas immédiatement préjudice aux activités et à la ligne éditoriale de l'entreprise qui atteint son plus haut volume de publications, diffuse les classiques du marxisme et des jeunes auteurs brésiliens influencés par le marxisme européen comme comme Carlos Nelson Coutinho e Leandro Konder. 1965 est aussi l'année de la sortie de la Revista da Civilização Brasileira qui est une tribune offerte à l'opposition contre les militaires et la politique libérale qu'ils appliquent. Le premier numéro de la revue est consacré à la révolution russe.

Les collaborateurs les plus réguliers de la revue, le «groupe » Civilização Brasileira, était composé par Antônio Callado, Carlos Heitor Cony, Nélson Werneck Sodré, Antônio Houaiss, Ferreira Gullar, Leandro Konder, Moacyr Félix, Manoel Cavalcanti Proença, Alex Viany, Dias Gomes e Paulo Francis. Viany fit entrer dans les pages de la revue la parole des cinemanovistas au travers de longs entretiens. Gustavo Dahl et Jean-Claude Bernardet y publièrent aussi des articles importants.

À partir de 1966, la maison d'éditions se ressent pourtant des persécutions directes ou indirectes des militaires qui, plutôt que d'imposer l'arrêt de ses activités de façon autoritaire, préfèrent en miner les bases matérielles et humaines. Des restrictions quant à l'obtention de crédit bancaire, diverses pressions sur les points de vente, l'appréhension et la destruction d'originaux et d'éditions complètes, sont les méthodes utilisées pour provoquer la faillite de l'entreprise. La répression atteint son apogée entre 1968 et 1976 avec des attentats à la bombe et des incendies criminels. Parallèlement, Silveira et les collaborateurs les plus prestigieux de la revue sont victimes de persécutions policières et d'emprisonnements arbitraires.

516Le quilombo de Palmares est une sorte de république créé par les noirs en rébellion et ayant résisté plus d'un siècle (1580-1694) aux tentatives de destruction de la société esclavagiste coloniale. D'autres quilombos de moindre importance sont apparus entre le XVIe et le XIXe siècle dans tous les états ayant eu recours à la main d'œuvre esclave lors des grands cycles économiques de l'histoire du Brésil (la canne à sucre et le Nordeste, l'or et les Minas Gerais ainsi que l'état de Rio de Janeiro, etc.).

$517 \mathrm{Il}$ existe dans le film une certaine confusion quant aux repères historiques, il semble parfois que les noms de Zumbi et Ganga Zumba soit intervertis ou alors qu'ils apparaissent comme les titres attribués au leader de la communauté noire. Ainsi, au début du film, c'est un messager de Zumbi qui vient chercher le jeune futur roi 
jeune esclave comme les autres, courtisant ses compagnes d'infortune et se révoltant contre les mauvais traitements qui sont infligés aux noirs. Le quilombo apparaît dans les discours des esclaves comme un lointain symbole de liberté dont l'existence même semble parfois remettre au mythe. Le jeune homme qui deviendra roi, ne sait lui-même que peu de choses sur le quilombo puisqu'il fut enlevé par les blancs encore nouveau-né pour être remis en captivité. Le film adopte la structure classique de la course-poursuite, puisque, l'évasion réalisée, le futur Zumbi / Ganga Zumba et ses compagnons sont poursuivis par des chasseurs à la solde des grands propriétaires. Mais l'étrange paradoxe de Ganga Zumba est qu'il s'agit d'une épopée intimiste. Par faute de moyens, la narration est centrée autour du petit groupe de fuyards. Le destin glorieux de Zumbi ne fait jamais de doute mais ce voyage en quête de Palmares représente le contraire de ce que sera sa vie future. Indistinct de ses compagnons, Zumbi ne gagne son nom définitif qu'à la fin du film, dans l'affrontement avec les chasseurs blancs, juste avant d'arriver au quilombo. De Palmares et des grandes batailles futures, le spectateur ne verra rien. Le fait que les scènes d'action soient rares et que la majeure partie du film se déroule pendant la nuit renforcent le caractère intimiste de la fiction.

Ganga Zumba est aussi un voyage initiatique puisque le futur roi va rencontrer d'autres noirs de diverses conditions l'amenant à prendre conscience des problèmes qui leur sont communs à tous. Dès la première séquence, avant le générique, nous voyons une esclave noire à demi-nue, morte et encore attachée au pilori où elle a été battue. Par la suite, nous rencontrons une esclave fort bien habillée qui bénéficie de la condition avantageuse de dame de compagnie. Nous apprenons aussi que des noirs se suicident par nostalgie de l'Afrique. Certaines rencontres frisent l'onirisme comme celle d'une beau jeune homme, esclave en fuite, qui, plutôt que de rejoindre un quilombo, préfère vivre en ermite et séduit la petite amie de Zumbi. Celle-ci préférera rester avec lui plutôt que de découvrir Palmares. Ces rencontres sont ponctuées par les déclarations des personnages quant à leur condition qui guident l'interprétation du spectateur par rapport aux scènes qui lui sont montrées :

«Tem escravo branco de branco, preto de preto, a gente tem de ser dono de si mesmo. »

« A gente vai lutar como bixo para não ser bixo mais. »

Ou encore :

«Tem de fazer alguma coisa. Tem muita gente que não quer ser bixo. ${ }^{518}$

et par la suite, les dialogues se réfèrent au vieux roi en l'appelant Zumbi, dans la séquence finale, le futur roi est appelé Ganga Zumba. Or, comme nous l'avons dit, dans l'histoire, c'est Zumbi qui succède à Ganga

Zumba et non le contraire. Le carton initial du film confirme cette inversion.

518 « Il y a des blancs qui ont des esclaves blancs, il y a des noirs qui ont des esclaves noirs, chacun doit être maître de lui-même. »; « Nous allons lutter comme des bêtes pour ne plus être traités comme des bêtes. »; «Il faut faire quelque chose. Il y a beaucoup de gens qui ne veulent plus être ravalés à l'état de bêtes. » 
Le caractère de «mot d'ordre » de ces petites phrases dont il est facile d'imaginer la résonance dans le contexte des années soixante est contrebalancé par le rythme lent de la fiction qui se présente comme une parenthèse, hors du temps, à la frontière du mythe, dimension renforcée par l'intimisme (des personnages coupés du monde) et l'aspect improbable de certaines rencontres. Une fois de plus, la transformation, au sein de la diégèse, est située dans l'après, le spectateur n'y assistera pas mais il sait qu'elle commence quand Zumbi prend son nom et qu'elle se réalisera à Palmares. Cette transformation prête cependant à caution du fait de certains indices disséminés au fil de la narration. De quelle transformation s'agira-t-il ? D'une simple inversion des rôles, les noirs devenant maître des blancs ? Le doute est transmis aux spectateurs par certaines phrases de dialogue, dont la première que nous avons citée et par certaines situations comme celle de ce jeune homme noir, également fugitif et apparemment intelligent, qui préfère rester à l'écart des quilombos. Le fait cependant que le chasseur d'esclaves décapité par Zumbi dans la dernière séquence soit noir est emblématique. Le premier long métrage de Carlos Diegues colle donc bien à l'analyse qui en est faite aujourd'hui par son auteur: Ganga Zumba est un film sur la liberté et ce que l'on en fait.

Réalisé dans le courant de l'année 1963, le long métrage aurait pu ne pas voir le jour. Il devait initialement être produit par la Tabajara Filmes qui avait déjà distribué Cinco vezes favela. Spécialisée dans la distribution de films soviétiques, cette entreprise possédait aussi des infrastructures et devait pourvoir au prêt d'équipement, à la fourniture de pellicule vierge et aux frais de laboratoires. Au bord de la faillite, la Tabajara Filmes cesse de remplir ses obligations en cours de tournage et Diegues doit alors partir à la recherche d'un nouveau producteur. C'est à ce moment-là que Jarbas Barbosa sauve le film selon les circonstances que nous avons déjà racontées. Le film est conclu au terme de deux mois de tournage et de vingt jours de montage, doublage et mixage à Rio de Janeiro.

Ganga Zumba ne déchaîne pas les passions qu'ont provoquées avant lui Os Cafajestes ou Porto das Caixas. La sortie du film reçoit une couverture médiatique assez importante de la part de la presse qui, cependant, ne discute pas l'œuvre en profondeur. Plusieurs journalistes mettent l'événement à profit pour interroger Diegues sur l'actualité des réformes en matière de législation dans le domaine du cinéma. Ganga Zumba sort dans dix ou douze salles ${ }^{519}$ au début de mars 1964 et il n'est ni un grand succès, ni un échec fracassant. Nous n'avons trouvé qu'un texte analysant le film de Diegues d'un point de vue politique. Il s'agit d'un article très négatif $^{520}$ paru dans $O$ Diário Carioca où il est reproché au cinéaste d'avoir réalisé un film

519MARCORELLES, Louis. «Rencontre avec le Cinema Nôvo : Joaquim Pedro de Andrade, Gustavo Dahl, Carlos Diegues, Leon Hirszman, Glauber Rocha, Paulo Cézar Saraceni » in Cahiers du cinéma, Paris, nº176, mars 1966, p. 53.

520Parmi les critiques les plus en vue, Moniz Vianna et Humberto Didonet, sont assez lapidaires et ne 
lyrique, plein de bonnes intentions et qui souffre de ses imprécisions historiques comme de son innocuité politique. L'article semble imprégné par les écrits de Nelson Werneck Sodré et dit en substance que l'on peut certes condamner l'esclavagisme, comme le cinéaste le fait, mais qu'il faudrait plutôt se demander s'il existaient d'autres solutions que le recours au travail esclave pour coloniser le Brésil. Autrement dit, il estime que Diegues ne prend guère de risque à condamner l'esclavagisme et que son film ne permet pas de comprendre la complexité et les contradictions de l'histoire. Pour lui, le romantisme du cinéaste l'empêche d'atteindre une réelle pertinence politique:

«O que acusamos no filme de Cacá é o obscuro. O medo de ter atacado realmente um dos mais emocionantes problemas do mundo moderno, que é o problema negro. Cacá fugiu para o evanescente, para o mais fácil, o que é lastimável.

A temática de Ganga Zumba inspira o épico, dá margem para que se estabeleça o conflito de classe, uma rara oportunidade para se explicar ao Brasil um dos entraves ao seu desenvolvimento. Cacá, porém, é um lírico, tremendamente lírico. Chega a colocar no filme inclusive um personagem estranho, um escravo meio 'play-boy' meio existencialista, que não é a favor dos negros nem dos brancos, mas de ir passear à noite, sozinho para tomar banho de mar e olhar a lua. $>{ }^{521}$

En n'exploitant pleinement ni l'épopée, ni l'analyse historique, qui était deux orientations possibles à ce sujet, Diegues échouerait donc à réaliser un film utile au contexte de 1964. Ganga Zumba ne réaliserait donc pas les objectifs qu'il affiche à l'époque :

« Nosso intuito foi fazer uma fábula, procurar encontrar o elo que ligue a consciência, cultura espontânea das massas a um grau mais elevado de crítica à realidade. Assim é que praticamente construímos um conto, com moral e tudo, em que situações, apesar de não serem rigidamente realistas, possam servir como exemplo de um comportamento para outras análogas e fundamentais no panorama humano e social do mundo moderno. $)^{522}$

reconnaissent à Ganga Zumba aucune qualité, mais leurs arguments sont exclusivement techniques. Le texte de Didonet est d'ailleurs représentatif du type de critique que les cinemanovistas voulaient voir disparaître. Le critique de Porto Alegre note les films en suivant la grille traditionnelle : scénario, direction, interprétation, musique...etc... Dans le cas de Ganga Zumba, tout est nul. Malgré quelques très mauvaises critiques, le premier long métrage de Diegues a bénéficié d'un bon accueil.

VIANA, Antônio Moniz. «Deus e o diabo na terra do sol » in Correio da manhã, Rio de Janeiro, mars 1964.

DIDONET, Humberto. « Ganga Zumba » in Jornal do dia, Porto Alegre, 29/07/1964.

521 « Ce que nous condamnons dans le film de Cacá, c'est son manque de clarté. La peur de s'attaquer réellement à l'un des plus émouvants problèmes du monde moderne qui est la question noire. Cacá a fui vers l'évanescent, vers le plus facile, ce qui est regrettable.

La thématique de Ganga Zumba suggère une narration épique, il offre l'opportunité de décrire le conflit de classes et d'expliquer au Brésil l'une des principales entraves de son développement. Cacá, cependant, est lyrique, extrêmement lyrique. Il parvient même à glisser dans son film un personnage étrange, un esclave à moitié ' play-boy ', à moitié existentialiste, qui n'est à faveur ni des noirs, ni des blancs, mais qui aime se promener la nuit tout seul, se baigner et regarder la lune. » in « Brancos e negros vão juntos para Palmares » in Diário carioca, Rio de Janeiro, 10/03/1964.

522 « Notre idée était de réaliser un conte, de trouver le lien qui lie la conscience, la culture spontanée des masses à un degré plus élevé de critique du réel. C'est ainsi que nous avons construit cette histoire avec une morale, dans laquelle les situations, bien que n'étant pas rigidement réalistes, peuvent servir comme modèle de comportement pour d'autres analogues et fondamentales dans le panorama humain et social du monde 
Il apparaîtra pourtant après coup que Ganga Zumba constituait une exception dans le panorama cinématographique de l'année 1964. Selon Bernardet, c'est le seul film brésilien dans lequel la figure du leader n'intervient pas pour assurer la médiation entre les classes dominantes et les opprimés et il ne s'agit pas non plus d'un film qui aille dans le sens de leur intégration au système hégémonique. Zumbi est un leader désigné par la communauté, peu importe qu'il soit un roi, pour accomplir sa politique et non une politique décidée pour elle, supposée trop ignorante ou aliénée pour avoir conscience de sa propre situation ${ }^{523}$. Quelques années plus tard, alors qu'il présente le film dans un programme de ciné-club, Diegues reprend cette remarque à son compte ${ }^{524}$. Mais, au moment de réaliser le film, sa posture était tout autre comme le montre la déclaration suivante, caractéristique de la façon de penser de l'époque :

«Acredito na fábula como exemplo, como meio de comunicação entre um cineasta pequeno-burguês e o povo que, na sua maioria, ainda não adquiriu consciência da sua problemática própria em termos objetivos. ${ }^{525}$

Il apparaît alors un décalage saisissant entre la posture du film, dans lequel la communauté révoltée a pris en main son destin, et celle du cinéaste, pour qui la communauté non seulement n'a pas pris en main son destin mais encore est aliénée et insuffisamment révoltée. De cette contradiction est née une fable, ou trop en avance sur son temps car elle se pose le problème de ce qui sera fait une fois la révolution réalisée, ou trop en retard car elle vise à provoquer la prise de conscience de la population potentiellement révolutionnaire de sa capacité à agir. Le coup d'état de la fin du mois de mars devait cruellement rappeler à quel point l'épopée de Palmares appartenait au domaine de l'utopie. Le choix de la fable est peut être au cœur des équivoques car elle pose à la fois, dans le contexte qui nous intéresse, le problème de la qualité du diagnostic sur la situation en court (ici, erroné), et celui de la profondeur de la morale (la partie du film la plus pertinente ${ }^{526}$ ). Nous retrouverons l'inspiration mythologique et épique de Ganga Zumba dans Deus e o diabo na terra do sol.

moderne. » in ACUIO, Carlos. « Ganga Zumba estréia importante da semana » in Diário carioca, Rio de Janeiro, 01/03/1964.

523BERNARDET, Jean-Claude. Brasil em tempo de cinema. Op.cit., p. 65.

524 DIEGUES, Carlos. « Ganga Zumba: Apresentação de Carlos Diegues » in Cineclube Cinuca, sans lieu, sans date.

525 «e crois au conte comme exemple, comme moyen de communication entre un cinéaste petit-bourgeois et le peuple qui, dans sa majorité, n'a pas encore acquis la conscience de sa problématique propre en termes objectifs. » in « Ganga Zumba : Cinema Nôvo brasileiro » in O Jornal, Rio de Janeiro, 01/03/1964.

526La morale du film est intéressante pour les raisons indiquées par Bernardet mais aussi parce que la structure narrative place la transformation dans un après diégétique qui est aussi un après non-diégétique. Parler sans cesse de Palmares sans le voir et d'arrêter la narration juste au moment d'y pénétrer confère au mythe une certaine force. 


\section{Maioria absoluta}

Le second film d'Hirszman après Pedreira de São Diogo est un documentaire de 16 minutes sur l'analphabétisme au Brésil. Ce thème n'est évidemment pas choisi au hasard puisque, comme nous l'avons déjà vu, la lutte pour l'alphabétisation représente un enjeu politique majeur dans le Brésil du début des années soixante. Avec Maioria absoluta, Hirszman signe l'un des rares films à traiter sans équivoque un sujet d'affrontement entre la droite et la gauche. Hirszman s'interdit pourtant d'évoquer les luttes partisanes. Ce qui l'intéresse avec Maioria absoluta, c'est de montrer que l'interdiction de voter faite aux analphabètes, s'inscrit dans une large série de dispositifs visant à museler les classes populaires. Les analphabètes sont la majorité absolue et, s'il leur est interdit de voter, c'est justement pour que puisse se perpétuer l'exploitation économique dont ils sont victimes.

Selon le témoignage qui nous a été apporté par Eduardo Coutinho ${ }^{527}$, malgré le fait que ce film ait souvent été associé au CPC et à l'UNE, Hirszman en a obtenu le financement directement auprès du Ministère de l'Éducation, sans médiation. Tout indique que la genèse du film doit être replacé dans ce contexte de grande proximité entre le gouvernement et les partis ou syndicats de gauche dont l'UNE. Rien cependant ne filtre des diverses entrevues accordées par Hirszman quant aux circonstances exactes de la préparation de ce court métrage $^{528}$. Maioria absoluta est tourné au second semestre de 1963 au Pernambouc et à Rio de Janeiro. Le montage date du premier trimestre 1964 mais le film n'est doublé qu'après le 1er avril. Le générique rassemble plusieurs éléments du Cinema Novo : Pereira dos Santos au montage, Jabor au son et Neves à la production. Ferreira Gullar, en voix off, dit le texte qu'il a écrit ${ }^{529}$. Le doublage est réalisé dans la clandestinité sans que l'équipe n'ait apparemment nourri la moindre illusion quant à ses chances de pouvoir être diffusé au Brésil ${ }^{530}$. Par l'intermédiaire de Neves, le film est envoyé à l'étranger et sera projeté à la fin du quatrième festival du cinéma latino-américain organisé par le Columbianum à Gênes. Maioria absoluta remporte lors de sa projection un énorme succès et acquiert le statut de film « culte $»^{531}$. Il est vu par très peu de personnes mais il est très apprécié et considéré comme un moment fort de

527Eduardo Coutinho. Entretien avec l'auteur, juin 2003.

528Salem ne nous apporte pas non plus d'informations sur ce sujet dans sa biographie d'Hirszman. SALEM, Helena. Leon Hirszman : o navegador das estrelas. Op. cit., pp. 146-153.

529Cf. VIANY, Alex. O processo do Cinema Novo. Op. cit., p. 292.

530Selon les archives de la censure, le film n'est pas présenté pour obtenir son visa d'exploitation avant 1981.

Or, tous les témoignages concordent pour dire qu'il a été interdit par la dictature, sans plus de détail. Il se peut fort bien que l'interdiction ait été exprimée par des voies informelles mais nous pensons plutôt que le film n'est pas visé par la censure parce que ses auteurs craignent de s'exposer et renoncent par anticipation à affronter une procédure lente, risquée et hasardeuse.

531Le film n'a pas été projeté au Brésil avant les années quatre-vingt. $C f$. VIANY, Alex. O processo do Cinema Novo. Op. cit., p. 293. 
l'histoire du Cinema Novo et du $\mathrm{CPC}^{532}$.

Le film commence avec un rapide exposé de son propos : «O tema deste filme não é a alfabetização mas o analfabetismo que marginaliza 40 milhões de irmãos nossos. Decidimos indagar as causas através da opinião e do depoimento de pessoas que vivem em diferentes níveis o problema brasileiro. ${ }^{533}$ Suit une compilation de témoignages recueillis à la plage, dans une belle maison, dans la rue, de personnages de la classe moyenne qui répètent des lieux communs et expriment à la fois leur désintérêt et leur méconnaissance du problème. La voix off apporte des données statistiques. Par la précision de ses informations et la rigueur du raisonnement, elle ridiculise ces premières interprétations dont elle s'écarte clairement. Elle passe ensuite la parole aux analphabètes : «Passemos à palavra do analfabeto. Eles são a maioria absoluta. $»^{534}$ Ayant été établi que l'analphabétisme ne sévit pas dans les centres urbains mais dans les campagnes où les revenus sont faibles et les services sociaux absents, le film nous emmène au Nordeste. La femme d'un homme malade auprès de son mari, une mendiante et surtout de nombreux paysans témoignent. Aucun n'évoque l'analphabétisme mais l'ensemble de leurs paroles ainsi que leurs visages prématurément ridés et leurs habits usés portent à notre connaissance les dures conditions d'une vie sans perspective, où le produit du travail éreintant de chacun peine à assurer l'alimentation quotidienne. Les responsables désignés de cette situation sont le latifundium et la monoculture :

Un paysan : « Quando os homens querem só apurar na cana, cana macia, cana pura, ninguém vê um pedaço de mandioca nenhum, de planta, nenhum de milho, nem favo de algodão, agora, volta e meia chega gente, aí muda essa situação completamente, escutando moço ? É o que se vê dentro da classe. [...] Se eu tivesse uma terra mais salgada, tivesse um pedaço de terra salgada, e lavrada e uma coisa que eu plantasse, desse até a minha vida era muito mais saudável, trabalhando. ${ }^{535}$

Un autre témoignage stigmatise l'achat des votes des paysans par les grands propriétaires, le dernier raconte comment l'administrateur de la fazenda où il vit, a arraché les plants de mandioca qu'il cultivait sur une aire inoccupée afin de ne plus avoir à acheter les produits alimentaires de première nécessité :

Un autre paysan : «Que plantar uma coisa prá passar a minha fome, a fome dos meus filhos, da

532Cf. ibid., p. 293 et SARACENI, Paulo César. Op. cit., p. 172 et 181.

533 «e thème de ce film n'est pas l'alphabétisation mais l'analphabétisme qui marginalise 40 millions de nos frères. Nous avons décidé d'enquêter sur les causes de ce problème brésilien en recueillant l'opinion et le témoignage de personnes qui vivent l'analphabétisme à différents niveaux. » (Voix off du film).

534« Passons la parole aux analphabètes. Ils sont la majorité absolue. » (Voix off du film).

535 « Quand les hommes veulent seulement cultiver la canne à sucre, une canne à sucre tendre et pure, personne ne voit de mandioca, de maïs, ni même une fève de coton, maintenant, si au contraire il vient du monde, la situation change, tu m'écoutes, jeune homme ? C'est ce dont on se rend compte au sein de la classe. [...] Si j'avais une terre plus fertile, si j'avais un lopin de terre fertile, et cultivé avec ce que je pourrais planter, à partir de là ma vie serait beaucoup plus saine, tout en travaillant. » (Dialogue du film) 
minha esposa, prá então vir um administrador de engenho arrancar, com terra desabitada [...] É essa situação que nós viemos agora, pedimos às autoridades que desse um direito ao camponês, não de tomar o que era do homem, mas de justiça ! É o que nós precisamos. $\gg{ }^{536}$

Selon le témoignage de Neves ${ }^{537}$, Maioria absoluta fut l'un des premiers films brésiliens avec Integração racial, O Circo et Memória de cangaço à bénéficier du son direct. Ceci avait été rendu possible grâce à l'obtention par Andrade d'une caméra avec Nagra (enregistreur permettant la synchronisation du son avec l'image) auprès de la Fondation Rockfeller. La possession de ce matériel rendait enfin possible la pratique du cinéma-vérité qui fascinaient tant les cinemanovistas depuis au moins Arraial do Cabo. Nous nous souvenons que celui-ci, sans matériel léger, n'avait pu retenir du cinéma-vérité que l'approche ethnologique. Maioria absoluta manifeste bien dès l'exposé de son propos l'intention de reprendre la méthode du cinéma-vérité basée sur la collecte de témoignages.

Malgré le contrat de lecture posé au début du film, il apparaîtra pourtant rapidement au spectateur que le court métrage recourt aux techniques du cinéma direct sans en être pour autant un représentant. Les règles édictées par Jean Rouch et Edgard Morin visent à l'effacement des auteurs du documentaire au profit de la révélation du réel par le témoignage des personnes qui y sont impliquées. L'intervieweur évite au maximum de se montrer directif dans le recueil des témoignages. Les personnes interrogées sont surprises dans leur activités quotidiennes. Le film est composé de fragments de réalité sélectionnés en fonction de leur authenticité selon l'appréciation du monteur. Les « accidents » et les «lapsus » sont souvent jugés révélateurs. L'œuvre est résolument ouverte. Il s'agit d'apporter au spectateur un ensemble hétérogène susceptible de « refléter» le réel en en exposant différents aspects. Or, bien que Maioria absoluta soit constitué d'une compilation d'entrevues filmées dans le cadre de vie quotidien des interviewés, la voix off et le montage manifestent l'intervention des auteurs et orientent ostensiblement l'interprétation du spectateur. Le discours filmique est construit de manière à démontrer une thèse et à impliquer le spectateur vis à vis de ses conséquences politiques et sociales. L'enchaînement rigoureux des plans et des séquences ne laisse aucune marge d'interprétation au spectateur et conduit à une conclusion unique qui correspond à la thèse défendue par le film.

Le film vise clairement à la prise de conscience par les classes moyennes urbaines de la situation des campagnes et de la réalité que recouvre le fléau désigné de l'analphabétisme.

536« À quoi ça sert de planter quelque chose pour se nourrir et nourrir sa famille si c'est pour voir venir l'administrateur de la plantation de canne à sucre et qu'il arrache tout, sur une terre qui était inhabité. C'est cette situation que nous venons de vivre, nous demandons aux autorités qu'elles donnent un droit aux paysans, pas le droit de prendre ce qui était à quelqu'un d'autre, mais le droit à la justice ! C'est cela dont nous avons besoin. » (Dialogue du film)

537NEVES, David. « Entrevista com Federico Cárdenas » in Hablemos del cine, Lima, n50-51, novembredécembre 1969 - janvier-février 1970. 
Le dispositif visant à cette prise de conscience repose d'abord sur la macrostructure du film et en particulier le contraste entre l'ignorance des personnages interviewés dans la première partie et la vérité telle qu'elle va nous être découverte au fur et à mesure de la progression de la narration. Or, l'identification du spectateur avec les personnages de la première partie est immédiate et ce pour plusieurs raisons. La première est que le spectateur brésilien de cinéma, dans son écrasante majorité, est un citadin, salarié, de classe moyenne ou ouvrière. Une grande part du public ne peut donc que se reconnaître ou reconnaître ses proches dans les personnages de la première partie. La deuxième raison à cette identification est que la sélection des témoignages a été soigneusement étudiée afin de refléter les lieux communs les plus répandus. La posture adoptée par le film est donc agressive puisqu'elle consiste à prendre le spectateur à défaut, le mettre en face à ses préjugés et ensuite les démonter.

La voix off du narrateur contribue largement à ce dispositif. Comme l'a analysé Bernardet, il s'agit d'une « voix du savoir ${ }^{538}$. En plus d'apporter des informations répondant à une codification scientifique (données chiffrées, informations géographiques et historiques), en plus d'introduire et de conclure les principales parties du film, cette voix du savoir juge de la validité des témoignages. Dans ses commentaires, elle confirme ou dément les propos des personnes interrogées en intervenant immédiatement après qu'ils aient été entendus ${ }^{539}$. L'organisation du discours filmique est fonction de ce jugement. La voix off oppose de façon dialectique la parole des représentants de la classe moyenne à celle des analphabètes. À une légitimation strictement verbale de leur parole, celle obtenue par l'approbation de leurs propos dans le commentaire, s'ajoute celle obtenue par le contraste né de la confrontation de la première partie du film avec la seconde. Les personnages de la classe moyenne se trompent grossièrement alors que les analphabètes identifient parfaitement les causes de leurs malheurs (le latifundium) et réclament justice (la réforme agraire). Cette confrontation est destinée à mettre l'emphase sur la justesse des représentations des classes populaires et à montrer à la classe moyenne qu'elle a tort de les estimer estimer incapables de raisonnement valide.

Mais montrer au spectateur qu'il nourrit des préjugés et que la réalité est autre que celle qu'il s'imagine ne suffit pas, il faut également l'engager à l'action. La voix off y contribue en cherchant à provoquer chez lui un sentiment de culpabilité. Comme l'a aussi montré Bernardet, l'utilisation $\mathrm{du}$ 《tu» et du «nous» dans le commentaire vise à impliquer le

538BERNARDET, Jean-Claude. Cineastas e imagens do povo. Op. cit., p. 33.

539Nous pourrons à ce titre établir un parallèle avec Memória do cangaço de Paulo Gil Soares. Ce documentaire commence avec l'exposé d'un professeur d'université sur le sertanejo alimenté par les théories déterministes et racistes de la fin du XIXe siècle pourtant depuis longtemps dépassées. À la fin de l'exposé, la voix off sanctionne. Les idées du professeur qui nourrissent des préjugés encore vivaces parmi la population, sont entièrement fausses. Commence alors l'enquête qui nous amène à découvrir les véritables causes du sousdéveloppement du Nordeste et de l'un de ses produits historiques, le cangaço. 
spectateur dans la situation qui est décrite ${ }^{540}$. Cette implication est renforcée par le recours à l'affect au travers de l'utilisation du mot « frères », de l'exaltation des liens patriotiques ou encore de la mise en évidence des liens de dépendance économique qui, dans une société, supposent la solidarité :

- dans l'introduction : «O tema deste filme não é a alfabetização mas o analfabetismo que marginaliza 40 milhões de irmãos nossos. »

- au milieu des témoignages des paysans : «Em 1964, fomos 80 milhões de brasileiros $\ldots \gg$

- à la fin : « Dos 40 milhões de brasileiros analfabetos, 25 milhões maiores de 18 anos estão proibidos de votar. No entanto eles produzem o teu açúcar, o teu café, o teu almoço diário. Eles dão ao país a sua vida e os seus filhos. E o país o que lhes dá ? $»^{541}$

Les stratégies du commentaire sont servies par le pathétisme qui émane des témoignages des paysans quant à leur misère et aux injustices dont ils ont été victimes mais aussi de leur image physique et de celle de leur milieu de vie.

Reste à indiquer les moyens de l'action. Le film se conclut par quatre plans de Brasília filmés à partir d'un hélicoptère et montrant en contre-plongée le palais présidentiel et le congrès. Il subsiste une ambiguïté quant à la procédure précise préférée par les auteurs du film, à savoir alphabétiser ou donner le droit de vote aux analphabètes directement ; quoiqu'il en soit, la solution passe par les institutions démocratiques du pays. Un montage sonore suggère que les députés pourraient s'intéresser à la condition des analphabètes. Sur le premier plan du congrès, bien qu'il s'agisse d'un plan extérieur, résonne le tumulte d'une séance parlementaire. Sur le dernier plan du congrès, on entend crier en son off « Atenção ! » comme si c'était le président du congrès qui avait crié cet ordre. Le cri est suivi d'un silence, raccord sur des plans montrant des paysans qui partent ou rentrent du travail. Nous comprenons donc que l'on attend du public (qui peut voter) qu'il fasse pression sur les élus ou se serve de son vote pour obtenir la réforme agraire et l'incorporation au corps des électeurs des analphabètes.

Le dispositif direct et sans ambiguïté de Maioria absoluta et sa parfaite identification $\mathrm{du}$ film avec l'idéologie du gouvernement Goulart sont les raisons de son absence de diffusion. De fait, ce film qui se distingue par sa « clarté » idéologique et qui est aussi l'un des rares films «fermés » du Cinema Novo, sinon le seul, est une expérience qui ne sera pas répétée. Plus jamais en effet, nous n'aurons de la part des cinemanovistas un film exposant de

540BERNARDET, Jean-Claude. Cineastas e imagens do povo. Op. cit., pp. 33-34.

541 « En 1964, nous avons été 80 millions de brésiliens... »; « Des 40 millions de brésiliens analphabètes, 25 millions sont majeurs mais le droit de vote leur est refusé. Malgré cela, ils produisent ton sucre, ton café, ton déjeuner quotidien. Ils donnent au pays leur vie et leurs enfants. Et le pays, que leur donne-t-il ? » (Voix off du film). 
façon aussi claire les ennemis à combattre et les méthodes à utiliser. Le retour au film ouvert, l'occultation ostensible de certains acteurs de la vie politique (les militaires) et le désinvestissement du documentaire au profit de la fiction, paradoxalement plus facile à réaliser et à diffuser, seront les règles de survie de ce cinéma en temps de dictature. 


\section{Chapitre 6 : Premières affirmations, la trilogie du sertão}

Entre deux orientations opposées, le film d'auteur sans thématique politique explicite et les films d'influence cepecista, et dans la continuité du cycle de Bahia, émergent des films manifestant le souci de traiter directement de la situation politique et sociale dans une forme mixte dans laquelle entrent en choc : les références à la cinéphilie des auteurs, des références à la culture classique brésilienne, des références à la culture populaire brésilienne, mais aussi une certaine résistance à la conceptualisation excessive du langage cinématographique par le biais d'une attitude anarchisante. Il s'agit ici d'intégrer les leçons d'Aruanda et de se défier autant des règles du cinéma classique que de celles de nouveaux cinémas. Dans des proportions diverses, les films de la trilogie du sertão tendent vers cette Esthétique de la faim qui sera conceptualisé a posteriori : au travers de la photographie de Vidas secas et Deus e o diabo na terra do sol, au travers du recours à un matériel populaire dans Deus e o diabo na terra do sol et Os Fuzis.

\subsection{Vidas secas et le réalisme critique}

L'adaptation du roman de Graciliano $\operatorname{Ramos}^{542}$ est un projet déjà ancien de Nelson Pereira dos Santos quand enfin il parvient à le réaliser entre la fin de l'année 1962 et le courant de 1963. L'idée surgit en 1958. Pendant cette période, Santos réalise des documentaires $^{543}$ et il a l'occasion de filmer la grande sécheresse qui s'abat sur les états de Pernambouc et Bahia. Son intérêt va à la situation d'extrême détresse des populations abandonnées à leur propre sort. Il écrit d'abord une sorte de compte-rendu journalistique mais

542Graciliano Ramos (1892-1953) est déjà considéré comme l'un des plus grands écrivains brésiliens du siècle quand Pereira dos Santos pense à adapter Vidas secas. Originaire d'Alagoas, il est maire de la ville de Palmeira dos Î́ndios de 1927 à 1930 puis directeur de l'Imprensa Oficial et de l'instruction publique de l'état de 1930 à 1936. Le Nordeste est la principale source d'inspiration de on œuvre qui commence en 1933 avec la publication de Caetés. Ce premier roman est rapidement suivi par São Bernardo (1934) et Angústia (1936). À l'époque de la publication de ce dernier, il est victime de la vague de répression policière qui succède à la tentative de soulèvement communiste de 1935. Il reste prisonnier pendant plus d'un an.

En 1938, il publie Vidas Sêcas et, un peu plus tard, il s'établit à Rio de Janeiro où il occupe les fonctions d'inspecteur fédéral de l'enseignement. En 1945, il entre au PCB qui vient d'être légalisé et publie un récit autobiographique, Infância. Les dernières années de sa vie sont consacrées à la rédaction de deux livres qui ne paraîtront qu'après son décès d'un cancer du poumon en 1953.

Le plus important d'entre eux est Memórias do cárcere (1953). Il s'agit du récit de sa détention comme prisonnier politique entre 1936 et 1937. Il y dénonce l'autoritarisme et les incohérences de la dictature qui s'installait alors au Brésil (L'Estado Novo est instauré le 10 novembre 1937). Pereira dos Santos adapte ce livre au cinéma en 1983.

543Dans une entrevue accordée à Viany en 1983, Pereira dos Santos déclare qu'il a réalisé un documentaire sur la vallée du São Francisco et un autre sur le barrage de Três Marias pour Isaac Rosemberg. Durant cette période, il a même travaillé pour Jean Manzon. In VIANY, Alex. O processo do Cinema Novo. Op. cit., p. 493. Ces documentaires ne sont pas connus et, à notre connaissance, n'ont jamais fait l'objet de la moindre étude. 
celui-ci ne le satisfait pas. C'est alors qu'il pense au roman publié par Ramos en $1938^{544}$. Le livre raconte l'histoire d'une famille composée par le père, Fabiano, la mère, Sinhá Vitória, deux petits garçons et leur chienne, Baléia, fuyant la sécheresse et errant dans la caatinga. L'une des principales caractéristiques de la narration est sa structure cyclique. Il est tout à fait possible de lire le premier chapitre comme une continuation du dernier. Au début et à la fin, la famille marche au travers des paysages arides à la recherche d'un endroit où s'installer. Une petite maison de torchis est découverte, le colonel, propriétaire de l'endroit, accepte que Fabiano s'installe en échange de quoi il doit travailler pour lui. La belle saison approche, Fabiano travaille comme vacher, la famille épargne quelques sous. Mais bientôt la sécheresse revient et avec elle la nécessité de migrer vers des terres meilleures. L'objectif de l'écrivain était de refléter une réalité sociale propre à cette région qu'il habitait. Le style décriture, extrêmement concis, vise à traduire la dureté de la situation en temps de sécheresse.

Le scénario est prêt en 1960, Santos réunit une petite équipe composée du chef opérateur de ses deux précédents longs métrages, Hélio Silva, et part pour Bahia afin de procéder au tournage. Arrivé sur place, au contraire de l'année 1958, 1960 se révèle pluvieuse, le paysage est complètement transformé et ne convient plus à cette histoire de sécheresse. Santos improvise une nouvelle histoire intitulée Mandacaru vermelho. Le tournage de Vidas secas est remis à plus tard. Une nouvelle occasion se présente en 1962 alors que Santos est en train de conclure son quatrième long métrage, Boca de ouro, pour le compte de Jece Valadão. Vidas secas est le premier film à bénéficier du succès de $O$ Assalto ao trem pagador. Les montages financiers des deux films sont à peu près les mêmes, ils sont co-produits par Herbert Richers et bénéficient de facilités de crédits auprès du BNMG par l'intermédiaire de son directeur José Luiz Magalhães Lins. Santos et Luís Carlos Barreto sont également coproducteurs. Pour ce dernier, il s'agit de sa première expérience en la matière. Cette structure permet d'offrir à Santos des conditions de travail qu'il n'a jusqu'à présent jamais connues. Même si le budget reste modeste par rapport aux productions internationales de l'époque (18 millions de Cr\$, soit $60000 \$ \$^{545}$ ), le cinéaste pourra par exemple se permettre de commencer le film en tournant chaque scène avec deux types différents de photographie.

Le premier, de type expérimental, est fait par Barreto dont c'est aussi la première expérience en tant que chef opérateur. Reporter photo de la prestigieuse revue, O Cruzeiro, Santos lui a demandé de transposer pour le cinéma le style qu'il pratique déjà dans le journalisme. En s'appuyant presque exclusivement sur la lumière naturelle, sans filtre, ni

544Selon le propre récit du cinéaste. In SANTOS, Nelson Pereira dos et alii. Manifesto para um cinema popular. Rio de Janeiro, Federação dos Cineclubes do Rio de Janeiro, Cineclube Macunaíma, Cineclube Gláuber Rocha, mars 1975, p. 10.

545SALEM, Helena. Nelson Pereira dos Santos - O Sonho possível do cinema brasileiro. Op. cit., p. 175. 
réflecteur, le chef opérateur devra transmettre la sensation de la lumière éblouissante, de la chaleur étouffante, et même de la poussière de la caatinga au travers de la surexposition de certaines parties de l'image et du grain de la photo. L'expérience est d'autant plus hasardeuse qu'elle est inédite et que les techniciens et les laboratoires brésiliens sont accoutumés aux techniques européennes classiques d'éclairage. Pour diminuer au maximum les pertes que pourraient causer ces expérimentations si leur résultat se révélait inexploitable, toutes les scènes sont filmées une seconde fois selon la méthode académique par le deuxième chef opérateur, également cameraman, José Rosas. Celui-ci est un collaborateur de Richers de longue date, un professionnel aguerri qui règle patiemment l'ouverture de son diaphragme en fonction des indications du photomètre. $\mathrm{Au}$ bout d'un mois, les premières épreuves parviennent sur les lieux du tournage. Santos et Barreto sont pleinement satisfaits par leur travail. À partir de ce moment-là, les scènes ne seront plus doublées.

Le tournage lui-même a lieu à proximité de Palmeira dos Índios, la ville où vécurent Ramos et ses personnages, en Alagoas. L'idée initiale de Santos était de n'utiliser que des acteurs non-professionnels, recrutés sur les lieux mêmes du tournage. Il s'agit là d'une intention inédite dans le long métrage de fiction cinemanovista car, malgré l'influence forte du néo-réalisme italien, ses personnages principaux sont toujours joués par des acteurs professionnels, quand bien même ils seraient débutants. Les acteurs de théâtres sont privilégiés, certains comme Paulo Autran ${ }^{546}$, Leonardo Vilar ${ }^{547}$ ou encore Sérgio Cardoso ${ }^{548}$ possèdent une formation classique, d'autres sont passés par le Teatro de Arena comme Paulo José $^{549}$, le CPC ou encore l'Escola de Teatro da Universidade de Bahia ${ }^{550}$. Certains ont été formés par la radio ou la télévision. Les non-acteurs du Cinema Novo, Antônio Pitanga ${ }^{551}$, Luíza Maranhão, Leila Diniz, Jofre Soares, Arduíno Colossanti, Márcia Rodrigues, deviennent très rapidement des professionnels et ne jouent pas dans leurs premiers films ce qu'ils sont dans la vie. L'intention de Santos de recruter parmi la population locale les acteurs de Vidas secas est donc bien une marque d'originalité et une nouvelle manifestation, après le choix du lieu du tournage, de sa recherche d'authenticité.

Son intention ne sera cependant que partiellement réalisée. À la demande de Richers,

546Paulo Autran joue le personnage du dictateur fasciste dans Terra em transe.

547Leonardo Vilar vient du Teatro Brasileiro de Comédia - TBC, il joue le rôle de Jasão, cangaceiro urbain dans A Grande Cidade.

548Sérgio Cardoso joue dans Os Herdeiros.

549Paulo José obtient les rôles principaux de O Padre e a moça et Macunaíma.

550C'est le cas de Geraldo del Rey (A Grande Feira, Deus e o diabo na terra do sol) et Helena Ignez (A Grande Feira, O Padre e a moça).

551Antônio Pitanga joue pour la première fois au cinéma dans Bahia de todos os santos, de son vrai nom Antônio Sampaio, il doit son nom d'artiste à ce premier film. Aussitôt après ce rôle, il prend des cours d'art dramatique à l'Escola de Teatro da Universidade de Bahia et enchaîne les tournages : A Grande Feira (Chico diabo) et Barravento (Firmino). Il apparaît dans des dizaines de films dont plusieurs du Cinema Novo. Dans Ganga Zumba, Menino de Engenho et $A$ Grande Cidade, il obtient l'un des rôles principaux. 
le rôle de Fabiano, est joué par Átila Iório que nous avons vu dans O Assalto ao trem pagador et que nous retrouverons dans Os Fuzis. C'est un acteur qui a débuté dans la chanchada. Orlando Macedo, un autre acteur, est engagé pour jouer un rôle-clef, celui du soldat Amarelo. Maria Ribeiro, dans le rôle de Sinhá Vitória, est la première non-actrice de la distribution ${ }^{552}$. Secrétaire aux laboratoires Líder de Rio de Janeiro, elle a été repérée par Santos qui voit en elle son personnage. Interpréter Sinhá Vitória n'en est pas moins pour elle un rôle de composition. Jofre Soares ${ }^{553}$, marin à la retraite, représentant de commerce et artiste amateur au cirque et au théâtre, est découvert par Santos, Barreto et Rosas lors de leur voyage de repérage à Palmeira dos Índios. Il est engagé comme assistant de production et assumera le rôle du colonel. C'est à lui que revient la tâche de compléter la distribution en faisant appel à la population locale. Il découvre les deux petits garçons qui sont les enfants du propriétaire d'un petit hôtel, la chienne Baléia et réunit la figuration.

Vidas secas commence en pleine caatinga. Un carton indique que nous sommes en 1940. Fabiano et sa petite famille sont en route, ils traversent le lit asséché des ruisseaux et partagent une poignée de farine. À bout de forces et affamés, ils mangent le perroquet que Sinhá Vitória transportait avec la malle qui est leur unique bagage. Seule, la chienne Baléia semble vive et animée. Bientôt, au milieu des branches enchevêtrées et nues apparaît une habitation. La famille prend cette direction. En s'approchant, Fabiano et Sinhá Vitória découvrent qu'il s'agit d'une petite ferme. Ils n'y sont pas encore arrivés que les nuages s'amoncellent et la pluie tombe. C'est la fin de la sécheresse. La maison de torchis est vide, c'est une maison de vacher. Plein d'enthousiasme, la famille s'installe. Dès le lendemain, le propriétaire apparaît à la tête d'un troupeau. Il engage Fabiano pour garder ses bêtes. Dans les séquences suivantes, Fabiano s'adonne aux travaux de la ferme. Le temps passe, nous sommes en 1941. Il dompte une jument sous l'oeil admiratif de son fils qui cherche ensuite à l'imiter. C'est une époque heureuse. Les choses se gâtent quand Fabiano doit recevoir son salaire.

Alors qu'il devait avoir un veau sur quatre, le propriétaire les lui rachète d'autorité, et quand il vient en ville recevoir l'argent, il apprend que ce dernier retire sur la somme qu'il lui doit le paiement des intérêts sur ce qu'il aurait avancé à Fabiano en le laissant vivre sur ses terres depuis un an. Fabiano tente de discuter mais en vain. Cet incident est le premier d'une série d'humiliations que Fabiano subit en ville et qui vont lui coûter une bonne part de l'argent

552Elle poursuivra sa carrière d'actrice de cinéma de façon intermittente mais sans accéder à la célébrité d'autres acteurs lancés par le Cinema Novo. Nous la retrouvons aux génériques de huit longs métrages dont $A$ Hora $e$ a vez de Augusto Matraga (1965), Os Herdeiros (1970) et deux autres films de Santos : O Amuleto de Ogum (1974) et A Terceira Margem do rio (1994).

553C'est le début d'une longue carrière débutée tardivement, à 45 ans, mais comptant plus de 80 longs métrages. Jofre Soares figure dans quatre autres films du Cinema Novo : A Grande Cidade, Terra em transe, O Dragão da Maldade contra o Santo Guerreiro et São Bernardo. 
qu'il possède. Le soldat Amarelo, en particulier, abuse de son pouvoir pour humilier gratuitement le pauvre vacher. Les mésaventures de Fabiano arrivent à un climax lors de sa seconde visite en ville. Après une partie de cartes malheureuse où il a eu le soldat pour partenaire, Fabiano sort brusquement. Se sentant offensé, le soldat poursuit Fabiano et le provoque. La dispute éclate. Après avoir osé répondre une seule fois, Fabiano est incarcéré et battu. Le lendemain matin, il est libéré de façon fortuite par une bande de cangaceiros. Il hésite à partir avec eux mais préfère rester avec la famille.

De retour à la ferme, Sinhá Vitória remarque les signes avant-coureurs de la sécheresse. Celle-ci ne tarde pas à arriver. Le bétail se meurt, le colonel vient le chercher pour l'emmener vers des pâturages mieux irrigués, il reprend même la jument domptée par Fabiano. Sinhá Vitória fait les comptes. Elle décide qu'il faut partir avant même que Fabiano ne reçoive le solde de son salaire. Avant le départ, il faut tuer la chienne qui n'a plus la vigueur d'antan et serait une charge. La famille quitte la ferme traumatisée par ce sacrifice et rêve d'un destin meilleur où il ne sera plus utile de fuir dans la forêt comme des animaux sauvages. Sinhá Vitória imagine qu'en ville les enfants auront accès à de meilleures conditions de vie.

Le film sort à Rio de Janeiro au mois d'août 1963 et il reçoit un accueil très favorable de la majeure partie de la critique. La justesse de l'adaptation sur grand écran du chef d'œuvre de Ramos est souvent soulignée. Pour beaucoup, Santos a su se montrer fidèle à l'esprit du roman tout en créant un film sachant exploiter pleinement les qualités expressives du langage cinématographique. Outre, la fidélité au texte littéraire, c'est donc aussi l'aspect formel de l'œuvre qui est applaudie. Le réalisme critique du grand romancier trouve sa parfaite traduction dans le style du cinéaste ${ }^{554}$ qui intègre de nombreux éléments esthétiques des cinémas nouveaux (la distanciation, les temps morts) mais échappe aux accusations de formalisme et de cosmopolitisme dont avaient été victimes Os Cafajestes et Porto das Caixas. Pour Claudio Mello e Souza, Vidas secas est « algo mais do que o melhor filme nacional. É o fundador de uma linguagem brasileira de cinema [...]. Com Vidas secas passamos a ter um verdadeiro, e por isso mesmo novo, cinema nacional. ${ }^{555}$ Ely Azeredo va jusqu'à comparer Santos à De Sica et désigner Vidas secas comme étant le premier chef d'œuvre du cinéma

554L'économie du style du cinéaste répond à la concision de l'écrivain. Ronald F. Monteiro nous donne un exemple de l'économie de moyen qui caractérise Vidas secas : « Il s'agit de l'aggravation de la sécheresse. Une séquence de dix plans montre, pratiquement en images fixes : le soleil, Fabiano préoccupé, le soleil, Baléia (la chienne) malade, le soleil, Fabiano préoccupé, le soleil. Il n'est pas nécessaire de développer l'intention de symétrie de la séquence (qui se répète, identique, dans une autre séquence de quatre plans sur la mort d'un bœuf). » ( MONTEIRO, Ronald F. « Nelson Pereira dos Santos » in PARANAGAU, Paulo Antônio, AUGUSTO, Sérgio. Le cinéma brésilien. Op. cit., p. 158.)

555 « quelque chose de mieux que le meilleur film national. Il est fondateur d'un langage brésilien de cinéma [...]. Avec Vidas secas, nous avons un véritable, et pour cela même nouveau, cinéma national. » in Estado de Minas, 20/10/1963. 
brésilien $^{556}$. Vidas secas est ainsi reconnu comme une révolution cinématographique, une première victoire dans la quête d'une dramaturgie authentiquement brésilienne.

L'aspect politique du film est en contrepartie moins commentée. La relation avec la réforme agraire est, dans le contexte de 1963, inévitable, et, partant de l'expérience vécue de la sécheresse de 1958, il est également vrai qu'il faisait partie des intentions de l'auteur de réveiller l'opinion publique au drame saisonnier par lequel passe le Nordeste. La crainte de la censure dont avaient déjà été victimes Rio, quarenta graus, puis Os Cafajestes mais aussi Boca de ouro, a cependant incité les producteurs à la prudence. Pour cette raison, l'action du film est située par un carton en 1940. Une datation un peu curieuse quand on sait que le livre fut publié en 1938 et que, tant qu'à faire, il n'aurait pas été gênant de situer l'action quelques années plus tôt. Remarquons que cela aurait été d'autant plus facile qu'à l'exception des cartons indiquant 1940 et 1941, rien ne fournit au spectateur de repère temporel. Les armes, les outils et les costumes sont pratiquement les mêmes dans le sertão de 1960. La première ambiguïté de Vidas secas est donc qu'il s'agit d'un film qui raconte des événements passés mais qui continuent au moment de sa sortie. La seconde, est qu'il s'agit d'une adaptation littéraire ${ }^{557}$ mais qui a toutes les caractéristiques d'un documentaire. L'adaptation littéraire, autrement dit la caution culturelle, et le fait que le film soit en première instance une fiction, jouent aussi le rôle de bouclier vis à vis des attaques éventuelles des secteurs conservateurs. Réalité ou fiction, passé ou présent, le contrat de lecture passé avec le spectateur repose donc sur une double-ambiguïté qui, si elle fut consciemment entretenue pour protéger la carrière du film de la censure, l'a peut être aussi empêché de devenir un libellé clair et franc en faveur de la réforme agraire, voire même une sorte d'étendard à cette cause.

Un autre élément peut expliquer que les partisans de la réforme ne se soient pas servi de ce film malgré le contexte favorable de 1963. Au travers du personnage de Fabiano, Santos donne du peuple une image fort peu complaisante. La passivité de Fabiano est souvent soulignée comme l'un des traits dominants de sa personnalité, plusieurs séquences lui sont consacrées. Face au colonel, il se montre systématiquement servile. C'est le cas lorsqu'il accepte de travailler pour lui selon une règle dont il devrait savoir qu'elle aboutit systématiquement à la spoliation du vacher ${ }^{558}$, c'est le cas encore lorsque le colonel lui impose de lui vendre ses veaux sans qu'il ne puisse même en discuter le prix, c'est le cas encore

556Tribuna da imprensa, 25 et 27/08/1963.

557Toutes les affiches mentionnent en gros « Vidas secas de Graciliano Ramos ». Archives de la Cinemateca Brasileira, sans datation.

558La quartiação, sur le troupeau dont le vacher a la garde, il doit gagner un sur quatre veaux nouveaux nés par an. Sur le papier, ce système paraît équitable. Dans la réalité, il n'a jamais fait la fortune d'aucun de ses bénéficiaires. Selon diverses méthodes, comme celle montrée par le film, le colonel finit toujours par spolier ses employés. 
lorsque celui-ci lui vole une grande part de son salaire pour payer des intérêts qui n'étaient pas fixés à l'origine et dont le mode de calcul n'est pas expliqué. Cette passivité culmine dans les confrontations avec le soldat Amarelo qui fait de cet homme simple son souffre-douleur. Dans l'une des dernières séquences du film, alors que Fabiano pourrait se venger facilement, il ne le fait pas et prononce cette phrase «Governo é governo.» (Le gouvernement, c'est le gouvernement). Une autre démonstration de la passivité de Fabiano est son choix de ne pas intégrer la bande de cangaceiros. Mais au-delà de sa passivité, Fabiano est d'une ignorance et d'une ingénuité qui frisent souvent la bêtise, il semble souvent comme un enfant dans un corps d'adulte. Nous le voyons dans l'épisode où il cherche à vendre des morceaux de porcs à une femme à la porte de sa maison et qu'il est surpris par le soldat et un percepteur d'impôt. Après avoir réussi à leur échapper une première fois, il tombe dans la gueule du loup facilement et perd tout le bénéfice de la vente. Nous le voyons aussi dans l'épisode des vêtements trop serrés et des chaussures qui font mal, lors de la visite à la ville de toute la famille. Enfin, se pose la question de la dignité de Fabiano qui n'est capable d'être véritablement homme et de susciter l'admiration de ses enfants que lorsqu'il revêt son armure de cuir ou dompte les chevaux. Pour le reste, il ne sait pas compter et c'est sa femme qui décide de tout.

Malgré ces éléments qui ont sans doute limité l'impact politique du film, quelques critiques mettent en exergue sa valeur de témoignage. Pour Neves, Vidas secas ne montre pas moins au spectateur « la vérité du Nordeste » et réussit à provoquer une prise de conscience d'un des problèmes fondamentaux de la société brésilienne en avançant à couvert de l'argument culturel : l'adaptation d'un roman de valeur reconnue ${ }^{559}$. Pour Antônio Silvio Lefèvre, il est un des premiers films fidèles au concept critique du Cinema Novo tel qu'il a été établi au début des années soixante et qui, pour lui, doit trouver son application dans le documentaire, ou, comme Vidas secas, dans la fusion entre le documentaire et la fiction ${ }^{560}$. De toutes, l'analyse de Maurice Capovilla est cependant la plus intéressante ${ }^{561}$. Celui-ci raconte un débat informel auquel il a participé à Rio de Janeiro et qui réunissait, entre autres, Andrade, Rocha, Saraceni, Lima et Bernardet. La question principale du débat était de savoir à qui si le film se destinait au peuple ou à la bourgeoisie, faisant ainsi partie de cette catégorie de films qui, selon ce que disait Rocha, expliqueraient le peuple à la bourgeoisie et non le peuple à lui-même. Dans le contexte de l'époque, la question est importante car, selon la réponse, Vidas secas serait un film révolutionnaire ou réformiste. Finalement, Capovilla

559NEVES, David. « A Verdade do Nordeste » in O Estado de São Paulo - Suplemento literário, São Paulo, 21/12/1963.

560LEFÈVRE, Antonio Silvio. « Cinema-nôvo » in O Estado de São Paulo - Suplemento literário, São Paulo, 12/08/1964.

561CAPOVILLA, Maurice. «Vidas secas : Obra-prima e instrumento de luta » in Revista Brasiliense, São Paulo, n51, janvier-février 1964. 
refuse cette alternative en déclarant ce qui suit :

« Entretanto me parece, que, mais importante do que notar a passividade do infeliz Fabiano, que recusa se incorporar a um bando de cangaceiros, para continuar pisoteando, junto com sua família, a caatinga hóstil do sertão, creio que se deva notar, a informação de um processo econômico e social, a localização de um estígma, que chama em todos os cidadãos a consciência de suas possibilidades históricas, ao permitir, pela omissão, a continuidade de uma estrutura agrária que arrasta à aniquilação, mais da metade dos brasileiros. É para refutar as dúvidas quanto à destinação de Vidas secas pode-se dizer que ele irá servir para todos aqueles que estão realmente interessados na libertação do país, isto porque é um filme claro, um filme que demonstra a evidência. ${ }^{562}$

Plusieurs années plus tard, dans son analyse de O Bravo Guerreiro, Bernardet aboutira à une conclusion similaire :

«Il s'agit donc plus de films sur la politique [O Bravo Guerreiro] que de films politiques. Les films antérieurs à 1964, du genre Vidas secas, qui ne s'intéressent pas à la technique politique mais qui pénètrent un mécanisme social global, ont certainement une perspective politique plus féconde. ${ }^{563}$

En fonction de tous les éléments que nous venons d'avancer, l'appréciation que nous pouvons porter sur Vidas secas est forcément nuancée. Pourquoi, une fois de plus, représenter le peuple comme incapable de se prendre en main ? Il va s'en dire que les mauvais traitements, la malnutrition et l'absence d'éducation gênent considérablement le développement cognitif et que beaucoup de vachers, encore de nos jours, sont intellectuellement limités et notamment incapables de compter au-delà de dix. Cela fait-il de Fabiano une figure représentative du peuple ? Rien n'est moins sûr. Pourquoi aussi ne pas traiter de l'actualité lorsque celle-ci, dans le contexte du début des années soixante, est si intense ? Autrement dit, l'action est-elle bien en accord avec les intentions affichées par les cinéastes ? Il ne s'agit pas ici de porter un jugement mais de montrer que certaines ambiguïtés demeurent et qu'il existe un décalage avec le projet initial du Cinema Novo. Cela peut aussi tenir à la conjoncture politique et aux diverses appréciations qu'elle pouvait susciter. Si l'on pensait, comme les communistes et une part de l'ISEB, que la révolution devait se faire en deux temps, d'abord la révolution bourgeoise et ensuite la révolution prolétaire, si l'on pensait que la bourgeoisie pouvait assumer un rôle d'avant-garde dans le processus de l'émancipation

$562 «$ Il me paraît que, plus important que de noter la passivité du malheureux Fabiano, qui refuse de s'engager dans une bande de cangaceiros, pour continuer à errer, avec sa famille, dans la caatinga hostile du sertão, je crois qu'il faut noter, l'information qui nous est donnée sur un processus économique et social, l'identification d'un stigmate, qui éveille chez tous les citoyens la conscience de ses possibilités historiques, ce processus, par omission, a permis la continuité d'une structure agraire qui annihile plus de la moitié des brésiliens. Pour réfuter les doutes quant à la destination de Vidas secas, nous pouvons dire qu'il pourra servir à tous ceux qui sont vraiment intéressés par la libération du pays, ceci parce qu'il s'agit d'un film clair, un film qui démontre l'évidence. » in CAPOVILLA, Maurice. «Vidas secas : Obra-prima e instrumento de luta », op. cit., p. 120.

563BERNARDET, Jean-Claude. «Étude : Politique, or, jacaranda, guérilla, paroles, suicide. » in Cinéma, Paris, $\mathrm{n}^{\circ} 150$, novembre 1970, p. 78. 
brésilienne, alors, Vidas secas trouvait parfaitement sa place et, selon la nomenclature de Rocha, appartenait bien à l'ensemble des films chargés d'expliquer le peuple à la bourgeoisie. La relation d'empathie qui est établie entre la famille de Fabiano et le spectateur, le didactisme des situations, permettent bien au long métrage d'assumer ce rôle.

Quoiqu'il en soit des justifications stratégiques de Vidas secas, il reste que le film marque d'un point de vue historique l'une des deux principales orientations du Cinema Novo, à savoir le réalisme critique. Celle-ci sera clairement reprise dans A Falecida, O Padre e a moça et São Bernardo. Nous pouvons également considérer que nous la retrouvons dans certains documentaires comme A Opinião pública ou Brasília, contradições de uma cidade nova. C'est aussi une orientation qui extrapole le Cinema Novo dans la mesure où des films de l'époque comme São Paulo Sociedade Anônima (Person, 1965) ou postérieurs comme Iracema, uma transa amazônica (Senna, Bodansky, 1976) en sont une continuation plus ou moins consciente. Notons par exemple que dans le cas de Vidas secas comme dans celui de São Paulo Sociedade Anônima, des rapprochements ont été effectués avec Salvatore Giuliano $^{564}$ de Francisco Rosi (Italie, 1962). Le réalisme critique n'est donc pas a priori un genre cinématographique purement brésilien mais il trouve sa pleine légitimité culturelle quand il est mis en relation, comme c'est le cas ici, avec l'héritage littéraire des écrivains réalistes des années trente, Ramos étant le plus prestigieux d'entre eux.

Bien que le réalisme critique de Vidas secas soit apparu à la plupart des acteurs en présence comme une orientation à même d'être identifiée avec le corps doctrinal du Cinema Novo, Rocha, qui en avait pourtant été l'un des principaux artisans, affirme la possibilité d'une seconde voie dès son deuxième long métrage. Avec Deus e o diabo na terra do sol, le Cinema Novo s'éloigne du naturalisme pour développer une esthétique versant dans le surréalisme. L'entreprise ne signifie pas pour autant un affranchissement des objectifs du réalisme critique. Il s'agira toujours d'apporter une interprétation du réel qui permette de dénoncer les mécanismes sociaux et politiques qui maintiennent le pays dans le sous-développement.

\subsection{Deus e o diabo na terra do sol : la conscientisation inachevée}

Deus e o diabo na terra do sol est, à tout point de vue, décisif quant à la carrière du Cinema Novo. Les apports du film se déclinent dans tous les domaines, esthétique, culturel et commercial. Son importance est reconnue par la critique unanime dès les premières séances privées du mois de mars 1964. Le succès d'estime remporté dans la presse internationale à

564Il s'agit d'une influence reconnue par Luís Sérgio Person dans plusieurs entrevues qu'il a accordé dans les années soixante. Dans le cas de Vidas secas, Barreto déclare qu'il a vu le film de Rosi pendant le tournage de Vidas secas. In «O Realismo fotográfico no filme Vidas secas » in O Estado de São Paulo, São Paulo, 1965. 
l'occasion de son passage au festival de Cannes accentue ce mouvement. En plus d'être la manifestation d'une nouvelle esthétique, Deus e o diabo na terra do sol impose le Cinema Novo simultanément sur les scènes nationales et internationales. La prise de pouvoir par les militaires le 1er avril 1964 ne perturbe en rien ce succès. Deus e o diabo na terra do sol est aussi un film déterminant dans la carrière de son auteur et pas seulement pour la renommée qu'il lui apporte. Alors que $A$ Revisão crítica do cinema brasileiro peut apparaître comme une somme et la synthèse de propositions que Rocha développait dans ses articles depuis la fin des années cinquante, ce deuxième long métrage relance son activité de théoricien. Autrefois critique des autres, Rocha s'intéresse à partir de ce moment-là avant tout à son œuvre. À ce titre, Deus e o diabo na terra do sol peut apparaître comme la matrice d'une théorie cinématographique qui se développe sous les formes les plus diverses, dans un aller-retour constant entre pratique et écriture. Les premiers fruits de ce regain d'inspiration apparaissent dès janvier 1965, dans le texte " A Estética da fome » qui sera traduit dans plusieurs langues et manifeste l'existence d'une nouvelle relation entre l'auteur et son œuvre.

Au contraire de Barravento que Rocha prend en main en cours de tournage, Deus e o diabo na terra do sol est un projet mûri de longue date et qu'il se réservait en propre. La raison de cet attachement est simple mais n'apparaîtra qu'assez longtemps a posteriori, il s'agit d'un film très personnel dans lequel l'auteur convoque ses souvenirs d'enfance. Rocha vit ses premières années à Vitória da Conquista. À l'époque, l'organisation sociale de la ville est encore dominée par le coronelismo. Pendant la même période, le père du cinéaste possède une entreprise de construction de routes et il emmène son fils avec lui dans quelques uns de ses grands voyages au travers du Nordeste. Mythes et réalité du sertão, cangaço, mysticisme et littérature de $\operatorname{cordel}^{565}$ peuplent alors l'imaginaire du futur cinéaste. Deus e o diabo na terra do sol est directement lié à cette expérience que Rocha s'attache à réactiver par des voyages de repérages dès le mois de janvier $1956^{566}$. Le long métrage est ainsi habité de remémorations. Le paysage que l'on peut voir en vue aérienne dans la séquence d'ouverture est comparable à celui dans lequel, petit garçon, il s'était perdu avec son père lors d'un voyage dans le Piauí. La figure d'Antônio das Mortes est elle-même inspirée par les hommes de main qu'il voyait, enfant, dans les rues de Vitória da Conquista, Antônio Pernambucano est l'un des personnages ayant réellement existés qui ont inspiré le chasseur de cangaceiros du film ${ }^{567}$.

\footnotetext{
565La littérature de cordel, ce sont des récits en vers vendus sous la forme de livrets à très bas prix. Le nom vient de ce que ces livrets sont présentés à la vente accrochés à une corde ou à un fil de fer.

566Cf. VENTURA, Tereza. A Poétika polytika de Rocha. Op. cit., p. 55.

567Sur les éléments biographiques dans l'œuvre de Rocha, $c f$. :

GOMES, João Carlos Teixeira. Op. cit.

LISBOA, Fátima Gomes. Op. cit.

VENTURA, Tereza. Op. cit.
} 
Rocha écrit un premier scénario intitulé $A$ Ira de Deus en 1959. Une nouvelle version est rédigée avec le même titre en 1960. Au mois de septembre de la même année, il fait mention de ce projet dans une lettre à Saraceni qui, à ce moment-là, étudie à Rome. Alors qu'il presse son ami à revenir au Brésil pour réaliser un long métrage dans l'état d'Amazonas, il déclare que le moment n'est pas encore venu pour lui de réaliser des films et que $A$ Ira de Deus ne pourra être fait que dans quelques années ${ }^{568}$. Entre 1959 et 1963, il ne cesse pourtant pas de revenir sur ce projet. En 1960, il fait un autre voyage d'étude dans le sertão en compagnie de Geraldo del Rey et Trigueirinho Neto au cours duquel il interviewe le major Rufino, ancien chasseur de cangaceiros et deuxième modèle pour le personnage d'Antônio das Mortes $^{569}$. Il mentionnera plus tard qu'il a rédigé cinq versions différentes du scénario, nous avons consulté les suivantes : A Ira de Deus ${ }^{570}$ (1959), Que viva a terra ${ }^{571}$ (1961 ou 1962) et Deus e o diabo na terra do sol (Uma Fábula do Nordeste) ${ }^{572}$ (1962 ou 1963). Cette intense activité d'écriture ne correspond à aucune tentative concrète de préparation du film avant 1962. Il semble alors que le succès recueilli par Barravento dans les festivals internationaux, et en particulier Karlovy Vary, aient convaincu le jeune homme à se consacrer à la réalisation.

Neves indique que le montage financier devant permettre la production du film n'a pas posé beaucoup de problèmes :

« No começo de 1963, GR projetava, ao mesmo tempo duas coisas : realizar Deus \& diabo na terra do sol e escrever um livro sobre ' Cinema Novo '. Ambicionava antes de tudo, o filme e aqui no Rio, lutou para a obtenção do financiamento que aos poucos foi se concretizando. Partiu para a Bahia ainda numa fase inicial deste processo. Foi enquanto esperava que começou e terminou o livro. Seu esquema inicial de produção era um financiamento bancário ; a insuficiência deste provocou a aproximação final de Luiz Augusto Mendes, baiano, rico, interessado por cinema e Jarbas Barbosa, o mais importante e ambicioso dos produtores do 'Cinema Novo'. Veio ao Rio para alinhavar problemas concretos da realização, entregou os originais a Ênio Silveira e retornou à Bahia. \$ $^{573}$

L'étude des différentes versions du scénario confirme le témoignage souvent entendu

568ROCHA, Glauber. Cartas ao mundo. Op. cit., p. 124. Moins de deux mois plus tard, il dirige Barravento. 569ROCHA Glauber et alii. Deus e o diabo na terra do sol. Op. cit., p. 125.

570ROCHA, Glauber. Roteiros do terceyro mundo. Rio de Janeiro, Alhambra/Embrafilme, 1985, pp. 5-45.

571ROCHA, Glauber. Que viva a terra. Scénario de 52 pages, archive du Tempo Glauber, sans date.

572ROCHA Glauber et alii. Deus e o diabo na terra do sol. Op. cit., pp. 33-109. Cette dernière version, visiblement antérieure au tournage, n'est certainement pas la dernière. D'une part, elle est encore très distante du film tel que nous le connaissons et, d'autre part, les témoignages de Rocha et de Lima concordent pour indiquer que le scénario a été repris juste avant et pendant le tournage.

573« Au début de 1963, GR projetait de faire deux choses en même temps : réaliser Deus \& diabo na terra do sol et écrire un livre sur le ' Cinema Novo '. Son ambition principale était de réaliser le film et c'est ici, à Rio, qu'il a lutté pour obtenir le financement qui s'est peu à peu concrétisé. Il est parti à Bahia dans une phase encore initiale de ce processus. C'est dans une période d'attente qu'il a commencé et terminé son livre. Sa stratégie initiale de production était un financement bancaire; l'insuffisance de cette idée a provoqué l'approximation finale avec Luiz Augusto Mendes, bahianais, riche, intéressé par le cinéma et Jarbas Barbosa, le plus important et ambitieux des producteurs du ' Cinema Novo '. Il est venu à Rio pour régler des problèmes concrets de la réalisation, il a remis les originaux à Ênio Silveira et il est retourné à Bahia. » in NEVES, David. « A Revisão de Rocha » in O Estado de São Paulo - Suplemento literário, São Paulo, $07 / 12 / 1963$. 
selon lequel Rocha écrivait un premier film, en tournait un second et en montait un troisième. L'écriture est pour le cinéaste un mode de préparation des films mais, dès Barravento, il s'éloigne de la conception du scénario-programme dans lequel tout est prévu et reste ouvert pendant le tournage et le montage, à l'improvisation et même à la remise en cause, totale ou partielle du langage du film. Les trois scénarios que nous avons cités plus haut fonctionnent comme d'authentiques «brouillons ». Le travail de réflexion sur la structure narrative est évident, l'auteur teste différentes propositions et enrichit la trame de l'histoire au fil des réécritures. Les personnages se multiplient, les conflits se précisent, la structure narrative globale se fait chaque fois plus complexe. Les personnages présents dès le premier scénario, A Ira de Deus, sont Manuel le vacher et sa femme Rosa ainsi que le cangaceiro Corisco, sa femme Dadá et un prédicateur qui n'est pas encore São Sebastião. Dans ce texte, nous découvrons aussi des séquences particulièrement fortes qui seront conservées dans les versions postérieures. Par exemple, il inclut déjà la séquence du pillage de la ferme, prévoyant cette déflagration de violence et cette mise en scène qui rappelleront Buñuel. Au fil des réécritures, l'histoire est totalement remaniée, elle comporte une, puis trois, puis deux parties $^{574}$. La présence de Lampião, le légendaire cangaceiro, est assez aléatoire. Dans certaines versions, il est un personnage à part entière, dans d'autres, il est seulement évoqué dans les dialogues. Antônio das Mortes et Cego Júlio apparaissent dans Que Viva a terra qui est apparemment le scénario le plus long, le plus détaillé et le plus explicite de Deus e o diabo na terra do sol.

Les changements de la dernière version au film final sont facilement repérables et intéressent la structure narrative à tous les niveaux. Les premières modifications que nous pouvons noter sont d'ordre pragmatique dans la mesure où le réalisateur doit se distancier du texte et improviser à cause de la précarité des moyens de production ${ }^{575}$. Toutes ne sont cependant pas le fait de la contrainte. Rocha se montre sensible aux ressources offertes par les décors naturels ${ }^{576}$ et aux suggestions des acteurs qui peuvent amener à des modifications

574Au sujet de la troisième partie, plusieurs versions semblent avoir été envisagées. Dans Que Viva a terra (p. 47 à 52), il s'agit d'un épilogue qui nous montre Manuel et Rosa, 5 ans après la mort de Corisco, victimes du travail esclave et implorant la venue d'un messie qui sauverait le peuple de l'oppression. Dans le débat du 24 mars 1964 retranscrit dans le livre, Deus e o diabo na terra do sol, Lima explique que la troisième partie devait être une sorte de documentaire, filmé par Paulo Gil Soares et non par Rocha, sur la situation des paysans dans les années soixante. Un peu plus loin, Rocha informe que cette troisième partie portait sur la révolte paysanne mais qu'elle n'a pas pu être faite car elle aurait prolongé le long métrage d'une heure de plus. Cf. ROCHA Glauber et alii. Deus e o diabo na terra do sol. Op. cit., p. 122 et 128.

$575 \mathrm{Il}$ en va ainsi de la suppression du personnage de Lampião et de la scène de bataille dans laquelle il devait apparaître ; plans 246 à 255 de Que Viva a terra; séquence 49, plans 282 et 283 de Deus e o diabo na terra do sol (Uma Fábula do Nordeste). De même, Antônio das Mortes devait être le chef d'un détachement de soldats chasseurs de cangaceiros, c'est le cas de toutes les versions où il apparait. Dans le film, il est seul.

576Séquence 3, la fabrication de la farine, séquence 7, la foire de Santana. ROCHA Glauber et alii. Deus e o diabo na terra do sol. Op. cit., p. 34 et p. 37. 
substantielles $^{577}$. Il apparaît cependant que son souci principal dépasse la poursuite d'une histoire forte et le travail sur une progression dramatique efficace à même d'émouvoir le public. Les réécritures successives sont motivés par la recherche d'une structure narrative qui respecte les deux contraintes propres au Cinema Novo : le compromis avec la réalité ou plus précisément avec ce qu'il semble possible à l'auteur dans le champ des transformations sociales, et l'imposition d'une distanciation qui depuis Bahia de todos os santos, entre autres éléments filmiques, s'appuie sur la structure narrative.

Dans cet ordre d'idées, nous pourrons remarquer que, de la même façon dont le scénario de Barravento est modifié de façon à se distancier de la vision hollywoodienne exotique et vaguement terrifiante des dieux primitifs qui finissent par triompher ${ }^{578}$, A Ira de Deus est réécrit, certainement parce qu'il est encore trop proche de O Cangaceiro (Lima Barreto, 1954) lui-même étant une adaptation de l'imagerie du Nordeste aux règles du western $^{579}$. Les éléments dramatiques initiaux sont réorganisés au sein d'une structure narrative qui évite les « recettes » pour devenir l'expression d'une idée.

Deus e o diabo na terra do sol est l'histoire du vacher Manuel et de sa femme Rosa qui, victimes de l'exploitation du latifundium, sont contraints à fuir après que le mari ait assassiné le coronel dans un moment de révolte. Ils se réfugient d'abord dans une communauté mystique dirigée par São Sebastião. Mais ce dernier entre en conflit avec Rosa qui ne reconnaît pas son autorité et n'accepte pas qu'il la prive de Manuel qui sombre rapidement dans le fanatisme. Pour «purifier Rosa», Sebastião exige le sacrifice d'un nouveau-né. Le crime accompli, Manuel doute. Sur ces entrefaits, Rosa poignarde Sebastião et Antônio das Mortes extermine la communauté religieuse sur le mandat d'un coronel et d'un prêtre qui craignent de voir leurs fermes et leurs églises désertées par le peuple. Seul rescapé du massacre, le couple est emmené par Cego Júlio, un chanteur aveugle, auprès du dernier cangaceiro, Corisco, également surnommé le Diable blond. Manuel entre dans le cangaço et prend le nom de Satanás. Dans une débauche de violence, la petite troupe pille une ferme un jour de mariage. Corisco viole la mariée. Satanás châtre le jeune époux. Plus tard, dans la caatinga, Corisco torture un homme qui, autrefois, l'a humilié. Il raconte aussi la fin de Lampião. De nouveau, Manuel doute de son engagement. Mais l'aveugle vient les prévenir de l'arrivée d'Antônio das Mortes. Pour Corisco, il est trop tard. Le chasseur de cangaceiro l'abat

577Séquences 40 et 48, Othon Bastos substitue le dialogue entre Lampião et Corisco par un monologue au cours duquel il interprète les deux personnages en alternance. Ibid., p. 80 et p. 98.

578Observation faite à partir de la comparaison entre le scénario et le film. $C f$. ROCHA, Glauber. Roteiros do terceyro mundo. Op. cit., pp. 47-114.

579Dans cette version, Manuel-Satanás est témoin des derniers jours de Corisco, héros d'un sertão accablé par la misère et la violence. Comme dans $O$ Cangaceiro, les cangaceiros se déplacent à cheval ce qui sera par la suite considéré comme une hérésie. 
et le décapite. Les deux illusions du vacher, le mysticisme et la révolte anarchique du cangaço, ayant été réduites au néant, le couple s'enfuit de nouveau mais, cette fois-ci, il court vers la mer, en direction de la libération finale.

Deus e o diabo na terra do sol est donc, comme Barravento, l'histoire d'une prise de conscience $^{580}$. Depuis le tournage de son premier long métrage, sans pour autant recourir aux procédés d'identification et de catharsis, il semblerait donc que Rocha estime que pour transformer la conscience des spectateurs, il faut les confronter à un personnage en crise. Cette idée semble influer directement sur sa réflexion quant à la structure narrative du film puisque son épure finale : exposition, phase du mysticisme, phase du cangaço, n'est pas présente dans les scénarios successifs qui comprenaient de nombreux flash-backs et faisaient intervenir le personnage de Lampião.

Manifestement, le cinéaste refuse de proposer un «discours fermé », pour cela, il s'appuie sur cette structure narrative pour rendre mieux lisibles les relations de symétrie et d'opposition entre ses personnages et rejeter tout manichéisme ${ }^{581}$ : Sebastião prêche le bien et sacrifie des enfants, c'est le Dieu noir ; Corisco tue et torture motivé par une révolte qui est juste, c'est le Diable blond ; Manuel est volontariste et naïf, Rosa est sceptique et lucide. Le film se termine sans que la prise de conscience du paysan soit complète, celui qui arrive à la mer, c'est le cinéaste et peut être, avec lui, le spectateur ${ }^{582}$. En deuxième lieu, intervient un aspect qui fut présent dès le premier scénario, c'est l'abandon du réalisme au profit du registre du récit mythologique. Le chanteur aveugle appelé Cego Júlio est à la fois le narrateur et le créateur de l'histoire puisque, non seulement, ses chansons ponctuent les différents épisodes de la narration mais en plus il intervient directement pour guider les personnages, c'est lui notamment qui conduit Manuel et Rosa à Corisco. Comme l'explique Rocha, il a voulu que

580Cette caractéristique du film apparaît dans le scénario intitulé Que viva a terra où le paysan se rebelle contre les excès de violence et de cruauté de Corisco. Celui-ci est justement immédiatement postérieur au tournage de Barravento au cours duquel surgit le thème de la prise de conscience. Si nous comparons le scénario initial de Barravento avec le film achevé, nous constaterons qu'il n'était pas question à l'origine de lutter contre le mysticisme des pêcheurs. La prise de conscience d'Aruan est absente du texte écrit. Par la suite, Terra em transe (1967) et O Dragão da maldade contra o santo guerreiro (1969) seront aussi des histoires de prise de conscience.

581Sebastião et Corisco sont introduits dans leur partie respective par le narrateur avec les mêmes formules : séquence 2, «Jusqu'à ce qu'un jour, par hasard, / est entré dans leur vie le saint Sebastião », et séquence 29, « Jusqu'à ce qu'un jour, par hasard, / est entré dans leur vie Corisco, le diable de Lampião. » Dans les deux parties, c'est la même musique de Villa-Lobos qui accompagne l'entrée de Manuel dans la communauté de Monte Santo, séquence 10, et son entrée dans le cangaço, séquence 30.

582La structure narrative permet de renvoyer dos à dos comme équivalents le mysticisme et le cangaço. Sur l'axe des enjeux et des valeurs, la morale est très claire, les deux grandes révoltes du sertão apparaissent comme des aliénations qui ne mènent pas à la libération désirée, le mysticisme nourrit les hommes de faux-espoirs et les condamne à une inaction stérile, le cangaço, dans sa logique même, porte sa fín certaine, la violence qui le constitue ne contribuant pas à une action transformatrice. Pour autant, l'histoire ne présente pas une conclusion fermée et prescriptive sur ce qu'il reste à faire une fois que l'on s'est affranchi des aliénations dénoncées par le film. La course finale indique une disponibilité à la révolte et au changement, mais la libération n'est pas accomplie. 
ses personnages soient des « synthèses » des types du Nordeste, de personnages existants ou ayant existé, en particulier Sebastião et Corisco.

Ainsi, dans une certaine mesure, nous pourrions comparer l'errance de Manuel à celle d'Ulysse dans L'Odyssée. Ulysse évolue dans un lieu et un espace qui ne sont ni tout à fait réels ni tout à fait imaginaires et rencontre des personnages qui sont mis sur sa route par les Dieux afin de le mettre à l'épreuve. Comme le héros de la mythologie grecque, Manuel est perdu dans un espace-temps qui ne lui est ni tout à fait étranger (puisqu'il y vit depuis toujours), ni tout à fait familier (puisqu'il semble le découvrir), confronté à des personnages qui incarnent le paroxysme des aliénations dont il peut être victime. Ces aliénations sont, sans qu'il en ait conscience le produit de l'oppression dont le sertanejo qu'il représente, est victime. Les Dieux qui contrôlent son destin sont le coronel et le prêtre qui payent des hommes de main pour maintenir leur autorité. Le recours à ce type d'écriture instaure une nouvelle relation au réel qui est une façon de renégocier le compromis présent dans le réalisme critique. Dès le début de son travail le cinéaste aura été sensible à ce type de narration qui lui est inspiré par la littérature de cordel et les conteurs de foires qu'il connaît bien ${ }^{583}$. Différemment du réalisme critique littéraire, ce mélange de « vérité et d'imagination » permet de concilier le témoignage et la dénonciation avec l'interprétation des faits réels tout en instaurant cette distanciation nécessaire à provoquer l'activité interprétative du spectateur.

Antônio das Mortes est un des élément clef du dispositif de distanciation. Personnage ambigu et choquant qui, en résumé, préfère tuer les pauvres plutôt que de les voir mourir de faim, il est aussi le trait d'union entre les opprimés et les oppresseurs. Avec Cego Júlio, il est le seul qui a conscience de la totalité qu'il contribue d'ailleurs à expliquer au spectateur, notamment par le biais de la scène de ses tractations avec le coronel et le prêtre. C'est donc un personnage qui cumule une fonction didactique avec une fonction de provocation. Le mystère et la violence de ce personnage doivent entraîner la participation du spectateur. Cego Júlio fonctionne comme le contrepoint d'Antônio. Les séquences où les deux hommes dialoguent

583Les emprunts au cordel sont pris en charge par le personnage / narrateur cego Júlio. Celui-ci semble parfois écrire l'histoire au moment même où elle se déroule. Dans ses interventions en voix off entre les différents épisodes, il est narrateur et chanteur. Omniscient, il semble alors parler à partir d'un moment où l'histoire est déjà finie. Il commente l'action, présente les personnages avant leur entrée en scène ou répète leurs paroles. Par exemple au moment de la mort de Corisco, c'est le chanteur en off qui répond à Antônio das Mortes les paroles originellement prononcées par Corisco : « Je ne me rends pas, non / je ne me rends pas au lieutenant, / je ne me rends pas au capitaine, / je me rends seulement à la mort, / le parabellum à la main. » Cette voix nous montre le travail d'écriture de la légende en train de se faire, la version versifiée de l'action précédant ou succédant juste sa représentation à l'écran. Juste après que cego Júlio ait appris de la bouche de Corisco la mort de Lampião et de Maria Bonita, nous entendons : « Lampião et Maria Bonita / pensaient qu'ils ne mourraient jamais. / Il est mort à la tombée de la nuit, / Maria Bonita au lever du soleil. » Là encore, c'est l'occasion de reposer au spectateur le problème de la relation de la légende à l'histoire car Corisco ne donne pas de détails sur l'heure de la mort des deux figures mythiques, Júlio les apprend-t-il plus tard, les invente-til ? Le fait d'assister au mécanisme même de la formation de la légende, de se poser ce type d'interrogation, induit le spectateur à une activité critique. 
sont parmi les plus significatives du film. Non seulement parce qu'elles sont les seules où Antônio prend la parole mais aussi parce qu'elles montrent qu'il existe des divergences entre les deux personnages qui ont justement cette conscience de la totalité que nous venons de mentionner. Leurs divergences sont d'autant plus importantes que cette conscience leur confère un statut qui, s'il n'est pas équivalent ${ }^{584}$, est au moins comparable.

L'ouverture à l'improvisation manifestée par Rocha au moment du tournage et $\mathrm{du}$ montage a permis de développer est d'approfondir les pistes offertes par les différentes versions du scénario. Plusieurs éléments ont été ajoutés qui contribuent à imposer au spectateur une distance critique avec l'objet à actualiser. Des registres narratifs d'origines hétérogènes sont juxtaposés. Aux séquences de style documentaire du début succèdent des passages de plus en plus surréalistes et lyriques à mesure que l'on approche du final. Le narrateur de cordel cohabite avec les citations de grands auteurs de la littérature brésilienne comme Euclides da Cunha, José Lins do Rego et Guimarães Rosa ${ }^{585}$. De même, la bande-son

584La relation au monde de ces deux personnages n'est pas la même. Le personnage de l'aveugle est une émanation de la culture populaire et s'avère capable de manipuler le réel et, en particulier, Manuel et Rosa, les deux personnages qui échappent, aux sens propre et figuré, à Antônio (celui-ci ne comprend pas que Rosa ait tué Sebastião). Antônio n'a pas les pouvoirs de Cego Júlio et il s'imagine prisonnier d'une destinée qu'il doit accomplir jusqu'au bout.

585José Lins do Rego (1901-1957) est un auteur contemporain de Graciliano Ramos dont il était l'ami. Tout deux pratiquaient ce que l'on appelle parfois le modernismo regionalista. Le monde rural du Nordeste était la source d'inspiration principale des deux hommes malgré leurs styles très différents. Rocha révèle avoir recueilli dans un essai de José Lins do Rego la prière que prononce Corisco avant d'affronter Antônio das Mortes («Eu, José, com a espada de Abraão serei coberto; eu, José, com o leite da Virgem Maria serei borrifado; eu, José, com o sangue de Cristo serei batizado; eu, José, na Arca de noé serei guardado; eu, José, com as chaves de São Pedro serei fechado onde não me possam ver e ferir, nem matar, nem o sangue do meu corpo tirar »). In ROCHA Glauber et alii. Deus e o diabo na terra do sol. Op. cit., p. 105.

Euclides da Cunha et Guimarães Roas sont respectivement les auteurs de Os sertões (1902), et Grande sertão : veredas, les deux principales références littéraires du film.

Euclides da Cunha (1866-1909) est, des trois auteurs, le seul qui ne soit pas contemporain du Cinema Novo. Os Sertões, son œuvre principale, est souvent présentée comme une thèse interprétative globale du Brésil. Le texte n'est pas à proprement parler une œuvre de fiction même s'il en comporte certains aspects. Bien qu'il puisse être lu comme l'épopée de la vie du sertanejo dans sa lutte quotidienne contre la rudesse du climat et l'arbitraire du pouvoir central, il s'apparente mieux au traité de sociologie, de géographie ou encore d'histoire. Calqué sur le schéma rigoureux du déterminisme de Taine, Os Sertões se divise en trois parties : « La Terre », « L'Homme » et « La Lutte »; et tente, à partir de cette approche, de comprendre la guerre de Canudos.

Bien que les thèses et les principes scientifiques utilisés aient par la suite été complètement dépassés, le livre est considéré comme une œuvre pré-modernista et fascine par son style. Celui-ci transmet en effet les impressions de souffrance et de lutte qui sont les caractéristiques propres à la vie du sertanejo. Il recourt aussi à de nombreux régionalisme qui lui apporte de l'authenticité.

João Guimarães Rosa (1908-1967) est le seul des trois auteurs qui soit contemporain du Cinema Novo. Médecin, écrivain et diplomate, les histoires de ses contes et de ses romans se déroulent principalement dans le sertão brésilien. Son œuvre se singularise le caractère innovateur de son langage qui puise dans la culture érudite de son auteur mais aussi et surtout, réutilise des éléments de la langue populaire et régionale. L'approche de Guimarães Rosa lui a permis de créer d'innombrables vocables et constructions syntaxiques atypiques par l'intégration d'archaïsmes et de modes d'expression empruntés à la tradition orale.

Ses livres les plus marquants sont Sagarana (1946) et Grande sertão : Veredas (1956), ce dernier étant l'une des principales influences de Deus e o diabo na terra do sol.

Les cinemanovistas ont eu l'occasion de rencontrer l'écrivain notamment à la V Rassegna do Cinema Latino Americano. Celui-ci appréciait le long métrage de Rocha. (Voir : NEVES, David. « Guimarães Rosa e o cinema » in O Estado de São Paulo - Suplemento literário, São Paulo, 27/01/1968.) 
alterne le style des chanteurs populaires du Nordeste et la musique symphonique d'Heitor Villa-Lobos. Cette absence d'homogénéité de la narration donne l'impression que l'histoire est racontée selon des perspectives divergentes. Cette impression est renforcée par certaines interventions off et les monologues ${ }^{586}$. Les mouvements erratiques de la caméra et le montage hors continuité de certaines séquences trahissent la présence d'une autre instance narratrice qui vient s'ajouter à la multiplicité de point de vue déjà créés. Le récit apparaît alors comme un ensemble rapiécé et peu sûr, absolument antagonique aux règles classiques du cinéma.

Malgré ou justement à cause de toutes ces audaces, le film reçoit un accueil qu'il n'est pas exagéré de qualifier de délirant. De nombreux témoignages concordent qui décrivent à la fois le ravissement et l'enthousiasme que Deus e o diabo na terra do sol provoque auprès du public de ses avant-premières cariocas du mois de mars $1964^{587}$. Dans ce contexte prérévolutionnaire, le long métrage cristallise l'espérance dans un changement que l'on imagine à portée de main. Voici un témoignage sur la réception du film à sa sortie par une personnalité qui n'est pas spécialiste de cinéma :

«Deus e o diabo na terra do sol, de Rocha, é o maior impacto cinematográfico do ano e um evento transformador de minha vida e de tantos outros que estavam na pré-estréia no cinema Ópera, na Praia de Botafago. O filme não só recebeu uma delirante ovação no final como foi aplaudido em tela aberta várias vezes em suas principais seqüências, como se estivéssemos num teatro ou num estádio e não num cinema. ${ }^{588}$

Le leader du Cinema Novo lui consacrera un ultime hommage dans le seul roman qu'il va publier : Riverão Sussuarana. L'écrivain est en effet à la fois l'un des personnages du roman et l'une de ses principales sources d'inspiration littéraire. (Cf. : ROCHA, Glauber. Riverão Sussuarana. Op. cit.)

586 « A técnica do monólogo e as técnicas de narração sonora de Deus e o diabo permitem, cristalizam, propostas complexas de descentramento do discurso, de transfiguração mútua do erudito e do popular, mas o fazem porque articuladas a outros elementos. Estes, podem vir da sintaxe, das expresses vocabulares, dos neologismos, das citações, como no caso de Guimarães Rosa ; ou da particular decupagem, encenação e arranjo geral que marcam o filme de Glauber. No fundo, é dessa dificuldade em localizar a fronteira entre as perspectivas que convergem no texto (ou no filme) que resulta sua riqueza de significações e o espaço de ambiguïdade que desafia leitor ou espectador. » (« La technique du monologue et les techniques de narration sonore de Deus e o diabo permettent, cristallisent, des propositions complexes de décentralisation du discours, de transfiguration mutuelle de l'érudit et du populaire, mais elles y parviennent parce qu'elles sont articulées à d'autres éléments. Ceux-ci peuvent venir de la syntaxe, d'expressions de vocabulaire, de néologismes, de citations, comme dans le cas de Guimarães Rosa ; ou du découpage si particulier, de la mise en scène et de l'arrangement général qui caractérisent le film de Glauber. Dans le fond, c'est dans cette difficulté à localiser la frontière entre les perspectives qui convergent dans le texte (ou dans le film) que résulte sa richesse en significations et l'espace d'ambiguïté qui défie le lecteur ou le spectateur. ») In XAVIER, Ismail. Sertão Mar - Rocha e a estética da fome. Op. cit., p144.

587José Carlos Avellar, Jean-Claude Bernardet, Eduardo Escorel, Orlando Senna et d'autres ont souvent apporté des témoignages qui concordent avec celui que nous transcrivons.

588« Deus e o diabo na terra do sol, de Rocha, est le plus grand choc cinématographique de l'année mais c'est aussi un évènement transformateur de ma vie et de celles de tant d'autres qui étaient présents à l'avantpremière au cinéma Ópera, à la plage de Botafago. Le film n'a pas seulement reçu une ovation délirante à la fin de la séance, il a été souvent applaudi pendant son déroulement comme si nous étions dans un théâtre ou dans un stade et non dans un cinéma. » Nelson Motta, auteur et producteur de musique célèbre au Brésil, dans son autobiographie Noites tropicais : solos, improvisos e memórias musicais, Objetiva, Rio de Janeiro, 2000 . 
Les nombreuses critiques qui paraissent dans la presse au cours de l'année sont au diapason de ce premier accueil. Le film fait l'unanimité au-delà des clivages esthétiques, politiques ou même interpersonnels et reçoit la plus grande couverture que ne recevra jamais aucun autre long métrage du Cinema Novo. Il faut reconnaître qu'il est aussi l'un de ceux dont la sortie commerciale est la mieux orchestrée et la plus heureuse. Aux avant-premières triomphales de mars succèdent rapidement le passage réussi au festival de Cannes et, immédiatement après, au mois de juin, le film bénéficie d'une sortie simultanée dans près de douze salles ${ }^{589}$ ce qui est pour l'époque, d'un point de vue commercial, réellement significatif. Ce concours de circonstances favorables contribue à faire de Deus e o diabo na terra do sol l'événement cinématographique de 1964.

Cependant, si nous pratiquons une lecture plus minutieuse des coupures de presse, audelà de l'impressionnante collection de dithyrambes, force est de constater que le film, au contraire de Os Cafajestes, Porto das Caixas ou Cinco vezes favela, ne provoque pas de réactions dans et par rapport au contexte politique de 1964. La majorité des textes restent au niveau de la réaction émotionnelle et de l'analyse esthétique formelle. Seuls Humberto Didonet et Ely Azeredo se préoccupent de l'impact idéologique du long métrage. À partir d'avril 1964, Didonet se fait le défenseur des idées de la droite catholique appuyant la dictature $^{590}$. Il est la seule voix discordante dans le chœur des louanges adressés à Deus e o diabo na terra do sol et signale le film comme exemple d'utilisation de l'art au profit « d'idéologies pernicieuses » :

« Vemos em jornais (não lemos apenas jornais de Porto Alegre) aparecerem críticos de cinema, elogiando personalidades marxistas no terreno da arte ou crítica cinematográfica. Para certos críticos brasileiros atuantes em jornais ultra-democráticos, o maior crítico do mundo é o italiano Guido Aristarco ; a melhor revista do universo e do sistema solar, é Cahiers du cinéma; e os melhores filmes são os de inspiração marxista, como é o caso de DEUS E O DIABO NA TERRA DO SOL, de Rocha. [...] Atenção, muita atenção, que as ideologias perniciosas continuam se refugiando na arte e, depois, vão estourar no social e no político. $\gg{ }^{591}$

589Selon les propos de Rocha. In MARCORELLES, Louis. « Rencontre avec le Cinema Nôvo : Joaquim Pedro de Andrade, Gustavo Dahl, Carlos Diegues, Leon Hirszman, Rocha, Paulo Cézar Saraceni » in Cahiers du cinéma, Paris, nº176, mars 1966.

590Son premier article paru après le premier avril, prétendument rédigé au mois de mars, critique l'appui du gouvernement de João Goulart à Ganga Zumba, Os Fuzis, Deus e o diabo et $O$ Mundo em que Getúlio viveu et termine par l'un des slogans de la droite favorable au coup d'État : «A república sindicalista totalitária aí está. » DIDONET, Humberto. «Alô, atenção : a agência nacional informa » in Jornal do dia, Porto Alegre, $17 / 04 / 1964$.

591 « Nous avons vu dans des journaux (nous ne lisons pas seulement les journaux de Porto Alegre) apparaître des critiques de cinéma, faisant l'éloge de personnalités marxistes dans les milieux de l'art ou de la critique cinématographique. Pour certains critiques brésiliens travaillant dans des journaux ultra-démocratiques, le plus grand critique du monde est Guido Aristarco ; la plus grande revue de l'univers et du système solaire est Les Cahiers du cinéma ; et les meilleurs films sont d'inspiration marxiste, comme cela est le cas de DEUS E O DIABO NA TERRA DO SOL, de Glauber Rocha. [...] Attention, très attention, à ce que les idéologies pernicieuses continuent à se réfugier dans les arts, car ensuite, elles vont exploser dans le social et le politique. » in DIDONET, Humberto. « Ideologias perniciosas refugiam-se na arte » in Jornal do dia, Porto Alegre, 08/08/1964. 
Représentatif de l'hystérie anti-communiste ayant favorisé le succès de la prise de pouvoir par les militaires, l'article de Didonet ne rencontre pourtant guère d'échos. Le film ne provoque pas de tollé auprès des secteurs les plus conservateurs comme ce fut le cas de $O s$ Cafajestes. Il n'inquiète pas non plus les nouveaux dirigeants. Comme nous le verrons plus tard, une commission militaire est nommée spécialement au mois d'avril et confirme l'autorisation qui avait déjà été donnée au film par la censure sous le gouvernement Goulart d'être projeté à Cannes. Par la suite, la carrière commerciale du film n'est pas gênée.

Affichant des opinions politiques opposées à celles de Didonet, Azeredo est le seul à replacer Deus e o diabo na terra do sol dans le contexte de la recherche d'un cinéma de prise de conscience :

«O que o filme não tem - ao contrário do que afirma o autor em sua apresentação ao público - é simplicidade. Muito pelo contrário, é obra complexa, repleta de influências (principalmente de Eisenstein e Buñuel), procurando cristalizar algumas das principais conquistas do cinema moderno e independente, simultaneamente alcançando uma simbiose do espetáculo e do cinema realista 'antiespetáculo' com o objetivo de transformar o público, de englobá-lo no processo libertário da arte cinematográfica - tudo isso a evidenciar uma cultura cinematográfica e um processo intelectual laborioso que estão nos antípodas da simplicidade. $»^{592}$

Mais, s'il admire, comme les autres critiques, la réussite esthétique constituée par le film, il est aussi l'un des premiers à douter que les intentions révolutionnaires réalisées dans le film puissent être suivies d'effets concrets dans le réel :

« Diga-se logo Deus e o diabo na terra do sol, épico desmistificador de épicos, explosão genial do misticismo nordestino em termos de antimisticismo e profilaxia ateista (mas sua eficácia nesse plano é discutível) grande matrimônio das influências de Buñuel e Eisenstein, não tem a admirável coesão e o impacto realista do filme de Nelson Pereira dos Santos, mas a pequeno e a longo prazo deve afirmar-se mais importante, mais tirador de chapeús para a revelação brasileira e, inclusive pelos possíveis excessos e defeitos, mais 'sensação de festival'. ॥" ${ }^{593}$

Le fait que le film ne soit pas un succès populaire malgré le lancement dont il a

$592 «$ Ce que le film n'a pas comme qualité - au contraire de ce qu'affirme l'auteur dans sa présentation au public - c'est la simplicité. Bien au contraire, c'est une œuvre complexe, pleine d'influences (en particulier Buñuel et Eisenstein), cherchant à cristalliser quelques unes des plus importantes conquêtes du cinéma moderne et indépendant, atteignant simultanément la symbiose du spectacle et du cinéma réaliste ' anti-spectacle ' avec l'objectif de transformer le public, de l'intégrer dans le processus libertaire de l'art cinématographique - tout ceci en montrant un culture cinématographique et un processus intellectuel laborieux qui sont aux antipodes de la simplicité. » in AZEREDO, Ely. « Deus \& diabo pode bisar Palma de ouro » in Tribuna da imprensa, Rio de Janeiro, 24/03/1964.

593 « Disons tout de suite que Deus e o diabo na terra do sol, épopée démystificatrice des épopées, explosion géniale de mysticisme nordestin en anti-mysticisme et prophylaxie athée (mais son efficacité sur ce point est discutable) grand mariage des influences de Buñuel et d'Eisenstein, n'a pas la même admirable cohésion et le même impact réaliste que le film de Nelson Pereira dos Santos, mais à court et à long terme, il va s'affirmer comme étant plus important, plus reconnu comme emblématique de la révélation brésilienne et, notamment pour ses possibles excès et défauts, plus ' sensation de festival '. » in AZEREDO, Ely. « Mau caráter genial para Cannes 64 » in Tribuna da imprensa, Rio de Janeiro, 21/03/1964. 
bénéficié confirme les remarques d'Azeredo. Sans pour autant avoir développé le sujet, le critique a alors touché du doigt le dilemme qui tourmentera les esprits des cinemanovistas à partir de l'année suivante. Comment Deus e o diabo na terra do sol peut-il être réussi dans sa forme et ne pas recevoir la sanction positive du public ni entraîner aucune forme de réaction dans la sphère sociale et politique qui corresponde aux intentions initiales ?

Nous n'avons pas ici la prétention de répondre à cette question, nous voudrions pourtant nous y arrêter car il nous semble qu'elle est au cœur de la problématique du Cinema Novo. Ce qui est important, c'est qu'elle soit posée comme telle et que l'on ne soit pas tenté d'y répondre trop rapidement car bien souvent sa résolution trop hâtive trahit les préjugés sociaux dont les cinemanovistas eux-mêmes n'ont pas été exempts. Le fait que le public populaire n'ait pas fait sien le film de Rocha et par extension tous ceux du Cinema Novo, le fait qu'il ne les ait pas intégrés à la culture populaire, voire même qu'il n'en ait pas fait des « instruments de lutte » a provoqué chez leurs partisans et chez le cinéaste lui-même des réactions de dépit consistant à dire que la faute de cet échec revenait à l'ignorance d'un public « provincial» ou « analphabète ». Les détracteurs du Cinema Novo n'ont pas fait preuve de préjugés différents lorsqu'ils ont incriminé la forme des films, leur trop grande complexité les rendant hermétiques aux foules. Ce débat commence à partir de la déception suscitée par la timide réception populaire de Deus e o diabo na terra do sol et amène à concevoir l'alternative assez peu stimulante selon laquelle il faudrait choisir entre un cinéma « artistique » et un cinéma « commercial ». Choisir un cinéma artistique revenant à s'aliéner la communication avec le public et choisir un cinéma commercial revenant à pervertir complètement l'intention de communication. Nous allons voir plus loin que, dans le cadre de ce dilemme, le Cinema Novo va chercher des voies de traverses.

Avant d'aller plus loin, il faut cependant relever combien les prémisses à cette discussion sont peu solides. Au-delà de la qualité esthétique du long métrage de Rocha, il faut en effet interroger le lieu d'où il parle. À ce titre, les citations et la démarche du cinéaste sont significatives. La référence à Grande sertão : Veredas ou le choix des Bachianas pour la bande-son, toutes inspirées par le patrimoine musical du sertão, nous précise la nature de la relation établie par le film entre la culture érudite et la culture populaire. Comme Guimarães Rosa ou Villa-Lobos, l'approche de Rocha consiste à filtrer sous une forme érudite ce qui vient du patrimoine populaire. Cette approche est absolument légitime et, comme dans les exemples cités, s'avère extrêmement féconde mais, dans la perspective qui nous occupe et dans une société aussi morcelée que la société brésilienne, il n'est pas sûr qu'elle puisse servir les intentions politiques de son auteur. Au final, sa production se rattache en effet au cadre de la culture dite érudite qui n'est pas investie par les classes populaires pour des raisons qui ne 
relèvent pas de ses compétences cognitives ni même seulement de l'absence d'éducation formelle ou de l'hermétisme des circuits de circulations des biens culturels mais aussi des clivages de classe. En dernière instance, les classes populaires ne sont pas seulement exclues de l'accès à la culture érudite par tout un ensemble de mécanismes de ségrégation économique et sociale, elle s'en défient également puisqu'il s'agit d'une culture ostensiblement conçue par et pour une élite et souvent avec l'idée implicite d'être la démonstration de l'hégémonie culturelle des classes qui en ont l'usufruit. Tout bien considéré, en choisissant telle démarche artistique, Rocha ne peut donc en aucun cas s'adresser aux masses populaires qu'il prétend pourtant atteindre. Peut-il cependant en être autrement? Une fois cette position assumée qui ne dépend pas tant du choix de l'artiste que de ce qui le constitue, une barrière infranchissable est érigée entre deux mondes qui sont inconciliables.

À ce premier élément, il faut également rajouter que ces deux univers culturels qui sont en fait hermétique l'un à l'autre ne sont pas sur un pied d'égalité. Vouloir parler en situation de dominant à et pour celui qui est en situation de dominé encourt les risques de la confusion et de l'ambiguïté de tout discours sur l'altérité. Deus e o diabo na terra do sol ne leur échappe pas. Comme dans Barravento, il s'agit de lutter contre les aliénations populaires qui sont tenues comme les principales responsables de l'état de sous-développement du pays. Si le peuple pouvait se débarrasser de ses aliénations, alors, tout pourrait changer. Il reconnaîtrait ses véritables ennemis et mettraient bas les structures qui l'oppriment. Le diagnostic est discutable et sera très justement remis en cause dans la deuxième partie de la carrière du Cinema Novo puisque la culture populaire, au lieu d'être critiquée comme un facteur d'aliénation sera au contraire peu à peu reconnue comme un élément de résistance à l'oppression.

Enfin, Deus e o diabo na terra do sol nous incite à remettre en cause la sincérité des intentions de son auteur car autant celui-ci a-t-il clamé vouloir réaliser un cinéma populaire ${ }^{594}$ et sans doute y a-t-il cru, autant il aura en pratique réalisé un cinéma destiné à sa propre classe. Nous avons vu plus haut combien, d'un point de vue esthétique et sociologique, le film se rattache clairement au cadre de la culture érudite, mais, comme l'a montré depuis longtemps Bernardet, ses personnages et sa morale intéressent aussi avant tout la classe moyenne. Antônio das Mortes est le représentant le plus achevé d'une série de personnages qui commence avec Firmino dans Barravento et se terminera avec le député de O Bravo

594Sur Deus e o diabo na terra do sol, Rocha a par exemple déclaré : «É um filme épico, à maneira popular ; é um filme social despido de demagogia política. Pretendi um filme popular. Narrativa cronológica, direta, sem artifícios de linguagem. » (C'est un film épique, au sens populaire du terme, c'est un film politique dépourvu de démagogie. J'ai voulu faire un film populaire, avec une narration linéaire et sans artifice de langage.) in ROCHA, Glauber et anonyme. « Rocha na terra do sol » in Diário de notícias - Suplemento Literário, Rio de Janeiro, 22/09/1963. 
Guerreiro en 1968.

Ces personnages sont des projections, au départ inconscientes, des auteurs des films au sein de la fabula et traduisent dans leur comportement les préjugés, les hésitations et les ambiguïtés qui sont les leurs et celles de toute la classe moyenne vis à vis de la problématique sociale et politique vécue par le pays. Leur trait de caractère principal est qu'ils sont oscillants. Témoins des conflits entre la classe dirigeante et le peuple, ils portent en eux la volonté de participer, mais conscients de leur isolement, ils hésitent quant à la place qu'ils doivent occuper. D'un côté, ils sont indignés par l'injustice dont sont victimes les opprimés, mais de l'autre, ils se les représentent comme des êtres ignorants, apathiques et aliénés, incapables de se sauver par eux-mêmes. Enfin, ce sont des personnages dépendants des oppresseurs qui sont souvent ceux qui les paient et dont ils sont socialement plus proches. Firmino et Antônio das Mortes cherchent à créer les conditions favorables afin que le peuple prennent l'initiative de faire la révolution mais eux-mêmes ne la font pas. Antônio das Mortes se dit favorable à la cause populaire mais il est un instrument de la répression et toute son ambiguïté réside dans le fait qu'il obéit au coronel pour des raisons qui sont en fait contraires à ses intérêts puisqu'il tue « contre sa volonté » et pour qu'arrive enfin la grande guerre du sertão :

« Um dia vai ter uma guerra maior nesse sertão... Uma guerra grande, sem a cegueira de Deus e do Diabo. E pra que essa guerra comece logo, eu, que já matei Sebastião, vou matar Corisco... E depois morrer de vez, que nós somos tudo uma mesma coisa... $»^{595}$

Le Cinema Novo d'après le coup d'État comprendra que la contribution la plus intéressante qu'il pourra apporter au contexte sociale et politique brésilien réside dans l'examen de conscience de ce personnage ambivalent. Antônio das Mortes a, d'une certaine façon, amené ses contradictions à leur paroxysme et permis leur prise de conscience dans un processus qui était beaucoup plus intuitif que réfléchi.

\subsection{Os Fuzis : le populisme entre en crise}

Contemporain de Vidas Secas et Deus e o diabo na terra do sol, Os Fuzis connut une histoire mouvementée. D'innombrables incidents perturbent la préparation, le tournage et le lancement du film à tel point que bien qu'il ait été commencé dans le courant de l'année 1962, il ne sort sur les écrans qu'au mois de janvier 1965 et dans une version mutilée. Au contraire de ses deux prédécesseurs focalisant le sertão du Nordeste, il est, au Brésil, un échec

$595 «$ Un jour, il y aura une grande guerre dans ce sertão... Une grande guerre, sans l'aveuglement de Dieu et du Diable. Et pour que cette guerre commence vite, moi, qui ai déjà tué Sebastião, je vais tuer Corisco... Et ensuite je mourrai à mon tour parce que nous sommes tous une même chose. » Description de Deus e o diabo na terra do sol, seq. 33 . 
commercial et critique total. Selon l'aveu de Guerra, le film passe inaperçu dans les salles ${ }^{596}$. Cet insuccès est si grand qu'il contribuera à l'écarter des plateaux de cinéma de son pays d'adoption pendant six ans. Cette longue période d'absence prendra fin avec le tournage de $O s$ Deuses e os mortos en 1970. Dans l'intervalle, le cinéaste retourne en France où il est engagé pour jouer le rôle titre dans le film de Serge Roullet, Benito Cereno (France, 1968). Il réalise aussi deux films, le long métrage Sweet Hunters (Panama, 1970) ${ }^{597}$ et le court Vocabulaire, épisode resté inédit de Loin du Vietnam (France, 1967). La reconnaissance dont bénéficie aujourd'hui Os Fuzis se doit avant tout à son succès critique en France ${ }^{598}$ et à ses ventes internationales sur le long terme ${ }^{599}$.

Le voyage des cinéastes vers le sertão du Nordeste, inauguré par Santos dans sa première tentative de filmer Vidas secas, correspond à une démarche consciente et réfléchie. Elle ne s'arrête d'ailleurs pas à la «trilogie du sertão » dont Os Fuzis fait partie. L'équipe mobile du CPC de l'UNE avec Eduardo Coutinho à sa tête investit également ces régions du Nordeste entre 1963 et 1964, année du tournage avorté du premier Cabra marcado para morrer. Paulo Gil Soares, assistant de direction de Rocha sur Deus e o diabo na terra do sol, retourne voir le major Rufino, modèle d'Antônio das Mortes, et Dadá, la femme de Corisco, pour réaliser Memórias do cangaço en 1964, film dédié, comme son nom l'indique, à l'histoire du cangaço. Le court métrage est ensuite incorporé à Brasil verdade (1968), le projet d'un producteur, Thomaz Farkas qui va se consacrer, entre 1969 et 70, à l'exploration du sertão dans une veine documentaire. Soares, de nouveau, et Geraldo Sarno sont les principaux réalisateurs des films alors produits. Cinq d'entre eux sont rassemblés dans le long métrage Herança do Nordeste (1972). À la même époque, Vladimir Carvalho, natif de la Paraíba, coscénariste non crédité de Aruanda et assistant de Coutinho sur l'inachevé Cabra marcado para morrer, termine un autre film emblématique de la cinématographie du sertão : Os País de São Saruê (1970).

Au final, l'ensemble de ces films est extrêmement hétérogène mais tous participent bien d'une même intention pouvant se décliner sur deux versants, l'un culturel et l'autre politique. Il s'agit de révéler le Brésil aux brésiliens pour que ceux-ci connaissent la diversité géographique humaine de leur pays et prennent conscience des mécanismes qui maintiennent

596GUERRA, Ruy. « Entretien avec Ruy Guerra par Jean-André Fieschi et Jean Narboni » in Cahiers du cinéma, Paris, $\mathrm{n}^{\circ} 189$, avril 1967, p.53.

597Sweet hunters est un film tourné en France en langue anglaise. Le pavillon du Panama s'explique par des raisons fiscales.

598Os Fuzis rassemble les suffrages des Cahiers du cinéma et de Positif. Voir : GUERRA, Ruy. « Entretien avec Ruy Guerra par Jean-André Fieschi et Jean Narboni », op. cit. ; PIERRE, Sylvie. « Poétique et politique : Os Fuzis (Les Fusils) » in Cahiers du cinéma, Paris, n¹90, mai 1967 ; CIMENT, Michel. « Le Dieu, le diable et les fusils » in Positif, Paris, n84, mai 1967.

599Sur les ventes à l'étranger, $c f$. paragraphe 7.3 . 
des injustices sociales absolument insupportables. Il n'est pas inutile de rappeler qu'à cette époque qui précède de peu la diffusion globale et massive de la télévision, les images du Brésil sont rares. Les paysages et les visages du Nordeste, les modes de vie et la culture de ses habitants sont aussi exotiques pour un pauliste ou un carioca qu'ils peuvent l'être pour un français ou un italien. À ce titre, le projet de Guerra s'inscrit dans un mouvement collectif et correspond pleinement à la problématique esthétique du Cinema Novo. L'authenticité de son approche est garantie par le secours de Miguel Torres. Fin connaisseur du Nordeste qu'il a déjà étudié de longues années pour écrire le scénario de Três cabras de Lampião ${ }^{600}$, l'ancien marin co-signe le scénario de Os Fuzis et accompagne le cinéaste dans toutes les étapes de la préparation du film. Plusieurs anecdotes historiques sont découvertes et réutilisées dans l'écriture d'une histoire dont les sources d'inspiration sont très proches de celles de Deus e o diabo na terra do sol.

Comme dans le long métrage de Rocha, le mysticisme tient une place importante. Le lieu de l'action est Milagres ${ }^{601}$, une cité du sertão de Bahia qui est aussi une ville religieuse et un lieu de pèlerinage. Nous retrouvons dans la narration un « saint » dont les prédications sur la colère de Dieu et son insatisfaction envers les hommes sont des références aux discours de Antônio Conselheiro, du Padre Cícero ou encore de Beato Lourenço. L'utilisation d'un bœuf sacré qui est d'abord vénéré par la communauté mystique puis dévoré, est un fait réel sur lequel Guerra a entendu un témoignage. Il faisait partie de l'intention du cinéaste montrer et de dénoncer le mysticisme du Nordeste :

« Mon film est une sorte de Canudos réduit. J'ai essayé de rendre tout le contexte superstitieux et fanatique du Nordeste brésilien. Tout le côté emprise mystique. La seule issue que les gens de cette région envisagent est d'ordre mystique, c'est le recours à Dieu. Lequel peut prendre pour eux les formes les plus

600Malgré la présence de Miguel Torres et Hélio Silva au générique (chef opérateur de Rio, quarenta graus et Rio, zona norte), ce long métrage d'Aurélio Teixeira de 1962 n'entre pas dans le cadre du Cinema Novo. $601 \mathrm{La}$ ville est découverte par Guerra et Torres au cours de leurs voyages de repérage. Elle sera par la suite réutilisée par Rocha qui y filmera $O$ Dragão da maldade contra o santo guerreiro. Un journaliste ayant suivi l'équipe de Os Fuzis nous a laissé une description de Milagres : «Trata-se de uma cidade bipartida, com um pé na terra e outro no céu. O bairro de baixo fica na beira da estrada e se chama Côrreas. O de cima fica a meia hora de subida ingreme, em meio a formações caprichosas de granito que dão idéia de uma espécie de Grand Canyon nordestino. [...] Milagres de cima é uma cidade religiosa, centrada numa igrejinha colonial caiada de branco, centro de peregrinações de toda a região. Dela se origina o nome da cidade : os romeiros que vêm todo ano se encarregam de espalhar a fama das curas milagrosas ocorridas na pequena igreja. Nela uma sala inteira é dedicada a guardar ex-votos, desde mechas de cabelo até esculturas em madeira e pinturas ingênuas em cartolina, fotografias e pedaços de roupa.» (« Il s'agit d'une ville divisée en deux, avec un pied à terre et un autre dans le ciel. Le quartier de la ville-basse se trouve au bord de la route et s'appelle Côrreas. Celui du haut est atteint après une demi-heure d'une montée en pente raide, parsemée de formation capricieuse de granit qui évoque une sorte de Grand Canyon nordestin. [...] Le Milagres du haut est une cité religieuse, construite autour d'une petite église coloniale branlante, centre des pèlerinages de toute la région. C'est d'elle que vient le nom de la cité : les romeiros qui viennent toute l'année se charge de répandre la renommée des guérisons miraculeuses obtenues dans la petite église. Dedans, une petite salle est entièrement dédiée à conserver les ex-votos, des mèches de cheveux jusqu'aux sculptures de bois et aux peintures ingénues sur carton, aux photographies et aux morceaux de vêtement. ») in « Lembrando as filmagens de $O s$ Fuzis » in O Jornal, Rio de Janeiro, 19/07/1964. 
diverses, les plus absurdes et contradictoires. Le bœuf est un événement qui a eu lieu vers 1924. Le bœuf a été tué par les militaires. Le mythe de cet animal commençait à prendre tant d'importance dans l'esprit des villageois qu'un autre prêtre très influent en a pris ombrage et a obtenu du gouvernement qu'on le fasse tuer. J'ai pris une seule liberté en ce qui concerne ce fait, celle de le faire manger ensuite par les gens du village. Tout le film est ainsi lié à une série de traditions du Brésil. ${ }^{602}$

Lors de ce travail de préparation, Guerra choisit de transposer dans le contexte du Brésil des années soixante un argument qu'il a imaginé plusieurs années plus tôt et qui devait se dérouler dans un village de montagne, en Grèce. Nous retrouvons dans l'histoire initiale un groupe de soldats détaché dans un lieu isolé et confronté à un climat de tension avec la population locale :

\begin{abstract}
« Des soldats, donc des gens armés, venaient protéger des villageois contre les loups. Et comme pendant cet hiver, les loups ne descendaient pas, il commençait à se créer une espèce de mythe chez les soldats, la même fascination des loups que celle qu'éprouvaient les villageois pour les armes. Les soldats en venaient à prendre peur eux-mêmes, à craindre ces gens dont ils ne comprenaient pas les réactions. Il se créait des rapports troubles en eux, alimentés par une façon différente de réagir aux mêmes choses. $»^{603}$
\end{abstract}

Comme dans le film de 1964, la tension existante entre les soldats et la population est partiellement fondée sur une relation d'altérité. Tous les personnages possèdent la même langue et la même nationalité mais ils sont fondamentalement étrangers les uns aux autres, incapables de se comprendre et d'anticiper leurs réactions respectives face aux événements. Les échanges entre les deux groupes sont superficiels et, comme le point de vue du narrateur s'identifie à celui des soldats, ce sont principalement les autochtones qui restent opaques, imprévisibles dans leurs réactions.

Guerra décide d'adapter l'histoire originale de Os Fuzis au Nordeste à partir du moment où il prend connaissance de l'exode de populations affamées et désespérées et des incidents qu'elles provoquent dans des villages similaires à ceux du film. Entre l'histoire grecque et l'histoire brésilienne, surgit alors une importante différence. Dans le contexte de la sécheresse et du sertão, le rôle des soldats n'est pas de protéger la population mais les stocks d'aliments qui sont destinés à être exportés vers les grandes villes. La relation d'altérité entre la troupe et les populations locales est maintenue, mais il y est ajouté les tensions de classe et le drame d'une structure économique criminelle qui, en concentrant la propriété de la terre entre quelques mains, induit un système d'exploitation destinée à satisfaire exclusivement la demande externe et qui ne permet pas une agriculture de subsistance locale ${ }^{604}$. Le latifundium

602In GUERRA, Ruy. «Entretien avec Ruy Guerra par Jean-André Fieschi et Jean Narboni », op. cit., p. 56. 603In ibid., p. 53.

$604 C e$ drame est dénoncé dans la littérature réaliste des années vingt et trente. Ainsi, A Bagaceira de José

Américo de Almeida (1928), racontait déjà comment les retirantes fuyant la sécheresse étaient aussi la principale main d'œuvre des grandes exploitations dans lesquelles ils sont accueillis quand revient la belle saison. Vidas secas ne raconte pas autre chose. Enfin, l'ISEB dans les années cinquante et soixante, s'est attaché à dénoncer le phénomène avec une approche scientifique. En fin de compte, les populations qui par la 
est stigmatisé dans la structure même de la narration puisque les conflits qui se dessinent entre les différents actants sont les conflits sociaux du sertão. Les soldats s'interposent entre le propriétaire des récoltes qui est aussi un élu local et le propriétaire des infrastructures municipales qui sont, comme par hasard, toutes destinées à soutenir son activité.

Selon le témoignage de Ruy Guerra, dès ses premières lectures dans le cercle des cinemanovistas et de leurs amis ${ }^{605}$, son scénario est critiqué pour donner une image négative de l'armée, opposée à celle de l'armée légaliste à laquelle la gauche voulait croire. La tentative de coup d'État des ministres militaires reste dans toutes les mémoires, mais le président Goulart lui-même prétend pouvoir s'appuyer sur le dispositif militaire qu'il a mis en place et qui doit en théorie assurer le respect de la légalité par l'armée, quand bien même les pressions provoquées par la promulgation des réformes de base seraient de plus en plus fortes. Cette première polémique autour de la question du rôle des militaires devaient cependant en annoncer bien d'autres qui s'ajouteraient aux incidents de tournage.

Le plus grave d'entre eux est la mort tragique de Miguel Torres, le 31 décembre 1962, dans un accident de voiture lors de repérages pour le film. Par la suite, la pluie impose des délais au tournage. Celui-ci est repoussé car il se met à pleuvoir à Milagres alors que les préparatifs à Rio sont conclus. Une fois sur place, le temps est constamment pluvieux. L'équipe doit rester 4 mois au lieu des 3 initialement prévus, le nombre de scènes en intérieur est augmenté pour recoller au plan de travail et, pour certaines séquences en extérieur, les bourgeons des arbres de la place publique sont arrachés afin que la scénographie corresponde au climat de sécheresse réclamé par l'histoire. En plus des caprices du temps, des problèmes de figuration se posent : le village compte à peine 200 personnes, ce nombre est insuffisant et il faut régulièrement aller chercher 200 autres figurants dans les fermes alentour. Un système de points de rationnements est mis en place pour payer les figurants afin de pallier au retard des paiements en provenance de Rio. Beaucoup en effet dépendaient de cet argent pour manger et, sans ce système, le tournage aurait été gravement menacé ${ }^{606}$.

Toutes les difficultés affrontées par l'équipe s'ajoutent à des conditions de tournage extrêmement difficiles, Milagres est une ville isolée, sans électricité ni eau courante et reliée au reste de l'état par des routes difficiles à parcourir et qui augmentent encore l'éloignement

force de leur travail font la prospérité des fazendeiros sont les mêmes qui sont privés de nourriture en temps de sécheresse.

605Pendant la première phase du Cinema Novo, il est assez courant que les cinéastes lisent et discutent de leurs scénarios entre eux et avec les autres artistes qui sont proches du Cinema Novo. Ainsi, entre 1962 et 1964 , lors de ce qui fut sans doute la période de plus grande cohésion du groupe, chacun connait les projets des uns et des autres dans le détail et la moindre idée peut être débattue. Malgré cela, la dimension individuelle des films est très largement préservée, voire même encouragée.

606Toutes ces informations proviennent des deux principales entrevues concédées par Ruy Guerra sur le film : GUERRA, Ruy. «Entretien avec Ruy Guerra par Jean-André Fieschi et Jean Narboni », op. cit., p. 53. GUERRA, Ruy. «Entrevista con Ruy Guerra » in Nuestro Cine, Madrid, nº5, septembre 1967. 
de la ville. Directeur, acteurs et techniciens dorment chez l'habitant, dans des maisons paysannes comparables à celles du XIXe siècle. Tous les films tournés dans le sertão se sont heurtés à des difficultés comparables ${ }^{607}$ mais, dans le cas de Os Fuzis, des tensions sont apparues au sein de l'équipe. Joel Barcellos s'en va avant que ne soient tournées toutes les scènes où son personnage devait apparaître. Bien que nous n'ayons pas eu accès au scénario original du film, toutes les déclarations de Guerra sur les circonstances du tournage indiquent que des modifications substantielles ont été apportées au cours de cette étape ${ }^{608}$. Au final pourtant, la cohérence du long métrage est exemplaire.

Le film commence avec un long plan fixe du ciel avec en son centre le soleil, éblouissant, et en voix off, la voix de l'acteur Antônio Pitanga, une voix cassée et rauque qui mugit d'inquiétantes prédications en relation avec la sécheresse. À ce premier plan succèdent deux autres renforçant l'impression de chaleur, les branches recroquevillées d'un arbre, un lézard et le générique avec ses inscriptions noires sur fond blanc. Tout au long du film, la bande-son incommode le spectateur. Les prédications du saint, qui n'est pas joué mais seulement doublé par Pitanga, succèdent aux chants et aux prières qui forment l'unique intervention orale de la population du village et des retirantes si l'on exclut les interventions du personnage de Luíza et les interviews du début du film. La structure narrative, au contraire de celles de Vidas secas et Deus e o diabo na terra do sol, n'est pas linéaire mais fragmentée et ceci est très clair dès la phase d'exposition qui nous montre en montage parallèle l'arrivée simultanée à Milagres des trois actants principaux : la troupe de retirantes commandée par le saint et rassemblée autour du bœuf sacré, le détachement militaire composé par un sergent et quatre soldats et le chauffeur de camion, Gaúcho.

Tout au long du film, le montage, jusque dans la composition interne des plans, renforce la séparation entre le groupe formé par la troupe et le chauffeur dans lequel tous les personnages sont caractérisés individuellement et les retirantes qui se fondent dans la population du village et forment avec elle une masse indistincte. Quand ils ne prient pas, les figurants sont muets et hiératiques. Trois séquences sont à ce sujet particulièrement frappantes. La première est celle du cours sur l'armement donné dans le bar du village par le soldat interprété par Paulo César Peréio. Les autres soldats et le chauffeur de camion sont assis ou debout, plaisantent entre eux et évoluent avec aisance entre les paysans silencieux et

607 Les conditions de tournage de Deus e do diabo na terra do sol ont aussi été très difficiles. Ainsi les deux pannes successives de caméra arrivées au début du tournage avaient coûtées plusieurs jours de tournage, le moindre aller-retour à Salvador prenant au minimum deux jours, un pour y aller et un pour revenir. 608Cf. GUERRA, Ruy. « Entrevista con Ruy Guerra », op. cit., p. 56.

Au sujet du départ de Joel Barcellos, nous pouvons nous demander si la mésentente avec le cinéaste n'a pas eu des fondements idéologiques. Comme dans Deus e o diabo na terra do sol ou encore Vidas secas, la représentation du peuple est très peu complaisante. Joel Barcellos, qui était aussi très impliqué dans le CPC, joue le rôle d'un paysan qui laisse son fils mourir de faim sans réagir. 
immobiles. La seconde séquence de ce genre est celle où le soldat Mário, interprété par Nelson Xavier, dans la maison de Luíza, raconte sa vie devant la famille de cette dernière. La silhouette sombre des parents apparaît au premier plan de l'image, le soldat est assis au milieu de la cuisine dans la lumière. Il s'agit là d'un monologue, à peine relancé par une intervention de la jeune femme. La troisième séquence est celle de la révolte de Gaúcho. Dans un premier temps, la foule rassemblée sur la place du village ne réagit pas à ses cris. Puis, quand il tire sur les camions qui s'en vont pleins de nourriture, les personnes qui se mettent à courir sont celles qui se trouvent sur leur trajectoire et tentent alors de ne pas se faire écraser. L'immobilité ou la difficulté à réagir peut alors être assimilée à de l'apathie.

Cette division très nette des actants et cette opposition ostensible entre un groupe ayant accès à une caractérisation individuelle et un second groupe n'y ayant pas droit, recoupe les conflits exposés de façon très didactique dès le début de la narration. Comme dans les autres films de la trilogie du sertão, les registres du documentaire et de la fiction se confondent. Dans Os Fuzis, les plans et les séquences de caractère documentaire visent avant tout à nous renseigner sur les conditions de vie dans le Nordeste. Il en va ainsi des images de la procession autour du bœuf sacré, de la procession autour de l'église et du long planséquence qui nous permet de visiter la maison de Luíza dans la scène que nous avons déjà citée. En plus de cette dimension informative générale, le registre documentaire est aussi celui qui pose le premier et principal conflit du film : celui qui, selon les termes de «L'Esthétique de la faim » est vécu mais pas compris, autrement dit la famine et à la sécheresse. Après le générique, deux entrevues de personnes du peuple nous apportent des témoignages sur les conséquences de la sécheresse : le chômage, l'exode et la mort. Dans la séquence suivante, nous apprenons que les soldats sont venus à Milagres protéger les magasins d'un commerçant local qui craint que la foule des retirantes affamés ne pillent sa marchandise avant que des camions ne viennent en prendre la livraison. La situation est exposée dans un dialogue entre le sergent et le commerçant. Le premier conflit oppose donc la foule affamée aux soldats. Le film s'attachera pourtant à montrer que ce conflit, malgré le fait qu'il soit le principal, est purement virtuel, la confrontation qui est crainte par les soldats et le commerçant n'arrivera pas.

À partir de là, deux sous-conflits sont articulés. Le premier est celui qui oppose Gaúcho aux soldats. Le second est interne à la population et aux retirantes. Dans les deux cas, il s'agit de consciences en crise. Gaúcho est immobilisé à Milagres avec sa cargaison d'oignons en raison d'une panne mécanique. Il attend de Salvador la pièce qui doit lui permettre de réparer son camion. Dans l'intervalle, il rencontre la troupe de soldats qui est arrivé au village en même temps que lui. Parmi les militaires, il reconnaît Mário. Les deux 
hommes ont servi ensemble par le passé mais Gaúcho a préféré quitter l'armée. Dès leur première rencontre, Gaúcho tente de sensibiliser Mário face à l'absurdité de sa mission. Dans une séquence où les deux hommes se retrouvent seul à seul, Mário dit à Gaúcho qu'il est venu au village pour contribuer au maintien de l'ordre. Le chauffeur de camion lui rit au nez en ironisant sur sa notion d'ordre. Pour lui, une situation dans laquelle la population meurt de faim sans qu'aucun secours ne lui soit apporté n'est pas vraiment représentative de l'ordre. À partir de là, Gaúcho va jouer le rôle de la mauvaise conscience des soldats qui vont être tiraillés entre respecter leur mission et, par là même, conserver le statut avantageux que l'uniforme leur confère ${ }^{609}$ ou mettre fin à une situation humainement inacceptable.

Les soldats sont plus ou moins sensible à la présence de Gaúcho. La majorité d'entre eux usent et abusent de leur statut, c'est notamment le cas quand le soldat joué par Peréio abat un paysan par maladresse dans un pari malheureux. Le sergent décide aussitôt de le couvrir et engage les soldats à apporter un faux témoignage à la population. Celle-ci n'est pas dupe comme le montre l'intervention de Luíza, mais reste passive. Le fait que Gaúcho devine ce qui s'est passé pèse à Mário et, dans une moindre mesure, au soldat joué par Carvana. Sans que rien ne soit réellement dit de façon explicite entre les personnages, l'incident vient alors confirmer le point de vue de Gaúcho à savoir que les soldats ne sont pas là pour maintenir l'ordre mais participent au contraire à propager le chaos.

Le conflit entre les soldats et Gaúcho qui est aussi une crise morale interne à la troupe atteint son paroxysme lorsque le chauffeur de camion décide d'inciter à la révolte. Quand les camions arrivent enfin pour emporter les marchandises que les soldats doivent protéger, un paysan apporte un enfant mort dans le bar où se tient Gaúcho. Il demande au paysan ce qui est arrivé. Celui-ci lui dit que son fils est mort de faim. Le chauffeur perd alors son calme, traite le paysan de couard, prend le fusil du soldat joué par Carvana et sort en tirant sur les camions et en criant à la foule de se révolter. Celle-ci reste passive. S'engage alors une course poursuite. Gaúcho est rattrapé. Mário tente de s'interposer pour ne pas qu'il soit tué mais il est aussitôt neutralisé. Le soldat joué par Carvana arrive par derrière et tire frénétiquement sur Gaúcho en criant «Chega ! Chega ! (Assez ! Assez !). Mário s'effondre en larmes sur le corps criblé de balles. Après l'authentique psychodrame qu'a provoqué la révolte de Gaúcho et son exécution, la troupe retrouve pourtant sa cohésion et même Mário, qui a hésité un court espace de temps, reprend la route avec ses camarades.

609À plusieurs reprises dans le film, et notamment dans les dialogues entre Mário et Gaúcho, les avantages économiques en termes de paye du soldat par rapport au chauffeur de camion sont soulignés. Il est aussi très clair que le chauffeur jouit d'une position privilégiée par rapport aux villageois et aux retirantes puisqu'il fréquente le bar aussi souvent que les soldats et ne souffre pas de la faim, autrement dit son niveau de vie dans le village est équivalent au leur et, effectivement, supérieur à la masse affamée. 
Le premier conflit est donc résolu d'une façon fort peu satisfaisante, nous sommes revenus à l'état initial de la narration et la crise reste ouverte, prête à être réactivée. L'observation blasée de Gaúcho laissait penser que ce n'était pas la première fois que l'armée assumait ce genre de mission, le spectateur peut donc facilement imaginer qu'à la fin, les soldats s'en vont vers de nouvelles missions aussi peu glorieuses que celle à laquelle il a assisté. Le second conflit, selon Guerra, connaît un épilogue plus heureux. C'est celui qui oppose les autochtones à leurs propres croyances, celles-ci les rendant passifs et incapables d'affronter leurs problèmes et de se défendre. Ce conflit existe du point de vue de Gaúcho, mais aussi du film, du cinéaste, et encore aujourd'hui d'une bonne partie de la critique : «Os camponeses, sem ação, adoram um boi e rezam, em vez de tomar atitude contra a fome, a seca e a retirada dos mantimentos. $»^{610}$ Autant le premier conflit présente une forte authenticité, autant le second correspond à des catégories valables seulement d'un point de vue extérieur au groupe concerné. Construction a priori de l'observateur sur un sujet qui lui est extérieur, la problématique qui est imposée aux opprimés est d'une pertinence discutable. Rien ne prouve que s'ils ne priaient pas, forcément, ils feraient la révolution. Le raccourci effectué par le scénariste est donc faux et simpliste, mais c'est sur lui que le second conflit du film repose. Celui-ci se résout après la séquence de la mort de Gaúcho. Les opprimés se retournent soudain contre le bœuf qui, selon les paroles du saint, perd son caractère sacré pour ne pas avoir accédé aux prières de la communauté. Il est alors tué et dépecé.

Le film est monté après le coup d'État, Guerra a d'abord dissimulé les bobines puis, voyant qu'il n'était pas inquiété, termine le film et le soumet aux autorités qui le sélectionne pour représenter officiellement le Brésil au Festival de Berlin de 1964. Os Fuzis bénéficie de l'appui des fonctionnaires favorables au Cinema Novo et qui sont toujours en place au service culturel du ministère des affaires étrangères du Brésil. Il faut cependant noter que pour sortir du pays, il reçoit l'assentiment de la censure et du comité de sécurité formé par les militaires. L'anecdote que raconte le cinéaste au sujet de l'approbation du film par ce comité est d'ailleurs exactement la même que celle circulant sur Deus e o diabo na terra do sol ${ }^{611}$. À Berlin, le film

610« Les paysans, inactifs, adorent un bœuf et prient à la place de réagir contre la faim, la sécheresse et le départ des vivres. » in VALENTE, Eduardo. « Os Fuzis, de Ruy Guerra / A Hora e a Vez de Augusto Matraga, de Roberto Santos » in Contracampo, revue en ligne consultée le 01/12/2005, http://www.contracampo.com.br/27/frames.htm.

611 «Quand le coup d'État s'est fait, la Commission de Sélection, dont les membres n'ont pas été changés tout de suite, l'a vite choisi pour Berlin. Sur ce, le Comité de Sécurité a demandé à la voir, parce que le bruit avait couru qu'à Cannes des cinéastes brésiliens avaient pris position contre le gouvernement nouveau. Dorénavant, tous les films devant représenter le Brésil devaient être vus par ce comité. Et le plus drôle, c'est qu'à la fin de la projection, un général s'est levé en disant : ' Ça, c'est un film de mâle ! ' Là-dessus, les autres n'ont pas voulu jouer les femelles, et le film est passé comme ça. Il a été le premier film à représenter le gouvernement après le coup d'État, et à Berlin, les gens ne comprenaient pas très bien ce qui se passait puisque le film est nettement antimilitariste. » in GUERRA, Ruy. «Entretien avec Ruy Guerra par JeanAndré Fieschi et Jean Narboni », op. cit., p. 53. 
remporte l'Ours d'argent. Malgré ce succès, Os Fuzis est très mal reçu par le microcosme carioca qui, d'habitude, assure la promotion du Cinema Novo ${ }^{612}$. Toujours selon Guerra, la mauvaise presse formelle et informelle faite au film à partir des premières sessions privées est due à des éléments extérieurs. À la même époque, il prend position contre la CAIC. Il pense également qu'une bonne part de rivalité entre en jeu et, peut être aussi, de racisme vis à vis du fait qu'il n'est pas brésilien et vient du Mozambique ${ }^{613}$. Rocha ridiculise le film en parlant d'un « Marienbad du sertão » ${ }^{614}$.

Influencé par ces mauvaises réactions, le producteur Jarbas Barbosa demande à Guerra l'autorisation de remonter le film. Mais le contrat qui le lie au réalisateur l'empêche d'imposer un nouveau montage. Ce dernier refuse de toucher à l'œuvre consacrée à Berlin. En guise de représailles, Barbosa choisit de ne pas sortir le film et d'attendre. Des semaines et des mois passent, endetté, Guerra doit se rendre aux exigences du producteur mais exige que son nom soit retiré du générique ${ }^{615}$. Malgré ce compromis, Barbosa offre à Os Fuzis le plus mauvais lancement des trois films du Cinema Novo qu'il a produit ${ }^{616}$. Les critiques brésiliens commenteront donc, pour une part la version originale vue à Berlin ou en session privée, et pour une autre part, celle sortie en salles. Ely Azeredo confirme le massacre effectué lors de ce montage sensé rendre le film plus commercial ${ }^{617}$. Enfin, certains critiques refusent d'exprimer leur opinion sur un film remonté par son producteur contre l'opinion de son

612Nous retrouvons un témoignage sur cette très mauvaise réception initiale du film dans l'article suivant : ACUIO, Carlos. « Mediocridade nacional causa pavor e piedade : Os Fuzis » in Diário carioca, Rio de Janeiro, 14/06/1964. Bien que le parti pris de l'auteur soit manifeste, le contenu de l'article reflète bien l'opinion qui va dominer pendant cette période à savoir que Os Fuzis est le ratage d'un cinéaste de grand talent.

613Cf. VIANY, Alex. O processo do Cinema Novo. Op. cit., pp. 379-391. Saraceni évoque dans son autobiographie son incompréhension vis à vis des critiques de son camarade envers le système de Lacerda qui «sauvait» littéralement des gens comme Santos d'une situation financière critique. La rivalité entre Guerra et Rocha est quant à elle de notoriété publique et elle se poursuivra par voie de presse interposée dans les années soixante-dix.

614Témoignage de Jean-Claude Bernardet à l'auteur.

615FERREIRA, Fernando C. « Cinema Nôvo já está com as barbas de môlho » in Jornal dos sports, sans lieu, 29/11/1964.

ALBERTO, Luiz. « Os Fuzis do doutor Barbosa » in Jornal do comércio, Rio de Janeiro, 27/01/1965.

616Deus e o diabo na terra do sol est sorti avec 12 copies, Ganga Zumba, 8 et Os Fuzis, seulement 3, chacun dans un circuit différent, respectivement le circuit Lívio Bruni, Severiano Ribeiro et Metro. Les entrées de Os Fuzis n'auraient même pas permis de payer les copies! Selon Barbosa, la personnalité difficile de Guerra est pour beaucoup dans l'insuccès du film. In OROZ, Silvia. 30 anos de Cinema Novo : Jarbas BarbosaEntrevista a Silvia Oroz. Op. cit., p.18-21.

617 « Quanto aos cortes, a pessoa que se encarregou deles está de parabéns : o serviço está tão bem feito que há rombos inesquecíveis entre certas cenas. Além do mais, os cortes destinavam-se a enquadrar a fita nos horários normais de duas horas. O cálculo foi tão bom que ainda coube no programa um jornal, dois trailers e um noticiário sob os fascinantes temas torneio de Wimbledon e cooperativa agrícola de Iquiritos. » («Quant aux coupes, la personne qui s'en est chargé peut être félicitée : le travail est si bien fait qu'il y a des blancs inoubliables entre certaines scènes. En plus de cela, les coupes servent à permettre au film de respecter les horaires traditionnels de la séance de deux heures. Le calcul a été si bien fait qu'il a encore été possible d'insérer au programme un journal, deux bandes annonces et deux reportages sur les thèmes fascinants du tournoi de Wimbledon et de la coopérative agricole de Iquiritos. ») in AZEREDO, Ely. « Uma Certa miséria luxuosa » in Tribuna da imprensa, Rio de Janeiro, 26/01/1965. 
réalisateur et occupent la totalité de leurs articles à expliquer ce parti pris ${ }^{618}$. Pour Guerra, il s'agissait surtout là d'un moyen hypocrite de ne pas discuter Os Fuzis ${ }^{619}$.

Deux points sont à retenir. Le premier, c'est que la polémique provoquée par le film est limitée au microcosme de l'intelligentsia carioca qui s'intéresse au cinéma. D'une certaine manière, nous pourrions même parler d'un réflexe collectif de rétention de l'œuvre par ce groupe puisqu'avec une sortie commerciale aussi catastrophique, il sera impossible de considérer qu'Os Fuzis a réellement été soumis au jugement du public. Le second point à retenir est que cette polémique oppose détracteurs et défenseurs du film autour d'une problématique commune qui est bien celle du Cinema Novo et de la création d'un cinéma de conscientisation. L'accusation la plus forte des détracteurs du film, dans la lignée de l'avis de Rocha, est celle du formalisme. Ainsi, Azeredo n'est pas moins cassant que Rocha lorsqu'il qualifie Os Fuzis en disant qu'il s'agit de «o mais pedante monumento formalista do cinema brasileiro » (le plus pédant monument formaliste du cinéma brésilien) dans un article intitulé «Uma certa miséria luxuosa ${ }^{620}$ (littéralement, « une certaine misère luxueuse »). Un auteur anonyme (Rocha ?) reprend la comparaison avec Marienbad:

«Em princípio, Os Fuzis é o Marienbad do Nordeste. Confuso, dispersivo. Visto num todo, o filme esvazia. Nem transmite nada, nem possui mensagem social, nem é retrato de situação alguma. E no entanto, apesar disto, eu diria que Rui Guerra é um DIRETOR de cinema ; ou melhor, um diretor de seqüências cinematográficas perfeitas. $)^{621}$

Les critiques défavorables au film nient donc avant tout sa capacité à faire comprendre quelque chose du réel ce qui, a posteriori, peut nous sembler assez étrange puisqu'au contraire, comme nous le montrerons en conclusion, Os Fuzis nous semble au contraire dire beaucoup sur la situation sociale et politique alors traversée par le Brésil. Il traduit même une lucidité qui n'a pas été atteinte par les autres films qui lui sont contemporains. Bien qu'il ait également reçu des critiques favorables dans cette période, notamment de la part d'Alex $V_{\text {Viany }}{ }^{622}$ qui était également soucieux des questions politiques, sa valeur est reconnue avec le temps. Rocha le premier revient sur son premier jugement avec un texte qui anticipe la perception de l'ambiguïté du personnage principal, Gaúcho, projection du cinéaste au sein de

618ALBERTO, Luiz. «Os Fuzis do doutor Barbosa » in Jornal do comércio, Rio de Janeiro, 27/01/1965. 619GUERRA, Ruy. «Entretien avec Ruy Guerra par Jean-André Fieschi et Jean Narboni », op. cit., p. 53. 620AZEREDO, Ely. « Uma Certa miséria luxuosa » in Tribuna da imprensa, Rio de Janeiro, 26/01/1965. 621 « En principe, Os Fuzis est le Marienbad du Nordeste. Confus, dispersé. Vu comme une unité, le film se vide de sa substance. Il ne transmet rien, ne possède pas de message social, n'est la description d'aucune situation réelle. Mais, malgré cela, je dirais que Rui Guerra est un RÉALISATEUR de cinéma ; ou mieux, un réalisateur de séquences cinématographiques parfaites. » in « Rui (Os Fuzis) Guerra : Um Moço que sabe fazer cinema » in Última hora, Rio de Janeiro, 25/05/1965. Outre la reprise de la comparaison à Marienbad, le style de l'article est très proche de celui de Rocha.

622VIANY, Alex. «O Filme é Os Fuzis » sans origine, 26/01/1965. Os Fuzis reçoit la note maximale, 5 étoiles, mais le texte n'est pas très approfondi. 
la diégèse. En ce sens, il pressent l'analyse de Bernardet des personnages oscillants et la posture réflexive qui sera adoptée par le Cinema Novo à partir de 1965 avec O Desafio :

« No bojo de Os Fuzis se processa uma terrível dialética entre o homem e o meio social, entre o homem telúrico e o herói errante que precisa de uma situação histórica determinada, para justificar sua própria existência. Neste ponto, Ruy Guerra se identifica com Gaúcho, o motorista do Sul que se envolve cônscio e sinceramente aos flagelados da seca e por isso vai à luta contra os soldados. [...] Aqui vence apenas o primeiro polo : aquele do homem errante, alienado. O homem gera o 'close-up' : a posição da câmera é uma questão de moral, logo a 'mise-en-scène' de Ruy Guerra é abstrata a partir dos seus próprios soldados ; e o filme não comunica na medida exata em que os seus personagens não se comunicam entre si. ${ }^{623}$

Plus tard, il ira jusqu'à estimer que Os Fuzis est un film qui met en application les principes de «L'Esthétique de la faim », qu'il écrit en janvier $1965^{624}$. Mais le texte le plus célèbre et le plus convaincant à revendiquer la capacité du long métrage de Guerra à déclencher un processus de prise de conscience chez le spectateur est celui de Roberto Schwarz dans la revue Civilização brasileira. Selon lui, Os Fuzis établit une problématique et met en cause le spectateur.

Il articule sa démonstration en quatre points. Il remarque d'abord que le cinéma nous permet de nous confronter à des expériences qui nous sont étrangères avec, cependant, une absence totale de risque (Ex. du lion dans la savane, du misérable dans le sertão). La compassion qu'il peut nous faire ressentir par rapport aux drames humains ne signifie pas pour autant la compréhension des mécanismes sociaux, politiques et économiques qui sont à leur origine. Aucune prise de conscience du spectateur de ses propres responsabilités n'est donc possible à partir du simple témoignage ou de la simple identification avec les personnages. Or, la force du film de Guerra est, justement, d'établir une distance entre la misère et le spectateur et de ne pas favoriser l'empathie comme le font Deus e o diabo na terra do sol et Vidas secas. La rupture formelle entre le registre documentaire et le fictionnel est renforcée par la rupture existante entre la figuration et les acteurs (voire l'équipe du film) et celle opposant les symboles du sous-développement à ceux de la technique (les fusils, le camion, la caméra).

623 « Au cœur de Os Fuzis se déploie une dialectique terrible entre l'homme et le milieu social, entre l'homme de la terre et le héros errant qui a besoin d'une situation historique déterminée pour justifier sa propre existence. Sur ce point, Ruy Guerra s'identifie avec Gaúcho, le chauffeur du Sud qui s'engage consciemment et sincèrement du côté des victimes de la sécheresse et, pour cette raison, prend les armes contre les soldats. [...] Ici, ne triomphe que le premier pôle, celui de l'homme errant, aliéné. L'homme exige le ' close-up ' : la position de la caméra est une question de morale, aussi la mise en scène de Ruy Guerra est abstraite du point de vue de ses propres soldats; et le film ne communique pas dans l'exacte mesure où ses personnages ne communiquent pas entre eux. » in ROCHA, Glauber. «Os Fuzis de Ruy Guerra » in O Jornal, Rio de Janeiro, 20/09/1964.

624 «Certains films brésiliens sont en accord avec l'esthétique de la violence : le personnage de Gaúcho dans $O s$ Fuzis de Ruy Guerra est dans l'esprit de cette esthétique parce qu'il déclenche un processus. » in ROCHA, Glauber. « Entretien avec Rocha » in Positif, Paris, n91, janvier 1968, p. 35. 
Tout se passe presque comme si nous avions deux films disjoints à la place d'un puisque nous avons également deux lignes narratives distinctes, celle de la révolte des paysans contre le bœuf sacré et celle de la révolte de Gaúcho. Cette structure narrative empêche une relation d'empathie avec les opprimés mais, en plus, l'identification du spectateur avec les soldats est négative. Ceux-ci agissent avec l'assurance de l'impunité et affichent la supériorité que leur confère leurs armes et leur statut social. Eux qui ne sont rien à la ville apparaissent comme des seigneurs dans ce village reculé. Leur apparente désinvolture s'oppose à la passivité des paysans. Cependant, la troupe est travaillée par la mauvaise conscience et oscille entre la désagrégation brutale et le respect à sa mission initiale. Enfin, le climax du film est faux dans la mesure où la révolte et la poursuite de Gaúcho est la résolution d'un conflit interne aux soldats, un conflit d'ordre moral, et ne met pas en jeu la problématique principale qui est celle de la propriété. Le seul groupe capable de transformation sera donc celui des villageois, leur action soudaine et violente laisse entrevoir leur possible accès à la raison.

De toutes les critiques écrites au Brésil sur Os Fuzis, celle de Schwarz est sans doute celle qui précise le mieux l'intention de Guerra. Il nous semble cependant utile d'articuler de nouvelles remarques à ce que nous venons d'exposer. Premièrement, nous maintenons que le conflit interne à la ligne narrative des paysans est inauthentique. Il révèle mieux les préjugés sociaux d'une classe sur une autre qu'il n'exprime une problématique existant dans le monde réel et dont la résolution hypothétique suffirait à enclencher un processus de transformation. En dernière instance, le mysticisme est beaucoup plus un symptôme qu'une cause aux inégalités sociales (sans encore pouvoir être réduit à cela), l'emphase qui lui est apporté résulte d'une inversion de perspectives qui sera corrigée plus tard. Ce qui est néanmoins intéressant et que Schwarz ne peut pas percevoir puisqu'il partage le point de vue de Guerra, c'est que l'aliénation de Gaúcho, symbolisée par la structure discontinue de la narration et le caractère individualiste de sa révolte, dénonce la validité de son point de vue et de celui du film. En résumé, le film nous donne une opinion sur la façon dont les opprimés tolèrent l'oppression et, en même temps, nous dit que ce point de vue peut très bien être faussé.

Dans ce même ordre d'idée, l'immobilisme de la population et son indifférence vis à vis du destin de Gaúcho peuvent prendre un sens tout à fait différent de celui qui consiste à conclure à son apathie et à sa passivité, elles signifient surtout que notre héros, ce personnage dont nous comprenons l'action et la révolte, n'est pas le sien. Et nous en venons maintenant à la lucidité du film de Guerra qui pressent avant tous les autres, que la position des classes moyennes «progressistes » est essentiellement le produit de leur moralisme. Ce dernier se révèle vite sans effet quand il est confronté aux mécanismes économiques, sociaux et culturels 
qui déterminent réellement les comportements humains. Ainsi, Os Fuzis se révèle prophétique pour tout ce qui tient aux réactions des soldats. L'évolution de la troupe mise en scène par le film peut en effet parfaitement fonctionner comme une métaphore de ce qui va se produire à partir de mars 1964.

Mais il faudra bien comprendre encore deux choses. La première, c'est que Os Fuzis pouvait et aurait finalement dû fonctionner plus comme un signal d'alarme à usage interne au groupe qui l'a produit que comme un véritable film populaire de prise de conscience générale. L'insistance de Guerra à montrer les soldats sous un jour défavorable qui lui semblait être le plus authentique, signale la pertinence de son approche. Son analyse était juste mais, venue trop tôt ou trop tard, elle s'est révélée sans effet. La seconde chose qu'il faut comprendre est qu'au-delà de la structure du film telle qu'elle est mise à jour par Schwarz, sa pertinence dérive des propres ambiguïtés du processus de création de Guerra et, par extension, de tout le Cinema Novo. Si nous confrontons les témoignages du cinéaste sur les conditions de tournage à Milagres et le film, nous pourrons nous rendre compte que le Milagres de la fiction n'est pas celui de la réalité. Cette observation qui pourrait paraître banale dans tous les contextes autres que celui du Cinema Novo, est ici significative. Loin de la posture de recherche ethnologique que nous avons commentée au sujet de Arraial do cabo, le cinéaste préfère à l'investigation du réel, une histoire existant $a$ priori à sa découverte du sertão pour son intérêt dramatique. Cette contradiction s'avère féconde presque par accident. Il convient cependant une fois de plus de remarquer que la praxis cinématographique ne correspond pas aux objectifs politiques affichés d'un cinéma de prise de conscience populaire. Dans le contexte du Cinema Novo, il aurait peut être plus cohérent d'écouter et de donner à entendre et à voir Milagres que de montrer ce que l'on projetait sur cette ville ${ }^{625}$.

\section{Conclusion de la deuxième partie}

Plusieurs éléments importants sont à relever dans cette première phase du Cinema Novo. La première observation que nous pouvons faire est que le Cinema Novo se nourrit principalement de références empruntées à la culture classique ou en passe d'être reconnues comme appartenant à la culture classique. Dans le rapport à la culture brésilienne, il s'agit de références essentiellement littéraires. Dans le rapport à la culture cinématographique, il s'agit de références aux grands maîtres du cinéma allant d'Eisenstein à Godard. L'origine sociale des 
cinéastes et l'éducation formelle qu'ils ont reçu, leur facilitaient l'accès à ce type de culture qui va déterminer leur rapport à l'art et au cinéma. Aussi, quant il est question de créer un nouveau cinéma, les cinemanovistas pensent à s'illustrer et à « faire œuvre » au sens où « faire œuvre » est entendu dans la culture classique. Cette conception de la culture n'est pas seulement manifeste dans l'esthétique des films qu'ils produisent mais aussi dans leur rapport aux structures économiques et aux espaces de légitimation qui sont investis par eux. Tout à leur ambition de faire œuvre, ils se tournent vers les réseaux de distribution et d'exploitation traditionnels du cinéma alors même que le CPC avait initié par la pratique la création de réseaux alternatifs de diffusion de la culture en allant à la rencontre des masses là où elles se trouvaient. Le marché du cinéma se montrant extrêmement réticent à la proposition du Cinema Novo, sa pénétration ne sera possible qu'avec le concours de la critique internationale et au prix de compromis avec des institutions publiques ou privées dirigées par des personnages idéologiquement opposés aux idéaux socialistes.

Le Brésil n'ayant jamais possédé de cinématographie à la hauteur des grandes cinématographies mondiales, réussir à participer aux grandes compétitions internationales sur un pied d'égalité avec Resnais, Antonioni ou Buñuel, apparaît déjà comme révolutionnaire aux yeux des cinemanovistas qui voudront y voir un accès du Brésil dans sa totalité à l'expression et sa participation à l'édification de la culture internationale, au sens noble et donc classique. De fait, l'accès à l'expression et à l'émancipation n'est pas une aventure collective mais seulement celle d'un petit nombre. Au Brésil, la diffusion des films du Cinema Novo est réduite aux grands centres urbains et là où ils sont diffusés leur succès auprès du public est limité. Au cours de cette première phase, et malgré l'importante couverture critique des films, seuls Os Cafajestes et $A$ Grande Feira sont des succès commerciaux. Les cinemanovistas se plaindront souvent de l'incompréhension des masses vis à vis de leurs films ${ }^{626}$. L'idéal d'un cinéma national populaire n'est donc pas réalisé. Cette constatation qui est déjà la leur ne sera pourtant jamais mise en relation avec l'inadéquation manifeste des moyens mis en œuvre avec les objectifs déclarés. Les structures traditionnelles, de par leurs logiques internes économiques et politiques, restreignent évidemment la possibilité de diffusion d'un message anticapitaliste. Au-delà de ce premier élément, la très inégale répartition géographique des salles de cinéma interdit pratiquement tout espoir de diffusion au-delà de l'axe Rio-São Paulo et de quelques grandes capitales. Rocha lui-même constatera qu'aucun film du Cinema Novo n'a encore été projeté à Manaus en $1965^{627}$. Le fait que le Cinema Novo recherche sa légitimité auprès des instances de la culture classique, que ce soit les festivals ou les 626Cf. DAHL, Gustavo. « Cinema Nôvo e seu público » in Revista Civilização Brasileira, Rio de Janeiro, n¹1- 
prestigieux suppléments culturels dans lesquels ses partisans écrivent, ne permet pas non plus de le rapprocher des masses populaires qui ne partagent pas ces référents. Enfin, sur l'esthétique des films, tous ne sont pas équivalents, mais, pour la majorité d'entre eux, ils manifestent une idéologie avec laquelle les masses pouvaient entrer en désaccord et s'insèrent dans une relation à l'art qui, une fois de plus imprégnée par la culture classique, peut lui paraître étrangère.

Le seul véritable objectif « révolutionnaire » atteint par le Cinema Novo en 1964 est de faire définitivement accepter le septième art comme tel dans le champ de la culture classique brésilienne, simultanément à ce qui arrive d'ailleurs dans d'autres pays comme l'Italie et la France ${ }^{628}$. Pour autant, il serait injuste d'en rester sur ce constat d'échec. L'analyse des films et de leur réception par la critique nous montrent bien que si l'ambiguïté de la posture du Cinema Novo est réelle, ses membres n'en sont pas moins animés d'un questionnement et d'une recherche authentique dont le pivot central est la culture populaire. Comme nous l'avons vu pour Barravento, Ganga Zumba, Deus e o diabo na terra do sol ou encore Os Fuzis, la culture populaire interroge en même temps qu'elle exerce une résistance qui met en échec les positions dogmatiques héritées de l'ISEB et du CPC. D'une façon tout à fait curieuse, les films qui sont censés être des films de conscientisation amorcent la critique de ce concept et de l'idéologie populiste qui lui est attaché. Le coup d'État de 1964 va accélérer cette remise en cause, une phase réflexive est ouverte avant que ne reviennent des ambitions de conscientisation sur d'autres bases idéologiques.

628Sur la reconnaissance du cinéma dans la culture classique, $C f$. : ESQUENAZI, Jean-Pierre. Godard et la société française des années 1960. Op. cit. 


\section{TROISIÈME PARTIE : Le Cinema Novo deuxième forme (1964- 1968)}

Le coup d'État militaire du ler avril 1964 prend l'ensemble des secteurs progressistes de surprise, les cinemanovistas inclus ${ }^{629}$. Paulo César Saraceni nous offre dans son autobiographie un témoignage assez significatif quant aux illusions de cette époque et à la façon dont les journées du 31 mars et du 1er avril sont vécues ${ }^{630}$. Malgré l'accroissement des tensions dans les semaines qui précèdent le coup d'État, il règne un certain enthousiasme lié à la certitude que le Brésil est en train de faire sa révolution, une révolution tranquille vers un socialisme à la brésilienne dont on ne sait trop s'il serait installé par João Goulart ou Juscelino Kubitschek. Ce dernier est en effet le vainqueur annoncé des élections présidentielles qui doivent se dérouler en 1965. Selon Saraceni, on s'imagine qu'une révolution démocratique est possible : «Seria uma revolução sem violência e sem sangue. Pois seria feito pelo presidente da República e pelo Congresso » ${ }^{631}$. Le 31 mars, avec Joaquim Pedro de Andrade et Gustavo Dahl, il assiste aux premiers mouvements de troupes à Rio mais la situation paraît être contrôlée par Goulart. Après l'habituelle discussion sur le cinéma autour d'une bière chacun rentre chez soi sans réelles inquiétudes. Le lendemain matin, la télévision annonce que le rapport de force a été inversé. Le 2 avril, la présidence est déclarée vacante, Goulart s'exile.

Le soutien inconditionnel des médias aux militaires et la confusion des premiers jours sont tels que les réactions peinent à s'organiser. Le fait que les généraux et les gouverneurs qui appuient le coup d'État prétendent vouloir respecter la constitution démocratique et le calendrier des prochaines élections contribue à maintenir de larges secteurs dans l'indécision. Les putschistes disent avoir réagi à une dérive du gouvernement vers le communisme et rien ne laisse alors présager que la dictature qui s'instaure ira en se consolidant et durera 21 ans. L'arrivée au pouvoir du Maréchal Castello Branco signifie le retour à une politique libérale mais elle peut passer pour un contretemps dans l'esprit de ceux qui s'imaginent que les prochaines élections leur rendront la parole. Peu à peu cependant, et selon les mêmes prétextes qui justifiaient le coup d'État, les élections présidentielles sont repoussées puis la constitution est modifiée par des actes institutionnels (AI).

629Selon Bernardet, des cinéastes de l'époque, seul Luís Sérgio Person, qui n'appartient pas au groupe du Cinema Novo, pressentait le coup d'État. Jean-Claude Bernardet. Entretiens avec l'auteur, mars et juillet 2003. Dahl, quant à lui, nous a dit que pour avoir été éloigné du Brésil pendant quatre ans il était assez sceptique devant l'enthousiasme de ces camarades. Il arrive à Rio le 24 mars 1964. Gustavo Dahl. Entretien avec l'auteur, février 2004.

630SARACENI, Paulo César. Op. cit., pp. 169-173.

631 « Ce serait une révolution sans violence ni effusion de sang. Car elle serait faite par le président de la République et le Congrès » in SARACENI, Paulo César. Op. cit., p. 169. 
Le 11 avril 1964, le premier AI donne le droit au gouvernement militaire de modifier la constitution, de casser les mandats d'élus, de suspendre les droits civiques d'une personne pendant dix ans et de mettre en disponibilité ou à la retraite les fonctionnaires suspects de menacer la sûreté nationale. Il permet une première épuration politique. Le 27 octobre 1965, l'AI-2 institue l'élection indirecte du président de la République, dissout les anciens partis ${ }^{632}$ et renforce considérablement les dispositifs répressifs et l'autorité du président qui peut déclarer l'état de siège et fermer le congrès à son gré. Les apparences d'un régime démocratique sont cependant maintenues. Le parlement fonctionne, un parti d'opposition existe, des élections ont lieu et la tête de l'exécutif est régulièrement renouvelée puisque les présidents ont un mandat d'une durée limitée. Le 5 février 1966, l'AI-3 établit des élections indirectes pour les gouverneurs d'État qui, à leur tour, nommeront les maires des capitales. Le 7 décembre 1966, l'AI-4 prépare l'adoption de la nouvelle constitution qui incorpore les actes institutionnels déjà promulgués. La loi de sécurité nationale est décrétée le 15 mars 1967. Le régime dévoilant peu à peu son véritable visage, l'agitation politique et sociale grandit et culmine avec les grandes manifestations de masse de l'année 1968. Le régime y répondra par la violence. Le 13 décembre 1968, l'AI-5 est adopté, véritable coup d'État dans l'état qui abolit les vestiges démocratiques qui pouvaient encore limiter les pouvoirs des militaires. D'une dictature honteuse d'elle-même et cherchant à préserver des apparences libérales nous passerons aux années de plomb.

Nous verrons dans cette partie comment le coup d'État d'avril 1964 a affecté le Cinema Novo et quelles ont été les stratégies qu'il a adopté pour survivre dans un contexte politique qui lui était brusquement devenu adverse. Pour ce faire, nous continuerons à étudier les films et les structures économiques qui ont permis leur production et leur diffusion mais nous examinerons aussi le positionnement du Cinema Novo au sein d'une gauche à présent divisée entre deux tendances, la première perpétuant l'idéal de la conscientisation et estimant que seul un peuple «conscient» et informé pourrait renverser la dictature et la seconde, prêchant et pratiquant la lutte armée. Enfin, nous étudierons la réponse apportée par l'État à l'activité du Cinema Novo au travers de l'étude des archives de la police politique et de la censure.

632La dissolution des partis instaure un système bipartite qui oppose l'Aliança Renovadora Nacional (Alliance rénovatrice nationale) - Arena, au Movimento Democrático Brasileiro (Mouvement démocratique national) MDB. Le MDB est le parti de l'opposition tolérée. Il jouera un rôle politique majeur dans les années 70 mais, dans les années 60, il passe pour un parti fantoche. L'Arena est le parti du gouvernement. Il est dominé par l'ancienne União Democrática Nacional (Union Démocratique Nationale) - UDN, deuxième parti du Brésil entre 1945 et 1962 et opposant historique au Partido Social Democrático (Parti Social Démocratique) - PSD fondé par Getúlio Vargas. 


\section{Chapitre 7 : Continuer à produire}

Comme nous l'avons déjà noté, le coup d'État d'avril 1964 est une surprise totale pour les cinemanovistas. Dans un premier temps, il souffle entre eux un vent de panique. Personne n'est en effet capable de dire jusqu'où ira la répression et craint d'être poursuivi pour ses films, pour ses opinions politiques ou encore pour ses liens avec le CPC et le gouvernement de João Goulart. La liste des membres du Comando dos Trabalhadores Intelectuais - CTI est publiée dans la presse ${ }^{633}$. Le CTI est un syndicat rassemblant les intellectuels progressistes qui, au côté de la CGT et de l'UNE, devait constituer l'avant-garde d'un vaste mouvement de soutien aux réformes de base. Constitué peu avant le coup d'État, il disparaît aussitôt après. La liste de ses membres inclut le nom de pratiquement tous les cinemanovistas. Autre événement inquiétant, l'interruption par l'armée du tournage du film du CPC, Cabra marcado para morrer, est également connue $\mathrm{e}^{634}$. La crainte de persécutions policières paraît donc justifiée. Dans une lettre collective à Rocha alors en Europe pour le passage à Cannes de Deus e o diabo na terra do $s o l^{635}$, il lui est conseillé de faire durer son séjour à l'étranger et de ne pas s'exposer par des déclarations hostiles au nouveau régime.

Malgré la crainte de la répression, jamais n'est mise en doute la nécessité de continuer le Cinema Novo qui est, plus que jamais, considéré comme un instrument de lutte politique. Il apparaît cependant nécessaire de s'adapter à une situation nouvelle et de tirer les enseignements de l'effondrement du régime de Goulart. Une fois la menace de persécutions directes des cinéastes écartée, collectivement ou individuellement, les projets laissés en suspens depuis avril sont réexaminés à lumière de la nouvelle donne politique. La volonté de produire des œuvres qui puissent être significatives sur un plan politique amène les cinéastes à se poser continuellement la question de ce qu'il est possible de dire et de faire sans risquer des représailles et une censure unilatérale. Comment en effet lutter contre un régime autoritaire sans condamner ses conditions d'existence? Le Cinema Novo, entre 1964 et 1968, apporte un certain type de réponse lisible dans sa filmographie. Certains films comme O Desafio, Terra em transe et $A$ Opinião pública sont des films sur la politique qui évoquent directement le traumatisme de 1964. D'autres comme A Falecida, Menino de engenho ou O Padre e a moça, évitent les thématiques politiques et développent des thématiques culturelles. Apparemment moins susceptibles de provoquer l'hostilité des censeurs, leur objectif n'en est pas moins

633Lettre de Lima à Rocha. Rio de Janeiro, 19/04/1964. In ROCHA, Glauber. Cartas ao mundo. Op. cit., p. 245. 634Lettre de Luís Carlos Maciel, Paulo César Saraceni, Leopoldo Serran, Rogério Duarte, Geraldo del Rey et

David Neves à Rocha. Rio de Janeiro, 13/04/1964. In ibid., 1997, p. 235. 635Ibid., pp. 232-235. Il est parti la semaine précédant le putsch. 
d'atteindre les bases de la société brésilienne pour obtenir la remise en question de ses valeurs. Que les films possèdent une thématique politique explicite ou non, le Cinema Novo persévère dans la voie d'un cinéma d'auteur en dialogue avec les cinémas nouveaux de son temps. À ce titre, les stratégies commerciales mises en place préfigurent celles des cinémas d'art et d'essai d'aujourd'hui et s'inscrivent dans la continuité de ce qui avait déjà été mis en place avant 1964.

\subsection{Continuation d'un cinéma d'auteur sans thématique politique explicite}

\section{Menino de engenho}

Parmi les films dont le projet date d'avant avril 1964, Menino de engenho est sans doute celui qui est le plus écarté de l'image que l'on peut se faire d'un cinéma engagé. L'aventure débute peu après le tournage de Deus e o diabo na terra do sol. Walter Lima Junior qui a été l'assistant de direction de Rocha sur ce film souhaite à son tour devenir réalisateur. Les deux hommes nourrissent une passion commune pour José Lins do Rego, écrivain qui, comme nous l'avons déjà vu, fut l'une des sources d'inspiration du film de Rocha. Lima décide d'adapter l'une des œuvres les plus connues du romancier du Nordeste : Menino de engenho, traduit en français sous le titre $L^{\prime}$ Enfant de la plantation. Ce roman semiautobiographique évoque la décadence de l'aristocratie rurale de la canne à sucre au début du XXe siècle au travers des yeux d'un enfant qui découvre la vie dans la plantation de son grand-père. Le premier traitement est écrit au mois de novembre $1963^{636}$. Dans son travail, Lima a complètement revisité les livres de l'écrivain connus sous le nom générique du « cycle de la canne à sucre »: Menino de engenho, Doidinho, Bangüê, Moleque Ricardo, Usina et Fogo morto. Certains passages du film seront d'ailleurs des emprunts à Bangüê, Usina et Fogo morto sans pour autant que ne soit compromis la fidélité de l'adaptation.

L'intention de l'auteur est la suivante :

« [...] eu tenciono manter a narrativa num tom horizontal e extrair disto " clímaxes » verticais. Quero um filme onde o menino está sempre perdendo as coisas do prólogo à penúltima seqüência. Onde as coisas estão desaparecendo antes que ele tenha tempo de vivê-las. E onde a erosão e transformação seja o principal personagem. Preciso ter cuidado é de evitar uma atmosfera tchecoviana, fachada, asfixiante. Não há disso no Brasil, tudo é muito aberto, muito triste. ${ }^{637}$

636MATTOS, Carlos Alberto. Op. cit., p. 97.

$637 \ll[. .$.$] mon intention est de maintenir la narration dans une tonalité horizontale et d'extraire tous les climax$ verticaux. Je veux un film dans lequel l'enfant est toujours en train de perdre les choses du prologue à l'avantdernière séquence. Dans lequel les choses disparaissent avant qu'il ait le temps de les vivre. Et où l'érosion et la transformation soit le personnage principal. Il faut faire attention à éviter une atmosphère à la Tchekov, fermée et asphyxiante. Il n'y a pas de ça au Brésil, tout est très ouvert, très triste. » in Lettre de Lima à Rocha. Rio de Janeiro, 19/04/1964. In ROCHA, Glauber. Cartas ao mundo. Op. cit., p. 249. 
L'ambition du cinéaste est plurielle. Il s'agit de rendre hommage à une œuvre importante de la littérature nationale et de porter à la connaissance du public un épisode de son histoire, celui de la fin du cycle de la canne à sucre.

Tout au long du deuxième semestre de 1963 et de l'année 1964, Lima travaille à la production de son film. Dans un premier temps, il effectue un voyage de repérage à la Paraíba, terre natale de Rego et, par l'intermédiaire de Carlos Heitor Cony ${ }^{638}$, obtient l'appui de la famille de l'écrivain. Le cinéaste reçoit ainsi l'autorisation de filmer sur les lieux mêmes de l'action du roman, la ferme où Rego a passé son enfance. Il mettra par la suite cette opportunité à profit et s'attachera à ce que tous les objets et lieux exploités dans la scénographie soit d'époque. Là encore, l'aide de la famille du romancier sera décisive à la réussite de son projet. Certaines critiques se montreront sensibles au caractère méticuleux de la reconstitution historique :

«Entre as preciosidades da mobiliaria colonial brasileira vista ao longo do filme, há peças com mais de 300 anos de idade, consideradas pelos especialistas como algumas das mais belas já mostradas. Jóias, adereços e ornamentos são autênticos. O filme mostra um cabriolé autêntico do século XIX e um dos primeiros automóveis chegados ao Brasil, além de um tronco de suplício cuja origem remonta à colonização da Paraíba. ${ }^{639}$

La méticulosité de la reconstitution historique participe pleinement de l'esthétique du film et trouve son prolongement jusque dans le choix des musiques.

La production démarre par un prix concédé au scénario par la $\mathrm{CAIC}^{640}$ en octobre $1964^{641}$. Le film sera financé par cette subvention, un emprunt au Banco do Estado da Guanabara et les dotations de l'État de la Paraíba. La famille de Rego apportera une aide matérielle décisive et concédera de ne recevoir les droits d'auteur qu'après l'exploitation du

638CONY, Carlos Heitor. « Da Arte de falar mal : Menino de engenho » sans source, 19/10/1963. Cony fut l'un des rares journalistes contemporains du Cinema Novo à critiquer ouvertement le coup d'État militaire dans ses articles. Il sera finalement écarté de la rédaction de son journal.

639 « Entre les raretés du mobilier colonial qui peuvent être vues tout au long du film, il y a des pièces vieilles de plus de 300 ans, considérées par les spécialistes comme quelques unes des plus belles jamais montrées. Bijoux et ornements sont authentiques. Le film montre une calèche authentique du XIXe siècle et une des premières automobiles arrivées au Brésil, en plus d'un tronc de supplicié dont l'origine remonte à la colonisation de la Paraíba. » in « Menino de engenho » in Diário da noite, Rio de Janeiro, 24/03/1966.

640La CAIC, et à suite, l'INC, se montreront très généreux à l'égard du film de Lima. Après avoir gagné le prix du scénario de la CAIC en 1964, il remporte fin 65, c'est à dire peu avant son lancement commercial, le prix de la qualité de l'État de la Guanabara (In « Distribuição dos prêmios da Guanabara » in Cine-reporter, São Paulo, janvier 1966). Dès sa création, fin 1966, l'INC attribue des prix concernant l'année révolue pour les longs métrages et les deux années révolues pour les courts. Lima empoche $2500000 \mathrm{Cr} \$$ de plus pour le scénario de Menino de engenho (In « Prêmios INC » in Filme Cultura, Rio de Janeiro, mars-avril 1967). Rappelons que la CAIC - Comissão de Auxílio à Indústria Cinematográfica, est une institution de l'état de la Guanabara, alors que l'INC - Instituto Nacional de Cinema, est une institution fédérale créée en 1966. La CAIC et l'INC vont cohabiter pendant un certain temps ce qui signifie en théorie que les films produits à Rio de Janeiro pourront bénéficier à la fois d'aides de l'état et d'aides fédérales.

641ROCHA, Glauber. «Cinema Novo levanta a cabeça » in O Jornal, Rio de Janeiro, 04/10/1964. 
film. Le budget total s'élève à 50 millions de Cruzeiros $^{642}$. L'équipe de tournage se limite à neuf personnes. Les principaux acteurs sont déjà des professionnels : Geraldo del Rey, Anecy Rocha, Antonio Pitanga et même Sávio Rolim qui joue le rôle de l'enfant, a été formé dans son état d'origine, la Paraíba. Le reste de l'équipe est formée par des débutants. Menino de engenho est le premier film de l'actrice Maria Lúcia Dahl, de l'assistant de direction Júlio Bressane et du chef opérateur Reynaldo Paes de Barros. Seulement trois acteurs sont originaires de la Paraíba, tous les autres membres de l'équipe découvrent cet état du Nordeste où, loin de Rio et São Paulo, le temps semble s'être arrêté à l'image du vieux train à vapeur encore en service que nous verrons dans les premières séquences du film. Le tournage a lieu au début de l'année 1965, il dure six semaines. Outre la plantation d'Itapuá de la famille de l'écrivain, sont utilisées les infrastructures de la plantation de Corredor qui, au moment du tournage, est encore en activité ainsi que d'autres constructions dans des localités assez proches. Le tournage a lieu à la Paraíba et dans l'état voisin du Pernambouc.

L'histoire du film est fidèle à celle du roman. Suite à la mort à la fois mystérieuse et violente de sa mère, le petit Carlinhos est transféré de Recife (capitale du Pernambouc) à la plantation Santa Rosa où il sera élevé par le colonel José Paulino. Sa tante Maria sera sa nouvelle maman et son oncle Juca lui expliquera le fonctionnement de l'exploitation, la dernière de la région à fonctionner selon le mode traditionnel. Le film raconte les quelques années que Carlinhos passe dans la plantation avant d'être envoyé en internat au collège. À partir de cet argument de base, la structure narrative se divise en deux lignes distinctes qui n'ont pas d'incidence l'une sur l'autre. La première est celle de la récupération du traumatisme de Carlinhos. Bien que cela ne soit pas explicite, tout indique que la mère de Carlinhos a été assassinée par son mari parce qu'elle l'aurait trompé. Les raisons de ce crime étant par avance jugées incompréhensibles par l'enfant, sa famille d'adoption les lui cache. Plane à partir de ce moment-là un non-dit qui alimente la culpabilité de l'enfant et fait grandir chez lui un sentiment de mélancolie et l'idée qu'il serait incapable de s'attacher une personne ou un objet. Tout au long de la narration, la tristesse de l'enfant est alimentée par des pertes successives qui viennent confirmer ses appréhensions. Des personnes avec lesquelles il entretient des relations d'affection le quittent prématurément. Sa cousine Lili meurt d'une maladie. Sa tante Maria quitte le domicile familial quand elle se marie. Enfin, son oncle Juca se fâche avec lui après qu'il ait regardé certaines photos qui étaient cachées dans la chambre.

La deuxième ligne narrative est celle du déclin de l'aristocratie rurale. Dès son arrivée

642Cf. MATTOS, Carlos Alberto. Op. cit., p. 101. Il ne faut pas comparer ce chiffre à ceux de Barravento, Os Cafajestes et Assalto ao trem pagador. En trois ans, la monnaie s'est tellement dévalorisée qu'il faudrait être capable de convertir les sommes avancées en « cruzeiro constant » ce qui réclamerait des calculs compliqués qui dépassent nos compétences. 
à la plantation, l'oncle Juca explique à l'enfant dans une séquence documentaire comment le sucre est produit en partant du lieu où la canne est amenée et en remontant la chaîne des différentes machines jusqu'au produit fini. Dans d'autres séquences est exposée la rivalité qui oppose le système traditionnel de production au nouveau, celui des usines, et comment et pourquoi le nouveau supplante peu à peu l'ancien. Le grand père de Carlinhos est présenté comme un élément combatif dans cette lutte qui apparaît cependant vouée à l'échec. Une séquence est consacrée à la visite de la plantation par Carlinhos et le colonel et à la visite d'un voisin dont l'exploitation est déjà morte. Prisonnier de temps révolus, celui-ci ne jure que par l'empereur et refuse de traiter avec la république dont il ne reconnaît pas la légitimité. Celleci, au moment de l'action du film, c'est à dire dans les années vingt, a été proclamée il y a plus de trente ans ! D'une certaine façon, dans ces séquences, l'oncle et le grand-père rendent compte directement à Carlinhos, et donc au spectateur, des raisons économiques, sociales et culturelles qui sont à l'origine du déclin de la plantation traditionnelle. L'opposition entre Juca et son père contribue également à expliquer ce phénomène comme un conflit entre le nouveau et l'ancien. Juca parle d'emprunts, d'investissements et de mécanisation quitte à accepter une relation de dépendance envers un groupe américain qui vient démarcher les propriétaires chez eux. Son père refuse tout changement et s'oppose fermement à concéder la moindre parcelle de son autorité sur ses terres.

Le monde de l'usine qui est le monde de la modernité reste une inconnue tout au long de la narration. Nous ne le voyons que de loin. Par contre, le monde de la plantation traditionnelle est largement décrit. La structure patriarcale est centrée autour de la figure du colonel qui décide sur tout, les hommes et les choses, et cumule, sur sa vaste propriété, tous les pouvoirs. Il est chef, juge et commissaire. Il répond aux requêtes de ses sujets et exige en échange que chacun fasse son travail. Son calme, sa mansuétude et son charisme contrastent avec des injustices criantes. Il est interdit à Carlinhos de jouer avec les enfants des employés qui vivent dans des maisons extrêmement précaires dont le sol est de terre battue. Carlinhos va à l'école à dos de mulet tandis que la petite fille noire qui l'accompagne suit à pied. Le personnage joué par Pitanga, Zé Guedes, subit dans une séquence le supplice du tronc pour être soupçonné d'avoir abusé d'une jeune femme noire. Finalement, on apprend que le coupable est l'oncle Juca. Guedes, que l'on voulait forcer à épouser la jeune femme, est libéré mais Juca ne reçoit pas un seul reproche. Le climax du film correspond au départ de Carlinhos pour le collège. Quand il prend le train, Guedes court après lui en criant à l'enfant de ne pas les oublier. Carlinhos quitte un monde finissant qui n'existera plus que dans le souvenir.

Outre le prêt de meubles coloniaux par des familles du local, de la découverte d'un tronc ayant servi au supplice d'esclaves et de l'utilisation de l'une des premières voitures ayant 
circulé dans l'état de la Paraíba, le train à vapeur et les infrastructures de la plantation de Corredor contribuent à l'authenticité de ce témoignage sur une époque charnière de l'histoire du Brésil. Pour apporter le maximum d'emphase au sentiment de perte, à l'idée de disparition d'un monde ancien, le réalisateur a même pensé utiliser des trucages évoquant les premiers temps du cinéma et de la photographie : filmer en sépia, utiliser une photo de l'enfant dans un cadre ovale pour le fond du générique, faire adopter à la famille une pose similaire aux vieilles photographies aux moments de l'arrivée et du départ de l'enfant à la gare de Pilar, utiliser un masque dans la séquence du baiser entre les deux enfants ${ }^{643}$. Ces idées ne sont pas réalisées mais les limites du budget contraignent à une économie de moyens bénéfique à cette esthétique du déclin et de la perte.

Point en effet de jeux de lentilles et d'objectifs sophistiqués, absence également de rails courbes pour les travellings, encore moins de grue, enfin, le générateur d'électricité à kérosène ne permet pas l'utilisation de plusieurs projecteurs au même moment. L'éclairage artificiel est donc limité et, comme dans les précédents films du Cinema Novo, il faudra s'adapter aux conditions naturelles de lumière et exploiter les ressources offertes par les lieux et la configuration originale de l'espace pour déterminer le placement des acteurs et de la caméra. Ces conditions de tournage déterminent une approche esthétique qui s'inscrit dans la continuité de celle de Vidas secas et se caractérise par un savant équilibre en classicisme et modernité. Nous retrouvons dans les deux films une structure narrative circulaire servie par un scénario construit de manière classique avec ses phases d'exposition et de complication, son climax et sa phase de résolution. La composition des plans et leur enchaînement suivent également les règles de la dramaturgie cinématographique classique. Toutes les innovations formelles apparaissent parfaitement justifiées du point de vue du sens de l'histoire. Dans la séquence de la mort de la cousine Lili, le désespoir de Carlinhos est exprimé par une brutale défocalisation de l'image et une soudaine ouverture de diaphragme qui a pour effet l'obtention d'une image envahie de lumière, totalement blanche. La fragmentation apparaît au moment du montage de certaines séquences clés, pour exprimer les émotions du personnage, montage rapide hors continuité dans la séquence de la mort de la mère, ellipse dans la séquence consacrée à l'initiation sexuelle de Carlinhos.

Autrement dit, et pour reprendre un terme utilisé par Xavier, les innovations formelles ne menacent jamais la «transparence $»^{644}$ du discours et contrairement à Deus e o diabo na terra do sol et par la suite Terra em transe et certains films de la mode tropicalista, le spectateur n'est pas mis dans des situations de doute vis à vis de l'interprétation de certains 643MATTOS, Carlos Alberto. Op. cit., p. 98. Ces idées seront néanmoins retenues au moment de la confection du matériel publicitaire. 644Cf. XAVIER, Ismail. O Cinema brasileiro moderno. São Paulo, coll. Leitura, Paz e terra, 2001. 
plans ou de certaines séquences. La narration conserve un parfaite fluidité. Cela n'empêche pas au film de garder une certaine ouverture. Dans la mesure où la narration adopte le point de vue de l'enfant au prise avec ses problèmes familiaux et existentiels, Menino de engenho reste strictement descriptif et se cantonne au témoignage neutre d'une époque révolue. Le dispositif de conscientisation du film repose sur la singularité du regard de Carlinhos sur la plantation de son grand-père. Le jeune citadin est avant tout préoccupé par la mort de sa mère, l'éloignement de son père et le mystère qui entoure ces événements qui ont bouleversé sa vie. La plantation de José Paulino est pour lui à la fois une terre d'adoption et d'exil. C'est une terre d'adoption parce qu'il s'intègre assez bien à ce nouvel univers dans lequel il bénéficie d'une statut privilégié. C'est une terre d'exil car c'est un lieu où il a été placé pour être protégé de la connaissance des circonstances exactes de la mort de sa mère et des conséquences du drame. L'éloignement spatial du local du crime s'identifie à l'interdit de la connaissance qui est une source de spéculation imaginative et d'anxiété. La véritable problématique de l'enfant n'est pas la critique sociale de la vie dans la plantation. Son point de vue est une absence de point de vue dans la mesure où tout pour lui y est naturel ou exotique. La modernité du film vient donc en partie de la structure circulaire de la narration (l'enfant se récupère mais rien n'est résolu vis à vis de son conflit interne) et de l'exemption d'un point de vue moral sur les règles de l'univers décrit où persistent une structure sociale et des coutumes directement issues de l'esclavagisme. D'une certain façon, tout l'intérêt du film réside dans ce décalage entre le regard innocent de l'enfant et celui, supposé plus critique, du spectateur. Pour le reste, le film remet au conflit entre l'ancien et le nouveau, à la vision dialectique du Brésil hérité de l'ISEB et opposant le modèle agraire conservateur et le modèle urbain industriel.

Menino de engenho entre dans une phase de post-production entre avril et octobre 1965. Sa finalisation est contrariée par des problèmes de financement qui seront réglés avec la création de la Mapa Filmes et de la Difilm. Le lancement du film est particulièrement bien pensé. Il sort le 3 janvier 1966 à João Pessoa, capitale de la Paraíba, afin de jouer sur l'intérêt des spectateurs à assister à un long métrage filmé chez eux et adapté d'un de leurs grands écrivains. C'est un succès retentissant qui ne se démentira plus lors de ses sorties successives dans les grandes capitales du Nordeste. Quand il arrive à São Paulo, le 9 mai $1966^{645}$, et à Rio de Janeiro, le 15 septembre 1966, il ne reste plus qu'à capitaliser sur les succès précédents. Menino de engenho devient, après Os Cafajestes, le second grand succès populaire du Cinema Novo avec 2 millions de spectateurs ${ }^{646}$. À titre de comparaison, jusqu'à 1965, les

645« Menino de engenho » in Diário popular, sans lieu, 01/05/1966.

646Chiffre avancé par le biographe de Lima. MATTOS, Carlos Alberto. Op. cit., p. 98. Plusieurs articles de l'époque soulignent l'importance du succès du film :

« Menino de engenho » in Diário da noite, Rio de Janeiro, 24/03/1966. 
cinemanovistas comptent sur une moyenne de 180000 entrées $^{647}$. La carrière du film est légèrement perturbée par l'intervention de la censure qui, selon les états, réagit de façon diverse à la séquence de l'initiation sexuelle de l'enfant ${ }^{648}$. D'un état à l'autre, la limite d'âge varie ainsi entre 10, 14 et 18 ans.

Tout au long de sa carrière, le film va recevoir une promotion importante de la part de la presse écrite, des critiques globalement positives mais peu d'analyses en profondeur. Tout se passe comme si l'immense succès publique dissimulait un consensus implicite tant sur sa valeur esthétique qu'idéologique. Le fait de présenter l'époque des plantations de canne à sucre comme un temps révolu, un chapitre clos de l'histoire brésilienne, et d'éviter de questionner l'héritage de cette période sur la période contemporaine ${ }^{649}$ ou de porter un jugement moral sur l'aristocratie rurale, préserve le film de toute réaction d'hostilité. À partir de là, deux points de vue s'opposent quant à la validité politique du long métrage. Le premier, en parfaite correspondance avec l'intention initiale de l'auteur, consiste à saluer la valeur culturelle de l'œuvre. Pour Ely Azeredo, Menino de engenho est une réussite dans la mesure où il fait montre d'une parfaite assimilation du comportement brésilien ${ }^{650}$. Louzada Filho estime quant à lui que le film, comme le livre, participe à la restitution au public d'une partie de son histoire et qu'à ce titre, il est une œuvre de défense du patrimoine du Brésil ${ }^{651}$. Paulo Perdigão apprécie la façon avec laquelle Lima a su recréé le roman dans un long métrage qu'il qualifie de «personnel, nostalgique et lyrique $»^{652}$.

Si le film remplit le cahier des charges du Cinema Novo d'un point de vue culturel, il présente, de par sa structure, l'étrange singularité d'éviter le débat et la controverse politique.

LOYOLA, Inácio de. «Viany deu 5 estrelas à Grande Cidade » in Última hora, Rio de Janeiro, 22/06/1966. Informe de la recette de Menino de engenho le premier jour d'exploitation à Rio : $1200000 \mathrm{Cr}$ \$. VIANY, Alex. «Bilheterias estão provando : filme nacional dá boa renda » in Folha da semana, sans lieu, 16-22/06/1966 : «E Menino de Engenho, de Lima, inédito nas grandes praças de São Paulo e Rio, praticamente já se pagou com as exibições realizadas até agora no Nordeste e em Belo Horizonte. » (Et Menino de engenho, de Lima, inédit sur les places de São Paulo et de Rio de Janeiro, a déjà pratiquement couvert son budget avec les projections réalisées dans le Nordeste et à Belo Horizonte) In

647Selon Carlos Diegues : DIEGUES, Carlos. «Entretien avec Carlos Diegues » in Cahiers du cinéma, Paris, n²25, novembre-décembre 1970.

648La controverse éclate lors du passage du film au Minas Gerais, état traditionnellement plus conservateur, mais l'incident sera transformé en argument publicitaire au moment de la sortie à Rio de Janeiro. Les annonces du film comprendront alors les annonces suivantes : « Você nunca viveu o que ele viveu ! (Vous n'avez jamais vécu ce qu'il a vécu !) « Agora no cinema o livro que escandalizou três gerações ! » (Aujourd'hui au cinéma le film qui a choqué trois générations !)

649Selon certains sociologues, l'industrialisation et l'urbanisation du Brésil n'ont pas fondamentalement transformé les relations dans les cadres professionnels et domestiques. Ainsi, les échanges entre patrons et employés, à l'usine et sur le chantier de construction, ou les échanges entre une famille et ses domestiques, dans l'appartement d'un gratte-ciel de capitale, sont pratiquement les mêmes que ceux qu'ils étaient à l'époque de la casa grande et de la senzala. Cf. BASTIDE, Roger. Op. cit., p. 9.

650AZEREDO, Ely et alii. « A Crítica e o Cinema Novo II » in Filme cultura, Rio de Janeiro, nº 3 , janvierfévrier 1967.

651LOUZADA FILHO, O.C. «O Menino, o engenho, a usina » in O Estado de São Paulo - Suplemento literário, São Paulo, 27/08/1966.

652PERDIGÃO, Paulo. « Menino de engenho » in Diário de notícias, Rio de Janeiro, 11/09/1965. 
Lors de sa préparation et notamment au moment du coup d'état, certains reprochent à Lima de s'occuper de l'histoire d'un enfant triste au moment de l'occupation du palais de la Guanabara $^{653}$. Par la suite, le film a été jugé moins « important» que d'autres qui auront attiré beaucoup moins de spectateurs. Le succès de Menino de engenho est un des éléments qui amène Dahl à rédiger un article qui fera date : «Cinema Nôvo e seu público » (« Le Cinema Novo et son public $»)^{654}$. Dans cet article, Dahl explique que plus le succès d'un film est grand, plus la profondeur de son propos et son impact sur la conscience des spectateurs serait faible. Très précisément, il estime que la « qualité » de la communication n'est pas compatible avec une grande « quantité » de communication et compare la difficulté de communication de l'art moderne avec celle des cinémas nouveaux. Les succès du Cinema Novo n'échapperaient pas à cette règle. À ce titre, Menino de engenho serait un bon film mais à la portée limitée par rapport à des œuvres plus fortes comme $O$ Desafio et $O$ Padre e a moça.

Plus critique encore, Bernardet ${ }^{655}$ voit dans le premier long métrage de Lima le prolongement de la thématique de « la décadence, de la décomposition et de l'étiolement» inaugurée par Porto das Caixas, un film qui a choqué en parlant d'une ville oubliée et abandonnée au marasme. Le climax de cette représentation démoralisante se situait dans la séquence du meeting mélangeant cachaça et réforme agraire. Cette thématique fut poursuivi dans $O$ Circo et $A$ Falecida. Menino de engenho serait un "film sérieux » de cette lignée, successeur de Engenhos e usinas (Humberto Mauro, 1955). Selon Bernardet, le jeu des acteurs, hiératiques, et le montage brisent le sentimentalisme que pourrait exprimer le film, la décadence de la plantation est décrite sans nostalgie, avec une certaine distance. Le parcours de l'enfant est celui d'une résurrection dans un monde qui agonise. La mort initiale de la mère, puis la seconde mort, cette fois symbolique, de la seconde mère, la tante Maria est parallèle à la découverte de la sexualité et de forces naturelles de la libération. L'enfant qui quitte la plantation est un enfant remis et fortifié de ses traumas. Malgré toutes ces qualités, le film entre tout à fait dans le cadre de l'idéologie du Cinema Novo qui se caractérise, d'une part par l'analyse de certains problèmes appartenant au passé et la condamnation de certains groupes sociaux, d'autre part par cette perspective optimiste de progrès vers un futur inconnu mais plein de promesses. Autrement dit, Menino de engenho serait le représentant d'un cinéma prétendument politique qui ne s'attaquerait pas aux véritables problèmes du Brésil moderne.

Cette critique est assez mal reçue ${ }^{656}$ car elle va bien à l'encontre du mythe du Cinema

653MATTOS, Carlos Alberto. Op. cit., p. 98.

654DAHL, Gustavo. « Cinema Nôvo e seu público », op. cit.

655BERNARDET, Jean-Claude. « Menino de engenho » in Artes, São Paulo, année I, n4, février 1966.

656Selon Mattos, Bernardet a transformé le sens de la dernière séquence du film afin de le faire entrer dans son argumentation. Aussi, le final ne serait pas aussi optimiste qu'il le prétend (MATTOS, Carlos Alberto. Op. cit., p. 120). L'enfant gardera pour toujours ce sentiment de perte qui vient du trauma causé par la mort de sa 
Novo qui est en train de se construire d'un cinéma engagé, soulevant systématiquement les problèmes que les secteurs conservateurs ne veulent pas voir discutés. Nous resterons quant à nous sur ce que nous en avons dit au moment de présenter notre analyse du film. Dans le contexte des années soixante,comme d'ailleurs aujourd'hui, il est indéniable qu'un film qui, comme Menino de engenho, est l'expression authentique de la culture brésilienne, au sens où l'authenticité est entendu dans le corps doctrinal du Cinema Novo, remplit une partie de ses objectifs et, indirectement, possède une dimension politique qui n'est pas négligeable. Cette dimension est d'autant moins négligeable quand le film est un succès. Si nous devions comparer Menino de engenho aux conditions actuelles du marché, ce succès représenterait un véritable exploit. Ceci dit, il est aussi légitime de considérer que l'urgence de la situation politique appelle un cinéma de mise en cause plus directe des injustices sociales. À ce titre, et contrairement aux préceptes du corps doctrinal du Cinema Novo, force est de constater que Menino de engenho ne transmet pas une vision critique de la situation qu'il expose. La critique reste à la charge du spectateur. Aux yeux de certains, l'innocence ostensible de l'enfant pourra passer pour une provocation à l'exercice de la pensée critique, beaucoup d'autres ne se choqueront pas des relations sociales asymétriques de la plantation qu'ils reproduisent dans leur vie quotidienne et qui sont pour eux naturelles.

\section{O Padre e a moça}

Dans le contexte des premières années de dictature, le deuxième long métrage de Joaquim Pedro de Andrade est un autre film assez éloigné de l'idée que nous pouvons nous faire d'un cinéma engagé. Comme Menino de engenho, il s'agit d'un projet dont l'origine est antérieure au coup d'État. Le scénario date du début de l'année 1964. Il s'agit de l'adaptation d'un poème de Carlos Drummond de Andrade ${ }^{657}$ intitulé « O Padre, a moça » (« Le Prêtre, la jeune femme »). Drummond est le deuxième écrivain associé au modernisme brésilien auquel le Cinema Novo rend hommage ${ }^{658}$. Prenant le relais du roman social des années trente, le modernisme deviendra à partir de Terra em transe et de l'émergence du tropicalismo la principale influence littéraire du Cinema Novo. O Padre e a moça est cependant encore éloigné des expériences de déconstruction du langage à venir. Comme Vidas secas ou Menino

mère. Cependant, la remarque de Mattos ne change rien au problème central. Le film reste évasif quant à la situation politique de 1965-66.

657Carlos Drummond de Andrade (1902-1987) est un écrivain déjà consacré et encore en pleine activité à l'époque du Cinema Novo. Bien qu'absent de la Semana de Arte Moderna de 1922 au cours de laquelle se sont illustrés Mário de Andrade, Oswald de Andrade et Manuel Bandeira, Drummond est souvent associé à ce mouvement pour avoir repris dans son œuvre certains de ses préceptes : la liberté linguistique, le vers libre, la métrique libre et le goût pour les thématiques quotidiennes, les événements apparemment triviaux de la vie ordinaire. «O Padre, a moça » est publié dans le recueil Lição de coisas de 1964. 658Après Manuel Bandeira dans O Mestre de Apipucos e o poeta do Castelo (Andrade, 1959). 
de engenho, il se caractérise par un équilibre savant entre classicisme et modernité. Le classicisme est manifeste dans le respect des règles conventionnelles de la construction dramatique, de la mise en scène, de la composition des plans et du montage. La modernité se déclare dans la raréfaction de l'action, les ellipses et l'ouverture du texte filmique qui laisse une grande marge d'interprétation au spectateur. Le film remplira le cahier des charges culturel du mouvement mais son impact politique direct sera l'objet de maintes controverses. Souvent jugé formaliste, il ira jusqu'à poser un problème de conscience à son auteur lui-même qui se montrera a posteriori extrêmement critique à son égard. Son entrevue avec Alex Viany pour la revue Civilização brasileira, «Crítica e autocrítica : O padre e a moça » («Critique et autocritique : Le Prêtre et la jeune femme $)^{659}$, représente un moment fort de la discussion quant à la difficulté du Cinema Novo à toucher un large public. Plus dérangeant cependant que Menino de engenho, $O$ Padre e a moça démontre l'intérêt d'un cinéma démystificateur qui ne s'adresse pas au plus grand nombre.

La production de $O$ Padre e a moça commence début 1964 par un voyage de repérage aux Minas Gerais avec le chef opérateur Mário Carneiro ${ }^{660}$. Au mois d'octobre, l'obtention par le scénario d'un prix de la CAIC dont bénéficient aussi $O$ Desafio, A Falecida, Menino de engenho et cinq autres films étrangers au Cinema Novo, apporte la base de financement du film. Son budget atteindra 60 millions de cruzeiros ${ }^{661}$. Pour mener à terme son projet, Andrade fonde sa propre maison de production, Filmes do Serro, du nom d'une localité proche de São Gonçalo dos Rios das Pedras où il a décidé de filmer. Il s'agit d'un village isolé, peuplé d'une centaine d'habitants, sans électricité ni eau courante. L'acteur principal, Paulo José, le décrit :

«São Gonçalo do Rio das Pedras é uma cidade morta, do ciclo do diamante, foi muito próspera no século passado. Tinha duas grandes igrejas matrizes e o rio Jequitinhonha cortava a cidade no meio. E a cidade foi ficando decadente, foi ficando vazia. Só tinha velhos, velhas com bócio, papudas, aquele problema de falta de vitamina A e D, e não tinha ninguém jovem. A cidade tinha delegacia, farmácia, prefeitura, correios e telégrafos, tudo fechado, mas ainda com as coisas dentro, na farmácia tinha prateleiras com remédios. $\gg{ }^{662}$

Le tournage débute en février 1965 dans des conditions extrêmement difficiles. Les

659VIANY, Alex. « Crítica e autocrítica : O padre e a moça-Alex Viany conversa com Joaquim Pedro de Andrade », op. cit.

660BENTES, Ivana. Op. cit., p. 49.

661 $\mathrm{Cf}$. VIANY, Alex. «Crítica e autocrítica : O padre e a moça - Alex Viany conversa com Joaquim Pedro de Andrade », op. cit.

662 « São Gonçalo do Rio das Pedras est une ville morte, datant du cycle du diamant, qui a été très prospère au siècle dernier. Elle avait deux grandes églises et la rivière Jequitinhonha passait au milieu de la cité. Puis, la ville est entrée en décadence et s'est vidée. Il n'y avait que des vieux avec le goître, des problèmes de santé causés par le manque des vitamines A et $\mathrm{D}$, et il n'y avait plus personne de jeune. La cité possédait un commissariat, une pharmacie, un bureau de poste et des télégraphes, tout était fermé, mais laissé dans l'état où ils étaient lors de leur activité, ainsi, la pharmacie contenait encore ses étagères sur lesquelles étaient rangés les remèdes. » in LINHART, Clara, MAROJA, Camila et CAETANO, Daniel. « Entrevista com Paulo José » in Contracampo, n42, http://www.contracampo.com.br/42/frames.htm, consulté le 29/12/2005. 
premières dépenses vont à la construction d'infrastructures de premières nécessités : des toilettes et un pont ${ }^{663}$. Chaque membre de l'équipe finit par exercer plusieurs fonctions. L'isolement pèse beaucoup d'un point de vue psychologique et pratique. Plusieurs heures en voiture sont nécessaires pour rejoindre la ville la plus proche et il n'est pas possible de vérifier la qualité de ce qui a été filmé avant plusieurs jours. Malgré ces difficultés, le site avait été choisi à dessein par le cinéaste afin de servir au mieux l'histoire qu'il souhaitait raconter.

O Padre e a moça commence par l'arrivée à dos de mulet d'un jeune prêtre (Paulo José) dans un village reculé des Minas Gerais. Après avoir traversé le hameau, il entre dans une maison remplie d'une foule endeuillée. Sans avoir rien fait d'autre que saluer brièvement, il pousse une porte et arrive au chevet du Père Antônio qui agonise. Auprès du lit du mourant, il rencontre Honorato (Mário Lago), le notable du village, et Vitorino (Fauzi Arap), le pharmacien. Il leur demande de le laisser seul avec le Père Antônio. Ceux-ci s'exécutent à contre-cœur. Avant qu'Honorato ne sorte, le mourant parle d'une certaine Mariana (Helena Ignez) à l'oreille du jeune prêtre. Nous avons aperçue celle-ci à sa fenêtre observer son arrivée. Nous la retrouvons dans la séquence suivante seule avec Honorato. Le dialogue nous informe qu'il est le père adoptif de Mariana et qu'il veut à présent qu'elle soit sa femme. Il s'inquiète de savoir si, quand elle était avec le père Antônio, celui-ci abusait de la situation et faisait les « choses » (sans plus de précision) que lui fait avec Mariana. Il s'inquiète aussi de savoir si la jeune femme l'avait dénoncé au prêtre. À chaque fois, elle répond par la négative. Enfin, il lui offre une robe de mariée qu'elle ne doit pas encore montrer. Suit l'enterrement du Père Antônio, Vitorino fait un scandale et crie que l'ancien curé ne voulait pas que les choses changent et que tout le monde au village s'est habitué au marasme ambiant. Il dit aussi que le Père n'était pas un saint mais qu'il n'était pas prêt à tolérer le manque de décence d'un homme âgé $^{664}$. L'allusion à Honorato qui le fait taire, semble claire.

À partir des quatre premières séquences du film, un premier conflit est posé. Vitorino et Honorato convoitent également Mariana, la jeune femme ( $a$ moça), et la présence du Père Antônio qui avait deviné les intentions d'Honorato, empêchait apparemment ce dernier de passer à l'acte. Le jeune curé devra se positionner face à ce problème délicat. Au lieu de développer immédiatement le conflit, les séquences suivantes décrivent l'extrême pauvreté du village. Propriétaire de l'épicerie, Honorato vend ses marchandises à crédit aux chercheurs de diamants et leur achète le peu de pierres qu'ils trouvent encore. Dans les faits, l'endettement

663LINHART, Clara, MAROJA, Camila et CAETANO, Daniel. « Entrevista com Mário Carneiro » in Contracampo, ${ }^{\circ} 42$, http://www.contracampo.com.br/42/frames.htm, consulté le 29/12/2005.

664Le personnage de Vitorino parle par ellipses, sa dernière phrase est la suivante : « Padre Antônio nunca tolerou pouca vergonha de velho. » (« Le Père Antonio n'a jamais toléré le manque de décence du vieux. ») 
de ces pauvres gens est tel que le notable n'a jamais besoin de les payer ${ }^{665}$. La chaussée défoncée et les maisons abandonnées, la pénurie de remèdes à la pharmacie, tout porte la trace de la décadence y compris les corps et les visages prématurément ridés ou déformés. L'alcoolisme de Vitorino et le désir incestueux d'Honorato signifient la fin de tout espoir dans un monde en décomposition où la beauté et la jeunesse de Mariana sont déplacées.

La situation se complique après la description de la situation sociale du village. Dans deux séquences distinctes, cherchant à faire pression sur le nouveau curé, Honorato et Vitorino lui déclarent chacun qu'ils ont couché avec Mariana. Dans une autre séquence, celleci réveille le prêtre pour lui dire qu'elle n'a jamais été la femme de personne. Elle lui fait aussi une déclaration d'amour enflammée. Sa visite nocturne est surprise par Vitorino qui l'épie constamment. Le curé est compromis. Le lendemain, plus personne n'accepte de lui parler mais ses propres sentiments paraissent ambigus. Au premier enjeu qui consistait à savoir ce que pourrait faire le prêtre pour secourir la jeune femme, se superpose un second qui est de savoir s'il assumera les sentiments qu'il éprouve pour elle. C'est un personnage en crise qui enlève la jeune femme et s'enfuit avec elle. Sur le chemin, alors qu'il prétend l'écarter du village pour la protéger, celle-ci continue à lui demander de l'aimer. Finalement, certains plans suggèrent qu'ils font l'amour mais, prisonnier de ses contradictions, le curé décide de revenir au village et s'isole dans son église. Le retour des deux fugitifs ne provoque d'abord aucune réaction puis, soudainement, la population se déchaîne. Le curé est enfermé. Mariana est agressée, on la force à revêtir sa robe de mariée. Enfin, on la jette dans les bras du prêtre qui vient de forcer la porte de l'église. En proie à une folie meurtrière, la population les prend en chasse. Le couple se réfugie dans une grotte à l'entrée de laquelle les villageoises mettent le feu. Alors que la fumée commence à les envelopper, le Père et la jeune femme se serrent l'un contre l'autre. L'image devient blanche est les vers de Drummond apparaissent :

« Ninguém prende aqueles dois,

Aquele um

Negro amor de rendas brancas. $»^{666}$

La durée du tournage excède les délais habituellement respectés par le Cinema Novo. L'équipe reste trois mois et demi à São Gonçalo dos Rios das Pedras. Les contretemps sont occasionnés par diverses mésaventures, l'inexpérience de l'équipe et le perfectionnisme du

665Selon Mário Lago, la situation sociale décrite par le film est absolument conforme à la situation réelle du village. Pour la séquence de la vente de diamants, il s'est directement inspiré de son alter ego réel, un certain Geraldo dont les pratiques révoltaient les membres de l'équipe. $C f$. LINHART, Clara, MAROJA, Camila et CAETANO, Daniel. «Entrevista com Mário Lago » in Contracampo, $n^{\circ} 42$, http://www.contracampo.com.br/42/frames.htm, consulté le 29/12/2005.

666 « Personne ne peut prendre ces deux-là,

Ce grand

Amour noir de dentelles blanches. » (Poème de Drummond). 
cinéaste. Andrade démontre un grand purisme par rapport aux concepts initiaux du Cinema Novo. Rejet de tous les artifices associés au cinéma hollywoodien, rejet du champ / contrechamp jugé manipulateur, rejet des effets de photographie ou de montage qui viseraient à forcer l'émotion ou ajouter une dimension dramatique étrangère à la scène filmée. Chaque plan est conçu comme un tout signifiant qui doit permettre l'intelligence des données sociales, psychologiques et culturelles qui pèsent sur l'action des personnages. La clarté des déterminants sociaux s'oppose à l'ambiguïté et à l'imprévisibilité des comportements. Comme pour les films précédents du Cinema Novo, les innovations formelles ne gênent pas la compréhension de la narration. L'histoire, telle que nous l'avons résumée, est donc parfaitement intelligible. Le spectateur «classique » pourra cependant être gêné par certains éléments de modernité.

O Padre e a moça est une œuvre « ouverte » dans laquelle on cherchera en vain des explications ou des justifications univoques pour un certain nombre d'éléments filmiques décisifs. Le prêtre et la jeune femme sont des personnages opaques. Rien dans le film ne nous dévoile leurs motivations intimes. Nous partageons l'incertitude du prêtre quant à l'innocence de Mariana et à l'authenticité de ses sentiments. Nous saurons moins bien que les autres personnages quelles ont été ses relations avec le père Antônio, Honorato et même le jeune curé puisque la scène d'amour est suggérée. Nous ne saurons donc pas si l'acte a été pleinement consommé. Du point de vue de la narration, cela importe peu. Mais du point de vue du spectateur habitué à porter un jugement moral dans la position d'omniscience qui lui est conférée par la narration classique, cela est très frustrant. L'absence de résolution des interrogations ouvertes depuis l'exposé de la situation initiale, la raréfaction de l'action et l'absence de redondance des informations successivement apportées contraignent le spectateur à prendre en compte ses propres lacunes dans son actualisation du film.

Comme Porto das Caixas dont l'action se situait aussi dans un lieu caractérisé par l'isolement et le déclin, $O$ Padre e a moça renvoie à la situation politique et sociale de façon métaphorique. L'ambition critique du film se réalise sur un plan symbolique. Il s'agit d'un film de négation (mise en scène, mode contenu d'interprétation des acteurs, importance dramatique des temps morts) sur un acte de négation (négation du prêtre et de la population du village) et sur la mise en évidence de ses raisons (l'isolement, le sous-développement). Le choix d'une situation-limite avec un village pauvre et reculé, une population vieillie et une belle jeune femme cristallisant les convoitises permet de mettre en lumière les mécanismes d'aliénation sociaux, culturels et psychologiques. Si nous comparons Menino de engenho et $O$ Padre e a $m o c ̧ a$, nous pourrons donc remarquer que la méthode des réalisateurs ne diffère pas et, dans les deux cas, cet équilibre entre classicisme et modernité que nous avons mentionné repose à 
peu près sur les mêmes éléments. Une grande différence intervient cependant entre les arguments des deux films, le premier est l'histoire d'un enfant qui va se reconstruire après un traumatisme, le second est celui d'un prêtre qui doute de ses valeurs morales. Il y a dans $O$ Padre e a moça une dimension subversive absente du film de Lima. La vulnérabilité du prêtre aux charmes de la jeune femme est une transgression.

Le parallèle est immanquable entre la séquence où il cède aux avances de la jeune femme et celui où, dans les évangiles, le Christ est tenté par le démon dans le désert. La situation d'isolement et le paysage aride contribuent à ce rapprochement. Mais le parallèle entre les deux situations n'implique pas une relation d'identification. Rien n'est plus éloigné du film que de suggérer que la jeune femme serait une incarnation du démon. Le fait que certaines séquences fassent douter de la virginité de la jeune femme ${ }^{667}$ sans que nous puissions discerner ou émettre un jugement moral clair sur son personnage, rajoute à la complexité de la situation. Mariana s'affirme en dépit du « déshonneur » passé et à venir, notamment en faisant fis des superstitions populaires sur les femmes de prêtres ${ }^{668}$. Confronté aux pulsions apparemment irraisonnées de sa compagne, le prêtre doute. Ce doute qui est conjugué à son propre désir, porte en lui le germe de la libération sexuelle, un processus pourtant risqué et difficile car il remettrait en cause toute la structure sociale et politique du village. Les dernières séquences montrent d'ailleurs bien un Honorato prostré, sans réaction, déchu de son rang de notable parce que le mariage qu'il souhaitait imposer est à présent impossible. La dimension libertaire du film émerge dans ses différences d'avec le poème. Le prêtre du poème sait résister, il ne doute pas, celui de Andrade cède. Le cinéaste explique :

«Escolhi esse tema porque encontrei no poema de Carlos Drummond de Andrade o problema de uma pessoa que sofre um processo de inibição em suas relações com outra pessoa. O tema do filme é apenas uma das muitas conotações que se encontram no poema. [...] O padre do filme é um sujeito em luta com uma ideologia castradora, corporificada na batina que veste. O padre do poema está longe de ser o padre de meu filme : é um outro padre, um padre poderoso, um ganharão de Deus, mas na imagem de um padre com uma moça estava a matéria de meu filme, por interpostas figuras. $»^{669}$

667 Au début du film, dans le seul dialogue qui unit Honorato et Mariana en tête à tête, ils évoquent ensemble les « choses » qu'il fait avec elle. Dans une autre séquence, muette celle-là, Vitorino et Mariana s'étreignent dans l'arrière boutique de l'épicerie / bar d'Honorato. Par la suite, les deux hommes vont prétendre avoir possédé Mariana ce qu'elle va nier.

668Mariana évoque la légende de la mule sans tête. Dans une des séquences coupées au montage, le jeune curé affrontait ce monstre mythologique. L'hallucination était destinée à exprimer la force de son sentiment de culpabilité après la réalisation de l'acte sexuel.

669 « J'ai choisi ce thème parce que j'ai trouvé dans le poème de Carlos Drummond de Andrade le problème d'une personne qui souffre d'inhibition dans ses relations avec les autres personnes. Le thème du film reprend seulement l'une des nombreuses connotations présentes dans le poème. [...] Le prêtre du film est un sujet en lutte contre une idéologie castratrice, incarnée par son costume de religieux. Le prêtre du poème est loin d'être celui de mon film : c'est un autre prêtre, un prêtre très fort, un soldat de Dieu, mais dans l'image d'un prêtre avec une jeune femme était la base de mon film, par figures interposées. » in VIANY, Alex. «Crítica e autocrítica : O padre e a moça - Alex Viany conversa com Joaquim Pedro de Andrade », op. cit. 
Curieusement, la dimension politique du film ne sera pas comprise par les fractions progressistes de la société brésiliennes alors qu'elle sera parfaitement entendue par les secteurs conservateurs. Les polémiques et l'intromission de la censure vont contrarier son lancement commercial ce qui ne facilitera pas sa rencontre avec le grand public.

Tout indique que les sessions privées antérieures à sa sortie commerciale ont été catastrophiques $^{670}$. O Padre e a moça est jugé lent et hermétique. Son esthétisme passe pour la manifestation d'une culture élitiste trahissant les origines « aristocratiques » de son auteur. Le film ravive le conflit entre le Cinema Novo et les anciens membres du CPC qui, comme cela avait déjà été le cas pour Porto das Caixas, lui reprochent de donner une image négative des classes populaires et de ne pas être un film pamphlétaire visant à dénoncer l'impérialisme ou le régime dictatorial. Pour Carneiro, cette opposition des anciens du CPC est une réaction sectaire et la manifestation des tendances totalitaires du $\mathrm{PC}^{671}$. L'antagonisme entre le CPC et le Cinema Novo est assimilé à celui qui, au temps de la Révolution russe, a opposé le Proletkult au Lev. Rocha reprend alors sa défense du cinéma d'auteur. Pour lui, O Padre e a moça doit être un modèle pour le cinéma d'auteur :

«Em primeira instância, antes de se discutir a significação ideológica ou estética deste ou daquele filme de arte, urge considerar gravemente que um filme de autor, na medida que se opõe ao industrialismo da mentira e da moral rotulada, é um filme anticonformista, um filme que desperta, por si mesmo, a polêmica no seio da indústria estabelecida. $\gg{ }^{672}$

José témoigne des réactions hostiles du CPC mais relativise l'antagonisme suggéré par de nombreux témoignages :

« E $O$ Padre e Moça veio exatamente em 65, 66, após o golpe, quando estava se pedindo aos artistas uma resposta mais direta ao golpe militar. E o Joaquim, ao invés de trazer um filme político, como era legítimo na época, traz $O$ Padre e a Moça. Uma história de um padre que tem um caso com uma moça no interior de Minas, né? Pô, que coisa mais alienada! Então na primeira sessão de estréia o pessoal do CPC da UNE tinha preparado uma ação para destruir a sessão, iam jogar gás sulfídrico, aquele que tem cheiro de ovo podre, fazer umas ações durante o filme. Foram preparados mesmo, mas o Joaquim era uma pessoa tão digna, tão decente, que as próprias pessoas que foram fazer esse ato cederam ao Joaquim, cederam ao filme... Houve um certo movimento no início, mas um silêncio durante o filme todo, e quando acabou o filme a gente viu uma reação muito estranha. Porque tinha tido muita gente que tinha ido para não gostar, para fazer esse ato contra o filme. Tinha sido preparado antes, isso aí, inclusive pessoas

670Rocha qui prend aussitôt la défense du film estime que cette mauvaise réception initiale a découragé les exploitants qui auront tendance à ne pas croire en son potentiel commercial. $C f$. ROCHA, Glauber. «A Fala do Cinema Novo » in O Jornal do Brasil - Suplemento Dominical, Rio de Janeiro, 14/04/1966.

671Voir le témoignage accordé à Ivana Bentes ou l'entretien reproduit dans la revue Contracampo : BENTES, Ivana. Op. cit., pp. 49-60.

LINHART, Clara, MAROJA, Camila et CAETANO, Daniel. « Entrevista com Mário Carneiro », op. cit.

672 «n premier lieu, avant de discuter la signification idéologique ou esthétique de tel ou tel film d'art, il faut diligemment considérer qu'un film d'auteur, dans la mesure où il s'oppose à l'industrialisation du mensonge et de la morale, est un film anticonformiste, un film qui réveille, par lui-même, la polémique au sein de l'industrie établie. » in ROCHA, Glauber. « A Fala do Cinema Novo » in O Jornal do Brasil - Suplemento Dominical, Rio de Janeiro, 14/04/1966. 
amigas nossas, mas que naquele momento exigiam do cinema um cinema político, de denúncia. Mas no final do filme todas essas pessoas ficaram sentadas, houve dificuldade de levantar do cinema. Porque o filme desconcertou as pessoas... porque não era um filme político, mas não era jamais um filme alienado. $\gg{ }^{673}$

Paradoxalement, certains critiques étrangers aux polémiques internes de l'intelligentsia progressiste ridiculisent le long métrage pour reprendre des « gimmicks gauchistes ». C'est le cas d'Ely Azeredo ${ }^{674}$ et de Carlos José Oliveira :

« [...] um filme que tinha tudo para ser uma obra-prima, não fora a intrusão da má fé, segundo a qual um padre não é um padre, e sim um revoltado que se desconhece, e uma moça não é uma moça, e sim uma ânsia de libertação que se debate cegamente no meio da maior miséria. $)^{675}$

L'opposition la plus forte que rencontrera le film sera celle des secteurs les plus conservateurs de la société brésilienne qui jugent l'œuvre anticléricale. O Padre e a moça est interdit dans l'état où il a été filmé et par les mêmes autorités qui lui auront apporté un appui logistique décisif (jeeps pour les déplacements de l'équipe et du matériel / caméra). Le gouvernement de Minas Gerais, sous la pression des associations catholiques, intervient de façon autoritaire, outrepasse ses prérogatives et annule la décision de la censure qui avait autorisé le film. Les réactions extrêmes et contradictoires provoquées par le second long métrage de Andrade tendent à la fois à expliquer et à légitimer la démarche de son auteur. Membre d'une famille originaire de Minas Gerais, le cinéaste savait qu'il s'exposerait à ce type de réaction. Mais il entendait bien remettre en questions les valeurs conservatrices de cette société qu'il connaissait bien. Cet élément ne l'empêchera pas de se montrer sensible aux critiques de la gauche et de douter de son approche. Après le coup d'État, Andrade a bien hésité à poursuivre son projet d'adaptation du poème de Drummond. Dans une entrevue

673« Et $O$ Padre e a moça est arrivé en 65, 66, après le coup d'État, quand il était demandé aux artistes une réponse directe au coup d'État militaire. Et Joaquim, au lieu de faire un film politique, comme cela était légitime à l'époque, réalise $O$ Padre e a moça. L'histoire d'un prêtre qui a une aventure avec une jeune femme de l'intérieur des Minas Gerais ! Rien de plus aliéné ! Alors, à la première, le personnel du CPC de l'UNE avait planifié une action pour gâcher le lancement du film, ils allaient jeter du gaz sulfurique, celui qui a une odeur d'œuf pourri, et perturber la projection par d'autres actions. Ils avaient vraiment tout préparé mais Joaquim qui est une personne très digne, très décente, les impressionnait suffisamment pour qu'ils renoncent à leur projet... Il y a eu une certaine agitation au début mais un grand silence pendant tout le film et, quand il a été fini, nous avons assisté à une réaction très étrange. Parce qu'il y avait beaucoup de gens qui étaient venus pour ne pas aimer, pour faire cet acte contre le film. Cela avait été préparé à l'avance, même par certains de nos amis, mais qui, à ce moment-là attendaient un cinéma politique, un cinéma de dénonciation. Mais, à la fin du film, toutes ces personnes sont restées assises, et ont éprouvé une certaine difficulté à se lever de leurs fauteuils. Parce que le film a beaucoup déconcerté... parce que ce n'était pas un film politique mais que ça ne serait jamais non plus un film aliéné. » in LINHART, Clara, MAROJA, Camila et CAETANO, Daniel. « Entrevista com Paulo José », op. cit.

674AZEREDO, Ely et alii. « A Crítica e o Cinema Novo II » in Filme cultura, Rio de Janeiro, n³, janvierfévrier 1967.

$675 \ll[\ldots]$ un film qui avait tout pour être un chef d'œuvre, sans l'intrusion de la mauvaise foi, selon laquelle un prêtre n'est pas un prêtre mais un rebelle qui s'ignore, et une jeune femme n'est pas une jeune femme, mais un besoin de liberté qui se débat aveuglement au sein de la misère la plus noire. » in OLIVEIRA, José Carlos. «O Falso Dilema » in Jornal do Brasil, Rio de Janeiro, 01/05/1966. 
contemporaine à la sortie du film, il se justifiait en ses termes :

\begin{abstract}
« Num momento em que o ideal seria tomar uma posição político-social, por que você optou pelo poético em seu último filme?

O filme foi realizado antes do golpe do dia $1^{\circ}$ de abril. Também acho que não optei pelo poético em meu filme. O que acontece é que o tratamento de um tema feito por interpostas figuras como do padre e da moça impedem a discussão direita deste tema. O filme, por causa disso, não tem uma posição crítica assumida com tanta clareza que se tornasse facilmente perceptível para a maioria do público. Ele é na verdade a descrição de uma luta, a luta de um homem contra seus inibições, seus medos, seus impulsos de negação. O filme termina com a derrota desse homem, que só se permite ter o amor da moça quando isso já não é mais possível pela iminência da morte. Esse desfecho dá informação necessária para a tomada de uma posição crítica por parte do espectador. $»^{676}$
\end{abstract}

Dans une critique tardive, Luiz Israël Febrot compare le film et le poème. Il est celui qui analyse le mieux l'intention de Andrade. Le poème de Drummond est mystique, il s'interroge sur cet «amour noir » entre un prêtre et une jeune femme sans condamner ni les amoureux, ni leurs bourreaux. Pourquoi Dieu semble-t-il se divertir en nous punissant, en nous infligeant des épreuves? Andrade traite d'une situation concrète : une jeune fille sur le point d'être mariée à son beau-père, un village misérable, l'amour entre deux jeunes gens :

«A idéia que ressalta o filme é que, aquela gente, por conveniência social, aceitava uma ligação não natural entre o tutor velho e a afilhada moça mas, rejeitou, por preconceito social, a ligação natural entre uma moça e um moço padre, porque estava preso ao voto. Gente que estava disposta a aceitar o amor não-natural entre o velho tutor e a jovem afilhada pobre, rejeitou, porém, o amor natural entre um moço e uma moça. Isto é prefiriu aceitar a convenção social sobre a verdade humana ; determinadas pessoas, numa situação social anacrônica, estão mais dispostas a transgredir uma lei da natureza do que uma convenção social. Afinal, são as convenções irracionais que contém e prolongam as situações sociais anacrônicas.

E esta história desenrola-se dentro de um contexto barroco e irremediavelmente arcaico [...]

Ligada a estória do filme ao contexto no qual se desenvolve, pode concluir que a idéia básica do filme de Joaquim Pedro é que numa estrutura social atrasada ou estagnada, mesmo as expressões mais vitais como o amor, são impossíveis.») ${ }^{677}$

676« Dans un moment où l'idéal serait de prendre position d'un point de vue politique et social, pourquoi avezvous opté pour un film poétique?

Le film a été réalisé avant le coup d'État du $1^{\circ}$ avril. Je crois aussi que je n'ai pas opté pour un film poétique. Ce qui arrive, c'est que le traitement du thème par des figures interposées empêche la discussion directe de ce thème. Le film, pour cette raison, n'a pas une position critique assumée avec une clarté suffisante pour qu'elle soit perceptible par la majorité du public. Il est en fait la description d'une lutte, celle d'un homme contre ses inhibitions, ses peurs, ses impulsions de négation. Le film termine avec la défaite de cet homme, qui ne se permet d'aimer la jeune femme que lorsque cela est rendu impossible par l'imminence de la mort. Ce final donne l'information nécessaire pour l'adoption d'une position critique par le spectateur. » in ALBERTO, Carlos. « Joaquim Pedro : o principal é vencer o medo » in Tribuna da imprensa, Rio de Janeiro, 09/04/1966.

677 « L'idée qui est mise en exergue par le film consiste à montrer que ces gens, par convention sociale, acceptent une relation non naturelle entre le vieux tuteur et sa fille adoptive mais rejettent, par préjugé, la relation naturelle entre une jeune femme et un jeune homme, parce que ce dernier est prêtre et lié par son vœu de chasteté. Ces gens qui étaient disposés à accepter un amour non-naturel entre le vieux tuteur et sa fille adoptive pauvre, ont refusé, pourtant, l'amour naturel entre un jeune homme et une jeune femme. Autrement dit, ils ont préféré la convention sociale à la vérité humaine ; certaines personnes, dans une situation sociale anachronique, sont mieux disposées à transgresser une loi de la nature qu'une convention sociale. En fin de compte, ce sont des conventions irrationnelles qui contiennent et prolongent des situations sociales anachroniques.

Et cette histoire se déroule dans un contexte baroque et irrémédiablement archaïque [...] En mettant en relation l'histoire du film avec le contexte dans lequel elle se déroule, on peut conclure que 
Le film sortira en salles en avril 1966 à Rio de Janeiro et en juin à São Paulo. Desservi par les polémiques et les critiques négatives qui l'ont précédé, il peine à faire passer la densité de son propos. Son insuccès aura pour conséquence son classement parmi les films maudits du Cinema Novo. Les cinemanovistas conçoivent alors comme impossible de concilier réussite commerciale et film de conscientisation. Bien que distant d'un cinéma explicitement politique, $O$ Padre e a moça initie une approche qui sera reprise sous d'autres formes dans d'autres films. Celle-ci est fondée sur deux idées. La première est celle selon laquelle le comportement individuel doit être mis en relation avec le contexte culturel, social, politique et économique vu comme un ensemble indissociable. La deuxième est celle selon laquelle le sous-développement et la dictature sont en partie appuyées par des valeurs de négation des impulsions légitimes de l'être humain, autrement dit par des valeurs anti-humanistes ancrées dans la culture brésilienne qu'il convient de dénoncer. Cette orientation va perdurer et sera préférée à un discours qui, sans être pour autant pamphlétaire, aurait pu remettre en cause plus directement des aspects de la vie politique et sociale du pays. Ce qui va peu à peu changer, c'est le sentiment qu'un film n'a un impact politique que s'il parvient à toucher le plus grand nombre.

\subsection{Organisation économique du Cinema Novo}

L'organisation économique du Cinema Novo se fait en 1965 parallèlement à la production de ces films qui évitent une thématique politique explicite, A Falecida, Menino de engenho, A Grande Cidade, $O$ Padre e a moça. L'objectif est d'assurer la pérennité économique du Cinema Novo dans le cadre des réseaux commerciaux traditionnels du cinéma. Plusieurs maisons de production sont créées. La principale est MAPA Filmes, plus ancienne, SAGA Filmes est « réactivée ». Jusqu'à 1965, les films avaient été réalisés à partir des opportunités de financement qui pouvaient se présenter, parfois sans plan de production rigoureusement rédigé en avance, sans connaissance exacte des prix de services techniques aussi importants que la réalisation de copies, le sous-titrage pour l'exportation, souvent sans même avoir la certitude de pouvoir terminer le film, enfin, sans arrangement anticipé avec un distributeur ou un exploitant ${ }^{678}$. Inutile aussi de mentionner l'existence d'un budget

l'idée de base du film de Joaquim Pedro est que, dans une structure sociale en retard ou en stagnation, même les expressions les plus vitales comme l'amour, sont impossibles. » in FEBROT, Luiz Israel. «O Padre e a moça : Filme e poema » in O Estado de São Paulo - Suplemento literário, São Paulo, 29/08/1971.

678Les exemples de cette absence de stratégie sont nombreux. Pour réaliser Couro de gato, Andrade vend sa part de la Saga Filmes mais l'argent dont il dispose ne suffit pas à couvrir la totalité des frais de production. Le film est terminé à Paris après de laborieuses négociations avec Sacha Gordini et, par la suite, il est d'abord distribué en France et en Belgique (Voir : Um Depoimento especial de Joaquim Pedro de Andrade. Folheto 
«promotion », le volontarisme dominait, il fallait produire avant tout, et un certain idéalisme aussi, consistant à penser que le succès des films serait proportionnel à leur qualité artistique. Après le coup d'état de 1964, comme nous l'avons déjà vu, une remise en question idéologique du Cinema Novo s'opère. Parallèlement, un premier bilan commercial est dressé. D'un côté, les cinemanovistas ont bien conscience d'avoir été sauvés par la CAIC qui a primé leurs films avec des sommes permettant de rembourser les dettes qui avaient été contractées. D'un autre côté, se pose la question du public. Plusieurs articles de l'époque attestent du fait que cette question est devenue centrale ${ }^{679}$. Les cinemanovistas ne sont pas satisfaits des résultats commerciaux de leurs films car ils pensent à ce moment-là que si les longs métrages ne touchent pas le grand public, la praxis politique à laquelle ils aspirent ne peut se mettre en œuvre. Cette inquiétude va entraîner une double réflexion, la première sur l'esthétique des films, la seconde sur les stratégies économiques à mettre en œuvre pour assurer la pérennité de la production et toucher le maximum de personnes.

Sur la question esthétique, les cinemanovistas prennent conscience du caractère avantgardiste de leur production. Ils abandonnent l'illusion qui consistait à penser que le cinéma d'auteur moderne, avec toutes les innovations formelles qu'il apportait par rapport au cinéma classique, allait être le cinéma du futur et se substituer complètement à lui ${ }^{600}$. Il surgit l'idée

organizado pelo Cineclube Macunaíma na ocasião da Retrospectiva Joaquim Pedro de Andrade em 1976, no Rio de Janeiro). Sans le sauvetage providentiel de Ganga Zumba par Jarbas Barbosa, le long métrage ne serait même pas arrivé à l'étape de montage. Barravento n'est pas distribué au Brésil avant le succès critique international de Rocha à Cannes en 1964 et là encore, il n'atteint pas le marché pauliste avant 1969 et la consécration de $O$ Dragão da maldade contra o santo guerreiro. Selon plusieurs témoignages, Cinco vezes favela n'a pas été distribué commercialement en-dehors de Rio de Janeiro. Les films du cycle de Bahia ne sont pas exploités de façon efficace en dehors de Salvador. Enfin, certains films qui parviennent à être distribués sont exploités dans des circuits inadaptés et condamnés à de cuisants échecs commerciaux, c'est le cas de Porto das Caixas et $A$ Falecida.

679MARCORELLES, Louis. « Rencontre avec le Cinema Nôvo : Joaquim Pedro de Andrade, Gustavo Dahl, Carlos Diegues, Leon Hirszman, Rocha, Paulo Cézar Saraceni » in Cahiers du cinéma, Paris, $\mathrm{n}^{\circ} 176$, mars 1966.

Entrevue réalisée chez Gustavo Dahl à Rio de Janeiro en septembre 1965 à l'occasion du Festival Internacional do Filme. Les deux principaux points traités sont : le cinéma en tant qu'instrument de connaissance et de démystification et la question de la relation avec le public. Dahl se demande si le principal problème n'est pas de s'adresser « à un public sous-développé », incapable de recevoir aucune critique. Hirszman indique l'importance qu'il y a à atteindre « le public aliéné », celui que le Cinema Novo n'a pas encore touché. Quelle que soit l'approche choisie, le problème reste le même. Comment atteindre un large public avec un cinéma qui, pour être un cinéma critique et de renouvellement esthétique, sera forcément un cinéma « difficile »? La question est développée dans les articles suivant :

DAHL, Gustavo. « Cinema Nôvo e estruturas econômicas tradicionais » in Revista Civilização Brasileira, Rio de Janeiro, n5-6, mars 1966.

DAHL, Gustavo. « Cinema Nôvo e seu público », op. cit.

DIEGUES, Carlos. « Cinema Nacional em questão : Carlos Diegues » in O Estado do Paraná, 02/10/1966.

680L'heure est au désenchantement vis à vis des possibilités d'expansion commerciale du cinéma d'auteur : « Deixando de lado o possível gênio de Antonioni, Godard ou Resnais, pergunta-se sempre como seus últimos filmes foram de bilheteria. Para obter quase sempre a mesma resposta : mal. Igualmente no Brasil, como o último Rocha, o último Guerra ou o último Saraceni. Mas Godard consegue salvar-se em virtude de seus orçamentos reduzidos, Antonioni e Resnais por suas vendas no mercado internacional, exatamente como o fazem, em outra escala, Bellochio e Bertolucci. » (« Laissant de côté le possible génie de Antonioni, Godard ou Resnais, on se demande toujours quelles ont été les recettes de leurs derniers films. Pour obtenir 
selon laquelle il est impossible de toucher un large public avec le cinéma qu'ils ont pratiqué jusque là et qu'il faut se tourner soit vers une esthétique de compromis, soit découvrir une nouvelle esthétique capable de conquérir le public sans trahir les fondamentaux du Cinema Novo. Malgré cela, entre 1964 et 1968, les cinéastes vont rester dans la ligne d'un cinéma d'avant-garde et ce sont surtout les stratégies économiques qui vont s'affiner. Dans ce contexte, Gustavo Dahl plaide pour l'adoption d'une mentalité d'entreprise qui ne serait efficace qu'avec des mesures concrètes de la part du gouvernement en matière d'encouragement à la production et de réglementation du marché interne. Il insiste aussi sur le fait que la fabrication du «produit cinématographique », et c'est bien ce terme qu'il emploie, est indissociable de son positionnement sur le marché ${ }^{681}$. Jusqu'à la terminologie employée a changé et la réflexion s'articule autour de la compréhension des logiques commerciales. Il s'opère alors un curieux divorce entre les idéaux politiques d'inspiration marxiste d'une société sans classe, les idéaux esthétiques d'un cinéma d'auteur démystificateur ${ }^{682}$ et l'assimilation de raisonnements qui préfigurent ce que l'on appellera bientôt le marketing.

Parce que les cinemanovistas s'intéressent avant tout à investir le marché cinématographique traditionnel, structuré par les règles classiques du capitalisme, ils se trouvent dans cette situation paradoxale consistant à assimiler les logiques d'un système qu'ils disaient au départ vouloir contester. Dans ce domaine, ils vont pourtant démontrer une capacité d'innovation remarquable, anticipant les stratégies contemporaines de positionnement du cinéma d'art et d'essai sur le marché, et appliquant une politique agressive et dynamique qui portera rapidement ses fruits. L'organisation des structures de production est concomitante à la création de structures de distribution et à l'instauration de négociations directes avec les exploitants avant la réalisation des films de manière à obtenir des engagements fermes garantissant leur diffusion sur le marché interne. La démonstration la plus claire de cette nouvelle approche est la création de la DIFILM qui est exactement contemporaine à celle de

presque toujours la même réponse : les recettes ont été mauvaises. De même au Brésil, au sujet du dernier Rocha, du dernier Guerra ou du dernier Saraceni. Mais Godard réussit à se sauver grâce à des budgets extrêmement réduits, Antonioni et Resnais grâce à leur vente sur le marché international, exactement comme le font, à un autre niveau, Bellochio e Bertolucci. ») in DAHL, Gustavo. « Cinema Nôvo e estruturas econômicas tradicionais ", op. cit., p. 195. À partir du moment où l'on a compris qu'un cinéma trop éloigné de l'esthétique hégémonique ne parviendra pas à rassembler les foules, la stratégie de positionnement commercial du film d'auteur consistera à éviter les investissements initiaux trop importants, exploiter au maximum les possibilités de rentabilité financière par rapport au public cible, c'est à dire les habitués du cinéma d'art et d'essai, et tirer le maximum de profit du marché international. L'inconvénient de ce type de stratégie est l'inévitable enfermement dans son segment de marché qui est finalement la conséquence logique de la structuration capitaliste des échanges marchands. En dernière instance, accepter les règles du marché revient à faire confiance à la dynamique capitaliste pour promouvoir l'évolution esthétique du septième art. 681 « [...] a colocação do produto cinematográfico no mercado é inseparável de sua fabricação. » in ibid. 682La trajectoire de Gustavo Dahl est à ce titre exemplaire. Défenseur de l'adoption d'une mentalité d'entreprise, d'une grande rigueur et lucidité dans la confrontation avec les règles du marché, il va réaliser deux films sans la moindre concession par rapport aux supposés goûts du public et recettes du succès : $O$ Bravo Guerreiro et Uirá, um índio em busca de Deus. 
MAPA Filmes. La DIFILM est une maison de distribution fondée par Marcos Faria, Carlos Diegues, Leon Hirszman, Roberto Farias, Rivanides Faria, Joaquim Pedro de Andrade, Paulo César Saraceni, Luiz Carlos Barreto, Walter Lima Júnior, Zelito Viana et Rocha ${ }^{683}$. Autrement dit, les réalisateurs-producteurs également responsables de MAPA Filmes, SAGA Filmes, Roberto Farias Produções Cinematográficas, Filmes do Serro et LCB Produções cinematográficas. La DIFILM va connaître deux périodes distinctes. Celle pendant laquelle les onze associés vont rester unis, de 1965 à 1969, et celle pendant laquelle Barreto va demeurer seul à sa direction, de 1969 à 1974, date à laquelle, comme beaucoup d'autres entreprises de cinéma brésiliennes, elle est absorbée par Embrafilme.

Barreto décrit la DIFILM originale dans ces termes :

«Foi uma empresa que era com onze sócios, todos eram realizadores e produtores, não tinha um cara que era dono, eram cotas iguais. E que operava com um sistema, todo mundo criando idéias, gerando idéias... A gente foi competir no mercado brabo, com os estrangeiros e tudo, e no espaço de dois anos ela já era a segunda ou terceira empresa no mercado da distribuição, com grande participação no mercado. Nós tivemos vários grandes sucessos, Todas as mulheres do mundo, Roberto Carlos em ritmo de aventura, Garota de Ipanema, Menino de Engenho, o próprio Terra em transe foi um sucesso. ${ }^{684}$

Dans A Revolução do Cinema Novo, Rocha confirme qu'avec la Difilm, le Cinema Novo est entré en concurrence avec les distributeurs traditionnels. Rapidement, le nouveau distributeur conquiert une importante part de marché et les résultats commerciaux des films sont dopés :

«A multiplicação das rendas foi rápida. E a receptividade do público aos filmes de cinema subiu de 40\% de 1964 para hoje. Qualquer filme de Cinema Novo tem apenas no Rio, mediante uma distribuição eficiente, uma média que vai de 50 a 100 mil espectadores. ${ }^{685}$

683De passage à Rio de Janeiro à l'occasion du FIF de septembre 1965, Robert Benayoun nous donne un instantané de l'ambiance régnant à l'époque de la création de l'entreprise : « Aujourd'hui, Luiz Carlos Barreto regroupe autour de lui toute une coopérative de production ou de distribution qui donne au Cinema Novo cet impact amical, cette unité d'action que n'eut jamais notre Nouvelle Vague. Dans son jardin accueillant et dénué de prétention, on retrouve quotidiennement, autour de sa femme et de ses enfants, lestes manieurs de caméras, et de la chienne Baleia, rescapée de Vidas secas, des réalisateurs aussi divers que Ruy Guerra, Carlos Diegues, Paulo Cézar Saraceni, Paulo Gil Soares, Walter Hugo Khouri, Leon Hirszman, Rocha, Joaquim Pedro de Andrade, Lima. sans compter les critiques David Neves, Alex Viany, Vinicius de Moraes, toutes personnes qui, déjà, ont convoqué un Congrès National du Cinéma Brésilien qui se définit sous forme de manifeste. » In BENAYOUN, Robert. « Cangaços 65 : Cris du Brésil » in Positif, Paris, n73, février 1966, pp. 1-21.

684 «C'était une entreprise qui rassemblait onze partenaires, tous étaient réalisateurs et producteurs, il n'y en avait aucun qui était le patron, les parts de chacun étaient identiques. Cette entreprise fonctionnait comme un système où tout le monde trouvait de nouvelles idées... Nous avons affronté la concurrence sur un marché difficile, avec les étrangers et tout, et, en l'espace de deux ans, la Difilm était déjà la deuxième ou troisième entreprise sur le marché de la distribution, avec une grande participation au marché de l'exploitation. Nous avons eu plusieurs grands succès, Todas as mulheres do mundo, Roberto Carlos em ritmo de aventura, Garota de Ipanema, Menino de Engenho, et même Terra em transe fut un succès. » in LINHART, Clara, MAROJA, Camila et CAETANO, Daniel. «Entrevista com Luiz Carlos Barreto » in Contracampo, $\mathrm{n}^{\circ} 42$, http://www.contracampo.com.br/42/frames.htm, consulté le 29/12/2005.

685 « L'augmentation des recettes a été rapide. Et la réceptivité du public aux films de cinéma a augmenté de $40 \%$ entre 1964 et aujourd'hui. N'importe quel film du Cinema Novo réunit, en comptant seulement Rio et 
La DIFILM a commencé à zéro, en s'appuyant sur l'expérience de Copacabana Filmes, l'entreprise de Barbosa, qui, en plus de les produire, avait aussi distribué Deus e o diabo na terra do sol, Vidas secas et Os Fuzis. Bien que destinée à défendre sur le marché un cinéma de qualité, la DIFILM, comme MAPA Filmes et SAGA Filmes, développe un catalogue varié s'appuyant aussi bien sur des titres remettant à un cinéma franchement commercial que sur des productions fidèles aux canons du cinéma d'auteur ${ }^{686}$. Les premiers films commercialisés, O Vigilante e os cinco valentes (Ary Fernandes, 1966) et Luta nos pampas (Alberto Severi, 1965), échappent à la ligne du Cinema Novo mais permettent de confronter la nouvelle structure au marché ${ }^{687}$. Suivront une trentaine de longs métrages correspondant à la filmographie des maisons de production respectives des onze partenaires, les plus gros succès de l'entreprise étant Roberto Carlos em ritmo de aventura (Roberto Farias, 1967) et Macunaíma. Autrement dit, une comédie yéyé et un film du Cinema Novo. Le succès du nouveau distributeur est tel que moins de deux ans après avoir débuté, il est en mesure d'avancer de l'argent et de co-produire plusieurs films de fiction aussi importants que $O$ Padre e a moça, Menino de engenho et Todas as mulheres do mundo (Domingos de Oliveira, 1967).

La DIFILM met au point des stratégies de lancement originales. Les années précédentes, certaines controverses avaient divisées les cinemanovistas et leurs différents partenaires commerciaux. Deux stratégies étaient envisagées, la sortie d'un film en simultané sur 15 écrans en s'appuyant sur la répercussion du succès critique international (solution adoptée pour Deus e o diabo na terra do sol) ou une sortie intimiste dans un seul cinéma mais avec une couverture dans la presse susceptible de créer un climat d'expectative. Chacune des deux solutions présentant ses avantages et ses inconvénients, la DIFILM saura éviter les erreurs du passé et peser de tout son poids pour éviter la suicide commercial de certains films facilité par la mauvaise volonté des exploitants à commercialiser le cinéma brésilien. Le lancement commercial de Menino de engenho, dont elle est responsable, montre aussi sa capacité à innover et à appliquer des stratégies adaptées au marché brésilien.

La DIFILM première forme cesse d'exister en 1969 quand Farias, fort du succès obtenus par ses films, se désolidarise des autres membres avec lesquels il ne partage pas la même éthique cinématographique. Il fonde Ipanema Filmes avec Rivanides Faria, Jarbas Barbosa, Jece Valadão et Herbert Richers qui s'inscrit résolument dans une ligne de conquête du marché avec un catalogue de films conçus pour répondre aux attentes du public. Délesté des ambitions esthétiques et politiques du Cinema Novo, Ipanema Filmes va connaître une

par l'intermédiaire d'une distribution efficace, une moyenne qui va de 50 à 100 mille spectateurs. » in ROCHA, Glauber. Revolução do Cinema Novo. Op. cit., p. 104.

686Voir le catalogue des trente films distribués par la DIFILM en annexe.

687RAMOS, Fernão et MIRANDA, Luís Felipe (org.). Enciclopédia do cinema brasileiro. Op. cit., p. 172. 
très grande prospérité entre 1969 et 1974 et distribuer un grand nombre de films dépassant le million d'entrées comme Os Paqueras (Reginaldo Faria, 1969), Marcelo, zona sul (Xavier de Oliveira, 1970), Roberto Carlos e o diamante cor-de-rosa (Roberto Farias, 1970), Pais quadrados, filhos avançados (J.B. Tanko, 1970), Roberto Carlos a 300 quilômetros por hora (Roberto Farias, 1972) ${ }^{688}$. En marge d'un catalogue dédié au cinéma commercial, cette entreprise distribuera cependant aussi Os Herdeiros. De son côté, MAPA Filmes prendra en main la distribution de ses films, d'ailleurs avec un certain bonheur puisque 1969 est l'année du succès de $O$ Dragão da maldade contra o santo guerreiro et de Máscara da traição (Roberto Pires, 1969).

Zelito Viana est le principal responsable de cette organisation économique du Cinema Novo qui est effectuée en 1965. Membre fondateur de la Difilm, il est aussi de l'aventure MAPA Filmes. Sa trajectoire est bien différente de celle des deux autres producteurs qui ont marqué le Cinema Novo, Barbosa et Barreto. Alors que ceux-ci sont déjà des personnes expérimentées, bénéficiant chacun d'un vaste réseau professionnel et dix ans plus vieux que les cinéastes qu'ils produisent, Viana est de la même génération qu'eux. Ingénieur de formation, il s'intéresse au cinéma grâce à son ami Leon Hirszman qui a fréquenté l'Escola Nacional de Engenharia - ENE en même temps que lui. Pendant les premières années du Cinema Novo, Viana reste extérieur aux événements. En 1962, il étudie pendant un an en France, notamment sur le site du Creusot ${ }^{689}$. Entre 1962 et 1963, il travaille dans une entreprise de sidérurgie qui doit fermer en 1964 en raison de la profonde crise économique que traverse le pays. C'est à partir de ce moment-là qu'il retrouve Hirszman et surtout Rocha ${ }^{690}$ qui vont l'encourager à investir le domaine de la production cinématographique. Le Cinema Novo manquait de cadres capables d'organiser rigoureusement la production et de se consacrer exclusivement aux tâches administratives et commerciales, Viana va remplir ce rôle pendant cinq ans avant de commencer lui-même une carrière de réalisateur. S'identifiant avec

688Les deux films mettant en scène Roberto Carlos dépasse 2500000 entrées, un record absolu pour l'époque.

$C f$. SILVA NETO, Antônio Leão Da. Op. cit.

689La plupart des informations que nous donnons sur la trajectoire de Zelito Viana nous ont été apportées par Zelito Viana lui-même. Nous avons également procédé à des recoupements, notamment avec l'Enciclopédia do Cinema Brasileiro. Pour Zelito Viana, la question de la production est centrale dans l'histoire du Cinema Novo. Selon lui, le langage des films du Cinema Novo est le produit direct des stratégies de production qui ont pu être mis en place et celles-ci, mieux que les esthétiques souvent très différentes des œuvres réalisées, sont à même de caractériser le mouvement.

Zelito Viana. Entretien avec l'auteur, septembre 2004.

RAMOS, Fernão et MIRANDA, Luís Felipe (org.). Enciclopédia do cinema brasileiro. Op. cit.

690Viana rencontre Rocha en 1964 au cours d'un débat sur la finalisation de Cabra marcado para morrer. Les rushes du film sont projetés au théâtre de l'Arena où les anciens du CPC se sont réunis pour discuter de cette question. Selon l'ingénieur, les conditions ne sont pas réunies pour que le film puisse être terminé et diffusé de la façon dont il devrait l'être. Il défend donc la thèse selon laquelle il vaut mieux ne pas le terminer. Rocha qui fait partie de l'assistance apprécie le discours de Viana et vient à sa rencontre en fin de réunion. Zelito Viana. Entretien avec l'auteur, septembre 2004. 
la proposition culturelle et cinématographique du groupe, il accepte la proposition de Rocha de s'occuper de la post-production de Menino de engenho par l'intermédiaire de la création d'une maison de production qui sera la MAPA Filmes du nom de la revue universitaire à laquelle Rocha avait contribué dans les années cinquante.

MAPA Filmes est créé en $1965^{691}$ à partir de l'association de Zelito Viana avec Rocha, Walter Lima Junior et Paulo César Saraceni. Pour monter l'entreprise, Viana vend deux camions et obtient un prêt auprès de la Companhia Progresso do Estado da Guanabara S/A COPEG. L'argent obtenu permet d'acheter une table de montage, une caméra Cameflex, un magnétophone Nagra et un réflecteur de lumière. Selon Viana, il n'en fallait pas beaucoup plus pour que l'entreprise devienne un véritable centre de production :

\footnotetext{
« Naquele tempo, se você estiver com a câmera e a moviola, bastava se ter dinheiro para o negativo e o laboratório, o resto, ninguém ganhava. Em Terra em transe, só o Dib ganhava dinheiro, só o cameraman ganhava dinheiro. [...] Atores ganhavam pouquíssimo. Todos ganhavam o mesmo. [...] Na minha moviola foi montado $80 \%$ do cinema brasileiro. $\gg{ }^{692}$
}

La table de montage de Viana est la seconde qui a appartenu en propre au Cinema Novo. Une première table et une caméra Éclair avaient été fournies par Paulo Carneiro quand il était ambassadeur à Paris. Ce matériel avait été installé dans la maison de Barreto qui était devenu par la suite le premier lieu de rencontre et de formation du groupe du Cinema Novo. MAPA Filmes devient un second centre de production. La nouvelle compagnie est installée dans une maison du quartier dénommé Urca qui comprend un bureau, une salle de montage et une salle où entreposer le matériel. L'entreprise emploie au départ trois fonctionnaires ${ }^{693}$, une administratrice, une secrétaire et Viana. Reprenant le rôle de producteur qu'il avait développé auprès de son ami Roberto Pires, Rocha passe énormément de temps à la MAPA Filmes qui va produire successivement, entre 1965 et 1972, Menino de engenho, O Desafio, A Grande

Cidade, O Homem que comprou o mundo, O Dragão da maldade contra o santo guerreiro, Memória de Helena, Máscara da traição, Der Leone have sept cabeças, A Construção de morte, Brasil ano 2000, Minha Namorada, Em Busca do Su\$exo, Cabezas cortadas, São

691Selon Mattos, MAPA a été fondée le 5 juillet 1965 avec un capital de 20 millions de Cruzeiros (environ 9 mille dollars US). L'un de ses membres fondateurs, Dico Wanderley devait rapidement quitter l'entreprise car, en tant que conseiller de la direction du Banco Nacional de Minas Gerais, il pouvait difficilement appartenir à la fois à l'organisme prêteur et à l'entreprise bénéficiaire des crédits financiers. Voir MATTOS, Carlos Alberto. Op. cit., p. 115.

692« Dans ce temps-là, si vous aviez une caméra et une table de montage, il suffisait d'avoir l'argent de l'achat du négatif et des travaux de laboratoire, pour le reste, personne ne recevait de salaire. Sur Terra em transe, seul Dib gagnait de l'argent, seul le cameraman gagnait de l'argent. [...] Les acteurs gagnaient très peu. Ils gagnaient tous la même chose. [...]Sur ma table de montage, ont été monté $80 \%$ du cinéma brésilien. » in Zelito Viana. Entretien avec l'auteur, septembre 2004.

693 Il ira jusqu'à employer 20 salariés et possédera une succursale à São Paulo. L'entreprise qui existe toujours aujourd'hui va cependant ralentir considérablement ses activités au moment où Embrafilme va centraliser à son profit la production et la distribution nationales. 
Bernardo, Na Boca da noite, Quando o carnaval chegar et Os Inconfidentes. L'essentiel de la production de MAPA Filmes s'est donc concentré sur le Cinema Novo sans toutefois s'opposer radicalement à un cinéma de vocation plus commerciale. Citons à titre d'exemple $O$ Homem que comprou o mundo, un film dans le ton des comédies cariocas de l'époque avec, il est vrai, une dimension satirique quant à la condition du Brésil comme puissance régionale et sous-impérialiste ; ou Máscara da traição, un thriller classique réalisé autour de quelques motifs susceptibles d'attirer le public. Le lieu principal de l'action est en effet le célèbre stade de football de Rio de Janeiro, le Maracaña.

MAPA Filmes se distingue à la fois comme la principale maison de production du Cinema Novo et comme un modèle de la capacité du groupe à innover en termes de stratégies économiques. Selon la propre appréciation de Viana, MAPA Filmes est, dans son fonctionnement, une entreprise capitaliste classique. Ses principales spécificités résident dans le choix de l'éthique qu'elle défend et dans le fait est qu'elle est née de l'association de cinéastes qui, pour être plus forts, ont résolu d'investir dans les films les uns des autres. À ce titre, le système coopératif de Rio, quarenta graus est réactivé mais avec un niveau de sophistication et de professionnalisme largement supérieur permis notamment par l'accumulation de cinq ans d'expérience de Cinema Novo. Selon Lécio Augusto Ramos, chercheur de l'UFF et conservateur du Tempo Glauber, Brasil ano 2000 constitue un bon exemple des stratégies de financement mises en œuvre. Le budget du film est réuni en accumulant un très grand nombre de parts d'origines diverses dont l'importance n'a pas excédé $10 \%$ du budget final, l'ensemble des partenaires financiers n'ayant pas forcément une implication directe dans la fabrication du film. Ainsi, selon les chiffres qu'il nous a communiqués $^{694}$, Lima a investi $18000 \mathrm{NCr} \$$ dont 10000 étaient issus d'un emprunt au Banco Nacional, Rocha a mis 14000 NCr\$ issus d'un emprunt au BNMG, Júlio Bressane, 10 000 NCr\$, un certain José Alberto du Banco Mineiro do Nordeste, 8500 NCr\$, MAPA Filmes, $8500 \mathrm{NCr}$, Barreto, initialement la même somme qui a augmenté jusqu'à atteindre $40000 \mathrm{NCr} \$$ et constitué la part individuelle la plus importante du budget.

Sur le total des sommes réunies, 200000 NCr\$ provenaient d'un emprunt au Banco Mineiro do Nordeste. MAPA Filmes était responsable de la gestion financière des fonds perçus et chacun devait être rétribué proportionnellement à la part qu'il avait investie. Les prêts étaient consentis sur le long terme et à des taux raisonnables. Malgré cela, l'espoir d'un réel bénéfice sur l'investissement était assez lointain et, dans ce cas précis, l'échec commercial du film a provoqué l'endettement à long terme de certains de ses partenaires les plus modestes dont le réalisateur. Certains réussissent à s'équilibrer grâce au succès d'autres productions. $\mathrm{Du}$ 694Lécio Augusto Ramos. Entretiens avec l'auteur, août 2003. 
propre aveu de Viana, O Dragão da maldade contra o santo guerreiro est à l'époque une opération extrêmement lucrative, notamment grâce aux ventes internationales. C'est aussi le seul moment de la carrière de Rocha où le cinéaste se trouve dans une position financière avantageuse qui lui permettra notamment d'acheter une belle maison à Botafogo, un quartier bourgeois de Rio de Janeiro.

Parallèlement à MAPA Filmes, la SAGA Filmes ${ }^{695}$ de Leon Hirszman et Marcos Faria développe des stratégies comparables avec une filmographie plus ouverte à un cinéma de compromis mais, paradoxalement, sans rencontrer le même succès. L'entreprise fait faillite avant le lancement commercial de São Bernardo qui a été réalisé dans des conditions très difficiles et sans que les membres de l'équipe puissent recevoir l'intégralité de leurs salaires. Contrairement à MAPA Filmes, cette maison de production n'aura pas pu compter sur le produit de ventes à l'étranger pour équilibrer ses comptes ${ }^{696}$. SAGA Filmes produit : la partie brésilienne de $A B C$ do Amor dirigée par Eduardo Coutinho (1967), Todas as mulheres do mundo (Domingos de Oliveira, 1967), Bebel, a garota-propaganda (Maurice Capovilla, 1967), Garota de Ipanema (Leon Hirszman, 1967), O Bravo Guerreiro (Gustavo Dahl, 1968), A Vida provisória (Maurício Gomes Leite, 1968), A Vingança dos doze (Marcos Faria, 1970), O Faustão (Eduardo Coutinho, 1970), Le Maître du temps (co-production franco-brésilienne, Jean-Daniel Pollet, 1970), O Barão Otelo no barato dos bilhões (Miguel Borges, 1971), Nelson Cavaquinho (Leon Hirszman, 1971), São Bernardo (Leon Hirszman, 1972).

\subsection{Les ventes à l'étranger}

La vente des films à l'étranger est un phénomène tardif comparé à l'exportation précoce du Cinema Novo dans les festivals internationaux. Ses ventes démarrent réellement en 1966, après la consolidation de ses infrastructures dans son pays d'origine. La recherche de des débouchés commerciaux qui permettraient d'équilibrer les finances du groupe et d'assurer la pérennité de sa production était cependant déjà ancienne. Les efforts de Joaquim Pedro de

695Créée en 1958 par Gérson Tavares et Sérgio Montagna et installée dans le garage de Joaquim Pedro de Andrade, la Saga Filmes possédait une caméra Caméflex et une table de montage. L'entreprise réalise d'abord des films publicitaires, puis, sous l'influence d'Andrade qui s'associe aux deux fondateurs, elle produit en 1959 O Mestre de Apipucos e o poeta do castelo et Arraial do Cabo. En 1960, Hirszman et Farias rachètent Saga Filmes, peut être en raison du voyage d'Andrade pour l'Europe et les États-Unis, et produisent Couro de gato. Inactive jusqu'en 1966, la Saga Filmes reprend du service pour l'épisode brésilien de la production internationale $A B C$ do amor. $C f$. RAMOS, Fernão et MIRANDA, Luís Felipe (org.). Op. cit., 480.

696L'histoire de SAGA Filmes montre bien que le désir d'une organisation plus rationnelle de la production n'a été qu'imparfaitement atteint. Malgré les résistances du marché et la précarité de ses structures, l'entreprise n'hésite pas à accumuler plusieurs productions importantes dans un espace de temps réduit. L'insuffisance de retours substantiels sur les dernières production s'est avéré fatal. 
Andrade pour vendre Couro de gato sont une première preuve de cette préoccupation quant à l'exportation des films produits. Les courriers de Gustavo Dahl à Rocha entre 1962 et 1964 témoignent de nouvelles tentatives de vente à l'étranger mais le marché européen présente un niveau de saturation au moins aussi fort que le marché brésilien ${ }^{697}$. Les difficultés sont d'autant plus grandes que l'importation de films est soumise aux aléas de la censure du pays d'origine, que les copies se perdent fréquemment dans leurs voyages entre les ambassades et les différents interlocuteurs qui peuvent entrer en jeu. Enfin, les coûts de promotion et de sous-titrage alourdissent les budgets nécessaires à leur mise à disposition des distributeurs et des exploitants. En 1963, Novais Teixeira raconte dans un article de la revue Projeção l'échec de la vente de Barravento à une télévision belge. Alors que le film avait connu un succès critique en Europe et qu'un contrat en bonne et due forme avait été signé, la vente n'avait pu se conclure. La raison en était que la partie brésilienne avait été incapable d'assumer les frais de copie et donc, d'honorer la vente ${ }^{698}$. En 1966, Dahl estime que les chances d'exportation du Cinema Novo en Europe sont à peu près nulles ${ }^{699}$, c'est pourtant cette année-là que le Cinema Novo commence à s'exporter.

Dans le cadre de la stratégie qui consistait à s'appuyer sur le succès du Cinema Novo à l'étranger pour s'imposer au Brésil, la vente des films a toujours été un enjeu important qui devait logiquement compléter le succès critique et une présence maintenue dans les compétitions cinématographiques internationales. Entre 1960 et 1966, peu de contrats sont conclus et, selon la propre expression de Louis Marcorelles ${ }^{700}$, la diffusion du nouveau cinéma brésilien reste cantonnée au cercle des happy few des festivals. Cette situation va évoluer à partir du festival de Cannes 1964 et de la rencontre des cinemanovistas avec un dénommé Claude Antoine. De cette date jusqu'à son décès en 1987, ce dernier va travailler presque exclusivement à la promotion du Cinema Novo en Europe. Très proche de Rocha, il accompagnera celui-ci dans les moments les plus difficiles de sa vie, pendant son exil du Brésil entre 1971 et 1976, dans ses derniers jours à Sintra en 1981. En tant que « mandataire exclusif de la production », selon la dénomination qui lui est donnée dans les contrats qu'il signe, son rôle consistera à assumer auprès des interlocuteurs internationaux les tâches qui incombent normalement au producteur pour tout ce qui relève de la vente des films et des relations avec les distributeurs et exploitants.

Peu connu des historiens du cinéma brésilien ainsi que de ses plus proches

697Cf. ROCHA, Glauber. Cartas ao mundo. Op. cit., pp. 188-192 et 195-206.

698TEIXEIRA, Novais. « Barravento faz sucesso » in Projeção, São Paulo, année V, n50, octobre 1963.

699DAHL, Gustavo. « Cinema Nôvo e estruturas econômicas tradicionais », op. cit.

700MARCORELLES, Louis. « Le Cinema Novo brésilien » in Cahiers du cinéma, Paris, n¹64, mars 1965. 
collaborateurs brésiliens, Luiz Carlos Barreto, Zelito Viana et Carlos Diegues ${ }^{701}$, Antoine est un personnage singulier au parcours absolument atypique. De son vrai nom Claude Antoine Vessière, de nationalité française, il est né dans une famille de la petite bourgeoisie française en 1921. Placé sous l'éducation des frères maristes dont il conservera le sens d'un travail rigoureux et bien organisé ${ }^{702}$, il développera aussi un certain anti-conformisme et une certaine défiance par rapport à l'ordre établi et aux institutions étatiques qui le rapproche peut être de l'esprit zazou de sa génération. Pendant la seconde guerre mondiale, en 1941 ou 1942, il déserte de l'armée française qui répond alors aux ordres de Vichy et tente de fuir par l'Espagne. Fait prisonnier par les autorités franquistes lors de sa traversée des Pyrénées, il restera incarcéré pendant près de deux ans dans les camps espagnols. À la fin de la guerre, il dirige une troupe de théâtre itinérante appelée Les Chevaliers errants. Ses membres qui se promènent pieds nus et avec de longues capes noires s'amusent à « effrayer le bourgeois ». Parallèlement, Antoine écrit des histoires dans une revue destinée aux enfants ${ }^{703}$. Jusqu'à cette époque, le français n'a aucun contact avec le monde du cinéma. Dans les années 50, il fréquente le quartier St Germain qui est alors le lieu d'une intense effervescence artistique ${ }^{704}$. En 1955, Claude Antoine s'inscrit au registre des métiers du tribunal de commerce de la

701Du propre aveu des personnes interrogées, souvent évasives quant aux origines du producteur français, tous ignoraient d'où il venait et notamment qu'il avait été cinéaste lui-même. Claude Antoine apparaît comme un personnage un peu mystérieux. Zelito Viana qui collabore avec lui entre 1967 et 1972 déclare : « As lendas eram muitas, mas as verdades não posso lhe dizer direito. Sei que era adepto do nudismo. Diziam que fora paraquedista do exército francês, e por aí afora. » («Les légendes étaient nombreuses, mais la vérité je ne la connais pas vraiment. Je sais qu'il était adepte du nudisme. On disait qu'il avait été parachutiste dans l'armée française et ainsi de suite. ») in Zelito Viana. Réponse à un questionnaire de l'auteur par courriel, 27 mai 2004. Carlos Diegues qui reconnaît avoir reçu du français une aide providentielle pendant son exil à Paris m'a d'abord écrit : « De todo modo, não tive mesmo muitas relações profissionais com Claude Antoine, ele era mais ligado a Rocha, em cujos arquivos você deve encontrar documentos importantes; (3) Em meus arquivos pessoais, não tenho nada de importante sobre o assunto, não posso lhe ser muito útil; (4) No entanto, conheço o papel importante que Claude Antoine teve na divulgação do cinema brasileiro na Europa, posso responder às suas perguntas se você enviá-las por email, permitindo-me assim respondê-las a qualquer hora, de qualquer dia; (5) No Brasil, as pessoas que melhor podem testemunhar sobre Claude Antoine são Luis Carlos Barreto e Zelito Viana, com quem Claude teve relações mais intensas e duradouras. » (« De toute façon, je n'étais pas très lié professionnellement à Claude Antoine, il était beaucoup plus lié avec Rocha dans les archives duquel vous devriez trouver des documents importants ; (3) Dans mes archives personnelles, je n'ai rien d'important sur le sujet, je ne peux pas vous être très utile ; (4) Cependant, je connais le rôle important de Claude Antoine dans la divulgation du cinéma brésilien en Europe et je peux répondre à vos questions si vous me les envoyez par e-mail, me permettant ainsi d'y répondre n'importe quel jour, à n'importe quelle heure ; Au Brésil, les personnes qui peuvent le mieux témoigner sur Claude Antoine sont Luis Carlos Barreto et Zelito Viana, avec qui Claude a eu des relations plus longues et plus intenses. ») in Carlos Diegues. Réponse à un questionnaire de l'auteur par courriel, 3 juin 2004. Barreto m'a quant à lui dressé exactement le même portrait que celui que m'avait déjà fait Viana. Luiz Carlos Barreto. Entretien avec l'auteur, septembre 2004.

702Le classement de ses archives privées est impeccable. Tous les documents sont classés par film, par distributeur ou par laboratoire dans des chemises distinctes. À l'intérieur de chaque chemise, les papiers sont rangés dans l'ordre chronologique.

703Dedy Lherm nous a montré des coupures de presse se référant à ces deux activités.

704C'est aussi au cours de cette décennie qu'il rencontre Dedy Lherm mais ce n'est qu'à partir des années soixante qu'ils vivront en couple. Plasticienne, Dedy Lherm s'est d'abord mariée avec un cinéaste américain avec qui elle aura une fille. Claude Antoine et Dedy Lherm ne se marieront pas mais ils ne se quitteront pas entre le début des années soixante et son décès des suites d'un cancer en 1987. 
Seine, «Objet du commerce : production de films de court métrage $»^{705}$. La démarche est inhabituelle mais elle marque le début de sa carrière de réalisateur et de négociateur avec le monde du cinéma et de la télévision. Ses productions sont toujours précédées d'un budget rigoureux et de l'assurance de la vente des films. Le côté bohème du personnage est équilibré par un grand pragmatisme qui en fera un vendeur redouté. Six films sont produits, Le P'tit Train (1955), Paris cette inconnue (1957), Conte sur le sable (1959), Jeanne au vitrail (1960) et Fugue à Lesbos (1961) ${ }^{706}$. Tous seront primés et certains passeront sur l'ORTF.

D'une décennie à l'autre, Claude Antoine commence à fréquenter les festivals du cinéma, en partie pour défendre ses propres films et en partie pour le plaisir. Selon le témoignage de sa compagne Dedy Lherm $^{707}$, son premier contact avec le Cinema Novo se fait au festival de Biarritz au début des années soixante. Son enthousiasme est tel que le critique Novais Teixeira lui suggère de se mettre en relation avec les cinemanovistas et de s'occuper de la commercialisation de leurs films en Europe ${ }^{708}$. Claude Antoine ne possède cependant aucune infrastructure et ne peut compter que sur la modeste expérience de commercialisation de ses propres films. Quoiqu'il en soit, au Festival de Cannes de 1964, il est introduit auprès de Barreto, Diegues et Rocha par Francisco de Almeida Salles que nous avons déjà cité et qui travaillait à l'ambassade du Brésil à Paris ${ }^{709}$. Le français obtient la confiance immédiate des brésiliens en concluant la vente de Vidas Secas lors de cette première rencontre ${ }^{710}$. Malgré leur succès critique, les négociants européens étaient loin de s'arracher les films du Cinema Novo qui, de leur côté, ne disposaient d'aucune infrastructure commerciale de promotion ${ }^{711}$. La

705 « Inscription au registre des métiers du tribunal de commerce de la Seine ». Document officiel daté du 13 avril 1955, archives privées de Claude Antoine.

706Aujourd'hui, ces films sont disponibles à la Cinémathèque de Toulouse. Le P'tit Train est un documentaire sur le train jaune de Cerdagne à la frontière franco-espagnole dans le Languedoc-Roussillon. Paris cette inconnue est un film sur les petits métiers de rue en voie de disparition dans les années cinquante. Conte sur le sable est un film d'animation réalisé avec des personnages et des décors de la fabrication de Dedy Lherm. Tous les films dénotent une grande sensibilité artistique.

707Dedy Lherm. Entretien avec l'auteur, juin 2004.

708Ici, le témoignage de Dedy Lherm recoupe celui de Zelito Viana. In Zelito Viana. Réponse à un questionnaire de l'auteur par courriel, 27 mai 2004.

709Carlos Diegues. Entretien avec l'auteur, septembre 2004. Zelito Viana. Entretien avec l'auteur, septembre 2004.

710Luiz Carlos Barreto. Entretien avec l'auteur, septembre 2004.

711Dans un article de 1964, de retour de Cannes, Diegues analyse la situation : « O aluguel de um stand na Croisette é de 150 dólares ; um mastro custa 100 dólares ; a exposição no 'Palais du Festival' de algumas fotos e cartazes, 150 ; o aluguel de uma sala de exibição varia de 50 a 100 ; o anúncio no 'Bulletin d'information' oficial, 200 ; um coquetel simples, sem muito luxo, em qualquer hotel que não faça vergonha para apresentar a delegação a outros países, nunca menos de 1000 dólares. E isso é o mínimo a se fazer. Mas acontece que para quem compra dólar a 1300 cruzeiros o mínimo é demais, e os produtores que conseguem fazer no Brasil um filme com orçamentos de 20 a 30 milhões, não têm possibilidade de gastar metade disto em cada Festival a que compareçam. Acaba custando o preço de um outro filme. » (« Le loyer d'un stand sur la Croisette est de 150 dollars ; un mastro coûte 100 dollars ; l'exposition au 'Palais du Festival' de quelques photos et affiches, 150 ; le loyer d'une salle de projection varie entre 50 a 100 ; l'annonce dans le 'Bulletin d'information' officiel, 200 ; un simple cocktail, dans n'importe quel hôtel, sans beaucoup de luxe mais qui ne fasse pas honte au moment de se présenter à la délégation d'autres pays, jamais moins de 1000 dollars. Et ceci est le moins qui puisse se faire. Mais il arrive que pour quelqu'un qui achète le dollar à 1300 cruzeiros, le 
description de la réception de Deus e o diabo na terra do sol par le public de la Croisette en dit long quant aux résistances qu'il restait encore à vaincre :

«Deus e o diabo foi um grande sucesso mas um grande sucesso dividido. Metade do público não entendeu nada, entendeu ? Me lembro dessa sessão de Cannes que é uma sessão que não vou me esquecer nunca, a sala estava cheia evidentemente, um filme em competição, e aos poucos você via as pessoas saindo da sala e você via que as pessoas estavam perplexas, como se tivessem visto um filme marciano ! Era uma coisa completamente... era uma geografia física e humana que nunca tinha sido visto no cinema. Eu acho que além da qualidade artística do filme, havia um choque cultural. Aquela música, aquelas pessoas, aqueles personagens, os cangaceiros, aqueles chapéus, aquela paisagem, eram coisas absolutamente inéditas no cinema, entendeu ? E as pessoas ficavam perplexas diante daquilo. E mesmo a metade que ficou no cinema, aplaudia freneticamente no final mas você via pela cara deles que também não tinham entendido direto, entendeu ? Havia um espécie de choque mesmo, um estado de choque... $»^{712}$

Vidas secas avait été beaucoup plus facilement assimilé mais il n'en restait pas moins un film au rythme très lent marqué par la raréfaction de l'action et des dialogues. En un mot, il ne s'agissait pas d'un film « commercial». Selon le témoignage de Barreto, la vente du film par un personnage surgi de nulle part crée un véritable enchantement. Antoine réussit là où, seuls, ils avaient jusque là tous échoués. À partir de ce moment-là, il s'instaure entre le français et le Cinema Novo une relation qui ne va pas évoluer jusqu'à la rupture du début des années soixante-dix. Antoine va se distinguer par ses qualités exceptionnelles de vendeur et un intérêt indéfectible pour le meilleur cinéma d'auteur brésilien. Il pourra cependant apparaître aux uns et aux autres qu'il n'était pas la solution idéale. Sans infrastructure, Antoine va agir en marchand, Viana écrit à Rocha qu'à Paris, il est appelé de façon méprisante « l'épicier » ${ }^{713}$. Selon Viana, le Cinema Novo a connu d'autres interlocuteurs en Europe mais l'étude de ses archives privées montre qu'Antoine a été responsable de quasiment la totalité des ventes de films réalisés à l'étranger avec des contrats qu'il a reconduit jusque dans les années quatre-vingt. Sur la relation qui s'instaure alors, Viana a cette déclaration assez significative :

minimum est déjà trop cher et les producteurs qui réussissent à faire au Brésil un film avec 20 ou 30 millions , ne peuvent se permettre de dépenser la moitié de cette somme à chaque festival. Il finirait par en coûter le prix d'un nouveau film. ») in DIEGUES, Carlos. « Cannes ainda tem domínio sobre cinema » in Tribuna, Rio de Janeiro, 9-10/05/1964.

712 «eus e o diabo a été un grand succès mais un succès divisé. La moitié du public n'a rien compris, tu comprends? Je me souviens de cette projection à Cannes que je n'oublierai jamais, la salle était pleine, évidemment, un film en compétition, et, après quelque temps, le public a commencé à sortir de la salle et on voyait qu'elles étaient perplexes comme si elles avaient vu un film de martiens ! C'était une chose complètement... c'était une géographie physique et humaine qui n'avait jamais été vue au cinéma. Je crois qu'au-delà de la qualité artistique du film, il y avait un choc de cultures. Cette musique, ces personnes, ces personnages, les cangaceiros; ces chapeaux, ce paysage étaient des choses complètement inédites au cinéma. Et les personnes sont restées perplexes face à cela. Même la moitié des spectateurs qui étaient restés dans la salle et applaudissaient frénétiquement, il était visible sur leurs visages, qu'il n'avait pas bien compris ce qu'ils avaient vu. Il y avait vraiment une espèce de choc, un état de choc... » in Carlos Diegues. Entretien avec l'auteur, septembre 2004. Zelito Viana. Entretien avec l'auteur, septembre 2004.

713Sans lieu, sans date (entre 1969 et 70, quand GR est avec Rosa Maria Pena), lettre de Zelito Viana à Rocha, manuscrite, en portugais, sans en-tête, archives Tempo Glauber. 
« Não sei, pois quando o conheci ele já era conhecido do resto do pessoal do cinema novo. O que sei é que sempre tentávamos outro distribuidor mas sempre acabávamos nas mãos do Claude pois, apesar de tudo era o único que verdadeiramente se interessava pelo cinema brasileiro $»^{714}$.

Le premier film sur lequel Antoine travaille est Vidas secas pour lequel il fait un déplacement jusqu'au festival de Moscou. Nous n'avons retrouvé dans ses archives aucun contrat se référant à ce film mais Dedy Lherm nous a signalé que ses archives étaient incomplètes en raison d'un vol dont il avait été victime en Espagne au début des années soixante-dix. Il existe cependant un cahier de relevé des différents contrats signés rédigés par Antoine lui-même. Selon ce document, il a réussi à signer 12 contrats de vente du film dont le plus important portait sur un montant de $10000 \$$ avec les pays socialistes ${ }^{715}$. Il s'agit d'ailleurs à notre connaissance du seul contrat de vente signé avec l'URSS. Malgré les ventes de Vidas secas, les débuts d'Antoine sont difficiles et ses trois premières années d'activité seront des années de prospection. Comme lui-même ne possède ni fortune personnelle, ni activités professionnelles qui lui apporteraient la mise en fond nécessaire lui permettant de tisser ses propres réseaux en attendant le fruit des ventes, les cinemanovistas vont lutter afin qu'il soit employé par l'Itamaraty. Pratiquement deux ans seront nécessaires avant que Carrilho réussisse à lui obtenir un poste pour lequel il recevra un traitement mensuel de $500 \$$ et qu'il conservera un an. Au tout début de ses activités, Antoine se sert de l'ambassade du Brésil à Paris comme base de travail ${ }^{716}$ mais très vite il s'organise de façon indépendante et fonde sa propre entreprise « Claude Antoine Filmès - Promotion du cinéma brésilien » qui aura une adresse à Paris et une autre à Rio de Janeiro. Ses activités lui imposent de fréquents voyages dans toute l'Europe et au Brésil où il vivra partiellement pendant près de 10 ans.

Dans les premiers temps, la correspondance échangée entre Antoine et Rocha montre que le français ne partage pas les ambiguïtés des brésiliens quant à la nature de leur propre cinéma qu'il traite immédiatement comme un cinéma d'art et d'essai nécessitant à ce titre une promotion adaptée. Plusieurs de ses voyages sont vains et le confrontent à des interlocuteurs

714 « Je ne sais pas. Car, quand je l'ai connu, il était déjà connu des autres membres du Cinema Novo. Ce que je sais, c'est que nous cherchions à chaque fois à trouver un autre distributeur mais que nous finissions toujours par nous en remettre à Claude car il était le seul qui s'intéressait vraiment au cinéma brésilien. » Zelito Viana. Réponse à un questionnaire de l'auteur par courriel, 27 mai 2004.

715 Nous avons découvert dans un document de la police politique brésilienne une mention quant à l'achat du film par les pays socialistes. Les agents du DOPS y voyaient comme une tentative de financement occulte du Cinema Novo par Moscou. Les soviétiques auraient chercher à soutenir financièrement un groupe de cinéma dédié à la diffusion d'une idéologie subversive. Il s'agit en fait d'un pur délire paranoïaque, Vidas secas est le seul film du Cinema Novo à avoir été vendu en URSS. Le nombre total de contrats signés avec les pays de l'Est est inférieur à ceux signés avec le France ou la RFA qui ont été, de loin, les meilleurs clients de Claude Antoine. Des pays du bloc communiste, seul Cuba a été un lieu de diffusion et de discussion du Cinema Novo en grande partie grâce à Alfredo Guevara, président de l'ICAIC.

716Carlos Diegues. Entretien avec l'auteur, septembre 2004. 
absolument rétifs à ce qu'il leur propose, non pas qu'ils jugent les films mauvais, mais ils ne sont pas commerciaux. L'absence de prestige commercial du Cinema Novo contraint également à envisager d'accepter des contrats financièrement peu intéressants dont l'objectif est juste de permettre un premier positionnement dans le marché. Ainsi, dans une de ses premières lettres à Rocha, Antoine écrit :

« Je préfère te dire sincèrement qu'il ne faut pas espérer faire de grosses recettes en Europe avec ton film [Deus e o diabo na terra do sol]. Le cinéma en Europe est en récession et non pas en expansion comme au Brésil. [...] Pour placer un film, il faut faire de gros efforts, beaucoup de projections. Pour cela, il faut beaucoup d'argent. [...] Je te parle franchement et amicalement comme j'ai parlé à Barreto, Diegues, Guerra... N'oubliez pas qu'il faut moins d'argent proportionnellement, pour lancer des 'merdes ' avec Bardot, Sinatra ou Liz Taylor, que pour diffuser un très bon film brésilien sans vedettes ou sans publicité organisée autour du cinéma brésilien. $\gg^{717}$

Malgré les résistances offertes par le marché, Antoine va finir par trouver ses marques mais il doit aussi composer avec la débilité financière de ses partenaires brésiliens pour lesquels le moindre frais s'avère insurmontable. Ainsi, au cours du dernier semestre de l'année 1966, il lui est impossible d'assurer la représentation de Menino de engenho en Europe car la réalisation des sous-titrages apparaît dans un premier temps trop coûteuse $\mathrm{e}^{718}$. De même, la sortie parisienne de Deus e o diabo na terra do sol initialement programmée le 5 octobre est annulée car le producteur Jarbas Barbosa n'a pas envoyé les copies assez vite pour que le sous-titrage puisse être effectué dans les temps. Dans ces lettres de la fin de l'année 1966, les griefs d'Antoine contre Barbosa ne cessent d'ailleurs de se multiplier puisque celui-ci n'envoie jamais le matériel dans les délais mettant en péril les contrats qui sont signés avec la France, la Tchécoslovaquie et la $\mathrm{RFA}^{719}$. Dans une lettre de Diegues à Rocha du mois d'octobre, le réalisateur de Ganga Zumba décrit aussi ce qui passe pour une escroquerie grossière de la part de Barbosa : Claude Antoine a retourné des factures que le premier aurait fait de sa propre main en mentionnant des prix deux fois plus grands que ceux pratiqués à Paris pour des frais de laboratoire devant être payés par des allemands ${ }^{720}$. Il apparaîtra par la suite que les tarifs étaient effectivement beaucoup plus élevés au Brésil qu'en France. Quoiqu'il en soit, afin de maîtriser au maximum les impondérables liés à la spécificité de la situation brésilienne,

717Lettre de Claude Antoine à Rocha. Paris, 10/08/1964.

718Lettre de Claude Antoine à Rocha. Paris, 28/09/1966.

719Lettre de Claude Antoine à Rocha. Paris, 10/08/1966; lettre de Claude Antoine à Rocha. Paris, 23/09/1966 ; lettre de Claude Antoine à Rocha. Paris, 28/09/1966.

L'insatisfaction de Claude Antoine vis à vis de Jarbas Barbosa est sans doute à mettre en relation avec la négociation des droits de Deus e o diabo na terra do sol par Rocha avec ses anciens producteurs. En 1968, un accord passé avec Augusto Mendes et Jarbas Barbosa fait du cinéaste l'unique propriétaire des droits du film. Les documents se référant aux transactions réalisées autour du film confirme ce changement de statut que Rocha annonce à Claude Antoine dans une lettre de mars 1968. Voir ROCHA, Glauber. Cartas ao mundo. Op. cit., pp. 312-314.

720Lettre de Carlos Diegues à Rocha, manuscrite, en portugais, sans en-tête, Paris, le 08/10/1966. 
Antoine ira jusqu'à s'assurer la garde des négatifs ${ }^{721}$ et fera réaliser tous les travaux de laboratoire pouvant s'avérer utiles lui-même, supervisant ainsi personnellement copie, doublage ou sous-titrage des films.

Les affaires démarrent vraiment en 1966. Agissant en tant que «mandataire exclusif» de la production selon des contrats qui définissent les territoires de prospection qui lui sont attribués et les commissions à percevoir pour son travail, Antoine va s'occuper de 22 films du Cinema Novo et conclure, en un peu moins de 25 ans, 165 contrats permettant d'assurer leur diffusion au quatre coins du globe avec une nette prédominance de l'Europe et de l'Amérique du Nord. Ces 22 films, parmi lesquels nous comptons les plus importants longs métrages du Cinema Novo, alimentent la quasi totalité de son activité professionnelle. Claude Antoine va en effet représenter 47 films et obtenir la signature de 201 contrats mais, sur ces 47 films, 11 seulement ne sont pas des films brésiliens et ils ne correspondent qu'à 3 contrats de vente. Les 14 autres films brésiliens dont il s'occupe sont immédiatement périphériques au Cinema Novo. Son catalogue est constitué de l'intégralité de la filmographie de Rocha à l'exception de A Idade da terra ${ }^{722}$ ainsi que d'autres films importants de la cinématographie brésilienne comme A Hora e a vez de Augusto Matraga (Roberto Santos, 1965), Cara a cara (Júlio Bressane, 1968), Jardim de guerra (Neville de Almeida, 1969) et surtout Iracema, uma transa amazônica (Orlando Senna, Jorge Bodansky, 1976) dont il assure la commercialisation alors même que le long métrage est interdit au Brésil. Au travers du choix des films qu'il défend, le français manifeste une véritable prédilection pour le cinéma d'auteur le plus exigent et les thématiques sociales et politiques. À aucun moment, Antoine ne s'est intéressé à réaliser un coup commercial en exploitant un film à l'esthétique consensuelle. Nous pensons par exemple à un film du type de Todas as mulheres do mundo (Domingos de Oliveira, 1967),

721 À l'époque où il rédige son cahier d'état des ventes, les négatifs ou contretypes des films suivants sont en Europe : Vidas secas, Deus e o diabo na terra do sol, Os Fuzis, Ganga Zumba, A Grande Cidade, Menino de engenho, Terra em transe, O Dragão da maldade contra o santo guerreiro et Barravento.

722Les documents de l'époque montrent qu'Embrafilme se défiait de Claude Antoine et a catégoriquement refusé qu'il prenne en main la commercialisation du film. L'entreprise de cinéma brésilienne avait pris l'habitude de traiter avec Gaumont pour ses propres productions. Le film n'a pas été distribué commercialement à l'extérieur du Brésil avant 2006. Lettre de Claude Antoine à Rocha, manuscite, sans en-tête, St Ouen, le 13/02/1980. Claude Antoine propose de s'occuper du nouveau film de GR de le faire vendre en Allemagne et de le présenter à Cannes selon la stratégie déjà employée avec Molière d'Ariane Mnouchkine.

Lettre de Claude Antoine à Rocha, dactylographiée, sans en-tête, sans lieu, le 28/05/1980. Claude Antoine discute de la stratégie de vente de $A$ Idade da terra et de sa rencontre avec Celso Amorim et Peregrino à Cannes qui s'opposent à son intervention sous prétexte que le film appartient à Embrafilme. Énumère les erreurs d'Embrafilme et mentionne un travail de distribution avec un film produit en Colombie. À ce moment là, Claude Antoine n'a pas encore vu le film et conseille de le montrer à Venise.

Resumo da situação dos filmes de Rocha. 3 feuillets dactylographiées rédigés par les services d'Embrafilme dressant l'état des lieux des droits et des contrats en cours sur la filmographie du cinéaste juste après sa mort, sans lieu, sans date, archives privées de Claude Antoine. Le document démontre la méfiance d'Embrafilme à l'égard du français mais aussi d'une certaine confusion dont le cinéaste était lui-même en grande partie responsable en raison d'un manque de rigueur dans la gestion de ses affaires, en particulier dans les cinq dernières années de sa vie. 
une comédie romantique qui a connu un grand succès commercial au Brésil et qui aurait certainement pu s'exporter en Europe et en Amérique du Nord.

Le plus gros des ventes est réalisé entre 1966 et 1972. La réalisation de plaquettes de présentation de Terra em transe par Antoine pour le festival de Cannes 1967 démontre qu'il a atteint à cette date un niveau d'organisation avancé ${ }^{723}$. Lherm témoigne qu'ils tiennent alors tous les deux un stand sur la Croisette du festival de Cannes elle-même consacrant ses compétences de plasticiennes à la réalisation d'affiches inédites. Terra em transe est le premier film dont Antoine s'occupe en amont et non plus seulement après que sa carrière dans les festivals ait déjà débutée. Le nombre total de contrats signés dans cette période, c'est à dire pendant l'existence du Cinema Novo (1964-1972), atteint 134. Les modalités de cession des droits de distribution sont définies dans des contrats types ${ }^{724}$ et obéissent à des règles simples. Les droits sont cédés pour une durée variant généralement entre 5 et 10 ans pour un territoire précis et un type d'exploitation particulier. Certains contrats prévoient que le distributeur devra se restreindre à l'exploitation cinématographique traditionnelle, d'autres au contraire ouvrent des droits sur des supports de diffusion qui «n'ont pas encore été inventées ${ }^{725}$. Le distributeur peut obtenir ces droits en échange d'une valeur forfaitaire qui le dispensera ensuite d'avoir à rendre des comptes au producteur. C'est le cas pour les pays dont le marché est peu porteur. Dans le cas des marchés plus importants, les contrats mentionnent le paiement d'une avance au producteur et règlent le partage des bénéfices obtenus par le distributeur pour toute la durée pendant laquelle il conserve les droits du film.

La France, la RFA (qui assure souvent la distribution dans les pays germanophones à l'exception de la RDA) et Cuba sont les clients les plus réguliers du Cinema Novo. Le contrat le plus intéressant sera cependant conclu en 1969 avec le groupe nord-américain Grove Press qui paie une avance non remboursable de 50000 US\$ afin d'acquérir les droits de distribution de $O$ Dragão da maldade contra o santo guerreiro pour les USA et le Canada ${ }^{726}$. Ce dernier film est d'ailleurs de très loin le film le plus vendu par Antoine. 34 contrats sont conclus dont 24 datent de la période qui a immédiatement suivi son passage à Cannes, les 10 autres étant des renouvellements de droits ou des contrats de diffusion télévisée. Arrivent en deuxième position Terra em transe avec 18 contrats et, en troisième position, Deus e o diabo na terra do sol avec 17 contrats juste devant Os Fuzis et ses 16 contrats. La part belle des contrats

\footnotetext{
723La qualité du document, couverture cartonnée, papier glacé, travail esthétique de présentation et de mise en page, est sans relation avec les press releases alors distribués au Brésil et qui sont en fait de simples feuillets dactylographiés.

724Antoine utilise les formulaires de la Chambre Syndicale de la Production Cinématographique Française. 725La reproduction et la vente sous la forme de vidéocassettes est envisagée bien avant que le produit n'existe. 726Contrat de vente des droits de distribution de Antônio das Mortes à Grove Press. Document dactylographié, 8 feuillets, 1969, archives privées de Claude Antoine.
} 
signés par Antoine va à Rocha. Sur les 165 contrats concernant des films du Cinema Novo, 80 portent sur ses films : Barravento, Deus e o diabo na terra do sol, Terra em transe et $O$ Dragão da maldade contra o santo guerreiro. 14 autres contrats portent sur Câncer, Der Leone have sept cabeças et Cabezas cortadas.

Parallèlement à cette activité de représentation, Antoine s'investit directement dans la production de deux films du Cinema Novo, O Dragão da maldade contra o santo guerreiro et Brasil ano 2000. Dans les deux cas, il participe directement au montage financier selon des modalités que nous avons déjà décrites dans le chapitre consacré au premier long métrage. Ses activités de producteur se prolongeront avec Der Leone have sept cabeças qui est le seul film pour lequel il se rend sur le plateau de tournage (au Congo) ${ }^{727}$ et bien plus tard avec Gamín, un documentaire de Ciro Durán sur les enfants des rues en Colombie (1978). C'est pourtant dans cette même période où les relations d'Antoine avec le Cinema Novo s'intensifient et apportent leurs plus grands bénéfices que les premières dissensions apparaissent. Le partenariat avec le français manque d'être rompu une première fois pendant la production de O Dragão da maldade contra o santo guerreiro ${ }^{728}$. La rupture ne se réalisera cependant qu'en 1972 quand Viana décide de ne plus travailler avec lui en raison de la commission trop élevée qu'il lui demandait pour la vente d'un film de Diegues. À partir de cette date, seul Rocha restera fidèle à Antoine et continuera à travailler avec lui. Selon Viana, les griefs allant à l'encontre d'Antoine sont ceux classiques que nous retrouvons dans les affaires du cinéma. Il était reproché au français de ne pas bien rendre compte des opérations qu'il réalisait au nom du Cinema Novo et de détourner des sommes qu'il aurait dû repasser aux producteurs dont il était le délégué. Cette suspicion des cinemanovistas à l'égard de Claude Antoine était alimentée par son train de vie dont ils avaient été témoins lors de leurs visites en France au

727Lettre de Rocha à Claude Antoine, Brazzaville entre septembre et octobre 1969. In ROCHA, Glauber. Cartas ao mundo. Op. cit., p. 350.

728Un certain nombre de correspondances inédites ou déjà publiées l'indique : Lettre de Adrienne Mancia (Museu of Modern Art) à Rocha, Johnny Amico, Carlos Diegues, au consul Bassos et au ministre Carlos Jacyntho de Barros. New York, 21/08/1968, archives Tempo Glauber. Leon Hirszman rencontré à Pesaro (où Rocha n'est donc pas allé) a informé Mancia que les brésiliens avaient rompu avec Claude Antoine (sans plus) et demande donc à Rocha de prendre la responsabilité d'être son interlocuteur principal pour la réalisation d'une rétrospective du cinéma brésilien. Ce courrier succède à d'autres lettres témoignant de l'insatisfaction des cinemanovistas envers Claude Antoine sans que cette insatisfaction soit vraiment expliquée :

Lettre de Carlos Diegues à Rocha, dactylographiée, en portugais, sans en-tête, Rio de Janeiro, le 20/04/1968. Évoque le projet de LC Barreto de quitter le Brésil et de monter la Difilmexport et donc... de se passer de Claude Antoine car « Não se pode mais atuar as babaquices de Claude » (sans plus de détails) et parce que celui-ci préparerait une chaîne de cinémas d'Arts et d'essais au Brésil dans et sur le dos du CN ! Lettre de Rocha à Claude Antoine, Rio de Janeiro, le 31/05/1968. S'inquiète de l'existence du contrat avec l'ORTF et du fait que MAPA soit exclu du contrat qui est signé avec Claude Antoine Filmès. In ROCHA, Glauber. Cartas ao mundo. Op. cit., p. 316.

Lettre de Rocha à Claude Antoine, Rio de Janeiro, sans date, et lettre de Rocha à Claude Antoine, sans lieu, sans date. Divergences sur le cachet proposé pour la réalisation de la série télévisée Antônio das Mortes. In ROCHA, Glauber. Cartas ao mundo. Op. cit., pp. 318-321. 
cours desquelles le français les avait reçus. Dedy Lherm nous a confirmé qu'ils menaient effectivement une vie bourgeoise et qu'Antoine s'était enrichi grâce à ses activités de producteur délégué. Aujourd'hui, Dedy Lherm mène au contraire une existence modeste. Aucun document ne nous permet d'infirmer ou de confirmer les suspicions des cinemanovistas mais plusieurs éléments évidents ont certainement facilité l'entretien de préjugés négatifs à l'encontre du français.

Cette dispute n'aurait pour nous aucun intérêt si elle ne révélait avant tout une différence profonde d'approche entre l'agent du Cinema Novo en Europe et ses commanditaires. Il y a bien sûr des raisons d'ordre personnel voire affective au différend ${ }^{729}$, mais fondamentalement, de la même façon qu'Antoine ne partageait pas la même approche que les cinemanovistas de leurs propres films et n'a pas cru un instant qu'ils pourraient être traités comme des films «populaires » destinés au grand public, Antoine n'a pas travaillé seulement pour le plaisir mais aussi pour vivre et gagner de l'argent. Cette démarche semble évidente mais elle peut apparaître assez choquante pour des cinéastes qui paient pour faire leurs films et ont le plus grand mal à s'en sortir financièrement avant l'arrivée d'Embrafilme. Le français est aussi un personnage qui ne partage pas les ambiguïtés de ses partenaires quant à la valeur marchande du Cinema Novo. De la même façon qu'il le considère dès le départ comme un cinéma d'art et d'essai, il sait bien, pour y être directement confronté, les résistances offertes par le marché à ce type de cinéma. Aujourd'hui encore, la valeur de l'œuvre du Cinema Novo est quasiment nulle pour les décideurs économiques et ceux-ci, comme dans les années soixante, sont loin de se bousculer pour restaurer et redistribuer les films au cinéma ou sur d'autres supports ${ }^{730}$. Malgré cela, les admirateurs et les proches des cinéastes s'imaginent que les films valent de l'or et ne comprennent pas pourquoi la valeur

729Tous les témoignages concordent pour décrire un personnage froid et sarcastique à l'opposé du tempérament brésilien plus chaleureux mais parfois hypocrite. Certainement déçu par certains aléas connus dès le début de ses affaires avec les brésiliens, dont certains que nous avons déjà évoqués, Antoine a pu reprocher un certain manque de « sérieux » à ses partenaires. Rocha lui-même évoque le côté sarcastique du personnage dans un de ses courriers (In ROCHA, Glauber. Cartas ao mundo. Op. cit., p. 316). À plus long terme, l'amitié et la confiance indéfectibles du principal cinéaste du Cinema Novo pour celui qu'il considérait comme « l'agent du Cinema Novo en Europe » a pu susciter les jalousies.

730Hors et après Claude Antoine, la distribution du Cinema Novo dans le monde est pratiquement nulle. Notons par exemple que les deux rééditions en dvd des films de Rocha ne sont pas distribués en France (ni dans aucun autre pays hors du Brésil). Notons également que sur ces vingt dernières années, il aura fallu atteindre l'année du Brésil en France (2005) pour revoir des films de Rocha à la télévision française (Antônio das Mortes a été diffusé dans le cadre d'un très court cycle du cinéma brésilien sur France 2 en troisième partie de soirée et Deus e o diabo na terra do sol a été diffusé sur LCP entre $18 \mathrm{~h} 30$ et 20h30). Ces diffusions succèdent à celles d'Antônio das Mortes datant de 1993 sur La 7 et Antenne 2 aux alentours de 23h. En dehors des films de Rocha, aucun film du Cinema Novo n'a été programmé à la télévision française à l'exception de Os Fuzis sur Arte. Aucune sortie sur format vidéo n'est à signaler et aucun nouveau lancement cinéma non plus à l'exception de celui d'Antônio das Mortes le 6 juillet 2006. La France ayant été l'un des marchés les plus ouverts au Cinema Novo avec le marché allemand, il est probable que la situation dans les autres pays soient encore pire et que les cinéastes brésiliens soient tombés dans un assez large oubli. 
artistique des œuvres ne correspondrait pas directement à leur valeur économique ${ }^{731}$. Dans toute l'histoire du Cinema Novo, Antoine est l'un des rares personnages qui a compris que cette valeur devait être travaillé à l'aide de stratégies adaptées. Conséquemment, il fut aussi l'un des rares sinon le seul à tirer un profit personnel et substantiel de la vente des films ${ }^{732}$.

Quels furent les bénéfices, pour le Cinema Novo, du travail de Claude Antoine ? Il est difficile de calculer les sommes qu'il a fait gagner aux cinemanovistas en raison des variations de valeur des monnaies et de l'ensemble des variables entrant en jeu ${ }^{733}$. Malgré les différends aujourd'hui passés, l'ensemble des personnes que nous avons interrogées concordent cependant pour admettre que, si le Cinema Novo n'aurait pas pu vivre des sommes repassées par Antoine, celles-ci ont néanmoins constituées une aide appréciable permettant souvent de conclure le remboursement des prêts contractés pour des films déficitaires sur le marché brésilien. L'activité du français a également permis pour $O$ Dragão da maldade contra o santo guerreiro la finalisation de l'un des montages financiers les plus avantageux de l'histoire du Cinema Novo puisque, pour une fois, le film était en grande partie déjà remboursé avant de connaître l'épreuve du marché. Les principaux mérites de Claude Antoine ne seront pas seulement d'ordre économique. En tant qu'artisan du plus grand succès international du Cinema Novo, il a également participé à augmenter le prestige culturel du groupe. Enfin et surtout, il a permis aux films de dépasser le cercle des happy few des festivals et de rencontrer un large public. Selon les chiffres que nous a communiqué le CNC, les entrées France connues sont les suivantes :

Terre en transe, visa 1967 - 48992 ;

Antônio das Mortes, 69 - 162724 ;

Le lion a sept têtes, 70 - 15435 ;

Têtes coupées, 71 - 7043 ;

Ganga Zumba, 67 - moins de 5000 ;

731La réédition, toujours en cours, des œuvres de Rocha a donné lieu à des controverses portant notamment sur les exigences disproportionnées des héritiers en termes financiers. En dernière instance, les exigences et les restrictions imposées par les familles finissent par nuire à la circulation et à la survie des œuvres. Une situation proche s'est produite avec les archives de Nelson Pereira dos Santos. Selon le témoignage de Lécio Augusto Ramos, un lieu avait été prévu à l'Universidade Federal Fluminense - UFF à Niterói pour permettre leur accès au public et lui-même avait participé à leur organisation. Au dernier moment, la fille du cinéaste a décidé de récupérer l'ensemble des documents qui devaient être ainsi mis en valeur et permettre, comme au Tempo Glauber, de donner accès à l'œuvre de l'un des plus grands cinéastes du Brésil. Elle attend une proposition financière à la hauteur de la valeur du patrimoine de son père. À ce jour, les archives sont toujours sous clef.

732Notons aussi qu'en devenant le mandataire exclusif des 22 meilleurs films du Cinema Novo (à l'exception de Como era gostoso o meu francês), Antoine se trouvait en situation de concentrer les gains apportés par la vente des longs métrages et, par voie de conséquence, il gagnait forcément plus que les cinéastes qui, au mieux, étaient les auteurs de quatre films chacun et « rejouaient» leurs profits, quant il y en avait, dans le film suivant.

733Calcul des frais qui sont, dans certains cas à déduire et dans d'autre non, nombre d'entrées et calcul des sommes correspondantes quand les contrats prévoient le retour d'un certain pourcentage au producteur. 
O Desafio, 67 - moins de 5000 ;

Les Fusils, 66 - 20036 ;

Macunaíma, 69 - 86460.

Sans surprise, le nombre d'entrées de certains films est plus que modeste, Macunaíma, Terra em transe et, surtout, Antônio das Mortes tirent cependant leur épingle du jeu avec des chiffres somme toutes appréciables. Selon Viana, le dernier film aurait été le film étranger (hors films US) à réaliser le plus d'entrées en France en 1969. Aux côtés de ces sorties cinéma, il faut aussi compter les diffusions télévisées touchant cette fois-ci plusieurs millions de téléspectateurs. Selon les informations communiquées par l'INA, Vidas secas a été diffusé le 22 août 1969 à $20 \mathrm{~h} 24$ sur la deuxième chaîne en VO et Antônio das Mortes, conformément à ce qui était prévu dans la convention signée avec l'ORTF, a été diffusé le 30 septembre de la même année à $20 \mathrm{~h} 05$ avec un rectangle blanc (interdit aux enfants). Inutile de préciser que la diffusion, sur une grande chaîne nationale, en prime time, de films de ce type est aujourd'hui parfaitement inimaginable, et, même pour l'époque, relève d'un véritable tour de force. Entre 1964 et 1972, Antoine s'affirme donc bien comme l'un des principaux artisans du succès du Cinema Novo dans le monde, succès qui le protégera dans son propre pays des attaques des censeurs et lui permettra ses plus grandes audaces. Entre 1964 et 68, il s'agira de O Desafio et Terra em transe, deux films isolés au sein de cette deuxième phase du Cinema Novo. 


\title{
Chapitre 8 : Le cinéma d'auteur d'agitation
}

Après la surprise et la peur, le troisième sentiment que suscite le coup d'État auprès des cinemanovistas est la perplexité. Avant avril 1964, le microcosme d'intellectuels progressistes auquel appartiennent les cinéastes, traverse une période d'espoir et même d'euphorie. Malgré les grandes difficultés économiques rencontrées pendant le gouvernement Goulart (78\% d'inflation en 1963), le rapprochement de la tête de l'État avec les socialistes les plus radicaux dont le PCB et l'intense mobilisation sociale donne l'impression que de grands changements sont sur le point d'être réalisés. Le pays semble être sur le bon chemin pour s'extirper du sous-développement. La sociologue Heloísa Buarque de Hollanda, qui a vécu ces années-là et appartenu à ce microcosme de l'intelligentsia progressiste, cite une phrase de Roberto Schwarz qui lui semble particulièrement représentative de l'état d'esprit de l'époque :

\begin{abstract}
«Houve um tempo, diz-nos Roberto Schwarz, em que o país estava irreconhecivelmente inteligente. ' Política externa independente ', ' reformas estruturais ', ' libertação nacional ', ' combate ao imperialismo e ao latifúndio' : um novo vocabulário - inegavelmente avançado para uma sociedade marcada pelo autoritarismo e pelo fantasma da imaturidade de seu povo - ganhava a cena, expressando um momento de intensa movimentação na vida brasileira. $»^{734}$
\end{abstract}

Le jargon et la rhétorique gauchistes se sont propagés dans les conversations quotidiennes. Selon Gustavo Dahl, la proximité de la gauche avec le pouvoir donnait réellement le sentiment de pouvoir infléchir le destin du pays ${ }^{735}$. L'enthousiasme est tel que le secrétaire-général du PCB, le fameux Luís Carlos Prestes, surnommé en d'autres temps le «cavalier de l'espérance» par l'écrivain Jorge Amado, se croit autorisé à déclarer à la télévision : « nous ne sommes pas au gouvernement mais nous détenons le pouvoir ». Le PCB est pourtant toujours à l'état de semi-clandestinité. Après le 1er avril, le réveil sera d'autant plus difficile que le rêve aura été intense. Il faudra du temps pour accepter et comprendre les événements. Il faudra aussi du temps pour savoir quelle attitude adopter face à une situation inattendue et complètement nouvelle.

Les cassations de mandats, les persécutions policières et la première vague d'exils marquent le retour de l'arbitraire et de la peur dans la vie de la société brésilienne. Tous ceux qui s'étaient investis dans le «processus révolutionnaire brésilien », qu'ils soient touchés ou

734 « Il y eu un temps, nous dit Roberto Schwarz, où le pays était incroyablement intelligent, ' Politique extérieure indépendante ', ' réformes structurelles ', ' libération nationale ', ' combat contre l'impérialisme et le latifúndio ' : un nouveau vocabulaire - incontestablement avancé pour une société encore marquée par l'autoritarisme et le fantasme d'immaturité de son peuple - envahissait la scène et signifiait l'intense animation de la vie brésilienne. » in HOLLANDA, Heloísa Buarque de, GONÇALVES, Marcos A. Cultura e participação nos anos 60. São Paulo, coll. Tudo é historia, n41, ed. Brasiliense, 1982, p. 8.

735Gustavo Dahl. Entretien avec l'auteur, février 2004. 
non par la répression, voient leurs perspectives bouleversées. Selon le témoignage d'Eduardo Escorel :

« [...] o golpe realmente foi como se mudasse a vida das pessoas, mudou tudo, a perspectiva de vida das pessoas, o que você achava que tinha sentido deixou de ter, o que você imaginava que sua vida seria deixou de ser... Foi como se virasse tudo pelo avesso. $\rangle^{736}$

Même si l'on pense que la dictature ne va pas durer, il semble impossible de rester indifférent aux exactions commises par le nouveau régime. La nécessité d'apporter une réponse appropriée s'impose même si en contrepartie la notion de risque est très présente. $O$ Desafio et Terra em transe sont deux films produits dans l'intention de réagir au coup d'État mais avec la crainte constante que les militaires empêchent leur réalisation puis leur diffusion.

\subsection{O Desafio}

Comme l'a bien résumé Alex Viany : «O Desafio é um dificílimo documentário subjetivo, existencial, em que o cineasta procura registrar as frustrações de um intelectual logo depois do dia $1^{\circ}$ de abril de 1964. $>^{737}$ C'est le premier film dans lequel est exprimée de façon claire et ostensible une opposition au régime militaire. Saraceni, dans la période ayant succédée au coup d'état, envisage d'abord un film «kamikaze » ${ }^{738}$ dans lequel il compte évoquer le conflit entre les étudiants de droite et de gauche, l'incendie criminel de l'immeuble de l'UNE $^{739}$ et la possible formation de mouvements de guérilla ${ }^{740}$. Il commence d'ailleurs à écrire un scénario contenant ces épisodes avec la poétesse Vera Pedrosa et son mari, l'économiste et commentateur politique, Luciano Martins. Mais, en cours de rédaction, il se ravise. Premièrement, il sait qu'un film incitant à prendre les armes ne passera pas la censure. Deuxièmement, il n'est pas sûr lui-même que la guérilla soit une bonne stratégie. Il choisit donc de resserrer sur l'argument initial du scénario tel qu'il l'avait proposé à Pedrosa au tout début de leur collaboration. Il coupe la partie de la rivalité entre les étudiants de droite et de

736« [...] le coup d'État a réellement changé la vie des personnes, il a tout changé, la perspective de vie des personnes, ce que vous pensiez avoir un sens a perdu toute signification, ce que vous imaginiez faire de votre vie a cessé d'exister... Tout a été totalement bouleversé. » Eduardo Escorel. Entretien avec l'auteur, août 2003.

737 \& Desafio est un documentaire subjectif, existentiel, dans lequel le cinéaste cherche à témoigner des frustrations d'un intellectuel immédiatement après le $1^{\circ}$ avril 1964. » in VIANY, Alex. «O Desafio » in Última hora, Rio de Janeiro, 27/04/1966.

738SARACENI, Paulo César. Op. cit., p. 171.

739Le 1er avril 1964, le Comando de Caça aos Comunistas - CCC envahit et incendie le siège de l'UNE à Rio de Janeiro. La semaine précédente, des bombes avaient déjà été jetées à partir de la plage du Flamengo sur l'immeuble. In BARCELLOS, Jalusa. UNE : 60 anos a favor do Brasil. Rio de Janeiro, ANC Comunicação \& Marketing Ltda, 1997, p. 56.

740SARACENI, Paulo César. Op. cit., p. 177. 
gauche et celle de la guérilla pour se concentrer sur le découragement d'un journaliste gauchiste après le putsch et son amour devenu impossible avec la femme d'un industriel.

Pour réaliser $O$ Desafio, Saraceni abandonne un autre projet commencé avant le coup d'état. Son titre est $O$ Desafio da fera da Penha ${ }^{741}$. Dans son idée, il s'agissait d'un nouveau film sur la condition féminine, plus radical et plus violent que Porto das Caixas. Une jeune femme catholique de la banlieue de Rio de Janeiro connaît un homme qu'elle croit célibataire. Pendant leur relation, elle tombe enceinte. La situation vire au cauchemar quand son amant menace de la quitter si elle n'avorte pas. Sa propre famille étant pauvre et conservatrice, elle se retrouve sans personne pour l'aider. Malgré les problèmes de conscience que cela lui pose, la femme doit donc avorter. Entre-temps, son amant disparaît. Désespérée, elle le cherche partout et réussit à découvrir où il habite. Elle découvre aussi qu'il est marié et a une petite fille de huit ans. Confrontée à l'ignorance de ses parents et à la trahison de son amant, dans un geste de folie. Elle kidnappe la petite fille et l'emmène dans un parc de diversion, puis, à la nuit tombée, l'emmène dans un autre parc désert et lui tire une balle dans la nuque. Elle brûle ensuite le corps dans un immense brasier. Le film termine avec une interview télévisée de ses parents qui ne comprennent pas ce qui a pu se passer.

La production de $O$ Desafio da fera da Penha était bien engagée. Comme Menino de engenho et $O$ Padre e a moça, le scénario avait été lauréat du concours de la CAIC qui lui apportait la somme 11,5 millions de cruzeiros. Jarbas Barbosa ${ }^{742}$ consentait à rajouter la même somme pour co-produire le film. Une partie de l'équipe avait même été engagée et une séquence avait été filmée dans un registre documentaire : la fête de la Penha. Saraceni se désengage pourtant du projet fin 1964, juste après avoir encaissé le prix de la CAIC $^{743}$. La somme reçue sera réinvestie dans son nouveau projet. Les collaborateurs pressentis pour travailler sur O Desafio da fera da Penha ne sont pas maintenus, Barbosa ne participe pas, le budget est réduit aux 11,5 millions de cruzeiros initiaux (20 mille dollars). Le tournage a lieu en février 1965 et dure à peine 13 jours. Il s'effectue dans une certaine fébrilité. Les dialogues sont écrits au jour le jour et les contrats des différents participants ne sont pas prêts. Enfin, le chef opérateur qui vient spécialement d'Italie, ne peut rester que 15 jours. L'équipe est réduite

\footnotetext{
741Traduction littérale : « Le Défi de la bête de la Penha ». La Penha est un quartier de la zone nord de Rio de Janeiro.

742Le co-producteur de Deus e o diabo na terra do sol, Ganga Zumba et Os Fuzis.

743SARACENI, Paulo César. Op. cit., pp. 178-179.
} 
à 8 personnes incluant le producteur Mário Fiorani $^{744}$, le chef opérateur italien Guido Cosulich $^{745}$ et le cameraman Dib Lufti. Sur les conseils de Rocha qui a lu le scénario en Italie début 1965, Saraceni propose à Oduvaldo Viana Filho le rôle du journaliste, Marcelo. Bien que pratiquement voisins, les deux hommes ne se parlaient plus depuis que l'acteur et dramaturge du CPC avait fait violemment campagne contre Porto das Caixas trois ans plus tôt $\mathrm{t}^{746}$. Malgré tout, Vianinha incarne Marcelo qui n'est ni plus ni moins la projection du cinéaste dans son propre film. Pour jouer ce rôle, l'acteur ira jusqu'à porter les chemises du réalisateur ${ }^{747}$. L'entente pendant le tournage et le doublage est parfaite.

$O$ Desafio commence par un générique avec un lettrage noir sur fond blanc et, en son off, le bruit de la rue. Ce début crée une tension, il y a l'attente qui est prolongée par le fait que l'on ne voit et n'entend rien de signifiant, il y a aussi le contraste entre le fond blanc éblouissant qui n'est pas une image naturelle ${ }^{748}$ et le bruit de la rue qui est familier, anonyme, et dont se dégage au contraire un sentiment de normalité. L'attente est encore prolongée dans la première séquence puisqu'un long silence sépare Ada et Marcelo, les deux personnages principaux. La jeune femme est au volant, la journée est radieuse et, apparemment, aucune action dramatique ne se déroule. Le dialogue qui commence bientôt entre Ada et Marcelo nous montre que, malgré la situation qui est celle d'une promenade de détente, Marcelo est profondément déprimé et que cette dépression est due à la récente « révolution ». Ada ne comprend pas cet abattement de Marcelo qu'elle juge disproportionné. Après tout, Marcelo n'est pas directement touché par les événements politiques. Il peut continuer son travail de journaliste et le livre qu'il rêvait d'écrire :

Ada : - Acho que você está exagerando o efeito da Revolução ! (Je pense que tu exagères l'effet de la Révolution !)

Marcelo : - Estou me sentido sem perspectiva. (Je me sens sans perspective.)

Marcelo exprime de façon très explicite ses sentiments et critique très vivement le régime militaire. Il donne notamment une anecdote très précise quant aux abus qui peuvent être commis grâce au climat d'épuration politique et à la peur concomitante qui s'installe. Il conclut : « Não posso estar em paz quando estou tão precisando de guerra ! » (Je ne peux pas

744Mário Fiorani va ensuite passer à la réalisation et produire coup sur coup A Derrota (1967) et $O$ Engano (1968).Tout indique cependant que ces deux films qui ont été photographiés par Mário Carneiro s'inscrivent dans une ligne proche du Cinema Novo et du Cinema Marginal. D'après le synopsis du Dicionário de filmes brasileiros, $A$ Derrota serait l'un des rares films de la période à traiter de la torture (SILVA NETO, Antônio Leão Da . Dicionário de filmes brasileiros. São Paulo, Gráfica Editora, 2002). Malheureusement, les deux films de Fiorani sont introuvables et il ne nous a pas été possible de les voir.

745Spécialement venu d'Italie pour travailler sur le film de Saraceni, Guido Cosulich sera aussi le chef opérateur de Brasil ano 2000, Macunaíma et Der Leone have sept cabeças (France, Italie, Congo, 1969).

746Paulo César Saraceni. Entretien avec l'auteur, février 2004.

747SARACENI, Paulo César. Op. cit., p. 188.

748La norme veut que l'on ait au contraire plus souvent un lettrage blanc sur fond noir. 
vivre en paix quand j'ai tant besoin de guerre !)

Dans la séquence suivante, Ada et Marcelo sont descendus de la voiture et se tiennent éloignés l'un de l'autre sur le ponton d'une construction sur pilotis, au bord d'un lac. De nouveau le silence s'est installé entre eux. En son off, venus d'une radio invisible, nous entendons une chanson de MPB puis les informations et la nouvelle de la promulgation d'un acte institutionnel par le haut-commandement militaire. Des cassations de mandats d'élus sont annoncés. Rompant le silence, Ada réclame de la froideur de Marcelo. Celui-ci se lance dans un long monologue :

Marcelo : - Eu, como os outros, queria acreditar no processo revolucionário brasileiro. Sabia que, mais cedo ou mais tarde, íamos viver juntos. Nós tínhamos afinidades e idéias comuns, você também acreditava numa visão coletiva, segura, linda. Desculpe meu bem, estou confuso, estou misturando tudo, mas aqui... a nossa idéia, o nosso amor, parecia a mesma coisa, nós estamos vivendo...

Ada : - Mas continuamos vivendo, não adianta a gente se entregar, agora mais do que nunca temos que nos unir...

Marcelo : - Não. [La fin de la réplique a été effacée par la censure :] A porra desse golpe militar que impede que a gente possa estar do mesmo lado $!^{749}$

Ada reste perplexe, comme elle l'a dit plus tôt à Marcelo, pour elle, l'amour est au-delà des contingences matérielles, politiques, de l'actualité.

Ces trois premières séquences (le générique, en voiture, au bord du lac) posent d'ores et déjà le dispositif sur lequel repose le film. Tout au long de la narration, l'action est nulle. À aucun moment, les personnages n'exercent sur le réel la moindre incidence. Même la rupture entre Ada et Marcelo qui paraît inévitable dès le début, ne se réalise que très progressivement et pratiquement à l'insu des intéressés qui tentent constamment de renouer mais constatent à chaque fois que leur union est impossible. Cette absence d'action contraste avec les discours des différents personnages qui clament sans cesse la nécessité d'agir mais restent cantonnés aux déclarations d'intentions. La parole ne semble plus avoir prise sur le réel.

Dans la séquence qui suit celle du lac, nous retrouvons Ada et Marcelo au lit, réconciliés. Sur les murs de la chambre, une reproduction de Guernica de Picasso et l'affiche de Deus e o diabo na terra do sol évoquent cependant la situation politique avec d'un côté le

749« Marcelo : - Moi, comme les autres, je voulais croire dans le processus révolutionnaire brésilien. Je savais que, tôt ou tard, nous allions vivre ensemble. Nous avions des affinités et des idées en commun, toi aussi tu croyais en une vision collective, sûre, belle. Excuse-moi ma chérie, je suis confus, je mélange tout, mais voilà... notre idéal, notre amour, paraissaient une même chose, nous sommes en train de vivre...

Ada : - Mais nous continuons à vivre, cela ne sert à rien de se rendre, aujourd'hui plus que jamais nous devons rester unis...

Marcelo : Non. [À partir d'ici, fin de la réplique effacée par la censure] Cette merde de coup d'État militaire nous empêche d'être du même côté ! » (Dialogue du film) 
rappel des massacres du fascisme et de l'autre l'appel à la révolte de Corisco. La réconciliation n'est que superficielle. En fin de journée, Ada réintègre sa luxueuse maison. Son petit garçon regarde la télévision et son mari rentrera tard du travail. Le lendemain, nous assistons à une discussion de Marcelo à la rédaction du journal où il est journaliste. La séquence est introduite par une série d'images fixes des unes les plus marquantes du magazine O Cruzeiro. Kennedy, Castro, les généraux brésiliens, l'actualité politique, nationale et internationale, à la fois proche et distante de la vie quotidienne, conditionne toutes les conversations. Les collègues gauchistes de Marcelo, également très déçus par le coup d'État, tentent d'adopter un discours positif. Un journaliste (Joel Barcelos) estime qu'il faut tirer les enseignements des échecs du présent et déclare : «A fase do otimismo leviano acabou.» (La phase de l'optimisme désinvolte est terminée.) Marcelo répond qu'il n'arrive pas à sortir de la dépression et prévient qu'il arrête la rédaction de son livre. Il lui semble impossible de créer dans un contexte politique aussi grave.

Chez elle, Ada se dispute avec son mari. De retour d'une réception mondaine, celui-ci s'inquiète d'abord de la voir déprimée. Elle critique alors de façon véhémente l'égoïsme et la futilité des gens de sa classe. Son mari l'informe qu'il ne voit aucune objection à ce qu'elle fréquente ses amis gauchistes mais que la situation a changé. Il lui parle de ses responsabilités et de ses obligations en tant que co-propriétaire avec lui d'une fabrique employant 1500 personnes et se félicite que la Révolution ait mis un terme à une crise politique qui menaçait directement leurs intérêts. Il voudrait enfin la voir assumer sa place à ses côtés dans la direction de l'entreprise et lui fait remarquer qu'elle n'y a jusqu'alors jamais mis les pieds.

Seul de son côté, Marcelo assiste à la pièce musicale Opinião ${ }^{750}$. Spectacle de conscientisation par excellence dans la lignée de ce que produisait le CPC pendant sa période d'activité, il est composé d'une série de chansons engagées orchestrées à la mode de la MPB. Maria Bethânia y chante notamment les statistiques concernant l'exode des nordestins poussés par la sécheresse et la faim vers les grandes villes du Sud comme Rio de Janeiro et São Paulo. Le public applaudit à tout rompre. Marcelo, par contre, ne sort toujours pas de sa torpeur.

Ada et Marcelo se rejoignent dans le pavillon d'un de leurs amis et partent ensuite visiter un immeuble qui a brûlé. Marcelo raconte à Ada qu'il s'agissait d'une pension à

\footnotetext{
750Le show Opinião, dirigé par Oduvaldo Viana Filho, Paulo Pontes et Armando Costa, a été lancé quelques mois après le coup d'État de 1964. Ont participé à l'événement la chanteuse Nara Leão et le sambista Zé Kéti. Après un certain nombre de représentations, Mara Bethânia remplace Nara Leão et c'est elle que nous voyons chanter Carcará de José Cândido et João do Vale. Parmi la liste des titres interprétées au cours de ce spectacle, nous trouvons des références au cinéma brésilien comme $A$ Marcha de Rio 40 graus de Zé Kéti et deux extraits de la bande originale de Deus e o diabo na terra do sol (textes de Rocha et musique de Sérgio Ricardo). Le show Opinião a eu un très grand succès et la critique musicale voit en lui un des moments les plus marquants de l'histoire de la MPB. Aujourd'hui encore, il est possible d'acquérir la réédition de l'enregistrement du spectacle en cd.
} 
laquelle l'un des locataires a mis le feu. Ce dernier, un poète, s'étant retrouvé sans le sou et dans l'incapacité de payer, avait commis cet acte de révolte et de négation. Dans les décombres, ils trouvent les fragments d'un poème qu'ils lisent ensemble, A Invenção de Orféu de Jorge de Lima. De retour au pavillon, Marcelo déclare qu'il ne peut être heureux quand le peuple est opprimé et meurt de faim. Il déclare qu'il existe entre Ada et lui un mur qui est celui de leur différence de classe. Ada ne pourra jamais adopter sincèrement la cause des classes populaires. Celle-ci se sent insultée mais garde continuellement l'amour comme point de référence. À présent, chacun ira de son côté.

Ada retourne chez elle et déprime en longeant sa grande piscine. Elle erre ensuite dans la ville en voiture et se décide à écrire un billet à Marcelo qu'elle glisse sous la porte de son appartement. Décidée à rompre avec son mari, elle se rend à la fabrique où elle surprend ce dernier en train de régler le problème des rendez-vous de la journée avec sa secrétaire. Débordé, il remet une rencontre avec les représentants syndicaux à la semaine suivante. Quand Ada apparaît, il décide pourtant de lui consacrer du temps. Pendant un court moment, elle doit attendre son mari au milieu des machines. Assourdie par le bruit, elle est prise d'un malaise et s'enfuit. Elle assiste ensuite à la sortie des ouvriers qui passent tout autour d'elle sans la voir. Finalement, elle renonce à parler à son mari.

De son côté, Marcelo passe une soirée à boire avec l'un de ses collègues de journal qu'il n'aime pas. Il s'agit d'un écrivain cynique et frustré qui est loin de partager ses opinions politiques. Comme il le déclare à Marcelo, pour lui, il y a eu et il y aura toujours des pauvres, la seule chose importante que l'artiste doit faire passer, est le sentiment tragique du monde. Le jeune homme se défie de la sous-philosophie nietzschéenne de son aîné. Selon lui, leurs divergences philosophiques, artistiques et politiques sont liées. Il traite son collègue de fasciste et, à un moment de leur conversation, il lui rétorque : «Se deve ter vibrado quando queimaram a UNE. » (Tu as dû vibrer quand ils ont brûlé l'immeuble de l'UNE.)

Malgré les désaccords ouverts qui règnent entre les deux hommes, Marcelo suit son collègue à son domicile. Arrivé là-bas, il se trouve confronté au climat malsain entretenu par l'écrivain et sa femme et refuse une proposition de triolisme. Il sort de la maison alors que le jour se lève et, en descendant un escalier croise une petite fille. Off, nous entendons la chanson «É um tempo de guerra» extraite de la pièce Arena conta Zumbi écrite par Gianfrancesco Guarnieri, Augusto Boal et Edu Lobo (1965). Le film se termine avec ces paroles de révolte :

«Eu sei que é preciso lutar

Eu sei que é preciso vencer

Eu sei que é preciso morrer 
Eu sei que é preciso matar

É um tempo de guerra

É um tempo sem sol $»^{751}$

L'esthétique du film est dominée par des plans séquences en caméra portée. L'objectif scrute les personnages, s'immisce dans leur intimité ou documente leur environnement immédiat afin de le mettre en relation avec leur psychologie. La mise au point semble parfois imparfaite comme dans la séquence de la rédaction du journal où le visage muet de Marcelo apparaît nettement alors que celui de son collègue qui parle, est flou. Les plans coupés dans l'axe et le montage hors continuité produisent un effet de dilatation du temps dans la séquence de la chambre où Ada monologue et dans celle de ses errances en ville. À chaque moment, la présence de la caméra est ostensible et renvoie le spectateur à sa position de voyeur. Aucun détail n'est laissé au hasard et chaque plan est signifiant même si, en contrepartie, le film reste ouvert. Rien en effet ne nous est dit de l'avenir d'Ada et Marcelo et comment Marcelo va s'engager contre la dictature.

Le film est prêt fin août $1965^{752}$ et reçoit un accueil chaleureux de la part des cinemanovistas qui le voient en séance privée ${ }^{753}$. Il est projeté pour la première fois en public à Rio dans le cadre du Festival Internacional do Filme, au sein de la programmation parallèle du Mercado Internacional de Filmes, le 23 septembre $^{754}$. O Desafio avait reçu pour cette projection une autorisation exceptionnelle de la censure, limitée à cette manifestation. Celle-ci renâcle en effet à libérer le film de façon définitive. Une nouvelle autorisation exceptionnelle est obtenue pour la Primeira Semana do Cinema Brasileiro ${ }^{755}$ organisée par Sales Gomes à Brasília. Ce festival a lieu entre le 15 et le 22 novembre 1965. Les démêlés du film avec la censure étant connues, sa projection attire le double de spectateurs que la salle ne pouvait en contenir. 3000 personnes assistent au long métrage. Le film est libéré au mois de février pour

\footnotetext{
$751 \ll$ Je sais qu'il faut lutter Je sais qu'il faut vaincre Je sais qu'il faut mourir Je sais qu'il faut tuer C'est un temps de guerre C'est un temps sans soleil » (Musique originale du film) 752SARACENI, Paulo César. Op. cit., p. 201.

753Pour Gustavo Dahl, il s'agit ni plus ni moins du film le plus important de l'année. Voir DAHL, Gustavo. « Le Défi de Saraceni » in Cahiers du cinéma, Paris, n²172, novembre 1965.

Dans son autobiographie, Saraceni rapporte également les réactions enthousiastes de Mário Carneiro, Joaquim Pedro de Andrade et Eduardo Escorel. In SARACENI, Paulo César. Op. cit., pp. 194 et 199.

754« Três países europeus adquirem fita do Brasil» in O Estado de São Paulo, São Paulo, 24/09/1965. 755Nous avons retrouvé les dates exactes de ce festival dans le document suivant :

Lettre de la Secretaria de Educação e Cultura do Distrito Federal au Diretor Geral do Departamento Federal de Segurança Pública, Brasília, 10/11/1965, Dossier «O Desafio », Archives ANDF / Censura prévia. La Primeira Semana do Cinema Brasileiro, promue par la Fundação Cultural de Brasília et plus précisément la Secretaria de Educação e Cultura do Distrito Federal, est l'ancêtre du Festival du Cinéma Brésilien de Brasília qui a encore lieu de nos jours.
} 
les plus de 18 ans avec l'exigence que certaines phrases des dialogues soient coupées dans la bande son. $O$ Desafio sera resté en tout six mois prisonnier de la censure ${ }^{756}$. Cet incident est utilisé comme argument publicitaire au moment de sa sortie ${ }^{757}$. Il est d'abord lancé à São Paulo où, selon Saraceni, il rencontre un certain succès auprès du public ${ }^{758}$, puis à Rio de Janeiro. Dans les deux villes, le film est très discuté par la critique cinématographique.

La sortie de $O$ Desafio a été précédée d'une réception très favorable de la critique internationale présente au FIF en octobre $1965^{759}$ et d'une défense passionnée par Sales Gomes suite à sa projection à Brasília ${ }^{760}$. En mai-juin 1966, les critiques sont globalement positives même si deux points de vue s'affrontent. Le premier recoupe l'opinion d'Ely Azeredo ${ }^{761}$. Selon lui, $O$ Desafio possède l'avantage d'être le seul film qui affiche de façon explicite son opposition au régime installé par la coup d'État d'avril 1964. En même temps, parce qu'il est un film d'art, $O$ Desafio ne s'adresse qu'à un public restreint et s'avère inefficace quant à la conscientisation des masses. D'autres critiques développent cette idée et stigmatisent à la fois le langage et le sujet du film. La caméra portée, les plans séquences et les temps morts sont rejetés par ceux qui ne voient dans ces figures de style que la marque d'un esthétisme vain ${ }^{762}$. Le film est considéré défaillant par Louzada Filho qui comprend mal en quoi la rupture entre Ada et Marcelo pourrait éclairer le spectateur sur les événements historiques traversés par le Brésil $^{763}$. José Carlos Oliveira ironise quant à la trajectoire de ces personnages déprimées évoluant dans des intérieurs luxueux : «O Desafio, filme de Paulo César Saraceni, é uma demonstração de revolta inautêntica e de inexperiência vaidosa de si $»^{764}$.

D'autres critiques considèrent au contraire que $O$ Desafio est un moment important de recul par rapport aux positions assumées par la gauche avant le coup d'État de $1964^{765}$.

756Nous traiterons en détail des relations entre la censure et le Cinema Novo dans un chapitre spécifique. 757Voir Press release.

758SARACENI, Paulo César. Op. cit., p. 210.

759En particulier Louis Marcorelles et Robert Benayoun qui proposeront une rétrospective du festival de Rio dans leurs magazines respectifs début 1966 :

MARCORELLES, Louis. « Rio : Bravo » in Cahiers du cinéma, Paris, n²172, novembre 1965. BENAYOUN, Robert. « Cangaços 65 : Cris du Brésil » in Positif, Paris, n73, février 1966, pp. 1-21.

760GOMES, Paulo Emílio. « Novembro em Brasília. » in O Estado de São Paulo - Suplemento literário, São Paulo, 18/12/1965.

761AZEREDO, Ely. « Desafio entre amigos » in Jornal do Brasil, Rio de Janeiro, 05/05/1966.

762MONTEIRO, José Carlos. « Cinema Nôvo : A Urgência de filmar » in Diners Club Magazine, sans lieu, septembre 1967.

763LOUZADA FILHO, O.C. «O Desafio sem resposta » in O Estado de São Paulo - Suplemento literário, São Paulo, 18/06/1966.

764« O Desafio, film de Paulo César Saraceni, est une démonstration de révolte inauthentique, d'inexpérience et de vanité. » in OLIVEIRA, José Carlos. « O Falso Dilema » in Jornal do Brasil, Rio de Janeiro, 01/05/1966.

765 Ce point de vue est défendu dans les articles suivants :

VIANY, Alex. «O Desafio » in Última hora, Rio de Janeiro, 27/04/1966.

SILVA, J.A. Pereira da. «O Desafio : O Cinema besouro » in Cineclube, Campinas, année II, nº novembre 1966.

IANNI, Octavio. «Un Défi au gauchisme urbain » in Cine cubano, La Havane, année 7, n42-43-44, juillet 1967. 
Bernardet approfondit cette approche dans plusieurs articles ${ }^{766}$ et dans son livre Brasil em tempo de cinema ${ }^{767}$. Selon lui, le marasme de Marcelo correspond à une recherche sur le passé récent et le présent qui est aussi une façon de passer à l'étape suivante. Le mouvement de la caméra rend concret cette attitude de recherche. Contrairement au cinéma classique, le personnage principal n'est pas le fil d'Ariane qui indique le chemin pour la résolution du problème. Le problème du comment lutter ou réagir n'est pas résolu à la fin du film et la seule transformation observée est celle de la disposition retrouvée à lutter. Toute la narration est donc centrée sur ce retournement du personnage sur lui-même, l'action est nulle, le personnage fait du «sur-place», mais le mouvement intérieur qu'il effectue, engage de profondes modifications dans sa manière de concevoir le monde et ouvre de nouvelles perspectives d'action. $O$ Desafio est à ce titre le récit d'une prise de conscience, celle de son personnage principal et celle du spectateur.

Cette prise de conscience est double, son premier aspect concerne la mort de l'utopie nacional-desenvolvimentista dont la génération de Marcelo se nourrissait. Le symbolisme de la rupture du journaliste avec Ada signifie que la stratégie de l'union de la haute-bourgeoisie progressiste, des classes moyennes et des classes populaires contre les intérêts impérialistes relevait beaucoup plus d'une projection intellectuelle abstraite que d'un processus historique réel. Ce point est développé de façon explicite dans les dialogues du film. D'abord dans ceux entre Ada et Marcelo, ce dernier finit toujours par se rappeler qu'au moment du coup d'État la haute-bourgeoisie s'est retrouvée unie derrière les putschistes. Les intérêts de classe ont prévalu sur les intérêts nationalistes. Pour Marcelo, il s'agit à la fois d'une amère trahison et de la démonstration que la haute-bourgeoisie ne sera jamais une force favorable à la révolution brésilienne. Le dialogue entre Ada et son mari, où l'industriel rappelle à sa femme ses responsabilités dans la conduite de l'usine, confirme pour le spectateur l'analyse du journaliste. Celui-ci y dit clairement que lui et ses amis ont appuyé le coup d'état. Au-delà du simple exposé des faits, la façon dont Ada et Marcelo finissent par rompre met en évidence les mécanismes invisibles qui interdisent à la jeune femme, malgré sa bonne volonté et sa frustration, de rompre avec son milieu et son style de vie. Le fait que la jeune femme soit incapable de rupture vaut pour l'intégralité de sa classe.

Le deuxième aspect de la prise de conscience engagée par $O$ Desafio réside dans la

766BERNARDET, Jean-Claude. «O Desafio : Depois da utopia » in Artes, São Paulo, année I, n³, janvier 1966.

SALLES, Francisco Luis de Almeida et alii. « Debate sobre O Desafio » in O Estado de São Paulo Suplemento literário, São Paulo, 04/06/1966. Pour ce deuxième article, il s'agit du compte-rendu d'une tableronde organisée à São Paulo au Clube dos Artistas e Amigos da Arte et qui a eu lieu le 20 mai 1966. Étaient présents Paulo César Saraceni, Jean-Claude Bernardet, Flávio de Carvalho, Gilda de Mello e Souza et Francisco Luiz de Almeida Salles.

767BERNARDET, Jean-Claude. Brasil em tempo de cinema. Op. cit. 
découverte selon laquelle la confiance accordée par la gauche dans les discours et la culture pour transformer la réalité, était excessive. Le divorce entre la parole et l'action est illustré par l'incapacité des personnages à passer à l'action et à réaliser leur intention. L'indifférence de Marcelo face au show Opinião peut aussi passer pour du scepticisme vis à vis de ce type d'activisme politique. Ces deux éléments expriment bien la nécessité de s'écarter d'un certain idéalisme inconséquent qui est aussi une manière de se donner bonne conscience sans réellement entrer dans une démarche de recherche et de transformation. Le fait que la caméra ne soit pas dans le film un simple instrument qui enregistre l'image mais se révèle active, exprime cette nécessité d'enquête et de remise en question constante. Enfin, si Marcelo apprend à se défier d'une action qui ne serait finalement que discursive, la prise de conscience induite par le film chez le spectateur est plus profonde. Bernardet remarque l'apparition de nouveaux personnages dans la cinématographie brésilienne : le chef d'entreprise et l'ouvrier sont traités selon un mode plus naturaliste et moins stéréotypé que dans les précédents films du Cinema Novo. Cette représentation plus naturaliste du social est à mettre en relation avec l'incapacité d'Ada à rompre avec son mari, l'impossibilité de résoudre les problèmes seulement par la parole et l'interprétation du rôle de la haute-bourgeoisie dans le coup d'état. Autrement dit, sans didactisme ni manipulation, $O$ Desafio engage le spectateur à une interprétation matérialiste de l'histoire et introduit dans le cinéma brésilien un phénomène qui n'avait pas été exprimé jusqu'alors : la lutte des classes.

Nous partagerons quant à nous cette analyse et nous constaterons a posteriori qu'elle se trouve confirmée par les critiques négatives faites contre le film. Nier la signification politique de $O$ Desafio ou prétendre que son impact politique serait négligeable parce que le film serait, par définition, un film d'art et donc destiné à un public restreint nous semble erroné. Dans le sens où le film est une critique à l'investissement exagéré qui peut être fait dans la culture avec des visées politiques, il renonce a priori au fantasme de l'omnipotence. Il n'est plus question de réaliser le film de conscientisation capable de toucher l'ensemble de la population et de l'inciter à changer son comportement dans un grand mouvement de révolte collectif. Le Cinema Novo assume le fait de ne pouvoir avoir qu'une portée limitée ce qui nous semble au contraire devoir renforcer son impact politique. L'impact du film est d'ailleurs visible dans la controverse qu'il a suscitée, l'influence qu'il a eu dans le cinéma brésilien et le fait qu'il représente un moment décisif dans la réflexion idéologique menée par la gauche à l'époque à laquelle participe pleinement le Cinema Novo, cité par des intellectuels étrangers à la sphère cinématographique et objet d'articles dans des revues à vocation culturelle et politique comme A Revista Civilização brasileira et aParte, outre les textes publiés dans la presse généraliste. 
Film décisif dans l'histoire du Cinema Novo, O Desafio permet son évolution vers une meilleure conscience de ce qu'il est, de ce qu'il veut et de ce qu'il peut proposer. Notons finalement que le film n'est pas conçu pour ne s'adresser qu'à un public restreint, ce sont avant tout les conditions concrètes de circulation des biens culturels qui le cantonne à ce public. Et, s'il faut reconnaître que son propos est complexe, ce ne peut pas être une source de critique à son égard. Estimer qu'il ne faut pas faire des films «compliqués » est aussi absurde que de penser qu'il faudrait que les scientifiques arrêtent d'écrire des livres pour communiquer leurs découvertes. Ce serait nier la dynamique selon laquelle procède le progrès humain.

\subsection{Terra em transe}

D'une certaine façon, Terra em transe exploite et développe la voie ouverte par $O$ Desafio. Écrit et réalisé entre 1965 et 1967, conçu à l'origine comme une réponse directe à l'instauration du régime militaire et une diatribe contre le fascisme latent qui lui apportait sa légitimité, il accompagne, sans que cela ait pu être prémédité, la polarisation des antagonismes dans la vie politique brésilienne, dictature contre guérilla ${ }^{768}$, et présage de

768 Des mouvements de guérilla urbaine ou rurale s'organisent dès avant la chute du gouvernement Goulart parallèlement au développement du terrorisme de droite. Ces mouvements restent pourtant très embryonnaires jusqu'à ce que l'accession au pouvoir du général Costa e Silva, en 1967, qui démontre que les espoirs d'un retour à la «normalité » démocratique appartiennent au domaine de l'utopie. Parallèlement, le livre de Régis Debray « Révolution dans la révolution? » publié à 200000 exemplaires à Cuba et l'épopée de Che Guevara en Bolivie enflamment les esprits. En 1968, la gauche est divisé en deux camps. Il y a ceux qui, dans la lignée de l'idéologie dominante d'avant 1964, pensent que seul un peuple « conscient » peut faire la révolution et ceux qui sont pour l'épreuve de force immédiate et pensent que seul le peuple « armé » peut faire la révolution. La promulgation de l'AI-5 en décembre 1968 marque l'effondrement de la première position, les mobilisations pacifiques de 1968 ayant échoué. La période allant de 1969 à 1971 marque l'apogée de la guérilla. Après quelques coups d'éclats, la répression policière maîtrise les mouvements guérilleros. Les principaux leaders du mouvement armé sont assassinés au moment de leur capture sans autre forme de procès, c'est le cas de Carlos Marighella (04/11/1969) et du capitaine Carlos Lamarca (17/09/1971). En 1974, d'énormes moyens sont mobilisés par l'armée pour écraser le dernier « foyer révolutionnaire ». Une route de $30 \mathrm{~km}$ est construite pour le déplacement des troupes, 5000 soldats sont transportés sur les lieux de l'opération, des hélicoptères sont utilisés. La cible de ce déploiement de forces est un groupe de soixante-dix étudiants trotskistes qui tentent depuis 1966 de créer un foyer révolutionnaire selon les méthodes de la guérilla rurale près du fleuve Araguaia (centre du Brésil). Ils seront pratiquement tous impitoyablement massacrés.

En mars/avril 2005, certains articles de presse relayaient les revendications de soldats ayant participé à l'opération. Ceux-ci souhaitaient être reconnus comme « anciens combattants » et bénéficier de pensions auquel ce statut leur donnerait droit.

Sur le nombre d'exemplaires de Révolution dans la révolution, nous avons été sur le site de Régis Debray : http://www.regisdebray.com/content.php?pgid=biblio, consulté le 29/01/2006. Révolution dans la Révolution?

Lutte armée et lutte politique en Amérique latine. Paris, éditions François Maspero, 1967. Coll. «Cahiers libres » $n^{\circ} 98$. Le titre original du livre d'abord publié à La Havane est Revolución en la revolución ?, il est aussitôt traduit en portugais pour le Brésil : Revolução na revolução / Regis Debray. Havana : Casa de las Americas, 1967.

Sur la division de la gauche en 1968, voir VENTURA, Zuenir. 1968 o ano que não terminou - A Aventura de uma geração. Rio de Janeiro, ed. Nova Fronteira, 1988.

Sur l'histoire des mouvements de guérilla, cf. GASPARI, Elio. As Ilusões armadas - A Ditadura 
l'explosion du tropicalismo, mouvement artistique en lui-même éphémère (1967-1968), mais qui marquera durablement la culture brésilienne. Alors même que le cinéma peine normalement à répondre à l'actualité sociale et politique, Terra em transe semble au contraire avoir tiré profit de sa longue maturation, réussissant grâce au dispositif d'accumulation anarchique qui lui donnera sa structure, à saisir cet espace de temps si décisif qui voit le Brésil passer d'une dictature honteuse d'elle-même aux terribles contradictions de la « modernisation conservatrice $»^{769}$. Paradoxalement, si Terra em transe n'est pas un grand succès de cinéma en termes commerciaux, il n'est un pas moins un des films les plus discutés et les plus emblématiques de l'époque. Plusieurs éléments indiqueront aussi que l'appel à la guérilla de son personnage principal a été entendu au premier degré. À défaut d'initier ce cinéma de conscientisation des masses dont le projet est temporairement mis entre parenthèses, Terra em transe affirme la validité d'un cinéma d'auteur d'agitation et confirme le nouveau positionnement idéologique du Cinema Novo déjà manifesté par $O$ Desafio, l'autocritique du populisme pré-64, l'autocritique de l'intellectuel gauchiste de classe moyenne et l'impuissance de la parole.

Terra em transe surgit exactement alors que le Cinema Novo a consolidé ses bases économiques avec la création de la MAPA Filmes et de la Difilm et que son prestige s'est accru grâce à sa présence dans les festivals internationaux et à ses ventes à l'étranger. Sa réalisation a pris beaucoup de temps et fut un moment de grandes expérimentations. Beaucoup de matériel avait été tourné sans que ne soit nécessairement suivies les indications du scénario ${ }^{770}$. Le film fut ensuite totalement reconstruit durant l'étape de montage qui a duré

envergonhada et As Ilusões armadas - A Ditadura escancarada. Op. cit. Voir aussi GASPARI, Elio. $O$ Sacerdote e o feitiçeiro - A Ditadura derrotada et $O$ Sacerdote e o feitiçeiro - A Ditadura encurralada. São Paulo, Companhia das letras, 2003.

769La modernisation conservatrice désigne le processus économique et politique suivant lequel le capital brésilien s'est adapté aux évolutions du capital mondial entre la fin des années soixante et le début des soixante-dix. La politique libérale inspirée par des ministres comme Delfim Neto a permis une croissance économique quasiment exponentielle sans toucher aux inégalités de la structure sociale brésilienne. Celles-ci se sont au contraire accrues. Cette période correspond au gouvernement Médici (1969-1974) : le « Milagre brasileiro » (Miracle brésilien) suscite alors l'admiration dans le monde entier alors que les opposants au régime traversent « os anos de chumbo » (les années de plomb). Le gouvernement du général Emílio Garrastazu Médici fut, de tous les gouvernements militaires, le plus répressif, il marque aussi l'apogée de la dictature. À partir de 1974, l'effet conjugué des crises pétrolières et des mobilisations sociales de plus en plus importantes contraignent le régime à la détente. Toute l'habilité politique du successeur de Médici, le général Ernesto Geisel, consistera à prendre l'initiative de la détente qui, selon ses propres termes, devait être « lente et graduelle ». 14 ans seront en effet nécessaires avant que le Brésil ne se dote d'une constitution démocratique.

770Dans un article de 1967, Rocha indiquait avoir utilisé 30000 mètres de négatifs. Le film terminé se présentant sous la forme de 12 bobines et $3600 \mathrm{~m}$ de pellicule au total, un peu plus de $10 \%$ du matériel filmé avait été retenu. In ROCHA, Glauber. « Rocha, o cineasta brasileiro de maior prestígio internacional, conta com exclusividade para Fatos \& Fotos porque faz filmes e porque fez Terra em transe » in Fatos \& Fotos, Rio de Janeiro, 1967.

En mars 1993, une partie de ce matériel non monté a été retrouvé. Un étudiant de l'Université Catholique PUC, de Minas Gerais, a rendu à la mère de Rocha, Dona Lúcia, 52 rouleaux de pellicule non montés du film Terra em transe. Selon les informations du journal Folha de São Paulo, ce matériel avait été déposé à PUC 
entre cinq et six mois ${ }^{771}$. Nous étudierons dans le chapitre suivant les versions successives du scénario de Terra em transe et d'un autre projet de Rocha resté inédit mais qui s'est un temps confondu avec lui, América nuestra. Notons pour l'heure que les textes écrits ne prévoyaient pas cette fragmentation du récit qui deviendra sa marque distinctive. Pour le spectateur habitué aux règles classiques de la narration cinématographique, la première vision de Terra em transe constitue une expérience déstabilisante et un choc. Rien ne se passe comme dans une fiction traditionnelle et, si le film fait sens, c'est en référence à la situation historique dramatique qu'il évoque et non pour la fabula dont il est censé constituer le récit. Le montage rapide, les faux-raccords, les incohérences, la violence des séquences considérées individuellement, le crescendo du délire du narrateur et la structure circulaire du film qui converge vers cet événement traumatisant que constitue le coup d'État contribuent à transmettre cette sensation d'agitation, de transe promise pour le titre.

De la fabula, il n'est possible de connaître que quelques moments. Le film se réduit à l'exposé de la situation initiale et à un enchaînement de séquences à la chronologie imprécise et dont on ne peut pas toujours savoir s'il s'agit de flash-backs ou de séquences oniriques. Dans un pays tropical nommé Eldorado, le gouverneur de la province Alecrim, Felipe Vieira, est menacé d'une intervention militaire. Isolé dans son palais avec une poignée de proches, il dicte à sa secrétaire Sara le texte de son abdication quand le journaliste Paulo Martins fait irruption pour l'exhorter à la résistance. Vieira le repousse et déclare qu'il ne veut pas provoquer d'effusion de sang. Martins quitte les lieux furieux avec Sara. Ils s'enfuient en voiture. Atteint par une balle après avoir refusé de s'arrêter à un barrage de police, Martins commence à délirer et se souvient. Commence alors l'enchaînement des flashbacks et séquences oniriques au statut incertain. Martins se souvient de son admiration pour Porfírio Diaz un politicien opportuniste de droite qu'il avait aidé à devenir sénateur et avec lequel il avait finalement rompu. Il l'imagine, accompagné d'un conquistador et d'un prêtre, rencontrant l'indien dans ce qui serait la scène primitive de l'invention du Brésil. Diaz, l'héritier de la tradition colonialiste, avait fini par le dégoûter. Il se rappelle ensuite sa rencontre avec Sara qui lui avait ouvert les yeux sur les injustices sociales dont le peuple d'Eldorado est victime. Il décide avec elle de fabriquer un leader de gauche pour la cause populaire, ce sera Vieira. Sara le lui présente, la campagne électorale commence et le futur gouverneur multiplie les promesses. Martins se souvient même qu'il a cru aussi pouvoir convaincre Júlio Fuentes, le

en 1968, par un ex-étudiant de l'Université qui avait travaillé comme assistant au montage du film. Nous n'avons pas eu accès à ces bobines qui permettent d'entretenir la légende d'autres versions possibles de Terra em transe. «Terra em transe tem imagens inéditas » in Folha de São Paulo, 07/03/1996.

771Cf. Entrevue avec Afonso Beato, Eduardo Escorel et John Howard Sherman, en présence de Dona Lúcia, par Elisabeth Versiani Formaggini, enregistrement du Tempo Glauber, cassettes 13 et 14, 12/03/1985. 
détenteur des mines, du pétrole, de la sidérurgie, de la presse et de la télévision, d'adopter une position progressiste. Mais, Vieira élu, le leader populiste peine à honorer ses promesses de campagne. Écœuré, Martins vacille. Revient-il ou non du côté de Diaz et de son ancienne amante, Sílvia ? S'écarte-t-il ou non de Sara avant le coup d'État ? Il est impossible de le savoir. Mais quand Fuentes retourne sa veste et se laisse convaincre par Diaz qu'il faut éliminer Vieira, Martins réalise son impuissance et conçoit la lutte armée comme le seul moyen d'échapper à la frustration et d'avoir une action de transformation sur le réel.

Les séquences à caractère ostensiblement onirique sont intercalées avec des séquences apparemment réalistes mais le montage hors continuité nous conduit toujours à nous demander s'il s'agit de reconstitutions « objectives » ou « subjectives » des événements de la fabula. Il en va ainsi, par exemple, de la première rencontre de Martins avec Sara. La répétition des images de l'entrée de la jeune femme porte l'emphase sur l'émotion subjective du personnage dans l'action du souvenir et nous amène à douter de la qualité informative de cette séquence et des circonstances exactes de l'événement évoqué. L'incertitude est constante sur ce qui doit être considéré comme un événement concret de l'histoire de Martins et ce qui en est la représentation déformée par le délire. À cette incertitude s'ajoute l'absence continuelle de repères spatiaux et temporels précis ainsi que la faible redondance des informations.

Il est par exemple difficile de se retrouver dans les oscillations de Martins entre Diaz, Fuentes et Vieira. Quand a-t-il soutenu Diaz ? Quand rejoint-il Fuentes ? A-t-il abandonné Vieira avant de tenter de le convaincre de résister au putsch ? La même confusion règne au sujet des positions et trajectoires respectives de Fuentes, Vieira et Diaz. Avant d'être convaincu par Martins que Diaz est son ennemi, Fuentes en parle une première fois de façon négative et une seconde fois de façon positive. Enfin, les situations géographiques respectives de Alecrim et Eldorado et leurs liens politiques ne sont pas expliquées. Dans les entrevues postérieures à la sortie du film, Rocha indiquait que cette absence de clarté était voulue.

Du point de vue du récit, cette confusion sur tous les éléments factuels qui devraient lui apporter sa cohérence s'explique partiellement par le fait qu'il est racontée par un personnage en crise qui vient d'être mortellement blessé et agonise en délirant ${ }^{772}$. Il convient cependant de nuancer la valeur de Martins comme instance narratrice. D'une part, si la voix off du journaliste conduit le récit et assure l'équilibre de sa structure circulaire, il est impossible d'être sûr que toutes ses interventions proviennent bien du Martins agonisant de la séquence quatre. Ainsi, la voix off de Martins se fait entendre avant même que ne commence 
le flashback (séquence 3) et, par la suite, le fait qu'elle soit le véhicule des poèmes lui donne une valeur particulière. Dans ces moments-là, nous pouvons nous demander si nous entendons ce que se dit Martins à lui-même au moment où il vit les événements qu'il raconte, s'il s'agit d'un commentaire formulé juste avant sa mort ou, encore, s'il ne parle pas d'un « ailleurs » qu'il nous est impossible d'identifier. Enfin, les dernières séquences qui nous montrent en parallèle l'agonie de Martins et le couronnement de Diaz alimentent nos doutes non seulement quant $\mathrm{au}(\mathrm{x}) \operatorname{lieu}(\mathrm{x})$ et $\mathrm{au}(\mathrm{x}) \operatorname{moment}(\mathrm{s})$ à partir de(s)quel(s) Martins nous raconte son histoire mais aussi quant à l'instance narratrice en charge du récit. Il est en effet impossible d'identifier la fin du flashback dont Martins serait le narrateur principal.

Dans le langage cinématographique classique, la fin d'un flashback est indiqué par le retour à une image exactement identique à celle où il avait été introduit. Tout se passe comme si le temps de l'action avait été « gelé » pour permettre la digression narrative du retour en arrière. Le personnage qui raconte est alors retrouvé dans la même attitude où nous l'avions laissé cinq, dix minutes ou une heure et demi en arrière pour suivre le fil de ses souvenirs. Dans Terra em transe, il n'existe pas une fin au flashback qui « colle» avec les images de la séquence qui l'a introduit. Il commence sur la plage où le journaliste marche avec difficulté, une mitraillette à la main (séquence 4). Nous savons que Martins a été blessé (séquence 3) alors qu'il fuyait avec Sara après que Vieira ait abdiqué (séquence 2). Mais nous ne savons pas comment il est arrivé, seul, au milieu des dunes de la plage. À la fin du film, le flash-back semble se conclure une première fois après la trahison de Fuentes et le retour à la scène de l'abdication (la séquence 2 se répète dans la séquence 40). Comme au début du long métrage, cette scène est suivie par celle de la fuite de Martins et Sara en voiture mais la séquence du début du flashback n'est pas répétée et nous trouvons à sa place, découpée en plusieurs séquences, la scène du couronnement de Diaz qui s'inscrit dans une parfaite continuité grâce au commentaire off de Martins qui commence dans la séquence 40 et se poursuit dans la séquence 41 , sur les images du leader fasciste triomphant. Il s'agit exactement du même commentaire que celui qui assurait la transition entre les séquences 3 et 4 , les images de la deuxième séquence sont, cette fois, différentes.

Fin de la séquence 3 et 40 , images et commentaires identiques :

Paulo (off) : - Não é mais possível esta festa de medalhas, este feliz aparato de glórias...

Début de la séquence 41, même commentaire qu'à la séquence 4 mais les images de Martins errant sur la plage sont remplacées par celles du sacre de Diaz :

Paulo (off) : -... esta esperança dourada nos planaltos ! Não é mais possível esta festa de bandeiras com Guerra e Cristo na mesma posição ! Assim não é possível, a impotência da 
fé, a ingenuidade da fé... ${ }^{773}$

Cette manipulation de la bande-son brise définitivement toute idée de chronologie puisque c'est dans la séquence suivante, la séquence 43, que Martins se sépare de Sara et s'enfonce entre les dunes. Autrement dit, nous entendons la fin du commentaire à deux moments distincts, la première fois après que Martins se soit perdu sur la plage et, la seconde fois, avant qu'il ne se perde sur la plage. L'absence de coïncidence entre le début et la fin du flashback ainsi que la répétition de certaines séquences augmentent encore la confusion par rapport aux repères spatio-temporels de la fabula et le lieu d'où nous parle la voix off de Martins. Rien ne nous indique non plus que c'est bien lui qui raconte de la séquence 40 à 44 puisqu'au début du film une autre instance narratrice a manifesté sa présence par l'utilisation d'intertitres (séquence 1) et que, logiquement, en fin de flashback, c'était à elle de reprendre la main après avoir délégué son rôle au journaliste. Remarquons également que la fin du flashback, non seulement n'est pas précisément datée, mais en plus s'accompagne d'une confusion croissante dans le récit. C'est en effet au moment où le narrateur délirant est censé laisser sa place à une instance narratrice supérieure que le récit perd définitivement sa cohérence. La prégnance de l'onirisme gagne sur le réalisme. C'est ainsi que deux scènes de couronnement de Diaz nous sont proposées (séquences 42 et 43). Dans la première, Martins fait irruption pour assassiner le nouvel empereur et un prêtre, dans la seconde, Diaz « ressuscité » exulte dans son propre délire mégalomane. Enfin, dans la dernière séquence, la bande-son reproduit des bruits de tirs et de bombardements, mais de quels affrontements peuvent provenir ces sons puisque, précisément, Vieira a capitulé ? Enfin, à l'horizon, une silhouette solitaire brandit une mitraillette vers le ciel. Il s'agit de Martins sans doute mais comment cela se peut-il puisque dans les scènes précédentes (séquences 4 et 43), blessé à mort, il marchait avec difficulté ?

Terra em transe se présente ainsi comme un dispositif filmique en constant effondrement sur lui-même car refusant de reposer sur l'illusion du réel. Sans cesse, le récit se dénonce comme objet de manipulation d'un tiers invisible et ce qui est vu est immédiatement remis en question. L'édifice tient au défi de toutes les règles de la narration filmique et semble ne devoir sa cohérence qu'à son incohérence systématique qui amène précisément à cet état de transe filmique dans lequel le spectateur se voit contraint d'accumuler les contradictions sans autre alternative que de remettre leurs résolutions à plus tard, c'est à dire à l'espace extradiégétique. Le texte extrapole les limites du temps de sa projection et réclame d'être mis en relation avec beaucoup d'autres éléments du réel pour pouvoir fonctionner. Au contraire du 
film de fiction classique qui, clos sur lui-même, est capable d'une certaine autonomie, Terra em transe exige d'être repensé à l'aune du réel pour que dans de constants allers-retours de l'un à l'autre quelque chose puisse être compris. Texte limite, car refusant de se plier aux codes culturels qui régissent notre pratique du cinéma, Terra em transe résiste à l'ensemble de ses transgressions qui sont autant de pulsions d'autodestruction en activant chez le spectateur les modes de lecture spectaculaire, esthétique, énergétique, fictionnel et, pour ses contemporains, privé ${ }^{774}$. Ainsi, en refusant au spectateur la jouissance des attraits classiques de la fiction, Terra em transe en propose d'autres qui se cumulent jusqu'à provoquer l'étourdissement des sens $^{775}$ et des émotions ${ }^{776}$.

Le mode de lecture spectaculaire qui consiste à voir le film comme un spectacle est activé par les séquences où le surréalisme est si grand qu'il est impossible de ne pas en apprécier les qualités de réalisation. Le film incite le spectateur à se demander comment ces séquences ont pu être faites. C'est le cas des meetings de Vieira dans lesquels la présence de la multitude est à la fois un facteur d'authenticité et de trouble. C'est « vrai » parce que la foule est là, présente et qu'elle n'a pas pu être « inventée » comme on pourrait le faire aujourd'hui en image de synthèse $\mathrm{e}^{777}$. C'est «faux » parce que ce que l'on voit est trop extraordinaire pour pouvoir être accepté comme vraisemblable sans preuve supplémentaire à celle que fournit l'image $^{778}$. La démesure confère à l'image un certain caractère d'abstraction et crée une distance qui entraîne sa prise en considération comme produit de spectacle. Le mystère de la réalisation concrète de l'image permet d'établir une relation de fascination entre le spectateur et l'objet filmique.

Le mode de lecture esthétique est engagé par la qualité de la photographie, de la scénographie et des poèmes qui ponctuent le récit. Il est soutenu par la surprise que provoquent les différentes innovations formelles qui surgissent au gré de la narration. Sa

774 ESQUENAZI, Jean-Pierre, ODIN Roger. « Cinéma et réception », op. cit., p. 57.

775Perte des repères spatio-temporelles, jouissance esthétique du texte filmique (rythme, cadrage, composition de l'image, mouvement de la caméra, couleurs, scénographie). Le noir et blanc des images de l'orgie est, par exemple, à même de créer une forte impression visuelle, notamment à cause du fort contraste qui règne dans cette scène d'intérieur.

776Terra em transe a parfois été décrit comme une suite ininterrompue de climax. La fragmentation de la narration est compensée par le fonctionnement pratiquement autonome des scènes qui sont toutes d'une grande intensité dramatique. Considérons à titre d'exemple la scène du coup d'État, celles des disputes entre Diaz et Martins, celle de la rencontre entre Sara et Martins. L'intensité dramatique est liée, soit aux crises de la grande histoire (les événements politiques décisifs), soit aux crises personnelles des personnages qui expriment leur frustration les uns envers les autres ou envers eux-mêmes (les disputes et les trahisons). Sans qu'il soit possible de reconstituer précisément la fabula, ces émotions basiques sont très clairement exprimées dans le texte filmique.

777Certains plans de la séquence du meeting de Vieira sont extraites du documentaire de Rocha intitulé Maranhão 66 sur la campagne électorale de José Sarney qui deviendra gouverneur du Maranhão.

$778 \mathrm{Ce}$ genre de remarque est possible car bien que situé dans un univers fictif qui ne peut être identifié à notre monde, la diégèse de Terra em transe n'en partage pas moins avec le notre les mêmes règles physiques et, pourrait-on dire, économiques, politiques et sociales. Le spectateur imagine donc que les règles du jeu politique dans Terra em transe sont comparables avec celles de son monde. 
fragmentation et l'option consistant à faire raconter l'histoire par un personnage en crise animé de délire peut apparaître comme un défi remettant à l'aspect ludique des jeux de langage. Le montage remettra constamment à ce mode de lecture soit en contribuant à la fragmentation du récit, soit en posant les bases du tropicalismo. Ce mouvement artistique qui commence avec Terra em transe consiste à exploiter les contradictions culturelles et sociales d'un pays sousdéveloppé. Ainsi, par les recours du montage visuel ou sonore, interne ou externe, trois grandes ruptures sont mises en scène : celle opposant modernité et archaïsme, celle opposant peuple et élite et celle existant entre l'éloquence de la parole et l'absence de l'action. En isolant des contradictions appartenant au réel dans l'œuvre d'art, le tropicalismo produit des effets surréalistes et s'impose comme l'art du collage. Mieux, la juxtaposition du surréalisme des séquences oniriques avec le surréalisme des séquences documentaires (le meeting) incite le spectateur à se poser la question de la validité d'une lecture esthétique non plus du film mais aussi et surtout du réel.

Le mode de lecture énergétique est également mobilisé simultanément à d'autres modes puisque autant la musique que les mouvements de caméra ou le montage hors continuité nous entraînent à vibrer au rythme des images et des sons. Les trois séquences d'ouverture sont à ce titre exemplaires. Nous arrivons par un vol rasant au-dessus de la mer et bientôt surgit une forêt dense et inquiétante (travelling aérien, séquence 1). Sans transition, nous sommes poussés au milieu d'un groupe de personnes en crise qui s'inquiètent, qui parlent fort, qui évoluent nerveusement. La caméra portée nous transmet à la fois une impression de proximité et d'agitation. L'impression d'avoir été poussé au milieu de la cohue et d'y participer soi-même est physique. Martins surgit, la caméra le suit et nous avec. Dans la séquence suivante, nous sommes déjà en fuite, Sara et Martins se disputent. L'absence de transition entre les séquences, le mouvement constant de la caméra et devant la caméra, le bruit, les cris, la musique, tout dans Terra em transe interdit la contemplation passive et participe à plonger le spectateur dans un certain état d'excitation en phase avec l'action du film.

L'ensemble des «tours de force » techniques et esthétiques ainsi que l'originalité du long métrage dans son intégralité engage l'activation du mode de lecture artistique, le film est vu comme la production de l'auteur déjà consacré «Rocha ». La séquence du début est d'ailleurs une référence intertextuelle remettant à son film précédent Deus e o diabo na terra do sol. L'image de la mer en plongée incite à intégrer le film dans le corpus d'une œuvre, la sienne. Pour autant, le singulier ne l'emporte pas sur le collectif et c'est peut être justement parce que la fragmentation de la narration gêne considérablement l'actualisation univoque de la fabula que le film peut et doit également engager le mode de lecture privé. Le fait qu'il commence avec la séquence du coup d'État n'est pas un hasard. D'une certaine façon, 
l'emphase apportée sur l'absence d'affrontements militaires, la crainte d'une effusion de sang et la couardise du gouverneur déposé sont des références claires qui contraignent le spectateur à identifier la situation montrée à l'écran avec celle du coup d'État du 1er avril 1964. Les différences factuelles importent peu. Pour autant, ce n'est pas le mode documentaire qui peut être activé car, comme nous l'avons vu, le film ne va pas cesser de se dénoncer comme un fabriquant d'illusions. C'est le mode de lecture privé qui est convoqué. Implicitement, cette séquence 2 engage le spectateur contemporain au film à le voir pour revenir sur son vécu et celui du groupe auquel il appartient, la nation brésilienne, aussi morcelée soit-elle.

Parmi les autres modes de lecture formalisées par Odin, nous ne pourrons exclure le mode fictionnel car, malgré l'inintelligibilité partielle de la fabula, il est tout de même possible de vibrer au rythme des événements racontés. Il est intéressant de noter à ce sujet que le texte filmique ne retient des événements que leur valeur symbolique et l'émotion que nous pouvons leur associer. Dans le cas de la séquence du coup d'État par exemple, toute dimension factuelle est évacuée car beaucoup trop embrouillée. Peu importe qui sont vraiment les acteurs en présence et l'engrenage des événements qui les a conduit à la situation qui nous est décrite, l'important est qu'il s'agît d'un coup d'État autoritaire, que ces gens sont soumis par la force et qu'ils sont envahis par la peur. Ainsi, au contraire de ce qui pouvait constituer l'essence du réalisme critique développé par le Cinema Novo, à savoir l'idée que l'émotion devait surgir d'une histoire non pas exploitée mais servie par le cinéma pour en transmettre toute la "vérité » et l' « authenticité », alors même que l'émotion ne devait pas être "forcée » mais « naître » de façon naturelle de la reconstitution du réel, révélé et interprété, Terra em transe dénonce cette démarche et exploite à plein rendement les artifices du cinéma ${ }^{779}$.

Le fait que le mode de lecture fictionnel ne puisse être exclu nous remet à l'analyse de ce qui constitue le fil rouge de l'histoire à savoir la trajectoire de Martins. Le journaliste de Terra em transe est l'archétype de l'anti-héros, c'est un personnage dont nous ne savons finalement que peu de choses, sinon qu'il se trompe constamment et qu'il a en conscience. Nous savons aussi que sa « soif de l'absolu » est suspecte et son identification avec Diaz est bien trop ostensible pour que l'on ne comprenne pas qu'il est aussi étranger que son ancien mentor aux véritables causes populaires. Martins est un individu qui ne peut concevoir son identité que dans une relation d'opposition avec la représentation qu'il se fait du peuple et de la collectivité. Cette représentation est vague, il s'agit d'une pure abstraction mentale, d'une catégorie de l'esprit qui tente de rendre compte du réel en tentant d'en réorganiser le chaos $a$ priori. Le «peuple» est pour Martins (comme il l'était pour Roland Corbisier) un tout réalisme critique. Il apparaît alors clairement deux orientations dans le Cinema Novo qui chacune vise le réel par des moyens différenciées. 
globalisant dont il a peur qu'il absorbe et détruise l'individu. Le peuple est faible, ignorant et lâche, il est l'antithèse de ce qui fait l'excellence dans l'homme, il est le fossoyeur de ces êtres d'exception qui portent, le temps d'une vie, le génie humain. L'avènement du peuple ne seraitil pas le signal de la fin de l'histoire et donc aussi de la vie ?

Ainsi, en même temps qu'il dit s'inquiéter des souffrances endurées par le peuple, Martins ne peut agir que dans une relation médiatisée au réel, par l'intermédiaire de son travail de journaliste ou par l'intermédiaire des élites politiques qu'il pense pouvoir manipuler tout en gardant son anonymat. Sa stratégie consiste continuellement à penser qu'il peut faire faire par d'autres cette action de transformation qu'il souhaite et, à la fois, éloigne de lui. L'ambivalence que trahit son comportement, repose sur une perception biaisée du réel fondée sur un réseau de préjugés et de croyances qui sont beaucoup plus l'écho de ses peurs intimes que de son approche circonstanciée du réel. Le journaliste se révèle incapable de réfléchir à chaque fois qu'il est question du «peuple» alors qu'il raisonne froidement pour tout ce qui concerne l'opposition des élites politiques. Ainsi, il pèse toujours sur lui la suspicion selon laquelle le désir de justice qui l'anime serait en fait un désir d'ordre mortifère dissimulant mal des tendances fascistes et autoritaires.

Outre ce déséquilibre patent dans l'économie intellectuelle du personnage, ses motivations sont troubles. L'oscillation constante de Martins le prive des idéaux qui pourraient lui permettre de donner un sens politique à cette révolution qu'il souhaite sans savoir ce vers quoi elle devrait tendre et comment elle devrait se faire. L'enjeu de la révolution est pour lui à la fois métaphysique et affectif. La révolution représente le moment de la coïncidence de l'individu avec l'histoire, autrement dit le moment où il pourra s'accomplir en tant que sujet et se rencontrer lui-même dans la plénitude de l'être achevé. Elle sera aussi le moment de la fin de cette douleur morale et intime qui le poursuit sans relâche. En mettant un terme à la souffrance des opprimés, la transformation effective du monde lui permettra aussi à lui, qui ne souffre pas comme « eux», de trouver la paix que sa conscience lui interdit. Martins est ainsi le produit d'une conscience inauthentique, prisonnier d'un cercle vicieux qui le rend incapable de penser le monde et de se penser dans le monde, il est pourtant notre guide dans un pays, Eldorado, transformé en labyrinthe.

Martins appartient a une série de personnages qui commence avec Firmino dans Barravento, continue avec Antônio das Mortes et Gaúcho dans Os Fuzis et se poursuit encore avec Marcelo dans $O$ Desafio. Cette série se terminera avec le député de O Bravo Guerreiro et le Tiradentes de Os Inconfidentes. L'idéologie de ces personnages et leur caractère oscillant, entre la droite et la gauche, les classes populaires et les classes dominantes, permettent, comme l'a analysé Bernardet dans Brasil em tempo de cinema, de les identifier 
aux cinéastes. Cette identification est d'abord inconsciente, c'est le cas tout au long de la première phase du Cinema Novo, entre 1960 et 1964. Mais, à partir de la deuxième phase et plus particulièrement de $O$ Desafio, cette identification devient consciente et travaillée. Les attributs de ces personnages sont d'ailleurs de plus en plus proches de ceux des cinéastes, ils deviennent journalistes, écrivains ou politiciens et, de façon assumée, ils vont servir à discuter les contradictions de l'intellectuel de gauche dans le contexte brésilien. Témoins de conflits entre la classe dirigeante et le peuple qui ne les atteignent pas directement, ils portent en eux la volonté de participer mais hésitent quant à la place qu'ils doivent occuper. D'un côté, ils sont indignés par l'injustice dont sont victimes les opprimés, mais de l'autre, ils se les représentent comme des êtres ignorants, apathiques et aliénés, incapables de se sauver par eux-mêmes. Enfin, ce sont des personnages dépendants des oppresseurs qui sont souvent ceux qui les paient et dont ils sont socialement plus proches.

Dans Terra em transe, la caractérisation des espaces permet de prolonger l'autocritique de l'intellectuel. Jean-Claude Bernardet et José Coelho Teixeira en ont proposé une analyse ${ }^{780}$. Ils constatent une nette prédominance des espaces fermés, qui sont les espaces de l'action et du pouvoir, par rapport aux espaces ouverts comme la mer et la forêt, qui caractérisent Eldorado comme un tout ${ }^{781}$ tout en restant des points obscurs de la connaissance des personnages et de la caméra. Les espaces fermés ne correspondent pas systématiquement aux intérieurs des édifices dans lesquelles évoluent les personnages. Il peut aussi s'agir de séquences d'extérieur dans lesquels l'espace a été circonscrit par le cadrage. Ainsi, la caméra nous interdit sans cesse de pénétrer une partie de l'espace d'Eldorado en focalisant sur les personnages qui semblent alors eux-même prisonniers des limites du cadre. Exactement de la même façon dont Martins est attaché à Diaz et Vieira, le spectateur est attaché aux personnages par la caméra et donc, dans l'incapacité de sortir de la configuration qu'ils dessinent. Bernardet et Teixeira remarquent aussi que les espaces fermés participent à la caractérisation des protagonistes principaux alors que les espaces ouverts ne caractérisent pas les individus qui les habitent. Les espaces de Diaz, de Vieira, de Fuentes et de Martins sont ainsi clairement différenciés.

Diaz évolue dans des espaces dominés par la verticalité, l'ordre et la solitude. Nous le retrouvons souvent isolé par le cadrage, au sommet de l'escalier de marbre sur lequel s'ouvre le hall de sa luxueuse maison, debout sur une voiture paradant avec son crucifix et son

780BERNARDET, Jean-Claude, TEIXEIRA, Coelho José (org.). Terra em transe Os Herdeiros : Espaços e poderes - Texto de trabalho. Op. cit.

781Dans la séquence 1, Eldorado est caractérisé comme un pays tropical par la bande-son (musique afrobrésilienne), le carton («Eldorado, país interior, Atlântico ») et les plans successifs de la mer, des montagnes et de la forêt, dense, impénétrable. 
drapeau noir, au sommet d'une montagne, toujours avec son drapeau et son crucifix, au-dessus de l'assemblée, dans la séquence du couronnement. Vieira, au contraire, évolue dans des espaces dominés par l'horizontalité, sans escalier, accompagné de personnages qui marchent à sa hauteur bien qu'il en soit séparé par le cadrage. Sa maison et son palais sont plus simples que la demeure de Diaz, lui-même se tient généralement à l'extérieur des bâtiments, en terrasse, mais l'espace est circonscrit par des murs opaques, comme dans la séquence du repas avec Martins et Sara, par la foule, comme dans les séquences de meeting, ou par la végétation. C'est le cas des arbres qui encerclent la terrasse du palais dans la séquence de son abdication. Les espaces de Fuentes (le bureau, lieu indéfini de l'orgie, le sommet de gratte-ciel avec son antenne de télévision) mettent l'emphase sur son pouvoir sur les hommes, la technologie et même la nature. Au contraire de Vieira qui se trouve cerné par une nature mystérieuse et hostile, Diaz évolue dans un parc où la nature est domestiquée et Fuentes dans un bureau où l'image de la nature est reproduite sur une tapisserie.

Martins transite dans ces différents espaces mais aussi dans d'autres qui lui sont propres. Ainsi, par exemple, son appartement est un duplex, ses échanges avec Sara et Silvia passent par la médiation des escaliers et sont caractérisés par l'instabilité. Il monte rejoindre Silvia pour une relation sexuelle strictement objectivée. Celle-ci est associée à l'univers de Diaz et, de façon significative, reste toujours muette. Martins descend pour trouver Sara qui le remet devant l'exigence d'une action transformatrice et lui demande de rejoindre Vieira. Quand Martins retrouve Sara, Silvia, allongée dans le hamac, demeure silencieuse au second plan $^{782}$. Les escaliers, dans Terra em transe, composent un véritable système qui définit les relations de Martins avec les différents centres du pouvoir entre lesquels il oscille. Ils révèlent autant les relations hiérarchiques qui unissent les différentes instances du pouvoir avec Diaz et Fuentes au-dessus des autres, qu'ils ne matérialisent les allers et venues de Martins entre leurs différents niveaux, voire même ses tentatives d'échapper à leur séduction ${ }^{783}$.

Les espaces ouverts sont le lieu d'une végétation dense et envahissante (la forêt), soudain inquiétante quand celle-ci « ferme » l'espace ouvert. C'est le cas des séquences dans lesquelles Vieira abdique, la forêt cerne la terrasse, interdit la fuite et en même temps condamne par son silence. Les espaces ouverts sont aussi les espaces du peuple. Dans ses espaces, la caméra échappe aux suggestions de position et de cadrage que lui soumettent les architectures des palais de Diaz ou de Vieira. Les baraquements des pauvres ne sont pas pris en compte par l'objectif de la même manière que le sont les scénographies des séquences rien, / Seule la chair me taraudait et en elle je me retrouvais. ») 
d'intérieures : ils sont ignorés. Ce refus de caractérisation du peuple par l'espace marque une rupture franche avec les procédés de caractérisation des autres personnages. Ainsi, le peuple n'existe que dans les propos de ceux qui s'en excluent et se conçoivent comme supérieurs à lui. Ses représentants sont bâillonnés ou assassinés comme dans la séquence du meeting. Le peuple n'existe que par des médiations et ce réflexe unanime des élites qui consiste à s'en écarter. De tous, Vieira est celui qui l'approche de plus près mais il entretient avec le peuple et la forêt qui sont Eldorado une relation de défiance et d'inquiétude. Eldorado nous apparaît alors comme un espace interdit par les personnages et la caméra qui s'enferment dans le microcosme politique qui prétend détenir le pouvoir.

L'incertitude qui pèse constamment sur l'identité de l'instance narratrice qui conduit le récit nous empêche de savoir vraiment si c'est Martins qui se figure lui-même dans un labyrinthe qui apparaît sans issue ou s'il est figuré dans ce labyrinthe par une instance narratrice qui serait hiérarchiquement plus élevée que la voix off. Cette nuance importe peu car l'important réside dans l'incapacité dans laquelle il se trouve d'inventer cette nouvelle poétique qui, selon lui, serait aussi une nouvelle politique. Prisonnier des centres du pouvoir qui exercent sur lui un magnétisme invisible, il est incapable de penser autrement qu'avec eux et selon eux, autrement dit sans cette entité vague et indéfinie qui serait le peuple. Cette contradiction interne à la psychologie et à la pensée politique de Martins est à la fois ce qui le pousse au délire et ce qui fournit l'axe principal de la trame fictionnel de Terra em transe. Ainsi, Eldorado nous est présenté au travers de la glace déformante d'un personnage acculé car incapable de voir clair et subjugué par une volonté d'omnipotence sans cesse frustrée.

Dans son monde recomposé par des allégories, Martins apparaît comme le seul personnage analogique. Sa particularité consiste à être un personnage réaliste dans un univers diégétique anti-naturaliste. Tous les autres personnages condensent des personnages historiques qui symbolisent les forces en action dans le Brésil des années soixante. Tous sont gagnés par la transe sauf Sara qui possède un statut particulier. Celle-ci apparaît comme le seul personnage rationnel et constant, le seul aussi à être porteur d'une humanité dont les autres sont dénués. De tous, elle est aussi la seule à détenir une conscience claire des événements, elle sait ce que Martins et avec lui le spectateur ne savent pas, elle est la seule à borner le délire que les autres alimentent. Ainsi, ses paroles résonnent de façon particulière quand, au contraire de ce qui fait le désespoir de Martins, elle lui affirme que « A culpa não é do povo. » (« Ce n'est pas la faute du peuple. ») C'est la deuxième référence intertextuelle à Deus e o diabo na terra do sol, puisque nous entendions déjà dans ce film exactement les mêmes mots. Ils étaient dits alors par le chanteur aveugle à Antônio das Mortes. Martins sera pourtant incapable d'entendre Sara à chaque fois qu'elle contestera son comportement. 
Il est intéressant de constater que, dans les dernières séquences, celles où devrait se terminer le flashback et avec lui la narration subjective, la mise en scène donne raison à Sara. Martins se transforme en allégorie de la guérilla et s'enfonce dans les dunes, seul et isolé, détaché de toute réalité. Sara reste sur la route dont le point de fuite nous est caché, prise aux choses du monde concret.

Contrairement aux idées reçues quant à la réception de Terra em transe, le troisième long métrage de Rocha ne fut pas, en son temps, si mal reçu ou si mal compris qu'on le dit généralement. Le film sort simultanément dans quinze salles de la chaîne de cinéma Lívio Bruni à Rio de Janeiro ${ }^{784}$ et rassemble 100000 spectateurs en trois semaines ${ }^{785}$. Carlos Diegues, co-producteur de Terra em transe, estimait en 1970 que le film devait avoir atteint les 180000 spectateurs sur le territoire brésilien ${ }^{786}$. Si ces chiffres sont très éloignés des «blockbusters » de l'époque qui dépassent le million d'entrées, ils n'en apportent pas moins la preuve d'un beau succès rapportés aux performances contemporaines du cinéma d'auteur. D'ailleurs, les coûts de production sont amortis sur la seule exploitation carioca.

Ces bons résultats sont certainement dûs à une excellente couverture des journaux et aux démêlés du film avec la censure. Nous traiterons dans une autre partie de la réception de Terra em transe par la censure car nous considérons que l'accueil fait aux films brésiliens par la censure était autonome de celle qui pouvait en être faite par le public et la critique. Toujours est-il que la libération du long métrage a été l'objet d'une lutte assez âpre suite à une première décision d'interdiction sur tout le territoire. Le scandale occasionné par cette décision favorise le lancement du film. Zelito Viana rappelle qu'avant sa sortie, Terra em transe a fait la première page des quotidiens à cause de cette interdiction ${ }^{787}$. Une fois de plus, le lancement du film coïncide avec son passage à Cannes et la presse ne manque pas d'opposer l'intolérance et l'arbitraire de la censure avec les excellentes critiques recueillies en Europe $^{788}$. Terra em transe sort au mois de mai, auréolé de son succès à Cannes. Après sa

784Information apportée par Zelito Viana. In SIMÕES, Eduardo et BIAGGIO, Jaime. « Violência e paixão » in O Globo, Segundo Caderno, Rio de Janeiro, 10/04/2005.

785ROCHA, Glauber. Depois do transe. Texte dactylographié, 4 pages, archives Tempo Glauber, sans date, probablement 1969.

786DIEGUES, Carlos. « Entretien avec Carlos Diegues » in Cahiers du cinéma, Paris, n²25, novembredécembre 1970.

787SIMÕES, Eduardo et BIAGGIO, Jaime. Op. cit.

788Depuis les débuts du Cinema Novo, la presse relaie régulièrement les critiques positives obtenues en Europe. Nous retrouvons ainsi des articles de type « revue de presse étrangère » avec la traduction de larges citations. Certains critiques français et italiens sont ainsi bien connus des cinéphiles brésiliens. Sur Terra em transe, Sérgio Motta du Correio da manhã met l'emphase sur les dithyrambes du journal Le Monde : «Terra em transe é uma obra soberba, de inspiração livre e de arrebatamento crítico, uma espécie de ópera grandiosa, às vezes um pouco longa, outras sublime, em que os poemas alternam com os diálogos e parecem ter a função de recitativos. » («Terra em transe est une œuvre superbe, d'inspiration libre et d'excellence critique, une espèce d'opéra grandiose, parfois un peu longue, parfois sublime, dans laquelle les poèmes alternent avec les dialogues et paraissent avoir la fonction de récitatifs. ») in MOTTA, Sérgio. «Le Monde : Terra em transe é ópera crítica e sublime » in Correio da manhã, Rio de Janeiro, 09/05/1967. 
sortie, la critique cinématographique brésilienne se détache cependant assez rapidement de l'exploitation de ces deux éléments factuels pour développer sa propre lecture de ce qui constitue déjà l'un des grands événements cinématographique de l'année.

Terra em transe sort dans les cinémas dans un contexte très particulier. En 1967, l'arrivée au pouvoir d'un second président militaire, le général Costa e Silva, qui, selon une pratique qui va se pérenniser, a été désigné par le haut-commandement des armées, balaye complètement les espoirs de retour à la démocratie entretenus par son prédécesseur, le Maréchal Castelo Branco. Parallèlement à la consolidation du régime, l'opposition se radicalise et se divise. Sans que cela ne corresponde pour autant à un massif passage à l'acte, l'option de la guérilla rassemble de plus en plus de sympathisants. Terra em transe, qui est le premier film brésilien à traiter de ce sujet, ouvre la boîte de Pandore quant au contenu fantasmatique que pouvait recéler l'image d'un homme, une arme brandie vers le ciel, rebelle à un régime injuste et autoritaire. À partir de là, comme le rappelle Luiz Carlos Barreto, plusieurs lectures parallèles de Terra em transe seront pratiquées : «O público universitário tinha uma leitura política do filme. E o grande público era conquistado pelo senso de espetáculo, pelo tom épico [...]. $\rangle^{789}$ Face à ces deux strates différenciées d'actualisation du film et s'obligeant à la prudence par crainte de la censure ${ }^{790}$, la critique cinématographique réserve au film un accueil positif ${ }^{791}$ et en pratique une lecture assez proche de celle que nous en avons faite plus haut. L'emphase est portée sur la dimension réflexive de l'œuvre qui ne peut en aucun cas être considérée comme un film de propagande pour une cause ou une autre.

Les critiques les plus élaborées concernant Terra em transe vont s'attacher à montrer comment la trajectoire de Martins permet de développer une critique de la culture politique brésilienne et de son incapacité à prendre en compte le réel et à agir sur lui autrement qu'en

789 « Le public universitaire avait une lecture politique du film. Et le grand public était conquis par le sens du spectacle, par le ton épique [...]. » in SIMÕES, Eduardo et BIAGGIO, Jaime. Op. cit.

790En 1967, les journaux ne sont pas encore soumis à la censure de façon systématique comme ils le seront après l'AI-5. Il subsiste une certaine liberté d'expression même si elle est peut être menacée de façon ponctuelle par le caractère arbitraire du régime. Conscients de la polarisation croissante de la vie politique du pays et de la menace d'un durcissement du régime, les journalistes d'opposition, qui ont contracté depuis longtemps l'habitude de travailler dans des quotidiens conservateurs, les seuls qui existent au Brésil, s'obligent certainement à une réserve supplémentaire sachant pertinemment que certaines limites ne sauraient être franchies. La situation politique encourage donc à la circonspection mais favorise également le doublejeu. Ceux qui exploitent les contradictions du système avec l'idée de transmettre des idées et des valeurs qui lui sont contraires côtoient ceux qui en sont des partisans. La situation se complique singulièrement dans le cas du cinéma où nous avons une censure institutionnalisée. Ainsi, une « bonne critique » pouvait « couler » un film en attirant sur lui l'attention de la censure alors qu'une « mauvaise » pouvait en assurer la libération. Quand un critique aussi influent que Moniz Viana écrit que Terra em transe est un film à la narration défaillante et parfaitement inintelligible, il rassure beaucoup mieux les censeurs que tous ceux qui articuleront une lecture politique et en parleront comme d'un film de conscientisation.

791 Terra em transe est notamment classé sixième meilleur film de l'année 1967 par le Jornal do Brasil en concurrence avec des films du niveau de El Ángel exterminador (L'Ange exterminateur, Luis Buñuel, Mexique, 1962) et Il Vangelo secondo Matteo (L'Évangile selon St Matthieu, Pier Paolo Pasolini, Italie, 1964) sortis tardivement au Brésil. In GOMES LEITE, Maurício. « Tropicália » in Jornal do Brasil, Rio de Janeiro, 31/01/1968. 
protégeant les intérêts des classes dominantes. Dans un article intitulé «As Metáforas da transigência », Mário Chamie défend la pertinence du choix de la structure du film, celle d'un poème épique dans la tradition latino-américaine, vis à vis des intentions critiques qui animaient l'auteur :

«A estrutura de Terra em transe, fundada nos processos típicos do poema longo não oferece mistérios. Não sofre vacilações ou exageros. Os aparentes excessos são previsíveis e codificados na sua articulação geral. [...] $\mathrm{O}$ caos foi ordenado. Todos os acontecimentos foram transformados em protótipos e os protótipos em metáforas. [...]

O reino da metáfora porém, é o da transigência porque não entra no centro dos acontecimentos para resolvê-los. Ao contrário, sublima-os em imagens absolutas e acabadas. Toda metáfora será sempre um belo tema justaposto aos problemas feios da realidade viva.

GR, ao organizar o desorganizado, ao compactuar com o universo poético de Martins, nos deixa em aberto o direito de sermos intransigentes par com Terra em transe. Apesar de sua estrutura clara. $\gg{ }^{792}$

Dans une lecture très proche de celle de Chamie, Tobias Tela ${ }^{793}$ retient l'esthétique baroque, la structure du poème long et la satire de la tradition latino-américaine. Nous retrouvons dans son texte cette idée selon laquelle la structure du film permet de critiquer une culture politique dans laquelle il est courant d'utiliser de grands discours et de belles métaphores afin de transiger avec la réalité. Ainsi, les défaillances ostensibles de la structure narrative et les interventions de la caméra et du montage, permettraient à Terra em transe d'identifier et de critiquer une pratique en l'adoptant lui-même et en en exagérant les traits. Il s'agirait d'une démarche proche de la démonstration par l'absurde teintée cependant d'une grande anxiété :

«A grandiloqüência é a nossa medida. Mas a grandiloqüência sempre foi madrasta. Sempre procurou tapar buracos e iludir conteúdos. Quando percebemos cristalinamente os atos e comportamentos que sustentam uma situação social iníqua, e nos vemos incapazes de resolver a iniqüidade e de racionalizar os meios para tanto, tornamo-nos declamadores para iludir o abismo de nossa frustração. ${ }^{794}$

792« La structure de Terra em transe, fondée sur les principes typiques du poème long, ne présente aucun mystère. Elle ne souffre pas non plus de vacillations ou d'exagérations. Les apparents excès sont prévisibles et codifiés dans son articulation générale. [...] Le chaos a été organisé. Tous les événements ont été transformés en prototypes et les prototypes en métaphores.

Le règne de la métaphore est pourtant aussi celui de la transigeance, parce qu'elle n'atteint pas le centre des événements pour les résoudre. Au contraire, elle les sublime dans des images absolues et achevées. Toute métaphore sera toujours un joli thème juxtaposé aux problèmes répugnants de la réalité vivante. GR, en organisant ce qui était désorganisé, en acceptant de se compromettre avec l'univers poétique de Martins, nous laisse libres d'être intransigeants envers Terra em transe. Malgré la clarté de sa structure. » in CHAMIE, Mário. « As Metáforas da transigência » in O Estado de São Paulo - Suplemento literário, São Paulo, 08/07/1967.

793TELA, Tobias. « Glauber ou a necessidade da frustração » in Mirante das artes, São Paulo, n 4 , juillet-août 1967 , p. 38.

$794 \ll$ La grandiloquence est notre mesure. Mais la grandiloquence a toujours été fausse. Elle a toujours cherché à cacher les failles et dissimuler le sens des choses. Quand nous comprenons de façon cristalline les actes et les comportements qui maintiennent une situation sociale inique, et que nous nous voyons incapables de résoudre l'iniquité et de concevoir les moyens de le faire, nous déclamons des poèmes pour nous dissimuler à nous-mêmes l'abîme de notre frustration. » in ibid. 
Il apparaît dans les critiques qui partagent cette lecture que Terra em transe se révèle un film démystificateur de proche en proche, pratiquement par contamination. En soumettant à l'activité critique du spectateur la trajectoire d'un poète « estruturalmente fascistoïde », selon les termes de Louzada Filho ${ }^{795}$, en mettant en exergue les errements de cette « cópia suja » (« copie sale ») de Diaz, tel qu'Álvaro le nommait dans le film, c'est bien le problème de la manutention du pouvoir par des élites fascisantes que l'on touche, puis celui de la nonreprésentation du peuple dans le jeu politique. Chamie explique ainsi comment le personnage de Diaz permet de dénoncer les mécanismes sur lesquels ces élites s'appuient pour se légitimer : la superstition, l'idolâtrie, la mythification du passé, le folklore sentimental et la nécessité de l'éternel sacrifice :

\begin{abstract}
« Diaz sabe [...] que a melhor forma de assegurar os interesses de mando da classe de que é prototipo é desprezar e manter o povo distante e proclamar a eterna proteção aos mitos consentidos em nosso inconsciente. E mais : é proclamar a implacabilidade de uma ação impiedosa contra os que querem levar o povo ao sacrilégio de reconhecer que, além de suas camadas profundas e de seus avatares espirituais, existem o cotidiano duro de nosso pão de cada dia. ${ }^{796}$
\end{abstract}

Louzada Filho explique que Terra em transe est un film politique sur la politique qui remet au centre des enjeux la question de la non-participation du peuple :

« Político, exige de uma forma ou outra, o comparecimento do povo. [...] está implícita no filme a possibilidade ou a necessidade de luta contra a miséria. Não estivesse, e não seria necessário o comparecimento de tais questões e dados, mais ainda : não haveria esse transe tomando Eldorado e o filme. $\gg{ }^{797}$

À côté de ces critiques, certaines, moins approfondies mais tout aussi favorables, développent aussi une analyse de la trajectoire oscillante de Martins ${ }^{798}$. D'autres encore estiment que le nouveau film de Rocha est pleinement réalisé dans son intention à déclencher une polémique constructive quant à la situation alors traversée par le pays ${ }^{799}$ :

«Dentre as qualidades de Terra em transe destaca-se a polêmica que produz no espectador

795 LOUZADA FILHO, O.C. « O Filme e o transe » in O Estado de São Paulo - Suplemento literário, São Paulo, 01/07/1967.

796« Diaz sait [...] que la meilleure façon de protéger les intérêts de la classe dont il est le prototype est de mépriser et de maintenir le peuple à distance et de proclamer l'éternelle tutelle des mythes acceptés par notre inconscient. Et plus : qu'il faut punir par une répression implacable ceux qui voudraient faire perpétrer au peuple ce sacrilège consistant à reconnaître que, au-delà de ses couches profondes et de ses avatars spirituels, il existe le dur quotidien du pain à gagner chaque jour. » in CHAMIE, Mário. Op. cit.

797 « Politique, le film exige d'une façon ou d'une autre, que le peuple se présente. [...] il est implicite dans le film la nécessité ou la possibilité de lutte contre la misère. Sans cela, l'évocation de telles questions ou de telles données ne serait pas utile, plus encore : il n'y aurait pas cette transe qui envahit Eldorado et tout le film. » in LOUZADA FILHO, O.C. «O Filme e o transe », Op. cit.

798GOMES LEITE, Maurício. «Tropicália » in Jornal do Brasil, Rio de Janeiro, 31/01/1968. Entre autres.

799AUGUSTO, Sérgio. « Terra em transe » in Jornal do Brasil, Rio de Janeiro, 09/05/1967. M.P. «Terra em transe » in O Globo, Rio de Janeiro, 10/05/1967. 
consigo mesmo e deste para os outros. [...] O público reage, coloca-se em ' transe '. Embora as reações sejam as mais variadas e oscilem em diversos níveis, o fato é que Terra em transe provoca, excita e instiga o público através de uma linguagem assistemática, nervosa, discursiva, moderna. $»^{800}$

Au contraire de Deus e o diabo na terra do sol, Terra em transe ne fait cependant pas l'unanimité. Au milieu d'un dossier de presse globalement favorable, il est aussi possible de trouver des critiques très négatives qui discutent à la fois les compétences et les intentions de cinéaste. L'influent Antônio Moniz Viana du Correio da Manhã estime que Terra em transe est un agrégat d'influences mal assimilées et présente une structure narrative qui, à trop vouloir désorienter le spectateur, finit par ne plus produire aucun sens. Pour lui, le film est inintelligible et représente une régression à un niveau inférieur à celui de Barravento, c'est à dire à un premier film ingénu et mal fait, pour un cinéaste qui avait pourtant su démontrer un potentiel prometteur avec Deus e o diabo na terra do $s o l^{801}$. Plus nuancée, Zulmira Ribeiro Tavares $^{802}$ rejoint Moniz Viana quand elle conclut que la démesure, dans Terra em transe, atteint l'incohérence. D'autres doutent des intentions progressistes de Rocha, José Carlos Monteiro estime que Terra em transe, comme $O$ Desafio et $O$ Padre e a moça, trahit les postulats de base du Cinema Novo mieux représentés par A Grande Cidade, A Hora e a vez de Augusto Matraga ou encore Menino de Engenho. Terra em transe est pour lui un film équivoque et formaliste ${ }^{803}$.

En plus de compiler tous les reproches déjà adressés par d'autres, Ely Azeredo remarque quant à lui que ce long métrage sur la politique latino-américaine présente de graves omissions et pratique des rapprochements discutables qui lui interdisent d'en constituer une expression juste et complète. Il note que les mouvements étudiants ou ouvriers sont absents, de même les questions du terrorisme et du militarisme du cône sud. Autrement dit, trois caractéristiques importantes de la vie politique latino-américaine sont oubliées au profit de la focalisation sur un personnage aliéné, un poète « romantique et tourmenté ${ }^{804}$.

Les coupures de presse ne nous transmettent pourtant pas toute la vigueur des polémiques déclenchées par Terra em transe, qui, selon différents témoignages, furent assez vives. Caricature des classes dominantes, Terra em transe pouvait difficilement satisfaire à

800 « Entre les qualités de Terra em transe, se distingue la polémique qu'il provoque chez le spectateur avec luimême et avec les autres spectateurs. [...] Le public réagit, entre en ' transe '. Bien que les réactions soient des plus variées et oscillent à divers niveaux, le fait est que Terra em transe provoque, excite et dérange le public par l'intermédiaire d'un langage non systématique, nerveux, discursif, moderne. » in M.P. «Terra em transe » in $O$ Globo, Rio de Janeiro, 10/05/1967.

801MONIZ VIANNA, Antônio. «Terra em transe » in Correio da Manhã, Rio de Janeiro, 11/05/1967.

802TAVARES, Zulmira Ribeiro. «A Desmedida com e sem aspas » in O Estado de São Paulo - Suplemento literário, São Paulo, 24/06/1967.

803MONTEIRO, José Carlos. « Cinema Nôvo : A Urgência de filmar » in Diners Club Magazine, sans lieu, septembre 1967, p. 52.

804AZEREDO, Ely. « As decepções do ' transe ' » in Jornal do Brasil, Rio de Janeiro, 10/05/1967. 
droite. Au prix de la censure des thèmes relevés par Azeredo, le film avait gagné le droit d'exister. Mais l'hostilité de la droite ne devait pas lui garantir la sympathie unanime de la gauche. Contrairement à ce qu'il a pu prétendre a posteriori, Rocha n'avait pas anticipé la violence des réactions que son film a provoqué. Après l'unanimité que Deus e o diabo na terra do sol avait rencontrée, les qualités de Terra em transe étaient contestées. Rocha écrit plusieurs textes dans lesquels il décrit et analyse ce qu'il conçoit comme un retour de bâton.

Le premier est «Perseguição e assassinato de Glauber Rocha pelos intelectuais do Hospício Carioca, sob a direção de Salvyano de Cavalcanti de Paiva 67 »(Persécution et assassinat de Glauber Rocha par les intellectuels de l'Hospice Carioca, sous le commandement de Salvyano de Cavalcanti de Paiva 67) ${ }^{805}$. Le second est «Depois do transe » (Après la transe) $)^{806}$, un texte rédigé pour un livre équivalent à celui qui était sorti sur Deus e o diabo na terra do sol en 1965, mais qui ne vit finalement pas le jour. La tonalité ironique du premier texte ne doit pas nous faire penser que Rocha considère les critiques qui lui sont adressées sans fondement. Il sait bien, comme l'ont également noté ses critiques les plus favorables, que Terra em transe est un film de négation, sur une frustration de politique, d'histoire et de transformation, et qu'il ne pourra pas refaire un film sur ce thème, à moins que la situation concrète ne change et n'ouvre de nouveaux horizons. La critique inaugurée avec $O$ Desafio a atteint ses dernières extrémités et il va bien falloir passer à l'action. Cette action pour lui revêt les apparences du cinéma épico-didactique qu'il définira dans des textes théoriques et qui nécessite une définition politique dont il n'a pas pu faire preuve avec Terra em transe.

L'ambiguïté idéologique de Terra em transe ne cessera pourtant pas d'alimenter les débats. Barreto se souvient :

«Após a estréia, em 8 de maio de 1967, lá estavam os dois lados, a esquerda moderada e os partidários da luta armada, atacando o filme. Para os que combatiam a ditadura dentro da ordem constitucional, Terra em transe estimulava a pegar em armas ; para os que efetivamente planejavam pegar em armas, era um filme alienado, não didático o suficiente. $»^{807}$

La guérilla est en effet devenu un thème central de la vie politique de la gauche brésilienne. Selon la lecture que nous avons faite du film, penser que Terra em transe encourage à choisir cette option de lutte est un contresens. C'était déjà ce qui ressortait des

805ROCHA, Glauber. Revolução do Cinema Novo. Op. cit., pp. 54-66.

806ROCHA, Glauber. Depois do transe. Texte dactylographié, 4 pages, archives Tempo Glauber, sans date, probablement 1969.

807 « Après sa sortie, le 8 mai 1967, nous avions la gauche modérée et la gauche partisane de la lutte armée, toute deux attaquant le film. Pour ceux qui combattaient la dictature dans le cadre de la constitution, Terra em transe stimulait à prendre les armes ; pour ceux qui, effectivement, projetaient de prendre les armes, c'était un film aliéné et pas assez didactique. » in SIMÕES, Eduardo et BIAGGIO, Jaime. Op. cit. 
critiques les plus approfondies du film et que nous pouvions trouver, clairement exprimé dans un article de 1968, par Bernardet :

«Com Terra em transe, a guerrilha se torna tema do cinema brasileiro. A guerrilha é a etapa terminal da evolução de um intelectual : diante da necessidade de transformação das coisas, diante da necessidade de uma transformação política, várias tentativas foram feitas e nenhuma deu certo. Ao cabo de uma série de fracassos, a guerrilha aparece como a única saída possível. Uma salvação. A guerrilha tende a se tornar, não uma opção realista, mas uma sublimação, um fenômeno compensatório, um mito, um objeto místico. O tratamento onírico dado ao apelo à violência no final de Terra em transe tornava claro esse aspecto da sublimação. ${ }^{808}$

Paradoxalement, une fraction non négligeable de la gauche prend au premier degré l'appel à la guérilla des dernières séquences du film. La confusion est d'autant plus grande qu'au contraire de ce qu'ils peuvent affirmer aujourd'hui, dans le clivage PC-résistance démocratique / lutte armée, les cinemanovistas se situaient majoritairement à faveur de la lutte armée ${ }^{809}$, Rocha en premier. Il ne faudrait pas penser qu'il existe un lien de causalité simple entre la réflexion proposée et partiellement développée par Terra em transe et le positionnement du cinéaste. Si, pendant le processus de création du film, l'identification de Rocha avec Martins ne fait aucun doute, la sensibilité exprimée par le cinéaste dépasse celle de l'homme public qui, dans la propre représentation qu'il se fait de lui-même, doit assumer le leadership du Cinema Novo et, politiquement, s'oppose aux positions officielles du PCB. Autrement dit, Rocha est Martins sans l'être et le fait que le film soit aussi une autocritique n'exclue pas qu'il rejoigne finalement les positions dont pourtant il se défie, à savoir ici la sympathie envers la guérilla. Il faut également rappeler que l'année 1967 est riche d'événements nouveaux qui remettent en cause les propositions du film.

$\mathrm{Au}$ Brésil, la dictature militaire s'installe avec la proclamation d'une nouvelle constitution en janvier et l'investiture de Costa e Silva en mars. Parallèlement, le mouvement d'opposition Frente Ampla qui réunit les ennemis politiques d'hier, Carlos Lacerda, Juscelino Kubitschek et João Goulart (les deux derniers étant exilés) peine à convaincre et à produire des résultats, il sera progressivement étouffé avant d'être interdit en 1968. La guérilla se développe de façon erratique. L'armée démantèle un groupe armé à Caparaó (Minas Gerais)

808« Avec Terra em transe, la guérilla devient un thème du cinéma brésilien. La guérilla est la dernière étape de l'évolution de l'intellectuel : devant la nécessité de transformation des choses, devant la nécessité de transformation politique, plusieurs tentatives ont été faites qui toutes ont échoué. Après toute une série d'échecs, la guérilla apparaît comme l'unique sortie possible. Une salvation. La guérilla devient, non pas une option réaliste, mais une sublimation, un phénomène de compensation, un mythe, un objet mystique. Le traitement onirique donné à l'appel à la violence à la fin de Terra em transe montrait clairement cet aspect de sublimation. » in BERNARDET, Jean-Claude. « Cinema, A Guerrilha » in A Gazeta, São Paulo, 18/10/1968. 809 À l'exception au moins de Santos et Hirszman, les deux cinéastes alors les plus proches de la ligne officielle du PCB sans en être pour autant parfaitement fidèles. 
alors que l'Ação Libertadora Nacional ${ }^{810}$ - ALN et la Vanguarda Popular Revolucionária ${ }^{811}$ VPR s'organisent dans l'ombre. Sur le plan international, la militarisation du cône Sud a progressé avec l'installation d'une quatrième dictature militaire en Argentine. Plusieurs mouvements de guérilla encouragés par Cuba ont été écrasés, notamment au Venezuela, mais la publication du livre de Régis Debray, Révolution dans la révolution en janvier 1967 et l'épopée de Che Guevara en Bolivie alimentent l'idée selon laquelle l'expérience cubaine pourrait se répéter dans d'autres pays d'Amérique Latine. La guérilla sandiniste éclate au Nicaragua. Enfin, aux États-Unis, la contestation contre la guerre au Vietnam s'amplifie considérablement. En avril, 500000 personnes manifestent à Central Park.

Plusieurs débats sont organisés autour de Terra em transe ${ }^{812}$ dont nous retrouverons d'ailleurs la trace dans les archives de la police politique ${ }^{813}$. Les cinemanovistas participent aux rencontres qui sont organisées à Rio de Janeiro et peuvent rassembler plus d'une centaine de personnes. Le climat n'est pas à l'analyse filmique circonspecte pratiquée par la critique dans les articles que nous avons analysés. De la même façon dont l'écriture et la réalisation du film ont été pour Rocha un moyen de développer sa réflexion politique ${ }^{814}$, Terra em transe permet à une partie du public de se projeter dans l'action. Le climat est à l'extrapolation. Fernando Gabeira, alors reporter au Jornal do Brasil s'opposait aux thèses des cinemanovistas qui défendaient le film :

« [...] o filme tinha um concepção muito depreciativa do povo brasileiro e acabava com uma solução elitista, de quem não acredita mesmo na ação organizada das massas : o ator principal, Jardel Filho, saia com sua metralhadora dando tiros a esmo, simbolizando desta forma uma revolta quase pessoal e desesperada. [...] Centrei minha intervenção na tese de que o filme discutia duas saídas através dos personagens e que escolhia a pior delas. ${ }^{815}$

Oduvaldo Viana Filho qui avait déjà polémiqué contre Porto das Caixas et $O$ Padre e $a$ moça, s'attaque également à Terra em transe ${ }^{816}$ à peu près avec les mêmes arguments de Gabeira. Au contraire de Rocha, sa position politique était claire et définie. Opposée à la lutte

810Littéralement, « Action Libératrice Nationale ». Cette organisation est créée par Carlos Marighella après sa rupture avec le PCB qui ne croyait pas à la lutte armée comme instrument d'action politique.

811 « Avant-garde Populaire Révolutionnaire. »

812Dans sa critique du film, Mário Chamie évoque un débat réalisé au Teatro da Universidade de São Paulo TUSP auquel il a participé avec Jean-Claude Bernardet le 16 juin 1967. In CHAMIE, Mário. Op. cit.

813 Nous reviendrons sur cette question dans la partie consacrée à l'étude des archives de la police.

$814 C f$. paragraphe 8.3 .

815 «.... le film démontrait une conception très dépréciative du peuple brésilien et terminait avec une solution élitiste, de celui qui ne croit pas dans l'action organisée des masses : l'acteur principal, Jardel Filho, sortait avec sa mitraillette en tirant au hasard, symbolisant ainsi une révolte quasi personnelle et désespérée. [...] J'ai centré mon intervention sur la thèse selon laquelle le film discutait de deux sorties au travers des personnages et choisissait la pire d'entre elles. » in GABEIRA, Fernando. O que é isso, companheiro ?. São Paulo, Companhia das letras, 1996 ( $2^{\circ}$ édition, $1^{\circ}$ édition : 1979), p. 32. Peu de temps après la sortie du film, Gabeira allait cependant rejoindre lui-même la guérilla urbaine.

816Voir sur ce sujet : RAMOS, Alcides Freire. « No Olho no furacão : Oduvaldo Vianna Filho e o Cinema Novo » in Revista de cultura Vozes, Petrópolis, vol. 93, n¹, 1999, pp. 167-170. 
armée qu'il ne considérait pas être une option réaliste, Vianinha, selon la ligne officielle du $\mathrm{PCB}$, appelait à la résistance et à la nécessité d'accumuler et de consolider les forces qui pourraient un jour opérer la transformation démocratique et balayer les fantômes du populisme, de l'oppression, des gouvernements militaires et les mécanismes d'exploitation et de paupérisation de l'Amérique du Sud. Ces divergences d'ordre politique ont été assimilées à d'autres divergences d'ordre esthétique puisque le dramaturge critiquait de longue date la préoccupation qu'il jugeait excessive des cinemanovistas pour l'expérimentation artistique au détriment de la transmission de messages politiques de portée immédiate.

Cette assimilation entre d'un côté une esthétique de rupture et une politique révolutionnaire et de l'autre côté une esthétique plus populaire et une politique réformiste était à l'époque couramment pratiquée. Nous voyons bien avec le recul qu'il s'agissait d'un raccourci trop rapide. Dans les faits, une esthétique «révolutionnaire " n'excluait pas une position « réformiste », c'est déjà le cas dans Terra em transe et cela le sera encore plus avec Fome de amor. Après avoir participé à montrer qu'aucune esthétique ne saurait être politiquement neutre et que le travail du cinéaste devait forcément s'inscrire dans un questionnement éthique, réfléchi et conscient, par rapport aux positions assumées par les films, Rocha, s'enferme aussi dans ce schéma réducteur. Ainsi déclare-t-il que l'avant-garde est le seul point de départ envisageable d'un art authentiquement socialiste ${ }^{817}$. Dans la ligne de ce qu'il écrivait déjà sur $O$ Padre e a moça, il déclare aussi :

«Qual a finalidade do cinema moderno ? A revolução se faz violentamente contra os padrões estéticos, morais e políticos do público. ${ }^{818}$

Nous verrons dans la quatrième partie que cette position amènera à une radicalisation outrancière du Cinema Novo qui déterminera en partie sa fin. Rocha dressait un bilan plus mesuré du film en évoquant la critique du populisme, la discussion politique qu'il a généré et le public qu'il a finalement touché.

« Críticas estéticas à margem, choveram demagogias em nome da revolução. Assim, muitos não hesitaram em me classificar de fascista. Então eu faço um filme de estrutura aberta, com discussões políticas no texto e na imagem, e o sujeito vem me chamar de fascista ? [...] O engraçado de tudo isto é que alguns atores e coleguinhas dos meios literários e teatrais distilaram estes venenos em nome do povo, do sagrado povo que não lê tantos livros e raramente vai a teatro, deste sagrado povo que não ia entender um filme desta espécie, feito contra o povo. No RJ, em 3 semanas, 100000 pessoas assistiram Terra em transe, das quais 90000 provavelmente do povo. Em SP, em Brasília e por todo o país, o filme circula há 2 anos e terá mais 3 de livre exibição. Foi pago em 3 meses e já foi distribuído em cerca de 10 países na Europa. É um filme, inclusive, comercial, pro espanto dos que acharam que ninguém ia ver e entender. $\gg{ }^{819}$

817ROCHA, Glauber. « Le Cinéaste tricontinental » in Cahiers du cinéma, Paris, n¹95, novembre 1967.

818«Quelle est la finalité du cinéma moderne ? La révolution se fait violemment contre les normes esthétiques, morales et politiques du public. » in ROCHA, Glauber. «O Novo Cinema no mundo » in O Cruzeiro, Rio de Janeiro, 30/03/1968.

819 «n dehors des critiques d'ordre esthétique, il a plu des déclarations démagogiques au nom de la révolution. 
Terra em transe prouvait l'existence d'une nouvelle voie qui était celle du film d'auteur d'agitation. Sa réception montrait qu'il était possible de concilier ses ambitions artistiques avec un film qui incite à la participation politique par l'intermédiaire de la polémique. Comme ses autres collègues du Cinema Novo, Rocha n'avait pourtant pas abandonné l'idée d'un cinéma de conscientisation des masses, l'objectif de cette conscientisation restant, plus que jamais, la révolution. L'étude de ses déclarations à la presse et des textes relatifs à l'un de ses principaux projets parallèle à Terra em transe, América nuestra, le prouve. La révolution était-elle encore possible et comment le cinéma pouvait la servir au mieux ? Telles étaient les interrogations qui l'animaient au moment où il écrivait ce deuxième projet qui n'aboutira jamais.

\subsection{América nuestra}

Avant et après Terra em transe, il y a eu América nuestra. Le projet de ce deuxième film qui n'a jamais vu le jour, occupe, au moins entre 1963 et 1972, une place particulière dans le processus créatif de Rocha. Certains exégètes du cinéaste voient même dans $A$ Idade da terra (1980) et les nombreux scénarios qui ont précédé et accompagné la réalisation de ce dernier long métrage, la prolongation de l'idée originale de América nuestra. Il est intéressant d'étudier ses scénarios successifs et de les comparer avec ceux de Terra em transe pour plusieurs raisons. La première réside dans le fait que ces scénarios ne sont pas des ébauches imparfaites des films réalisés mais de véritables propositions alternatives pour un cinéma de conscientisation à rapprocher de cet idéal d'un cinéma épico-didactique que le cinéaste évoque dans ses textes théoriques entre 1967 et $71^{820}$. La deuxième raison de l'étude des scénarios d'América nuestra est que ces textes nous montrent que les ambiguïtés idéologiques de Martins dans le film Terra em transe étaient bien celles de Rocha et que l'intérêt majeur du film aura été de les mettre en crise, peut être à son insu comme le suggère l'étude des espaces

Ainsi, beaucoup n'ont pas hésité à me qualifier de fasciste. Alors, je fais un film de structure ouverte, avec des discussions politiques dans le texte et l'image, et on vient me traiter de fasciste ? [...] Le plus drôle de tout cela est que certains acteurs et collègues des milieux littéraires et du théâtre ont distillé ces poisons au nom du peuple, du peuple sacré qui n'allait pas comprendre un film de cette sorte, fait contre le peuple. À RJ, en 3 semaines, 100000 personnes ont vu Terra em transe, parmi lesquelles 90000 appartiennent certainement au peuple. À SP, à Brasília et dans le pays entier, le film circule depuis 2 ans et dispose encore de 3 ans de libre exhibition. Il s'est payé en 3 semaines et a déjà été distribué dans 10 pays européens. C'est un film, par voie de conséquence, commercial, à la grande surprise de ceux qui pensaient que personne n'allait le voir et le comprendre. » in ROCHA, Glauber. « Depois do transe », op. cit.

820ROCHA, Glauber. « A Revolução é uma estética », " Revolução cinematográfica », « Tricontinental , «América nuestra 69» in Revolução do Cinema Novo. Op. cit., pp. 66-78 et 130-138. 
de Bernardet et Coelho. Avant de développer ces sujets, retraçons l'historique d'América nuestra qui se confond d'abord intimement avec Terra em transe $e^{821}$.

En novembre 1962, Rocha évoque pour la première fois América nuestra dans une lettre adressée à Alfredo Guevara :

« Estou pensando num grande filme sobre a América Latina e cujo plano inicial seria América nuestra (América nossa) que poderia ser realizado em Cuba, Argentina, Brasil, México, num sistema de co-produção, mas produzido também em todos os outros países para equipes locais fixarem o drama da América em luta. Seria um filme de três ou quatro horas - e o epílogo seria CUBA socialista como exemplo diante de nós outros oprimidos e explorados. $\rangle^{822}$

Le projet ressurgit plus de deux ans plus tard. Rocha voyage au Mexique où il doit assurer la promotion de Deus e o diabo na terra do sol au festival d'Acapulco. Là-bas, il rencontre Buñuel pour la première fois et s'intéresse aux vestiges archéologiques de la civilisation aztèque. Vivement impressionné par ce qu'il découvre, il reprend son projet d'un film sur l'Amérique latine. De plus en plus intéressé par son histoire et sa culture, Rocha établit un parallèle entre la situation brésilienne et celle des pays de langue espagnole. Il lui vient alors une idée qu'il va entretenir tout le temps qu'il travaillera à América nuestra ${ }^{823}$ :

«A consciença latina começa se popularizar. A descoberta de que o Brasil, México, Argentina, Peru, Bolivia etc. fazem parte do mesmo bloco de exploração norte-americana e de que esta exploração é uma das causas mais profundas do subdesenvolvimento se concretizar cada dia que passa e o mais

821Pour reconstituer l'historique de Terra em transe, en plus des scénarios et synopsis recueillis au Tempo Glauber, nous nous sommes appuyé sur les travaux de José Carlos Avellar qui est le premier à avoir exhumé le projet América nuestra et montré son importance dans l'œuvre du cinéaste venu de Bahia. Cf. AVELLAR, José Carlos. « Rascunho de pássaro » in Cult, São Paulo, n 67, mars 2003.

822 «e suis en train de réfléchir à un grand film sur l'Amérique Latine dont le plan initial serait América nuestra (Notre Amérique) et qui pourrait être réalisé à Cuba, en Argentine, au Brésil, au Mexique, dans un système de co-production, mais aussi dans d'autres pays par des équipes locales qui seraient chargées de capter le drame de l'Amérique en lutte. Ce serait un film de trois ou quatre heures - et l'épilogue serait CUBA socialiste comme exemple donné aux opprimés et aux exploités. » in ROCHA, Glauber. Cartas ao mundo. Op. cit., p. 176.

823C'est à dire jusqu'à son long séjour à Cuba, en 1971, et la désillusion qui va en résulter. Cette désillusion sera toujours tue. Les témoignages sont rares quant au séjour de Rocha à Cuba et, lui-même, a peu commenté cet épisode qui a pourtant marqué un tournant de sa vie . Cuba, ne l'oublions pas, était la destination et le camp d'entraînement de tous les aspirants à guérilleros de l'Amérique latine. À peine sorti de la réalisation de Der Leone have sept cabeças qu'il avait fait pour Fidel Castro et qu'il offre gratuitement à Cuba, après avoir tourné le dos à toutes les propositions mirifiques qui lui avaient été faites après sa victoire à Cannes en 1969, Rocha se rend sur l'île qui tient tête aux États-Unis pour mettre son talent de cinéaste au service de la Révolution. Plus qu'un geste politique, il s'agit d'une quête existentielle. Là-bas, il retrouve nombre de gauchistes brésiliens qui ont effectivement participé à la guérilla. Il admet cependant rapidement qu'il ne se sent pas très à l'aise avec eux. Les divergences qui affleurent sont d'ordre idéologique, ce sont exactement les mêmes que celles qui ont été à l'origine des dissensions entre le Cinema Novo et le CPC. Le dogmatisme et les conceptions anti-libertaires des militants communistes sont totalement opposés à ses propres idées politiques. Il découvre aussi que depuis 1960, les arts sont solidement encadrés par le régime castriste. Contrairement à ce qu'il voulait croire, il n'existe pas sur l'île la liberté d'expression à laquelle il aspirait. Finalement, bien qu'ayant été reçu comme un hôte de marque, Rocha quitte Cuba sans avoir finalisé aucun projet avec l'ICAIC. Câncer est monté sur l'île mais n'est pas distribué. História do Brasil est commencé et sera conclu à la va-vite et de façon provisoire à Rome. Il ne sera pas distribué non plus. Au final, Cuba n'aura pas plus soutenu Rocha que les autres pays socialistes. 
importante, se populariza. A noção de América Latina supera a noção de nacionalismos. Existe um problema comum : a miséria. Existe um objetivo comum : a libertação econômica, política e cultural de fazer um cinema latino. Um cinema empenhado, didático, épico, revolucionário. Um cinema sem fronteiras, de língua e problemas comuns. $\rangle^{824}$

Le voyage au Mexique qui marque le début d'une curiosité concrète pour l'Amérique latine en dehors des frontières du Brésil est immédiatement suivi par un voyage en Italie et la découverte du mythe de Simon Bolivar, «El Libertador » (Le Libérateur) :

« Arnaldo Carrilho me disse uma vez diante das ruínas de Pompéia (era um domingo entre janeiro e março 1965) que Simon Bolivar subiu no Vesúvio e de lá meditou sobre a América Latina : daí partiu para sua ação política. Verdade ou mentira quero partir do vulcão. $\rangle^{825}$

Jeté presque par hasard sur les traces du Napoléon créole après avoir découvert les vestiges des civilisations précolombiennes mexicaines, le cinéaste ne peut résister à condenser les images que lui suggèrent les épopées du passé pour le temps présent. Début 1965, il rédige plusieurs synopsis d'une dizaine de pages intitulés : América nuestra : a terra em transe ${ }^{826}$. Adepte du scénario-dispositif, il a deux objectifs principaux, mûrir le système des actants en tentant diverses combinaisons des caractéristiques des personnages, et poser une trame linéaire de l'intrigue quitte à la bouleverser totalement au tournage et au montage comme il le fait depuis Barravento. Les premiers synopsis fixent la macrostructure du récit qui ne variera pas dans toutes les versions de América nuestra jusqu'à 1968.

L'action se situe dans des pays imaginaires, Eldorado et / ou Vera Cruz ou Alecrim ${ }^{827}$.

824 « La conscience latine commence à se populariser. La découverte que le Brésil, le Mexique, l'Argentine, le Pérou, la Bolivie, etc. font partie du même bloc d'exploitation nord-américain et que cette exploitation est l'une des causes les plus profondes du sous-développement se concrétise chaque jour et, plus important, se popularise. La notion d'Amérique Latine surpasse les nationalismes. Il existe un problème commun : la misère. Il existe un objectif commun : la libération économique, politique et culturelle de faire un cinéma latino. Un cinéma appliqué, didactique, épique, révolutionnaire. Un cinéma sans frontière, de langue et de problèmes communs. » in ROCHA, Glauber. « Teoria e prática do cinema latino-americano 67 » in Revolução do Cinema Novo. Op. cit., p. 49.

825 « Arnaldo Carrilho m'a dit une fois devant les ruines de Pompéi (c'était un dimanche entre janvier et mars 1965) que Simon Bolivar était monté au sommet du Vésuve et, de là, avait médité sur l'Amérique Latine : il a ensuite initié son activité politique. Vérité ou mensonge, je veux partir du volcan. » in ROCHA, Glauber. «América nuestra 69 » in Revolução do Cinema Novo. Op. cit., p. 133. Rocha passe les premiers mois de l'année 1965 en Italie. Il est notamment hébergé par le diplomate Arnaldo Carrilho alors en poste dans ce pays. Ce dernier a souvent témoigné que le scénario de Terra em transe avait été écrit chez lui. Comme pour Barravento ou Deus e o diabo na terra do sol, le cinéaste reviendra sur ce premier texte écrit et le remaniera profondément pratiquement jusqu'au montage en 1967. Ainsi, en aurait-il existé cinq versions. Nous en avons retrouvé trois.

826Cf. AVELLAR, José Carlos. « Rascunho de pássaro », op. cit, p. 44.

América nuestra : A Terra em transe. 10 pages pages dactylographiées avec annotations manuscrites, archives Tempo Glauber, sans date.

América nuestra. 7 pages dactylographiées avec annotations manuscrites, archives Tempo Glauber, sans date.

827La nature exacte de Vera Cruz, Eldorado et Alecrim n'est pas très bien définie et restera dans le flou, il en ira de même de la géographie de Terra em transe, le film. Dans América nuestra, tout porte à croire qu'Eldorado est l'un des états d'une fédération dont la capitale se trouverait à Vera Cruz. Mais rien ne nous dit si Vera Cruz est le nom de la capitale, de l'état où se trouve la capitale ou de la fédération dans sa globalité. Dans certaines versions, il semblerait même que Vera Cruz et Eldorado soient deux états indépendants. Dans tous 
Tout commence par un coup d'état. Un homme politique d'idéologie libérale, appuyé par les multinationales américaines et de tendances autoritaires sinon fascisantes, prend le pouvoir dans la liesse générale. Son nom varie en fonction des scénarios, le plus souvent, il s'appelle « Dias » (Diaz dans Terra em transe). Dias favorise les multinationales et contrarie les intérêts des chefs d'entreprise nationaux. Un magnat de l'industrie et des médias les représente. Le plus souvent, il est appelé Júlio Fuentes. Il se dit progressiste et nationaliste et souhaite mener une campagne de presse écrite et télévisée contre Dias. Pour cela, il engage Juan Morales, un poète à l'éducation aristocratique. Ce dernier, selon des raisons qui varient en fonction des versions, s'était exilé de la capitale. Opposé à Dias, Juan accepte de travailler pour Fuentes. Mais, avant de retourner à la capitale (selon les versions Vera Cruz ou Eldorado), il entend parler d'un troisième personnage qui le fascine, le guérillero Bolivar qui vit caché dans les montagnes de la province (selon les versions Eldorado ou Alecrim). De retour à la capitale, Juan prend la direction de la campagne médiatique contre Dias. Il est aussitôt confronté à lui au cours d'un face à face dans lequel on apprend qu'il est son ancien mentor. Suite à ce conflit, Juan s'enfuit et rejoint le chef guérillero dans les montagnes. Selon les versions, il sera successivement surnommé Pablo, Bolivar ou El (ce dernier nom apparaît dans les versions post-67). La guérilla est déclenchée, Eldorado et Vera Cruz sont conquis malgré la disproportion des forces entre l'armée régulière équipée de chars et d'avions et les insurgés. Juan pratique un travail de propagandiste qui prépare et facilite les succès militaires de la guérilla. Acculé et abandonné de ses généraux, Dias est exécuté dans son palais. La nuit de la victoire, les conflits internes éclatent entre les différents chefs de la révolution. Fuentes et Juan sont fusillés pour s'être compromis par le passé avec Dias. Bien qu'ils feignent d'être progressistes et qu'ils ont aidé la guérilla, ce sont dans le fond des hommes " anciens » qui doivent laisser la place à l'homme nouveau incarné par le guérillero total, celui qui vient des classes populaires et n'a jamais oscillé dans ses opinions et ses actes. L'histoire se termine avec le débarquement des forces américaines dont l'objectif est de renverser Bolivar.

En février/mars 1965, une première version de Terra em transe ${ }^{828}$ est écrite à Rome. Bien que les personnages et les conflits qui les opposent soient assez similaires à ce que nous trouvons dans América nuestra, l'histoire est différente. L'action ne se déroule plus dans un pays imaginaire mais au Brésil et le personnage du guérillero a disparu. Un journaliste du

les cas, Eldorado est un état pauvre qui se trouve constamment sous la menace de l'autorité et de la puissance de Vera Cruz. Rappelons enfin que le choix des noms n'est pas l'effet du hasard. « Vera Cruz » est l'un des premiers noms donnés au Brésil par la couronne portugaise et « Eldorado » est le pays fabuleux situé au nord de l'Amérique du Sud supposé regorger d'or et de produits précieux qui faisait rêver les conquistadors. Dans Terra em transe, Vera Cruz disparaît, Eldorado devient le nom de la fédération et Alecrim est le nom de cet état éloigné de la capitale d'où pourrait venir le changement.

828 A Terra em transe I. 33 pages dactylographiées avec annotations manuscrites, archives Tempo Glauber, Rome, février/mars 1965. 
nom de Martins démissionne de son journal après la censure de l'un de ses articles sur les persécutions policières dans la favela. Désabusé, il rend visite à son ancien mentor, Silvino (le Diaz de América nuestra) mais ne trouve guère de réconfort à ses côtés. Il part alors dans le Nordeste où il rencontre le gouverneur Silveira (Fernandez dans d'autres versions) et se trouve confronté à la complexité et à la violence de la lutte entre les paysans sans terre et les grands propriétaires. Il prend le parti de Silveira qui cherche constamment à faire patienter les paysans et à éviter une action violente de leur part tout en leur assurant qu'il va les représenter politiquement et défendre leurs droits. Martins assure à Silveira qu'il peut compter sur Billy Menezes (le Júlio Fuentes de América nuestra). De retour à la capitale, il convainc Menezes de déclencher une campagne médiatique contre Silvino et d'appuyer Silveira pour lui donner la possibilité de lutter contre les grands propriétaires fonciers. À partir de ce moment, Martins pense être capable de manipuler les différentes forces en présence pour faire avancer le cause populaire. Il dirige la campagne contre Silvino et assure la publicité de Silveira. Un meeting est organisé dans la plus pure tradition populiste. Silvino pourtant ne se laisse pas faire, après avoir reproché directement à Martins de l'avoir trahi, il fait valoir son influence auprès du président et convainc Menezes de changer de camp. Silveira est dénigré dans la presse et une intervention militaire fédérale est décidée visant l'état qu'il dirige. Le gouverneur préfère alors ne pas résister et tous les paysans qu'il tentait jusque là de protéger d'une action répressive sont massacrés. Martins s'enfuit avec sa compagne Sara et, dans une sorte de délire, s'imagine d'abord, poursuivi par une horde de misérable, et ensuite assassinant Diaz.

Curieusement, l'écriture de Terra em transe ne signifie pas l'abandon de América nuestra. Un scénario de quarante-trois pages est écrit à Rio en avril $1966^{829}$ parallèlement à de nouvelles versions de Terra em transe ${ }^{830}$. Les deux histoires présentent des similitudes importantes, le système des actants est quasiment le même et certains dialogues et séquences se retrouvent intégralement, dans l'un et l'autre texte. Le lieu de l'action de América nuestra est Eldorado, l'action de Terra em transe est située au Brésil, mais dans le film, Eldorado prévaut. Le personnage principal de América nuestra, Juan Morales, est le Martins de Terra em transe. Si tous les deux sont poètes, le premier a fait de la poésie son métier alors que le second est avant tout journaliste.

L'une des différences notables entre América nuestra et Terra em transe est, dans le

829América nuestra. Scénario inédit, 43 pages dactylographiées avec annotations manuscrites, chemise «Produções Cinematográficas Mapa Ltda », Cinemateca do Museu de Arte Moderna do Rio de Janeiro, avril 1966.

830A Terra em transe. 32 pages dactylographiées avec annotations manuscrites, archives Tempo Glauber, sans date.

Terra em transe. 26 pages dactylographiées avec annotations manuscrites, archives Tempo Glauber, sans date. 
premier texte, le recours à une écriture qui transforme l'aspiration de l'auteur pour la révolution en mythe. América nuestra se déroule dans un espace situé entre le rêve, la légende et la réalité. De façon plus ostensible encore que dans Deus e o diabo na terra do sol, dans lequel le sertão des confins de Bahia et d'Alagoas est déréalisé, Rocha mythologise l'espace latino-américain et condense ce qui constituerait son essence. Le chaos présent est l'état inversé de la réalisation de l'utopie révolutionnaire à laquelle le continent serait promis. Eldorado est un espace magique, lieu d'une origine mythique pour les personnages et pour l'Amérique latine. La valeur d'Eldorado est étroitement liée à l'identité du protagoniste principal. Ainsi, Tereza Ventura qui a étudié le texte de 1966 observe très justement : « Juan não é somente intelectual e poeta, ele é fruto da terra, nativo de Eldorado. Sua origem remonta ao universo arcaico em que a vida do povo era contada pelas musas e pelos cantos essencialmente míticos e puros. $\gg{ }^{831}$ Dans Terra em transe, Eldorado n'est qu'un masque pour le Brésil et Martins et dénué de toute dimension mythique. C'est un personnage réaliste, au même titre que Marcelo dans $O$ Desafio.

Le personnage de Juan Morales possèdent deux adjuvants féminins qui complètent sa caractérisation en séparant deux aspects antagoniques de sa personnalité. Dans América nuestra, Silvia est une prostituée de luxe qui a systématiquement couché avec les hommes de pouvoir. Elle est aussi l'amante de Juan malgré le fait qu'il ne soit pas encore un « grand » et l'unit, par delà les conflits, à son ancien mentor, Dias. Elle s'offre d'ailleurs au dictateur au moment même de l'invasion d'Eldorado, peu de temps avant sa mort comme si, elle aussi, devait disparaître avec l'avènement de la révolution. Il existe une dimension tragique dans Silvia : elle a conscience de la vacuité de son existence et de la proximité de sa fin. Elle est à la fois une femme sensuelle et la messagère de la mort, auprès de Dias, comme nous l'avons dit, puis de Juan Morales, elle est la dernière personne qu'il rencontre avant d'être exécuté. Dans Terra em transe, Silvia est une des deux amantes de Martins. C'est une présence fantomatique qui revient à ses côtés à chaque fois qu'il oscille «à droite » et ne croit plus à la possibilité de transformation du pays.

Amor est la deuxième amante de Morales. Il s'agit d'une muse qui habite dans son village natal, en Alecrim, et partage avec lui cette origine mythique dont nous avons parlé plus haut. Il s'agit au départ d'un personnage «pur », attaché à la terre et endurant patiemment la pauvreté. Amor ne partage pas le déchirement de Juan qui se sent investi d'une mission et souffre dans sa chair les injustices et les errances du pouvoir alors qu'il ne les subit pas luimême. Consciente que Juan ne peut rester longtemps éloigné des luttes politiques, elle 
l'encourage à retourner à Eldorado. Amor correspondrait à Sara dans Terra em transe mais c'est un personnage qui va parvenir jusqu'au film passablement transformé. Sara va subir le transfert de qualités d'abord possédés par le gouverneur Silveira et devenir peu à peu cette militante communiste modérée, humaniste et persévérante que nous retrouverons dans le long métrage. Nous pourrons également remarquer qu'elle est progressivement détachée de l'univers d'Alecrim puisque les séquences présentes dans le scénario qui permettaient d'associer clairement Sara et Alecrim sont supprimées dans le film.

Le Manuel Dias de América nuestra est le Porfírio Diaz de Terra em transe ${ }^{832}$. Il est une synthèse des dictateurs et autres hommes politiques brésiliens à tendance autoritaire ou fasciste (Plínio Salgado, Getúlio Vargas, Carlos Lacerda...). Ventura le décrit avec justesse : «Dias, ainda que por meio de uma trajetória ambivalente, é o agente que representa a restauração da tradição colonialista. Defende o nacionalismo, apoiado pelo capital americano. $1{ }^{833}$ Pour composer ce personnage qui traverse les différentes versions de scénario sans bouger, Rocha utilise un mélange de symboles chrétiens et fascistes. Dias est un opportuniste pour lequel tous les moyens sont bons afin de conquérir le pouvoir pour lequel il se croit élu. Il est chargé de faire régner sur terre un ordre immanent qui aurait été décidé par Dieu pour les hommes.

Le gouverneur Fernandez est le Felipe Vieira de Terra em transe. Au contraire de Dias, c'est un personnage dont la personnalité change beaucoup. Son rôle est considérablement réduit dans América nuestra puisqu'il est évacué dès les premières séquences. Son «ancêtre », le Silveira des premiers synopsis, est un personnage combatif, manifestant une réelle empathie envers les pauvres. À l'image d'une partie de la gauche et du PC brésilien des années soixante, il pense que la cause populaire n'a rien à gagner d'un affrontement violent avec les classes dominantes. Il pratique donc une politique de compromis et de conciliation entre les classes en attendant que le rapport des forces change. Au fil des différentes versions de Terra em transe et América nuestra, les qualités de ce personnage seront transférés à Sara, l'amante de Martins. Dans le texte de 1966, Fernandez est devenu un gouverneur pusillanime, pour Juan, c'est un couard qui n'a pas su s'allier avec le peuple. Dans le film, Vieira est un authentique imposteur, un personnage sans envergure qui se laisse porter par la vague progressiste pour accéder à un pouvoir dont il ne sait pas quoi faire. Cette évolution du personnage du gouverneur montre que Rocha s'est d'abord inspiré des leaders progressistes du Nordeste comme Miguel Arraes, le modèle de Silveira, avant de préférer la critique du populisme varguista et de stigmatiser le manque de courage de Goulart. L'idée 832Ou encore le Manuel de Prado Diaz de Cabezas cortadas (Espagne, 1970). nationalisme appuyé par le capital américain. » in VENTURA, Tereza. Op. cit., p. 210. 
dominante de la gauche de l'époque était en effet que l'ancien président était un personnage sans envergure, politiquement peu habile et ayant agi avec couardise au moment du coup d'État.

Júlio Fuentes est l'industriel progressiste nationaliste qui possède «toutes » les richesses d'Eldorado. Successivement playboy et fils à papa (le Billy Menezes des premiers synopsis), il est, dans América nuestra, un entrepreneur audacieux et engagé. Dans Terra em transe, il devient un personnage pusillanime et sans véritable conscience politique, un irresponsable qu'il se laissera manipuler par Martins et ensuite par Diaz.

Bolívar est un personnage messianique et incorruptible qui accomplit un destin absolu tracé à l'avance. C'est celui qui déclenche la grande guerre qu'Antônio das Mortes prédit dans Deus e o diabo na terra do sol. C'est peut être le Christ guérillero de A Idade da terra et plus probablement encore le pasteur de Cabezas cortadas. Le personnage ne reçoit pratiquement aucune caractérisation et n'apparaît pas dans Terra em transe, le film, ni aucun de ses scénarios. Le second personnage à ne pas apparaître dans le film, est le général Lyra, un libéral proche de la First Company (Explint dans le long métrage) et donc des monopoles impérialistes. Le troisième personnage dont on peut dire qu'il est vu brièvement dans Terra em transe sans que l'on sache trop qui c'est, est Alto, un général nationaliste qui, après avoir longtemps hésité à s'allier à Bolívar, devient fanatique une fois qu'il est passé du côté de la guérilla. Comme nous le voyons, dans América nuestra, Rocha a tenu à exposer les divisions qui partageaient le haut-commandement de l'armée brésilienne. Très rapidement en effet, les observateurs politiques remarquent les conflits opposant les libéraux pro-américains et les nationalistes. Dès les années soixante, le cinéaste espère l'arrivée au pouvoir d'un nationaliste et l'ascension du général Albuquerque Lima qui passe un temps pour un candidat sérieux à la présidence de la République.

Dernier personnage à ne pas figurer dans le film, mais que nous retrouvons dans les scénarios de Terra em transe : Mr. Morgan. Il s'agit d'un américain représentant directement les intérêts des multinationales de son pays auprès des gouvernements latino-américain. Plusieurs personnages réels ont pu inspirer la création de Mr Morgan à commencer par l'ambassadeur des États-Unis en poste en 1964, Lincoln Gordon ${ }^{834}$, ou même Harry Stone qui

834Lincoln Gordon fut l'un des intermédiaires privilégiés entre les conspirateurs et le gouvernement des ÉtatsUnis. Farouchement opposé à João Goulart, il leur garantit un appui de l'armée américaine qui, en théorie, devait être seulement logistique. En cas de conflit armé, les États-Unis avait préparé une opération portant le nom « Brother Sam ». Cette opération déclenchée le 31 mars 1964 consistait dans l'envoi de 100 tonnes d'armes légères et de munitions, de tankers pétroliers avec une capacité de 130 mille barils de carburant, une escadrille d'avions de chasse, un navire de transport d'hélicoptères avec 50 appareils avec équipages et armements complets, un porte-avion de type Forrestal, six destroyers, un cuirasser, un navire de transport de troupes, et 25 avions C-135 pour le transport de matériel militaire. $C f$. BANDEIRA, Luiz Alberto Moniz. $O p$. cit., pp. $145-146$ et 169-170. 
représentait les intérêts des compagnies de cinéma américaines au Brésil. Mr. Morgan est remplacé par la multinationale EXPLINT qui n'est représentée par aucun personnage mais à laquelle il est constamment fait référence dans les dialogues.

Certaines séquences d'América nuestra indispensables à la caractérisation des personnages se retrouvent, pratiquement identiques, dans les scénarios de Terra em transe et dans le film. C'est le cas du sacre de Diaz qui imite ceux des monarques absolus du XIXe siècle et son discours sur l'harmonie entre les peuples :

«Eu quero uma sociedade justa, onde o homem pobre possa receber casa e educação sem a necessidade de ódio que os inimigos da democracia fazem questão de espalhar entre as classes. [...] Eu quero um programa de felicidade para meu povo, não só do povo de Eldorado mas para todos os povos da America. Nesta trilha segui e nesta trilha fui ferido, três vezes fui expulso do Senado, três vezes fui preso, três vezes ressurgi e fui eleito, pois o povo confiava em mim, o povo me dava sua bandeira para representá-lo... As minhas ambições são puras... Dias no palanque, fecha os olhos olhando para o céu, como agradecendo a Deus de ter chegado ao poder. ${ }^{835}$

Revient aussi systématiquement le poème de renoncement de Juan à la vie politique :

« Não anuncio cantos de paz, nem me interessam as flores do estilo como por dia mil notícias amargas que definem o mundo em que vivo. Não me causam os crepúsculos a mesma dor da adolescência, devolvo tranqüilo à paisagem os vômitos da experiência. $»^{836}$

La séquence consacrée au court métrage réalisé par Juan pour dénigrer Diaz est développée dans le scénario de América nuestra (séquence 18). Les images sont toutefois légèrement différentes, ici, Dias se costume en fonction des différentes régions qu'il visite. Le ton est tout aussi satyrique.

La séquence de la confrontation entre Diaz et Juan est également récurrente ainsi que

835« Je veux une société juste, où l'homme pauvre puisse recevoir logis et éducation sans la nécessité de la haine que les ennemis de la démocratie insistent à propager entre les classes. [...] Je veux un programme de félicité pour mon peuple, pas seulement pour celui d'Eldorado mais pour tous les peuples d'Amérique. C'est le chemin de cet idéal que j'ai toujours suivi et c'est sur ce chemin que j'ai été blessé, trois fois j'ai été expulsé du sénat, trois fois j'ai été prisonnier, trois fois je suis revenu et j'ai été élu, parce que le peuple me faisait confiance, parce que le peuple me donnait son drapeau pour que je le représente... Mes ambitions sont pures... Dias ferme les yeux et regarde vers le ciel comme remerciant Dieu de lui avoir accordé d'être arrivé au pouvoir. \ in América nuestra. Op. cit., avril 1966, p. 3.

836« Je n'annonce pas des chants de paix, et ne m'intéressent aucunement les fleurs du style comme tous les jours les mille mauvaises nouvelles qui définissent le monde dans lequel je vis.

Les crépuscules ne me causent plus la même douleur qu'à l'adolescence je rends tranquille au paysage les vomis de l'expérience. » in ibid., p. 6. 
les phrases de dialogue qui lui sont associées : «O que são interesses políticos diante da amizade ? Diante da amizade nada existe, um amigo sempre aceita o outro na mais absoluta degradação um amigo aceita o outro. $\rangle^{837}$

Avellar observe très justement que : «Terra em transe é como se a história de América nuestra se interrompesse na metade com a morte de Martins. América nuestra é como se Terra em transe continuasse com Martins indo ao encontro do guerrilheiro Bolívar para mais tarde retornar a Eldorado e derrubar Porfírio Diaz. $1{ }^{838}$ Comme dans le film de 1967 , les personnages sont des synthèses représentant les forces sociales en présence dans un pays d'Amérique Latine : le candidat à dictateur à l'idéologie fasciste, le président démocrate réformiste, le grand bourgeois qui oscille entre la défense d'une politique nationaliste et le compromis avec le capital étranger, le représentant des monopoles impérialistes, le syndicaliste, le représentant des masses misérables, la figure de l'intellectuel de classe moyenne.

Le poète est un personnage qui oscille entre des positions politiques radicalement opposées, il cherche auprès des figures symboliques qui incarnent ces différentes positions une place qui lui permette de participer à la révolution totale qui mettra fin aux contradictions sociales, politiques, culturelles et économiques qui sont celles d'Eldorado. Il passe ainsi de Dias à Fernandez, puis de Fernandez à Bolívar autrement dit du fascisme au socialisme réformateur et du socialisme réformateur au messianisme guérillero dans sa quête aussi existentielle que politique d'une solution pour le chaos qu'il conçoit tout autour de lui.

Bien qu'il s'agisse à chaque fois de revirements spectaculaires, le poète ne saurait être taxé d'opportunisme, sa quête est la recherche obsessive d'un antidote aux souffrances collectives qui sont pour lui comme une douleur intime. Ses mutations sont chacune provoquées par une prise de conscience plus claire de la nature humaine et des mécanismes du pouvoir. Si le socialisme réformiste s'avère une impasse à cause de l'opposition des classes dominantes et des monopoles étrangers, le messianisme guérillero présente des risques de dérives autoritaires si la conscience populaire n'est pas effectivement transformée. Rocha pressent alors la dérive autoritaire du modèle cubain même si, à l'époque, il veut encore croire en sa validité. L'instauration d'un régime socialiste ne garantit pas non plus l'avènement d'une société sans classe et prospère. Le pouvoir politique conquis, la révolution reste à faire. L'une des dernières déclarations du poète pendant «La Nuit du gouvernement provisoire »,

837 « Que sont les intérêts politiques au regard de l'amitié ? Devant l'amitié rien n'existe, un ami accepte toujours un autre ami, dans la plus absolue dégradation un ami accepte toujours l'autre. » in ibid., p. 15.

838« Terra em transe est comme América nuestra si l'histoire s'interrompait à la moitié avec la mort de Martins. América nuestra est comme Terra em transe si l'histoire continuait avec Martins partant à la rencontre du guérillero Bolivar pour ensuite revenir à Eldorado et provoquer la chute de Porfirio Diaz. » in AVELLAR, José Carlos. « Rascunho de pássaro », op. cit, pp. 44-45. 
autrement dit le dernier acte de América nuestra, est à ce titre très explicite : «Matem-me porque duvidarei sempre da verdade ! ${ }^{839}$ Une fois le scénario envisagé d'une révolution équivalente à celle de Cuba au Brésil, l'auteur partage le conflit de son personnage principal et, devant l'inévitable flambée de la violence qu'il conçoit ${ }^{840}$, doute que la voie de la guérilla soit la bonne sans être capable encore d'en imaginer une autre.

Finalement, dans le courant de l'année 1966, une fois que les deux projets sont devenus distincts, Terra em transe est préféré à América nuestra. Ce choix est significatif à plus d'un titre. América nuestra dissertait sur une révolution qui apparaissait peu probable et qui, si elle arrivait, risquait fort, selon Rocha, de renier ses propres principes. Dans ce texte, il anticipe les scénarios possibles de l'émancipation de l'Amérique latine. Paradoxalement, alors même qu'il met toutes ses forces à imaginer les évènements les plus improbables comme la répétition du processus cubain à l'échelle du Brésil, il finit toujours par abandonner la croyance dans le processus révolutionnaire ou à s'exclure lui-même de ce processus car, bien évidemment, que ce soit Morales ou Martins, dans América nuestra comme dans Terra em transe, c'est lui qui se projette dans la diégèse de l'histoire qu'il crée. Or, confronté aux contradictions des évènements envisagés, que ce soit à l'échelle collective ou à l'échelle individuelle, il ne parvient pas à trouver une issue heureuse à la révolution. D'un côté, Le succès de la guérilla entraîne des sacrifices humains chaque fois plus grands et, de l'autre, l'individu est écrasé par la raison collective qui soudain, envahit tout ${ }^{841}$. L'auteur se retrouve

839« Tuez-moi car je douterai toujours de la vérité ! » in América nuestra. Op. cit., avril 1966, p. 38. 840L'épilogue de América nuestra montre clairement que les luttes ne finiront pas avec la prise de pouvoir de Bolívar. Premièrement, Rocha anticipe une intervention américaine d'une envergure plus importante que le débarquement de la Baie des Cochons destiné à renverser le pouvoir castriste. (Le 16 avril 1961, environ 2000 anti-castristes émigrés aux États-Unis après la révolution cubaine et l'arrivée de Fidel Castro au pouvoir, ont débarqué à Cuba après avoir subi un entraînement prodigué par l'armée et les services secrets américains. L'opération fut un échec. Il est possible aussi que l'opération Brother Sam ait été connue ou largement suspectée par de nombreux éléments de la gauche avant que l'ouverture des archives américaines et les témoignages de l'ambassadeur américain n'en brisent définitivement le secret.)

Deuxièmement, «La Nuit du gouvernement provisoire » qui occupe pratiquement un quart du volume du scénario de América nuestra, laisse présager de façon assez claire de violentes luttes internes entre les révolutionnaires dans la dispute du pouvoir. Là encore, l'histoire connue de l'indépendance de l'Algérie pouvait alimenter la réflexion du cinéaste. La guerre d'Algérie était un symbole fort de la lutte contre l'impérialisme pour les gauchistes brésiliens depuis le début des années soixante. À partir de ce moment-là, les dissensions sanglantes à l'intérieur du FLN et le coup d'État de Houari Boumédiène contre Ahmed Ben Bella en juin 1965 ne pouvaient échapper aux cinemanovistas. Par ailleurs, les exemples célèbres de déchirements internes au sein de partis révolutionnaires ne manquent pas.

841Tout au long de la carrière de Rocha, et en particulier dans ses textes, une contradiction fondamentale est manifeste. Fasciné par l'idéologie et l'histoire du communisme, fasciné également par les qualités individuelles dont sont capables certains militants communistes (l'ascétisme et le don de soi, le sacrifice de la vie privée), le cinéaste considère comme inconciliables les intérêts collectifs et individuels. Se référant aux trajectoires des grands leaders communistes brésiliens qui ont passé pratiquement toute leur vie dans la clandestinité quand ils n'ont pas connu en plus la torture et la prison, il ne comprend pas bien comment, pour construire une société qui permettrait l'épanouissement individuel de chacun, il faudrait lutter dans la négation de soi. Se référant aussi aux combats sanglants qu'il faudrait mener pour imposer un gouvernement socialiste, il ne comprend pas non plus comment, pour mettre fin à l'oppression et à la violence, il faudrait d'abord faire usage de la force. La perspective de Rocha est humaniste et libertaire. Il oscille constamment entre deux idées de la révolution. La première serait en fait la somme de micro-révolutions individuelles, 
face à un paradoxe qui lui semble insurmontable. Lui qui se dit constamment « révolutionnaire » vient précisément émettre des réserves quant au succès des mouvements socialistes armés. Au lieu de persévérer dans la voie d'une fiction politique qui, finalement, ne reposait sur rien de concret puisque les mouvements guérilleros sont encore balbutiants dans le Brésil de 1966, Rocha opte plutôt pour la réflexion sur un événement historique passé et reprend et reformule bien des éléments déjà présents dans $O$ Desafio ${ }^{842}$.

Ce revirement en dit long sur la fonction du scénario dans l'œuvre de Rocha. Si, pour Barravento et Deus e o diabo na terra do sol, les réécritures successives sont motivées par les nécessités de clarification quant à un but à atteindre qui ne se réalisera que dans le film terminé, il s'agit à présent d'expérimenter ou de multiplier les alternatives avant d'en choisir une qui deviendra celle sur laquelle on travaillera au moment du tournage. Ce besoin de multiplication des alternatives apparaît dans la polarisation América nuestra / Terra em transe, mais aussi dans une seconde polarisation interne aux versions de Terra em transe entre la veine allégorique qui sera finalement exploitée dans le film, et une veine plus réaliste, plus explicite quant à la charge contre le régime dictatorial et qui sera écartée selon un réflexe d'autocensure. Il est, à ce titre, intéressant de constater qu'une version de Terra em transe dans la veine réaliste a été donnée au Tempo Glauber par l'acteur Sérgio Brito en 2001. Autrement dit, l'indécision du cinéaste a été si longue que certains comédiens pressentis pour jouer dans Terra em transe ont reçu le scénario qui n'a pas été filmé ${ }^{843}$ !

Tous ces textes qui ne seront pas filmés présentent des éléments qui nous permettent de les rapprocher de l'idée d'un cinéma épico-didactique tel que Rocha le théorise entre 1966 et 1969. L'idée du cinéma épico-didactique est simple, le cinéaste l'explique dans ces termes :

c'est la perspective libertaire du Cinema Novo, l'éveil et la transformation des consciences individuelles par l'art. C'est l'approche qu'il pratique par l'action, dans son cinéma. C'est aussi la valorisation de l'expression personnelle de l'artiste dans la politique des auteurs adoptée par le Cinema Novo. À cette première idée de la révolution se superpose une seconde qui est de l'ordre de l'appréciation concrète et raisonnée des processus politiques. Il pense que l'instauration d'un régime nationaliste et socialiste et l'application d'une politique $a d$ hoc ne peuvent se faire que par la force et la confrontation violente avec les intérêts du capital national et international. C'est pour cette raison qu'il ne fait pas confiance à la démocratie et se prononce, à la fin de sa vie, en faveur de la manutention du système dictatorial en attendant l'arrivée providentielle d'un président véritablement nationaliste. Parallèlement, l'oscillation entre les deux idées de la révolution se manifeste dans sa constatation de l'échec des régimes socialistes tout autour du monde. La situation est sans issue, la révolution n'est pas possible sans un régime fort et autoritaire mais les régimes forts et autoritaires socialistes n'ont jamais réalisé la révolution. Dès Terra em transe et América nuestra, l'utopie est assumée comme appartenant à un monde imaginaire étranger à l'expérience humaine et la quête du chaînon manquant entre la réalité et les conditions concrètes de sa transformation trouble les spéculations individuelles du cinéaste. Nous sommes déjà sur la voie de «L'Esthétique du rêve » (1971).

842Rocha annonce la réalisation de Terra em transe seulement un mois après avoir conclu ce qui restera le scénario le plus consistant d'América nuestra. SGANZERLA, Rogério. « Fala Rocha I » in $O$ Estado de São Paulo - Suplemento literário, São Paulo, 07/05/1966.

843 Sérgio Brito avait déjà joué le rôle de l'industriel dans $O$ Desafio. Nous ne connaissons pas les raisons pour lesquels il n'a pas joué dans Terra em transe, le fait qu'il ait possédé un scénario montre qu'il a sans doute été pressenti pour le rôle de Júlio Menezes /Fuentes qui sera finalement tenu par Paulo Gracindo. 
« A didática e a épica devem funcionar simultaneamente no processo revolucionário :

A didática : alfabetizar, informar, educar, conscientizar as massas ignorantes, as classes médias alienadas. A épica : provocar o estímulo revolucionário.

A didática será científica.

A épica será uma prática poética, que terá de ser revolucionária do ponto de vista estético para que projete revolucionariamente seu objetivo ético. $»^{844}$

Dans cette nouvelle théorie d'un cinéma révolutionnaire que Rocha conçoit aussi comme un hommage à Eisenstein, le terme «didactique» renvoie à la transmission d'informations sur une situation donnée et le terme "épique » renvoie à l'épopée, à l'idée de conquérir le spectateur par l'émotion exprimée par la poésie et lui donner le goût irrépréhensible d'agir sur l'histoire, de devenir un sujet historique. Il s'agit clairement de renouer avec un cinéma d'action et de conscientisation général après une phase nécessaire de remise en question de l'artiste lui-même et de critique des positions assumées avant 1964. Dans cet ordre d'idées, Rocha explique en 1966 que : « [...] o cinema brasileiro está tendendo, depois da falência de um cinema politico-programático, com a revolução de março, à superação de um realismo crítico-comportado e ruma a um realismo poético revolucionário. ${ }^{845}$ Bien qu'il parle surtout pour lui et à partir de son expérience personnelle, il donne au Cinema Novo un nouvel objectif qui s'inscrit dans la continuité de l'étape franchie par $O$ Desafio. Cette idée implique un engagement concret de l'artiste dans les luttes politiques et la fin des personnages oscillants qui le caractérisaient. Elle expliquera en grande partie la définition du personnage d'Antônio das Mortes dans O Dragão da maldade contra o santo guerreiro. Dans le cas de Terra em transe, la comparaison entre les scénarios de la veine réaliste et le film, nous montre que le passage, initialement prévu avec ce long métrage, à un cinéma épico-didactique ne s'est pas réalisé.

Les transformations qui surgissent entre le film et les scénarios réalistes vont en effet beaucoup plus loin que la substitution du mot «Brésil» par «Eldorado ». Nous retrouvons dans chacun des deux scénarios la volonté d'expliquer la situation politique du pays. Il s'agit non seulement distinguer les forces en présence mais aussi de montrer les mécanismes de pression qui agissent sur les élites dirigeantes et les médias ainsi que de dénoncer les

844« La didactique et l'épopée doivent fonctionner simultanément dans le processus révolutionnaire :

La didactique : alphabétiser, informer, éduquer, conscientiser les masses ignorantes, les classes moyennes aliénés.

L'épopée : provoquer le stimulus révolutionnaire.

La didactique sera scientifique.

L'épopée sera une pratique poétique, qui devra être révolutionnaire du point de vue esthétique pour projeter révolutionnairement son objectif éthique. » in ROCHA, Glauber. «A Revolução é uma estética 67 » in Revolução do Cinema Novo. Op. cit., p. 67.

845 « [...] le cinéma brésilien essaye, depuis l'échec du cinéma politique-programmatique, avec la révolution de mars, de surpasser un réalisme critique bien éduqué pour évoluer vers un réalisme poétique révolutionnaire. » in SGANZERLA, Rogério. «Fala Rocha I » in O Estado de São Paulo - Suplemento literário, São Paulo, 07/05/1966. 
méthodes utilisées par ces mêmes élites pour se maintenir au pouvoir. S'il est vrai que nous retrouvons dans le long métrage le personnage de Fuentes, qui est là pour nous montrer la dépendance des organes d'informations envers le capital, et le personnage de Diaz, qui est caractéristique de l'absence de scrupules et du mépris des élites pour le peuple, le système des actants est beaucoup moins complet que dans les scénarios.

Les modifications apportées au personnage du gouverneur progressiste Silveira / Vieira participent à l'affaiblissement de la capacité du système des actants à expliquer les conflits politiques qui ont débouché sur la crise de 1964. Plus proche de Miguel Arraes que de l'idée que l'on se faisait de João Goulart ${ }^{846}$, le gouverneur tel qu'il est caractérisé dans les scénarios, permettait de développer, d'un côté, le problème des ligues paysannes et de l'autre, le problème des alliances contre-nature auquel la gauche s'est crue obligée dans la période 1962-1964. La polarisation récurrente capitale/province sinistrée que nous retrouvons dans les toutes les versions de América nuestra et Terra em transe, est donc bien capitale/Nordeste pour les scénarios réalistes. Dans ces scénarios, c'est bien les luttes des ligues paysannes que le journaliste découvre avec en contrepartie la répression criminelle pratiquée par les grands propriétaires. La province des scénarios réalistes est donc moins une aire pauvre ou mythique, comme dans les autres versions, qu'un espace de non-droit et de confrontation armée au bord de la guerre civile. La présence de ce gouverneur proche de l'image classique du dirigeant communiste brésilien, paternaliste mais néanmoins réellement engagé dans la lutte, est un élément de complexité. D'une certaine manière, pour éviter le déflagration de la guerre civile, il doit temporiser et protéger les grands propriétaires, commanditaires d'exécutions sommaires de paysans en rébellion. Enfin, l'alliance entre le magnat de l'industrie progressiste et le gouverneur est également dénoncée. Si ce dernier est contraint d'accepter l'aide de Menezes / Fuentes parce qu'il lui faut bien des appuis à l'échelle nationale, il ne croit pas une seconde dans la sincérité de l'homme d'affaires.

Au contraire du film où le gouverneur est l'objet d'un jugement moral lapidaire pour son inconsistance et sa couardise, les scénarios s'appliquent à restituer toute la complexité de la situation dans laquelle se trouvait les leaders progressistes populistes dans la période précédents le coup d'état. Ils les montrent soucieux d'apporter un mieux-être à la population mais pris entre deux feux, celui de leurs opposants de droite, décidés à paralyser toutes leurs tentatives d'action, et celui des radicaux de gauche, incapables de comprendre que leur impatience devait être mesurée. Dans les scénarios de Terra em transe, nous sommes encore loin d'une liquidation unilatérale du populisme pré-64. Ces textes montrent au contraire que, 
dans la situation dans laquelle se trouvait le Brésil, toutes les positions (de gauche) se justifiaient et qu'il était bien difficile de savoir quel parti prendre. Le populisme apparaît presque comme une étape obligée pour ceux qui voulaient sans tenir à une position réformiste. Il n'est pas célébré comme une voie malheureusement interdite par le coup d'état, mais il n'est pas non plus condamné avec intransigeance. Ce dont Rocha s'inquiète, c'est de l'absence de forces sur lesquelles le leader populiste peut s'appuyer. Dans cet optique, il montre, avec le personnage de Fuentes/Menezes que l'alliance avec la bourgeoisie progressiste est un leurre et, avec la séquence du meeting, que le soutien populaire est une mascarade s'il est le fruit de manipulations médiatiques. Cette séquence clé du film, qui apparaît dans le second scénario de $A$ Terra em transe, montre que le responsable de cette mascarade n'est pas le gouverneur, qui a été contraint d'y participer, mais Martins qui pense pouvoir prendre le contrôle de la situation et manipuler les forces en présence en s'alliant avec Menezes / Fuentes.

En plus des modifications subtiles mais significatives qui surgissent entre le système des actants des scénarios et du film, plusieurs séquences ont été supprimées. Tout d'abord, nous avons perdu une séquence retraçant la traque d'un noir dans une favela ${ }^{847}$. Dans le scénario de 1966, cette séquence était montée en parallèle avec le discours de Silvino / Diaz pour en dénoncer la fausseté ${ }^{848}$. Les déclarations éloquentes du leader fasciste sont démenties par les images d'injustice sociale et de répression policière qu'elles tentent de dissimuler. Nous retrouverons d'ailleurs dans le scénario de Macunaíma une séquence comparable visant à informer et à dénoncer une pratique déjà ancienne et qui sera bientôt associée aux « escadrons de la mort ». Au Brésil, le terme « escadrons de la mort» sera aussi bien utilisé pour désigner les groupes paramilitaires destinés à éliminer de façon expéditive les individus politiquement nuisibles que pour ceux exécutant des expéditions punitives ou d'intimidation dans les quartiers pauvres. La pauvreté étant facilement assimilée à la criminalité dans l'imaginaire politique de la classe moyenne, cette pratique a toujours bénéficié d'une certaine indulgence de la part de l'opinion publique. Elle s'inscrit aussi dans une longue tradition de mépris des droits des plus démunis qui, au moment de l'instauration de la République, à la fin du XIXe siècle, s'était traduite par des campagnes de vaccination menées, comme des opérations militaires, sans information, sous la contrainte et avec invasion des foyers. Cette tradition de

84711 nous semble bien, à lire cette séquence dans les deux scénarios de Terra em transe, que Rocha voulait répéter l'impact d'une autre séquence de Cinema Novo qu'il évoquera souvent dans ses textes rétrospectifs sur l'histoire du mouvement, celle où des femmes et des enfants recherchaient leur pitance dans une énorme décharge de Rio, survolés par des vautours. Cette séquence appartient au film O Favelado de Marcos Farias, épisode de Cinco vezes favela.

848Dans le scénario de 1965, de façon prémonitoire, Martins démissionne de son journal parce que son article sur cet épisode de la traque d'un noir dans la favela est censuré. Rocha, qui a conscience que ce type d'information ne « passe » pas, finira bien par se censurer lui-même. La répétition de la scène dans deux scénarios de Terra em transe montre pourtant qu'il y tenait. 
mépris s'était aussi caractérisée, toujours à la même époque, par des déplacements de population arbitraire dans le cadre de la restructuration urbaine de Rio de Janeiro.

Parmi les séquences du voyage de Martins au Nordeste, celles mettant en scène les mobilisations et revendications paysannes (les ligues paysannes ne sont pas nommées) ou celles qui montrent l'opposition menaçante du grand propriétaire et la possibilité constante d'une action violente de ses hommes de main, sont supprimées ou réduites ${ }^{849}$. Ainsi, nous verrons bien dans le long métrage le personnage de Felício qui vient réclamer du gouverneur élu la défense des droits des paysans avant d'être humilié publiquement par Martins ${ }^{850}$, nous verrons aussi la communauté des manoeuvres agricoles venir le pleurer après qu'il ait été assassiné par un tueur du colone ${ }^{851}$. Mais, le caractère allégorique du film ainsi que le brouillage volontaire des repères géographiques nuit considérablement à la clarté de l'exposé de la situation d'autant plus que certains changements dans la caractérisation des personnages et des conflits provoquent un glissement de sens. Alors que dans les scénarios, Felício apparaît comme le leader d'un mouvement possédant une véritable force politique difficile à manipuler, il est dans le long-métrage réduit à la dimension d'un représentant que l'on peut facilement ignorer. Les paysans des scénarios sont offensifs et revendicatifs, ceux du film sont serviles et désespérés. Le colonel Moreira est physiquement présent dans une scène de confrontation avec les paysans dans les scénarios, dans le film, il n'est plus qu'un nom. Enfin, alors que les scénarios expliquent, à partir de tous ces éléments et de façon très didactique, la difficulté du gouverneur à articuler son action dans un paysage politique très polarisé, le film réduit le problème du gouverneur à l'absence de réelles propositions de sa part pour tenir les promesses données lors de sa campagne électorale. Autrement dit, l'explication matérialiste des conflits politiques cède la place à l'exposé d'une crise morale ${ }^{852}$ qui aurait pu être facilement résolue par un gouverneur pugnace, politiquement habile et porteur de propositions concrètes. De plus, l'affaiblissement de la force et de la représentativité des leaders populaires,

849Séquences 13 à 17 de $A$ Terra em transe I. 33 pages dactylographiées avec annotations manuscrites, archives Tempo Glauber, Rome, février/mars 1965.

Séquence 4, 6 et 37 de Terra em transe. 32 pages dactylographiées avec annotations manuscrites, document donné par Sérgio Brito archives Tempo Glauber, sans date.

850Séquence 16 de la description du film par Orlando Senna. In ROCHA, Glauber. Roteiros do terceyro mundo. Op. cit., pp. 295-296.

851Séquence 18 de la description du film par Orlando Senna. Ibid., p. 297.

852Dans les scénarii, nous avons un gouverneur populiste de gauche qui ne parvient pas à appliquer sa politique parce qu'il ne dispose pas de forces suffisantes pour vaincre ses adversaires. Dans le film, nous avons un personnage inconséquent qui ne sait pas comment tenir ses promesses électorales parce qu'il n'a ni idées, ni programme concret. La voix off de Martins expose le problème dans la séquence 15 :

«E vencemos ! [...] Na calma daquela varanda onde tínhamos planejado em festa a luta, eu, agora a teu lado, pensava nos problemas que surgiriam e me perguntava como responderia o Governador eleito às promessas do candidato. » (« Et nous avons vaincu ! [...] Dans le calme de la véranda où nous avions planifié la lutte dans l'allégresse, maintenant à tes côtés, je pensais aux problèmes qui allaient surgir et je me demandais comme le gouverneur élu donnerait suite aux promesses de campagne. ») in ibid., p. 295. 
paysans ou ouvriers, amène le film à ne plus traiter que de politique au sommet. Seul compte finalement le triangle Diaz, Fuentes, Vieira dans le règlement des destinées du pays.

Comme nous le voyons, pendant la période de gestation de Terra em transe, le projet cinématographique de Rocha s'est décliné selon trois orientations différentes. Les deux premières matérialisées par le projet de América nuestra et les scénarios de Terra em transe, constituaient deux propositions différentes de ce qu'aurait pu être un « réalisme poétique révolutionnaire » ou encore un "cinéma épico-didactique ». América nuestra proposait d'approfondir la voie de l'écriture mythologisante inaugurée par Barravento et Deus e o diabo na terra do sol dans la perspective d'un véritable Octobre d'anticipation qui raconterait, avant qu'elle ne se produise et pour qu'elle se produise, la grande révolution latino-américaine. Projet de pure spéculation prospective, exemple type de fiction politique, América nuestra ne se pliait pas moins à une exigence d'information et d'authenticité par rapport à la justesse de l'analyse politique de sa situation de départ qui est la situation politique réelle de l'Amérique latine dans les années soixante. Aussi, la narration cherche-t-elle à suivre l'articulation des mécanismes politiques qui se mettraient en branle si un nouveau foyer révolutionnaire réussissait à prendre de l'ampleur. Se remettant à une direction parfaitement opposée, les scénarii de Terra em transe renouaient avec le réalisme et l'analyse a posteriori des événements du début des années soixante, la dimension poétique résidant dans le tragique de l'histoire collective et l'avortement des idéaux individuels. Comme dans O Desafio, le triomphe de la réaction prive l'individu conscient du droit au bonheur. Les deux propositions apparemment opposées que constituent América nuestra et les scénarii de Terra em transe, présentent le même souci d'information, d'exhaustivité et de clarté qui nous semble bien devoir être identifié au volet « didactique » du cinéma épico-didactique. Ils recouvrent aussi la même nécessité de définition politique de la part de l'instance narratrice or, ces deux dernières dimensions sont absentes du film du fait des modifications du système des actants et de la narration que nous avons précédemment mis en exergue. Terra em transe n'est pas didactique. América nuestra témoigne de la recherche d'alternative à un cinéma d'avant-garde introspectif, aussi politique soit-il. Provoquer la révolution par le cinéma reste l'obsession du cinéaste.

Rocha reprend et abandonne successivement América nuestra en 1967, 1969 et 1971 au profit d'autres réalisations dans lesquels nous retrouverons les fruits de sa réflexion sur le cinéma épico-didactique : O Dragão da maldade contra o santo guerreiro, Der Leone have sept cabeças, Cabezas cortadas et História do Brasil. Avellar a raison de dire que «o roteiro filmado funciona todo este tempo como um texto teórico, como uma reflexão que impulsiona a prática. Muitas vezes apanhado, trabalhado e deixado por adiante - mais por falta de 
condições de trabalho que por um desejo de retrabalhar o projeto -, este roteiro não filmado é que estimula Glauber a filmar. ${ }^{853}$

Le thème principal de América nuestra qui est l'intégration latino-américaine, est sa principale motivation à revenir sans cesse sur cette histoire. L'intégration latino-américaine représente pour Rocha un objectif révolutionnaire ${ }^{854}$. Mais cependant il ne croit pas en la possibilité d'une mobilisation populaire sans intervention d'un leader charismatique. La mort tragique de Guevara en Bolivie le 9 octobre 1967 relance l'écriture de América nuestra avec l'apparition d'un nouveau guérillero El qui surclasse le Bolivar des versions antérieures. Bolivar représentait le romantisme du XIXe siècle, El est l'homme nouveau capable d'affronter les contradictions du système capitaliste moderne et de créer une nouvelle société. Sans pour autant citer América nuestra, Rocha explique ce revirement invisible de son œuvre

«Je trouve que la réponse aux doutes d'un personnage comme Paulo - doutes qui d'ailleurs caractérisent très bien toute ma génération et moi-même - c'est la figure de Guevara. Je ne dis pas cela parce que l'on parle de sa mort, car j'y ai déjà beaucoup pensé, et tout me porte en ce moment à faire un film sur un personnage comme lui, un bourgeois qui se coupe de sa culture et fait la révolution. Il donne une réponse par sa propre existence et maintenant avec sa légende il apporte une réponse à toute une série de problèmes de l'Amérique Latine. $)^{855}$

Le fait que ce projet n'ait jamais été filmé ne s'explique pas seulement, selon nous, par la précarité de moyens mais par une certaine insatisfaction de l'auteur envers la structure narrative. Il exprime d'ailleurs celle-ci dans le texte América nuestra $69^{856}$ sans donner de détails. La première raison possible à cette insatisfaction est, dans les versions de 1968 et 1969, qu'il peine à se détacher du système des actants qui reste très proche de celui de Terra em transe. La seconde raison peut être également qu'au fil des événements, l'enthousiasme initial qu'il avait ressenti pour les mouvements de guérilla va s'affaiblir jusqu'à se consumer totalement. La foi dans la venue d'une figure messianique va pourtant demeurer. Dans les années soixante-dix, Rocha se dote de nouveaux modèles politiques comme Juan Velasco

853 « le scénario non filmé fonctionne pendant tout ce temps comme un texte théorique, comme une réflexion qui nourrit la pratique. Plusieurs fois repris, retravaillé et de nouveau laissé de côté - plus du fait d'un manque de conditions de travail que par le désir de retravailler le projet -, ce scénario est ce qui stimule Glauber à filmer. » in AVELLAR, José Carlos. A Ponte clandestina : Birri, Glauber, Solanas, García Espinosa, Sanjinés, Alea - Teorias de cinema na América latina. Rio de Janeiro / São Paulo, ed. 34 / edusp, 1995, p. 12.

854Il l'explique abondamment dans des entretiens qui ont été récemment publiés et qu'il a accordé au moment de son séjour à Cuba. Voir ROCHA, Eryk (org.). Rocha que voa-América latina, África, o papel do intelectual, cinema, poesia, política, a memória em transe. A integra da entrevistas de Glauber que deram origem ao filme de Eryk Rocha. Rio de Janeiro, Aeroplano, 2002.

855ROCHA, Glauber. « Entretien avec Rocha » in Positif, Paris, nº1, janvier 1968, p. 29.

856ROCHA, Glauber. A Revoluçäo do Cinema Novo. Op. cit., pp. 130-138. 
Alvarado $^{857}$, Mouammar Kadhafi ${ }^{858}$ ou encore l'ayatollah Khomeiny ${ }^{859}$. Ses derniers scénarios montrent qu'il ne voyait une issue à l'oppression qu'au travers d'une intervention divine ou de l'émergence d'un mouvement populaire fort dirigé par un leader mystique conjuguée à la rivalité d'élites toutes puissantes se déchirant pareillement aux anciennes élites romaines ${ }^{860}$. Autant dire que Rocha accordera de moins en moins de crédit aux thèses révolutionnaires marxistes et même à la possibilité de conscientisation du peuple parce que les élites réussiraient toujours à l'empêcher par une série d'actions auxquelles il sentait le Cinema Novo directement confronté : la manipulation et la répression.

857Président militaire du Pérou entre 1968 et 1975.

858Chef d'État de la Lybie depuis 1969.

859Guide spirituel de la révolution iranienne de 1979 qui renversa le shah d'Iran : Mohammad Reza Pahlavi. Il installa une théocratie chiite qu'il gouverna du renversement du chah à sa mort en 1989. L'influence de ce personnage est visible dans les derniers scénarios écrits entre 1977 et 1981 où apparaît un prophète religieux qui est aussi un chef guérillero sorte de synthèse de Antônio conselheiro et de Khomeiny. L'exemple de l'Iran signifiait au yeux de Rocha qu'un mouvement religieux, même intégriste, pouvait assumer un rôle révolutionnaire en restituant au peuple son identité et son pouvoir face à l'impérialisme matérialiste occidental.

860 Cf. FICAMOS Bertrand. «De la violence des rêves : l'écriture singulière de Glauber Rocha » in Territoires du scénario. Dijon, Centre Gaston Bachelard de Recherches sur l'Imaginaire et la Rationalité, Université de Bourgogne, 2006. 


\section{Chapitre 9 : Cinema Novo et répression}

Il est généralement acquis, dans les différentes études qui sont faites sur le Cinema Novo, que celui-ci s'est très rapidement heurté au système répressif mis en place par la dictature, en particulier la censure et la police politique, sans que ne soit réellement mis en relation un certain nombre de contradictions. Considéré a priori comme un cinéma révolutionnaire, les heurts du Cinema Novo avec le pouvoir apparaissent comme la confirmation de cette qualité. Comme nous le verrons plus bas, plusieurs événements montrent que les cinemanovistas ont effectivement souffert de l'arbitraire du régime autoritaire. Nous rappellerons ici les démêlés avec la censure de certains films, les emprisonnements de Glauber Rocha, Joaquim Pedro de Andrade et Walter Lima Júnior, les intimidations à l'exil et le fichage systématique de l'ensemble des membres du groupe. Pour autant, il convient de détailler et de nuancer l'action de la répression et de s'interroger sur sa véritable signification. Nous avons déjà vu dans d'autres chapitres l'ambivalence manifestée par l'État envers le Cinema Novo. Celui-ci ne met-il pas en place de dispositifs d'aide à la production qui se révéleront finalement les principaux supports financiers du groupe ? Les changements erratiques de politique de l'Itamaraty ou des institutions de cinéma dans leur relation spécifique aux cinemanovistas trouvent leur équivalent dans les oscillations des instruments répressifs qui obéissent à des logiques internes spécifiques mais expriment tout autant les contradictions d'un système autoritaire idéologiquement divisé.

Dans ce chapitre, nous allons découvrir que la division idéologique du régime avec laquelle le Cinema Novo doit composer, s'articule sur deux axes principaux indépendants l'un de l'autre. Le premier et finalement le mieux connu est celui des grandes orientations politiques. Aussi curieux que cela puisse paraître, dès l'examen de Deus e o diabo na terra do sol, au lendemain même du coup d'État de 1964, certains militaires ne sont pas insensibles au nationalisme exacerbé du film. Le nationalisme et la conception de la culture sur laquelle repose le Cinema Novo vont devenir des points d'entente avec certains éléments de la hiérarchie du régime. Ceci expliquera des retournements de situation et des rapprochements assez surprenants. Entre les libéraux et les nationalistes qui alternent au sommet de l'État, les cinemanovistas vont trouver avec les seconds un terrain d'entente basé sur un désir commun de défense de la culture nationale et l'idée que le Cinema Novo en est un digne représentant.

La deuxième division s'opère sur l'appréciation de la dangerosité du Cinema Novo en termes de subversion. Quelque soit la sensibilité des dirigeants au nationalisme du groupe, les archives montrent qu'ils n'ont pas été dupes de ses tendances marxistes. Il apparaît alors deux 
tendances. La première est en phase avec la paranoïa du régime et ses pulsions de contrôle total de la société. Elle consiste à prôner l'interdiction totale des films et la poursuite des cinéastes. La seconde consiste au contraire à accepter la circulation des œuvres et à consentir aux cinéastes une liberté surveillée sur la base de l'appréciation suivante : le Cinema Novo ne remplit pas ses objectifs de conscientisation des masses, d'une part parce que la circulation des films sur le marché est limitée, et d'autre part, parce que les films ne sont pas compris ou n'intéressent pas les publics qui ne sont pas déjà convaincus des idées qu'ils véhiculent. Afin de sauvegarder les apparences « démocratiques » du régime vis à vis des pays étrangers, voire même de capitaliser sur le prestige des cinéastes, les dirigeants opteront pour une permissivité condescendante envers un cinéma qui se déclare pourtant « révolutionnaire ${ }^{861}$.

Dans ce chapitre, nous allons étudier les relations du Cinema Novo avec l'État au travers de deux instances de contrôle directe. La première est la censure cinématographique à laquelle était soumis tout film destiné à être projeté sur le territoire brésilien. La seconde est la police politique qui, alliée aux services de renseignements des armées, a exercé des activités de surveillance et d'intimidation des cinéastes. Dans ces deux cas, l'ignorance et l'incompétence des agents de ces institutions, le caractère absurde de certaines situations ou l'incohérence de certaines actions répressives ne devront pas nous faire sous-estimer le fait que les principales décisions étaient emportées en haut-lieu. $\mathrm{Si}$, comme le démontrent certaines anecdotes tristement pittoresques, nombre de généraux ne manifestaient aucune réflexion politique concernant la culture, d'autres au contraire possédaient une parfaite intelligence des situations et de leurs intérêts. Bien que ponctuelles, leurs interventions se sont toujours révélées décisives. L'appréciation qui a finalement prévalu quant à la non-dangerosité du Cinema Novo s'est quant à elle basée sur la reconnaissance d'un troisième mécanisme de contrôle qui ne dépendait pas directement de l'État, le marché, qui se chargeait lui-même et selon ses propres logiques de limiter la diffusion des films.

861La relation qui va peu à peu s'établir entre le régime dictatorial et le Cinema Novo est un peu équivalente à celle qui existe à la même époque entre un certain nombre d'anciens du CPC et TV Globo. Le dirigeant de la grande chaîne de télévision brésilienne, Roberto Marinho, l'un des magnats de l'information les plus importants de l'histoire du Brésil, avait l'habitude d'entendre les inquiétudes de ses amis quant au fait qu'il employait des artistes communistes. Il leur répondait invariablement : « Deixe que eu cuido dos meus comunistas. » («Laissez, je m'en occupe de mes communistes »). La situation est toujours la même, d'un côté, les dirigeants pensent capter la créativité et le prestige d'artistes reconnus à leur bénéfice, de l'autre, ces mêmes artistes dont l'idéologie est contraire à celle de leurs protecteurs pensent être capable d'infiltrer le système et de le modifier de l'intérieur en s'appuyant sur les outils de large diffusion auquel il leur permet d'accéder. Selon Eduardo Coutinho, dans l'entretien qu'il nous a accordé, la permissivité des dirigeants se fondait sur un grand pragmatisme. Si, comme cela est souvent dit, en France et avec la Nouvelle Vague, le talent était à droite, au Brésil, avec le Cinema Novo et le CPC, le talent était à gauche (Eduardo Coutinho. Entretien avec l'auteur, juin 2003). Il s'établit un jeu de dupe dans lequel chacun pense abuser l'autre. Nous constaterons que les mécanismes de contrôle étaient puissants et que les artistes n'ont pas réussi à subvertir le système. Pour autant, certaines œuvres ou fragments d'œuvre ont le mérite d'exister et de faire vivre les contradictions de ce processus historique. 


\subsection{La diffusion des films politiques sous la dictature}

Comme nous l'avons déjà dit, le coup d'État d'avril 1964 est un événement qui n'avait absolument pas été anticipé par les membres du groupe du Cinema Novo. Dans la confusion généralisée qui règne dans les jours qui suivent la chute de Goulart, les négatifs de films en cours sont cachés, des projets sont remis en cause. Mais, dans la majorité des cas, le monde du cinéma n'est pas directement menacé par les mesures d'épuration qui frappent les élus, les partis, les syndicats, les administrations et toutes les personnes qui, d'une façon ou d'une autre, ont pu être associées à l'activisme de gauche ou d'extrême-gauche par la presse ou les services de renseignement. Vidas secas, Deus e o diabo na terra et Os Fuzis, trois films clairement mis en relation avec le marxisme par les spectateurs, y compris les militaires, ne sont pas interdits par la censure, sortent dans les cinémas, circulent librement dans le monde et représentent le Brésil jusque dans les plus prestigieux festivals. Par la suite, tous les films du Cinema Novo présentés au Serviço da Censura dos Divertimentos Públicos - SCDP obtiendront leurs visas d'exploitation et leurs visas d'exportation et de projection dans les festivals internationaux.

Quels sont alors les films qui sont interdits et pourquoi le sont-ils ? En 1964, un événement a lieu qui fondera les appréhensions des cinéastes quant à la surveillance exercée par le nouveau régime à l'encontre du cinéma. Le tournage de Cabra marcado para morrer d'Eduardo Coutinho est interrompu le jour même du coup d'État par une intervention directe de l'armée. Cet événement va déterminer la politique des cinemanovistas vis à vis de l'État et renforcer des mécanismes d'autocensure qui étaient déjà présents. Compromis d'un point de vue idéologique et économique avec l'ancien régime, Maioria absoluta et Integração racial ne sont pas soumis à la censure. Les mécanismes d'autocensure se font ensuite moins visibles et se jouent sur le rejet de certains sujets dont il est estimé d'avance qu'ils ne passeront pas. Parallèlement au Cinema Novo, d'autres cinéastes engagés politiquement sont passés outre avec des résultats contrastés.

\section{Cabra marcado para morrer}

Le seul film qui ait immédiatement et directement souffert de la première vague de répression politique qui accompagne le coup d'État de 1964, n'est pas un film du Cinema Novo. Il s'agit d'un long métrage de fiction sur les ligues paysannes qui est resté inachevé et dont on ne connaîtrait pas l'histoire si, en 1981, son auteur, le cinéaste Eduardo Coutinho, n'en 
avait pas repris le tournage sous la forme d'un documentaire. Deux films distincts portent donc le titre de Cabra marcado para morrer : le projet de 1964 et le documentaire de 1984. Le film de 1964 devait retracer la trajectoire de João Pedro Teixeira, fondateur de la première ligue paysanne et leader historique du mouvement. Bien que Coutinho ait repris son projet quinze ans plus tard et dans un sens tout à fait différent, le film documentaire est notre principale source d'informations sur l'expérience de 1964. Il est important de réfléchir sur l'interdiction du film de Coutinho car, au lendemain du putsch, il s'est agi de la principale référence à laquelle les cinéastes ont pu se fier pour se représenter l'espace de liberté dont il pouvait encore disposer.

Coutinho est un cinéaste de la même génération que ceux du Cinema Novo. Né en 1933, son origine sociale et sa trajectoire sont similaires à celles de ses camarades. Natif de São Paulo, il commence des études de droit qu'il ne mène pas à leur terme. Passionné de cinéma, il suit le séminaire de cinéma du Museu de Arte Moderna de São Paulo en 1954. Lauréat d'un jeu télévisé, il utilise la somme gagnée pour aller étudier à l'IDHEC en France. Là-bas, il acquiert aussi une expérience de théâtre qu'il va réinvestir dès son retour au Brésil, en 1960, comme assistant de direction sur la pièce Quarto de despejo de Eddy Lima. Rapidement, il s'intéresse au CPC qu'il intègre dès sa formation et monte la pièce Mutirão en novo sol représenté au I Congresso dos Trabalhadores agrícolas à Belo Horizonte. Il participe ensuite à Cinco vezes favela comme gérant de production, intègre l'UNE-volante puis se consacre au projet de Cabra Marcado para morrer.

Après le coup d'État d'avril 1964, Coutinho est l'un des plus proches collaborateurs de Leon Hirszman. Il co-signe les scénarios des deux premiers longs métrages du cinemanovista, A Falecida et Garota de Ipanema, et dirige trois films de fiction pour Saga Filmes : O Pacto, deuxième épisode de la co-production internationale $A B C$ do amor, $O$ Homem que comprou $O$ mundo (1968) et O Faustão (1970). Malgré leur succès dans les salles (O Faustão atteint 400 000 spectateurs $^{862}$ ), ils n'obtinrent aucun succès critique et Coutinho lui-même ne leur accorde guère d'importance. Pendant toute cette période, le futur documentariste évolue à la périphérie du Cinema Novo, l'esthétique de ses films diverge de ceux produits par le groupe dont il n'est pas membre malgré sa proximité avec Hirszman et Faria ${ }^{863}$.

Selon son propre aveu, Coutinho est dans les années soixante un cinéaste insatisfait, peu sûr de lui, et frustré de ne pas avoir pu achever Cabra marcado para morrer ${ }^{864}$. Dans les années soixante-dix, il collabore à l'écriture de scénarios de cinéma ${ }^{865}$ et surtout, en 1975 ,

862RAMOS, Fernão et MIRANDA, Luís Felipe (org.). Op. cit., p. 159.

863Cf. VIANY, Alex. O processo do Cinema Novo. Op. cit., p. 421.

864Eduardo Coutinho. Entretien avec l'auteur, juin 2003.

865Os Condenados (Zelito Viana, 1973), Lição de amor (Eduardo Escorel, 1975), Dona Flor e seus dois 
travaille dans le programme Globo Repórter de la $T V$ Globo comme rédacteur, monteur et directeur de reportages. La télévision est pour lui une école du documentaire. C'est à la suite de cette expérience qu'il va reprendre la réalisation de Cabra marcado para morrer et développer la carrière de documentariste grâce à laquelle il obtient une renommée internationale ${ }^{866}$.

Le Cabra marcado prá morrer de 1984 prend pour point de départ ce qui reste de celui de 1964, des images (les rushes et huit photos de scène), des coupures de presse et des souvenirs. La première partie du documentaire rappelle le contexte de l'époque et raconte l'histoire du film inachevé. Nous la résumerons ici en complétant avec les informations apportées par le cinéaste dans les entrevues parues dans la presse. Tout commence en 1962, Coutinho sort du tournage de Cinco vezes favela. Il doit partir avec l'équipe de cinéma qui va suivre l'UNE-volante dans son voyage dans le Nordeste. L'objectif de l'UNE-Volante est de stimuler la création de nouveaux CPC au travers du pays. Dans la perspective de l'idéologie nationale-populaire de l'époque, l'équipe de cinéma doit mettre à profit cette expédition pour filmer ce Brésil pauvre et sous-développé que l'on ne montre jamais. Pour diverses raisons, ces images ne seront pas exploitées à l'époque de leur tournage. Le passage de l'UNE-volante à Recife coïncide avec une manifestation paysanne en réaction au récent assassinat du leader paysan João Pedro Teixeira, le 2 avril 1962. À cette occasion, Coutinho interviewe sa femme, Elizabeth Teixeira. De cette première rencontre, surgit l'idée de réaliser un film sur la trajectoire de son mari.

De retour à Rio de Janeiro, Carlos Estevam Martins désigne Coutinho pour réaliser un long métrage de fiction. Ce dernier désire filmer le Nordeste et pense d'abord à une adaptation cinématographique des poèmes sociaux de João Cabral de Melo Neto ${ }^{867}$ avec pour point de départ celui qui s'intitule $O \mathrm{Rio}^{868}$. Certainement pour ne pas prendre le risque d'être identifié avec le CPC, l'écrivain impose son veto. Coutinho choisira alors de se passer du filtre de l'adaptation littéraire pour traiter la réalité du Nordeste.. Se basant exclusivement sur le témoignage d'Elizabeth Teixeira, il écrit un scénario qui retrace la vie de son mari de son enfance jusqu'à son assassinat. L'emphase est portée sur les conditions de vie du travailleur rural et la lutte des ligues paysannes. Différence notable d'avec les films du Cinema Novo, le

maridos (Bruno Barreto, 1976).

866Au-delà de Cabra marcado prá morrer (1984) qui est un succès critique et commercial international, les films suivants de Coutinho, Fio da memória (1989-1991), Santo forte (1999), Babilonia 2000 (2000),

Edifício Master (2002) et Peões (2004), ont été des films très commentés et ont réussi à toucher le public audelà les limites habituelles du cinéma documentaire.

867João Cabral de Melo Neto (1920-1999), diplomate et poète consacré par de nombreux prix internationaux, est issu d'une famille traditionnelle du Pernambouc. Il est cousin de Manuel Bandeira et Gilberto Freyre.

868Cf. GALANO, Ana Maria et alii. «A Cumplicidade com a Vida : Entrevista com Eduardo Coutinho » in Contracampo, n²7, revue électronique, http://www.contracampo.com.br/27/realsemaspas.htm, consulté le 22/12/2005, réédition d'une interview parue dans Filme Cultura, Rio de Janeiro, n44, 1984. 
cinéaste prévoit que, dans la mesure du possible, les personnages réels, historiques, de la création de la ligue de Sapé, joueront leur propre rôle. Il prévoit aussi de tourner à Sapé, aux endroits mêmes où se sont déroulés les épisodes réels qui sont repris dans le scénario.

L'UNE de Rio de Janeiro et le MCP de Recife s'engagent à produire le film mais de nombreux retards dans le versement des crédits provoquent le report continuel du tournage pendant un an. Quand l'argent est enfin versé, Sapé est le théâtre d'un violent conflit entre la police et les paysans. 11 d'entre eux sont tués par les forces de l'ordre. Les tensions générées par l'événement excluent toute possibilité de tournage à cet endroit. Coutinho et son équipe ne se découragent pourtant pas et choisissent de faire le film dans l'état voisin, à Galiléia, berceau des ligues paysannes. Au lieu réel de l'action est donc substitué un lieu qui reste hautement symbolique pour les ligues paysannes. Des compagnons de vie et de lutte de Teixeira, seul reste son épouse, Elizabeth. Les autres acteurs sont recrutés in loco, plusieurs d'entre eux sont membres de la SAPPP ${ }^{869}$, l'histoire du leader paysan ne leur est donc pas étrangère.

Le tournage commence au mois de février 1964. Il va durer 35 jours. Il est interrompu dans la nuit du 31 mars 1964 par l'invasion de la troupe. Celle-ci a pour mission d'interrompre le tournage, de saisir l'intégralité du matériel présent sur le local et de faire prisonniers l'équipe technique du film et les leaders paysans. Un tiers environ du scénario était tourné. Selon l'un des participants du tournage, l'unité chargée de cette mission venait de la Paraíba et non du Pernambouc, comme cela aurait été logique. Galiléia est une commune du Pernambouc. Averti de l'arrivée des militaires, l'équipe technique a le temps de s'enfuir. Ses membres parviennent à s'échapper et rejoignent Recife avant de rentrer à Rio de Janeiro. De retour dans l'ancienne capitale fédérale, aucun d'eux ne sera inquiété. Les acteurs paysans restés dans le Nordeste souffrent au contraire des répressions policières et connaissent des périodes de détention plus ou moins longues. Elizabeth Teixeira est incarcérée peu de temps. Elle met à profit un moment de répit pour s'enfuir au Rio Grande do Norte où elle vivra dans la clandestinité pendant seize ans séparée de huit de ses dix enfants.

Par un heureux concours de circonstances, les négatifs du premier mois de tournage avaient été envoyés au laboratoire, à Rio de Janeiro, le 15 mars 1964. Après le coup d'État, ils seront dissimulés sous le lit du père de David Neves, pourtant lui-même général en activité ${ }^{870}$. Le scénario du film est récupéré deux ans après les événements par Coutinho lui-même dans

869La toute première ligue paysanne. $C f$. paragraphe 2.2 .

870 L'anecdote est connue et largement divulguée. Nous en retrouvons mention, entre autres, dans :

GALANO, Ana Maria et alii. Op. cit.

RAMOS, Fernão et MIRANDA, Luís Felipe (org.). Op. cit., p. 159.

NEVES, David. Muito prazer. Op. cit., p. 27. 
le commissariat où le texte avait été gardé après avoir été saisi. Dans la chaleur des événements d'avril 1964, l'opération militaire qui avait mis fin au tournage avait pourtant fait grand bruit. Les journaux parlaient de la saisie de matériel subversif et de la liquidation d'un foyer de guérilla rurale encadré par des cubains.

L'UNE, le MPC et le CPC interdits, les membres des ligues paysannes persécutés dans tout le Nordeste, le contexte ne se prêtait guère à ce que l'équipe du film actionne un recours légal pour protester contre cette intervention violente et non justifiée. Dans ce contexte précis, la chaleur des événements d'avril exemptait le nouveau régime de la moindre justification. Avec le recul, et si l'on veut bien exclure que les autorités militaires pensaient réellement détruire un foyer de guérilla, l'explication la plus sûre à leur intervention est la présence de leaders des ligues paysannes, dont Elizabeth Teixeira, et le soupçon qu'un film complaisant envers le mouvement puisse être fait. Pour les cinéastes, cet événement signifiait que, dans la nouvelle période qui commençait, certains sujets seraient interdits parmi lesquels celui des ligues paysannes. Si Cabra marcado para morrer était interdit d'un côté et que, d'un autre, il était possible de diffuser Vidas secas et Deus e o diabo na terra do sol, cela indiquait qu'il était possible de parler de la misère dans le Nordeste, qu'il était même possible de désigner le latifundium et l'Église comme les causes des injustices, mais qu'il était impossible de traiter des mouvements contemporains de rébellions populaires. Ce raisonnement qui, finalement, ne se base que sur des hypothèses, annonçait l'autocensure à venir.

Fin 64, des anciens du CPC et les membres du Cinema Novo se réunissent au Teatro de arena pour voir les rushes qui avaient été sauvés et discuter d'une éventuelle reprise de la réalisation du film. Le public est divisé. Zelito Viana défend la thèse selon laquelle les conditions ne sont pas réunies pour que le film puisse être terminé et projeté en restant fidèle au projet initial ${ }^{871}$. Sa thèse l'emporte. Cabra marcado para morrer est donc victime d'autocensure. Alors que le régime militaire est à présent en place depuis plusieurs mois, il n'y a eu aucun remaniement des institutions de la censure cinématographique et aucune politique claire dans ce domaine n'a été définie. Comme la censure n'examine les films qu'une fois qu'ils sont terminés, les cinéastes anticipent les limites qui seraient imposées par le régime et décident de s'y tenir. Il n'est pas imaginé par exemple qu'un film puisse être fait avec la certitude qu'il sera interdit mais avec des objectifs politiques qui passeraient par des stratégies de diffusion alternative ou l'envoi clandestin de la pellicule à l'étranger.

Le deuxième point intéressant du raisonnement qui pourra être tenu à partir de l'interdiction de Cabra marcado para morrer est le suivant. Dans quel mesure, l'interdiction

871Zelito Viana. Entretien avec l'auteur, février 2004. C'est au cours de ce débat qu'il rencontre Rocha pour la première fois. Ce dernier approuve la position que le futur producteur a défendue. 
d'un film sous le régime dictatorial constituerait une reconnaissance implicite de ce dernier que le film est bien dangereux et remplit des objectifs politiques qui lui sont contraires ? Et, réciproquement, dans quelle mesure le fait qu'un film "passe » les fourches caudines de la censure prouve que celui-ci n'est pas aussi subversif que ses auteurs le prétendent ? Au moment de l'analyse des films de la trilogie du sertão, nous avons relevé certaines ambiguïtés concernant l'idéologie manifestée par ses films et en particulier le fait que tous les trois présentent du peuple une image assez dépréciative selon laquelle son aliénation mystique et son inculture lui interdisent toute action politique conséquente. Cette représentation du peuple est congruente avec le mythe de son immaturité qui est entretenu par la dictature et lui apporte sa légitimité. La dictature est nécessaire parce que le peuple n'est pas encore mûr pour se diriger lui-même. Plus tard, les récits des réactions des militaires après le visionnage en séance privée de Deus e o diabo na terra do sol et Os Fuzis va tendre à confirmer que ces films présentent bien des éléments d'entente avec l'idéologie d'une partie non négligeable d'entre eux. Bien plus tard encore, la trajectoire des cinemanovistas et leur participation à la création d'Embrafilme va confirmer que les points de mésentente étaient finalement moins fort que les points d'entente avec les militaires nationalistes et qu'une collaboration entre les deux parties étaient possible. Sur la question de la censure du régime comme véritable arbitre du caractère subversif des films, l'interdiction de Cabra marcado para morrer apporte des éléments de réflexion car le film s'annonçait comme un film politique absolument étranger à la ligne du Cinema Novo.

Selon son propre témoignage ${ }^{872}$, en 1964 , Coutinho n'est pas sûr de lui. Il est inexpérimenté et craint de ne pas dominer les règles du langage cinématographique. Il en est, ne l'oublions pas, à son tout premier film comme réalisateur. En plus de cela, il choisit de s'intéresser à un monde qui lui est étranger, la paysannerie. Cette deuxième inconnue est un autre facteur d'anxiété. Dans le Cabra marcado para morrer de 1984, il souligne à plusieurs reprises l'insuffisance de ses recherches préliminaires au tournage sur le sujet. Malgré son manque d'assurance, il est sûr de ce qu'il ne veut pas. Il ne veut pas d'un langage démagogique et du recours aux « trucs hollywoodiens ». Il n'entend pas non plus suivre l'orientation donnée par Martins lors de la controverse de septembre 1962 avec Rocha et Diegues. Enfin, et en rupture totale avec le Cinema Novo, il ne prétend pas non plus faire du « cinéma d'auteur ». D'une part parce qu'il ne s'en sent pas capable, et, d'autre part, parce qu'il se méfie autant de la posture du CPC que de celle du Cinema Novo. Toutes deux, selon des méthodes différentes, prétendent la même chose, réaliser un cinéma de conscientisation. Or, Coutinho estime déjà que les deux partis surévaluent les pouvoirs du cinéma et de la culture et se déclare sceptique 872Eduardo Coutinho. Entretien avec l'auteur, juin 2003. 
quant à l'idée selon laquelle la jeunesse politisée de classe moyenne, dans un geste messianique, doit apporter la connaissance aux classes populaires pour que celles-ci se révoltent. Il s'écarte donc de la relation au cinéma que ces postures impliquent.

Dans la pratique, son film prend une dimension quasiment expérimentale. Au-delà de l'argument du film et du choix de travailleurs ruraux pour jouer leur propre rôle, la méthode de mise en scène adoptée par Coutinho s'inscrit de façon cohérente avec son projet initial et ses convictions. Il répète les scènes avec les paysans de façon à ce qu'ils transforment les dialogues et se les approprient complètement en les « traduisant » dans leur propre langue. $\mathrm{Au}$ moment de filmer, il évite les gros plans qui n'auraient une valeur exclusivement fonctionnelle et privilégie les plans d'ensemble. Sensible à certains préceptes du Cinema Novo, Coutinho rejette les effets dramatiques qui seraient basées sur les manipulations du montage et de la bande son. Vidas secas s'était déjà rapproché de cet idéal où prises de vue et montage traduisent une situation sans forcer l'émotion. Malgré les différences opposant les deux histoires $^{873}$, il recherche une économie de moyen comparable. Dans les deux cas, l'émotion doit naître de la confrontation à une situation réelle exprimée sans artifice et ce, pour des questions éthiques, le cinéaste répugnant à s'approprier une histoire qui n'était pas la sienne, mais aussi dans un souci d'efficacité. Il ne suffit pas en effet d'informer de la lutte qui agite les campagnes dans un registre factuel, il faut aussi en transmettre l'exacte dimension humaine. Tout indique que, peut être sans le savoir, dans sa transposition pour le grand écran de l'histoire que lui avait raconté Elizabeth Teixeira, Coutinho recherche déjà ce qui deviendra par la suite sa principale caractéristique, donner la parole au sujet filmé ${ }^{874}$.

Le résultat partiel, tel que nous le voyons dans les rushes insérés dans le Cabra marcado para morrer de 1984, n'est certainement pas très concluant. Le metteur en scène semble s'interdire de diriger les acteurs. Ceux-ci restent figés et les plans sont coupés trop tôt comme si à chaque fois la caméra craignait de trop s'approcher des visages ou d'offrir matière à un montage qui conduirait trop facilement l'action et les sentiments du spectateur. Le cinéaste le reconnaît lui-même.

«Talvez não fosse um bom filme - se é que essa expressão tem sentido - mas certamente seria um documento sobre um momento que não volta mais. Seria, por exemplo, o único filme feito com o movimento organizado da gente do campo. [...], é que teria sido um filme precário. Eu não sabia dirigir os atores, o diálogo era banal e o roteiro era quase todo baseado nas informações de Elizabeth sobre a vida de João Pedro Teixeira, sem invenção. O filme é uma coisa, a realidade, outra. E o roteiro do filme original tinha mil "barrigas", ele terminava duas vezes, era convencional, com personagens muito

873L'histoire de João Pedro Teixeira possède une dimension épique que Vidas secas n'a pas. De ce point de vue, Cabra marcado para morrer serait même l'antithèse du film de Santos.

874Dans le témoignage qu'il nous a accordé, Coutinho souligne ses préoccupations éthiques de l'époque : « não impor o seu discurso ao outro » (Ne pas imposer son discours à l'autre) et « não fazer do outro o que ele não era » (ne pas faire de l'autre ce qu'il n'était pas). Eduardo Coutinho. Entretien avec l'auteur, juin 2003. 
tipificados - tinha o cara exaltado, o covarde, o cara de bom senso. Eu ia pecar por isso. Tanto, que a única cena do filme original que eu dublei era a única cena que talvez indicasse o melhor caminho de se fazer um filme. Nela, os diálogos foram feitos pelos próprios camponeses. Não digo a estrutura, mas os diálogos. E eles disseram coisas que um roteirista jamais poderia escrever. $\gg{ }^{875}$

Il nous sera impossible de dire dans quelle mesure les militaires qui sont intervenus pour interrompre le tournage de Cabra marcado para morrer était informé du projet de Coutinho. Mais, connaissant les préjugés de classe l'époque qui incluait un traitement différencié des citoyens en fonction de leur origine sociale, nous pouvons avancer l'hypothèse selon laquelle le fait qu'un groupe de jeunes de classes privilégiées de Rio ou Salvador viennent filmer dans le sertão n'inquiétait pas outre mesure les militaires conservateurs. Par contre, l'idée qu'un film puisse être finalement "co-écrit» avec des membres des ligues paysannes, qu'il soit possible que les ligues paysannes initient une série de films dans lesquels elles pourraient s'exprimer, a été ressenti comme quelque chose d'insupportable. Par rapport à la question de l'autocensure par le microcosme intellectuel de Rio qui décide collectivement de ne pas continuer le film, nous pouvons aussi nous demander si, en plus de la peur de la répression, il n'y a pas eu un désaccord ou tout au point une absence de connivence idéologique avec le projet de Coutinho qui manifestait une idéologie divergente de celle qui avait été manifestée par le Cinema Novo d'un côté, et par le CPC de l'autre. Cette absence de connivence expliquerait le désengagement du projet.

Cabra marcado para morrer, que ce soit par la nature de son projet ou le caractère très particulier de l'intervention dont il a été l'objet, est un cas unique dans l'histoire du cinéma brésilien. Par la suite, le même type de projet ne sera pas remis en chantier et l'opposition du régime à certains films pour des raisons idéologiques passera par la voie légale des services de censure chargés de consentir les visas d'exploitation. Entre 1964 et 1968, aucune interdiction définitive n'est prononcée et les restrictions de l'État se manifestent au travers de la demande de coupes et de l'imposition d'une limite d'âge. Le Cinema Novo, comme nous le détaillerons dans le paragraphe suivant, est alors en effet la principale victime des services de censure. Le régime fait par ailleurs la démonstration d'une libéralité étonnante. Parmi les films politiques brésiliens étrangers au Cinema Novo, plusieurs longs métrages passent sans difficulté les

875« Peut être que ça n'aurait pas été un bon film - si jamais cette expression a un sens - mais cela aurait certainement été un document sur un moment qui ne reviendrait jamais. Cela aurait été, par exemple, le seul film sur le mouvement organisé des paysans. [...], cela aurait été un film de petits moyens. Je ne savais pas diriger les acteurs, les dialogues étaient banales et le scénario était tout entier basé sur les informations apportées par Elizabeth sur la vie de João Pedro Teixeira, sans invention. Le film est une chose, la réalité, une autre. Et le scénario avait mille défauts, il terminait deux fois, il était conventionnel, avec des personnages très typés - il y avait le personnage exalté, le lâche, le personnage de bon sens. J'allais pécher pour cela. Tant et si bien que la seule et unique scène du film que j'ai doublé était la seule qui, peut être, indiquait quel était la meilleure façon de faire le film. Dans celle-ci, les dialogues avaient été écrits par les propres paysans. Je ne dis pas la structure, mais les dialogues. Et ils ont dit des choses que jamais un scénariste ne pourrait écrire. » in GALANO, Ana Maria et alii. Op. cit. 
filets de la censure, un peu comme si celle-ci s'est avérée incompétente à repérer des œuvres qui dénonçaient l'idéologie du régime.

\section{Une étonnante libéralité}

Parallèlement au Cinema Novo et parfois en franche opposition avec lui, d'autres tentatives de cinéma politique sont menées : les documentaires de Thomaz Farkas et les longs métrages de fiction de Maurice Capovilla et Luis Sérgio Person.

Né à Budapest en 1924, Farkas immigre au Brésil dans sa petite enfance. Diplômé comme ingénieur par l'Universidade de São Paulo - USP, il intègre l'entreprise familiale de vente et de réparation de matériel photographique et s'inscrit à des clubs de photo amateurs. Dans le cadre de ses activités professionnelles, il travaille pour le Museu de Arte de São Paulo - MASP, entre 1948 et 1950. À la même époque, il commence à tourner petits films institutionnels ou d'actualité. Son entrée définitive dans le monde du cinéma a lieu dix ans plus tard, en 1963, à l'occasion de la présence au Brésil de l'argentin Fernando Birri, pionnier de l'école documentaire de Santa Fé où d'autres futurs cinéastes dont Maurice Capovilla et Sérgio Muniz avaient étudié. Exilé au Brésil pour des raisons politiques, Birri n'est pas venu seul. Les futurs cinéastes paulistes et les cinéastes argentins qui sont venus avec lui (Edgardo Pallero et Manuel Horácio Gimenez) vont former un petit groupe qui va vouloir prolonger l'expérience de l'école de Santa Fé et intégrer à son esthétique des éléments du cinéma vérité alors très en vogue. Farkas se propose de produire une série de documentaires. Pallero se charge de la production exécutive, Gimenez réalise Nossa Escola de samba, un autre cinéaste pauliste Geraldo Sarno, réalise Viramundo, Capovilla est l'auteur de Subterrâneos de futebol, enfin, Memória do cangaço est un film de Paulo Gil Soares, compagnon de Glauber Rocha depuis l'adolescence à qui Farkas demande une contribution. Les quatre documentaires seront plus tard réunis sous la forme d'un long métrage intitulé Brasil verdade (Brésil vérité) en référence au cinéma vérité.

Malgré la présence de Soares et la sympathie de Capovilla et Farkas pour le groupe et le concept critique du Cinema Novo, l'esthétique de leur cinéma diffère de façon assez significative des films cariocas. Le documentaire est préféré à la fiction et le présent est préféré à l'histoire. La sociologie se substitue aussi aux références artistiques puisque Viramundo est basé sur les travaux du chercheur pauliste Octávio Ianni. À ce titre les commentaires en voix off développent une argumentation basée sur des statistiques et des analyses scientifiques. Les quatre films s'inscrivent dans la continuité du combat des grandes aliénations populaires, le mysticisme, le football et le carnaval, déjà caractéristique du CPC et 
du Cinema Novo. Enfin, même si, comme l'observe Bernardet, la voix off est une voix du savoir et la structure du film dans son ensemble trahit une relation inégale dans laquelle ce qu'elle dit l'emporte sur ce que disent les personnes interrogés, entendre des membres des classes populaires constitue une nouveauté dans le cinéma brésilien. La parole du populaire, par son originalité et par sa force, remet en cause les valeurs, les représentations et, d'une manière générale, les modes de légitimation des classes dominantes. Le Brésil de Farkas ne colle pas au cliché selon lequel le peuple accepterait la misère sans perdre la bonne humeur qui serait sa caractéristique principale.

Parallèlement à cela, ses documentaires jouent de leur ancrage dans le présent pour discuter directement de grands thèmes politiques : l'immigration des nordestins vers São Paulo dans Viramundo, la manipulation des masses par le football dans Subterrâneos de futebol et même Memória do cangaço qui reprend le thème historique du cangaço le fait à partir du présent, notamment en dénonçant la persistance de thèses racistes parmi les universitaires brésiliens de l'époque. Sans s'orienter vers le cinéma militant qu'aurait attendu le CPC, se prévalant de leur dimension documentaire et didactique, ces films mettent en cause de façon beaucoup plus claire que ne le font les films du Cinema Novo les mécanismes responsables du sous-développement et de la misère. Nous pourrons le constater en comparant Garrincha, alegria do povo (Andrade, 1963) et Subterrâneos de futebol.

Les deux films poursuivent le même objectif : dénoncer l'aliénation des masses par le football. Le film d'Andrade attire l'attention par son ambiguïté. Les cinquante premières minutes font l'apologie de Garrincha. En s'appuyant dans le montage sur une longue série d'images fixes qui crée un effet d'attente, une emphase émotionnelle est apportée aux plus belles actions du joueur qui sont montrées avec des images animées et rappellent sa participation à deux victoires en championnat du monde. Ce n'est que dans les dix dernières minutes du film que le spectateur est mis en garde contre le fait que le football sert aussi les dirigeants pour détourner le peuple des «véritables problèmes ». Dans un montage assez rapide, le gouverneur Carlos Lacerda apparaît furtivement. Après plus des trois quarts de film qui servent à montrer que le football est un sport beau esthétiquement et pourvoyeur d'émotions collectives intenses, il est assez douteux que la fin, par ailleurs confuse en raison du montage et des non-dits du texte, puisse atteindre ses objectifs de conscientisation.

Le film de Capovilla est entièrement construit pour évoluer vers cette même conclusion en s'appuyant essentiellement sur deux éléments. Le premier est la dénonciation des conditions de vie des joueurs. Pour un Garrincha et un Pelé qui font une grande carrière et sont couverts d'honneurs, il est montré qu'un joueur de football est exploité comme n'importe quel ouvrier. Un joueur est engagé pour produire un profit. La moindre chute de 
« rentabilité », la moindre blessure peut signifier son licenciement immédiat. C'est donc un personnage qui vit dans l'inquiétude, sous une pression constante, et dont la carrière est très courte. Le deuxième élément sur lequel s'appuie la démonstration de Capovilla est l'aliénation des supporters. La caméra portée et le son direct permettent de recueillir leurs témoignages et surtout de les filmer dans l'état d'excitation dans lequel ils se trouvent au moment des matchs. La dénonciation du football par sa face cachée est plus convaincante que l'épopée héroïque de Garrincha. D'autre part, le narrateur en voix off abandonne le ton neutre et supposément objectif du premier documentaire. Le texte est d'une grande clarté quant à l'opinion des auteurs du film et à leurs objectifs. Sur des images de joueurs blessés, de dispute entre supporters, d'invasion de terrain et de répression policière, on entend le commentaire suivant :

« Por trás da bele jogada está um problema humano escondido do público. A imprensa concorre pela criação de mitos, mitos que valem dinheiro. Na realidade o jogador é um operário de vida curta. O jogador é uma mercadoria facilmente vencida. O seu valor está estabelecido pelos interesses do seu clube e de seus dirigentes. $\mathrm{O}$ jogador ganha pouco, arrisca muito e é uma fonte de renda. Nas arquibancadas a torcida sempre húmilde sofre com as derrotas, se alegre com as vitórias. Como uma válvula de escape, o futebol compensa uma semana de excesso de trabalho, de pouco dinheiro. Quem ganha com isto ? ${ }^{876}$

Ces quatre documentaires, parce qu'ils montraient des aspects du Brésil que les conservateurs préféraient ne pas voir et parce qu'ils étaient la transposition sur grand écran d'une sociologie d'inspiration marxiste, auraient dû, logiquement, s'attirer les foudres de la censure. En octobre et novembre 1965, Viramundo, Nossa Escola de Samba et Subterrâneos de futebol obtiennent leurs visas d'exploitation sans difficulté. Si les censeurs n'ont guère apprécié les films, ils n'ont pas pour autant trouvé de motifs pour les interdire ni même retarder l'émission des visas. En 1967, Brasil verdade qui réunit les quatre longs métrages ne rencontrera pas de difficultés non plus ${ }^{877}$.

D'autres films dénonçant des mécanismes généraux d'aliénation sont également libérés par la censure sans coupe mais seulement pour les plus de dix-huit ans. Il s'agit de Bebel, uma garota propaganda et São Paulo SA.

Né en 1936 dans une petite ville de l'état de São Paulo, Maurice Capovilla a été camarade de lycée de Gustavo Dahl avant de se former en littérature à USP. En 1961, après le

876« Derrière le beau jeu, un problème humain est caché au public. La presse crée des mythes et ces mythes valent de l'argent. En réalité, le joueur est un ouvrier à la vie courte. Un joueur est une marchandise qui arrive vite à sa date de péremption. Sa valeur est déterminée par les intérêts de son club et de ses dirigeants. Le joueur gagne peu et risque beaucoup. Il est une source de profit. Sur les gradins, les supporters qui sont toujours des gens d'origine modeste souffrent avec les défaites et vibrent avec les victoires. Comme une soupape de sûreté, le football compense une semaine d'excès de travail et de maigres revenus. Qui profite de tout cela? » (Voix off du film).

$877 C f$. Chemises des films respectifs. Dossiers comprenant les demandes de visas, les comptes rendus des censeurs et un double des certificats émis ainsi que tout document annexe étant intervenus dans la décision des censeurs. ARQUIVO NACIONAL - COREG DF, Brasília. 
départ de Dahl à l'étranger, Capovilla prend sa place à la Cinemateca brasileira, il y retrouve Bernardet qu'il connaissait déjà pour avoir fréquenté avec lui le ciné-club du Centro Dom Vital. Parallèlement, Capovilla commence à écrire sur le cinéma dans la revue Brasiliense fondée par l'un des membres les plus éminents de l'ISEB, Caio Prado Júnior. La revue Brasiliense est le véhicule de la pensée de l'institut jusqu'à l'interruption de sa parution en 1964. Inscrit au parti communiste depuis 1960, Capovilla participe aussi à une travail politique dans le Sindicato da Construção Civil. Son action auprès des ouvriers consistait à passer des films et discuter à partir de ces films sur des thèmes politiques. La réalisation d'un court métrage documentaire qui devait s'intituler A Luta a également été initiée dans le cadre de cette activisme politique. Capovilla se déclare cependant frustré par cette expérience, peu d'ouvriers s'intéressaient aux discussions sur les films et l'interaction qu'il cherchait à obtenir au cours de la réalisation de ce documentaire n'a pas été aussi poussée qu'il le désirait. Son intérêt pour le documentaire n'en est pas pour autant entamé ${ }^{878}$. Sa rencontre avec Birri, déjà mentionnée plus haut, décide de sa participation au projet de Farkas. Subterrâneos de futebol est son premier film. Capovilla reviendra au documentaire dans les années soixante-dix. Avant cela, en 1967, il se lance dans l'aventure de la fiction pour Bebel, uma garota propaganda, un film qui témoigne à la fois de son admiration pour Rocha et de l'affirmation d'une orientation toutefois différente à celle du Cinema Novo.

L'inspiration cinemanovista est visible au travers de la fragmentation de la narration, le film est divisé en quatre blocs au cours desquels la trajectoire de Bebel est racontée par quatre personnages différents qui l'ont croisé à un moment donné. L'inspiration cinemanovista est également visible au travers de la dimension avant-gardiste du film : le narrateur principal est le cinéaste lui-même, visible à l'écran dans certaines séquences sous les traits d'un reporter qui cherche à faire un documentaire dans le style du cinéma vérité, ce personnage donne l'impression que nous voyons le film en train de se faire dans l'ordre dans lequel les séquences sont filmées. Le film se différencie du Cinema Novo comme les documentaires de Farkas, par son ancrage dans la contemporanéité et le primat de l'approche sociologique sur l'approche historique. Bebel raconte la rapide ascension et la longue descente aux enfers d'un mannequin rendu célèbre grâce à une campagne de publicité nationale pour un savon. Les hommes d'affaire qui séduisent Bebel sont montrés comme des personnages cyniques et peu scrupuleux. L'exploitation de la jeune femme, qui se transforme rapidement en exploitation sexuelle, est montrée de façon assez crue et osée pour l'époque. L'absence de glamour vise à dénoncer le mensonge qui serait dissimulé derrière les paillettes de la télévision. D'une certaine façon, Bebel est une transposition dans le monde du mannequinat de ce que racontait 878Maurice Capovilla. Entretien avec l'auteur, juin 2003. 
déjà Subterrâneos dans le monde du football.

Le film est l'objet d'une controverse et ses producteurs entrent en conflit avec les censure pour des raisons cependant étrangères à la problématique principale du film. Dans une séquence, un enfant est renversé par une voiture. Le coupable de l'accident est un député fédéral. Acculé par plusieurs témoins, il est tabassé à mort par un personnage très violent que l'on sait par ailleurs impliqué dans des réseaux de prostitution. Les censeurs ont vu dans cette séquence une atteinte à la dignité de la fonction de député fédéral. Ils réclament de couper la séquence. Les producteurs recourent contre cette décision, le film est finalement libéré après un mois de négociation sans coupe mais avec une restriction d'âge aux plus de 18 ans.

De portée plus large que Bebel..., São Paulo S.A. (1965) de Luís Sérgio Person stigmatise le fascisme latent d'une société dans laquelle le cynisme et le conformisme permettent de s'accommoder de la corruption et de l'égoïsme nécessaires à l'élévation sociale. Né en 1936, Person est un cinéaste qui a souvent été assimilé, à tort, au Cinema Novo. Bien qu'il soit de la même génération que ses collègues cariocas et qu'il manifeste dans ses entrevues et ses films un regard de gauche, Person n'appartient pas au groupe du Cinema Novo. En premier lieu, sa formation et ses références sont distinctes de celles des cinemanovistas. Élève du CEC de Rome où il arrive juste après le départ de Saraceni, Person revendique comme principales références le cinéma politique italien de Francesco Rossi, Elio Petri et Valerio Zurlini. D'un point de vue idéologique, il n'adhère pas aux thèses de l'ISEB sur le rôle des intellectuels et le processus de conscientisation. Enfin, il ne s'entend pas avec les cinéastes cariocas, Rocha en particulier. De fait, bien que ses films, et surtout le premier, manifestent une grande maîtrise des apports formels du cinéma moderne, leur esthétique s'écarte radicalement de celle du Cinema Novo. São Paulo S.A., film pionnier d'une dramaturgie urbaine, présente les mécanismes sociaux d'écrasement de l'individu absolument dénués de dimension épique.

L'histoire du film est la suivante. À la fin des années 50, à São Paulo, le bond spectaculaire connu alors par l'industrie automobile permet à Carlos, ouvrier spécialisé, de devenir l'associé d'une firme de fabrication de pièces automobiles. Cette rapide ascension sociale ne fait pourtant pas son bonheur. Carlos ne supporte pas son quotidien routinier et dénué de sens tout comme le conformisme de ses proches. Déprimé, il décide d'abandonner femme, enfant et emploi pour partir à la recherche d'une nouvelle vie. Lors de la journée qui suit la rupture, il se remémore les différentes étapes de son succès professionnel, les irrégularités grandes et petites qu'il a commises pour assurer son ascension sociale, et parallèlement les aléas de sa vie sentimentale. Incapable de concevoir une issue à son malêtre, il se résout finalement à rentrer. À partir du moment de crise initial, la narration est 
fragmentée mais parfaitement intelligible, les innovations formelles ne servent pas à égarer le spectateur mais à servir au mieux l'histoire et même à traduire une vision de ce que sera la génération de la modernisation conservatrice, c'est à dire cette génération qui va connaître une ascension fulgurante dans le contexte de l'industrialisation rapide du Brésil des années soixante au prix cependant de bien des renoncements et notamment de l'accommodation à des archaïsmes comme la corruption des employés du secteur privé et des agents de l'État et la persistance du travail au noir mis en scène dans des séquences clés du film.

La justesse de la critique sociale, la démystification de valeurs fondatrices de la droite comme la famille et le travail, justifieront d'interdire le film au moins de 18 ans sans toutefois aller plus loin. Le visa d'exploitation de São Paulo S.A. est obtenu dans les délais usuels et le film ne se heurtera pas après sa sortie à des réactions de la société civile ou de la hiérarchie militaire qui aurait pu remettre en cause la décision de la censure. L'histoire se répète avec le second film de Person. Une fois de plus, il s'agit d'une œuvre qui possède une dimension de contestation politique évidente. Sorti sur les écrans en 1967 et co-écrit avec Bernardet, $O$ Caso dos irmãos Naves met en scène une fameuse erreur judiciaire arrivée à l'époque de l'Estado Novo. Le film est la reconstitution scrupuleuse des faits survenus en 1937, dans la petite ville d'Araguari. Cette année-là, un homme disparaît en emportant une grosse somme d'argent. Ses associés, Sebastião et Joaquim Naves, sont accusés de l'avoir tué par l'opinion publique et un lieutenant de police. Le lieutenant se charge de l'enquête et, persuadé de la culpabilité des deux hommes, il tente de les faire avouer par la torture. Un jeune avocat prend alors leur défense et dénonce le traitement qui leur est imposé. Malgré le fait qu'il réussisse à montrer que les preuves sont insuffisantes pour établir leur culpabilité, les deux frères sont condamnés pour un crime dont on découvrira 15 ans plus tard, avec la réapparition subite du disparu, qu'il n'a jamais eu lieu !

Dans le contexte de l'année 1967 et du retour à un régime dictatorial, l'enjeu du film est bien évidemment de dénoncer la torture dont on sait déjà qu'elle sévit de nouveau depuis 1964. Person et Bernardet s'attendent d'ailleurs à ce que les autorités s'opposent à la diffusion du film et les attaquent. C'est pour cette raison qu'ils ont choisi de se baser sur des faits réels et qu'ils ont rassemblé une importante documentation qui serviraient, le cas échéant, à prouver qu'ils n'ont rien inventé. Cette précaution s'avère pourtant inutile. Les rapports des censeurs montrent que ceux-ci n'ont absolument pas saisi en quoi le film constituait une critique contre le régime en place et visait à alerter le public des dérives dont le pays était la victime. Le film est interdit au moins de 14 ans sur la base des scènes de violence qui sont effectivement montrées de façon crue et sans aucune forme d'esthétisme qui pourrait en atténuer l'horreur. Il est libéré dans les délais usuels et remporte un certain succès commercial. Il faudra attendre 
1972 pour qu'un général en voyage à New York, tombe sur l'affiche du film et s'inquiète de son contenu. Il écrit aussitôt au service de censure pour réclamer de leur manque de vigilance. Ce général s'exprime dans ces termes :

«[...]vi no cinema Carnegie Hall, na 7a avenida, esquina com rua 57, em cartaz, o filme THE CASE OF THE NAVES BROTHERS, em que toda a propaganda é ostensivamente contrária ao Governo Brasileiro, que todos nós sabemos vem, de 1964 para cá, sob as garantias dos princípios revolucionários, dirigindo o país com acerto, moral e trabalho, recuperando-o do cáos e da falência moral e financeira, firmando nosso conceito internacional e dando um desenvolvimento impar a todos os setores da economia nacional. Entre os cartazes há um preso aparece puxado pelos lábios a alicato, por policiais e os dizeres são os seguintes : The case of the Naves Brothers is a stunning study of police brutality and injustice under Military Governement. Brazil torture probe urged. Brazil: Government by torture. ${ }^{879}$

Cette prise de conscience tardive n'est pas moins curieuse que la réponse qui lui sera adressée. Le directeur du DPF fait appel à Harry Stone, le président de la puissante Associação Brasileira Cinematográfica, pour éclaircir cette affaire. Alors qu'aucune confusion n'est possible, celui-ci envoie une copie d'une critique américaine du film de Person qui est assez neutre et estime que le film dont le général a vu l'affiche à New York ne doit pas être le film brésilien! L'affaire reste sans suite et $O$ Caso dos irmãos Naves ne provoquera pas d'autres réactions du régime militaire.

\section{Les Années de plomb}

Après 1968, la censure cinématographique se durcit. Plusieurs films seront interdits pendant plusieurs années comme Manhã cinzenta (Olney dos Santos, 1969), O País de São Saruê (Vladimir Carvalho, 1970), Cabezas cortadas (Glauber Rocha, 1970) et Iracema, uma transa amazônica (Jorge Bodansky, Orlando Senna, 1974). Plusieurs remarques doivent cependant être émises. Premièrement, et comme nous allons le développer dans le chapitre suivant, s'il est vrai que le régime se durcit et que la censure se fait aussi plus agressive, les archives montrent que ses pratiques et ses structures n'évoluent pas. Même si certains officiers de la police fédérale ont, à un moment donné, une réflexion dans ce sens, la censure politique n'est jamais officialisée et donc, encore moins dotée d'instruments et de critères qui permettent

879 « [...] j'ai vu le film O CASO DOS IRMÃOS NAVES à l'affiche au cinéma Carnegie Hall, sur la septième avenue au coin de la 57ième rue. Toute la publicité faite autour du film est ostensiblement contraire au gouvernement brésilien qui, comme chacun sait, dirige le pays sous la garantie des principes révolutionnaires avec intelligence, respect de la moralité et sens du travail depuis 1964 jusqu'à aujourd'hui, nous sauvant du chaos et de la faillite morale et financière, renforçant notre prestige international et permettant un développement jusqu'alors inédit dans tous les secteurs de notre économie. Sur une affiche, il y a un prisonnier dont les policiers tirent les lèvres avec une pince et il est écrit ceci : L'Affaire des frères Naves est une étude captivante de la brutalité policière et de l'injustice sous un gouvernement militaire. Une enquête sur la torture au Brésil est urgente. Brésil : le gouvernement par la torture. » Lettre de Evandro Ayres de Moura au général Oscar Jansen Barroso, Fortaleza, 02/10/1972, dossier O Caso dos irmãos Naves, dossier du fonds Divisão de Censura de Diversões Públicas - DCDP. ARQUIVO NACIONAL - COREG DF, Brasília. 
aux censeurs de pratiquer une analyse politique systématique et idéologiquement orientée. Les censeurs savent bien, même confusément, qu'ils doivent barrer la route aux «idéologies subversives » mais leurs comptes rendus, quand la critique politique se fait explicite, ne vont pas au-delà de la citation du concept de «sécurité nationale» qui reste d'ailleurs parcimonieuse et assez vague. Dans le cas de O País de São Saruê, qui constitue une critique très claire au latifundium, le film est interdit sept ans sur la base d'une conclusion très laconique «O filme não atende aos interesses nacionais [...]» (Le film ne satisfait pas les intérêts nationaux $)^{880}$.

Deuxième élément à prendre en compte, la dictature ne sera pas confrontée à une production militante aux messages explicites de gauche ou d'extrême-gauche dans ou hors des structures traditionnelles du cinéma comme le préconise par exemple en Argentine Solanas avec La Hora de los hornos (1968). Comme il n'a pas à faire face à une telle menace, l'État ne développe pas d'outils de censure politique différents de ceux qu'ils possèdent déjà et qui, comme nous le verrons dans le paragraphe suivant, vont s'avérer parfaitement adaptés à la situation. Enfin, les rares films qui souffrent une interdiction unilatérale sont des cas particuliers. Aucun n'appartient à la cinématographie du Cinema Novo.

\subsection{Le Cinema Novo et les services de censure des divertissements publics}

Pour rédiger ce paragraphe, nous avons analysé les archives du SCDP relatives aux films du Cinema Novo. Les archives du SCDP sont conservées à Brasília à l'Arquivo Nacional - COREG et se trouvent dans un remarquable état de conservation et de classement. L'étude de ces documents montre une première chose importante, au moment de leur première sortie commerciale, aucun certificat de censure n'a été refusé de façon définitive, autrement dit, tous les films du Cinema Novo ${ }^{881}$ ont reçu l'autorisation d'être exploité commercialement dans leur pays pendant la dictature militaire. Ceci dit, la censure a bel et bien représenté un obstacle et une source de préoccupations pour les cinéastes. Si les interdictions ont été rares (deux seulement, Terra em transe et Os Herdeiros) et purent être levées, la censure avait également les moyens de jouer sur les coupes, les restrictions par tranche d'âge, les circuits de diffusion et les délais de traitement de dossier. Ainsi, alors que le certificat de censure devait

880Compte rendu de censeur du 27/09/1971, dossier O País de São Saruê, dossier du fonds Divisão de Censura de Diversões Públicas - DCDP. ARQUIVO NACIONAL - COREG DF, Brasília.

$881 \mathrm{Il}$ faudrait préciser, tous les films présentés à la censure. Comme nous l'avons vu dans la deuxième partie, juste après le coup d'État, les cinemanovistas ont renoncé à présenter Maioria absoluta et Integração racial. Le premier n'est soumis à la censure qu'en octobre 1981 par Leon Hirszman lui-même. Il obtient un certificat spécial provisoire d'un an (ce type de certificat était délivré pour une projection en festival). Integração racial est soumis au SCDP en 1970, cinq ans après avoir été conclu. 
en général être émis en l'espace de quelques jours, un délai de plus d'une semaine signifiait d'évidentes restrictions envers un film. À côté de cela, dès 1962, l'exploitation commerciale d'un film pouvait être très bien autorisée en salle de cinéma et interdit à la télévision ${ }^{882}$. Dans certains cas, les films pourront être projetés sans coupe dans les festivals internationaux mais pas pour le public brésilien. La limite d'âge pour voir un film pourra également varier si le certificat ouvre droit à l'exploitation dans le circuit traditionnel ou celui des ciné-clubs. Comme il existait la possibilité de recourir contre les décisions de la censure, c'est à la longueur des négociations et à la gravité des restrictions initialement imposées que se mesurent les difficultés rencontrées par les films du Cinema Novo.

\section{La censure moraliste}

L'une des caractéristiques les plus marquantes de l'action de la censure auprès du Cinema Novo est de donner le sentiment de répondre systématiquement à côté des transgressions effectivement commises par les films et d'être incapable d'en saisir le véritable sens. Pendant le traitement d'un dossier ou après l'émission d'une décision de la censure qui paraissait injuste, le producteur d'un film avait la possibilité d'émettre un recours, soit par voie juridique, soit de façon informelle en allant discuter directement avec les fonctionnaires et chefs de la censure. La plupart des maisons de production avaient d'ailleurs un représentant à Brasília chargé de mener les démarches nécessaires à l'obtention des visas et, dans le cas du Cinema Novo, il n'est pas rare que les producteurs et réalisateurs aient fait le déplacement pour tenter de résoudre les crises les plus aiguës. Les témoignages de Zelito Viana, Luiz Carlos Barreto, Jarbas Barbosa ou Nelson Pereira dos Santos abondent en anecdotes qui ont contribué à donner de la censure l'image d'une institution gérée par des fonctionnaires sans préparation ni culture et déterminant les coupes à effectuer dans des comptes rendus risibles tant l'ignorance témoignée y était grande. Dans une première étude des archives de la censure, Inimá Simões ${ }^{883}$ confirmait cette image en relevant les résumés inexacts et les appréciations lapidaires que contenaient de nombreux documents. Les anecdotes les plus marquantes dans ce domaine renvoient au caractère moraliste de la censure.

Cette dimension moraliste de la censure n'est pas propre à la période dictatoriale. Nous avons déjà commenté, dans la partie que nous avons consacrée à Os Cafajestes, la réception faite au film et le tollé qu'il a déclenché auprès des secteurs les plus conservateurs. Prétextant les scènes de nu et d'usage de stupéfiants, une partie de l'opinion assimile le film à un produit de série $\mathrm{b}$ tentant de capitaliser sur des séquences choquantes et pornographiques et obtient 
son interdiction totale dans les états de Guanabara et de Minas Gerais ainsi que l'élévation de la restriction d'âge à 21 ans dans l'état de São Paulo. Le scandale provoqué par Os Cafajestes en préfigure d'autres arrivés après 1964. Pendant toute cette période, nous allons assister à l'étrange paradoxe suivant : la censure va constituer un obstacle à la libération de films sans toutefois en pratiquer la lecture politique explicite correspondant aux intentions des auteurs.

Les films qui ont eu le plus de difficultés en raison d'une éventuelle atteinte aux bonnes mœurs sont les suivants :

- Menino de engenho - les réclamations portent sur un plan dans lequel il est suggéré que le jeune garçon se masturbe dans un trou pratiqué dans un tronc de bananier ;

- O Padre e a moça - immoralité de la situation de séduction du prêtre par la jeune femme, plan du baiser du prêtre sur le dos nu de la jeune femme ;

Après 1968, la censure moraliste frappera encore deux films du Cinema Novo :

- Macunaíma - un premier rapport suggère une liste de plus de 15 coupes, principalement des plans où apparaissent des fesses ou des seins nus ;

- Como era gostoso o meu francês - problème posé par la nudité des personnages et, en particulier, le fait que soient visibles les organes génitaux du français.

\section{Menino de engenho}

Les secteurs conservateurs se manifestent dans les cas de Menino de engenho et de $O$ Padre e a moça. En temps de dictature militaire, ils sont rapidement entendus et réussissent à obtenir la révision de certificats de censure déjà émis. Dans le cas de Menino de engenho, le SCDP avait émis un premier certificat le 10 décembre 1965 qui indiquait pour toute restriction l'interdiction du film au moins de dix ans ce après quoi l'exploitation du long métrage avait pu commencer avec le succès que l'on sait. Le compte-rendu du censeur de l'époque isolait cependant déjà la séquence du tronc de bananier qui allait effectivement provoquer la colère des conservateurs. Au mois de mars 1966, lors du passage de film à Belo Horizonte, le juge d'enfants de la ville obtient que la restriction d'âge soit élevée à 18 ans pour le Minas Gerais et expulse personnellement des enfants du cinéma Metrópole ${ }^{884}$. La situation se répète au moment du passage du film à Rio de Janeiro mais cette fois-ci avec une remise en cause du certificat de la censure fédérale. Curieusement, c'est le même censeur qui avait opiné pour l'interdiction du film au moins de dix ans qui alerte sa hiérarchie de la nécessité d'élever cette interdiction à dix-huit ans. Après avoir assisté à une projection commerciale du film, il allègue que la réaction du public est «altamente comprometedora para o bom nome da 
censura federal $»^{885}$. En moins de trois jours, le même censeur participe à la réévaluation du long métrage et rédige un compte rendu commun avec deux autres censeurs chargés de ce travail ${ }^{886}$. La restriction d'âge est augmentée à 18 ans le 22 août 1966 soit plus de neuf mois après l'émission du premier certificat et après que Menino de engenho ait été exploité sur plus de la moitié du territoire national.

Zelito Viana, en tant que représentant de MAPA Filmes, réagit dans un courrier du 19 septembre 1966. Il met l'emphase sur la contradiction juridique que constitue cette révision et insiste sur le fait que le certificat de la censure constitue à la fois une garantie et une orientation pour le producteur quant au mode d'exploitation qu'il peut envisager pour son film. Une modification imprévisible et intempestive du cadre légal de commercialisation d'un long métrage équivaut à des préjudices financiers pour l'entreprise et met en cause la crédibilité du SCDP. Il défend aussi le sérieux de l'œuvre et à l'inadéquation du jugement qui en a été fait par les techniciens de la censure. L'argument «culturel» est un argument que nous retrouverons dans les contentieux portant sur Como era gostoso o meu francês et São

\section{Bernardo :}

« $\underline{\mathrm{O} q u e}$ é certo, porém, é que se trata de uma obra de cinema sério, sem quaisquer concessões ao gosto vulgar e sem apelos, tão em voga, à baixa sensualidade e à violência. $O$ filme é baseado no livro de JOSÉ LINS DO REGO, o qual têm servido, nas nossas escolas, como protótipo de boa literatura, e a obra cinematográfica dele decorrente, segundo depoimentos de críticos e educadores publicados em toda a imprensa do país RETRATOU dentro de um espírito puramente artístico, a obra literária. ${ }^{887}$

Viana conclut que si la censure donne le droit à certains groupes d'obtenir la révision de l'un de ses jugements, les producteurs d'un film doivent aussi avoir ce droit. Sa lettre sera entendue. Une nouvelle commission de censeurs émet un jugement plus nuancé qui diverge absolument de celui du mois d'août. La restriction d'âge est abaissé à 14 ans mais l'interdiction dans l'état de Guanabara est maintenue en raison d'un jugement qui aurait été prononcé par le tribunal des enfants. La confusion est donc totale à plusieurs niveaux. L'un des fonctionnaires du SCDP ne manque d'ailleurs pas de le faire remarquer à ses supérieurs en notant au dos de

885 « hautement compromettante pour le renom de la censure fédérale » Lettre du 19/08/1966 au chef de la censure, dossier Menino de engenho, Arquivo Nacional - COREG, fonds Divisão de Censura de Diversões Públicas - DCDP, Brasília.

886Il ne s'agit pas d'une pratique usuelle. Généralement, chaque censeur devait rédiger un compte rendu individuel. Tout indique que ce réexamen répond à une action concertée dans laquelle entre également en cause une part de manipulation puisque les deux appréciations rédigées à neuf mois d'écart par le même censeur sont absolument distinctes, sinon divergentes.

887 « Ce qui est sûr, c'est qu'il s'agit d'une œuvre sérieuse, sans vulgarité ni recours à la basse sensualité et à la violence qui sont tellement à la mode. Le film est basé sur un livre de JOSÉ LINS DO REGO, lequel est présenté dans nos écoles comme un modèle de bonne littérature et l'adaptation cinématographique qui en a été faite, selon l'avis de critiques et d'éducateurs publiés dans la presse, est resté fidèle, dans un esprit purement artistique, à l'œuvre littéraire. » Lettre du 08/11/1966 de Zelito Viana au chef de la censure, dossier Menino de engenho, dossier Menino de engenho, op. cit. 
son compte-rendu lors du deuxième examen du film :

«É inadmissível que um representante da Censura Federal, faça uma ressalva em termos desprimorosos à central da censura, endossando totalmente a portaria [?] Do juizado de menores da Guanabara. - Mais ainda, após tal informação ainda é incluido no grupo de censores revisores para o referido filme[...]. ${ }^{888}$

La désorganisation de la censure, l'incohérence de ses revirements intempestifs, le caractère absurde de restrictions susceptibles d'inégalité géographique, sont ici patents. Réciproquement, il est aussi surprenant que ce soit un film comme Menino de engenho qui pose problème alors qu'à l'époque déjà, il est reconnu comme un des films de moindre impact politique du Cinema $\mathrm{Novo}^{889}$. Une fois de plus, la réaction de la censure semble inadéquate et sans relation avec la proposition de conscientisation du Cinema Novo.

\section{O Padre e a moça}

La situation apparaît plus ambiguë avec $O$ Padre e a moça dont la trajectoire est comparable. Le long métrage est soumis SCDP le 31 janvier 1966 et reçoit son certificat le 2 février. Le film est interdit au moins de 18 ans en raison du son thème et, selon les censeurs, de sa médiocre qualité artistique et technique. La restriction d'âge n'est pas pour autant préoccupante dans la mesure où le film ne s'adresse pas à un public jeune.

Quatre mois plus tard, le thème du film initialement toléré, devient insupportable sous la pression des secteurs catholiques qui voient dans l'histoire de ce prêtre soumis au doute et à la tentation une offense envers l'Église. Le 6 juin 1966, le chef du SCDP résout de procéder à un nouvel examen du long métrage car il considère qu'il revient à son service de : « [...] selar pela preservação da moral, cultura e tradições religiosas do povo brasileiro, - muitas veses ameaçadas por críticas irrevercutes [sic] de que são veículos espetáculos de diversões públicas $\gg{ }^{890}$

Une nouvelle commission de quatre censeurs est réunie (le nombre usuel est trois). Comme cela était déjà le cas pour Menino de engenho, les nouveaux comptes-rendus s'accordent au diapason des plaintes qui ont motivé le nouvel examen. Le Père Lúcio Remuzat

888 « Il est inadmissible qu'un représentant de la Censure Fédérale émettent des restrictions dans des termes diffamants à la centrale de la censure et endosse totalement le décret [?] du juge des mineurs de la Guanabara. Pire encore, après un tel précédent, il est inclus au groupe de censeurs qui doit réexaminer le film en question [...] » Compte-rendu de censeur daté du 22/11/1966, dossier Menino de engenho, op. cit.

889Cf. BERNARDET, Jean-Claude. « Menino de engenho » et DAHL, Gustavo. « Cinema Nôvo e seu público », op. cit.

890 « [...] veiller à la préservation de la morale, de la culture et de traditions religieuses du peuple brésilien souvent menacées par les critiques [mot inexistant, sans doute irrévérencieuses] dont les spectacles de diversion publique sont les véhicules. » Portaria n ${ }^{\circ}$ 54/66-SCDP, dossier O Padre e a moça, Arquivo Nacional - COREG, fonds Divisão de Censura de Diversões Públicas - DCDP, Brasília. 
Rennó, appelé comme consultant sur ce cas difficile, consigne les remarques suivantes :

« Reputo um filme altamente ofensivo à moral, não só pelo áspeto religioso como no moral propriamente dito. A desenvoltura e liberdade das cenas eróticas constituem, sobretudo para a juventude, um roteiro de licensiosidade. A tese defendida, em que pese a relutância do jovem padre, é sem dúvida uma exaltação ao amor livre, sem pêias, livre dos dogmas e convenções, com gravíssima influência na mentalidade juvenil. ${ }^{891}$

Un autre censeur estime que le producteur n'a pas su adapter avec décence le poème de Drummond « saindo para cenas de sexo » (dérapant vers des scènes de sexe).

Malgré le fait que le premier censeur réagisse sur la ligne du thème de la liberté sexuelle qui est effectivement sous-jacent à la remise en cause globale des normes sociales que le film met en jeu, il est assez frappant de constater à quel point l'œuvre n'est pas comprise et combien les censeurs parviennent à y voir des choses qui n'existent pas. Ainsi, la première préoccupation du prêtre, en conformité avec sa mission de pasteur, est bien de protéger la jeune femme, l'attraction physique et amoureuse vient après. Enfin, la qualification de « scènes de sexe » est absolument inadéquate à ce qui est effectivement visible dans le film et à la tension dramatique qui accompagne les plans où la jeune femme apparaît (très pudiquement) dénudée. Ce sont cependant précisément ces séquences que les censeurs demandent de couper : celle où le prêtre embrasse le dos de la jeune femme et la séquence finale de la grotte.

Andrade réagit dans une lettre au chef du 21 juin et proteste contre les coupes qui élimineraient des parties indispensables à la compréhension du film. Il prend lui-même l'initiative du compromis qui va régler le problème : augmenter la restriction d'âge à 21 ans. Sa proposition est acceptée par le chef du SCDP dans une note du 10 août 1966. Un nouveau certificat est émis le jour même.

\section{La censure moraliste après 1968, Macunaíma}

Après 1968, la censure de type moraliste se concentrant sur la suppression des plans de nudité et les gros mots va atteindre des sommets avec l'examen des dossiers de Macunaíma et Como era gostoso o meu francês, cette fois-ci sans nul besoin de l'intervention de la société civile, le SCDP anticipant les réactions des secteurs les plus réactionnaires.

Le parcours de Macunaíma dans les services de censure sera long, environ trois mois,

891 « J'estime qu'il s'agit d'un film offensant gravement la morale, pas seulement sur le thème religieux mais sur le thème moral en général. La désinvolture et la liberté des scènes érotiques constituent, avant tout pour la jeunesse, un traité de luxure. La thèse défendue, sur laquelle pèsent les réticences du prêtre, est sans aucun doute une apologie de l'amour libre, sans contrainte, libre des dogmes et des conventions, d'une très grave influence sur la mentalité juvénile. » Compte rendu de censeur du 14/06/1966, dossier O Padre e a moça, op. cit. 
et tourmenté. Le 30 juillet 1969, un premier rapport suggère une liste de plus de 15 coupes et nous offre un résumé lapidaire du film : «Macunaíma, um preto que vira branco e vai para a cidade dar vazão aos seus instintos sexuais, voltando depois para a selva, de onde viera. $\gg{ }^{892}$ Comme dans le cas des films précédents, Macunaíma reçoit une évaluation absolument inadéquate à ce qu'il est vraiment. Toutes les dimensions de critique sociale du film et de réflexion sur l'histoire et l'identité nationale sont évacuées au profit de l'assimilation de l'œuvre à une série b de caractère pornographique.

Les demandes de coupes se concentrent sur les plans où apparaissent des fesses et des seins nus, une seule possède un caractère politique, celle qui consiste à retirer les plans où apparaissent l'insigne de l'Aliança pelo progresso sur la veste de l'un des personnages féminins du début du film. Selon Andrade, l'ensemble des coupes qui lui étaient demandées équivalaient à 20 minutes de film. Ces suppressions, au-delà de mutiler l'œuvre de façon définitive, allait également la rendre parfaitement inintelligible. Sa stratégie consiste alors à rentrer en contact avec le chef de la police fédérale, supérieur au chef de la censure, afin de tenter de diminuer le nombre de coupes. Une session est organisée à la salle de la projection du SCDP pour laquelle l'officier se fait accompagner de sa femme et de plusieurs de ses amies appelées comme « consultants ». Une fois de plus, l'absence de critère et le caractère arbitraire de la censure sont la règle. De la même façon que le chef du SCDP peut aller à l'encontre de l'avis des censeurs, le chef de la police fédérale peut annuler les décisions prises par ses subordonnés selon un dispositif aussi informel. Plus loin, nous verrons aussi que le ministre, à son tour, peut régler un contentieux en quelques lignes et ridiculiser d'un trait les dispositions prises avant lui par les services compétents. Selon le cinéaste monté tout exprès à Brasília, cette session s'est révélée désastreuse :

«O filme foi para Brasília, mas não me deixaram assistir à sessão. Então eu olhava por um buraquinho da cabina de projeção. E assisti a uma das senhoras tampando o olho de uma das moças que estava ao lado dela numa das cenas do filme, para ela não ver. Quando eles saíram da projeção, eu me aproximei do Chefe de Polícia que estava com uma cara carrancuda. Ele disse que o filme tinha ido muito mal; pessoalmente achava o filme uma droga; além disso as opiniões tinham sido péssimas ; as notas que o filme tinha recebido eram baixíssimas. [...] Havia uma sobrinha dele, de 17-18 anos, que naquele momento ele abraçava. E então me disse : - A minha sobrinha aqui, por exemplo, que eu acho uma pessoa muito inteligente, de muito bom senso, deu zero para o seu filme. ${ }^{893}$

892 « Macunaíma, un noir qui devient blanc et part pour la ville pour laisser libre cours à ses instincts sexuels et revenir ensuite dans la jungle d'où il est venu. » Compte rendu de censeur du 30/07/1969, dossier Macunaíma, Arquivo Nacional - COREG, fonds Divisão de Censura de Diversões Públicas - DCDP, Brasília.

$893 \ll$ Le film est parti pour Brasília mais ils ne m'ont pas laissé assister à la séance. Alors je regardais par un trou de la cabine de projection. J'ai vu une des dames mettre la main devant les yeux d'une jeune fille qui était présente. Quand ils sont sortis, je me suis approché du chef de la police qui avait l'air renfrogné. Il me dit que le film avait beaucoup déplu, qu'il trouvait personnellement qu'il était nul ; en plus de ça les autres opinions avaient été très mauvaises, le film avait reçu des notes très basses. [...]. Il y avait une de ses nièces, de 17-18 ans, qu'il tenait dans ses bras. Il m'a dit alors : -Ma nièce par exemple qui est ici et que je juge être une 
L'ultime recours d'Andrade a reposé sur le succès du film auprès de la critique internationale au Festival de Venise de la même année. Nouvelle contradiction de l'époque, alors que la censure se refusait à libérer Macunaíma pour son exploitation commerciale sur le territoire national, le film avait reçu son certificat de libre exportation bien plus tôt en conséquence de quoi il avait été projeté à Venise en version intégrale. Toujours selon son témoignage, le cinéaste a laissé un dossier de presse au chef de la police fédérale. Deux articles, l'un du journal Herald Tribune, l'autre de $O$ Globo, tous les deux datés du trois septembre 1969 sont effectivement présents dans le dossier de Macunaíma. Selon le témoignage d'Andrade, le chef de la police fédérale s'est révélé sensible à ce dernier argument. Après avoir fait lire les critiques à sa femme, il change d'opinion, accepte de baisser le nombre de coupes à trois et demande au réalisateur de les choisir lui-même dans la liste initiale des coupes exigées par le SCDP. Les télégrammes présents dans le dossier du film montrent que quatre coupes ont été retenues, trois de nus et une de plus concernant l'insigne de l'Alliance pour le progrès. La réception du film par la censure, en focalisant des aspects superficiels de son esthétique et en en pratiquant une interprétation totalement erronée, fait une fois de plus l'économie de la discussion politique que le film pouvait initier, notamment sur la base d'une critique à la modernisation conservatrice alors en route.

\section{Como era gostoso o meu francês}

L'histoire de Macunaíma présente bien des points communs avec celle de Como era gostoso o meu francês. Également retenu en raison d'images de nus, le film de Santos ne recevra son certificat de censure qu'après de longues négociations et la médiation du chef de la police fédérale ainsi que l'imposition de nombreuses coupes. Son examen sera cependant encore plus long (sept mois), fastidieux et contradictoire que le précédent. La première demande de libération du film date du 6 mai 1971. Alors que la demande concernait les trois aspects généralement requis pour une exploitation complète du film (autorisation d'exploitation sur le territoire national, mention de bonne qualité et de libre exportation), seule une autorisation spéciale est accordée pour le Festival de Cannes. Deux comptes rendus sont rédigés, l'un est très favorable malgré une interdiction au moins de 18 ans et l'autre, qui emporte la décision, plaide en faveur de la prudence et d'examens supplémentaires plus détaillés avant la libération pour le territoire national. Fait peu commun, une nouvelle

personne très intelligente, de bon sens, a donné zéro à votre film. » in Um Depoimento especial de Joaquim Pedro de Andrade. Folheto organizado pelo Cineclube Macunaíma na ocasião da Retrospectiva Joaquim Pedro de Andrade em 1976, no Rio de Janeiro. 
demande de censure est déposée à la fin du mois de mai. Elle provoque un nouvel examen du film par une commission de cinq censeurs. Leurs avis sont divisés mais majoritairement négatifs, ils oscillent entre l'interdiction au moins de dix-huit ans et l'interdiction totale. La divergence d'appréciations quant au caractère de la nudité des personnages constitue le seul véritable obstacle à la libération du film.

Au mois de juillet, alors qu'aucune interdiction formelle n'a été promulguée, Como era gostoso o meu francês est examiné une troisième fois, apparemment après qu'une nouvelle version ait été présentée au $\mathrm{SCDP}^{894}$. Les trois censeurs convoqués reconnaissent la qualité de la reconstitution historique et l'absence de caractère érotique à la nudité des personnages. Ils s'accordent donc pour une libération pour les plus de 18 ans. Malgré le consensus présenté par ces nouveaux avis, au mois d'août, la portaria ${ }^{\circ}$ 039/71 du SCDP interdit le film sur tout le territoire national. À la fin du mois d'août, Barreto présente un recours officiel devant le chef de la police fédérale ${ }^{895}$. Ses arguments en faveur de la libération du film sont d'ordres juridiques et culturels. La bonne réception faite au film aux festivals de Cannes et de Berlin est également avancée. Parallèlement au dépôt de ce recours, Santos se rend à Brasília afin de négocier directement avec les autorités. Il témoignera par la suite à plusieurs reprises du caractère surréaliste des échanges qu'il a eu avec les officiers de la police fédérale. Le nu masculin est, en dernière instance, l'élément qui a le plus choqué la hiérarchie de la police, certains, en plus de la simple vision du sexe masculin, allant jusqu'à s'offusquer de la différence de taille entre le pénis du français et ceux des indiens.

Les résistances de la censure sont finalement vaincues au prix de quatre coupes, l'une d'elle mutilant une scène clé du film, le dernier tête-à-tête intime entre les deux personnages principaux. Ces coupes réalisées, une première libération est consentie par le chef de la police fédérale pour les plus de 14 ans le 5 novembre puis par le chef du SCDP, sans restriction d'âge, le 8 novembre. Le retournement de situation est complet et deux documents postérieurs à la libération du film montrent que certains délégués régionaux du SCDP se sont cru obligés d'aviser leurs supérieurs de l'éventuelle incohérence d'une libération sans restriction d'âge. Une fois de plus, il est bien évident que la censure n'a pas pris en compte la dimension philosophique et politique du film. L'imprévisibilité de ses décisions contrarient cependant beaucoup producteurs et réalisateurs qui investissent dans les films et savent que chaque jour de retard correspond à une augmentation des intérêts à payer sur les sommes empruntées.

894Aucun document écrit n'a été conservé concernant un nouveau montage du film qui serait intervenu entre mai et juillet. Certaines notes contenues dans les compte-rendu du 20 juillet mentionnent cependant que le film a été remonté depuis ces présentations initiales. Dossier Como era gostoso o meu francês, Arquivo Nacional COREG, fonds Divisão de Censura de Diversões Públicas - DCDP, Brasília.

895Lettre de Luiz Carlos Barreto au Diretor Geral do Departamento de Polícia Federal, Rio de Janeiro, le 31/08/1971, dossier Como era gostoso o meu francês, op. cit. 


\section{La censure politique}

Aussi surprenant que cela puisse paraître, en matière de cinéma, tout au long de la période dictatoriale, la censure de caractère politique ne s'est pas exprimée de manière moins superficielle et erratique que la censure de caractère moraliste. Certains documents révélés par la revue Parte $^{896}$ montrent que dès 1965, il a existé au sein des services de censure la tentation de mettre en place une censure politique formelle, systématique, fondée sur des critères précis et prévoyant des cours d'instruction des censeurs. Certains documents datant du début des années 70 et les cas d'interdiction de films sur une longue durée déjà cités témoignent de la persistance de la tentation d'un tel type de censure ${ }^{897}$. En pratique cependant, tout indique que cette tendance pour l'adoption d'une « ligne dure » consistant à ne rien laisser passer, n'a pas réussi à s'implanter. La ligne politique de la censure est demeurée parfaitement erratique et imprévisible. Cela est particulièrement visible avec les exemples de films qui ont connu des sanctions absolument disproportionnées par rapport à d'autres qui sont passés immunes et ont connu une carrière commerciale satisfaisante. Pour autant, il ne faudrait pas déduire de cette absence apparente de cohérence un manque de réflexion claire du pouvoir militaire quant à la censure cinématographique. Le maintien d'une censure, sans véritables critères ni pouvoir, démontre le triomphe d'une tendance libérale qui, en évitant de valoriser de façon excessive l'impact politique éventuel des films, s'attache à éviter les scandales et les affrontements directs. La censure libère les films du Cinema Novo mais la menace qu'elle représente constamment conditionne sa relation au marché et délimite de façon assez efficace le champ d'une critique consentie.

Les films qui ont eu le plus de difficultés pour des raisons politiques sont les suivants :

- O Desafio est retenu 6 mois par les services de censure sans motif officiel, le film n'est pas interdit mais il n'est pas libéré non plus ;

- Terra em transe est interdit pour contenir « uma mensagem de cunho esquerdista, contrária aos interesses nacionais $»^{898}$ (un message gauchiste contraire aux intérêts nationaux). Il est libéré une semaine plus tard par le ministre de la justice.

Après 1968, des arguments politiques seront de nouveau avancés et perturberont l'obtention de leur visa de trois films :

- Os Herdeiros est accusé d'aller à l'encontre de la loi de sécurité nationale pour évoquer des

896« Dossiê censura » in aParte, publicação do Teatro dos Universitários de São Paulo, São Paulo, n², maijuin 1968.

897Cf. dossiers Ofícios de solicitação et Cursos, Arquivo Nacional - COREG, fonds Divisão de Censura de Diversões Públicas - DCDP, Brasília.

898Lettre du chef du SCDP au chef de la Seção de Censura du 19/04/1967, dossier Terra em transe, Arquivo Nacional - COREG, fonds Divisão de Censura de Diversões Públicas - DCDP, Brasília. 
événements historiques récents dans un moment politique qui ne s'y prête pas, le film est interdit par le SCDP puis libéré par le ministre ;

- Integração racial attendra sept mois un visa d'exploitation qui lui ferme de fait les portes du circuit commercial pour avoir suggéré l'existence de ségrégation raciale et de racisme au Brésil ;

- São Bernardo : plus de six mois seront nécessaires à la libération sans coupe de cette nouvelle adaptation de Graciliano Ramos qui critique le latifundium.

Dans l'intervalle, certains films rencontreront des difficultés mineures ou tardives qui révèlent les incohérences de la censure brésilienne. L'exploitation de Vidas secas, qui avait reçu son certificat de censure avant le coup d'État, n'est pas perturbée. Deus e o diabo na terra do sol est l'objet d'une attention particulière. Nous avons déjà raconté comment, au lendemain du coup d'État, le film était passé par un examen informel de la hiérarchie militaire afin de vérifier s'il devait ou non être envoyé à Cannes. Par la suite, le SCDP ne mobilisera pas moins de sept censeurs pour procéder à un nouvel examen du film. Aucun élément présent dans le dossier n'apporte de justificatif quant à cette mobilisation exceptionnelle. Aucun censeur ne se hasarde à une interprétation politique et, malgré ses scènes de violence, le film est libéré sans coupe pour les plus de 18 ans. Sa tournée brésilienne sera émaillée de trois incidents sans véritables conséquences. Le 25 juillet 1964, la saisie de toutes les copies est annoncée dans la presse, l'annonce reste sans suite. Le 25 juillet 1967, le Département Fédéral de la Sécurité Publique saisit une copie à Goiânia. Parallèlement, le film est interdit au Maranhão sans que le motif de cette interdiction soit clairement défini. Enfin, Os Fuzis reçoit son visa d'exploitation le jour même du dépôt de la demande de censure, le 6 janvier 1965. Douze ans plus tard, une copie de la version allemande est saisie à la douane. Il s'ensuit un imbroglio de plusieurs mois au cours duquel le film est examiné par un censeur du SCDP qui écrit :

«Um filme típicamente subversivo, em que somente cenas deprimentes do nosso país são apresentadas, não imaginando o Censor que o examinou como pôde esta película ter sua exportação autorizada $[\ldots] »^{899}$

Au moment même de cet incident, le film bénéficiait d'un visa d'exploitation en cours de validité. Il était aussi l'un des films du Cinema Novo les plus vendus à l'étranger.

899 «Un film typiquement subversif, dans lequel ne sont présentées que des scènes déprimantes de notre pays, le censeur qui a examiné ce film n'imagine pas comment son exportation a pu être autorisé [...] » Compte rendu de censeur du 24/06/1977, dossier Os Fuzis, Arquivo Nacional - COREG, fonds Divisão de Censura de Diversões Públicas - DCDP, Brasília. 


\section{O Desafio}

O Desafio est le premier film du Cinema Novo à connaître des ennuis sérieux avec le SCDP. Conclu dans l'urgence en août 1965 afin de pouvoir être présenté au FIF qui devait se dérouler à Rio de Janeiro le mois suivant, le long métrage est envoyé à la censure au début du mois de septembre. Ce premier examen ne présente pas de problèmes majeurs dans la mesure où le censeur opine pour la libération du film dans le cadre du festival et émet le jugement suivant, caractéristique de la ligne libérale de la censure. Selon lui, en effet, le film présente : «[...] idéias repetidas de jornais e autores que se dizem de esquerda mas que não comprometem a ordem estabelecida do país. [...] Salvo superior deliberação, julgo o filme inofensivo, sob o ponto de vista da crítica ao regime vigente, desde que, obviamente, seja proibido aos menores até 18 anos. $\gg{ }^{900}$

$O$ Desafio est effectivement projeté dans une programme parallèle à la compétition officielle du festival mais le certificat définitif du film tarde à venir. Le 15 octobre, une nouvelle demande de certificat de censure est déposée par la société de production Imago et entraîne un deuxième examen par trois censeurs. Deux autres commissions seront encore réunies avant la libération du film au mois de février 1966. Loin de partager l'avis catégorique du censeur du mois de septembre, les techniciens de la censure s'en remettent à l'avis de leur chef au sujet d'un film dont ils louent les qualités techniques et reconnaissent la franche opposition au régime dictatorial :

«História de amor mesclada com assuntos políticos da atualidade brasileira. Identificam a situação insegura e angustiante de amantes adúlteros com a conjuntura socio-econômica pósrevolucionária. É uma mensagem de revolta, radicalista e desagregadora. Desempenho e direção dignos de louvor. Do ponto de vista puramente artístico, a obra nada deixa a desejar, equipando-se ao melhor padrão internacional. $»^{901}$

Le même censeur qui reconnaît la qualité artistique du film opine cependant pour son interdiction. Les avis contradictoires conduisent à reporter encore la décision finale. Au début du mois de novembre, le SNIC (syndicat de défense des producteurs) envoie une lettre de réclamation au chef du SCDP afin de réclamer que le service de censure se prononce enfin.

$900 \ll[\ldots]$ des idées répétées par les auteurs et les journaux qui se disent de gauche mais ne remettent pas en cause l'ordre établi. Sauf jugement supérieur contraire, je juge le film inoffensif du point de vue de la critique au régime en vigueur, à partir du moment où il sera interdit, évidemment, au moins de 18 ans. » Compte rendu de censeur du 13/09/1965, dossier O Desafio, Arquivo Nacional - COREG, fonds Divisão de Censura de Diversões Públicas - DCDP, Brasília.

901 « Histoire d'amour mélangée avec des sujets politiques de l'actualité brésilienne. La situation instable et angoissante d'amants adultères est identifiée avec la conjoncture socio-économique post-révolutionnaire. C'est un message de révolte, radical et désagrégateur. Réalisation technique et direction dignes d'applaudissement. D'un point de vue strictement artistique, le film ne laisse pas à désirer, il égale la concurrence internationale. » Compte rendu de censeur du 15/10/1965, dossier O Desafio, op. cit. 
Parallèlement, Sales Gomes obtient que le film soit projeté lors de la première semaine du cinéma brésilien qu'il organise à Brasília. Le secrétariat de l'éducation et de la culture du district fédéral envoie une demande d'autorisation spéciale au général Kruel, directeur général du Departamento Federal de Segurança Pública le 10 novembre. O Desafio est effectivement projeté lors de ce festival mais les pourparlers avec le général pour l'obtention de la libération définitive du film restent sans succès. Saraceni, qui fait le déplacement tout exprès à Brasília, se voit opposer une fin de non recevoir sous prétexte que le film contient des dialogues trop subversifs. Malgré tout, le long métrage est réexaminé le 17/12/1965 et le 01/02/1966. Certains comptes rendus sont assez significatifs et rejoignent l'idée du tout premier censeur quant au caractère inoffensif du film. Ainsi, Guilherme de Sena Varjão développe l'avis suivant :

« [...] o que o nosso herói verifica - e o espectador também - é que a história e o autor mostram o vasio do esquema social e político da esquerda brasileira, que nada palpável possuia para oferecer aos seus adeptos. - Daí considerarmos a película, antes de mais nada, um libelo contra a própria esquerda. $)^{902}$

Un deuxième censeur qui étudie bien la possible relation « filme-revolução » rejoint cet avis en estimant que le film démontre que la gauche n'a rien à offrir et que la Révolution est venue pour combler son absence de propositions politiques et le vide existentiel auquel elle conduirait ses partisans. Il faut croire que les chefs de la censure n'ont pas été convaincus par l'argumentation de ces deux censeurs qui indiquèrent également une première série de coupes. Un courrier de la DIFILM daté de fin janvier sollicitant de nouveau la conclusion des examens de la censure motive un quatrième et dernier examen. Au contraire des précédents censeurs, les nouveaux estiment que $O$ Desafio est extrêmement médiocre et, pour cette raison même, qu'il ne pourra jamais influencer le grand public. Les censeurs précisent les coupes à effectuer et le certificat de censure est émis le 02 février 1966 après cinq mois d'une interdiction officieuse. Le certificat mentionne une interdiction au moins de 18 ans et énumère 5 coupes portant sur les dialogues, plusieurs d'entre elles comportant le mot «merda $»^{903}$. L'absence de la mention de libre exportation contraindra plus tard Saraceni à établir une demande spécifique dans ce sens à laquelle sera vraisemblablement apportée une réponse positive puisque le film sera exploité en France.

La trajectoire de $O$ Desafio est assez exemplaire de la façon dont Cinema Novo et

$902 «[\ldots]$ ce que notre héros vérifie, et avec lui le spectateur, c'est que l'histoire et l'auteur démontrent la vacuité du programme social et politique de la gauche brésilienne qui n'avait rien à proposer de palpable à ses adeptes. Pour cela nous considérons que ce film est avant tout un libellé contre la gauche. » Compte rendu de censeur du 17/12/1965, dossier O Desafio, op. cit.

903La seule phrase vraiment significative qui est coupée est : « Agora mais do que nunca não podermos ser livre» (Maintenant moins que jamais nous ne pouvons être libre.) 
censure vont se conditionner réciproquement. Le traitement du dossier du film représente aussi certainement un point de bascule entre les deux orientations principales entre lesquelles la censure hésite alors. Tout vient du fait qu'il s'agisse d'un film de structure ouverte. De façon évidente, cette structure, qui laisse la marge à des interprétations opposées, déstabilise les militaires qui restent longtemps indécis. Si l'option adoptée par le Cinema Novo avait été un cinéma militant mettant directement en scène les conflits sociaux et politiques des années 60 , ces derniers n'auraient pas eu d'autre choix que d'adopter la tendance "ligne dure », d'interdire les films et de poursuivre les cinéastes. Dans le cas de $O$ Desafio, la structure ouverte a suscité l'émission d'avis absolument contradictoires par les censeurs. Nous pouvons trouver leurs appréciations assez sommaires et catégoriques mais, en donnant à voir avec sincérité les doutes d'une certaine gauche, le film n'en offre certainement pas un portrait complaisant. De là à constituer un « libellé contre la gauche », il n'y a qu'un pas à franchir. Nombre de spectateurs insensibles aux inégalités sociales pourront en effet se conforter dans leurs positions et voir dans la crise de Marcelo, la preuve de l'invalidité de ses opinions politiques. Cas rare dans l'histoire de la censure, l'avis des techniciens du SCDP l'a emporté sur les appréhensions de leur hiérarchie. Alors que le chef du SCDP et le général Kruel n'ont pas eu le courage d'assumer une décision définitive, les censeurs successifs, bien que développant des analyses divergentes, ont insisté sur l'idée que le film n'aurait aucun impact dans l'opinion. Le principe s'est donc imposé selon lequel un film contraire au régime militaire pouvait être libéré dans la mesure où, d'un point de vue pragmatique, il était jugé incapable de toucher le grand public.

L'espace de liberté concédée par la censure est ainsi conditionné par la représentation que la censure se fait de l'impact que peut avoir le type de cinéma proposé par le Cinema Novo et, réciproquement, ce dernier va chercher à occuper ce terrain à la délimitation imprécise. De nombreux éléments vont confirmer ce phénomène d'accommodation tacite et réciproque. Avant d'en étudier plus avant les contradictions, il convient de mentionner que cet espace de liberté n'est pas resté statique. L'histoire de Terra em transe montre une fois de plus la confrontation entre la ligne dure et la ligne libérale de la censure.

\section{Terra em transe}

Comme nous le verrons dans le chapitre suivant, Terra em transe est le seul film de l'époque à avoir connu une censure préliminaire au tournage. Des agents du DOPS se sont en effet rendus au bureau de MAPA Filmes demander le synopsis du film, demande à laquelle Rocha a répondu en rédigeant un véritable pastiche de ce qu'il détestait le plus au cinéma 
lequel, sans pour autant mentir sur l'intrigue et la thématique du film, en détournait le sens ${ }^{904}$. Bien qu'ayant donné leur feu vert à la réalisation de Terra em transe, les autorités se tenaient sur le qui-vive. Présenté au SCDP le 10 avril 1967, le long métrage est interdit le 19 après avoir été visionné par une commission de six censeurs. Parmi eux, trois opinent pour l'interdiction, deux ne rendent pas d'avis définitif et le dernier concède la libération pour les plus de 18 ans. Aucun censeur ne s'est laissé duper par le choix d'un pays imaginaire pour situer l'action et reconnaît que la critique exprimée par le film concerne bien le Brésil contemporain. Le seul censeur en faveur de la libération insiste sur le fait qu'il s'agit d'une fiction et qu'un film d'une telle nouveauté formelle sera difficile à assimiler par les masses.

MAPA Filmes réagit à l'interdiction par l'intermédiaire de son avocat dans un long courrier de cinq pages daté du 24 avril. Reprenant les arguments usuels de caractère économique (le développement du cinéma national et l'importance des sommes investies) et culturel (abandon de la chanchada, développement du cinéma sérieux et reconnaissance internationale), la lettre atteint son objectif. Le film est visionné par le chef du DPF et le ministre de la justice Luiz Antônio Gama e Silva qui décident sa libération parce qu'ils considèrent, entre autres, «[...] ser sútil a mensagem ideológica contida na película examinada, somente percebida por um público esclarecido e que por isso não se deixará impressionar por ela $»^{905}$. Le certificat de censure est émis le 03 mai 1967. Terra em transe est interdit au moins de 18 ans mais bénéficie des mentions «bonne qualité » et «libre pour exportation ». Le film suivant de Rocha, O Dragão da maldade contra o santo guerreiro, sera libéré dans les délais usuels avec quelques coupes sans importance et une interdiction au moins de 18 ans. Nous verrons cependant qu'il s'agit d'un des films qui correspond le mieux aux intentions politiques révolutionnaires du Cinema Novo.

\section{La censure politique à partir de 1968, Os Herdeiros}

Les années de plomb (1969-1974) correspondent à un moment de durcissement de la censure vis à vis du Cinema Novo. Os Herdeiros est le premier film à en faire les frais. Le film est interdit le jour suivant le dépôt de la demande de censure, le 30 août. En accord avec l'avis d'un censeur, le chef du SCDP se range à cet avis dans une note du 31 et justifie l'interdiction dans ces termes : «o filme [...] atenta contra a segurança nacional, pois trará ao público problemas políticos por demais recentes, cujas interpretações são passíveis de

904Cf. 9.3 .

905 « [...] que le message idéologique contenu par le film est subtil et ne pourra être compris que par un public éclairé qui, justement pour cette raison, ne se laissera pas impressionner. » Résolution du chef du DPF datée du 01/05/1967, dossier Terra em transe, op. cit. 
distorções $»^{906}$. De façon tout à fait paradoxale, alors même que le SCDP se prononce pour l'interdiction, le cabinet du chef du DPF sollicite un examen supplémentaire du film par des diplomates du ministère des affaires étrangères. La contradiction principale réside dans le fait suivant. Os Herdeiros est un film financé par l'INC et la CAIC et vient d'être désigné par la première institution comme étant le film le plus à même de défendre les couleurs du Brésil au Festival de Venise 69. Le 1er août, les deux diplomates désignés par l'Itamaraty émettent un avis commun extrêmement favorable à la libération du film.

La situation aurait pu rester insoluble si, dans l'intervalle, Diegues n'avait pas agi. Le 31 juillet, il écrit au ministre de la justice afin de demander une révision de la censure. Ses arguments sont de nature économique, culturelle et politique. Il s'appuie notamment sur la structure ouverte de l'œuvre pour en démontrer la neutralité politique et assure une absence de contradiction avec les orientations du gouvernement militaire :

«Com uma linguagem moderna, séria, profunda (pelo menos nas intenções), procuramos fazer um cinema brasileiro, na descoberta de uma forma nacional para um conteúdo tão original quanto esse país o é. Cremos que é essa linha, polêmica mas legal, que faz os grandes movimentos artísticos em todo o mundo, em todas as épocas. Foi assim que nasceu o romance e a poesia brasileiros, e é assim que queremos fazer o nosso cinema : independente, sem ferir a Autoridade ; livre, mas responsável ; um diálogo permanente entre o crescimento do país e o de sua cultura; um encontro com o grande Brasil que cada um de nós deseja construir em seu setor. $»^{907}$

Le 4 août, le chef du SCDP justifie sa décision auprès du chef du DPF sans que l'on puisse savoir s'il le fait en réponse à une procédure déclenchée par l'avis favorable des diplomates à la libération ou à une demande du ministre. Toujours est-il que le cinéaste réitère sa demande dans un courrier du 13 août et que, le 14 août, le ministre Luiz Antônio da Gama e Silva rédige lui-même un compte-rendu sur le film qu'il a demandé à voir. Son avis est absolument opposé à celui du SCDP. Selon lui, le film ne véhicule aucun message contraire aux idéaux et aux objectifs de la Révolution. Il décide donc sa libération et détermine luimême quatre coupes destinées à effacer la présence du portrait de Getúlio Vargas dans le cadre de l'image. Il apparaît clairement au travers de ses coupes que l'inquiétude des censeurs était que le film «réveille» dans le public une certaine sympathie pour Vargas, adversaire

906« Le film porte attente à la sécurité car il présentera au public des problèmes politiques trop récents et dont l'interprétation est passible de distorsion ». Portaria n 66/69 - SCDP de 31/07/69, dossier Os Herdeiros, Arquivo Nacional - COREG, fonds Divisão de Censura de Diversões Públicas - DCDP, Brasília.

907« Avec un langage moderne, sérieux, profond (au moins dans l'intention), nous cherchons à faire un cinéma brésilien, à la découverte d'une forme nationale pour un pays aussi original que le nôtre. Nous croyons que c'est cette ligne polémique la plus juste, que c'est ainsi que se font les grands mouvements artistiques à toutes les époques et dans tous les pays. C'est ainsi que la poésie et le roman brésiliens sont nés, c'est ainsi que nous voulons faire notre cinéma : indépendant, mais respectueux de l'Autorité ; libre, mais responsable ; dans un dialogue permanent entre le développement du pays et sa culture ; à la rencontre de ce grand Brésil que chacun d'entre nous rêve de construire dans son domaine. » Lettre de Carlos Diegues au ministre de la Justice du 31/07/1969, dossier Os Herdeiros, op. cit. 
historique et symbole de tout ce que je rejette le parti qui fait le putsch de 1964.

Le certificat de censure est émis le jour même, le long métrage est interdit au moins de 18 ans et à la télévision. Pour d'autres raisons étrangères à l'action de la censure, Os Herdeiros n'est pas présenté à Venise et voit son exploitation commerciale reportée à l'année suivante. À cette occasion, une demande de révision du visa de censure est déposée. L'abaissement de la restriction d'âge à 14 ans est obtenu. Os Herdeiros répétait l'histoire de Terra em transe. L'interdiction apparaît dans les deux cas comme la manifestation de l'insécurité des censeurs vis à vis des pressions contradictoires auxquelles ils sont soumis. Le retournement rapide de la situation fait que, dans aucun de ces deux cas, l'action du SCDP n'a été défavorable à la carrière des films. Pour autant, ce comportement erratique de l'État dans son action de contrôle du cinéma participait à installer un climat de défiance. Le rapport de force restait déséquilibré entre des auteurs-producteurs qui investissaient de leur poche et une institution qui, d'un coup de stylo, pouvait leur faire tout perdre.

\section{Integração racial}

Integração racial est soumis au SCDP le 9 novembre 1970, c'est à dire six ans après avoir été terminé dans des conditions précaires puisque l'Itamaraty, qui subventionnait le film, abandonne la production après le coup d'État. Le film est soumis aux censeurs un mois après le dépôt de demande de censure. Deux sur trois estiment qu'il s'agit d'un film contraire aux intérêts de la sécurité nationale, le troisième estime qu'il contient des éléments susceptibles d'encourager la lutte des classes. Tous se prononcent contre sa libération. Le défaut principal reproché à Integração racial est de remettre en question l'intégration raciale et de ne pas donner du Brésil l'image positive d'une démocratie raciale pleinement réalisée. Après cette série d'avis très négatifs donnés par les censeurs, Integração racial attendra sept mois son visa d'exploitation. C'est un des délais les plus longs enregistrés par le Cinema Novo. De plus, il est interdit à l'exportation, au moins de dix-huit ans et ne bénéficie pas de la mention « Bonne qualité », ce qui le prive de tous les avantages concédés au cinéma national. Il n'est donc pas interdit mais condamné à une circulation très réduite, voire nulle.

\section{São Bernardo}

São Bernardo est terminé en mars 1972, juste à temps pour participer au Festival de Cannes. Une première demande est déposée dans ce sens auprès du SCDP qui délivre aussitôt un certificat spécial. Pour autant, les conclusions du compte rendu du premier censeur annoncent déjà les difficultés à venir en exprimant la contradiction devenu classique entre 
l'autorisation de diffusion à l'extérieur et l'interdiction sur le marché interne :

«Trata-se de uma obra que mostra os conflitos existentes entre classes sociais em determinadas regiões de nosso País, onde os famosos coronéis exploram os trabalhos de seus colonos. Existem também algumas citações que poderão ser consideradas como ofensivas ao nosso regime vigente, assim como ' OS HOMENS DO GOVERNO ESTÃO COM OS PARAFUSOS SOLTOS ' e algumas pornografias. Assim, se se tratasse de uma exibição interna, o meu voto seria de interdição, de acordo com o Decreto-Lei 1.077 e 20.493. Todavia, como se trata de certificado especial para exibição no exterior, opino no sentido que seja expedido o referido certificado. $»^{908}$

São Bernardo, comme d'autres films du Cinema Novo, est donc libéré sans coupe pour un grand festival international mais il pèse de lourdes réserves quant à son exploitation sur le territoire national. La demande de censure quant à celle-ci est déposée en mai. Un mois va se passer avant qu'elle soit traitée. Quatre censeurs sont réunis et rendent leur verdict entre le 7 et le 13 juin. Le premier opine pour la libération pour les plus de 18 ans sans coupe en argumentant que le film ne comporte aucune forme de prosélytisme. Le second se prononce pour l'interdiction sur la base de dialogues manifestant «uma ideologia suspeita» (une idéologie suspecte). Les troisième et quatrième émettent dans un texte commun un avis équidistant des deux précédents et recommandent une interdiction au moins de 18 ans et la réalisation de coupes. Leur position repose sur l'appréciation suivante :

« Apesar do filme apresentar a vida miserável do colono, as arbitrariedades do patrão como senhor absoluto, algumas exaltações sociais, não podemos considerá-lo como socialista (subversivo). $»^{909}$

Nous pourrons noter au passage l'assimilation faite entre « socialiste » et « subversif». Les coupes portent sur deux passages des dialogues où l'évocation directe de la révolution et du socialisme pourrait amener le spectateur à mettre en relation la situation décrite dans le film et le socialisme comme remède aux injustices, par ailleurs reconnues par les censeurs. Le film est libéré le 14 juin conformément à l'avis émis dans ce dernier compte-rendu. Hirszman recourt de cette décision dans une lettre du 29 juin dans laquelle il se prévaut de l'argument culturel quant à la reconnaissance dont jouit déjà l'œuvre de Graciliano Ramos et la fidélité de son adaptation. Il explique aussi que les coupes demandées feraient perdre à l'œuvre toute sa

908 «Il s'agit d'une œuvre qui montre les conflits existant entre classes sociales dans certaines régions de notre pays, où les fameux cononéis exploitent le travail des paysans. Elle contient aussi des citations qui pourront être considérées comme offensantes pour le régime, comme par exemple, ' LES HOMMES DU GOUVERNEMENT ONT UN BOULON EN MOINS ' et certaines allusions pornographiques. Ainsi, s'il s'agissait d'une projection interne je serai pour l'interdiction, en accord avec les Décrets 1.077 e 20.493. Cependant, comme il s'agit d'un certificat spécial pour l'étranger, j'opine pour une autorisation. » Compte rendu de censeur du 20/03/1972, dossier São Bernardo, Arquivo Nacional - COREG, fonds Divisão de Censura de Diversões Públicas - DCDP, Brasília.

909 «Bien que le film présente la vie misérable du colon, les punitions arbitraires du patron qui agit en seigneur absolu, quelques exaltations sociales, nous ne pouvons pas le considérer comme socialiste (subversif). » Compte rendu de censeur, dossier São Bernardo, op. cit. 
cohérence si elles devaient être appliquées. Parallèlement, et selon une stratégie assez similaire à celle de Diegues pour Os Herdeiros, il affirme que le film ne contient attaque contre le gouvernement ou le latifundium. Son argumentation est extrêmement cohérente et le terrain sur lequel elle se déploie nous montre de quelle façon les cinemanovistas avaient intériorisé les limites imposées par la censure et élaboré les stratégies adéquates à la circulation de leurs œuvres. Pour autant, plus de quatre mois seront encore nécessaires pour qu'une réponse favorable lui soit accordée. Un nouveau certificat est émis le 10 novembre 1972 qui libère le film sans coupe. São Bernardo ne sera pourtant lancé sur le circuit commercial qu'au deuxième semestre de l'année 1973. Dans l'intervalle, la maison de production du cinéaste a fait faillite, Hirszman ne signera pas de nouveau long métrage avant Eles não usam black-tie em 1981.

Malgré ces cinq films assez hétérogènes sur lesquels la censure a effectivement pratiqué une analyse politique et démontré une parfaite compréhension des intentions des auteurs, force est de constater que l'immense majorité des films du Cinema Novo est passé immune au travers des fourches caudines de la censure. Sur 42 films que nous avons étudiés et assimilés au Cinema Novo, seuls trois ont connus de réelles difficultés pour des raisons politiques avouées : O Desafio, Integração racial et São Bernardo. Si la censure avait appliqué une analyse politique rigoureuse des films et avait eu pour orientation d'interdire systématiquement les films développant un discours critique envers le régime et ou tout au moins contraire à ses valeurs, alors pratiquement tous les films du Cinema Novo auraient dû être interdits ou connaître les mêmes difficultés au moment de leur passage devant le SCDP. Or, même pendant les années de plomb, ce ne sera pas le cas. La libération des films susceptibles d'une interprétation politique est perturbée de façon aléatoire et repose très étroitement sur les circonstances et la sensibilité personnelle des censeurs. Le Cinema Novo ne reçoit pas non plus de traitement différencié de la part de la censure, l'expression est ellemême peu utilisée dans ses archives.

En laissant la censure cinématographique aux mains d'un service privé d'orientations précises et réellement préparé à sa mission, en refusant l'établissement d'une censure politique systématique et critériée, le régime n'en manifestait pas moins un choix stratégique qui a consisté à s'inquiéter mieux de la diffusion des films que de leur contenu. Les documents qui témoignent qu'il y a effectivement eu débat autour de l'adoption d'une ligne dure ou du maintien d'une ligne libérale (et que nous retrouverons dans les archives de la police politique) montrent que la permissivité du régime a été relative. Le maintien de la ligne libérale s'est fondé sur la connaissance de la censure économique à laquelle était soumise le Cinema Novo, le cinéma brésilien «sérieux » dans son ensemble et le cinéma politique en 
particulier. Les échecs commerciaux de films comme Porto das Caixas et A Falecida, dont les lancements sont sabotés par l'adoption de stratégies commerciales inadaptées ${ }^{910}$, sont utilisés par la profession comme des arguments de l'absence de viabilité économique du cinéma brésilien. La télévision quant à elle, n'est pas soumise aux mêmes obligations que le cinéma et tourne résolument le dos aux films nationaux dont elles ne diffuse qu'un nombre infime $^{911}$. Enfin, si le Cinema Novo connaît quelques succès commerciaux, sa diffusion reste limitée aux grands centres urbains et à un public régulier estimé à 100000 spectateurs ${ }^{912}$, ce qui est beaucoup pour un cinéma d'art et d'essai, mais n'est pas pris en compte par le régime comme une véritable menace politique.

Livré à lui-même, le SCDP va aussi appliquer un principe de précaution en décidant des restrictions plus fortes pour la télévision que pour le cinéma tout au long des années soixante-dix et quatre-vingts. Pendant cette période, il n'est pas rare qu'un film autorisé au cinéma soit interdit à la télévision ou autorisé avec des coupes et / ou seulement après un horaire tardif. De plus, le certificat de censure n'est valide que pour une période de cinq ans au terme de laquelle il faut demander un renouvellement de censure et reprendre la procédure à zéro. Dans de nombreux cas, la censure requiert de nouveau les coupes et restrictions qui avaient pu être évitées lors de négociations au moment de l'obtention du premier certificat. Il est donc à nouveau nécessaire de négocier ce qui occasionne des contretemps et des démarches supplémentaires qui découragent logiquement distributeurs et exploitants. La censure contribue ainsi à circonscrire l'espace de diffusion du Cinema Novo. Cet espace constitue l'espace d'une critique consentie par le régime dans les salles de cinéma. Son volume a été déterminé par la nature même du Cinema Novo et montre qu'il a été partiellement toléré.

\subsection{Le Cinema Novo et la police politique}

Comme le montre Gaspari dans ses livres sur la dictature brésilienne entre 1964 et 1980, la question de la répression politique est une question centrale pour toute cette période historique. L'hypertrophie des services de renseignements et l'usage de la torture sont les deux caractéristiques principales d'un régime qui, par ailleurs, ne pourra pas être accusé de

910Cf. BERNARDET, Jean-Claude. Cinema brasileiro : propostas para uma história. Op. cit., p. 70.

911En 1973, sur 1446 films diffusés par les chaines de télévision de Rio de Janeiro, 10 étaient brésiliens. En 1974, la proportion était de 35 pour 1704. In BERNARDET, Jean-Claude. Cinema brasileiro : propostas para uma história. Op. cit., p. 12.

912Estimation faite par les cinemanovistas eux-mêmes et confirmée par Carlos Diegues dans l'entretien concédé à l'auteur. Voir DINES, Alberto, FERNANDES JÚNIOR, Florestan, SALOMÃO, Nelma. « Nelson Pereira dos Santos » in História do poder, 100 anos de política no Brasil, vol. 2 : Ecos do parlamento. São Paulo, Editora 34, 2000, pp. 115-135. $C f$. Annexe pour les résultats commerciaux connus des films du Cinema Novo. 
totalitarisme puisqu'il ne possède pas une idéologie clairement conceptualisée qu'il aurait pour objectif de faire accepter par tous. La dictature ne s'est pas faite pour imposer un ordre nouveau mais pour lutter contre le communisme et la corruption. Pour le reste, les gouvernements militaires successifs oscilleront entre les deux orientations classiques de la politique brésilienne : le libéralisme économique et le desenvolvimentismo. L'épuration qui est effectuée au lendemain du coup d'État touche les mouvements de base, les syndicats, les fonctionnaires et les politiciens qui s'étaient engagés dans le gouvernement Goulart ou qui pouvaient être identifiés avec le militantisme de gauche. Entre 1964 et 1968, il existe une certaine liberté d'expression mais la liberté d'action est extrêmement réduite ${ }^{913}$. Les mouvements de contestation de l'année 1968 entraîneront le durcissement du régime et la censure de l'ensemble des médias. Ce durcissement signifiera une plus grande intolérance aux idées de gauche et une plus grande violence des moyens de répression. Pour autant, le régime continuera à souffrir de la même imprécision idéologique et des mêmes divisions.

Entre 1964 et 1975, un département de police est chargé de surveiller et éventuellement réprimer toutes activités politiques susceptibles de mettre en cause le régime, il s'agit du Departamento de Ordem Política e Social - DOPS ${ }^{914}$. Comme dans le cas de la censure, le DOPS existe déjà avant le coup d'État de 1964. Il est lui-même l'héritier d'autres organes de police politique dont les sigles et les missions ont varié depuis le début du siècle. Créé en 1962, le DOPS est réformé une première fois en 1963 puis en 1968. À cette date, il intègre la Comunidade de Informação (Communauté d'information) coordonnée par le SNI. Dans les faits, il n'est pas utile d'attendre 1968 pour voir le DOPS recevoir et communiquer des archives aux services de renseignements des armées et au SNI. Au cours des années de plomb, le DOPS se rendra tristement célèbre dans sa lutte contre la guérilla par ses méthodes expéditives (exécutions sommaires et torture). Dès avant 1964, ses missions sont les suivantes: surveillance des syndicats, surveillance des milieux culturels, identification des dirigeants et activistes subversifs, protection de personnalités, surveillance de meetings et autres manifestations, contrôle des associations corporatives afin d'éviter qu'elles soient infiltrées par des éléments subversifs ${ }^{915}$.

$\mathrm{Au}$ côté d'objectifs précis et facilement identifiables comme la lutte contre les structures et les personnalités politiques de gauche, le DOPS, comme le SCDP, souffre de l'absence d'une conceptualisation précise des termes « communisme » et « subversion ». Alors

913Voir SCHWARZ, Roberto. Cultura e política. São Paulo, coll. Leitura, Paz e terra, 2001.

914Le DOPS sera lui-même remplacé par le Departamento Geral de Investigações Especiais - DGIE en 1975. Officiellement, il n'existe plus de police politique au Brésil depuis 1988.

915Cf. ARQUIVO PÚBLICO DO RIO DE JANEIRO. Os Arquivos das polícias políticas, reflexos de nossa história contemporânea. Rio de Janeiro, Fundação de amparo à pesquisa do DOPS, 1996, p. 25. 
que la gauche de l'époque est extrêmement fragmentée entre socialistes et communistes, révolutionnaires et réformistes, gauche festive et organisations clandestines extrêmement disciplinées, les archives montrent que les organes de répression ne s'embarrassent pas des subtilités idéologiques ou stratégiques, assimilent toutes les tendances entre elles et visent à leur extinction totale. L'absence de conceptualisation du «communisme » et de la « subversion » pose problème car la police politique entend prévenir les actes subversifs en plus de les punir. Se pose alors la question du niveau de présomption à partir duquel la police doit agir. Comment caractériser la subversion ? Quand intervenir? Le problème se pose tout particulièrement pour les milieux culturels dans lesquels l'affiliation des individus à tel ou tel parti n'est pas toujours claire et où les modalités de participation politique peuvent échapper aux catégories classiques (meetings, pamphlets).

Nous verrons ici que le cinéma n'est pas pris en compte par la police politique comme une activité subversive. Il n'existe pas de traces de coopération entre la police politique et les organes de censure. Les films sont très rarement commentés et, en 1964, les cinemanovistas ne sont même pas connus par le DOPS. La situation évolue peu par la suite. Les cinéastes seront fichés et inquiétés pour leurs déclarations dans la presse contraires au régime et certaines manifestations ponctuelles ou sympathies avec des personnes impliquées dans la guérilla ou le militantisme politique. Eux-mêmes ne seront jamais que très superficiellement impliquées dans ce type d'activité. Ainsi, l'exil de Rocha entre 1971 et 1976 est la conséquence de deux ou trois entrevues dans la presse étrangère et notamment dans $L e$ Monde où il fut particulièrement véhément contre la dictature. Du reste, Terra em transe ou Antônio das Mortes n'ont compté pour rien. Un dernier point intéresse la police politique, l'activisme des cinemanovistas pour influer sur la politique cinématographique du pays en infiltrant l'INC. Là encore cependant, les enquêtes du DOPS manquent de suivi. Entre autre lacune troublante comme le séjour d'un an de Rocha à Cuba (1971), aucune information n'est présente sur la réorganisation d'EMBRAFILME qui sera pourtant décisive et marque le moment où les cinemanovistas ont eu le plus d'influence (1972-1975).

\section{Les archives relatives au Cinema Novo}

Pour rédiger ce paragraphe, nous n'avons pas consulté l'ensemble des archives du DOPS au niveau national mais celles du DOPS des états de la Guanabara et de Rio de Janeiro qui sont aujourd'hui conservées à l'Arquivo Estadual de l'ancienne capitale fédérale. Il s'agit donc d'une étude partielle mais elle nous semble suffisante dans le cadre de notre thèse puisque, comme nous le savons, le lieu principal de résidence et de travail des cinemanovistas 
était Rio et donc, s'ils ont effectivement fait l'objet d'une surveillance policière particulière, c'est au DOPS de cette ville que ce travail revenait. L'ouverture de ces archives au public date des années quatre-vingt-dix ce qui explique que, pour l'instant, elles n'ont pas été prises en compte dans les travaux des historiens du cinéma. Le travail de conservation des archives qui a déjà été effectué et leur informatisation permet d'avoir accès à la logique interne des anciens archivistes du DOPS. Dans notre recherche, nous avons privilégié deux entrées : par titres de films et par noms.

Une étude quantitative des réponses aux entrées sollicitées permet déjà de relever quatre éléments intéressants. Le premier est l'absence totale d'un travail d'analyse des films ou d'enquête sur les films (tournages, financements) de la part du DOPS. La recherche par titre de film donne très peu de résultats et, dans la majorité des cas, le titre d'un film apparaît seulement parce qu'il est cité dans la filmographie d'un réalisateur ou le programme d'un cinéclub. Il n'existe pas non plus de trace de communication avec les organes de la censure. Cette absence de documents sur la production cinématographique n'est pas une spécificité du Cinema Novo. Les entrées « filme» ou « cinema político » remettent à un nombre négligeable de documents et aucun d'eux ne met en évidence une surveillance même ponctuelle des secteurs de la production, de la distribution, de l'exploitation ou même de la réception des films politiques à Rio. Nous n'avons trouvé que deux exceptions à cette absence de surveillance des milieux du cinéma : quelques documents sur Terra em transe et la brochure «Cinema político » de 1974 que nous commenterons plus bas.

Le second élément que nous pouvons constater dans une analyse quantitative et qui peut pourtant paraître contradictoire avec le premier est, qu'effectivement, les cinemanovistas ont été surveillés, la plupart d'entre eux possèdent un prontuário (dossier nominatif), ce qui montre la préoccupation du DOPS à leur sujet. C'est le cas de Diegues, Guerra, Santos, Andrade, Jabor, Viana, Barreto et Rocha. Curieusement, Hirszman, connu comme le « communiste » du groupe et celui dont l'implication dans le CPC, l'UNE et le gouvernement Goulart avait été la plus forte n'a pas de prontuário $^{916}$. Saraceni, Dahl, et Lima, autrement dit, les auteurs de films sur des thématiques politiques explicites ou / et qui ont eu des démêlés avec la censure n'ont pas de prontuário. Autre élément intéressant, le Cinema Novo est reconnu comme une entité à part entière (ce qui n'était pas le cas dans la presse ni pour la censure) comme le montre un dossier du Cenimar de quinze pages classifié secret et daté du

916Une raison simple et désarmante à cette absence est la graphie difficile de son nom qui a apparemment découragé les fonctionnaires du DOPS. L'un des rares documents le mentionnant porte une mention manuscrite à sujet. Le lecteur du dossier corrige, d'ailleurs de façon erronée, le nom du cinéaste d'origine polonaise. Ailleurs, nous retrouvons le nom « Hirszman » déformé des plus diverses manières. 
21 janvier 1971 qui porte le titre : Considerações gerais sobre o "Cinema Novo ${ }^{917}$. Comme cela est déjà le cas dans les études cinématographiques, il y a donc une identification claire entre la liste de noms cités plus haut et le Cinema Novo. À aucun moment, le DOPS assimile au Cinema Novo d'autres cinéastes comme Anselmo Duarte, Walter Hugo Khouri, Luis Sérgio Person ou même Roberto Farias. Autrement dit, nous retrouvons bien dans les archives du DOPS, sans pour autant que cela devienne un concept opérant pour lui, une notion très claire de ce qu'est le Cinema Novo. Il n'est pas considéré comme une école ou un mouvement de cinéma mais comme un groupe avec des opinions, des intérêts et des pratiques communes.

Troisième élément digne d'être mentionné, l'entrée par nom permet de trouver des documents pour chaque cinemanovista mais le nombre et la qualité des documents ne sont pas les mêmes pour chacun d'entre eux. De très loin, l'entrée « Glauber Rocha » renvoie au plus grand nombre de documents (35). Il est suivi par Barreto (19), Andrade (10), Viana (8), Lima (6), Farias, Santos, Saraceni, Hirszman (4), Dahl (3) et Diegues (2) ${ }^{918}$. Certains documents remettent à des faits sans relation avec le Cinema Novo. Le fait qu'un nom renvoie à une page d'archive signifie seulement que le nom est cité. Il peut être le sujet principal du document mais il peut aussi figurer dans une très longue liste de noms sans implication majeure par rapport au fait traité ${ }^{919}$. Enfin, il peut aussi être cité dans une demande de recherche d'archives effectuée au temps de l'activité du DOPS sans pour autant que cette recherche ait eu des résultats. Ce type de document nous montre seulement qu'à un moment donné, on ${ }^{920}$ s'est intéressé aux antécédents politiques de telle ou telle personnalité. Il convient de souligner qu'à partir des documents auxquels nous avons eu accès, Rocha est réellement le seul pour lequel nous constatons l'existence d'une surveillance systématique. Dans son cas, le nombre important de documents auxquels son nom renvoie correspond à des documents dont il est le sujet principal. Il ne s'agit pas d'un nom cité parmi d'autres sans plus de conséquences.

Si l'intérêt du DOPS pour le Cinema Novo n'a pas été causé par les films du groupes et si les cinemanovistas, à l'exception de Rocha, n'ont pas été l'objet d'une surveillance systématique, quels sont les documents que nous trouvons à leur sujet dans le fond des polices politiques? Nous pouvons les présenter dans l'ordre chronologique.

Les documents les plus anciens remettent à l'épuration immédiatement consécutive au coup d'État. Le premier est Relatório periódico de informação $n^{\circ} 18$ daté du 20 mai 1964 du

917Setor Secreto, pasta 78, folha 192, Arquivo Público Estadual, fonds Polícias Políticas, Rio de Janeiro. 918Dans tous les cas, nous avons utilisé comme entrée le nom complet et les différentes graphies usuelles. Curieusement, l'entrée « Ruy Guerra » ne remet à aucun document mais le réalisateur possède un prontuário.

919Voir par exemple : Setor Secreto, pasta 04, folhas 61-71, « Relação de endereços encontrados no material apreendido pelo DOPS e recolhido ao Regimento Escola de Infanteria », liste des abonnés des revues Cuba e Boletim de Corea, juin 1964, Arquivo Público Estadual, fonds Polícias Políticas, Rio de Janeiro.

920Les auteurs de ce type de demande ne sont pas identifiables. Il peut s'agir de personnes étrangères au DOPS. 
Ministério da Guerra ${ }^{921}$ classé secret. Dans ce document, nous lisons les noms de Barreto et Diegues qui sont identifiés comme des «jornalistas comunistas » entre beaucoup d'autres parmi lesquels Alex Viany, Otto Maria Carpeaux et Ferreira Gullar. Le deuxième document est un rapport de trois pages sur le CGTI, Comando Geral dos Trabalhadores Intelectuais ${ }^{922}$. Daté du 23 juillet 1964, produit par la «Seção de Atividades Antidemocráticas » du Secretário de Segurança Pública da Guanabara, il décrit cette organisation et explique qu'elle n'a pas fonctionné puisqu'elle a été créé juste avant le coup d'État. Le CGTI était composé de 14 disciplines allant de l'architecture au théâtre en passant par l'éducation. La discipline « cinema » réunissait le groupe du Cinema Novo, entre autres personnalités, et se distinguait en troisième position des disciplines les mieux représentées ex aequo avec la radio et la télévision (26 membres). La littérature comptait 37 membres et le théâtre, 30. Le CGTI rassemblait l'intelligentsia carioca de l'époque et notamment les grandes figures de l'ISEB comme Sodré et Vieira Pinto. Le rédacteur du rapport s'est contenté de lister les noms sans chercher à identifier les disciplines qui seraient les plus mobilisées politiquement (les chiffres avancés plus haut sont les nôtres). Les noms sont mal orthographiés, preuve du peu de crédit alors attribué aux cinéastes : « Caluber Rocha », « Leon Hirazam », « Arnaldo Jabour ».

La surveillance des cinemanovistas devient plus rigoureuse à la suite d'un événement aujourd'hui largement oublié, la publication par le journal Correio da Manhã du 6 mai 1965 du « Manifesto dos intelectuais contra a intervenção dos EEUU no Caribe ${ }^{923}$. Cet événement est suivi le 17 novembre de la même année par la manifestation à l'Hotel Glória contre la réunion de l'Organisation des États d'Amérique - $\mathrm{OEA}^{924}$. Le premier événement implique 130 signataires parmi lesquels Rocha, Andrade, Hirszman, Barreto et Santos. L'objectif de ce manifeste était de protester contre l'intervention militaire nord-américaine en République dominicaine. Cette pétition motive une première demande de recherche dans les archives du DOPS et la rédaction d'un document de quatre pages intitulé « Informação n ${ }^{\circ} \mathrm{SP} / 121$ » qui contient de petits résumés relatifs à tous les signataires comprenant leur état civil, leur activité professionnelle et leurs éventuels antécédents. Ce type de document nommé « resposta a pedido de busca », écrit par des bureaucrates sans connaissances et sans initiative, aura pour effet d'apporter de l'emphase, par la répétition mécanique, à des événements par ailleurs jugés de faible importance par le DOPS lui-même, c'est le cas de la participation des cinéastes au CGTI qui va revenir régulièrement pendant près de vingt ans.

921Setor Secreto, pasta 8, folha 93, Arquivo Público Estadual, fonds Polícias Políticas, Rio de Janeiro. 922Setor DOPS, pasta 10, folha 60 a 58, op. cit.

923(Manifeste des intellectuels contre l'intervention des USA dans les Caraïbes) Setor Geral, pasta 98, dossiê 4, coupure de presse, op. cit.

924Setor DOPS, pasta 77, folhas 217, 5 e 6, op. cit. 
Le « Manifesto dos intelectuais » est un autre événement de faible importance pourtant consigné par le DOPS. Il est cependant intéressant de noter que, selon José Roberto Arruda, c'est à partir de sa publication que Rocha a commencé à se sentir surveillée ${ }^{925}$. L'épisode de l'hôtel Glória a quant à lui était consigné dans les biographies de Rocha ${ }^{926}$ et Andrade ${ }^{927}$. Les deux cinéastes accompagnés de Mário Carneiro, Carlos Heitor Cony, Flávio Rangel, Antônio Callado, Mário Emanuel Moreira Alves et Jayme Azevedo Rodrigues ont brandi des banderoles de protestation contre la dictature au moment de l'arrivée du Président Castello Branco à la réunion de l'OEA à l'hôtel Glória. Cet acte isolé, sans relation avec une activité militante régulière, a engendré une certaine confusion aux seins des différents services de police et de renseignements comme en témoignent les correspondances qu'ils échangèrent entre eux et le rapport final daté du 25 novembre, soit huit jours après les faits ${ }^{928}$. Surpris par le fait que le nouveau régime puisse être publiquement dénoncé et que ce soit des jeunes gens de bonnes familles qui le fassent, les différents services sont pris de court. La détention des huit personnalités durera presque un mois.

En 1966, un document daté du 21 septembre et émis par le « Ministério da Marinha / Estado Maior da Armada » affirme :

« O contrôle da indústria cinematográfica e das exibições de filmes está atualmente nas mãos de comunistas a quem compete a seleção, indicação e distribuição das películas, coisa do maior interesse. Os executores das diretivas partidárias do PC [...] são Alex Vianny, Joaquim Pedro de Andrade, Leon Hirschmann, Paulo César Saraceni, Carlos Diegues [...], Glauber Rocha, Arnaldo Carrilho, David Neves, Paulo Emílio Salles Gomes, Ruy Guerra, Arnaldo Jabor, Luis Carlos Barreto, Mario Lago, Geraldo M. Torinho. $\gg{ }^{929}$

Ces affirmations ne sont étayées par aucun document et sont en très grande partie fausses. Les cinemanovistas sont parfaitement identifiés mais ils ne détenaient pas le « contrôle » de l'industrie cinématographique ${ }^{930}$ au-delà de l'aide qu'ils avaient à l'époque déjà reçue de la part de la CAIC et du ministère des affaires étrangères. En aucun cas ils n'exécutaient non plus les directives du PC avec lequel ils entraient régulièrement en conflit.

925ARRUDA, José Alberto. Lúcia a mãe de Glauber. São Paulo, Geração editorial, 1999, p. 151.

926GOMES, João Carlos Teixeira. Op. cit., p. 188.

927BENTES, Ivana. Op. cit., p.65.

928Setor DOPS, pasta 85, folhas 12 a 10, Arquivo Público Estadual, fonds Polícias Políticas, Rio de Janeiro.

929« Le contrôle de l'industrie cinématographique et de l'exploitation des films est actuellement dans les mains de communistes à qui revient la sélection, l'indication et la distribution des films, chose du plus grand intérêt. Les exécutants des directives du PC sont [...] são Alex Vianny, Joaquim Pedro de Andrade, Leon Hirschmann, Paulo César Saraceni, Carlos Diegues [...], Glauber Rocha, Arnaldo Carrilho, David Neves, Paulo Emílio Salles Gomes, Ruy Guerra, Arnaldo Jabor, Luis Carlos Barreto, Mario Lago, Geraldo M.

Torinho. » in Setor Secreto, pasta 11, folha 248, op. cit.

9301966 est l'année de la création de l'INC et le temps de la prédominance des « universalistes » dirigés par Flávio Tambellini. Identifié à droite, ce groupe est opposé au Cinema Novo. $C f$. SIMIS, Anita. Op. cit. et RAMOS, José Mário Ortiz. Cinema, estado e lutas culturais (anos 50-60-70). Rio de Janeiro, Paz e terra, 1983. 
La motivation de la production de ce document est inconnue, notons cependant que l'INC est créé le mois suivant. Il est probable que l'on se soit inquiété dès lors de l'infiltration possible de l'institution par des "gauchistes », thème qui deviendra par la suite et comme nous le verrons le principal sujet d'inquiétude du DOPS.

Toujours en 1966, le 17 octobre, deux réunions publiques réalisées le même soir justifient l'envoi d'agent du DOPS qui produisent aussitôt un compte rendu des événements. La première réunion est une conférence organisée dans le quartier Leblon par les éditions Civilização Brasileira sur le thème «Função social do cinema » (fonction sociale du cinéma) avec Barreto, Diegues, Saraceni, Hirszman, dos Santos et Viany. La deuxième réunion est un débat organisé à Botafogo après la pièce de théâtre $O$ Santo Inquérito en présence de son auteur Dias Gomes, de Rocha et Nelson Werneck Sodré. Quatre documents sont produits sur ces réunions publiques qui tournent autour d'une seule préoccupation : savoir si on allait y parler du régime en mal $^{931}$.

En 1967, nous constatons un cas unique de censure anticipée d'un film et cette censure est réalisée par le DOPS et non le SCDP. Trois documents sont produits ${ }^{932}$. Le premier, le protocole $n^{\circ} 7$ du 3 janvier 1967, aujourd'hui perdu, demande que l'on vérifie le contenu du scénario et de l'argument du film Terra em transe. Nous avons la référence à cette demande dans sa réponse datée du 12 janvier qui indique qu'un agent s'est rendu au siège de MAPA Filmes pour demander le résumé du film que l'on trouve indexé. Dans celui-ci, très certainement écrit par Rocha lui-même, la dimension politique du film est très atténuée sans pour autant mentir sur l'intrigue et les principaux personnages. Une analyse de deux pages de ce résumé se trouve indexé à un troisième document classé secret qui conclut que « a exemplo da maioria dos filmes europeus e americanos, como é da tradição do cinema, o artista central é um místico romântico que se envolve num conflito entre gente poderosa, por amor a uma mulher. ${ }^{933}$ Le tournage ne sera perturbé par aucune intervention policière.

Dans un document confidentiel et urgent de la Marine du 5 novembre $1968^{934}$, il est craint la création d'un «nouvel ISEB » par la direction académique de la faculté de sciences politiques et économiques de Rio de Janeiro. Celle-ci aurait en effet créé un institut pour le développement composé d'un grand nombre d'intellectuels ayant fait partie de l'ISEB : Sodré, Corbisier et Hélio Jaguaribe. Rocha apparaît comme responsable du département de

931Setor DOPS, pasta 97 , folhas $46-7$, pasta 116 , folha 77 , pasta 118 , folha 430 , Setor Secreto, pasta 12 , folha 22 , op. cit.

932Setor DOPS, pasta 76, folhas 112 a 108, op. cit.

$933 \ll[\ldots]$ comme la plupart des films européens et américains, et comme c'est la tradition au cinéma, l'artiste principal [sic] est un mystique romantique qui s'implique dans un conflit entre des gens puissant pour l'amour d'une femme. » Cette conclusion était directement induite par le résumé de Rocha dont elle reprend les termes.

934Setor Secreto, pasta 34, folhas 7 a 11, op. cit. 
« comunicação de massa » (communication de masse). Aucun autre document ne mentionne cet institut dont nous ne savons pas par ailleurs s'il a jamais existé.

La documentation la plus volumineuse relative au Cinema Novo est postérieure à 1968 et concerne l'administration de l'INC par Ricardo Cravo Albim entre 1970 et $1971^{935}$. Les titres des rapports sont assez explicites : «A Esquerda controlando o Instituto Nacional do Cinema e a Embrafilme através de Ricardo Cravo Albim », "O Caso do Festival de Berlim », «O Domínio da Embrafilme pela esquerda ${ }^{936}$. Ici, comme cela avait déjà été le cas dans le document de 1966, on s'inquiète de voir la gauche prendre le contrôle du cinéma et des financements que lui prodigue l'État. Dans le texte «Considerações sobre o Cinema Novo no Brasil » daté du 21 janvier 1970 et produit par le Cenimar, l'auteur calcule que la gauche contrôlerait quasiment trente millions de nouveaux Cruzeiros au travers de la concession de financements par Embrafilme ou l'INC pour «realizar filmes políticos, ou simbólicos, atacando o Brasil com dinheiro dado pelo governo brasileiro $»^{937}$.

Il faut noter qu'à la même époque, les services de renseignements accordent une plus grande importance aux déclarations des cinéastes dans la presse étrangère et établissent une relation directe entre le caractère subversif de ces déclarations, la proximité des cinéastes avec Albim et la concession de financements. Toujours dans le même texte, nous trouvons un recueil de coupures de presse parues à l'étranger depuis 1965 qui permet de montrer que :

« Já naquele ano, como também nos subsequentes, vários cineastas brasileiros (Glauber Rocha, Joaquim Pedro de Andrade, Luiz Carlos Barreto, Nelson Pereira dos Santos, Gustavo Dahl, Paulo César Saraceni e outros) faziam críticas severas ao governo brasileiro, quando entrevistados por jornais e revistas da Europa, principalmente na França, Itália e Alemanha. ${ }^{938}$

La lecture du prontuário de Rocha renforce cette idée d'une extrême sensibilité de la police aux discours tenus dans la presse étrangère puisqu'il est composé de très nombreuses coupures de presse accompagnées de traductions et incluant un dossier spécial consacré à trois articles de 1971 : «Glauber Rocha, un rêve libérateur », Le Monde, 11 mars, « Brazil, the next Vietnam », Time out, sans date, « Brazil too totalitarian so Rocha says in exile », Variety, 7 juillet. Le DOPS accuse alors Rocha de critiquer le gouvernement « révolutionnaire », de donner une image déformée du Brésil et de véhiculer des « conceitos humilhantes para com o

935Setor Secreto, pasta 78, folhas 193 a 185, pasta 89, folha 260, pasta 41, folhas 36 a 38, pasta 140, folhas 34 a 40 , op. cit.

936« La gauche contrôlant l'INC et Embrafilme au travers de Ricardo Cravo Albim », « L'affaire du festival de Berlin » et « La domination d'Embrafilme par la gauche ».

$937 \ll[\ldots]$ réaliser des films politiques et symboliques contre le Brésil avec l'aide de l'argent du gouvernement brésilien. »

938« Déjà cette année-là, comme les années suivantes, de nombreux cinéastes [liste des cinemanovistas] critiquaient sévèrement le gouvernement brésilien quand ils accordaient une entrevue dans les journaux et les revues européennes, spécialement en France, en Italie et en Allemagne. » 
seu povo » (concepts humiliants contre son peuple). Dans le même dossier, il est demandé «a cópia do depoimento que o nominado deverá prestar, caso regresse ao Brasil ${ }^{939}$. Rocha ne reviendra pas d'exil avant juin 1976.

1970 et 1971 marquent certainement le moment de plus forte tension entre la police politique et le Cinema Novo. C'est aussi le moment où l'on assiste à un début de prise en compte systématique des films produits dans la caractérisation des activités subversives. Cela apparaît clairement dans l'attention apportée au film Cabezas cortadas qui, parallèlement, est interdit par la censure et la circulation de la brochure Cinema político d'auteur et d'origine non mentionnés mais qui a apparemment été écrite pour apprendre aux agents de la police politique à reconnaître les films «subversifs ». Mais ce pic d'attention précède aussi une détente soudaine de la surveillance du Cinema Novo. À partir de 1972 et jusqu'à 1988, nous ne retrouverons aucun document pertinent relatif au Cinema Novo sinon les demandes de recherche d'archives qui ont précédé la nomination aux postes les plus importants d'Embrafilme au moment de sa reformulation en 1975. Enfin, le prontuário de Rocha, contient un télex de la présidence qui ordonne : «CASO SE CONCRETIZE O RETORNO DE GLAUBER ROCHA AO BRASIL VG NENHUMA RESTRIÇÃO DEVERÁ SER IMPOSTA SUA LIBERDADE PESSOAL EM CONSEQUENCIAS DE SUAS ATIVIDADES E PRONUNCIAMENTOS ANTERIORES PT $» .^{940}$

\section{Errements et perspicacité du DOPS}

Le relevé que nous avons effectué des documents relatifs au Cinema Novo dans les archives du DOPS montre la difficulté de la police et des services de renseignements à prendre en compte les films comme des actes politiques en eux-mêmes, dignes d'entraîner des actions de répression et même la surveillance des cinéastes. Nous avons vu que les cinéastes ont été fichés avant tout pour des actes de contestation de type classique : pétitions, réunions et déclarations publiques. Cela apparaît clairement dans l'importance accordée à la manifestation de l'hôtel Glória et à celle accordée aux déclarations dans la presse étrangère. Le DOPS a aussi soigneusement contrôlé la formation de groupes analogues à ceux qui s'étaient développés avant le coup d'État, il a alors espionné les tentatives d'organisation de structures qui auraient pu devenir un nouveau CPC ou un nouvel ISEB. Dans le cas du Cinema Novo, ces activités politiques de type classique, très ponctuelles et sans lien avec aucune structure, délimitent cependant très mal une nouvelle ligne d'action parallèle à la

939 « [...]la copie de la déposition que l'intéressé devra faire, dans le cas où il reviendrait au Brésil. » 940« Au cas où le retour de Glauber Rocha au Brésil se concrétise, aucune restriction ne devra être imposée à sa liberté personnelle en conséquences de ses activités ou pour ses déclarations antérieures. » 
production des films. Difficile cependant de dire que le DOPS s'est trompé en ne prenant pas en compte les films. D'un côté, leur analyse, qui n'a pas été faite par la police, aurait dû entraîner une réaction de sa part, mais de l'autre, sa permissivité s'explique par le fait qu'aucun événement politique, aucune manifestation, n'a pu être lié de façon directe, aux films du Cinema Novo. Quand bien même les films étaient subversifs, l'absence d'un impact directement observable justifie la ligne d'action de la police qui apparaît alors cohérente avec celle de la censure.

Le point sur lequel le DOPS ne s'est pas trompé, quelque soit le point de vue adopté, est l'identification du lobbying institutionnel comme l'un des principaux modes de participation politique du Cinema Novo. Nous avons déjà détaillé dans des chapitres précédents comment le Cinema Novo fait siennes les revendications du secteur cinématographique remontant aux années cinquante et quelle fut son influence dans la création de la CAIC. La participation de plusieurs cinemanovistas à la reformulation d'Embrafilme en 1975 va démontrer plus tard à quel point il s'agissait d'une de ses orientations politiques principales. Le but de ce lobbying auprès des institutions d'État dédiées au cinéma était d'influencer la politique culturelle du pays et, bien sûr, d'obtenir des moyens financiers pour continuer à produire. Il est certain que le coup d'État de 1964 a durement touché le cinéma et qu'au-delà de la remise en cause des idéaux et des espoirs antérieurs à cet événement, la crainte constante d'une intervention du régime entraîne des mécanismes d'autocensure. Nous l'avons vu dans les hésitations de Rocha sur le script à réaliser au moment de tourner Terra em transe. Hirszman, de son côté, avait déjà adopté un profil bas en réalisant un film sans thématique politique explicite et sous couvert d'adaptation théâtrale, $A$ Falecida ou l'histoire d'une femme adultère de banlieue qui se laisse mourir. La période immédiatement postérieure au putsch est une période de remise en question mais aussi d'attente par rapport aux dispositions que le régime est susceptible de prendre concernant le cinéma.

Parallèlement, à cette autocensure, le Cinema Novo continue à pratiquer le lobbying institutionnel qui l'avait caractérisé avant 64 et, dès sa création en 1966, il va tenter de trouver des appuis au sein de l'INC sans toutefois négliger les aides que peuvent toujours apporter la CAIC et l'Itamaraty. Miguel Pereira confirme qu'à cette époque :

« [...] o Cinema Novo conseguiu sobreviver até com o apoio do estado autoritário. É evidente que essas idas e voltas [entre les différentes institutions d'État] eram inseridas numa estratégia em que os autores eram o escudo, mas a ação era dos produtores ou das pessoas que tinham maior acesso a « certas pessoas ». Na verdade, o Cinema Novo praticou uma política bastante tradicional no Brasil que acabou permitindo essa estranha combinação : um cinema progressista num estado autoritário. ${ }^{941}$

$941 \ll[\ldots]$ le Cinema Novo a même réussi à survivre avec l'appui de la dictature. Il est évident que ces allées et 
Cette ambivalence de l'État peut être vérifiée en examinant les primes et subventions qui continuent à être versées à des cinemanovistas après 1964.

Cette situation se maintient à peu près jusqu'à la fin des années soixante au cours de laquelle, selon le témoignage de Diegues et de familiers de Rocha, ces cinéastes sont victimes de manœuvres d'intimidation de la part des autorités. Nous n'avons pas retrouvé de trace de ces faits dans les archives du DOPS mais Diegues a dit avoir été soumis à trois enquêtes militaires ${ }^{942}$ et Rocha aurait eu son passeport confisqué au moment de son embarquement en avion vers l'étranger en $1968^{943}$. De plus, selon Lúcia Rocha ${ }^{944}$, des agents de police lui ont clairement demandé de ne pas revenir et l'ont menacé quand il est parti en exil en 1971. Dans un tel contexte, nous pouvons présumer que les prisons de Lima $^{945}$ et Andrade ${ }^{946}$ ont été d'autres manœuvres d'intimidation. Parallèlement, les portes des différentes institutions se ferment et la période comprise entre 1971 et 1974 correspond au moment de plus grande précarité des cinemanovistas : Rocha, Guerra, Hirszman et Lima ne filmeront plus avant la deuxième moitié des années 70, Saraceni, Diegues et Santos réalisent des films mineurs avec peu de moyens. L'un des rares qui parvient à monter un projet ambitieux est Jabor avec Toda nudez será castigada, adaptation d'un dramaturge qui parle bien de la dictature et mal du Cinema Novo : Nelson Rodrigues.

Ce ralentissement des activités des cinemanovistas semble coïncider avec l'attention apportée au DOPS à la proximité existant entre les cinemanovistas et Albim et à son éviction postérieure de la direction de l'INC qui a aussi coïncidé avec l'annulation des financements qui devaient être attribués aux cinéastes ${ }^{947}$. Autrement dit, la volumineuse documentation alors constituée par le DOPS sur le Cinema Novo aurait été suivie d'effet. Il est intéressant de noter aussi que, non seulement le groupe du Cinema Novo était parfaitement identifié mais

venues [entre les différentes institutions d'État] étaient insérées dans une stratégie dont les cinéastes étaient la partie visible mais où l'action appartenait aux producteurs et aux personnes qui avaient accès à ' certaines personnes '. En vérité, le Cinema Novo a pratiqué une politique assez traditionnelle au Brésil qui a permis cette étrange combinaison : un cinéma progressiste dans un État autoritaire. » in BERNARDET, Jean-Claude, PEREIRA, Miguel e XAVIER, Ismail. O Desafio do cinema : a política do Estado e a política dos autores.

Rio de Janeiro, Séries Brasil os anos de autorismo, Jorge Zahar editor, 1985, p.60.

942VIANY, Alex. O processo do Cinema Novo. Op. cit., p. 446.

943ARRUDA, José Alberto. Op. cit., p. 153.

944GOMES, João Carlos Teixeira. Op. cit., p. 253.

945Lima est incarcéré et interrogé dans le cadre d'une enquête sur la VPR et le FLN. Le rapport du DOPS montre qu'il a été considéré comme un témoin mineur et qu'il a été rapidement établi que ses relations avec la guérilla étaient superficielles. (Setor Inquéritos, pasta 18, folha 416). Le contenu du petit paragraphe dédié à l'interrogatoire de Lima correspond exactement à la version des faits de son biographe. $C f$. MATTOS, Carlos Alberto. Op. cit., pp. 165-170.

946En mars 1969, Andrade est arrêté sur la base d'une présomption à appartenir au PC et à organiser des réunions politiques à son domicile. Il est rapidement libéré. « Libertação de Joaquim Pedro acabou com crise no FIF » in Última hora, Rio de Janeiro, 21/03/1969.

947Setor Secreto, pasta 78, folhas 188 e 187, Arquivo Público Estadual, fonds Polícias Políticas, Rio de Janeiro. Ce document comprend la liste des financements annulés. 
aussi ses auxiliaires qui étaient méconnus du grand public : Antoine pour les ventes à l'étranger, Neves et Carrilho pour les facilités obtenues par l'intermédiaire de l'Itamaraty afin que le Cinema Novo puisse représenter le Brésil dans les festivals étrangers. Nous pouvons donc dire que bien que le DOPS n'ait pas traité des films comme d'actes politiques en euxmêmes, il a parfaitement réussi à identifier le rôle de chacun dans la géopolitique du cinéma brésilien et réussit, au moins jusqu'en 1972, à réprimer l'infiltration de l'INC et d'Embrafilme par les cinemanovistas.

Dès 1968, la crainte de la répression est très forte et, alors que les films sont finalement peu en cause, le Cinema Novo, sous l'effet conjugué de l'autocensure et de la pression externe, se trouve peu à peu dans l'incapacité de poursuivre son discours intentionnellement démystificateur sur la réalité brésilienne. Pourtant, il apparaît des failles importantes dans la documentation constituée par le DOPS pendant les années de plomb. Dans le prontuário de Rocha, des faits aggravants comme son séjour à Cuba en 1971 et ses relations avec l'ICAIC depuis le début des années soixante n'ont pas été consignés. De façon générale, aucune information n'a été recueillie sur les manœuvres qui ont permis au groupe du Cinema Novo de participer à la reformulation d'Embrafilme. Selon André Gatti, des négociations avaient été entamées en juin 1972 au Primeiro Congresso da Indústria Cinematográfica Brasileira ${ }^{948}$. Les témoignages cités par Salem et Bentes dans les biographies respectives de Santos et Andrade, et la confirmation apportée à l'auteur par Barreto, révèlent que les cinemanovistas ont eu des échanges suivis avec le ministre Reis Velloso sur ce sujet.

$\mathrm{Au}$ cours de cette même période, 1972-1975, nous trouvons deux documents intéressants capables d'expliquer ce revirement de l'État dans son traitement du Cinema Novo. Le premier est la brochure Cinema político ${ }^{949}$ que nous avons déjà citée et le second, un résumé de l'article «Censura e cultura », publié dans le Jornal do Brasil, le 9 février $1975^{950}$. La brochure est composée d'un texte original et de la compilation des articles suivants : AVELLAR, José Carlos. «Cinema político » in Jornal do Brasil, Caderno B, 24.03.1974, ROCHA, Glauber. «A Revisão histórica de Glauber» in Jornal do Brasil, Caderno B, 16.1.1973, «A Encruzilhada do Cinema Político» in Visão, 23.4.1973. L'auteur de la brochure assimile cinéma politique et cinéma « subversif », désigne Jean-Luc Godard comme le chef et l'inventeur de ce cinéma, lui attribue des effets psychologiques comparables à ceux d'un lavage de cerveau et conclut que la production de ces films fait partie d'un vaste plan de subversion de la jeunesse mis en place par les soviétiques. La compilation des articles

948RAMOS, Fernão, MIRANDA, Luiz Felipe (Org.). Enciclopédia do Cinema Brasileiro. Op. cit., p. 212. 949Setor Comunismo, pasta 126, folhas 155 a 176, Arquivo Público Estadual, fonds Polícias Políticas, Rio de Janeiro.

950Setor DOPS, pasta 218, folha 299, Arquivo Público Estadual, fonds Polícias Políticas, Rio de Janeiro. 
présente des analyses plus pertinentes et mieux élaborées dans lesquels sont évoqués le problème du langage et la controverse opposant les partisans d'un cinéma politique qui utilise les ressources dramatiques du cinéma classique comme Costa Gavras et ceux qui pensent qu'il n'est pas possible de changer les mentalités en se prévalant des mêmes recettes qu'un cinéma d'évasion. Sont également évoqués l'obstacle d'un public habitué à un cinéma de diversion et non de réflexion, les contradictions politiques des cinéastes et la censure économique exercée par les structures traditionnelles du marché cinématographique. La brochure elle-même, par le caractère contradictoire de son contenu, les coupures de presse invalidant les dires de son organisateur, matérialise les hésitations des polices politiques et, par extension, de tout le régime autoritaire face à la production d'un cinéma politique au Brésil : répression ou permissivité ? Les articles de presse montrent clairement qu'une forte répression crée de l'antipathie envers le régime et apporte une excellente publicité à des films qui, sans cela, ont le plus grand mal à être diffusé et à modifier les opinions et les pratiques du public.

Enfin, le second document "Censura e cultura » met en garde contre la fuite des cerveaux, la pénétration de la culture étrangère au Brésil et le déclin de la projection culturelle du pays. Il souligne aussi que les principaux intellectuels brésiliens possèdent des antécédents idéologiques et cite Chico Buarque, Vieira Pinto, Valnice Galvão et Rocha. Ce type d'arguments se retrouve dans des documents contenus dans les archives de la censure ${ }^{951}$ et montre cette préoccupation du régime quant à un éventuel déclin culturel du pays. Pour éviter la production de discours qui lui seraient contraires et éviter ce déclin, la dictature prendra les devants en créant des institutions destinées à stimuler la production culturelle. Dans le secteur du cinéma, ce sera l'objet de la création d'Embrafilme. Cette entreprise permettra au régime de se concilier ses opposants dans la classe cinématographique en accédant à une grande partie de leur revendications et en ouvrant à certains d'entre eux des postes de haute responsabilité. La libéralité apparente dont fait alors preuve le régime dissimule mal les liens de dépendance qu'une telle situation instaure. Pratiquement nationalisé avec l'assentiment de ses principaux responsables, le cinéma brésilien ne s'en trouve pas moins parfaitement « encadré ». Les films produits à partir de 1974 peinent à atteindre le niveau de contestation qui était celui de ceux des années soixante.

\section{Conclusion de la troisième partie}

Avec le coup d'État du 1er avril 1964, s'ouvre pour le Cinema Novo une phase 
marquée par l'introspection et la remise en cause des idéaux hérités de l'ISEB. La déroute de la gauche en 1964 est largement attribuée aux failles de l'idéologie populiste. Les films, les entretiens et les scénarios des cinéastes montrent qu'ils remettent en question cette idéologie et son corollaire, à savoir le rôle messianique qu'elle attribue aux intellectuels et à la classe moyenne. Une réflexion est entamée sur la place de l'intellectuel dans la société et le combat politique. Au cours de cette phase d'autocritique, l'ambition de créer un cinéma populaire est mise entre parenthèse. Le cinéma d'auteur conçu comme un cinéma de réflexion est favorisé au détriment de la recherche d'une esthétique à même de conquérir le grand public. La dimension avant-gardiste du Cinema Novo est à présent admise et assumée. Parallèlement, les créations de MAPA Filmes et de DIFILM, quelques succès commerciaux internes, une présence continue dans les festivals internationaux et le début des ventes à l'étranger permettent de viabiliser cette proposition d'un cinéma d'auteur qui a temporairement renoncé à remplir les salles. Au terme de cette phase, la valeur politique d'un cinéma destiné à un public restreint est reconnue s'il sert l'un des deux objectifs suivants : l'affirmation de l'identité culturelle brésilienne (la lutte contre le complexe colonial d'infériorité reste d'actualité) et, dans le cas particulier de Terra em transe, l'agitation politique par la polémique et le débat, éventuellement le scandale. Longtemps indécis quant à l'attitude à tenir vis à vis de ce cinéma manifestant des valeurs opposées aux siennes, la dictature consentira à lui céder ce que luimême finalement réclame, l'espace d'une opposition tolérée mais strictement encadrée. En ce qui concerne la censure, un cadre implicite est posé qui bougera peu pendant les années à venir. 


\section{QUATRIÈME PARTIE : Le Cinema Novo troisième forme (1968- 1972)}

En 1964, le coup d'État surprend et provoque l'évolution du Cinema Novo. Entre 1968 et 1972, celui-ci anticipe et interprète, souvent avec justesse, le durcissement du régime. Ayant tiré les enseignements de sa phase réflexive où il avait momentanément mis entre parenthèses ses ambitions quant à la réalisation d'un cinéma populaire de conscientisation, le Cinema Novo se découvre pluriel. Des films comme $O$ Padre e a moça et Terra em transe avaient montré la validité politique d'un cinéma d'auteur reconnu comme restreint à la petite fraction du public intellectualisé et intéressé par le cinéma comme instrument de médiation au monde. À partir du moment où l'entreprise s'avère économiquement viable, ce cinéma de recherche ne sera plus remis en question. Il sera de nouveau pratiqué avec des visées distinctes dans Capitu, Fome de amor, O Bravo Guerreiro, Os Inconfidentes, São Bernardo.

À côté de cette orientation à présent pleinement assumée, le Cinema Novo troisième(s) forme(s) n'en est pas moins marqué par de nouvelles tentatives de conquête du grand public. Alors que pendant la seconde phase, dominait l'idée selon laquelle un cinéma de conscientisation était incompatible avec un cinéma populaire, de nouveaux essais vont être réalisés avec des films qui rompent avec l'Esthétique de la faim. Un nouveau style est inauguré : le cinemão. L'idée de base consiste à concilier la réalisation d'une esthétique originale avec la transmission d'une vision démystificatrice du réel et la prise en compte les goûts du public. Il se décline en deux axes, le premier est marqué par un changement de point de vue envers la culture populaire et tourne le dos à une sophistication excessive du langage. Incarné par Macunaíma et Como era gostoso o meu francês, ce cinemão va connaître le succès. Le deuxième développe au contraire un langage fondé sur l'abstraction et les références à la culture classique. Il échoue dans ses tentatives de conquête du public, il s'agit de Brasil ano 2000, Os Herdeiros et Pindorama.

Bien qu'il affronte les années de plomb en ordre dispersé et avec des résultats inégaux, quelque soit l'orientation adoptée, le Cinema Novo fait de la thématique libertaire une thématique centrale et exprime la conviction selon laquelle aucun changement politique n'est possible sans une révolution des mœurs en rapport avec le statut de la femme et la sexualité. Au-delà de la critique contre la dictature, le Cinema Novo s'attaque au capitalisme moderne et convoque Marcuse et Reich au chevet du sous-développement. 


\section{Chapitre 10 : L'utopie libertaire}

S'il a souvent été commenté que les films du Cinema Novo engageaient le spectateur à une critique du populisme, la dimension libertaire est beaucoup moins commentée. Cette dimension est pourtant indissociable de l'intention politique des films du Cinema Novo, elle est présente depuis la première phase et s'affirme de plus en plus au fil des années, particulièrement dans la veine des films les plus avant-gardistes.

Depuis Os Cafajestes, et en partie peut être à cause de l'influence de la Nouvelle Vague, le Cinema Novo a mis en scène des personnages dont le comportement sexuel s'écartait des règles imposées par la morale chrétienne. Le thème est nouveau mais les cinemanovistas n'en font pas le sujet principal de leurs films. La sexualité joue en général le rôle de co-adjuvant à l'organisation de la narration et aucun jugement moral n'est lisible sur les agissements des protagonistes. La liberté des femmes à disposer de leur sexualité et de leur désir semble aller de soi. Dans Os Cafajestes, si le point de vue du film sur les traquenards tendus par Jandir et Vavá trahit un jugement moral implicite assez dur du cinéaste, les comportements de Leda et Vilma qui disposent librement de leur sexualité pour atteindre des objectifs existentiels ou affectifs, ne font pas l'objet du même traitement. Il n'est d'ailleurs pas impossible que le scandale de Os Cafajestes soit dû avant tout à cette reconnaissance implicite de la liberté féminine sur laquelle le film joue constamment. Dans une société extrêmement traditionnelle où les jeunes femmes doivent se dédier à garder leur virginité jusqu'au mariage, nous avons :

- une actrice, Norma Bengell, qui accepte de se dévêtir, autrement dit de disposer librement de son corps, pour s'engager dans une démarche artistique ;

- un premier personnage, Leda, qui reconnaît sa propre solitude dans celle de Jandir et s'offre à lui librement, malgré l'humiliation qu'il lui a fait subir sur la plage ;

- un second personnage, Vilma, qui couche avec Jandir pour enfin réussir à briser les résistances de Vavá et réaliser son couple avec lui.

Paradoxalement, pour les ligues de protection des bonnes mœurs, le nu féminin au cinéma ne pouvait être compris que dans la pornographie et rejeté dans le secret des lieux spécialisés sur l'existence desquels elles devaient fermer les yeux, admettant leur existence comme un mal nécessaire. De même, il était incompréhensible que les personnages féminins ne soient pas moralement condamnées dans le film puisqu'elles étaient successivement « déshonorées ». Le scandale fut à la hauteur de l'offense ressenti et le thème principal de $O s$ Cafajestes qui était la vacuité existentielle de la vie de deux jeunes cariocas s'est trouvé 
passablement occulté.

Pratiquement à la même époque, Porto das Caixas marque le retour d'un personnage féminin également désinvolte vis à vis des liens sacrés du mariage et de la protection de sa vertu. Obsédée par le meurtre de son mari, la jeune femme jouée par Irma Alvarez ne va pas hésiter à user de ses charmes pour réussir à se trouver un complice. Elle a un amant mais comme il se refuse à passer à l'acte, elle tente de séduire d'autres hommes dont un jeune soldat. Nous avons donc une femme qui n'hésite pas à se servir de sa sexualité et de l'attirance qu'elle peut exercer sur les hommes comme d'une arme contre eux, pour se libérer de leur tutelle. Elle abandonnera d'ailleurs son amant quand le crime aura été commis. La plupart des critiques s'arrêteront à la condamnation de l'amoralité du personnage sans réfléchir à ce que sa trajectoire veut révéler.

Dans Deus e o diabo na terra do sol, la suggestion de relations homosexuelles entre Rosa et Dadá et la scène d'amour entre Corisco et Rosa n'ont pas soulevé autant de commentaires que les transgressions des personnages des deux films précédents. Rosa s'identifie dans un premier temps à Dadá qui pose sur sa tête le voile de la mariée (séquence du pillage de la ferme). La femme de Corisco représente en effet son avenir si Manuel choisit de dédier sa vie au cangaço. À la femme cangaceira, une pleine réalisation féminine est interdite. Pour survivre, elle doit devenir un homme. Dadá possède tous les attributs du cangaceiro et, séparée de sa fille, doit renoncer à la maternité. Attirée l'une par l'autre, les gestes tendres des deux femmes entre elles contrastent avec la violence des rapports humains qui les entourent. Un peu plus tard, alors que Manuel est parti en patrouille et que la fin approche, Rosa se donne à Corisco avec passion. Leur étreinte est sublimée par la musique romantique de Villa-Lobos et la caméra qui tourne autour d'eux. Dans cette séquence, Rosa retrouve symboliquement la féminité qui lui avait été niée jusque là, par l'indifférence que lui témoignait Manuel et la pauvreté. Quand celui-ci revient, sans savoir ce qui s'est produit, il promet de l'écouter et de prendre en compte ses désirs, ce qu'il n'avait pas fait jusqu'alors.

Cette absence de sacralisation des vertus féminines traditionnelles que sont la virginité avant le mariage et la fidélité à son mari, se retrouve encore une fois dans $O$ Desafio dans lequel la liaison adultère entre Marcelo et Ada n'est à aucun moment mise en question. Aucun jugement n'est porté dans le film sur leur union, pas même du point de vue classique, gauchiste, consistant à stigmatiser les relations sexuelles « illicites » de la grande bourgeoise comme le signe de la décadence morale de cette classe ${ }^{952}$. Dans son autobiographie, Saraceni

952Nous retrouvions cette approche dans l'épisode de Cinco vezes favela, Zé da Cachorra, où le propriétaire du terrain de la favela invitent des prostituées qu'il partage avec son fils en l'absence de son épouse. Dans un autre épisode, O Favelado, le sexe était une fois de plus associé au « mal » quand la petite amie du caïd qui cherchait à enrôler Migliaccio dans son équipe, tentait ouvertement de le séduire en prenant des poses 
se remémore une anecdote assez significative quant à la réception du film et de ce qu'il a pensé à l'époque du débat organisé par Sales Gomes et Almeida Sales au Clube dos Artistas e Amigos da Arte à São Paulo : «Adorei o debate. Achei engraçado, e ri muito quando, depois de mais três horas de debate, Flávio de Carvalho comenta achar estranho que ninguém tinha falado do adultério explícito que o filme contém : a protagonista trai o marido como se bebesse um copo d'água... ${ }^{953}$

Avec $O$ Padre e a moça, la contestation des règles de la morale traditionnelle devenait le thème principal du film. Au cours de la troisième phase du Cinema Novo, cette contestation s'amplifie. Le moralisme ostensible de la société brésilienne ainsi que l'hypocrisie et le machisme qui en constituent les faces cachées, agacent les cinemanovistas. D'abord du fait d'un phénomène générationnel, ils ne se reconnaissent pas dans les valeurs traditionnelles. N'oublions pas que la révolution sexuelle sera l'un des grands thèmes des années soixante, au moins dans le monde occidental. Ensuite, ils découvrent rapidement que ces valeurs constituent une entrave à la liberté d'expression. Cela est particulièrement évident pour $O s$ Cafajestes et $O$ Padre e a moça qui souffrent d'une censure pudibonde et moraliste et pour lesquels le scandale dévie l'attention du message principal des films. Enfin, les événements politiques semblent démontrer que les valeurs traditionnelles vont de pair avec le conservatisme économique et politique. La Marcha da Família com Deus pela Liberdade contre le gouvernement de João Goulart est un exemple de cette collusion entre conservatisme culturel et politique qui n'a pas pu échapper aux cinemanovistas. De même, le pouvoir exagéré et les interventions arbitraires de l'Église dans la société, bien que n'ayant été le sujet d'aucun film, est un autre élément dont on ne pouvait pas ne pas avoir conscience.

De proche en proche, la nécessité de discuter directement ces thèmes se concrétise. L'idée est présente dès le scénario de Garota de Ipanema de Rocha en 1966. L'auteur essaye de nous montrer alors que les normes de comportement que la société impose et que nous nous imposons à nous-mêmes doivent être l'objet d'un questionnement critique car ils peuvent être une entrave à l'épanouissement de l'individu. Hirszman conserve cette orientation dans le film qui sort en décembre 1967. Avec Capitu, Saraceni montre comment la jalousie obsessive d'un homme est directement liée à son incapacité à supporter l'autonomie et la liberté de sa sensuelles.

953 « J'ai beaucoup aimé ce débat. Je l'ai trouvé très drôle et j'ai ri beaucoup quand, après trois heures et demi de discussion, Flávio de Carvalho a dit trouver étrange que personne n'ait évoqué l'adultère explicite que le film contient : la protagoniste principale trahit le mari avec le même naturel qu'elle mettrait à boire un verre d'eau... » in SARACENI, Paulo César. Op. cit., p. 204. Saraceni évoque le débat sur O Desafio qui a eu lieu au Clube dos Artistas e Amigos da Arte, en sa présence et avec Jean-Claude Bernardet, Flávio de Carvalho, Gilda de Mello e Souza et Francisco Luiz de Almeida Salles. Dans l'article publié par O Estado de São Paulo sur le débat, figure effectivement la remarque de Flávio de Carvalho à laquelle il fait référence. $C f$. : SALLES, Francisco Luis de Almeida et alii. « Debate sobre O Desafio » in O Estado de São Paulo Suplemento literário, São Paulo, 04/06/1966. 
femme. Cette incapacité à tolérer un adultère hypothétique, causée par la prégnance d'une norme sociale contraire à la liberté de la femme, conduit ce personnage à sa perte. Enfin, Fome de amor de Pereira dos Santos relie l'intime et le politique et tempère les nouveaux dogmes qui voudraient identifier systématiquement liberté et jouissance sexuelle, héros guérillero et rédemption nationale. Une nouvelle morale se dessine qui met au centre de ses préoccupations la réalisation de l'homme, individuellement et collectivement. Nous allons développer à présent l'analyse de ces trois films.

\subsection{Garota de Ipanema}

L'idée d'adapter pour le grand écran la plus célèbre chanson de la bossa nova ${ }^{954}$ apparaît dans un contexte bien précis et s'articule à un projet plus vaste de Leon Hirszman et Marcos Farias qui motive la réactivation de Saga Filmes. Leur objectif est simple : réaliser un cinéma démystificateur sur la base de thèmes commercialement attractifs. Cette proposition surgit dans le courant de l'année 1965, à un moment où les cinemanovistas se déclarent insatisfaits des résultats de leurs films au box office et tentent d'imaginer les solutions qui leur permettraient d'augmenter leurs parts de marché tout en restant fidèles à leur conception du cinéma comme instrument de connaissance et de désaliénation. Cette réflexion est contemporaine à la réorganisation financière et commerciale du Cinema Novo avec, entre autres, la création de la Difilm et de la Mapa Filmes. À côté de l'élaboration de nouvelles stratégies économiques, la question de la relation avec le public au travers des films est centrale. Elle est l'objet d'un débat qui va animer le Cinema Novo jusqu'à sa fin $^{955}$. La première trace que nous en avons trouvé est une entrevue collective menée par Louis Marcorelles pour Les Cahiers du cinéma avec Joaquim Pedro de Andrade, Gustavo Dahl, Carlos Diegues, Leon Hirszman, Glauber Rocha, Paulo Cézar Saraceni. Cette entrevue réalisée à l'occasion du Festival Internacional do Filme, en septembre 1965 à Rio de Janeiro, coïncide avec les premières nouvelles que Leon Hirszman nous donne de son projet et de Garota de Ipanema.

954Écrite et composée par Vinícius de Morais et Antônio Carlos Jobim en 1962, Garota de Ipanema est adaptée en anglais en 1963 par Norman Gimbel. La version la plus connue est celle de Stan Getz, Astrud Gilberto et João Gilberto, sur l'album Getz/Gilberto qui popularise la bossa nova dans le monde. Aussi interprétée par Frank Sinatra qui demandera à Tom Jobim d'écrire pour lui, elle serait la deuxième chanson la plus enregistrée au monde après Yesterday des Beatles.

955Celui-ci alimente de nombreux écrits de Rocha entre 1966 et 1969 à commencer par sa défense de $O$ Padre e a moça. Gustavo Dahl se penche sur la question dans un texte qui fait date : DAHL, Gustavo. « Cinema Nôvo e seu público », op. cit. Au-delà des argumentations déployées, s'opère une prise de conscience difficile. Les cinemanovistas réalisent que, contrairement à ce qu'ils pensaient au début des années soixante, le cinéma moderne n'est pas le cinéma du futur. Il représente un type de production possible au côté des productions commerciales traditionnelles. La conquête du marché apparaît momentanément inconciliable avec les hautes ambitions artistiques initiales qui seront pourtant maintenues. 
« Si l'on veut démystifier, on doit affronter le problème de la relation de notre œuvre avec le public. Il faut tout d'abord, qu'il aille la voir. Notre cinéma n'a pas établi de véritable communication avec les couches profondes du public brésilien. [...] En ce qui me concerne, j'ai l'intention de faire une expérience qui sera la suivante. Je veux appliquer cette conception du cinéma d'auteur à certains mythes actuels. Ainsi, quelque chose comme la 'chanchada', qui est une comédie musico-carnavalesque à petit budget a son importance. C'est un certain type de comédie simplificateur et primaire mais qui, né entre 1945 et 1960, répond à la nécessité qu'éprouva un certain public de se voir, fut-il représenté avec maladresse et manque d'expérience. Je voudrais partir, moi, de la présence de mythes sociaux dans notre réalité. Ainsi, après le coup d'État d'avril, la peur, la crainte de la persécution, l'absence d'une activité définie, tout cela représente une mythologie sociale bien précise dont il faut analyser les aspects concrets. C'est pour tout cela que je veux tourner Garota de Ipanema. Le mythe de cette jeune fille est une chose très vivante pour le nordestin, par exemple. Il s'agit donc pour moi d'utiliser le cinéma comme un outil pour la connaissance de notre réalité, sans toutefois lui imposer aucune limitation. Analysant les aspects de cette réalité susceptibles de conduire le spectateur au cinéma, je peux dès lors, lui permettre d'adopter, face à ses problèmes, une position critique. $\rangle^{956}$

Garota de Ipanema sera le premier d'une série de films produits par Saga Filmes et construits sur cette idée d'un cinéma démystificateur qui se fixe pour but de revisiter des genres populaires. Eduardo Coutinho collabore à ce projet en tant que co-scénariste et réalisateur ${ }^{957}$. Avec $O$ Faustão qu'il dirige en 1970 et $A$ Vingança dos doze de Marcos Farias (également de 1970), la Saga Filmes va tenter d'exploiter le filon du film de cangaço avec une approche comparable à celle des westerns spaghetti politiques de la même époque. Dans cette série de films, Garota de Ipanema occupe une place particulière et ce, pour plusieurs raisons. Tout d'abord, parce que ce premier film conserve pour dominante l'orientation d'un cinéma d'auteur intimiste et innovateur dans la forme. Ensuite, le genre revisité est la chanchada ce qui constitue un retournement majeur par rapport à l'appréhension des genres populaires par le Cinema Novo. Jusqu'à récemment, la chanchada était un genre honni dont le succès était conçu comme la preuve de l'aliénation des masses et du complexe d'infériorité colonial brésilien. Enfin, au contraire des films de cangaço qui reprendront des thèmes de contestation classiques économiques et politiques, Garota de Ipanema s'attaque à la critique de mœurs, et en particulier à celle des mœurs de la classe moyenne carioca.

Cet intérêt pour la classe moyenne et sa culture apparaît dans le Cinema Novo exactement après le coup d'État de 1964. Après s'être focalisé sur les classes les plus démunies et les marginaux dans la période allant de 1960 à 1964, les cinemanovistas s'interrogent sur leur propre classe et son rôle face à la prise de pouvoir des militaires. Celle-

956MARCORELLES, Louis. « Rencontre avec le Cinema Nôvo : Joaquim Pedro de Andrade, Gustavo Dahl, Carlos Diegues, Leon Hirszman, Glauber Rocha, Paulo Cézar Saraceni », op. cit.

957Quand il travaille pour Saga Filmes, Coutinho se conçoit comme l'« agente de um projeto que lhe era externo » (agent d'un projet qui lui était externe). In Eduardo Coutinho. Entretien avec l'auteur, juin 2003. O Homem que comprou o mundo est une application de l'approche envisagée par Hirszman et Farias. Le film adopte la forme des comédies pour adolescents alors à la mode dans la production carioca et, au travers de l'itinéraire d'un homme ordinaire qui devient subitement détenteur de toute la fortune du monde, critique le sous-impérialisme brésilien. 
ci, soit s'est montrée passive, soit a soutenu activement la déposition de Goulart. Avant le coup d'État, les premières séquences de Maioria absoluta mettaient déjà en exergue l'aliénation de la classe moyenne face à un des problèmes les plus graves de la société brésilienne, l'analphabétisme et l'exclusion sociale, politique et économique qu'il entraînait. Réalisé en 1965, A Opinião pública apparaît comme la première étude de la classe moyenne en tant qu'acteur politique. Selon Arnaldo Jabor, la classe moyenne avait pratiqué le coup d'État contre elle-même. Ce film documentaire qui adopte l'approche du cinéma vérité comblait un manque :

«[...] es una película sobre la conciencia de la classe media, tema muy abstracto para una película. [...] Hasta entonces, sólo se interpretaba a la clase media a través de lugares comunes. Se decía que la clase media era neutra, que no haría nada que carecía de ideología. De la misma manera que se utilizaban lugares comunes para dirigirse a las otras clases, al imperialismo, al ejército. [...] En 1964 no habíamos comprendido todavía que la psicología social es algo importante. No teníamos nada más que clichés. Hemos olvidado que el irracionalismo existe, que existe la propaganda, el miedo, etcétera. $)^{958}$

L'objectif de A Opinião pública était de rechercher les causes du malheur brésilien et le résultat de cette investigation a conduit Jabor à conclure que l'une des causes aux contradictions sociales du pays était l'aliénation de la classe moyenne et la vacuité de son idéologie, si tant est justement que l'on puisse lui attribuer une idéologie. L'individu de classe moyenne, selon lui, ne s'appartient pas et l'opinion publique, largement influençable, est avant tout celle des classes dominantes.

En pratiquant un travail d'immersion de près de six mois dans les appartements et les immeubles de Copacabana, le cinéaste découvre des individus insatisfaits mais soumis, incapables de penser le monde autrement qu'il ne s'offre à eux et partagés entre le souci de la réussite matérielle et un mysticisme d'évasion. Les valeurs dominantes que sont la jeunesse, le travail, la famille, la patrie et la religion sont passées au crible. L'idée reçue selon laquelle le jeune est rebelle est battue en brèche. Pour les élèves des lycées de la classe moyenne, «o futuro é apenas o mundo dos adultos $»^{959}$. Ils se préparent à y entrer sans enthousiasme, prêts pourtant à se soumettre à ses règles comme ils se soumettent déjà aux modèles que leur propose la société de consommation. Leurs pères sont montrés sur les lieux de leur travail. Questionnés sur ce qu'ils font, ils admettent qu'ils n'en comprennent pas toujours le sens et

\footnotetext{
$958 \ll[\ldots]$ c'est un film sur la conscience de la classe moyenne, un thème très abstrait pour un film. [...] Jusqu'à maintenant, la classe moyenne n'était expliquée qu'au travers de lieux communs. On disait que la classe moyenne était neutre, qu'elle ne ferait rien, qu'elle manquait d'idéologie. De la même façon que nous utilisions des lieux communs pour penser les autres classes, l'impérialisme, l'armée. [...] En 1964, nous n'avions pas compris que la psychologie sociale est quelque chose d'important. Nous n'avions rien d'autre que des clichés. Nous avions oublié que l'irrationalité existe, qu'il existe la propagande, la peur, etc. » in JABOR, Arnaldo. « Entrevista con Arnaldo Jabor » in Nuestro Cine, Madrid, n65, septembre 1967, pp. 64-65. 959 «e futur est seulement le monde des adultes ». Dialogue du film.
} 
s'en remettent à une hiérarchie qu'ils ne questionnent pas. Tout dans la vie de ces personnes fonctionne sur le mode de la compensation et de l'évasion. Incapables de se satisfaire des études, du travail ou de la vie domestique, comme cette femme au foyer qui trouve sa vie « chata demais» («trop ennuyeuse»), les individus passent leur temps à attendre les moments de plaisir qui leur permettent de « tenir le coup », la virée en boîte, le dimanche à la plage. Dans l'attente d'un messie ou d'un miracle, la transe collective qui est une constante de différentes manifestations religieuses brésiliennes joue aussi le rôle d'exutoire. Tous sont conscients des inégalités de la société brésilienne, mais aussi bien individuellement que collectivement, les membres de la classe moyenne sont incapables de proposer des solutions à ses problèmes et, paradoxalement, cultivent leur aveuglement.

Avec A Opinião pública, la classe moyenne apparaît comme un personnage nouveau du cinéma brésilien et celui-ci met directement en cause les cinéastes qui, jusque là, s'étaient cantonnés à la description des souffrances des classes inférieures. La critique de la classe moyenne implique forcément l'auteur de cinéma qui, d'un côté, vit au quotidien au sein de cette classe et, de l'autre, se distingue par ses idées. Avec Garota de Ipanema, il ne s'agit plus de montrer l'aliénation de la classe moyenne, puisque cela a déjà été fait, mais d'établir la communication avec elle et de tenter de l'amener à prendre du recul sur elle-même par des moyens détournés, en évitant une approche directe et provocatrice comparable à celle pratiquée par Jabor :

« Meu próximo trabalho será Garota de Ipanema, a ser realizado em princípios de 66. Será um filme em cores, um musical, com história de minha autoria e Vinícius de Moraes. Não será um filme simplesmente nos termos tradicionais de um cinema de ficção alienante. Procurarei documentar a vida deste pequeno mundo que circunda a garota de Ipanema, utilizando para isso a realidade, isto é, usando Vinícius de Moraes como Vinícius [...] e assim por diante. $»^{960}$

La stratégie d'Hirszman a d'abord séduit ses collègues du Cinema Novo. Joaquim Pedro de Andrade la résume très bien dans une entrevue avec Alex Viany :

«Um bom exemplo é o de Leon Hirszman, que vai fazer Garota de Ipanema, propondo-se desmitificar um mito através da utilização do próprio mito como fator de comunicação com a massa. É um programa que me parece viável e interessante. Assim, Leon chega a equacionar o problema em termos práticos, partindo para uma solução com grande possibilidade de alcançá-la. ${ }^{961}$

960« Mon prochain film sera Garota de Ipanema qui doit être réalisé au début de 1966. Ce sera un film en couleur, une comédie musicale, avec une histoire écrite par moi et Vinícius de Moraes. Ce ne sera pas un simple film de fiction aliénant. Je chercherai à apporter des informations sur la vie de ce petit monde qui entoure la jeune fille d'Ipanema, utilisant la réalité, autrement dit, utilisant Vinícius de Moraes comme Vinícius [...] et ainsi de suite. » in HIRSZMAN, Leon. « Entrevista de Leon Hirszman » in Jornal do Brasil, Rio de Janeiro, 21/09/1965.

961 « Un bon exemple est celui de Leon Hirszman avec Garota de Ipanema qui se propose de démystifier un mythe en utilisant le propre mythe comme facteur de communication avec les masses. C'est un programme qui me paraît viable et intéressant. Ainsi, Leon parvient à poser le problème dans des termes pratiques et va 
Tout indique cependant que sa mise à exécution s'est avérée plus complexe que prévue. Alors que le tournage du film est annoncé pour le courant 1966, l'écriture du scénario semble poser de graves difficultés à Hirszman et Morais qui ont résolu de travailler ensemble. Rocha, puis Coutinho, sont appelés à la rescousse. Comment concilier les attraits d'une chanson qui parle de plage, de soleil et d'une jolie fille qui passe avec la critique de la classe moyenne ? Qui plus est en collaborant avec le propre auteur de la chanson et en partageant soi-même les habitudes des personnages du film ? L'argument tel qu'il est présenté par Morais ne semble guère se prêter à des objectifs de conscientisation :

« Inspirados nessa aura que a canção deixou e no próprio mito de Ipanema, quisemos mostrar um verão de garota da zona sul, justamente no momento em que ela está querendo ir prá frente, querendo viver. Quisemos assim registrar suas relações familiares, o comportamento de seu grupo de amigos, suas primeiras experiências amorosas, e sua necessidade de sentir-se mulher. É o processo da crisálida, o momento em que ela quer bater as asas. $॥{ }^{962}$

Rocha résout le problème dans un scénario qui rappelle beaucoup le film de Walter Lima Jr à venir, Brasil, ano 2000. Dans ce texte qui ne sera pas filmé, l'alternance de séquences de comédie musicale et de passages plus intimistes ou dramatiques épouse les oscillations du caractère cyclothymique de la jeune fille. Rocha joue sur l'identification entre le spectateur adolescent et la jeune fille et lui fait suivre un parcours initiatique au terme duquel elle va tourner le dos aux normes sociales qui interdisent son épanouissement.

Tout commence au bord de la mer, une équipe de télévision l'invite à participer à un concours pour gagner un voyage aux États-Unis, elle accepte d'être filmée et un groupe se rassemble autour d'elle pour faire le show mais, finalement, son copain surfer la dissuade de participer. Elle laisse tout en plan et part avec lui et d'autres copains en voiture. À la maison, l'ambiance est moins joyeuse. La mère évoque ses réunions de charité, le père critique les garçons aux cheveux longs et pense au gendre idéal. La jeune fille sort avec une amie plus âgée qu'elle pour faire du shopping, celle-ci lui parle de la pilule, la jeune fille prend un air dégoûté. Elles partent ensuite toutes les deux à une fête où elles rencontrent Chico Buarque, Nara Leão, Vinícius de Morais dans leurs propres rôles... Entre deux chansons, on parle d'art, de politique et de psychanalyse. Un critique s'interroge : «O que adianta falar de favela

mettre en œuvre une solution qui sera très probablement la bonne. » in VIANY, Alex. « Crítica e autocrítica :

O padre e a moça - Alex Viany conversa com Joaquim Pedro de Andrade », op. cit.

962 «nspirés par le succès de la chanson et le mythe d'Ipanema, nous avons voulu montrer l'été d'une jeune fille de la zone Sud, justement au moment où elle veut aller de l'avant, justement au moment où elle veut vivre. Nous avons ainsi cherché à filmer ses relations familiales, le comportement de son groupe d'amis, ses premières expériences amoureuses, et son désir de se sentir femme. C'est le processus de la chrysalide, le moment où elle veut battre des ailes. » in «Vinícius fala de sua garota », sans origine, sans date. 
sentado na praia ? Falar em fome deitado num sofá da Oca ? ${ }^{963}$ Un invité reproche à la jeune fille d'utiliser une expression typique d'une jeune d'Ipanema. Inexplicablement, celle-ci va pleurer dans la salle de bain.

Le temps passe. Pendant l'été, nous retrouvons la jeune fille sur un yacht avec son petit ami. À l'automne, c'est la rentrée. La jeune fille entre à la faculté et rencontre un poète « beat », il lui écrit un poème, elle n'y comprend rien, il le lui reproche. Les deux jeunes gens se disputent. Soudain, autour d'eux, les autres étudiants se mettent à chanter en chœur, un ballet est improvisé dans les jardins de la PUC, la jeune fille et le poète chantent en duo une chanson sur les avions à réaction, les bombes, l'amour libre, la lune, Mars, le communisme, l'impérialisme, l'anarchisme, la crise des sentiments...etc... Un prêtre progressiste entre en scène, puis un prêtre réactionnaire. Enfin, un groupe de gauchistes entonne une chanson subversive lyrique et le spectacle se transforme en meeting.

Après cette journée, la jeune fille reprend ses habitudes. Elle apprend un jour que le poète a été arrêté. Un peu plus tard, elle accepte l'invitation au restaurant d'un playboy millionnaire qui tente de la séduire. De retour à la maison, elle se dispute avec sa mère qui lui reproche de rentrer tard et de sortir avec des hommes différents. Alors que la jeune fille lui fait part de ses doutes sur la vie et les garçons, ses paroles réveillent chez sa mère le sentiment de solitude et d'échec dans son propre couple.

Quelques jours plus tard, à une autre fête, le playboy millionnaire et un jeune industriel se battent pour la jeune fille. L'industriel est blessé, la jeune fille l'accompagne à l'hôpital, ils se disputent, elle sort. Devant l'hôpital, elle se retrouve aux milieux des ambulances qui apportent des blessés, un médecin l'informe sur les statistiques de la violence, un samedi soir. Ne sachant quoi faire, elle accepte qu'il l'emmène en stop. Plutôt que rentrer chez, elle préfère passer la soirée avec lui et découvre l'univers des classes moyennes en voie de prolétarisation de Copacabana. Elle voit les personnages à la dérive de la nuit carioca, un strip-tease sordide, les prostituées, un univers évidemment bien éloigné du sien. À la fin de la nuit, elle rejoint Maria Bethânia, Gilberto Gil, Gal Costa, Caetano Veloso à la plage. La fête continue jusqu'à l'aurore, de retour à la maison, elle dort toute la journée et quand elle se réveille, elle va au cinéma voir Vivre sa vie.

Le temps passe de nouveau, la jeune fille retrouve le poète beat à la faculté. Il lui exprime sa colère d'avoir été emprisonné, ses projets soit de tout casser, soit de partir étudier en France, enfin il la demande en mariage et lui promet de changer si elle accepte. Elle est

963« À quoi ça sert de parler de la favela assis sur la plage ? Parler au nom de la faim allongé dans un sofa d'Urca [quartier résidentiel de Rio de Janeiro] ? » in ROCHA, Glauber. Garota de Ipanema. Scénario accompagné d'une lettre d'Eduardo Coutinho à la cinémathèque, 25 pages, sans date. Cinemateca Brasileira, São Paulo. 
émue. L'idylle est de courte durée, le poète veut faire l'amour, la jeune fille non, ils se disputent et se séparent. Plus tard, elle retrouve le playboy millionnaire qui la demande aussi en mariage en lui promettant une vie entre Paris, Londres et New York. La jeune fille refuse en lui disant la confusion qu'elle ressent devant le monde, la faculté, ses amis intellectuels et toutes les choses différentes et contradictoires qu'elle entend. De nouveau dans une fête réunissant, intellectuels, journalistes politiques et jeunes entrepreneurs, les hommes parlent politique et les femmes de la pilule, de la sexualité et de la liberté. Un journaliste qui apprend que la jeune fille étudie la sociologie lui demande si elle fait partie de la " gauche festive », elle ne comprend pas. Elle écoute ensuite une amie qui lui avoue avoir connu l'amour mais que ça s'est mal fini. Pendant que la jeune fille la console, les discussions sur l'art et la politique atteignent leur climax.

Le lendemain, la jeune fille s'achète un sac à main. Elle rencontre un beau jeune homme brun, ils ne se disent presque rien, il l'emmène dans son appartement, ils font l'amour. Après ça, le jeune homme lui fait un discours existentiel évoquant les faits les plus tragiques de l'actualité. La jeune fille reprend sa vie quotidienne et voit les choses autrement. Elle couche avec le poète beat et le playboy millionnaire, devient mannequin, hôtesse de l'air, le film termine joyeusement avec le carnaval.

L'approche de Rocha est assez simple dans ce texte où, selon Coutinho, pour une fois il n'essaie pas de sauver l'humanité ${ }^{964}$. D'un été à l'autre, la jeune fille transite d'un monde où tout est beau et tout est simple mais dans lequel elle est frustrée, à un monde enfin révélé où les conflits politiques et sociaux n'offrent pas de réjouissantes perspectives mais dans lequel elle a décidé d'assumer ses désirs et son identité. Le passage d'un monde à l'autre coïncide avec la libération sexuelle, la perte de l'innocence dépasse ici la simple perte de la virginité qui, finalement, a bien peu d'importance face aux enjeux individuels et collectifs qu'elle découvre. La frustration de la mère est là pour nous montrer le risque qu'il y a à ne pas prendre de risque, autrement dit à ne pas oser ouvrir les yeux et assumer le fait que les normes sociales ne sont pas forcément celles que l'on doit suivre personnellement. La nécessité de rupture apparaît clairement. Ironiquement, dans la séquence de l'happy end, la mère aussi est contente. Rocha note que la jeune fille pense qu'elle a peut être trouvé un amant.

La prise de conscience de la jeune fille se réalise le long d'un parcours initiatique dans lequel Rocha met en scène deux contradictions qui lui apparaissent propre à la classe moyenne aisée carioca. La première contradiction est l'isolement spatial et humain de cette classe. Repliée sur elle-même, dans ses appartements, ses restaurants et ses yachts, cette classe mène une vie facile en comparaison à celle des classes plus modestes. Il faudra que la 
jeune fille entre en crise pour découvrir qu'il existe un monde en dehors du circuit fermé de son université, de sa maison et de ses loisirs. Ce sera la nuit de son errance solitaire dans le Rio de Janeiro d'un samedi soir, des urgences saturées à une boîte sordide de strip-tease. Ce parcours est aussi fait de rencontres et de discussions, avec des personnages très typés qui dévoilent chacun une façon de voir différente de celle à laquelle elle est habituée.

Il tient également à cœur à Rocha de montrer les contradictions internes de cette classe moyenne dont les personnages sont extrêmement divers, la famille conservatrice strictement patriarcale, le jeune industriel égoïste, le playboy sophistiqué, le poète gauchiste en colère, les autres étudiants aliénés et enfin cette gauche festive que l'on retrouve dans les fêtes, très concerné par les injustices du monde, un verre de whisky dans une main et une guitare dans l'autre. Au-dessus de toutes ces personnes qui sont finalement ramenées sur un pied d'égalité, la musique. La musique est le fil rouge de cette histoire, omniprésente dans les moments tristes comme dans les moments d'euphorie, les musiciens vont et viennent dans les fêtes, sur les plages et, quand ils ne sont pas là, on écoute leurs disques. La bossa-nova domine, à la fois triste et gaie, sans que l'on ne puisse vraiment savoir s'il s'agit d'un fond sonore gratuit ou signifiant. Toujours est-il qu'à défaut de transformer le monde, on peut chanter à tue-tête et se retrouver au milieu du carnaval selon le texte : «A libertação musical. A libertação que explode até quarta-feira de cinzas.» («La libération musicale. La libération qui explose jusqu'au mercredi des cendres »). L'idée qui reste constamment sous-entendue est la suivante : la libération du corps est aussi celle de l'esprit et celle de chacun, un jour, pourrait être celle de tous.

Rédigé en novembre 1966, ce scénario n'a apparemment pas convaincu Hirszman et Morais. Coutinho expliquera plus tard qu'il a été jugé trop glauberiano, c'est à dire trop fantaisiste et surréaliste d'un côté et avec des personnages trop archétypiques de l'autre. Nous avons en effet reconnu, comme dans Terra em transe, le bourgeois progressiste (le playboy millionnaire), le bourgeois libéral (l'industriel égoïste), l'intellectuel gauchiste (le poète beat) et l'homme du peuple (curieusement ici un médecin qui expose la situation de chaos social dans laquelle se trouve Rio). Hirszman et Morais, cette fois-ci avec le concours de Coutinho, ne vont pas garder la trame narrative de Rocha avec son idée d'un parcours initiatique fait de rencontres et de confrontations avec certains aspects de la vie carioca. Les personnages trop archétypiques sont également éliminés. Seront conservés les séquences de fêtes avec les vedettes cariocas, le conflit de génération à l'intérieur de la famille et l'amant mystérieux de la fin de la narration.

Le film commence avec des plans larges d'Ipanema, en voix off, la jeune fille se présente avec un ton mélancolique : «Meu nome é Márcia, tenho 17 anos, já é verão em 
Ipanema. » («Mon nom est Márcia, j'ai 17 ans, c'est déjà l'été à Ipanema. ») Cette première séquence est suivie du générique avec un travail de fondu enchaîné entre des photos et des dessins en polychromie dans un style très pop-art. En fond sonore, nous entendons une version instrumentale de Garota de Ipanema, nous n'entendrons jamais le succès dans sa version intégrale de tout le film. Nous retrouvons la jeune fille sur la plage. Une équipe américaine de cinéma veut la filmer. Son petit ami que nous venons de voir surfer l'a rejointe et refuse qu'elle participe. Ils partent en voiture et retrouvent un groupe d'amis sur un yacht. Après être restée à bronzer sur le pont, Márcia rejoint son petit ami, ils ont l'air de se disputer. Dans la séquence suivante, Márcia, seule avec une amie dans une vila, dit qu'elle a rompu et ajoute : «Que tal a gente caçar em vez de ser caçada? " (« Pourquoi ne pas draguer à la place d'être draguée ?»)

Márcia participe à une fête dans un appartement. Chico Buarque, Nara Leão et Eduardo Coutinho sont présents, l'ex-petit ami aussi. Chico Buarque chante ${ }^{965}$, Márcia et son ex-petit ami se font la tête. Un peu plus tard, elle sort et déambule dans les rues. Sur la bandeson, nous continuons à entendre la chanson de Chico Buarque. Plus tard, la jeune fille retrouve un ami dans un bar qui lui raconte qu'il a été en France. Dans la séquence suivante, nous retrouvons de nouveau Márcia dans une fête. Légèrement éméchée, elle flirte avec Chico Buarque. De retour à la maison, l'ambiance n'est pas très bonne, la grand-mère qui boit trop déclenche un psychodrame. Les jours suivants, la jeune fille continue à fréquenter des fêtes, dans l'une d'elles, son ex-petit ami est blessé dans une bagarre. Márcia s'occupe de lui mais soudain, un autre garçon qui est resté avec eux les hypnotise. Le lendemain, à l'université, elle raconte l'incident à son amie. Le soir, de nouveau, Márcia participe à une fête. À un moment donné, elle assiste à une cérémonie de candomblé sur la plage. D'autres participants de la fête y assistent également. Ensuite, elle retrouve l'hypnotiseur. Ils s'allongent sur le sable, s'embrassent et prennent un bain de minuit. Le lendemain matin, au petit-déjeuner, Márcia se dispute avec sa mère qui s'inquiète pour ses études, sa santé mais aussi (sous-entendu) sa vertu. La jeune fille est blessée par les suspicions de sa mère.

Márcia retrouve l'hypnotiseur dans une chambre obscure où il révèle des portraits qu'il a fait d'elle. La séquence devient ensuite onirique. Dans un studio, l'hypnotiseur joue au photographe, Márcia est métamorphosée par des changements instantanés de costumes. Elle

965Playlist de la bande-originale du film : Noite Dos Mascarados - Chico Buarque, Elis Regina ; Lamento Do Morro - Nara Leão ; Surfboard - Orquestra ; Ela é Carioca - Tamba Trio ; Poema Dos Olhos Da Amada Vinicius de Moraes ; A Queda - Orquestra ; Tema De Abertura : Garota de Ipanema ; Por Você - Ronnie Von ; Chorinho - Chico Buarque ; Aria Para Se Morrer De Amor - Baden Powell ; Rancho Das Namoradas MPB-4, Quarteto em Cy ; Garota De Ipanema - Orquestra. Garota de Ipanema - Trilha Sonora do Filme, disques Philips / Mercury, no du Lp : R 765022 L, sorti le 1 novembre 1967 selon le site www.brazil-onguitar.de, consulté le 17/02/2006. 
recherche son identité, il lui propose de choisir celle qu'elle veut. Il explique qu'il est contre le travail, qu'il est aussi un peu magicien, un peu voyant, un peu aventurier. Elle s'envole dans les nuages. L'hypnotiseur continue à parler en voix off. Il veut qu'elle oublie tous les maux de la terre, il lui offre la lune et... l'amour. Ils retombent sur la plage. Ils s'embrassent mais elle refuse d'aller plus loin, elle a peur. De nouveau seul, Márcia va retrouver son ami du bar qui est aussi son confident. Il l'avertit, l'hypnotiseur est marié et bien marié. Ce n'est donc pas une histoire romantique « classique » qu'il propose. La jeune fille doit se décider en connaissance de cause. Márcia se rend alors à la boutique dont la femme de l'hypnotiseur est propriétaire. Elle ne fait que la voir. De retour auprès de l'hypnotiseur, celui-ci s'étonne du changement de l'attitude de Márcia. Il comprend qu'elle se rétracte et lui dit : « Medo do instante. Você não vê como se afasta da vida e a vida se afasta de você. » (« La peur de l'instant. Tu ne vois pas comme tu t'éloignes de la vie et comme la vie s'éloigne de toi. ») Il disparaît dans un éclair, nous entendons le tonnerre et la pluie se met à tomber.

Après cette nouvelle rupture, la jeune fille est mélancolique et se cache chez elle. Son confident ne réussit même pas à lui parler au téléphone. Le temps passe, de retour sur la plage avec ses amis, elle voit son ex-petit ami avec une autre fille et dit à son confident qu'elle déprime. La voix de son interlocuteur se perd tandis que la caméra se rapproche de son visage triste. Dans la dernière séquence nous la voyons, déguisée dans une fête en train de danser avec un garçon, puis, dans le dernier plan du film, en train de marcher seule dans la rue.

Comme nous le voyons, les scénaristes ont cherché à rendre les personnages un peu moins transparents qu'ils ne l'étaient dans le texte de Rocha et à respecter un peu plus la lettre de la chanson. Cette fidélité réside dans la tension constante existant entre la beauté de la fille et des paysages, le caractère agréable des lieux par lesquels elle transite et cette nostalgie indéfinissable qui l'envahit pendant les temps morts. Curieusement pourtant, alors que les paroles de la chanson portent l'emphase sur le sentiment de ravissement et de désir qui s'empare du passant à la vision de la jeune fille, le film adopte le point de vue de la jeune fille. La mélancolie n'est plus ce sentiment qui précède l'amour chez celui qui la voit passer mais un sentiment de frustration de la fille vis à vis de sa propre vie. L'emballage luxueux du film, la couleur, le travail sur la photographie, le défilé de vedettes, les grands succès de la chanson, mettent en valeur ce monde idyllique dans lequel elle évolue. Elle a tout pour elle, la beauté, l'argent, les amis et quels amis ! Comme dans les rêves de toute jeune brésilienne de son temps, elle a l'occasion de flirter avec Chico Buarque et de croiser Vinícius de Morais. Malgré cela, elle n'est pas heureuse.

L'explication à cette tristesse est limpide, comme tout adolescent la jeune fille se cherche. La dispute avec la mère et la séance virtuelle de photographie le montrent de façon 
assez explicite. Jusque là, nous n'avons rien de bien révolutionnaire ni de très critique envers les mœurs de la classe moyenne carioca. Contrairement à l'histoire de Rocha, les contradictions de cadre idyllique avec le réel ne sont pas expliquées, de même, les enjeux de la recherche d'identité de la jeune fille ne sont pas non plus révélés. Nous restons en effet constamment enfermés dans son monde merveilleux, un monde aux couleurs pastels comme le générique et la photographie nous le suggère, et après que sa vie de luxe et de loisirs nous ait été exposée, nous entrons dans le monde onirique de l'hypnotiseur. Tout se joue finalement dans le refus de la jeune fille d'avoir des relations sexuelles avec le magicien.

À ce sujet, la structure du film reste ouverte. Soit le spectateur juge que la jeune fille a eu tort de ne pas aller jusqu'au bout de ses désirs, soit il pense qu'elle a bien agi et que cette dépression dans laquelle elle s'enfonce après la rupture n'est que passagère : « Elle est jeune et elle oubliera." Le discours de l'hypnotiseur est un argument en faveur de la première interprétation, en refusant de s'engager, la jeune fille ne prend pas le risque de se perdre, mais elle ne prend pas non plus celui de se gagner, c'est à dire de se réaliser. La frustration qu'elle exprime et la sensation de vide qui se dégage constamment du film jouent aussi en la faveur de cette interprétation. D'autres éléments jouent, au contraire, en faveur d'une interprétation moraliste. L'hypnotiseur apparaît seulement dans des séquences de caractère onirique. La caractérisation du personnage peut même nous faire douter de son humanité. Cet homme qui apparaît et disparaît à volonté est-il bien fait de chair et de sang ? Si tel n'est pas le cas, il échappe aux compromissions d'un homme ordinaire et aux risques d'une liaison amoureuse, fut-elle adultère ou non. C'est donc un vulgaire tentateur, un garçon qui n'est « pas sérieux ». Enfin, le fait qu'il n'y ait pas de happy end nous empêche de savoir ce qui serait advenu si, en assumant cette relation, Márcia avait été pleinement satisfaisante. Aurait-elle vraiment vécu un processus de libération?

Au final, un peu à l'image de la jeune fille qui n'ose pas se réaliser, le film ne va pas au bout de ses intentions initiales de démystification. La jeune fille d'Ipanema est une adolescente comme les autres, une condition sociale privilégiée et la beauté en plus, mais qui en a jamais douté et quelle importance cela a-t-il de le révéler ? Cette volonté à laisser le film ouvert quant à la question de la transgression sexuelle et l'explication des enjeux de cette libération d'un point de vue social et politique conduit le film à un degré de critique des mœurs très acceptable. Tout au plus pose-t-on la question consistant à se demander si la jeune fille a eu raison de suivre les conseils de sa maman ou non. Le fait que les deux interprétations du long métrage puisse coexister, la première libertaire et la seconde moraliste, est peut être l'une des raisons de son grand succès auprès du public. Les critiques, au contraire, se sont retrouvés dans une quasi unanimité pour stigmatiser la faiblesse du scénario et des dialogues, 
et applaudir la qualité de la photographie de Ricardo Aranovich. La bande originale, composée pour la plupart de succès déjà connus, reflétait l'air du temps avec une nette préférence pour la musique brésilienne et en particulier la bossa nova. Le défilé des vedettes a quant à lui été diversement apprécié. Pour certains, le procédé ne faisait que reproduire la stratégie des chroniques mondaines et ne représentait pas beaucoup d'intérêt ${ }^{966}$. L'évaluation finale des critiques, basée sur les mêmes éléments d'appréciation, a donc oscillé entre le très mauvais (pour la majorité) et quelques avis positifs $^{967}$ qui voyaient dans le film un changement d'orientation du Cinema Novo vers un cinéma commercial de bon goût et d'excellent niveau technique.

En l'absence d'informations qualitatives quant à la réception du film par le grand public, il nous est impossible de savoir si le clivage que nous observons entre le succès de billetterie et le rejet des critiques est significatif. Il n'est pas impossible que ce qui est passé pour une guimauve sans intérêt aux yeux d'un public adulte ait pris un autre sens pour le public adolescent. Garota de Ipanema restera pourtant une tentative isolée dans la cinématographie du Cinema Novo. Selon la formule ironique de Bernardet, le «cocktail Mazzaropi-Glauber Rocha $»^{968}$ ne fera pas école. Dans son long-métrage suivant, São Bernardo, Hirszman reviendra au réalisme critique avec une nouvelle adaptation de Graciliano Ramos. Il n'est pas interdit cependant de voir l'affirmation d'un démarche ici débutante dans des films plus affirmés où l'on va retrouver la valorisation d'éléments de la chanchada comme Macunaima, Os Herdeiros et Brasil ano 2000. Enfin, Garota de Ipanema est bien le premier film à faire du thème de la libération sexuelle un thème central.

\subsection{Capitu}

Capitu est le nom de l'héroïne d'un roman de Machado de Assis ${ }^{969}$ intitulé Dom Casmurro. Le livre a été publié pour la première fois en 1900 et son action se déroule dans le

966MONTEIRO, Eduardo Nova.« Garôta de Ipanema une imagem e côr da juventude Zona Sul » in Tribuna da Imprensa, Rio de Janeiro, 28/12/1967.

OLIVEIRA, José Carlos. « Os defeitos da Garota » in Jornal do Brasil, Rio de Janeiro, 29/12/1967.

967Nous avons dénombré 17 critiques négatives et trois critiques positives, un rapport qui est assez rare pour le Cinema Novo, normalement plus apprécié. Le film a déçu jusqu'à ses supporters habituels, entre autres, José Carlos Avellar et Maurício Gomes Leite (cf. AUGUSTO, Sérgio et alii. « Garôta de Ipanema » in Jornal do Brasil, Rio de Janeiro, 31/12/1967.)

968BERNARDET, Jean-Claude. « Garota de dois gumes » in aParte, publicação do Teatro dos Universitários de São Paulo, São Paulo, n², mai-juin 1968. Acteur, producteur et réalisateur de comédies à grand succès, Amácio Mazzaropi (1912-1981) était détesté par la critique cinématographique.

969Joaquim Maria Machado de Assis, écrivain de Rio de Janeiro (1839-1908), est considéré comme l'un des plus grands écrivains brésiliens. Romancier, novelliste, poète et critique littéraire, ses œuvres les plus marquantes, Memórias Póstumas de Brás Cubas, Dom Casmurro et O Alienista, ont été adaptées au cinéma. Il fut le fondateur de l'équivalent de l'Académie française, pour le Brésil, l'Academia Brasileira de Letras. 
Rio de Janeiro, du second empire pendant la décennie de 1870. Capitu est devenue, depuis le succès de ce roman, un personnage emblématique de la culture brésilienne. Femme en apparence soumise mais dont les pensées restent impénétrables, « ses yeux de tzigane et son regard oblique » constamment nous font douter de ce qu'elle pourrait cacher et des procédés qu'elle pourrait mettre en œuvre pour assouvir ses désirs. Machado de Assis évoque «o olhar de ressaca », littéralement « un regard de ressac » pour exprimer tout le mystère de cette femme qui, à la fois, saurait s'offrir et se garder, comme ces vagues qui avancent et se retirent dans le même mouvement. Ce regard de ressac est celui de la femme rouée aux arts de la manipulation et de la dissimulation qui lui servent à se jouer des hommes sans affronter directement leur autorité.

Le regard de Capitu suggère une forte sensualité. Fernanda Montenegro, dans un court essai sur le personnage, en fait l'analyse :

«Esse olhar é a nossa miscigenação, a nossa aparente submissão, são as nossas olheiras amorosamente gulosas, quentes e erotizadas. É o olhar que denuncia a marginal vitória desse ser-mulher colonizado. Olhar de quem dissimuladamente aceita o jogo surdo, silencioso, de carrasco e vítima, jogo fascinante e cruel na aparente aceitação das diversas manifestações do relacionamento humano. ${ }^{970}$

L'histoire de Capitu et de Bentinho se joue entièrement sur le mystère et la sensualité de ce regard. Amis depuis l'enfance, ils se promettent l'un à l'autre au tournant de l'adolescence. Pour Capitu, Bento abandonne sa vocation à la prêtrise et ses études au séminaire. Mais quand enfin ils sont mariés, il connaît des crises de jalousie de plus en plus fréquentes et intenses. D'insignifiants malentendus font douter Bento de la dévotion complète de Capitu, il s'étonne que leur union ne soit pas absolue, Capitu lui apparaît soudain comme une individualité irréductible à ce qu'il pense et ce qu'il veut qu'elle soit ou fasse. De proche en proche, certains éléments de la vie quotidienne lui font même penser que Capitu l'a trahi avec son meilleur ami, Escobar. Sans jamais rencontrer aucune preuve tangible de la trahison, sans jamais que le comportement de Capitu à son égard n'ait changé, sans que personne ne le confirme dans ses doutes, il perd sa confiance dans sa femme et résout de briser le cadre idyllique de leur mariage.

L'histoire de Capitu et Bentinho apparaît à Saraceni comme le support idéal à la discussion sur les contradictions du couple, l'émancipation sexuelle, la valeur du mariage et le

970« Ce regard est notre métissage, notre apparente submission, ce sont nos œillades amoureusement gloutonnes, chaudes et érotisées. C'est ce regard qui dénonce la victoire marginale de cet être femmecolonisée. Regard de qui accepte sans le montrer le jeu sourd, silencieux, de bourreau et de victime, jeu fascinant et cruel dans l'apparente acceptation des diverses manifestations des relations humaines. » in MONTENEGRO, Fernanda. «Os olhos de ressaca, de cigana oblíqua e dissimulada da personagem de Machado de Assis são um patrimônio feminino brasileiro », site de la revue Época, http://epoca.globo.com/especiais/rev500anos/olhar.htm, consulté le 17/02/2006. 
machisme. Toutes ces questions qui traversaient la vie personnelle du cinéaste, étaient aussi dans l'air du temps. Dans une entrevue à Filme Cultura, en 1972, Saraceni se souvient de ses principales intentions pour l'adaptation de Dom Casmurro :

«Trabalhei bastante na cenografia, nos figurinos e nos personagens para que Capitu resultasse, antes de tudo, um filme de época. Mas não me interessava falar da época de Machado de Assis porque a entendia muito pouco. Não sou grande machadiano. Queria sim era falar da época atual, da transformação que está havendo, de uma revolução sexual numa época precisa. ${ }^{971}$

Pour écrire le scénario du film, il demande l'assistance de Paulo Emílio Sales Gomes et Lygia Fagundes Telles. Dans son autobiographie, il se rappelle de son voyage à São Paulo et de l'état d'esprit avec lequel il a travaillé avec eux :

« Vivia ali em São Paulo, graças a Machado de Assis e o enigma de Capitu, a revolução sexual de Reich, e a revolução pelo lazer e prazer de Marcuse. [...] eu sentia, enquanto me aprofundava em Machado de Assis, conduzindo pelos mestres Lígia, Paulo Emílio e Almeida Sales, e vendo o movimento estudantil do Brasil se movimentar contra a ditadura, o mesmo que tinha visto na Europa e no Chile : o mundo ia sofrer uma profunda mudança, eu não sabia bem o que era, mas seria nos costumes. Seria uma revolução, diferente do comunismo e diferente do capitalismo. O casamento, assim como todas as outras instituições, iam ser abaladíssimos e o filme que eu queria fazer tinha muito a ver com isso, como também com o que o cubano Alfredo Guevara me contara da Revolução Cubana. ${ }^{972}$

Bien que Capitu ait été un film à gros budget pour l'époque et les critères du Cinema $\mathrm{Novo}^{973}$, moins d'un an ont été nécessaire pour monter son financement, écrire le scénario et choisir les lieux qui permettraient de recréer l'ambiance du XIXe siècle ${ }^{974}$. Le film est tourné aux mois de novembre et décembre 1967 et sort sur les écrans en 1968. La lecture du scénario publié en $1993^{975}$ montre que le texte écrit avec Salles Gomes et Fagundes Telles a été

971« J'ai travaillé la scénographie, les costumes et les personnages pour que Capitu soit, avant tout, un film historique. Mais cela ne m'intéressait pas beaucoup de parler de l'époque de Machado de Assis car je la comprenais peu. Je ne suis pas un grand machadien. Ce que je voulais était parler de l'époque actuelle, de la transformation qui se jouait, de la révolution sexuelle à une époque précise. » inSARACENI, Paulo César. « A Crônica de A Casa assassinada - Entrevista a José Carlos Monteiro e Marcos Riba de Faria » in Filme cultura, Rio de Janeiro, n²0, mai-juin 1972, p. 36.

972 «e vivais là-bas à São Paulo, grâce à Machado de Assis et à l'énigme de Capitu la révolution sexuelle de Reich, et la révolution du loisir et du plaisir de Marcuse. [...] je sentais, à mesure que j'approfondissais ma lecture de Machado de Assis, orienté par les maîtres que sont Lígia, Paulo Emílio et Almeida Sales, et voyant le mouvement étudiant du Brésil prendre position contre la dictature, comme cela arrivait en Europe et au Chili : le monde allait passer par une profonde mutation, je ne savais pas bien ce que ce serait, mais je savais que ce serait dans le domaine des mœurs. Ce serait une révolution différente du communisme et du capitalisme. Le mariage, comme toutes les autres institutions, seraient très ébranlés et le film que je voulais faire avait beaucoup à voir avec cela, comme aussi avec ce qu'Alfredo Guevara m'avait raconté de la Révolution Cubaine. » in SARACENI, Paulo César. Op. cit., p. 225.

973Saraceni indique un montant de 120000 \$. In SARACENI, Paulo César. Op. cit., p. 228.

974Il s'agissait d'une mission assez ardue puisque, du Rio de Janeiro du XIXe siècle, il ne restait déjà pratiquement rien dans les années soixante. La majeure partie du film a été tournée à la Casa de Rui Barbosa (musée dédié à l'un des plus grands politiciens brésiliens de la fin de l'Empire et de la Première République) dans le quartier Botafogo. Pour le reste, l'ancienne ville impériale, Petrópolis, a pu offrir un environnement plus adéquat à ce film de costumes.

975FAGUNDES TELLES, Lygia et SALES GOMES, Paulo Emílio. Capitu : Adaptação livre para um roteiro baseado no romance Dom Casmurro de Machado de Assis, Siciliano, São Paulo, 1993. 
fidèlement suivi. Les modifications introduites pendant le tournage se limitent à des critères d'économie dramatique et, peut être aussi, à des limitations matérielles dont on ne pouvait prendre conscience qu'en situation. Les choix principaux qui ont orienté le travail d'adaptation étaient les suivants. Le premier consistait, comme le changement de titre l'indique, à déplacer l'attention du public de Bentinho vers Capitu, autrement dit, de la transparence du personnage masculin à l'opacité du personnage féminin. Le second choix était de ne pas prendre partie vis à vis de la méfiance de Bentinho. Le spectateur, pas plus que le lecteur, ne saura si Capitu est une «' perfeita calculista ' desde a infância ou uma ' coitadinha ' assessiada por um ciumento obsessivo $»{ }^{976}$. Plutôt que comparer le scénario et le film, nous pourrons donc parler du livre.

Dom Casmurro, littéralement «Monsieur Maussade» ou «Monsieur le Taciturne », est le surnom de Bento, dans le livre de Machado de Assis. Bien que Bento reconnaisse dans une séquence qu'il n'est pas une personne très sociable, cet aspect de sa personnalité n'est pas exploitée plus avant dans le film. Nous n'y entendrons d'ailleurs jamais ce surnom. Les éventuelles interprétations du comportement du mari par la fragilité de son caractère sont reléguées au second plan. Le film se détache aussi de l'approche psychologique pratiquée par l'écrivain en abandonnant l'utilisation de Bento comme narrateur de sa propre histoire. Ce procédé, qui est identique à celui employé par Maupassant dans Le Horla ${ }^{977}$, permet de garder les questions sans réponse jusqu'à la fin, puisque l'histoire ne peut compter qu'avec la perspective subjective du narrateur. Le lecteur du roman se trouve ainsi confronté à deux alternatives, ou Bento est victime d'un délire de jalousie autrement dit de psychose, ou Capitu l'a effectivement trahi avec Escobar. Dans le film, nous avons un narrateur omniscient. Si, à certains moments la caméra nous montre ce que Bento voit, à d'autres, elle nous montre aussi des choses qu'il ne peut pas voir ${ }^{978}$. Le spectateur est confronté à une sorte d'aller-retour entre la perspective de Bento et une perspective sur Bento.

Un bon exemple de ce va et vient est la séquence du bal. Au cours de la quadrilha, debout au bord de la piste de danse, Bento regarde Capitu, bras nus, virevolter de cavalier en cavalier. Le jeu du champ / contrechamp nous permet de voir Capitu de la place de Bento, puis Bento de face, isolé du reste de la pièce et des autres participants de la fête par le cadrage. Une fois que l'espace a été construit par une succession de plans à partir du moment

976« [...]' parfaite calculatrice ' depuis l'enfance ou une ' pauvre femme ' tourmentée par un homme d'une jalousie obsessive. » in ibid., p. 12.

977Machado de Assis augmente la narration subjective d'interventions métalinguistiques. Bento, qui écrit sa propre histoire, expose aux lecteurs ses doutes quant à ses choix en tant qu'écrivain, il discute le titre et le choix de la métaphore pour «olhos de ressaca ». Cf. l'oeuvre originale de Machado de Assis.

978Entre autres exemples, dans la séquence de la visite nocturne d'Escobar, la caméra zoome sur le visage de Capitu, en haut de l'escalier, alors que Bento, vient de lui tourner le dos et redescend avec Escobar (planséquence).

Dans la séquence de la soirée du jeu de cartes, la caméra passe d'une pièce à l'autre et nous montre successivement Bento et Sancha sur le balcon puis Escobar et Capitu au piano. 
où Bento a donné l'autorisation à Capitu de danser sans lui, le champ de la caméra s'est resserré, dans un effet de zoom, sur le visage de Bento et sur les bras nus de Capitu. Les utilisations répétées du zoom et du gros plan nous donnent à voir les modifications qui s'opèrent sur la physionomie de Bento à mesure que le temps s'écoule. La caméra subjective qui se rapproche sans cesse du plan général au gros plan sur les bras de Capitu exprime comment son attention se focalise progressivement sur ce détail. La musique, le mouvement tourbillonnant des danseuses et le montage participent à exprimer le sentiment de vertige qui envahit Bento et la domination progressive du délire de jalousie sur son raisonnement. Le rythme de la séquence est brisé quand Bento, pris de malaise, détourne les yeux de Capitu et s'écarte dans le couloir.

Les raisons de ce malaise apparaissent clairement dans les dialogues qui suivent, d'abord entre Bento et Escobar qui s'inquiète de la santé de son ami, puis entre Bento et Capitu, quand de retour chez eux, Bento exprime son profond mécontentement envers la conduite de sa femme. La situation peut paraître incongrue aux yeux du spectateur du XXe siècle. Selon les critères modernes, la tenue de Capitu n'avait en effet rien d'indécent et pouvait correspondre à l'idée que l'on se fait d'une tenue de bal de riche bourgeoise ou de grande aristocrate du XIXe siècle. Nous apprenons cependant dans ces dialogues que Capitu a cédé à une nouvelle mode en découvrant ses bras ${ }^{979}$. Le fait que Capitu ait offert à la vue de tous une parcelle du corps féminin qui jusque là devait être cachée provoque chez Bento la honte et le doute quant à la moralité de sa femme. Premièrement, les autres ont vu une partie du corps de Capitu qu'il estime devoir lui être réservée. Deuxièmement, il voit dans cette coquetterie l'expression d'un désir de se «donner» à d'autres qu'il ne comprend pas ou comprend comme une trahison. Ainsi, quand il dit qu'il lui a profondément déplu de voir Capitu passer de mains en mains, bras nus, c'est parce qu'il a assimilé métaphoriquement la danse, qui est parfaitement codifiée et ne devrait donc pas souffrir ce genre d'interprétation, avec l'acte sexuel. Capitu manifestait le désir de «s'offrir » physiquement, par sa tenue et ses mouvements, et les autres cavaliers répondaient positivement en la « prenant » chacun à leur tour. Enfin, quand Bento dit à Capitu que Sancha, la femme d'Escobar, n'avait pas les bras nus, celle-ci ne le rassure évidemment pas en lui répondant que c'est tout simplement parce qu'elle n'a pas des bras aussi beaux que les siens.

Au cours de ces séquences comme pendant l'intégralité du film, la position de la caméra et le montage de la bande-son participent à provoquer un effet de distanciation avec le point de vue de Bento. C'est à dire que nous avons un accès privilégié à la façon dont ce 
personnage vit les événements successifs de cette histoire, comme dans les séquences précédentes, la mise en scène nous permet de comprendre parfaitement ses réactions, mais il nous est impossible de nous identifier à lui. La première cause en est ce jeu de champcontrechamp qui envahit les différents niveaux de l'organisation filmique. Nous le comprenons de la façon suivante. Le champ c'est, ce que ressent, pense ou voit Bento, et le contrechamp, c'est ce qui arrive indépendamment de son point de vue. Le fait de montrer deux aspects d'un même événement incite forcément le spectateur à la comparaison. Or, et nous en arrivons ici à la deuxième cause de l'impossibilité de l'identification, dès les premières séquences, le spectateur est forcé de constater l'absence de coïncidence entre le point de vue de Bento et le réel diégétique.

Par exemple, au tout début du film, pendant leur voyage de noces à la Tijuca, Bento et Capitu se remémorent leurs souvenirs d'enfance. Bento se souvient que José Diaz, son précepteur, a tenté de les séparer. Le fait est d'importance dans leur histoire commune mais, curieusement, Capitu ne s'en souvient pas. Plus troublant, dans le flashback que l'incident déclenche, nous retrouvons Bento et Capitu enfants. Ils n'apparaissent pas dans le champ et c'est José Diaz que nous voyons. Il croise les deux enfants dans le jardin où ils jouent et tout dans son attitude traduit au contraire la bienveillance envers eux. La séquence ne remet pas exactement à l'épisode évoqué par Bento et n'apporte pas la preuve qu'il se trompe. Cependant, son contenu est contradictoire avec une éventuelle hostilité de Diaz envers son union avec Capitu. Par la suite, nous retrouverons le précepteur âgé, compagnon de la mère de Bento, veuve depuis longtemps, et il ne manifestera jamais la moindre antipathie envers Capitu. Autre exemple, vers la fin du film, alors que Bento commence à douter que le fils de Capitu soit bien le sien et croit percevoir un changement d'attitude de sa mère envers eux qui confirmerait ses doutes, c'est Diaz qui dément formellement et lui dit franchement qu'il se fait des idées. Là encore nous ne pourrons pas nous faire notre propre idée du comportement de la mère puisqu'aucune séquence où elle serait en présence de Capitu et Ezequiel ne nous permet de juger de son comportement.

Ainsi, les désaccords de Bento avec les autres personnages sur leur interprétation du réel et l'absence de «sanction » positive ou négative pour le spectateur par le narrateur extradiégétique participe à l'établissement d'une distanciation critique constamment maintenue en alerte. Le fait que ce narrateur ne nous permette pas de nous identifier avec Bento mais ne nous apporte pas non plus la clef de l'énigme «Capitu » est à rapprocher d'un troisième élément de distanciation. Bento est un personnage du XIXe siècle et de la haute bourgeoisie carioca de son temps. Alors que dans le cinéma classique de tels éléments sont généralement exploités pour leur valeur romanesque et facilitent l'entrée du spectateur dans la fiction, ici, ils 
posent problème et nous maintiennent à la périphérie du personnage.

Le premier conflit qui s'établit avec le spectateur est, pour ainsi dire, un conflit de génération. Plusieurs épisodes sont à ce titre exemplaires. Lors de la première visite d'Escobar à Bentinho, les deux amis décident de laisser leurs deux épouses entre elles et de s'isoler dans la bibliothèque pour fumer. Capitu réclame de leur abandon et s'exclame : «Vamos aprender a fumar também !» (« Nous aussi allons apprendre à fumer !») Sancha lui dit qu'en Europe, les femmes commencent à fumer en société. Acide, Bento rétorque en se tournant vers Escobar : «Um certo tipo de mulher talvez. » («Un certain genre de femmes, peut être. ») Les femmes qui fument en société sont pour Bento des femmes de mauvaises mœurs, autrement dit des prostituées. À une époque où les femmes fument avec la même liberté que les hommes, ce préjugé de Bento ne manquera pas de surprendre.

Le même type de situation se reproduit avec l'épisode du bal. Bento se contrarie du raccourcissement des manches de la robe de sa femme comme les générations qui l'ont suivi se sont choquées du raccourcissement des jupes. Plus personne ne pourrait comprendre aujourd'hui que l'on se scandalise à la vue des genoux découverts d'un femme en tailleur. La réaction de Bento aux bras nus de sa femme est conçu pour provoquer le même sentiment d'étrangeté. La thématique vestimentaire devrait aussi rappeler au spectateur des années soixante la polémique à laquelle il est contemporain. La mode des mini-jupes soulève en effet la colère des ligues bien pensantes qui comptent pourtant, dans leur propre rang, des femmes qui ont adopté les raccourcissements de manche et de jupe autrefois jugés outrageants. C'est cette incohérence sur laquelle Saraceni voudrait attirer l'attention tout en insistant aussi sur le caractère machiste de ces résistances successives à l'expression de la liberté féminine.

Les polémiques sur les modes vestimentaires féminines ne sont évidemment que le symptôme d'un problème plus grave qui est la liberté de la femme à disposer d'elle-même. Quand Sancha répond à Capitu qu'il y a en Europe des femmes qui fument, elle veut dire que rien d'autre ne les empêche de fumer que l'habitude de ne pas le faire. Bento aussitôt indique que celles qui s'aventureraient à changer cette habitude transgresseraient une norme sociale et donc s'excluraient d'elle-même de la société. Quand il dit qu'il n'y a que « certaines » femmes qui fument en public, il veut dire que ce sont des femmes de mauvaises mœurs, des femmes qui ne bénéficient plus de la considération des hommes. Le caractère arbitraire de l'interdiction qu'il fait aux femmes de fumer ne peut pas échapper au spectateur. À partir de là, la valeur de son intervention se résume à une manifestation de pouvoir. De même, toutes les contrariétés ressenties par Bento dans sa relation à Capitu s'expliquent avant tout par le fait qu'il sente son empire sur elle menacé. La question de l'adultère devient alors aussi une question de pouvoir. 
Si Capitu a eu de relations sexuelles avec Escobar, le fait est passé inaperçu aux yeux de tous et n'a pas modifié la vie du couple. D'un point de vue pragmatique, l'événement n'a pas reçu de sanctions sociales d'exclusion, comme celles sous-entendues au sujet de l'acte de fumer, et n'a pas altéré la réalisation du couple comme le montre la séquence de bonheur conjugal qui précède la mort d'Escobar. Ce qui contrarie Bento, c'est donc que sa femme échappe à son contrôle et non le fait, toujours incertain, qu'elle l'ait déshonoré. Il ne supporte pas que celle-ci sorte de la relation objectivée dans laquelle il cherche à la maintenir et parvienne à la condition de sujet, autrement dit, qu'elle puisse être l'exercice d'une liberté. Bento va faire son malheur et celui de sa famille pour la simple raison qu'il ne peut dominer complètement Capitu. Aussi, le spectateur qui focaliserait sur l'incertitude qui demeure quant à l'adultère applique un schéma moraliste à une œuvre qui vise justement à critiquer ce genre d'attitude. Ce qui est important dans Capitu, ce n'est pas que l'épouse ait « trahi », ce qui est important c'est que le mari ne puisse pas le savoir et qu'il devrait accepter de ne pas pouvoir le savoir. Cet abandon constituerait le deuil de l'illusion de sa toute-puissance sur sa femme, il signifierait la reconnaissance de sa liberté et contribuerait sans aucun doute à un mieux-être.

Cette interprétation de la relation entre Bento et Capitu n'est possible que dans le film, grâce à la spécificité du régime narratif adoptée par Saraceni en comparaison au roman et à cette distanciation qu'il instaure entre Bento et le spectateur. Les effets de la distanciation d'avec Bento vont cependant plus loin que la simple reconnaissance de la liberté de l'épouse. $\mathrm{Au}$ «conflit de génération » évoqué plus haut, se greffe un conflit de classe. Comme si la scénographie et les costumes ne suffisaient pas à le montrer, Escobar, au début du film rappelle à son ami qu'il est riche, très, très riche. Bento appartient à la haute bourgeoisie carioca de son temps, héritier de la fortune de son père, il fait partie de cette première génération des classes dominantes à s'être installée en ville. Pour autant, Bento conserve les habitudes de l'aristocratie rurale et l'un de ses traits les plus caractéristiques est la possession d'esclaves. Certains plans du film illustrent cette question de la hiérarchie sociale.

Le premier, dans la séquence du déjeuner sur l'herbe, est celui qui nous donne à voir pratiquement côte à côte la mère de Bento, habillée dans une robe noire à manche longue et au col serré, et la nounou d'Ezequiel, une femme noire habillée dans une robe blanche sans manche et décolletée. Cette esclave anonyme que nous ne voyons qu'une fois et dont nous reconnaissons immédiatement le rôle, est évidemment l'objet d'une grande indifférence. Son rôle est d'apparaître au moment où l'on a besoin d'elle et d'être invisible le reste du temps. Il faut qu'elle soit discrète et se cantonne à sa tâche. Son entrée dans le plan montre d'ailleurs très bien cette qualité à s'effacer, elle n'est là qu'au moment où on l'appelle. Le fait qu'elle ait ou non les bras nus n'a guère d'importance puisqu'en tant qu'esclave, elle n'est l'objet d'aucune 
considération. L'extrême rigueur du costume de la mère crée un contraste avec celui de l'esclave qui est bien mieux adapté au climat tropical. Dans ces différences entre les habits et la conduite de la mère et de l'esclave surgissent tout un ensemble de codes qui s'articulent à la dialectique connue du maître et de l'esclave.

Le maître, pour manifester sa supériorité hiérarchique, doit se soumettre lui-même à un ensemble de contraintes dont le but est de le distinguer de l'esclave. Les éléments de cette distinction sont fondés sur des préjugés racistes. L'esclave est un être fruste et amoral, un sauvage mal adapté aux règles de la civilisation. Parmi les contraintes que le maître s'impose, apparaît le respect de certains codes vestimentaires. Le maitre adopte la mode européenne pour se distinguer de l'esclave car l'Europe est considérée comme étant le foyer de la civilisation. Au début de la séquence où Escobar est retrouvé noyé, un esclave vient avertir Bento. Dans le plan qui les réunit, le rôle du costume comme vecteur de distinction sociale ressurgit. Bento, dans un costume trois-pièces, est dans une position surélevée par rapport à l'esclave qui est le torse nu. Porter de tels vêtements alors que la température dépasse quotidiennement les trente degrés est une lourde contrainte. Une fois de plus les habitudes vestimentaires en disent long sur la culture et la psychologie. L'astreinte que représente le fait de porter de tels habits en dit long sur la capacité d'une classe à réprimer une part de son humanité pour se convaincre de sa supériorité.

Il en ira donc des vêtements comme de la sexualité. Si Bento ne peut pas supporter que Capitu soit libre, c'est aussi qu'il est jaloux de cette liberté ou qu'il en a peur pour lui-même. Assimilée à une pulsion animale dans la morale chrétienne, l'assouvissement du désir sexuel est considéré humainement dégradant. Bento, qui dans l'enfance a cultivé la vocation de la prêtrise et n'a renoncé à ses études aux séminaires que pour Capitu, est garant de cette morale. Quand il dit à Escobar qu'il désapprouve cette nouvelle mode des bras nus, il se conçoit luimême comme un puritain. Mais cette identité lui impose de se réprimer lui-même dans la séquence où, seule avec Sancha sur le balcon, celle-ci appuie avec insistance sa main sur la sienne, sous un pretexte anodin, et que celui-ci s'en trouve troublé. Il s'isole ensuite dans son bureau et fantasme sur cet adultère. Le lendemain matin, au réveil, quand Capitu lui demande s'il n'a jamais désiré une autre femme, il répond évidemment que non.

Finalement, c'est la charge démesurée de cette culture de répression du corps et de la sexualité qui va conduire au drame. En plus de la distanciation d'avec Bento que la narration $\mathrm{du}$ film nous impose, une autre distanciation d'avec l'ensemble de l'histoire cette fois, est introduite par le générique et les cartons qui se superposent à la première séquence de la nuit de noces. Ces cartons qui nous rappellent la définition traditionnelle du mariage, nous incitent à comparer la teneur des compromis assumés par les jeunes mariés avec ce que sera 
effectivement leur vie de couple. Sur ce sujet, les différences entre la fabula du récit littéraire et celle du récit cinématographique sont significatives.

Bento, dans Dom Casmurro, raconte toute l'histoire avec une certaine dose d'autodérision manifeste notamment dans le choix du titre. Il est déjà un vieillard et focalise son récit sur la période de l'adolescence ${ }^{980}$. C'est cette époque de sa vie à laquelle il est le plus attaché et il va occuper plus de la moitié du roman à conter comment les liens avec Capitu, qui était déjà son amie d'enfance, se sont graduellement resserrés jusqu'à ce qu'il prenne conscience qu'il l'aimait et que la décision du mariage soit prise. Cette partie du roman met à jour des éléments de la caractérisation des personnages et des conflits qui alimentent la réflexion du lecteur quant à la personnalité de la jeune fille. La mère de Bento, Dona Glória, avait connu deux grands tragédies dans sa vie. La première était d'avoir eu un premier enfant mort-né, la seconde, d'avoir perdu son mari alors que Bento n'était pas encore entré à l'école. Après la perte de son premier enfant, dans l'anxiété de ne pas pouvoir être mère, elle avait promis à Dieu de donner à l'Église son deuxième enfant s'il lui accordait d'en avoir un. Bento, depuis sa naissance, était donc destiné au séminaire. Cette promesse fut néanmoins constamment repoussée par la mère qui, devenue veuve, répugnait à se séparer de son fils. C'est dans cet intervalle de temps où Bento aurait déjà dû être au séminaire que se glisse Capitu. Dès le troisième chapitre, José Diaz avertit Dona Glória qu'une éventuelle idylle entre Bento et Capitu pourrait contrarier ses projets et sous-entend que la jeune fille, de condition modeste, est calculatrice et que son intérêt serait de séduire Bento à des fins de promotion sociale. Les autres personnages n'accordent pas de crédit aux prédictions de Diaz.

Comme nous l'avons montré, Bento n'est pas le narrateur de Capitu. La narration de la fabula n'est pas enchâssée dans un énorme flashback. Il n'existe donc pas de recul de Bento sur lui-même et le spectateur suit les événements de la fabula quand ils se produisent. Au contraire du roman, le récit ne commence pas quand Bento a 15 ans et Capitu en a 14, il commence quand ces deux personnages, déjà adultes, se marient. La bande-son du générique du début est composée par une musique religieuse de mariage et la première séquence est celle de la nuit de noces avec les cartons évoqués plus haut. Au contraire du narrateur du roman, le narrateur du film met l'emphase sur la réalisation du mariage et non sur celle du couple. Il s'agit d'une différence de taille. La réalisation du couple est effective à partir du moment où Capitu et Bento ont reconnu leur amour l'un pour l'autre et ont pris la décision de vivre ensemble. La réalisation du mariage passe par la reconnaissance sociale du couple et l'assentiment des autres à leur union, sanctionnée par la cérémonie et l'obtention du statut de

980Le début du récit est daté, il commence en 1857. Cf. « Capítulo III : A Denúncia » in ASSIS, Joaquim Maria Machado de. Dom Casmurro. Rio de Janeiro, Ediouro, 1986. 
mari et femme, puis, par l'évaluation du respect des engagements contractés au moment de la cérémonie, tout au long de la vie du « mariage », qui peut finir avec la rupture du couple ou la mort des conjoints. La réalisation du mariage est autrement plus complexe que celle du couple $^{981}$. En général, le cinéma s'intéresse plutôt à la réalisation du couple qui, de façon classique, est suivi par un mariage. Comme dans les contes pour enfants, la partie la plus difficile est résumé par la formule consacrée : «Ils vécurent heureux et eurent beaucoup d'enfants ». Capitu commence là où la plupart des comédies romantiques finissent.

Malgré quelques flashbacks portant sur des événements très ponctuels de l'enfance et de l'adolescence de Bento, les conflits développés dans la première partie du roman sont totalement absents du film dans lequel Dona Glória et José Diaz ont d'ailleurs des rôles très secondaires. Ainsi, si nous savons que Bento a nourri pendant longtemps la vocation à être prêtre, l'intérêt de la mère à ce que cette vocation s'accomplisse n'apparaît pas. Il n'y a donc pas de conflit entre la mère et Capitu qui puisse faire douter qu'elle soit une belle-fille modèle. Il n'y a pas non plus dans le film cette ambiguïté sur les véritables objectifs de Capitu remettant au caractère vénal et sensuel de la femme. Rien ne nous est dit sur une éventuelle différence d'origine sociale entre Bento et Capitu et son intérêt à réaliser un bon mariage, cas de figure connu au Brésil par l'expression «golpe do baú » ${ }^{982}$ qui est évidemment très péjorative. Alors que dans le roman, il va toujours peser le soupçon selon lequel la coquetterie de Capitu fait partie d'un plan de séduction, dans le film, l'absence de l'exposé de possibles bas intérêts exclue une telle interprétation. La coquetterie de Capitu n'est alors rien de plus que l'expression de sa féminité et c'est elle seulement qui pose problème. Capitu apparaît constamment au spectateur de cinéma comme une épouse aimante et dévouée soucieuse du bien-être de son mari. Comme lui cependant nous pouvons douter de sa parfaite fidélité mais ceci, dans des circonstances bien particulières.

Dans le livre comme dans le film, un seul élément concret penche pour l'hypothèse de l'adultère. La ressemblance entre Ezequiel et Escobar. Cette ressemblance n'est pas évidente pour le spectateur qui voit un petit garçon blond, comme le meilleur ami de Bento, alors que ses deux parents sont bruns. Sur cet élément, et seulement sur celui-ci, la perception de Bento

981Dans l'absolu, la réalisation du couple peut être très brève et ne comporte pas de réel engagement entre les conjoints. Un couple est réalisé à partir du moment où, à un instant « $\mathrm{t}$ », deux personnes se sont unis. Le fait qu'ils se séparent l'instant d'après ne remet pas en cause le fait que le couple se soit réalisé puisqu'il y a effectivement eu union.

982Littéralement : « Le coup de la commode », autrement dit le vol des biens familiaux par l'intermédiaire de la séduction et du mariage. Le sanctuaire de la famille est violé par l'intrusion d'un personnage aux basses intentions. Il va évidemment dans cette expression d'une bonne dose de préjugés sociaux et d'hypocrisie. Les familles bourgeoises répugnent en fait aux mariages en-dehors de leur classe et préfèrent de loin le scénario de deux fortunes qui s'unissent à celui d'une fortune qui se divise. Le premier cas de figure est jugé respectable et moins le second. La sincérité de tout prétendant à une fortune plus élevée que la sienne sera donc a priori remise en doute mais pas celle de celui qui veut unir deux fortunes égales. 
recevra la sanction positive d'un tiers. Dans l'avant-dernière séquence, Capitu reconnaît que cette ressemblance existe sans toutefois admettre l'adultère. D'autres éléments alimentent les présomptions quant à la réalisation de l'adultère. Le premier est cette séquence où, bien des années plus tôt, Bento qui revient du théâtre, retrouve son ami sur le pas de sa porte en pleine nuit. Ce soir-là, alléguant qu'elle était lasse, Capitu avait refusé d'aller au théâtre pour assister à une représentation pour laquelle une loge avait été réservée de longue date. Le prétexte n'est pas très consistant, Bento est surpris et part tout seul. Au cours de la représentation, il s'inquiète et quitte la salle de spectacle avant la fin de la pièce. De retour à son domicile, il retrouve Escobar sur le palier. Celui-ci, fébrile, s'inquiète de la rétractation d'un témoin dans une affaire de justice qui le concerne. Bento qui est aussi son avocat, le rassure. Ils montent ensemble pour prendre des nouvelles de Capitu qui apparemment va bien. Quand ils redescendent, un plan rapproché de Capitu nous permet de saisir sur son visage une expression inquiète que les deux autres personnages, qui ont déjà le dos tourné, ne peuvent pas voir. Escobar prend congé brusquement.

Dans cette séquence, les motivations de Capitu et Escobar paraissent peu solides et peuvent passer pour les alibis fragiles d'une rencontre secrète arrangée à l'avance. Bento s'étonne du refus de Capitu de l'accompagner au théâtre comme il s'étonne de l'agitation d'Escobar mais il ne nourrit pas encore de soupçons quant à la fidélité de sa femme. Ce n'est que plus tard dans le film qu'il se souviendra de cet incident comme d'une preuve de la culpabilité de Capitu. À ce moment-là, ce n'est pas Bento qui doute de la fidélité de Capitu mais nous, spectateurs du film. Nous en doutons depuis le début peut être, sans doute à cause de ce que Saraceni appelle lui-même une mise en scène "érotisée » et qui a consisté à conserver par toute une série d'éléments filmiques l'enjeu de la possession sexuelle de la femme par le mari comme un défi sans cesse renouvelé. Bento est constamment confronté au vertige d'un combat particulier dans lequel le corps de sa femme est à la fois obstacle et trophée.

Ce combat est particulier car sans opposant, pire encore que de ne pas rencontrer de résistance, le désir de sa femme pour lui est manifeste, et son désir à elle de consommer l'acte sexuel est effrayant. Il est effrayant pour deux raisons. La première est qu'il est l'expression d'une individualité irréductible et la seconde est qu'il représente pour Bento l'expérience de l'altérité. Or, comme nous le savons bien, la sexualité féminine est le point obscur de la connaissance de l'homme et pour cela elle lui fait peur. De là à inférer que l'homme a toujours tenté de circonscrire la liberté de la femme pour tenter de dominer sa sexualité, il n'y a évidemment qu'un pas. Si, dans l'acte sexuel se réalise la fusion, celle-ci est extrêmement ponctuelle et, après la réalisation de cet acte, le corps de la femme a retrouvé dans la 
perception de l'homme son indépendance et sa disponibilité, pour lui, évidemment, dont le désir va bientôt revenir comme s'il n'avait jamais été satisfait mais pourquoi pas aussi pour d'autres puisque le désir de la femme est autonome et qu'il est pour son partenaire un mystère.

Nous avons deux séquences qui expriment parfaitement cette tension sexuelle entre Capitu et Bento, celle de la nuit de noces et celle du retour du bal. Lors de la première séquence, Capitu, en chemise de nuit, et Bento, se tiennent face à face, à côté du lit. Dans la deuxième séquence, Bento après avoir tenté de gronder sa femme, marque un temps d'arrêt, le visage soudainement décomposé, quand celle-ci, hors-champ lui apparaît nue ${ }^{983}$. Cette érotisation de la mise en scène est également présente dans les séquences où les deux couples sont réunis. Dans la première, Escobar lit dans les lignes de la main de Capitu et en profite pour la complimenter. Difficile de ne pas penser qu'il s'agit d'un truc de séducteur, Bento aussitôt lui demande de faire de même avec les lignes de sa main. Une légère pose est perceptible avant qu'Escobar n'accepte, comme si quelque chose d'important se jouait à cet instant. En fait, cela pouvait bien sûr ne représenter que le temps de la réflexion pour trouver quelque chose de spirituel à dire sur la main de Bento. Enfin, la séquence de la promenade sur la plage, où les deux couples sont réunis pour la dernière fois avant la mort d'Escobar, est particulière.

Escobar, avec un air distant, marche près de l'eau, détaché du reste du groupe, Sancha, Capitu, Bento, Dona Glória et José Diaz. Sa fille, appelé Capitolina en l'honneur de Capitu, et Ezequiel, nommé ainsi en hommage à Escobar, marchent en tête. Sancha commente qu'ils pourraient connaître le même destin que Bento et Capitu. Dona Glória et José Diaz sont en retrait. Bento paraît satisfait. Le ciel, en contre-plongée, apparaît couvert et strié de lumière. Cette séquence annonce la mort d'Escobar qui va périr noyé le jour suivant, trois séquences plus tard. Elle marque aussi un point culminant dans la complexité des relations qui unissent les deux couples et la condensation des tensions sexuelles. Le soir, dans la séquence du jeu de cartes, l'échange de partenaires est symboliquement consommé. Escobar, qui a gagné la partie s'isole avec Capitu à côté du piano et Bento, se retrouve sur le balcon avec Sancha qui pose la main sur la sienne. Après cette séquence, seule la mort d'un des quatre personnages peut interrompre le processus qui s'est engagé.

Bien que certains événements soient présents dans le livre comme la main de Sancha sur celle de Bento et le désir de celui-ci pour elle, cette dimension érotique de la mise en scène ne pouvait appartenir qu'au cinéma. La conclusion du récit cinématographique est quant à elle différente de celle du roman. Le retournement de l'attitude de Bento envers Capitu se produit exactement au même moment dans les deux récits. La prise de conscience de Bento a 
la soudaineté d'un insight lors de la veillée funéraire d'Escobar. Dans Dom Casmurro, ce sont les larmes de Capitu et l'intensité de l'un de ses regards vers le défunt qui convainquent brusquement Bento que sa femme a été l'amante de son meilleur ami ${ }^{984}$ et que ce dernier est le véritable père de son fils. Dans le film, rien dans l'attitude de Capitu au cours de la veillée funèbre ne trahit la particularité de sentiments qu'elle aurait nourris envers le défunt. Le changement d'attitude de Bento ne s'explique pas par un événement précis. Dans le livre comme dans le film, pendant les jours qui suivent l'enterrement, Bento s'isole de Capitu. Fou de jalousie, il hésite alors entre l'assassiner et se suicider.

Un matin, après avoir pris la décision de se donner la mort, il verse un poison dans une tasse de café en même temps qu'il écrit sa lettre d'adieu. Incapable de conclure la rédaction de sa lettre, il est surpris par Ezequiel qui doit partir à la messe avec sa mère. À ce moment-là, une idée horrible traverse l'esprit de Bento, assassiner l'enfant. Dans le livre, il se rétracte juste avant de faire boire café au petit garçon, dans le film, il le lui fait boire. Dans les deux récits, Capitu arrive et s'étonne de son agitation. Il lui dit qu'Ezequiel n'est pas son fils, elle est offensée, se défend mais, devant son obstination, elle demande la séparation puis s'en va avec l'enfant à la messe en reprochant à son mari de ne pas réellement croire en Dieu. Le film s'arrête là, Ezequiel, condamné à mort, part à l'église avec sa mère. Dans le livre, Ezequiel et Capitu reviennent de la messe, Bento arrange ensuite leur exil en Europe, sous le prétexte des études du fils, et les abandonne là-bas. Bien plus tard, après la mort de Capitu, Ezequiel qui ignore tout du refus de paternité de Bento, le retrouve brièvement avant de repartir en Afrique où il trouve la mort.

Dans le film, l'hypothèse de la psychose de Bento ne peut donc pas être écartée mais elle vient en second lieu dans la liste des interprétations possibles. La gravité de sa vengeance déplace en effet l'appréciation du spectateur de la psychose vers le crime passionnel. La jalousie de Bento devait trouver un exutoire pour calmer se frustration à ne pas avoir pu contrôler totalement Capitu. Il a d'abord pensé à se tuer car son premier réflexe était logiquement de sentir sa virilité remise en cause par cette incapacité à être, réellement, le maître de sa femme. Il pense ensuite à assassiner Capitu, la véritable coupable, puisqu'elle a enfreint les vœux du mariage. Le meurtre de l'enfant, qui lui est innocent, de toutes les solutions, est la plus cruelle. La mort d'Ezequiel est censée évidemment punir Capitu par là où elle a « péché » et la priver de la compagnie continue d'Escobar à ses côtés. Il est aussi un acte de négation de la vie.

Mais, quand bien même l'hypothèse de la «trahison » de Capitu serait vérifiée, qui, d'elle, de Bento ou même d'Escobar, serait, devant Dieu et les serments du mariage, le 984« Capítulo, CXXIII, Olhos de ressaca » in ibid. 
véritable coupable du dénouement dramatique de leur histoire ? Il faut appliquer au jugement du comportement des personnages le cadre qu'ils s'imposent à eux-mêmes. Bento, ne l'oublions pas, est un ex-séminariste, et, à plusieurs moments, il démontre clairement posséder pour lui-même l'image d'un personnage respectant les « bonnes mœurs ». Cette rigidité qui est une imperméabilité au doute et à la remise en question, témoigne paradoxalement d'une exclusion totale de la présence de Dieu dans sa façon de voir et d'agir le monde. Bento ne peut accepter que le réel échappe à la réification logique et morale qu'il cherche à lui appliquer, les contradictions humaines ou même l'expression de désirs contradictoires aux normes préconçues qu'il croit devoir être respectées, sont pour lui une source d'anxiété mortifère. Ainsi, le fait qu'il assiste à Othello après la mort d'Escobar, aussi grotesque cela puisse-t-il paraître, joue le rôle de déclencheur avant le passage à l'acte. Si Othello assassine Desdémona sur la seule foi d'un mouchoir alors qu'elle n'est pas coupable, il peut bien punir à son tour Capitu avec beaucoup plus de cruauté puisqu'elle, il en est sûr à présent, est coupable.

Le refus de l'incertitude, le refus de reconnaître aux personnes qui lui sont les plus proches une part de mystère et l'application d'une logique sans conscience entraînent Bento à trahir les fondamentaux de sa propre morale : il tue dans son cœur son affection pour Escobar, il détruit la vie de Capitu et assassine son propre enfant. Plus que tous les autres, il met bas les vœux prononcés lors du sacrement du mariage. En dernière instance, son attitude trahit aussi son incapacité à s'en remettre à Dieu pour toutes les choses sur lesquelles il ne peut pas agir. Ainsi, il faut se souvenir, au début du film, bien avant la naissance d'Ezequiel, de la séquence où il confie à Escobar son angoisse de ne pas réussir à avoir un enfant, la seule chose qui lui manquait pour que son bonheur avec Capitu soit complet. Il semblait presque implorer à demi-mot son ami de lui donner ce qu'une éventuelle stérilité le rendait incapable d'avoir. L'hypothèse du don de l'enfant par l'intermédiaire d'un pacte secret entre Escobar et Capitu peut alors être évoquée. D'autant plus que les dernières paroles de Capitu à Bento résonnent de façon étrange avec ce qu'avait alors dit Escobar. Au «Deus dará » d'Escobar répond en effet les reproches de Capitu quant au fait que Bento, dans le fond, ne croirait pas vraiment en Dieu.

Dans Capitu, c'est donc l'absence de foi qui transforme Bento en infanticide. Le spectateur est contraint d'adopter une position critique vis à vis du personnage de façon d'autant plus forte que l'enfant, que son père «biologique » soit ou non Escobar, est bien celui que Dieu a confié à Bento. C'est par rapport à son propre référent moral que Bento est coupable. Or, ce référent est dans les années soixante, encore largement partagé par de larges fractions de la population et des classes bourgeoises, qui, sous le prétexte du respect de l'ordre et de la morale, empêchent le nouveau Brésil de se développer. Le lien entre conservatisme 
culturel et politique n'est pas explicitement traité dans Capitu mais il n'en est pas moins présent. Dans Terra em transe, la présence de Diaz aux côtés de l'indien, du conquistador et de la croix dans une allégorie de la découverte du Brésil, permettait de condenser passé et présent et d'indiquer que Diaz était le continuateur de la tradition coloniale. Les valeurs de la civilisation occidentale, le christianisme, le rationalisme et le technicisme ${ }^{985}$, sont imposées $a$ priori par l'élite coloniale à un espace géographique et humain sans que soit pris en compte les spécificités de cet espace.

Dans Capitu, le caractère aberrant du comportement de Bento dans la sphère domestique renvoie de façon métonymique à un mode de conception du monde qui s'applique aussi bien aux affaires privées que publiques. Le fait que le personnage appartienne à la haute-bourgeoisie coloniale du second empire n'est pas un hasard. La fragmentation sociale est clairement signifiée par le rejet hors-champ de tout ce qui ne compte pas dans sa représentation du monde, l'humanité de ses propres esclaves, l'espace physique situé endehors des espaces du personnage caractérisées par le calme, le luxe, les mondanités et toute une culture d'importation européenne. L'aliénation culturelle du personnage est totale, contrairement au livre où il part plusieurs fois à la rencontre de «l'homme de la rue ». Si, dans Terra em transe, Diaz participe d'une allégorie visant à dénoncer la tradition coloniale, Bento en est un authentique acteur. Dans les déclarations de Saraceni comme dans sa filmographie à venir, en particulier A Casa assassinada et José Anchieta do Brasil, il est tout à fait clair que la condamnation du moralisme de Bento devait remettre à celle de sa classe au XIXe et au XXe siècle et au fait que celle-ci ignore et opprime le Brésil authentique, celui du métissage ethnique, culturel et social, du syncrétisme religieux et de la libération sexuelle.

Les enjeux de la libération sexuelle sont d'ailleurs au Brésil plus forts qu'en Europe. Dans la mesure où le moralisme chrétien est conçu comme allant de pair avec l'oppression culturelle, sociale et économique du système colonial, l'émancipation nationale doit nécessairement passer par sa remise en cause. Avec Como era gostoso o meu francês cette contestation de la morale chrétienne reviendra par l'intermédiaire d'un indianisme revisité. Pour en revenir à Capitu, selon le propre aveu de Saraceni dans son autobiographie, à l'exception de Miguel Borges dans un article paru dans la Revista Civilização brasileira, aucun critique n'aura su mettre en relation le long métrage avec le thème de la libération sexuelle et comprendre tout son potentiel subversif ${ }^{986}$.

Privé du support d'un carrière festivalière par les événements de mai $1968^{987}$, Capitu

985Le terme « technicisme » est entendu ici comme la tendance à accorder à la technique, à la technicisation une place prédominante dans l'ensemble des activités.

986SARACENI, Paulo César. Op. cit., p. 226.

987La tournée européenne de Saraceni est, d'un point de vue commercial, gâchée par l'annulation du Festival de 
rencontre peu d'écho et s'inscrit en creux dans une filmographie autrement largement commentée. La violence des affrontements politiques au Brésil et dans le monde contribue à faire sous-estimer ce film qui est vu comme une simple histoire de jalousie sans aucun lien avec l'urgence du moment. L'un des rares commentaires que nous avons trouvé sur Capitu, illustre bien l'état d'esprit de l'époque. Dans un article ambigu d'Armindo Blanco pour le journal $O$ Globo, l'auteur traite de façon globale du Cinema Novo et passe sans transition d'arguments en sa faveur à d'autres arguments en sa défaveur. Sur Capitu, il écrit :

«Entre a guerra ao consumo fácil desencadeada pelo cinema vietcong de Godard (filmes baratos, elitistas no fundo e na forma) e a busca do sucesso a qualquer preço, persiste uma filosofia antipopular de que é paradigma Paulo César Saraceni, deixando em suspenso uma interrogação urgente : se certos autores de filmes não amam o povo como pode o povo amar os seus filmes ? $\gg^{988}$

La sophistication du long métrage est jugée comme la manifestation d'une mentalité élitiste et donc aussi bourgeoise. Le raccourci semble quelque peu absurde si nous observons qu'en contrepartie il signifie qu'une œuvre artistique populaire devrait forcément être simpliste alors même que l'histoire montre que les productions artistiques populaires atteignent fréquemment un niveau de complexité tout à fait remarquable quelque soit le pays ou la culture considérée. Ainsi, celui qui se pose comme le défenseur des intérêts du peuple adopte un point de vue tout aussi méprisant que celui qu'il critique et nous retombons dans les débats sans fin de l'époque où chacun accuse l'autre d'être le plus « aliéné ». Il nous semble quant à nous que l'intégrité de la démarche artistique de Saraceni n'est pas contestable. Si son point de vue et son esthétique trahissent ses origines sociales, la réalisation et la distribution de Capitu peuvent difficilement passer pour des actes nuisibles à l'émancipation du peuple brésilien. La dureté de la critique ne peut s'expliquer que par le climat des passions exacerbées de l'époque et la foi disproportionnée dans le pouvoir et la signification culturelle d'un film isolé. Un film, tout au plus, apporte à ses spectateurs la possibilité de réfléchir le réel, Capitu offre bien cette possibilité. Cela peut paraître peu face à l'urgence de certains enjeux politiques, mais cela représente beaucoup au regard d'une production cinématographique qui, dans sa majorité, n'offre pas cette possibilité.

Cannes et la confusion régnant alors en France. Le cinéaste perd la copie du film lors de son passage dans notre pays et continue son voyage en Europe sans pouvoir montrer Capitu dans les autres pays où il se rend (Allemagne, Italie, Tchécoslovaquie). Cf. SARACENI, Paulo César. Op. cit., p. 241.

988 « Entre la guerre à la consommation facile déclenchée par le cinéma vietcong de Godard (des films bon marché mais élitistes dans le fond et la forme) et la recherche du succès à tout prix, il persiste une philosophie anti-populaire dont le paradigme est Paulo César Saraceni, laissant en suspens une question urgente : si certains auteurs n'aiment pas le peuple, comment le peuple peut-il aimer leurs films ? » in BLANCO, Armindo. «Sôbre o penoso diálogo entre filmes e público » in $O$ Globo, Rio de Janeiro, 02/09/1968. 


\subsection{Fome de amor}

Fome de amor est un film de Nelson Pereira dos Santos, tourné en 1967 et sorti en juin 1968. L'idée principale du long métrage repose sur l'emploi de l'actrice Leila Diniz qui est alors en passe de devenir au Brésil l'icône pop de la révolution sexuelle. Née en 1945, Leila Diniz commence à jouer la comédie sous l'impulsion de son premier mari, le metteur en scène de théâtre et bientôt de cinéma, Domingos de Oliveira. Elle débute dans une pièce pour enfants en 1964, enchaîne très rapidement pour des rôles dans des telenovelas et participe à des émissions de télévision. En 1966, Oliveira lui offre le rôle principal dans son premier long métrage, Todas as mulheres do mundo. Cette comédie sentimentale devient le plus grand succès de cinéma de l'année 1967 et fait de son actrice une authentique star. En à peine sept ans de carrière (Diniz meurt tragiquement dans un accident d'avion en 1972), l'actrice jouera dans 14 films, 12 telenovelas et plusieurs pièces de théâtre. C'est cependant avant tout par son style de vie et ses déclarations à la presse que la jeune femme va marquer son époque. Todas as mulheres do mundo est en fait un hommage rendu à un amour déjà fini. Quand Oliveira réalise ce film, sa séparation avec sa Diniz est consommée. Jeune, belle et dotée d'une forte personnalité, celle-ci va s'afficher comme une femme libérée et anti-conformiste capable d'évoquer sans tabou une vie sexuelle active et étrangère au respect des « bonnes mœurs ». La société bien pensante est choquée par l'emploi fréquent de gros mots dans sa façon de parler et quelques déclarations provocantes comme : «Trepo de manhã, de tarde e de noite » (« Je baise le matin, l'après-midi et la nuit ») ou encore « Você pode muito bem amar uma pessoa e ir para cama com outra. Já aconteceu comigo » («Vous pouvez très bien aimer une personne et coucher avec une autre. Cela m'est déjà arrivé »).

Une autre de ses déclarations éclaire peut être mieux l'état d'esprit de l'époque : « [...] só me arrependo do que deixei de fazer por preconceito, problema e neurose. » («[...] je ne me repens que de ce que je n'ai pas fait en raison de préjugés, d'empêchements ou de névrose »). Les faits les plus marquants de la carrière de sex symbol de Leila Diniz sont en fait postérieurs à la réalisation de Fome de amor. Il s'agit de l'entrevue accordée au journal satirique $O$ Pasquim en 1969 et de photographies qui la montre enceinte, en bikini, sur la plage d'Ipanema en 1971. L'entrevue parue dans O Pasquim servira de prétexte à l'instauration de la censure préliminaire de la presse par le ministre de la justice Alfredo Buzaid. Cette mesure sera connue sous le nom « décret Leila Diniz ». Détestée par la droite, poursuivie par la police politique, elle doit se cacher pendant un certain temps entre 1969 et 1970. Avant tout cela, sa personnalité marque profondément les réalisateurs du Cinema Novo. Santos la fait 
tourner dans Fome de amor et Azyllo muito louco, elle fera aussi une courte apparition dans Amor, carnaval e sonhos (1972) de Saraceni, celui-ci et Rocha, dans leurs écrits respectifs, lui rendront d'ailleurs un hommage ému, enfin elle épouse Ruy Guerra à qui elle donne une fille en 1972. Fome de amor ne peut pas être compris sans que ne soit pris en compte la force de Leila Diniz comme icône de la libération sexuelle et sujet de l'admiration des cinemanovistas. Cette force, tout entière fondée sur des éléments extra-diégétiques, donne raison à son personnage sur les autres et éclaire l'ensemble du dispositif filmique.

Dans Fome de amor, Leila Diniz joue son propre rôle, celui d'une femme libérée et provocante. Son intervention va servir la critique d'une prétendue élite gauchiste qui entretenait un certain nombre de mythes sur le peuple, la guérilla et les grandes figures révolutionnaires comme Che Guevara tout en s'aliénant le réel. Le film prolonge la critique déjà présente dans Terra em transe du révolutionnaire fanatique qui obéit beaucoup plus à des impulsions intimes et moralistes qu'à un véritable goût de rencontre et de construction avec le peuple qui demeure irréductible et inconnu. L'échec des guérillas est prévu non pas par la condamnation morale de la violence mais par la critique des présupposés moraux et psychologiques de ceux qui seraient prêts à y participer. Il en va aussi du rejet de la croyance selon laquelle les problèmes sociaux, politiques et économiques du Brésil pourraient être réglés par l'intermédiaire d'un événement historique rapide et violent au cours duquel des personnages d'exception assumeraient la responsabilité des transformations nécessaires à l'émancipation du pays.

Le huitième long métrage de Santos est un film politique sur la politique qui légitime les films du versant culturel du Cinema Novo comme Capitu. Le véritable rôle du cinéma apparaît alors comme la nécessité de discuter le présent plutôt que de rechercher des résultats politiques immédiatement observables. Alors que toute la gauche de l'époque hésite entre la lutte armée et un travail de conscientisation ramené à des ambitions bien plus modestes que par le passé, le Cinema Novo choisit, dans la pratique, la conscientisation et rejoint la position du PCB consistant à se défier des chances de succès de la guérilla. L'idée de conscientisation se greffe de nouveau sur celle de la libération sexuelle. Fome de amor possède un sous-titre explicite Você nunca tomou banho de sol inteiramente nua ? La question peut paraître déplacée et même étonnamment superficielle mais il y a bien dans le déshabillage et l'exposition du corps nu, l'idée de l'implication dans le réel et du risque qui est inhérente à la critique du film envers une fraction de la gauche. Les films du Cinema Novo qui traitent de la révolution sexuelle ne le font jamais dans une perspective strictement épicurienne qui consisterait à penser l'affranchissement des normes sociales dans le seul but de la quête d'un plaisir individuel. Questionner les mœurs revient toujours à questionner la culture et la 
politique de façon globale.

Avant de continuer l'analyse du long métrage, il convient de donner quelques précisions sur ses conditions de production. Fome de amor est un film de commande dont l'initiative revient au producteur Paulo Porto. Santos ne répond positivement à sa demande qu'avec beaucoup de réticence et adoptera par la suite une attitude très ambivalente en relation au projet qui lui permettra dans les faits de faire ce qu'il voudra. Dans sa filmographie, Fome de amor est consécutif à El Justicero, un autre film de circonstance réalisé avant tout pour se maintenir en activité, dans lequel il ne s'est pas beaucoup investi et qui n'a pas rencontré de succès auprès de la critique. Fome de amor est l'adaptation d'une nouvelle intitulée História para se ouvir de noite, écrite par un auteur contemporain, Guilherme Figueiredo. Très impliqué, Porto a l'idée du titre et jouera dans le film le rôle d'Alfredo. La nouvelle est adaptée sous la forme d'un scénario de cinéma par Luís Carlos Ripper, un ancien élève de Santos alors qu'il enseignait le cinéma à l'UnB. Santos n'aime pas le livre de Figueiredo. Il ne l'a d'ailleurs même pas lu en entier. Le scénario de son ancien élève et scénographe attitré ne le convainc pas non plus ${ }^{989}$. À la manière de Godard, c'est à dire se prévalant de l'adaptation comme alibi vis à vis des producteurs pour réaliser un film sans relation avec le support original, le cinéaste improvise au jour le jour pendant le tournage ${ }^{990}$.

En pleine période de desbunde (laissé aller), Santos manifeste une grande désinvolture dans la direction des opérations et une ambiance festive gagne techniciens et acteurs qui exaspère l'acteur-producteur Paulo Porto. Le plan de travail n'est pas respecté. Les quatre semaines de tournage à Angra dos Reis initialement prévues sont multipliées par deux. Certaines séquences sont tournées à New York en octobre, puis, au grand désespoir des producteurs (Richers s'est associé à Porto), Santos décide de retourner filmer des séquences additionnelles à Angra dos Reis. Enfin, pendant la phase de montage le cinéaste abandonne le film sur la base de divergences quant au versement de son salaire. Il s'agit de la dernière péripétie d'une réalisation particulièrement tumultueuse $\mathrm{e}^{991}$.

Nous sommes dans une période où la gauche est divisée entre deux attitudes. D'un côté, nous avons la rigueur et la discipline extrême des mouvements militants clandestins ou semi-clandestins. De l'autre, la gauche dite « festive » manifeste son désenchantement face à la Révolution de 1964 et à la répression croissante du régime militaire en adoptant une

989Luís Carlos Ripper a occupé diverses fonctions sur les plateaux de tournage de El Justicero (costumier et scénographe), Como era gostoso o meu francês (recherches ethnographiques) et Azyllo muito louco (scénographie).

990Sur l'histoire de la production du film, voir : BLANCO, Armindo. « Novo Filme de Nelson tira zero do placar » in $O$ Globo, Rio de Janeiro, 06/06/1968.

991Pour connaître en détail l'histoire de la réalisation de Fome de amor, cf. SALEM, Helena. Nelson Pereira dos Santos - O Sonho possivel do cinema brasileiro. Op. cit., pp. 211-218. 
attitude anti-conformiste et libertaire inspirée par les mouvements beatniks et hippies américains. Santos adopte cette attitude. Pour Fome de amor qui est filmé à Angra dos Reis comme pour la trilogie de Paraty, Como era gostoso o meu francês, Azyllo muito louco et Quem é Bêta?, les équipes de tournage changent peu et vivent en communauté dans une sorte d'exil à l'intérieur même du Brésil. Le choix des lieux de tournage, les sites féeriques de Angra dos Reis ou Paraty ${ }^{992}$, témoigne de cette volonté d'isolement et de liberté. L'atmosphère générale des tournages se situe entre a fossa e o desbunde (la dépression et la désinvolture) et marque l'esthétique des films réalisés.

Débarrassé d'un véritable scénario, le film va se faire sur la base d'un dispositif alliant les dispositions des différents acteurs à quelques lignes directrices : New York, une île isolée d'Angra dos Reis, la musique concrète, quelques éléments de caractérisation des personnages, un mélange de réalisme et d'onirisme, le choix de l'absurde et une attitude provocatrice et agressive. Quatre personnages très différents sont réunis sur une île du littoral fluminense. Alfredo (Paulo porto), sourd, aveugle et muet, à la suite d'un récent accident, est le propriétaire des lieux. Il est à la fois un éminent botaniste et un ancien guérillero, cet île est son refuge. Il est marié à Ula (Leila Diniz), une femme sensuelle beaucoup plus jeune que lui. Mariana (Irene Stefânia) est une jeune femme riche qui étudie la musique concrète aux ÉtatsUnis. Elle a été amenée sur l'île par Felipe (Arduíno Colosanti), son mari et son premier amour, qu'elle a rencontré à New York. Tout semble distinguer Felipe de Mariana, le jeune homme est un peintre médiocre avant tout passionné de plongée sous-marine et volontiers fêtard. La jeune femme est réservée, studieuse et exaltée, elle passe son temps repliée sur ellemême à enregistrer des sons pour ses créations musicales ou à relire le petit livre rouge de Mao et les discours de Che Guevara datant de la conférence tricontinentale. Rapidement, surgissent entre les personnages des rapports de passion et de haine et le voyage du jeune couple à Angra dos Reis devient pour Mariana un véritable cauchemar.

La promiscuité et l'isolement des deux couples rendent l'atmosphère oppressante. Les relations entre Felipe et Mariana se dégradent car aucun des deux ne prend goût aux activités de l'autre. Ula prend le parti de Felipe et reproche à Mariana le fait qu'elle reste constamment repliée sur elle-même et ne soit pas un peu plus vivante et spontanée. C'est elle qui s'inquiète de savoir, avec une pointe de provocation, si elle n'a jamais pris de bain de soleil complètement nue. Au fur et à mesure que le temps passe, Ula se rapproche de Felipe et le

992Angra dos Reis et Paraty sont deux villes du littoral de l'État de Rio de Janeiro présentant toutes deux un patrimoine historique très riche. Angra dos Reis est un port important qui se situe dans un archipel composé de 365 îles où demeurent des vestiges de la forêt Atlantique, sauvage et exubérante. Paraty est une ville plus petite qui se trouve un peu plus au Sud. Avant Nelson Pereira dos Santos, Walter Lima Jr investit les lieux pour tourner Brasil ano 2000 (1969). Angra dos Reis et Paraty sont aujourd'hui d'importants sites touristiques, ce n'était pas encore le cas dans les années soixante. 
nouveau couple abandonne Mariana et Alfredo à leurs solitudes respectives. Felipe peint Ula à demi-nue et sort avec elle en ville. Mariana se donne à Alfredo qui la fascine depuis le début sans qu'il n'ait pourtant jamais été possible de réellement communiquer avec lui. À partir du moment où la rupture semble consommée entre Felipe et Mariana, celle-ci s'imagine qu'il prémédite avec Ula son assassinat et celui d'Alfredo. Elle pense aussi que Felipe l'a séduite dans le seul but de la dépouiller de son argent et qu'il était d'accord depuis le début avec Ula qu'il connaissait déjà.

L'intrigue de la machination, thème récurrent du cinéma classique, n'est cependant pas prise au sérieux. La narration de Fome de amor est à tel point fragmentée qu'il est impossible de reconstituer l'ordre chronologique des événements ni même de distinguer avec certitude les séquences réalistes des séquences oniriques. Le film déroge aux règles traditionnelles de la narration en refusant de nous informer du bien-fondé des inquiétudes de Mariana et de l'avancement des projets supposés de Felipe. Cette fragmentation du récit contribue à communiquer l'angoisse de Mariana. La seule impression fiable sur laquelle le spectateur semble pouvoir s'appuyer réside dans l'identification de certaines séquences au point de vue de Mariana et d'autres à un point de vue sur Mariana, selon un procédé comparable d'ailleurs à celui mis en œuvre dans Capitu. La volonté affichée de désorienter le spectateur n'est pas sans rappeler Terra em transe. Santos manifeste cependant une ironie désabusée et se distancie de son modèle en ridiculisant sa grandiloquence. Fome de amor substitue en effet à la politique au sommet et aux chocs des principales forces en présence dans un pays de dimensions continentales, un huis-clos psychologique entre quatre personnages sans importance historique, rejeté physiquement et symboliquement aux marges du monde.

Au-delà de son inquiétante confusion, l'intrigue est aussi volontairement bouffonne. La caricature est évidente dans la caractérisation des personnages, elle l'est aussi dans les situations décrites. Le climax de la machination supposée en fournit l'exemple. Dans l'avantdernière séquence, une petite fête nocturne est organisée entre les deux couples et le Dr. Manfredo, énigmatique psychiatre pour chien à l'allure bonhomme qui vient accompagné de deux ravissantes jeunes femmes dont on peut penser qu'elles sont des prostituées. Mariana, victime d'une crise de désespoir, évolue en marge des assistants qui ne lui prêtent pas la moindre attention avant d'implorer le docteur de l'aider. Mais celui-ci ne comprend pas sa détresse et l'invite à s'amuser. Ula, pour se moquer du goût de Mariana pour la musique concrète, allume plusieurs postes de radio en même temps et commence à la chahuter. Elle décide ensuite d'improviser un carnaval et tout le monde sort pour se déguiser. Alfredo luimême est affublé d'un costume de papa Noël et d'une casquette étoilée. Debout sur une petite colonne, drapée d'un voile blanc qui ne dissimule pas sa poitrine nue, Ula proclame : « Eu sou 
a verdade ! » (« Je suis la vérité ! »), puis elle descend et présente Alfredo à Mariana : « Olha, Mariana ! É exatamente o que você queria o papai Noël da América latina.» («Regarde Mariana! C'est exactement ce que tu voulais, le papa Noël de l'Amérique latine. »)

La photographie, en noir et blanc, volontairement surexposée, gomme les contrastes. Les personnages, dans la séquence précédant le générique, semblent se fondre dans le décor dont les caractéristiques sont indiscernables. Ainsi, au début du film, ce type de procédé allié au montage cut qui alterne les flashbacks des États-Unis et la présence déjà effective du couple sur l'île brésilienne condense à la fois le temps et les distances jusqu'à détacher les personnages eux-mêmes d'un lieu situé historiquement. Le couple Mariana-Felipe, alors qu'il se trouve à New York, se replie dans un ailleurs indéfinissable : le «fondu au blanc» de la séquence d'ouverture, la séquence de leur première relation sexuelle dans les draps blancs immaculés. Sur l'île, Felipe gagne un ancrage spatial. C'est un lieu où il est connu et dans lequel il évolue de façon naturelle alors que Mariana établit toujours des distances, en accumulant les médiations, les livres, les enregistrements ou en alimentant sa psychose sans réagir. La dernière séquence qui la montre prisonnière d'une autre petite île en train de tourner en rond et de lire à voix haute des textes détachés de tout contexte réel semble bien plus une allégorie de son isolement psychologique qu'une scène réaliste. Enfin, les séquences nocturnes sont des moments de définition. À ce titre, pendant le générique, la nuit à New York, nous voyons Felipe mais pas Mariana. C'est encore la nuit que Felipe et Ula scellent leur union. C'est toujours la nuit que Ula met bas le masque de Mariana et de ses utopies absurdes.

La fragmentation de la narration, l'emploi de la musique concrète, l'impossibilité constante de décider l'ordre et la nature des événements présentés à l'écran et le caractère bouffon de l'intrigue contribuent à créer une atmosphère oppressante et angoissante au sein de laquelle le spectateur cherchera en vain des «éléments d'accroche». Toute tentative de compréhension de la machination dont serait victime Mariana s'avère inutile. Mais savoir si elle est vraie ou prendre parti pour elle contre Ula et Felipe n'a pas beaucoup d'intérêt, il faudrait au contraire éviter de le faire pour comprendre que le fond du problème réside dans la critique de l'aliénation de Mariana, le seul personnage qui, dans le récit, est réellement transparent pour le spectateur. Des autres personnages, nous ne savons rien ou très peu de choses. De Felipe et Ula, nous ne savons que leur agacement envers le comportement de Mariana. Leurs sentiments comme leurs motivations ou même leurs histoires nous sont inconnus. Nous savons qu'Ula, Felipe et Alfredo se connaissent bien avant l'arrivée de Mariana sur l'île, nous savons aussi, dans l'avant-dernière séquence, qu'Ula sait qui était réellement Alfredo avant son accident alors que Mariana s'identifie à un personnage qui, pour 
être muet, sourd et aveugle, n'a pas pu offrir de résistance à ce qu'elle projette en lui ses propres fantasmes. Alfredo est un non-personnage dont moins encore que tous les autres, nous pouvons connaître le point de vue.

Le mode de récit adopté par Santos concourt à une mise en abîme de l'incompréhension de Mariana vis à vis de sa propre histoire avec l'incompréhension du spectateur par rapport au texte filmique. Felipe, le Dr. Manfredo est surtout Ula sont là pour se moquer de Mariana mais de nous aussi qui risquons de vouloir prendre l'intrigue trop au sérieux. Le manque apparent de cohérence du dispositif narratif nous amène à comparer l'aliénation de Mariana à nos propres limites dans l'actualisation du texte filmique. Il nous faut reconstituer un puzzle dont il nous manque des pièces. Seule, cependant, Mariana nous encourage dans cette entreprise dont le résultat conduirait à partager son enfermement et son aliénation. Ula, au contraire, suggère de se laisser aller à la fête, au dérèglement des sens et c'est justement dans cette incapacité du récit à s'expliquer que réside son pouvoir de provocation, son caractère instigateur. À partir du moment où l'on renonce à poursuivre l'hypothèse de la machination dans notre actualisation du film, le personnage de Mariana devient l'objet d'un questionnement critique. L'attention est détournée du mystère de l'île et de ses habitants vers elle, et comme la psychologie de ce personnage, précisément, n'offre pas de mystères, ses contradictions nous renvoient à des questionnements plus larges que ceux qui occupent traditionnellement la fiction ${ }^{993}$. Mais si Mariana ne peut nous expliquer ce qui se joue entre elle et les trois autres personnages alors que peut bien nous apprendre ce personnage?

La séquence qui répond à ce questionnement est exactement située au milieu du récit, c'est à dire dans le groupe de séquences au cours duquel s'effectue la seule véritable transformation de la narration, celle de l'échange de partenaires entre les deux couples en présence $^{994}$. Après que Felipe ait forcé Mariana à l'accompagner dans une promenade en barque, ils sont allés ensemble au restaurant. Sur le chemin du retour, de nouveau en barque, Mariana admire le paysage magnifique de la baie. Au loin sont visibles les montagnes recouvertes de forêt Atlantique qui surplombent la côte fluminense. Interrompant soudain son

993Nous nous référons ici de nouveau aux modes de lecture de Roger Odin. D'une certaine façon, les défaillances du dispositif narratif et les caractéristiques du personnage de Mariana provoquent un décrochage. Devant l'échec du mode de lecture de fiction, le spectateur doit rechercher un autre mode de lecture adapté au texte filmique. À notre avis, il peut hésiter entre le mode documentaire ou le mode parabolisant. L'activation du mode documentaire est motivée par la caractérisation du personnage de Mariana comme jeune et riche intellectuelle. L'activation du mode parabolisant est motivée par la trajectoire de Mariana qui s'enfonce dans une aliénation croissante alors qu'elle pourrait réagir en mettant ses pensées en conformité avec ses actions ou l'inverse, autrement dit cesser d'avoir des préoccupations sociales sans agir ou au contraire aller à la rencontre des opprimés dont elle prétend se préoccuper.

994Les deux couples du début sont bien Felipe-Mariana, Alfredo-Ula, et ceux de la fin, Felipe-Ula, AlfredoMariana même s'il ne faut pas oublier le caractère allégorique de la dernière séquence. 
monologue intérieur, elle déclare à Felipe que ces montagnes seraient le lieu idéal pour la guérilla. Celui-ci lui répond qu'il a un ami qui envisage de faire un film dans ce même décor. Quelques instants plus tard, ils dépassent un ponton où jouent des enfants pauvres. Mariana leur fait un signe de main timide et hésitant.

Le décalage entre ce que dit Mariana et la réponse de Felipe est significatif de la distance qui les sépare et renvoie aux différents types de réaction opposée à la dictature et à l'oppression qui sont contemporains du film. Felipe évoque une action concrète, modeste rapportée à la suggestion de son épouse mais faisable. Mariana envisage une action grandiose et hérö̈que mais dont la réalisation concrète, en particulier par elle, semble bien lointaine. Rien dans la caractérisation du personnage ne suggère qu'elle puisse passer à l'acte, d'ailleurs, au-delà de la lecture de ses livres, rien n'indique qu'elle soit engagée dans la moindre association politique. Il n'existe aucun enjeu dans la méfiance que nous pouvons témoigner envers les intentions de Mariana. Le problème se complique si, comme la structure du film nous indique à le faire, nous comparons l'authenticité de ses intentions et la qualité de son discours au nôtre, puisque le film implique le spectateur, et à ceux d'autres révolutionnaires auto-proclamés qui, comme elle, sont parfaitement intégrés au système tel qu'il est et ne témoignent de préoccupations sociales que par la parole. Le film fonctionne ainsi selon différents niveaux de lecture. Avec le recul, nous savons que parmi les révolutionnaires autodéclarées des années soixante, tous ne brûlaient pas de la même ardeur ni n'avaient de conceptions politiques bien définies.

De façon plus prosaïque, le film renvoie aussi le spectateur de l'époque à une question simple : la guérilla, aussi héroïque et romantique soit-elle, est-elle une option lucide, adaptée à la situation politique du Brésil en 1968 ? Cette question est immédiatement liée à celle de la non-relation entre l'enfant et Mariana. Elle s'adresse au spectateur qui s'affiche favorable à la guérilla. Où en est-il de ses relations avec cet enfant qu'il prétend vouloir protéger ? Que faitil de cette distance qui, par la différence de classe, de culture et de lieu de vie, le sépare de lui ? Cette question de l'altérité est fondamentale. Mariana projette une révolution en faisant l'économie dans ses raisonnements du principal intéressé, le peuple, comme si sa participation allait plus ou moins de soi. Or, un simple enfant la plonge dans la perplexité et un sentiment d'étrangeté. La réponse de Felipe montre qu'il n'a pas ce sentiment d'omnipotence qui permet de concevoir par le raisonnement les différentes étapes de la révolution et de considérer ensuite que le réel répondra de façon docile aux mêmes opérations logiques que celle de la pensée. Plus terre à terre, il évoque une action qui ne le concerne pas directement et dont l'ampleur et l'impact politique sont mineurs comparés à une guérilla : « faire un film ». Or, par la bouche de Felipe, c'est aussi Santos qui intervient directement dans la diégèse et s'implique 
à son tour. «Faire des films », c'est ce qu'il fait et ce n'est pas entrer dans la guérilla. Le film dont Felipe parle, s'intitule Como era gostoso o meu francês. Il s'agit du projet qui tient réellement à cœur au cinéaste et auquel il pense depuis qu'il a terminé Vidas secas.

D'un côté, nous avons donc la guérilla, de l'autre, nous avons un film, et, dans les deux cas, le triangle qui se répète, un personnage, un projet qui s'inscrit dans un espace historique, le littoral fluminense, et l'enfant pauvre, anonyme, qui joue et grimace sur le ponton. Est-ce à dire que les deux projets se valent, qu'ils peuvent être comparés ? Qu'est-ce que cela représente «faire un film »? La structure du film reste résolument ouverte vis à vis de toutes ces questions. L'intervention du personnage de Leila Diniz empêche Mariana de cultiver ses illusions et la bonne conscience qu'elles pouvaient lui apporter et, dans le même mouvement, extirpe le spectateur de ce questionnement angoissant au terme duquel, comme pour Mariana, seul vaudrait l'acte capable de tout changer d'un seul coup. D'une certaine façon, la spontanéité et la sensualité de l'actrice précipitent Mariana dans la psychose et, paradoxalement, libèrent le spectateur. La situation est grave, mais personne ne peut se demander à lui seul de la résoudre. Le seul point sur lequel aucun doute n'est possible est la nécessité du passage à l'acte. La trajectoire de Mariana nous montre que la passivité est la pire des solutions. Celle-ci n'a pas compris qu'elle devait d'abord s'affranchir d'elle-même avant de songer pouvoir penser à affranchir les autres. Le thème de la révolution sexuelle revient en creux. Bien qu'ayant transgressé certains tabous, Mariana n'a pas assimilé l'essentiel de cette révolution car ses actes ne correspondent pas à une véritable liberté.

Fome de amor nous renvoie finalement à des notions simples, l'intérêt pour les autres, le goût du possible et l'implication personnelle. Il soulève des questionnements éthiques par rapport au contexte politique et social de 1968. Globalement bien accueilli par la critique ${ }^{995}$, il s'est cependant trouvé des détracteurs au film qui l'ont jugé ou hermétique, ou antirévolutionnaire, ou les deux cumulés. L'argumentation récurrente qui avait déjà été développée à l'encontre d'autres films du Cinema Novo, consiste à dire que la sophistication du langage participe de la culture bourgeoise qu'il faut combattre. Comme nous l'avons déjà vu, les origines de ce débat remontent à la polémique entre le CPC et le Cinema Novo et relèvent d'une certaine confusion des genres. Santos n'élude cependant pas le problème. Sa réponse, et celle du Cinema Novo, est qu'il est légitime, voir nécessaire, de poursuivre un cinéma de recherche formelle dans un pays soumis à une dictature militaire et à d'inacceptables inégalités sociales. Notons cependant, comme José Carlos Avellar le fait dans sa critique du film ${ }^{996}$, que l'esthétique du film agresse en premier lieu le public de cinéma qui 
n'a finalement du septième art qu'une représentation assez conformiste et limitée. Il ne s'agit donc pas d'un esthétisme vain mais d'un esthétisme visant à faire penser sur des problématiques sociales et culturelles.

Comme dans le cas de Terra em transe, la critique de l'intellectuel gauchiste n'a pas non plus toujours été bien comprise et, identifiant les personnages de Mariana et Alfredo à la gauche révolutionnaire, certains ont pensé que Santos voulait la stigmatiser et qu'il avait « changé de bord ». Le cinéaste lui-même rapporte l'anecdote selon laquelle, après la sortie du film, certaines personnes venaient lui demander s'il était toujours révolutionnaire, ce à quoi il répondait positivement ${ }^{997}$. La plupart des critiques ne se sont cependant pas trompés sur le véritable propos du film et sont passés sans difficulté outre son supposé hermétisme pour extrapoler ce qu'il pouvait nous dire de la situation complexe alors vécue par le Brésil. La connexion avec Reich et Marcuse qui sont alors deux penseurs à la mode, est établie, ce qui n'avait pas été le cas pour Capitu, bien que Saraceni ait partagé ces référents. Salvyano Cavalcanti de Paiva, bien qu'émettant un avis globalement négatif sur Fome de amor, note que l'idéologie de Santos a évolué depuis Rio, quarenta graus. Selon lui, il associe à présent marxisme, psychanalyse freudienne et érotisme pour se rapprocher de la critique de la société industrielle établie par Marcuse et aboutir à l'idée qu'il serait nécessaire d'érotiser les échanges sociaux pour anarchiser le système et lui restituer la fraternité qui lui manque cruellement ${ }^{998}$. Sérgio Augusto, au contraire dithyrambique, ne dit pas autre chose quand il explique que Santos développe dans son film le contenu sociologique et politique des catégories psychologiques au lieu d'appliquer la psychologie à l'analyse des faits sociaux et politiques. La combinaison du sexe et du pouvoir, l'association de l'Eros avec la révolution, serait nécessaire à la lutte contre la servitude croissante qui accompagne la modernisation technologique des modes de communication et de production ${ }^{999}$.

D'une manière générale, bon nombre de critiques témoignent d'une prise de conscience et d'un changement de paradigme assez important dans l'idéologie de la gauche. Lors des deux premières phases du Cinema Novo, l'influence de l'ISEB avait conduit à penser que les inégalités sociales au Brésil, étaient liées au sous-développement industriel du pays. La conception du développement était alors assez univoque, il n'y avait qu'une seule voie possible, celle qu'avait suivie les pays industriels nord-américains et européens. D'une certaine façon, le Brésil, ou tout au moins des aires importantes du Brésil comme le Nordeste vivaient encore dans le passé, avec des modes d'échange et de production archaïques. C'est cet archaïsme qui expliquait la misère. La région sud-est, industriellement développée, était 997SALEM, Helena. Nelson Pereira dos Santos - O Sonho possivel do cinema brasileiro. Op. cit., p. 216. 998PAIVA, Salvyano Cavalcanti de. «Fome de amor $1^{\circ} »$ in Correio da manhã , Rio de Janeiro, 12/06/1968. 999AUGUSTO, Sérgio et alii. «Fome de amor » in Jornal do Brasil, Rio de Janeiro, 1968. 
opposée aux autres qui devaient se hisser à son niveau. Le principal obstacle à cette transformation étant l'aristocratie rurale, elle-même assimilée parfois à une aristocratie seigneuriale de type moyen-âgeux, celle-ci était opposée à la bourgeoisie urbaine jugée $a$ priori plus progressiste. Selon une conception téléologique de l'histoire, le PCB avait même admis l'idée selon laquelle il était nécessaire de passer par une révolution bourgeoise avant de penser à la révolution prolétarienne.

Dès la seconde phase du Cinema Novo, la capacité de la bourgeoisie urbaine à assurer, même à son insu, un rôle progressiste dans le processus historique est remise en doute. Dans la troisième phase du Cinema Novo, et en particulier avec Fome de amor, il apparaît que non seulement la bourgeoisie n'est pas fiable mais aussi que le progrès technique ne s'accompagnera pas forcément d'un progrès social mais qu'il peut au contraire concourir au renforcement des mécanismes de subordination et d'asservissement. La dictature n'est plus comprise comme la réaction d'un Brésil arriéré, moraliste et conservateur mais comme la solution politique permettant l'accomplissement de ce que l'on appellera bientôt la « modernisation conservatrice ${ }^{1000}$. L'économie brésilienne passe par une phase d'adaptation à l'évolution du capital international qui est assuré par les technocrates auxquels les militaires confient la gestion du pouvoir, eux-même se contentant finalement de l'exécutif. Comme souvent dans les pays du tiers-monde, l'armée en est réduite à une fonction policière visant à contenir et annihiler les mouvements de résistance aux transformations décidées par les élites économiques.

Les textes de plusieurs critiques témoignent de cette évolution dans la perception $d u$ Brésil par le monde cinématographique. Míriam Alencar, Alberto Shatovsky, José Carlos Avellar et Maurício Gomes Leite ${ }^{1001}$ notent tous les quatre que Fome de amor est un film politique qui, en mélangeant mélodrame, amitié, trahison, mystère et futur incertain, pose des questions dérangeantes et dénonce, d'un côté, l'aliénation d'une certaine catégorie d'intellectuels et, d'un autre côté, révèle le contrôle croissant de la société, sa dérive orwellienne. Ely Azeredo et Jean-Claude Bernardet ${ }^{1002}$, chacun pour des raisons différentes, mettent l'emphase sur la dimension satirique du film. Azeredo estime en effet qu'il y a dans ce long-métrage anti-naturaliste une révolte baroque contre les lieux-communs du cinéma commercial qui n'est pas sans humour dans la mesure où il met le spectateur en quête de

1000La modernisation conservatrice passera notamment par la mécanisation des grands domaines agricoles dont la modernité fait aujourd'hui la fierté des libéraux. Dans les faits, la dépendance économique du Brésil vis à vis des grandes puissances n'a pas changée. La capacité de production a augmenté mais la majorité de la population continue à vivre dans la misère.

1001AUGUSTO, Sérgio et alii. « Fome de amor » in Jornal do Brasil, Rio de Janeiro, 1968.

1002BERNARDET, Jean-Claude. «O Cinema Fome de amor em forma de acidente », A Gazeta, São Paulo, $25 / 09 / 1968$. 
divertissement et de bonne conscience dans une situation inconfortable. Bernardet commente seulement la scène de la bacchanale qu'il compare à celles de La Dolce Vita ${ }^{1003}$ et Popiól $i$ diament $^{1004}$. Selon lui, au contraire de ces deux bacchanales, celles de Fome de amor ne présente aucune grandeur, c'est une bacchanale de pays sous-développé, copiée du modèle européen, pour une bourgeoisie sous-développée, imitatrice elle aussi du modèle européen. Échantillon d'un cinéma supposément élitiste et donc «bourgeois», Fome de amor manifesterait donc aussi l'incapacité du Cinema Novo à se conformer à ce rôle.

L'option libertaire passe enfin dans la manière même d'envisager le cinéma dont Fome de amor est le produit. Ce dernier aspect de la problématique posée par le film est revendiqué par Santos lui-même. Bien qu'il ait correspondu à un moment difficile de sa carrière et de l'histoire du Brésil, le cinéaste place ce long métrage parmi ses préférés. Après avoir craint de ne pas pouvoir sortir du réalisme critique de Vidas secas, il s'est essayé avec plaisir à une grande liberté formelle et d'improvisation ${ }^{1005}$. La dimension politique de cette liberté dans l'acte de filmer n'est perçue à l'époque que dans une courte critique de Glauber Rocha :

«É como um quadro mágico, caleidoscópio : poderemos ver e ouvir Fome de amor cem vezes e a cada projeção este delírio seria mais delírio e mais realidade. É um filme tão novo que exigirá um espectador novo um crítico novo, uma sociedade nova. O filme pelo seu estilo, arrebenta as velhas estruturas, mergulha nas montanhas em guerra, no mar recomeçando, enquanto caem na aurora cinzenta os frutos apodrecidos do velho mundo.

É um verdadeiro filme revolucionário, não existe o esteticismo purista. O que é cada imagem para cada emoção, cada movimento para cada significação, cada som para cada idéia. $\rangle^{1006}$

En amenant jusqu'à ses dernières possibilités l'esthétique de la négation et de l'effondrement du langage découverte avec Terra em transe, en reprenant une fois de plus le thème de l'aliénation de l'intellectuel bourgeois progressiste mais avec la distance imposée par le personnage de Leila Diniz, Fome de amor reconnaissait les limites du pouvoir du cinéma, désignait de nouveaux obstacles et contraignait à de nouveaux dépassements. Sur le timide adieu de Mariana à l'enfant pauvre et anonyme jouant sur le ponton résonnait une question simple : «O povo ? Onde está o povo ? (Le peuple ? Où est le peuple ?). Il faudrait bien, en définitive, revenir à lui, ce sera l'objet du nouveau Cinema Novo qui, même de façon éphémère, parviendra à établir la communication avec cette parcelle du peuple brésilien qui

1003Federico Fellini, Italie, 1960.

1004Cendres et diamant, Andrzej Wajda, Pologne, 1958.

1005SALEM, Helena. Nelson Pereira dos Santos - O Sonho possível do cinema brasileiro. Op. cit., p. 211.

1006« C'est comme un écran magique, kaléidoscopique : nous pourrons voir et entendre Fome de amor cent fois

et, à chaque projection, ce délire sera un peu plus du délire et un peu plus la réalité. Le film, par son style, démolit les vieilles structures, plonge dans les montagnes en guerre, dans la mer recommencée, pendant que tombent dans la grise aurore les fruits en décomposition du vieux monde.

C'est un véritable film révolutionnaire, il n'existe pas d'esthétisme pur. Ce qui est chaque image pour une émotion, chaque mouvement pour une signification, chaque son pour une idée. » in ROCHA, Glauber. «A Visão por dentro » in Correio da manhã, Rio de Janeiro, 12/06/1968. 
est le public de cinéma. 


\title{
Chapitre 11 : La culture populaire revalorisée
}

\begin{abstract}
« J'ai subi partiellement dans mes premiers films l'influence de préjugés dans le sens d'une mythologie cinématographique et littéraire. J'ai échoué parce que je voulais faire des films populaires et que j'ai fait des films trop intellectuels et trop difficiles. Je veux faire des films plus populaires, mais le problème, c'est que je ne veux faire ni des films populistes ni des films 'réalistes-socialistes' donc académiques. Je pense qu'une position révolutionnaire doit commencer et finir dans une expression révolutionnaire. $\gg^{1007}$
\end{abstract}

Glauber Rocha, 1968.

Depuis 1965 et le premier constat quant à la difficulté du Cinema Novo à atteindre le grand public, le problème n'a pas cessé de préoccuper les cinéastes. Certaines réponses ont déjà été apportées au travers de la réorganisation économique du Cinema Novo qui lui permet d'affronter un marché hostile au cinéma national. Parallèlement, les cinemanovistas envisagent de faire évoluer l'esthétique de leurs films dans le sens d'une plus grande ouverture populaire. La problématique, sur le papier, est simple : comment produire un cinéma valide d'un point de vue esthétique et politique et, en même temps, toucher le plus grand nombre ? La question posée à l'heure du bilan de la première phase du Cinema Novo est cruciale. Le Cinema Novo qui se pose comme un cinéma participant, a pour seule raison d'être le peuple brésilien. S'il ne parvient pas à ne communiquer qu'avec une partie de l'inteligentsia brésilienne, peut-il vraiment prétendre infléchir la vie culturelle et politique du pays ? Réciproquement, au travers de cette capacité ou incapacité à toucher l'homme de la rue, se pose la question du statut de l'intellectuel dans la société. Le statut lui ayant été conféré par l'ISEB étant à présent remis en cause, quelle place l'intellectuel engagé doit-il à présent occuper?

Dans le Brésil des années soixante, la question rencontre les développements complexes que nous avons déjà exposés dans l'analyse des films de la deuxième phase du Cinema Novo. O Desafio, Terra em transe mais aussi des films contemporains de la troisième phase, O Bravo Guerreiro et Os Inconfidentes, mettent au jour les contradictions de l'intellectuel proche des centres du pouvoir et, bien que progressiste, aliéné de la véritable condition populaire. Le principal problème soulevé par les films est la légitimité de l'intellectuel de classe moyenne à parler et agir au nom des classes populaires. Sa sincérité, dans son alignement à la cause des opprimés, peut également être remise en doute. Dans la réalité, ces questions de légitimité et de sincérité sont, pour les cinemanovistas, reléguées au second plan derrière des questions de survie plus immédiate : comment trouver les moyens financiers pour continuer à faire du cinéma et comment faire qu'un film soit un succès ? En ce 
qui concerne les choix économiques du Cinema Novo, le pragmatisme est la règle. Parallèlement à l'idée que le Cinema Novo doit être un cinéma d'auteurs (comme Antonioni, Fellini, Resnais, Godard...), la question de la communication se restreint donc au paradigme commercial $^{1008}$. Conséquemment, il ne s'agit plus de communiquer avec le peuple mais avec le public et ce fait n'est pas sans incidence puisqu'il détourne clairement le Cinema Novo d'expériences passées ou à venir du cinéma politique exploitant des circuits de distribution alternatifs au circuit commercial.

Nous pourrons bien sûr nous demander une fois de plus si les questions que se sont posées aux cinemanovistas étaient bien posées. Toucher le grand public n'était peut être pas un enjeu aussi décisif qu'on l'a pensé. Comme l'a souvent rappelé Joaquim Pedro de Andrade $^{1009}$, il est impossible de traiter les problème de la communication sans s'intéresser au contenu de ce que l'on souhaite communiquer. Les films du Cinema Novo demandaient aux personnes une véritable réflexion, l'adoption d'une position critique par rapport au thème développé et au cinéma lui-même ainsi que la modification de leur comportement quotidien dans la perspective d'une action politique ou sociale. Atteindre, avec une intention aussi ambitieuse, un public moyen estimé à 100000 spectateurs $^{1010}$ n'aurait pas dû apparaître comme un résultat insatisfaisant, bien au contraire. À trop valoriser la dimension quantitative de la communication, on courait le risque de la dilution. Pour de nombreux critiques, celle-ci sera effective dans la deuxième partie des années soixante-dix, quand le cinéma nationalpopulaire réalisé par les anciens cinemanovistas et produit par Embrafilme atteindra le grand public.

La deuxième question qui peut paraître mal posée est celle du statut de l'intellectuel. À s'inquiéter sur sa légitimité en raison de ses origines sociales, on n'a pas assez questionné sa pratique. Dans le cas du Cinema Novo, nous voyons bien que les références culturelles des cinéastes ont pris le pas sur toute considération tactique qui aurait été en adéquation avec l'objectif initial de création d'un cinéma de conscientisation populaire. Alors même que le CPC se posait le problème de la diffusion de ses œuvres dans les syndicats, les favelas, sur les places publiques et en dehors de l'axe Rio-São Paulo, le Cinema Novo s'inquiète de l'occupation des structures traditionnelles du cinéma qui devaient induire les stratégies commerciales adoptées en plus de le soumettre au contrôle de l'État et donc l'écarter du contact avec les classes populaires. Malgré les auto-justifications de Rocha, le Cinema Novo

1008Le Cinema Novo, comme nous l'avons vu, innove en termes de stratégies commerciales dans un « segment » de marché encore à ses débuts qui est celui du cinéma d'art et d'essai.

1009Voir : Um Depoimento especial de Joaquim Pedro de Andrade. Fascicule organisé par le Cineclube Macunaíma à l'occasion d'une rétrospective Joaquim Pedro de Andrade en 1976, à Rio de Janeiro.

Voir également : VIANY, Alex. O processo do Cinema Novo. Op. cit., p. 267.

1010DINES, Alberto, FERNANDES JÚNIOR, Florestan, SALOMÃO, Nelma. Op. cit. 
s'interdisait ainsi la possibilité d'être un cinéma guérillero pas forcément pamphlétaire mais en dialogue avec les masses.

Quelque soit la validité des prémisses qui ont influencé les réflexions des cinemanovistas, une nouvelle stratégie est inaugurée en 1968. Un article de la revue Veja qui s'intitule «Novo Cinema Novo » ${ }^{1011}$ annonce la production de trois longs métrages d'un budget supérieur à $300000 \mathrm{NCr} \$$, O Dragão da maldade contra o santo guerreiro, O Brado retumbante (en fait Os Herdeiros) et Macunaíma. C'est ce que l'on appellera le « cinemão» (littéralement, le « grand » cinéma) en raison de ces budgets qui, bien que modestes comparés aux budgets moyens européens ou américains, battent des records selon les critères de la production brésilienne. Dans la continuité de Garota de Ipanema, il s'agit de produire des films en couleur avec un niveau d'achèvement technique « international ». L'objectif est de tourner le dos à la tradition du film maudit du Cinema Novo (Porto das Caixas, A Falecida, O Padre e a moça...) et assumer le fait que le cinéma soit aussi un spectacle.

Parmi les modifications esthétiques importantes qui, selon les termes de l'article de Veja, doivent «trazer o público aos cinemas sem baixar o nível dos filmes » («attirer le public au cinéma sans baisser le niveau des films »), les cinemanovistas commencent à valoriser de façon systématique la culture populaire et principalement la tradition carnavalesque et le syncrétisme religieux. Cette évolution du Cinema Novo est cohérente avec l'évolution des conceptions politiques de ses membres. Dans le changement de paradigme qui s'effectue à gauche, le développement technique et industriel n'est plus assimilé au progrès social et les éléments de la culture populaire qui échappent à la massification de la société de consommation apparaissent comme des formes de résistance aux différentes formes d'asservissement économiques et politiques. Loin cependant d'adopter une attitude passéiste consistant à défendre une représentation figée de la culture populaire, il s'agit de lui faire incorporer les éléments culturels de la modernité avant que l'implantation de la culture moderne au Brésil ne la détruise. Autrement dit, selon l'image de l'anthropophagie qui est alors utilisée, il faut manger l'autre et s'approprier ses qualités avant que ce ne soit l'autre qui nous mange.

Le Tropicalismo surgit alors, en musique, au cinéma, au théâtre et dans les arts plastiques, comme un mouvement culturel qui mélange influences nationales et internationales, avant-garde, culture populaire et yéyé. Appliquant à la réalité socio-culturelle $\mathrm{du}$ tiers-monde la technique de collage pop art, il permet d'exprimer les contradictions du Brésil et de son développement économique inégal. Selon Roberto Schwarz, la méthode du tropicalismo consiste à exposer les archaïsmes du pays «à luz branca do ultramoderno 1011« Novo Cinema Novo » in Veja, São Paulo, 1968. 
apresentando o resultado como um alegoria do Brasil. » («à la lumière blanche de l'ultramoderne et à présenter le résultat comme une allégorie du Brésil) ${ }^{1012}$ Volontairement iconoclastes, les tropicalistas se réclament autant du modernisme brésilien et de ses grands écrivains Oswald de Andrade, Mário de Andrade qu'ils redécouvrent, que du concrétisme ou de la littérature de cordel. Ils apprécient aussi les Beatles ou Roberto Carlos, l'icône yéyé brésilienne jusque là honnie par les défenseurs du samba, sans pour autant ne plus écouter Villa-Lobos, João Gilberto ou Cartola et Nelson Cavaquinho. Selon Caetano Veloso, auteur avec la chanson Alegria, alegria (1967) d'un véritable manifeste tropicalista, les deux précurseurs immédiats au mouvement ont été José Celso Martines Corrêa avec son montage de la pièce $O$ Rei da vela et Glauber Rocha avec Terra em transe.

Dans sa recherche de l'équilibre entre qualité artistique et succès public, profondément influencé par le tropicalismo, le Cinema Novo va atteindre ses objectifs à trois reprises, avec O Dragão da maldade contra o santo guerreiro, Macunaíma et Como era gostoso o meu francês. Ces succès qui sont contrebalancés par les échecs cuisants que nous verrons dans le chapitre suivant, constituent un aboutissement dans la carrière du Cinema Novo et sont les produits d'une conjoncture spécifique. S'ils peuvent être vus comme des précurseurs du cinéma national-populaire d'Embrafilme, ils s'en distinguent par un certain avant-gardisme qui ne sera bientôt plus de mise. Dans ces films, le Cinema Novo renonce au discours à la première personne pour, de nouveau, se confronter à l'altérité mais sans toutefois les défauts de la posture du début des années soixante. Nous allons à présent étudier les propositions de ces trois films pour un cinéma de conscientisation.

\subsection{O Dragão da maldade contra o santo guerreiro}

«As revoluções se fazem na imprevisibilidade da prática histórica que é a cabala do encontro das forças irracionais das massas pobres. A tomada do poder não implica o êxito revolucionário.

Há que tocar, pela comunhão, o ponto vital da pobreza que é seu misticismo. Este misticismo é a única linguagem que transcende ao esquema racional de opressão. A revolução é uma mágica porque é o imprevisto dentro da razão dominadora. No máximo é vista como uma possibilidade compreensível. Mas a revolução deve ser uma impossibilidade de compreensão para a razão dominadora de tal forma que ela mesma se negue e se devore na sua impossibilidade de compreender. $\rangle^{1013}$

Plus que toute autre déclaration de Rocha, cette citation de l' « Esthétique du rêve » est

1012Cité par Favaretto in FAVARETTO, Celso. Tropicália: alegoria, alegria. São Paulo, Kairos, 1979, p. 79. 1013 «es révolutions se font dans l'imprévisibilité de la pratique historique qui est la cabale de la rencontre des forces irrationnelles des masses misérables. La prise du pouvoir n'implique pas le succès de la révolution. Il faut toucher, par la communion, le point vital de la pauvreté qui est son mysticisme. Ce mysticisme est le seul langage qui transcende le schéma rationnel de l'oppression. La révolution est une magie qui est l'imprévisible à l'intérieur de la raison dominatrice de telle sorte qu'elle-même se contredise et se dévore dans son impossibilité de comprendre. » In ROCHA, Glauber. « Estética do sonho »in Revolução do Cinema Novo. Op. cit., p. 220. 
à même de nous éclairer quant au sens de son quatrième long métrage $O$ Dragão da maldade contra o santo guerreiro. Le texte écrit en 1971 explique en effet le film réalisé en 1968 comme 1' «Esthétique de la faim » expliquait Deus e o diabo na terra do sol, même si, une fois de plus, aucun lien de causalité simple ne saurait être établi entre les textes écrits et les textes filmiques correspondants. Ce que nous pouvons déjà dire des lignes reproduites plus haut, c'est qu'elles signifient l'abandon du matérialisme dialectique auquel le cinéaste s'était jusque là toujours référé et qui avait largement influencé son œuvre jusqu'à Terra em transe. Pourquoi et comment s'opère cette transformation, vers quelle nouvelle conception politique Rocha évolue-t-il ? O Dragão da maldade contra o santo guerreiro nous le dévoile dans son langage allégorique. Pour le comprendre pleinement, il faudra cependant revenir sur l'histoire de la réalisation du film et sur les étapes précédentes de la carrière du cinéaste.

O Dragão da maldade contra o santo guerreiro, connu dans le monde entier à l'extérieur du Brésil sous le titre Antônio das Mortes, ne doit son existence qu'à l'insistance de son co-producteur français, Claude Antoine. Ce dernier suggère à Rocha de réutiliser le personnage d'Antônio das Mortes suite au succès remporté auprès de la critique internationale avec Deus e o diabo na terra do sol. L'agent du cinéma brésilien en Europe est certain de conclure un contrat intéressant avec l'ORTF et Telepool dès 1966. Deux projets distincts sont négociés, un feuilleton télévisé et un film de long métrage pour le cinéma ${ }^{1014}$. Un premier manuscrit intitulé Antônio das Mortes, chasseur de cangaceiros est déposé par Claude Antoine à l'association des auteurs de films en juillet $1966^{1015}$. Un autre manuscrit portant le même titre est déposé en janvier $1967^{1016}$, il est précisé cette fois-ci qu'il porte sur une série de 13 émissions dramatiques. Dans l'intervalle, les correspondances échangées entre Rocha et Antoine témoignent des démarches du producteur français.

Dans deux lettres de septembre 1966, Claude Antoine réclame l'envoi « urgent » des

1014Selon Zelito Viana, l'idée d'une série de 13 épisodes sur Antonio das Mortes en co-production avec l'ORTF était de Walter Lima Jr. Il confirme d'ailleurs que les 13 épisodes ont effectivement été rédigés ce que peu de gens le savent puisqu'il n'existe pas de copie des scénarios au Brésil. Comme le projet n'avançait pas, Rocha et Viana ont demandé à Antoine de négocier le financement d'au moins un long métrage. Zelito Viana. Réponse à un questionnaire de l'auteur par courriel, 27 mai 2004.

Nous noterons cependant que l'idée de la série télévisée a fait long feu. Au mois de mars 1968, alors que le long métrage est sur le point d'être tourné. Rocha envoie à Antoine de nouveaux synopsis pour la télévision française. Il concorde d'avance aux éventuelles demandes de modifications et de réécritures et donne à son agent tous les pouvoirs pour mener les négociations en son nom (Lettre de Glauber Rocha à Claude Antoine, Rio de Janeiro, 03/1968. Archives Tempo Glauber.) De son côté, Claude Antoine a renouvelé le certificat de dépôt de manuscrit des scénarios pour la télévision en janvier 1970 ce qui laisse penser qu'il alimentait encore l'espoir de produire cette série.

1015Antônio das Mortes, chasseur de cangaceiros. Certificat de dépôt de manuscrit effectué par Claude Antoine à l'association des auteurs de films ( $\left.{ }^{\circ} 26819\right), 12 / 07 / 1966$. Archives Claude Antoine.

1016Certificat de dépôt de manuscrit à l'association des auteurs et compositeurs dramatiques, 22/01/1967. Sous le titre Antônio das Mortes, chasseur de cangaceiros, 13 émissions dramatiques, déposé par GR et CA. Renouvelé le 22/01/1970. 
textes qu'il doit présenter à la télévision française ${ }^{1017}$. Dans une autre lettre de novembre, après avoir reçu et présenté aux télévisions allemandes et françaises une première série de textes, il demande à Rocha de revoir les trois dernières histoires jugées trop violentes et mélodramatiques par ses interlocuteurs. Début 1967, il annonce qu'il est sur le point de conclure le contrat avec l'ORTF et qu'il faudra tourner un pilote au Brésil ${ }^{1018}$. Un an se passe sans que rien pourtant ne soit concrétisé. Le 19 janvier 1968, Antoine reçoit la promesse de la participation de Telepool à hauteur de $100000 \mathrm{DM}^{1019}$. En février de la même année, l'ORTF annonce sa participation par télégramme à hauteur de 200000 Francs $^{1020}$. Dans une lettre assez succincte à Michel Ciment daté du premier mars, Rocha annonce le tournage, pour dans quinze jours, d'un « film en couleurs » dans lequel il reprendra le personnage de Antônio das Mortes $^{1021}$. Les témoignages concordent pour indiquer que, dans le courant du mois de mars 1968, Rocha est prêt à retourner dans le Nordeste filmer Antônio das Mortes. Un contretemps de deux mois sera malheureusement occasionné par un imbroglio avec les autorités douanières au moment de l'importation de la pellicule couleur ${ }^{1022}$. O Dragão da maldade contra o santo guerreiro est tourné à Milagres ${ }^{1023}$ (Bahia) en juillet-août 1968.

Première co-production internationale de MAPA Filmes, le quatrième long-métrage de Rocha bénéficie d'excellentes conditions financières en comparaison aux précédents films du Cinema Novo. Les contrats signés à l'étranger assurent en effet plus de la moitié du financement sans d'autre exigence que sa réalisation. La liberté du cinéaste est complète et, pour une fois, le long métrage est pratiquement payé avant sa sortie en salles. Rocha éprouve cependant une certaine appréhension à le réaliser. Pour lui, O Dragão da maldade contra o

1017Lettre de Claude Antoine à Glauber Rocha, papier à en-tête « Claude-Antoine, Promotion du Cinéma Brésilien, Rio-de-Janeiro - Paris », Paris, le 23/09/1966. Archives Tempo Glauber.

Lettre de Claude Antoine à Glauber Rocha, papier à en-tête « Claude-Antoine, Promotion du Cinéma Brésilien, Rio-de-Janeiro - Paris », Paris, le 28/09/1966. Archives Tempo Glauber.

1018Lettre de Claude Antoine à Glauber Rocha, sans en-tête, Paris, le 03/01/1967. Archives Tempo Glauber.

1019Lettre de Telepool à « Claude Antoine Production Promotion Cinéma Brésilien », dactylographiée, en français, Munich, le 19/01/1968. Archives Claude Antoine.

Le contrat définitif est signé la semaine suivante et rectifié à deux reprises :

Antonio das Mortes. Contrat de co-production entre Bayerischer Rundfunk, représenté par Telepool, et Claude Antoine - Production Promotion Cinéma Brésilien, Munich, 25/01/1968. Archives Claude Antoine. Antonio das Mortes. Modification du contrat entre Telepool et Claude Antoine, Munich, 09/02/1968. Archives Claude Antoine.

Antonio das Mortes. Rectification de Telepool sur les sommes à verser à Claude Antoine, Munich, 20/03/1968. Archives Claude Antoine.

1020Cable de l'ORTF à Claude Antoine. Paris, 17/02/1968. Archives Claude Antoine.

Le contrat définitif est signé en juin mais cette date a peu d'importance puisque les sommes promises par l'ORTF ne devaient être versées qu'une fois le film tourné :

Antonio das Mortes. Convention entre l'ORTF et Claude Antoine Films sur la production du film. Paris, 30/06/1968. Archives Claude Antoine.

1021Lettre de Glauber Rocha à Michel Ciment, Rio, 01/03/1968 in ROCHA, Glauber. Cartas ao mundo. São Paulo, Companhia das letras, 1997, p. 309 - 310.

1022Zelito Viana. Réponse à un questionnaire de l'auteur par courriel, 27 mai 2004.

1023La ville où Ruy Guerra avait déjà tourné Os Fuzis. 
santo guerreiro est un film de commande. Parmi les motivations qui le poussent à accepter ce travail, il va pour une part de reconnaissance envers la France où il a souvent reçu un appui inespéré, il va aussi pour une part d'opportunisme, lié aux conditions financières favorables et à la perspective d'une forte exposition internationale. Selon le témoignage de Claude Antoine, il se référera plus tard à Antônio das Mortes comme à un « coup » ${ }^{1024}$. Pour le reste, ce film dont il n'a pas pris l'initiative le perturbe quelque peu dans ses projets.

Pendant le deuxième semestre de 1966, son attention est logiquement concentrée sur Terra em transe et, comme nous l'avons vu, il prend du retard dans la livraison des scénarios pour les télévisions européennes. Après la sortie de Terra em transe, alors que les pourparlers sont toujours en cours pour une suite à Deus e o diabo na terra do sol, il annonce publiquement la réalisation de América nuestra ${ }^{1025}$. Entre 1967 et 1971, cette histoire qui tourne autour du mythe de la révolution bolivarienne ne cesse pas de le fasciner. Son intérêt à son égard est relancé par la mort de Che Guevara en octobre 1967. Le guérillero cubain, fréquemment cité par le cinéaste dans ses entretiens publiés dans la presse ${ }^{1026}$, inspire un nouveau personnage «El», qui s'ajoute à Bolivar. Dans les nouvelles versions de América nuestra que Rocha écrit à partir de 1967, Bolivar est l'archétype du révolutionnaire romantique et humaniste du XIXe siècle. Une fois arrivé au pouvoir, ce personnage se révèle incapable de faire face aux contradictions sociales, politiques et économiques du monde moderne. Il se confond avec la figure de Fernandez, le leader démocrate déposé par Diaz. El est l'archétype du guérillero moderne, il ne souffre aucun compromis avec les classes et les idéaux de l'ancien monde. Véritable cavalier de l'apocalypse, il fera ce qu'il faudra pour libérer l'Amérique latine, quitte à sacrifier ses amis et à déclencher cent Vietnams. C'est une figure messianique taciturne et inflexible, c'est peut être pour Rocha, dont les biographes soulignent la formation protestante, le Dieu de colère de l'Ancien Testament.

L'étude de ses archives personnelles et de ses déclarations à la presse confirme un certain déséquilibre entre l'intérêt qu'il porte à América nuestra et celui qu'il porte à $O$ Dragão da maldade contra o santo guerreiro. Alors qu'il évoque publiquement América nuestra, rien ne filtre dans les journaux au sujet de O Dragão da maldade contra o santo guerreiro avant le tournage du film ${ }^{1027}$. De même, s'il passe beaucoup de temps à écrire et

1024Lettre de Claude Antoine à Lúcia Rocha. St Ouen, 26/03/1987.

1025ROCHA, Glauber. « Glauber Rocha, o cineasta brasileiro de maior prestígio internacional, conta com exclusividade para Fatos \& Fotos porque faz filmes e porque fez Terra em transe » in Fatos \& Fotos, Rio de Janeiro, 1967. Rocha s'exprime sur la quête de financement pour les films d'auteurs, une bataille systématiquement recommencée à zéro : « Para realizar o próximo (que já está escrito) América nuestra, enfrentarei a mesma batalha. »

1026ROCHA, Glauber. « Le Cinéaste tricontinental » in Cahiers du cinéma, Paris, n ${ }^{\circ} 195$, novembre 1967. ROCHA, Glauber. «Entretien avec Glauber Rocha » in Positif, Paris, n 91 , janvier 1968. 1027 À l'exception de l'article publié par Veja et commenté plus haut. 
récrire América nuestra ${ }^{1028}$, une seule version préliminaire du scénario de $O$ Dragão da maldade contra o santo guerreiro a été découverte jusqu'à ce jour. Cette version s'intitule Antônio das Mortes $^{1029}$, l'histoire qu'elle raconte est assez différente de celle du film ${ }^{1030}$. Une certaine réticence à revisiter le personnage d'Antônio das Mortes transparaît également dans les témoignages sur le début de tournage. Zelito Viana, co-producteur ${ }^{1031}$, raconte qu'il est arrivé à Milagres avec quelques jours de retard et qu'il a rencontré le cinéaste agité et inquiet de la réception de son travail par la télévision française. Rocha avait déjà organisé la production et commencé à filmer mais il était convaincu ne pas savoir faire ce que l'ORTF devait attendre. Viana lui dit de ne se soucier de rien et de faire les choses à sa manière. Les plans qui avaient été filmés jusque là ne seront pas retenus dans le montage final.

O Dragão da maldade contra o santo guerreiro correspond à un moment où Rocha se pose beaucoup de questions, sur la participation politique, sur l'esthétique cinématographique et, plus intimement, sur son avenir comme cinéaste. Aussi, quand il commence le film, il se demande vraiment s'il est en train de faire le bon choix. América nuestra est de nouveau repoussé en raison d'une certaine insatisfaction envers le scénario, Rocha peine à trouver une solution satisfaisante pour cette histoire de politique-fiction qui lui sert également à évaluer les chances réelles d'une révolution socialiste au Brésil. Nous avons déjà expliqué dans l'analyse de Terra em transe la contradiction dans laquelle se trouve l'auteur.

Bien qu'il se réclame sans cesse «révolutionnaire», il ne parvient pas à concevoir d'issue à la situation d'oppression et d'exploitation dans laquelle se trouve son pays. Prenant en compte les arguments des partisans de la lutte armée, il est d'accord avec l'idée selon laquelle une transformation significative ne peut arriver sans confrontation violente avec les représentants du capital national et international. Prenant en compte les arguments des réformistes, il pense aussi que si une lutte armée s'engage, elle sera sanglante sans pour autant apporter de réelles garanties quant à une transformation réelle porteuse de justice sociale et de respect des droits fondamentaux. Terra em transe exprimait ses doutes quant à la lutte armée.

1028Liste des textes en relation directe avec América nuestra postérieurs à la sortie de Terra em transe : América nuestra. Deux cahiers manuscrits, sans date (probablement 1967/1969). Tempo Glauber, Rio de Janeiro.

América nuestra. 4 pages, sans date. Tempo Glauber, Rio de Janeiro. América nuestra. 2 pages, sans date. Tempo Glauber, Rio de Janeiro.

América nuestra : Operação III. 14 pages, sans date. Tempo Glauber, Rio de Janeiro.

1029ROCHA, Glauber. « Antônio das mortes » in Roteiros do terceyro mundo. Op. cit., pp. 143-192.

10303 pages de notes sur Antônio das mortes peuvent aussi être lues dans le premier cahier manuscrit de América nuestra. À mi-chemin entre le premier traitement publié dans Roteiros do Terceiro Mundo et le film, ces quelques feuillets présentent le conflit occasionné par la prise de conscience d'Antônio mais les personnages sont les mêmes que ceux du premier traitement retranscrit dans le livre. ROCHA, Glauber. «Antonio luta e mata cangaceiros» in América nuestra. Deux cahiers manuscrits, op. cit., pp. 26-29.

1031Les quatre producteurs de O Dragão... sont Glauber Rocha, Zelito Viana, Luiz Carlos Barreto et Claude Antoine. Antoine ne s'est jamais présenté sur aucun plateau de tournage à l'exception de Der Leone have sept cabeças où il a passé une ou deux semaines avec Rocha au Congo. 
L'expédition de Che Guevara en Bolivie a ravivé sa "foi » dans la guérilla. L'histoire de l'expédition tragique du leader cubain en Bolivie représente pour Rocha une "épopée didactique ». Pour autant, il ne conclut pas América nuestra qu'il reprendra encore après $O$ Dragão da maldade contra o santo guerreiro. Différemment de Terra em transe, ce quatrième long métrage ne relèvera donc pas non plus du cinéma épico-didactique, concept attaché à América nuestra et jamais réellement réalisé ${ }^{1032}$.

À cette même époque où il oscille entre América nuestra et Antônio das mortes, Rocha cherche un moyen de s'investir plus directement dans un contexte politique qui est marqué par de grandes manifestations de contestation contre la dictature brésilienne et de l'ascension des mouvements armés. Selon le témoignage de Gustavo Dahl, il entre en contact avec le mouvement clandestin $\mathrm{ALN}^{1033}$. Parallèlement, comme Leon Hirszman et José Carlos Avellar,

1032Les deux films de Rocha qui se rapprocheraient le plus de la définition qu'il donne du cinéma épicodidactique sont Der Leone have sept cabeças et História do Brasil. Certains synopsis inédits de la période 1968-1974 nous aident à comprendre ce que Rocha entend concrètement avec cette appellation car, mieux que tous ses films, ils correspondent à la description qu'il donne de ce concept dans plusieurs textes de la période 1967-1969 ( A Revolução é uma estética 67 », « Revolução cinematográfica », « Tricontinental , «América nuestra 69» in ROCHA, Glauber. Revolução do Cinema Novo. Op. cit., 1981.)

Ces synopsis prévoient la réalisation de longs métrages divisés en plusieurs parties, une ou plusieurs de ces parties étant documentaires. Les parties documentaires devaient exposer de façon claire et concise, sans détour, l'histoire de l'Amérique latine et dévoiler les mécanismes sociaux, politiques et économiques d'exploitation du cône sud, pratiquement à la manière du Solanas de La Hora de los hornos.

América nuestra. 4 pages, sans date. Divisé en quatre actes. Le tronc commun de América nuestra est répété deux fois, la première fois pour l'ascension de Bolivar, la seconde fois pour celle de El Acte II : El, guérillero surgit après une évocation de l'histoire de l'Amérique Latine des Aztèques à la domination impérialiste.

América nuestra. 2 pages, sans date. Première partie : Histoire intégrée de l'Amérique Latine de Cortez à Peron et Vargas en passant par la dégénérescence des indiens, les jésuites, la révolution mexicaine... jusqu'à la domination américaine, au militarisme et l'éclosion des guérillas. Prévoit l'utilisation d'images de documentaires. La deuxième et la troisième partie reprennent le tronc commun de América nuestra. La partie documentaire et didactique sert à dévoluer une problématique réelle, la partie fictionnelle permet d'exposer les mécanismes du pouvoir en mouvement.

América nuestra : Operação III. 14 pages, sans date. Scénario directement inspiré par la guérilla rurale de Guevara en Bolivie et la guérilla urbaine de Marighella au Brésil. Des fragments du journal de Bolivie sont cités. Dans une séquence, les représentants de tous les partis politiques s'expriment par rapport à Guevara : général pro-américain, capitaliste espérant concilier capitalisme national et monopoles étrangers, évêque progressiste, leader politique exilé. Séquence décrivant les stratégies de la guérilla en territoire rural. América nuestra: A Conquista de Eldorado. 14 pages, sans date, probablement à Cuba. Scénario 89 séquences. Le personnage principal attend, discute et fait de nombreux projets en relation avec la révolution tout en menant une vie de privilégié à Cuba. Totalement autobiographique. Dialectique paradis cubain où vit Juan Morales où l'intégration de l'homme par le travail est possible, où les aléas de l'amour sont possibles, avec les cauchemars de Juan et ses tentatives d'articulation d'un coup d'état très hypothétique. Séquences documentaires sur l'économie cubaine. Montage des discours les plus significatifs de Fidel Castro, du Che. Brasil. 6 pages, sans date (probablement 1972). Archives Tempo Glauber. Synopsis de film apparemment écrit pour l'ICAIC qui serait un portrait critique du Brésil entre 1968 et 1972 inspiré de faits réels et prévoyant l'utilisation d'images de films du Cinema Novo, d'images d'actualité et d'images conçues pour le film et jouant sur le registre de la caricature citant et mettant en scène des personnages de la scène politique avec leur nom réel. En relation avec América nuestra et História do Brasil.

1033Tout indique que les relations des cinemanovistas avec les organisations clandestines de guérilla ont été superficielles.

Nelson Pereira dos Santos et Luiz Carlos Barreto nous ont dit ne jamais avoir cru à la possibilité d'un éventuel succès de la guérilla. (Nelson Pereira dos Santos. Entretien avec l'auteur, juin 2003. Luiz Carlos Barreto. Entretien avec l'auteur, septembre 2004.)

Gustavo Dahl et, paradoxalement, Walter Lima Jr, l'un des membres les moins politisés du Cinema Novo, ont eu des contacts plus rapprochés avec, respectivement, la DI et la VPR. (Gustavo Dahl. Entretien avec 
il entreprend de filmer les manifestations qui se déroulent à Rio de Janeiro. L'un des objectifs de ces tournages est de faire circuler les images de la contestation dans tout le pays afin de favoriser l'amplification du mouvement et l'élaboration de réseaux de résistance civile. L'entreprise avorte rapidement car les cinéastes s'aperçoivent que ces films sont des armes à double-tranchant. Ils peuvent en effet être confisqués par la police et servir à l'identification et à la poursuite « d'éléments subversifs ». La plupart des images tournées sont restées à l'état de rushes. Plusieurs années plus tard, Rocha fera don des images filmées avec Afonso Beato à la Cinemateca Brasileira. De façon significative, il choisit de ne pas ajouter de commentaire ni de bande-son au film qui reste muet. Malgré la timidité et le manque de définition de cette tentative, l'existence de ces images prouve l'actualité d'alors d'un cinéma d'action. Rocha, comme les autres cinéastes brésiliens qui filment la rue, a entendu parler des expériences du cinéma de guérilla vietcong ${ }^{1034}$ et a peut être vu, comme Maurice Capovilla ${ }^{1035}$, ces films qui expliquent aux jeunes américains comment échapper au recrutement obligatoire pour aller se battre au Vietnam.

Après América nuestra et 1968 , la troisième alternative à Antônio das mortes est celle du Cinema Marginal. Parallèlement à l'annonce et à la réalisation de films du Cinema Novo correspondant à l'option cinemão, une nouvelle vague de jeunes cinéastes débutants accusent les cinemanovistas de trahir les préceptes de l'Esthétique de la Faim et contestent la prédominance esthétique et idéologique qu'ils exercent sur le cinéma brésilien. L'opposition entre le Cinema Novo et le Cinema Marginal ${ }^{1036}$ va se cristalliser autour de la sortie de films et

l'auteur, février 2004.)

Sans pour autant entrer dans la clandestinité, chacun a pratiqué des actes relevant bien plus de la militantisme politique que de la lutte armée. Selon les archives du DOPS de Rio de Janeiro, Dahl a participé à un « comício relâmpago » contre la promulgation de la nouvelle constitution de 1967 (Secteur Comunismo, chemise 142, page 137. Arquivos Estadual do Rio de Janeiro, fonds « Polícias políticas do Rio de Janeiro »). Quant à Walter Lima Jr, approché par des guérilleros après la prison de son frère qui participait du MR-8. Il a collaboré avec la VPR pour l'envoi à l'étranger de documents témoignant d'actes de torture et de violations des droits de l'homme. Arrêté et incarcéré du 15 mai au 2 juillet 1970 au DOI/CODI, Lima Jr a été relâché après que le police politique ait vérifié qu'il ne possédait pas d'informations décisives. (MATTOS, Carlos Alberto. Op. cit., et Secteur Inquéritos, page 416, chemise 18. Arquivos Estadual do Rio de Janeiro, fonds « Polícias políticas do Rio de Janeiro ».)

De tous les cinemanovistas, c'est sans doute Rocha qui se rapprochera le plus de ces mouvements puiqu'il est allé jusqu'à s'exiler un an à Cuba où il a côtoyé de nombreux guérilleros brésiliens. Malgré cet investissement personnel, il n'a jamais trouvé la place de « cinéaste-guérillero » à laquelle il aspirait. (ROCHA, Eryk (org.). Rocha que voa-América latina, África, o papel do intelectual, cinema, poesia, política, a memória em transe. A integra da entrevistas de Glauber que deram origem ao filme de Eryk Rocha. Rio de Janeiro, Aeroplano, 2002.)

1034Le cinéma vietcong était le sujet d'un article de la revue paulista aParte en 1968. Cf. aParte, publicação do Teatro dos Universitários de São Paulo, São Paulo, 1968 (1-2).

1035Capovilla nous a raconté avoir assisté à un film où l'on montrait aux jeunes américains comment se couper le pouce pour être réformé. Maurice Capovilla. Entretien avec l'auteur, juin 2003.

1036Ce nouveau mouvement cinématographique, peu connu en Europe, aurait dû être la troisième génération du Cinema Novo. Les conflits idéologiques, esthétiques et interpersonnels en feront une sorte de mouvement « ultra », radicalisant les préceptes de « L'Esthétique de la faim ». À la fois continuation du Cinema Novo et contestation des nouvelles orientations assumées à partir de 1968, l'esthétique du Cinema Marginal sera en grande partie tributaire des innovations apportées par Terra em transe : subjectivité du point de vue du 
de la publication d'articles entre la fin de l'année 1968 et le courant de l'année 1969. Au premier semestre 1968, les signes avant-coureurs de ce conflit sont déjà perceptibles. Un film précurseur est déjà sorti, A Margem de Ozualdo Candeias (1967). Il est suivi en mai 1968 du manifeste « Cinema fora da lei ${ }^{1037}$ de Rogério Sganzerla qui écrit sur le long métrage qu'il est en train de réaliser $O$ Bandido da luz vermelha (1968). D'autres cinéastes comme Neville d'Almeida ou Sérgio Bernardes filho sont également à pied d'œuvre pour réaliser des films «sans argent et presque sans pellicule ${ }^{1038}$. Rocha est sensible à l'éclosion d'un nouveau mouvement cinématographique qui est perçu comme plus radical que le Cinema Novo. Aussi, il met à profit les contretemps qui retardent le tournage de $O$ Dragão da maldade contra $o$ santo guerreiro pour filmer Câncer.

Le film ne sera terminé qu'en 1972 en Italie après l'étape cubaine de 1971 où il aura été post-synchronisé avec beaucoup de difficulté ${ }^{1039}$. Tourné sur quatre jours en $16 \mathrm{~mm}$ et en noir et blanc à Rio de Janeiro en juillet 1968, son esthétique s'oppose partiellement à celle de O Dragão da maldade contra o santo guerreiro. Film urbain dénué d'une trame narrative évidente, il réunit trois personnages principaux, un couple de classe moyenne interprété par Hugo Carvana et Odete Lara, et un clochard interprété par Antônio Pitanga, qui s'opposent successivement les uns aux autres dans des situations qui soulignent leur aliénation sociale, psychologique et culturelle. Chaque situation est montrée dans de longs plans séquences dont l'idée originale était d'épuiser un rouleau de pellicule entier (12 minutes de film) et, parallèlement, le potentiel dramatique de chaque scène par ailleurs totalement improvisée. Les acteurs agissent sur les indications sommaires du directeur dont il est possible d'entendre, de voir ou encore de deviner la présence, de façon ponctuelle, à l'intérieur du cadre visuel ou sonore. Tout concourt à ce que Câncer soit un film de dénonciation sociale et politique, teinté à la fois par le désespoir et un esprit ludique qui correspond à la maxime de Sganzerla : «Quando um personagem não pode fazer nada, ele avacalha. » ${ }^{1040}$

Parmi les trois propositions de cinéma absolument distinctes considérées alors par

narrateur, fragmentation de la narration, montage hors continuité, plans séquences, caméra portée, répétitions de plans, disjonction entre l'image et la bande-son, crise aiguë entre l'individu et le politique, impotence du personnage principal et adoption d'un comportement auto-destructeur. Les films les plus connus du Cinema Marginal sont ceux de Rogério Sganzerla ( $O$ Bandido da luz vermelha, A Mulher de todos) et de Júlio Bressane (Cara a cara, Matou a família e foi ao cinema, O Anjo nasceu).

1037Ce manifeste est reproduit intégralement dans l'article suivant : LEITE, Maurício Gomes. « As explosões necessárias » in Jornal do Brasil, Rio de Janeiro, 01/06/1968.

1038LEITE, Maurício Gomes. « As explosões necessárias » in Jornal do Brasil, Rio de Janeiro, 01/06/1968. 1039Voir le témoignage de la monteuse cubaine dans le film Rocha que voa (Eryk Rocha, Brésil, Cuba, 2002). Dans l'impossibilité de synchroniser le son direct et l'image, la bande-son est ralentie dans certaines séquences. Cette solution technique de la dernière chance produit un effet inattendu. Le ralentissement de la voix de l'acteur Antônio Pitanga participe de la caractérisation de son personnage de marginal désespéré et à bout de souffle.

1040« Quand un personnage ne peut rien faire, il déconne. » in LEITE, Maurício Gomes. « As explosões necessárias », op. cit. 
Rocha, aucune ne peut cependant être identifiée à ce qui va arriver. Les scénarios de América nuestra et le premier traitement Antônio das mortes écrits dans le courant de l'année 1967 montraient chacun sa fidélité au matérialisme dialectique. 1968 ou Câncer ne pouvaient laisser présager un changement majeur dans la pensée politique du cinéaste. L'originalité de la proposition que constitue $O$ Dragão da maldade contra o santo guerreiro est due à la synthèse d'éléments esthétiques présents dans les expériences précédentes et à l'intégration de nouveaux éléments dont la valorisation de l'élément religieux présent dans la culture populaire brésilienne, une thématique à laquelle Rocha revient donc presque par hasard puisqu'il n'arrive à Antônio das mortes qu'après un nouveau renoncement à América nuestra. Enfin, et comme nous allons le voir à présent, il n'est pas non plus exclu qu'une fois de plus, après Terra em transe, la peur de la censure ait considérablement influencé l'esthétique en entraînant le renoncement à plusieurs éléments de la critique du latifundium présent dans Antônio das mortes, le premier traitement de O Dragão da maldade contra o santo guerreiro.

Curieusement, dans une entrevue accordée en 1970 à Miguel Torres pour Ciné cubano, les motivations exposées par Rocha pour réaliser O Dragão da maldade contra o santo guerreiro correspondaient mieux à celles qui sont lisibles dans le premier traitement du scénario que dans le film :

«Realicé Antônio das Mortes por varios motivos. El primero, quería hablar otra vez de los problemas del Nordeste del Brasil, desde un punto de vista distinto al de Dios y el diablo en la terra del sol porque Dios y el diablo en la terra del sol me parece hoy una película muy romántica en relación a su tema. Por otra parte, quería ofrecer con Antônio das Mortes una visión más reflexiva sobre el problema del Nordeste, sobre todo las contradicciones sociales y políticas dentro del contexto místico. En el Nordeste del Brasil no se puede olvidar que el misticismo es la fuerza más viva del pueblo, y aunque negativa como fenómeno sociológico yo creo que, desde el punto de vista subjetivo e inconsciente es une fuerza muy positiva porque significa una constante rebelión del pueblo contra la opresión tradicional en esta región. " ${ }^{1041}$

Ce décalage n'est pas si étonnant si l'on prend en compte le fait que le cinéaste a certainement dû chercher à ménager les réticences possibles de ses interlocuteurs communistes quant à sa nouvelle conception de la religiosité et du mysticisme. Il est néanmoins significatif de constater que le décalage qui intervient entre cette déclaration et le film est exactement le même que celui qui intervient entre le film et le premier traitement du

1041« J'ai réalisé Antônio das Mortes pour plusieurs motifs. Le premier est que je voulais revenir aux problèmes du Nordeste mais d'une façon différente de ce que j'avais fait avec Deus e o diabo na terra do sol qui me paraît aujourd'hui un film très romantique dans le traitement de son sujet. D'un autre côté, je voulais offrir avec Antônio das Mortes une vision plus réflexive sur le problème du Nordeste, sur les contradictions sociales et politiques dans un contexte imprégné par le mysticisme. Nous ne pouvons pas oublier que dans le Nordeste du Brésil, le mysticisme est la plus grande force vive du peuple, et, bien que négative d'un point de vue sociologique, je crois que, du point de vue subjectif et inconscient, c'est une force très positive car elle signifie une constante rébellion du peuple contre l'oppression traditionnelle de cette région. » in ROCHA, Glauber. « Entrevista con Glauber Rocha sobre su película Antônio das Mortes - Miguel Torres » in Cine cubano, La Havane, $n^{\circ} 60-1$, mars 1970. 
scénario. Dans Antônio das mortes qu'il écrit en octobre 1967 à Paris, Rocha reprend de nombreux éléments de Deus e o diabo na terra do sol, le personnage du tueur de cangaceiros, Antônio das mortes, mais aussi Cego Júlio qui retrouve la même fonction que celle qu'il avait dans le film précédent. L'action, bien qu'elle ne soit pas datée, semble se dérouler dans les années trente compte tenu de la présence d'un bande complète de cangaceiros et de la teneur des conflits opposant les coronéis nordestins (élevage traditionnel contre industrialisation). Nous retrouvons enfin une communauté religieuse regroupée, non plus autour d'un saint mais d'une sainte, Santa Clara, dont la virginité garantit les dons d'oracle et de guérison.

Différemment pourtant de ce qui était le cas dans Deus e o diabo na terra do sol, le personnage d'Antônio das mortes est clairement défini. Il n'obéit plus à présent aux grands propriétaires, mué par une mystérieuse contradiction. Dès le départ, c'est un homme en repentance qui a pris le parti des opprimés. Nous le retrouvons d'ailleurs dans la séquence 9 auprès d'un prêtre occupé à secourir les familles pauvres et affamées. Soudain rappelé à son métier de tueur à gage par les propositions de deux coronéis sans scrupule, il est confronté à une situation classique de spoliation de terres qui est expliquée par le scénario de manière très didactique. Deux communautés de cultivateurs sont expulsés des terres qu'elles occupaient depuis près d'un siècle par les hommes de main des coronéis dont les intérêts sont contradictoires. L'une de ses communautés est favorable à récupérer son bien par la force mais l'autre, qui est rassemblée autour de la sainte, refuse l'usage de la violence. Les affrontements entre les différentes forces en présence sont perturbées par l'arrivée d'une bande de cangaceiros dans laquelle se distingue un certain Coirana. Feignant d'abord de prêter attention aux propositions des coronéis, Antônio s'appliquera ensuite à restituer aux paysans les terres qui leur ont été volées. Incapable d'y parvenir seul à cause de la malhonnêteté des coronéis qu'il sauve des cangaceiros, il utilisera, cette fois-ci avec succès, la même stratégie que Firmino dans Barravento consistant à faire perdre sa virginité au personnage sacré. Unies et avec l'aide d'Antônio, les deux communautés vont reconquérir leurs terres et chasser définitivement coronéis et cangaceiros.

Dans ce scénario comme dans les films précédents de Rocha, la religion est vue comme un obstacle à la participation active du peuple à la défense de ses intérêts. Bien qu'elle puisse être perçue, d'un point de vue culturel, comme une force positive, elle est stigmatisée comme « sociologiquement » négative. Il n'est pas évident que ce soit déjà en prenant du recul par rapport à cette conception marxiste classique du religieux que Rocha ait abandonné ce premier traitement. Bien que remarquablement structurée, le récit présente deux écueils majeurs. Le premier réside dans la description directe des méthodes de spoliation de terres, d'achat de l'électorat et de recours au meurtre par les grands propriétaires terriens. Du scénario 
au film, la charge contre l'aristocratie rurale est édulcorée. La tentation d'exposer avec précision ces mécanismes d'oppression du latifundium revient sans cesse dans les scénarios de Rocha mais le cinéaste s'autocensure. Cela avait déjà été le cas avec Que viva a terra et les différents traitements de Terra em transe et América nuestra ${ }^{1042}$. Le deuxième obstacle à la réalisation de ce scénario a sans doute résidé dans la dimension tragi-comique des scènes d'humiliation des coronéis et une certaine similitude, dans le propos, avec le western-spaghetti à message politique alors en vogue. Il est vraisemblable que la définition du personnage d'Antônio das mortes soit apparue à Rocha comme un appauvrissement de la narration et qu'il ait craint, avec une telle histoire, d'évoluer vers un cinéma académique.

Dans le film, un retournement majeur intervient en comparaison au scénario : les rôles sont inversés, Antônio n'est plus le vecteur de la conscientisation ni le garant du droit et de la justice. Il est une âme en peine, rongée par le remord et le doute, longtemps après que les derniers cangaceiros aient disparu. Le personnage renoue, tout au moins dans la première partie, avec ses ambiguïtés passées et lutte contre les cangaceiros. La sainte, fragile, hiératique et taciturne marque par sa présence l'éternel retour d'une religiosité irrationnelle. Privé de terre, de nourriture et du droit à la parole, la communauté qui s'est rassemblée autour d'elle, répète des rites qui semblent remonter à des temps immémoriaux. Le peuple affamé est vaincu mais ses chants et ses danses signifient sa révolte vis à vis de l'ordre en vigueur. Cet « être ensemble » conclu sous le signe des mythes, de la poésie et de la transe ne peut trouver de justification ni d'utilité d'un point de vue matérialiste. Cependant, la fête de ces hommes muets menace par sa force poétique l'hégémonie des valeurs esthétiques, religieuses et morales des classes dominantes. Le désir de liberté transformée dans le spectacle vivant de ces corps en mouvement et de de ces voix à l'unisson menace les bases matérielles d'un ordre injuste. La poésie populaire est faite de chair, bientôt elle peut dégénérer en action anarchique. L'étrange contraste, formée par la sainte immobile et le peuple fébrile, est ce qui trouble Antônio et le fait changer de camp. Comme les précédents films de Rocha, O Dragão da maldade contra o Santo Guerreiro est l'histoire d'un prise de conscience.

Le film commence par une représentation populaire de Saint Georges terrassant le

1042Nous retrouvons bien dans Deus e o diabo na terra do sol et $O$ Dragão da maldade contra o santo guerreiro une dénonciation assez claire des méthodes cruelles et expéditives de l'élite rurale mais certaines séquences capables de renforcer la révolte du spectateur à son encontre ont été supprimées. Il s'agit des toute la partie consacrée au travail esclave et à l'achat des votes de Que viva a terra. Il s'agit des séquences mettant en scène le coronel Moreira et ses jagunços responsables de l'assassinat de Felício dans A Terra em transe. Dans le cas de Antônio das mortes, les huit premières séquences dans lesquelles sont décrits les arrangements des coronéis avec les représentants de la justice et les assassinats de paysans innocents ont été supprimées suivants les mêmes processus d'autocensure. Depuis Cabra marcado para morrer, le sentiment avait été intériorisé qu'il existait une limite à ne pas franchir. Cette limite supposée se révélera bien réelle dans le cas de la censure du film de Vladimir Carvalho, O País de São Saruê (1970), interdit de façon unilatérale pendant presque dix ans. 
dragon. L'image est immédiatement suivie par celle d'Antônio das mortes qui traverse le plan de droite à gauche. Quelques instants plus tard, un cangaceiro agonisant entre dans le plan par là où en est sorti Antônio, titube et s'écroule sur le sol au milieu du champ de la caméra. Cette courte séquence suffit à replacer le personnage dans son contexte et bien que l'immobilité de la caméra et la couleur distinguent déjà fortement $O$ Dragão... de Deus e o diabo na terra do sol, le décor et la situation nous remettent à la scène du duel d'Antônio avec Corisco dans le film précédent. Le rapprochement entre les deux longs métrages nous introduit aussi à une caractéristique importante de la nouvelle narration. La succession d'un plan nous montrant Saint Georges terrassant le dragon et d'un plan nous montrant Antônio qui abat un cangaceiro devrait nous permettre d'identifier Antônio à Saint Georges et le bandit au dragon. Nous savons cependant depuis Deus e o diabo na terra do sol que cangaceiros et béats se réclament volontiers de Saint Georges. Antônio est-il alors Saint Georges ou le dragon ? O Dragão... va jouer constamment sur l'ambiguïté de ses personnages et leur capacité à changer de camp. Pendant toute la première partie, Antônio incarne le dragon, mais lui, comme d'autres personnages vont adopter une nouvelle attitude au gré des événements ponctuant une narration linéaire et d'une remarquable clarté comparée à Terra em transe.

L'action se situe à Jardim dos Piranhas, la ville est envahie par une troupe mixte formée de béats et de cangaceiros. Le coronel Horácio qui est aveugle, son valet Batista, sa femme Laura, le chef de la police Matos, le curé et l'instituteur assistent à l'arrivée de la troupe menée par la Sainte, son bras droit Antão et Coirana, le chef des cangaceiros. Ce dernier menace de dévaster la cité. Matos réagit en allant à la grande ville la plus proche où il rencontre Antônio das Mortes qu'il engage aussitôt pour se débarrasser de Coirana. Antônio n'accepte que pour vérifier s'il est vrai qu'il existe encore des cangaceiros et refuse d'être payé. Arrivé à Jardim de Piranhas, il se heurte à l'hostilité du coronel qui se méfie de lui. Bientôt pourtant, il affronte Coirana dans un duel à la machette où chacun évolue au rythme des chansons de la troupe de béats et en se tenant par un foulard serré entre les dents. Antônio blesse gravement Coirana au ventre. La sainte, Laura et l'instituteur s'interposent aussitôt avant qu'il n'achève le cangaceiro. Sur les ordres du coronel, Matos peine à faire revenir le calme, les béats continuent à chanter pendant qu'Antônio, l'air hagard, évolue lentement au milieu du tumulte. Après avoir reçu des premiers soins rudimentaires, Coirana est restitué à la communauté des béats qui s'est installée dans une grande caverne à l'écart de la ville. Antônio cherche à se rapprocher de la sainte dont les paroles renforcent sa mauvaise conscience. Dans une séquence onirique, il entend ensuite Coirana lui chanter son triste parcours qui est aussi celui de toutes les personnes misérables qui souffrent les injustices du Nordeste. De retour à Jardim das Piranhas, visiblement bouleversé, Antônio se recueille dans l'église et demande à 
Matos d'intercéder auprès du coronel pour qu'ils ouvrent les portes de ses magasins afin de palier à la famine et qu'il concède les terres qui seront nécessaires pour que chacun puisse s'installer et vivre de son travail.

Dans un premier temps, Matos refuse mais, grâce au montage parallèle de plusieurs séquences, nous apprenons simultanément qu'il planifiait l'assassinat du coronel avec Laura qui est son amante. Incapable de passer à l'acte lui-même, il présente les revendications d'Antônio à son maître. Peut-être espère-t-il à ce moment là que le conflit que cela va provoquer lui permettra de se débarrasser d'Horácio. L'effet produit par ses paroles est dévastateur, le vieil homme handicapé décide de reprendre ses affaires en main et d'écarter Matos qui semblait jusque là dominer la situation. Ce dernier se précipite auprès d'Antônio pour le persuader de s'en aller mais il est surpris par l'instituteur qui se moque de lui. Le jour suivant, arrive une troupe de jagunços commandés par Mata-Vaca. L'adultère de Laura avec Matos est dénoncé par le valet Batista. La première mission de Mata-Vaca consistera à venger le coronel de cet affront. Laura décide cependant de prendre les devants, et, pour rester dans les bonnes grâces de son mari, assassine son amant de plusieurs coups de couteau sur la place publique. Par la suite, l'instituteur et Laura emmènent le corps de Matos à l'extérieur de la ville pour l'enterrer. De son côté, dans un acte de repentance, Antônio fait de même avec le corps de Coirana qui est mort après une longue agonie. Simultanément, le coronel décide de l'extermination des béats. Le curé tente de prévenir l'instituteur mais celui-ci le repousse et embrasse Laura en se roulant sur le corps de Matos. Antônio entend les coups de feu au loin mais il hésite à abandonner le corps de Coirana. Quand lui et l'instituteur arrivent à la grotte toute la troupe de béats a été exterminée à l'exception de la sainte et de Antão. Dépités, Antônio et l'instituteur se retrouvent à la station routière en contrebas de la ville.

Après un moment d'abattement commun passé au bord de la route sur laquelle passent voitures, camions et bus, sans pour autant échanger aucune parole, Antônio et l'instituteur se rejoignent et décident de retourner à Jardim das Piranhas. Sur le chemin, en traversant la caatinga, ils croisent la dépouille de Coirana, érigée contre un tronc d'arbre, les bras en croix. Armé jusqu'aux dents, le curé passe devant eux d'un pas résolu. L'instituteur s'empare des armes de Coirana. La Sainte et Antão viennent à la rencontre des deux hommes. La jeune femme restitue à Antônio le chapeau et le fusil qu'il avait laissé derrière lui. Le moment est venu du duel final entre le saint guerrier et le dragon. Sur la bande-son, nous entendons la chanson du cordel célèbre, «A Chegada de Lampião no inferno » (L'arrivée de Lampião en enfer). L'histoire continue sur les images du coronel qui, sur une chaise à porteurs, traverse aussi la caatinga. Arrivé sur la grand place de Jardim de Piranhas, il provoque Antônio qui est caché dans l'église avec l'instituteur. Ce dernier sort de l'église de façon théâtrale pour 
répondre à ses imprécations. Il est aussitôt rejoint par Antônio et le duel s'engage avec les hommes de Mata-Vaca qui sont rapidement décimés. Vers la fin du combat, Antão surgit à cheval avec la sainte assise derrière lui et transperce avec une lance la poitrine du coronel. L'instituteur embrasse Laura agonisante. Après la victoire, les différents personnages se séparent. Antônio redescend vers la gare routière et reprend sa route en solitaire. Le film se conclut avec l'image de Saint Georges du début.

$O$ Dragão... reprend les thèmes du mysticisme et de la culture populaire déjà traités par le cinéaste dans ses précédents films. Les conflits entre les différents actants de la narration sont aussi pratiquement les mêmes. Ce quatrième long métrage met cependant un terme à l'ambiguïté qui habitait prédécesseurs. De Barravento à Terra em transe, la culture populaire était vue comme une manifestation de l'ignorance et de l'aliénation des masses et le rôle du personnage dans lequel se projetait l'auteur consistait à « conscientiser » la population pour qu'elle emploie son énergie à vaincre ses véritables ennemis. Paradoxalement, l'esthétique des films était nourrie par des éléments de la culture populaire auxquels elle offrait une reconnaissance et un prestige que le septième art et, à travers lui, la culture érudite, ne lui avait jamais offert. Ainsi, dans Barravento, Firmino dénonce-t-il le mysticisme comme l'une des causes du «retard» de la communauté de pêcheurs alors que le film célèbre le mystère des rites du candomblé et la poésie de la légende de Yemanjá. Dans Deus e o diabo na terra do sol, Antônio das Mortes intervient pour détourner Manuel des deux aliénations que représentent São Sebastião et Corisco, mais c'est la littérature de cordel et des mythes de Lampião et Antônio Conselheiro qui inspirent et structurent la narration. Dans Terra em transe, Paulo Martins préfère les manipulations machiavéliques de la politique au sommet plutôt qu'un militantisme laborieux, il méprise le peuple qu'il pense faible et soumis, ce même peuple qui pourtant inquiète et se dresse comme une inconnue. Dans O Dragão..., Antônio tourne le dos à son passé et à ses origines et se range finalement du côté de la Sainte sans tenter de la « désaliéner » comme cela était le cas dans le premier traitement du scénario. Sa prise de conscience n'est pas le fruit d'une réflexion formelle coupée du réel, elle est le résultat de sa confrontation au retour des cangaceiros et des béats et à son immersion dans leur communauté. C'est le peuple qui est à présent le vecteur de la conscientisation et non un personnage qui lui est étranger et, supposément, supérieur. Mieux, la prise de conscience est plurielle. Antônio n'est pas le seul à prendre le risque de prendre le parti du peuple, l'instituteur et le curé font de même.

Le retournement de valeurs en faveur de la culture populaire est perceptible dans d'autres aspects esthétiques du film que sa morale. Comme dans Deus e o diabo na terra do 
sol, la structure de la narration emprunte à la littérature de cordel $^{1043}$ mais un changement important intervient dans la façon de filmer qui permet de dignifier l'expression des sujets présents devant l'objectif. Des plans séquences aux mouvements lents et mesurés se sont substitués aux mouvements erratiques et indépendants de la caméra du long métrage précédent ${ }^{1044}$. La caméra ne tourne plus autour des acteurs comme pour documenter une scène en train de se dérouler, elle est placée face à eux et ils représentent pour elle sur un mode souvent allégorique ou théâtral. De fait, une certaine emphase est apportée à ce qui se déroule dans le champ parce que la caméra se fige et parce que les personnages s'adressent au spectateur. Cette méthode permet de valoriser la parole de la sainte, d'Antão et de Coirana. D'une certaine manière, ces personnages semblent même capables, lors de leurs apparitions, de « diriger » la caméra ${ }^{1045}$. Nous pouvons aussi observer qu'ils focalisent l'attention d'Antônio et que notre attention converge avec la sienne puisque notre regard est « tourné » vers ces personnages qui nous interrogent autant qu'ils interrogent le tueur de cangaceiros $^{1046}$.

Cette nouvelle façon de filmer permet aussi de valoriser l'expression visuelle de la culture populaire. C'est le cas, par exemple, dans la séquence du duel entre Coirana et Antônio. En évitant de filmer la scène comme une séquence d'action classique, en refusant le recours aux effets de la multiplication des prises de vue et d'un montage rapide, en filmant sur un mode statique, Rocha renforce la tension dramatique et décrit un rite du folklore nordestin. Notre attention est moins attirée par le combat que par les spécificités ethnologiques de la situation. Celle-ci répond à une codification culturelle précise, elle nous montre des personnages qui se conforment à leur rôle malgré les risques encourus ${ }^{1047}$ et, enfin, elle offre

1043Les emprunts à la littérature de cordel sont les suivants : linéarité de la structure narrative, recours à un parler populaire esthétisé, recours à un langage allégorique (les séquences de caractère onirique), condensation dans le temps des épisodes d'action violente en référence à l'expression « num abrir e fechar de olhos » (« dans un battement de cil ») d'ailleurs citée par Antônio dans son premier entretien avec Matos, commentaire social (le récit est à la fois narration semi-fictionnelle et critique) et théâtralité des dialogues (les séquences de combat sont à chaque fois introduits par des échanges verbaux grandiloquents). La littérature de cordel est aussi directement citée au travers du recours au chanteur traditionnel qui commente l'action avec ses chansons en voix off. Pour autant, il n'y a pas dans $O$ Dragão... un personnage équivalent à celui de Cego Júlio qui, dans Deus e o diabo na terra do sol, intervenait directement dans la narration.

1044La subjectivité du regard de l'auteur compte à présent moins que l'occupation du champ visuel par les personnages et leur culture.

1045Le meilleur exemple en est celui de la séquence 4 au cours de laquelle la présentation de Coirana, qui s'adresse directement à la caméra, succède au défilé de la troupe des cangaceiros et des béats au moment de leur entrée dans Jardim das Piranhas. Ce défilé doit être aussi compris comme une démonstration de force, non pas guerrière, mais culturelle. La participation égale des cangaceiros et des béats, les costumes et les chants sont un mode d'affirmation et « d'être au monde ».

1046Dans la séquence 10 qui est composé par un plan moyen fixe, Antão, la sainte et Coirana, sont assis face à la caméra. La sainte immobile et pensive se tient au milieu du champ pendant que Coirana et Antão se disputent sur l'attitude guerrière ou pacifiste qu'ils devraient adopter. Les deux personnages parlent entre eux et, bien que nous entendions ce dialogue qui est important d'un point de vue dramatique, notre attention est attirée par le silence de la sainte à cause de sa place dans le cadre et de la pose qu'elle adopte.

1047L'ensemble des actants respecte le déroulement du rite jusqu'à son dénouement malgré la dangerosité de l'événement. Il est ainsi remarquable que Coirana, bien que désarmé, continue à serrer le foulard entre ses dents dans l'attente du coup mortel. De même, la sainte et les autres membres du public n'interviennent 
des qualités plastiques inédites. Les adversaires, qui s'affrontent avec leurs longs couteaux typiques $\mathrm{du}$ Nordeste, sont reliés par un foulard qu'ils tiennent entre leurs dents. Leurs déplacements sont rythmés par les chants du public qui participe ainsi directement à la danse macabre. Dans cette séquence et tout au long du film, la couleur est également au service de l'hommage qui est fait à la culture populaire car elle nous permet d'avoir accès à toute la richesse esthétique des décors et des costumes des personnages qui, comme pour le carnaval, sont souvent très sophistiqués. Ainsi, l'utilisation de la couleur n'est pas seulement le résultat d'une pression commerciale et participe pleinement du projet esthétique du film ${ }^{1048}$.

Malgré la valorisation de l'objet filmé, l'effet de distanciation recherché dans les autres films du Cinema Novo est toujours présent. Seulement, il est obtenu selon des procédés divergents de ce qui étaient employés autrefois. Comme le décrit justement Avellar ${ }^{1049}$, dans Deus e o diabo na terra do sol, la caméra à l'épaule trahissait constamment la présence de « l'auteur » et donc la tension entre celui qui regarde et ce qui est regardé. Dans O Dragão..., les longs plans fixes ou peu mouvementés, la récurrence des plans rapprochés, les effets de zoom et les regards-caméras dénoncent aussi la présence de la caméra mais l'emphase est déplacée de l'implication de l'auteur vers l'implication du spectateur. Ce sentiment est renforcé par la sensation que donne le cadrage d'être toujours trop serré, comme s'il voulait nous projeter malgré nous au cœur de l'action et contre les personnages, autrement dit dans un lieu violent et dangereux que nous sommes par ailleurs incliné à vouloir garder à distance. La nouvelle façon de filmer employée n'a donc pas seulement pour effet d'apporter une plus grande densité à ce qui est vu, elle cherche aussi à provoquer l'implication du spectateur.

Au-delà de la valorisation de la culture populaire, le film instaure une opposition dialectique entre le folklore revisité par le septième art et la culture dominante contemporaine. Cette opposition n'est pas développée de façon explicite et le conflit qui se joue entre les deux cultures est posé sans pour autant être résolu. Le problème est dévolu au spectateur en jouant sur les anachronismes. Au contraire de Deus e o diabo na terra do sol dont l'action se situe dans les années 30, O Dragão... pose le problème de la contemporanéité. Plusieurs séquences replacent en effet sans la moindre ambiguïté le temps et le lieu de l'action dans le Brésil de

qu'une fois que la cangaceiro est vaincu. Le respect du rite prime donc sur toute autre considération, notamment d'ordre tactique dans l'affrontement des cangaceiros avec Antônio das Mortes.

1048Rocha s'est exprimé en ces termes sur l'utilisation de la couleur : « Ahora bien, los colores del filme son los colores naturales de la región, pues toda la ciudad donde filmé es, de hecho, la ciudad construída por el pueblo, todas las ropas de Antônio das Mortes son ropas de la dramática popular. Quería evidenciar esta riqueza de la cultura popular, incluso como un desafío en relación a las formas culturales de opresión, pues me interessaba también demostrar que el pueblo oprimido económica y políticamente tiene una gran fuerza creadora en su música, sus ropas y su coreografía. » in ROCHA, Glauber. « Entrevista con Glauber Rocha sobre su película Antônio das Mortes - Miguel Torres », op. cit., p. 73.

1049AVELLAR, José Carlos. Deus e o diabo na terra do sol - a linha reta, o melaço de cana e o retrato do artista quando jovem. Op. cit. 
1968. Cette contemporanéité pose immédiatement problème. De façon très prosaïque, il faudra en effet que le spectateur accepte que les trente ans qui se sont écoulées depuis la mort de Corisco, n'ont pas eu de prise sur Antônio das Mortes. Cette invraisemblance nous renvoie à une série d'anachronismes à commencer par le retour des cangaceiros et des béats, et, conséquemment, à la persistance du mode d'organisation sociale pratiquement féodal qui domine la ville de Jardim das Piranhas. Du point de vue de l'allégorie, il est normal qu'Antônio n'ait pas vieilli puisque les cangaceiros, les béats et les grands propriétaires existent encore. La ville toute entière est un anachronisme, une enclave du passé dans le présent, qui n'a pas été touchée par les transformations auxquels le reste du monde a été soumis. Monde réel ou fictionnel, l'archaïsme de Jardim das Piranhas suscite bien des interrogations. Celles-ci recoupent celles d'Antônio qui accepte l'offre de Matos pour vérifier s'il est vrai que les cangaceiros existent encore.

Le montage exploite cette contradiction entre cette ville ayant échappé au changement et le monde extérieur. Au début du film, la séquence du défilé de la célébration de l'indépendance dans la grande ville suit immédiatement la séquence de l'arrivée de la troupe des béats et des cangaceiros à Jardim de Piranhas. Deux manifestations de l'identité nationale sont ainsi mises en parallèle. Celle de la culture populaire est développée dans le film. Celle du défilé n'est pas développée mais les banderoles « Independência ou morte » et l'image des autorités locales installées sur une estrade et toisant la foule sur un mode hiératique ne sont pas sans évoquer un certain nationalisme officiel et chauvin, souvent surnommé «verde amarelo », qui, quelque soit le régime, exprime la vision du Brésil des classes dominantes. Nous savons que le Cinema Novo, bien qu'étant à l'origine le produit typique d'une culture de classe moyenne supérieure, a toujours cherché à s'inscrire en rupture avec l'histoire officielle et à en critiquer les fondements et les valeurs. L'ambiguïté du cri d'Ipiranga, « L'Indépendance ou la mort », ne pouvait échapper à ses membres. En 1968, la gauche discutait toujours le fait que le pays soit réellement indépendant.

Pour les séquences 37 et 40 dans lesquels les personnages reviennent au bord de la route où passent les camions, Rocha a tiré partie de la topographie de Milagres divisée entre une partie haute et une partie basse pour exprimer cette idée d'un lieu qui se trouve à la fois en marge de l'histoire et qui, pourtant, n'est pas complètement isolé. Dans la séquence 37, Antônio et l'instituteur ivre-mort errent au bord de la route et dans la gare routière. Le contraste est complet entre le monde moderne et motorisé et la ville de Jardim de Piranhas que nous venons de quitter. Oublié du Brésil et du progrès, la ville du coronel Horácio témoigne de la persistance du sous-développement et remet en question, par sa seule existence, le mythe du «miracle économique », sur laquelle la dictature va bientôt fonder sa 
légitimité politique. Rocha met en exergue les inégalités du développement pour dénoncer un modèle économique et social inique. Dans la séquence 40, le fait qu'Antônio das Mortes s'éloignent sous l'insigne du station d'essence Shell contrarie l'optimisme des fins similaires des films du Cinema Novo de la première phase. L'emblème de la multinationale est là pour nous rappeler les nouvelles formes d'exploitation et de colonialisme. Le grand propriétaire foncier vient à peine de mourir que le dragon de la cruauté a déjà changé de visage.

Le conflit entre la culture populaire et la culture «moderne » est donc ouvert avec cependant deux prémisses, l'aliénation de la culture de la classe dominante et la nécessité d'une plus grande identification avec la culture populaire et le peuple lui-même. Le parti de Rocha est de se ranger au côté des opprimés tout en acceptant le fait que l'absence d'une pensée politique conceptualisée n'est pas forcément synonyme d'aliénation. La raison de l'intellectuel ayant failli à transformer le pays au moment de la chute de Goulart, ce dernier doit s'ouvrir à une nouvelle voie qui est celle de la « déraison» du peuple et apprendre à ses côtés plutôt que de vouloir absolument être son professeur. L'éternel retour des mythologies, le cangaço et le mysticisme, apporte la preuve de la vitalité de la culture populaire et montre qu'il s'agit de la seule force réellement du côté du peuple et, donc, susceptible de transformer le pays. La référence à la culture populaire ne signifie pas pour autant l'adoption d'une attitude passéiste. Dans les dialogues du film, Coirana avertit clairement Antão des dangers qu'il y aurait à rechercher systématiquement dans le passé la solution des problèmes présents ${ }^{1050}$. Le fait que $O$ Dragão... soit un représentant du tropicalismo démontre aussi la volonté de Rocha d'éviter tout dogmatisme. Le mélange des registres folkloriques, érudits ou modernes indique qu'il possède une conception dynamique de la culture populaire et démontre sa confiance dans la capacité qu'elle aurait à assimiler des éléments hétéroclites.

La modification esthétique et politique effectuée avec $O$ Dragão... tend à identifier le tropicalismo avec la nouvelle posture adoptée par le Cinema Novo. L'intellectuel doit abandonner sa prétention à assumer le rôle de guide de la nation à laquelle il prétendait pour son érudition et sa maîtrise de la logique cartésienne et adopter le comportement orgiastique qui constituerait l'essence de l'identité brésilienne tropicale et tiers-mondiste. Dissertant après coup sur le tropicalismo et ses relations avec la tradition du carnaval, Caetano Veloso décrit la nature de cette force à laquelle l'artiste cherche à s'intégrer :

«O que a gente tem feito, de uma certa forma, está muito ligado com a forma do carnaval

1050Dans la séquence 10, Antão plaide pour une attitude passive et le conformisme vis à vis de la condition misérable de la communauté. Il dit que son rêve est de revenir au pays de ses ancêtres, en Afrique. Coirana lui répond: «Nego Antão, tu tá nos cafundó do medo e nos confim da ignorança. O futuro tá em cima do futuro e não de baixo do passado... » (Antão, tu es aux confins de la peur et de l'ignorance. Le futur est audessus du futur et non en-dessous du passé). Dialogue du film. 
baiano. [...] Agora, eu não quero discutir o negócio da convenção ser de três dias : e depois, saber em que medida essa explosão pode se generalizar, pode se estender para o ano inteiro. Eu não tenho nenhuma proposta política a fazer sobre o assunto. Não é omissão, não. Não é, também, que o carnaval sugira uma sociedade ideal, não. O carnaval, nesta sociedade real, desempenha um papel fundamental. Terapia, também. É estética. É uma força cega, pode ser política. $»^{1051}$

Rocha se référait à la même force au comportement irrationnel et imprévisible quand il définissait le comportement orgiastique au journal Le Monde :

«C'est un état permanent de folie où l'improvisation imaginative remplace l'ignorance, où l'irresponsabilité et le sens de l'humour, de la dérision, pallient l'absence de valeurs établies, où l'agressivité tente de masquer un complexe social de sous-développement. [...] Le tropicalisme - que remonte à la tradition fréquemment interrompue d'une culture brésilienne de quatre siècles - c'est oser entrer dans cet état orgiastique et essayer de le comprendre, de l'analyser en brisant toutes les manifestations de peur et d'autocensure. [...] Pour nous, le tropicalisme, c'est l'amour pour notre pays sans avoir honte de dire qu'il est sous-développé, barbare, corrompu ; c'est, une fois tombés tous les masques, un vrai tête à tête avec l'Amérique latine. ${ }^{1052}$

$\mathrm{Au}$ Brésil, le lancement commercial de O Dragão da maldade contra o Santo Guerreiro, suit exactement la même stratégie que celle qui avait déjà été employée pour Deus e o diabo na terra do sol et Terra em transe. Le film sort à Rio de Janeiro le 9 juin 1969 et bénéficie du succès critique international remporté à Cannes. L'obtention de la palme de meilleur réalisateur par Rocha est largement répercutée et les critiques sont bonnes. Malgré cela, $O$ Dragão... ne parvient ni à susciter l'unanimité qui avait entouré Deus e o diabo na terra do sol, ni à renouveler la polémique provoquée par Terra em transe. Le fait que le long métrage n'ait pas suscité d'aussi fortes réactions que ses prédécesseurs peut surprendre compte tenu de la qualité de son message politique. Plusieurs facteurs peuvent cependant l'expliquer. Les premiers sont d'ordre extra-filmiques. Quand O Dragão... arrive sur les écrans dans le courant de l'année 1969, l'AI-5 est entré en vigueur depuis plus de six mois et, avec lui, la relative liberté d'expression qui avait subsisté entre 1964 et 1968 a été supprimée. La répression policière et la censure se sont accentués, les rapports entre les personnes sont faussées. Dans un tel climat, dans la crainte de représailles directes ou contre les films, la critique cinématographique est contrainte à se dépolitiser.

1051 « Ce que nous avons fait, d'une certaine façon, est très lié avec l'esthétique du carnaval de Bahia. [...] Maintenant, je ne veux pas discuter la question de la convention selon laquelle il doit durer trois jours : et ensuite, savoir si cette explosion peut se généraliser et s'étendre à l'année entière. Je n'ai aucune proposition politique à faire sur ce thème. Ce n'est pas par omission, non. Je ne dis pas non plus que du carnaval surgira une société idéale, non. Le carnaval, dans la société réelle, joue un rôle fondamental. Thérapeutique, aussi. C'est une expression esthétique. C'est une force aveugle qui peut être politique. » in VELOSO, Caetano. Alegria, alegria. Rio de Janeiro, Pedra que ronca, 1977, pp. 97-98. Cité par FAVARETTO, Celso. Tropicália: alegria, alegria. São Paulo, Kairos, 1979, p. 91.

1052BARONCELLI, Jean de, et BABY, Yvonne. "Antonio-das-mortes de Glauber Rocha », in Le Monde, 30/10 - 30/10 - 05/11/1969. Les citations de Rocha que nous avons retranscrites ont aussi été traduites au Brésil dans l'article suivant : REGO, Norma Pereira. «O Tropicalismo : Glauber entra no debate contra José Celso » in Última hora, Rio de Janeiro, 01/11/1969. 
Cette dépolitisation de la critique cinématographique et, allant, du cinéma brésilien, est patente sur l'ensemble de cette période. Parmi les 14 critiques que nous avons recensées concernant $O$ Dragão..., seul José Wolf ${ }^{1053}$ pratique une lecture politique du film et met l'emphase sur le personnage d'Antônio en montrant qu'il s'agit d'un personnage qui met à mal un système inégalitaire et ouvre le chemin de la révolution. Pour le reste, qu'elles soient positives ou négatives, les critiques sont soit superficielles, soit formalistes, ou même d'approche économique, mais en aucun cas elles n'établissent de relations claires avec l'évolution de la pensée de la gauche et la situation politique traversée par le Brésil. Il s'agit d'un paradoxe important puisqu'il s'agit là des principaux sujets du film. L'approche économique est développée par la revue Veja qui, après avoir annoncé le réalisation du film sous le titre « Novo Cinema Novo», consacre sa couverture à Rocha et $O$ Dragão après le succès cannois. L'article au titre très explicite, « O Nosso Cinema internacional » ${ }^{1054}$, explique en substance que malgré l'étonnement que cela peut provoquer auprès de certaines fractions du public ${ }^{1055}$, c'est le Cinema Novo qui parvient le mieux à s'exporter. D'un point de vue strictement commercial, il s'agit donc d'un type de cinéma digne de considération ${ }^{1056}$.

Les approches formalistes proposent une évaluation du film en termes d'innovation esthétique et d'équilibre des formes. Malgré le fait qu'il s'inscrive dans cette approche Viany semble revenir par la bande à des préoccupations nationalistes et politiques, peut être parce qu'il est de ceux qui ont le mieux compris le film. Il évoque la mémoire de Miguel Torres afin de rappeler le projet original du Cinema Novo et la nécessité de la recherche d'un cinéma typiquement brésilien. Dans ce sens, il estime que la réussite de Rocha et de son «óperamacumba» est complète. Usant lui-même des images tropicalistas et de métaphores convoquant l'anthropophagie et le syncrétisme, il déclare :

«Há que mastigar com força e expelir violentamente a cultura européia. E, nesse sentido, o filme de Glauber Rocha tem a forma e a força de um purgante sincrético. Portanto é um filme de sujeira e limpeza, que mistura tudo no mais atroz vale-tudo de nosso subdesenvolvimento.»» ${ }^{1057}$

1053AVELLAR, José Carlos et alii. « O filme em questão: O Dragão da Maldade contra o Santo Guerreiro » in Jornal do Brasil, Rio de Janeiro, sans date.

1054« O Nosso Cinema internacional » in Veja, São Paulo, 28/05/1969.

1055L'article ne décrit pas bien les raisons de cette défiance vis à vis du Cinema Novo qui, d'une certaine façon, iraient de soi. Nous devinons que les réserves exprimées concernent le « gauchisme » des réalisateurs et les sujets de leurs films. Le préjugé classique concerne le fait que le Cinema Novo ne donne pas du Brésil une représentation positive et s'attarde sur des aspects « sales, barbares et misérables » du pays.

1056L'auteur appuie son propos avec les résultats d'un sondage qui montre que le public a une très bonne opinion du Cinema Novo et préfère un cinéma réfléchissant sur les problèmes de la société brésilienne à un cinéma de divertissement, selon l'institut de sondage IBOPE, 800000 téléspectateurs auraient regardé $O$ Dragão da maldade sur la TV Globo. Nous n'avons pas retrouvé de traces de cette diffusion télévisée. 1057 « Il faut mastiquer avec force et recracher violemment la culture européenne. Et, dans ce sens, le film de Glauber Rocha possède la forme et la force d'un expurgeant syncrétique. Aussi, s'agit-il d'un film de saleté et 
Pour le reste, de nombreux critiques admirent la transposition cinématographique de la culture populaire brésilienne. Celle-ci est souvent jugé brillante, y compris par ceux qui donnent $\mathrm{du}$ film une appréciation globale négative ${ }^{1058}$. D'autres se plaisent à imaginer que Rocha pourrait être l'initiateur d'un nouveau genre cinématographique qui devienne pour le Brésil l'équivalent de ce qu'est le western pour les États-Unis ${ }^{1059}$. L'utilisation de plans longs et peu mouvementés est diversement apprécié sans pour autant être clairement analysé. Azeredo ${ }^{1060}$ critique le manque de dynamisme des plans qu'il estime statiques et bavards. Il saisit cet argument pour fustiger l'hermétisme du film et le caractère primaire de ses allégories. Selon lui, le langage de $O$ Dragão... serait paradoxalement à la fois trop évident et trop obscur... Cette contradiction dissimule mal les motivations idéologiques de son rejet du film, motivations que nous trouvons également chez José Carlos Oliveira qui estime que le scénario est bancal et que l'ensemble des conflits exposés par la narration sont résolus dès la première partie ${ }^{1061}$. Par rapport aux questions qui nous intéressent, il n'est donc pas possible de savoir si la modification de la pensée esthétique et politique que le film traduit a été bien comprise par la critique. Paradoxalement, il n'est pas évident que cette modification ait été très claire pour son auteur lui-même.

$O$ Dragão... fut à plus d'un titre, comme nous l'avons montré, le résultat de circonstances particulières. Il est réalisé par le cinéaste à un moment où celui-ci hésite entre diverses orientations et ne concrétise vraiment aucune d'elles. Occupés par ses réflexions sur le cinéma militant, le Cinema Marginal et le cinéma épico-didactique, Rocha réalise son quatrième long métrage comme s'il s'agissait d'un film de commande. En grande partie improvisé, comme le veut l'adoption du comportement orgiastique tropicalista, ce dernier va constituer une proposition de cinéma totalement inédite et intégrera de façon inégale certains éléments de 1968, Câncer et América nuestra. De 1968, nous retrouverons le goût des images prises sur le vif pour ce qu'elles disent et non pas ceux que l'on veut leur faire dire. L'auteur se place dans une position de lecteur et d'interprète et non de démiurge manipulateur. C'est

de propreté, qui mélange tout dans le plus atroce nivellement de valeurs de notre sous-développement. » in AVELLAR, José Carlos et alii. «O filme em questão: O Dragão da Maldade contra o Santo Guerreiro », op. cit.

1058TAVARES, Zulmira Ribeiro. «Os Confins da ignorância » in O Estado de São Paulo - Suplemento literário, São Paulo, 26/071969.

1059VIANNA, Antônio Moniz. « O Dragão da Maldade Contra o Santo Guerreiro » in Correio da Manhã, Rio de Janeiro, 14/06/1969.

ALENCAR, Miriam in AVELLAR, José Carlos et alii. «O filme em questão: O Dragão da Maldade contra o Santo Guerreiro », op. cit.

1060AZEREDO, Ely. « O Dragão da maldade contra o santo guerreiro » in Jornal do Brasil, Rio de Janeiro, 12/06/1969.

AVELLAR, José Carlos et alii. « O filme em questão: O Dragão da Maldade contra o Santo Guerreiro », op. cit.

1061OLIVEIRA, José Carlos. « O Dragão da Maldade Contra o Santo Guerreiro » in Jornal do Brasil, Rio de Janeiro, 01/07/1969. 
notamment le cas dans la séquence du duel entre Coirana et Antônio das Mortes ${ }^{1062}$. De Câncer, nous retrouverons les plans longs et le travail à partir de l'improvisation des acteurs $^{1063}$. À América nuestra, nous devons la dimension didactique du long métrage présente dans les dialogues de Coirana et la définition du personnage d'Antônio das Mortes. À plus d'un titre, ce dernier peut être rapproché du personnage de El qui apparaît dans les scénarios et synopsis de América nuestra à partir de 1967. Enfin, bien que cela soit peu commenté dans les critiques que nous avons analysées ci-dessus, il n'a pas échappé aux contemporains du film sa parenté avec Che Guevara ou le capitaine Lamarca.

L'analyse de l'œuvre postérieure du cinéaste montrent cependant que Rocha n'a pas cherché à persévérer dans la veine de ce nouveau Cinema Novo inauguré par O Dragão... et que le film n'a représenté qu'une étape dans l'évolution de sa pensée. Dans les années soixante-dix, ses scénarios non réalisés renouent avec la thématique de la politique au sommet traitée dans Terra em transe et s'inspirent de la «littérature des tyrans » pratiquée, par exemple, par Augusto Roa Ramos dans Yo, el supremo ${ }^{1064}$. Répétant à l'échelle planétaire ou cosmique le système des actants d'América nuestra, Rocha y intégrera un leader religieux capable de fédérer les masses populaires ${ }^{1065}$. La soif de pouvoir du leader fasciste ou

1062Cf. ROCHA, Glauber, DELAHAYE, Michel, KAST, Pierre et NARBONI, Jean. « Entretien avec Glauber Rocha » in Cahiers du cinéma, Paris, n²14, juillet-août 1969, pp. 23-41. La dimension " documentaire » se retrouve dans la méthode de tournage et dans l'usage du son direct. Sur ces différents sujets, Rocha déclare : « [...] dans Antônio das Mortes, il y avait des acteurs qui travaillaient avec un texte écrit et d'autres qui travaillaient en direct, pour éviter toute systématisation. Quand on en arrive là, c'est presque un documentaire. » (p. 33)

«Dans Antônio das Mortes, il y a une séquence que je préfère, celle du combat entre le cangaceiro et Antônio das Mortes. Eh, bien ! Ça, ce n'est pas une mise en scène que j'ai inventée. Je devais tourner à quatre heure de l'après-midi, il n'y avait plus de soleil. J'ai dit : ' Nous n'allons pas tourner ça maintenant, nous sommes fatigués... » Et puis, le lendemain, à sept heures du matin, j'ai dit à l'équipe : ' Bon, nous allons tourner le combat de Saint Georges et du dragon '. J'ai parlé avec eux, et il y avait une vieille dame qui a dit : «Ah ! Le combat, je me souviens, je connais une chanson '. Puis une autre vieille a dit : ' Je connais une autre chanson '. Au moment où elle commençait à chanter, nous nous sommes tous disposés pour voir le combat. En même temps, certains acteurs se sont mis à bouger sous l'effet de la musique, et j'ai vu la représentation. J'ai mis là les acteurs, les personnages du film. Ça a été mon unique intervention. J'étais à la fois spectateur et participant. Ils ont tous trouvé leur place naturellement. On a tourné tout en un plan, il n'a pas été nécessaire de couper, c'était très vrai, même au moment où Antônio das Mortes blesse le cangaceiro : c'est eux qui en ont décidé ainsi. Ce n'est pas du spontanéisme, c'est un travail lié à des racines profondes de représentation. » (p. 33)

1063Sur Câncer, l'improvisation et le son direct, Rocha déclare : « À Montréal, j'ai montré Terre en transes à Renoir. Il m'a dit : ' Il faut tourner en son direct. Comme c'est un film verbal, si vous tournez en son direct, vous obtiendrez un résultat verbal total. ' Alors, je me suis dit : bon, je tourne un film de fiction en seize et en direct pour m'entraîner du point de vue de la technique... C'était pour Antônio das Mortes. » In ROCHA, Glauber, DELAHAYE, Michel, KAST, Pierre et NARBONI, Jean. « Entretien avec Glauber Rocha » in Cahiers du cinéma, Paris, n²14, juillet-août 1969, p. 34.

Sur le rôle de Câncer dans la préparation de O Dragão da maldade contra o Santo Guerreiro, cf. LEANDRO, Anita Leandro. " L'essai filmé, un autre scénario » in Territoires du scénario. Dijon, Centre Gaston Bachelard de Recherches sur l'Imaginaire et la Rationalité, Université de Bourgogne, 2006.

1064Roman du Paraguay publié pour la première fois en 1974. Sur la « littérature des tyrans » appelé aussi " roman des dictateurs », $c f$. l'article de CHAO, Ramón. « Tyrans et despotes dans la littérature latinoaméricaine » in Le Monde diplomatique, Paris, mai 2002, consulté en ligne à l'adresse http://www.mondediplomatique.fr/2002/05/CHAO/16516, le 28/03/2006.

1065Dans les archives de Claude Antoine : O Império de Napoleão (L'Empire de Napoléon). 2 Synopsis, l'un en 
absolutiste et les conflits qu'elle provoque entre les grands de l'empire semblent obéir à des règles ontologiques qui ne peuvent être perturbées que par l'intervention d'un élément externe et imprévisible. Autant le tyran, promu à la condition d'Empereur-Dieu, que le personnage dans lequel se projette l'auteur, et qui est fréquemment un journaliste, voient que les événements finissent par leur échapper, les efforts du plus grand comme du plus faible sont réduits au néant par des forces qui les dépassent. Entre les deux derniers scénarios de Rocha, L'Empire de Napoléon et Le Destin de l'humanité (1981), il restait à résoudre si les populations opprimées par la tyrannie seraient sauvées par une force divine ou par le jeu des forces sociales et politiques en conflit.

Pour aller plus loin, nous pourrions même suggérer que Rocha résout avec $O$ Dragão..., l'impasse dans laquelle la réalisation de Terra em transe et son incapacité à donner une forme définitive à América nuestra l'avaient laissé. Rocha s'était convaincu au cours du processus d'écriture de ces récits de l'impossibilité concrète d'un révolution socialiste au Brésil. Selon les concepts marxistes du matérialisme dialectique et historique tels qu'il les comprend, les forces contraires à l'exploitation capitaliste et impérialiste du Brésil ne seraient jamais assez grandes pour provoquer les transformations nécessaires à l'établissement d'un système plus équitable. Une « troisième voie » lui apparaît dans O Dragão..., celle de la sainte et de la fascination qu'elle exerce sur Antônio, autrement dit celle du mysticisme et de la place qu'il occupe dans la société brésilienne. Ce n'est pas une véritable conscience politique qui provoque la définition d'Antônio, ce qui le motive à changer de camp n'est pas explicable. À partir de cette idée de l'irruption d'un phénomène collectif, irrationnel et transformateur, Rocha écrit «L'Esthétique du rêve » qui constitue la partie la plus intéressante d'un nouveau concept philosophique qu'il invente dans les années soixante-dix et qui pourra paraître fumeux à ce qui en entendront parler : la «trialectique ». Nous savons que la dialectique, terme à partir duquel Rocha forme son néologisme, est une philosophie dont il s'est longtemps réclamé et qui fait du dynamisme, du mouvement par contradiction ou opposition, le principe d'évolution du monde et de la pensée humaine. Rocha propose de remplacer le matérialisme historique et le matérialisme dialectique par sa «trialectique» pour former la base d'une conception philosophique de la réalité totale dont ses films futurs auraient du être l'expression.

français, l'autre en portugais, Sintra, 1981.

Dans les archives du Tempo Glauber : A Conquista de Eldorado. 82 pages, sans date ; O Destino da humanidade. 140 pages, Sintra, 1981 ; A Guerra civil. 7 pages, Rome, sans date ; A Guerra civil. 2 pages, sans date ; La Guerre civile. 46 pages, sans date ; Malok. 36 pages, sans date ; O Nascimento dos deuses. 189 pages, 1981; O Nascimento da terra. 1 page, sans date ; La Naissance de la terre. 10 pages, sans date. Tous ces textes ne sont pas sans relation avec le projet d'adaptation de la Xénopédie de Xénophon et les scénarios attachés à ce projet : O Nascimento dos deuses. 189 pages, 1981.

Sur ces questions, $c f$. FICAMOS, Bertrand. « De la violence des rêves : la singulière écriture de Glauber Rocha » dans les actes du colloque «L'écriture de scénario, hier et aujourd'hui », organisé par le Centre Gaston Bachelard sur l'Image et la Rationalité, les 31/03/2005 et 01/04/2005. 
Pour diverses raisons, il est difficile d'évaluer si Claro (1975) ou A Idade da Terra (1980) participent de cette nouvelle proposition. Quoiqu'il en soit, nous pourrons constater que les films de Rocha postérieurs à $O$ Dragão... s'inscriront en rupture avec le cinéma narratif de fiction auquel il ne reviendra plus. Le succès critique, mais aussi et surtout public du film aurait cependant dû l'inciter à rechercher de nouveau cet équilibre qu'il y avait atteint entre «compromis commercial» et ambitions artistiques ${ }^{1066}$. D'une certaine façon, la continuation de la stratégie inaugurée par son quatrième long métrage sera assumée par d'autres films du Cinema Novo, Macunaíma et Como era gostoso meu francês, puis, par le concept du cinéma «a reboque do povo », inventé par Santos dans la deuxième moitié des années soixante-dix. Il y a en effet, à notre avis, bien des relations à établir entre $O$ Dragão... et $O$ Amuleto de Ogum (Santos, 1974).

\subsection{Macunaíma}

De l'aveu même de son auteur, Joaquim Pedro de Andrade, Macunaíma fut un film réalisé dans l'opposition avec son prédécesseur, $O$ Padre e a moça, qui avait été pour lui une expérience frustrante du point de vue de sa relation avec le cinéma et le public ${ }^{1067}$. Après un premier long métrage de fiction au rythme lent, à la plastique épurée et à la thématique aride, Andrade voulait changer d'orientation esthétique. Il entre dans une phase de réflexion au cours de laquelle il participe au débat concernant les difficultés de communication du Cinema Novo avec le grand public ${ }^{1068}$ et réalise deux documentaires qui, paradoxalement, ne sont pas destinés à une large diffusion. Il s'agit de Cinema Novo et Brasília, contradições de uma cidade nova, tout deux de 1967. Cet intermède de deux ans (1966-1968) est aussi la conséquence de l'insuccès de $O$ Padre e a moça, le film lui a laissé des dettes qui seront

1066Nous nous référons ici à ce que Laurent Creton nomme respectivement " stratégie ' marketing ' » et « stratégie ' artistique ' » et au diagramme qu'il construit pour faire apparaître les divers positionnements possibles qui résultent de la combinatoire de ces deux dimensions du fait artistique. Nous nous plaçons évidemment ici dans le cadre des productions artistiques transformées en « biens culturels » et dont la circulation obéit aux règles de l'économie de marché. In CRETON, Laurent. Économie du cinéma : perspectives stratégiques. Paris, Nathan, 1994, p. 166.

Le terme « marketing » n'appartenait pas à la terminologie cinemanovista des années soixante. Nous constaterons cependant dans une autre partie, qu'à plus d'un titre, le Cinema Novo a tenu un rôle pionnier en ce qui concerne les stratégies commerciales du cinéma d'auteur.

1067Programa Luzes, Câmera $n^{\circ} 31$ : Entrevista de Joaquim Pedro de Andrade a Sylvia Bahiense. Transcription d'une entrevue télévisée diffusée sur la chaîne TV Cultura le 08/06/1976, consulté sur le site http://www.filmesdoserro.com.br/, le 13/03/2006.

1068Le problème de la communication du Cinema Novo avec le public est le thème central de l'entretien accordé par Andrade à Viany pour la revue Civilização brasileira en 1966. Cf. VIANY, Alex. « Crítica e autocrítica : O padre e a moça-Alex Viany conversa com Joaquim Pedro de Andrade », op. cit. D'une manière générale, cette question est un thème récurrent dans les entretiens accordés par le cinéaste entre 1965 et la fin de sa carrière. Lui-même oscillera entre des films de grande répercussion auprès du public, Macunaíma (1969) et Guerra conjugal (1975), et des films de circulation intimiste, O Padre e a moça (1965), Os Inconfidentes (1972), O Homem do pau Brasil (1982). 
longues à rembourser et peu de crédit auprès des producteurs cinématographiques. Avec Macunaíma, sur lequel il commence à travailler au début de l'année $1968^{1069}$, Andrade cherche à vaincre les contradictions du Cinema Novo qui sont aussi les siennes, il s'agit de conquérir le public sans rien concéder des intentions esthétiques et politiques du mouvement. Le choix de l'adaptation d'un roman de Mário de Andrade est à ce titre significatif. D'une certaine façon, le modernisme brésilien, comme le Cinema Novo, n'avait pas réussi sa rencontre avec le peuple. De thématiques nationalistes et populaires, chacun avait vu son auditoire restreint à une petite élite intellectuelle. Il fallait briser cet isolement. Avec l'adaptation cinématographique de Macunaíma, l'objectif était que la culture de masse puisse s'approprier le modernisme et le Cinema Novo et, en retour, que l'intellectuel puisse gagner une véritable utilité.

La réflexion de Andrade sur l'incapacité de l'élite intellectuelle à produire un art qui participe concrètement de la vie de la nation, se distingue de celle de Rocha sur deux points. Le premier est lié à la conception même du rôle de l'intellectuel. Celle de Rocha n'est finalement pas très claire. Aussi paradoxal que cela puisse paraître, l'étude des scénarios inédits de América nuestra nous montre qu'il ne croit pas que l'artiste puisse demeurer « artiste », au sens où lui l'entend, dans un processus révolutionnaire ou dans le contact avec le peuple. Le personnage de Juan Morales devient un propagandiste quand il se met au service de la guérilla. Quand le gouvernement réactionnaire est renversé, compromis avec les valeurs du vieux monde, il doit lui aussi disparaître. Dans Terra em transe, l'intellectuel de classe moyenne, aliéné du peuple et de sa culture, est un personnage politiquement discrédité. Et si enfin, dans $O$ Dragão... , Antônio encourage l'instituteur à continuer de lutter avec ses idées, son rôle est néanmoins marginalisé à l'aune de l'importance donnée au comportement orgiastique et au rêve irrationnel des mythes et des légendes qui ne lui appartiennent pas. Rocha transpose ces mythes et ces légendes dans le domaine du septième art. D'une certaine façon, il se fait passeur. Sans pour autant abandonner ses objectifs de conscientisation et de transformation sociale, à court terme, il privilégie dans la culture sa capacité à « distinguer », c'est à dire à sauvegarder ou défendre une identité brésilienne.

La posture assumée par Andrade au moment de la réalisation de Macunaíma montre qu'il n'a pas perdu quant à lui sa «foi » dans le rôle et l'importance de l'intellectuel. Conformément à l'esprit original du Cinema Novo, il pense toujours que l'artiste peut et doit apporter sa participation au processus historique et social même si son intervention ne peut plus être pratiquée comme elle l'avait été lors de la première phase du Cinema Novo, c'est à dire avec cette prétention à donner des leçons et corriger des défauts. À partir de cette absence 1069Andrade a écrit l'adaptation de Macunaíma entre février et juin 1968. Cf. BENTES, Ivana. Op. cit., p. 90. 
de complexe à assumer son identité et sa fonction d'intellectuel, Andrade conserve une conception du cinéma et de la culture plus rationaliste que celle de Rocha mais pas forcément plus traditionnelle. Se gardant d'invoquer le réveil de forces mystiques, il continue à penser que le cinéma peut et doit être un instrument de politique indirecte destiné à élever le niveau de conscience générale. Son opposition au cinéma hollywoodien ne se jauge pas seulement à la nécessité d'une expression artistique originale et distincte de la culture dominante, elle se base également sur une question éthique et un choix de civilisation. Andrade attend toujours de l'art qu'il établisse une communication de pleine conscience entre ses interlocuteurs ce qui n'est pas le cas dans l'esthétique du cinéma dominant :

«Em geral as pessoas procuram o cinema como uma fuga. Essa vontade de viver, pelo menos no plano da imaginação, outras vidas, é muito razoável. Quando um filme pretende colocar um problema, solicitar do espectador uma reflexão, uma atituda ativa, está agredindo o homem que vai ao cinema para ficar numa espécie de embalo. Toda a tradição do cinema comercial evita que o espectador seja obrigado a pensar. O próprio processo de fazer o filme, a montagem fluida, um plano pedindo o plano seguinte, o corte praticamente imperceptível no decurso do movimento, fazem de tudo uma trajetória única, através do qual o espectador é levado sem nenhum esforço. Esse é um processo perigoso, e muitas vezes insidioso. Os americanos fizeram exportação de uma filosofia da vida através de Hollywood. $»^{1070}$

Le second point qui différencie la réflexion de Rocha de celle d'Andrade concerne l'interaction entre culture populaire et culture érudite. Dans O Dragão da maldade contra o Santo Guerreiro, Rocha travaille la matière de la culture populaire pour «l'élever » à la dignité de la culture érudite. Les innovations esthétiques du cinéma d'avant-garde sont mises au service des mythes et des modes d'expression folkloriques. Dans Macunaíma, Andrade va au contraire s'attacher à transformer un roman d'avant-garde dans un film intelligible par le plus grand nombre. Ainsi, son chemin va pratiquement être inverse à celui parcouru par Rocha. Il s'agit d'une intention délibérée :

« Tive a intenção deliberada, desde o início, de procurar uma comunicação popular tão espontânea, tão imediata, como a da chanchada, sem ser nunca subserviente ao público. Apesar de não ser subserviente, o filme não é paternalista, no sentido em que talvez fossem paternalistas os primeiros filmes do Cinema Novo: dando uma lição. Ele procura ser feito do povo para o povo, é a orquestração mais simples possível, mais direta de motivos populares, atendendo à definição de rapsódia, que foi como Mário de Andrade qualificou o livro. $\rangle^{1071}$

1070« En général, les personnes attendent du cinéma qu'il leur procure une sensation d'évasion. Cette volonté de vivre, au moins sur le plan de l'imagination, d'autres vies, est très raisonnable. Quand un film prétend poser un problème, solliciter du spectateur une réflexion, une attitude active, il agresse la personne qui va au cinéma pour trouver une sorte d'amusement. Toute la tradition du cinéma commercial évite que le spectateur soit obligé à penser. La façon de faire un film, le montage fluide, un plan appelant le plan suivant, la coupe pratiquement imperceptible dans l'accomplissement du mouvement, font de l'ensemble une trajectoire linéaire, dans laquelle le spectateur est emporté sans que ne soit exigé le moindre effort de sa part. Ce mécanisme du cinéma est dangereux et souvent insidieux. Les américains ont exporté toute une philosophie de vie au travers d'Hollywood. » in ANDRADE, Joaquim Pedro. « Macunaíma e seu diretor » in Visão, São Paulo, 28/02/1969, pp. 78-79.

1071« J'ai eu l'intention délibérée, dès le début, de rechercher une forme de communication populaire si 
Différemment de $O$ Dragão..., Macunaíma va donc s'affilier au mouvement tropicalista. Différemment car, comme nous venons de le montrer, la perspective des deux cinéastes n'est pas tout à fait la même. Différemment aussi, car, s'il y avait déjà dans le long métrage de Rocha le mélange d'éléments de registres culturels hétérogènes, il y avait aussi l'idée que la culture brésilienne possédait une « racine » populaire qui devait prévaloir. Dans Macunaíma, le Brésil souffre précisément de l'inexistence d'un socle culturel historique. L'absence de tradition, le nivellement des valeurs de bon et de mauvais goût, la fragmentation et le cosmopolitisme prévalent dans un univers où les relations humaines sont dominées par l' «Anthropophagie et autophagie » ${ }^{1072}$. Tout se vaut dans la grande "geléia geral» (gelée générale) où le trait culturel dominant est de ne pas en avoir. Le Brésil se singularise seulement par sa capacité à absorber sans discernement des éléments culturels disparates et les transformer totalement. Andrade, qui ne se soucie pas comme Rocha de trouver une solution pour le Brésil, se concentre sur l'idée de dénoncer à lui-même un pays qui dévore ses propres habitants. Ce qui l'intéresse, dans le tropicalismo, c'est de pouvoir se référer au concept d'anthropophagie culturel développé par le moderniste Oswald de Andrade. Mais, celui-ci, s'il s'avère fécond d'un point de vue artistique, se révélera funeste pour son personnage principal. Selon les propres termes de Joaquim Pedro de Andrade : «Macunaíma est l'histoire d'un brésilien dévoré par le Brésil. ${ }^{1073}$

L'ensemble des nuances que nous pouvons établir entre le Rocha du Dragão... et le Andrade de Macunaíma nous amène à distinguer deux stratégies de conscientisation assez différente. Quand le premier recherche un cinéma de « contagion », capable de communiquer un état de transe qui, sans motivation rationnelle, pourrait se révéler transformateur, le second persévère dans un cinéma de dénonciation et développe une orientation satirique jusque là inexistante dans sa filmographie en s'inspirant du mouvement tropicalista alors à son apogée. Dans Macunaima, il n'est plus question, comme le préconisait l'Esthétique de la faim, de

spontanée et immédiate que celle de la chanchada, sans jamais me montrer servile vis à vis du public. Bien qu'il ne soit pas servile, le film n'est pas non plus paternaliste, dans le sens où les premiers films du Cinema Novo l'ont peut être été : donnant une leçon. J'ai cherché à faire un film du peuple pour le peuple, avec l'orchestration la plus simple possible, la plus directe des motifs populaires, me calant sur la définition de rhapsodie, terme par lequel Mário de Andrade a qualifié le livre. » in ANDRADE, Joaquim Pedro de. «Macunaíma : o cinema do herói vital, entrevista a Oswaldo Caldeira » in O Cruzeiro, 21/08/1969. Le terme « rhapsodie » correspond tout à fait à l'esprit tropicalista puisque le terme désigne, dans la littérature, un ouvrage en vers ou en prose fait de morceaux divers, mal liés entre eux, et, en musique, une œuvre instrumentale ou orchestrale de forme libre, composée de thèmes juxtaposés, d'inspiration populaire ou régionale.

1072Titre du manifeste écrit par Andrade pour présenter son film. ANDRADE, Joaquim Pedro de. « Anthropophagie et autophagie ». Press release français de Macunaíma, 3 pages dactylographiées. Archives privées de Claude Antoine. 
cultiver un cinéma qui, parce qu'il est l'expression du sous-développement, se doit de placer le spectateur dans une situation inconfortable. Il est possible à présent de jouer sur les séductions que le spectacle cinématographique peut offrir, la couleur, les trucages, l'humour, sans pour autant céder sur les objectifs culturels et politiques du Cinema Novo. Macunaíma conserve cette ambition originale qui était de révéler le Brésil aux brésiliens, et bien que le film cherche à divertir, fidèle à l'esprit de la satire qui consiste à instruire par le rire, il s'agit d'une comédie où « tout le monde mange tout le monde ». Le long métrage induit des modes de lecture fictionnalisant et parabolisant qui se mettent en fonctionnement à mesure que la narration se développe. Le rire qui est provoqué par les mésaventures de Macunaíma, fait progressivement place à la mélancolie et à la critique car si, considérées isolément, les frasques du « héros » sont comiques, son destin, qui est celui de la majorité des brésiliens, est tragique.

Le film est divisé en quatre grandes parties : l'enfance de Macunaíma dans la forêt, de sa naissance jusqu'à son départ pour la grande ville, sa découverte de la mégalopole et son idylle avec Ci, la femme guérillero, son combat contre le géant Venceslau Pietro Pietra, l'épilogue du retour dans la forêt et la mort dans les bras de Iará, un personnage de la mythologie indienne. Un narrateur en voix off prend en charge certaines ellipses de la bandeimage, explique les sentiments des personnages et commente l'action. Son discours est teinté d'une certaine ironie pince-sans-rire qui est manifeste, par exemple, dans son obstination à désigner Macunaíma avec le terme « herói » (héros) alors que ce dernier, dès les premières séquences, n'en réunit absolument pas les attributs. Cette ironie et le ton neutre et bienveillant de la voix off crée un effet de distanciation à l'intérieur du récit. Le narrateur n'est jamais dupe, comme Macunaíma, des mésaventures dans lesquelles son ignorance ou sa naïveté vont le précipiter. Le narrateur sait, comme nous, spectateur, nous savons. Aussi, cette distance qui s'établit entre lui et les personnages de l'histoire, nous est transmise. Jamais cependant, le discours de la voix off ne tend à se substituer à notre propre jugement des actions et des situations. La connivence qui nous unit à elle, participe d'un effet d'attente qui renforce la dimension comique de plusieurs séquences. Dans la mesure où la relation qui existe entre l'image et la voix off n'est jamais ni illustrative, ni interprétative, le spectateur conserve une grande liberté dans l'actualisation des valeurs de la morale de l'histoire. Surréaliste dans plusieurs de ses aspects, le film laisse au spectateur la même liberté que celle qu'il manifeste dans son esthétique.

Toute la première partie du récit a valeur d'exposition et participe de la caractérisation du personnage principal. Macunaíma naît noir avec un corps d'adulte, petit et disgracieux. Il est joué par l'acteur Grande Othelo. Nous assistons à sa naissance (séquence 1), sa mère, qui a déjà l'allure d'une vieille femme, accouche debout, à la mode indienne. L'enfant tombe 
brusquement sur le sol et se met aussitôt à crier. Il est accueilli chaleureusement par ses frères Manaape et Jiquê. Très vite, Macunaíma se montre paresseux, malicieux et lubrique. À six ans, il prononce ses premiers mots : «Ai que preguiça !" (Ah, quelle paresse !). Dans l'intervalle, il évite soigneusement les tâches domestiques et profite déjà de la moindre occasion pour tripoter sa belle-sœur, Sofará. Leurs relations se compliquent quand, celle-ci, qui est un peu sorcière, invente à l'insu de tous un sortilège qui transforme Macunaíma en prince de conte de fée, pour elle et elle seulement, il devient alors blond et blanc. À partir de ce moment-là, ils s'isolent tous les deux dans la forêt jusqu'à ce que Jiquê les découvre et chasse Sofará. Celle-ci n'est pourtant que la première de ses femmes qui sera séduite par son frère cadet. Tout au long du film, Macunaíma va abuser de sa confiance et de sa crédulité avec ses deux autres compagnes, Iriqui et Suzy. C'est seulement après sa rupture avec cette troisième que la voix off nous annonce : «Jiquê e Maanape decidiram que o herói era muito sem caráter : ele tinha jurado que nem olhava prá Suzi. » (« Jiquê et Maanape conclurent que le héros n'avait vraiment aucune parole : il avait juré qu'il ne s'intéressait pas à Suzi. »)

Cette première partie où Macunaíma est noir et vit dans la forêt permet de recréer un univers totalement fantaisiste autour d'éléments de folklore des communautés indiennes d'Amazonie. La dimension comique des situations repose sur le jeu de massacre auquel est soumis le mythe rousseauiste du «bon sauvage» et la crédulité de Macunaíma dans sa rencontre avec les divinités de la mythologie amérindienne. Bien que tout, dans le quotidien de la famille de Macunaíma, évoque le mode de vie des indiens d'Amazonie, la maloca (la maison indienne), les hamacs, les activités de cueillette et de pêche, chacun démontre dans ses relations avec les autres un égoïsme et une intolérance qui n'ont rien à devoir à ceux de l'homme « civilisé ». Macunaíma ne sort de son inactivité que pour ridiculiser son frère Jiquê. Il attrape un tamanoir que celui-ci chassait et pavoise devant tout la famille. Très irrité Jiquê partage l'animal cuit à la broche et réserve les tripes à son cadet. Les autres que cette injustice avantage, se montrent indifférents aux réclamations de Macunaíma. Plus tard, lors d'une famine, Macunaíma garde une réserve de nourriture en cachette des autres. Quand sa mère le sait, elle se venge en abandonnant Macunaíma loin de leur maison. Bien qu'habitant la forêt, Macunaíma démontre envers ce milieu la même ignorance et la même incrédulité qu'il manifestera lors de sa découverte du monde urbain. Après avoir été abandonné par sa mère, il rencontre un mauvais génie nommé Currupira qui lui donne à manger un morceau de chair qu'il découpe de son mollet. La viande qui est possédée par un esprit maléfique se met à crier dans son ventre et le génie court à la poursuite de l'ingénu qui ne comprend pas bien ce qui lui arrive. Il se sauve in extremis en crachant le morceau de chair ingurgité et en se réfugiant chez une sorcière nommée Cotia et dont il ignore tout. 
Dans la deuxième partie, après le décès de leur mère, Macunaíma et ses frères émigrent vers la grande ville. Avant d'arriver là-bas, un miracle se produit. Macunaíma se baigne dans une fontaine et devient blanc, conservant définitivement le corps que le sortilège de Sofará lui avait déjà attribué de façon ponctuelle. La découverte du milieu urbain par cet esprit naïf est l'occasion de souligner les absurdités de la vie moderne. Macunaíma ne comprend pas l'effervescence des activités humaines et l'omniprésence des machines. C'est avec un regard plein d'étonnement qu'il observe le trafic automobile et la multitude de passants qui sillonnent les rues d'un pas pressé. Sa surprise n'est pas moins grande quand, déambulant avec ses frères sans but précis, il est témoin d'un affrontement entre $\mathrm{Ci}$, la femme guérillero et une troupe d'hommes habillés de noir. La situation est évidemment tout à fait opaque pour lui et ses frères, leur étonnement est ostensible dans leur attitude. Cette ignorance des personnages renvoie à la compréhension de la scène par le spectateur contemporain de la sortie du film au cinéma et qui, au moins au travers des actualités, est au fait des agissements de groupuscules présentés comme des «terroristes » par la presse et le pouvoir. L'opacité de la situation pour Macunaíma et ses frères donne à la séquence sa dimension surréaliste. Celleci est aussitôt renforcée par le montage et la bande-son qui transforme ce décalage en un point de vue irrévérencieux envers les autorités et le public en inversant tous les clichés sur la guérilla.

Premièrement, l'image qui est donnée ici de la guérilla ne correspond en rien à la représentation sordide véhiculée par les autorités. Le cliché officiel est écarté. Deuxièmement, l'association d'un montage de film d'aventure et de la musique yé-yé de Roberto Carlos qui nous chante que «cette fille est terrible ${ }^{1074}$ correspond à la perception de Macunaíma qui tombe aussitôt sous le charme. L'image chic et glamour de la guérilla que nous donne $\mathrm{Ci}$, mélange de Barbarella et de James Bond féminin, n'est pas pour autant «politiquement correcte ». Le public d'une culture pop de divertissement, a priori considéré comme bourgeois et aliéné des thématiques politiques, retrouvera dans cette séquence des éléments de séduction et de répulsion, James Bond est généralement du côté de l'ordre établi et Roberto Carlos

1074La chanson s'intitule É papo firme (Renato Correa, Donaldson Gonçalves) et elle est interprétée par Roberto Carlos. La séquence n'est pas sans rappeler le film Roberto Carlos em ritmo de aventura (Roberto Farias, 1967) et autres comédies cariocas du même genre. Inspiré par les films des Beatles et jouant sur les codes du cinéma en pratiquant un humour au second degré (arrêt sur image en pleine bagarre, Roberto Carlos s'adresse au spectateur et introduit la transition avec la poursuite en voiture de sport), le film de Farias se gardait cependant bien de contenir quoique ce soit qui puisse choquer les militaires, la haute bourgeoisie ou les sociétés de bonnes mœurs. Enjoué et faussement rebelle, Roberto Carlos em ritmo de aventura se voulait un hymne à la joie de vivre. Les jeunes devaient aller de l'avant et s'adonner aux plaisirs simples de leur âge (l'amour, l'amitié, les études et les loisirs). Comme dans l'un des grands tubes de l'icône pop des années 60, « tout le reste pouvait aller en enfer » (Quero que vá tudo pro inferno, 1965). Le film de 1967 se terminait d'ailleurs par un véritable spot publicitaire en hommage aux forces armées. Arrivés par accident au milieu d'un champ de manœuvres, Roberto Carlos qui se demande d'abord si «c'est la guerre », fraternise avec les soldats entre les déflagrations d'obus et vainc ses poursuivants qui se retrouvent complètement désorientés. 
cultivait l'image du gendre parfait. En troisième lieu, ce « spot publicitaire » pour la guérilla, en forçant le trait du romantisme que ses sympathisants lui attribuaient, ne peut guère leur convenir. Cette séquence de la guérilla urbaine fonctionne d'une certaine façon comme les deux parties situées dans la mégalopole. L'ironie exprimée par la narrateur envers Macunaíma se retourne contre le spectateur et, par le jeu de collages improbables et volontairement provocateurs, implique le réel.

Immédiatement séduit par la jeune femme mais sans pour autant avoir le courage de s'interposer entre elle et ses adversaires, Macunaíma la poursuit de ses assiduités dans le parking aérien où elle s'est réfugiée après avoir semé ses poursuivants. La situation est déjà saugrenue en elle-même s'il ne fallait encore y rajouter les méthodes peu romantiques du héros et le décor de l'ascenseur à voiture. Macunaíma rejoint $\mathrm{Ci}$ sur cet ascenseur dont le fonctionnement est d'abord pour lui une source de surprises. Malgré son étonnement, sans aucune subtilité ni préambule, il fait ses avances à la jeune femme qui le repousse aussitôt. Une lutte s'engage au cours de laquelle il s'exclame d'une façon absolument antichevaleresque : «Mulher comigo não bate não, apanha!» (Les femmes avec moi ne donnent pas des coups, elles en prennent !). Ci prend le dessus mais au moment où elle s'apprête à sortir de l'ascenseur et du parking, il l'assomme avec une pierre et prend le contrôle de l'ascenseur afin d'emporter le corps avec lui hors d'atteinte de ses frères qui la convoite aussi avec concupiscence. Quand Ci se réveille, apparemment excitée par le combat et les coups, elle prend fiévreusement Macunaíma dans ses bras et l'ascenseur monte et redescend au grand désespoir des Jiquê et Maanape que Macunaíma a encore doublés. C'est le début d'un grande passion au cours de laquelle le héros va s'accommoder d'un rôle d'homme au foyer pendant que $\mathrm{Ci}$ pose des bombes et dévalise des banques.

Dans cette seconde partie du film comme dans l'exemple précis de la séquence de l'ascenseur, les rapports entre Macunaíma et les accessoires de la modernité s'inversent. La surprise cède la place à la fascination et à la jouissance du confort. La technologie et l'argent ne changent ni sa vision du monde, ni son caractère et, au final, le spectateur s'aperçoit que rien ne distingue cet homme «primitif» de l'homme moderne une fois qu'il a été habillé et installé dans un appartement présentant tous les attributs vantés par la société de consommation. Le fait que Macunaíma puisse indifféremment être blanc ou noir participe aussi de cette remise en question des préjugés. Il faut bien, une fois de plus, souligner la tonalité irrévérencieuse du film et sa capacité à impliquer le spectateur qui, en dernière instance, est cet homme moderne que nous sommes invités à comparer à Macunaíma, à présent parfaitement intégré à son nouvel univers. Cette impertinence est d'autant plus forte qu'il a existé et existe encore à l'égard des communautés indiennes dites « primitives » de très 
forts préjugés et que le brésilien de classe moyenne voit justement dans le respect de la morale, de la religion et dans les attributs professionnels et domestiques de la modernité sa distinction envers ce Brésil archaïque et «barbare » qu'il craint et dont il a honte dans un complexe d'infériorité sans cesse rénovée envers les modèles européens et nord-américains. Macunaíma jette à terre ces conceptions en montrant que la culture de l'homme de classe moyenne ne serait qu'un vernis incapable de dissimuler son égoïsme, sa cupidité, sa sensualité et son ignorance.

L'idylle avec $\mathrm{Ci}$ ne durera cependant qu'un temps. Celle-ci est en effet victime de l'explosion prématurée de l'une de ses bombes et son décès laissera Macunaíma inconsolable. Celui-ci se ressaisit pourtant de façon temporaire et sa vie prend de nouveau un sens quand il voit dans le journal la photographie du millionnaire Venceslau Pietro Pietra avec autour du cou la pierre porte-bonheur appelée Miuriquitã. Cette pierre appartenait à Ci qui ne la quittait jamais. Après son décès, dans l'impossibilité de retrouver son corps volatisé du fait de la puissance de la déflagration, Macunaíma avait enterré un cercueil vide et ne s'était plus soucié du bijou. Quand il le voit au cou de Venceslau, il conçoit aussitôt le projet de le récupérer. Le duel qui se prépare rappelle évidemment celui du Dragon de la cruauté contre le Saint Guerrier tant il est vrai que Venceslau cumule les attributs du millionnaire capitaliste arrogant ne devant sa fortune qu'à l'exploitation de ses semblables. Le fait qu'il soit un ogre constitue une allégorie assez claire à ce sujet. Macunaíma, par contre, est dépourvu de tous les attributs du Saint Guerrier.

Du point de vue de son comportement, il n'a pas changé. Toujours aussi paresseux, égoïste et lubrique, à peine consolé de la mort de $\mathrm{Ci}$, il a contracté le muguet ${ }^{1075}$ suite à de nouvelles frasques sexuelles avec une mère et ses deux filles. D'autre part, il a abandonné ses frères dans une situation périlleuse où ils risquaient de se faire lyncher suite à un imbroglio qu'il avait lui-même provoqué. Enfin, incapable de travailler et de se prendre en charge, sa crédulité l'a successivement poussé à acheter une oie censé déféquer de la monnaie et à écraser d'un coup de pierre ses propres testicules sous prétexte qu'il pouvait s'agir d'un met délicieux. Le chagrin n'a donc pas transformé notre héros dont les motivations ne présentent aucune dimension révolutionnaire. Macunaíma cherche à récupérer la pierre sans autre raison qu'un vague sentimentalisme qui le ramène au passé. Le combat inégal qui va l'opposer au géant est donc aussi un combat inutile même si, paradoxalement, le fait de s'opposer au capitalisme et à l'impérialisme le fasse s'identifier sous nos yeux au Brésil. Les chansons de la bande-son contribuent à cette identification ${ }^{1076}$. Macunaíma est le plus faible mais sa malice 
lui permet de se sauver des situations les plus désespérées et de remporter la victoire dans un retournement inattendu. Il entre dans l'hôtel particulier du géant successivement habillée en femme, puis deux fois par effraction, et enfin, invité par Venceslau lui-même. Dans ce dernier face à face, il porte un frac jaune et vert, les couleurs du Brésil. Paraissant à la merci de l'ogre, dans un ultime coup de théâtre, il réussit à arracher la pierre de son cou et à le précipiter dans la feijoada géante qu'il était lui-même supposé agrémenter.

Une fois qu'il a vaincu le géant, Macunaíma reprend le chemin de la forêt avec ses frères, une princesse et des appareils électro-ménagers qu'il emporte comme des trophées de guerre. De retour à la maloca dont le toit et les murs tombent en lambeaux, le héros sombre dans la plus profonde apathie. Il est alors abandonné par ses frères et la princesse qui n'acceptent plus qu'il ne participe ni aux tâches ménagères, ni à la chasse et à la cueillette. Il rencontre un perroquet à qui il raconte ses aventures, c'est à ce perroquet que le narrateur doit de pouvoir nous transmettre le récit. Un jour, Macunaíma retrouve pourtant ses dispositions et part se baigner. Il voit alors Iará, une divinité mythologique au corps de femme qui flotte nue au milieu de l'étang. Fasciné par cette apparition, il plonge pour la rejoindre mais il est entraîné au fond de l'eau et dévoré. Cet épilogue est évidemment propre à décevoir. Comment Macunaíma, après avoir réussi l'exploit de vaincre le géant, peut-il revenir à son point de départ et souffrir une fin aussi misérable ? De sa victoire, « o herói da nossa gente » (notre héros), ne fait rien. Celle-ci n'est synonyme d'aucune transformation, ni pour le personnage, ni pour la collectivité. L'impuissance et l'inconséquence de Macunaíma l'excluent de la catégorie des héros, il n'est pas sûr non plus qu'il soit nôtre, sinon par l'absurdité de son destin. Ainsi, parce que sa trajectoire est à la fois insignifiante et significative, Macunaíma reflète le Brésil mieux que tous les héros copiés des mythologies nationalistes européennes.

Comme nous l'avons montré cependant, si le film adopte un point de vue critique envers son personnage principal et le spectateur lui-même, les positions qui transparaissent au fil de la narration ne sont pas pour autant résolutives et aucun dispositif n'est prévu pour qu'elles s'imposent comme des vérités au spectateur sans offrir, à leur tour, le flanc à la critique. La morale du film reste ouverte et la narration, dans sa globalité, fonctionne comme une immense provocation capable d'impliquer à divers niveaux des individus de partis et de points de vue opposés dans le contexte socio-politique brésilien de la fin des années soixante. Macunaíma reflète le Brésil mais il n'est pas le brésilien moyen. Il est avant tout un savant

amarelo. Ces musiques sont Desfile aos heróis do Brasil et Paisagens da Minha Terra, toutes deux d'Heitor Villa-Lobos. La trajectoire de Macunaíma montre que ces hymnes ne correspondent à rien de réel dans un pays où chacun est abandonné à son propre sort. Le film condamne ce nationalisme pour ce qu'il est : une formidable tentative d'auto-suggestion par laquelle on se donne bonne conscience en se convainquant que l'idéal de la démocratie raciale a été atteint par le Brésil. 
mélange de clichés qu'il dénonce à mesure qu'il les incarne. En matérialisant un certain nombre d'idées reçues selon les méthodes de détournement et collage propres au tropicalismo, il renvoie le public à ses propres contradictions culturelles et idéologiques. Le dénouement déceptif de la fabula prend toute sa dimension à partir des contradictions mises au jour par la trajectoire et la personnalité de l'anti-héros. L'intention de Andrade est à notre avis pleinement réalisé quand il déclare :

«Visto hoje, Macunaíma está no passado. Inclusive porque continuamos vivos depois que ele morreu. Não há nenhuma tranqüilidade em verificar, pela descrição da vida de Macunaíma desde o nascimento até a morte, passando por tantas aventuras que o herói de nossa gente (será?) viveu em vão. Apesar de termos uma consciência melhor informada, não seremos nós, os espectadores de Macunaíma, os primeiros a terem o poder de morrer tranqüilos. ${ }^{1077}$

La trajectoire de Macunaíma, nous l'avons déjà dit, renvoie aux propres contradictions du Brésil. Les terribles inégalités du développement économique sont montrées dans la persistance de modes de vie primitifs de la forêt au côté des modes de vie modernes que nous retrouvons dans la mégalopole. À peine esquissée, l'opposition classique centre urbain développé et civilisé / forêt sous-développée et sauvage, est rapidement battue en brèche par la critique de l'homme moderne et les injustices sociales dont la ville est le théâtre. Les rencontres de Macunaíma avec les prostituées, les mendiants, les petits escrocs, Ci et le géant Venceslau montrent bien que le monde moderne de béton et de machines n'est pas le lieu d'un plus grand épanouissement de l'homme mais bien celui de nouvelles formes d'exploitation et d'exclusion. Certaines séquences participent d'ailleurs d'une dénonciation directe, c'est à dire non-allégorique, de plusieurs des aspects les plus choquant de la société brésilienne de cette fin des années soixante.

La première séquence est celle qui montre rapidement un voyage de «pau-dearara $»^{1078}$ quand Macunaíma, après la mort de sa mère, quitte la forêt avec ses frères. Les conditions inhumaines du voyage et la perspective de mauvais traitements, sont présentées

$1077 « \mathrm{Vu}$ aujourd'hui, Macunaíma appartient au passé. Notamment parce que nous sommes toujours en vie après que lui soit mort. Il n'est pas très confortable de vérifier, avec la description de la vie de Macunaíma depuis sa naissance jusqu'à sa mort, en passant par tant d'aventures, que notre héros a vécu en vain. Bien que nous soyons mieux informés, nous ne serons pas, nous autres spectateurs de Macunaíma, les premiers à avoir le privilège de mourir la conscience tranquille. » in ANDRADE, Joaquim Pedro de. «Macunaíma : o cinema do herói vital, entrevista a Oswaldo Caldeira », op. cit.

1078Le terme « pau-de-arara » désigne aussi bien les camions qui assurent le transport des émigrés du Nordeste allant chercher fortune dans les États plus riches de São Paulo et Rio de Janeiro que leurs occupants. Ceux-ci effectuent un voyage long de plusieurs milliers de kilomètres dans des conditions dangereuses et inconfortables. Pour se maintenir en équilibre le long du trajet, les voyageurs doivent s'accrocher aux barres transversales qui soutiennent une capote souvent improvisée. C'est le fait de devoir s'accrocher, comme un perroquet dans une cage, à un barre transversale qui a donné son nom à ce mode d'émigration, « pau-dearara », littéralement « barre de ara ». Les circonstances de ce voyage sont toujours dramatiques. Les émigrants, appelés retirantes, quittent leur région d'origine chassés par la sécheresse et la faim et se trouvent par la suite exposés à la mendicité ou à différentes formes d'exploitation quand ils parviennent à trouver un travail. 
sans emphase mais l'absence de soin apporté à l'éclairage et à l'encadrement apporte une tonalité documentaire et donc authentique aux images. Nous y voyons d'abord Macunaíma au milieu des retirantes. De jour, le camion avance sur une route de terre. Le personnage, comme les autres figurants, se tient à l'une des barres transversales sur lesquelles est posée une capote en plastique qui abrite la plate-forme arrière du véhicule. Une fois arrivé près de la ville de destination, toujours en rase-campagne, femmes et enfants descendent du camion en sautant et s'enfoncent dans la forêt. Off, le chauffeur de camion crie ses paroles peu rassurantes :

«Pronto, ponto final. Daqui não passa. Desce todo mundo e vai a pé pelo mato. Se o governo vê vocês chegando vai tudo mundo preso de volta prá roça. Diz que já têm mendigos demais na cidade. Vamos embora gente ! Agora é cada um por si e Deus contra ! ${ }^{1079}$

La deuxième séquence est celle des déambulations de Macunaíma, de ses frères et de Iriqui en ville, avant la rencontre avec $\mathrm{Ci}$. Cette séquence soulève deux problèmes. Elle permet le développement d'une critique de la société moderne proche de celle de Marcuse et pose le problème de la prostitution qui est étroitement lié à celui de la misère et de l'absence de protection des jeunes femmes d'origine pauvre. Macunaíma passe sa première nuit à Rio de Janeiro dans une maison de passe tandis que sa belle-sœur, Iriqui, « é prontamente contratada e desaparece do filme. » («[...] est aussitôt recrutée et disparaît du film. ») Le destin d'Iriqui n'est évidemment pas sans rappeler celui de milliers de jeunes femmes. Le thème de la prostitution avait déjà été évoqué par Tocaia no asfalto, il le sera de nouveau dans d'autres films post-Cinema Novo comme Lúcia Mac Cartney, uma garota de programa (Neves, 1971) et Iracema, uma transa amazônica (Senna et Bodanzki, 1976).

Sur la critique de la société moderne, le texte de la séquence 26 de l'un des traitements intermédiaires du scénario de Macunaíma était très clair. Plutôt que de décrire la séquence, Andrade avait noté ce qu'il voulait montrer :

« A exploração do homem pelo homem, a violência do homem contra o homem, misturados com fórmulas convencionais de polidez, aparecem massificadas e quando não vêm a primeiro plano, uma comédia da violência, uma sátira aos bons costumes, um demistificação dos bons sentimentos. As máquinas, humanizadas ou arredias, independentes, lutam com os homens e às vezes entre si - como servem aos homens - e Macunaíma especula sobre essas relações, muito aflito a princípio, sem saber se as máquinas é que são os homens ou vice-versa, depois tranquilizado quando decide que há empate nessa luta. $»^{1080}$

1079« Stop, terminus. Personne ne va plus loin. Tout le monde descend et continue à pied en passant par la forêt. Si le gouvernement vous voit arriver tous ensemble, tout le monde sera fait prisonnier et ramené à la campagne. Ils disent qu'il y a déjà trop de mendiants dans la cité. Dispersez-vous ! Maintenant, c'est chacun pour soi et Dieu contre tous. » Dialogue du film.

1080« L'exploitation de l'homme par l'homme, la violence de l'homme contre l'homme, voilés par des formules conventionnelles de politesse, apparaissent multipliées en masse et, quand elles ne sont pas au premier plan, une comédie de la violence, une satire des bonnes mœurs, une démystification des bons sentiments. Les machines, humanisées ou hostiles, indépendantes, luttent avec les hommes et parfois entre elles - comme elles servent aux hommes - et Macunaíma spécule sur ces relations, très triste au début, sans savoir si ce sont 
Comme dans Fome de amor, nous retrouvons donc la référence à Marcuse et l'idée qu'avec le progrès technologique et l'urbanisation sont arrivées de nouvelles formes de contrôle et d'exploitation plus rigoureuses et cruelles que les anciennes. Nous ne savons pas très bien à quelles machines Andrade pensaient quand il a écrit la séquence, il s'agit a priori d'engins présents dans la rue. Dans le film, la voix off reprend à son compte le texte écrit dans le scénario et, sur la bande-image, nous verrons Macunaíma déambuler dans la rue avec ses frères et s'étonner du trafic automobile et de l'agitation humaine. Dans d'autres séquences, nous retrouverons l'ascenseur pour voiture et les appareils électro-domestiques. Quoiqu'il en soit, l'ambiguïté qui apparaît dans la relation homme-machine participe bien de cette idée selon laquelle les machines construites pour servir les hommes se retourneraient contre eux, les hommes qui les ont créées commençant à vivre pour elles dans une relation d'interdépendance et de mimétisme. L'homme tendrait alors à se conformer à sa création qui représenterait son idéal. Cette vision pessimiste de la technologie et de l'avenir de l'humanité s'inscrit dans une rupture complète avec les présupposés initiaux du Cinema Novo. Fome de amor marquait l'appropriation de ces idées par rapport au contexte politique du Brésil. Macunaíma les rapporte au contexte social et culturel et au concept d'anthropophagie. Au travers de la triste trajectoire de Macunaíma, c'est bien la tragédie d'une société qui s'autodévore que le film cherche à dénoncer :

«Aparte de las relaciones entre las personas básicamente antropofágicas, esa civilización burguesa competitiva donde los hombres, existe otro fenómeno tal vez más importante, ciertamente más numeroso, el fenómeno de la antropofagia nacional. El Brasil devora a los brasileños, porque el número de brasileños que mueren constantemente víctimas de las condiciones en que vive el propio país, es decir, víctimas de la pobreza, del subdesarrollo, de la miseria, es enorme, un verdadero genocidio que ocurre permanentemente. La película trata de representar todo eso. $»^{1081}$

Avant de continuer l'analyse de Macunaíma, il convient de noter qu'un certain nombre de modifications sont intervenues entre les premiers traitements du scénario ${ }^{1082}$ et l'histoire qui sera effectivement tournée. Au final, la charge satirique du film est essentiellement

les machines qui sont les hommes ou le contraire, ensuite, il se tranquillise en décidant qu'il y a égalité dans cette lutte. » in Séquence 26. ANDRADE, Joaquim Pedro de. O Herói sem caráter : Adaptação para o cinema do livro Macunaíma de Mário de Andrade, segundo tratamento. Texte dactylographié, 57 pages, sans date, p. 16.

1081 «En marge des relations entre les personnes qui sont fondamentalement anthropophages, cette civilisation bourgeoise de compétition dans laquelle les hommes se dévorent entre eux, il existe un autre phénomène, certainement plus important, qui est celui de l'anthropophagie nationale. Le Brésil dévore les brésiliens qui meurent constamment victimes des conditions dans lesquels vit leur propre pays, autrement dit, de la pauvreté, du sous-développement, de la misère, c'est énorme, c'est un véritable génocide qui se déroule sans interruption. Le film essaye de montrer cela. » in ANDRADE, Joaquim Pedro. « Una tarde con Joaquim Pedro de Andrade - Macunaíma política indirecta - Mario Jacob / José Wainer » in Cine Cubano, La Havane, $n^{\circ} 66-67$, janvier 1971.

1082ANDRADE, Joaquim Pedro de. O Herói sem caráter : Adaptação para o cinema do livro Macunaíma de Mário de Andrade, segundo tratamento. Op. cit. 
allégorique et nécessite, comme nous l'avons vu, une actualisation assez fine du caractère et de la trajectoire du personnage principal de sa naissance à sa mort tragique. Les premiers scénarios ne diffèrent pas beaucoup du film quant à la structure générale de la narration, dans l'ordre et le nombre d'épisodes ou encore dans le système des actants. À côté du souci constant de simplification et de synthèse manifesté par l'auteur en comparaison au roman, il apparaît cependant qu'une séquence complète, un certain nombre de plans et des phrases de dialogue destinés à dénoncer de façon explicite les aspects les plus révoltants de la société brésilienne des années soixante ont été supprimés. La suppression de ces passages et la permanence de ceux que nous avons cités qui mettent en cause la prostitution et les pau-dearara montrent le souci de l'auteur à rechercher la limite de ce que la censure lui permettra. La présence de ces éléments de dénonciation directe confirme la nature des intentions d'Andrade qui apparaissent dès les premières versions de l'adaptation du livre de Mário de Andrade.

Une séquence mettant directement en scène les escadrons de la mort est supprimée du film. Ceux-ci devaient être décrits dans toute leur horreur à la séquence 30 :

\begin{abstract}
« Os irmãos agora, [...], vão andando por um lugar desolado e se aproximam do rio da Guarda onde vem boiando um cadáver de mendigo. Os mesmos homenzarrões que tinham perseguido Ci estão tirando mais mendigos de um caminhote preta, dessas de carregar gente presa. Os homens maltratam e espancam e torturam os mendigos, homens e mulheres depois os atiram no rio, mais mortos que vivos, às vezes com pedras amarradas no corpo. Se divertem com as maldades que fazem e a coisa tem mesmo sua graça, menos para os mendigos. » ${ }^{1083}$
\end{abstract}

$\mathrm{Au}$ côté des scandales que constituent la prostitution, les paus-de-arara et les escadrons de la mort, la misère « ordinaire » de Rio de Janeiro est omniprésente. Elle fait partie de la trajectoire du personnage principal et de ses frères qui suivent le même parcours que celui des autres retirantes qui se retrouvent perdus dans la métropole. Plusieurs passages qui s'y référent directement seront pourtant retranchés du film. Dans la séquence 34, comme les nombreux sans logis qui s'installent au bord d'une avenue, d'une route ou sur une place, Macunaíma devait étendre son linge dans la rue, sur la place de la Cinelândia ${ }^{1084}$, dans la séquence 56, par distraction, il trébuchait sur un corps humain qui était allongé par terre ${ }^{1085}$.

1083 « Les frères [...] s'en vont maintenant vers un lieu isolé et s'approchent de la rivière de la Guarda où dérive le cadavre d'un mendiant. Les mêmes personnages brutaux qui avaient poursuivi $\mathrm{Ci}$, sont en train de sortir encore plus de mendiants d'une camionnette noire, de celles-là même où on emporte les gens qui viennent de se faire arrêter. Les hommes maltraitent, battent et torturent les mendiants, hommes ou femmes et les jettent dans le cours d'eau, plus morts que vivants, parfois en lestant le corps avec des pierres. Ils s'amusent des méchancetés qu'ils font et il est vrai que la chose a vraiment un côté amusant, sauf évidemment pour les mendiants. » in ibid.

1084Cette image renvoie à la situation des retirantes qui s'installent au bord des routes ou sur les places des grandes villes et dont l'espace privé, signalé par la présence d'accessoires domestiques et de vêtements, est exposé à tous les regards.

1085Il s'agit là d'une autre scène de la vie ordinaire carioca. De jour comme de nuit, de nombreuses personnes 
En plus de la dénonciation explicite de la misère urbaine et des exactions qu'elle facilite, les critiques directes à la politique du gouvernement militaire seront également censurées. Au cours de la séquence 28, dans l'appartement de $\mathrm{Ci}$, au milieu des accessoires indispensables à la guérilla urbaine, la caméra devait montrer une cible de tir représentant la silhouette d'un militaire. Dans la séquence 37, un journaliste devait interviewer le géant et millionnaire, Venceslau. Une question directe sur la politique économique du gouvernement était posée à laquelle Venceslau répondait qu'il trouvait cette politique magnifique puisque tous les jours, lui qui était déjà immensément riche, continuait à enrichir. L'impérialisme est aussi évoqué, séquence 64 , dans une boutade du géant interrogé lors de la fête finale sur l'absence de sa fille. Il indique qu'il l'a envoyée étudier aux États-Unis car elle devenait « bonzinha demais » (trop gentille).

L'absence de ces passages ne nuit ni au sens ni à la compréhension générale du long métrage. Bien que Macunaíma recourt à un langage allégorique, comme finalement tous les films du Cinema Novo de cette période, il nous semble qu'il échappe à tout hermétisme car son actualisation ne nécessite pas la mobilisation de connaissances que le spectateur pourrait ne pas avoir. Le processus de pleine compréhension du film demande une interprétation assez fine mais sa complexité ne se pose pas dans les mêmes termes que se posait celle de Fome de amor ou de Capitu qui demandaient des connaissances politiques, historiques,

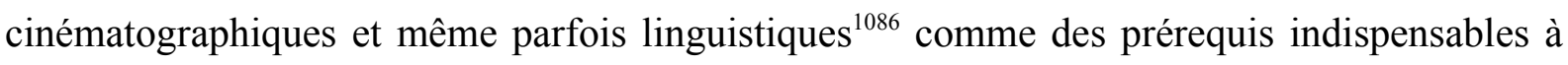
ce processus. Enfin, le langage de Macunaíma, en réaction à celui de O Padre e a moça, écarte toute sophistication. Selon les paroles d'Andrade lui-même : « Macunaíma é um filme, digamos, chocantemente informal. ${ }^{1087}$ Pour autant, il ne s'est pas agi d'accepter le cadre du cinéma classique ou hégémonique entendant, comme cela est souvent le cas, qu'il s'agit là de la seule méthode qui permette à un auteur de se faire comprendre. Andrade, comme Rocha, soumet le langage cinématographique à de sévères restrictions qui sont d'abord la conséquence d'une éthique. Il récuse le montage fluide, le jeu du champ / contre-champ et dans le cas précis de Macunaíma, il explique :

«Macunaíma é um filme que não tem close, para evitar a individuação dos problemas,

dorment dans les rues à même le trottoir, souvent seulement habillé d'un caleçon. Il arrive aussi que l'immobilité du corps soit telle que l'on en vienne à douter que la personne soit morte ou vivante. Les sentiments d'indifférence, d'impuissance ou de peur sont si généralisés qu'il est bien rare de voir quelqu'un s'inquiéter de l'état de santé de ces personnes.

1086Certains passages de Fome de amor sont en anglais et en espagnol, sans sous-titrage dans la version originale. De plus, qui ignorait que l'on citait Mao ou Che Guevara perdait nécessairement de la saveur de nombreuses séquences. Le problème se reposera avec Os Herdeiros dans lequel le personnage joué par JeanPierre Léaud parle en français, une fois de plus sans sous-titrage. La question des langues étrangères est un élément parmi d'autres qui, dans plusieurs des films du Cinema Novo, créent une distance cognitive qui exclut de larges parcelles du public.

1087 « Macunaíma est un film, disons, violemment informel. » in ANDRADE, Joaquim Pedro de. « Macunaíma : o cinema do herói vital, entrevista a Oswaldo Caldeira », op. cit. 
para levar aquilo a qualquer brasileiro que pudesse passar por uma situação daquelas; que despreza qualquer limite rigoroso no enquadramento. $\rangle^{1088}$

Une fois ces restrictions adoptées, le cinéaste reprend à sa manière les orientations tracées par Leon Hirszman avec Garota de Ipanema et développe l'idée d'un cinéma qui saurait cumuler impact critique et attraits commerciaux. Plus précisément, il recourt à la couleur et poursuit le travail de réhabilitation de la chanchada commencé par Hirszman. Comme dans Garota de Ipanema et O Dragão..., l'usage de la couleur n'est pas gratuit. Audelà de la préoccupation commerciale consistant à répondre à la demande du marché pour des films en couleur, celle-ci est parfaitement intégrée à l'esthétique du film. La multiplication des couleurs criardes et des assortiments de mauvais goût pour les costumes des frères et les intérieurs du palais du géant participe des allégories tropicalistas. La chanchada est citée dans le recours à certains de ces acteurs comme Grande Othelo ainsi que dans la pratique d'un humour grossier qui participe de la caractérisation des personnages ${ }^{1089}$.

Le succès populaire et critique du film tend à démontrer que Macunaíma a été parfaitement compris et assimilé par le public. Sa sortie à Rio de Janeiro, au début du mois de novembre 1969, est précédée par ses démêlés avec la censure et son succès auprès de la critique internationale à Venise ${ }^{1090}$. Malgré le caractère irrévérencieux de l'œuvre, les mauvaises critiques sont rares. Carlos Maul, du Jornal do comércio, fait écho à l'agacement provoqué par le film auprès des secteurs les plus conservateurs. Selon lui, le livre de Mário de Andrade était déjà un dépôt de monstruosités, il en va de même pour le film qui donne une vision déformée du pays. Le critique déclare :

«O gigante coberto de pedrarias representa o Brasil, o Macunaíma borboleteia numa área de equívocos em que sangue e miséria se confundem... O consumo do escatológico e do pornográfico é abundante nos gestos e nos vocábulos. Os intérpretes se degradam na encarnação dos tipos, requintam nas suas expansões que vão do grotesco ao infecto... $»^{1091}$

L'irritation est parfois dissimulée par le même mépris que celui qui pouvait être

1088« Macunaíma est un film sans premier plan, pour éviter l'individualisation des problèmes, pour pouvoir amener tout ceci à n'importe quel brésilien qui pourrait passer par l'une de ces situations ; qui méprise toute limite rigoureuse du point de vue du cadrage. » in HERMANNS, Ute. « Joaquim Pedro levou literatura às telas » in Folha de São Paulo, São Paulo, 21/04/1990.

1089L'humour des personnages est souvent grossier mais pas celui du film qui procède d'associations surréalistes interprétables selon différents niveaux de lecture. C'est notamment ce que nous avons vu avec l'analyse des séquences où $\mathrm{Ci}$ apparaît et où elle se bat avec Macunaíma. La séquence où elle poursuit Macunaíma en le battant avec des branches d'ortie aurait aussi mérité une analyse dans ce sens.

1090GUIDEZ, Guylaine et TEIXEIRA, Novais. «Veneza: - Macunaíma é o Brasil Senhor do Festival in Última Hora, 04/09/1969.

1091« Le géant couvert de pierres précieuses représente le Brésil, Macunaíma virevolte dans un milieu d'équivoques où le sang et la misère se confondent... l'exploitation du scatologique et du pornographique est abondant dans les gestes et les vocables. Les interprètes se dégradent dans l'incarnation des différents types, et s'appliquent dans leurs expressions qui vont du grotesque à l'infect... » in MAUL, Carlos. « Ressurreição de Macunaíma » in Jornal do comércio, Rio de Janeiro, 20/11/1969. 
adressé autrefois à la chanchada. C'est le cas de Nelson Hoineff qui estime que Macunaíma n'est pas un bon film mais qu'il est communicatif ${ }^{1092}$. À l'opposé de ces points de vue conservateurs, Flávio Costa da Moreira, pourtant supporter du Cinema Novo sur lequel il a coordonné un ouvrage en $1966^{1093}$, développe l'idée selon laquelle les films à gros budget, et donc Macunaima, ont «trahi » et ne sont plus des films du Cinema Novo mais des films du système. Au-delà de cette soumission aux règles du marché, il estime que l'allégorie totalisante de Macunaíma est moralisatrice. Il articule sa critique à celle de Graciliano Ramos du livre de Mário de Andrade et reprend d'anciens reproches qui pouvaient être adressées au Cinema Novo, à savoir que le brésilien moyen, le travailleur des champs ou de l'usine, demeurait absent des écrans. Macunaíma, selon lui, ne peut rendre compte du Brésil réel. Paradoxalement, c'est à partir des mêmes prémisses et d'une analyse assez proche, qu'Ely Azeredo écrit une critique très positive du film.

Le critique du Jornal do Brasil pense aussi que Macunaíma est un film de rupture avec le Cinema Novo mais, au contraire de Moreira, il voit dans les changements qu'il inaugure un pas en avant dans la recherche d'une définition du cinéma brésilien. Selon lui, le film de Andrade marque l'abandon de l'obsession à réaliser des œuvres d'art parfaites et éternelles, renoue habilement avec l'ancien au travers de la chanchada et pratique une autocritique du Cinema Novo à partir de la thèse du héros sans caractère. L'esthétique de Macunaíma constituerait une proposition de cinéma sans caractère pour un public encore inconnu. Le long métrage triompherait en vivant le manque de précision de son héros. En partant d'une position plus humble que ses prédécesseurs, il réussirait là où les autres avaient échoué $^{1094}$. Quatre ans plus tard, dans un article consacré à Tati, a garota (Bruno Barreto, 1973), Azeredo développe son point de vue :

\footnotetext{
« Cada filme queria ser o universo (ou o Nordeste, ou a América Latina, ou o Terceiro Mundo, etc.) antes que fosse alcançado um mínimo de identificação cinematográfica do protagonista-mor, aquele capaz de interessar ao público nacional : o homem brasileiro. [...] Com raras exceções, o Cinema Novo não captou o bancário engarrafado num fusca, o atribulado funcionário público, o homem do campo com um problema muito concreto de subsistência, o estudante no gargalo do vestibular, o repórter entre o drama coletivo e a notícia de consumo, o comerciário frente ao sonho da casa própria, etc. Entre a pesquisa de linguagem e (na maioria dos casos) a volúpia do brilho pessoal, o cinemanovista isolou-se do público e queimou uma oportunidade histórica para fazer do cinema o melhor parlamento. $»^{1095}$
}

1092HOINEFF, Nélson. « Macunaíma » in Diário de notícias, Rio de Janeiro, 07/11/1969.

1093COSTA, Flávio Moreira Da. (Org.). Cinema moderno Cinema Nôvo. Rio de Janeiro, José Alvaro Editor S.A., 1966.

1094AZEREDO, Ely. « Macunaíma » in Jornal do Brasil, Rio de Janeiro, 07/01/1969.

1095« Chaque film prétendait être un univers (ou le Nordeste, ou l'Amérique Latine, ou le Tiers Monde, etc.) avant que ne soit atteint un minimum d'identification avec le principal personnage susceptible d'intéresser le public brésilien : l'homme brésilien. [...] Sauf dans de rares exceptions, le Cinema Novo n'a pas capté le banquier [l'employé de banque ?] prisonnier d'un embouteillage dans sa coccinelle, le fonctionnaire public surchargé de travail, l'homme de la campagne confronté à un problème très concret de subsistance, l'étudiant confronté à l'épreuve du vestibular [concours d'entrée à la faculté], le reporter hésitant entre le drame collectif 
En abandonnant ses ambitions avant-gardistes, le Cinema Novo se donnait enfin la possibilité de construire, dans une véritable interaction avec le public, le cinéma brésilien comme, supposément, les grands cinémas mondiaux s'étaient bâtis. Il n'est pas sûr, comme nous l'avons vu, que l'on puisse systématiser les ambitions avant-gardistes à tous les films du Cinema Novo. S'il s'agit bien d'un reproche récurrent qu'il lui a été adressé, les cinemanovistas se sont quant à eux toujours défendus de pratiquer un quelconque esthétisme, défaut qu'ils reprochaient à d'autres réalisateurs comme Walter Hugo Khoury. Dans l'esprit de Andrade, il était sans aucun doute beaucoup plus question d'une évolution que d'une rupture ou d'un retournement par rapport aux postulats initiaux du Cinema Novo. En rencontrant l'approbation du public tout en restant un film critique, Macunaíma remplit le cahier des charges du mouvement autant du point de vue culturel que politique. Rocha écrit un article dithyrambique sur le film qu'il resitue précisément par rapport à cet ancien objectif de la conquête du marché avec des films décolonisés et décolonisateurs :

«É preciso distinguir entre CONQUISTAR o mercado com filmes DESCOLONIZADOS E DESCOLONIZADORES e EXPLORAR o mercado com filmes COLONIZADOS e COLONIZADORES.

Vou trocar em miúdos pela última vez; filmes descolonizados são aqueles que se recusam a imitar modelos americanos e buscam refazer o cinema nacional a partir de nossas verdadeiras raízes culturais. Ex : Macunaíma, grande êxito de público e crítica. Isto é CONQUISTAR o público.

Filmes colonizados são aqueles que utilizam as fórmulas pornográficas e violentas do cinema estrangeiro. Ex : as habituais comédias de iê-iê-iê ou os filmes de sexo que infestam o mercado. Isto é EXPLORAR o público. $\gg{ }^{1096}$

Como era gostoso o meu francês devait réussir la même prouesse.

\subsection{Como era gostoso o meu francês}

Après Macunaíma, Como era gostoso o meu francês revient au thème de l'anthropophagie selon une approche à la fois simple et parfaitement intelligible sans pour

et le scoop vendeur, le commerçant rêvant d'accéder à la propriété de sa maison, etc. Entre la recherche formelle et (dans la plupart des cas) la volupté de l'étalage de sa virtuosité, le cinemanovista s'est isolé du public et a raté une chance historique de faire du cinéma le meilleur parlement. » in AZEREDO, Ely. "Tati substantiva » in Jornal do Brasil, Rio de Janeiro, 19/04/1973.

1096« Il faut faire la différence entre CONQUÉRIR le marché avec des films DÉCOLONISÉS ET DÉCOLONISATEURS et EXPLOITER le marché avec des films COLONISÉS ET COLONISATEURS. Je vais l'expliquer une dernière fois ; les films décolonisateurs sont ceux qui refusent d'imiter les modèles américains et cherchent à refaire le cinéma national à partir de nos véritables racines culturelles. Ex : Macunaima, grand succès public et critique. Ceci est CONQUÉRIR le public.

Les films colonisés sont ceux qui utilisent les formules pornographiques et violentes du cinéma étranger. Ex : les habituelles comédies yéyé ou les films de sexe qui infestent le marché. Ceci est EXPLOITER le public. » in ROCHA, Glauber. « Contra direitas e esquerdas o nosso cinema segue em frente » in Última hora, Rio de Janeiro, 12/02/1970. 
autant sacrifier à la complexité du propos. Les différences entre les deux films sont assez grandes. Macunaíma propose une relecture du Modernismo qui présente deux principales qualités. La première est de permettre l'actualisation d'un des mouvements artistiques les plus intéressants de l'histoire du Brésil et de réintégrer l'intellectuel dans une pratique participante expurgée du paternalisme qui lui avait nuit en de nombreuses occasions. La deuxième qualité est de proposer une vision démystificatrice du Brésil coïncidant avec les impostures de l'époque du Miracle économique et du nationalisme chauvin et fasciste du «Brasil grande ». Como era gostoso o meu francês présente aussi cette valeur vulgarisatrice du Modernismo, le roman de Mário de Andrade étant ici substitué par le Manifeste anthropophage d'Oswald de Andrade. Mais, au contraire d'Andrade qui s'attache à dénoncer les inégalités d'un Brésil qui «s'auto-dévore », Santos se propose de transmettre au pays une philosophie de vie qui lui permette de faire de ses contradictions une force et dont l'adoption ne permettrait pas seulement une révolution nationale mais une révolution mondiale totale grâce à la réalisation d'une utopie à la fois proche et lointaine : la « Révolution caraïbe ».

Avant d'entrer plus avant dans l'analyse, il convient d'expliquer que le mouvement moderniste brésilien se divisait en deux tendances. La première était marquée par l'idée de la «grandeur » du Brésil. Celle-ci s'inscrivait en complète contradiction avec la mentalité des élites brésiliennes du XIXe siècle et de la República Velha convaincues de son incapacité technologique et de sa vocation à rester un pays rural et périphérique des grands centres civilisateurs. Cette volonté d'identifier le sentiment national avec un sentiment de "fierté » (ufanismo) conduit à établir une relation mimétique avec les nationalismes européens. Elle va donner naissance à un patriotisme cocardier, exalté et mystificateur, le « verde-amarelismo », dont les meilleurs représentants sont le roman Martim Cererê (1928) de Cassiano Ricardo et le film O Descobrimento do Brasil (1937) de Humberto Mauro. La critique qui peut être faite à cette tendance du Modernismo est la même que celle que Graciliano Ramos a faite au film de Mauro. Cherchant à fonder dans l'événement de la découverte du Brésil, le mythe des origines de la «démocratie raciale», l'envahisseur portugais, mais aussi l'indigène amérindien ${ }^{1097}$, ont été parés de qualités ${ }^{1098}$ qu'ils n'avaient pas. La division du Modernismo en deux tendances recouvre aussi un clivage politique. La première tendance va s'identifier à des

1097Ce que Ramos ne remarque pas.

1098Le portugais apporte au Brésil les « richesses » de la civilisation occidentale : la science et la religion chrétienne, l'indien se révèle en retour un disciple attentif, il offre spontanément sa cordialité, son énergie et sa force de travail. Il est également prêté aux indiens des défauts qu'il n'avait pas. Dans le film de Mauro, ils ne semblent pas adaptés à leur propre milieu, souffrant les attaques d'insectes et arborant une gestuelle ridicule. Les valeurs de la civilisation leur apporte enfin un cadre qui leur permettra de s'extirper de leur primitivisme et d'accéder à de meilleures conditions de vie. Voir à ce sujet :

FICAMOS Bertrand. Educação e propaganda no cinema de Humberto Mauro : Uma Outra Abordagem do filme O Descobrimento do Brasil (1937) in Locus : revista de história. Juiz de Fora, vol. 8, n², 2002. 
idéologies autoritaires et fascisantes auxquelles le parti Integralista puis l'Estado Novo donnent, dans les années trente, une expression politique concrète. Ce patriotisme chauvin survivra au Modernismo et la propagande de la dictature, en particulier pendant le gouvernement Médici, va se l'approprier ${ }^{1099}$.

La seconde tendance du Modernismo prônait au contraire un nationalisme critique, sensible aux inégalités sociales et à la diversité culturelle du Brésil. Rompant avec la construction d'un modèle idéal de brasilidade qui devrait s'imposer à tous, conscient aussi que ce modèle était fondé sur une réécriture romantique et partiale du passé, cette seconde tendance s'opposait aux utopies de la « raça nova » et de la "démocratie biologique » ou « démocratie raciale ». À l'instar de Sérgio Buarque de Hollanda qui critiquait le mythe de la « cordialité » de l'homme brésilien, il fallait remettre en question celui de la fusion des races, dont les qualités supposées ontologiques se compléteraient entre elles. C'est dans un esprit de contestation que Mário et Oswald de Andrade fondèrent le mouvement anthropophagique. Au lieu d'encourager un retour sur un passé mystifié, ce mouvement plaide pour l'acceptation du caractère hybride de la culture brésilienne et l'assimilation des idées, des valeurs et des modes de symbolisation des cultures étrangères pour faire émerger une vision du monde originale, brésilienne. Le choix du terme « anthropophagie » est motivé par la richesse de la métaphore qui renvoie à une pratique originale des indiens de l'époque de la colonisation. Ceux-ci croyaient qu'ils pourraient assimiler la force, le savoir, l'intelligence de leurs ennemis, et notamment l'homme blanc, par un rituel cannibale pour développer leur propre identité. L'anthropophagie culturelle identifie ainsi la brasilidade à une recherche constante basée sur le processus d'assimilation des qualités d'autrui. Il s'agit d'un concept identitaire dynamique, fondé sur le rapport avec l'autre et qui rejette l'idée d'une complétude au profit d'une quête toujours inachevée.

Anarchiste et révolutionnaire, le Manifeste anthropophage énonce les premiers postulats du mouvement. Il est publié en 1928 dans le premier exemplaire de la Revista de Antropofagia dont les exemplaires étaient numérotés de la façon suivante « primeira dentição, segunda dentição » (première dentition, seconde dentition), etc. Le texte cite Montaigne, Rousseau, Goethe, Marx, Freud, André Breton et met en pratique cette posture à la fois indépendante, irrévérencieuse et d'assimilation critique de la culture européenne qu'il préconise. Il s'agit de mettre un terme à l'intériorisation de l'ethnocentrisme européen par les brésiliens. La charge est particulièrement virulente envers l'héritage portugais et l'œuvre des missionnaires. Le Père Antônio Vieira, généralement révéré pour avoir plaidé contre 
l'esclavage des indiens, est ici stigmatisé comme le responsable du premier emprunt financier du Brésil pour lequel il aurait reçu rétribution. La catéchèse et la figure de l'éminent jésuite sont dénoncées comme étant le premières formes de colonisation culturelle et économique, ancêtres directs des formes de colonisation modernes. Filant la métaphore de l'anthropophagie indigène, Oswald de Andrade invite les brésiliens à voir dans les amérindiens leurs véritables ascendants. Pour cette raison, il signe le manifeste comme ayant été écrit à Piratininga (le nom indigène du plateau où a été fondé São Paulo) en 374 de la déglutition de l'Évêque Sardinha. Cette référence remet à un fait historique. Dom Pedro Fernandes Sardinha fut le premier évêque du Brésil où il débarque en 1550. Assez indifférent au sort des indigènes et connu pour son caractère autoritaire, il entre vite en conflit avec les autorités de la colonie. En 1556, il s'embarque pour Lisbonne afin de demander raison au Roi. Mais son bateau fait naufrage. Capturé par les indiens Caetés, il est dévoré dans un banquet rituel avec les 90 membres de l'équipage.

Les idées du Manifeste anthropophage seront retranscrites dans le film de Santos qui lui est intégralement fidèle. L'anthropophagie est le trait caractéristique de l'identité brésilienne, elle est aussi une caractéristique universelle de l'homme :

«Só a Antropofagia nos une. Socialmente. Economicamente. Filosoficamente. / Única lei do mundo. Expressão mascarada de todos os individualismos, de todos os coletivismos. De todas as religiões. De todos os tratados de paz. / Tupi, or not tupi that is the question. / [...] Só me interessa o que não é meu. Lei do homem. Lei do antropófago. $\gg{ }^{1100}$

Philosophie libertaire et païenne, en faveur d'un primitivisme défait de l'idéalisme du «bon sauvage », l'anthropophagie rejette le «vernis» de la culture européenne et son hypocrisie :

« Estamos fatigados de todos os maridos católicos suspeitosos postos em drama. Freud acabou com o enigma mulher e com outros sustos da psicologia impressa. / O que atropelava a verdade era a roupa, o impermeável entre o mundo interior e o mundo exterior. A reação contra o homem vestido. $\rangle^{1101}$

Ce bouleversement de point de vue, cette insurrection contre le rationalisme d'importation, recèle en lui-même la transformation totale du monde et la réalisation de l'Eden

1100« Seule l'anthropophagie nous unit. Socialement. Économiquement. Philosophiquement. / Unique loi du monde. Expression masquée de tous les individualismes, de tous les collectivismes. De toutes les religions. De tous les traités de paix. / Tupi, or not tupi that is the question. / [...] Je ne m'intéresse qu'à ce qui ne m'appartient pas. Loi de l'homme. Loi de l'anthropophage. » ANDRADE, Oswald de. «O Manifesto antropófago » in Revista de antropofagia, première année, $\mathrm{n}^{\circ} 1$, mai 1928.

1101 «ous étions fatigués de tous ces maris catholiques soupçonneux et mis en crise. Freud en a terminé avec l'énigme de la femme et toutes les peurs de la psychologie de journal. / Ce qui nous empêchait de voir la vérité, était le vêtement, l'imperméable entre le monde intérieur et le monde extérieur. La réaction contre l'homme habillé. » in ibid. 
en Amérique. La Révolution caraïbe est l'utopie promise par le Manifeste anthropophage :

«Queremos a Revolução Caraiba. Maior que a Revolução Francesa. A unificação de todas as revoltas eficazes na direção do homem. Sem nós a Europa não teria sequer a sua pobre declaração dos direitos do homem. / A idade de ouro anunciada pela América. A idade de ouro. E todas as girls. $\gg{ }^{1102}$

Le manifeste se réfère aux idées exposées par Freud dans Totem et tabou (1912) selon lequel, dans des temps très reculés, le Père de la tribu primitive aurait été tué et mangé par ses fils puis sacralisé. Lois et interdits se sont ensuite créés autour du Totem, forme sous laquelle sa mémoire s'est perpétuée. L'acte d'anthropophagie rituelle des amérindiens est alors conçue comme la transformation permanente et répétée du tabou en totem. Il est une célébration de la vie et de la transformation :

« Tínhamos a justiça codificação da vingança. A ciência codificação da Magia. Antropofagia. A transformação permanente do Tabu em totem. / Contra o mundo reversível e as idéias objetivadas. Cadaverizadas. O stop do pensamento que é dinâmico. O indivíduo vítima do sistema. Fonte das injustiças clássicas. Das injustiças românticas. E o esquecimento das conquistas interiores. $\rangle^{1103}$

Loin d'être pur, ingénu et innocent, l'indien devient malicieux et intéressé, il est un prédateur pour l'étranger. Pour Oswald de Andrade, le Brésil entier serait un pays cannibale. C'est un point de vue subversif puisqu'il inverse la relation colonisateur (actif) / colonisé (passif). Le colonisé assimile le colonisateur. Autrement dit, ce n'est pas la culture occidentale, portugaise, européenne, blanche, qui occupe le Brésil, mais c'est l'indien qui dévore tout ce qui lui vient de l'extérieur. En pratiquant cet acte, il fait siennes les qualités de ses ennemis et devient plus fort et plus brésilien :

«Contra a verdade dos povos missionários, definida pela sagacidade de um antropófago, o Visconde de Cairu: - É mentira muitas vezes repetida. / Mas não foram cruzados que vieram. Foram fugitivos de uma civilização que estamos comendo, porque somos fortes e vingativos como o Jabuti. $)^{1104}$

Malgré la violence de l'acte anthropophagique, l'horizon de cette philosophie est le bonheur. L'anthropophagie s'oppose à une raison déshumanisée capable de légitimer l'absurde. Le Brésil n'avait pas besoin des endoctrinements de la culture européenne :

1102« Nous voulons la Révolution Caraïbe. Plus grande que la Révolution Française. L'unification de toutes les révoltes efficaces en faveur de l'homme. Sans nous, l'Europe n'aurait même pas sa pauvre déclaration des droits de l'homme. / L'âge d'or annoncé par l'Amérique. L'âge d'or. Et toutes les girls. » in ibid.

1103« Nous avions la justice codifiée de la vengeance. La science codifiée de la Magie. Anthropophagie. La transformation permanente du Tabou en totem. / Contre le monde réversible et les idées objectives. Transformées en cadavres. Le stop de la pensée qui est dynamique. L'individu victime du système. Source des injustices classiques. Des injustices romantiques. Et l'oubli des conquêtes antérieures. » in ibid.

1104« Contre la vérité des peuples missionnaires, définie par la sagacité d'un anthropophage, le Vicomte de Cairu : C'est du mensonge répété plusieurs fois. / Mais ce ne sont pas des croisés qui sont venus. Ce sont les fugitifs d'une civilisation que nous sommes en train de manger, parce que nous sommes forts et vindicatifs comme la tortue jabuti. » in ibid. 
«Antes dos portugueses descobrirem o Brasil, o Brasil tinha descoberto a felicidade. / [...] A alegria é a prova dos nove.[répété plusieurs fois] $»^{1105}$

La réalisation de Como era gostoso o meu francês est annoncée conjointement à celles de $O$ Brado retumbante et Brasil ano 2000 par Glauber Rocha dans un article de mai $1966^{1106}$. Selon Salem, le projet est cependant encore plus ancien. Il remonte à l'époque du tournage de Vidas secas, en 1962-63. Santos a alors l'occasion d'entrer en contact avec une tribu indigène du Nordeste qui se trouve au bord du génocide culturel. Il est aussi sensible à l'histoire de l'évêque Sardinha qui est un épisode d'autant plus célèbre et tragique que la mort du prélat avait provoqué une guerre de représailles. Au cours de cette guerre, les Caetés furent presque totalement exterminés. Bien plus tard, ce génocide est le thème du premier roman de Graciliano Ramos, Caetés (1933), auquel le cinéaste donne une interprétation toute modernista. Selon lui, Ramos a écrit son livre «numa tentativa de retornar à brasilidade, procurando gritar 'nós somos todos índios', e se colocando numa situação interna de reencontrar em si mesmo aquilo que podia subsistir do índio da primeira época do Brasil - o índio capaz de devorar um bispo - para se sentir mais ' homem de seu tempo '. Eu achei esse ponto de partida interessante, mas não me baseei na história de Ramos, que é psicológica. $)^{1107}$

Sept ans seront nécessaires avant que le cinéaste ne puisse mettre en place la production du film. Ce délai s'explique par le caractère exceptionnellement ambitieux du projet. Dès le départ, l'intention de Santos est de réaliser un film historique situé au premier siècle de la colonisation et dont le thème sera le choc des cultures entre des nations indiennes encore maîtresses de leurs territoires et les premiers colons français ${ }^{1108}$ et portugais qui se sont établis au Brésil, s'appuyant sur une économie encore limitée à l'exportation d'épices et de pau brasil. Un important travail de reconstitution s'impose dont l'élément le plus coûteux sera

1105« Avant que les portugais ne découvrent le Brésil, le Brésil avait découvert le bonheur. / [...] La joie est la preuve par neuf. [répété plusieurs fois]. » in ibid.

1106 SGANZERLA, Rogério. «Fala Glauber Rocha I » in O Estado de São Paulo - Suplemento literário, São Paulo, 07/05/1966.

1107 « [...] dans une tentative de revenir à la brasilité, en cherchant à crier ' nous sommes tous des indiens ', et en se plaçant dans un état de pensée susceptible de lui faire trouver en lui-même ce qui pouvait subsister de l'indien des premiers temps du Brésil - l'indien capable de dévorer un cardinal - pour se sentir mieux comme un ' homme de son temps '. J'ai trouvé ce point de départ intéressant, mais je ne me suis pas basé sur l'histoire de Ramos qui est trop psychologique. » in SALEM, Helena. Nelson Pereira dos Santos - O Sonho possível do cinema brasileiro. Op. cit., p. 257-258.

1108Dans les premiers temps de la colonisation du Brésil, la rivalité entre les français et les portugais a été très forte. Irrespectueux du traité de Tordesillas (1494) qui avait délimité le partage du Nouveau Monde entre l'Espagne et le Portugal, les français profitent de l'impossibilité dans laquelle se trouve les portugais de contrôler l'intégralité du leur immense empire pour développer des activités de contrebande et même des comptoirs permanents de commerce au Brésil. L'intérêt principal de ces contrebandiers dont certains membres s'intégrent aux communautés indigènes était le pau-brasil (bois-brésil) dont l'exploitation ne nécessitait pas le recours à la main d'œuvre esclave. La France tente même la création de deux colonies : la « France antarctique » (1555-1560) et la « France équinoxiale» (1612-1615). Les deux tentatives sont des échecs cuisants mais elles sont directement à l'origine, pour la première, de la fondation de Rio de Janeiro (1565) et pour la seconde de la fondation de São Luís de Maranhão (1612). 
la construction d'un village indien. Como era gostoso o meu francês nécessitera aussi une très nombreuse figuration. Le cinéaste écrit une histoire originale en s'inspirant du génocide des Caetés mais aussi et surtout de l'histoire de Hans Staden. Staden était un artilleur allemand au service des portugais. Fait prisonnier des Tupinambás, une nation indienne alliée des français, il devait être mangé dans un banquet rituel et connaître la même fin que l'évêque Sardinha. Sa mise à mort fut cependant constamment repoussée tant il s'était bien intégré à la vie de la tribu. Finalement, il fut sauvé par les français qui n'interféraient pourtant jamais dans les rituels cannibales des Tupinambás. De retour en Europe, Staden va raconter son séjour chez les Tupinambás dans un livre qui reste jusqu'à aujourd'hui l'un des plus importants témoignages sur cette période historique. Nus, féroces et anthropophages ${ }^{1109}$ paraît en 1557 et connaît un succès retentissant. Les gravures originelles du livre seront utilisées dans le générique et le matériel publicitaire du film.

Santos va reprendre dans son argument la situation vécue par Staden et poursuivre son travail de documentation en se référant aux autres chroniqueurs de l'époque : les français Jean de Léry ${ }^{1110}$, l'abbé Thevet ${ }^{1111}$, les missionnaires portugais Nobrega ${ }^{1112}$ et Anchieta ${ }^{1113}$. Il est évident qu'au cours du processus de maturation du projet, le cinéaste n'a pas été insensible aux évolutions de la production artistique brésilienne auxquelles il a lui-même activement participé. Como era gostoso o meu francês aurait sans doute été bien différent s'il avait pu être réalisé en 1963 ou en 1966. Le succès du tropicalismo et le retour en grâce de l'œuvre d'Oswald de Andrade qui avait été « oublié » jusqu'au montage pionnier de sa pièce $O$ Rei $d a$

1109 Curieusement, le livre est connu au Brésil avec le titre bien moins sensationnaliste Viagem ao Brasil (Voyage au Brésil).

1110Jean de Léry (1536-1613) faisait partie du groupe de genevois envoyés par Calvin à Villegagnon lors de sa tentative d'établissement de la France Antarctique. Arrivé au Fort Coligny en mars 1557, il rentre en Europe en janvier 1558 du fait des disputes théologiques qui divisent les colons français. Il écrit son livre, Histoire d'un voyage faict en la terre du Brésil (Genève, 1578) répond à celui d'André Thevet qui attribuait la responsabilité de l'échec de la France Antarctique aux protestants.

1111André Thevet (1502-1590) était l'aumônier de l'expédition du vice-amiral Villegagnon pour coloniser le Brésil. Il a rapporté de son voyage de nombreux spécimens d'animaux, de végétaux et de minéraux, ainsi que des poteries ou des armes. Malade, il n'a jamais pu descendre à terre et c'est donc sur la foi des matelots qu'il a rédigé Les Singularités de la France antarctique (1574) dans lequel nous pouvons lire les premières descriptions du manioc, de l'ananas, de l'arachide, du tabac, du grand ara, du paresseux et du tapir.

1112Le Père jésuite Manuel da Nóbrega (1517-1570) fut le conseiller du premier et du troisième gouverneurgénéral du Brésil. Dès son arrivée en 1549, il n'a pas cessé de voyager le long du littoral et même à l'intérieur des terres participant à la fondation de Salvador (1549), de São Paulo (1554) et de Rio de Janeiro (1565). Artisan avec Anchieta de la pacification des Tamoios qui étaient les alliés des français, il permit la déroute définitive de leur tentative d'installation dans la baie de Guanabara. Parmi ses écrits, nous pouvons citer : Diálogo sobre a Conversação do Gentio, de 1557 ; Caso de Consciência sobre a Liberdade dos Índios, de 1567 ; Informação da Terra do Brasil, de 1549 ; Informação das Coisas da Terra e Necessidade Que Há Para Bem Proceder Nela, de 1558 ; Tratado Contra a Antropofagia, de 1559.

1113Le Père jésuite José de Anchieta (1534-1597) a débarqué au Brésil en 1553 et participé à la fondation de la ville de São Paulo l'année suivante. Totalement dévoué à la catéchèse des indiens, sa production, théâtrale et poétique, est restée dans les annales de la littérature brésilienne de l'époque coloniale. Fervent supporter de sa béatification, Saraceni retrace sa vie et son œuvre dans le long métrage Anchieta, José do Brasil (1978). Selon le cinéaste, ce n'est pas Anchieta qui a colonisé le Brésil mais le Brésil qui a colonisé Anchieta. La béatification du missionnaire sera concédée par le pape Jean-Paul II. 
vela par José Celso Martines Corrêa en 1967, ont de toute évidence éclairé d'un jour nouveau l'idée originale de Santos. Pour autant, celui-ci va rompre très clairement avec la démarche des allégories totalisantes chaque fois plus sophistiquées et conceptuelles produites à la même époque $^{1114}$. Como era gostoso o meu francês renoue avec le réalisme critique et l'approche ethnologique datant des débuts du Cinema Novo. Sans pour autant s'apparenter à une narration académique, le film s'appuie sur une structure linéaire et s'organise comme un processus de connaissance. Ce processus est fondé sur l'articulation dialectique du regard du colonisateur et du colonisé. Como era gostoso o meu francês est un film historique dont la mise en relation avec le présent reste à la charge du spectateur. Le film engage les modes de lecture fictionnalisant et parabolisant.

À l'époque de la France Antarctique, dans la baie de la Guanabara, un français nommé Jean est fait prisonnier par les indiens Tupinambás. Le chef de la tribu, Cunhambebe décide qu'il sera mangé dans un banquet rituel au bout de huit mois. En attendant, et comme le veut la coutume, il peut vivre normalement, on lui donne même une femme, Seboipep (sangsue en tupi). Ce bon traitement paraît contradictoire à Jean et, au début, il a un peu de mal à comprendre la situation. L'arrivée d'un marchand français qui commerce avec la tribu nourrit ses espoirs de libération. Malheureusement, ce nouveau personnage s'avère rapidement machiavélique et cupide. Jean lui est plus utile prisonnier que libre. Il l'encourage à emmagasiner du pau-brasil et lui promet de l'emmener dans l'un de ses prochains voyages. Suivant ses conseils, le jeune homme se met au travail et s'accommode de la situation. Au fil du temps, il apprend et adopte les us et coutumes de la tribu. Il s'intéresse aux mythes et légendes des tupinambás. Il se coupe les cheveux et la barbe, se rase les poils du corps et participe des activités agricoles de la communauté. Il s'attache aussi à Seboipep et, grâce à elle, il découvre un trésor.

Quand le marchand français revient prendre livraison d'épices et de pau-brasil, il refuse une fois de plus d'aider Jean à s'échapper. Le jeune homme lui demande alors de lui vendre des barils de poudre et lui montre le trésor qu'il a découvert dans une tombe. Une fois de plus, le marchand cherche à doubler son compatriote et à s'accaparer le trésor. Une lutte s'ensuit et Jean le tue. La caravelle est là et Jean peut fuir. Mais, au dernier moment, Seboipep le surprend. Il l'invite à venir avec lui. Elle refuse, la caravelle s'en va, il reste. La date de sa mise à mort approchant, Jean essaye de trouver le moyen de la reporter. Prétendant avoir une relation privilégiée avec les Dieux, il livre au compte-goutte les barils de poudre qu'il avait soigneusement cachés. Par la suite, il participe des préparatifs de la guerre contre les tupininquins, ennemis héréditaires des tupinambás. Enfin, il met ses talents d'artilleur au 1114Brasil ano 2000, Os Herdeiros, Os Deuses e os mortos, Pindorama, Azyllo muito louco. 
service de la tribu et, grâce à lui, la bataille est gagnée. Malgré cela, Cunhambebe confirme sa mise à mort imminente et décide du partage des différentes parties de son corps. Jean planifie de nouveau sa fuite mais il ne veut pas partir sans le trésor. Avant son départ, il demande à Seboipep de lui expliquer comment se déroulera le rituel anthropophage. Elle le fait avec sensualité mimant les différents moments de la cérémonie. Après qu'elle ait terminé, ils roulent derrière un rocher et font l'amour. Quand Jean se réveille, Seboipep a disparu. Il retourne chercher le trésor pour le charger dans sa pirogue. Alors qu'il court sur la plage, Seboipep lui tire une flèche dans la jambe, il se traîne jusqu'à la pirogue et s'aperçoit qu'elle a été sabotée. Dans la dernière séquence, Jean est tué et mangé selon le rituel tupinambá. Seboipep se divertit beaucoup en mangeant une part de son petit français.

Qui sont les sauvages et qui sont les hommes civilisés ? Dans les premières séquences du film, quand Jean est pris par les Tupinambás, il cherche à prouver qu'il est français. Ceuxci devraient alors le libérer puisqu'il est un allié. Curieusement, au lieu de se rendre à l'évidence, Cunhambebe décide qu'il sera mangé et maintient sa sentence jusqu'au dernier moment alors qu'il n'y a plus aucun doute sur la nationalité du jeune homme. Son obstination, à laquelle participe toute la tribu à commencer par Seboipep, ne sera pas expliquée. Ou, au contraire, elle recevra une excellente raison dans sa sérénité et sa satisfaction quand elle évoque le rituel et finit par le pratiquer. Portugais ou français, aussi inoffensif puisse-t-il se montrer, il fallait manger le colonisateur, l'ingérer, le digérer, le faire sien avant que lui-même ne détruise l'indien, physiquement ou en lui imposant son mode de relation au monde. La joie, le sentiment d'achèvement temporaire offert par l'acte anthropophage, en garantit la légitimité et la justesse et résout les contradictions apparentes de la situation. Seboipep peut aimer Jean et ne jamais abandonner l'idée de le dévorer : «La joie est la preuve par neuf ». Le naturel et la détermination du colonisé est à mettre en relation avec cette phrase toujours répétée par Jean quand on lui demande au début de prouver qu'il est français : « Les barbares marchent tout nu et nous nous marchons inconnus. »

Tout au long du film, les indiens et les blancs se révèlent également violents et cruels. Les scènes de bataille sont nombreuses et d'un grand réalisme. Européens et indiens sont également divisés, les français s'opposent aux portugais, les tupinambás aux tupininquins, les premiers sont mus par l'avidité, une avidité à laquelle Jean n'échappe d'ailleurs pas puisqu'il ne conçoit pas de s'enfuir sans le trésor, les seconds sont agis par un désir de vengeance héréditaire. Ce désir est bien montré dans les phrases de dialogue de Cunhambebe quand il s'affaire aux préparatifs de la guerre et dans la légitimité que donne le pagé (le sorcier ou shaman) à son projet. Nous le retrouvons aussi dans le manifeste anthropophage : « Tínhamos a justiça codificação da vingança. A ciência codificação da Magia. » La différence 
fondamentale entre les blancs et les indiens réside dans l'hypocrisie des seconds et leur insistance à nier leur propre nature. Voilà pourquoi «nous marchons inconnus ». Cette hypocrisie est immédiatement liée à la symbolique du vêtement et à l'invention du péché de la chair. Dans le Manifeste anthropophage, nous retrouvons cette idée : «O que atropelava a verdade era a roupa, o impermeável entre o mundo interior e o mundo exterior. » Celle-ci est parfaitement exprimée dans première séquence du film où Villegagnon, en voix off, lit une lettre où il informe Calvin des progrès de la France antarctique.

L'amiral français explique que les indiens sont nus, qu'ils ignorent tout des bonnes mœurs et sont pareils à des animaux. Sur ces paroles, nous voyons des indiennes affables, accueillir les français en leur servant des boissons, et les hommes ravis d'être si bien reçus et charmés par la beauté de leurs hôtesses. Villegagnon explique ensuite qu'il a établi sa colonie sur une île et qu'il a commencé à faire venir les colons par couples afin que ses hommes soient isolés des indiens et de la tentation du péché de la chair. Sur ces paroles, nous voyons des indiennes qui sont habillées de force par les soldats. Mais, dès qu'elles s'éloignent, elles enlèvent vite la robe qui leur a été donnée et la font tournoyer autour de leurs têtes avant de la jeter. Entre l'ascétisme et la vie de labeurs proposé par l'amiral et l'invitation des femmes indigènes, un groupe d'hommes dont Jean fait partie n'a guère d'hésitation. Off, Villegagnon assimile leur fuite à une rébellion et raconte qu'il les a fait pourchasser par des hommes en armes. Mais il ment quand il dit qu'il a détaché l'un deux afin de lui donner la possibilité de se défendre et que celui-ci s'est noyé en tentant de fuir. À l'image, Jean est exécuté sommairement avec l'assistance d'un prêtre. Enchaîné et avec un boulet au pied, il est précipité dans la mer du haut d'un rocher et n'échappera à la noyade que par miracle.

L'aliénation de la culture occidentale est dénoncée dans cette séquence. Il s'agit d'une double aliénation, de l'hypocrisie comme nous l'avons déjà dit, mais aussi de la coercition, de la nécessité de subjuguer autrui sur le mode de l'autoritarisme et de l'intolérance. Le dogmatisme de Villegagnon le conduit à encadrer ses hommes dans une relation de soumission et d'objectivation, les hommes ne sont plus des hommes mais les instruments de leur chef, lui-même aliéné dans son rôle de commandant et incapable de renouer avec le réel. Les colonisateurs cherchent à diffuser leur mode de relation aux autres identifiable à la dialectique du maître et de l'esclave selon des motivations que l'abondance des terres tropicales rendent absurdes. Les indiens eux n'ont pas perdu le lien à la nature et à la terre et c'est cette capacité à réaliser leur intégration cosmique qui leur permet d'échapper aux aliénations de l'homme « civilisé ». La liberté des indigènes en opposition à l'aliénation de l'homme blanc donne à l'anthropophagie sa dimension politique. Oswald de Andrade oppose très clairement la capacité d'aimer des indiens au « modus vivendi do capitalismo » et dans sa 
conclusion met très clairement en relation le mal être de l'homme occidental avec les impositions de son mode de relation au monde :

« Contra a realidade social, vestida e opressora, cadastrada por Freud - a realidade sem complexos, sem loucura, sem prostituições e sem penitenciárias do matriarcado de Pindorama. " ${ }^{1115}$

L'histoire de Como era gostoso o meu francês, au travers de la séquence consacrée à Villegagnon mais aussi autour du thème du "trésor» et de la cupidité exprime ces contradictions avec beaucoup de clarté. Son caractère subversif dépasse cependant de beaucoup la simple dénonciation de la culture occidentale. Dès la première séquence, il apparaît que le mode de vie des indigènes séduit également les colons. Le groupe des français dont Jean fait partie préfère fuir l'île de Coligny et tenter de vivre auprès des indiens. Plus tard, la trajectoire de Jean et la transformation qu'il subit pendant ses huit mois de captivité, son adoption des coutumes indiennes, son plaisir à partager le quotidien de la communauté indigène démontrent aussi cette séduction et ce goût retrouvé du lien avec la nature. La séquence finale du film est d'ailleurs très explicite à ce sujet. Juste avant d'être tué, Jean refuse de prononcer les paroles rituelles en tupi. Cependant, dans sa colère, pour montrer qu'il refuse de se plier au rituel, il arrête de parler tupi et il les dit en français. Le fait est significatif car le sens de ces paroles remettent à cette «justice codifiée de la vengeance » des indiens. Jean voudrait redevenir français mais il ne le peut plus. Il est entré dans la logique indigène. Ses paroles montrent que son acculturation est totale. De la condition de « colonisateur », il est passé à celle de «colonisé ». Cette inversion nous remet à la "révolution caraïbe » du manifeste anthropophage et à l'idée que la plus grande des révolutions devrait venir de la réalisation de l'utopie libertaire de «l'âge d'or» de l'Amérique. Les colons auraient détruit cette utopie pour leur plus grand mal. Elle est valable pour tous.

La narration de Como era gostoso o meu francês prime par sa clarté. Cette clarté est étroitement liée au mode de récit choisi par Santos et dont la première séquence est bien représentative. Dès le début du film, une certaine connivence est établie avec le spectateur au travers de la satire. Le ton de la voix off qui est censée incarner Villegagnon imite celui, volontiers professoral et donneur de leçons, des locuteurs de ciné-journal. La musique qui l'accompagne est, selon Salem, celle des Actualités françaises qui étaient diffusées dans les cinémas du Brésil dans les années soixante-dix ${ }^{1116}$. Mais les images échappent à la fonction illustrative qu'elles ont généralement dans les reportages d'information et le décalage entre ce que nous dit Villegagnon et ce que nous voyons garantit un effet comique et irrévérencieux

1115 «Contre la réalité sociale, habillée et oppressive, castrée par Freud - la réalité sans complexe, sans folie, sans prostitutions et sans les pénitenciers du matriarcat de Pindorama. » in ANDRADE, Oswald de. Op. cit. 1116SALEM, Helena. Nelson Pereira dos Santos - O Sonho possível do cinema brasileiro. Op. cit., p. 259. 
très plaisant. L'anachronisme évident participe aussi de cet effet comique mais il instaure aussi le mode de lecture parabolisant en suggérant qu'il existe une relation entre les événements passés, le point de vue de Villegagnon et la réalité présente. Deuxièmement, la structure de cette séquence anticipe celle du film dans son intégralité. Après le générique (séquence 2), les différentes péripéties de l'aventure de Jean seront précédées par des cartons sur lesquels seront retranscrites des citations de personnages historiques ou de chroniqueurs de cette époque. Il sera assez facile à comprendre que le contenu de ces citations sera à mettre en relation avec la séquence qui suit. L'usage des cartons se substituera donc à celui de la voix off mais la relation entre les images et le texte écrit ne sera jamais du registre de la simple illustration. Alors que les textes expriment le point de vue du colonisateur, l'image retranscrit celui de l'indigène. Celui-ci n'est jamais idéalisé ou esthétisé. La capacité du cinéma à recréer des mondes disparus est utilisé avec un souci éthique constant. D'une certaine façon, le film permet de donner une voix aux indigènes et la possibilité de s'opposer à la version de l'histoire écrite par les vainqueurs. L'interprétation des contradictions qui naissent des décalages observables entre texte et l'image reste cependant à la charge du spectateur.

À partir de ce dispositif assez simple, le film s'organise comme un processus de connaissance, pour ses auteurs, d'un côté, et pour le public, de l'autre. La parodie de cinéjournal de la première séquence sera le seul anachronisme du film. De façon significative, cette entorse à la rigueur quasi scientifique de la narration est placée avant le générique. En plus des fonctions que nous lui avons déjà attribuées, cette séquence est aussi un avertissement, nous sommes devant un film de cinéma, devant un spectacle, et si, avec l'aventure de Jean, il nous est aussi proposé une réflexion sur l'histoire du Brésil, nous restons dans le domaine de la fiction. Le film se dénonce en tant que tel et n'entend pas imposer une vérité définitive, achevée et incontestable. Cet avertissement posé, le générique et ses gravures extraites du livre de Staden, ainsi que la précision des citations qui comprennent toujours la date et le nom de leur auteur instaurent un climat de recherche et supposent une dialectique entre les témoignages du passé, dont la partialité est évidente, et la reconstitution minutieuse du mode de vie des indiens, qui également, peuvent se révéler faillibles. Le film en entier est parlé en tupi mais il s'agit évidemment d'une langue reconstituée par les anthropologues du XXe siècle, un tupi littéraire certainement assez éloigné du véritable tupi ${ }^{1117}$. L'important ne réside cependant pas dans les limites de la reconstitution mais dans cette volonté d'approcher l'autre et de retrouver le fier indigène des premiers temps de la colonisation. L'intérêt du film dans sa relation à l'histoire réside beaucoup mieux dans sa 
posture que dans sa capacité à énoncer des vérités scientifiques.

Pour autant, force est de constater qu'aujourd'hui encore, la reconstitution de Santos reste d'une incroyable cohérence avec ce que l'historiographie la plus récente a pu produire sur le sujet ${ }^{1118}$. Attaché au principe du réalisme critique, tout au moins pour réaliser ce long métrage, le cinéaste était passé lui-même par une phase de documentation intense avant de se lancer dans l'écriture du scénario. Ce travail avait ensuite été poursuivi par le scénographe Luiz Carlos Ripper qui avait effectué une recherche ethnographique de quatre mois afin d'anticiper les besoins en termes de production. C'est notamment sur la base de ces recherches que sera reconstitué le village indien près de Paraty. Toutes les informations recueillies par l'équipe pour le film dans leur tentative d'approcher et de comprendre le Brésil des origines (le Brésil n'existait pas avant d'être « inventé » par les européens, il est le fruit d'une rencontre) se retrouvent dans le film. Au lieu d'apporter au spectateur les conclusions d'une recherche, il lui est permis de refaire le même chemin que les auteurs du film, de suivre à son tour le même parcours de découverte. Les zones d'ombre sont les mêmes que celles auxquelles se heurtent l'historien mais le déroulement factuel est parfaitement clair. Comme dans Macunaíma, aucun élément ne vient perturber ou interrompre le mode de lecture fictionnalisant. Tout est « vrai », participe d'une démarche authentique de recherche et, en même temps, le film reste un film d'aventure, un spectacle fascinant.

Le tournage de Como era gostoso o meu francês commence en mars 1970 et dure environ quatre mois. Le film est terminé à temps pour participer aux festivals de Cannes et de Berlin en 1971. Paradoxe courant de l'époque, si le film est libéré par la censure pour participer aux grandes compétitions internationales, il est interdit sur le territoire national en raison des nus, en particulier masculins. Les négociations usuelles ont lieu et finalement le film sort en janvier 1972 sans restriction d'âge. Le succès est énorme et n'est pas loin d'égaler celui de Macunaíma. Loin de penser que le public a réellement pu appréhender la dimension libertaire de l'œuvre, certains attribueront ce succès au fait que les acteurs sont nus du début à la fin ou encore à la présence quasi continue des sous-titrages qui aurait permis de vaincre les préjugés classiques en l'encontre du cinéma national. Santos lui-même ne se satisfait pas de ce succès de masse car, selon lui, les spectateurs ne se sont pas identifiés à ses idées («Le Manifeste anthropophage ») mais au français dont ils ont lamenté la mort sans comprendre que le véritable héros du film était l'indien ${ }^{1119}$. L'étude de la réception de la presse écrite nous donne quelques éléments pour contrebalancer ce constat quelque peu pessimiste. D'un point de vue quantitatif, sur treize critiques extraites des principaux quotidiens du pays, douze ont 
été très positives sinon dithyrambiques ${ }^{1120}$. D'un point de vue qualitatif, toutes évidemment ne se valent pas mais huit mettent très clairement en relation l'histoire du film et le complexe colonial $^{1121}$, six se référent directement au concept littéraire d'anthropophagie ${ }^{1122}$ et deux perçoivent la critique du capitalisme ${ }^{1123}$. Nous pouvons donc dire que la fonction parabolisante de la narration a été bien saisie par la critique. Rien ne nous empêche donc de penser qu'une part importante du public a pu faire de même. À partir de là, tout nous invite à penser que le film de Santos a été un très grand succès sous tous les points de vue réalisant comme rarement cela aura été le cas l'intégralité du cahier des charges du Cinema Novo.

1120« A Análise - Como Era Gostoso o Meu Francês » in O Jornal, 14/01/1972.

AZEREDO, Ely. « Cinematográfico - Como Era Gostoso o Meu Francês » in Jornal do Brasil, Rio de Janeiro, 17/01/1972.

BARROS, Luiz Alípio de. « Cinema - Considerações sôbre o Francês » in Última Hora, Rio de Janeiro, 26/01/1972.

FASSONI, Orlando L. « Antropofagia, um grande tema » in Folha de São Paulo, São Paulo, 02/03/1972. PERDIGÃO, Paulo. «Crítica Como Era Gostoso o Meu Francês » in Correio da Manhã, Rio de Janeiro, 08/08/1972.

«Antropofagia x genocídio : Como era gostoso meu francês » in Zero hora, Porto Alegre, 17/05/1972.

AVELLAR, José Carlos. " Manifesto Pau-Brasil : Como era gostoso meu francês » in Jornal do Brasil, Rio de Janeiro, 17/01/1972.

CRUZ, Nonato. «Antropofagia cinematográfica » in O Dia, Rio de Janeiro, 16/01/1972. (+)

LIMA, S. « Como é decepcionante a fábula deste francês » in O Estado de São Paulo, São Paulo, sans date. (-, non moraliste)

MONTEIRO, José Carlos. « Como Era Gostoso o Meu Francês : História do Brasil na tela » in O Globo, Rio de Janeiro, 12/01/1972.

NASCIMENTO, Hélio. « Como era gostoso o meu francês » in Jornal do comércio, Porto Alegre, 10/05/1972.

PARANHOS, Alberto. «A Institucionalização do canibalismo » in Tribuna da imprensa, Rio de Janeiro, sans date.

SILVA, Sérgio. « Não só gostoso como importante, este francês » in Diário de notícias, Porto Alegre, 06/05/1972.

1121Fassoni, Perdigão, Zero Hora, Avellar, Cruz, Monteiro, Nascimento, Paranhos, Silva.

1122 Zero hora, Cruz, Avellar, Fassoni, Paranhos, Perdigão.

1123Perdigão, Paranhos. 


\section{Chapitre 12 : Les allégories totalisantes érudites}

Tout effort de classification rigide des films du Cinema Novo comporte des risques d'écrasement de l'objet d'étude ou de simplification exagérée qui peuvent être effectués à divers niveaux. Nous avons des cinéastes, nous avons des critiques, nous avons des discours tenus sur les films, le cinéma, la société et l'histoire et nous avons les œuvres elles-mêmes en tant que textes filmiques. À leur tour, celles-ci appartiennent encore à des ensembles plus vastes et complexes en tant que « faits filmiques » où les « autres » (l'État, le public, le monde du cinéma) et leurs propres contradictions interviennent. Enfin, nous avons le cinéma qui, à l'échelle nationale et mondiale, connaît dans les années soixante d'importantes transformations. Comme nous l'avons vu, la cohérence du Cinema Novo dépend de l'unité d'un groupe qui est soudé par des liens de solidarité et une vision commune du cinéma et du rôle de l'intellectuel. Pour autant, ces deux prémisses ne constituent pas un cadre figé et n'excluent pas une pratique individualisée et dynamique. Aussi, la filmographie du Cinema Novo est-elle extrêmement différenciée, bien que reposant sur un certains nombres d'idées, de stratégies et de principes communs qui la distingue à son tour au sein de la filmographie nationale et au sein des cinémas nouveaux qui lui sont contemporains.

La troisième phase du Cinema Novo, plus encore que les deux précédentes, est marquée par les contradictions et les ambiguïtés alors même que nous voudrions la voir comme une phase de définition. À partir du moment où nous considérons que le groupe du Cinema Novo ne survit pas aux années Médici, il est en effet tentant d'appliquer à son histoire une scénario résolutif. Le premier est calqué sur le schéma classique : thèse, antithèse, synthèse. La thèse correspond à la première phase du Cinema Novo et à la posture «populiste», autrement appelée «pédago-illuministe»par Ismail Xavier ${ }^{1124}$. L'antithèse correspond à la phase réflexive, la phase d'autocritique de cette posture, incarnée par Terra em transe et $O$ Desafio. La synthèse nous est offerte par les films qui traduisent une revalorisation du peuple et de sa culture, O Dragão da maldade, Macunaíma et Como era gostoso o meu francês. Le deuxième scénario résolutif est celui qui nous amènerait à distinguer dans la troisième phase deux voies offertes et jugées également valides pour un cinéma participatif : la voie allégorique (O Dragão da maldade, Macunaíma, Brasil ano 2000, Os Herdeiros, Pindorama, Os Deuses e os mortos) et la voie du réalisme critique avec laquelle le Cinema Novo renoue alors ${ }^{125}$ (Capitu, Como era gostoso o meu francês, Os

1124XAVIER, Ismail. Alegorias do desengano : a resposta do cinema novo a modernizacao conservadora.

Thèse de livre docência, ECA-USP, São Paulo, 1989, p. 2.

1125Sur le retour au réalisme critique, voir : XAVIER, Ismail. « Em torno de São Bernardo » in Argumento, Rio 
Inconfidentes, São Bernardo, Uirá, um índio em busca de Deus). Ces deux scénarios, qui, d'ailleurs, ne s'excluent pas l'un l'autre, présentent un avantage certain : ils nous permettraient de décrire un éventuel « héritage » du Cinema Novo ou de circonscrire le « leg » que pourrait nous offrir une expérience en tout point exceptionnelle dans l'histoire du cinéma.

Bien que séduisants, ces scénarios correspondent mieux à une interprétation $a$ posteriori que nous pouvons faire pour nous de l'histoire du Cinema Novo qu'au déroulement effectif des événements et au sens qu'ils ont pris pour les différents acteurs au moment où ils les vivaient. À l'opposé de toute idée de résolution, l'étude du corpus des films du Cinema Novo de la troisième phase nous révèle justement la permanence de contradictions et d'ambiguïtés déjà présentes dans les phases précédentes et dont il faut reconnaître qu'elles n'avaient alors pas encore été surmontées par les cinéastes eux-mêmes. Nous pouvons les mettre à jour en utilisant la même méthode que celle que nous avons utilisée jusqu'à maintenant et qui a consisté à mettre en crise les définitions et recoupements que nous a laissé l'historiographie critique qui est née avec le Cinema Novo. Souvenons-nous que l'historiographie du cinéma brésilien prend son essor parallèlement au développement du Cinema Novo et lui accorde une place centrale dans l'histoire du cinéma national. Cette historiographie propose aussi une définition de ce phénomène artistique et divise son temps de vie en trois phases ${ }^{1126}$. C'est partiellement en discutant cette définition et ce découpage que nous avons jusqu'ici développé notre propos. Selon la même méthode et en opposant plusieurs classifications entre elles, nous constatons la permanence de contradictions et d'ambiguïtés du mouvement au cours de la troisième phase.

Nous avons vu que la division temporelle des trois phases du Cinema Novo pose certaines difficultés. C'est le cas dans le passage de la première à la deuxième phase. Certains films comme Menino de engenho, O Padre e a moça ou même $A$ Falecida, n'expriment pas de réelle prise en compte de l'actualité traversée par le pays entre 64 et 66 et s'inscrivent dans la continuité des films de la première phase. De même, pour le passage de la deuxième à la troisième phase, Fome de amor, Azyllo muito louco, O Bravo guerreiro et Os Inconfidentes perpétuent la critique de l'intellectuel oscillant de classe moyenne qui est caractéristique de la phase réflexive du Cinema Novo. Si nous considérons à présent seulement le corpus des films de la troisième phase, nous voyons bien que l'orientation dite de revalorisation de la culture populaire est inégalement suivie. Si, dans la période allant de 1965 à 1970, les discours des cinemanovistas sont dominés par la problématique de la conquête du grand public, dans la pratique, les préoccupations d'expression de « l'auteur » cinématographique l'emportent.

de Janeiro, année I, n³, janvier 1974.

1126RAMOS, Fernão (org.). História do cinema brasileiro. Op. cit. 
C'est ainsi par exemple que plusieurs films du Cinema Novo de cette période ne peuvent être inclus dans la catégorie cinemão dont les caractéristiques consistent justement à adopter des signes extérieurs ostensibles de séduction : la couleur, les chants, les danses, les références au tropicalismo et à la chanchada. C'est le cas de Capitu, Fome de amor, O Bravo Guerreiro, Memória de Helena, Os Inconfidentes, Uirá, um índio em busca de deus. Chacun de ces films se présente comme un objet de spéculation politique, historique, sociologique, psychologique ou encore anthropologique qui a pour vocation d'exister en soi et non d'atteindre le grand public. D'un point de vue économique, l'entreprise est viabilisée si elle atteint le segment de public choisi pour lequel le cinéma est aussi un objet de spéculation culturelle ${ }^{1127}$. C'est dans cette même logique «d'expression» que plusieurs cinemanovistas réalisent leur film «underground». Ces rapprochements ponctuels avec la démarche du Cinema Marginal sont conçus comme l'occasion de procéder à des recherches esthétiques qui semblent proscrites dans le cadre du Cinema Novo, et parfois même comme une façon de rompre avec une approche du cinéma devenue pesante et inadaptée à la conjoncture sociopolitique des années de plomb. Rocha réalise Câncer ${ }^{1128}$, Hirszman, Sexta-Feira da Paixão, Sábado de Aleluia ${ }^{1129}$, Lima Junior, Na Boca da noite ${ }^{1130}$, Santos, Quem é Beta ${ }^{1131}$ Les allégories totalisantes : Brasil ano 2000, Os Herdeiros, Pindorama, Os Deuses e os mortos

Parallèlement, tous les films du cinemão ne peuvent pas réellement être attachés à l'option populaire. Comme nous avons cherché à le montrer au travers de l'étude de $O$ Dragão

1127Les ventes à l'international joue alors un rôle décisif puisque le marché intérieur peut ne pas suffire à amortir les coûts de production.

1128Monté à Cuba et terminé à Rome en 1972, ce long métrage de Glauber Rocha est resté inédit jusqu'en 1984 où il a été projeté au Brésil dans le cadre d'une rétrospective itinérante de l'œuvre du cinéaste.

1129Il s'agit d'un des quatre épisodes de América do Sexo (Brésil, 1969) qui comprenait également Bandeira Zero de Rubens Maia, Colagem de Luiz Rosemberg Filho et Balanço de Flávio Moreira da Costa. Comme la majorité des films du Cinema Marginal, la circulation de ce film est restée très confidentielle. Beaucoup n'ont même pas été présentés à la censure et ne sont jamais sortis au cinéma.

$1130 \mathrm{Na}$ Boca da noite est tourné en quelques jours avec un budget insignifiant et des restes de pellicule noir et blanc périmés mais encore utilisables cédés par Thomas Farkaz. Le film raconte, en longs plans séquences et en son direct, le cambriolage d'une banque. Sur ce film, $c f$. MATTOS, Carlos Alberto. Op. cit., pp. 160-165.

1131Selon Salem, Santos avait fait un premier film underground en 1968. Le cinéaste lui a décrit son expérience dans ces termes : «A gente começava a conversar sobre tudo. Primeiro, desde falar sobre como seria fazer sexo todo mundo junto, suruba e tal. Depois, a coisa foi indo para o lado político. Havia aquela repressão toda, então surgiram as propostas mais incríveis como dinamitar o Forte de Copacabana, explodir quartéis e tudo. E a câmera filmando. No segundo encontro, já veio menos gente. Mas teve. No terceiro, era para levar uma mala e ir para um lugar que ninguém sabia qual era. Daí não foi ninguém. Pediram para destruir o filme, nem cheguei a montar. » (« Nous commencions à parler sur tous les sujets. Premièrement, sur comment ça serait d'avoir des relations sexuelles tous ensemble, de faire une partouze, ce genre de choses. Ensuite, nous parlions politique. Il y avait toute cette répression et alors ont surgi des propositions incroyables comme celle de faire sauter le fort de Copacabana, de faire exploser des casernes et tout. Et la caméra continuant à filmer. $\mathrm{Au}$ deuxième rendez-vous, il y avait déjà moins de monde. Pour le troisième rendez-vous, chacun devait amener ses valises et nous avions dit que nous partirions sans que personne ne sache à l'avance vers quelle destination. Cette fois-là, personne n'est venu. Les participants m'ont demandé de détruire le film, je ne l'ai jamais monté. ») in SALEM, Helena. Nelson Pereira dos Santos - O Sonho possível do cinema brasileiro. Op. cit., pp. 243-244.

Quem é Beta? Est un film de 1972, proche également de l'esthétique du Cinema Marginal. 
da maldade, Macunaíma ou Como era gostoso o meu francês, l'option populaire se caractérise par le souci de se mettre au niveau du public sans pour autant utiliser un langage académique et / ou didactique. En d'autres termes, il s'agit de proposer un spectacle « nouveau », attrayant et qui n'offre pas de résistance majeure d'ordre cognitif. Par analogie avec les productions artistiques de la culture populaire, l'esthétique d'un long métrage peut recourir à des formes d'expression allégorique et atteindre un haut niveau de sophistication mais elle ne doit pas mobiliser des connaissances politiques, historiques, cinématographiques et même parfois linguistiques comme des prérequis indispensables à la lecture du texte filmique. D'une certaine façon, O Dragão da maldade, Macunaíma et Como era gostoso o meu francês sont trois films qui réussissent, avec des stratégies différentes, à remplir ce cahier des charges. $O$ Dragão da maldade y parvient de par son caractère épique et sa capacité à revisiter la culture populaire, Macunaíma, grâce à un langage «chocantemente informal » et à sa tonalité satirique, Como era gostoso o meu francês, en renouant avec le réalisme critique. Rappelons également que les trois films rompent avec le ton paternaliste de la première phase du Cinema Novo et proposent des histoires susceptibles d'intéresser le plus grand nombre. Enfin, ces trois propositions ont reçu une sanction commerciale positive puisqu'il ont réussi à atteindre un public plus large que celui qui était généralement atteint par le Cinema Novo.

Les quatre autres films que nous pouvons rattacher à l'étiquette cinemão : Brasil ano 2000, Os Herdeiros, Pindorama, Os Deuses e os mortos, démontrent cependant que la rupture d'un cinéma réflexif et ultra-référencé en faveur d'un cinéma destiné au grand public est alors loin d'être consommée. Ces quatre films présentent plusieurs points communs. Alors même qu'ils ont bénéficié de conditions de lancement comparables à celles des trois succès que nous venons de citer $^{1132}$, ils n'ont pas réussi à intéresser le public au-delà du cercle des habitués du Cinema Novo, allant même jusqu'à décevoir certains critiques ayant jusque là supporté ce groupe. Cet insuccès s'explique évidemment par divers facteurs. Nous verrons cependant ici que, contrairement aux succès du cinemão et comme les autres films du Cinema Novo, ils restent des films de la classe moyenne pour la classe moyenne qui établissent une distanciation avec le grand public sur la base de thématiques et de référentiels propres à une culture cosmopolite, érudite et formelle. Comme cela pouvait être le cas de films importants comme $O$ Desafio ou Terra em transe, les thèmes développés par ces films ne font pas forcément sens pour le grand public. De même, l'éclatement progressif de la narration

1132Dans tous la majorité des cas, les films ont souffert des mêmes inconvénients et des mêmes avantages. Le scénario de lancement de ces films a pratiquement été toujours identique : démêlés avec la censure au moment de demander l'autorisation d'exploiter le film, succès critique international dans un ou plusieurs festivals prestigieux, libération du film et sortie en salle accompagnée d'une couverture promotionnelle répercutée par les plus grands quotidiens du pays. 
classique linéaire au profit d'un langage allégorique totalement abstrait ou plus proche des innovations du cinéma européen que de la culture brésilienne barrent l'accès de ces films. Le pari consistant à résumer toute la problématique historique, politique, sociale et psychosociale du Brésil en un seul film conduit ces œuvres à pousser le langage cinématographique à un effondrement qui le rend inintelligible et rapproche parfois le Cinema Novo des stratégies d'agression de l'Esthétique du détritus ( A Estética do lixo») pratiquée par le Cinema Marginal.

\subsection{Brasil ano 2000}

Les encarts publicitaires de Brasil ano 2000 publiés dans la presse proposaient ce sous-titre : «Como promover um índio a astronauta ?» (Comment faire d'un indien un astronaute ?) Pour le public des années soixante, la question renvoyait aux vieux préjugés concernant l'arriération des indiens du Brésil. Se référant à un lieu commun, elle ne le concernait pas et, tout au plus, pouvait sembler farfelue. La question recélait pourtant une forte dose de provocation qui ne pouvait être comprise qu'à la lecture des entretiens accordés par le cinéaste, Walter Lima Junior, ou mieux encore, à la vision du film. Comme pour Como era gostoso..., les indiens devaient être assimilés aux brésiliens de l'époque contemporaine. L'incapacité technologique qui était attribuée à "l'homme primitif» et qui faisait son infériorité en comparaison à l'homme moderne, était à présent celle du brésilien en comparaison au natif des grandes puissances impérialistes. Le cliché étant inversé, la question impliquait donc directement le lecteur. Brasil ano 2000 allait reposer tout entier sur le même principe et mêler l'ironie à l'impertinence. Sur le registre de la satire, Lima n'épargnera personne, ni la famille, ni les institutions, ni les supposés rebelles à l'ordre établi. Se faisant, il employait une stratégie audacieuse. D'un côté il utilisait les attributs d'une comédie musicale dans l'air du temps yé-yé pour attirer le public et de l'autre il l'impliquait directement dans une critique d'une rare violence. En donnant au public une image extrêmement négative de luimême, il visait à obtenir une réaction de répulsion qui lui serait salutaire. Le langage allégorique et très référencé du film ne faciliterait cependant pas l'intelligence de son propos par le plus grand nombre.

Le second film de Lima est à l'origine un projet exactement contemporain à $O s$ Herdeiros et Como era gostoso o meu francês. Rocha est le premier à annoncer la production des trois films dans un entretien paru dans la presse en mai $1966^{1133}$. Le mois suivant, Lima

1133SGANZERLA, Rogério. « Fala Glauber Rocha I » in O Estado de São Paulo - Suplemento literário, São Paulo, 07/05/1966. 
confirme qu'il travaille sur Brasil ano 2000 qui doit être une satire, " espécie de ficção científica sem ciência sobre a marginalidade em que vive o subdesenvolvido, fora de sua época ${ }^{1134}$. Selon Mattos, Lima imagine d'abord un film sombre et sinistre en noir et blanc ${ }^{1135}$ qui reflète son désarroi et son manque d'optimisme vis à vis de la situation politique. Il est cependant aussi sensible à l'idée de réconcilier spectacle et réflexion qui agite alors le Cinema Novo. Deux ans plus tard, fin 68, début 69, dans les entretiens qu'il donne afin d'assurer la promotion du film, Lima va souvent répéter qu'il a cherché à concevoir une œuvre ouverte au grand public ${ }^{1136}$. Ce revirement s'explique peut être par la lecture du scénario proposé par Rocha pour Garota de Ipanema au second semestre de 1966. Nous y retrouvons cette idée d'une comédie musicale tropicalista douce-amère dans laquelle l'action serait brusquement interrompue par des chants et des danses incluant les acteurs principaux. Le recours au registre de la satire rappelle quant à lui Macunaíma. Pour autant, il faudra noter une différence importante entre le scénario de Rocha, le film d'Andrade et celui de Lima. Dans les deux premiers, le parcours du personnage principal s'articule à des séquences réalistes, ancrées dans la contemporanéité, dans Brasil ano 2000, toute l'histoire se situe dans un ailleurs futuriste. Lima opte pour un langage strictement allégorique.

Pensé à l'origine comme un cauchemar, Brasil ano 2000 va peu à peu se transformer pour se parer des attraits qui font les films du cinemão. Les éléments de séduction adoptés par Lima sont la couleur, les chants, le charme de l'actrice principale, les scénographies surréalistes et les costumes chamarrés. Cette évolution du film est liée à l'éclosion et au développement du mouvement tropicalista auquel il participe en coulisse. Encore une fois selon Mattos, Lima a l'idée d'intégrer des scènes musicales à la narration de Brasil ano 2000 dès le début du projet. C'est dans ce sens qu'il commence à écrire les paroles des chansons qu'il soumet à Gilberto Gil et José Carlos Capinan qui seront ensuite parmi les principaux artisans du tropicalismo. Ces chansons qui sont écrites et enregistrées à partir de la fin de 1966 et dans le courant de 1967 procèdent déjà par collages, sont très imagées et jouent sur cette fusion du moderne et de l'archaïque qui sera la principale caractéristique du mouvement. Les mélodies et les arrangements anticipent la fusion entre la bossa-nova et la pop anglaise contemporaine. Comme dans Garota de Ipanema, la référence aux yé-yé et à la culture pop engage l'auteur à critiquer la famille. Lima explique clairement ses intentions dans les

1134 « [...] une espèce de science-fiction sans science sur la marginalité dans laquelle vit l'homme sousdéveloppé, en dehors de son époque » in LIMA JUNIOR, Walter. « Walter Lima Júnior explica o seu filme » in O Estado de São Paulo, São Paulo, 18/06/1966.

1135 « Um futuro fantasmagórico. Um filme sombrio, em preto e branco, cheio de contraluzes, que sugerisse um pesadelo. » («Un futur fantasmagorique. Un film sombre, en noir et blanc, plein de contre-jours, qui suggère un cauchemar. ») in MATTOS, Carlos Alberto. Op. cit. p. 139.

1136Voir notamment : «Brasil Ano 2 Mil é Salto de Qualidade » in Diário de Notícias, Rio de Janeiro, sans date. 
entretiens qu'il donne pour la promotion du film :

«Me Esqueci é uma caricatura da nossa marginalidade. É a mesma janela, onde debruçamos nossos sonhos, nossas serenatas, nossas melancolias. É uma síntese do nosso esquecimento. A cristaleira nós a identificamos como uma espécie de museu que geralmente ocupa um bom lugar nas nossas salas. No filme, ela é carregada nas costas como a lembrar os compromissos familiares. Meu filme é, sobretudo um espetáculo aberto sobre a crise política e estrutural da família. A família como compromisso de segurança, de apoio está falida. $\rangle^{1137}$

Nous comprenons de ces entretiens promotionnels que le cinéaste entend mettre en relation sa critique du symbolisme attaché à la famille avec une critique plus vaste de la classe moyenne brésilienne. Selon lui, cette famille qui, pour se protéger, se replie sur elle-même et finit par étouffer ses membres, méprise son propre pays et ne lui accorde aucun crédit. Le mythe de l'impuissance brésilienne qui est une manifestation du complexe colonial, permet à la famille de classe moyenne de se dédouaner de toute participation politique. Elle vit dans une illusion en s'identifiant aux familles de classe moyenne du premier monde, en s'entourant des mêmes « fétiches ». Mais en fait, elle ne comprend pas ou ne veut pas comprendre qu'elle regarde passer le progrès par sa fenêtre sans y participer et doit faire un effort pour s'affirmer, affirmer son identité, ses désirs. Elle estime faire partie de la classe des colons quand elle est en fait colonisée. En ce sens, Brasil ano 2000 prolonge la critique de l'aliénation de la classe moyenne débutée avec $A$ Opinião pública. Le film, cependant, se veut aussi un puissant signal d'alarme. Si la classe moyenne ne prend pas conscience de son aliénation, le Brésil sera vaincu dans son combat contre l'impérialisme. L'identité et la culture brésiliennes disparaîtront comme ont disparu en leur temps l'identité et la culture indigène, brisées par le complexe d'infériorité colonial.

La situation initiale de Brasil ano 2000 remet clairement à cette problématique de la lutte contre l'impérialisme. En l'an 2000, le monde a été dévasté par la troisième guerre mondiale. Les grands puissances ont été emportées par le feu nucléaire et le Brésil lui-même a été partiellement dévasté. Une famille composée d'une mère et de ses deux enfants déjà adultes cherche à émigrer vers le Nord dans des zones supposées désertes pour avoir été longtemps interdites. En chemin, ils arrivent dans une ville appelée « Me Esqueci » («J'ai oublié »). Sans ressource, le trio accepte de se grimer en indien afin d'aider un fonctionnaire

1137« Me esqueci [la ville du film] est une caricature de notre marginalité. C'est la même fenêtre que celle au bord de laquelle nous nous penchons sur nos rêves, nos sérénades, notre mélancolie. C'est la synthèse de notre oubli de nous-mêmes. Le vaisselier, nous l'identifions comme un espèce de musée qui occupe généralement une place de choix dans nos salons. Dans le film, il est traîné partout comme pour nous rappeler nos compromis familiaux. Mon film est, avant tout, un spectacle ouvert sur la crise politique et structurelle de la famille. La famille n'est plus cette structure de protection et d'appui qu'elle était autrefois. » in MONTEIRO, Eduardo Nova. « Sobre Brasil ano 2000 » in Tribuna da imprensa, Rio de Janeiro, $27 / 06 / 1969$ 
du Serviço de Educação do Índio-SEI, qui, justement, n'a plus de vrais indiens dont il pourrait s'occuper et craint de perdre son poste. Il s'agit d'une situation humiliante qui crée une tension entre les membres de la famille. Faut-il s'intégrer au système ou préserver sa liberté individuelle, collaborer à l'hypocrisie collective ou dénoncer cette farce grossière ? Pendant que la famille évolue vers la désagrégation, la ville reçoit un général qui doit assister au lancement de la première fusée brésilienne. Un reporter cynique et désabusé joue le rôle de catalyseur des conflits mais réalise son impuissance à provoquer une prise de conscience collective. Ana (jouée par Anecy Rocha), la seule de la famille à porter un prénom, se décide pour la rupture et, sans personne pour l'accompagner, quitte la ville vers un avenir incertain.

Le film remet au cinéma moderne et à un langage allégorique dès son générique. Sur des images nous présentant des chiffres écrits dans des couleurs vives, nous entendons une musique concrète composée de notes dissonantes de synthétiseur et de sons de la campagne. Dans la séquence suivante, la famille se recueille autour de la tombe du père qui, curieusement, se trouve au bord de la route, dans un lieu désert. La vieille dame impatiente ses deux enfants qui souhaitent poursuivre leur chemin. Dès ce moment, le film accumule clins d'œil et références dont l'actualisation sera indispensable à la compréhension de la situation initiale. La famille reprend la route au son de Objeto não identificado chantée par Gal Costa et dont les paroles, mises en relation avec la dispute qui vient d'arriver, évoquent déjà le désir de découverte de l'amour et d'abandon du cocon familial d'Ana. Simultanément, une légende indique : «In Memoriam... ou quando os últimos já eram os primeiros » et, le plan suivant, « (... e únicos)» («In memoriam... ou quand les derniers étaient déjà les premiers... et les seuls »). Un autre carton nous a indiqué que le monde avait été dévasté en 1989. Un camion arrive avec sur sa remorque inscrits à la peinture la distribution du film, sur sa plaque d'immatriculation, le « Tupi or not tupi » emprunté au « Manifeste anthropophage ». Le chauffeur accepte d'emmener la famille et le vaisselier de la mère contenant des bibelots fragiles. Quand ils arrivent à Me Esqueci, il fait nuit, les phares éclairent un mur sur lequel est inscrit « Não é só nos anos que são os enganos » (Ce n'est pas seulement dans les années que sont les mensonges). Curieusement, les inscriptions ont disparu de la remorque du camion. Le chauffeur ne se souvient plus du nom de la ville où ils sont arrivés jusqu'à ce qu'il s'exclame que « Me Esqueci » est le nom de la ville.

Si nous comparons le début de Brasil ano 2000 avec celui de Macunaíma, nous pourrons constater que la musique fonctionne à chaque fois comme un commentaire aux images et que les références métalinguistiques ne sont pas absentes. Dans Macunaíma, l'intelligence de l'approche de l'auteur n'est cependant pas utile à la compréhension du film et ne risque pas de dérouter d'emblée le spectateur. Au contraire, le gag de la naissance du héros 
établit une connivence et «accroche » le spectateur. Dans Brasil ano 2000, les références affichées dès le début ne sont pas sans humour mais elles mobilisent un référent culturel qui n'est pas celui du plus grand nombre. Le gag qui consiste à montrer un homme grimaçant habillé en femme et accouchant d'un enfant qui n'est pas de la même couleur que lui et qui est déjà adulte, est une situation facilement assimilable par tous. La mention «Tupi or not tupi » peinte sur la place d'immatriculation et qui apparaît comme le détail furtif d'une séquence est en soi peu évidente. L'ironie de la proposition ne sera goûtée que par ceux qui la remarquent, sont capables de lui donner un sens et partagent un tant soit peu l'impertinence de la provocation. La référence « tupi ${ }^{1138}$ exige des connaissances historiques et littéraires qui vont des temps de la colonisation portugaise du Brésil à l'importance symbolique donnée à l'héritage indien à dans les années 20 et 30 et à l'hégémonie de l'idée selon laquelle l'identité nationale devait s'appuyer sur le concept de la fusion des peuples blancs, noirs et indiens. Le personnage du fonctionnaire du SEI que nous retrouverons plus tard remet également à cette période. La formule ironise par rapport à la validité des thèses qui ont alors prévalues et par rapport aussi à une quête de l'identité nationale qui, résolument tournée vers le passé, cherchait à fonder l'unité nationale dans un mythe des origines rénové ${ }^{1139}$.

Nous pouvons approfondir notre analyse en nous référant aux règles régissant le cinéma classique. Nous savons qu'il existe quatre types de motivation qui peuvent justifier un événement d'une narration filmique ${ }^{1140}$. Dans le langage classique, ces motivations répondent à une hiérarchie assez stricte. Nous avons en premier le justificatif de composition, autrement dit les événements sont liés par des relations de causalité qui participent à la construction dramatique. Nous avons en second les règles de vraisemblance, les événements doivent être plausibles dans le cadre de l'univers de la diégèse. En troisième lieu, les justificatifs peuvent être relatifs au genre et respecter les conventions établies par tout un ensemble d'œuvres comme les séquences de chant et de danse des comédies musicales. Enfin, un événement peut répondre à une justification artistique. Bien que s'éloignant du registre du cinéma hégémonique hollywoodien, Macunaíma ne dérogeait pas à cette hiérarchisation. Dans Brasil ano 2000, les motivations artistiques passent en premier lieu dès les premières séquences, en particulier au travers de la disparition ostensible des noms du générique qui étaient peints sur

1138Le terme « Tupi-guarani » désigne à la fois le tronc commun de diverses langues indigènes latinoaméricaines et les tribus qui pratiquaient ces langues et habitaient le littoral du Brésil au XVIe siècle.

1139 Terra em transe faisait déjà référence à ce mythe de la fusion des trois races dans la séquence onirique remettant au débarquement des conquistadors au Brésil.

1140MOREIRA, Roberto Franco. « As Estratégias narrativas do cinema clássico ». Cours de la discipline 5202 de Pós-graduação du département Cinema Rádio e Televisão - CTR de l'Escola de Comunicação e ArteECA, Universidade de São Paulo-USP, premier semestre 2003. Voir également : MOREIRA, Roberto Franco. «O Cinema hegemônico ». Thèse de doctorat disponible en ligne à l'adresse http://homepage.mac.com/robertom/index/artigose/tese/ocinemah.html, consulté le 14/04/2006. 
la remorque du camion. Autre exemple, quand les « nouveaux indiens » du SEI sont présentés à la communauté, la bande son est occupée par une musique de cirque et suggère que la supercherie est évidente ${ }^{1141}$. Alors que dans un film classique, il est attendu qu'un certain nombre d'éléments filmiques entretiennent le suspens quant à la découverte de la supercherie, ici, la bande-son s'écarte ostensiblement de sa fonction conventionnelle et vient contrarier l'application de la stratégie de lecture que la situation semblait appeler.

Ce type de décrochage rompt l'illusion filmique et contraint le spectateur à accepter que la hiérarchie des motivations soient inversées. Le mode de lecture fictionnalisant est remis en cause pour un autre mode de lecture qui peut lui paraître ambigu. Pour qu'il continue à s'intéresser au film, il faut qu'il soit prêt à ce décrochage et possède avec le cinéma une relation qui lui permette d'envisager d'autres modes de lecture que ceux correspondant au cinéma classique. Par opposition à Macunaíma, Brasil ano 2000 n'est pas un film «chocantemente informal» et nous pouvons voir dans sa sophistication une stratégie de sélection du public qui, si elle n'est pas pensée comme telle au moment de la réalisation, n'en est pas moins fortement exprimée. «L'auteur» se manifeste et s'impose au détriment de la capacité de l'œuvre à rassembler un large public.

La suite du film ne permettra pas au spectateur de trouver des points de repère plus fermes lui permettant de revenir à un mode de lecture classique. Les décrochages par rapport aux règles de composition dramatique et de vraisemblance physique dans l'univers diégétique sont nombreux et augmentent la déstabilisation qui est recherchée au travers d'une allégorie totalisante du Brésil qui file sans cesse dans la direction d'une provocation plus caustique et impertinente. Ces décrochages ont à voir avec le caractère surréaliste des situations. L'histoire du film, dans sa globalité, est surréaliste. Mais nous pouvons aussi citer des situations plus spécifiques comme le duel final opposant le frère d'Ana au reporter chacun étant armé de couverts géants. La composition de l'espace et du temps présente aussi de curieuses anomalies. La ville de Paraty a été choisie à dessein car il s'agissait, dans les années soixante, d'un village oublié et difficile d'accès ${ }^{1142}$. Coincée entre l'océan et des montagnes recouvertes d'une forêt tropicale impénétrable, cette ville aux rues désertes et aux bâtiments vétustes et sales nous remet face à une parcelle de Brésil archaïque, oubliée en marge du temps et du progrès. Cette caractérisation de la ville rend la présence d'une base de lancement de fusées complètement inattendue et font paraître les espaces souterrains d'autant plus étranges (une

1141Lors de cette séquence, la bande son est occupée par une musique de cirque.

1142À l'époque de la réalisation du film, il était impossible d'accéder directement de Rio de Janeiro à Paraty. Alors que l'ancienne cité coloniale est distante de seulement $267 \mathrm{~km}$ de la métropole, il était nécessaire de voyager en voiture de longues heures par des routes de montagne assez difficiles et de prendre le bateau sur une partie du trajet. Le voyage durait pratiquement 10 heures. $C f$. MATTOS, Carlos Alberto. Op. cit., p. 143. 
immense bibliothèque où se trouve enfermé un intellectuel et la salle de contrôle de la base remplie d'ordinateurs). L'incohérence de la composition de l'espace appelle une lecture symbolique des lieux, le souci est manifeste de faire cohabiter au même endroit l'ancien et le nouveau. Les décrochages effectués sur l'axe spatial de la narration renvoient à ceux effectués sur son axe temporel.

L'histoire du lancement de la fusée et celle de la désagrégation familiale permettent d'accumuler les anachronismes. L'emphase est portée sur le passage du temps par le titre «Brasil ano 2000 » et par les transformations historiques annoncées par les séquences initiales du film : la disparition des grandes puissances et l'entrée du Brésil dans la course à l'espace. Le fait que le film propose de nous confronter à une projection du Brésil 31 ans en avant dans le futur incite également aux comparaisons avec le temps présent (1969). Dérogeant aux règles de genre de la science-fiction, Brasil ano 2000 ne nous communique cependant ni l'émerveillement que procure généralement les fantastiques réalisations technologiques du futur, ni l'effroi que peuvent nous inspirer ses visions apocalyptiques où l'humanité aurait régressé à un état de quasi bestialité. Tout au contraire est placé sous le signe de l'anachronisme et de l'absence de transformation. Les accessoires sont identiques à ceux qui existent déjà dans les années soixante : le camion du début, l'appareil photo et le magnétophone du reporter, le téléphone et la jeep utilisés par le général, les ordinateurs de la base de lancement. Le reporter lui-même insistera sur le fait que la fusée est copiée sur les anciennes fusées de fabrication nord-américaine. Enfin, Me Esqueci est semblable à n'importe quelle ville provinciale du Brésil des années soixante.

Cette impression de stagnation est renforcée par la permanence du SEI, identique à ce qu'il était dans les années trente, et par la «sous-allégorie» totalisante de l'église dans laquelle est réunie une foule iconoclaste composée de personnages différenciés par le costume et les espaces occupés. Selon le principe tropicalista de collage de l'ancien et du moderne, cette sous-allégorie accumule les éléments nous remettant à l'imagerie du Brésil pré-industriel que chacun semble occupé à perpétuer de façon compulsive et répétitive sous la tutelle d'un prêtre, la seule autorité reconnue.

En plus de contrarier les conventions de lecture du cinéma de fiction et de faire appel à nombre de références historiques et littéraires inconnues du plus grand nombre, pour ce que chacun pourra en comprendre, Brasil ano 2000 offre une vision du futur et du Brésil particulièrement pessimiste. La stagnation et la répétition de l'ancien qui caractérisent $\mathrm{Me}$ Esqueci doivent être rapprochées de l'argument initial du film. L'idée est simple : même délivré de l'exploitation impérialiste des grandes puissances, le pays se révélerait incapable de se délivrer des structures qui le maintiennent dans le sous-développement. Condamné à 
l'immobilisme, il s'attacherait à perpétuer des institutions privées de leur raison d'être, à l'image d'un SEI sans indien, et serait encore dominé par une dictature militaire (le général). Selon cette allégorie, les raisons du marasme national ne seraient donc pas uniquement économiques mais aussi ontologiques, liés à la nature même de "l'homme brésilien », à sa passivité et à son incapacité créatrice. Défait de la présence physique du colonisateur, le brésilien resterait un être colonisé incapable de s'émanciper.

Il est difficile de dire, au visionnage du film, si le texte filmique assume cette thèse comme vraie ou s'il s'agit seulement de grossir le trait afin de provoquer la conscientisation du spectateur $^{1143}$. Toujours est-il qu'en exploitant à égalité les lignes narratives du lancement de la fusée et celle de la désagrégation familiale, il nous incite à établir des liens entre le drame familial et le drame collectif. Les dialogues du film accumulent volontairement les lieux communs et les phrases toutes faites sur la question du conflit entre les générations qui, ellesmêmes, nous remettent à cette question de l'acceptation des normes sociales. La famille de Brasil ano 2000 souffre exactement des mêmes problèmes qu'une famille typique de classe moyenne des années soixante. Les jeunes se rebellent confusément contre les contraintes qui leur sont imposées et dont ils sentent l'absurdité sans être capables de proposer une quelconque alternative ni même d'assumer une franche rupture.

Quand la famille arrive à Me Esqueci et accepte le contrat que lui propose le fonctionnaire du SEI, elle intègre sans le savoir ce mécanisme que nous avons décrit plus haut de reproduction répétitive du même auquel participe l'ensemble de la communauté. La proposition du fonctionnaire paraît insolite et absurde mais elle ne l'est pas puisqu'elle s'intègre à une logique globale qui la justifie et la légitime. La mère accepte sans sourciller. Elle n'est pas dupe de l'hypocrisie de la situation mais elle joue le jeu car elle ne voit pas d'autre alternative à l'intégration de la famille dans la communauté. Elle faut bien manger, elle faut donc bien travailler et travailler, c'est effectuer une activité en échange d'un paiement, à partir de là, la sens de l'activité est indifférent. Les contradictions de son comportement ne lui

1143Mattos écrit : «O filme se insurgia contra a mania brasileira de esperar sentado, e, com isso, não granjeava simpatia política de parte alguma. » (« Le film s'insurgeait contre cette manie brésilienne d'attendre assi et de laisser faire, et, pour cela, ne pouvait susciter de sympathie politique d'aucun côté. » in MATTOS, Carlos Alberto. Op. cit., p. 149.) Cette interprétation suggère que la passivité est une caractéristique brésilienne ce qui nous semble un préjugé sans fondement scientifique. Il est possible que Lima ait partagé ce préjugé. Le film est plus riche que cela et, en amenant jusqu'à leurs dernières extrémités les implications logiques d'une telle affirmation, il permet au contraire de la remettre en doute. Brasil ano 2000 pose la question de façon provocante : « Sommes-nous aussi médiocres que cela ? » Pour nous, il va sans dire que le sousdéveloppement ne peut s'expliquer par une hypothétique " nature ontologique de l'homme brésilien », même si celle-ci est considérée comme étant exclusivement culturelle. Le sous-développement et ses implications sociales et culturelles sont bien en première instance d'origine matérielle. Les inégalités sociales et les situations de pénurie expliquent un certain nombre de comportements. Si, jusqu'à aujourd'hui, les classes dominantes ont toujours réussi à maintenir leur hégémonie, le pays n'en est pas moins passé par de violents conflits et survit dans un état de fragmentation et de chaos social qui contredit totalement l'idée d'une nature indolente et d'une mentalité où l'on préfère « attendre assis ». 
apparaissent pas et sa situation est facilitée par le fait qu'elle s'identifie avec la figure du fonctionnaire du SEI. Il s'agit d'un homme de la même génération que la sienne et, symboliquement, il remplace le père et le mari, une autorité à laquelle on peut se remettre pour éviter d'avoir à choisir pour soi-même. Dans toutes les séquences où la mère et le fonctionnaire du SEI sont ensemble, la solidarité qui les unit est plus forte que celle qui unit la mère à ses propres enfants.

Ceux-ci vivent au contraire très mal la situation. Leur premier problème est celui de l'aliénation. Ils souffrent le fait de devoir refouler leur véritable identité au profit d'une autre dans laquelle ils ne se reconnaissent pas du tout et qui en plus leur semble humiliante ${ }^{1144}$. Ils acceptent aussi très mal le fait de devoir participer de l'hypocrisie ambiante. Mais ils semblent incapables de manifester leur désaccord au-delà du classique psychodrame familial. La crise traversée par les jeunes gens montre bien que le problème général de l'aliénation collective est aussi un problème intime d'aliénation individuelle, d'écrasement de la personnalité et de malêtre. La rupture, cependant, ne va pas de soi pour l'individu qui se trouve isolé et désemparé face à des mécanismes collectifs qui le dépassent. Il doit également assumer les compromis familiaux, c'est bien la famille qui devrait le protéger qui, en premier lieu, le contraint à accepter les mécanismes d'aliénation collective. Les compromis familiaux sont symbolisés par le vaisselier de cristal que la mère s'attache à emmener avec elle dans leur exode vers le Nord. Il s'agit d'un meuble extrêmement embarrassant et sans aucune utilité. Il est l'exact pendant pour la famille de la sous-allégorie totalisante de l'église pour la communauté. Nous remarquerons aussi que la tension entre le frère et la sœur n'est jamais aussi forte que lorsque l'un deux d'entre eux menace de quitter le cocon familial. À ce moment-là, l'autre lui rappelle ses compromis envers lui-même et leur mère.

En intervenant aussi bien dans l'histoire familiale que dans l'histoire collective, la figure du reporter devrait s'imposer comme la pièce maîtresse du dispositif de démystification matérialisé par le film. La caractérisation du personnage induit cette lecture. Son anticonformisme, son éloquence et son caractère vindicatif remettent au personnage de Glauber Rocha, la coupe de cheveux et le pull à col roulé orange rappellent Caetano Veloso, la barbe et le cigare renvoient aux révolutionnaires cubains. Au fil de la narration, il essaye successivement d'inciter le frère et la sœur à la révolte. Constatant leur incapacité à rompre avec le passé, il dénonce lui-même la supercherie à laquelle ils participent au cœur de l'église où toute la communauté est rassemblée. À chaque fois cependant, l'agressivité du reporter est vaine, dans l'interview du général comme dans l'église, le journaliste peut se permettre toutes

1144Voir la séquence du maquillage, dans la partie du film correspondant au carton « 8 ». Tout en se maquillant, le frère et la sœur répètent obsessivement « Eu sou índio » (Je suis indien). 
les impertinences, il peut même tout révéler des arrangements malhonnêtes du pouvoir, il ne sera pas écouté et recueillera à peine des froncements de sourcil. Dans l'église, alors qu'il harangue l'assistance, chacun lui tourne le dos signifiant clairement qu'il ne veut rien entendre, et rien changer. Dans l'entretien entre le général, le prêtre, le fonctionnaire du SEI et lui-même qui décidera du sort des « faux indiens », il se permet même de gagner au poker. Le général se montre totalement indifférent à cette victoire. Malgré lui, le reporter fait partie intégrante du «cirque » qu'il voudrait dénoncer. Quand la jeune fille décide finalement de partir, elle le fait de son propre chef, moins sous l'effet d'une véritable prise de conscience d'ailleurs que d'un vif désir de liberté.

Il y a, sans doute, à partir du moment où le Cinema Novo recherche de nouveau à concilier ambition esthétique et grand public, une contradiction qui n'a pu être vaincue que dans un petit nombre de films, les trois que nous avons fait correspondre à l'option populaire, et au prix d'un double-renoncement. Pour atteindre le grand public, il fallait renoncer aux stratégies d'agression théorisées dans l'Esthétique de la faim et se dégager de films réflexifs à usage privé. Avec les films de la seconde phase du Cinema Novo, la démystification de la posture populiste ayant été effectuée, il fallait passer à une nouvelle étape, autrement dit, prendre position et agir, ou continuer dans le registre d'un cinéma d'avant-garde, en admettant ne pouvoir toucher qu'un public limité, ou chercher un compromis avec les attentes du grand public sans compromettre ses intentions démystificatrices. Ce compromis est atteint avec des films qui ne déjouent pas les stratégies de lecture traditionnelles et ne comportent pas des références érudites comme indispensables à une première lecture. De même, l'idée selon laquelle l'esthétique du film devait placer le spectateur dans une situation d'inconfort est abandonnée au profit de la recherche d'une certaine connivence qui, si elle ne recouvre pas les relations d'identification du cinéma classique, ne s'éloigne pas moins des stratégies de la fragmentation de Terra em transe.

Malgré le succès de Menino de engenho, malgré une campagne de promotion sans équivalent dans la carrière du Cinema Novo $^{1145}$ et malgré aussi les chansons de Gil et Veloso, le « tropicolor» et les attraits du cinemão, Brasil ano 2000 est un échec commercial duquel Lima, principal producteur du film, sort criblé de dettes ${ }^{1146}$. Sa carrière s'en ressentira beaucoup puisque, à l'exception du long métrage underground, Na boca da noite (1970), il faudra attendre 1977 avant qu'il ne conclue un nouveau long métrage (A Lira do delírio).

1145Nous avons compté 14 articles de promotion dans le dossier de presse que nous avons réuni, c'est à dire 14 articles qui ne sont pas des critiques du film mais apportent des informations sur sa production ou / et rapporte des propos de Lima Junior à son sujet. Il s'agit d'une couverture tout à fait exceptionnelle dont nous n'avons pas trouvé d'équivalent pour d'autres films du Cinema Novo.

1146MATTOS, Carlos Alberto. Op. cit., p. 174. 
Certains commentateurs attribuent l'échec de Brasil ano 2000 au fait que le film soit sorti trop tard. En 1969, la mode du tropicalismo serait déjà passée ${ }^{147}$. Ces mêmes commentateurs oublient que Macunaíma, qui doit aussi beaucoup à ce mouvement artistique, sort plusieurs mois plus tard et n'en est pas moins un grand succès de cinéma. À notre avis, les causes de l'échec de Brasil ano 2000, sont doubles. La première, comme pour les films que nous allons voir par la suite, est d'avoir développé une allégorie requérant des savoirs et une approche du cinéma qui ne pouvaient pas être ceux du plus grand nombre. La seconde cause à son échec réside dans le caractère ironique de la narration or, l'ironie est toujours difficile à manier. Dans le cas présent, ou l'ironie n'était pas perçue et cela devait entrainer le rejet du film, ou elle était perçue mais pouvait ne pas être reconnue comme pertinente.

La réception critique mitigée faite au film dans la presse brésilienne, et ce, malgré la récompense obtenue au festival de Berlin, tendrait à confirmer cette évaluation ${ }^{1148}$. Brasil ano 2000 est jugé « formaliste » et rapproché de Palácio dos anjos (Khoury, 1969) par Miguel Pereira $^{1149}$ et Carlos Frederico ${ }^{1150}$. Pereira salue le souci manifeste d'évoluer vers une meilleure qualité technique des films mais pour Frederico le terme "formalisme» remet Brasil ano 2000 à la catégorie des films vides et inutiles exprimant un esthétisme vain. Cette appréciation est d'autant mieux partagée que l'allégorie est très inégalement comprise et appréciée. Certains critiques ne s'aventurent même pas à la commenter et, parfois, malgré un parti pris favorable à Lima, expriment une gêne par rapport à l'orientation suivie dans Brasil ano 2000. C'est le cas de José Lino Grunewald ${ }^{1151}$ et d'Alex Viany ${ }^{1152}$ qui soulignent les intentions louables du cinéaste mais un manque de maturité dans l'exécution. Pereira, déjà cité, estime que la thématique du long métrage est confuse et que la critique de la famille ne repose sur aucun fondement sociologique. Enfin, Ely Azeredo et Rubens Ewald Filho rejettent pareillement la démarche dont procède le film et la pertinence de l'allégorie :

«[...] em vão procuramos alguma substância de realidade brasileira ; não a encontramos sequer sob a linguagem cifrada da alegoria. $\rangle^{1153}$

Seule, Tati Moraes ${ }^{1154}$ semble s'identifier au point de vue critique du film. Elle analyse Brasil ano 2000 comme étant un Vidas secas futuriste. Le traitement de l'histoire de la famille

1147C'est le cas de Mattos. Ibid., p. 152.

1148Sur les huit critiques que nous avons inventoriées, 6 sont négatives et 2 sont positives. Les deux critiques positives comportent néanmoins chacune des réserves. L'une d'entre elles affichent la mention « razoável », autrement dit « régulier » ou « correct ».

1149PEREIRA, Miguel. « Brasil, Ano $2000 »$ in $O$ Globo, 03/06/1970.

1150 Palácio dos anjos est en compétition officielle à Cannes en 1970.

1151GRUNEWALD, José Lino. « Brasil ano 2000 » in Correio da Manhã, 02/06/1970.

1152 VIANY, Alex. « Brasil ano $2000 »$ sans origine, sans date (après juin 69).

$1153 \ll[\ldots]$ en vain nous cherchons la moindre parcelle de réalité brésilienne; nous ne la trouvons pas sous ce langage chiffrée de l'allégorie. » in AZEREDO, Ely. « Brasil ano 2000 » in Jornal do Brasil, Rio de Janeiro, sans date.

1154MORAES, Tati. "Temperamento mal aproveitado", Ultima Hora, 04/06/1970. 
brésilienne projetée dans la situation d'un monde post-troisième guerre mondiale lui paraît réaliste et elle met en avant le contrepoint «tempérament brésilien », joyeux et créatif des musiques, et la situation tragique et sans espoir décrite. Enfin, elle pose la question, jusqu'à quand l'absence de combativité va durer ? Après que le personnage oscillant ait perdu de sa pertinence, il restait important de toucher la classe moyenne. L'analyse développée par Brasil ano 2000 était juste en ce qui concerne l'aliénation de la classe moyenne. Mais, en ne prenant en compte aucun critère pragmatique et en restant ambiguë, elle s'est perdue. En fin de compte, Brasil ano 2000 pouvait aussi bien renforcer les préjugés sur la passivité et l'incapacité créative que les remettre en question.

\subsection{Os Herdeiros}

Os Herdeiros (Les Héritiers) est le troisième long métrage de Carlos Diegues. Il succède dans sa carrière à l'un des premiers grands succès public du Cinema Novo, $A$ Grande Cidade (1966) qui avait su concilier ambition artistique et communication de masse. Avec Os Herdeiros, Diegues tourne le dos à une esthétique qui lui avait pourtant permis d'atteindre, selon ses propres termes, « uma certa atmosfera de brasilidade » (une certaine atmosphère de ' brasilianité ' $)^{1155}$. Son objectif est à présent de retracer 40 ans de l'histoire du Brésil en 100 minutes, de la Révolution de 1930 au coup d'État de 1964, et de créer un «spectacle nouveau » : « De um romantismo aberto à crise da linguagem, capaz de restituir ao cinema parte de sua magia original $»^{1156}$. En pratique, le cinéaste s'essaye au langage allégorique et fragmenté initié par Terra em transe dont il reprend aussi de nombreux thèmes. Le résultat est une œuvre ambiguë qui expose au grand jour les contradictions qui continuent à habiter le Cinema Novo. Les observations que nous ferons sur Os Herdeiros recoupent celles que nous avons déjà faites sur Brasil ano 2000. Nous retrouverons premièrement une certaine ambiguïté dans le propos. La mise en scène rigoureuse de l'opéra politique remet à une analyse assez discutable de l'histoire du Brésil. Secondement, le bouleversement de l'ordre des motivations qui régissent la narration classique trahit une certaine inadéquation entre la fin et les moyens. L'élargissement du public est recherché en persévérant dans la pratique d'un langage très référencé nécessitant de la part du spectateur l'application de modes de lecture seulement envisageables après l'acquisition d'une expérience culturelle sociologiquement située.

1155Cf. DIEGUES, Carlos. « Os Herdeiros é o testemunho de minha paixão pelo Brasil » in Jornal do Brasil, Rio de Janeiro, 11/05/1970.

1156« D'un romantisme ouvert à la crise du langage, capable de restituer au cinéma une partie de sa magie originale. » in Os Herdeiros. Press release, 1969. Archives Cinemateca Brasileira, São Paulo. 
Le titre initial de Os Herdeiros devait être $O$ Brado retumbante (littéralement, L'Appel retentissant). Il s'agissait d'une citation des premières lignes de l'hymne national du Brésil « Ouviram do Ipiranga as margens plácidas / De um povo heróico o brado retumbante [...]» qui elles-mêmes se référaient au « Cri de l'Ipiranga » par lequel le futur empereur Dom Pedro I avait proclamé l'indépendance du Brésil en 1822. Supposant à l'auteur des intentions sarcastiques, la censure avait fait savoir à Carlos Diegues qu'elle ne laisserait pas sortir le film avec un tel titre ${ }^{157}$. Il est vrai, comme nous l'avons déjà expliqué, que le cri d'Ipiranga est une imposture historique dans la mesure où l'indépendance du Brésil ne correspond en rien au schéma insurrectionnel inspiré de l'indépendance des États-Unis ou de la Révolution française que l'historiographie officielle a cherché à plaquer sur elle. En plus d'être une imposture, la situation même de la déclaration d'indépendance remet à une imagerie surréaliste «pourtant vraie » dans laquelle les cinemanovistas veulent voir un trait caractéristique de la «tragédie nationale ». Après en avoir décidé avec son père le roi de Portugal qui doit revenir dans la métropole après un exil de presque quinze ans ${ }^{1158}$, Dom Pedro, accompagné de la haute aristocratie brésilienne, s'arrête au bord du fleuve Ipiranga, sort son sabre, proclame l'indépendance et s'écrit « Independência ou morte », il range son sabre. La troupe reprend son chemin. Sa déclaration suggère une situation épique, des combats, de l'engagement, du danger, il n'en est rien. Comme Terra em transe, Os Herdeiros va chercher à mettre en scène ce déphasage constant entre la grandiloquence des discours et l'insignifiance des actes. Il va aussi chercher à montrer le drame d'une histoire nationale dont les grandes décisions sont toujours prises par les classes dominantes à l'insu du reste de la population. Enfin, l'hymne national renvoie aussi à l'affect. Le Brésil envers et contre les trahisons, les défaites et les injustices, demeure un domaine d'investissement émotionnel. Il faudra donc montrer comment la critique historique peut intégrer cet amour irraisonné d'une patrie constamment dérobée à elle-même.

Si la référence à l'hymne national n'a pas été possible, le film n'en débute pas moins par une musique de Villa-Lobos remettant au même type de patriotisme : Invocação em defesa da pátria. La narration est ensuite divisée en quatre époques distinctes correspondants à quatre périodes historiques particulièrement importantes. Le film commence avec la Révolution de 1930 qui a amené Getúlio Vargas au pouvoir (première séquence). Il se

1157Le projet du cinéaste avait été divulgué dans la presse dès 1966 et de nombreux articles contemporains de l'écriture et de la réalisation du film se réfèrent à lui avec ce titre.

1158Au moment des invasions napoléoniennes, au contraire de la cour espagnole, la cour portugaise avait préféré fuir dans l'une de ses possessions d'outre-mer. Rio de Janeiro est ainsi devenue, de 1807 à 1821, la capitale de l'empire portugais. Le retour de João VI dans son pays ne sera pas l'immédiate conséquence de la libération de son pays mais le résultat des contradictions économiques et politiques dont est alors victime le Portugal. 
poursuit dix ans plus tard avec l'apogée de la dictature de l'Estado Novo au début des années quarante $^{1159}$. Après la chute de l'Estado Novo, une ellipse recouvre les années du gouvernement Dutra (1945-1950). La narration reprend avec le retour de Vargas au pouvoir $(1950-1954)^{1160}$. Après son suicide, une nouvelle ellipse permet de faire l'économie des gouvernements de Café Filho et Kubitschek. Enfin, la période 1960-1964 est traitée, de l'inauguration de Brasília au coup d'État militaire de 1964.

Au cours de ces quatre périodes, nous est raconté la saga d'une famille brésilienne de la haute-bourgeoisie. La narration est centrée sur le personnage de Jorge Ramos (Sérgio Cardoso), un journaliste ambitieux qui se marie par intérêt avec la fille d'un baron du café nommé Almeida (Mário Lago). Déjà ruiné par la crise du café, avec la victoire de Vargas, celui-ci perd le pouvoir et le prestige qui lui restait. Dix ans plus tard, en pleine répression de l'Estado Novo, Ramos qui participait à des activités subversives se réfugie chez lui sur le conseil de Medeiros (Paulo Porto), le patron du journal où il travaille. Le journaliste séduit le vieil homme en lui promettant de rendre à son exploitation le lustre d'antan et se marie avec sa fille. Dès le retour de la démocratie, en 1946, il retourne pourtant en ville et, au prix de nouvelles trahisons, il gravit rapidement les différents échelons du pouvoir. Dans les années soixante, quand son fils est en âge de prendre sa succession, malgré une première et violente opposition de principe, il accepte d'assumer l'héritage du père et de reproduire son mode de domination.

Dans un entretien qu'il accorde à la sortie du film ${ }^{1161}$, Diegues déclare avoir été aidé au cours de l'écriture du scénario par le visionnage de Terra em transe qui venait de sortir. Avec Os Herdeiros, il dit vouloir reprendre et développer la polémique initiée par ce long métrage. Son film devait donc continuer la thématique de la politique au sommet et de l'exclusion des classes populaires des décisions historiques concernant l'avenir du pays. L'idée centrale de l'argument est que le peuple est exclu de l'histoire et que la bourgeoisie, pour se maintenir au pouvoir, trahit invariablement les partis dits progressistes ${ }^{1162}$. L'esthétique qu'il développe pour élaborer sa critique du populisme pré-64 consiste à éliminer du cadre le peuple et l'action. Le peuple est absent de la bande-image et les paroles ne sont jamais associées à une action concrète. Diegues expliquait ses choix aux Cahiers du cinéma dans ces termes :

1159Du carton « São Paulo, dez anos depois » au carton « Rio de Janeiro, quatro anos depois ». 1160Du carton « Rio de Janeiro, quatro anos depois » au carton « Brasília, 21 de abril 1960 ». 1161In DIEGUES, Carlos. « Os Herdeiros é o testemunho de minha paixão pelo Brasil », op. cit. Terra em transe est une référence récurrente dans les entretiens accordés par Diegues au sujet de $O s$ Herdeiros. À ce sujet, voir aussi : DIEGUES, Carlos. «Entretien avec Carlos Diegues » in Cahiers $d u$ cinéma, Paris, n²25, novembre-décembre 1970.

1162Après avoir trahi son ami David Martins, dirigeant du parti communiste dans la clandestinité à l'époque de l'Estado Novo, Jorge Ramos va également trahir le professeur Maia, un autre dirigeant communiste, après le coup d'État de 1964. 
«Ce n'est pas un film sur le peuple, mais sur ceux qui ont parlé et agi en son nom, sur les classes non-révolutionnaires. Dans la séquence à Brasília, par exemple, où il devait y avoir du monde, j'avais fait venir des figurants, et j'y ai renoncé à la dernière minute ; la même chose s'est passée pour la séquence du meeting, au début du film, quand Ramos et ses camarades distribuent des tracts - il n'y a personne. On ne voit le peuple que dans trois séquences : à la mort de Vargas, parce qu'il était profondément concerné (j'ai néanmoins essayé de tourner ça avec une certaine distance); à la fête dans le jardin de chez Ramos, où le peuple est dans son rôle caricatural et folklorique (on sent qu'ils dansent la samba parce qu'ils sont payés pour ça); enfin, la séquence où Joaquim va à la tenda. $\rangle^{1163}$

Tout au long du film, l'absence du peuple est d'autant plus forte que la bande-son est composée de bruitages et de chansons populaires qui suggèrent constamment sa présence hors-champ. Jorge Moreno a étudié les relations entre image et son off dans Os Herdeiros et il en a tiré les observations suivantes :

« Na seqüência da Rádio do Povo, o som off da multidão nos leva a crer que existe um auditório aplaudindo o espetáculo, mas notamos que na verdade não existe ninguém no auditório e que o som corresponde a um plano onde é estilizada uma manifestação de insatisfação. Talvez não mostrando um auditório repleto, demonstre todo um distanciamento entre a rádio e o povo. O som off, sendo de uma multidão revoltosa, cria também significados que elaboram uma estrutura que reforça a ausência do povo durante todo o filme. $»^{1164}$

Il remarque également que le son off est souvent utilisé pour suggérer des images qui ne se réaliseront pas à l'écran exactement comme elles sont attendues. Le décalage est créateur de sens et de significations nouvelles. Nous remarquerons pour nous que la bande son, plus riche et contradictoire que la bande image, semble bien le domaine du réel, du peuple et de l'émotion. Son caractère anarchique entre en contradiction avec celui de la bande image qui est au contraire classique, parfaitement ordonnée, froid dans sa rigueur et sa théâtralité affecté. La composition de l'image, en plus d'être caractérisée par l'éviction de l'élément populaire, est dominée par les relations de symétrie qui s'établissent à partir d'un plan vertical qui se confond avec l'axe de la caméra et s'appuient sur l'architecture géométrique des palais et des bâtiments luxueux où évoluent les personnages. Pedro della Paschoa Junior ${ }^{1165}$ note que ce plan vertical qui divise l'image en deux parties égales fonctionne comme un miroir qui reproduit symétriquement la droite et la gauche. Zooms, travellings ou mouvements latéraux de la caméra ne remettent jamais en cause la rigidité de

1163DIEGUES, Carlos. «Entretien avec Carlos Diegues », op. cit.,, p. 53.

1164« Dans la séquence de la Rádio do Povo (Radio du Peuple), le son off de la multitude nous fait croire qu'il existe un auditoire qui applaudit le spectacle, mais nous notons qu'en vérité, il n'y a personne dans l'auditoire et que le son correspond à un plan où une manifestation de protestation est stylisée. Peut être qu'en ne montrant pas un auditoire rempli, on démontre qu'il existe une distanciation entre la radio et le peuple. Le son off, étant celui d'une multitude révoltée, il est aussi créé une structure de signifiants qui renforce l'absence du peuple pendant tout le film. » in BERNARDET, Jean-Claude, TEIXEIRA, Coelho (org.). Terra em transe Os Herdeiros : Espaços e poderes - Texto de trabalho. Op. cit., p. 61.

1165Ibid., pp. 47-58. 
cette organisation de l'espace et, au contraire, la renforcent. Cette symétrie de l'image se superpose avec les conflits des personnages.

L'opposition idéologique droite-gauche tend à être nivelée dans une relation d'équivalence au sein de laquelle la gauche n'ira jamais au-delà des protestations idéalistes. Cette idée des contraires qui s'annulent est présente dans l'exacte similitude de la scénographie de la droite et de la gauche ou dans des relations ambiguës d'opposition comme dans l'une des rares images de protestation populaire où nous voyons d'un côté un panneau avec la phrase «Getúlio lacaio do comunismo » et de l'autre «Getúlio lacaio do imperialismo » (Getúlio laquais du communisme / Getúlio laquais de l'impérialisme). Cette idée des contraires qui s'annulent est également présente dans la dernière partie du film où s'opposent les deux fils de Ramos, Joaquim, le fils de son épouse légitime, élevé à la fazenda São Martinho, et David, le fils de sa maîtresse, élevé à Rio de Janeiro. L'un est de gauche, l'autre est de droite. Nous aurons un plan de type " photo de famille » où Ramos, au centre de l'image et avec Joaquim d'un côté et David de l'autre, déclare qu'il est bon de réunir dans une même famille la gauche et la droite.

Il faut aussi noter les constantes inversions de symboles. David est de droite alors qu'il a été élevé en ville au sein de la bourgeoisie urbaine supposée progressiste et qu'il porte le prénom du dirigeant communiste trahi pendant l'Estado Novo. Joaquim, parce qu'élevé par Almeida et issu de l'aristocratie rurale réactionnaire et décadente, devrait être le fils de droite, il est au contraire celui de gauche. À la fin du film, seul héritier de son père après l'assassinat de son frère, il choisit de trahir ses idéaux. Reinaldo da Costa Maia ${ }^{1166}$ remarque aussi une inversion des symboles et les relations d'équivalence qui s'établissent au travers des codes de couleur du film. Le rouge est la couleur de la fazenda, du monde rural, du café, autrement dit de «l'ancien», il est aussi la couleur des militants communistes qui distribuent leurs tracts dans une des séquences consacrées à l'Estado Novo. Le blanc symbolise l'aristocratie rurale, c'est la couleur de la casa grande, mais c'est aussi la couleur de la mariée qui porte en elle un possible renouveau et il s'oppose au noir qui sera associé au pouvoir urbain et à la nouvelle classe économique et politique qui émerge avec l'industrialisation. Cette classe qui devait permettre le développement du Brésil et l'avènement du «nouveau » porte la couleur de la mort. Enfin, dans ce réseau de relations symétriques, il faudra également commenter les trajectoires d'Almeida et Ramos. Almeida, fidèle représentant de l'aristocratie rurale, devient un opposant farouche à la dictature de Vargas et, de façon contradictoire, en vient à assumer un rôle progressiste. Ramos, opposant à Vargas et militant communiste sous l'Estado Novo, nationaliste et serviteur de l'ancien dictateur à son retour au pouvoir, s'allie finalement aux 
monopoles impérialistes ${ }^{1167}$ et assume un rôle réactionnaire. Dans ce chassé-croisé, les intérêts matériels et privés, constamment, prévalent ${ }^{1168}$.

L'axe de symétrie qui passe par la caméra dévolue également au spectateur une position particulière. Il bénéficie d'un point de vue privilégié, son regard se confond avec l'axe de la caméra, la vision qui s'offre à lui est parfaitement organisée, il se trouve aussi en tête à tête avec l'instance du pouvoir au travers d'un objet ou d'un personnage se trouvant au centre de l'image, ou encore, au travers de la monumentalité de la scénographie. Cette position exceptionnelle donne parfois l'illusion de se tenir au centre même des grands événements historiques, c'est le cas de la séquence initiale où il est placé au cœur des négociations au cours desquels se décident l'accession au pouvoir de Vargas. C'est le cas des séquences du second gouvernement Vargas et notamment de celle qui se déroule dans le palais présidentiel du Catete, juste avant le suicide du chef de l'État. C'est le cas aussi de la séquence de l'inauguration de Brasília quand le journaliste français s'agite autour de Ramos, impassible et tranquille au centre de l'image, et que l'axe de la caméra se déplace du Congrès (il se confond alors avec l'axe Est-Ouest de la ville aussi appelé « Axe monumental ») vers le palais de l'Alvorada (le palais présidentiel, l'axe de la caméra est alors parallèle à l'axe nord-sud).

En contrepartie, le regard du spectateur, parce qu'il est constamment dirigé, ne lui appartient pas, soit à cause du hiératisme des mouvements de caméra, soit à cause des déplacements rectilignes et précis des personnages, soit à cause de la scénographie qui se décline selon quatre modalités : l'espace ouvert mais parfaitement symétrique ; le rideau, la toile ou la façade ; le couloir ou le coin de pièce ou de balcon. Le classicisme de la composition de l'image élimine toute diversité et, dans sa monumentalité, impose une facilité de lecture trompeuse. Nous sommes ici à l'opposé de la relation établie par la caméra dans Deus e o diabo na terra do sol, O Desafio, ou même encore Terra em transe, car si, dans ce dernier, le pouvoir est bien constamment replacé au centre du cadre (toutes les séquences incluant Vieira ou Diaz), s'il est aussi exploité les axes de symétrie offert par la scénographie, l'agitation constante de la caméra, des personnages et la fragmentation de la narration remettent constamment en question la justesse des propositions du film sur tel ou tel aspect de sa thématique. Dans Os Herdeiros, nous avons, comme dans Terra em transe, la volonté de dénoncer l'exclusion du peuple des décisions politiques et l'illusion consistant à penser que la bourgeoisie nationale pourrait jouer un rôle progressiste dans le processus historique. Mais

1167Ceux-ci sont symbolisés par le personnage du « gringo » (l'étranger), un « ami » que le nationaliste Ramos, va « voler » au libéral Medeiros et avec lequel son propre fils va s'allier après avoir assumé sa succession.

1168Almeida s'oppose à la dictature de Vargas dans le but de revenir à l'ordre politique d'autrefois. Ce sont les circonstances qui donnent à son comportement une valeur progressiste. De même, à chaque échelon gravi vers le pouvoir, Ramos cède un peu plus à la fascination que celui-ci exerce sur lui. 
ici, la relation établie avec le spectateur acquiert des modalités autoritaires et tend à imposer la représentation de l'histoire comme vraie. Ainsi, le film s'inscrit dans une étrange contradiction, la théâtralisation de l'espace filmique (scénographie, placement de la caméra et jeu des acteurs) établit dans un même mouvement une distanciation, le film s'affirme comme une « représentation », mais la monumentalité même de cette représentation impose pour vrai ce dont elle se fait la messagère.

Della Paschoa Junior énonce en ces termes cette contradiction :

« Em Os Herdeiros não há dois pólos e visão multifacética do real como em Terra em transe. Há somente um eixo - o poder visto por um narrador que se nos apresenta absoluto como o poder que pretende criticar. Curiosa coincidência. Não há subjetividades mas uma única subjetividade, a de seu narrador excluído da cena que se oculta detrás do que mostra. As características do poder exibidas e a postura do narrador, almejando a oposição se superpõem. $\rangle^{1169}$

Comme dans Brasil ano 2000, le formalisme du film et la vision pessimiste de l'histoire qu'il nous apporte lui font courir le risque de nous faire accepter comme inéluctable la situation qu'il dénonce. Ce risque est d'autant plus fort que les conflits opposants les différents actants de la narration s'identifient aux déchirements grandioses des tragédies classiques et confèrent ainsi un caractère « noble » à une situation sordide. Les fils trahissent les pères (symboliques ou réels), se rebellent contre eux, mais finissent par les imiter après les avoir supplantés. Ramos trahit ainsi Almeida après lui avoir pris sa fille et promis la renaissance de São Martinho, il trahit ensuite Medeiros, le patron du quotidien qui l'introduit dans les hautes sphères du journalisme, et, au bout de ce processus il sera devenu conservateur comme le premier et libéral comme le second. Joaquim trahit son père pour se venger personnellement, venger sa mère et venger ses amis socialistes. Il le pousse au suicide et s'estime accompli quand il peut enfin déclarer « Eu vi ele fraco, eu vi ele morrer. » (Je l'ai vu en situation d'infériorité, je l'ai vu mourir). Il trahit alors à son tour et prend la place du père. L'élimination du peuple du cadre de l'image semble nous signifier que l'histoire s'est toujours faite sans lui et que cela continuera ainsi. Le jeu des trahisons successives de Ramos et de son fils signifie un déterminisme inflexible au sein des classes supérieures, le titre semble alors devoir être entendu dans l'acception que lui a donné Pierre Bourdieu et stigmatise les mécanismes de reproduction et le déterminisme culturel à l'intérieur d'une même classe. Dans le film de Diegues, aucune transformation ne semble possible, même à long terme.

1169« Dans Os Herdeiros, il n'y a pas deux pôles et une vision à plusieurs facettes du réel comme dans Terra em transe. Il y a seulement un axe - le pouvoir vu par un narrateur que se présente à nous absolu comme le pouvoir qu'il prétend critiquer. Curieuse coïncidence. Il n'y a pas plusieurs subjectivités mais une subjectivité unique, celle du narrateur exclu de la scène qui est dissimulé derrière ce qu'il montre. Les caractéristiques du pouvoir qui nous sont montrées et la posture du narrateur, alors qu'elles sont destinées à s'opposer, elles se superposent. » in ibid, p. 51. 
Est-ce à dire pour autant qu'il faudra se conformer à une réalité certes cruelle mais définitive et « faire avec » ? Comme dans le cas de Brasil ano 2000, le caractère pessimiste du constat peut amener des réactions diverses et, aussi bien, la réaction que l'apathie. L'écriture d'une histoire du Brésil qui insiste sur l'exclusion du peuple peut aussi bien corroborer les thèses concernant sa passivité et son immaturité que celles stigmatisant le caractère autoritaire des institutions au travers des différents régimes. Nous avons noté que la bande-son ne répondait pas aux principes d'organisation de la bande-image, plus diverse, plus anarchique, plus contradictoire, elle est aussi le domaine du peuple, par la simple suggestion de son insaisissable présence, et de l'émotion au travers des musiques et de leur capacité à évoquer telle ou telle période historique. Bien que le peuple soit exclu et que, jusque dans ses rares apparitions, c'est un peuple aliéné, manipulé qui nous est donné à voir, la bande-son manifeste un « être-là » de l'entité qui est finalement la raison d'être de la tragédie. Comme dans Terra em transe, l'emphase qui, selon différentes figures de style, est portée sur son absence, est une manière de rappeler que la narration n'a de sens que parce qu'il existe et se trouve soumis à des injustices et des souffrances concrètes. La musique évoque également sa présence au travers de la notion du succès. Le fait qu'une musique puisse avoir la capacité d'évoquer une période historique renvoie aussi au fait qu'elle a été l'objet d'un investissement affectif du public. L'utilisation de la musique est sans doute à mettre en relation avec les intentions de Diegues d'établir une relation à la fois critique et émotionnelle au travers de ce qu'il concevait comme un «mélodrame politique ». Selon ce qu'il expliquait à l'époque à Cine Cubano, il avait recherché un langage moins intellectualisé que celui qui était habituellement celui du Cinema Novo pour réussir à émouvoir profondément le spectateur :

\footnotetext{
« Estoy convencido de que para que el cine se transforme como lenguaje y al mismo tiempo dialogue con el público tendrá de ser un cine necesariamente portador de una carga de emociones mucho mayor que todo lo conocido hasta hoy. Que transforme en verdad al público, que cree un espectador ligado al filme casi desde las entrañas, no desde el corazón ni la cabeza, sino de las propias entrañas. Fue eso lo que intenté hacer. $»^{1170}$
}

Dans le même entretien, il compare d'ailleurs sa démarche à celle de Rocha dans $O$ Dragão... et nous explique que là où Rocha tente de parvenir à une relation à la fois critique et émotionnelle à partir d'une narration épique, lui tente d'établir le même type de relation à partir d'un mélodrame politique. Il s'agit d'intégrer l'émotion au processus de conscientisation,

1170 « Je suis convaincu que, pour que le cinéma se transforme comme langage et, en même temps, dialogue avec le public, il faut nécessairement qu'il soit porteur d'une charge d'émotions supérieure à tout ce qui a été connu jusqu'à aujourd'hui. Pour que le cinéma transforme le public, il faut qu'il prenne le spectateur aux tripes, non pas qu'il parle au cœur ou à la raison, mais qu'il prenne aux tripes mêmes. C'est ce que j'ai essayé de faire. » in DIEGUES, Carlos. « Entrevista con el director brasileño Carlos Diegues realizador del filme los Herederos - Miguel Torres » in Cine cubano, La Havane, n60-1, mars 1970, p. 87. 
de prendre en compte l'irrationnel pour ce qu'il pouvait présenter de positif et de transformateur. Il est intéressant de noter l'intérêt de Diegues pour cette démarche qui recoupe l'idée de l'Esthétique du rêve à venir car, finalement, peu de films en-dehors de O Dragão... peuvent être mis en relation avec cette nouvelle théorie. Macunaíma et Como era gostoso... constituent de vraies propositions pour un cinéma populaire en abandonnant des stratégies d'agression et de désorientation mais ce sont des films qui demeurent dans le cadre humaniste et rationaliste dominant le Cinema Novo. Ils ne proposent pas la rupture de l'Esthétique du rêve. À côté de cela, il est évident que la réalisation d'une esthétique à la fois critique et émotionnelle peut sembler un exercice périlleux risquant l'écueil de la démagogie. Il nous semble cependant que $O$ Dragão... constituait un essai valide dans ce sens et que la relation à la musique dans Os Herdeiros est aussi tout à fait concluante. Diegues lui-même semble le revendiquer quand, rétrospectivement, il évoque ses premiers flirts avec la musique et «sua transparência no mundo $»^{1171}$ («sa transparence au monde »). Pour le reste, pour les raisons que nous avons vues et d'autres qui nous restent à exposer, Os Herdeiros ne nous semble que très imparfaitement réaliser cette esthétique à la fois critique et émotionnelle.

Premièrement, parce que, comme nous l'avons vu, la dimension critique de ce film qui renvoie dos à dos la gauche et la droite et n'offre aucune perspective est discutable. Deuxièmement, parce que, à l'opposé du résultat revendiqué d'un cinéma «émotionnel » ou « charnel », l'idée ou le concept prend le pas dans la démarche de Diegues sur un authentique cinéma de recherche. S'écartant peu d'un scénario très écrit au moment du tournage, Diegues s'écarte du réalisme en optant pour une figuration brechtienne et, comme Lima, fait précéder les motivations de composition et de vraisemblance par les motivations artistiques. Sa démarche est parfaitement cohérente d'un point de vue formel mais pas d'un point de vue pragmatique. Il la décrit dans ces termes :

«Os Herdeiros está construído de tal forma que cada episódio é tratado de uma maneira completamente diversa do anterior. Em alguns destes episódios, procurei recriar um clima determinado referente à época tratada. »

Et, sur chaque période particulière :

«Embora eu tenha realizado cada episódio com total independência do outro, verifiquei na montagem que tinha chegado a um método narrativo praticamente comum a todos : a ação se inicia de uma maneira muito realista e vai se exacerbando, se conflitando até chegar a uma espécie de síntese poética em que os tempos e a própria ação não têm mais nenhuma ligação com o real da seqüência. ${ }^{1172}$

1171Cf. DIEGUES, Carlos. « Um cineasta em busca da brasilidade » in O Estado de São Paulo, São Paulo, $15 / 05 / 2000$.

1172«Os Herdeiros est construit de telle sorte que chaque épisode est traitée d'une manière complètement différente à celle de l'épisode antérieur. Dans certains de ces épisodes, j'ai cherché à recréer un climat déterminé correspondant à l'époque traitée. » et « Bien que j'aie réalisé chaque épisode indépendamment des autres, j'ai vérifié au cours du montage que j'étais arrivé à une structure narrative pratiquement identique à tous : l'action commence d'une manière très réaliste et elle évolue vers un climax dramatique, les conflits explosent jusqu'à ce qu'une synthèse poétique soit atteinte dans laquelle le temps et l'action n'ont plus aucune 
Dans sa critique du film, José Carlos Avellar confirmait la réussite de Carlos Diegues dans la réussite de cet arrangement en en précisant le sens et la portée :

«Em todos os momentos, Diegues recusa a ilustração simples ou a narração de caráter naturalista para perseguir uma imagem entre a alegoria e o sonho capaz de atuar como uma síntese crítica superior à de uma imagem que se situa no plano real. ${ }^{1173}$

Comme nous pouvons le constater, la construction narrative décrite est extrêmement originale et s'inscrit en totale rupture avec la narration classique traditionnelle dans laquelle les conflits s'organisent à partir du parcours d'un personnage principal et doivent se résoudre à la fin du film. D'un autre côté, cette construction relève d'un type d'abstraction étroitement lié à la maîtrise d'une éducation formelle et littéraire qui n'appartient au patrimoine culturel que d'une fraction réduite du public. Os Herdeiros démontre une grande sophistication dans son organisation textuelle, pour autant, l'obstacle n'est pas dans la sophistication en elle-même, l'obstacle à la communication de masse réside dans le type de sophistication dont procède l'œuvre. O Dragão..., Macunaíma ou Como era gostoso..., ne nécessitent pas de connaissances ou un certain mode de relation à la culture qui, pour n'appartenir qu'à un petit nombre, bloqueraient l'accès du film aux autres. Ou, tout au moins, un premier accès au film est possible au plus grand nombre même si l'on sait bien que seul un petit nombre en réalisera une actualisation pleine et entière. Os Herdeiros, comme Brasil ano 2000 et, plus tard, Pindorama ne permettent pas ce type de lecture intermédiaire.

$\mathrm{Au}$ final, il nous semble que le troisième long métrage de Carlos Diegues souffre des mêmes ambiguïtés que Brasil ano 2000. Nous retrouvons bien dans les deux films certaines caractéristiques qui nous permettent de les inclure à l'option cinemão. L'élévation des coûts de production et le recours à la couleur expriment la volonté de renouer avec des valeurs de spectacle. Au travers des scénographies, des costumes, des maquillages et du jeu des acteurs, nous retrouvons même dans Os Herdeiros un glamour, ou viscontien, ou hollywoodien, jusque là inédit dans le Cinema Novo ${ }^{1174}$. Nous retrouvons également, dans l'évocation des différentes périodes historiques, la pratique de cette nouvelle relation avec la culture industrialisée inaugurée par le tropicalismo. De la méfiance originale du Cinema Novo envers les manifestations de cette culture, nous sommes passés à une phase d'assimilation qui se

relation avec la réalité de la séquence. » in DIEGUES, Carlos. «Os Herdeiros é o testemunho de minha paixão pelo Brasil », op. cit.

1173« À chaque instant, Diegues refuse la simple illustration ou la narration naturaliste pour rechercher une image entre l'allégorie et le rêve capable d'offrir une synthèse critique supérieure à celle que pourrait offrir une image qui se situerait sur le plan du réel. » in VIANY, Alex et alii. « O filme em questão : Os Herdeiros, de Carlos Diegues » in Jornal do Brasil, Rio de Janeiro, 22/05/1970.

1174Le prestation d'Odete Lara est sans doute le meilleur exemple de cette volonté en plus des costumes et des décors somptueux. 
traduit par les références au théâtre de boulevard, à la Rádio Nacional et à la télévision. Dans le même esprit, la chanchada et la musique, même étrangère, sont également convoquées pour participer à la construction de cette grande fresque temporel de l'histoire du Brésil. À côté de ces éléments de séduction, le caractère formel de la construction narrative suppose un mode de relation au cinéma et à l'art en général qui fera obstacle à l'assimilation du spectacle par le plus grand nombre. Le film requiert également des connaissances historiques sur les périodes traitées qui permettront de combler les ellipses de la narration, d'identifier les personnages secondaires et de comprendre les problématiques historiques qui ne sont pas exposé avec beaucoup de clarté. Il faudra aussi parler le français pour comprendre les interventions du journaliste interprété par Jean-Pierre Léaud ${ }^{1175}$.

Enfin, comme dans Brasil ano 2000, il ne nous semble pas que la problématique développée par le film puisse réellement faire sens pour l'immense majorité du public. En plus, comme nous l'avons déjà vu, de donner de l'histoire une version ambiguë, le point de vue développé par le film est somme toute très spécifique à une classe et à une génération donnée. Premièrement, il s'appuie sur les concepts théoriques de l'ISEB qui superposait aux conflits de classes une contradiction plus importante qui serait la division du Brésil entre un pays agraire et sous-développé et un pays industriel développé. Bien sûr, le film critique cette interprétation et en particulier les conceptions politiques qu'elle a induite. Il n'en reste pas moins «prisonnier» de ce schéma même s'il s'attache à montrer l'absurdité de l'idée qu'une alliance était possible entre le prolétariat et la bourgeoisie nationale pour réaliser la « révolution » dont le Brésil avait besoin. La critique est juste, mais elle n'intéressera jamais que ceux pour qui cette idée a un jour réellement eu un sens ${ }^{1176}$. Or, il n'est pas du tout évident que le populisme ait été vécu de la même façon par les classes moyennes et les classes populaires.

La deuxième raison pour laquelle le film pouvait difficilement intéresser une grande partie du public est son caractère introspectif. Qui sont les héritiers ? Comme Terra em transe, et $O$ Desafio, mais pour des raisons différentes, la problématique du film intéresse de façon spécifique cette fraction réduite de la classe moyenne qui a pu un jour se sentir dans cette relation de face à face avec le pouvoir que la position de la caméra nous attribue tout au long de la narration. Cette illusion de pouvoir participer aux décisions historiques qui se prenaient au sujet de l'avenir du pays, la génération de Diegues l'a eu dans la période du gouvernement

1175Le journaliste parle en français sans sous-titrage en portugais.

1176Rappelons que l'historiographie moderne a remis en question les interprétations qui ont été donné «à chaud »du succès du coup d'État militaire. Os Herdeiros reste à notre sens encore trop proche de ces premières interprétations qui souffraient d'un manque de distanciation évidente par rapport aux idéologies pré-64. 
de João Goulart qui a été marqué, comme nous le savons, par une approximation entre la direction des syndicats étudiants et le cabinet présidentiel. Dans l'entretien qu'il nous a concédé, Dahl a évoqué cette impression de participation et de proximité avec le pouvoir que procurait le fait de vivre à Rio de Janeiro. Dans sa critique, Sérgio Augusto manifeste directement son identification avec la problématique du film de Diegues. Pour lui, Os Herdeiros est le film que toute une génération aurait aimé faire. Il est l'inventaire sentimental de la bourgeoisie nationale, de ses errances et de son opportunisme, l'expression assez juste d'une histoire qui se répète sans cesse. Il nous semble assez difficile de transmettre une telle problématique à des personnes qui se débattaient dans des problèmes matériels d'un autre ordre et n'ont jamais eu le sentiment d'occuper une place privilégiée. Il y a, au contraire, une contradiction assez dure à supporter entre la place que la caméra concède au spectateur, la version de l'histoire qu'elle donne et son exclusion de tous ceux qui ne pourront pas s'identifier aux « héritiers » et le réel.

Comme Brasil ano 2000 et les autres films du Cinema Novo développant des allégories totalisantes avec une démarche intellectualisée et conceptuelle, Os Herdeiros n'a pas eu beaucoup de succès auprès du public. De même, son accueil par la critique a été mitigé. Peu de journalistes ont discuté le film et leurs avis ont été très partagés. Les critiques du Jornal do Brasil ont donné un avis globalement positif mais les ellipses contenues par leurs propres textes sont souvent assez significatives. Ainsi, Alex Viany écrit :

«Este Os Herdeiros do próprio Carlos Diegues, é mais um filme manancial. Não me interessa muito que seja imperfeito em sua narrativa ou impreciso em algumas de suas conceituações históricas. Interessam-me, sim, o que o filme propõe em termos de cor dramática ; interessam-me as suas experiências felizes de mise en scène (com uma combinação criadora dos talentos de Dib Lufti, Luiz Carlos Ripper, Grande Othelo e outros) ; interessam-me, enfim, essa visão lírico-debochativa de certos episódios da história do Brasil. $»^{1177}$

Supporter inconditionnel du Cinema Novo, Viany exprime peu à peu des réserves de plus en plus fortes envers la démarche dont procèdent les allégories totalisantes. Nous remarquons ici qu'il s'attache à des aspects superficiels du film sans vouloir questionner son esthétique dans sa globalité. Avellar et Augusto, ou retiennent la charge du film contre les classes dominantes, ou s'identifient, comme nous l'avons déjà vu, au point de vue de l'auteur.

1177 «Os Herdeiros de Carlos Diegues est un nouveau film abondant en innovations formelles et suggestions dramatiques. Discuter le fait que le film comporte des imperfections dans sa narration ou soit imprécis sur certaines questions historiques ne m'intéresse pas. Ce qui m'intéresse, c'est ce que le film propose en termes de couleur dramatique ; ce qui m'intéresse, ce sont ses expérimentations heureuses sur le plan de la mise en scène (la combinaison créative des talents de Dib Lufti, Luiz Carlos Ripper, Grande Othelo et les autres) ; ce qui m'intéresse, enfin, c'est cette vision lyrique et débauchée de certains épisodes de l'histoire du Brésil. » in VIANY, Alex et alii. « O filme em questão : Os Herdeiros, de Carlos Diegues », op. cit. 
Sans réellement diverger de ces analyses, les critiques qui se révéleront négatives ${ }^{1178}$ ont accordé une importance plus grande à ses imprécisions historiques. Parmi eux, certains trouveront « ridicules » la mise en scène et le jeu des acteurs. S'il était utile de repérer, comme nous l'avons fait, l'ambiguïté du propos et l'inadéquation entre la fin et les moyens manifestes dans Os Herdeiros, il était sans doute aussi très exagéré de ne pas accorder plus d'importance à une œuvre somme toute singulière. Les réactions de ces journalistes montraient toutefois que cette évolution du Cinema Novo dans un registre allégorique extrêmement codifié et conceptuel approchait de ses limites.

\subsection{Pindorama}

Pindorama est le premier long métrage de fiction d'Arnaldo Jabor. Pour sa première expérience dans ce domaine, le cinéaste choisit de réaliser un film historique sur le premier siècle de la colonisation. "Pindorama » signifie la « région des grands arbres », il s'agit du nom que donnaient les indiens au Brésil. Le propos du long métrage est assez proche de celui de Como era gostoso o meu francês qui lui est exactement contemporain ${ }^{1179}$. Chacun traite du choc des cultures et comporte des références au «Manifeste anthropophage » d'Oswald de Andrade. Les deux films se basent sur de longues recherches historiques et bénéficient du travail de documentation ethnographique du même scénographe, Luiz Carlos Ripper ${ }^{1180}$. Pour autant, la comparaison s'arrête là puisque l'approche de Jabor est absolument distincte de celle de Santos. Alors que ce dernier renoue avec une certaine simplicité dans la narration qui rend son film largement accessible, Jabor décide d'imiter Lima Junior et Diegues et conçoit une grande fresque allégorique qui exige beaucoup du spectateur, tant du point de vue des connaissances historiques et littéraires, que de la disponibilité à affronter un langage riche et déroutant. Rejeté par le public et la critique, Pindorama est un film «raté » si nous nous référons au projet initial du cinemão. Il présente néanmoins deux intérêts. Le premier est d'avoir amené jusqu'à ses dernières limites l'orientation des allégories érudites qui sera abandonnée conséquemment à son échec. Le deuxième intérêt de Pindorama réside dans la qualité de la relecture de l'histoire du Brésil qu'il pratique et dans l'interprétation de la situation politique dramatique que le pays traversait à l'apogée de la dictature militaire.

À plus d'un titre, et comme le reconnaîtra Jabor lui-même, Pindorama était un projet

1178« Brasil obscuro » in Veja, São Paulo, 27/05/1970.

«Os herdeiros » in Correio da Manhã, Rio de Janeiro, 13/05/1970.

BANDEIRA, Roberto. « Os Herdeiros » in A Notícia, Rio de Janeiro, 29/05/1970.

1179Les deux films sont tournés à peu près en même temps, sont projetés dans les grands festivals internationaux de l'année 1971 et sortiront au Brésil en 1972.

1180Cf. Press release de Pindorama, copie consultée le 22/04/2006, sur le site http://memoriacinebr.com.br/index $2 . h t m$. 
fou $^{1181}$. Superproduction mise au service d'un cinéma conceptuel et de refus radical des règles classiques de narration, le film témoignait aussi des ambitions quasiment délirantes que recouvraient le terme "allégorie totalisante ». Juste après avoir terminé son film, Jabor résumait ses intentions dans ces termes :

«Pindorama me satisfait vraiment car je crois avoir suivi la ligne que je m'étais fixée : faire une peinture fabuleuse et semi-allégorique de toute la réalité de notre conscience de peuple, de notre conscience de nation. C'est une sorte de grande ébauche de notre psychologie sociale, d'une psychologie qui s'est formée depuis quatre cent ans. $\rangle^{1182}$

Du projet initial à la sortie du film en salles, quatre ans se sont écoulés. Ce délai, qui est particulièrement long pour l'époque, s'explique par l'ampleur de la production qui dispose de très gros moyens. Le film a bénéficié des fonds retenus par l'INC sur le rapatriement des bénéfices effectués sur le marché brésilien par les compagnies américaines Columbia Pictures et Screen Gems. Jabor a donné le récit suivant de la réalisation de Pindorama :

« J'ai commencé à l'écrire en 1968 et j'ai terminé en 1969. Environ neuf mois, approximativement, de travail de scénariste. Ensuite, j'ai passé quatre mois, essayant de trouver un financement. Aux environs de décembre 1969, la production était déjà en train. De janvier à mai, j'ai recherché les lieux de tournage. Au départ, cela devait se passer à São Paulo, mais j'ai fini par choisir l'île d'Itaparica, à Bahia. Pendant trois mois j'ai procédé à la préparation du tournage du film dont les décors et les costumes sont très compliqués. J'ai commencé à filmer le 11 mai 1970, pour terminer le 18 juillet. $)^{1183}$

Les conditions de financement exceptionnelles offertes à Pindorama feront de lui l'un des films les plus chers de l'époque. Elles permettront notamment la reconstitution intégrale d'un village des pionniers composé de maisons de terre ${ }^{1184}$. Nous verrons aussi dans le film un quilombo et un voilier. Les moyens dont dispose Jabor lui permettent aussi de réunir une très nombreuse figuration et de multiplier costumes et accessoires. Ces derniers éléments sont particulièrement importants car ils permettront d'identifier les différents personnages entrant en scène et de rendre compte de la fragmentation culturelle, ethnique et politique du Brésil des premiers temps. Enfin, le niveau d'achèvement technique est irréprochable que ce soit la qualité de la photographie ou du son direct. Nous allons à présent décrire le film.

Voir Pindorama sans une solide information préalable sur la démarche de l'auteur et ses références littéraires et historiques est une expérience à la fois frustrante et désagréable. Cela tient à ses deux principales caractéristiques esthétiques : le refus systématique des

1181Cf. JABOR, Arnaldo. Témoignage à Carla Camurati sur Pindorama, diffusé sur Canal Brasil en 2003 dans le cadre du festival « Arnaldo Jabor ».

1182In JABOR, Arnaldo. « Le Véritable Artiste doit montrer beaucoup de fermeté » in Filme cultura, Rio de Janeiro, Spécial Cannes 1971, p. 14. Traduction en français d'un entretien déjà paru dans un numéro de l'année précédente. Voir Filme cultura, Rio de Janeiro, n¹7, novembre-décembre, 1970. 
conventions classiques de la narration cinématographique et l'usage de stratégies d'agression. De prime abord, le long métrage se présente comme un ensemble de séquences qui se suivent sans qu'aucun lien de causalité évident n'explique l'ordre et la valeur des événements qui nous sont donnés à voir. Les moments d'action sont rares, le rythme de la narration est assez lent. Le film se singularise par le rejet de tout réalisme au profit d'un symbolisme complexe manifeste dans la conception des situations, le choix des accessoires et la figuration brechtienne des acteurs. D'une certaine façon, Pindorama se présente comme une séquelle de la séquence onirique de Terra em transe où nous avions une allégorie de la découverte du Brésil. L'étirement de ce mode de représentation à l'intégralité d'un long métrage ne simplifie pas la compréhension d'un propos dont nous mesurerons plus tard la complexité. Dans Pindorama, les personnages dialoguent rarement. Les longs monologues auxquels ils se livrent parfois ne permettent cependant pas toujours au spectateur de comprendre les motivations de leurs actes qui apparaissent souvent contradictoires entre eux. Du reste, ils crient ou restent prostrés longtemps offrant le spectacle d'une affliction tout aussi hermétique que le reste de leur comportement. Pour toutes ces raisons, l'intrigue est inintelligible au delà de l'exposé du conflit initial.

Dom Sebastião (Maurício do Valle) est le personnage principal. Noble de prestigieuse ascendance, il est aussi un homme d'une force physique phénoménale et d'un grand charisme. Au début de la narration, il vit seul avec sa femme Sofia (Itala Nandi) exilé des territoires qu'il a conquis depuis cinq ans. Alors que celle-ci maudit sa fidélité à la couronne portugaise ( Quero que o Rei morra com a maldita bandeira a que obedece o meu marido $»^{1185}$ ), Sebastião répète inlassablement sa loyauté jusque dans son oraison funèbre au fils qu'il enterre enveloppé dans le drapeau du Portugal. Il rappelle qu'il ne peut pas retourner à Pindorama à moins que son souverain ne le lui demande. Selon lui, son ancienne ville est devenue la patrie des traîtres à la couronne. Son épouse ne voit pas les choses de la même façon :

« Sebastião : - Pindorama é hoje terra dos traidores do Rei. [...] O Rei me quer aqui.

Sofia : - É mentira. Eles afastaram você porque atrapalhava os poderosos. » ${ }^{1186}$

Le lendemain pourtant les mêmes notables qui, selon Sofia, avaient chassé son mari de la ville, viennent le supplier de revenir à Pindorama pour y rétablir l'ordre. Richement habillés, les «gens de bien» s'offusquent du comportement du peuple : «O povo enlouquece »; «O Rei manda civilizar a selva »; «Essa gente precisa de chicote». Dom

1185« Je veux que le Roi meurt avec le maudit drapeau auquel obéit mon mari. » Dialogue du film, séquence 2 , la première étant le générique.

1186« Sebastião : - Pindorama est aujourd'hui dominé par les traîtres à la couronne. [...] Le Roi me veut ici. Sofia : - C'est un mensonge. Ils t'ont écarté parce que tu gênais les puissants. » Dialogue du film, séquence 3. 
Sebastião leur répond qu'il les avait prévenus et qu'il ne peut rien faire : « Cabe ao Rei me mandar prá lá. ${ }^{1187}$ L'ordre royal arrive aussitôt d'outre-mer. Dom Sebastião revient sur un voilier vers la ville dont il s'était exilé entouré de tout l'apparat qui sied à sa condition.

Mais que s'est-il passé à Pindorama qui justifie son soudain retour ? En montage parallèle, la capitale de la colonie nous est donnée à voir pour la première fois. Entouré de conquistadors et installé sur une chaise à porteur, le gouverneur (Hugo Carvana) entre dans la cité sous les vivas de la foule misérable qui se presse dans les rues étroites. Personnage ambivalent, débauché et auto-critique, il recueille les applaudissements alors même qu'il harangue la foule sur un ton provocateur en expliquant qu'il est un oppresseur sans scrupule :

«Essa gente devia me matar e me comer aos pedaços, se soubessem das minhas bandalheiras. Me joguem fora, gente, no lixo ! Você não precisam de mim... ou precisam ? [acquiescement général] Precisam dessa fantasia de chefe, desse homem feliz e poderoso. Eu sou a lei, o amor, o bem. Todo mundo trabalhando para ter certeza que tem um homem feliz nesta cidade. Eu sou feliz !

Ora gente, eu nunca fiz nada por vocês, nada ! Tudo acontece por si, sem mim ! Não adianta ! Vocês deviam me matar e me carregam como se eu fosse a rainha das abelhas mas eu vou continuar representando o meu papel nesta palhaçada. Segunda, quarta e sexta, eu vou ser bom. Terça e quinta, vou ser cruel. Ô, homem bom que dia é hoje ? [L'homme répond]

Sábado ?! Aarrh... Se eu pudesse aprender a esses idiotas o que aprendi, como o mundo se move mas não adianta. Abaixo eu ! Abaixo eu ! Erro por erro, continuo no governo. Rei por Rei, cumprirei a lei. Farsa por farsa, continuo nesta praça! ${ }^{1188}$

Sous les vivas, le gouverneur cède ensuite la parole à un deuxième personnage important, Diogo (Wilson Grey), l'homme riche qui domine la ville matériellement et doit se marier le même jour à une indienne : «Eu sou o homem mais rico deste país, sou o ouro, sou o comércio e hoje me caso porque o meu amor não conhece nem raça nem cor. ${ }^{1189}{ }^{\text {S'ensuit }}$ un long monologue qui participe de la caractérisation du personnage dans lequel Diogo annonce qu'il est le « personnage contradictoire ». Tout autour de lui, le faste de la cérémonie contraste avec le cadre misérable des maisons de terre.

À son arrivée à Pindorama, Sebastião est convié à un banquet au cours duquel le

1187« Le peuple devient fou. » « Le Roi a ordonné de civiliser la jungle. » « Ces gens ont besoin du fouet. » « Il revient au Roi de m'envoyer là-bas. » Dialogue du film, séquence 5.

1188« Ces gens devrait me tuer et me découper en petits morceaux, s'ils savaient combien je vole et détourne les richesses à mon profit personnel. Jetez-moi dehors, bonnes gens, jetez-moi aux ordures ! Vous avez besoin de moi ou... vous n'avez pas besoin de moi ? [acquiescement général] Ils ont besoin de cette farce de chef, de cet homme heureux et puissant. Je suis la loi, l'amour et le bien. Tout le monde travaille pour avoir la certitude qu'il y a au moins un homme heureux dans cette cité. Je suis heureux !

Oyez bonnes gens, je n'ai jamais rien fait pour vous, rien! Tout arrive tout seul, sans moi ! Ça ne sert à rien ! Vous devriez me tuer et vous me transportez comme si j'étais la reine des abeilles mais je vais continuer à jouer mon rôle dans cette farce. Lundi, mercredi et vendredi, je vais être bon. Mardi et jeudi, je serai cruel. Ô, brave homme, quel jour sommes-nous aujourd'hui ? [L'homme répond.]

Samedi ?! Aarrh... Si je pouvais enseigner à ces idiots tout ce que j'ai appris, comme va le monde, mais ça ne sert à rien. À bas moi ! À bas moi ! Erreur pour erreur, je reste au gouvernement. Roi pour Roi, je ferai appliquer la loi. Farce pour farce, je resterai sur cette place ! » Dialogue du film, séquence 7.

1189 « Je suis l'homme le plus riche de ce pays, je suis l'or, je suis le commerce et aujourd'hui je me marie car mon amour ne connaît ni race ni couleur. » Dialogue du film, séquence 7. 
gouverneur, l'homme riche, sa femme indienne, Sebastião, Sofia et les notables qui sont venus le chercher sont réunis et isolés de la foule misérable dont les mains se tendent au travers d'excavations pratiquées dans les murs. L'homme riche scandalise Sebastião en expliquant qu'il sera capable de tous les opportunismes et retournements de veste pour répondre aux manifestations de mécontentement populaire. S'il faut crier «Abaixo o Rei» («À bas le Roi »), il le fera. Sur ces entrefaites, surgit Gregório, un poète anarchiste et fier de ses origines créoles dont le monologue permet de conclure la longue exposition du film. Gregório dénonce la politique d'exploitation du Roi et réclame qu'il ne veut être sauvé par aucun saint personnage. Sebastião se montre d'abord sensible à son discours et chasse Diogo dont il comprend qu'il est le premier oppresseur du peuple. Il remercie Gregório qui ne se satisfait pas de cette reconnaissance et le traite d'idiot, incapable de comprendre que sa fidélité au Roi est contraire aux intérêts et au bonheur de son peuple. Les mendiants applaudissent le poète mais Sebastião le fait aussitôt battre à coups de bâton et expulser. Les principaux personnages et enjeux ont été posés. Après cette séquence du banquet, les événements vont se précipiter.

Gregório séquestre Diogo dans un quilombo et le sacre roi de Pindorama. Le quilombo est attaqué par l'armée de Sebastião et tout ses membres exterminés. Seul survivant Gregório s'enfuit. Après ce génocide, Sebastião semble frappé de folie. Abandonnant ses armes, il commence seul une longue errance au terme de laquelle il retrouve Gregório et le fait prisonnier. De retour à Pindorama, il découvre que le gouverneur a été assassiné par les notables et que l'un d'eux a pris sa place. Fou de rage, il tue le nouveau gouverneur et Sofia qui s'était rangé du côté des notables.

L'actualisation des événements qui suivent la définition des conflits est rendu difficile par plusieurs éléments. La caractérisation des notables, au contraire de celles des autres personnages principaux, est clairement défaillante. Alors que le gouverneur et l'homme riche se présentent dans de longs monologues, les notables sont bien présents mais leurs rôles et leurs motivations restent occultes. Le retournement de la séquence finale apparaît donc obscur. Le refus du réalisme au profit d'une figuration brechtienne peut paraître plaisant, il offre notamment aux acteurs Hugo Carvana et Wilson Grey, l'occasion de véritables moments de bravoure, mais celle-ci peut aussi paraître déconcertante. Il est évident que le spectateur non averti des intentions de l'auteur risque fort de ne pas comprendre pourquoi les personnages se dénoncent de façon aussi explicite, à voix haute et sans déclencher l'ire populaire. De même, la séquence de la bataille déroge aux règles de toutes les séquences de bataille où les figurants courent dans tous les sens et se battent avec furie. Ici, tout le monde reste immobile, le duel se résume à celui de deux musiques, la musique jazz qui caractérise le Brésil populaire et la musique sacrée qui caractérise Sebastião. Un coup de canon est tiré et 
les assiégés se laissent exécuter sans esquisser le moindre signe de résistance. Cette option de la figuration brechtienne interdit au spectateur d'activer le mode de lecture fictionnalisant sans pour autant pouvoir saisir où le film veut l'emmener.

Ce refus du mode fictionnalisant classique, nous le retrouvons dans les films $\mathrm{du}$ Cinema Marginal contemporain où l'éclatement de la narration et la présence à l'écran de la caméra donnent, de façon provocante, l'illusion d'un film «mal fait». Ce refus ostensible qui est signifié au spectateur d'entrer dans l'illusion filmique participe aussi de stratégies d'agression qui passent par le recours à ce que Fernão Ramos nomme «as figuras da abjeção » (les figures de l'abject) ${ }^{1190}$. Le Cinema Marginal recourt au grotesque, au difforme, nous verrons du vomis, de la bave, des excréments, des scènes de torture, enfin, les personnages hurlent. Dans Pindorama, nous n'avons pas les références à la contre-culture et le détournement parodique de la culture industrialisée qui constituent l'autre versant du Cinema Marginal, mais nous avons bien le recours aux figures de l'abject. Les personnages évoluent constamment dans la boue, ils crient fréquemment sans qu'il soit toujours possible de comprendre les raisons de leur hystérie et enfin une musique jazz anachronique et assourdissante complète l'établissement d'une atmosphère malsaine et oppressante. Pindorama ne peut pas être assimilé au Cinema Marginal mais les stratégies d'agression qu'il développe sont proches de cet autre cinéma qui émerge dans le contexte des années de plomb.

L'actualisation de Pindorama ne saurait être pleinement réalisée sans le recours à des auxiliaires externes au texte filmique. Outre les solides connaissances historiques qui sont utiles pour démêler les anachronismes sciemment opérés par Jabor, trois sources spécifiques devront être mobilisées. Le première nous est indiquée par une légende qui apparaît à l'écran à la fin du film : « ... ' confiança no futuro, que não pode ser pior que o passado. ' Paulo Prado / ' Retrato do Brasil ' ». Dans cet essai interprétatif de l'histoire du Brésil, Prado ${ }^{1191}$ émettait la thèse selon laquelle la luxure et la cupidité des premiers colons portugais avaient déterminé le trait distinctif du caractère de l'homme brésilien qui serait la tristesse. Le press release du film

1190RAMOS, Fernão et MIRANDA, Luís Felipe (org.). Enciclopédia do cinema brasileiro. Op. cit., p. 142. 1191Paulo Prado (1869-1943), issu de l'une des familles les plus riches de l'aristocratie paulista du café, fut un des mécènes les plus actifs des modernistas. Son œuvre la plus importante Retrato do Brasil : ensaio sobre a tristeza brasileira (Portrait du Brésil, essai sur la tristesse brésilienne, 1928) a connu en son temps un vif succès. La thèse selon laquelle le trait de caractère le plus caractéristique du brésilien est la tristesse peut être comprise de deux façons. En première instance, Prado considère que la tristesse est un obstacle à la résolution des difficultés du pays car elle prive le brésilien des qualités nécessaires pour les affronter. Ces qualités sont pour lui : l'intérêt, le dynamisme, l'énergie, la curiosité et l'ambition dont il voit l'expression chez les pionniers de la colonisation paulista. Si la «tristesse » peut être assimilée à une débilité ontologique interdisant toute perspective de développement, au contraire des thèses racistes du XIXième siècle, l'historien n'attribue pas cette faiblesse au métissage mais à la luxure et la cupidité des premiers colons portugais au moment de la rencontre de l'indien et du blanc. La façon dont s'est réalisée la rencontre de cultures absolument dissemblables a déterminé cette tristesse qui est, en dernière instance, l'expression de la frustration de réalisation de l'être brésilien. $C f$. PRADO, Paulo. Retrato do Brasil : Ensaio sobre a tristeza brasileira. Huitième édition, São Paulo, Companhia da letras, 1997. 
et le scénario original disponibles à la Cinemateca do MAM rendent possible la reconstruction de la narration en aidant à compléter la caractérisation des personnages et en donnant accès à des séquences supprimées qui permettent de mieux comprendre certaines situations du film. La lecture du scénario original permet aussi de prendre connaissance des commentaires que Jabor se fait à lui-même au moment de l'élaboration du texte. De façon paradoxale, comme pour les scénarios de Rocha, nous nous apercevons alors que ces films si singuliers reposent sur des scénarios dans lesquels la conception du système des actants a été l'objet d'un soin extrêmement attentif et conforme finalement à une approche romanesque classique. Loin de nous l'idée pourtant de suggérer que Pindorama devrait avoir suivi des règles conventionnelles. Ce dont nous nous sommes aperçu, c'est qu'un «livret» condensant les informations des différentes sources que nous avons citées rendraient le film parfaitement intelligible en même temps qu'il établirait une forme de médiation à l'œuvre plus proche de celle de l'art contemporain que du cinéma traditionnel.

Interpréter Pindorama sur la base de ces informations va nous contraindre à quelques détours. Si nous nous référons à Ismail Xavier qui n'analyse pas le film dans sa thèse Alegorias do desengano, nous pourrons utilement nous interroger sur le sens de la première fiction de Jabor. Selon le chercheur brésilien, Brasil ano 2000 aurait dénoncé la mystification de la technologie, Macunaíma, celle du malandro et Os Herdeiros, celle du populisme, autrement dit, autant de «totems» de l'idéologie de la classe moyenne. À côté de la destruction de ces mythes simplificateurs, O Dragão... aurait exprimé la crise de la solution messianique et Os Deuses e os mortos, la « malédiction de l'histoire ». De tous ces films, celui de Guerra est sans doute le plus proche de Pindorama.

La «malédiction de l'histoire » est en effet au centre de chacun des deux films. Dans Os Deuses e os mortos, l'emphase est portée sur la dénonciation de l'impérialisme. Guerra propose un dispositif filmique dans lequel la conscientisation du spectateur doit se réaliser conjointement à celle de son personnage principal qui est un être mythique dont la soif de pouvoir aboutit au néant au travers de l'annihilation de la communauté dans sa globalité et de chaque individu en particulier. Dans les années trente, au moment de la crise du cacao, dans l'état de Bahia, se croisent les destins de plusieurs personnages qui sont à la fois les témoins et les victimes des luttes sanglantes que se livrent les grands coronéis de la région. Entre ces personnages, surgit la figure de «Sept fois », un personnage mystérieux, sans passé et sans avenir, défiguré par les nombreuses blessures qu'il a déjà reçues. Obsédé par le pouvoir, il réussit au prix d'un véritable génocide à prendre le contrôle sur cette région, déjà hantée pourtant par les morts qui se montrent et puis se cachent. Mais quand il est enfin le maître, il s'aperçoit qu'il existe un empire encore plus grand que le sien, l'Empire britannique, qui tire 
les ficelles et décide des prix du cacao et donc de toute l'activité économique et humaine de la région. Les conflits les plus violents et le renversement des oligarchies ne peuvent jamais remettre en cause les inégalités sociales car le pouvoir qui est externe, reste immune aux bouleversements internes et subordonne mécaniquement et de façon impersonnelle la colonie à ses intérêts matériels. Les morts qui évoluent entre les personnages vivants sans que l'on puisse jamais savoir si ceux-ci les voient ou non, sont là pour nous rappeler que la crise du cacao n'est qu'un épisode d'un processus plus vaste qui s'est inlassablement répété dans les autres cycles économiques du pays. La séquence initiale nous montre des paus de arara à l'époque contemporaine. À peine descendus du camion, ceux-ci sont aussitôt entourés par les morts. Ces images expriment clairement la pérennité des mécanismes de domination dénoncés dans le contexte de la crise du cacao.

L'intitulé « la malédiction de l'histoire » nous invite à nous interroger sur la nature de cette «malédiction ». L'intérêt du film de Guerra est de convoquer les registres du mythique au sein d'une organisation textuelle très conceptuelle. Le film se compose comme un puzzle, les premières séquences ont un rythme très lent et n'expliquent pas le conflit principal de la narration. Les personnages principaux ne sont pas présentés ce qui ajoute à la confusion déjà produite par la présence des «morts ». La désorientation du spectateur est complète et c'est seulement au fil de la narration qu'il comprend le symbolisme attaché aux personnages et surtout le rôle de Sept fois. Ce contraste entre le thème du mysticisme et une organisation textuelle très rationnelle nous amène directement au message principal de l'œuvre qui est le déterminisme que les mécanismes socio-économiques font peser sur les comportements et la culture. Dans le cas précis de Os Deuses e os mortos, l'auteur dénonce l'extrême violence des relations d'oppression à l'intérieur de la société brésilienne ${ }^{1192}$ et, dans le même mouvement, récuse toute interprétation moraliste sur la «nature intrinsèque » de l'homme brésilien au profit d'une interprétation matérialiste. La violence des rapports sociaux à l'intérieur du Brésil s'explique par l'organisation coloniale de son économie. D'un côté, celle-ci provoque une

1192La violence a longtemps été niée ou refoulée dans les discours dominants des brésiliens sur eux-mêmes. Longtemps, on a préféré louer « l'homme cordial » et toujours affable même dans la pire misère, le caractère pacifiste de tout un peuple qui, au contraire des peuples européens, aurait toujours su éviter le recours à la guerre dans ses relations internationales, ou même encore une tradition démocratique fictive que l'historiographie moderne s'est attachée à dénoncer.

Aujourd'hui, la violence a été intégrée dans la représentation que la société se fait d'elle-même. La situation a changé ces vingt dernières années face à l'explosion de la violence urbaine. Mais, une fois de plus, c'est la violence de la criminalité présente au cœur des favelas et donc au sein des classes populaires qui est stigmatisée. Les classes moyennes refusent toujours de voir les mécanismes d'oppression plus généraux qui se perpétuent et qui sont évidemment largement occultés par les principaux médias. Le travail au noir qui prive l'ouvrier de la protection des lois du travail et le travail esclave qui en constitue l'une des expressions les plus dramatiques sont aujourd'hui encore des fléaux endémiques. Pour autant, il ne s'agit que de deux exemples significatifs extraits d'un réseau complexe et dense de violences concrètes et symboliques qui s'exercent envers les plus pauvres dans une situation qui est bien de l'ordre du chaos social le plus choquant. 
situation de pénurie des denrées nécessaires à la population et l'atrophie du marché intérieur. Organisée pour satisfaire des besoins externes, la colonie survit dans un état constant de précarité. D'un autre côté, la structure économique coloniale divise la société entre ses bourreaux et ses esclaves. La précarité favorise l'abondance d'une main-d'œuvre corvéable à merci. Au sein de l'élite, la compétition est rude pour éliminer ses rivaux et garantir l'exclusivité du produit des échanges avec le marché international. Le personnage de Sept fois est parfaitement adapté à cette compétition qui nécessite une totale absence de scrupule et une disposition à la violence la plus extrême.

Nouveau film sur la «malédiction de l'histoire», toujours appuyé sur une interprétation matérialiste, Pindorama adopte une perspective inverse par rapport à celle de Os Deuses e os mortos. Si Guerra montre comment l'impérialisme façonne de l'extérieur la société brésilienne, Jabor revient au début de la colonisation pour se demander quel rapport de forces lui a permis de s'installer et de se perpétuer. La question du déterminisme est mise en regard avec celle des complicités internes à l'établissement du régime colonial et des dispositions culturelles et psychologiques des acteurs historiques. De ce point de vue, les conflits qui se dessinent entre les principaux actants nous renvoient aussi bien au Brésil primitif qu'à celui des années soixante et soixante-dix. Dans ce contexte, la référence à Paulo Prado n'est évidemment pas innocente ${ }^{1193}$. Jabor s'approprie les thèses de l'auteur de Retrato do Brasil sur la luxure et la cupidité des premiers colons portugais afin de les mettre en relation avec les interprétations matérialistes plus récentes produites par l'ISEB. À la lumière $\mathrm{du}$ «Manifeste anthropophage », il replace aussi en perspective la «tristesse brésilienne » pour identifier la frustration de l'être brésilien avec celle de la "Révolution Caraïbe » que le métissage racial et culturel du Brésil des premiers temps semblaient augurer. En accord avec son temps, le cinéaste adopte un point de vue libertaire qui le distingue du moralisme de sa principale source d'inspiration. Comme Oswald de Andrade, il oppose la liberté des mœurs des indigènes à l'intégration du Brésil dans le capitalisme international qui en était encore à sa phase marchande.

Le press release de Pindorama débute par une sorte de préface qui est très claire quant à ce qui constitue bien la « thèse » principale du film :

«[...] o negócio é que o desregramento não-civilizado impede a organização capitalista mercantilista nacional, logo é necessário mudar o ethos dos habitantes para submetê-los ao progresso que interessa ao Rei e aos seus filhos - a moleza, sacanagem nativa, a fudelança, a miscigenação, o paganismo, estão CORROMPENDO o ' modus ' europeu [...]. ASSIM, para dominar economicamente, é preciso dominar cultural, ética e militarmente. $\gg{ }^{1194}$

1193Pindorama, comme Retrato do Brasil, constitue bien un essai interprétatif de l'histoire du Brésil. 1194« [...] l'idée, c'est que la déréglementation non-civilisée empêche l'organisation mercantile nationale, aussi, 
L'historiographie la plus récente indique que les conflits sur lesquels reposent la narration de Pindorama recoupent bien ceux du Brésil des premiers temps. Les débuts de la colonisation sont extrêmement difficiles et celui-ci est en effet le théâtre d'événements assez inattendus. Après sa découverte par Pedro Álvares Cabral, en 1500, la première tentative portugaise de colonisation du territoire s'avère un échec. Des quinze capitanias cédées par le Roi à des membres de la noblesse afin qu'ils en assurent le développement, seule celle de Pernambouc était parvenue à prospérer. Il faudra attendre 1548, année au cours de laquelle est nommé le premier gouverneur général du Brésil, pour que la colonisation s'intensifie de façon systématique et rationnelle. Un « règlement» est élaboré qui vient se substituer au système des donataires et signifie l'intervention directe de la couronne. Les échanges avec le Portugal augmentent mais cet essor est conditionné par la soumission des peuples indiens qui étaient entrés en conflit avec les premiers noyaux de colonisation allant parfois jusqu'à en assurer la destruction complète (Bahia, São Tomé, Espírito Santo). Paradoxalement, alors que les portugais réussissent peu à peu à prendre le contrôle de l'immense territoire qui ne leur appartenait jusque là que de façon virtuelle, ils vont rencontrer certains de leurs prédécesseurs qui ont fait souche, allant jusqu'à adopter la langue et les mœurs tupis. Des personnages comme João Ramalho pour l'actuel état de São Paulo et Caramuru ${ }^{1195}$ pour celui de Bahia scandalisent les missionnaires jésuites par la liberté de leurs mœurs et leur participation aux rituels anthropophages. Ils s'avèreront cependant des auxiliaires précieux pour l'établissement de l'autorité coloniale.

Tout le premier siècle est dominé par un intense métissage ethnique et culturel. L'absence de femmes blanches favorise le concubinage, puis le mariage, avec les indigènes. Un tupi normalisé et imprégné de portugais va servir à la communication sur l'ensemble du littoral. La multiplication des établissements portugais provoque la fragmentation du corps social. Les indiens, en plus de leurs divisions ethniques, se scindent entre ceux qui se sont convertis au christianisme, ceux qui sont réduits en esclavage et ceux qui conservent leur mode de vie et leurs rites païens. Les blancs se répartissent quant à eux entre créoles, nouveaux colons et administrateurs publics destinés à revenir à la métropole. Acquis aux us et coutumes indigènes, les créoles vont jouer le rôle de médiateurs entre les différentes communautés. Parmi les nouveaux colons, la majorité s'identifie aux créoles mais la nouvelle

est-il nécessaire de changer l'ethos des habitants pour les soumettre au progrès qui intéresse le Roi et ses fils

- la mollesse, l'indolence native, le je m'en foutisme, le métissage, le paganisme, sont en train de

CORROMPRE le modus européen [...]. Ainsi, pour dominer économiquement, il faut dominer sur les plans

culturels, éthiques et militaires. » in Press release de Pindorama, op. cit.

1195Nom tupi de Diogo Álvares Correia (1475? — 1557). 
politique coloniale va favoriser de façon volontaire et dès que cela sera possible la ségrégation avec les communautés indiennes libres. L'esclavage des indiens sera proscrit mais leur entrée dans les villes sera conditionnée à leur conversion à la foi catholique et à leur intégration aux nouveaux outils de production. Les jésuites sont là pour assurer l'assimilation des indiens qui doivent absolument se plier aux normes morales européennes. Au-delà de cet objectif, il s'agit bien de neutraliser toute opposition au projet colonial qui se base sur l'exploitation de la canne à sucre. Les indiens sont tolérés à partir du moment où ils peuvent stimuler l'essor de la population coloniale (par le mariage) et qu'ils ne gênent pas l'expansion des engenhos.

La lettre que reçoit Dom Sebastião au début du film peut être assimilée à l'instauration $\mathrm{du}$ nouveau règlement par la couronne portugaise et à sa volonté de reprise en main du territoire brésilien qui arrive en 1548. Le Roi João III a alors effectivement écrit à Caramuru pour lui demander de créer des conditions favorables à l'établissement du premier gouverneur général. Dans le film, Sebastião synthétise la figure du pionnier des premiers temps (Ramalho, Caramuru) et celle du missionnaire jésuite. Du premier, il n'a pas conservé l'adoption des mœurs indigènes mais le prestige de l'aventurier des premiers temps et cet attachement à la terre qui préfigure le nationalisme brésilien. Du second, il garde le dévouement à une mission supposée civilisatrice. Comme le note Jabor dans sa préface, comme ses modèles, «Sebastião é um reformador ético, só. É absolutamente alienado economicamente. $»^{1196}$ Tout à leur mission civilisatrice et croyant agir pour le « bien », ces personnages ont fréquemment été utilisés pour servir des intérêts matériels qui les dépassaient. Ainsi, par exemple, le travail de pacification et «d'éducation» des jésuites facilite souvent les opérations de domination militaire qui se traduisent par des génocides dramatiques $^{1197}$. L'absence totale de relativisme culturel des missionnaires leur interdit de saisir l'ambiguïté de leur rôle. Elle en fait les auxiliaires idéaux de l'établissement de l'ordre colonial. Leur action sera décisive d'un point de vue stratégique et culturel puisque les indiens convertis n'ont plus de résistances à offrir aux nouvelles autorités dont la supériorité se pare des atours de la légitimité.

Parmi les nouveaux colons, apparaissent les intermédiaires du commerce impérial qui sont soutenus par les administrateurs de la Couronne. Ceux sont ces derniers qui sont animés

1196« Sebastião est seulement un réformateur éthique. Il est absolument aliéné du point de vue économique. » Press release de Pindorama, op. cit.

$1197 C^{\prime}$ est le cas après la pacification des Tamoios par les pères Nóbrega et Anchieta en 1563. Même après le démantèlement du Fort Coligny, la présence française autour de la baie de Guanabara menaçait les intérêts portugais. Les français possédaient pour alliés les indiens Tamoios qui formaient une confédération puissante. Les jésuites craignant pour la pérennité de leur mission si les portugais devaient être défaits, réussirent à obtenir la signature d'un traité de paix avec ces derniers, c'est le traité d'Iperoig. Deux ans plus tard, une escadre portugaise commandée par Estácio de Sá devait réduire les dernières résistances françaises et exterminer leurs anciens alliés. Ceux qui échapperont au massacre connaîtront un répit d'un peu moins de vingt ans avant de subir de nouvelles persécutions. 
par la luxure et la cupidité. Quand le Portugal renforce ses positions au Brésil, les rapports de force sont inversées au sein de la colonie. Alors que les premiers colons avaient dû s'intégrer à un territoire encore largement dominé par les indiens et s'accommoder de leurs coutumes, les nouveaux notables ou les anciens administrateurs et pionniers qui avaient prospéré doivent s'adapter aux progrès de l'administration portugaise. C'est ce moment que Pindorama tente de nous montrer notamment au travers des comportements du gouverneur, de l'homme riche mais aussi de Sofia, la femme de Sebastião. Le fidalgo avait quitté une ville envahie par les indiens scandalisé par l'indulgence et voir même l'émerveillement de la majorité des pionniers confrontés à des libertés nouvelles. Diogo et le gouverneur abusaient de leur position pour s'abandonner à la luxure en faisant travailler les autres pour leur propre compte. Sebastião revient sur ordre du Roi accélérer une transformation qui, même s'il n'en a pas conscience, a déjà commencé. Les notables qui sont les intermédiaires du commerce impérialiste complotent contre le gouverneur qu'ils estiment trop libéral. Sofia est prête à tout pour réintégrer l'élite de Pindorama. Diogo quant à lui est ravi de la libération sexuelle et de l'éviction de l'Église du Brésil primitif, il n'a aucun respect particulier pour l'autorité du Roi mais, pour préserver ses intérêts, il saura adopter un comportement hypocrite et feindre de respecter toutes les valeurs qui seront nécessaires à la prospérité de ses affaires.

Comme nous le voyons, à partir du moment où les notables auront pris le pouvoir, aucune force ne pourra s'opposer à l'établissement du régime répressif qui leur permettra d'optimiser le rendement commercial de la colonie. Le film montre bien que le peuple n'est pas dupe ou complice, les indiens mangent un missionnaire hystérique, les esclaves noirs se rebellent et se retranchent dans leur quilombo, les caboclos misérables n'ont de respect ni pour le Roi, ni pour Dom Sebastião. Le gouverneur, Diogo et les notables le savent bien, et c'est pour cela qu'ils composent constamment avec les forces en présence, mais ils savent aussi que le peuple est fragmenté et démuni. La force militaire et la technologie sont du côté des autorités royales. Appuyée par les intérêts convergents des classes dominantes de Pindorama, la mécanique colonialiste va se mettre en marche de façon implacable et il s'agit bien d'une mécanique de soumission morale et physique des habitants au profit d'intérêts matériels étrangers à l'intérêt général. Dans le système des actants, le poète Gregório est une figure singulière, à la fois solidaire du peuple et isolé de lui, il a une conscience aiguë de ce qui se passe. Jabor décrit le personnage de la façon suivante dans son scénario :

« Gregório vê e entende tudo isto [les conflits exposés plus haut], detestando em primeiro lugar a ' nova ética', por ser nativo e livre, segundo porque entende que está deslanchado o processo de escravização do brasileiro a uma ' civilização de empréstimo' e que se ele e o povo já estão numa ' MERDA PORÉM LIVRE', ficarão ' NUMA MERDA PRESA ', repressiva e sem nenhuma chance de 
salvação pela pureza dos naturais progressos econômicos. NÃO PODERÃO MAIS INVENTAR NENHUMA CIVILIZAÇÃO, NENHUM ETHOS, NEM ECONOMIA, ELES ESTARÃO CONDENADOS ! $»^{198}$

D'une certaine façon, Gregório et Dom Sebastião sont deux personnages anachroniques puisqu'ils préfigurent chacun un versant du nationalisme brésilien qui ne se réalisera qu'au XXe siècle. Gregório représente le nationalisme libertaire du «Manifeste anthropophage », il a compris que le Brésil devait se faire en prenant comme point de départ la fragmentation et la diversité pour, éventuellement, développer une identité originale dans un processus organique et dynamique dont le résultat est inconnu. Sebastião représente le nationalisme verde amarelo, il est également soucieux du bien-être de son peuple mais il oppose à l'éthique de Gregório une approche moraliste. Il pense en terme de « salut » et celuici ne peut être obtenu que par le respect des valeurs de la morale chrétienne. Ainsi, Sebastião se retrouve dans une situation paradoxale où il doit lutter contre son peuple pour le sauver. Il ne comprend pas que les perspectives libertaires de Gregório se confondent avec les perspectives d'achèvement moral et spirituel qu'il envisage, mais dans un cadre nouveau de réalisation humaine, à la fois individuelle et collective.

Comme dans Como era gostoso o meu francês, tout se joue sur l'intuition de la «Révolution caraïbe ». En dehors de toute catéchèse, la réalisation organique de l'identité brésilienne devait aboutir à la création d'un monde nouveau, «L'âge d'or promis par l'Amérique ». Cette opportunité n'ayant pas pu être saisie, le pays soumis à l'oppression coloniale est un pays dont le développement culturel est brisé. De là, la caractérisation de l'homme brésilien comme un homme "sans caractère », selon l'allégorie de Macunaíma, ou un homme «triste », selon la thèse de Retrato do Brasil. Nous pouvons même proposer que Pindorama articule entre elles ces deux caractérisations. Dans le film de Jabor en effet, l'homme sans caractère n'est pas celui du peuple mais bien les membres de son élite. Ceux-ci sont «sans caractère » parce que cupides comme Diogo et les notables, lascifs comme le gouverneur, ou aliénés comme Sebastião. Ceux sont eux les premiers responsables de la tragédie brésilienne. L'homme «triste » est celui du peuple et les photos en noir et blanc du générique de début du film qui nous montrent des indiens sales, pauvres, parqués et encadrés par les blancs, brisés dans leur fierté, sont à ce sujet sans ambiguïté. Pindorama nous remet à

1198« Gregório voit et entend tout ceci [les conflits exposés plus haut], détestant en premier lieu la ' nouvelle éthique ', parce qu'il est natif et libre, ensuite parce qu'il comprend que commence un processus de mise en esclavage du peuple brésilien au travers d'une ' civilisation de l'emprunt ' et que, si lui et le peuple sont dans une ' MERDE MAIS LIBRES ', ils seront bientôt dans une ' MERDE MAIS PRISONNIERS ', enchaînés par un système répressif et sans la moindre chance de salvation par la pureté des progrès économiques naturels. ILS NE POURRONT JAMAIS INVENTER AUCUNE CIVILISATION, AUCUN ETHOS, AUCUNE ÉCONOMIE, ILS SERONT CONDAMNÉS ! » in JABOR, Arnaldo. Pindorama. Texte dactylographié avec plusieurs annotations manuscrites, 139 pages, sans date, Cinemateca do MAM, Rio de Janeiro. 
la dialectique de l'aliénation coloniale où colonisateur et colonisé sont tous les deux des êtres à la culture « inauthentique ».

Ces photos qui succèdent à une carte du monde datant de la Renaissance, comme le locuteur de style radiophonique du début de Como era gostoso o meu francês, nous indiquent aussi clairement que la narration doit être une mise en relation avec le temps présent. La démarche du cinéaste s'identifie d'ailleurs ici avec celle de Prado auquel il fait référence. L'historien avait en effet complété son ouvrage par un post-scriptum dans lequel il mettait en relation le fruit de ses études sur le Brésil du premier siècle avec l'actualité politique de son temps. Il retrouvait dans l'élite de la Première République l'expression de la luxure et de la cupidité qu'il avait identifié chez les colons primitifs. Dans les années 20, celles-ci s'exprimaient au travers d'une politique qui mettait l'appareil d'état au service des intérêts particuliers et à court terme d'une minorité de privilégiés. Jabor ne partage pas le moralisme de Prado, de plus, le contexte historique est très diffèrent. Pour autant, il n'est pas difficile de faire le rapprochement entre les actants de Pindorama et ceux du Brésil de la modernisation conservatrice. Ce n'est pas un hasard si le cinéaste choisit de condenser dans la ville de Pindorama les contradictions du Brésil du premier siècle. En plus de l'intérêt qu'il y a à montrer la diversité culturelle et le bouillonnement anarchique de l'époque qui, rétrospectivement, a nourri les fantasmes autour de la « Révolution Caraïbe », Jabor veut nous faire comparer la première intégration du Brésil au marché mondial avec celle qui se joue dans les années 60-70 et au cours de laquelle le pays conserve sa position périphérique et subalterne malgré l'illusion du développement technologique.

Les deux notables qui manipulent Don Sebastião sont les représentants de la bourgeoisie nationale dont les intérêts sont liés à la manutention de la structure coloniale, ils sont les intermédiaires du pouvoir impérial. Toute leur fortune est basée sur l'exploitation de la colonie. Ils peuvent aussi représenter d'un côté, les libéraux, et de l'autre, les technocrates. Le libéral pourrait être celui qui se fait élire gouverneur à la fin du film et finit assassiné par Dom Sebastião. Toute ressemblance avec la trajectoire de Carlos Lacerda n'est pas fortuite. Pro-américain, il avait été l'un des principaux instigateurs civils du putsch de 1964 dans le but d'éliminer ses rivaux politiques dans la perspective des élections présidentielles de 1966. Contrariant ses calculs, les militaires conserveront le pouvoir et l'écarteront définitivement de la vie politique à partir de 1968. Cultivant une profonde défiance à l'égard des « politiques », ils confieront le pouvoir à des technocrates qui leur proposent une vision apparemment rationnelle et prometteuse du développement économique du pays. Ces technocrates, dont les figures emblématiques seraient Delfim Neto ou Roberto Campos, occupent des postes ministériels. N'ayant pas pour vocation d'occuper les premières lignes, ils s'accommodent très 
bien du fait que les militaires assument les principales responsabilités. Fin 68, ils appuient massivement la promulgation de l'AI-5 qui leur donne les moyens de mettre en application leur politique de modernisation conservatrice sans souffrir les contestations liées à l'accroissement des inégalités sociales qu'elle devait entraîner.

Dans le film, au cours du banquet, l'un des notables, celui qui pourrait représenter les technocrates, tape sur l'épaule de Dom Sebastião en l'appelant « Grande Jaguar » plusieurs fois et en le regardant fixement, comme admiratif. L'hommage affecté du notable envers l'aventurier n'est pas gratuit. Il suggère que le couple militaire-technocrate des années soixante-dix repose lui-aussi sur un malentendu et que les militaires sont manipulés par les technocrates. Cette interprétation est confirmée par la caractérisation du personnage de Dom Sebastião. Celui-ci est le personnage le plus anachronique du film. En réunissant les attributs $\mathrm{du}$ missionnaire et du pionnier des premiers temps, il incarne un type de personnage absolument improbable pour le premier siècle de la colonisation mais conforme au soldat des années soixante, imprégné de nationalisme verde amarelo, imbu d'une très haute idée du rôle de l'armée dans la société brésilienne, moraliste et autoritaire. Avec Brasil ano 2000, Pindorama est l'un des rares films à incriminer les militaires. Leur psychologie et leur rôle sont cependant assez bien identifiés par les cinemanovistas dès le début des années soixante. Un article de David Neves le montre. Lui-même fils de général, il citait un autre journaliste dont il trouvait l'analyse assez juste :

«... a formação patriótica dos militares faz com que eles fiquem indignados com $o$ subdesenvolvimento brasileiro. A sua mentalidade de classe média os obriga a buscarem causas de ordem moral para o subdesenvolvimento. E a sua formação profissional (de mistura com a mentalidade da classe média) faz com que fiquem encantados com o arquétipo norte-americano - no que diz respeito sobretudo à cultura de massas, ao excesso de bens de consumo, ao progresso tecnológico e ao equipamento militar. » ${ }^{1199}$

Plus de dix ans plus tard, les entretiens de Rocha réalisés à La Havane en 1971 montrent que les cinemanovistas pouvaient avoir une vision assez claire et lucide de la modernisation conservatrice et notamment $\mathrm{du}$ fonctionnement du couple militairestechnocrates pendant les années de plomb ${ }^{1200}$. Ces interprétations seront d'ailleurs

1199« ... la formation patriotique des militaires fait qu'ils s'indignent du sous-développement du Brésil. Leur mentalité de classe moyenne les oblige à rechercher des causes d'ordre moral au sous-développement. Et leur formation professionnelle (mélangée à la mentalité de classe moyenne) les conduit à s'émerveiller face à l'archétype nord-américain - en relation à la culture de masse, à l'excès des biens de consommation, au progrès technologique et à l'équipement militaire. » in NEVES, David. « Cinema, política e alienação » in Diário carioca, Rio de Janeiro, sans date.

1200Cf. ROCHA, Eryk (org.). Rocha que voa-América latina, África, o papel do intelectual, cinema, poesia, política, a memória em transe. A integra da entrevistas de Glauber que deram origem ao filme de Eryk Rocha. Op. cit. 
indirectement confirmées par l'étude d'Elio Gaspari ${ }^{1201}$ puisque, selon lui, les principaux instigateurs de la dictature, Golberi do Couto e Silva et Ernesto Geisel, ont bien été animés par un désir de rationalisation de l'appareil d'état qui devait se traduire par l'éradication du communisme mais aussi et surtout de la corruption des politiciens civils auxquels ils attribuaient tous les maux du Brésil. La caractérisation de Dom Sebastião nous apparaît donc a posteriori assez juste. Notons aussi qu'elle exprime une critique qui, à l'époque, ne pouvait pas être plus explicite.

En déplaçant le conflit principal du film sur les contradictions de l'association des notables avec Dom Sebastião ou des technocrates avec les militaires, Pindorama n'abandonne pas pour autant la critique du populisme et de celle de l'ambiguïté des intellectuels qui reviendra encore dans Os Inconfidentes. Dans Pindorama, la représentation du populisme acquiert une configuration originale, cruelle et ironique qu'elle n'avait pas eu jusque là. Le gouverneur qui sera finalement déposé n'est plus un lâche ni un stratège médiocre comme dans Terra em transe ou $O$ Bravo Guerreiro. Il cède peu à peu à l'anarchie et au dérèglement de l'appareil administratif parce qu'il s'est laissé séduire par la culture populaire et la liberté de Pindorama. Il a cette propriété qui devrait être celle de Sebastião de l'émerveillement par rapport à la culture indigène. Cynique, irresponsable et inconséquent, il pourrait être le gouverneur-samba qui se laisserait emporter par la masse et redevenir un homme ordinaire au sein de la foule s'il ne lui coûtait pas un peu de perdre ses avantages. La comparaison avec la trajectoire de João Goulart peut paraître osée, mais le président déposé comme le gouverneur de Pindorama se voit reprocher par les élites militaires et économiques, leur trop grande permissivité envers les manifestations populaires. Tous les deux sont renversés sur la base d'une suspicion, celle d'avoir été contaminé par l'ethos anarchisant de la colonie. Dans Pindorama, il semblerait que l'utopie de la Révolution Brésilienne du début des années soixante puisse être comparée à celle de la Révolution Caraïbe et que d'une certaine façon, la crise d'intelligence traversée par le pays (pour se référer à Roberto Schwarz) ait aussi été une crise de folie et l'expression du refoulé de la psychologie brésilienne, autrement dit l'expression de sa nature orgiaque qui aurait atteint la sphère politique et contaminé de la base vers le sommet, une partie des élites brésiliennes.

À partir du moment où il est assumé, comme dans Terra em transe ou Os Herdeiros, que le dispositif populiste ne pouvait pas réaliser la Révolution rêvée, qu'il était totalement illusoire d'imaginer qu'il aurait pu fonctionner, nous pouvons nous demander si sa propre

1201GASPARI, Elio. As Ilusões armadas - A Ditadura envergonhada. Op. cit. GASPARI, Elio. As Ilusões armadas - A Ditadura escancarada. Op. cit. GASPARI, Elio. O Sacerdote e o feitiçeiro - A Ditadura derrotada. Op. cit. GASPARI, Elio. O Sacerdote e o feitiçeiro - A Ditadura encurralada. Op. cit. 
existence historique ne relève pas de l'irrationnel. Cette impression est confirmée quand Jabor continue le jeu de massacre et fait kidnapper Diogo par Gregório. L'homme riche représente la fameuse bourgeoisie nationale sur laquelle l'élite intellectuelle progressiste représentée par Gregório pensait qu'il était possible de s'appuyer dans le conflit contre la bourgeoisie transnationale. Ici, le rapport des forces est ironiquement inversé. Gregório ne croit pas une seconde au potentiel révolutionnaire de Diogo qu'il désigne à Sebastião comme un exploitateur du peuple. Cependant, au lieu de tenter de s'allier avec le gouverneur, comme l'élite intellectuelle progressiste l'avait fait avec Goulart, Gregório décide de proclamer directement Diogo pour Roi et de le mettre dans la position de défendre un pays indépendant et dont il serait le souverain. Logiquement, il l'installe sur un trône au milieu du quilombo. L'image est savoureuse, les esclaves rebelles sont disposés à se battre pour leur liberté mais l'homme riche n'est évidemment pas à sa place et attend avec inquiétude l'armée de Sebastião. Il s'agit d'une caricature qui montre toute l'absurdité de la représentation téléologique de l'histoire qui faisait précéder la révolution prolétarienne par la révolution bourgeoise.

Enfin, Gregório qui incarne la projection de l'auteur dans le film n'a plus rien des personnages oscillants des phases précédentes du Cinema Novo. Il ne partage plus ni leurs ambiguïtés, ni leur vocation messianique. Nous voyons bien en effet qu'il assume parfaitement son identité créole et, s'il est bien un agitateur, il ne prétend plus pouvoir être un guide. Son intervention avec le kidnapping de Diogo est d'ailleurs, d'un point de vue stratégique, absolument catastrophique. En contraignant ce dernier à prendre la tête du quilombo, il attire sur lui l'armée de Sebastião. Le point commun de Gregório avec les personnages de sa lignée est peut être en dernière instance le désespoir, Gregório a une conscience assez claire du déroulement des événements mais cette conscience ne suffit pas à en infléchir le cours. Cette idée selon laquelle la conscience ne suffit pas à changer le réel émerge assez tardivement dans le Cinema Novo, elle surgit sous l'effet conjugué de l'intensification de la répression avec l'AI-5 et du succès du Cinema Marginal qui exprime le deuil de la position pédago-illuministe. Isolé au sein de sa classe et de la société dans son ensemble comme Gregório peut l'être dans le monde de Pindorama, l'intellectuel se conçoit à présent comme un être au pouvoir limité qui vit intensément la tristesse de l'homme brésilien. Sans légitimité ni véritable espace d'expression, il est réduit au rôle d'agitateur inconséquent ou de bouffon du Roi, c'est d'ailleurs la façon dont le gouverneur considère Gregório quand celui-ci apparaît au banquet. Sa trajectoire dans le film est aussi une véritable descente en enfer et celle-ci est d'autant plus cruelle que son sacrifice est vain.

Pindorama propose donc une vision de l'histoire ancienne et récente du Brésil tout à fait pertinente et provocatrice. Celle-ci marque une avancée significative par rapport à d'autres 
films comme Brasil ano 2000 ou Os Herdeiros qui reprenaient des idées déjà développées dans d'autres films et trahissaient dans leur analyse de la société brésilienne un recul insuffisant par rapport au point de vue spécifique de la classe moyenne et à ses valeurs. Cette vision pertinente et provocante ne sera cependant pas comprise au moment de la sortie du long métrage. L'objectif de la démystification n'est pas réalisé. Pindorama est un échec commercial retentissant et provoque l'exaspération des critiques pour qui les expérimentations de langage de l'époque atteignent un seuil intolérable. Jabor l'admet aujourd'hui :

« Não foi sucesso porque muita gente não entendeu o que estava se passando, porque ele era tão oculto para poder criticar que a própria crítica ficou incompreensível. [...] Representou o Brasil em Cannes. Ninguém entendeu nada literalmente do filme em Cannes. Eu acho que o filme tem uma loucura de linguagem de que realmente me orgulho e é também um exemplo deste momento histórico do cinema brasileiro daquela falta de liberdade, daquela loucura que se instalou no Brasil no início dos anos 70. As pessoas ficaram completamente malucas e inclusive eu. ${ }^{1202}$

Insistons cependant sur le fait que le film n'emprunte pas seulement au langage allégorique pour pouvoir critiquer le régime, l'argument est d'autant plus réfutable qu'à la même époque, Hirszman avec São Bernardo ou Santos avec Como era gostoso o meu francês, reviennent au réalisme critique et produisent deux des films les plus intéressants du Cinema Novo toujours ancrés dans cette volonté de connaître et de discuter le Brésil. Pindorama emprunte au registre allégorique car il renoue avec le projet de la création d'un langage cinématographique original, de rupture complète avec ceux déjà existant, et, partant, typiquement brésilien. Nous n'avons retrouvé que six critiques, une seule d'entre elles étant positive $^{1203}$. Pour la majorité, Pindorama est une « allégorie chaotique », un film sans queue ni tête dans lequel la scénographie et la musique finissent par voler la vedette aux autres éléments de langage et dont la confusion renvoie au vide. José Carlos Avellar qui a pourtant toujours été d'une fidélité exemplaire envers le Cinema Novo est déçu et assimile Pindorama à une « porte fermée ». Selon lui, la composition allégorique que le long métrage constitue est impossible à déchiffrer. Des acteurs se substituent aux personnages, un climat incommode

$1202 «$ Ce n'a pas été un succès parce que beaucoup de gens ne comprenait rien à ce qu'il racontait, parce qu'il était si occulte pour pouvoir critiquer le régime que la propre critique est devenue hermétique. [...] Il a représenté le Brésil à Cannes. Personne n'a rien compris du film à Cannes. Je crois que le film est une folie d'un point de vue formel et j'en suis très fier de ce point de vue, il est aussi un exemple de ce moment historique du cinéma brésilien caractérisé par le manque de liberté, c'est un témoignage de la démence qui a envahi le Brésil au début des années 70. Les gens sont devenus complètement fous, moi y compris. » Présentation du film par Arnaldo Jabor sur Canal Brasil, premier semestre 2003.

1203GUIMARÃES, Jorge. « Desencontro em Pindorama Jazz no Paissandu » in Correio da Manhã, Rio de Janeiro, 14/03/1972

MONTEIRO, José Carlos. «Pindorama alegoria caótica » in O Globo, Rio de Janeiro, 15/03/1972.

HOINEFF, Nélson. « Cinema - A Análise Pindorama » in O Jornal, Rio de Janeiro, 16/03/1972.

AVELLAR, José Carlos. «A porta fechada » in Jornal do Brasil, Rio de Janeiro, 17/03/1972.

OMAR, Artur. « Um gênero novo no cinema nacional » in Correio da Manhã, Rio de Janeiro, 19/03/1972.

«Pindorama ou o assassínio da crítica » in Correio Braziliense, Brasília, 15/10/1975. 
remplace une véritable narration et les rares moments présentant au spectateur des éléments de compréhension lui permettront, au maximum, d'établir avec le film une relation superficielle. Alex Viany déclare, dans un article de 1974 que Pindorama est l'un des pires films qu'il ait vu dans sa vie ${ }^{1204}$.

Seul, Artur Omar émet une appréciation positive sur Pindorama ${ }^{1205}$. Selon lui, comme Terra em transe, O Dragão..., Macunaíma, Azyllo muito louco, Os Deuses e os mortos et Os Herdeiros, le film de Jabor ouvre la voie à un nouveau genre qui se cherche et dans lequel la narration cède peu à peu la place à l'allégorie. Au contraire de tous les autres critiques, il pense que le principal défaut de ces films est de ne pas avoir réussi encore à éliminer totalement la narration, de ne pas avoir suffisamment travaillé l'allégorie pour que la communication avec le spectateur soit possible et enfin de rester à un niveau de traitement de l'histoire superficiel. Le genre n'a pas encore atteint un stade de maturité où il pourra articuler un discours populaire à un discours critique sur l'histoire réelle. Mais il possède un potentiel qui réside en ce qu'il conjugue la réflexion sur le langage et le spectacle. Par ailleurs, tous les ingrédients susceptibles d'attirer l'attention du spectateur sont présents : la violence, la musique, la danse, les foules, les couleurs, les costumes, le sang, le théâtre, la passion. Omar nous explique en somme que Pindorama est un échec car il n'est pas allé assez loin :

« Narra-se de través, intercalando monólogos, abrindo subespaços teatrais dentro do próprio filme, multiplicando os planos de ação, investindo a força do espetáculo em pontos-chaves, onde a ação já passou mas as significações se cristalizam com mais clareza.

Procurou-se furar os limites da narração, mas não se ousou abandoná-la. E, nessas formações de compromissos, o filme vacila, porque não assume sua vocação de alegoria pura, ou seja, o rigor do código que a alegoria permite. $\gg{ }^{1206}$

Enfin, toujours à contre-courant des avis émis dans les autres critiques du film, il conclut : «Não é um gênero intelectualista, ou deixará de sê-lo quando se cristalizar. » ${ }^{1207}$ L'histoire ne nous permettra pas de savoir si le genre nouveau dont Pindorama aurait été un pionnier avait effectivement des chances de plus amples développements. C'est une orientation qui sera abandonnée sans avoir réellement abouti. Il n'en reste pas moins vrai qu'au côté des défauts que nous avons relevés et qui empêchent que la communication se

1204VIANY, Alex. O processo do Cinema Novo. Op. cit., p. 197.

1205Omar deviendra par la suite un cinéaste et un plasticien reconnu mais isolé autant du Cinema Novo que du Cinema Marginal. OMAR, Artur. « Um gênero novo no cinema nacional » in Correio da Manhã, Rio de Janeiro, 19/03/1972.

1206« La narration est faite par la bande, intercalant des monologues, ouvrant des sous-espaces théâtraux à l'intérieur du film même, multipliant les plans de l'action, investissant sur la force du spectacle sur des pointsclefs, quand l'action s'est déjà consumée mais où les significations se cristallisent avec plus de clarté.

On a cherché à dépasser les limites de la narration, mais on n'a pas osé l'abandonner. Et, dans ce compromis, le film vacille, parce qu'il n'assume pas la vocation de l'allégorie pure, autrement dit, de la rigueur du code que l'allégorie permet. » in ibid.

1207 «Ce n'est pas un genre intellectuel, et, s'il l'est, il cessera de l'être quand il se sera cristallisé. » in ibid. 
fasse, Pindorama présente un ensemble de propositions intéressantes, notamment quand il emprunte à la mystique du carnaval et joue sur les inversions de rôles. C'est le cas dans les séquences de présentation du gouverneur et de l'homme riche, c'est aussi le cas quand ce dernier est déclaré Roi de Pindorama. Le film reprend ainsi des orientations posées par Rocha dans l'Esthétique du rêve dont la réalisation pleine et entière restera donc incertaine.

\section{Conclusion de la quatrième partie}

Comme nous l'avons vu dans la troisième partie, dès les premières années de la dictature, l'espace de liberté du Cinema Novo avait été défini de façon informelle et ne devait pas vraiment évoluer pendant les années de plomb malgré le durcissement de la censure dans les autres médias. Un cadre était donc posé à l'intérieur duquel les cinemanovistas entendaient renouer avec leur idéal d'un cinéma de conscientisation même s'il était ramené à des objectifs plus pragmatiques que ceux qui avaient prévalus avant 1964. À partir de 1968, ces cinéastesintellectuels ne se conçoivent plus à l'avant-garde de la conscience critique. La transformation totale de la conscience du peuple ne leur paraît d'ailleurs même plus indispensable à la réalisation de la révolution. Le mysticisme, l'ethos libertaire ou la simple conscience que le peuple a par lui-même de sa condition leur semblent être à présent les moteurs possibles de changements politiques. Les cinemanovistas entretiennent aussi avec le marché du cinéma une relation plus lucide. Ils n'ont plus la prétention de parler au peuple mais savent s'adresser à un public spécifique. Ces différentes prises de conscience contribuent à ce qu'ils assument la modestie de leur rôle dans un éventuel processus révolutionnaire. D'un côté, nous avons donc la continuation d'un cinéma d'auteur critique entendu comme un cinéma de recherche et de réflexion mais non de conquête du public. De l'autre, nous avons des tentatives d'élargissement de l'audience avec le cinemão. Celui-ci ne fonctionne pas quand l'actualisation du film est impossible sans la maîtrise d'une pratique de l'art et de référents qui sont propres à la culture classique. Par contre, les films qui permettent plusieurs niveaux de lecture et pratiquent une réelle ouverture en direction de la culture populaire sont des succès. 


\section{CONCLUSION}

Pendant la troisième phase du Cinema Novo, la problématique soulevée au début des années soixante d'un cinéma populaire de conscientisation, d'un cinéma conçu pour que la révolution se réalise et que l'individu aliéné du tiers-monde accède à la condition de sujet historique, se résout finalement sous l'effet conjugué de plusieurs événements. Le premier, et sans doute le plus décisif, est l'affirmation du cinéma militant avec la réalisation en Argentine de La Hora de los hornos ${ }^{1208}$ accompagné par le manifeste de ses auteurs, Fernando Solanas et Octavio Gettino, « Hacia el tercer cine » (Vers le troisième cinéma) paru à La Havane dans la revue Tricontinental ${ }^{1209}$. Le deuxième est la rédaction par le critique Sales Gomes du texte «Cinema : Trajetória no subdesenvolvimento » (Cinéma : Trajectoire dans le sousdéveloppement) qui analyse la trajectoire du cinéma brésilien jusqu'au début des années soixante-dix et tourne la page d'une période historique.

« Hacia el tercer cine » écrit simultanément à la diffusion de La Hora de los hornos, entre 1968 et 1969, produit un très fort impact auprès des cinéphiles du monde entier. La proposition de cinéma révolutionnaire formulée par les deux argentins convainc et supplante dans les esprits la représentation que l'on en avait jusque là et qui se fondait largement sur la lecture que l'on pratiquait du Cinema Novo en-dehors des frontières du Brésil. Ce texte a déjà été longuement discuté. Pour autant, il nous importe d'en reprendre ici quelques aspects reportés à l'expérience du Cinema Novo d'autant plus que celui-ci y est plusieurs fois cité.

Bien qu'issus d'un contexte différent du contexte brésilien, les similitudes entre les deux argentins et les cinemanovistas sont nombreuses. Issus des classes moyennes dans un pays d'Amérique latine également touché par une intense fragmentation sociale, Solanas et Gettino partagent avec les cinemanovistas des références théoriques communes qui ellesmêmes entraînent l'utilisation des mêmes concepts centrés autour de la question de l'aliénation. Leur interprétation de la situation vécue par l'Argentine, qu'ils étendent à l'ensemble de l'Amérique latine, dans un mouvement de pensée d'ailleurs parallèle à celui des cinemanovistas, les incite aussi à mettre en relation les questions d'oppression économique et politique avec les questions culturelles et à concevoir un conflit entre la culture de l'occupant et la culture de l'occupé. C'est à dire entre une culture qui légitime la structure économique et politique de leur pays et le maintient dans une situation de dépendance et d'exploitation, et une culture, qui reste à inventer, et qui pourrait saper les bases de cette structure en la faisant 
voir telle qu'elle est, c'est à dire inacceptable, et stimuler les actions de transformation, y compris armées. Le terme «conscientisation » n'est pas utilisé par Solanas et Gettino mais c'est bien de cela dont il s'agit.

Malgré toutes ces similitudes, les argentins arrivent dans un contexte politique et cinématographique qui, d'une certaine façon, leur interdit d'entretenir les illusions qui auront été celles des cinemanovistas à leur début. Tout d'abord, ils se trouvent directement confrontés à l'extension des dictatures militaires à l'ensemble du cône sud et ne peuvent que constater l'échec des régimes populistes de gauche. Contrairement au Cinema Novo qui aura d'abord été solidaire de la posture populiste avant de passer une longue période à en faire le deuil, Solanas et Gettino possèdent un positionnement clair pro-guérilla. Du point de vue cinématographique, ils bénéficient aussi du résultat des expériences menées depuis le début des années soixante et s'estiment en droit d'en dresser un bilan afin de formuler une proposition qui prendrait en compte les erreurs stratégiques commises par d'autres.

L'ensemble de ces réflexions conduisent Solanas et Gettino à classer le cinéma en trois catégories. Le premier cinéma est le cinéma hollywoodien ou d'imitation hollywoodienne dont les caractéristiques de production et de diffusion ainsi que les caractéristiques esthétiques sont à la fois le produit et le vecteur de l'idéologie et des valeurs du capital financier nordaméricain. Le deuxième cinéma, catégorie dans laquelle ils classent la Nouvelle Vague et le Cinema Novo, est un cinéma dans lequel les cinéastes essayent de rompre avec les règles esthétiques du premier cinéma afin d'atteindre une expression personnelle et, dans le cas des pays du tiers-monde, une expression culturelle décolonisée. Selon eux, il s'agit cependant d'une tentative vaine dans la mesure où ce cinéma ne rompt pas aussi avec les structures traditionnelles du marché cinématographique et se trouvera donc contraint d'obéir à des logiques économiques et politiques contraires à l'expression d'une esthétique anti-capitaliste.

Ils proposent donc de créer un troisième cinéma qui serait un cinéma de rupture esthétique diffusé par des réseaux alternatifs pouvant varier d'un pays à l'autre mais devant s'appuyer sur les structures politiques d'extrême-gauche engagées dans la lutte révolutionnaire. Solanas et Gettino proposent une nouvelle pratique cinématographique ancrée dans le militantisme, un «cinéma-guérilla » comme ils le proclament eux-mêmes citant en modèle ou en exemple leur propre expérience mais aussi Joris Ivens, Chris Marker, les groupes Medvedkine, le mouvement documentaire cubain mené par Santiago Alvarez, les Cinegiornali liberi en Italie, Newsreel aux USA, le cinéma vietcong ou encore les États généraux du cinéma en France, des références certes hétérogènes mais qui permettent bien de préciser leur projet.

Il ne nous appartient pas ici de dresser le bilan de quarante ans de troisième cinéma ni 
d'entrer dans la discussion sur les éventuelles exagérations et approximations théoriques du texte de Solanas et Gettino. Il ne nous intéresse pas non plus de critiquer le film lui-même, $L a$ Hora de los hornos, mais bien plutôt de reconnaître la justesse des contradictions repérées autour du deuxième cinéma et qui furent effectivement vécues par le Cinema Novo. Comme nous l'avons vu, au cours de la première phase du Cinema Novo la volonté de faire œuvre se confond avec la conviction qu'accéder à l'expression artistique équivaut à produire une culture à la fois désaliéné et désaliénante. Aucune réflexion n'est menée sur les structures traditionnelles de l'industrie cinématographique autre que la critique des politiques gouvernementales dans le sens où l'on attend de l'État qu'il encourage et facilite la production et la diffusion de ce type de cinéma. D'un côté, l'identification entre cinéma d'auteur et cinéma désaliéné trahit la prégnance des modèles occidentaux que nous discuterons plus bas. De l'autre, la stratégie de recherche de l'appui de l'État, restera longtemps comme un vestige de la posture populiste initiale puisque jusqu'à EMBRAFILME il sera imaginé (ou prétendu ? ${ }^{1210}$ ) qu'une connivence est possible entre l'État et un cinéma qui se veut révolutionnaire.

De plus, entièrement tourné vers des questions d'ordre esthétique, le Cinema Novo endosse une position contradictoire. Il investit le marché traditionnel de l'exploitation cinématographique et, parallèlement, refuse de prendre en compte le succès commercial des films comme un indicateur valide quant aux éventuelles directions à emprunter pour toucher le public. Ainsi, aucune réflexion de fond n'est menée à partir des succès de Assalto ao trem pagador et $O$ Pagador de promessas, et le Cinema Novo lui-même ne tente jamais de capitaliser sur ses propres succès comme Menino de engenho ou A Grande Cidade. La recherche d'une certaine expression par les cinéastes prend le pas sur l'établissement d'un dialogue suivi avec le grand public et l'idée, pourtant présente dans le concept initial du Cinema Novo, d'une co-construction de son esthétique dans une relation d'interaction entre le public et les cinéastes. En ce sens, le Cinema Novo est un cinéma d'auteur dans son acception la plus radicale puisque c'est bien l'expression du cinéaste qui occupe le premier plan. L'opposition entre cinéma d'auteur et cinéma commercial a été dommageable au Cinema Novo dans la mesure où elle n'a pas permis aux cinéastes de comprendre que la prise en compte de la réception du public pouvait signifier autre chose que la soumission à un certain académisme cinématographique.

Cette caractérisation du Cinema Novo comme « cinéma d'auteur », absolument fidèle au concept popularisé par François Truffaut et la Nouvelle Vague dans la seconde moitié des

1210Les anciens cinemanovistas prétendront toujours avoir bénéficié d'une parfaite indépendance au sein d'EMBRAFILME. Dans le cas de Rocha, il est difficile de savoir si ses démonstrations de sympathie envers les présidents Geisel et Figueiredo étaient le fruit du délire, du désenchantement ou d'une stratégie visant à la réalisation de son dernier film, A Idade da terra effectivement produit par EMBRAFILME. 
années cinquante, est à notre sens de première importance puisqu'elle implique une conception de l'art et de la pratique du cinéma extrêmement situées. Les cinemanovistas critiquent violemment Hollywood et le manque d'engagement politique des films de la Nouvelle Vague, mais leurs références, leurs « grands cinéastes » sont absolument les mêmes. Leurs articles parus dans les années soixante le montrent et le livre de Rocha, O Século do cinema $^{1211}$, le confirme, notamment en accordant d'amples développements aux «auteurs» ayant réussi à Hollywood. Le choix de la pratique d'un cinéma d'auteur, parce qu'il ne remet pas en cause les structures traditionnelles du cinéma, apparaîtra rapidement inadéquat avec la réalisation d'un cinéma populaire de conscientisation, objectif initial affiché. Les raisons en sont multiples.

Premièrement, et comme nous l'avons déjà remarqué, le réseau des salles d'exploitation, concentré autour de l'axe Rio-São Paulo et structuré autour de la clientèle urbaine de classe moyenne, ne touche pas ou peu les classes populaires misérables exclues des circuits de consommation des biens culturels, classes conçues comme potentiellement révolutionnaires par le PC et les cinemanovistas eux-mêmes qui la mettent en scène dans leurs premiers films. Deuxièmement, le choix du cinéma d'auteur contraint les cinemanovistas à adopter des stratégies commerciales qui passent par l'investissement des festivals étrangers, de la critique et de réseaux de distribution et d'exploitation qui l'éloignent physiquement des classes populaires et constituent des instances de légitimation qu'elles ne partagent pas et ce, plus que par simple ignorance. Enfin, l'investissement des structures traditionnelles exposent le Cinema Novo à la censure formelle de l'État et à celle, informelle, mais dont ils se sont souvent plaints, des distributeurs et exploitants ${ }^{1212}$.

Cette censure économique s'explique par plusieurs facteurs. Au-delà de la question de la nouveauté du langage qui constitue un risque commercial, les films du Cinema Novo exigent une réflexion et souvent une remise en question des valeurs du spectateur. Or, ces valeurs sont précisément celles qui permettent à l'individu de classe moyenne de rationaliser son expérience quotidienne et d'accepter les situations d'oppression ou la mauvaise conscience provoquée par l'exposition directe à la misère. Ces films placent donc le spectateur dans une situation inconfortable et, par voie de conséquence, sont moins commerciaux que ceux qui éviteront toute remise en cause de l'individu. Une censure politique est aussi exercée au travers de l'interprétation donnée par les exploitants du discours critique sur le Brésil que constitue la filmographie du Cinema Novo. Plusieurs d'entre eux, conformément à de larges secteurs des classes moyennes, rejetteront ce discours comme anti-patriotique.

1211Cf. ROCHA, Glauber. O Século do cinema. Rio de Janeiro, Alhambra/Embrafilme, 1985.

1212Sur la censure informelle des exploitants, cf. BERNARDET, Jean-Claude. Cinema brasileiro : propostas para uma história. Rio de Janeiro, Paz e terra, 1978, pp. 10-16. 
La critique de Solanas et Gettino, vis à vis d'un deuxième cinéma bridé par les restrictions imposées par les structures traditionnelles d'exploitation, prend donc tout son sens appliquée au cas particulier du Cinema Novo et ce d'autant plus que l'on aura en mémoire les exemples d'auto-censure mis en évidence dans l'analyse des scénarios de Terra em transe et Macunaíma. Cette question prend de l'ampleur si l'on veut bien la relier à celle du militantisme et à ce choix, revendiqué comme volontaire par le Cinema Novo, d'être libre de toutes structures politiques (à la place de quoi, comme nous le voyons il acceptait la censure de l'État et du marché). Pour Solanas et Gettino, la réponse aux restrictions du marché traditionnel réside dans l'investissement ou la création de réseaux alternatifs reposant sur des structures politiques ou associatives. Pour le Cinema Novo, il serait possible d'infiltrer les structures de l'État et d'assurer ainsi la continuité d'un discours révolutionnaire. Il s'agit d'une divergence d'autant plus grande entre les argentins et les brésiliens que ces derniers assument une position très critique vis à vis du $\mathrm{PC}$ et se défient des tentatives d'instrumentalisation, toujours craintes mais jamais réalisées, des différentes fractions de la gauche.

Au-delà de la recherche d'une position d'indépendance et de liberté artistique se posait pourtant bien, et cela est particulièrement clair dans la trajectoire de Rocha, la question de l'engagement politique. Une fois que la critique de l'intellectuel oscillant était parvenue à son terme avec Terra em transe et qu'il était posée, comme dans O Dragão da maldade contra o santo guerreiro, celle de l'engagement concret auprès des masses opprimées malgré la différence d'origine sociale, il n'était plus possible de maintenir cette position consistant à dire qu'il existait un lieu à partir duquel l'intellectuel pouvait développer et diffuser un discours critique exempt de toute pression et de toute partialité. Dès América nuestra, c'est à dire dès 1966, dans un éventuel processus révolutionnaire, Rocha se projette dans le rôle d'un artisteguérillero chargé d'un travail de propagande auprès des masses paysannes devant appuyer et relayer l'insurrection armée. Référence commune avec Solanas et Gettino, l'émergence de la figure de Che Guevara en 1967 alimente cette certitude que l'engagement est nécessaire si l'on se prétend effectivement révolutionnaire. Enfin, ce n'est sans doute pas pour rien que le leader du Cinema Novo saborde sa carrière après le succès du Dragão et, contrairement à un Bertolucci, refuse les offres mirobolantes qui lui sont faites alors pour partir à La Havane mettre ses talents à la disposition de la révolution tricontinentale.

La démarche, sans doute naïve à bien des égards, n'en était pas moins sincère et montrait l'existence d'une véritable contradiction entre la volonté de création d'un cinéma révolutionnaire et les conditions concrètes de sa réalisation. Rocha, finalement, ne s'essaiera au troisième cinéma qu'en 1974. Relégué à la condition d'un collaborateur anonyme, il se fond à un collectif de techniciens du cinéma et de la télévision portugaise qui filme la Révolution 
des Eillets. Le film s'intitule As armas e o povo ${ }^{1213}$. Un tel cinéma n'était pas possible dans le Brésil dictatorial où il décidera pourtant de revenir. Entre un deuxième cinéma contraint à accepter les compromis pour occuper un mince espace de liberté et un troisième cinéma condamné par la répression policière, le choix restait donc ouvert et malaisé pour quiconque voulait s'engager dans la voie d'un art transformateur. Nous allons pourtant prolonger notre réflexion en prenant pour référence un autre texte que celui de Solanas et Gettino. Publié au Brésil en 1973, ce deuxième texte nous éclaire sur les ambiguïtés du Cinema Novo en même temps qu'il tourne la page d'une période historique. Il s'agit de «Cinema : Trajetória no subdesenvolvimento ».

Comme « Hacia el tercer cine », « Cinema : Trajetória no subdesenvolvimento » est un texte très connu et déjà largement commenté, tout au moins au Brésil. Sales Gomes y fait un rapide bilan comparatif des différentes cinématographies mondiales, hindoue, japonaise, arabe (en particulier les cinématographies égyptienne et libanaise) avant de revenir à la cinématographie brésilienne dont il fait l'historique tout en s'appuyant sur le concept d'identité culturelle et de cette fameuse "authenticité » qui semble inatteignable aux pays du tiersmonde. Selon lui en effet, même lorsqu'elles sont économiquement florissantes, comme c'est le cas du cinéma hindou, les cinématographies du tiers-monde peinent à exprimer la culture originale de leurs pays respectifs et traduisent souvent, selon des mécanismes distincts, l'intériorisation par les producteurs et les spectateurs d'une vision occidentale de leurs propres traditions et modes de vie. Le cinéma demeure une manifestation culturelle « inauthentique » et une preuve de l'aliénation coloniale même dans des pays anciens et pourtant détenteurs d'une forte identité culturelle. Le Japon échappe à cette inauthenticité car il n'a jamais été économiquement soumis aux grandes puissances occidentales. Le cas du Brésil est à la fois plus complexe et tragique car c'est un pays colonial dont la population et la culture d'avant la colonisation ont été détruites. Selon Sales Gomes, le Brésil ne possède pas une culture originale mais tient pour sienne une culture transplantée qui est la culture occidentale.

Le critique établit alors le constat suivant : «Não somos europeus nem americanos do norte, mas destituídos de cultura original, nada nos é estrangeiro, pois tudo o é. » (Nous ne sommes pas européens ou américains du Nord, mais privés de culture propre, rien ne nous est étranger puisque tout nous est étranger.) Il retrace ensuite les principaux épisodes de l'histoire de la production de longs métrages au Brésil qu'il voit comme une illustration de cette difficulté à la fois historique et ontologique de l'homme brésilien à assumer une identité propre. L'un des aspects les plus commentés du texte est cette qualité que Sales Gomes repère dans le développement du cinéma brésilien d'une "incompetência criativa em copiar» 
(incapacité créative de copier) qui est elle-même le fait de la précarité des moyens de production dans un pays du tiers-monde. Selon lui, les moments les plus intéressants de l'histoire du cinéma brésilien, le cinéma de la Belle Époque (1909-1912), la chanchada (19401960) et le Cinema Novo (qu'il estime avoir duré de 1962 à 1968) sont les produits de cette incapacité créative à copier. Le désir d'expression prend toujours pour point de départ des modèles étrangers prestigieux mais le contexte humain, physique et financier divergeant, l'artiste finit par produire une esthétique nouvelle qui, si elle n'est pas pour autant achevée ou pleinement satisfaisante, ne traduit pas moins un point de vue brésilien sur le monde.

«Cinema : Trajetória no subdesenvolvimento » n'est pas exempt lui-même d'approximations théoriques et d'ambiguïtés. C'est justement sur la principale d'entre elles que nous voudrions insister. De façon significative, le texte reste ouvert sur un point qui concerne avant tout le Cinema Novo : l'identification incertaine au statut «d'occupant» ou « d'occupé ». Sales Gomes utilise les mêmes concepts qu'il utilisait déjà au début des années soixante quant il écrivait «Uma Situação colonial » à une exception près, celle de la prise en compte de la contradiction sociale interne au Brésil : «Qualquer estatística de variada origem que a imprensa divulga confirma o que percebe a intuição ética a respeito da deformidade do corpo social brasileiro. Toda a vida nacional em termos de produção e consumo que possam ser definidos envolve apenas trinta por cento da população. » (Toute étude statistique de quelques origines qu'elle soit et que la presse relaie confirme l'intuition éthique au sujet de la difformité du corps social brésilien. Toute la vie nationale en termes de production et de consommation qui peuvent être définis n'implique que trente pour cent de la population.) L'observation de cette contradiction que nous avons évoquée dès notre introduction en nous appuyant sur les travaux de Roger Bastide conduit Sales Gomes à se poser la question de l'altérité, à qualifier les $30 \%$ "privilégiés » d'occupants et les 70 autres d'occupés et surtout à insérer le Cinema Novo parmi les occupants.

Il s'agit d'une grande nouveauté si l'on veut bien se souvenir que, selon l'ISEB, il existait déjà des brésiliens relais de l'impérialisme, la bourgeoisie nationale cosmopolite alliée des grandes multinationales et dont la richesse reposait sur la prospérité du modèle économique colonial, mais il n'était pas question d'identifier toute la population ayant accès aux biens de consommation aux occupants. Au contraire, dans la mesure où les intérêts d'une partie de celle-ci devaient compromettre la structure coloniale, les forces vives d'une émancipation possible se trouvaient au sein des trente pour cent à présent stigmatisés comme « occupants ». L'ambiguïté de «Cinema : Trajetória no subdesenvolvimento » réside dans le fait que son auteur ne cherche pas à mieux préciser ou situer occupants et occupés. Il ne peut d'ailleurs pas nous échapper qu'une partie des occupants, ceux qui sont attentifs à cette 
situation de "difformité sociale» et souffrent par ailleurs des impositions de l'occupant, comme dans le cas du cinéma tel que sa situation était conceptualisée jusqu'alors, se trouvent dans la délicate situation d'être à la fois occupants et occupés. Laissant planer l'ambiguïté, Sales Gomes s'intéresse avant tout aux problèmes de conscience que la situation provoque et caractérise comme une posture créative le fait que certaines parcelles de l'intelligentsia se désolidarise de sa culture d'origine et tente d'adopter le point de vue de l'occupé.

Cette évolution de la pensée de Sales Gomes épouse absolument celle des cinemanovistas qui se sont d'ailleurs reconnus dans ses propos ${ }^{1214}$. Ce n'est pas une surprise si nous nous référons aux analyses que nous avons faites de leurs films, en particulier ceux de la troisième phase comme Como era gostoso o meu francês ou Pindorama dont les personnages principaux sont justement tiraillés dans cet « entre d'eux », être colons ou colonisés. Au-delà de la caractérisation de l'occupant et de l'occupé, ce qui nous paraît le plus intéressant est cependant la reconnaissance de l'altérité et de l'inconnue que constitue pour les $30 \%$ qui ont leur vie réifiée par une culture occidentale, même mal adaptée aux tropiques et au sousdéveloppement, les $70 \%$ jusqu'à récemment considérés comme exclus, marginaux ou aliénés. Aussi généreux avait-il pu être et aussi paradoxal que cela puisse paraitre, il faut bien convenir que le point de vue des occupants intéressés par une transformation sociale n'avait jamais reconnu ceux qu'ils voulaient « sauver » comme des sujets et, il faut bien reconnaître à leur décharge qu'ils ne pouvaient pas le faire puisque ce qui les constituaient eux comme sujet, c'est précisément ce que les autres n'avaient pas, à savoir cette relation très spécifique, qui n'était pas encore conçue comme socialement située, avec la culture.

La vision réductrice de l'indigent et du misérable qu'ils possédaient avait été remise en cause au fur et à mesure que la posture populiste voyait ses bases théoriques et politiques discréditées. Partageant les préjugés de la classe moyenne quant aux classes populaires, le cinéma, curieusement, portait en lui les germes du doute. D'un côté, nous l'avons vu dans la première et la deuxième phase du Cinema Novo, la critique de la capacité de la classe moyenne à assumer un rôle messianique est d'abord amorcée puis développée. Parallèlement, et cela était sans doute plus difficile, la perception du peuple devait également évoluer. Nous l'avons vu autonome et combatif, bien que vaincu, dans Bahia de todos os santos, ce n'est pourtant pas selon cette orientation qu'il allait s'affirmer. C'est l'originalité et la force de sa culture présentes dès Barravento et qui ressurgiraient de façon intermittente jusqu'à $O$ Dragão da maldade contra o santo guerreiro et Como era gostoso o meu francês qui allaient permettre au peuple de retrouver une certaine dignité, même mal comprise et plus ou moins 
bien acceptée, dans les raisonnements des cinemanovistas et allant de l'ensemble des contemporains du Cinema Novo qui avait accompagné ses évolutions et pour qui les films avaient été un réel matériel de réflexion. Si nous mettons en relation ce que nous dit Sales Gomes avec les derniers films, nous pouvons concorder avec ses propositions et les prolonger en admettant que le Cinema Novo a nourri l'esthétique de ses films d'éléments de la culture populaire et a effectivement tenté, mais sans jamais y réussir, d'adopter le point de vue des occupés, tout en restant dans le cadre d'une culture classique distincte et très éloignée de la culture populaire.

Le problème ne réside pas seulement dans la différence d'origine sociale et la différence de point de vue sur le monde qu'elle entraînerait mais dans le fait que l'intense fragmentation de la société brésilienne évoquée dans l'introduction et redécouverte dans les films équivaut à la juxtaposition dans le même espace de mondes différents, à la culture si différente que la communication entre ses différentes strates en devient très difficile. Le constat quant à la difficulté qu'il y avait à se faire comprendre des masses populaires, quand effectivement, le marché lui permettait d'accéder aux films, avait été assez rapide. Il est établi dès 1964. Mais l'interprétation donnée à cette absence de dialogue avait d'abord été l'ignorance et l'aliénation des masses, il faudra attendre la troisième phase du Cinema Novo pour voir cette l'interprétation remplacée par la reconnaissance d'une altérité culturelle et, là encore, il n'est pas évident que chaque cinemanovista ait été jusqu'au bout du raisonnement. Il nous semble cependant que le film de Gustavo Dahl, Uirá um índio em busca de Deus, montre bien l'aboutissement de cette prise de conscience en montrant la trajectoire d'un indien qui, entièrement absorbé par un drame personnel, tente d'y répondre avec les éléments que lui apporte sa culture et rejette férocement les dispositifs d'aide à l'intégration qui se dressent devant lui comme des obstacles et témoignent de la volonté du colon à organiser la vie selon ses propres règles culturelles.

Cette prise de conscience quant à la duplicité du Cinema Novo, artefact culturel produit de la culture de l'occupant et vecteur ambiguë d'une idéologie progressiste mais toujours selon les valeurs de l'occupant, ne doit pas cependant être interprétée comme un constat d'échec quant à la réalisation de l'idéal initial du groupe. L'un des principaux intérêts du Cinema Novo est justement d'avoir assumé un certain positionnement idéologique et d'avoir permis sa critique tout en participant à son évolution au cours de presque dix ans de l'histoire du Brésil. Ce Cinema Novo qui n'a pas su se rendre populaire a néanmoins eu un véritable rôle d'agitation et de réflexion politique pour un public réduit, qui ressemblait à ses auteurs, et peut être le seul véritable public qu'il pouvait toucher avec continuité compte tenu des restrictions imposées au média cinéma que nous avons rappelées plus haut. Son impact est 
visible au travers du grand nombre d'articles de presse que nous avons cité sur les films pris individuellement et sur le Cinema Novo en général et les échos de cet impact se font encore ressentir aujourd'hui au travers des publications dont il a été l'objet et dont la majorité se trouve répertoriée dans notre bibliographie. Cette qualité que le Cinema Novo a eu d'animer et d'alimenter le débat politique, même au sein d'un groupe de personnes réduit, n'est à notre sens pas négligeable.

La deuxième réussite du Cinema Novo est d'avoir montré, avec O Dragão..., Macunaima et Como era gostoso o meu francês, que la rencontre avec le public autour d'un cinéma critique et de réflexion sociale et politique était possible. Il ne nous échappera pas cependant que ces films sont déjà à la limite du concept de conscientisation dans la mesure où leur esthétique démontre une volonté de dialogue et de nivellement entre la position de l'intellectuel et celle du spectateur, la hiérarchie instaurée maintenue dans la posture populiste ayant à présent tendance à disparaître. Dans les deux cas de figures, l'expérience du Cinema Novo nous conduit à nuancer la condamnation du deuxième cinéma faite par Solanas et Gettino même si sa réussite se joue sur la critique de son idéal initial et sur la reconnaissance des limites du cinéma quant au nombre de personnes pouvant être touchées et à la qualité de la communication pouvant être établie avec chacun. Après le Cinema Novo, il ne nous semble pas qu'un groupe, un mouvement ou une école ait pu avoir autant d'impact que celui qu'il a connu. Le bilan des années EMBRAFILME, marquées par l'ambiguïté de la collaboration avec le régime dictatorial, reste encore à établir mais la moindre audace manifestée dans les films et l'incapacité de l'entreprise à installer durablement le cinéma brésilien dans le paysage audiovisuel nous conduisent à en minimiser les bénéfices.

Notre recherche d'un art transformateur auprès du Cinema Novo ouvre finalement autant de pistes qu'elle en a fermé. La résolution mentionnée plus haut de la problématique du Cinema Novo se résume en fait dans la critique du concept de conscientisation hérité de l'ISEB appliqué au cinéma et dans son deuil nécessaire, d'ailleurs déjà largement effectué par l'histoire. Pour autant de nouvelles perspectives sont ouvertes dans les deuxième et troisième cinémas puisque l'expérience du Cinema Novo montre, de façon positive ou par défaut, la possibilité de dépasser certaines oppositions comme cinéma artistique / cinéma commercial ou certaines identifications abusives comme cinéma militant / cinéma propagandiste. 


\section{FILMOGRAPHIE}

\section{Filmographie détaillée (Cinema Novo et films annexes analysés dans la thèse)}

1960

Arraial do cabo

(Non-fiction, court métrage, noir et blanc, $17 \mathrm{~min}$ )

Réalisateurs : Paulo César Saraceni et Mário Carneiro

Production : Sérgio Montana, Joaquim Pedro de Andrade, Geraldo Markan

Financement : subvention du Museu Nacional

Photographie : Mário Carneiro

Montage : Mário Carneiro

Texte de la narration : Claudio Mello e Souza

Narration : Italo Rossi

Acteurs principaux : les pêcheurs et les ouvriers d'Arraial do Cabo

Note : Film visionné sur support vidéo, cassette vhs, SARACENI, Paulo Cézar. O Cinema de

Paulo Cézar Saraceni. Rio de Janeiro, coll. Brasilianas, Ministério da Cultura / Funarte, sans indication de date.

Résumé : Arraial do Cabo est une cité au bord de la mer, au nord de Rio de Janeiro. L'idée du film était de réaliser un portrait social et humain de cette communauté basé sur des recherches du Museu Nacional. Le film montre le contraste entre la permanence de la pêche, encore pratiquée selon des méthodes primitives, et la présence d'une usine. Celle-ci, au lieu de se révéler un vecteur de progrès, pollue la mer et menace l'activité des pêcheurs. De leur côté, les pêcheurs ne s'adaptent pas à la vie ouvrière et ne peuvent pas travailler à l'usine. La main d'oeuvre est importée de l'extérieur. La dernière scène montre pêcheurs et ouvriers réunis au bar et, bien que souriant, les visages marqués par la misère, la fatigue et la fatalité.

\section{Aruanda}

(Non-fiction, court métrage, noir et blanc, $21 \mathrm{~min}$ )

Réalisateur : Linduarte Noronha, Assistants : Vladimir Carvalho et João Ramiro Mello Production : Instituto Joaquim Nabuco de Pesquisas Sociais (Recife), Instituto Nacional do Cinema Educativo (Rio de Janeiro), Secretaria de Educação e Cultura e D.E.R. (João Pessoa), 
Associação dos Críticos Cinematográficos da Paraíba.

Scénario : Linduarte Noronha

Photographie : Rucker Vieira

Montage : Rucker Vieira

Musique : Chansons populaires du Nordeste

Note : Film visionné sur support vidéo, cassette vhs, Noronha, Linduarte e outros. Rio de Janeiro, coll. Brasilianas, Ministério da Cultura / Funarte, sans indication de date.

Résumé : Au milieu du XIXe siècle, dans le Nordeste, Zé Bento et sa famille fuient la société esclavagiste des plantations de canne à sucre à la recherche d'une terre qui « n'appartiendrait à personne ». Arrivé à un point d'eau qu'ils jugent suffisamment éloigné de son point de départ, ils s'installent et fondent, sans le savoir encore, le quilombo Olho d'Água. D'autres fugitifs le rejoindront et à l'époque du tournage du film, la communauté qui s'était ainsi formée, subsistait encore selon les modes économiques primitifs qui avaient permis sa survie le siècle précédent : la plantation de coton et la poterie. Le film décrit surtout l'artisanat de la céramique et la vente de ses produits aux foires voisines.

\section{Bahia de todos os santos}

(Fiction, long métrage, noir et blanc, $100 \mathrm{~min}$ )

Réalisateur : Trigueirinho Neto

Production : Trigueirinho Neto, Lorenzo Serrano, Trigueirinho Neto Produções Cinematográficas et Lorenzo Serrano Produções Cinematográficas

Scénario : Trigueirinho Neto

Photographie : Guglielmo Lombardi

Montage : Maria Guadalupe

Musique : Antônio Bento da Cunha

Acteurs principaux : Jurandir Pimentel, Araçary de Oliveira, Geraldo del Rey, Antônio (Pitanga) Sampaio

Distribution : Ubayara filmes

Note : Copie cinéma visionnée à la Cinemateca brasileira.

Résumé : À Salvador, pendant la dictature de l'Estado Novo, un jeune métis, Tônio, vit à michemin entre deux mondes, celui de ses origines noires et celui de la société blanche. Tônio est un marginal qui vit de petits boulots, vole parfois et fait le gigolo. Rejeté par sa mère et ne connaissant pas son père, il habite avec un groupe multiracial de marginaux avec lequel il partage une maison de paille sur la plage. Le frère de son camarade Pitanga promeut une grève afin de créer un syndicat mais il meurt dans un affrontement entre les ouvriers du port 
de Salvador et la police. Tônio aide la famille de Pitanga à fuir. Mais il est dénoncé à la police par une de ses amantes bourgeoises avec laquelle il avait une relation plus ou moins suivie. Il ne dit pas où se trouvent Pitanga et sa famille mais dans la scène finale, il empêche un de ses amis de voler pour pouvoir subvenir aux besoins de son couple.

1961

\section{A Grande Feira}

(Fiction, long métrage, noir et blanc, $90 \mathrm{~min}$ )

Réalisateur : Roberto Pires

Production : Rex Schindler et Braga Neto, Iglu Filmes

Producteur exécutif : Glauber Rocha

Scénario : Roberto Pires

Photographie : Hélio Silva

Montage : Roberto Pires

Musique : Remo Usai

Acteurs principaux : Luiza Maranhão, Geraldo del Rey, Helena Ignez, Antônio Pitanga

Distribution : Cinedistri

Note : Film visionné à la télévision sur Canal Brasil.

Résumé : Un marin appelé le Suédois en raison de ses cheveux blonds, se trouve de passage à Salvador au moment où la ville est en proie à une vive agitation. La foire permanente de Água dos Meninos est menacée de disparaître sous la pression de promoteurs qui veulent s'approprier le terrain. Pendant que la tension monte, le Suédois est partagé entre deux femmes, une prostituée, noire, qui appartient au monde pittoresque des camelots et des bars populaires et une bourgeoise, blanche, qui fréquente les bas-fonds en quête de sensations fortes. Le film attend son climax lorsqu'un bandit, Chico Diabo menace de faire sauter toute la ville plutôt que de laisser la population se faire déposséder sans rien obtenir de concret.

1962

Assalto ao trem pagador

(Fiction, long métrage, noir et blanc, $89 \mathrm{~min}$ )

Réalisateur : Roberto Farias

Production : Herbert Richers et Roberto Farias, Produções Cinematográficas Herbert Richers

Scénario : Roberto Farias sur un argument de Roberto Farias, Luiz Carlos Barreto et Alinor Azevedo

Montage : Rafael Justo Valverde 
Musique : Remo Usai

Photographie : Amleto Daissé

Acteurs principaux : Eliezer Gomes, Reginaldo Faria, Grande Otelo, Átila Iório, Ruth de Souza, Luiza Maranhão, Helena Ignez

Distribution : Fama filmes

Note : Film visionné sur support vidéo, dvd : FARIAS, Roberto. Assalto ao trem pagador. Rio de Janeiro, Funarte, 2004.

Résumé : Basé sur un fait divers réel arrivé en 1960 à Japeri. Six hommes dirigés par Tião Medonho réussissent à dévaliser de façon spectaculaire un train postal dans l'intérieur de l'État de Rio de Janeiro. Pour ne pas se faire repérer, ils décident de ne pas dépenser plus de dix pour cent de leur part. Mais, rapidement, les tentations, les doutes et les rivalités minent le groupe. Cinq des membres du groupe habitent la favela et sont soumis à de dures nécessités tandis que le sixième, parce qu'il est blanc, blond et beau, prétend qu'il peut déjà se faire plaisir et parader dans la zone sud de Rio de Janeiro, parce que, lui, n'attirera pas l'attention. Les erreurs qu'ils commettent ne tarderont pas à permettre à la police de les retrouver.

\section{Barravento (Tempête)}

(Fiction, long métrage, noir et blanc, $80 \mathrm{~min}$ )

Réalisateur : Glauber Rocha

Production : Rex Schindler, Braga Neto et David Singer, Iglu Filmes

Scénario : Glauber Rocha sur une idée originale de Luiz Paulino dos Santos

Photographie : Tony Rabatoni

Montage : Nelson Pereira dos Santos

Musique : Washington Bruno da Silva et Batatinha

Acteurs principaux : Antônio (Pitanga) Sampaio, Luiza Maranhão, Lucy de Carvalho, Lídio Silva

Distribution : Horus Filmes

Note : Film visionné à la télévision sur Canal Brasil.

Résumé : De retour de la grande ville à son village au bord de la mer, Firmino cherche à transformer les habitudes des siens et à les faire se révolter contre l'exploitation économique dont ils sont victimes. Les pêcheurs louent leur filet pour un prix si important qu'il ne reste du produit de leur travail qu'à peine de quoi survivre. Soumis à cet état de fait qu'ils acceptent comme une fatalité, ils se réfugient dans la mysticisme et comptent sur Aruã, un jeune homme qu'ils croient protégé par la déesse Yemanjá. Firmino va successivement détruire le filet et pousser sa compagne à faire perdre à Aruan sa virginité et donc, ses pouvoirs. La stratégie de 
Firmino échoue et le village, malgré le fait que la situation ait empiré, ne remet pas en cause ses traditions et ses valeurs. Seul, Aruan décide de partir pour aller chercher en ville les richesses qui pourront améliorer la condition des siens.

\section{Os Cafajestes (La Plage du désir)}

(Fiction, long métrage, noir et blanc, $100 \mathrm{~min}$ )

Réalisateur : Ruy Guerra, Magnus Filmes

Production : Gerson Tavares

Scénario : Ruy Guerra sur un argument de Miguel Torres et Ruy Guerra

Photographie : Tony Rabatoni

Montage : Nello Melli et Zélia Feijó

Musique : Luiz Bonfá

Acteurs principaux : Jece Valadão, Norma Benguell, Daniel Filho, Glauce Rocha, Hugo Carvana, Lucy de Carvalho

Distribution : Fama Filmes

Note : Copie cinéma visionnée à la Cinemateca brasileira.

Résumé : Deux amis désoeuvrés de la zone sud de Rio de Janeiro, Jandir et Vavá, ont pour activité principale d'emmener des jeunes filles sur des plages désertes, de les convaincre à se déshabiller pour ensuite les photographier et faire chanter leurs amis ou les membres de leurs familles. Séduite par Jandir, Leda est victime de leur stratagème. Malgré l'humiliation qu'elle subit, elle les aidera pourtant à piéger sa cousine Vilma.

\section{Porto das Caixas}

(Fiction, long métrage, noir et blanc, $76 \mathrm{~min}$ )

Réalisateur : Paulo César Saraceni

Production : Elísio de Souza Freitas

Scénario : Paulo César Saraceni sur un argument de Lúcio Cardoso

Photographie : Mário Carneiro

Montage : Nello Melli

Musique : Antônio Carlos Jobim

Acteurs principaux : Irma Alvarez, Paulo Padilha, Reginaldo Faria

Distribution : U.C.B. - União cinematográfica brasileira

Note : Copie cinéma visionnée à la Cinemateca brasileira.

Résumé : Une jeune et belle femme mariée à un fonctionnaire des chemins de fer vit avec lui dans une maison misérable, dans une petite ville perdue, Porto das Caixas. La présence d'une 
fabrique abandonnée et d'un parc d'attractions désert laisse penser que la ville a connu des jours meilleurs. Pour sortir de cette vie sordide, la jeune femme décide de tuer son mari qu'elle ne supporte plus. Elle demande alors successivement à son amant, à un soldat de passage et à un barbier de l'aider. Tous se refusent à commettre un tel acte. Finalement, elle tuera son mari de sa propre main, d'un coup de hache. Puis, s'éloignera de la ville.

\section{Cinco vezes favela}

(Fiction, film composé de cinq courts métrages, $91 \mathrm{~min}$ )

Production : Leon Hirszman, Marcos Faria, Paulo César Saraceni, Tabajara Filmes, Centro Popular de Cultura, Instituto Nacional do Livro

Montage final : Ruy Guerra et Nelson Pereira dos Santos

Distribution : Unida Filmes, Tabajara Filmes, Paris Filmes et Seleção de Filmes.

Note : Pour Couro de gato, copie cinéma visionnée à la Cinemateca brasileira, intégralité du film visionnée en vidéo : Cinco vezes favela. Santana de Parnaíba, coll. Cinema Novo, Frontlog, sans indication de date.

\section{1 - Um Favelado}

Réalisateur : Marcos Farias

Scénario : Marcos Farias

Montage : Saul Lachtermacher

Musique : Mário Rocha

Acteurs principaux : Isabella, Flávio Migliáccio, Alex Viany, Sérgio Augusto, Carlos Estevão Résumé : Le favelado est un habitant de la favela. Sans emploi et sans argent, à charge de famille, il est menacé d'expulsion par des hommes de main qui lui réclament un loyer. Pour bien se faire comprendre, ceux-ci le passent à tabac et le laissent à terre en lui laissant une journée pour réunir l'argent. Le lendemain matin, celui-ci quitte sa famille et déambule en ville en quête d'un travail. Après avoir essuyer un refus, il hésite à cambrioler un kiosque à journaux, enfin, il décide de s'en remettre à un malfrat qui lui avait souvent proposé de travailler avec lui. Il participe au vol de la recette d'un autobus. Au moment de l'attaque, il est abandonné par ses complices, rattrapé, battu, et arrêté par la police.

\section{2 - Zé da Cachorra}

Réalisateur : Miguel Borges

Scénario : Miguel Borges

Photographie : George (Jiri) Dusek 
Montage : Saul Lachtermacher

Musique : Mário Rocha

Acteurs principaux : Waldir Onofre, Ângelo Labanca, José Saenz, Paulo C. Barroso

Résumé : Une famille de plus arrive dans une favela mais leur installation pose un problème. Il n'y a plus de place et le propriétaire du terrain a interdit l'accès de nouvelles familles. Malgré cela, l'un des habitants, Zé da Cachorra, prend sur lui d'accepter que cette famille puisse emménager dans le dernier local de libre, la cabane à outils du propriétaire qui est luimême un spéculateur immobilier et attend le bon moment pour faire construire. Averti de cette intrusion, ce dernier cherche à expulser les nouveaux arrivants par la négociation. Pour cela, il fait appel à un politicien dont il appuiera la campagne à condition qu'il prenne en charge les tractations avec la communauté de la favela. Celui-ci obtient qu'une délégation rendent visite au propriétaire. Zé da Cachorra, jugé trop véhément, est exclu par ses pairs. Chez le propriétaire, la délégation se soumet sans demander la moindre contrepartie. De retour à la favela, ils informent le chef de la famille des nouveaux arrivants qu'il a deux semaines pour s'en aller. Celui-ci se accepte cette décision. Excédé par tant de lâcheté, Zé da Cachorra exige son expulsion immédiate et part occuper lui-même la cabane à outils.

\section{3 - Escola de samba Alegria de viver}

Réalisateur : Carlos Diegues

Scénario : Carlos Diegues sur un argument de Carlos Estevão

Photographie : Owen Sermet

Montage : Ruy Guerra

Musique : Carlos Lyra

Acteurs principaux : Oduvaldo Vianna Filho, Abdias do Nascimento, Maria da Graça, École de Samba Unidos do Cabuçu

Résumé : Dans la favela, une école de samba se prépare au carnaval. Un nouveau président, jeune et dynamique, est élu. Il obtient un crédit pour acheter une nouvelle banderole et d'autres accessoires utiles au défilé. Ce même président est en conflit avec sa femme qui s'investit dans la vie syndicale et méprise l'école de samba. Lui-même ne comprend pas sa femme et assiste sans réagir aux brimades dont elle peut être l'objet par les autres favelados. Pendant le mois qui s'écoule, le couple se sépare et l'école est sans cesse relancée par ses créditeurs qui sollicitent le remboursement du paiement. Finalement, le jour même du carnaval, des hommes de main sont envoyé pour récupérer la somme. Juste avant le défilé, la confrontation est inévitable et la banderole est brûlée. En larmes, le jeune président décide de mener le défilé malgré tout. Le porte-étendard, par contre, abandonne la troupe et remonte 
vers les bidonvilles dans son déguisement.

\section{4 - Couro de gato}

Réalisateur : Joaquim Pedro de Andrade

Photographie : Mário Carneiro

Montage : Jacqueline Aubrey

Musique : Carlos Lyra

Acteurs principaux : Paulinho Manhães, Francisco de Assis, Riva Nimitz, Henrique César, Milton Gonçalves, Napoleão Muniz Freire, Domingos de Oliveira.

Résumé : À l'approche du carnaval, les enfants de la favela se font un peu d'argent en capturant les chats dont le cuir sera utilisé pour la fabrication de tambourins. Nous suivons le parcours et les ruses de plusieurs enfants dans Rio de Janeiro en montage parallèle. Des chats sont capturés dans la favela, à la terrasse des cafés, dans le jardin d'une maison bourgeoise, au parc, au nez et à la barbe de leurs propriétaires et des passants qui, parfois, réussissent à empêcher le larcin, parfois non. L'un des enfants réussit à attraper un très beau chat angora et à l'amener dans la favela, il passe un moment avec le chat avant de le donner, avec un mélange de regret et de fermeté, à l'artisan qui fabrique les tambourins.

\section{5 - Pedreira de São Diogo}

Réalisateur : Leon Hirszman

Scénario : Leon Hirszman et Flávio Migliáccio

Montage : Nelson Pereira dos Santos

Musique : Hélcio Milito

Acteurs principaux : Glauce Rocha, Francisco de Assis, Sady Cabral, Joel Barcelos

Résumé : À Rio de Janeiro, les travaux menés dans une carrière de pierre commencent à menacer l'existence d'une favela qui est située au-dessus de la carrière. Conscients du danger, les ouvriers vont alerter les habitants de la favela pour qu'ils se présentent tous en haut de la carrière juste avant l'explosion fatidique de façon à contraindre leur patron à arrêter les travaux.

Garrincha, alegria do povo

(non-fiction, long-métrage, noir et blanc, $70 \mathrm{~min}$ )

Réalisateur : Joaquim Pedro de Andrade

Production : Armando Nogueira, Produções Cinematográficas L.C. Barreto et Armando Nogueira Produções Cinematográficas 
Scénario : Joaquim Pedro de Andrade, Luiz Carlos Barreto, Armando Nogueira, Mário Carneiro et David Neves

Photographie : Mário Carneiro

Montage : Nello Melli et Joaquim Pedro de Andrade

Narrateur : Heron Domingues

Musique : Carlos Lyra

Note : Copie cinéma visionnée à la Cinemateca brasileira.

Résumé : Portrait du footballeur Garrincha avec l'historique de ses exploits sportifs, en particulier en coupe du monde, ses caractéristiques de joueur et des scènes de sa vie privée. $\mathrm{Au}$ final du film s'accomplit un surprenant décrochage au cours duquel est stigmatisée l'hystérie des supporters de football et où il est montré que la passion des brésiliens pour le ballon rond permettrait à la classe politique de les manipuler plus aisément qu'elle ne le ferait sans ça.

\section{O Pagador de promessas (La Parole donnée)}

(Fiction, long métrage, noir et blanc, )

Réalisateur : Anselmo Duarte

Production : Oswaldo Massaini, Anselmo Duarte et Cinedistri

Scénario : Anselmo Duarte adaptation de la pièce homonyme de Dias Gomes

Photographie : H.C. Fowle

Montage : Carlos Coimbra

Musique : Gabriel Migliori

Acteurs principaux : Leonardo Villar, Glória Menezes, Dionísio Azevedo, Norma Benguell, Geraldo del Rey, Othon Bastos, Antônio (Pitanga) Sampaio

Distribution : Cinedistri

Note : Film visionné sur Canal Brasil.

Résumé : Zé do Burro, portant une énorme croix de bois sur ses épaules, et sa femme Rosa arrivent à Salvador et s'installent sur de hauts escaliers en face d'une église. Celui-ci a promis à Santa Bárbara, sur un terrain de Candomblé, que si son âne avait la vie sauve suite à un éclair qui venait de le frapper, il la remercierait en donnant la moitié de sa terre et en apportant une grande croix de bois à pied dans une église de Salvador. Alors qu'il semble arrivé au bout de ses peines, les obstacles pourtant se multiplient pour Zé do Burro. Sa femme, exténuée et victime de son ingénuité, cède aux avances d'un maquereau pour passer une nuit au chaud et à l'abris. Le prêtre en charge de l'église refuse son accès à Zé do Burro, sous prétexte que celui-ci cherche à honorer une parole donnée sur un terrain de candomblé. 
L'obstination du paysan attire la curiosité des badauds et des journaux, la tension monte jusqu'à ce que Zé do Burro soit tué alors qu'il tentait de forcer la porte de l'église. Le peuple réagit en le portant, allongé sur la croix dans la position du crucifié, à l'intérieur de l'église sans que les autorités ne puissent à présent s'y opposer.

\section{Tocaia no asfalto}

(Fiction, long métrage, noir et blanc, $109 \mathrm{~min}$ )

Réalisateur : Roberto Pires

Production : Rex Schindler, Iglu Filmes

Scénario : Roberto Pires

Photographie : Hélio Silva

Montage : Roberto Pires

Musique : Remo Usai

Acteurs principaux : Agildo Ribeiro, Araçary de Oliveira, Adriano Lisboa, Geraldo del Rey, Othon Bastos

Distribution : Fama Filmes

Note : Film visionné à la télévision sur Canal Brasil.

Résumé : À Bahia, la trajectoire tragique d'un jeune tueur à gages.

1964

Os Fuzis (Les Fusils)

(Fiction, long métrage, noir et blanc, $81 \mathrm{~min}$ )

Réalisateur : Ruy Guerra

Production : Jarbas Barbosa, Copacabana Filmes, Daga Filmes et Inbracine Filmes

Scénario : Ruy Guerra et Miguel Torres

Photographie : Ricardo Aranovich

Montage : Raimundo Higino

Musique : Moacir Santos

Acteurs principaux : Átila Iório, Nelson Xavier, Hugo Carvana, Paulo César Pereio, Joel Barcellos

Distribution : Produções Cinematográficas Herbert Richers

Note : Film visionné à la télévision sur Canal Brasil.

Résumé : Lors d'une période de famine, dans un village du Nordeste, un groupe de soldats est détaché pour protéger du pillage un dépôt d'aliments. De passage dans la ville, le camion d'un chauffeur routier tombe en panne et il se retrouve obligé de rester quelques jours avant de 
pouvoir repartir. Le personnage se sensibilise peu à peu à l'absurdité de la situation en voyant les habitants mourir de faim malgré la présence de nourriture. Il tente de montrer aux soldats que le rôle que les autorités leur font jouer est immoral et criminel, en vain. La passivité d'un père de famille devant la mort de son enfant le pousse à tenter le coup de feu, incitant par là la population à la révolte. Il est immédiatement rattrapé et tué par les soldats.

\section{Deus e o diabo na terra do sol (Le Dieu noir et le diable blond)}

(Fiction, long métrage, noir et blanc, $125 \mathrm{~min}$ )

Réalisateur : Glauber Rocha

Production : Luiz Augusto Mendes, Copacabana Filmes

Scénario : Glauber Rocha et Walter Lima Jr, dialogue : Glauber Rocha et Paulo Gil Soares

Photographie : Waldemar Lima

Montage : Rafael Justo Valverde

Musique : Heitor Villa Lobos, Sérgio Ricardo et Glauber Rocha

Acteurs principaux : Geraldo del Rey, Yoná Magalhães, Maurício do Valle, Othon Bastos, Lídio Silva, Marrom et les habitants de Monte Santo

Distribution : Copacabana Filmes

Note : Film visionné sur support vidéo, dvd : ROCHA, Glauber. Deus e o diabo na terra do sol. Rio de Janeiro, Riofilme, 2003.

Résumé : Dans le Nordeste, Manuel pratique le métier de vacher et vit avec sa femme Rosa dans la misère. Un jour où il ramène des vaches à son employeur, au moment où il réclame les bêtes qui lui avaient été promises en paiement de son travail, celui-ci lui déclare que les bêtes qui sont accidentellement mortes sous sa garde étaient les siennes. Révolté, Manuel assassine le colonel et se trouve ensuite obligé de fuir de sa maison avec sa femme Rosa. Il décide alors de rejoindre la communauté d'un prédicateur qui promet que le sertão, bientôt, deviendra mer et la mer, sertão. Les conflits entre le prédicateur et Rosa et l'irruption d'Antonio das Mortes qui massacre la communauté, contraignent Manuel à chercher son salut autre part. Il se met alors au service de Corisco, un cangaceiro, qui lui raconte la mort de Lampião et se met à douter lui-même de la justesse de ses choix. Antonio das Mortes, guidé par un chanteur aveugle, est remis sur la trace de Corisco et finit par le tuer. Manuel et Rosa sont une fois de plus contraints de s'enfuir. Le film se conclut avec des prises de vue de l'océan.

\section{Ganga Zumba (Ganga Zumba)}

(Fiction, long métrage, noir et blanc, $92 \mathrm{~min}$ )

Réalisateur : Carlos Diegues 
Production : Jarbas Barbosa, Luiz Fernando Goulart, Roberto Quartim et Carlos Diegues, Copacabana Filmes

Scénario : Leopoldo Serran, Rubem Rocha Filho et Carlos Diegues, adaptation du roman homonyme de João Felício dos Santos

Photographie : Fernando Duarte

Montage : Ismar Porto

Musique : Moacir Santos

Acteurs principaux : Antônio Pitanga, Luiza Maranhão, Jorge Coutinho, Eliezer Gomes

Distribution : Produções Cinematográficas Herbert Richers

Note : Copie vidéo visionnée au Serviço de Biblioteca - SBD de l'Escola de Arte e Comunicações - ECA.

Résumé : Au XVIe siècle, Zumbi, neveu de Ganga Zumba, roi du quilombo de Palmares, fuit la senzala où il est né et où il aurait dû vivre comme esclave se consacrant à l'exploitation de la canne à sucre au profit de son seigneur. Le quilombo de Palmares est une communauté bâtie par des noirs fuyant l'esclavage et qui a jouit d'une exceptionnelle prospérité devenant ainsi un symbole de liberté.

Sur le chemin de Palmares, Zumbi va rencontrer d'autres noirs de diverses conditions l'amenant à prendre conscience des problèmes qui leur sont communs à tous. Poursuivi par des chasseurs à la solde des grands propriétaires, il parviendra à la fin à gagner le quilombo où il doit succéder à son oncle.

\section{Integração racial}

(non-fiction, court métrage, noir et blanc, $36 \mathrm{~min}$ )

Production : Divisão de Difusão Cultural do Ministério das Relações Exteriores

Producteur exécutif : Arnaldo Carrilho

Réalisation : Setor de Filmes Documentários da Diretoria do Patrimônio Histórico e Artístico

Nacional

Réalisateur : Paulo César Saraceni

Scénario : Paulo César Saraceni

Assistant de direction et continuité : Paulo Bastos Martins

Chef opérateur et cameraman : David E. Neves

Son direct : Arnaldo Jabor

Post-synchronisation : Eduardo Escorel

Montage : Gustavo Dahl

Lettrage du générique : Lygia Pape 
Note : Copie cinéma visionnée à la Funarte.

Résumé : Dans la nuit, une femme noire en transe danse au son des tambours sur un terrain de candomblé. La caméra s'attarde sur des visages avant de donner un plan d'ensemble de la scène et de montrer des accessoires du rituel. Vient ensuite une série d'entrevues dans le style du cinéma-vérité où l'on interroge des personnes de couleurs et d'origines diverses sur la question du racisme et de l'intégration racial au Brésil. Au début, la question principale semble être l'intégration des noirs mais l'intégration des japonais est également traitée. Plusieurs séquences montrent que, malgré les préjugés qui persistent chez certaines personnes, les différences sont oubliées lors de manifestations culturelles typiquement brésiliennes : le football, le candomblé, le carnaval.

\section{Maioria absoluta}

(non-fiction, court métrage, noir et blanc, $16 \mathrm{~min}$ )

Réalisateur : Leon Hirszman

Production : Leon Hirszman, financement du ministère de l'éducation, coordination de la production par David Neves.

Scénario : Leon Hirszman

Chef-opérateur, cameraman : Luiz Carlos Saldanha

Texte et voix off : Ferreira Gullar

Lettrage du générique : Lygia Pape

Montage : Nelson Pereira dos Santos

Son direct : Arnaldo Jabor

Le film n'a pas été distribué.

Note : Cassette vhs visionnée à la vidéothèque de l'Instituto de Artes, Universidade de Campinas.

Résumé : Commençant avec des interviews du style du cinéma-vérité, le film montre les dramatiques conséquences du taux important d'analphabétisme qu'il y avait encore au Brésil en 1963-1964. Pour Leon Hirszman, la « majorité publique », ce sont ces masses misérables qui sont à la fois, par leur simple existence, la matérialisation du sous-développement, et les plus intéressés à ce que la situation politiquement et économiquement change. La plus importante et la plus injuste des conséquences de l'analphabétisme est donc l'écartement de la vie civique des classes les plus misérables puisque les analphabètes n'avaient pas le droit de voter. Dans le contexte des vastes campagnes d'alphabétisation qui ont marqué la fin du gouvernement janguista, le film en appelle aux autorités démocratiques pour lutter contre ce fléau. 
Vidas secas (Sécheresse)

(Fiction, long métrage, noir et blanc, $103 \mathrm{~min}$ )

Réalisateur : Nelson Pereira dos Santos

Production : Luiz Carlos Barreto, Herbert Richers, Danilo Trelles, Produções Cinematográficas L.C. Barreto, Produções Cinematográficas Herbert Richers et Nelson Pereira dos Santos Produções Cinematográficas

Scénario : Nelson Pereira dos Santos, adaptation du roman homonyme de Graciliano Ramos Photographie : Luiz Carlos Barreto et José Rosa

Montage : Rafael Justo Valverde

Musique : Leonardo Alencar

Acteurs principaux : Átila Iório, Maria Ribeiro, Jofre Soares, les enfants Gilvan et Genivaldo Lima

Distribution : Sino Filmes

Note : Copie cinéma visionnée à la Cinemateca brasileira.

Résumé : Dans les années 1940, Fabiano, sa femme, ses deux enfants et leur chienne Baleia, errent, affamés, dans le sertão du Nordeste. Bientôt, ils trouvent une maison en torchis où ils s'installent. Le propriétaire des lieux leur permet de rester quand Fabiano lui propose ses services comme vacher. Durant presque deux ans, la famille vit dans cette maison. Mais, finalement, Fabiano s'indispose avec un policier du village voisin et le propriétaire lui-même. Fabiano est alors successivement victime des abus de pouvoir du premier et de l'avarice du second. La famille doit repartir sur les routes aussi misérable qu'elle était arrivé, sinon plus, puisqu'il faut se débarrasser de Baleia qui, vieille et inutile, représente une bouche de trop à nourrir.

1965

O Desafio (Le Défi)

(Fiction, long métrage, noir et blanc, $90 \mathrm{~min}$ )

Réalisateur : Paulo César Saraceni

Production : Paulo César Saraceni, Sérgio Saraceni, Imago Filmes et Produções Cinematográficas Mapa Filmes

Scénario : Paulo César Saraceni

Photographie : Guido Cosulich, caméra : Dib Lufti

Montage : Ismar Porto

Musique : Heitor Villa-Lobos, Wolfgang Amadeus Mozart, chansons de Edu Lobos, 
Gianfrancesco Guarnieri, Carlos Lyra, Caetano Veloso, José Cândido, João de Paula, Zé Ketti, Vinicius de Moraes

Acteurs principaux : Isabella, Oduvaldo Vianna Filho, Gianina Singulani, Joel Barcellos, Hugo Carvana

Distribution : Difilm

Note : Film visionné sur support vidéo, cassette vhs : SARACENI, Paulo César. O Desafio. Rio de Janeiro, Riofilme, sans indication de date.

Résumé : Après le coup d'état militaire de 1964, un jeune journaliste de gauche, Marcelo, s'interroge sur les raisons de l'échec du projet politique de son parti. La dure désillusion que représente l'installation du régime dictatorial l'amène également à remettre en cause sa liaison avec Ada, une jeune femme qui est aussi l'épouse d'un industriel. Ne réussissant à trouver le réconfort ni auprès de ses amis, ni auprès de son amante, il finit par rompre avec elle et à ne plus chercher qu'en lui-même la volonté de continuer la lutte dans un contexte totalement rénové.

\section{A Grande Cidade}

(Fiction, long métrage, noir et blanc, $85 \mathrm{~min}$ )

Réalisateur : Carlos Diegues

Production : Luiz Carlos Barreto, Carlos Diegues, Mapa Filmes et Produções Cinematográficas L.C. Barreto

Scénario : Leopoldo Serran et Carlos Diegues

Photographie : Fernando Duarte, caméra : Dib Lufti

Montage : Gustavo Dahl

Musique : Zé Ketti, Pixinguinha, Ernesto Nazareth, Heitor Villa-Lobos, Francisco Mignone, Heckel Tavares

Acteurs principaux : Leonardo Villar, Anecy Rocha, Joel Barcellos, Antônio Pitanga et la participation d'Arnaldo Jabor, Gustavo Dahl et David Neves

Distribution : Difilm

Note : Film visionné à la télévision sur Canal Brasil.

Résumé : Une jeune femme venue du Nordeste, Luzia vient à Rio de Janeiro pour retrouver son fiancé, Jasão, qui, l'ayant précédé dans la ville, ne lui donnait plus de nouvelles. À son arrivée, elle rencontre Calunga qui la guide dans cet environnement totalement nouveau pour elle, il lui présente aussi un jeune homme, Inácio, qui vient aussi du Nordeste. Celui-ci, à l'exemple de tant d'autres, avait immigré dans l'espoir de trouver de meilleures conditions de vie qui, malheureusement, ne se sont pas réalisées. Il vit dans l'angoissante nostalgie de sa 
terre natale cherchant à retrouver ses traditions en dehors de leur lieu d'appartenance. Finalement, Luzia retrouve Jasão qui est devenu un terrible bandit, sorte de cangaceiro urbain. Calunga le dénonce par accident en parlant trop fort dans un bar. Perplexe et distant, il ne peut plus qu'assister qu'au dénouement tragique du destin du jeune couple.

\section{A Falecida (La Morte)}

(Fiction, long métrage, noir et blanc, $85 \mathrm{~min}$ )

Réalisateur : Leon Hirszman

Production : Joffre Rodrigues, Produções Cinematográficas Meta

Scénario : Leon Hirszman et Eduardo Coutinho, adaptation de la pièce homonyme de Nelson Rodrigues

Photographie : José Medeiros, caméra : Dib Lufti

Montage : Nello Melli

Musique : Radamés Gnatalli, Nelson Cavaquinho et Amâncio Cardozo

Acteurs principaux : Fernanda Montenegro, Paulo Gracindo, Ivan Cândido, Nelson Xavier, Joel Barcellos

Distribution : Produções Cinematográficas Meta et Produções Cinematográficas Herbert Richers

Note : Film visionné sur support vidéo, cassette vhs : HIRSZMAN, Leon. A Falecida. Rio de Janeiro, Funarte / Riofilme, sans indication de date.

Résumé : Profondément déprimée par la vie misérable et routinière qu'elle mène dans un quartier de la banlieue de Rio de Janeiro, Zulmira rêve d'un enterrement luxueux. Bien qu'étant en parfaite santé, elle se convainc qu'elle est atteinte de tuberculose et que ses jours sont comptés. Elle demande à son mari, qui est sans emploi, de persuader Monsieur Guimarães, l'homme le plus riche du quartier, de lui donner l'argent nécessaire. Mais celui-ci refuse tout en avouant qu'il a été l'amant de Zulmira. Blessé dans son amour propre, le mari fait chanter le notable. Quand Zulmira meurt, il commande alors les funérailles les moins chères et se rend à un match de football au lieu d'assister à l'enterrement.

\section{Menino de engenho (L'Enfant de la plantation)}

(Fiction, long métrage, noir et blanc, $110 \mathrm{~min}$ )

Réalisateur : Walter Lima Júnior

Production : Glauber Rocha, Walter Lima Júnior, Mapa Filmes

Financement : CAIC

Scénario : Walter Lima Júnior, adaptation du roman homonyme de José Lins do Rego 
Photographie : Renaldo Paes de Barros

Montage : João Ramiro Mello et Júlio Bressane

Musique : Pedro dos Santos, Alberto Nepomuceno, Heitor Villa-Lobos, João Nepomuceno

Acteurs principaux : Sávio Rolim, Geraldo del Rey, Anecy Rocha, Maria Lúcia Dahl, Antônio

Pitanga

Distribution : Difilm

Note : Cassette vhs visionnée au SBD de l'ECA.

Résumé : Suite à la mort à la fois mystérieuse et violente de sa mère, le petit Carlinhos est envoyé à la plantation de Santa Rosa où il sera élevé par le colonel José Paulino. Sa tante Maria sera sa nouvelle maman et son oncle Juca lui expliquera les rouages du fonctionnement de l'exploitation. Alors que l'enfant grandit et découvre la vie dans un milieu où il est privilégié, il est également témoin de la décadence de la plantation, vestige d'un régime économique désormais obsolète et d'un Brésil mythique qui disparaît peu à peu sous les assauts de la modernité.

\section{São Paulo S.A.}

(Fiction, long métrage, noir et blanc, $111 \mathrm{~min}$ )

Réalisateur : Luís Sérgio Person

Production : Renato Magalhães Gouvea, Socine Produções Cinematográficas

Scénario : Luís Sérgio Person

Photographie : Ricardo Aranovich

Montage : Glauco Mirko Laurelli

Musique : Claudio Petráglia

Acteurs principaux : Walmor Chagas, Eva Wilma, Otello Zelloni, Ana Esmeralda, Darlene Glória

Distribution : Columbia Pictures do Brasil

Note : Copie vidéo cédée par Marina Person au cours du processus de restauration du film.

Résumé : À la fin des années 50, à São Paulo, le bond spectaculaire connu alors par l'industrie automobile permet à Carlos, ouvrier spécialisé, de devenir l'associé d'une firme de fabrication de pièces automobiles. Cette rapide ascension sociale ne fait pourtant pas son bonheur. Carlos ne supporte pas son quotidien routinier et dénué de sens tout comme le conformisme de ses proches. Déprimé, il décide d'abandonner femme, enfant et emploi pour partir à la recherche d'une nouvelle vie. Lors de la journée qui suit la rupture, il se remémore les différentes étapes de son succès professionnel parallèlement aux aléas de sa vie sentimentale puis, incapable de concevoir une issue à son mal-être, il se résoud finalement à rentrer. 
1966

Amazonas, Amazonas

(non-fiction, court métrage, noir et blanc, $15 \mathrm{~min}$ )

Réalisateur : Glauber Rocha

Production : Luiz Augusto Mendes, Departamento de Turismo e Promoções do Estado de Amazonas

Photographie : Fernando Duarte

Musique : Heitor Villa Lobos

Note : Copie vidéo visionnée au Tempo Glauber.

Résumé : Documentaire de commande à visée initialement touristique sur l'état d'Amazonas mais qui focalise sur la décadence et le marasme économique consécutifs à la fin du cycle du caoutchouc. Premier film en couleur de Rocha.

\section{O Circo}

(non-fiction, court métrage, couleurs, $30 \mathrm{~min}$ )

Production : Divisão de Difusão Cultural do Ministério das Relações Exteriores, Instituto Nacional de Cinema Educativo

Réalisation : Setor de Filmes Documentários da Diretoria do Patrimônio Histórico e Artístico Nacional

Planification et direction : Arnaldo Jabor

Assistant de direction et de production : Antonio Carlos Fontoura

Chef opérateur, cameraman et post-synchronisation : Affonso Henrique Beato

Son direct : Carlos Arthur Liuzi

Montage : Carlos Diegues

Lettrage du générique : Maria Thereza Simões Correa

Note : Film visionné sur support vidéo, cassette vhs : JABOR, Arnaldo. O Circo. Sans indication de lieu, Globo Vídeo, sans indication de date.

Résumé : Documentaire sur un métier et un divertissement autrefois populaire en voie de disparition, le cirque.

\section{Maranhão 66}

(non-fiction, court métrage, noir et blanc, $11 \mathrm{~min}$ )

Réalisateur : Glauber Rocha

Production : Luís Carlos Barreto et Zelito Viana, Mapa Filmes 
Photographie : Fernando Duarte

Montage : João Ramiro Melo

Note : Copie vidéo visionnée au Tempo Glauber.

Résumé : Documentaire sur le Maranhão réalisé dans le contexte de la campagne de José Sarney pour la conquête du titre de gouverneur de l'état. Source d'inspiration pour Terra em transe, quelques images issues du tournage de ce documentaire seront utilisées dans le long métrage de fiction.

\section{O Padre e a moça}

(Fiction, long métrage, noir et blanc, $91 \mathrm{~min}$ )

Réalisateur : Joaquim Pedro de Andrade

Production : Luiz Carlos Barreto et Joaquim Pedro de Andrade, J.P.A. Filmes et Produções

Cinematográficas L.C. Barreto

Financement : CAIC, BEG et BNMG

Scénario : Joaquim Pedro de Andrade, basé sur le poème Negro amor de rendas brancas de Carlos Drummond de Andrade

Photographie : Mário Carneiro

Montage : Eduardo Escorel

Musique : Carlos Lyra

Acteurs principaux : Helena Ignez, Paulo José, Mário Lago, Fauzi Arap et les habitants de São Gonçalvo do Rio das Pedras

Distribution : Difilm

Note : Film visionné à la télévision sur Canal Brasil.

Résumé : L'irruption d'un nouveau et jeune curé secoue les habitudes d'une petite ville des Minas Gerais. L'immobilisme et le marasme économique de la ville semble dissimuler autant de frustrations que de drames inavouables. Entre le père et une jeune fille dont la beauté semble faire injure à la tristesse des lieux et à l'aigreur de ses habitants, une passion ardente se noue. Prisonnier des contradictions de ses sentiments, le jeune curé fuit d'abord le village en compagnie de la jeune fille avant finalement de se décider à revenir. En proie à une folie meurtrière, la population leur fait alors la chasse. Le couple se réfugie dans une grotte à l'entrée de laquelle les villageoises mettent le feu.

\section{Bebel, garota propaganda}

(Fiction, long métrage, noir et blanc, $103 \mathrm{~min}$ ) 
Réalisateur : Maurice Capovilla

Production : José A. Reis, Alpha Filmes, C.P.S. Produções Cinematográficas, George Jonas Produções Cinematográficas et Saga Filmes

Scénario : Maurice Capovilla, basé sur le roman Bebel, que a cidade comeu de Ignácio Loyola Photographie : Waldemar Lima

Montage : Sylvio Renoldi

Musique : Carlos Imperial, arrangement : Rogério Duprat

Acteurs principaux : Rossana Ghessa, John Herbert, Paulo José, Geraldo del Rey, Maurício do Valle

Distribution : Difilm

Note : Film visionné à la télévision sur Canal Brasil.

Résumé : Dans le style du cinéma-vérité, un journaliste et son cameraman interrogent les différents personnages qui ont joué un rôle lors de la rapide ascension et de la longue descente aux enfers de Bebel, un mannequin rendu célèbre grâce à une campagne de publicité nationale pour un savon. L'histoire montre comment le système utilise une jeune femme puis la « jette» lorsqu'elle ne lui est plus utile.

Brasília, contradições de uma cidade nova

(non-fiction, moyen métrage, couleurs, $45 \mathrm{~min}$ )

Réalisateur : Joaquim Pedro de Andrade

Production : Filmes do Sêrro pour Olivetti do Brasil

Scénario : Joaquim Pedro de Andrade, Luís Saia et Jean-Claude Bernardet

Photographie : Affonso Beato

Note : Copie vidéo visionnée à la Funarte.

Résumé : Portrait de la « Novacap » (Nouvelle Capitale) devenue une grande ville comme les autres quelques années seulement après son inauguration. Il s'agit du premier film brésilien à s'attaquer au mythe de Brasília.

\section{O Caso dos irmãos Naves}

(Fiction, long métrage, noir et blanc, $92 \mathrm{~min}$ )

Réalisateur : Luís Sérgio Person

Production : Glauco Mirko Laurelli et Luís Sérgio Person, Lauper Filmes et MC Filmes (Mário Civelli)

Scénario : Luís Sérgio Person et Jean-Claude Bernardet, adaptation de la nouvelle homonyme de João Alamy Filho 
Photographie : Osvaldo de Oliveira

Montage : Glauco Mirko Laurelli

Musique : Claudio Petráglia

Acteurs principaux : John Herbert, Juca de Oliveira, Raul Cortez, Anselmo Duarte et nonprofessionnels de la ville d'Araguari

Distribution : MC Filmes

Note : Film visionné sur support vidéo, cassette vhs : PERSON, Luis Sérgio. O Caso dos irmãos Naves. Sans indication de lieu, Globo vídeo, sans indication de date.

Résumé : En 1937, à l'époque de l'Estado Novo, dans la petite ville d'Araguari, un homme disparaît en emportant une grande somme d'argent. Ses associés, Sebastião et Joaquim Naves, sont accusés de l'avoir tué par l'opinion publique et un lieutenant de police. Le lieutenant se charge de l'enquête et tente de les faire avouer par la torture. Un jeune avocat prend alors la défense des deux hommes, dénonce le traitement qui leur est imposé et montre que les preuves sont insuffisantes pour les établir leur culpabilité. Les deux frères sont pourtant condamnés pour un crime qu'ils n'ont pas commis et ce n'est que 15 ans plus, avec la réapparition subite du disparu, qu'ils seront réhabilités.

\section{Cinema Novo (Improvisiert und Zielbbewusst)}

(non-fiction, court métrage, noir et blanc, $30 \mathrm{~min}$ )

Réalisateur : Joaquim Pedro de Andrade

Production : K.M. Eckstein, ZDF

Photographie : Hans Bantel

Montage : Bearbara Riedel

Texte et narration en allemand : K.M. Eckstein

Narration en portugais : Paulo José

Note : Copie vidéo visionnée au Tempo Glauber.

Résumé : Le film dresse un portrait du Cinema Novo avec des images des cinéastes lors des diverses activités de leur profession. Tournage de El Justicero de Nelson Pereira dos Santos ; lecture des dialogues de Terra em transe avec les acteurs et le réalisateur, images du tournage de Terra em transe avec Paulo Autran, Dib Lufti, Jardel Filho, Luíz Carlos Barreto et Glauber Rocha ; visionnage des rushes de Todas as mulheres do mundo ; apéritif au bar près des laboratoires Líder avec Luiza Maranhão ; fête avec Leon Hirszman, Vinicius de Moraes et Maria Bethânia; Gustavo Dahl en train d'écrire ; Arnaldo Jabor en train de monter A Opinião pública ; Carlos Diegues faisant le tour des cinémas au moment de la sortie de $A$ Grande Cidade; scène du meeting de Terra em transe. 


\section{Garota de Ipanema}

(Fiction, long métrage, couleurs, $99 \mathrm{~min}$ )

Réalisateur : Leon Hirszman

Production : Luiz Carlos Pires Fernandes, Leon Hirszman, Vinicius de Moraes, Saga Filmes et CPS Produções Cinematográficas

Scénario : Leon Hirszman et Eduardo Coutinho, argument de Vinicius de Moraes, Leon Hirszman, Eduardo Coutinho et Glauber Rocha, inspiré de la chanson de Vinicius de Moraes et Antônio Carlos Jobim

Photographie : Ricardo Aranovich

Montage : Nello Melli

Musique : Antônio Carlos Jobim, Vinicius de Moraes, Chico Buarque et autres

Acteurs principaux : Márcia Rodrigues, Adriano Reys, Arduíno Colosanti, Irene Stefânia et beaucoup d'artistes jouant leur propre rôle

Distribution : Difilm

Note : Copie vidéo visionnée à la Funarte.

Résumé : Márcia est une jeune fille typique de classe moyenne. Elle habite la zone sud de Rio de Janeiro, étudie à l'Université Pontificale Catholique - PUC, fréquente la plage et les fêtes où se retrouvent les artistes et les intellectuels. À la recherche d'elle-même, elle rompt avec son petit ami surfer, flirte un temps avec la vedette de la chanson, Chico Buarque, puis découvre un garçon dont elle est véritablement amoureuse mais qui est déjà marié. Après quelques hésitations, elle s'arrange pour croiser la femme du garçon dans un magasin de maillots de bain. La rencontre, furtive et anonyme, la met mal à l'aise. Elle préfère alors retourner avec le surfer.

\section{A Opinião pública (Opinion publique)}

(Non-fiction, long métrage, noir et blanc, $65 \mathrm{~min}$ )

Réalisateur : Arnaldo Jabor, assistant : Wladimir Carvalho

Production : Arnaldo Jabor, Nelson Pereira dos Santos, Film-Indústria, Verba Filmes et CAIC-BEG

Scénario : Arnaldo Jabor

Photographie : Dib Lufti

Montage : João Ramiro Mello, Gilberto Macedo et Arnaldo Jabor

Narration : Fernando Garcia

Musique : Gilberto Macedo 
Acteurs principaux : Valéria Amar, Isaltina, Wanderley Cardoso, Yoná Magalhães, Chacrinha Distribution : Difilm

Note : Film visionné à la télévision sur Canal Brasil.

Résumé : Étude de la classe moyenne du Rio de Janeiro après le coup d'état de 1964. Le film s'appuie sur des témoignages d'étudiants, de parents, de fonctionnaires et de passants et focalise sur des sujets qui lui paraissent caractéristiques de la classe moyenne, les idoles de la jeunesse, le goût pour les phénomènes sensationnels, le mysticisme, la politique, les médias. En résumé, il est demandé à la classe moyenne qui elle est et ce qu'elle veut et il est montré qu'elle est doté d'une mentalité rétrograde et égoïste, et qu'elle n'aspire à rien d'autre qu'à un quotidien routinier avec un minimum de confort matériel. Certaines images utilisées proviennent du tournage de Maioria absoluta de Leon Hirszman.

\section{Terra em transe (Terre en transe)}

(Fiction, long métrage, noir et blanc, $115 \mathrm{~min}$ )

Réalisateur : Glauber Rocha

Production : Zelito Viana, Luiz Carlos Barreto, Carlos Diegues, Raimundo Wanderley et Glauber Rocha, Mapa Filmes et Difilm

Scénario : Glauber Rocha

Photographie : Luiz Carlos Barreto, caméra : Dib Lufti

Montage : Eduardo Escorel

Musique : O Guarani de Carlos Gomes, Bachianas 3 et 6 de Heitor Villa-Lobos, L'ouverture d'Othello de Verdi, Canto Negro Alué du Candomblé de Bahia, Samba de favela de Rio de Janeiro

Acteurs principaux : Jardel Filho, Paulo Autran, Glauce Rocha, José Lewgoy, Glauce Rocha, Paulo Gracindo, Danusa Leão

Distribution : Difilm

Note : Film visionné sur support vidéo, dvd : ROCHA, Glauber. Terra em transe. Rio de Janeiro, Grupo Novo de cinema e tv, Paloma Cinematográfica, 2005.

Résumé : Dans un pays fictif nommé Eldorado, le gouverneur Vieira est déposé par un coup d'État. Au moment où celui-ci, isolé dans son palais avec une poignée de proches, se résout à abdiquer, le journaliste Paulo Martins fait irruption pour l'exhorter à la résistance. Vieira le repousse et Paulo Martins quitte les lieux avec sa compagne qui est également journaliste. Atteint par une balle après avoir refusé de s'arrêter à un barrage de police, il commence à délirer et se souvient. Il se souvient qu'il a appuyé Vieira lors de sa campagne électorale, qu'il a cru aussi pouvoir convaincre Don Júlio Fuentes, le détenteur des mines, du pétrole, de la 
sidérurgie, de la presse et de la télévision, d'adopter une position progressiste, il se souvient même qu'il avait autrefois été proche de l'ennemi d'aujourd'hui, le sénateur Porfírio Diaz. Il réalise aussi que son ancien sentiment d'omnipotence était une illusion et que sa soif d'absolu s'identifie avec les tendances fascisantes et autoritaires de son père spirituel et actuel dictateur.

1968

1968

(Non-fiction, court métrage, noir et blanc, muet, $22 \mathrm{~min}$ )

Rio de Janeiro, 1968.

Réalisateurs : Glauber Rocha et Afonso Beato

Photographie et caméra : Afonso Beato

Note : Copie vidéo visionnée au Tempo Glauber.

Résumé : Images prises sur le vif lors de l'une des grandes manifestations de l'année 1968 au centre de Rio de Janeiro.

\section{Brasil verdade}

(non-fiction, film composé de quatre courts métrages produits en 1965, noir et blanc, durée totale : $130 \mathrm{~min}$ )

Production : Thomas Farkaz, Thomas Farkaz Produções Cinematográficas, Divisão Cultural do Ministério das Relações Exteriores, Setor de filmes documentários, Diretoria do Patrimônio Histórico e Artístico Nacional

Note : film visionné sur support vidéo, réédition séparée des quatre courts métrages sur plusieurs cassettes vhs produite par la Funarte.

\section{1- Memória do Cangaço}

Réalisateur : Paulo Gil Soares

Gérant de production : David Neves

Producteur exécutif : Edgardo Pallero

Scénario : Paulo Gil Soares

Photographie : Affonso Beato

Post-synchronisation et son direct : Paulo Gil Soares e Affonso Henriques Beato

Montage : João Ramiro Melo

Musique : Gilberto Gil

Résumé : Réalisé parallèlement au film Deus e o diabo na terra do sol de Glauber Rocha, le film commence par dénoncer un certain nombre de préjugés pesant sur l'homme du Nordeste 
pour ensuite évoquer le destin tragique des cangaceiros. Le major José Rufino qui a inspiré le personnage d'Antonio das Mortes est interrogé sur ses exploits de chasseur de cangaceiros. Des fragments d'images d'archives sont utilisés dont celles de Benjamin Abraão qui avait partagé l'intimité de la bande de Lampião en 1936.

\section{2- Nossa Escola de Samba}

Réalisateur : Manoel Horácio Gimenez

Scénario : Manoel Horácio Gimenez

Photographie : Alberto Salvá et Thomas Farkas

Montage : José Frade et Manoel Horácio Gimenez

Musique : Gilberto Gil

Résumé : La vie d'une école de samba à Rio de Janeiro, la préparation du Carnaval, le défilé, le retour à la vie quotidienne.

\section{3- Subterrâneos de futebol}

Réalisateur : Maurice Capovilla

Scénario : Maurice Capovilla et Armando Barreto sur un argument de Clarice Herzog

Texte : Celso Brandão

Photographie : Thomaz Farkas et Armando Barreto

Montage : Luiz Elias

Musique : Gilberto Gil

Acteurs principaux : Pelé, Vavá, Zózimo et Vincente Feola

Résumé : Dans les coulisses du sport préféré des brésiliens, nous découvrons qu'à l'instar de n'importe quel ouvrier, le joueur de football est un travailleur exploité, qui ne reçoit qu'une infime partie des bénéfices qu'il génère, subit des conditions de travail extrêmement dures et se retrouve rejeté sa courte carrière finie que ce soit victime de l'âge ou d'une blessure.

\section{4-Viramundo}

Réalisateur : Geraldo Sarno

Scénario : Geraldo Sarno

Photographie : Thomaz Farkas et Armando Barreto

Montage : Sylvio Renoldi et Roberto Santos

Musique : Caetano Veloso et José Carlos Capinam

Résumé : Documentaire sur l'arrivée massive à São Paulo, premier centre industriel de l'Amérique Latine, des immigrants en provenance de la zone rurale du Nordeste. Le film 
décrit les difficultés d'adaptation de ces personnes qui vont passer de la condition de paysans à celle d'ouvriers non qualifiés. Il est montré comment les utopies générées par la métropole moderne se mutent en douloureuses désillusions pour l'immigré et comment la culture du Nordeste transforme à son tour le paysage urbain.

\section{Capitu}

(Fiction, long métrage, noir et blanc, $105 \mathrm{~min}$ )

\section{Réalisateur : Paulo César Saraceni}

Production : Sérgio Saraceni, Produções Cinematográficas Imago, L.C. Barreto Produções Cinematográficas, Carlos Diegues Produções, Saga Filmes, Tekla Filmes, J.P. Produção Administração Cinematográfica

Financement : CAIC, BESP, BNMG

Scénario : Paulo César Saraceni, Emílio Sales Gomes, adaptation de Dom Casmurro de Machado de Assis

Photographie : Mário Carneiro

Montage : Nello Melli

Musique : Marcos Nobre

Acteurs principaux : Isabella, Othon Bastos, Marília Carneiro, Raul Cortez

Distribution : Difilm

Note : Film visionné à la télévision sur Canal Brasil.

Résumé : Au XIXe siècle, chronique d'un couple bourgeois. Bento et Capitu s'aiment depuis leur enfance et, arrivé à l'âge adulte, Bento renonce à la prêtrise à laquelle sa mère le destinait pour se marier avec son amie de toujours. Tout se passe pour le mieux jusqu'à la mort du meilleur ami de Bento. Ce dernier commence à douter de sa femme et réinterprète certains faits arrivés avant la mort de son ami. Il pense finalement que celui-ci était l'amant de sa femme et qu'il est le véritable père de l'unique enfant du couple. Il hésite entre le suicide et le meurtre de sa famille jusqu'à l'instant où il fait boire à son fils du café empoisonné.

\section{Câncer}

(Fiction, long métrage, noir et blanc, 86 min, le film n'est terminé qu'en 1972)

Réalisateur : Glauber Rocha

Production : Gianni Barcelloni, Mapa Filmes, RAI - Radiotelevisione Italiana

Scénario : Glauber Rocha

Photographie : Luiz Carlos Saldanha

Montage : Tineca \& Mireta 
Acteurs principaux : Odete Lara, Hugo Carvana, Antônio Pitanga, Eduardo Coutinho, Rogério Duarte, Hélio Oiticica, José Medeiros, Luiz Carlos Saldanha, Zelito Viana et les habitants de la favela de la Mangueira, Rio de Janeiro

Note : Copie vidéo visionnée au Tempo Glauber.

Résumé : Les errances, au travers de Rio de Janeiro, d'un marginal noir qui incommode les passants et autres personnages en les interpellant. Son comportement et les réactions qu'il suscite vérifient la force des préjugés raciaux et des préjugés sociaux, l'inégalité des chances et le caractère hypocrite d'une morale prétendument basée sur le respect du travail. Parallèlement, un couple de classe moyenne passe son temps à se répéter des platitudes faussement existentielles ou politiques. Finalement, sur une plage, le marginal rencontre le couple et séduit l'épouse.

\section{Fome de amor (Você nunca tomou banho de sol inteiramente nua?)}

(Fiction, long métrage, noir et blanc, $76 \mathrm{~min}$ )

Réalisateur : Nelson Pereira dos Santos

Production : Herbert Richers, Paulo Porto, Paulo Porto Produções Cinematográficas et Herbert Richers Produções Cinematográficas

Scénario : Nelson Pereira dos Santos et Luiz Carlos Ripper, inspiré de la nouvelle História para se ouvir de noite de Guilherme de Figueiredo

Photographie : Dib Lufti

Montage : Rafael Justo Valverde

Musique : Guilherme Magalhães Vaz

Acteurs principaux : Paulo Porto, Irene Stefânia, Leila Diniz, Arduíno Colossanti

Distribution : Herbert Richers Produções Cinematográficas

Note : Film visionné sur support vidéo, cassette vhs : SANTOS, Nelson Pereira dos. Fome de Amor. Sans indication de lieu, Manchete video, sans indication de date.

Résumé : Quatre personnages très différents sont réunis sur une île du littoral fluminense. Alfredo, sourd, aveugle et muet, à la suite d'un récent accident, est le propriétaire des lieux. C'est également un ancien guérillero, cet île est son refuge. Il est marié à la sensuelle Ula. Mariana est une jeune femme réservée qui étudie la musique concrète. Elle a été amené sur l'île par Felipe, son mari et son premier amour, qui lui a dit qu'il s'agissait là de sa propriété. Rapidement, surgissent entre les personnages des rapports de passion et de haine. Felipe et Ula deviennent amants et se moquent d'Alfredo qui ne peut ni les voir, ni les entendre, tandis que Mariana, au contraire, se rapproche de l'ancien révolutionnaire et partage peu à peu son isolement. À la fin, seule sur la plage, elle lit le petit livre rouge de Mao. 
Photographie : Dib Lufti

1969

Brasil ano 2000

(Fiction, long métrage, couleurs, $95 \mathrm{~min}$ )

Réalisateur : Walter Lima Júnior

Production : Luiz Carlos Barreto, Walter Lima Júnior, Glauber Rocha, José Alberto Reis, Claude Antoine, Produções Cinematográficas Mapa

Scénario : Walter Lima Júnior

Photographie : Guido Cosulich

Montage : Nello Melli

Musique : Rogério Duprat et Gilberto Gil

Acteurs principaux : Anecy Rocha, Hélio Fernando, Ênio Gonçalves, Manfredo Colossanti Note : Film visionné à la télévision sur Canal Brasil.

Résumé : En l'an 2000, une guerre nucléaire a balayé de la terre les grandes puissances mondiales. Le Brésil est toujours une dictature mais son territoire a été en grande partie amputé. Le Nord serait invivable du fait de la persistance des radiations. C'est dans ce contexte qu'une famille composée d'une mère, d'une jeune femme et d'un jeune homme décide, malgré le danger, d'émigrer vers le Nord. Ils s'installent dans une ville appelée « Je me suis oubliée ». L'agent du service de protection des indiens les engage car il n'a plus d'indiens et la ville attend la visite d'un général. Celui-ci vient assister au lancement d'une fusée spatiale mais, rien ne se passera comme prévu.

\section{O Bravo Guerreiro}

(Fiction, long métrage, noir et blanc, $80 \mathrm{~min}$ )

Réalisateur : Gustavo Dahl

Production : Gustavo Dahl, Joe Kantor, Gustavo Dahl Produções Cinematográficas, Joe Kantor Produções Cinematográficas et Saga Filmes

Scénario : Gustavo Dahl et Roberto Marinho de Azevedo

Photographie : Affonso Beato

Montage : Eduardo Escorel

Musique : Remo Usai

Acteurs principaux : Paulo César Pereio, Mário Lago, Ítalo Rossi, Maria Lúcia Dahl, Paulo

Gracindo

Distribution : Difilm 
Note : Film visionné à la télévision sur Canal Brasil.

Résumé : Un jeune député de l'opposition décide de quitter son parti. Il le juge trop minoritaire pour avoir une action efficace et veut intégrer le parti au pouvoir. Il pense en effet que c'est seulement en infiltrant le gouvernement qu'il pourra servir de façon décisive les intérêts du peuple. Au terme de négociations, il réussit à se faire accepter de ses nouveaux amis politiques mais réalise rapidement qu'il n'en est pas plus avancé. Parallèlement, un groupe ayant repris le projet de loi qui lui tient le plus à cœur menace la direction du syndicat à laquelle il était allié. Malgré l'avis de sa femme, il se rend sur place et raconte dans un long discours quel fut sa trajectoire politique. Il conclut qu'il n'est plus la personne la mieux indiquée pour défendre leurs intérêts. De retour chez lui, il se met un canon de revolver dans la bouche.

\section{O Dragão da maldade contra o santo guerreiro (Antonio das Mortes)}

(Fiction, long métrage, couleurs, $105 \mathrm{~min}$ )

Réalisateur : Glauber Rocha

Production : Glauber Rocha, Zelito Viana, Claude Antoine, Mapa Filmes

Scénario : Glauber Rocha

Photographie : Affonso Beato

Montage : Eduardo Escorel

Musique : Marlos Nobre, Walter Queiroz, Sérgio Ricardo, Luiz Gonzaga et Humberto Teixeira, Amorim Roxo et Zé Gonzaga, José Pacheco, thèmes populaires du Nordeste, interprétations de Maria Bethânia

Acteurs principaux : Maurício do Valle, Odete Lara, Othon Bastos, Maria Rosa Pena, Jofre Soares, Hugo Carvana

Distribution : Mapa Filmes

Note : Copie cinéma visionnée à la Cinémathèque de Toulouse.

Résumé : Bien des années après avoir tué Corisco, le dernier cangaceiro, Antônio das Mortes apprend qu'un nouveau cangaceiro, Coraina, a fait son apparition dans une ville nommée Jardim de Piranhas. Il décide d'aller sur place se rendre compte par lui-même. Il découvre une cité en proie à une vive agitation. Le cangaceiro est accompagné d'une sainte et d'un groupe de dévots, ils s'opposent au colonel des lieux qui est pris de folies des grandeurs mais vit dans un passé distant aujourd'hui décadent, le délégué de police nourrit des ambitions politiques et la femme du colonel, qui est aussi son amante, l'encourage à tuer son mari pour réaliser ses ambitions. Antônio, victime de ses concepts contradictoires de morale et de justice, s'oppose d'abord au cangaceiro qu'il blesse mortellement, mais pendant la longue agonie de celui-ci, il 
prend conscience en parlant avec la sainte, qu'il doit prendre le parti du peuple. Le colonel est tué par un noir porteur d'une lance, une troupe de jagunços attaquent la ville mais Antônio, allié à l'instituteur, les massacre. À peine vaincu, le dragon lui apparaît pourtant rapidement sous un nouveau visage. Ayant regagné la route, il se retrouve au milieu du trafic des camions et passe sous l'enseigne de la multinationale Shell.

\section{Os Herdeiros (Les Héritiers)}

(Fiction, long métrage, couleurs, $103 \mathrm{~min}$ )

Réalisateur : Carlos Diegues

Production : Luiz Carlos Barreto, Carlos Diegues Produções Cinematográficas, Produções Cinematográficas L.C. Barreto, J.B. Produções Cinematográficas, Novocine, INC - Instituto Nacional de Cinema

Scénario : Carlos Diegues, argument : Carlos Diegues, David Neves et Arnaldo Jabor

Photographie : Dib Lufti

Montage : Eduardo Escorel

Musique : Heitor Villa-Lobos et des chansons populaires des années trente aux années soixante : Carmen Miranda, Bing Crosby, César Ladeira, Francisco Alves, Dick Farney, Gregório Barros, Orlando Silva et Silas de Oliveira

Acteurs principaux : Sérgio Cardoso, Odete Lara, Grande Otelo, Paulo Porto, Isabel Ribeiro, Jean-Pierre Léaud

Distribution : Paramount Filmes do Brasil, Condor Filmes et Difilm

Note : Film visionné à la télévision sur Canal Brasil.

Résumé : Au cours de quarante années particulièrement mouvementées de l'histoire du Brésil, de la chute des barons du café au coup d'état militaire de 1964, en passant par la dictature de Getúlio Vargas et la construction de Brasília, les trahisons successives d'un journaliste opportuniste lui permette de gravir les échelons du pouvoir. Quand son fils est en âge de prendre sa succession, malgré une première et violente opposition de principe, il accepte d'assumer l'héritage du père et de reproduire son mode de domination.

\section{Macunaíma (Macunaíma)}

(Fiction, long métrage, couleurs, $108 \mathrm{~min}$ )

Réalisateur : Joaquim Pedro de Andrade

Production : K.M. Eckstein, Joaquim Pedro de Andrade, Filmes do Serro, Grupo Filmes, INC, Condor Filmes

Scénario : Joaquim Pedro de Andrade, adaptation du roman homonyme de Mário de Andrade 
Photographie : Guido Cosulich et Affonso Beato

Montage : Eduardo Escorel

Musique : Antônio Maria, Carlos Gomes, Geraldo Nunes, Sady Cabral, Tião Macalé, Lamartine Babo, Heitor Villa-Lobos, Orestes Barbosa, Roberto Carlos

Acteurs principaux : Grande Otelo, Paulo José, Milton Gonçalves, Dina Sfat, Jardel Filho

Narration : Tite de Lemos

Distribution : Difilm

Note : Film visionné à la télévision sur Canal Brasil.

Résumé : Macunaíma naît noir dans un village de la forêt tropicale. Paresseux, rusé et sensuel, il passe son temps à courir les filles et vivre au dépend des autres. Après plusieurs aventures où il rencontre des divinités de la forêt, il décide de quitter son village avec ses frères. En chemin, une fontaine magique le fait devenir blanc. La métamorphose lui apporte bien des avantages. Arrivé dans la grande ville, il séduit une femme guérillero et vit à son crochet dans un bel appartement. Il apprécie alors de tout le confort de la société de consommation. Bientôt pourtant, il rompt avec ce quotidien routinier et se met en tête de voler le talisman du géant Wenceslau Pietro Pietra. Pour sa première tentative, il se travestit en femme. C'est un échec. Pour sa seconde tentative, il porte un costume jaune et vert, les couleurs du Brésil, et parvient à précipiter le géant dans la feijoada géante, grouillante de piranhas à laquelle il devait en principe servir d'ingrédient. Le géant vaincu, Macunaíma perd pourtant le goût de vivre. Il retourne dans la forêt avec les oripeaux dont l'a revêtu la société de consommation et dont il se délaisse peu à peu. Seul dans son village, il cède aux appels de Iará, qui sous l'aspect d'une jolie jeune femme l'attire dans les eaux pour le dévorer.

\section{Memória de Helena}

(Fiction, long métrage, couleurs, $80 \mathrm{~min}$ )

Réalisateur : David Neves

Production : Júlio Bressane, David Neves, Filmes da Matriz, Produções Cinematográficas Mapa

Scénario : David Neves et Paulo Emílio Sales Gomes, inspiré du roman Minha Vida de menina de Helena Morley

Photographie : David Drew Zingg

Montage : João Ramiro Mello

Musique : Brahms, Beethoven, Grieg, Haendel

Acteurs principaux : Maria Rosa Pena, Arduíno Colossanti, Adriana Prieto, Joel Barcellos

Distribution : Servicine et U.C.B - União Cinematográfica Brasileira 
Note : Film visionné à la télévision sur Canal Brasil.

Résumé : Deux amis d'Helena, Renato et Rosa, se remémorent la vie de leur amie Helena au travers des films amateurs et du journal de l'adolescente. Ces documents leur permettent de comprendre l'isolement dont elle se ressentait dans sa petite ville de l'intérieur des Minas Gerais, le poids des conventions morales de son environnement provincial, ses amours déçues et sa lente et sûre descente vers un irrémédiable état de dépression.

1970

Os Deuses e os mortos (Les Dieux et les morts)

(Fiction, long métrage, couleurs, $100 \mathrm{~min}$ )

Réalisateur : Ruy Guerra

Production : César Thedim, Paulo José, Daga Filmes e Produções Cinematográficas, Grupo

Filmes, C.C.F.B - Companhia Cinematográfica de Filmes Brasileiros, Companhia Cinematográfica Vera Cruz

Scénario : Ruy Guerra, Paulo José, Flávio Império, argument : Ruy Guerra

Photographie : Dib Lufti

Montage : Ruy Guerra et Sérgio Sanz

Musique : Milton Nascimento

Acteurs principaux : Othon Bastos, Ítala Nandi, Norma Benguell, Ruy Polanah, Nelson Xavier, Dina Sfat

Distribution : Columbia Pictures do Brasil

Note : Cassette vhs visionnée au SBD de l'ECA.

Résumé : Dans les années trente, au moment de la crise du cacao, dans l'état de Bahia, se croisent les destins de plusieurs personnages qui sont à la fois les témoins et les victimes des luttes sanglantes que se livrent les grands colonels de la région. Entre ces personnages, surgit la figure de «Sept fois », un personnage mystérieux, sans passé et sans avenir, défiguré par les nombreuses blessures qu'il a déjà reçues. Obsédé par le pouvoir, il réussit au prix d'un véritable génocide à prendre le contrôle sur cette région, déjà hantée pourtant par les morts qui se montrent et puis se cachent. Mais quand il est enfin le maître, il s'aperçoit qu'il existe un empire encore plus grand que le sien, l'empire britannique, qui tire les ficelles et décide des prix du cacao et donc de toute l'activité économique et humaine de la région.

1971

Azyllo muito louco

(Fiction, long métrage, couleurs, ) 
Réalisateur : Nelson Pereira dos Santos

Production : Luiz Carlos Barreto, Nelson Pereira dos Santos, Roberto Farias, Produções Cinematográficas L.C. Barreto, Nelson Pereira dos Santos Produções Cinematográficas, Produções Cinematográficas R.F. Farias, Difilm

Scénario : Nelson Pereira dos Santos, adaptation du conte O Alienista de Machado de Assis

Photographie : Dib Lufti

Montage : Rafael Justo Valverde

Musique : Guilherme Magalhães Vaz

Acteurs principaux : Nildo Parente, Isabel Ribeiro, Arduino Colossanti, Irene Stefânia, Leila Diniz

Distribution : Ipanema Filmes

Note : Film visionné sur support vidéo, cassette vhs : SANTOS, Nelson Pereira dos. Azyllo muito louco. Rio de Janeiro, Riofilme, sans indication de date.

Résumé : Dans la province de Serafim, vit une population très dévote mais sans prêtre. Cette lacune est bientôt comblé avec l'arrivée du père Simão. Cependant, celui-ci semble bien plus préoccupé par la santé mentale de ses ouailles que par le salut de leurs âmes. Il fait construire un asile avec le concours d'une riche dame des lieux qui devient son bras droit. Puis, sans que quiconque n'ose s'opposer à son autorité, il fait interner de plus en plus de personnes, révisant à chaque fois ce qui lui semble être un comportement sain et ce qui ne l'est pas. Au bout d'un certain temps, tout le village est interné, nobles et paysans, et l'ordre public est compromis. Les nobles finissent par vouloir reprendre le contrôle de la situation, et, dans la plus grande confusion, de révolutions en contre-révolutions, on conclue finalement que le mieux est d'interner seulement l'aliéniste.

\section{Como era gostoso o meu francês (Qu'il était bon mon petit français)}

(Fiction, long métrage, couleurs, $83 \mathrm{~min}$ )

Réalisateur : Nelson Pereira dos Santos

Production : Luiz Carlos Barreto, Nelson Pereira dos Santos, César Thedim, K.M. Eckstein, Produções Cinematográficas L.C. Barreto, Condor Filmes

Scénario : Nelson Pereira dos Santos

Dialogue en Tupi : Humberto Mauro

Photographie : Dib Lufti

Montage : Carlos Alberto Camuyrano

Musique : Guilherme Magalhães Vaz et Zé Rodrix

Acteurs principaux : Arduíno Colossanti, Ana Maria Magalhães, Eduardo Embassahy Filho, 
Manfredo Colossanti

Narration : Célio Moreira

Distribution : Condor Filmes

Note : Film visionné sur support vidéo, cassette vhs : SANTOS, Nelson Pereira dos. Como era gostoso o meu francês. Rio de Janeiro, Riofilme, sans indication de date.

Résumé : Au XVIe siècle, un français nommé Jean est fait prisonnier par les indiens. Grâce à ses connaissances d'artilleur, il parvient à échapper à la mort, mais c'est seulement de façon temporaire. Les indiens ont déjà prévu quel jour il sera mangé. En attendant, il peut vivre normalement, on lui donne même une femme. Peu à peu, le jeune homme apprend les us et coutumes de la tribu et s'attache à la femme qui lui a été donnée. On lui dit aussi l'existence d'un trésor qu'il découvre avec l'aide d'un contrebandier. Celui-ci cherche alors à le trahir mais le français le tue. Ayant la possibilité de fuir, il invite sa compagne à venir avec lui. Elle refuse, il reste. La tribu gagne une bataille contre une tribu adverse. Jean est au menu du banquet de commémoration de cette victoire. Sa compagne se divertit beaucoup en mangeant une part de son petit français.

\section{Pindorama}

(Fiction, long métrage, couleurs, $95 \mathrm{~min}$ )

Réalisateur : Arnaldo Jabor

Production : Walter Hugo Khouri et Arnaldo Jabor, Companhia Cinematográfica Vera Cruz, Kâmera Filmes et Screem Gems do Brasil

Scénario : Arnaldo Jabor

Photographie : Affonso Beato

Montage : João Ramiro Mello et Arnaldo Jabor

Musique : Guilherme Magalhães Vaz

Acteurs principaux : Maurício do Valle, Ítala Nandi, Hugo Carvana, Wilson Grey, Jesus Pingo

Distribution : Columbia Pictures do Brasil

Note : Film visionné à la télévision sur Canal Brasil.

Résumé : Au XVIe siècle, Dom Sebastião fonde Pindorama, autrement dit la région des grands arbres. En raison des conditions de vie difficiles liées au climat, à la forêt et aux indiens, il décide cependant d'abandonner la colonie qui va ainsi usufruir une période de liberté. Mais, le roi ordonne bientôt à Dom Sebastião de réinvestir les lieux qu'il a quitté. Quand il revient, la situation a bien évolué et il se trouve le jouet de manipulations politiques. Finalement, ayant pris conscience de son impuissance vis à vis de la nouvelle situation, il 
devient fou.

1972

Os Inconfidentes

(Fiction, long métrage, couleurs, $100 \mathrm{~min}$ )

Réalisateur : Joaquim Pedro de Andrade

Production : Produções Cinematográficas Mapa, Filmes do Serro, Grupo Filmes

Scénario : Joaquim Pedro de Andrade et Eduardo Escorel, basé sur Autos da Devassa de Tomás Antônio Gonzaga, Cláudio M. Costa et Alvarenga Peixoto, et Romanceiro da Inconfidência de Cecília Meirelles

Photographie : Pedro de Moraes et Antônio Ventura

Montage : Eduardo Escorel

Musique : Ary Barboso, Antônio Carlos Jobim, Agustin Lara, João Gilberto

Acteurs principaux : José Wilker, Luiz Linhares, Paulo César Pereio, Fernando Torres, Carlos Kroeber

Distribution : Servicine

Note : Film visionné à la télévision sur Canal Brasil.

Résumé : Le film retrace l'histoire de la conspiration d'un groupe issu de l'élite des Minas Gerais, des religieux, des juges, des poètes et des militaires, pour libérer le Brésil du joug portugais. À l'intérieur de ce groupe, le plus décidé est Joaquim da Silva Xavier, également connu sous le nom de Tiradentes. C'est aussi celui dont le statut social est le moins prestigieux. Quand la conspiration est découverte, la prison et les tortures auxquelles sont soumis les différents membres du groupe les font renier leurs idéaux et reporter les torts sur Tiradentes. Devant la couardise généralisée, Tiradentes, qui fut le seul à conserver sa dignité, assume toutes les responsabilités et cherche à protéger ses anciens amis. Il est le seul à être condamné à mort. Les images de sa pendaison sont alternées avec des images des célébrations du 150e anniversaire de l'indépendance qui avait lieu à l'époque de la production.

\section{São Bernardo}

(Fiction, long métrage, couleurs, $110 \mathrm{~min}$ )

Réalisateur : Leon Hirszman

Production : Marcos Farias, Saga Filmes, Mapa Filmes, Produções Cinematográficas L.C. Barreto

Scénario : Leon Hirszman, adaptation du roman homonyme de Graciliano Ramos

Photographie : Lauro Escorel 
Montage : Eduardo Escorel

Musique : Caetano Veloso

Acteurs principaux : Othon Bastos, Isabel Ribeiro, Nildo Parente, Wanda Lacerda, Mário

Lago, Jofre Soares

Distribution : Embrafilme

Note : Film visionné sur support vidéo, cassette vhs : HIRSZMAN, Leon. São Bernardo. Pas d'indication de ville, Globo Vídeo, pas d'indication de date.

Résumé : Dans l'état d'Alagoas, Paulo Honório est un humble vendeur ambulant qui travaille énormément et épargne sous après sous. Il a une obsession, arracher la ferme de São Bernardo à son propriétaire, ultime descendant d'une famille de grands propriétaires fonciers, qui dilapide ses biens au jeu et laisse la ferme improductive. Pour réussir à posséder cette ferme qu'il est loin de pouvoir acheter, Paulo Honório devient l'ami de son propriétaire et lui prête de l'argent. Le moment venu, il exige le remboursement de ses prêts et s'empare de la ferme qu'il fait ensuite prospérer par l'astuce et la violence. Craint de ses voisins et de ses employés, Paulo Honório pense qu'il est temps pour lui de se marier. Il réussit à convaincre une institutrice gauchiste qui lui semble représenter un certain idéal d'élégance et d'érudition. Mais celle-ci supporte mal la rudesse de son mari et Paulo Honório a vite le sentiment qu'elle le trahit physiquement et politiquement. Dévoré par une jalousie obsessive, contrarié dans son unique mode de relation au monde : la possession, Paulo Honório perd de plus en plus souvent son sang-froid et accuse sa femme ouvertement. Madalena se suicide et lui échappe pour toujours. Déprimé, solitaire et rongé par le doute, Paulo Honório écrit ses mémoires.

\section{Uirá, um índio em busca de Deus}

(Fiction, long métrage, couleurs, $90 \mathrm{~min}$ )

Réalisateur : Gustavo Dahl

Production : Alter Filmes, TV RAI (Italie)

Scénario : Gustavo Dahl, argument : Darcy Ribeiro

Photographie : Rogerio Noel

Montage : Gilberto Santeiro

Musique : Gustavo Dahl

Acteurs principaux : Ana Maria Magalhães, Érico Vidal, Gustavo Dahl, João Borges

Distribution : Embrafilme

Note : Film visionné à la télévision sur Canal Brasil.

Résumé : En 1939, un indien tourmenté par la mort de son fils quitte son village avec femme et enfants afin de retrouver Maira, la créatrice du monde, qu'il sait vivre par-delà les rivières. 
Sur son chemin, il rencontre des éléments de la société blanche qui ne vont pas tarder à interférer dans son voyage. Fait prisonnier suite à une altercation avec des paysans, Uirá est pris en charge par un agent du SPI - Serviço de Proteção do Índio, qui ne comprend pas plus que les autres les raisons de son voyage. Malgré le fait qu'il ait alors retrouvé sa famille et qu'il soit bien traité, Uirá fuit le zèle colonisateur des blancs pour continuer sa quête. Arrivé auprès d'une rivière, après avoir fait ses adieux à sa famille, il s'immerge dans les eaux, pensant sans doute par la mort, réussir à pénétrer le domaine de Maira.

\section{4}

Cabra marcado prá morrer

(non-fiction, long métrage, noir et blanc et couleurs, $119 \mathrm{~min}$ )

Réalisateur : Eduardo Coutinho

Production : Produções Cinematográficas Mapa, Eduardo Coutinho Produções Cinematográficas

Scénario : Eduardo Coutinho

Photographie : Fernando Duarte (1964), Edgard Moura (1981)

Montage : Eduardo Escorel

Musique : Rogério Rossini

Acteurs principaux : Elizabeth Teixeira, ex-présidente de la ligue paysanne de Sapé et sa famille, João Virgínio Silva et les habitants de la plantation Galiléia

Narration : Ferreira Gullar, Tite de Lemos et Eduardo Coutinho

Note : Film visionné à la télévision sur Canal Brasil.

Résumé : En 1964, Eduardo Coutinho est en train de filmer l'histoire de João Pedro Teixeira, leader paysan assassiné sur ordre de grands propriétaires du Nordeste. Le tournage a lieu sur les lieux du drame avec les paysans qui participèrent des événements. Il est interrompu par le coup d'état militaire. 17 ans plus tard, Eduardo Coutinho part à la recherche des protagonistes de l'histoire afin de savoir ce qu'ils sont devenus et de leur montrer les rushes du film inachevé. Il découvre notamment que Elizabeth Teixeira, qui était l'épouse de João Pedro Teixeira, a été contrainte à vivre dans la clandestinité, perdant le contact et la reconnaissance d'une partie de ses nombreux enfants. Malgré les persécutions dont elle a été victime, elle montre qu'elle n'a ni renié ses convictions, ni perdu sa combativité.

\section{Filmographie abrégée}


ANDRADE, Joaquim Pedro de. O Mestre de Apipucos. Saga filmes, 8 min, 1959.

ANDRADE, Joaquim Pedro de. O Poeta do castelo. Saga filmes, 10 min, 1959.

ANDRADE, Joaquim Pedro de. Guerra conjugal. Joaquim Pedro de Andrade, I.C.B Indústria Cinematográfica Brasileira et Filmes do Serro, 90 min, 1974.

ANDRADE, Joaquim Pedro de. O Homem do pau-brasil. Filmes do Serro, Lynx Filmes, Embrafilme, 112 min, 1981.

BARRETO, Lima. O Cangaceiro. Companhia Cinematográfica Vera Cruz, 90 min, 1953.

BARRETO, Lima. Painel. Alberto Cavalcanti / Companhia Cinematográfica Vera Cruz, 17 $\min , 1950$.

BARRETO, Lima. Santuário. Alberto Cavalcanti / Companhia Cinematográfica Vera Cruz, $10 \mathrm{~min}, 1952$.

BRESSANE, Júlio. Matou a família e foi ao cinema. Júlio Bressane, Belair Filmes et Júlio Bressane Produções Cinematográficas, 85 min, 1968.

BRESSANE, Júlio. O Anjo nasceu. Júlio Bressane, 82 min, 1969.

CAPOVILLA, Maurice. O Profeta da fome. Odécio Lopes dos Santos, Fotograma Produtora e Distribuidora de Filmes, 93 min, 1970.

CAVALCANTI, Alberto. O Canto do mar. Alberto Cavalcanti, Kino Filmes, 124 min, 1954.

D'ALMEIDA, Neville. Jardim de guerra. J.P. Carvalho, Neville D'Almeida, Neville Duarte D'Almeida Produções Cinematográficas, J.P. Produções Cinematográficas et Tekla Filmes, $100 \min , 1968$.

DIEGUES, Carlos. Quando o carnaval chegar. Carlos Diegues, Produções Cinematográficas Mapa, 98 min, 1972.

DIEGUES, Carlos. Bye-bye Brasil. Luiz Carlos Barreto, Produções Cinematográficas L.C.Barreto, $110 \mathrm{~min}, 1979$.

DIEGUES, Carlos. Joanna Francesa. Ney Slourevich, Pierre Cardin, Zoom Cinematográfica, $113 \min , 1973$.

DIEGUES, Carlos. Quilombo. Augusto Arraes, CDK Filmes et Embrafilme, 119 min, 1984.

DIEGUES, Carlos. Xica da Silva. Jarbas Barbosa, Terra Filmes, 117 min, 1976.

DUARTE, Anselmo. Absolutamente certo. Oswaldo Massaini, 95 min, 1957.

ESCOREL, Eduardo. Lição de amor. Luiz Carlos Barreto, Eduardo Escorel, Produções Cinematográficas L.C. Barreto, Corisco Filmes, 80 min, 1974.

FARIAS, Roberto. Toda Donzela tem um pai que é uma fera. John Herbert, Produções

Cinematográficas L.C. Barreto et Produções Cinematográficas R. F. Farias, 101 min, 1966.

FARIAS, Roberto. Roberto Carlos em ritmo de aventura. Roberto Farias, Produções Cinematográficas R.F. Farias, 90 min, 1968. 
HIRSZMAN, Leon. Eles não usam black-tie. Leon Hirszman, Leon Hirszman Produções Cinematográficas, Embrafilme, 134 min, 1981.

JABOR, Arnaldo. Eu te amo. Walter Clark, Flávio Tavares Filmes, 110 min, 1980.

JABOR, Arnaldo. O Casamento. Paulo Porto, Ventania Produções Cinematográficas, Sagitário Filmes et Produções Cinematográficas R.F., 110 min, 1975.

JABOR, Arnaldo. Toda nudez será castigada. Paulo Porto, Ventania Produções Cinematográficas, Produções Cinematográficas R.F. Farias, 107 min, 1973.

JABOR, Arnaldo. Tudo bem. Arnaldo Jabor, Arnaldo Jabor Produções Cinematográficas, Sagitarius Produções Cinematográficas, Embrafilme, 110 min, 1978.

LIMA JÚNIOR, Walter. A Lira do delírio. Walter Lima Júnior, Walter Lima Júnior Produções Cinematográficas, Produções Cinematográficas R.F. Farias, Embrafilme, 105 min, 1977.

MANGA, Carlos. Nem Sansão nem Dalilah. Atlântida cinematográfica, 88 min, 1954.

MAURO, Humberto. Argila. Carmen Santos / Brasil Vita filmes, 103 min, 1940.

MAURO, Humberto. Brasa dormida. Agenor Cortes de Barros, Homero Cortes Domingues et Phebo-Sul América filmes, 120 min, 1928.

MAURO, Humberto. Ganga bruta. Adhemar Gonzaga, Cinédia et Saturnino da Silva, 85 min, 1933.

MAURO, Humberto. Lábios sem beijo. Adhemar Gonzaga et Cinédia, 53 min, 1930.

MAURO, Humberto. O Descobrimento do Brasil. Alberto Campiglia, Brazilia filme et Instituto de Cacau da Bahia, 62 min, 1936.

MAURO, Humberto. Sangue mineiro. Agenor Cortes de Barros, Homero Cortes Domingues, Carmen Santos et Phebo Brasil Filme, 82 min, 1929.

MAURO, Humberto. Tesouro perdido. Agenor Cortes de Barros, Homero Cortes Domingues et Phebo-Sul América filmes, 50 min, 1927.

PAYNE, Tom. Sinhá moça. Edgar Batista Pereira et Companhia Cinematográfica Vera Cruz, $105 \min , 1953$.

PEIXOTO, Mário. Limite. Mário Peixoto, 120 min, 1931.

PIRES, Roberto. Máscara da traição. Zelito Viana, Produções Cinematográficas Mapa, 95 $\min , 1968$.

ROCHA, Glauber. Cabezas cortadas. José Antonio Perez Giner et Modesto Peres Redondo, Barcelona Profilmes (Barcelone), Filmes Contacto (Espagne), et Mapa Filmes, 95 min, 1970. ROCHA, Glauber. Claro. Alberto Marrucchi, Marco Tamburella, DPT-SPA, 110 min, 1975. ROCHA, Glauber. Der Leone have sept cabeças. Gianni Barcelloni, Claude Antoine, Mapa Filmes, Polifilm (Rome), 95 min, 1970. 
ROCHA, Glauber. Di Cavalcanti. Embrafilme, 18 min, 1977.

ROCHA, Glauber. História do Brasil. Benzo Rosselini, ICAIC - Instituto Cubano de Arte e Indústria Cinematográfica, Tricontinental, 166 min, 1974.

ROCHA, Glauber. A Idade da terra (L'Âge de la terre). Glauber Rocha, Glauber Rocha Produções Artísticas, CPC Filmes, Filmes 3 et Embrafilme, 134 min, 1980.

ROCHA, Glauber. O Pátio. 11 min, 1959.

SANTOS, Nelson Pereira dos. Boca de ouro. Jarbas Barbosa, Gilberto Perrone, Copacana Filmes, Inbracine Filmes et Fama Filmes, 102 min, 1963.

SANTOS, Nelson Pereira dos. El Justicero (O Rei da farsa e da fossa). Condor Filmes, 80 $\min , 1966$.

SANTOS, Nelson Pereira dos. Mandacaru vermelho. Nelson Pereira dos Santos et Danilo Trelles, Nelson Pereira dos Santos produções cinematográficas et Danilo Trelles (Uruguai), $76 \min , 1961$.

SANTOS, Nelson Pereira dos. Rio, quarenta graus. Nelson Pereira dos Santos, Ciro Freire Curi, Equipe Moacyr Fenelon, 97 min, 1955.

SANTOS, Nelson Pereira dos. Rio, zona norte. Nelson Pereira dos Santos, Ciro Freire Curi, Roberto Santos et Nelson Pereira dos Santos produções cinematográficas, 86 min, 1957.

SANTOS, Nelson Pereira dos. Who is Bêta? (Qui est Bêta ?). Regina Filmes, Desenfilmes, M.F. Produções, Dahlia Film (Paris), 1972.

SANTOS, Nelson Pereira dos. Amuleto de Ogum. Nelson Pereira dos Santos, 117 min, 1974.

SANTOS, Nelson Pereira dos. Memórias do cárcere. Lucy, Luiz Carlos Barreto, Nelson Pereira dos Santos, Produções Cinematográficas L.C.Barreto, Regina Filmes et Embrafilme, $197 \min , 1984$.

SANTOS, Roberto. O Grande Momento. Nelson Pereira dos Santos, Mario Marinho, Roberto Santos et Nelson Pereira dos Santos produções cinematográficas, 80 MIN, 1958.

SARACENI, Paulo César. A Casa assassinada. Sérgio Saraceni, Paulo César Saraceni, Mário Carneiro, Planiscope Filme, 103 min, 1971.

SARACENI, Paulo César. Amor, carnaval e sonhos. Luiz Severiano Ribeiro, Planiscope Filmes, Atlântida Cinematográfica, 80 min, 1960.

SARACENI, Paulo César. Anchieta, José do Brasil. Paulo César Saraceni et Sérgio Saraceni, Santana Filmes et Embrafilme, 150 min, 1978.

SARACENI, Paulo César. Ao sul do meu corpo. Sant'Anna Filmes, Embrafilme, 102 min, 1982.

SINDICATO DOS TRABALHADORES DA PRODUÇÃO DE CINEMA E TELEVISÃO (collectif comprenant Glauber Rocha). As Armas e o povo. Sindicato dos Trabalhadores da 
Produção de Cinema e Televisão (Lisbonne), 80 min, 1974.

SGANZERLA, Rogério. O Bandido da luz vermelha. José da Costa Cordeiro, José Alberto dos Reis, Rogério Sganzerla et Urânio Filmes, 92 min, 1968.

SGANZERLA, Rogério. A Mulher de todos. Alfredo Palácios, Rogério Sganzerla, Servicine, Rogério Sganzerla Produções Cinematográficas, 93 min, 1969. 


\section{SOURCES ET BIBLIOGRAPHIE}

\section{Archives}

\subsection{Archives privées de Claude Antoine (Bize Minervois, France)}

\subsubsection{Contrats}

Antonio das Mortes. Certificats de dépôt de manuscrit, certificat d'auteur, contrats de coproduction, convention avec l'ORTF, factures de l'ORTF, certificat de la censure brésilienne, contrats de distribution,

Barravento. Certificat d'auteur, contrat de mandataire de vente, contrats de distribution.

Brasil ano 2000. Contrat de co-production, contrat de mandataire de vente, contrats de distribution.

Câncer. Contrat de mandataire de vente, contrats de distribution.

O Circo. Certificat d'auteur.

Cabezas cortadas. Contrats de mandataire de ventes, contrat de mandataire de vente, contrats de distribution, contrat de cession des droits télévision, câble, CATV, télévision payante, contrat de cession forfaitaire des droits, contrat pour diffusion télévisée.

Deus e o diabo na terra do sol. Certificat d'auteur, contrats de mandataire de vente, contrats de distribution, contrat de cession forfaitaire des droits, contrat pour diffusions télévisées.

A Falecida. Contrat de mandataire de vente, contrat de distribution.

Os Fuzis. Certificat d'auteur, contrat de mandataire de vente, contrats de distribution, mandats de distribution, contrat pour diffusions télévisées.

Ganga Zumba. Contrat de distribution.

A Grande Cidade. Contrat de distribution.

História do Brasil. Contrat de mandataire de vente.

Iracema. Contrats de distribution.

Le Lion a sept têtes. Contrat de co-production, protocoles d'accord avec les autorités du Congo, contrat de producteur exécutif, certificat d'auteur, contrats de financement, cession gracieuse des droits d'exploitation de trois films de Glauber Rocha au Congo-Brazzaville, contrats de distribution, bordereaux au producteur des Cinémas Associées, contrat de cession des droits télévision, câble, CATV, télévision payante. 
Macunaíma. Contrat de mandataire de vente, contrats de distribution.

Memória de Helena. Contrat de mandataire de vente, contrats de distribution.

Menino de engenho. Contrat de mandataire de vente, contrats de distribution.

A Noite do espantalho. Contrat de mandataire de vente.

A Opinião pública et $O$ Circo. Contrats de distribution, contrat pour une diffusion télévisée.

Terra em transe. Certificat d'auteur, contrat de mandataire de vente, mandats de distribution, cession au forfait, contrat de distribution, facture du lavandère.

\subsubsection{Correspondance}

Lettre de Telepool à Claude Antoine. Munich, 19/01/1968.

Lettre de Telepool à Claude Antoine. Munich, 26/01/1968.

Cable de l'ORTF à Claude Antoine. Paris, 17/02/1968.

Lettre de Produzioni Atlas Cinematografica à Claude Antoine. Sans lieu, 04/06/1969.

Lettre de Grove Press à Claude Antoine. New York, 16/07/1969.

Lettre de Glauber Rocha à Claude Antoine. Sans lieu, 12/08/1969.

Lettre de Produzioni Atlas Cinematografica à Claude Antoine. Sans lieu, 12/08/1969.

Lettre de Produzioni Atlas Cinematografica à Claude Antoine. Sans lieu, 01/09/1969.

Lettre de Sandrew Film \& Teater à Claude Antoine. Stockholm, 10/09/1969.

Lettre de l'ORTF à Claude Antoine. Paris, 16/09/1969.

Lettre de Produzioni Atlas Cinematografica à Claude Antoine. Sans lieu, 12/01/1970.

Lettre de Profilmes à Claude Antoine. Barcelone, 03/07/1970.

Lettre de Gianni Barcelloni à Claude Antoine. Rome, 1970/72.

Lettre des Cinémas Associés à Claude Antoine. Sans lieu, 18/01/1971.

Lettre de Polifilm à Claude Antoine. Rome, 22/02/1971.

Lettre de la Société Générale de Travaux Cinématographiques, GTC, à Claude Antoine, Joinville le Pont, O5/07/1973.

Lettre de Claude Antoine à la Société Générale de Travaux Cinématographiques, GTC, Paris, 13/07/1973.

Lettre de la Société Générale de Travaux Cinématographiques, GTC, à Claude Antoine, Joinville le Pont, 23/07/1973.

Lettre de Grove Press à Claude Antoine. New York, 19/07/1979.

Lettre de Grovepress à Claude Antoine avec bilan des recettes pour Antonio das Mortes. New York, 04/09/1979.

Lettre de Herbert Kloiber à Claude Antoine. Cannes, 23/05/1981 . 
Lettre de Connoisseur Films à Claude Antoine. Londres, 20/07/1981.

Télex de Claude Antoine à Celso Amorim. Sans lieu, après la mort de Glauber Rocha, 1981.

Lettre de Connoisseur Films à Claude Antoine. Londres, 05/11/1981.

Lettre de Connoisseur Films à Claude Antoine. Londres, 29/01/1981.

Lettre de Telepool à Claude Antoine. Munich, 25/05/1982.

Lettre de Claude Antoine à Telepool. Paris, 22/06/1982.

Lettre de Connoisseur Films à Claude Antoine. Londres, 16/11/1982.

Lettre de la Direction Générale du CNC à Claude Antoine, 01/12/1983.

Lettre de The Other Cinema à Claude Antoine. Londres, 17/01/1984.

Lettre de Claude Antoine à Marin Karmitz avec récapitulatif des droits pour Antonio-dasMortes, Le Dieu noir et le diable blond, Terre en transe et Les Fusils, St Ouen, 24/12/1986.

\subsubsection{Matériel publicitaire}

Antonio das Mortes. Press release, Festival de Cannes 1969.

Cabezas cortadas. Lettre de présentation de Glauber Rocha, Barcelone, mai 1970.

Le Lion a sept têtes. Présentation des Cinémas Associés, sans date.

Menino de engenho. Press release brésiliens (2), sans date.

Terre en transe. Press release, Festival de Cannes 1967.

\subsubsection{Autre}

ANTOINE, Claude. État des ventes. Cahier manuscrit comprenant le récapitulatif des ventes réalisées par film, sans date.

ANTOINE, Claude et ROCHA, Glauber. L'Empire de Napoléon. Synopsis, Sintra, juillet 1981.

LHERM, Dedy. Liste de copies de films, sans date.

LHERM, Dedy. Antonio-das-Mortes. Récapitulatif des ventes de 1969 à 1994, sans date.

LHERM, Dedy. Le Lion a sept têtes. Récapitulatif des ventes de 1970 à 1985, sans date.

ROCHA, Glauber. O Império de Napoleão (L'Empire de Napoléon). Synopsis, Sintra, 1981.

Antonio das Mortes. Fiche technique, sans date.

Antonio das Mortes. Préface, interprètes et résumé, sans date.

Cabezas cortadas. Fiche technique, sans date.

Macunaíma. Textes de présentation, sans date. 
1.2 Arquivo Edgard Leunroth (Instituto de Filosofia e Ciências Humanas, Universidade de Campinas)

Consultation du catalogue des archives privées de Leon Hirszman.

Synopsis de Que viva América, Tiradentes et BR-480.

\subsection{Arquivo estadual do Rio de Janeiro, Fonds " Polícias políticas no Rio de Janeiro "}

Prontuário de Glauber Rocha.

Documents répondant aux entrées :

- Cinema Novo, CPC, Difilm, Embrafilme, INC, Mapa Filmes, Censura, Serviço de Censura das Diversões Públicas - SCDP ;

- Ricardo Cravo Albim, Joaquim Pedro de Andrade, Claude Antoine, Luiz Carlos Barreto, Livio Bruni, Maurice Capovilla, Arnaldo Carrilho, Eduardo Coutinho, Gustavo Dahl, Carlos Diegues, Roberto Farias, Ruy Guerra, Leon Hirszman, Walter Lima Jr, Luís Sérgio Person, Glauber Rocha, Nelson Pereira dos Santos, Paulo César Saraceni, Zelito Viana ;

- Brasil ano 2000, Cabra marcado para morrer, O Caso dos irmãos Naves, Cinco vezes favela, O Desafio, Os Herdeiros, A Idade da terra, Maioria absoluta, Macunaíma, São Bernardo, Terra em transe.

1.4 Arquivo nacional - COREG DF (Brasília), Fonds « Divisão de Censura de Diversões Públicas - DCDP, Seção Censura Prévia, Série Cinema, Subséries Filmes e programação cinematográfica »

Dossiers correspondants à tous les films de la bibliographie.

Dossiers « Cursos », « Informações sigilosas » et « Ofícios de solicitação »

\subsection{Cinemateca Brasileira (São Paulo)}

\subsubsection{Textes}


ANDRADE, João Batista de. Vidas secas. Fiche technique de la Cinemateca brasileira, São Paulo, 1965.

BERNARDET, Jean-Claude. Aruanda. Fiche technique de la Cinemateca brasileira, São Paulo, 1962.

BERNARDET, Jean-Claude. Sans titre. Étude de 8 succès du cinéma brésilien, 13 pages, sans date.

BERNARDET, Jean-Claude. Bernardet e Trigueirinho Neto. Entrevue, 10 pages, 1986.

DEHEINZELIN, Jacques. Situação econômica e financeira do cinema nacional. Prefeitura do município de São Paulo, Secretaria de Educação e cultura, Comissão municipal de cinema, 1955.

GUERRA, Ruy. Los Espectros interiores : Entrevista con René Capriles Farfán. Original d'un texte pour Hablemos del cine, décembre 1970.

PERSON, Luis Sérgio. Person fala sobre São Paulo S.A. e sobre Person. Centro Dom Vital, Sociedade Amigos da Cinemateca, São Paulo, 1965.

SANTOS, Nelson Pereira dos. O Problema do conteúdo do cinema brasileiro : Tese apresentada no I Congresso Paulista do Cinema Brasileiro.

SILVA, J.A. Pereira da. Bahia de todos os santos. Fiche technique de la Cinemateca brasileira, São Paulo, 1962.

VIANY, Alex. A Jovem Mentalidade dos produtores. 5 pages, sans date.

1.5.2 Synopsis, scénarii, transcription de dialogues

PERSON, Luis Sérgio et BERNARDET, Jean-Claude. A Hora dos ruminantes. São Paulo, juillet 1967.

ROCHA, Glauber. Garota de Ipanema. Scénario accompagné d'une lettre d'Eduardo Coutinho à la cinémathèque, 25 pages, sans date.

Maioria absoluta. Dialogues du film, 6 pages, sans date.

São Bernardo. Dialogues de la bande-annonce, sans date.

\subsubsection{Matériel publicitaire}

Bahia de todos os santos. Press release, São Paulo, juillet/août 1960.

Barravento. Annonce dans O Estado de São Paulo, 29/09/1967.

Bebel, garôta-propaganda. Press release, sans date.

Brasil ano 2000. Press release, 1969. 
Brasil ano 2000. Annonce dans la presse, sans date.

Brasil verdade. Annonce dans O Estado de São Paulo, 15/09/1968.

Brasil verdade. Press release, sans date.

O Bravo Guerreiro. Annonce dans O Estado de São Paulo, 11/05/1969.

O Bravo Guerreiro. Press release, sans date.

Os Cafajestes. Annonce dans O Estado de São Paulo, 24/05/1962.

A Cartomante. Press release, sans date.

O Caso dos irmãos Neves. Annonce dans O Estado de São Paulo, 23/06/1967.

O Caso dos irmãos Neves. Press release (2), sans date.

Cinco vezes favela. Press release, sans date.

Cinco vezes favela. Invitation à l'avant-première, São Paulo, 22/03/?.

A Falecida. Annonces dans O Estado de São Paulo, 27/11/1965 et 02/12/1965.

Fogo morto. Press release (2), sans date.

Fome de amor. Annonce dans O Estado de São Paulo, 18/08/1968.

Garota de Ipanema. Press relase, sans date.

Garota de Ipanema. Annonces dans O Estado de São Paulo, 05/01/1968 et 26/01/1968.

Garrincha alegria do povo. Annonce dans O Estado de São Paulo, 18/10/1964.

A Grande Cidade. Press release, sans date.

A Grande Feira. Annonces (2) dans la presse, sans date.

A Grande Feira. Article dans la revue professionnelle $O$ Exibidor, n 90 , année VII, août 1961.

Os Herdeiros. Press release, 1969.

Macunaíma. Photos publicitaires, sans date.

Macunaíma. Press release, 1979.

Menino de engenho. Annonce dans O Estado de São Paulo, 10/07/1966.

A Opinião pública. Annonce dans O Estado de São Paulo, 26/09/1967.

O Profeta da fome. Press release, sans date.

São Bernardo. Press release (2), sans date.

Terra em transe. Annonce dans O Estado de São Paulo,18/05/1969.

Vidas secas. Affichette, sans date.

Vidas secas. Annonces dans O Estado de São Paulo, 10/05/1967 et 09/05/1967.

Viramundo. Press release, sans date. 


\subsection{Cinemateca do Museu de Arte Moderna (Rio de Janeiro)}

\subsubsection{Matériel publicitaire}

Assalto ao trem pagador. Press release, sans date.

Bebel garôta propaganda. Annonce dans la presse, sans date.

Como era gostoso o meu francês. Annonces (2) dans la presse, janvier 1972.

Como era gostoso o meu francês. Press release (2), sans date.

O Desafio. Press release, sans date.

Deus e o diabo na terra do sol. Annonce dans la presse, sans date.

Fome de amor. Annonce dans la presse, sans date.

O Pagador de promessa. Press release, sans date.

O Pagador de promessa. Annonce dans A Folha de São Paulo, 26/08/1962.

Macunaíma. Annonce dans la presse, sans date.

MAPA Filmes. Plaquettes (2) destinées aux exploitants de salles, 1969.

\subsubsection{Synopsis, scénarii}

ANDRADE, Joaquim Pedro de. O Herói sem caráter : Adaptação para o cinema do livro Macunaíma de Mário de Andrade, segundo tratamento. Texte dactylographié, 57 pages, sans date.

ANDRADE, Joaquim Pedro de, ESCOREL, Eduardo. Inconfidência mineira : Diálogos feitos com material dos Autos da Devassa e versos de Claudio Manoel da Costa, Tomás Antônio Gonzaga, Alvarenga Peixoto e Cecilia Meireles. Texte dactylographié, 48 pages, sans date.

JABOR, Arnaldo. Pindorama. Texte dactylographié avec plusieurs annotations manuscrites, 139 pages, sans date.

ROCHA, Glauber. América nuestra. Texte dactylographié, 43 pages, Rio de Janeiro, avril 1966.

ROCHA, Glauber. O Descobrimento do Brasil. Texte dactylographié, 13 pages, sans date (probablement 1975/1976).

\subsubsection{Autres}

Assalto ao trem pagador. Résumé du budget prévu pour le film, 1 page, sans date.

Boletim informativo SIP : Anuário de 1973. INC/MEC, ano III, 1974. 
Boletim informativo SIP : Anuário de 1974. INC/MEC, ano IV, 1975.

\subsection{Biblioteca Jenny Klabin Segall (São Paulo)}

GREMIO FAU. Cinema Novo. São Paulo.

SANTOS, Nelson Pereira dos et alii. Manifesto para um cinema popular. Rio de Janeiro, Federação dos Cineclubes do Rio de Janeiro, Cineclube Macunaíma, Cineclube Gláuber Rocha, mars 1975.

\subsection{Tempo glauber (Rio de Janeiro)}

\subsubsection{Correspondance inédite}

Lettre de Paulo César Saraceni à Glauber Rocha. Rio de Janeiro, 12/01/1962.

Lettre de Carlos Diegues à Glauber Rocha. Rio de Janeiro, 02/01/1963.

Lettre de Carlos Diegues à Glauber Rocha. Rio de Janeiro, 15/01/1963.

Lettre de Carlos Diegues à Glauber Rocha. Rio de Janeiro, 14/03/1963.

Lettre de Carlos Diegues à Glauber Rocha. Rio de Janeiro, 21/03/1963.

Lettre de Carlos Diegues à Glauber Rocha. Rio de Janeiro, 31/03/1963.

Lettre de Gustavo Dahl à Glauber Rocha. Paris, 03/05/1963.

Lettre de Carlos Diegues à Glauber Rocha. Rio de Janeiro, 08/07/1963.

Lettre de Carlos Diegues à Glauber Rocha. Rio de Janeiro,30/07/1963.

Lettre de Carlos Diegues à Glauber Rocha. Rio de Janeiro, 21/08/1963.

Lettre de Claude Antoine à Glauber Rocha. Paris, 10/08/1964.

Lettre de José Luiz de Magalhães Lins à Glauber Rocha. Rio de Janeiro, 18/10/1965.

Lettre de Carlos Diegues à Glauber Rocha. Paris, 08/10/1966.

Lettre de Claude Antoine à Glauber Rocha. Paris, 23/09/1966.

Lettre de Walter Lima Jr à Glauber Rocha. Paris, 27/09/1966.

Lettre de Claude Antoine à Glauber Rocha. Paris, 28/09/1966.

Lettre de Claude Antoine à Glauber Rocha. Paris, 30/11/1966.

Lettre de Claude Antoine à Glauber Rocha. Paris, 03/01/1967.

Lettre de Gustavo Dahl à Glauber Rocha. Paris, 20/06/1967.

Lettre de Eduardo Escorel à Glauber Rocha. Rio de Janeiro, 31/07/1967. 
Lettre de Walter Lima Jr à Glauber Rocha. Rio de Janeiro, 12/09/1967.

Lettre de Telepool à Claude Antoine. Munich, 19/01/1968.

Lettre de Walter Lima Jr à Glauber Rocha. Parati, 29/01/1968.

Lettre de Carlos Diegues à Glauber Rocha. Rio de Janeiro, 20/04/1968.

Lettre de Zelito Viana à Glauber Rocha. Rio de Janeiro, 20/04/1968.

Lettre de Adrienne Mancia (Museu of Modern Art) à Glauber Rocha. New York, 21/08/1968.

Lettre de Claude Antoine à Glauber Rocha. Paris, 23/09/1968.

Lettre de Carlos Diegues à Glauber Rocha. Paris, 19/12/1969.

Lettre de Claude Antoine à Glauber Rocha. Paris, le 09/01/1970.

Lettre de Carlos Diegues à Glauber Rocha. Sans lieu, sans date, 1969/70.

Lettre de Zelito Viana à Glauber Rocha. Sans lieu, sans date, 1969/72.

Lettre de Glauber Rocha à Zelito Viana et Tacito. Sans lieu, sans date, 1970/71.

Lettre de Glauber Rocha à Zelito Viana. Barcelone, sans date 1970/71.

Lettre de Claude Antoine à Glauber Rocha. Paris, 19/12/1970.

Réponse de Glauber Rocha. Sans lieu, sans date.

Lettre de Claude Antoine à Glauber Rocha. Paris, le 06/01/1971.

Lettre de Carlos Lamarca [?] à Miguel Arraes. La Havane, 20/11/1971.

Fragment de lettre. Sans auteur (possiblement un italien), sans lieu, sans date.

Lettre de Paulo César Saraceni à Glauber Rocha. 1973.

Lettre de Glauber Rocha à Carlos Diegues. Paris, juin 1973.

Lettre de Glauber Rocha à Zelito Viana. Rome, 06/01/1974.

Lettre de Glauber Rocha à Carlos Diegues. Paris, juillet 1974.

Proposta. Proposition de la production de O Nascimento da terra à l'URSS, sans date.

Lettre de Claude Antoine à Glauber Rocha. Rio de Janeiro, 29/01/1976.

Lettre de Claude Antoine à Glauber Rocha. Sans lieu, 03/03/1976.

Mot de Claude Antoine à Glauber Rocha. Sans lieu, 07/04/1976.

Mot de Claude Antoine à Glauber Rocha. Sans lieu, 09/10/1976.

Mot de Claude Antoine à Glauber Rocha. Sans lieu, 21/11/1976.

Lettre de Claude Antoine à Glauber Rocha. Sans lieu, 14/10/1977.

Lettre de Orlando Senna à Glauber Rocha. Rio de Janeiro, 12/11/1977.

Lettre de Claude Antoine à Glauber Rocha. St Ouen, 29/03/1978.

Lettre de Glauber Rocha à Dan Talbot. Rio de Janeiro, 06/08/1978.

Lettre de Glauber Rocha à Roberto Farias. Rio de Janeiro, 15/11/1978.

Mot de Claude Antoine à Glauber Rocha. St Ouen, 17/12/1979.

Lettre de Claude Antoine à Glauber Rocha. St Ouen, 13/02/1980. 
Lettre de Claude Antoine à Glauber Rocha. Sans lieu, 28/05/1980.

Lettre de Glauber Rocha à Celso Amorim. Paris, 30/12/1980.

Lettre de Glauber Rocha à Tom Luddy. Sintra, 16/07/1981.

Lettre de Claude Antoine à Lúcia Rocha. St Ouen, 26/03/1987.

\subsubsection{Articles, essais non publiés de Glauber Rocha}

Além das torres do Kremlin. 11 pages, Brasília, 1977.

O Cineasta é a máquina que faz o filme. 8 pages, Rome, sans date.

Depois do transe. 4 pages, sans date.

Fogo na kultura. 6 pages, sans date.

As Forças armadas brasileiras. 10 pages, Rome, 15/02/1975.

Glauberoperopera. 65 pages, Los Angeles, mai 1976.

Humanysmo. 2 pages, sans date.

Independência do Brasil. 10 pages, Paris, 1972.

O Itamaraty e o cinema. 11 pages, Paris, 30/11/1975.

Quarta-feira de cinzas. 7 pages, sans date.

Tupy Guarani. 27 pages, sans date.

Liste de projets : livres et films. 1 page, sans date.

1.8.3 Synopsis, scénarii et story board de Glauber Rocha

Alvorada. 4 pages, sans date.

Alvorada. 3 pages, sans date.

Alvorada segundo Kryzto. 3 pages, sans date.

América nuestra: A Terra em transe. 10 pages, sans date.

América nuestra. 7 pages, sans date.

América nuestra. Deux cahiers manuscrits, sans date (probablement 1968/1969).

América nuestra: A Conquista de Eldorado. 14 pages, sans date.

América nuestra. 4 pages, sans date.

América nuestra. 2 pages, sans date.

América nuestra: Operação III. 14 pages, sans date.

Brasil. 6 pages, sans date.

A Conquista de Eldorado. 8 pages, sans date.

A Conquista de Eldorado. Texte dactylographié et manuscrit, 24 pages, pages 1 à 8 sans date, 
pages 9 à 24, identiques au seize dernières pages de ROCHA, Glauber. América nuestra. Scénario inédit, 43 p. Dactylographiées avec annotations manuscrites, chemise « Produções Cinematográficas Mapa Ltda », Cinemateca do Museu de Arte Moderna do Rio de Janeiro, avril 1966.

A Conquista de Eldorado. 82 pages, sans date.

O Destino da humanidade. 140 pages, Sintra, 1981.

Estoria de Manuel. 52 pages, sans date.

Garota de Ipanema. 25 pages, sans date ${ }^{1215}$.

A Guerra civil. 7 pages, Rome, sans date.

A Guerra civil. 2 pages, sans date.

La Guerre civile. 46 pages, sans date.

O Império de Napolão. 3 pages, sans date.

Ladrão que rouba ladrão tem cem anos de perdão. 6 pages, sans date.

Malok, o preço da vida. 10 pages, Rio de Janeiro, 1980.

Malok. 36 pages, sans date.

O Nascimento dos deuses. 189 pages, 1981.

O Nascimento da terra. 1 page, sans date.

O Nascimento da terra.

La Naissance de la terre. 10 pages, sans date.

A Terra em transe I. 33 pages, Rome, février/mars 1965.

A Terra em transe. 32 pages, sans date.

Terra em transe. 26 pages, sans date.

\subsubsection{Enregistrement audio}

Entrevue avec Afonso Beato, Eduardo Escorel et John Howard Sherman, en présence de Dona Lúcia, par Elisabeth Versiani Formaggini, enregistrement du Tempo Glauber, cassettes 13 et $14,12 / 03 / 1985$.

\subsubsection{Autre}

Despezas do produtor Luiz Augusto Mendes no filme "Deus e o diabo na terra do sol ». 3 pages, $9 / 11 / 1963,07 / 01 / 1963$ et 28/12/1963. 


\subsection{Quotidiens, magazines, revues}

1.9.1 Revues de cinéma

Cahiers du cinéma, Paris.

Cine Cubano, La Havane.

Cinéma, Paris, $n^{\circ} 150$, novembre 1970.

Filme Cultura, Rio de Janeiro, 1966-1988.

Hablemos del cine, Lima.

Image et son, Paris, $\mathrm{n}^{\circ} 218$, juin-juil. 1968.

Nuestro Cine, Madrid, n63-64-65.

Positif, Paris.

Revista de cinema, Belo Horizonte, 1954-1957, 1961, 1964.

Revista de Cultura Cinematográfica, Belo Horizonte, 1957-1963.

\subsubsection{Revues à caractère culturel}

aParte, publicação do Teatro dos Universitários de São Paulo, São Paulo, 1968 (1-2).

Artes, São Paulo, 1965-1971 .

Revista Brasiliense, São Paulo, 1955-64.

Revista Civilização Brasileira, Rio de Janeiro, 1965-68.

Revista de cultura Vozes, Petrópolis, 1970.

Mirante das artes, São Paulo, 1967-1968.

Práxis, instauração crítica e criativa, São Paulo, 1962-1964.

Teoria e prática, São Paulo, 1967- 1968.

\subsubsection{Publications professionnelles}

Cine Reporter, São Paulo.

Espetáculos, São Paulo.

O EXIBIDOR. Anuário. 1962 et 1963.

Guia de filmes, INC, Rio de Janeiro, n²12, décembre 1967.

Projeção, São Paulo.

\subsubsection{Magazines}


O Cruzeiro, Rio de Janeiro.

Opinião, Rio de Janeiro,1972-1977.

Status, São Paulo.

Veja, São Paulo, 1968-

Visão, São Paulo, 1952-

1.9.5 Journaux (seulement ceux ayant plusieurs occurrences)

Correio da manhã, Rio de Janeiro.

O Dia, Rio de Janeiro.

Diário carioca, Rio de Janeiro.

Diário de São Paulo, São Paulo.

Diário da noite, Rio de Janeiro.

Diário de notícias, Rio de Janeiro.

Diário de notícias - Suplemento Literário, Rio de Janeiro.

Diário de notícias, Salvador.

Diário de São Paulo, São Paulo.

O Estado de São Paulo, São Paulo.

O Estado de São Paulo - Suplemento literário, São Paulo.

Folha de São Paulo, São Paulo.

O Globo, Rio de Janeiro.

Hora do povo, Rio de Janeiro.

O Jornal, Rio de Janeiro.

Jornal da Bahia, Salvador.

Jornal do Brasil, Rio de Janeiro.

Jornal do Brasil - Caderno B, Rio de Janeiro.

Jornal do comércio, Rio de Janeiro.

O Jornal do Comércio - Suplemento literário, Manaus.

Jornal do dia, Porto Alegre.

Jornal da tarde, sans lieu.

O Metropolitano, Rio de Janeiro.

Tribuna da Imprensa, Rio de Janeiro.

Última hora, Rio de Janeiro. 


\section{Bibliographie}

\subsection{MÉTHODOLOGIE, PROBLÉMATIQUE, RÉFLEXION SUR LE CINÉMA}

BERTIN-MAGHIT, Jean-Pierre. « Encadrer et contrôler le documentaire de propagande sous l'Occupation » in XXème SIECLE , revue d'histoire, n³, juillet 1999.

BERTIN-MAGHIT, Jean-Pierre. Les Documenteurs des années noires. Paris, Nouveau Monde Éditions, 2004.

CAHIERS DU CINEMA, Le siècle du cinéma, Hors-série novembre 2000.

CRETON, Laurent. « De l'indépendance en économie de marché : le paradigme stratégique en question », in Cinéma et indépendance : une économie politique. Paris, coll. Théorème, Presse de la Sorbonne Nouvelle, 1998.

CRETON, Laurent. Économie du cinéma : perspectives stratégiques. Paris, Nathan, 1994.

ECO, Umberto. Como se faz uma tese. Réédition, São Paulo, ed. Perspectiva, 2002 [1977].

ECO, Umberto. Lector in fabula - Le rôle du lecteur ou la Coopération interprétative dans les textes narratifs. Paris, coll. Réédition, Le livre de poche, Grasset et Fasquelle, 1985 [1979].

ELLUL, Jacques. Propagandes. Réédition, Paris, coll. Classiques des Sciences Sociales, éd. Economica, 1990 [1962].

ESQUENAZI, Jean-Pierre, ODIN Roger. « Cinéma et réception », in Réseaux, Paris, Hermès Sciences Publication, 2000.

ESQUENAZI, Jean-Pierre. Godard et la société française des années 1960. Paris, coll. Armand colin Cinéma, Armand Colin, 2004.

FERRO, Marc. Cinéma et histoire : le cinéma, agent et source de l'histoire. Paris, Denoël, Gonthier, 1977.

LINDEPERG, Sylvie. Les écrans de l'ombre - La Seconde Guerre Mondiale dans le cinéma français. Paris, CNRS Éditions, 1997.

MARIE, Michel. La Nouvelle Vague - une école artistique. Paris, coll. 128, Nathan, 1997.

ODIN, Roger. «Rhétorique du film de famille». Revue d'esthétique - Rhétoriques, sémiotiques, $n^{\circ} 1-2$, Paris, 10/18, Union Générale d'Édition, 1979.

ODIN, Roger. « Semio-pragmática : sobre o interese do diálogo ». In : Estudos de cinema, ano1 nº1, São Paulo, Educ, 1998, tradução de Magnólia Costa.

MOREIRA, Roberto Franco. «As Estratégias narrativas do cinema clássico ». Cours de la discipline 5202 de Pós-Graduação du département Cinema Rádio e Televisão - CTR de 
l'Escola de Comunicação e Arte-ECA, Universidade de São Paulo-USP, premier semestre 2003.

MOREIRA, Roberto Franco. «O Cinema hegemônico ». Article disponible sur le site de l'auteur, http:/homepage.mac.com/robertom/index/artigose/tese/ocinemah.html, consulté le $14 / 04 / 2006$.

SOLANAS, Fernando et GETTINO, Octávio. «Towards a third cinema » in NICHOLS, Bill, Movies and methods: An Anthology. Berkeley/Los Angeles/London, University of California Press, 1976. (Traduction de SOLANAS, Fernando et GETTINO, Octávio. «Hacia el tercer cine » in Tricontinental, La Havane, $\left.\mathrm{n}^{\circ} 13,1969.\right)$

\subsection{CINEMA NOVO ET CINÉMA BRÉSILIEN, HISTOIRE, ANALYSES FILMIQUES, CRITIQUES}

AMICO, Gianni. « Les deux Brésil ». Trafic, Revue de cinéma, Paris, n¹0, printemps 1994, pp. 87-95.

ANDRADE, João Batista de. «Uma Trajetória particular » in Estudos avançados, São Paulo, n46, septembre-décembre 2002, pp. 248-269.

AVEllar, José Carlos. A Ponte clandestina : Birri, Glauber, Solanas, García Espinosa, Sanjinés, Alea - Teorias de cinema na América latina. Rio de Janeiro / São Paulo, ed. 34 / edusp, 1995.

AVELLAR, José Carlos. Deus e o diabo na terra do sol - a linha reta, o melaço de cana e o retrato do artista quando jovem. Rio de Janeiro, Rocco, 1995.

AVELLAR, José Carlos. « Rascunho de pássaro » in Cult, São Paulo, n 67, mars 2003.

BELMANS Jacques et allii, ss la dir. de ESTEVES Michel. Le "cinema novo" brésilien 1. Paris, coll. Etudes cinématographiques, Lettres Modernes, 1972.

BERNARDET, Jean-Claude. Brasil em tempo de cinema. Rio de Janeiro, Paz e Terra, 1967. BERNARDET, Jean-Claude. «Le Cinema Novo et la société brésilienne ». Les Temps modernes, $\mathrm{n}^{\circ} 257$, oct. 1967.

BERNARDET, Jean-Claude. Cineastas e imagens do povo. São Paulo, ed. Brasiliense, 1985. BERNARDET, Jean-Claude. Cinema brasileiro : propostas para uma história. Rio de Janeiro, Paz e terra, 1978.

BERNARDET, Jean-Claude. Historiografia clássica do cinema brasileiro - Metodologia e pedagogia. São Paulo, Annablume, 1995.

BERNARDET, Jean-Claude, GALVÃO, Maria Rita. Cinema - Repercussões numa caixa de eco ideológica. São Paulo, coll. O Nacional e o popular na cultura brasileira, Embrafilme / 
ed. Brasiliense, 1983.

BERNARDET, Jean-Claude. São Paulo S.A. - O Filme de Person descrito por Jean-Claude Bernardet. Rio de Janeiro, Embrafilme / Alhambra, 1987.

BERNARDET, Jean-Claude, TEIXEIRA, Coelho (org.). Terra em transe Os Herdeiros : Espaços e poderes - Texto de trabalho. São Paulo, ed. Com-Arte, 1982.

BERNARDET, Jean-Claude. Vitória sobre a lata de lixo da história. Original cédé par l'auteur et destiné à être inclus à la réédition augmentée de Cineastas e imagens do povo, 2003.

CAETANO, Maria do Rosário. Cangaço : O Nordestern no cinema brasileiro. Brasília, Avathar Soluções Gráficas, 2005.

CARVALHO DA NOVA, Christiane. L'histoire en transe : le temps et l'histoire dans l'oeuvre de Glauber Rocha. Thèse de doctorat dirigée par Michèle Lagny, Université de la Sorbonne nouvelle-Paris III, Paris, 2003.

COSTA, Flávio Moreira Da. (Org.). Cinema moderno Cinema Nôvo. Rio de Janeiro, José Alvaro Editor S.A., 1966.

D'AVILA, Roberto. Os Cineastas - Conversas com Roberto d'Avila. Rio de Janeiro, Bom Texto, 2002.

DIEGUES, Carlos. Idéias e imagens. Porto Alegre, Editora da Universidade, Universidade Federal do Rio Grande do Sul, 1988.

DIEGUES, Carlos, CAMARGO, Maria Silvia. O que é ser diretor de cinema :Memórias profissionais de Cacá Diegues. Rio de Janeiro, Record, 2004.

DINES, Alberto, FERNANDES JÚNIOR, Florestan, SALOMÃO, Nelma. « Nelson Pereira dos Santos » in História do poder, 100 anos de política no Brasil, vol. 2 : Ecos do parlamento. São Paulo, Editora 34, 2000, pp. 115-135.

FAGUNDES TELLES, Lygia, SALES GOMES, Paulo Emílio. Capitu : Adaptação livre para um roteiro baseado no romance Dom Casmurro de Machado de Assis, São Paulo, Siciliano, 1993.

FAVARETTO, Celso. Tropicália: alegoria, alegria. São Paulo, Kairos, 1979, pp. 79-95.

FAVRE R., TEIXIDOR E. et alii. Encyclopédie alpha du cinéma. Editions Grammont, 1978.

FEIJÓ, Martin Cézar. Anabasis Glauber - Da Idade dos homens à idade dos deuses. São Paulo, Anabasis, 1996.

FERREIRA, Alexandre Figueiroa. La Vague du Cinema Novo en France fut-elle une invention de la critique? , Paris, L'Harmattan, 2000.

FICAMOS Bertrand. «Educação e propaganda no cinema de Humberto Mauro : Uma Outra Abordagem do filme O Descobrimento do Brasil (1937)» in Locus : revista de história. Juiz 
de Fora, vol. 8, $\mathrm{n}^{\circ} 2,2002$.

FICAMOS Bertrand. « De la violence des rêves : l'écriture singulière de Glauber Rocha » in Territoires du scénario. Dijon, Centre Gaston Bachelard de Recherches sur l'Imaginaire et la Rationalité, Université de Bourgogne, 2006.

GALVÃO, Maria Rita. «O desenvolvimento das idéias sobre cinema independente ». Cadernos da cinemateca, n4, São Paulo, 1980.

GERBER, Raquel (org.). Glauber Rocha. São Paulo, Paz e Terra, 1977.

GERBER, Raquel. "O processo cinemanovista », in $O$ Mito da civilização atlántica, Petrópolis, ed. Vozes, 1977, pp. 152-169.

GOMES, Paulo Emílio Sales. Humberto Mauro, Cataguases, Cinearte. São Paulo, Perspectiva, 1974.

GOMES, Paulo Emílio Sales. Réédition, Cinema : trajetória no subdesenvolvimento, coll. Leitura, Paz e Terra, São Paulo, 1996 [1980].

GRUNEWALD, José Lino. Um filme é um filme. São Paulo, Companhia das letras, 2000.

HENNEBELlE, Guy, GUMUCIO-DAGRON, Alfonso (org.). Les Cinémas de l'Amérique Latine. Paris, coll. Le Cinéma et son histoire, ed. Lherminier, 1981.

HIRSZMAN, Leon. É bom falar, Mostra Leon de ouro. Rio de Janeiro, Centro cultural do Banco do Brasil, 1995.

HOLLANDA, Heloísa Buarque de. Macunaíma : da literatura ao cinema - Depoimentos de Mário de Andrade e Joaquim Pedro de Andrade. Rio de Janeiro, Livraria José Olympio Editora / Embrafilme, 1978.

JOHNSON, Randal, STAM, Robert. Brazilian cinema. Réédition, Columbia University Press, 1995 [1982].

JOHNSON, Randal. Cinema Novo x 5 : Masters of contemporary Brazilian film. Austin, University of Texas, 1984.

LABAKI, Amir et alii. O Cinema Brasileiro - de O pagador de promessas a Central do Brasil. São Paulo, PubliFolha, 1998.

LABAKI, Amir (org.). Person por Person. São Paulo, coll. Biblioteca É tudo verdade, ed. A. Labaki, 2002.

LEANDRO, Anita Leandro. "L'essai filmé, un autre scénario » in Territoires du scénario. Dijon, Centre Gaston Bachelard de Recherches sur l'Imaginaire et la Rationalité, Université de Bourgogne, 2006.

LINO, Sônia. « Humberto Mauro e o Cinema Novo ». Locus : revista de história. Juiz de Fora, vol. 6, n²1, 2000, pp. 117-126.

LISBOA, Fátima Gomes. Un Artiste intellectuel : Glauber Rocha et l'utopie du Cinema Novo 
(1955-1971). Thèse de doctorat dirigée par Pierre Vayssière, Études Latino-Américaines Université de Toulouse 2, Toulouse, décembre 2000.

MICCICHE, Lino et allii, ss la dir. de ESTEVES, Michel. Le "cinema nôvo" brésilien Gláuber Rocha. Paris, coll. Etudes cinématographiques, Lettres Modernes, 1973.

MORENO, Antônio. Cinema brasileiro, História e relações com o Estado. Niterói/Goiânia, EDUFF/UFG, 1994.

NEVES, David. Cinema Novo no Brasil. Petrópolis, coll. Nosso Tempo, ed. Vozes, 1966.

NEVES, David. Muito prazer. Catalogue de la rétrospective des films de David Neves organisée par le CCBB - Centro Cultural do Banco do Brasil du 9 au 21 septembre 2004.

NICOLAS. «Cinéma et politique : l'exemple de Glauber Rocha ». Ornitho, n¹5, août 1999, http://www.ornitho.org/numero15/cinema/rocha.html

OMS, Marcel. « Le Cinema Novo brésilien ». CinémAction, n55, 1990, pp. 105-113.

OROZ, Silvia. Carlos Diegues : os filmes que não filmei-Entrevistas com Silvia Oroz. Rio de Janeiro, Rocco, 1984.

OROZ, Silvia. 30 anos de Cinema Novo : Jarbas Barbosa - Entrevista a Silvia Oroz. Rio de Janeiro, Imprensa da Cidade, 1993.

PARANAGAU, Paulo Antônio, AUGUSTO, Sérgio (org.). Le cinéma brésilien. Paris, coll. Cinema Pluriel, Ed. Centre Pompidou, 1987. (José Carlos Avellar, Le Cinema Novo : les années soixante, Ismail Xavier, Glauber Rocha : le désir de l'Histoire, Ronald F. Monteiro, Nelson Pereira dos Santos)

PIERRE, Sylvie. Glauber Rocha. Paris, Cahiers du cinéma, 1987.

RAMOS, Alcides Freire. « No olho do furacão : Oduvaldo Viana filho e o Cinema Novo » in Cultura Vozes, n²1, vol. 93, 1999, pp. 167-170.

RAMOS, Fernão (org.). História do cinema brasileiro. São Paulo, Art editora, 1987.

RAMOS, Fernão et MIRANDA, Luís Felipe (org.). Enciclopédia do cinema brasileiro. São Paulo, SENAC, 2000.

RANDAL, Johnson. Cinema Novo x 5 : masters of contemporary brazilian cinema. Austin, University of Texas Press, 1984.

REZENDE, Sydney (org.). Idéario de Glauber Rocha. Rio de Janeiro, Philobiblion, 1986.

RIBEIRO, José Américo. «Revistas de cinema - Cinema brasileiro » in O Cineclubismo em Belo Horizonte : do cineclubismo à produção cinematográfica na década de 60, Belo Horizonte, Universidade Federal de Minas Gerais, 2002, pp. 103-130.

ROCHA, Eryk (org.). Rocha que voa-América latina, África, o papel do intelectual, cinema, poesia, política, a memória em transe. A integra da entrevistas de Glauber que deram origem ao filme de Eryk Rocha. Rio de Janeiro, Aeroplano, 2002. 
ROCHA Glauber. Revisão crítica do cinema brasileiro. Rio de Janeiro, Civilização brasileira, 1963.

ROCHA Glauber et alii. Deus e o diabo na terra do sol. Rio de Janeiro, ed. Civilização brasileira, 1965.

ROCHA, Glauber. Revolução do Cinema Novo. Rio de Janeiro, Alhambra/Embrafilme, 1981.

ROCHA, Glauber. Roteiros do terceyro mundo. Rio de Janeiro, Alhambra/Embrafilme, 1985.

ROCHA, Glauber. O Século do cinema. Rio de Janeiro, Alhambra/Embrafilme, 1985.

ROCHA, Glauber. Cartas ao mundo. São Paulo, Companhia das letras, 1997.

SCHVARZMAN, Sheila. Humberto Mauro e as imagens do Brasil. Thèse de doctorat dirigée par Edgar Salvadori De Decca, Instituto de Filosofia e Ciências Humanas da Unicamp, Campinas, 2000.

SILVA, Alberto. Cinema e humanismo. Rio de Janeiro, Pallas S.A., 1975.

SILVA NETO, Antônio Leão Da. Dicionário de filmes brasileiros. São Paulo, Gráfica Editora, 2002.

SIMÕES, Inimá. Roteiro da intolerância : A Censura cinematográfica no Brasil. São Paulo, SENAC, 1998.

STAM, Robert. Tropical multiculturalism - A Comparative history of race in brazilian cinema and culture. Duke University Press, 1997.

VENTURA, Tereza. A Poétika polytika de Glauber Rocha. Rio de Janeiro, Ministério da Cultura, Funarte, 2000.

VIANY, Alex. O Velho e o novo. SAC, 1967.

VIANY, Alex. O processo do Cinema Novo. Rio de Janeiro, Aeroplano, 1999.

XAVIER, Ismail. Sertão Mar - Glauber Rocha e a estética da fome. São Paulo, ed. Brasiliense, 1983.

XAVIER, Ismail. O Cinema brasileiro moderno. São Paulo, coll. Leitura, Paz e terra, 2001. XAVIER, Ismail. Alegorias do desengano : a resposta do cinema novo a modernizacao conservadora. Thèse de livre docência, Escola de Comunicações e Arte, Université de São Paulo, São Paulo, 1989.

\subsection{BIOGRAPHIES}

ARRUDA, José Roberto. Lúcia - A Mãe de Glauber. São Paulo : Geração Editorial, 1999.

BENTES, Ivana. Joaquim Pedro de Andrade - A Revolução intimista. Rio de Janeiro, ed. Relume Dumará, co-ed. Prefeitura do Rio, 1996.

GOMES, João Carlos Teixeira. Glauber Rocha - Esse vulcão. Rio de Janeiro, ed. Nova 
Fronteira, 1997.

LISBOA, Fátima Gomes. Un Artiste intellectuel : Glauber Rocha et l'utopie du Cinema Novo (1955-1971). Thèse de doctorat dirigée par Pierre Vayssière, Études sur l'Amérique Latine, Université Toulouse-Le-Mirail, Toulouse, décembre 2000.

MATTOS, Carlos Alberto. Walter Lima Júnior - Viver cinema. Rio de Janeiro, Casa da palavra, 2002.

MELO SOUZA, José Inácio de. Paulo Emílio no Paraíso. Rio de Janeiro, Record, 2002.

SALEM, Helena. Nelson Pereira dos Santos - O Sonho possível do cinema brasileiro. Rio de Janeiro, ed. Nova Fronteira, 1987.

SALEM, Helena. Leon Hirszman : o navegador das estrelas. Rio de Janeiro, Rocco, 1997.

SARACENI, Paulo César. Por dentro do Cinema Novo - Minha Viagem. Rio de Janeiro, Nova Fronteira, 1993.

\section{4 ÉTAT ET CINÉMA AU BRÉSIL}

DAHL, Gustavo. « O Estado das coisas » in Caderno Diplô, São Paulo, n 2, 2002.

RANDAL, Johnson. The film industry in Brazil : Culture and the state. Pittsburgh, University of Pittsburgh Press, 1987.

SANTOS PEREIRA, Geraldo. Plano geral do cinema brasileiro:história, cultura, economia e legislação. Rio de Janeiro, Borsoi, 1973.

SIMIS, Anita. Estado e cinema no Brasil. São Paulo, Annablume, 1996.

SOUZA PINTO, Leonor Estela. Le Cinéma brésilien au risque de la censure pendant la dictature militaire de 1964 à 1985. Thèse de doctorat réalisée sous la direction de Guy Chapouillie, 441 pages et 1 cd-rom, Université Toulouse-Le Mirail, École Supérieure d'Audiovisuel, décembre 2001.

XAVIER, Ismail, BERNARDET, Jean-Claude e PEREIRA, Miguel. O Desafio do cinema : a política do Estado e a política dos autores. Rio de Janeiro, Jorge Zahar editor, Séries Brasil os anos de autorismo, 1985.

\subsection{HISTOIRE DU BRÉSIL}

ARQUIVO PÚBLICO DO RIO DE JANEIRO. Os Arquivos das polícias políticas, reflexos de nossa história contemporânea. Rio de Janeiro, Fundação de amparo à pesquisa do DOPS, segunda edição, 1996.

BANDEIRA, Luiz Alberto Moniz. O Governo João Goulart - As Lutas sociais no Brasil 
1961-1964. Septième édition révisée et augmentée, Rio de Janeiro / Brasília, Revan / Universidade nacional de Brasília, 2001 [1978].

BARCELLOS, Jalusa. UNE : 60 anos a favor do Brasil. Rio de Janeiro, ANC Comunicação \& Marketing Ltda, 1997.

BASTIDE, Roger. Brésil : Terre de contrastes. Réédition, Paris, L'Harmattan, 1999 [1957].

BENNASSAR, Bartolomé, MARIN, Richard. Histoire du Brésil - 1500-2000. Paris, Fayard, 2000 .

FAUSTO, Boris. História do Brasil. São Paulo, Edusp, 1995.

GABEIRA, Fernando. O que é isso, companheiro ?. São Paulo, Companhia das letras, 1996 ( $2^{\circ}$ édition, $1^{\circ}$ édition : 1979 ).

GASPARI, Elio. As Ilusões armadas - A Ditadura envergonhada. São Paulo, Companhia das letras, 2002.

GASPARI, Elio. As Ilusões armadas - A Ditadura escancarada. São Paulo, Companhia das letras, 2002.

GASPARI, Elio. O Sacerdote e o feitiçeiro - A Ditadura derrotada. São Paulo, Companhia das letras, 2003.

GASPARI, Elio. O Sacerdote e o feitiçeiro - A Ditadura encurralada. São Paulo, Companhia das letras, 2003.

HOLLANDA, Heloísa Buarque de. Impressões de viagem - cpc, vanguarda e desbunde : 1960/70. São Paulo, ed. Brasiliense, 1980.

HOLLANDA, Heloísa Buarque de, GONÇALVES Marcos A. Cultura e participação nos anos 60. São Paulo, coll. Tudo é historia, n41, ed. Brasiliense, 1982.

ORTIZ, Renato. Cultura brasileira \& identidade nacional. São Paulo, ed. Brasiliense, 1985.

PRADO, Paulo. Retrato do Brasil : Ensaio sobre a tristeza brasileira. Huitième édition, São Paulo, Companhia da letras, 1997 [1928].

REVISTA BRASILEIRA DE HISTÓRIA, Brasil 1954 1964, ANPUH/ Marco Zero, São Paulo, 1994.

SCHWARZ, Roberto. Cultura e política. São Paulo, coll. Leitura, Paz e terra, 2001.

SODRÉ, Werneck Nelson. Formação histórica do Brasil. Treizième édition, Rio de Janeiro, Bertrand Brasil, 1990 [1962].

UNIÃO NACIONAL DOS ESTUDANTES. UNE Histórico 60 anos. Rio de Janeiro, ANC Comunicação \& Marketing Ltda, 1997.

VENTURA, Zuenir. 1968 o ano que não terminou - A Aventura de uma geração. Rio de Janeiro, ed. Nova Fronteira, 1988. 


\subsection{PHILOSOPHIE}

CORBISIER, Roland. Responsabilidades das elites. Rio de Janeiro, Livraria Martias Edição, 1955.

CORBISIER, Roland. Formação e problema da cultura brasileira. Deuxième édition, Rio de Janeiro, coll. Textos brasileiros de filosofia, Ministério da Educação e da Cultura, Instituto Superior de Estudos Brasileiros, 1960 [1956].

MARTINS, Carlos Estevam. A questão da cultura popular. Rio de Janeiro, Tempo brasileiro, 1963.

PINTO, Álvaro Vieira. Consciência e realidade nacional - $2 e$ vol : a consciência crítica. Troisième édition, Rio de Janeiro, coll. Textos brasileiros de filosofia, Ministério da Educação e da Cultura, Instituto Superior de Estudos Brasileiros, 1963.

\subsection{ROMANS}

ANDRADE, Joaquim Pedro de. O Imponderável Bento contra o crioulo voador. São Paulo, Marco Zero/Cinemateca Brasileira, 1990.

ROCHA, Glauber. Riverão Sussuarana. Rio de Janeiro, Record, 1977.

\subsection{THÉÂTRE, PÉDAGOGIE ET LITTÉRATURE}

FREIRE, Paulo. Pédagogie des opprimés. Paris, coll. Petite Collection Maspéro, Maspéro, 1974.

PEIXOTO, Fernando. O Melhor Teatro do CPC da UNE. São Paulo, Global Editora, 1989.

PEIXOTO, Fernando (org.). Vianinha : teatro, televisão, política. São Paulo, coll. Antologias e biografias, ed. Brasiliense, 1983.

\section{Entretiens}

Mário Carneiro. Joel Pizzini entrevista Mário Carneiro. Copie intégrale de l'enregistrement de l'entretien aimablement cédé par Joel Pizzini, février 2002.

Jean-Claude Bernardet. Entretiens avec l'auteur, mars et juillet 2003.

Diogo Gomes dos Santos. Entretien avec l'auteur, mai 2003.

Marina Person. Entretien avec l'auteur, mai 2003. 
Maurice Capovilla. Entretien avec l'auteur, juin 2003.

Nelson Pereira dos Santos. Entretien avec l'auteur, juin 2003.

Eduardo Coutinho. Entretien avec l'auteur, juin 2003.

Eduardo Escorel. Entretien avec l'auteur, août 2003.

Lécio Augusto Ramos. Entretiens avec l'auteur, août 2003.

Ruy Guerra. Entretien avec l'auteur, février 2004.

José Carlos Avellar. Entretien avec l'auteur, février 2004.

Paulo César Saraceni. Entretien avec l'auteur, février 2004.

Gustavo Dahl. Entretien avec l'auteur, février 2004.

Dedy Lherm. Entretien avec l'auteur, juin 2004.

Zelito Viana. Réponse à un questionnaire de l'auteur par courriel, 27 mai 2004.

Zelito Viana. Entretien avec l'auteur, septembre 2004.

Luiz Carlos Barreto. Entretien avec l'auteur, septembre 2004.

Lúcia Rocha. Entretien avec l'auteur, septembre 2004.

Carlos Diegues. Réponse à un questionnaire de l'auteur par courriel, 3 juin 2004.

Carlos Diegues. Entretien avec l'auteur, septembre 2004. 


\section{ANNEXE 1 : Dvd joint à la thèse, liste et origine des extraits}

Les extraits des films présents sur le dvd ont été enregistrés sur cassette vhs lors de leur passage sur la chaîne de télévision Canal Brasil entre 2002 et 2003 sauf indication.

O Cangaceiro (Lima Barreto, 1953)

Nem Sansão nem Dalilah (Carlos Manga, 1954)

O Grande Momento (Roberto Santos, 1958)

Arraial do Cabo (Paulo César Saraceni et Mário Carneiro, 1960) extrait de la cassette vhs :

SARACENI, Paulo Cézar. O Cinema de Paulo Cézar Saraceni. Rio de Janeiro, coll. Brasilianas, Ministério da Cultura / Funarte, sans indication de date.

Aruanda (Linduarte Noronha, 1960) extrait de la cassette vhs : Noronha, Linduarte e outros. Rio de Janeiro, coll. Brasilianas, Ministério da Cultura / Funarte, sans indication de date.

A Grande Feira (Roberto Pires, 1961)

Os Cafajestes (Ruy Guerra, 1962)

Cinco vezes favela (Collectif, 1962) extrait de la cassette vhs : Cinco vezes favela. Santana de Parnaíba, coll. Cinema Novo, Frontlog, sans indication de date.

Porto das Caixas (Paulo César Saraceni, 1965)

Vidas secas (Nelson Pereira dos Santos, 1963) extrait du dvd : SANTOS, Nelson Pereira dos. Vidas secas. New York, New Yorker Video, 2006.

Deus e o diabo na terra do sol (Glauber Rocha, 1964) extrait du dvd : ROCHA, Glauber. Deus e o diabo na terra do sol. Rio de Janeiro, Riofilme, 2003.

Os Fuzis (Ruy Guerra, 1964) extrait de la cassette vhs : GUERRA, Ruy. Os Fuzis. Rio de Janeiro, Sagres Filmes, sans indication de date.

O Pagador de promessas (Anselmo Duarte, 1962) extrait du dvd : DUARTE, Anselmo. $O$ Pagador de promessas. São Paulo, Dynafilmes, 2006.

Assalto ao trem pagador (Roberto Farias, 1962) extrait du dvd : FARIAS, Roberto. Assalto ao trem pagador. Rio de Janeiro, Funarte, 2004.

O Desafio (Paulo César Saraceni, 1965) extrait de la cassette vhs : SARACENI, Paulo César. O Desafio. Rio de Janeiro, Riofilme, sans indication de date.

O Padre e a moça (Joaquim Pedro de Andrade, 1966)

Terra em transe (Glauber Rocha, 1967) extrait du dvd : ROCHA, Glauber. Terra em transe. Rio de Janeiro, Grupo Novo de cinema e tv, Paloma Cinematográfica, 2005.

Cabra marcado para morrer (Eduardo Coutinho, 1984) 
O Caso dos irmãos Naves (Luis Sérgio Person, 1967)

Capitu (Paulo César Saraceni, 1968)

Fome de amor (Nelson Pereira dos Santos, 1968) extrait de la cassette vhs : SANTOS, Nelson Pereira dos. Fome de Amor. Rio de Janeiro, Riofilme, sans indication de date.

O Dragão da maldade contra o santo guerreiro (Glauber Rocha, 1969) extrait du dvd : ROCHA, Glauber. Antonio das Mortes. Paris, Le Cinéma du Monde, 2006.

Brasil ano 2000 (Walter Lima Jr., 1969)

Os Herdeiros (Carlos Diegues, 1969)

Macunaíma (Joaquim Pedro de Andrade, 1969) extrait du dvd : ANDRADE, Joaquim Pedro de. Macunaíma. Paris, Carlotta Films, 2007.

Como era gostoso o meu francês (Nelson Pereira dos Santos, 1971) extrait du dvd : SANTOS, Nelson Pereira dos. Como era gostoso o meu francês. New York, New Yorker Video, 2007.

Pindorama (Arnaldo Jabor, 1971)

A Mulher de todos (Rogério Sganzerla, 1969)

História do Brasil (Glauber Rocha, 1972-74) extrait d'une cassette vhs non commerciale cédée par le Tempo Glauber.

Iracema, uma transa amazônica (Orlando Senna et Jorge Bodanski, 1974) extrait du dvd : SENNA, Orlando, BODANSKI, Jorge. Iracema, uma transa amazônica. Manaus, Video Filmes, 2005.

Tudo bem (Arnaldo Jabor, 1978) extrait du dvd : JABOR, Arnaldo. Tudo bem. São Paulo, Versatil Home Video, 2005. 


\section{ANNEXE 2 : Distribution en pourcentage du chiffre d'affaire des salles de cinéma en 1964}

Pour se repérer, la carte du découpage administratif du Brésil dans les années soixante :

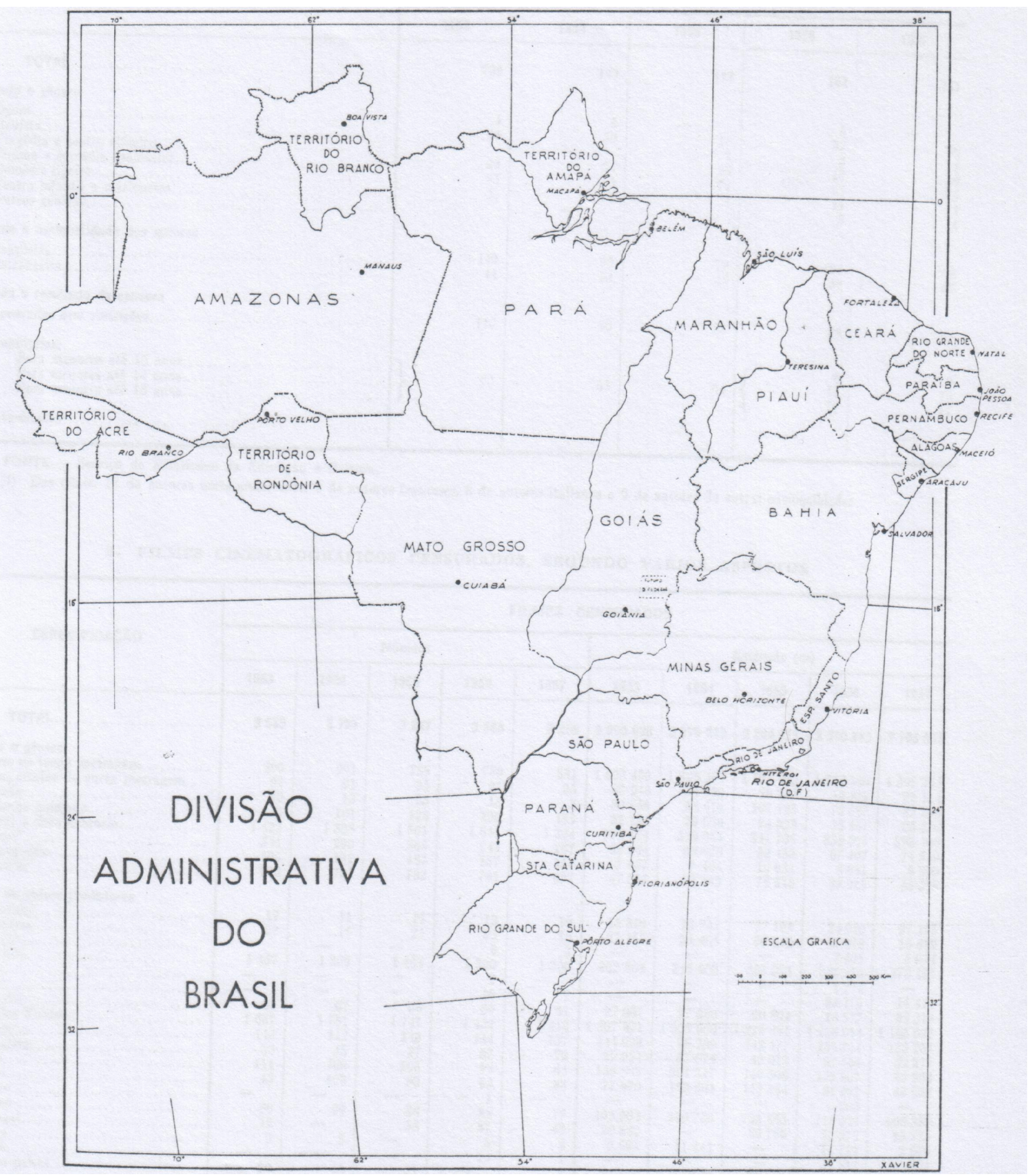

Source : Anuário Estastístico do Brasil. IBGE, 1960. 
Distribution en pourcentage du chiffre d'affaire des salles de cinéma en 1964 :

État de Guanabara (actuelle ville de Rio de Janeiro) : $20 \%$

État de Rio de Janeiro (actuel état de Rio de Janeiro sans l'ancienne capitale fédérale) : $5 \%$

Ville de São Paulo : $20 \%$

État de São Paulo (sans la capitale) : $10 \%$

Total territoires correspondant aux actuels états de São Paulo et de Rio de Janeiro : 55 \%

Reste du territoire :

États du Sud-Est autres que Rio de Janeiro et São Paulo :

Minas Gerais : $1 \%$

Espírito Santo : $2 \%$

État du Sud du Brésil :

Paraná : $5 \%$

Santa Catarina : $8 \%$

Rio Grande do Sul : $8 \%$

Centre-ouest :

Mato Grosso : $1 \%$

Goiás : $1 \%$

Brasília : $1 \%$

Bahia, Sergipe et Alagoas : $6 \%$

Pernambuco et tous les états du Nord du pays : $12 \%$

Total : $45 \%$

Source : SANTOS PEREIRA, Geraldo. Plano geral do cinema brasileiro:história, cultura, economia e legislação. Rio de Janeiro, Borsoi, 1973, p. 64. 


\section{ANNEXE 3 : Évolution de la réserve de marché pour les longs métrages}

Législation

Quotas

$\%$ par an

\begin{tabular}{|c|c|c|c|}
\hline 1932 & Décret 21,240 & $\begin{array}{l}1 \text { court métrage pour chaque programme de } \\
\text { films étrangers }\end{array}$ & $0 \%$ \\
\hline 1939 & Décret-loi 1,494 & 1 long métrage par an, 7 jours & $2 \%$ \\
\hline 1946 & Décret 20,493 & 3 longs métrages par an, 7 jours par film & $6 \%$ \\
\hline 1951 & Décret 30,179 & $\begin{array}{l}1 \text { long métrage tous les } 8 \text { longs métrages } \\
\text { étrangers }\end{array}$ & $8 \%$ \\
\hline 1959 & Décret 47,466 & 42 jours par an & $12 \%$ \\
\hline 1963 & Décret 52,745 & 56 jours par an & $15 \%$ \\
\hline 1969 & Rés. INC 31 & 63 jours par an & $17 \%$ \\
\hline 1970 & Rés. INC 35 & 77 jours par an & $21 \%$ \\
\hline 1971 & Rés. INC 69 & 84 jours par an & $23 \%$ \\
\hline 1975 & Rés. INC 106 & 112 jours par an & $31 \%$ \\
\hline 1978 & Rés. CONCINE 23 & 133 jours par an & $36 \%$ \\
\hline 1980 & Rés. CONCINE 62 & 140 jours par an & $38 \%$ \\
\hline
\end{tabular}

Remarque : Il a été calculé par le Ministério da Cultura que l'obligation d'exhibition d'un long métrage national pour huit étrangers, entre 1951 et 1958, avait été équivalent à une réserve de marché de 31 jours par an. Le pourcentage indiqué dans la troisième colonne se base sur cette évaluation.

Source : MELLO, Alcino Teixeira de. Legislação do cinema brasileiro. Rio de Janeiro, EMBRAFILME, 1978. 


\section{ANNEXE 4 : Les films distribués par la Difilm}

(Première période d'activité de la maison de distribution, 1965-1969)

30 titres.

1965, 4 films: Crime de amor de Rex Endsleigh, O Desafio de Paulo César Saraceni, Menino do engenho de Walter Lima Jr, Quatro brasileiros em Paris de Geraldo Vietri.

1966, 4 films : A Grande cidade de Carlos Diegues, A Hora e a vez de Augusto Matraga de Roberto Santos, O Padre e a moça de Joaquim Pedro de Andrade, Toda donzela tem um pai que é uma fera de Roberto Farias.

1967, 6 films : ABC do amor, épisode brésilien, O Pacto de Eduardo Coutinho, A Derrota de Mário Fiorani, Garota de Ipanema de Leon Hirszman, Opinião pública de Arnaldo Jabor, Terra em transe de Glauber Rocha, Todas as mulheres do mundo de Domingos de Oliveira. 1968, 5 films : Bebel, garota propaganda de Maurice Capovilla, Brasil Verdade avec des épisodes de Paulo Gil Soares, Manoel H. Gimenez, Maurice Capovilla et Geraldo Sarno, Capitu de Paulo César Saraceni, Cara a cara de Júlio Bressane, Roberto Carlos em ritmo de aventura de Roberto Farias.

1969, 7 films : Brasil ano 2000 de Walter Lima Jr, O Bravo guerreiro de Gustavo Dahl, Copacabana me engana de Antônio Carlos Fontoura, Macunaíma de Joaquim Pedro de Andrade, Máscara da traição de Roberto Pires, Os Paqueras de Reginaldo Farias, Vida provisória de Maurício Gomes Leite.

1970, 1 film : Os Herdeiros de Carlos Diegues en association avec Paramount Filmes do Brasil e Condor Filmes.

Sources : Enciclopédia do cinema brasileiro, Dicionário de filmes brasileiros, Crédits des films. 


\section{ANNEXE 5 : Chiffres disponibles sur le succès commercial du Cinema Novo}

Avant la création de l'INC en 1967, il n'existe au Brésil aucune donnée officielle sur les entrées réalisées par un film sur l'ensemble du territoire national. La mise en place d'une fiscalisation efficace des tickets de cinéma prendra elle-même plusieurs années. Les chiffres dont nous disposons sont partiels et sujets à caution.

Deus e o diabo na terra do sol : 80000 spectateurs

Menino de engenho : 1 million de spectateurs

O Dragão da maldade contra o santo guerreiro : 1,5 millions de spectateurs

Macunaíma : 2 millions de spectateurs

Os Deuses e os mortos : 81152 spectateurs

Azyllo muito louco : 68032 spectateurs

Pindorama : 23942 spectateurs

Como era gostoso o meu francês : 875468 spectateurs

Os Inconfidentes : 132399 spectateurs

São Bernardo : 62783 spectateurs

Uirá, um indio em busca de Deus : 17080 spectateurs

Nelson Pereira dos Santos a déclaré que les producteurs du Cinema Novo ont estimé à partir des revenus qu'ils enregistraient que les films du Cinema Novo réunissait un public moyen de 100000 spectateurs $^{1216}$.

Sources :

Boletim informativo SIP : Anuário de 1973. INC/MEC, ano III, 1974, archives Cinemateca do MAM.

Boletim informativo SIP : Anuário de 1974. INC/MEC, ano IV, 1975, archives Cinemateca do MAM.

MICHILES, Aurélio. Que viva Glauber, TV Cultura, 1991.

RAMOS, Fernão et MIRANDA, Luís Felipe (org.). Enciclopédia do cinema brasileiro. São Paulo, SENAC, 2000, pp. 172 et 354.

1216DINES, Alberto, FERNANDES JÚNIOR, Florestan, SALOMÃO, Nelma. « Nelson Pereira dos Santos » in História do poder, 100 anos de política no Brasil, vol. 2 : Ecos do parlamento. São Paulo, Editora 34, 2000, pp. 115-135. 